Andrews University

Digital Commons @ Andrews University

\title{
The Early Bronze Age Ceramic Assemblage from Tell Ta'annek, Palestine
}

Mark S. Ziese

Andrews University

Follow this and additional works at: https://digitalcommons.andrews.edu/dissertations

Part of the History of Art, Architecture, and Archaeology Commons, and the Near Eastern Languages and Societies Commons

\section{Recommended Citation}

Ziese, Mark S., "The Early Bronze Age Ceramic Assemblage from Tell Ta'annek, Palestine" (2002).

Dissertations. 173.

https://digitalcommons.andrews.edu/dissertations/173

https://dx.doi.org/10.32597/dissertations/624

This Dissertation is brought to you for free and open access by the Graduate Research at Digital Commons @ Andrews University. It has been accepted for inclusion in Dissertations by an authorized administrator of Digital Commons@ Andrews University. For more information, please contact repository@andrews.edu. 


\section{Andrews \$university}

Seek Knowledge. Affirm Faith. Change the World.

Thank you for your interest in the

\section{Andrews University Digital Library of Dissertations and Theses.}

Please honor the copyright of this document by not duplicating or distributing additional copies in any form without the author's express written permission. Thanks for your cooperation. 


\title{
NOTE TO USERS
}

\author{
Page(s) not included in the original manuscript and are \\ unavailable from the author or university. The manuscript \\ was scanned as received.
}

This reproduction is the best copy available.

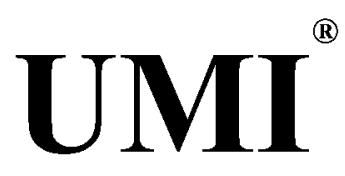


Andrews University

Seventh-day Adventist Theological Seminary

THE EARLY BRONZE AGE CERAMIC ASSEMBLAGE FROM TELL TA'ANNEK, PALESTINE

\author{
A Dissertation \\ Presented in Partial Fulfillment \\ of the Requirements for the Degree \\ Doctor of Philosophy
}

by

Mark S. Ziese

July 2002 
UMI Number: 3110131

\title{
INFORMATION TO USERS
}

The quality of this reproduction is dependent upon the quality of the copy submitted. Broken or indistinct print, colored or poor quality illustrations and photographs, print bleed-through, substandard margins, and improper alignment can adversely affect reproduction.

In the unlikely event that the author did not send a complete manuscript and there are missing pages, these will be noted. Also, if unauthorized copyright material had to be removed, a note will indicate the deletion.

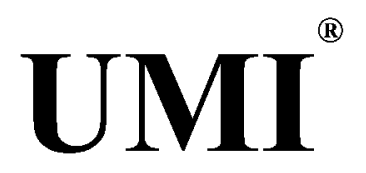

UMI Microform 3110131

Copyright 2004 by ProQuest Information and Learning Company.

All rights reserved. This microform edition is protected against unauthorized copying under Title 17, United States Code.

\author{
ProQuest Information and Learning Company \\ 300 North Zeeb Road \\ P.O. Box 1346 \\ Ann Arbor, MI 48106-1346
}




\section{THE EARLY BRONZE AGE CERAMIC ASSEMBLAGE}

\section{FROM TELL TA' ANNEK, PALESTINE}

A dissertation

presented in partial fulfillment

of the requirements for the degree

Doctor of Philosophy

by

Mark S. Ziese

APPROVAL BY THE COMMITTEE:
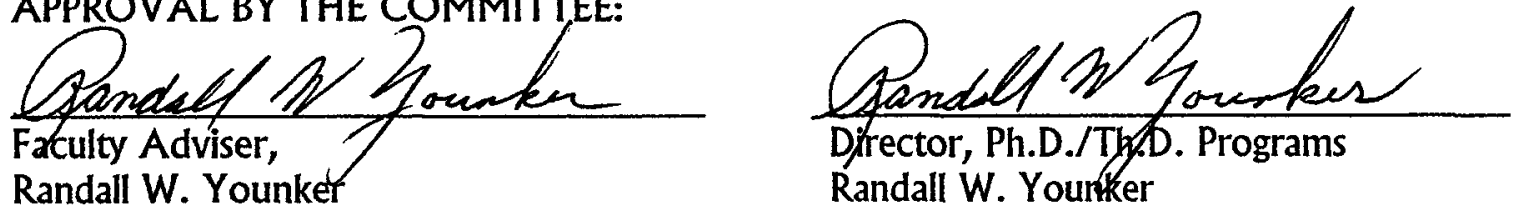

Professor of Old Testament and Biblical

Archaeology

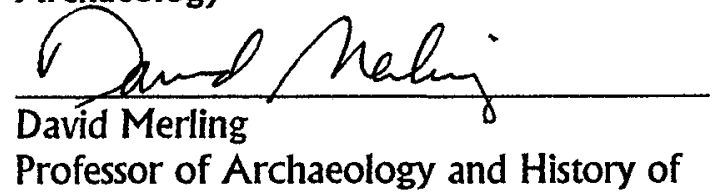

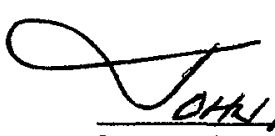

Dean, SDA Theglogical Seminary John K. McValy

Antiquity

Eystein S. LaBiancd

Professor of Anthropology

James R. Fisher

tamed R. Fisher

Associate Professor of Archaeology and

History of Antiquity

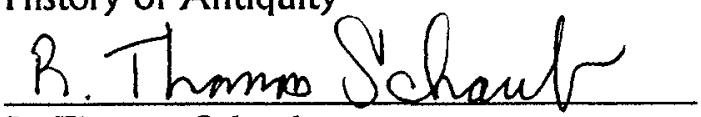

R. Thomas Schaub

Professor of Religion, Emeritus

Indiana University of Pennsylvania

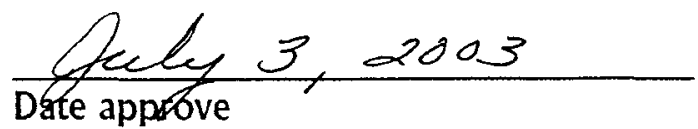


ABSTRACT

THE EARLY BRONZE AGE CERAMIC ASSEMBLAGE FROM TELL TA'ANNEK, PALESTINE

$$
\text { by }
$$

Mark S. Ziese

Adviser: Randall W. Younker 


\title{
ABSTRACT OF GRADUATE STUDENT RESEARCH \\ Dissertation
}

\author{
Andrews University \\ Seventh-day Adventist Theological Seminary
}

\section{Title: THE EARLY BRONZE AGE CERAMIC ASSEMBLAGE FROM TELL TA'ANNEK, PALESTINE}

Name of researcher: Mark S. Ziese

Name and degree of faculty adviser: Randall W. Younker, Ph.D.

Date completed: July, 2002

The Problem

Greenberg has recently stated that isolating temporal ceramic indicators for the Early Bronze II-III periods is "one of the thorniest issues in the archaeology of Palestine" (2000: 183). Part of the problem stems from the homogenous nature of ceramic assemblages from Early Bronze Age Palestine; part of it stems from a continued lack of published information. Both of these issues are addressed by this study. Excavations at Tell Ta'annek between 1963 and 1967 unearthed the remains of a multi-period site, including the residues of an Early Bronze II-III fortified settlement. It is purposed here to isolate that portion of the site in the collected records and residues in order to produce a ceramic sample that is stratigraphically derived. From this sample, inferences may be drawn concerning chronology, technology, and trade. 


\section{Method}

On the basis of data drawn from field records, a relative chronology of the settlement was built by square and locus. This sequence was tested by the retrieval and analysis of saved ceramic sherds. Index forms forced alterations in the sequence, that, in turn, prompted additional stratigraphic work. This cycle produced approximately 400 isolated loci and a working sample of some 2,000 sherds. This assemblage was then analyzed internally, in typological and technological terms, and externally, through comparison with other published assemblages from North Palestine.

\section{Results}

Deposition from Tell Ta'annek suggests three distinct Early Bronze Age strata and a corresponding ceramic sequence stretching from EB I (Stratum 1), through EB II (Stratum 2), and early EB III (Stratum 3). While the presence of fortification and destruction debris is indicative of destabilization and armed conflict, the ceramic record of "Common Ware" is stable and fairly homogenous, interrupted only by the presence of Metallic Ware and Khirbet Kerak Ware.

\section{Conclusion}

Using Metallic Ware and Khirbet Kerak Ware as reference points, select "Common Ware" features may be isolated. These contribute to a growing set of knowledge that offers promise for isolating temporal ceramic indicators for the Early Bronze II-III periods. In addition, it is suggested that most residents of Tell Ta'annek were removed from--or resistant to--"imported" potting traditions that left a powerful imprint elsewhere in North Palestine. A preference for local wares over more expensive or exotic forms underlines a rural conservatism that is consistent with the site's location. 
TABLE OF CONTENTS

LIST OF FIGURES $\ldots \ldots \ldots \ldots \ldots \ldots \ldots \ldots \ldots \ldots \ldots \ldots \ldots \ldots \ldots \ldots$

LIST OF TABLES $\ldots \ldots \ldots \ldots \ldots \ldots \ldots \ldots \ldots \ldots \ldots \ldots \ldots \ldots \ldots \ldots$

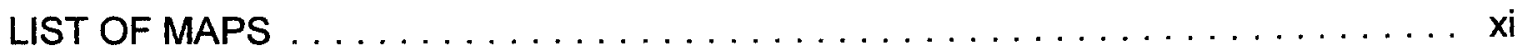

PREFACE $\ldots \ldots \ldots \ldots \ldots \ldots \ldots \ldots \ldots \ldots \ldots \ldots \ldots \ldots \ldots \ldots \ldots \ldots$

\section{Chapter}

I. INTRODUCING THE PROBLEM, THE EARLY BRONZE AGE, AND TELL TA'ANNEK $\ldots \ldots \ldots \ldots \ldots \ldots \ldots \ldots$

Introduction $\ldots \ldots \ldots \ldots \ldots \ldots \ldots \ldots \ldots \ldots \ldots \ldots$

The Problem and Method of Approach in the Present Study . . . . . . 3

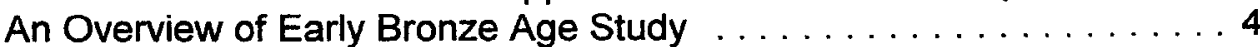

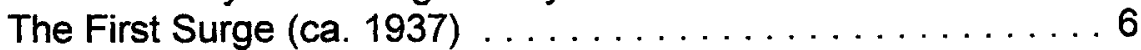

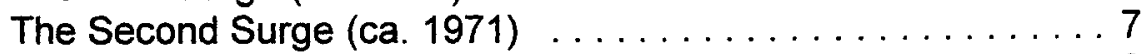

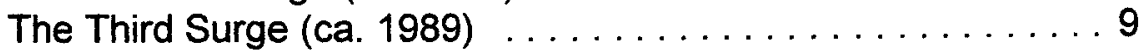

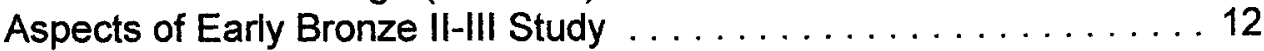

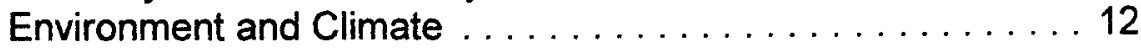

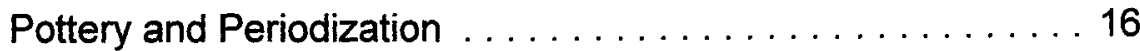

Beginning of EB $\| \ldots \ldots \ldots \ldots \ldots \ldots \ldots$

Subperiods in EB $\| \ldots \ldots \ldots \ldots \ldots \ldots \ldots \ldots$

Transition from EB II to EB III . . . . . . . . . . 20

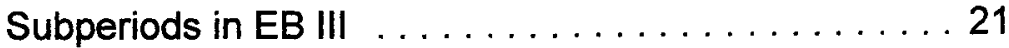

End of EB III . . . . . . . . . . . . . . . . . 22

Settlement and Society . . . . . . . . . . . . . 23

Settlement size and distribution $\ldots \ldots \ldots \ldots \ldots \ldots 23$

"Ruralism" versus "urbanism" . . . . . . . . . . 25

Social complexity ................ 26

Tell Ta'annek and Its Investigators . . . . . . . . . . . 28

The Location, Description, and Environment of

Tell Ta'annek ..................... 28

Excavation History of Tell Ta'annek . . . . . . . . . . 31

The excavations of Sellin ............... 31

The Taanach Excavations ............. 34

The Birzeit University Excavations . . . . . . . . . 35

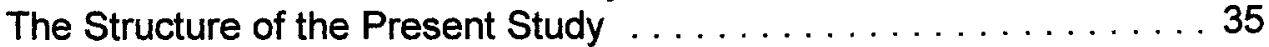

Summary .......................... 36

iii 
II. THE EARLY BRONZE AGE HORIZON AT TELL TA'ANNEK:

Introduction . . . . . . . . . . . . . . . . . . . 39

Sources for Reconstruction . . . . . . . . . . . . . . . 39

Field Books . . . . . . . . . . . . . . . . . . 39

Preliminary Reports . . . . . . . . . . . . . . 40

Graphic Records . . . . . . . . . . . . . . . . 40

Pottery Corpus . . . . . . . . . . . . . . . . . . 41

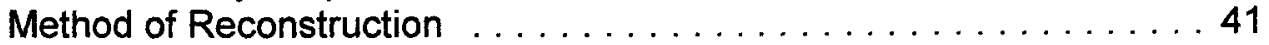

Creating a Harris Matrix . . . . . . . . . . . . . 42

Postulating Stratigraphic Phases ... . . . . . . . 42

Isolating Secure Loci . . . . . . . . . . . . . . . . . . . 44

Procedures of The Taanach Excavations . . . . . . . . . . . 45

Excavation ..................... 45

Registration .................... 48

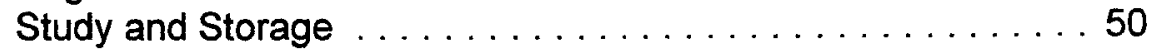

Definitions .......................... 52

Summary . . . . . . . . . . . . . . . . . 54

III. THE EARLY BRONZE AGE HORIZON AT TELL TA'ANNEK:

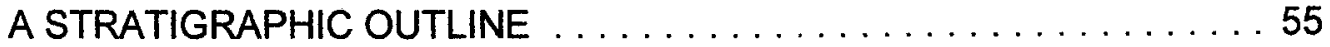

Introduction . ........................ 55

Stratigraphic Description and Analysis in Field A . . . . . . . . 55

Field A, Outline by Square . . . . . . . . . . . . . . 57

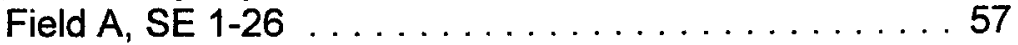

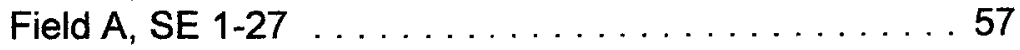

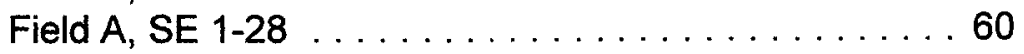

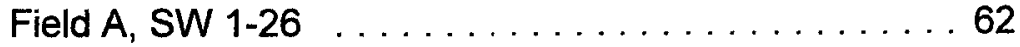

Field A, SW 1-27 . . . . . . . . . . . . . . 64

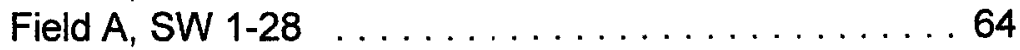

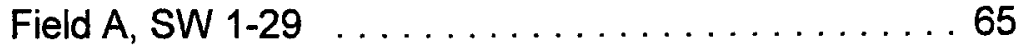

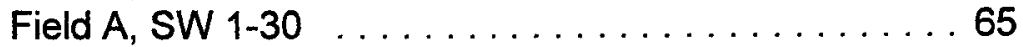

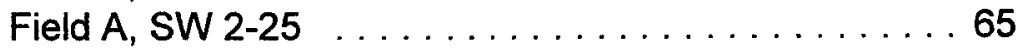

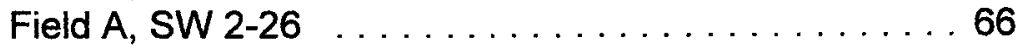

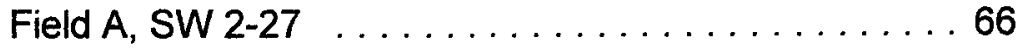

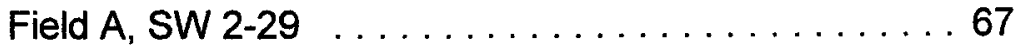

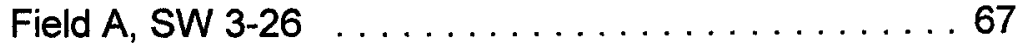

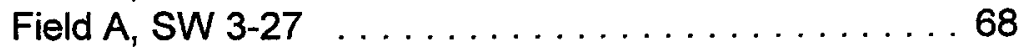

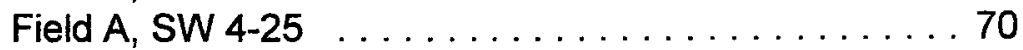

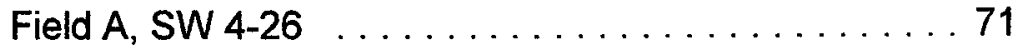

Field A, SW 4-27 . . . . . . . . . . . . . 71

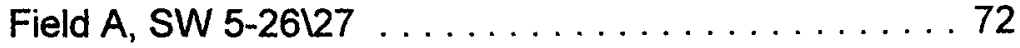

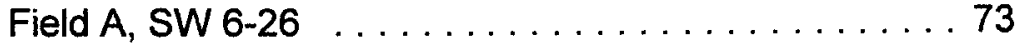

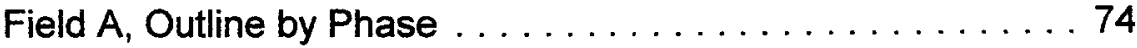

Stratigraphic Description and Analysis in Field B . . . . . . . . 76

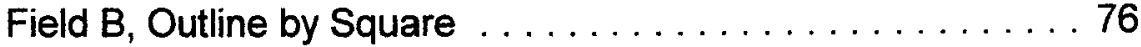

iv 
Field $\mathrm{B}, \mathrm{SW} 1-7 \ldots \ldots \ldots \ldots \ldots \ldots \ldots$

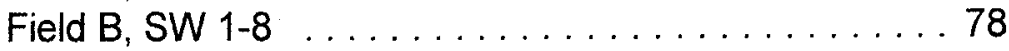

Field $B$, SW $1-9 \ldots \ldots \ldots \ldots \ldots \ldots$. . . . . . .

Field B, SW $2-7 \ldots \ldots \ldots \ldots \ldots \ldots \ldots \ldots$. $\ldots \ldots \ldots$

Field $B$, SW $3-5 \ldots \ldots \ldots \ldots \ldots \ldots \ldots$

Field B, SW $3-6 \ldots \ldots \ldots \ldots \ldots$

Field $B$, SW $3-7 \ldots \ldots \ldots \ldots \ldots$

Field B, Outline by Phase . . . . . . . . . . . 83

Stratigraphic Description and Analysis in Field $C \ldots \ldots \ldots \ldots$

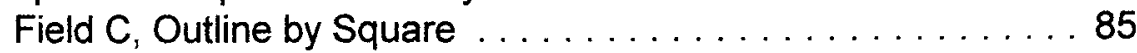

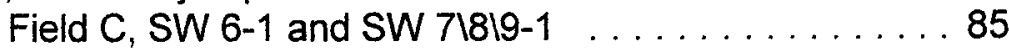

Field $\mathrm{C}$, NW $9-1 \ldots \ldots \ldots \ldots \ldots$

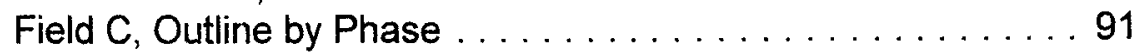

Stratigraphic Description and Analysis in Field D . . . . . . . . . 94

Field $D$, Outline by Square . . . . . . . . . . . . . 94

Field D, SW 6-7 . . . . . . . . . . . . . . . . . 94

Field $D$, SW $7-7 \ldots \ldots \ldots \ldots \ldots \ldots \ldots$

Field $D$, Outline by Phase $\ldots \ldots \ldots \ldots \ldots \ldots$

Stratigraphic Description and Analysis in Field $E \ldots \ldots \ldots \ldots . \ldots 98$

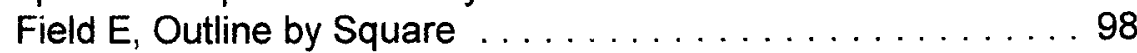

Field $\mathrm{E}$, NEO $2 \ldots \ldots \ldots \ldots \ldots \ldots \ldots$

Field $E$, Outline by Phase $\ldots \ldots \ldots \ldots \ldots \ldots$

Summary .......................... 100

IV. THE EARLY BRONZE AGE HORIZON AT TELL TA'ANNEK:

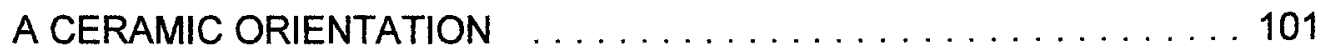

Introduction . . . . . . . . . . . . . . . . . . 101

Creating and Reading the Database ... . . . . . . . . . 101

Tier One: Identification, Location, and Form . . . . . . . 103

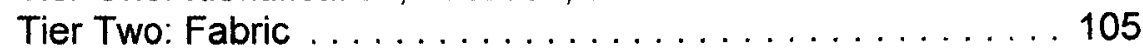

Tier Three: Finish . . . . . . . . . . . . . . . 106

Tier Four: Other $\ldots \ldots \ldots \ldots \ldots \ldots \ldots \ldots \ldots \ldots \ldots \ldots \ldots \ldots \ldots$

Tier Five: Drawing . . . . . . . . . . . . . . . . . . . 107

Ceramic Forms: Typology and Technology . . . . . . . . . . . 107

Rim Assignments . . . . . . . . . . . . . . . . . . . . . 107

Coil- or Brim-made Vessels: Neckless

Bowl and Jar Rims ... . . . . . . . . . . . . 108

Coil- or Brim-made Vessels: Necked

Jar Rims . . . . . . . . . . . . . . . 116

Mold-made Vessels: Bowl and Platter Rims . . . . . 120

Handle Assignments . . . . . . . . . . . . . . 127

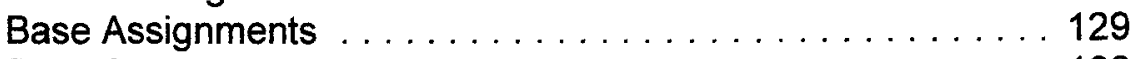

Body Sherds . . . . . . . . . . . . . . . . . 133

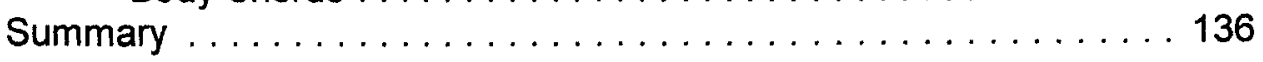

V. THE EARLY BRONZE AGE HORIZON AT TELL TA'ANNEK:

A CERAMIC OUTLINE 
Introduction ........................... 140

Analysis by Field and Phase $\ldots \ldots \ldots \ldots \ldots \ldots \ldots \ldots \ldots \ldots \ldots \ldots$

Field A, Phase 1A . . . . . . . . . . . . . . . . 141

Analysis and summary . . . . . . . . . . . 141

Field A, Phase 1B . . . . . . . . . . . . . . . . . . 141

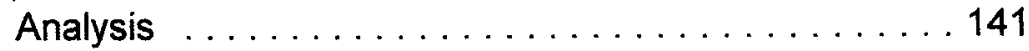

Summary ..................... 143

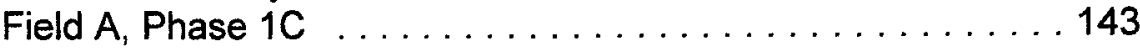

Analysis ..................... 143

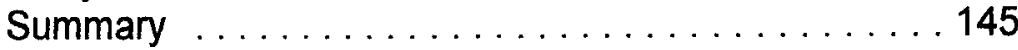

Field A, Phase 2 A . . . . . . . . . . . . . . . . 145

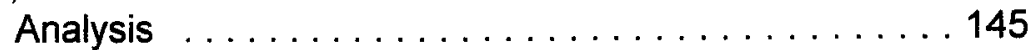

Summary . . . . . . . . . . . . . . . . 147

Field A, Phase 2B . . . . . . . . . . . . . . . . . . 147

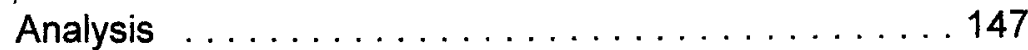

Summary . . . . . . . . . . . . . . . . . . 148

Field A, Phase 3 A . . . . . . . . . . . . . . . . . . . . 149

Analysis . . . . . . . . . . . . . . . . . 149

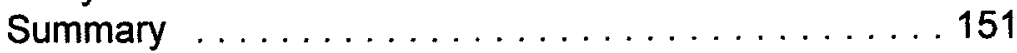

Field A, Phase 3B . . . . . . . . . . . . . . . . 152

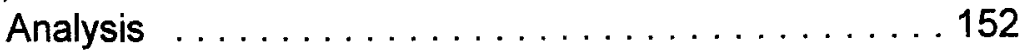

Summary .................... 153

Field A, Phase 4A . . . . . . . . . . . . . . . 153

Analysis and summary . . . . . . . . . . . . . . . 153

Field A, Phase 4B . . . . . . . . . . . . . . . . . . 153

Analysis ....................... 153

Summary ........................ 155

Field A, Unphased Loci . . . . . . . . . . . . . . . . 155

Analysis and summary . . . . . . . . . . 155

Field B, Phase 1A . . . . . . . . . . . . . . . . . . . 156

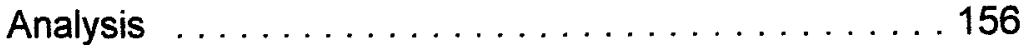

Summary .................... 156

Field B, Phase 1B . . . . . . . . . . . . . . . 156

Analysis and summary $\ldots \ldots \ldots \ldots \ldots \ldots \ldots$

Field $B$, Phase $1 C \ldots \ldots \ldots \ldots \ldots \ldots \ldots \ldots \ldots$

Analysis . . . . . . . . . . . . . . . . . . 157

Summary . . . . . . . . . . . . . . . 158

Field B, Phase 2B . . . . . . . . . . . . . . . . . . . 159

Analysis . . . . . . . . . . . . . . . . . . . . 159

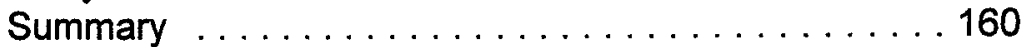

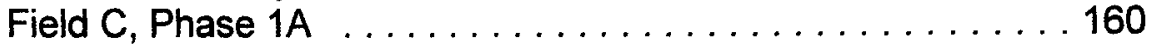

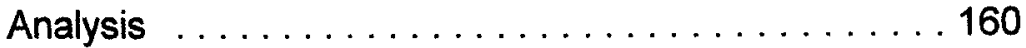

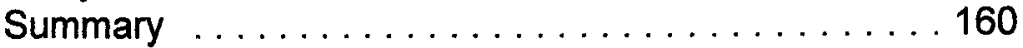

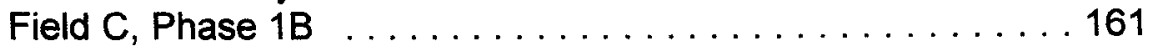

Analysis and summary ............... 161

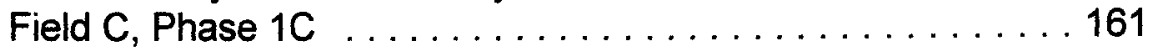

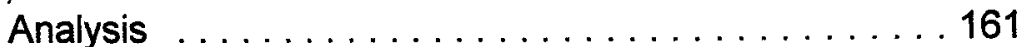

Summary . . . . . . . . . . . . . . . . . 162

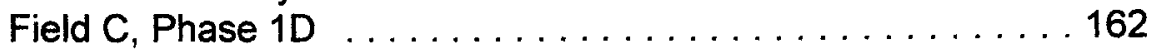

vi 


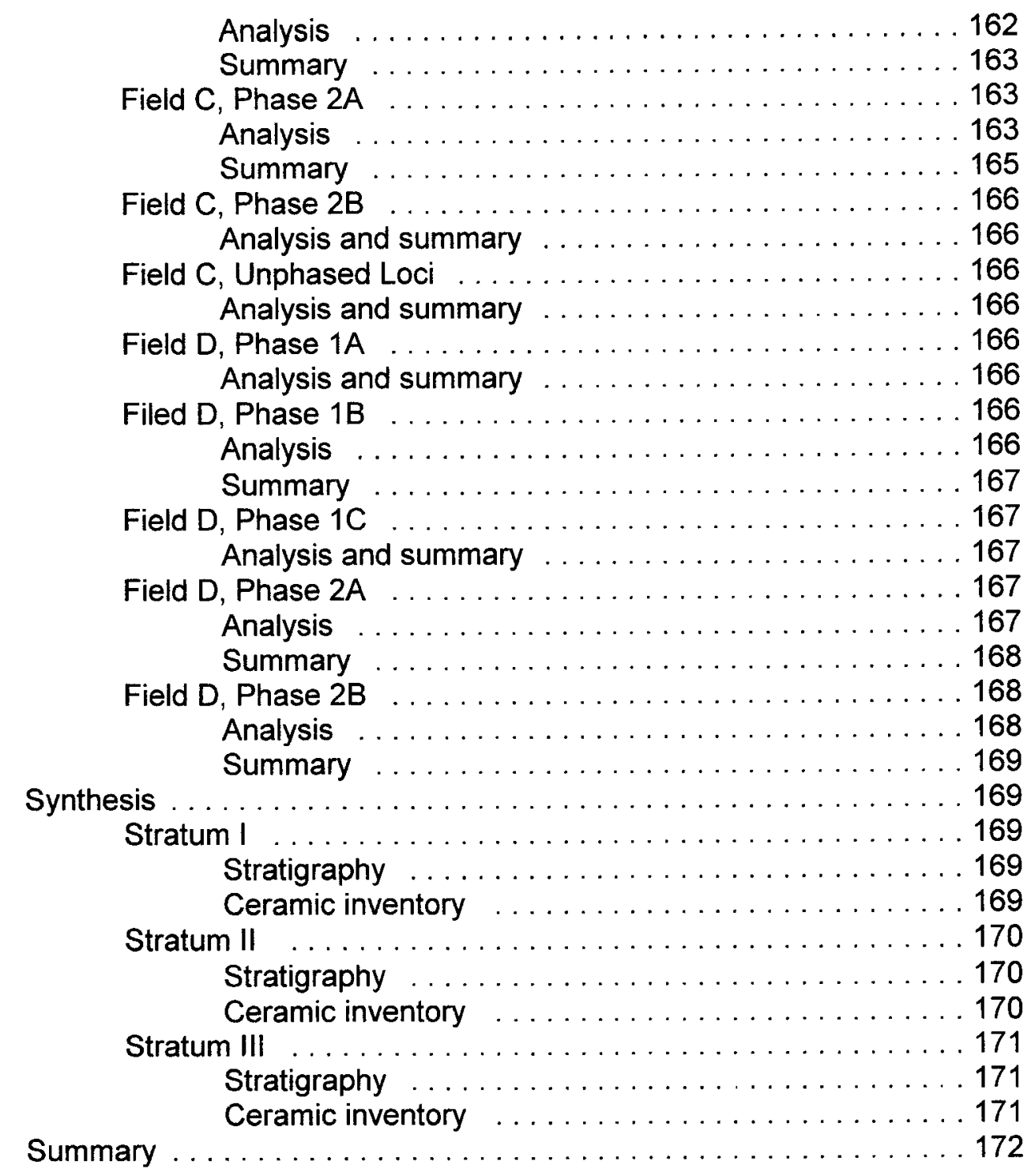

VI. LOOKING BACK, AROUND, AND FORWARD FROM

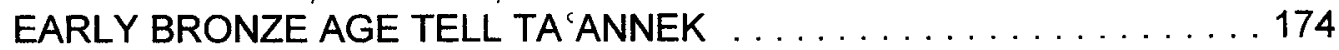

Introduction .............................. 174

Looking Back from Tell Ta'annek: Glock's "Fabric Families" . . . . . . 174

The Agenda . . . . . . . . . . . . . . . . . . . . . . . . . 174

An Unreached Goal . . . . . . . . . . . . . . . . . 176

The Legacy . . . . . . . . . . . . . . . . . . . . 178

Looking Around from Tell Ta'annek: Persistent Potters and the

Dynamics of Resistance . . . . . . . . . . . . . . . 179

Tell Ta'annek, Early Bronze II, and Metallic Ware . . . . . . . 180

The Numbers . . . . . . . . . . . . . . . . . . . . . . . 180

A Metallic Ware curve . . . . . . . . . . . . . . 181

The end of the line ................ 183

Persistent potters . . . . . . . . . . . . 188

vii 
Tell Ta'annek, Early Bronze III, and Khirbet Kerak Ware . . . 192

The numbers . . . . . . . . . . . . . . . . . . . 192

A mesh . . . . . . . . . . . . . . . . . . . . 194

Persistent potters . . . . . . . . . . . . . . . . . . . . 194

Looking Forward from Tell Ta'annek: New Vistas . . . . . . . . . . . . 197

Appendix

I. INDEX TO PHASED LOCI BY PLATE ASSIGNMENT . . . . . . . 200

11. INDEX TO PHASED LOCI BY SQUARE AND FIELD

ASSIGNMENT . . . . . . . . . . . . . . . . . . . . . . . . 205

III. A PETROGRPHIC ANALYSIS OF SAMPLES FROM THE EARLY BRONZE AGE ASSEMBLAGE OF TELL TA'ANNEK:

A CONTRIBUTION BY TAHANI SALEM

WITH MARK ZIESE . . . . . . . . . . . . . . . . . . . . 207

IV. PLATES ............................. 218

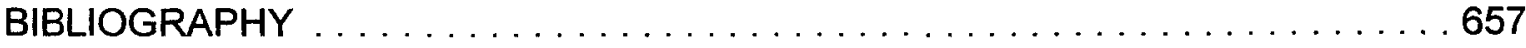

viii 


\section{LIST OF FIGURES}

1a. View Southwest to Tell Ta'annek in the Early 1960 s $\ldots \ldots \ldots \ldots \ldots 33$

1b. Aerial View to Tell Ta'annek . . . . . . . . . . . . . . . 33

2. A Sample of a Harris Matrix, Showing all Loci Relationships and Ceramic Field Readings from SW $2-29 \ldots \ldots \ldots 43$

3a. Excavation in Progress (1968) $\ldots \ldots \ldots \ldots \ldots \ldots \ldots \ldots \ldots$

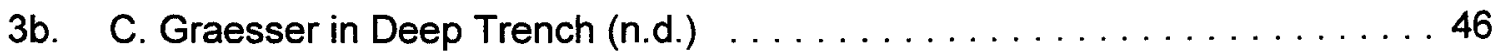

4. J. Sauer and Camp Worker Arrange Sherds Drying in the Sun (1963) . . . . 49

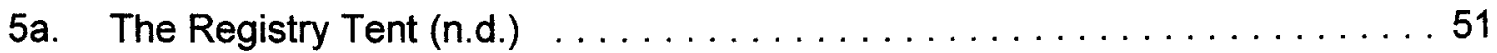

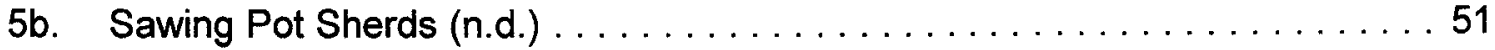

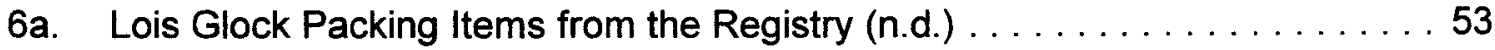

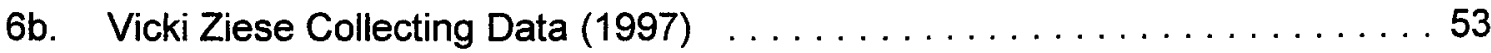

7. View East to EBA Fortifications in Section, SE 1-26 and 1-27 $\ldots \ldots \ldots 59$

8. View East to Excavated EBA Fortifications in Field A (1968) . . . . . . . . . 61

9. View West to EBA Fortifications in Section, Field $A \ldots \ldots \ldots$

10. View West to EBA Fortifications in Section, SW 3-26 and 3-27 . . . . . 69

11. View North to Phase 1 Domestic Complex in Field B (n.d.) . . . . . . . 79

12. View North to Phase 2 Domestic Complex in Field $B$ (n.d.) $\ldots \ldots \ldots \ldots$

13. View South to EBA Fortifications in Section, Field $C \ldots \ldots \ldots \ldots$

14. View to Enigmatic Pedestals in Field $C$ (n.d.) $\ldots \ldots \ldots \ldots \ldots$

15. View South to EBA Fortifications in Section, NW $9-1 \ldots \ldots \ldots \ldots 2$

16. View to EBA Fortifications in Section, SW $7-7 \ldots \ldots \ldots \ldots$ 
17. Worksheet ............................ 102

18. Neckless Vessels: Rim Typological Assignments (R01-R29) . . . . . . . 109

19a. Neckless (Holemouth) Bowl Defined . . . . . . . . . . . . . . . . . 110

19b. Neckless (Holemouth) Jar Defined . . . . . . . . . . . . . . . 110

20. View to the Interior Wall of Two Holemouth Forms . . . . . . . . . . 112

21. Necked Vessels, Rim Typological Assignments (R30-R43) . . . . . . 117

22. Bowls and Platters, Rim Typological Assignments (R50-R60) . . . . . . 121

23. Concave Margins on Mold-made Vessels . . . . . . . . . . . . 123

24. Bowls with Sooty Rims, likely used as Lamps . . . . . . . . . . . . . 124

25. Exterior Wall and "Keel" of a Carinated Bowl . . . . . . . . . . . . 126

26. Handle Typological Assignments . . . . . . . . . . . . . 128

27. Base Typological Assignments . . . . . . . . . . . . . . . 130

28a. A String-cut Base? . . . . . . . . . . . . . . . . 132

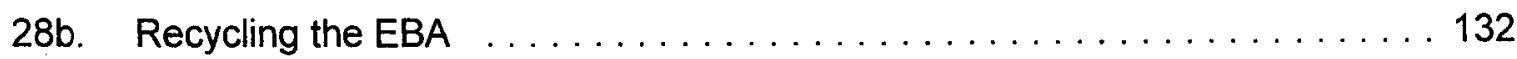

29a. A Metallic Ware Jug Base in Section . . . . . . . . . . . . . 134

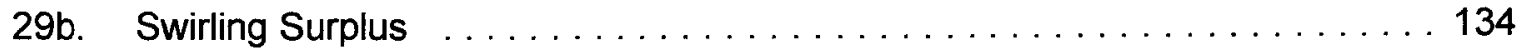

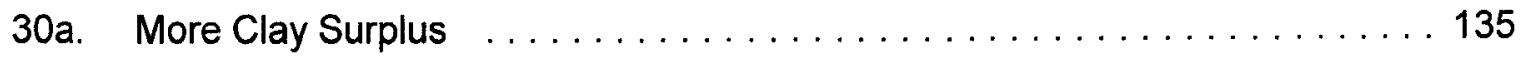

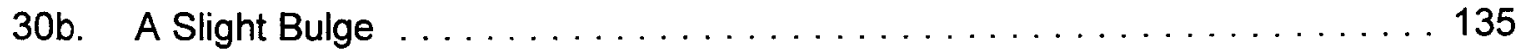

31a. Samples of Incisions or Potter's Marks . . . . . . . . . . . . . 137

31b. Samples of Combed Metallic Ware $\ldots \ldots \ldots \ldots \ldots \ldots \ldots \ldots$

32. Samples of Painted Decoration $\ldots \ldots \ldots \ldots \ldots \ldots \ldots \ldots \ldots \ldots$ 


\section{LIST OF TABLES}

1. Tell $\mathrm{Ta}^{\mathrm{c}}$ annek Occupation as Summarized by Glock $\ldots \ldots \ldots \ldots \ldots . \ldots 37$

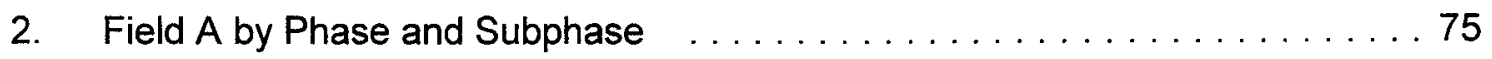

3. Field $B$ by Phase and Subphase $\ldots \ldots \ldots \ldots \ldots \ldots \ldots \ldots \ldots$

4. Field $\mathrm{C}$ by Phase and Subphase $\ldots \ldots \ldots \ldots \ldots \ldots \ldots \ldots \ldots \ldots$

5. Field $\mathrm{D}$ by Phase and Subphase $\ldots \ldots \ldots \ldots \ldots \ldots \ldots$

6. Metallic Ware in the Tell Ta'annek Assemblage by Stratum $\ldots \ldots \ldots 182$

7. Khirbet Kerak Ware in the Tell Ta'annek Assemblage by Stratum ..... 195

\section{LIST OF MAPS}

1. Location of Tell Ta'annek ........................... 30

2. Sketch of Tell Ta' annek and Locations of

Excavated Fields $\ldots \ldots \ldots \ldots \ldots \ldots \ldots \ldots \ldots \ldots \ldots$

3. Top Plan of EBA Structures in Field A $\ldots \ldots \ldots \ldots \ldots \ldots \ldots \ldots \ldots$

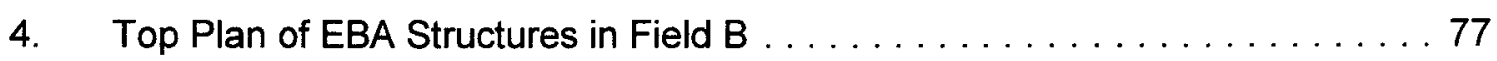

$x i$ 


\section{PREFACE}

Nearly 150 years ago, the explorer and scholar Edward Robinson returned to Palestine to revisit the landscape which, in his view, held the key to unlocking the secrets of the past. In search of biblical connections, he initiated the study of an historical geography anchored firmly in research and personal observations, rather than in ecclesiastical traditions.

On April 21, 1852, he stood on the crest of a "noble tell" known as Ta'annek. There, he observed how this place "would indeed present a splendid site for a city; but there is no trace, of any kind, to show that a city ever stood there" (1856: 117). Of course, we know now that the city Robinson sought was resting quietly under his feet, and that time has a way of turning busy cities into silent mounds.

My own explorations would have never been possible without the gracious help of many institutions and individuals. They have quietly supported me even when I was unsure of my own vision. The Cincinnati Bible College and Seminary granted me a study sabbatical for the 1996-1997 school year and funded the stay for our family in Palestine. The ready support of David Grubbs, Jim North, Bill Weber, Dan Dyke, and Jon Weatherly is appreciated. The same must be said of Robert Gulley, who remains my friend even after the supreme effort of lugging an enormous set of electronic gear overseas, only to find himself handcuffed, hauled off, and put behind bars when it was mistaken for something else. Besides Robert, other students, family, or friends who assisted in the collection of data and their analysis include Eric Ankeman, Traber Cass, 
Patrick Mahoney, Sarah Patrick, Walter Reiter, Andrea Ritze, Nathan Wheeler, Karen Ziese, and Vicki Ziese.

The kind direction of Walt Rast, Nancy Lapp, and Lois Glock is a credit to the legacy of The Taanach Excavations. Each in his or her own way proved to be extremely helpful to one who was still in diapers in the year Paul Lapp, Al Glock, and others first took to the field.

A thank you must also be extended to Tom Schaub who graciously stepped in at the last moment to help push this work through the dissertation process.

At Andrews University, I am fortunate to count Randy Younker, фystein LaBianca, and David Merling as not only professional advisors and colleagues, but genuine friends. Recognition must also go to Bonnie Proctor who gave this manuscript a close read and offered many helpful suggestions.

I am grateful to the American Schools of Oriental Research (ASOR) for an Endowment for Biblical Research Travel Grant for the summer of 1998.

The Albright Institute of Archaeological Research (AIAR) graciously granted me a Research Fellowship for the year 1996-1997. The resources of the library and helpful people like Arlene Rosen, Ruth Amiran, Amir Golani, Alex Joffe, and Raphael Greenberg proved invaluable for this work. The same might be said of relaxing Sunday afternoons in the warm company of Bob and Anne-Marie Miller and Jeff and Brauna Blakely. The hospitality of Sy Gitin and the staff of the AIAR will be long remembered. They provided a warm and welcome enclave in difficult hours.

Words fail me when I attempt to thank my friends in Palestine for their resilience, graciousness, and kindness. $1996-1997$ was in some ways a very difficult period of time, and yet, I am honored to have shared it with some wonderful people. The Spiro 
Jasser family invited my family into their Birzeit home and made us part of their daily life. God knew what He was doing when He sent us to you.

Khalid Nashef and the staff of the Palestinian Institute of Archaeology also were gracious in granting us a place to study, work, and play. Mohammed Muqbil, Nail Jelal, Ibrahim Iqteit, Hamed Salem, and Tahani Salem were generous with personal hospitality and professional advice. Andrew and Alice Hicks came in the nick of time to catalogue the PIA library and be our friends also.

Finally, personal thanks must be extended to Hamdan Taha and the Palestinian Department of Antiquities as well as Hava Katz and the Israel Antiquities Authority. Their cooperation in facilitating the movement of a portion of the Tell Ta'annek assemblage for study was essential for the completion of this project.

One of the least mentioned, yet more significant qualities of God's grace is that we are spared a full knowledge of the future. I wonder which road I would have taken if the twists and turns, much less the dead ends, were obvious at the start. Certainly if I had known what would be involved in the production of this report, I would have stepped quickly in a different direction. Yet, if that had happened, my bag of life experiences would have been smaller and certainly poorer for having missed many things.

Thank you Vicki, Tanner, and Moriah for your patience and help through all of this. Let's go camping! 


\title{
CHAPTER I
}

\section{INTRODUCING THE PROBLEM, THE EARLY BRONZE AGE,}

\author{
AND TELL TA'ANNEK
}

\section{Introduction}

Human residue configurations identified with the Early Bronze Age (hereafter EBA) in Palestine have been viewed from a variety of perspectives which seize upon certain aspects of the whole. ${ }^{1}$ In one view, that residue trajectory is plotted as the first wave in a series of settlement intensifications, framed on either side by troughs of settlement abatement. In other views, the EBA in Palestine appears as the outgrowth of "protoliterate" and "preurban" societies, a provincial or semi-complex "state," or even in one case, a kind of "kingdom,"' pressed between the more "developed" cultures of the Nile and Mesopotamian basins. Still another view plots the trajectory of EBA society along the lines of "the generation, resolution and regeneration of contradiction" (Joffe 1993: 90). ${ }^{3}$ Such colorful conceptions suggest that the study of the EBA has been, is

${ }^{1}$ Here, the use of the term "Early Bronze Age" loosely corresponds to what might be termed "phase" or "pattern" within the Midwestern Taxonomic Method (Willey and Sabloff 1980: 106-7) or "culture" or "culture-group" within the proposal of Clarke (1968: 300). Despite certain weaknesses of "the Three Ages' System" (e.g., the criticism of Chapman 1989, 1990), it remains the preferred venue of description, interpretation, and explanation in the archaeological traditions of Palestine.

${ }^{2}$ Lapp (1970: 114) suggests that unity characterized the fortified villages of the EBA and that such unity bespeaks "a fairly unified kingdom" (emphasis mine).

${ }^{3}$ Fargo (1979b: 5) identified a similar idea couched in the progression of "disturbance," "equilibrium," and "disturbance" to describe the "urban EB III culture and 
now, and promises to be in the future, a vibrant and lively debate. Consensus, in terms of nomenclature, dates, and the nature of EBA society, has been hard won, and in many cases, is yet to be realized.

It is purposed here to sketch the contours of such struggles and realizations in this century. This is mandated by several reasons, not least of which involves the (re)creative process of scholarship and the struggle to confront and control the past. ${ }^{1}$ To the degree that this is possible, this introductory chapter presents five descriptions. The first description offers a brief statement of the problem addressed by the present study and the method used to approach the problem. The second description provides an overview of EBA research since about 1937. The third description magnifies the scale of examination to detail aspects of Early Bronze (hereafter EB) II-III study. The fourth description introduces the investigators and investigations of Tell Ta'annek in the 20th century. The fifth and final description introduces the larger structure of the present study. Viewed consecutively, these five descriptions follow movements within the field of EBA research, and, hence, sketch a context for the work at hand; viewed together, these descriptions suggest the dimension of depth achieved over the course of nearly a century of research.

the ensuing demise of the city-state system."

${ }^{1}$ Trigger (1989: 16) soberly warns, "while archaeological data are being collected constantly, the results are not necessarily as cumulative as many archaeologists believe. Indeed, archaeologists often seem to build more on what their predecessors concluded about the past than on the evidence on which these conclusions were based." 


\section{The Problem and Method of Approach \\ in the Present Study}

This study attempts to isolate, describe, and analyze a ceramic sample drawn from the EBA residues of Tell Ta'annek. It proposes that the data recovered by The Taanach Excavations may be used to establish a relative chronology of the site, and hence, a distinct ceramic sequence within the EB II-III periods. Such a sequence firmly fixes the site of Tell Ta'annek within a matrix of EBA sites in North Palestine and makes it possible to explore inferences about typology, technology, and trade.

The method used to address this problem is admittedly heuristic, empirical, and at times, intuitive. It proceeds along several lines--often simultaneously-moving between ceramic and stratigraphic data. However, it is also quickly realized that there is a reality "not of our own making" (Wylie 1992: 21) and therefore, imposed limits which cannot be ignored. Hence, a return to the excavator's field books and to published ceramic parallels has been characteristic of the process by which this study was shaped. Much more could be offered here by way of method, but given later discussions in chapters 2,3 , and 4 , it is enough for the moment to simply trace a profile of thought.

On the basis of the written records from The Taanach Excavations, a stratigraphic sequence of the EBA horizon at Tell Ta'annek is proposed by square and locus. This sequence was tested by the retrieval and analysis of saved ceramic sherds. Index forms (typically rims, handles, and bases) forced alterations of the reconstruction, oftentimes midstream, which, in turn, required additional reshuffling. This effort ultimately affirmed an EB II-III sequence and led to the isolation of a set of about 2,000 sherds drawn from living surfaces and fills. Each sherd was catalogued, described, drawn, and is presented in this study. Such an assemblage is a powerful conclusion in 
and of itself for the study of typological and technological features. However, as a stratigraphically-derived assemblage, these data may also be compared with data elsewhere in the region and used as a springboard for framing larger conclusions about chronological and social issues in the study of EBA North Palestine. ${ }^{1}$

\section{An Overview of Early Bronze Age Study}

Isolating "stages" or "surges" in the historical development of a discipline risks assuming a steady (if not unilinear) progression of knowledge, and thereby slipping into a positivist's or hyper-positivist's camp. False starts, detours, competing ideas, and other awkward steps are as heuristically valuable as the "real breakthroughs" so often chronicled. By the same token, history has been a cruel critic of positions believed by contemporaries to be "comprehensive" or "state of the art."

It is recognized that archaeological preoccupations in the present day have deep and often overlooked roots in the past. Ideas touted as "new" may only be "new" as the framework in which they are voiced has changed. To "do" a history of the discipline (or some small part thereof) therefore requires that keen attention be paid to such larger frameworks. For this reason, Kuhn's theory of paradigm "shifts" (1970) has proved a useful, albeit provocative, tool for the chroniclers of intellectual history. ${ }^{2}$

'The choice to present the ceramic material by locus rather than by type or form is consistent with the precedent of Rast (1978: 1) and underlines a continuing commitment to the priority of stratigraphic orientation.

${ }^{2}$ Both Dever (1980a; 1988) and Blakely (1990) have presented views concerning the history of Palestinian archaeology that utilize Kuhn's theory of paradigm shifts. Sharp differences arise, however, in the definition and interpretation of these shifts. As one example, in Dever's view, the discipline has moved through several paradigms, the last of which is associated with his own work in the 1960s and 1970s and the "revolution" ushered in by the "New Archaeology." Blakely, on the other hand, argues that the influence of the New Archaeology is merely one of "perception and image" with little substance (1990: 232). In his view, the story of excavation publication displays no significant change of consensus beyond the Petrie-Bliss paradigm initiated at the 
Archaeological methods in Palestine continue to be firmly rooted in ideas first explored by Petrie (1904) and Bliss (1894). ${ }^{1}$ While enormous refinements in process and interpretation are a significant part of the story of archaeology in Palestine, the fundamental conclusions associated with these pioneers has yet to be overturned. Therefore, the history of EBA study may be presented as a series of surges and crests within a single, larger paradigm. Surges are built upon the strengths of previous work, and while crests may redress the discussion in new or imported terms and ideas, they can ultimately be judged successful only to the degree that they are grounded in the basic principles of stratigraphic excavation and a chronologically built ceramic typology. These controlling principles require no justification; they are assumed valid by the consensus of the current paradigm (Kuhn 1970: 19-20; Walker 1978: 4-6; Blakely and Toombs 1980: 5-6, 22-23).

In this description, three "surges" of EBA study are lightly traced in the 20th century. Each of these surges is associated with significant "crests" that provide a certain vantage point for viewing the contemporary discussion. The first surge witnessed the "birth" and "refinement" of the EBA and its subperiods. Its crest is associated with the pioneering work of Wright (1937). The second surge witnessed a massive collection of EBA data and the attempt to synthesize and explain these data in historical terms. A second crest is associated with the presentations of de Vaux (1971) and Callaway (1972). A third surge witnessed the infusion of ideas associated with the beginning of the 20th century.

${ }^{1}$ Two observations focused the course of archaeological investigation in Palestine at the turn of the century. The first observation was that tell sites contained the remains of cultural debris that could be recovered stratigraphically. The second observation was that an established ceramic typology could be used as a tool to chronologically assess recovered strata. 
"New Archaeology" and its subsequent failure to produce the consensus necessary to overturn the present paradigm. While several publications are arguably "crest"-like for this third surge, the most pivotal are two collaborative efforts which reflect materials presented in a conference setting (Miroschedji 1989b; Philip and Baird 2000).

\section{The First Surge (ca. 1937)}

Work in the first half of the 20th century was focused primarily on implementing the ideas of Petrie and Bliss. Developing excavation methodology and activating more stringent recording procedures forced the paradigm away from analysis on the order of an entire city, as Bliss envisioned, to focus on specific architectural features, as Reisner and Fisher envisioned (Blakely 1990: 140). Discussion was fueled by the work of Albright in developing a ceramic typology for the region as well as the discovery of culture contacts with Egypt. Wright's well-known 1937 synthesis initiated the systematic study of the EBA by utilizing the sum of published ceramic data to produce the fourfold division of the period largely held today (EB I, II, III, IV). ${ }^{1}$ This heuristic effort was drawn from scant materials excavated in the early part of the century at Tell el-Mutesellim (Megiddo), Tell el-Husn (Beth-shan), Et-Tell ('Ai), and Tell es-Sultan (Jericho), as well as ideas from Albright himself. ${ }^{2}$

In the decades that followed, additional information became accessible through the publication of new survey or excavation projects at EBA sites including 'Afula,

${ }^{1}$ Wright originally shied away from this use of Roman numerals because of the wider confusion their use might create. His original proposal called for EBA phases designated by Greek letters, e.g., "Alpha phase," "Beta phase," "Gamma phase," and "Delta phase" (Wright 1936: 13).

${ }^{2}$ Wright acknowledged the foundational work of his teacher, Albright, who had already subdivided the EBA into three phases in his study of the Tell Beit Mirsim material. See the opening paragraph to Wright's earlier work (1936: 12). 
Khirbet el-Kerak (Beth-yerah), Bab edh-Dhra', Tell Dothan, Tell esh-Sheikh Ahmed el'Areini ('Erani), Tell el Far'ah (N), Tell es-Sultan (Jericho), Tell ed-Duweir (Lachish), and Khirbet el-Musheyrife (Rosh ha-Niqra). ${ }^{1}$ As a result, Wright's original synthesis was further modified (1958 and 1961) and tested by others (Albright 1954; Yeivin 1961; Amiran 1967).

Perhaps the most thorough test was produced by Ben-Tor (1968) who clearly anticipated the second surge in EBA studies. While focused specifically on the EB II and III periods, Ben-Tor effectively surveyed the stratigraphic evidence available at the time. Architectural types, weapons, seals, and other small finds were summarized. However, the strength of Ben-Tor's contribution rested on his ceramic surveys of Khirbet Kerak Ware and Abydos/Metallic Ware groups both within and without Palestine.

Significantly, the basic outline of Wright continued to stand although it was filled and finely adjusted.

\section{The Second Surge (ca. 1971)}

A flurry of excavation and survey projects took to the field in the 1960 s and early 1970s at sites including Tell 'Arad, Khirbet el-Kerak (Beth-yerah), Khirbet el-Yarmuk (Yarmuth), Et-Tell ('Ai), Tell Ta'annek, Tell el-Hesi, and Bab edh-Dhra'. Refinements in excavation methodology and recording procedures continued to narrow the unit of study within the Petrie-Bliss paradigm. Whereas Bliss envisioned excavation on the order of cities and Reisner-Fisher on the order of significant architecture, the Wheeler-Kenyon approach demanded attention be given to discrete soil layers (Blakely 1990: 193).

${ }^{1}$ Presenting maps, bibliographies and summaries for each of these sites is beyond the scope of the present study. Up-to-date information along these lines is immediately available in Meyers (1997) or Stern (1993). A thorough, although now dated bibliography of EBA sites and publications is available in the work of Ross (1987). 
Paradoxically, while this narrowing of the unit of study had the potential for generating greater control, it also multiplied the units of study to such an extent that full synthesis and publication of the data was rendered difficult, if not impossible. ${ }^{1}$

Demonstration of this point comes from Callaway's publication of the EBA sanctuary at Et-Tell (1972). While the excavation proceeded explicitly along the lines of a Wheeler-Kenyon model, the final report resorted to a Reisner-Fisher format. ${ }^{2}$

Callaway discussed only select loci and made no attempt to deliver a full loci matrix.

While reasons for these choices may be surmised, the result renders full reconstruction of the site impossible. Despite these criticisms, however, Callaway's work is exceedingly significant as the first effort to publish the stratigraphy and ceramics of a major EBA site.

To what extent de Vaux was appraised of the developments at et-Tell remains an open question. Certainly, select details were known to him as seen by their inclusion in his EBA synthesis released in advance of Callaway's publication. De Vaux's 1971 effort surveyed the history of EBA excavation and outlined a chronological overview of each subperiod. Evident in de Vaux's work are themes common to this "surge" including urbanization (Amiran 1970), periodization (Dever 1973), ethnicity and cultural diffusion (Ben-Tor 1968; Lapp 1968), architecture (Wagner 1972; Ben-Tor 1973; Helms 1976), international contacts (Amiran 1952, 1960; Yeivin 1960; Hennessy 1967), spatial

1Blakely (1990: 194-5) writes, "For tell sites, the publication of broad exposures in a Wheeler-Kenyon soil-layer format is almost unknown. . . It is suggested that the successful publication of the areas at Jericho, Hesi, and Gezer can be attributed to one of two factors, or both. Either they were the sole projects to record their data with sufficient precision to allow soil layers to be stratified for publication, or the analysts were the only individuals willing to bother to make such an attempt. Neither of these suggestions is appealing, but one or both must be valid."

${ }^{2}$ This point was made by Blakely in print (1990: 194) and in a series of oral communications with the writer. 
patterns (Gophna 1974; Rast and Schaub 1974; Kempinski 1978; Zori 1977; Fargo 1979b; Thompson 1979), and pottery (Amiran 1967 and 1969; Callaway 1964; Schaub 1973; Amiran 1974; Fargo 1979a). De Vaux even cautiously explored biblical connections, although not to the same extent as others (Wright 1961, 1962; Freedman 1978; Pettinato 1979). Ambitious syntheses of the period and its issues demonstrate the surge which accompanied this crest (Lapp 1970; Kenyon 1970; Wright 1971; Miroschedji 1971; Callaway 1978; Fargo 1979b; Ross 1980). While innovative edges (such as Miroschedji's ecological emphasis) both revived and anticipated other ideas, more central concerns of this surge were those initially raised by Wright concerning the terminology and nature of transition periods.

\section{The Third Surge (ca. 1989)}

In the period associated with the third surge and leading up to the present, traditional concerns continued to be addressed while elements of the "New Archaeology" introduced both disorientation and resolution into the field. Language imported from the social sciences became prolific; project strategies and methods grew more explicit. It has been proposed that these "tremors" signaled the end of a consensus involving the goals of archaeological interpretation (historical explanation vs. nomothetic generalization) and the method by which those goals were sought (Dever 1988: 339).

To engage this proposal fully is beyond the scope of this sketch. However, it may be pointed out that while the rhetoric on this issue has been fierce and wideranging in the literature and classroom, few changes have actually been witnessed on the ground. What appears new (but not without antecedent) includes strategies designed to retrieve nonceramic categories of evidence such as flora, fauna and lithic, 
and strategies designed to extract nonchronological data from ceramic remains. In both cases, thrusts in the direction of "total retrieval" have produced a mass of valuable, yet frequently indigestible data, adding complexity to the task of producing a final analysis. Whether these categories can be advanced from the position of "appendix" or "specialist's report" to be systematically and comprehensively integrated into a final publication remains to be seen. Beyond this inability to merge theory and practice, the failure of the "New Archaeology" movement to produce a consensus on even the most fundamental terms such as "culture change" suggests that its wholesale import into the field of Syro-Palestinian archaeology should be cautiously regarded.

Despite this basic theoretical disorientation, survey projects, major excavations, and salvage operations multiplied in the era leading up to the present. A review of notices in Excavations and Surveys in /srael demonstrates active work at more than 50 sites with EBA residues between 1987 and $1999 .^{1}$ Projects from Jordan lengthen this list. $^{2}$ Unfortunately, beyond brief notices, most of these data remain unpublished. On the other hand, projects in the southern Levant that include EBA material and have

${ }^{1}$ Sites in Excavations and Surveys in Israel include: Tell Malot, Jerusalem (Pisgat Ze'ev-East A and Nahal Refa'im), Upper and Lower Horvat 'Illin, Yarmut, Kabri, Horvat 'Uza, Qiryat Ata, Nizzanim, Beth-shan, Palmahim-Quarry, Sataf, Tel Nes, Khirbet 'Umdan, Tel Rumeideh (Hebron), Taur Ikhbeina, Tel Yin'am, Tel Qashish, Horvat Menorim, Tel 'Erani, Tel Halif, Hartuv, Hayonim Terrace, Me'ona, Tel Na'ama, Palmahim, Tel Shalem, Horvat Tov, Tell el-Wawiyat, Tel Yoqne'am, Oshrat, Tel Gat Hefer, Shoham, Tel 'Amal, Azor, Jericho (Tell es-Sultan), Ashqelon (Hatayyasim Street and Afridar), and Shefayyim. Surveys published in ESI and reporting EBA materials include Rosh Pinna Map, Nazareth Map, 'Afula Map, Beth Shemesh Map, New Harim Map, Hula Valley, Land of Geshur, Zur Natan, Har Loz (Northeast) Map, Bet Govrin Map, el-Maghayir Map and Har Karkom.

${ }^{2}$ Tell es-Sa idiyeh, Pella, Iktanu, Abila, Abu Thawwab, Tell el-Handaquq, Tell eshShuna (N), Tell Um Hammad esh-Sharqi, Tell el-Mugheiyn, Mughayyir, Khirbet ezZeraqon, Telul edh-Dhahab, Arqub edh Dhahr, Tell Abu al-Kharaz, Bab edh-Dhra', Numeira, Tell Jalul, Tell el-'Umeiri, Balua' ,Tell al-Hammam, Sahab, Amman Citadel, Khirbet Iskander, Es-Safi, Feifeh, Khanazir, and Tell Mustah. 
reached final publication status in the era leading up to the present include: En Shadud (Braun 1985), the Madaba Plains (Geraty 1989, 1991), Yarmouth (Miroschedji 1988), the Wadi al Hasa Archaeological Survey (MacDonald 1988), Khirbet Iskander (Richard and Boraas 1988), Bab edh-Dhra' (Rast and Schaub 1981; Schaub and Rast 1989), Kibbutz Hazorea (Meyerhof 1989), Tell Halif (Seger et al. 1990), Tel 'Erani (Kempinski and Gilead 1991), the Kerak Plateau (Miller 1991), Tell Um Hammad (Betts 1992), Tel Dan Excavations (Biran 1996), Tell 'Arad (Amiran and Ilan 1996), Hazor (Ben-Tor and Bonfil 1997), Yiftah 'el (Braun 1997), and Megiddo (Finkelstein, Ussishkin, and Halpern 2000).

Synthetic overviews continue to be produced as individual studies (Richard 1987; Miroschedji 1989a; Braun 1996) or as part of larger, multiperiod surveys (e.g., Mazar 1990; Stager 1992; Ben-Tor 1991; Rast 1992). Special investigations have been devoted to issues of trade (Ben-Tor 1982, 1986; Esse and Hopke 1986), architecture (Braun 1989; Gophna 1992), pottery (Esse 1984; Beck 1985) possible biblical connections (Pettinato 1981; Bright 1981; Sauer 1994), stratigraphy (Seger 1989; Brandl 1989), and periodizations (Dever 1980b; Hanbury-Tenison 1986). Survey and environmental analysis have located new sites and suggested larger settlement (or spatial) patterns (Esse 1982; Rast and Schaub 1981; Joffe 1993, Harrison 1997), population fluctuations (Broshi and Gophna 1984), and subsistence strategies (McCreery 1980; Esse 1982; Levy 1983).

Demonstration of the variety of trends and tensions in this third surge is difficult to achieve within the limits of this simple sketch. Its outline, however, is suggested in a volume edited by Miroschedji (1989b). The papers which constitute this work were originally prepared for a conference on the state of EBA research held in 1986 . The overarching theme of the conference revolved around the dynamic of urbanization, 
hence the title; the range of included topics was broadly organized around poles such as the beginning and end of urbanization, environment, economy, foreign relations, and the EBA in the Negev-Sinai. The richness of these specialists' reports suggests the work as a crest in this third surge of study.

Similarly, the volume edited by Philip and Baird (2000) is a result of a focused workshop held in 1995. The thrust of this workshop was to encourage dialogue among those with research interests in EBA ceramics. Ironically, the published essays, when taken as a whole, highlight the continued disparity in terminology, chronology, and even the mode of presenting ceramic data that continues to exist among specialists.

Continued excavation and publication demonstrate how EBA studies have not stagnated from 1937 to the present time. Creative thinking from several quarters points to future surges. At present, however, the scale of examination must be reduced to consider select aspects of contemporary EB II-II study.

\section{Aspects of Early Bronze II-III Study}

Cultural residues attributed to EB II-III periods continue to be the focus of study in the present century. Contemporary gains have not been made without controversy but may be reviewed under three headings: environment and climate, pottery and periodization, and settlement and society. Attention will be directed toward North Palestine, as this third descriptive effort contextualizes the position of Tell Ta'annek and lays important groundwork for conclusions offered later in this work.

\section{Environment and Climate}

"North Palestine" is a difficult label to use with precision due to variegated landforms, complex geology, and changing political boundaries. From a larger view, the 
area is easily identified with southwestern Asia and the southern Levant. As such, it shares in the climatic and phytogeographic properties of other Mediterranean zone regions. ${ }^{1}$ However, even this statement is not sufficient when the scale of examination is amplified. A closer look reveals how disunity, rather than unity, characterizes the region.

Such disunity begins at the deepest levels. Structural trends throughout the southern Levant move roughly in a north-south direction. This tendency is illustrated by the Great Rift Valley in the largest sense, but also by subregions such as the coastal plain, the Western Highlands, and the Eastern Plateau of Transjordan. Routes of transportation have moved regularly and with relative ease along the plains, shoulders, and ridges of these landforms. However, areas of structural disruption such as the Carmel massif and the Valley of Jezreel intersect these north-south trends and pose opportunities for east-west travel.

Because of this structural disunity, geologists and geographers hesitate to attempt the descriptive task of a broad region such as North Palestine under a single heading. Karmon (1971) breaks his discussion into two major units following political boundaries. More specifically, he takes the region from the Jezreel Valley to the north as a unit and handles the central mountains south of Jenin as a separate section labeled "Samaria." Orni and Efrat (1980) isolate their discussion of the highlands from the lowlands. Again, discussion of the Jezreel Valley is separated from that of Lower Galilee and the "Samarian Hills." Baly (1974) handles various morphological features together, isolating his discussion of "the Central Valley" from "the Basin of Samaria."

${ }^{1}$ The climatic and phytogeographic properties of Mediterranean zones have been discussed elsewhere. In addition to Esse (1991), see Orni and Efrat (1980: 167-70) or Gal (1992: 1-11). 
While such approaches are reasonable for the task of describing topography or geology, they do not do justice to the total landscape as a resource for human use. A more synthetic view takes into account both highland and lowland, pasture and field, as conjoint contributors to human subsistence strategies. Fargo moves in this direction in her discussion of EBA settlement in "Southern Palestine" (1979b). For her, "Southern Palestine" extends south from Jerusalem, or more exactly, south of the 130 Palestinian Grid reference. The suggestion is that areas to the north of Jerusalem be considered as "Northern," or perhaps, as some sort of "Middle Palestine." Within Fargo's work, issues of climate and land use for the entire region are sketched, particularly in her "southern" unit.

For Esse (1991), "North Palestine" is defined as the region stretching from the 300 Palestinian Grid line in the north to the 160 Palestinian Grid line in the south and from the 240 Palestinian Grid line in the east to the Mediterranean coast. Such a sweep is large, perhaps to the point of awkwardness. It includes Upper and Lower Galilee, the Hulah basin, the Jordan Valley, the Jezreel Valley, the Carmel ridge, northern portions of the Central Hill country, and the coastal plains. However, it does capture the variegated landforms and subclimates required for mustering a regional story of land use. For this reason and despite the disunity of the regions involved, Esse's definition of North Palestine is adopted here.

Esse's analysis (1991: 1-31) has the value of suggesting the environmental opportunities and constraints placed upon the EBA population of North Palestine. He builds a comprehensive model on the basis of modern and premodern (Ottoman period) observations, taking into account geomorphology, soils, phytogeography, rainfall, 
hydrology, and topography. ${ }^{1}$ Esse highlights the tension created by microclimatic rhythms--the shifting "borders of aridity" between Mediterranean and Irano-turanian zones--and the subsistence strategies necessary for human settlement in a marginal or near-marginal environment. ${ }^{2} \mathrm{He}$ concludes that the environment of North Palestine is potentially able to support a self-sufficient, mixed economy based on cultivation and animal husbandry. Furthermore, the strategic location of the area ensures a role in larger systems of trade.

While Esse's observations are intuitively satisfying, the leap to reconstructed paleoenvironments must be taken cautiously. To the degree that the EBA environment was identical to that of the preindustrial period, Esse's summaries are useful. Without a doubt, "agriculturalists had to work the same ground" (Esse 1991: 19), and variations in the Holocene are minimal in comparison with the larger geologic and geobotanic record (Picard 1943: 84). However, any demonstration that the range of climatic variation has shifted over time and that phytogeographic lines must be significantly or periodically redrawn reduces the usefulness of Esse's work and poses a critical impasse (Sauer 1994: 368). While some indicators suggest that the climatic and edaphic conditions which prevail today are the same as that of EB II-III periods (Liphschitz and Waisel 1980; Liphschitz, Gophna, and Lev-Yadun 1989: 266), ${ }^{3}$ other data suggest that such

\footnotetext{
${ }^{1}$ Esse stands in good company in drawing such parallels. Compare to the previous work of Harlan (1985).

${ }^{2}$ See also the presentation of Esse (1989: 93).

${ }^{3}$ One study of dendroarchaeological samples retrieved from Tell Ta'annek demonstrated the presence of eight species of trees, seven species of edible fruits and five species of weeds. These samples were drawn from various contexts, in EBA through Arab periods. All species continue to inhabit the area today, which led the investigators to suggest that macroclimatic continuity, rather than discontinuity, characterizes the region. See Liphschitz and Waisel (1980).
} 
conditions have been less static and may have been one factor in the ultimate destabilization of EB II-III culture (Fargo 1979b; Rosen 1983, 1989, 1995; Shehadeh 1985; Goldberg and Rosen 1987; Sauer 1994). ${ }^{1}$ This deadlock suggests that future work with paleogeography and paleoenvironments is sorely needed to inform a cogent reconstruction--a call, incidentally, which is now more than a decade old (Goldberg and Bar-Yosef 1990: 84).

\section{Pottery and Periodization}

The "lumping" together of EB II and EB III periods into a single time-frame has been a characteristic of EBA study since Wright. This undoubtedly stems from the difficulty in isolating distinctive features in a ceramic repertoire that is, for the most part, simple and handmade. Moreover, the ceramic landscape presents itself as more unified and less regionally fragmented than in the previous EB I period. Such observations have added to the claim that cultural continuity or stability, rather than cultural change, is intrinsic to this 700- to 800-year period in Palestine (e.g., Mazar 1990: 109-10).

A second characteristic of EBA study since Wright is the attempt to synchronize the periodization of Palestine with the paradigm of early Egyptian "history." In chronological terms, it may be proverbially asserted, "as goes Egypt, so goes Palestine." Revisions of early Egyptian chronology have profoundly affected Palestinian chronology in the past, and basic insecurities on the Egyptian side raise the possibility of lurking surprises in the future (e.g., Lasken 1990; Mazar 1990: 28-9; James et al., 1991; Rohl 1995). At present, while stratigraphy, typology, foreign correlations, settlement

${ }^{1}$ In contrast to his doctoral thesis where environmental continuity is essentially maintained, Esse's later work emphasizes environmental change in the EBA (cf. 1989: 93 and 1991: 19). This shift may reflect new data and the growing consensus that the climate has changed considerably since the EBA. 
patterns, and some scientifically achieved absolute dates have been synthesized to achieve a general profile of the EBA structure, real ambiguities remain, particularly at the level of subperiods. ${ }^{1}$

Beginning of EB II. EB II follows EB I by definition. Still, considerable discussion has been offered to attempt to fix an horizon between these two periods (Ben-Tor 1968: 149-59; Rast 1980: 10-11; Esse 1991: 63-4; Joffe 1993: 56-8, 65; Braun 1996: 29-30). Guidelines remain fuzzy and continue to be established almost exclusively on the grounds of ceramic study (Braun 1996: 30). Radiocarbon analysis may eventually provide a corrective; at present, such claims are controversial and premature (Dessel and Joffe 2000). In the meantime, significant attention has been focused on a class of pottery alternatively called Abydos Ware, Red Polished Ware, Metallic Ware, or Metallic Burnished Ware. ${ }^{2}$ Study of this class (following Greenberg's "Metallic Ware" label here) has cast considerable light not only on the technology and economics of the period, but on foreign relations and chronology as well. Wright fixed the beginning of EB II with the appearance of Metallic Ware pitchers in First Dynasty tombs in Egypt (1937: 70-2). This correlation continues to stand and receives support from the excavations at Tell 'Arad, although, as noted above, the discussion of absolute

'Ben-Tor (1991: 82) pointed out nearly a decade ago that radiocarbon dates for the EBA total nearly 100 . However, "the scholarly attitude toward them may be characterized as mixed or cautious. There is a clear tendency to prefer dates based on written records. . . . The Egyptian chronological framework remains the main anchor of Palestinian chronology for the whole of the Early Bronze Age."

${ }^{2}$ For "Abydos Ware" see Prausnitz (1954). For "Red Polished Ware," see BenTor (1968: 80-2) or Esse (1991: 104-7). For "Metallic Ware," see Greenberg and Porat (1996: 5-24). For both "Metallic Ware" and "Metallic Burnished Ware" see Fischer (2000). 
dates has fluctuated with models of Egyptian chronology. ${ }^{1}$ Wright opted for the socalled "low chronology" of his teacher, Albright, placing the beginning of EB II in the 29th century. ${ }^{2}$ This view was followed by Amiran (1969: 12) and others (Campbell 1961; Freedman 1961). However, an alignment with the "high chronology," defended by BenTor (1968) and used in the Cambridge Ancient History ${ }^{3}$, is almost unanimously assumed today (Stager 1992). Radiocarbon assignments confirm this consensus (Carmi and Segal 1992: 127-9; Fischer 2000: 228) and push the beginning of EB II upward to the 31 st century.

What is clear is that despite much continuity in ceramic forms in the transition from EB I to EB II, regional ceramic "families" or geographic-cultural assemblages gradually collapse. ${ }^{3}$ As Joffe has pointed out, Grain Wash Wares, Line-Group Painted Wares, Crackled Wares, fenestrated forms, forms with conoid projections, high-handled cups, distinctive "teapots," and omphalos bowls disappear by the end of EB I (1991: 248). The resulting picture for the duration of the EB II-III periods is one which approaches homogeneity. This situation prompted Greenberg's lament that isolating ceramic indications for the EB II and EB III period is "one of the thorniest issues in the archaeology of Palestine" (2000: 183).

${ }^{1}$ Ben-Tor follows the string of argument, "The Arad excavations have provided the most conclusive evidence regarding the absolute chronology of the Early Bronze Age. Abydos ware does not appear in Egypt in tombs ascribed to the period of the first two kings of the First Dynasty, Narmer and Hor-Aha, but only during the reign of the third king, Djer. Similarly, at Arad, in stratum IV of the Early Bronze Age I, where an Egyptian vessel bearing the serekh of Narmer was found, Abydos ware does not yet occur; it appears only in stratum III of the Early Bronze Age II, which must therefore be dated from the reign of Djer onward" (1991: 108).

2See Albright's own presentation of this "low chronology" in Ehrich (1965: 47-60).

${ }^{3}$ See Joffe (1993: 66) for details. An alternative picture suggests that this difference is due to the fact that the ceramic assemblages of EB I are largely tomb groups, whereas the assemblages of EB II-III are from occupational debris (Ben-Tor 1991: 105). 
Subperiods in EB II. Recognizing subperiods within the EB II has proved difficult. What Wright called "EB IC" in a later revision effort (1958: 43) was first embraced (Callaway 1972, 1978; Lapp 1968, 1970) and then eliminated (Schaub and Rast 1984: 36; Esse 1984). It has been suggested that the material remains which compose this mirage chronologique be lowered into the subsequent period (Esse 1984: 324-5; Miroschedji 1989a: 64-5). Such shifting acknowledges the fluidity of Wright's EB IC "fossil" indicators--platters with inverted rims, pushed-up ledge handles, and ridged, hole-mouth jars--which begin in EB I and continue uninterruptedly into EB II.

Subperiodizations are produced on the basis of the stratigraphic examination of particular sites; hence, apart from a broad, multi-site and multi-phase synthesis, there is little power for organizing a larger region. ${ }^{1}$ Within North Palestine, the sites of Megiddo, Beth-shan, 'Affulah, Tel Qashish, Tell Ta'annek, Hazor, Tel Reqet (Kh. Quneitra), Rosh ha-Niqra (Kh. Musherifa), Tell Qishyon, Qadesh Naphtali, and Tell esh-Shuneh have recently been reassessed with scrutiny by Esse to build an impressive stratigraphic context. Unfortunately, Esse concludes that the EB II period "is not well known, and more ceramic refinement is necessary before the period can be fully understood and subdivided" (1991: 98). ${ }^{2}$

Joffe also acknowledges the difficulty of subdividing EB II and criticizes existing sequences, such as that put forth for Et-Tell, as having "limited" usefulness "for understanding larger patterns" (1993: 65). Yet he does hazard an EB II subchronology of his own, consisting of an "initial phase," a "developed phase," and possibly a

${ }^{1}$ This discussion within an EBA context may be noted as early as Vincent (1934: 43), who contended that the Megiddo sequence was merely a local culture which lacked larger organizational power.

${ }^{2}$ This sentiment echoes the conclusion of Miroschedji who has insisted that the EB II be provisionally considered as a single unit until more data are collected (1989a: 65). 
"transitional phase" leading into EB III. An inventory of ceramic indicators for his "initial" and "developed" phases is given (1993: 66-7).

Transition from EB II to EB III. For Wright, the transition from EB II to III was marked by the importation and imitation of Egyptian vessels (stone bowls from Et Tell and "flaring-rim cups") in the period of the late Second and Third Dynasty (1937: 77). Even more significant was the arrival of a new potting tradition, dubbed Khirbet Kerak (or Beth-yerah) Ware because of its initial association with that site $(1937: 72-3,77)$. Due to its "exotic" form, finish, distribution, and temporal location, this class attracted significant attention as an EB III "marker." Wright acknowledged the difficulty of assigning an absolute date to this transition "zone" and throughout his work tentatively suggested dates between the 27th and 24th centuries (Wright 1937: 78; 1961: 100). In time, the view which coordinated the beginning of the Old Kingdom in Egypt (Third Dynasty) with the beginning of EB III in Palestine was embraced (Hennessy 1967; Ben-Tor 1968; Amiran 1969; Callaway 1978; Richard 1987; Mazar 1990). Foreign contacts (Hennessy 1967: 88) and limited radiocarbon tests link this transition to an absolute date of about $2700 \mathrm{BC}$ (Callaway 1978: 55) although questions remain. Fischer still calls it a "blurry transition" (2000: 228) while Stager suggests that no "deep or systemic" changes are apparent (1992: 107).

Others who have examined the ceramic continuum point to changes that are more subtle in nature and regional in appearance. Trends are identified in central and southern Palestine (Miroschedji 1989a: 65), in Transjordan (Homes-Fredericq and Franken 1986: 82-3), as well as in North Palestine. Ben Tor (1991: 108) notes that in

${ }^{1}$ For Khirbet Kerak Ware, see Albright (1926), Mazar, Stekelis, and Avi-Yonah (1952), Ben-Tor (1968: 93-100; 1991: 109-12), Burney (1989), Esse (1991: 51-2), Mazar, Ziv-Esudri, and Cohen-Weinberger (2000). 
the EB III, Metallic (Red Polished) Ware forms lose their painted decoration, jug bases become more elongated, and juglets become more common. Greenberg and Porat (1996: 12) point out that Metallic Ware forms appear largely the same from EB II to EB III, but the overall percentage of this class decreases steadily and "drastically."1 Moreover, while a variety of shapes are recognized in EB II contexts, only a few, large, key vessels continued to be manufactured in EB III.

Subperiods in EB III. Albright's statement that "Early Bronze III is the best known and best dated period of E.B." (1965: 51) was clearly premature. As in the case of EB II, attempts to distinguish the sequence and structure of EB III remain extremely problematic. Much of this confusion is the result of efforts to identify the fourth and final phase of the EBA and the EB III linkage to it. The literature preserves differences of opinion not only for subperiod designations, but also for the content of the corresponding ceramic taxa. While ceramic regionality does not seem to be as deep an issue in EB III as elsewhere, delayed or inadequate final reports continue to impede larger organizational efforts.

Wright originally offered no subdivisions for the period; Albright later proposed a simple tripartite organization (1965: 52). His EB IIIA preceded the arrival of Khirbet Kerak Ware; his EB IIIB coincided with the use of Khirbet Kerak Ware in the north; and his EB IIIC was a post-Khirbet Kerak Ware period, coinciding with the Egyptian Sixth Dynasty.

${ }^{1}$ Greenberg and Porat agree that the flourit of Metallic Ware is in EB II; however a limited presence in the EB III is also visible. Where it does continue "the sole typological development . . from EB III contexts is the appearance of the sharply everted feathered-edge folded rim and rope-decorated neck on pithoi" (1996: 12). 
While the diffusion of Khirbet Kerak Ware renders Albright's proposal of limited use, the notion of an "early EB III" and a "late EB III" has continued. Hennessy grouped the six phases of EB III stratigraphy at Jericho into two such primary divisions (1967: 135, 22-4), as did Ben-Tor with the Yarmuth materials (1975: 55-87), Dever and Richard at Tell Beit Mirsim (1977: 2), Callaway at et-Tell (1978), and Fargo in her study of "southern Palestine" (1979b: 117-99). Even though these investigators share common taxa, the published assemblages indicate some disagreement over what the contents of these taxa should be.

Miroschedji has recently suggested that the stratigraphic evidence from Tel Yarmouth is ample and distinctive enough to allow for the fixing of an internal chronology for the period (1989a: $65 ; 2000: 320)$. Only full publication will confirm this claim. ${ }^{1}$ The same need is evident in North Palestine, where sites with "early" and "late" EB III indicators have yet to be fully published on a stratigraphic basis.

End of EB III. Wright had difficulty assigning an end to EB III. In his 1937 synthesis, he offered an end-date ca. the 24th century in order to allow adequate time for a "transition culture," which he labeled EB IV, to run its course. However, in his 1961 synthesis, he abandoned the EB IV terminology altogether, and instead extended his EB III into a "B" phase. ${ }^{2}$ This enigmatic "EB IIIB," in his view, began in the 24th century and ended at the feet of the Middle Bronze (hereafter, MB) I, ca. 20th century. Although Wright was willing to swap labels, he remained committed to the essential sequence and continuity of the culture (Wright 1961: 106).

${ }^{1}$ Fargo also emphasized "the necessity of closely stratified sequences before further refinements in the ceramic chronology can be achieved" (1979b: 199).

${ }^{2}$ For a detailed discussion of the struggle for consensus on the end of the EBA, see the articles by Richard (1980: 5-34) and Dever (1980b: 35-64). 
More recent efforts have demonstrated that the ceramic landscape begins to fragment regionally in EB III and continues to do so throughout EB IV. This movement is viewed as both evolutionary and indigenous, and results in no less than five regional "families" or geographic-cultural assemblages by EB IV B-C (Dever 1980b: 45). Hence, it appears that from a ceramic perspective, EB IV represents a return to an earlier balance achieved in EB I: a demonstrated cycle which moves upward from a less homogeneous (EBI) to more homogeneous assemblage (EB III) and then backs down again (EB IV). Such dynamics are considered to reflect larger social realities.

\section{Settlement and Society}

Efforts to describe EB II-III society in Palestine may be ordered under three headings: settlement size and distribution; "ruralism" versus "urbanism", and the question of social complexity.

Settlement size and distribution. Several attempts have been made to plot the settlement size and distribution of EB II-III sites along spatial and temporal lines (Kempinski 1978; Fargo 1979b; Thompson 1979; Gophna 1984; Broshi and Gophna 1984; Falconer 1987; Esse 1991; and Joffe 1993). Joffe has thoughtfully approached the dangers of "settlement archaeology" sorting them into three categories: survey design and execution, formation processes, and material interpretation (Joffe 1993: 121). These dangers become particularly acute when dealing with EBA, where access to data is often limited by small samples from deep trenches (in the case of tell sites) and an absence of written records. Nonetheless, a broad consensus appears to have been reached, certainly not from the perspective of understanding the nature of EBA society or those factors which transformed it, but at least in describing certain trends and patterns. 
Using data assembled and reviewed by Esse (1991: 146-56), these statements may be directed specifically and briefly to a discussion of North Palestine. ${ }^{1}$ First, there is a decrease in the number of sites when moving from the EB I to the EB II-III periods. The percentage of decrease varies from region to region and even within subregions. As one example, the northwestern Jezreel Valley appears to have been only moderately affected; total counts drop from 15 sites in EB I to 10 sites in EB II-III. However, in the southwestern quarter of the same valley, the decrease approaches 83 percent, as total counts drop from 35 to 6 sites. $^{2}$

Second, while the raw number of sites decreases from EB I to EB II-III, both the mean and median sizes of these settlements increase, approaching 300 percent in some cases. As has been noted, when this observation of increasing site size is coupled with the trend of decreasing site numbers, the suggestion that population agglomeration, rather than population growth, as an operative dynamic becomes clear.

Third and finally, these trends seemingly reverse themselves when moving from EB II-III to EB IV. EB IV site size and distribution approach that of EB I in the marginal zones, but less so, however, in the more fertile regions (Esse 1991: 153, 175). Further details, breakdowns, and revisions of these data are deserving of elaboration, but are unfortunately beyond the scope of this introductory sketch.

${ }^{1}$ Unfortunately, no effort is made in Esse's work (1991) to isolate EB II from EB III contexts. This "lumping" may also be seen in the work of Broshi and Gophna (1984) and is a reflection of the continued struggle to separate the ceramics of these periods.

${ }^{2}$ Contradicting this trend are the conclusions of more recent study that identify an increase in the total number of EB II sites associated with abundant Metallic Ware counts (Greenberg and Porat 1996: 19). Such appears to be the case in the Hula basin, the Northern Golan, the Galilee highlands, and the Lebanese Biqa'. 
These trends have not gone unnoticed by those seeking to explain the "urban" process. As a period free from the constraints imposed by written texts, the EBA has proved itself a fertile field for theoretical exercise.

"Ruralism" versus "urbanism." The notion of "city-state" has been regularly associated with EB II-III periods. This conclusion is drawn from presuppositions concerning the nature of "urbanism," its archaeological correlates, and mental templates drawn from other, much later, historical periods. Such presuppositions have rightly been challenged.

The strongest challenge has come from Falconer's reassessment of the EBA settlement data (1987: 160-76). He argues that scholarship has fallen prey to an "urbanocentric" view and, in rebuttal, emphasizes the rural aspects of settlement in Palestine. He rightly argues that a symbiotic relationship existed between urban and rural lifeways and that one cannot be understood in isolation from the other (1987: 49). His understanding of "urbanism" is influenced by the contrast between the scale of society in ancient Mesopotamia and that in ancient Palestine. This becomes clear when considering that Falconer's criterion for an "urban" site hinges singularly on the ability of a population to secure food. A village is self-sufficient, it can feed itself; a city cannot feed itself. Methods for determining population numbers, densities, and agricultural sustaining areas are tested with a most curious result: assuming Falconer's definition and coefficients excludes every known site in Palestine from the category of "urban," even in the height of the EB III period (1987: 164). In his view, the conception of "citystate" is a poor fit for EBA Palestine; a more accurate beginning point is one of "rural complexity." 
Falconer's work initiated needed reflection upon the loose use of terms like "urbanism" and "city-state" and provided a timely reminder on the issue of scale. He has demonstrated that social growth and differentiation may have rural origins and that the structure of Bronze Age Palestine needs to be considered on its own terms. Still, in criticism, his definition of "urban" is unnecessarily narrow and does not give justice to other dynamics of the social process.

Social complexity. Many tangible features of the EB II-III periods are well documented: defensive systems, public buildings, domestic quarters, trade items, and so forth. When these are added to the previous discussion of settlement distribution, the complex nature of EBA society is approached. Among recent presentations of these data and inferences drawn from it, Esse (1991), Joffe (1993), and Greenberg (2000) are the most thorough.

Contextualizing patterns of EBA subsistence and trade are the strength of Esse's work (1991). The site of Beth-yerah (Khirbet Kerak) is placed in its local, regional, and international setting by the examination of specific correlates, largely, but not entirely, ceramic. Through these, reciprocity, redistribution, and market exchange are demonstrated. One conclusion Esse reaches is that trade with Egypt was a powerful engine driving the development of Palestine. Its stimulus in EB II prompted social specialization, stratification, and organization, while its complete cessation by EB IV contributed to disintegration and a shift in the direction of pastoralism. Like Falconer, Esse is aware of the important issue of scale and views the relationship between Egypt and Palestine as that of a "primary civilization interacting with a secondary civilization" (1991: 175). Esse is careful to bring into his discussion the many issues of social complexity to present a balanced picture. 
The study of Joffe (1993) is more period-specific than the work of either Falconer (1987) or Esse (1991). Joffe's work focuses on EB I-II dynamics and has as a goal to discuss "the shift from village to 'urban' society" (1991: 1). The elucidation of settlement patterns constitutes one of Joffe's primary contributions, although somewhat ironically, a powerful critique is offered which demonstrates the inadequacies of current settlement pattern data for drawing larger inferences about society. Like Esse, Joffe views Egyptian influence as significant for "intensifying a local trajectory towards rising complexity, but without creating economic dependence or leaving lasting sociopolitical or cultural influence" (1993: 39). Unlike Esse, however, primary data in Joffe's 1993 publication are often hard to come by; even the settlement patterns he proposes and questions are illustrated only as unlabeled dots on maps without a coordinating catalogue. This severe weakness hampers use of the work and limits Joffe's contribution to that of an exercise in the application of social theory.

Greenberg's work focuses on EBA contexts in North Palestine. Through studies that are both regional (1996b) and site specific (1996a, 1997), Greenberg has posited ideas about social change based upon settlement patterns, ethnographic analogy, and ceramic analysis. His treatment of Metallic Ware is the basis for the suggestion that EB II North Palestine was energized by a "process of colonization" which is visible through unified architectural and technological traditions (Greenberg and Porat 1996: 20). He surmises that this unity bespeaks an egalitarian order that crested in EB II, then subsequently broke down in EB III North Palestine. Increased social stratification and fragmentation were the result of this erosion that preceded the EB IV collapse. 
Three ceramic traditions defined by Greenberg play an important role in the present analysis: Metallic Ware, Khirbet Kerak Ware, and common ware (2000: 18491). ${ }^{1}$ Greenberg's definitions are adopted here and will be applied in chapters 4 and 5 .

\section{Tell Ta'annek and Its Investigators}

Within the context of these larger concerns, the focus of the present study rests upon the site of Tell Ta'annek. Introductory comments here describe the location, description, and environment of the site and the history of archaeological excavations at the site.

The Location, Description, and Environment of Tell Ta'annek

The 11-acre (4.45 hectares; 45 dunam) urban ruin-mound known as Tell Ta'annek (map ref. 171214 ) projects from the northern flanks of the central hill country into the fertile valley known alternatively as the Meri ibn 'Amir, Jezreel, Esdraelon, or plain of Megiddo (see Map 1). It rises visibly some $400 \mathrm{~m}$ southeast from the intersection of the modern highway 66 and secondary road 596, approximately $7 \mathrm{~km}$ southeast of Tell el-Mutasellim (Meggido) and $10 \mathrm{~km}$ northwest of modern Jenin. This location, between hills and valley, offered not only protection to those who once lived in the region, but ready access to a hinterland of valuable natural resources and accessible trade-routes. Such issues may be used to explain the attraction of the site which has been more or less occupied from the EBA to the present.

${ }^{1}$ As Metallic Ware and Khirbet Kerak Ware are established ceramic categories, little more need be added here. However, Greenberg's "common ware" is defined as vessels "made of raw materials which could be obtained in the vicinity of the sites, and tended to be fired to considerably lower temperatures. . . The end product was thus softer, of coarser fabric, and often coated with a thick slip which tended to peel" (2000: 184-6). 
A perennial spring emerges on the north side of the tell, while the modern village (known also as Ta 'annek) is located on its southeast shoulder. The tell itself appears "egg shaped" from above, with the point toward the south. Its length is approximately $340 \mathrm{~m}$, while its breadth measures some $160 \mathrm{~m}$. Viewed from a distance, the mound assumes a classic "shelved" form, with a central plateau rising to an elevation of ca. 241 $\mathrm{m}$ above sea level, approximately $2 \mathrm{~m}$ above the lower shelf and some $50 \mathrm{~m}$ above the plain and spring below. On the east and south the slopes drop sharply; the northern slope steps down more slowly in stages (Fig. 1a). Bedrock emerges in several places.

Geologically, Tell Ta'annek rests at a strategic, albeit complex, intersection of three major features (Baly 1974: 144-51, 166-72; Orni and Efrat 1980: 53). Spreading out expansively to the north and east of the site is the Merj ibn 'Amir (Jezreel Valley) with its rich, mixed, alluvial soils. Southeast of the site rises the rolling Nablus syncline, topped by Eocene chalk but flanked with the still softer and erodible Senonian strata. To the west, running up to and under the site is the hard Cenomanian limestone of the Umm al-Fahm upwarp. The significance of each of these features for human exploitation was likely played out by the site's inhabitants on several levels, not least of which involve subsistence, communication, and defense.

From the perspective of subsistence, the location of Tell Ta'annek offered ready access to both highland and lowland. Mixed subsistence strategies involving agriculture and pastoralism could be exploited by the EBA inhabitants of the site. From the perspective of communication, Tell Ta'annek rested along what was likely a welltraveled corridor which traced the southern rim of the Merj ibn 'Amir (Jezreel Valley). Such a path avoided the swamps of the central Jezreel plain and the more difficult route through the highlands. Moreover, access to a network of Jezreel Valley sites would have been simple; 'Afula, Jenin, Megiddo, and Yoqne' am are less than $10 \mathrm{~km}$ 


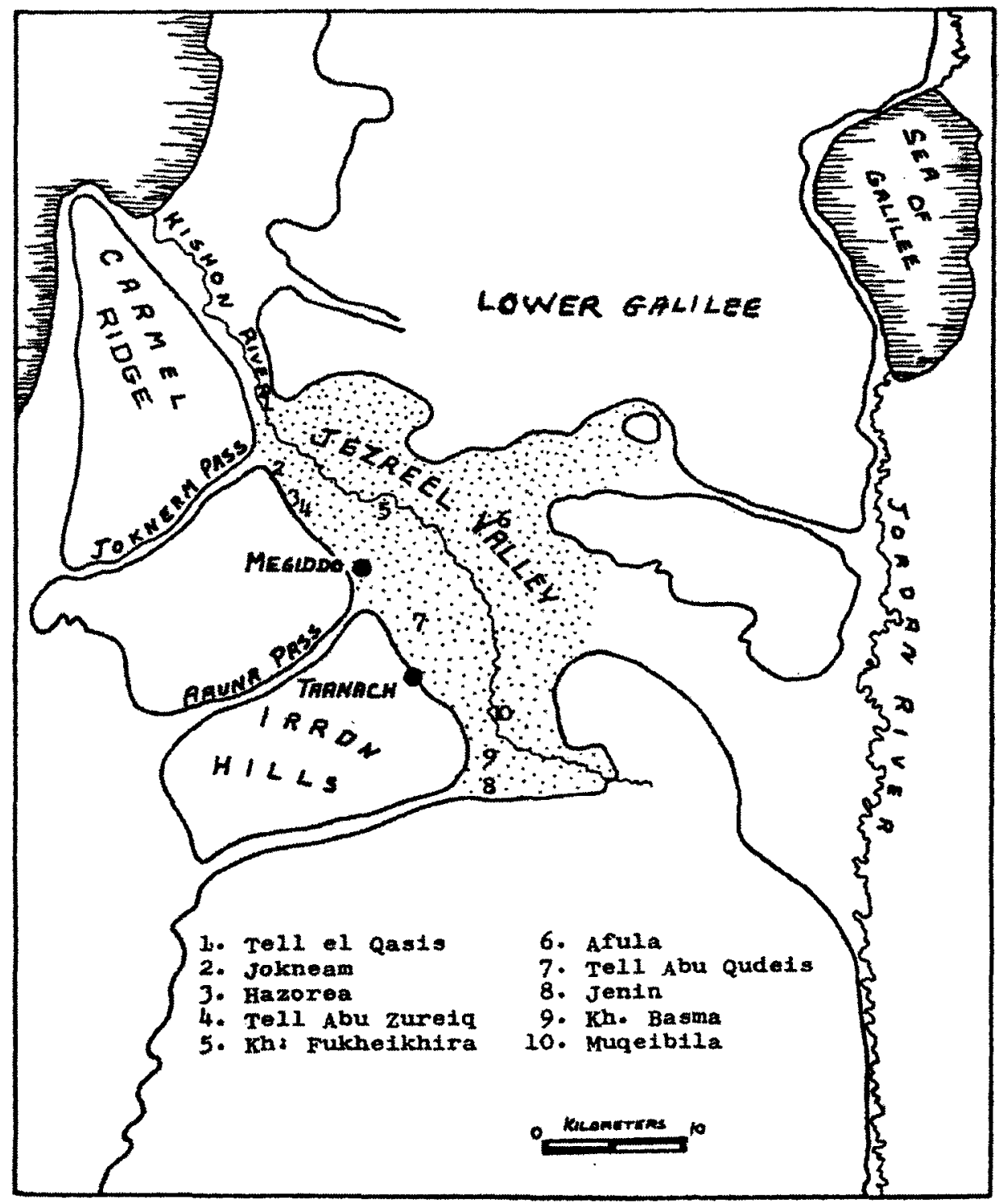

Map 1. Location of Tell Ta'annek. From Glock (1972: Fig. 1). 
distant. Egress into the highlands to nearby Tell Dothan would be more difficult, the Plain of Sharon, Beth Shan Valley and Lower Galilee more distant, but all were within a single day's walk. Finally, from the perspective of defense, the position of Tell Ta'annek atop a steep hill provided excellent visibility in all directions and the opportunity to exploit natural fortifications for the construction of a perimeter wall.

\section{Excavation History of Tell Ta'annek}

The history of human activity on the site has been studied from the perspective of textual sources (Lapp 1967a; Glock 1993; Meehl 1995: 6-11). Archaeological sources are of a different scale and complexity and have been less forthcoming. Three teams have conducted formal investigations in the 20th century: the first associated with Ernst Sellin and The German Oriental Society, the second with Paul Lapp and The Taanach Excavations, and the third with Albert Glock and Birzeit University.

The excavations of Sellin. Archaeological investigations at Tell Ta'annek were initiated nearly 100 years ago under the supervision of Ernst Sellin from the University of Vienna (see Fig. 1b). Three seasons of excavation were conducted on the site between 1902 and 1904. Reports of these efforts were made public less than two years later (1904, 1905). Although Sellin's trenching and recording techniques might be judged as crude by today's standards, his prompt publications displayed an early awareness of both stratigraphic process and ceramic typology, a paradigm shift in the making. He wrote already in 1904 ,

Potsherds provide the key for (unlocking) the archaeology of Palestine, we owe this insight especially to Flinders Petrie. ... It was then carried out in detail by his pupil Bliss. ... Since we are in complete agreement with them, we begin our presentation of the cultural-historical results with 
the pottery. This will provide a secure basis for scientific evaluation of the other finds (Sellin 1904: 89). ${ }^{1}$

Sellin distinguished a total of four layers on the mound, divided into two subdivisions each. These were chronologically arranged between the 15th to 14th centuries B.C. to the present. ${ }^{2}$ Because he did not find any city walls, Sellin concluded that the site was defended by a series of "fortresses" whose remains were investigated. His trenches also revealed a "cult stand" and the largest group of cuneiform tablets yet found in Palestine. ${ }^{3}$

Despite the large site sample recovered through excavation, the conceptual advances offered, and the contributions noted from an artifactual point of view, the 1902-1904 work at Tell Ta'annek has been judged of limited stratigraphic value (Meehl 1995: 36). Subsequent study has revealed that finds from different periods were lumped together. Published drawings and photographs were inadequate to permit the reconstruction of excavated areas. Even the pottery, that Sellin acknowledged was a "key" for unlocking the past, was rarely described, drawn, or photographed.

Following his third and final campaign, Sellin quipped, "there is not much more worth talking about, at any rate no sizable building, to be found on the mound" (Lapp 1964: 5, note 4). Understanding Sellin's conclusions added to the challenge of the next generation of Tell Ta'annek excavators.

${ }^{1}$ Translation of Sellin's work generally follows that of Hillers (1962a).

${ }^{2}$ This figure of the $15^{\text {th }}$ to $14^{\text {th }}$ centuries B.C. is a revision drawn from Sellin's 1905 publication. He originally believed that his " $1 a$ " city was founded between 2500 and 2000 B.C. (Hillers 1962b: 125).

${ }^{3} \mathrm{~A}$ beginning point for investigating these tablets is Glock (1971). 


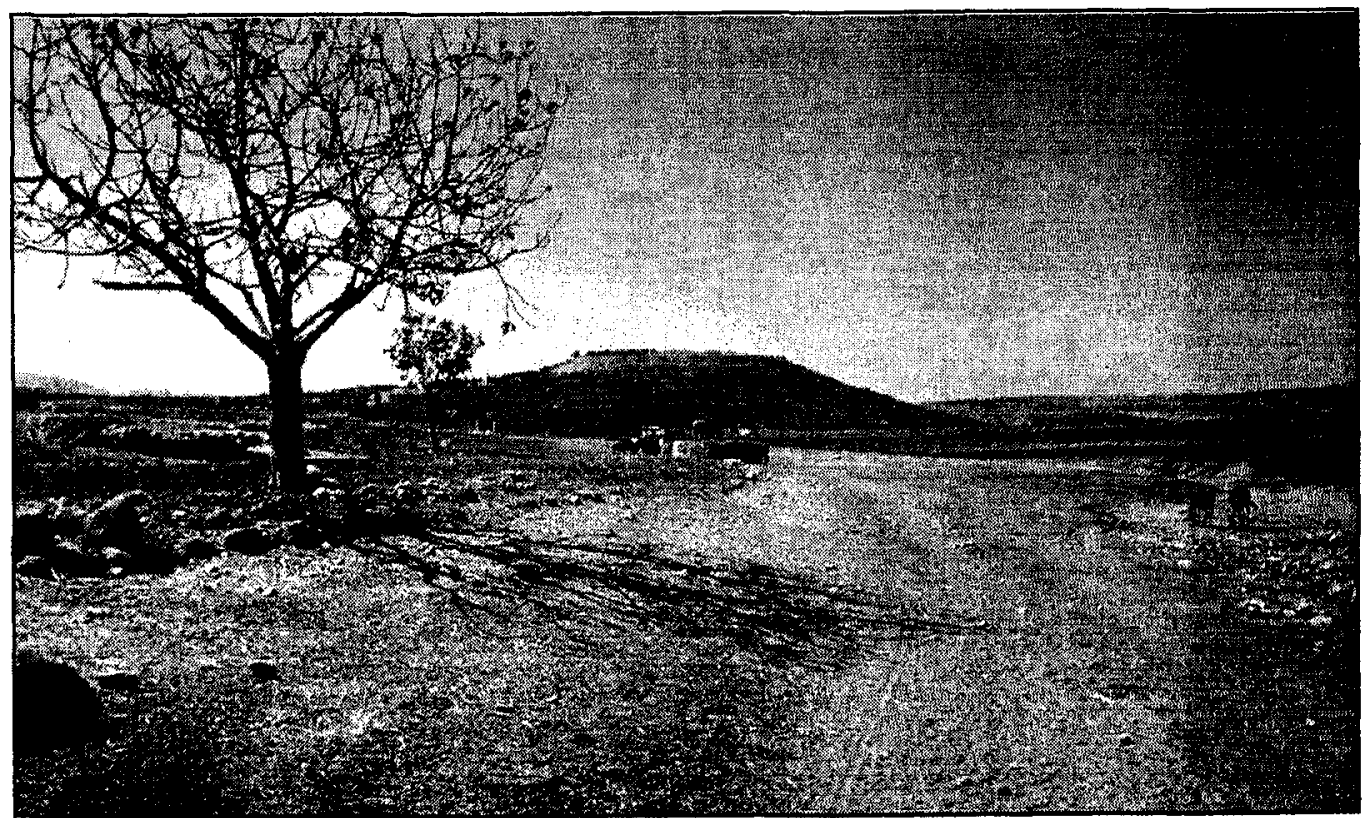

Fig. 1a. View Southwest to Tell Ta'annek in the Early 1960s.

Photograph from The Taanach Excavations archives.

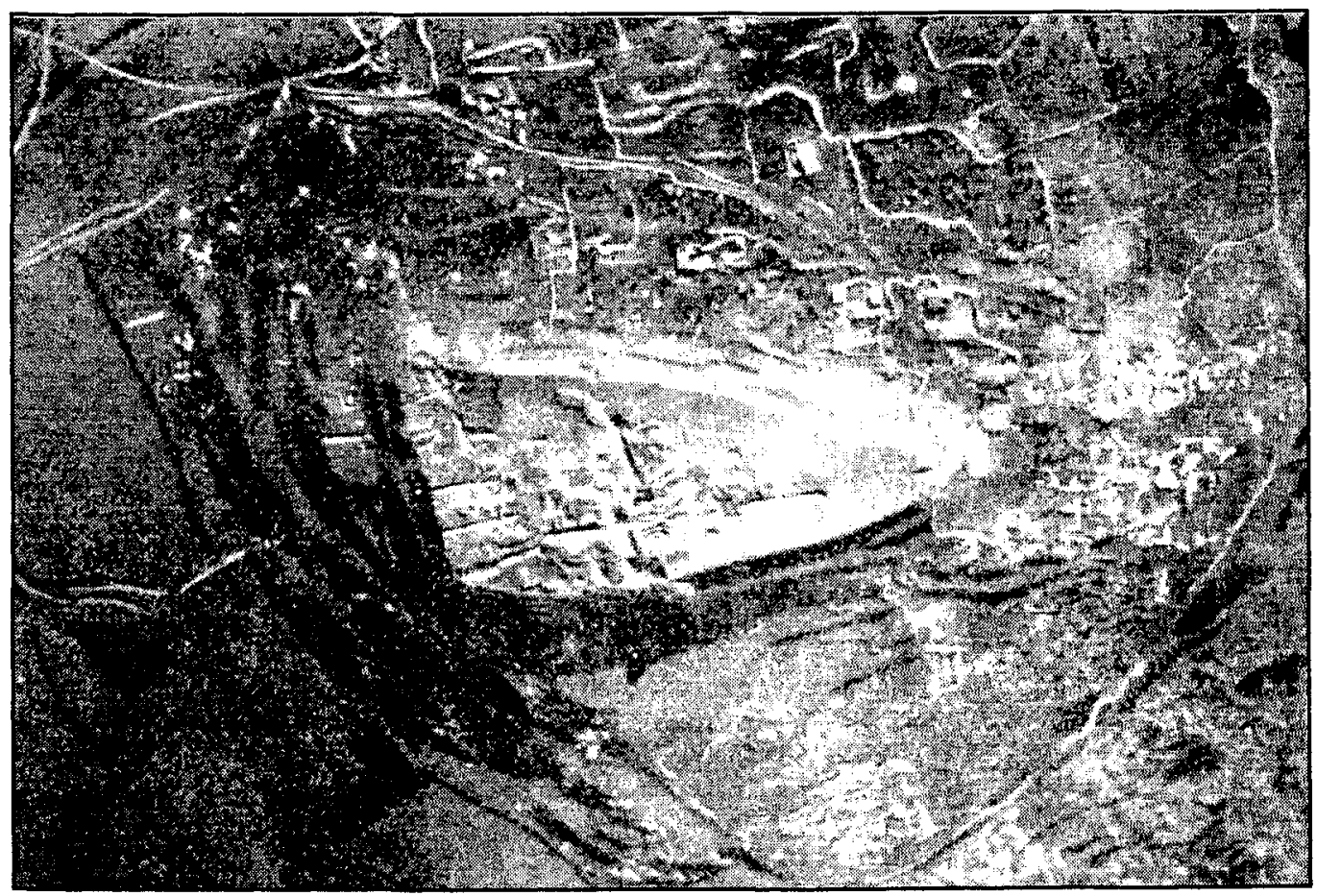

Fig. 1b. Aerial View to Tell Ta'annek.

This pre-1917 view reveals the shape of the site (east is at the top of the photograph) as well as the trenches dug by Sellin between 1902 and 1904. Photograph from The Taanach Excavations archives. 
The Taanach Excavations. Three campaigns of The Taanach Excavations were jointly sponsored by the Concordia Seminary of St. Louis, Missouri, and the American Schools of Oriental Research in 1963, 1966, and 1968. ${ }^{1}$ The director of the excavations was Paul Lapp. The broad goals of the project were articulated from the beginning of the work, "to provide opportunity for field experience in archaeology, to contribute to our understanding of the history of Taanach and its times, and to clarify the German discoveries at the site where possible" (Lapp 1964: 5). It was assumed from the beginning that the remains at Tell Ta'annek be identified with biblical Ta 'anach, a likely assumption that established the project's name, "The Taanach Excavations."

Lapp's larger goal of "understanding the history of Taanach and its times" was found in the dig strategy. Four key aspects of material culture were identified and spatially related to the site surface. It was anticipated that Area A, located on the more vulnerable south slope of the tell, would reveal a wall, gate, and other monumental or military constructions. Area $B$, located in the center of the tell and adjacent to the findspot of an incense altar in the Sellin excavations, was selected in hopes of uncovering religious/cultic aspects of the site. Adjacent to Sellin's Westburg, Area C was opened to reveal structures and artifacts related to public administration and government. Finally, Area D was selected to illuminate domestic and economic aspects of the site. These specific goals were only partially realized.

Details of dig procedures will be picked up again in chapters 2 and 3 when issues of stratigraphy and ceramic sample are discussed. At present, it is enough to

${ }^{1}$ Published dates for the three seasons were as follows: June 17 through August 10, 1963; July 11 through August 26, 1966; and June 4 through August 10, 1968.

${ }^{2}$ Biblical references to Taanach include Josh 12:21, 17:11, 21:25; Judg 1:27, 5:19; $1 \mathrm{Kgs} \mathrm{4:12;} \mathrm{and} 1 \mathrm{Chr} 7: 25$. 
note that The Taanach Excavations utilized a balk-debris method of excavation within an established grid. These efforts revealed the occupational history of a site that stretched from the EBA through the Late Abbasid and Crusader periods. Table 1 demonstrates an initial assessment of this history. Defensive structures, public and domestic building complexes, water systems, streets, and other elements were recovered.

Complementing this architecture was a rich collection of artifacts and ecofacts. These have been detailed in a series of preliminary reports (Lapp 1964, 1967b, 1969).

The Birzeit University Excavations. The most recent investigations into the history and culture of Tell Ta'annek are associated with the Palestinian Institute of Archaeology at Birzeit University and its late director, Albert Glock. Excavations were conducted between $1985-87$ on the southwest shoulder of the site where a MamlukOttoman village rested atop Byzantine remains. Results of this effort are described in the work of Ziadeh $(1991,1995)$.

\section{The Structure of the Present Study}

Following these introductory comments, the subject of stratigraphy will be addressed. Chapter 2 describes the method of excavation and recording used by The Taanach Excavations. Such an outline makes explicit the sources and limits that underlie a stratigraphic reconstruction. Moreover, it hints at how the EBA ceramic corpus was discovered and shaped. Chapter 3 offers a brief description and analysis of the EBA stratigraphic horizon at Tell Ta'annek. These steps are viewed as a necessary prerequisite to the presentation of the ceramic assemblage. Chapters 4 and 5 form the core of the work, outlining and activating a method of ceramic description and analysis. At the conclusion of chapter 5 , a site-wide synthesis of EBA residues is offered. 
Chapter 6 offers concluding comments and inferences which close this study and prompt questions for further investigation.

\section{Summary}

This chapter has presented five uneven, and at times, unwieldy, descriptions of EBA study in an effort to contextualize the present work. The first description introduced the problem addressed by this study and the method used to approach it. The second description introduced the broader field, noting significant issues and turning points in the history of EBA research. The third description examined the EB II-III periods specifically, isolating contemporary issues in the area of environment and climate, pottery and periodization, and settlement and society. The fourth description provided an orientation to the site of Tell Ta'annek and the recovery efforts expended there. The fifth description introduced the outline of the present study.

These descriptions suggest limits upon what is, and what is not retrievable from the past. Some efforts have clearly pressed beyond the evidence and have assumed a creative reality of their own. Others have anticipated future discovery or have constructed paradigms in such a way that future data may be assimilated and organized. Whether it is possible to negotiate an approach to the past without slipping into the extreme camps of the positivists or the relativists remains to be seen. Nonetheless, future study must be prepared to acknowledge that approaches to the past are no more than that--approaches--and humbly accept Trigger's dictum:

The past therefore had, and in that sense retains, a reality of its own that is independent of the reconstructions and explanations that archaeologists may give it (1989: 381 ). 
TABLE 1

TELL TA'ANNEK OCCUPATION AS SUMMARIZED BY GLOCK (1972)

\begin{tabular}{ll}
\hline Period & Dates \\
\hline Early Bronze II-III & $27^{\text {th }}-25^{\text {th }}$ centuries B.C. \\
Middle Bronze IIC - Late Bronze I & $17^{\text {th }}-$ mid $15^{\text {th }}$ centuries B.C. \\
Iron I-II & $12^{\text {th }}-10^{\text {th }}$ centuries B.C. \\
Persian & $5^{\text {th }}$ century B.C. \\
Late Abassid & $10^{\text {th }}-11^{\text {th }}$ centuries A.D. \\
Ottoman - Present & $17^{\text {th }}$ century A.D. - Present \\
\end{tabular}


Recognition of this dictum may serve as both a conclusion to the present chapter and an introduction to the next. The excavations of Tell Ta'annek revealed many "pieces" of EBA lifeways, not frozen in place, but affected by a variety of known and unknown processes. A reconstruction of those pieces and processes begins with the most foundational task of archaeological analysis: stratigraphy. 


\section{CHAPTER II}

\section{THE EARLY BRONZE AGE HORIZON AT TELL TA'ANNEK:}

\section{A STRATIGRAPHIC ORIENTATION}

\section{Introduction}

The purpose of this chapter is to outline the sources, limits, and method which underlie the proposed EBA stratigraphic sequence at Tell Ta'annek. As only a partial reconstruction, this effort should not be misconstrued as a full or final stratigraphic report of the site, but neither should it be viewed as inconsequential to the larger challenge of the present study. Every artifact has a specific locational address at any point in time. While complex formation processes explain artifact movement or modification, it is assumed that controlled excavation may lead to viable statements concerning the position of an artifact and its relation to other artifacts.

\section{Sources for Reconstruction}

Several primary and secondary sources have been used in reconstructing the stratigraphy outlined in chapter 3. These include field books, preliminary reports, graphic records, and the pottery corpus.

\section{Field Books}

These books represent the most basic level of the recording system used by The Taanach Excavations. They contain locus descriptions, basket lists, square plans and 
sections, preliminary pottery readings, some pottery counts, and a daily log of square activity and observations. In addition to these original entries, occasional marks and marginalia from other hands are offered. These secondary marks are often initialed, and typically represent the activity of site synthesis by the those who prepared preliminary reports.

To the credit of the Palestinian Institute of Archaeology, the original field books have been well preserved. Each is bound (sewn) in heavy card stock covers with a cloth binder down the spine. Individual pages are horizontally lined on the front side for field notes and metrically graphed with orange lines on the back for drawings. All original notes and drawings are in pencil.

\section{Preliminary Reports}

A second source used in this stratigraphic reconstruction is published and unpublished preliminary reports. Published preliminary reports have already been noted (Lapp 1964, 1967b, 1969). Where possible, unpublished interseasonal reports from field directors A. Glock, C. Graesser, D. Hillers, W. E. Rast, and A. von Rohr Sauer have been gleaned for data and balanced against the field book observations.

\section{Graphic Records}

A third source used in the present effort is the assorted photographs, drawings, sections, and maps attached to the collection of Tell Ta'annek materials. These are currently stored at the Palestinian Institute of Archaeology and were made available for the present study. Additionally, a collection of A. Glock's color slide transparencies related to the excavation has been preserved and studied. 


\section{Pottery Corpus}

A final source used for this stratigraphic effort is the pottery corpus itself. While field calls recorded in the field books represent the first examination of the corpus and the basis upon which the stratigraphic sequence of the preliminary reports is arranged, further reflection and study upon the corpus were needed to confirm, adjust, or rearrange the initial look. Hence, the major effort of the present study has been to retrieve the preserved corpus, locus by locus, basket by basket, sherd by sherd, for a second evaluation. Such retrieval and examination was possible through two routes. The first and most obvious route was by way of the realia themselves: the sherd material packed in cardboard boxes at the Palestinian Institute of Archaeology. The second, more vicarious route of accessing the corpus was through a "needle card" index, also stored in Birzeit. ${ }^{1}$ Individual "needle" or "punched" cards were prepared for each sherd and contain valuable information such as provenance, description, a pencil drawing of the sherd profile, and, in some cases, a black-and-white photograph with scale glued to the card. Accessing the Tell Ta'annek pottery in these two ways provided one method of testing the proposed stratigraphic structure in this chapter. However, before engaging these sources, strata, and structures directly, a description of the method by which this stratigraphic reevaluation was determined is necessary.

\section{Method of Reconstruction}

Harris suggests that

the process of phasing has two parts. The first is the making of the stratigraphic sequence and the second is the division of that sequence into phases and periods (1979: 89).

${ }^{1}$ See a partial description of this effort in Glock (1975). 
The present study has attempted to follow these two steps in a modified way by creating a Harris Matrix for select squares and areas, postulating stratigraphic phases, and isolating secure loci. Thus the methodology outlined here is key to understanding how the data of the following chapters are integrated.

\section{Creating a Harris Matrix}

On the basis of the field books, a Harris Matrix was prepared for portions of each square containing mixed and unmixed EBA remains. ${ }^{1}$ These schematic diagrams, created by applying the "law" of superposition, proved invaluable as a primary thinkspace and workspace for expressing the intersquare and intrasquare relationships of loci (see Fig. 2). Furthermore, they eased the task of balancing the original observations of the square supervisors, who typically deliver more particulars than are usable, with the published (or unpublished) preliminary reports of the field supervisors, whose syntheses often come at the expense of the particulars.

\section{Postulating Stratigraphic Phases}

Once the matrixes were generated, the tedious task of isolating specific phases was attempted. Again, the "law" of superposition governed the effort, as the sequence of horizontal and vertical feature interfaces was determined. One of four assignments was given to each loci and used for the purpose of phasing the site: preconstruction, use, destruction, or abandonment. Each of these assignments represents a locus function, or more specifically, a "temporal state," and was determined on the basis of

${ }^{1}$ Glock also prepared Harris Matrixes for squares which contained EBA material. However, these were not made available to the present writer at the time of this study and therefore are not represented in this work. 


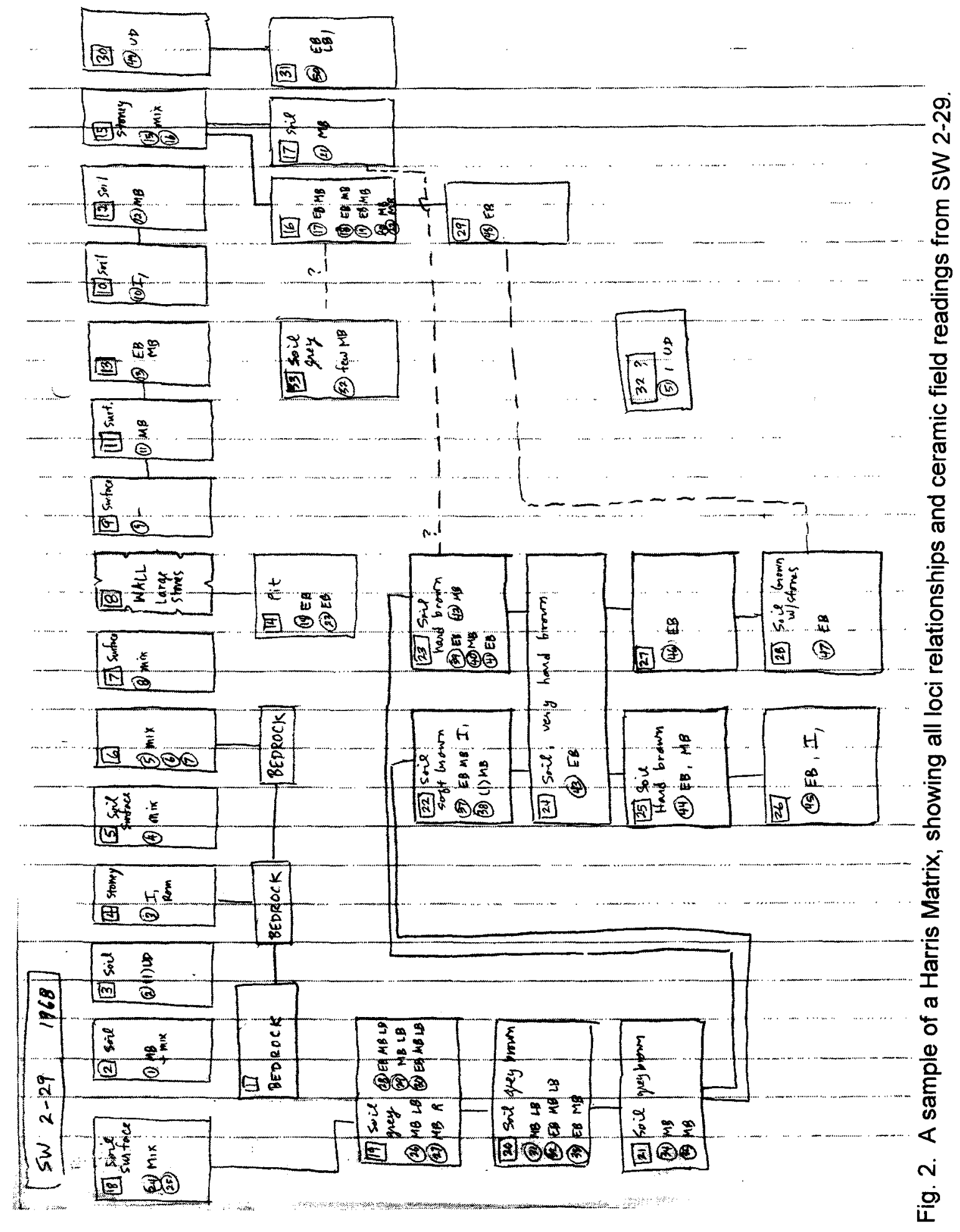


position and content. When accomplished, the preliminary reports were consulted for feedback, balk sections were colored with marking pens, and if necessary, the process was repeated.

\section{Isolating Secure Loci}

As common elsewhere, the Tell Ta'annek excavators used the locus as the primary unit of recorded excavated data. For the present study, the process of isolating secure loci began with the review of the matrixes described above. If a locus was clearly sealed by a surface or architectural feature, it was tagged for further investigation. Pits and other intrusive features were given careful attention when noted. Only after loci were identified as potentially "secure" on the basis of stratigraphic relationships were their contents physically examined for evidence of contamination, i.e., intrusive pottery from later periods. This process may be compared with that used by Rast (1978: 1) to establish "primary comparative loci" (PCL). This step is crucial, for as Harris argues, "the validity of the artifactual comparisons depends ultimately on the quality of the stratigraphic record" (1979: 99). Hence, while the heuristic at work in this study may resemble a "circular" argument, it is ultimately an interpretive spiral which returns repeatedly to the stratigraphic "ground."

Thus, by using these sources and methods, a secure, stratigraphic reconstruction of the EBA horizon at Tell Ta'annek is approached. This horizon will be outlined in chapter 3 , following a brief description of the procedures that shaped the excavated sample.

"Viewing the interpretative craft in terms of a "spiral" has been a regular feature of literary studies. For more on the use of this metaphor see Osborne (1991). For an application of this notion in the field of archaeology see Hodder (1999: 30-65). 


\section{Procedures of The Taanach Excavations}

The procedures used by members of The Taanach Excavations may be discussed under three headings: excavation, registration, and study and storage.

\section{Excavation}

The work of excavating Tell Ta'annek was facilitated by groups of hired, local laborers under the supervision of square supervisors and field supervisors (see Figs. 3a and 3b). Labor teams averaged six or seven persons per square and responsibilities were usually divided between a pickman, hoeman, basket carriers, and a wheelbarrowman. Technical staff also provided important assistance.

Squares were excavated leaving standing balks as a stratigraphic check. Emphasis was placed on vertical sections, which were regularly trimmed, analyzed, and drawn. The degree to which the project was committed to vertical as well as horizontal analysis finds ample illustration. The digging of long, narrow areas such as the 1963 effort known as "The South Trench" which "stepped" down the south slope of the tell, or the more modest and specific problem-finding trench in SW 4-25, may be cited.

Still another illustration of the project's commitment to the vertical section is seen where reexcavation of the 1902-1904 Sellin trenches was initiated. In Field C, an innovative method of digging into the eroded trench balk was detailed in a preliminary report. ${ }^{1}$ Once the vertical section was established, the excavations moved forward along conventional lines into the unexcavated area adjacent to the older trench. This approach created not only a way by which the Sellin reports could be integrated with the present excavation, but an excellent section from which to launch and gauge the new

${ }^{1}$ C. Graesser, Jr. (n.d.: 11). 


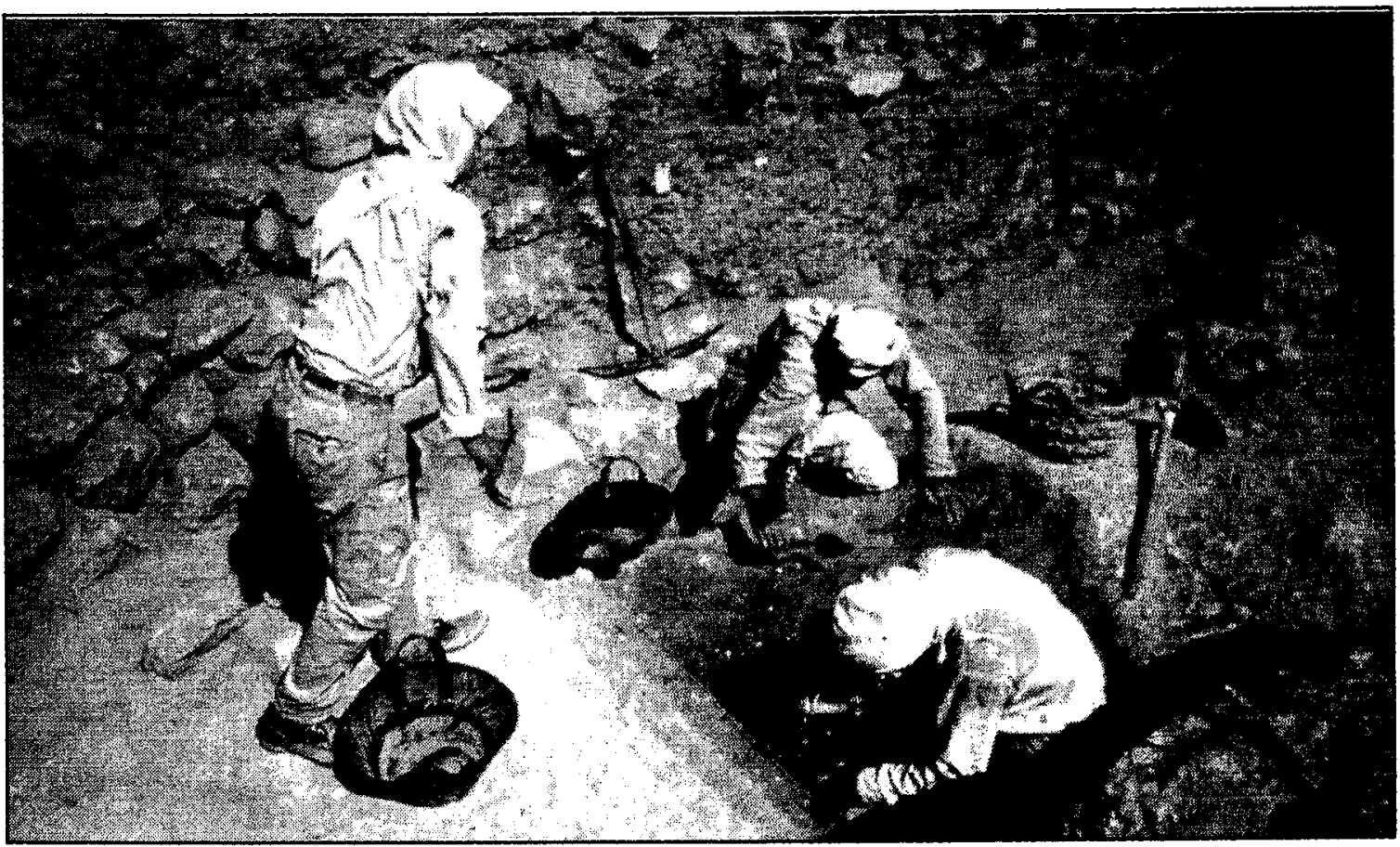

Fig. 3a. Excavation in Progress (1968).

Photograph from The Taanach Excavations archives.

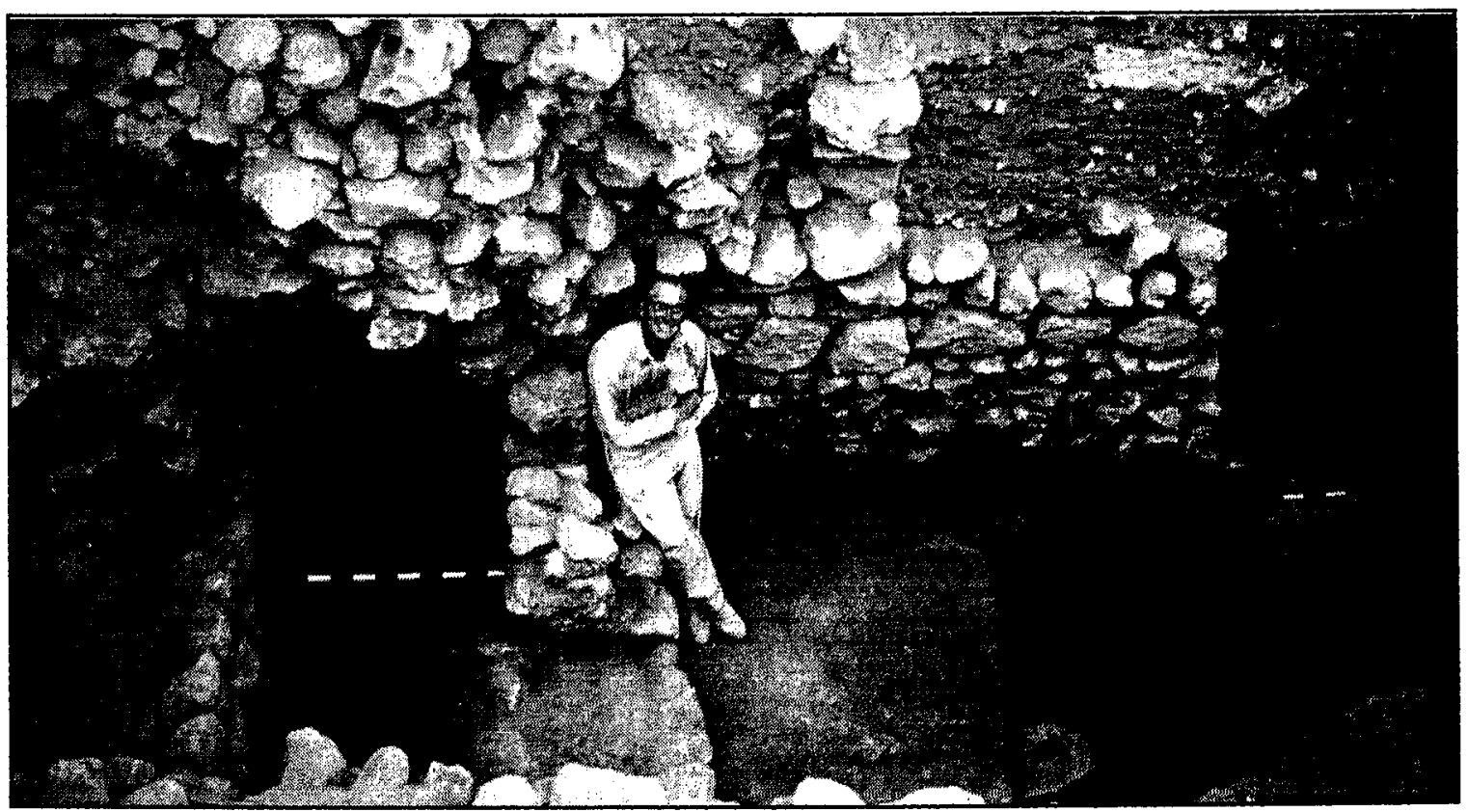

Fig. 3b. C. Graesser in a Deep Trench (n.d.).

Photograph from The Taanach Excavation archives. 
work. Such applications of the balk-debris method by The Taanach Excavations are witness to both the strengths and weaknesses of the evolving paradigm.

While these efforts produced a very limited horizontal exposure, they drew a deep sample from the site's history. Elaborate section drawings depict the variety of features and depositional layers encountered. Correspondingly, these trenches also exposed the continuing struggle to correlate loci excavated and recorded on a horizontal plain with the final vertical section. In retrospect, three problems hinder a full reconstruction of the stratigraphy at Tell Ta'annek. First, absolute elevations were recorded at significant architectural features only, not all loci. Second, while many primary balks were drawn in elaborate detail, others were not drawn at all; furthermore, while secondary balks were used occasionally, these were never drawn. Third, confidence in the recording system led to a casual regard for keeping a given excavation area together, "in phase." These difficulties have isolated portions of the excavated material and challenge the intuitive skills of the interpreter. ${ }^{1}$

Immediate supervision of each square was handled by square supervisors who were also responsible for the task of recording the details described above in the field books. ${ }^{2}$ Field supervisors guided the square supervisors in digging method, strategy,

${ }^{1}$ The development of field method from the techniques used by Petrie and Bliss to the practice of tell excavation today is well known and need not be discussed here. While virtually all legitimate archaeological efforts in the second half of the $20^{\text {th }}$ century acknowledge the foundational importance of this tradition, the application and evolution of its tenants have varied greatly from site to site, while continuing refinements have been made from season to season. Measuring The Taanach Excavations by contemporary standards is as inappropriate as the evaluation of present excavation against benchmarks established 30 years hence. This is not to imply that all criticism is inappropriate or that recent work is superior to work done in the past; it is merely a recognition that every project is, in part, a product of its time.

${ }^{2}$ As is typical at any dig, the order of presented data, as well as the level of recording thoroughness, varies tremendously from supervisor to supervisor; moreover, the narrative structure of the field notebooks lends itself, at times, to the exclusion of 
and recording procedures. The director, in turn, provided administrative oversight and was engaged in the daily developments of excavation.

Pottery sherds and vessels recovered in the field were placed into labeled baskets. Basket numbers were recorded in the field notebooks. At the end of the workday, these baskets were brought into the tent camp where the process of registration began.

\section{Registration}

Once the sherds were brought in from the field, they were washed and laid out in groups on mats to dry in the sun (Fig. 4). Field readings were done by Lapp in conjunction with the field supervisors, area supervisors, and other interested parties.

Field books demonstrate that sherd totals were recorded by period; however, only those sherds which were diagnostic, mendable, or those with unique decoration were kept, inked, and grouped by locus. One estimate of total saved sherds is $33,243 .^{1}$ This figure is further broken down by field and period. ${ }^{2}$ The rest were sent to the pottery "dump," which, for at least a time, was a nearby cistern. ${ }^{3}$

certain details such as the relationship between individual loci and particular object (registry) numbers. Some of this lack has been augmented by later hands; marginal notes indicate some sub- and supra-loci or phase/stratum assignments. Field A.

${ }^{1}$ This handwritten tally is recorded on the first page of the pottery field book for

${ }^{2}$ Only two periods are recorded, Bronze and iron. No further breakdown into subperiods is found. A sense of the totals is suggested by the following figures totaling the Bronze Age sherds for all three excavation seasons: Field A, 4,375; Field B, 5, 192; Field C, 4,842; and Field D, 4,854. This suggests a total of 19,263 Bronze Age sherds were saved.

Curiously, a second tally, with slightly higher figures (roughly 3 percent), is suggested on the back page of the same fieldbook.

${ }^{3}$ Personal communication with John Landgraft (1997). 


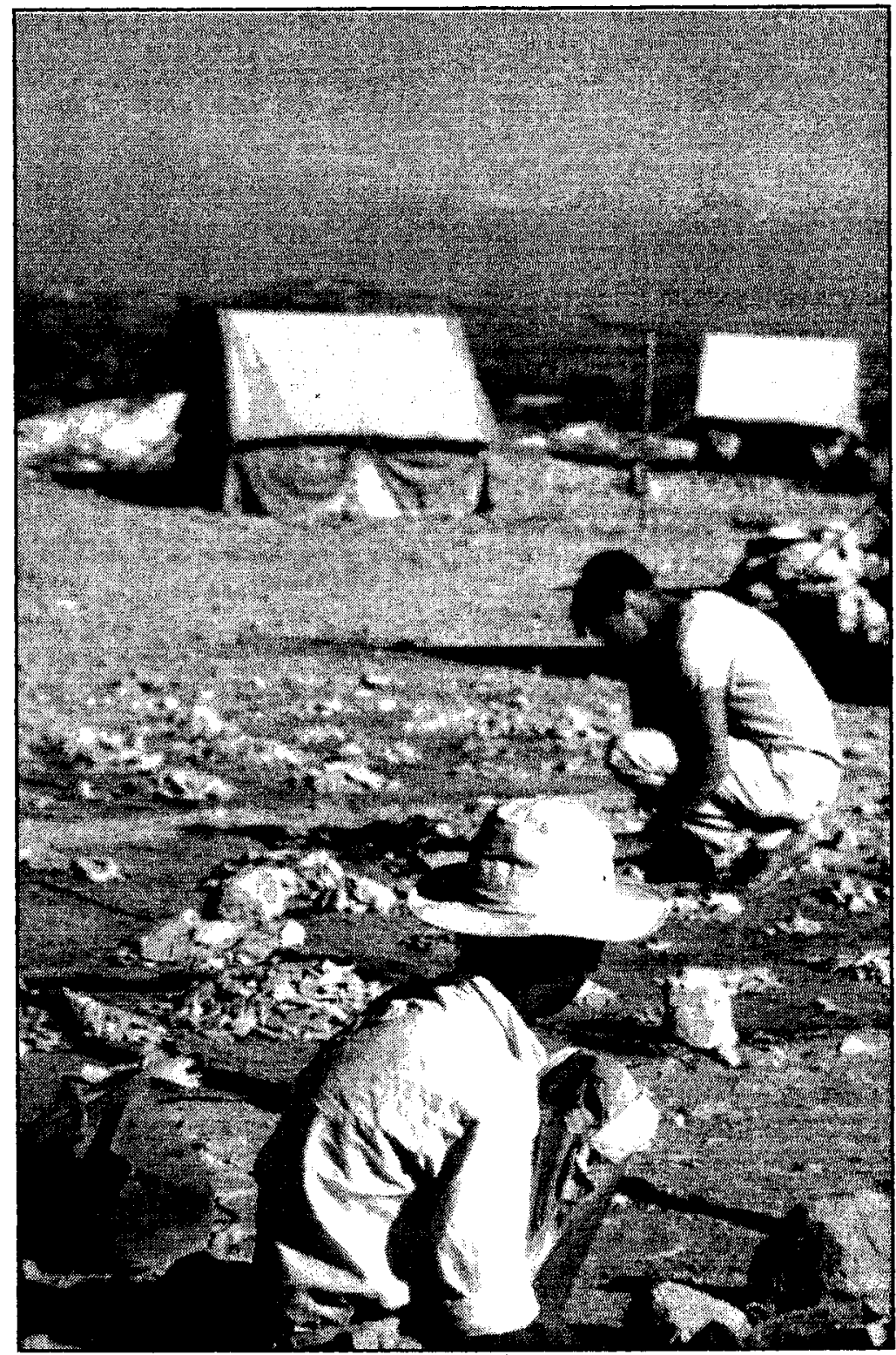

Fig. 4. J. Sauer and Camp Worker Arrange Sherds Drying in the Sun (1963).

Photograph from The Taanach Excavations archives. 


\section{Study and Storage}

In the years following excavation, the ceramic sample from $\mathrm{Tell}_{\mathrm{Ta}} \mathrm{T}^{\text {annek }}$ was regularly moved, sorted, studied, and consequently, shaped (see Fig. 5a). The corpus currently rests in the basement of the Palestinian Institute of Archaeology. Profile drawings of select sherds were prepared by F. Zoghbi, I. Zoghbi, and most recently, by I. Iqtait. The Iron Age material was pulled and published (Rast 1978). Sherds from some of the most significant EBA strata were made available to archaeology students at Birzeit University for seminar papers. Likewise, visiting scholars consulted the corpus on occasion.

Most transformational, though, was the fabric analysis of the collection initiated by $A$. Glock, which required the sectioning of some 25,000 sherds (Glock 1975). These were sawed perpendicularly to the stance of the sherd at the point where the most extensive profile was available (see Fig. 5b). Consequently, nearly all the sherds examined in this study were sectioned, oftentimes in such a way that the registration number inked on the sherd was rendered illegible. To resolve this difficulty, the current writer sought out the corresponding sherd half (when available) and reviewed the sherd card index prepared under Glock's direction. Additional work was required to resort sherds from these "ware family" groups back into their original locus and basket bags (See Figs. $6 a$ and $6 b$ ). Needless to say, even with the responsible oversight of the collection over the course of some 30 years, portions have been displaced. 


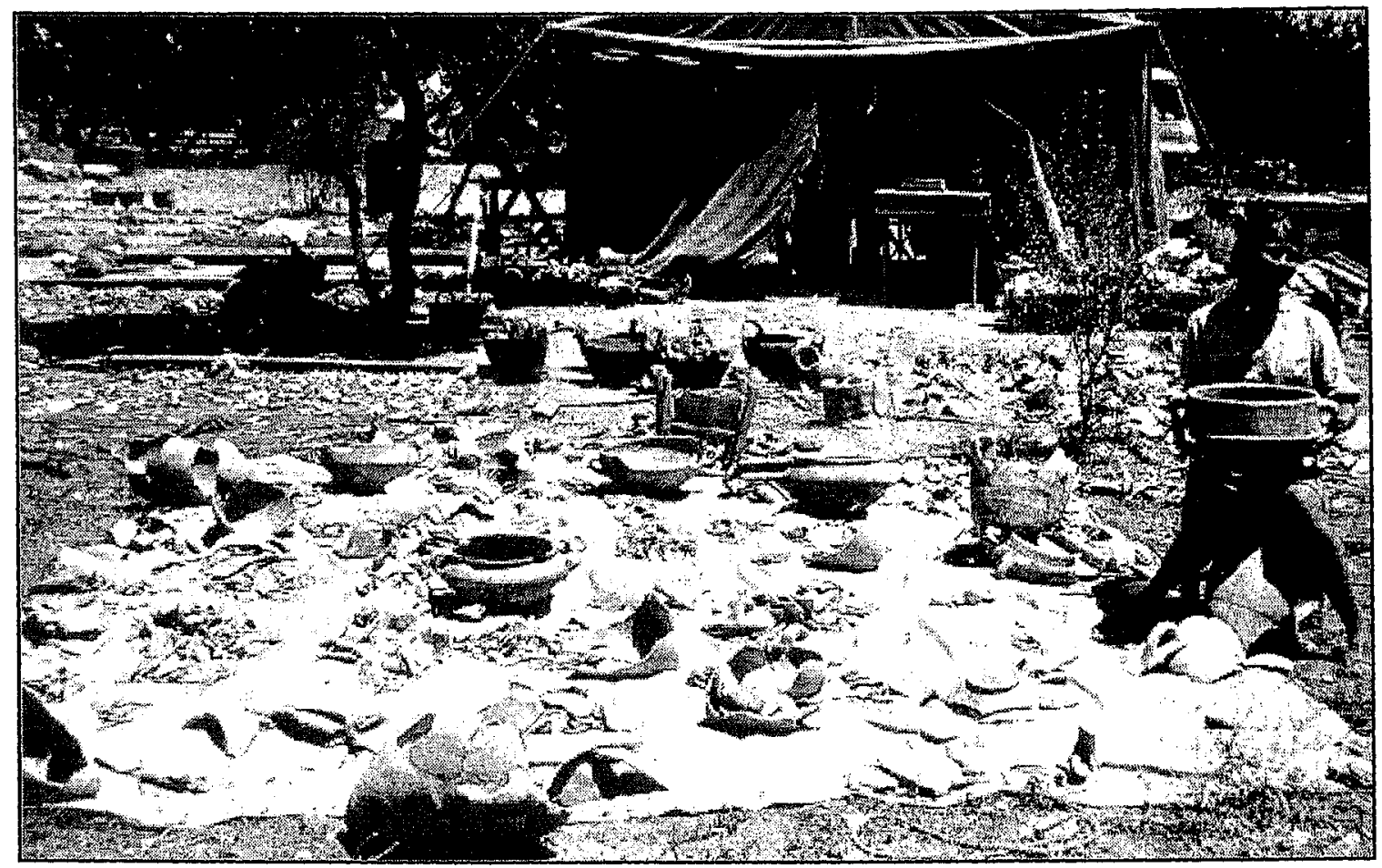

Fig. 5a. The Registry Tent (n.d.).

Photograph from The Taanach Excavations archives.

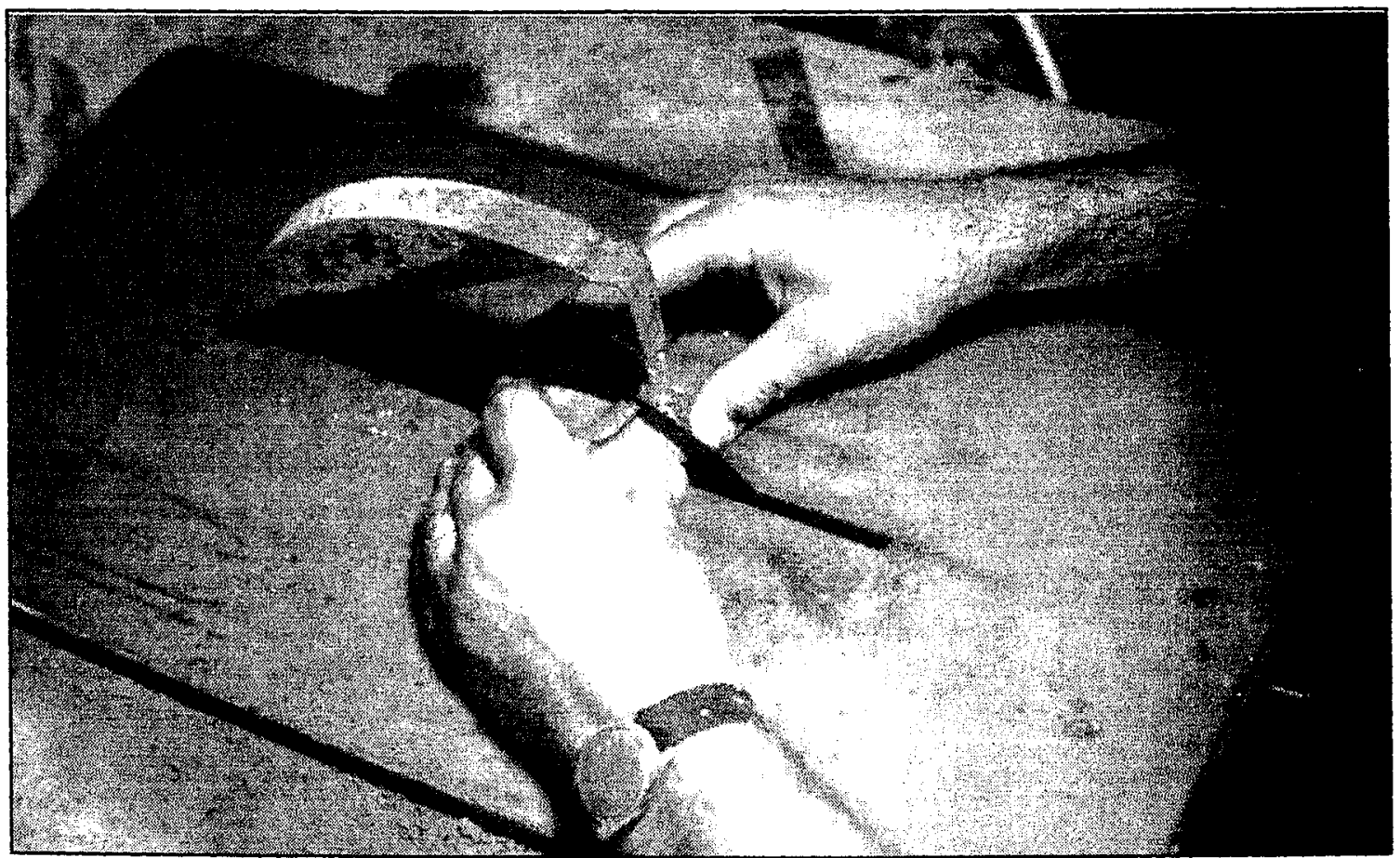

Fig. 5b. Sawing Pot Sherds (n.d.).

This effort was an essential part of Glock's study of ceramic fabrics.

Photograph from The Taanach Excavations archives. 


\section{Definitions}

Despite the widespread use of the following terms, specific definitions must be given to designate their nuanced use within the records of The Taanach Excavations.

Basket: The wicker basket is a collecting point for artifacts taken from a single locus on a single day of an excavation season or even in part of a single day. More than one basket may be assigned to the same locus. In this work it is abbreviated as "B."

Locus: A locus is the primary unit of excavation, uniformly composed of the same material or features. Here, a locus may refer to a soil deposition, architectural feature, excavated object, or even a "trial trench." In this work it is abbreviated as "L."

Phase: A phase is a loci cluster judged as sharing a common "use" in the same point in time. Pre-construction, use, destruction, and abandonment phases are sought in the context of the present work. Further separation of these phases into subphases may be determined if demonstrable change in architecture or pottery is noted.

Square: The square is a potential zone of excavation, determined according to a grid imposed horizontally upon the site for locational purposes. In the case of The Taanach Excavations, a grid of six-by-eight-meter rectangles was used (they are still called "squares" though, by force of convention). ${ }^{2}$ These are addressed first by quadrant, e.g., NW, NE, SW, SE, and then by vertical and horizontal axis according to the numbering of squares, e.g., 5-1, 6-1, 3-25 (point $0-0$ is hypothetically in the center of the tell).

'This last situation becomes awkward at times, as a "trial trench" is hardly a homogeneous deposit. Equally awkward is the frequent situation when a wall is given one locus number when encountered, and a second locus number when excavated.

${ }^{2}$ This sized area, larger than the typical six-by-six $m$ square, was selected in order to retrieve more data without losing stratigraphic control (Rast, personal communication, 1997). 


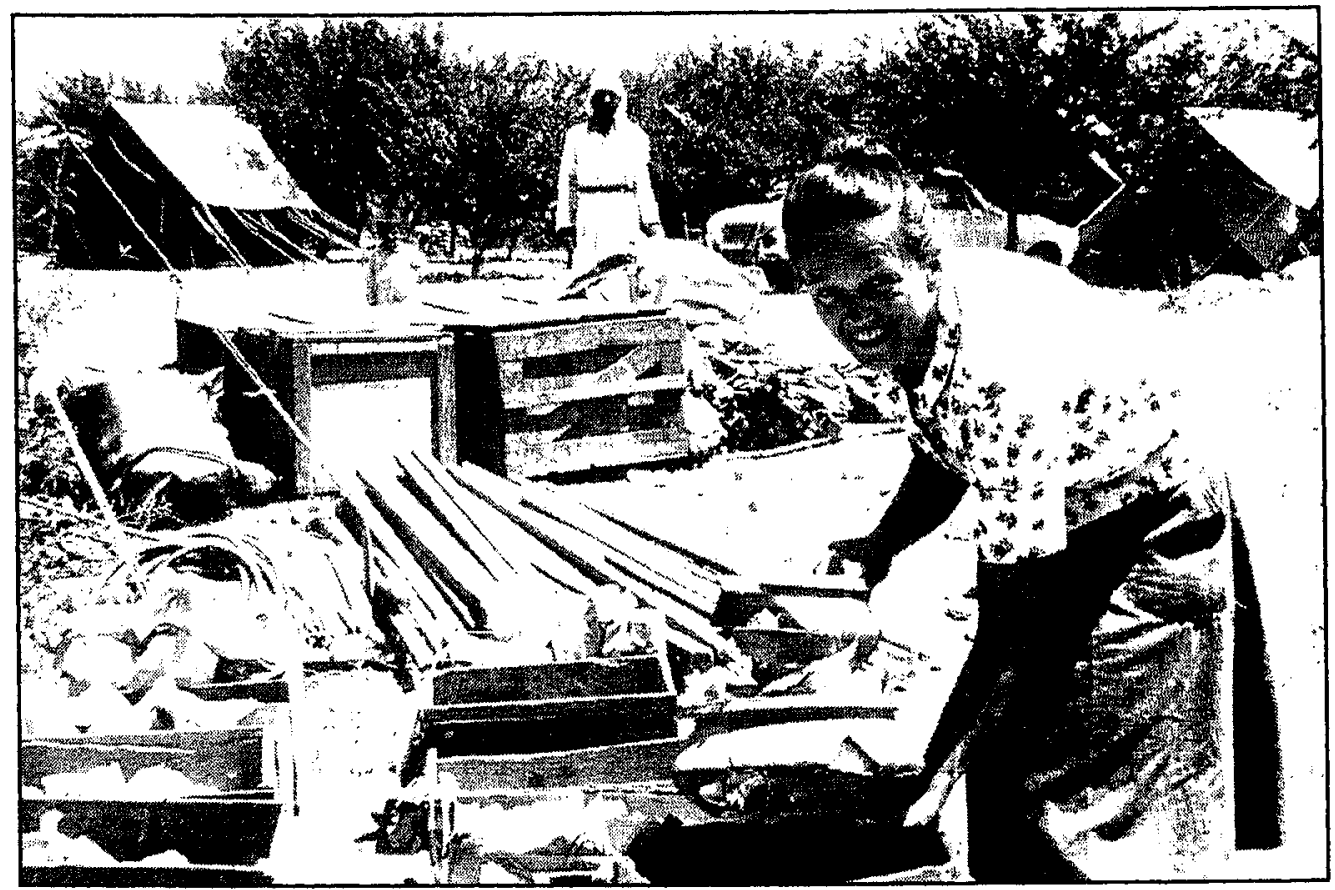

Fig. 6a. Lois Glock Packing Items from the Registry (n.d.). Photograph from The Tell Taanach Excavations archives.

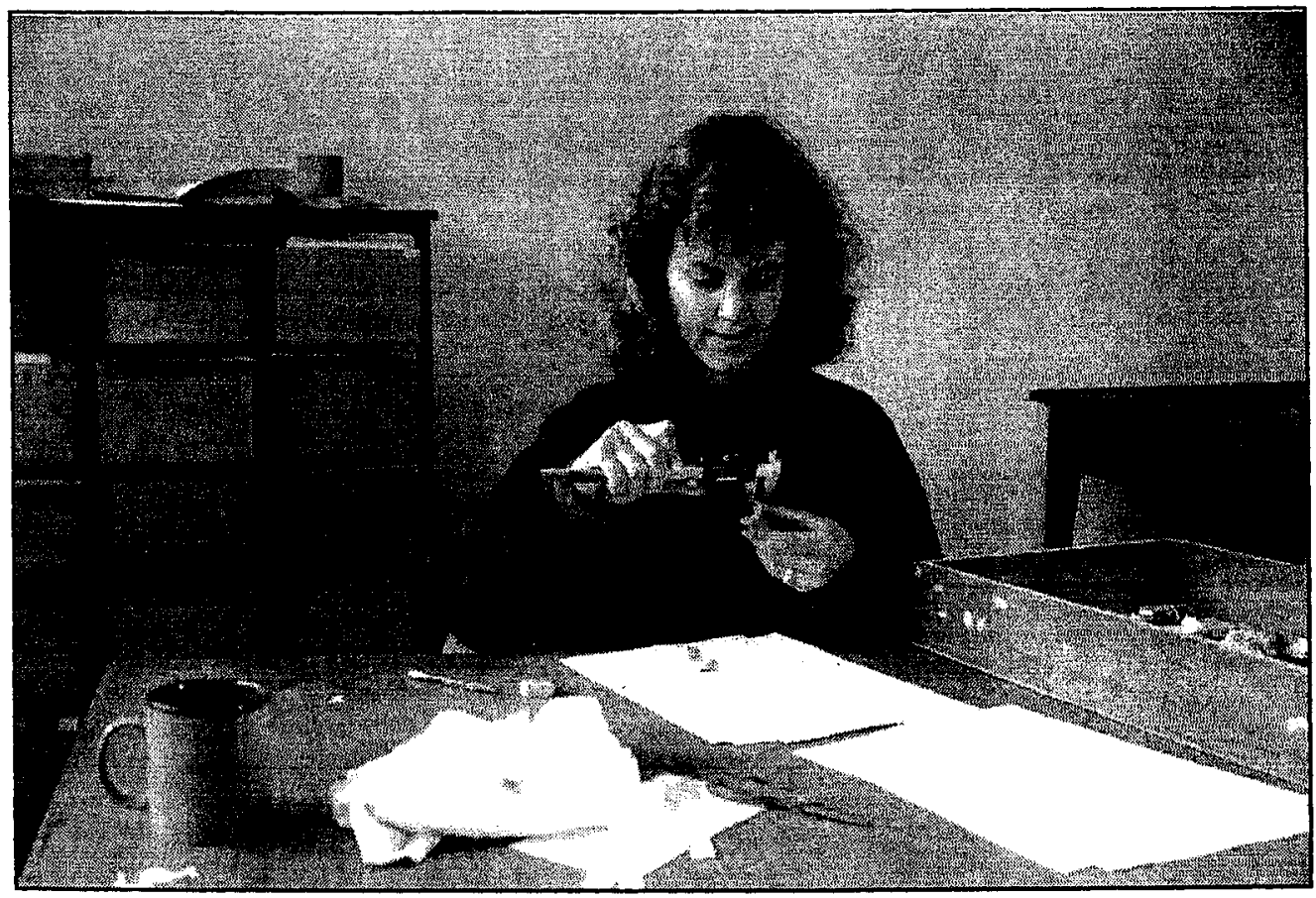

Fig. 6b. Vicki Ziese Collecting Data (1997).

Note the cabinet in the background containing Glock's original "needle card" database of sectioned sherds. Photograph taken in the Palestinian Institute of Archaeology, Birzeit University. 
Field: Although this term did not readily find its way into use by the project ("site" and "area" were its predecessors), a field is a cluster of adjacent squares under the supervision of a single person. Five major "fields" were excavated in the course of the three excavation seasons, designated as $A, B, C, D$, and $E$. The location of these fields and their respective squares is detailed below.

\section{Summary}

The methods of excavation and recording used by The Taanach Excavations at Tell Ta'annek are sufficient to produce viable statements concerning the EBA presence at the site. On this ground, a stratigraphic sequence may be approached that contextualizes the retrieved ceramic record. 
CHAPTER III

\section{THE EARLY BRONZE AGE HORIZON AT TELL TA'ANNEK:}

\section{A STRATIGRAPHIC OUTLINE}

\section{Introduction}

EBA sherds were recovered at Tell Ta'annek in nearly every excavated area (Map 2). However, the majority of such evidence came from mixed fills as natural and cultural transforms subsequent to the EBA continued to use and churn up earlier material. The following survey identifies and describes key loci associated with the architectural phases of the EBA horizon. Description and analysis are presented by field $(A, B, C, D$, and $E)$, and are organized along two constructs: first, on the scale of individual field and square, and second, more paradigmatically, on the scale of field and phase. This outline provides a ready reference for identifying the stratigraphic position for each sherd presented in this study.

\section{Stratigraphic Description and Analysis in Field A}

Field A, dubbed "The South Slope Excavations," was located on the southernmost flank of the tell. The objective in choosing to dig in this area was to reveal the defensive structures of the site. The 1963 effort began by excavating through the bottom of a trench previously dug by Sellin, but was later expanded to the south and to the east in an effort to follow exposed wall lines. Squares associated with Field A included SE 1-26, SE 1-27, SE 1-28, SW 1-25, SW 1-26, SW 1-27, SW 1-28, SW 1-29, 


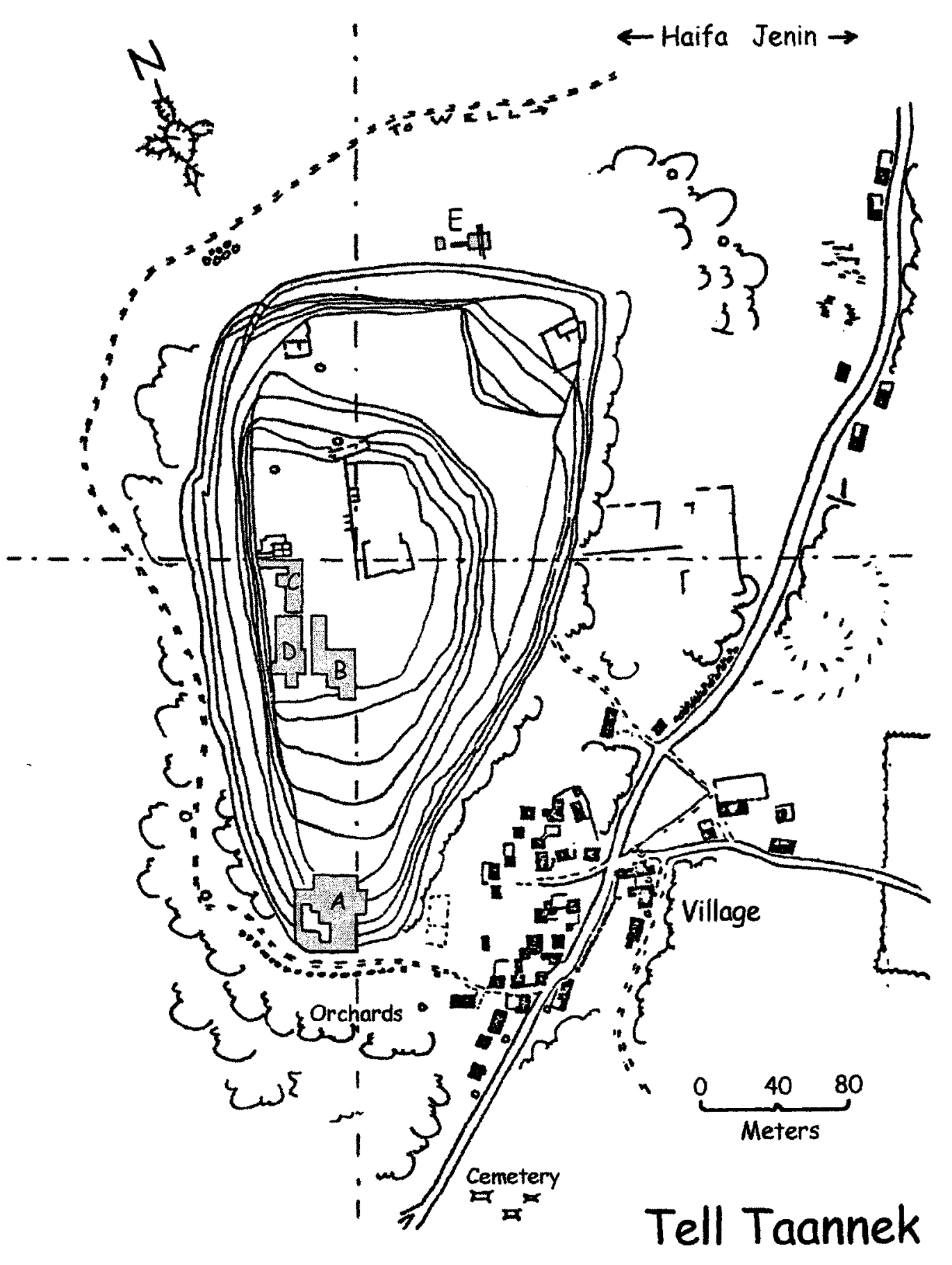

Map 2. Sketch of Tell Ta'annek and Locations of Excavated Fields.

Note the relationship between the tell, fields excavated 1963-1968 (shaded gray), finds by Sellin (dark lines on the tell), modern roads, use areas, and the village of $\mathrm{Ta}$ 'annek. Adapted from a sketch in an unpublished manuscript by A. Glock (1972). 
SW 1-30, SW 2-25, SW 2-26, SW 2-27, SW 2-29, SW 3-26, SW 3-27, SW 4-25, SW 426, SW 4-27, SW 5-26, SW 5-27, and SW 6-26. The goals for the field in reaching defensive structures were achieved as elements of two partially superimposed enclosure walls, a revetment system, and a monumental tower were identified. These were assigned to four major architectural phases by the excavators, a construct essentially confirmed here (Map 3).

Field A, Outline by Square

Field A, SE 1-26. Two aspects of the EBA defenses were identified in this square. The second phase enclosure wall (W 42), its base--or foundation trench--( $W$ 51), and possible "tower" (W 47 and SW 1-26: L 174) were excavated, as was the northeast corner of a "tower" associated with the fourth phase of the EBA defenses (L 43). Significant loci include L 53 and 54 , which were found immediately above bedrock but sealed below a thick huwwar fill ( $L 52)$. Large stones ( $L 50)$, as well as soil lenses ( $L$ $40,46,48$, and 49) and fragments of a possible plaster surface, rested over this huwwar and tipped away northward in piecemeal fashion from the inner face of $W 42$. The same loci (without the note of plaster) abutted the fourth phase "tower" (W 43) and faded northward as well. Evidence of burning was noted in $L 48$ and especially $L 40$.

Other loci of note include $L 57$ and 58 , taken from the second phase foundations (W 51) for dating purposes, and a small probe ( $L$ 61) executed beneath or into the lowest levels of the enclosure wall (W 42).

Field A, SE 1-27. While the distinction between the first and second phase enclosure walls was not well defined in the eastern end of the field, their trajectories clearly diverged in the west. In SE 1-27, the south face of the first phase wall emerged 


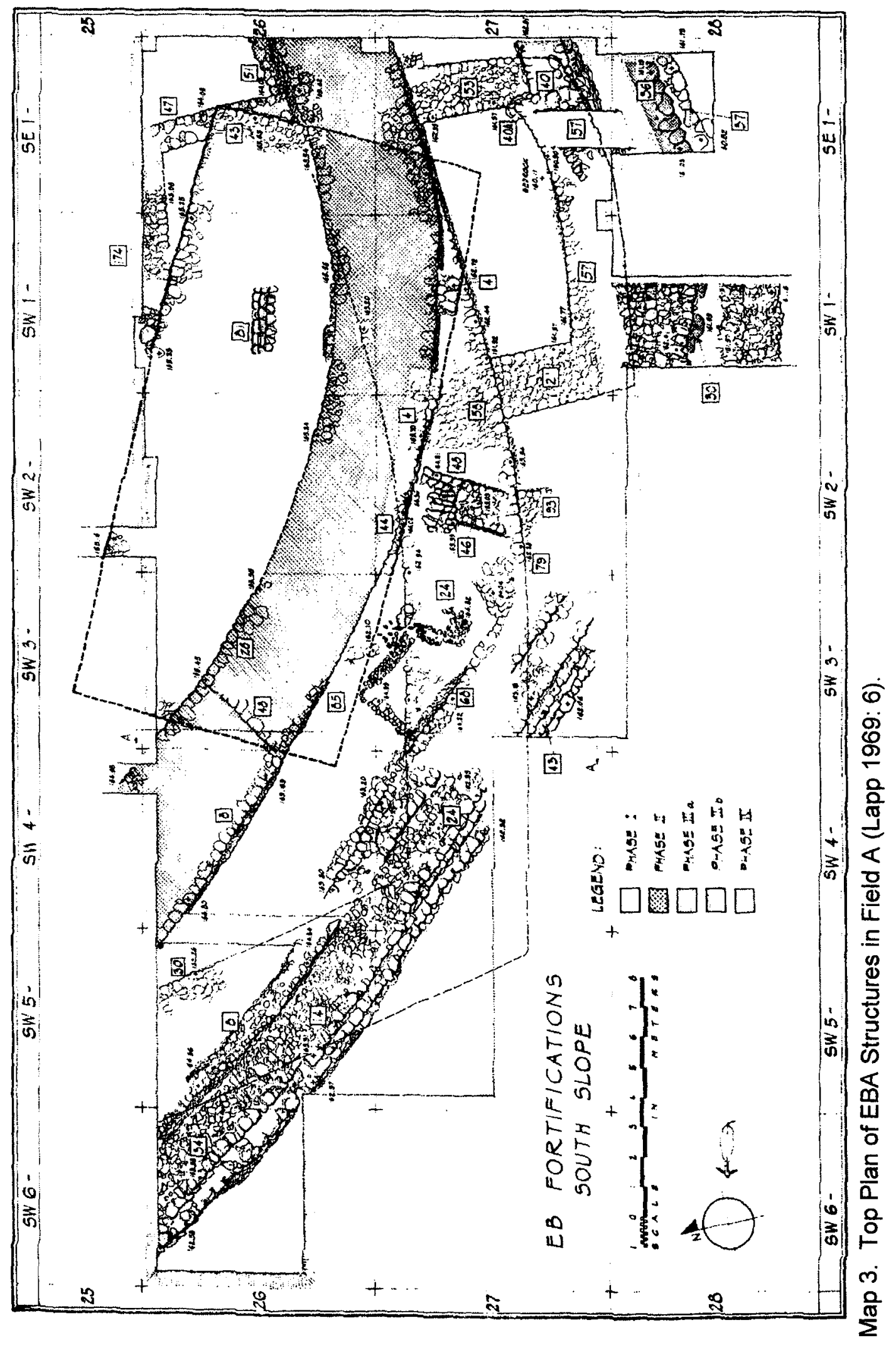


60

from under the second phase wall and assumed a course downslope from it. Portions of a rectangular "tower" (W 53 and W 57), abutting the first phase wall, were also revealed. Later construction features located over and downslope from this first phase "tower" were noted here (W 40) and in SE 1-28: W 36 and 37; the precise function and phase assignments of these are unclear, although they presumably relate to a revetment foundation.

From a stratigraphic perspective, significant loci were excavated inside and outside the first phase "tower" enclosure. According to the fieldbook, L 54 (described as "brown dirt and stone") infilled the "tower" from bedrock to the top of the preserved courses of $W 53 .{ }^{1}$ Fills outside and east of the "tower" include $L 50,52,55,56,59$, and 60 , but were not pursued to bedrock. These walls and fills were subsequently sealed by a thick huwwar upbuild ( $L 46,48$, and 49 ), presumably in anticipation of its construction. Above this huwwar and north of W 40 , late disturbances render conclusive statements impossible. Lenses of broken huwwar $(L 30)$, rubble, and ash suggest the presence of a glacis system clarified elsewhere. ${ }^{2}$

Field A, SE 1-28. As noted above, the south face of the third phase rampart walls (W 36 and 37) was revealed in this square dug to bedrock. Soil pockets ( $L 39$ ) in the bedrock were sealed by $L 41$, which ran beneath $W 36$ and $W 37$. $L 41$ also extended into SE 1-27 where it abutted and sealed the first phase tower wall (SE 1-27: 1-27.

${ }^{1} A$ more precise stratigraphy taken from inside the tower walls came from $\mathrm{SW}$

${ }^{2} A$ section was taken through $W 40$ in the 1968 season, presumably to clarify the relationship between $W 40$ and $W 57$. No section drawing of this effort could be located. In his field report, Glock reports that SE 1-28: $L 41$ covered the first phase "tower" wall (SE 1-27: L 57) and that it is continuous with SW 1-27: L 43; SW 2-27: L 19, 76A; and SW 3-27: L 78. 


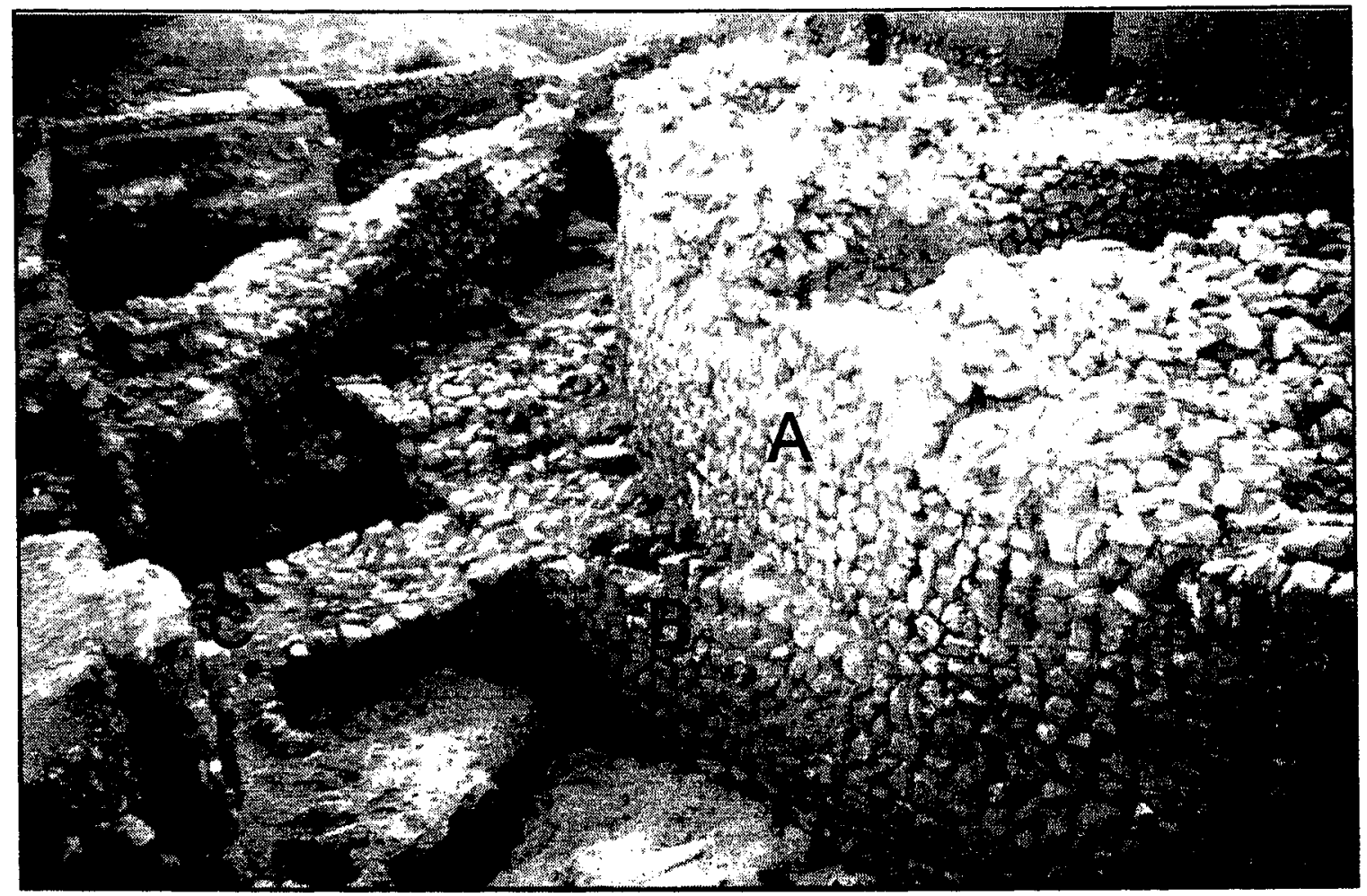

Fig. 8. View East to Excavated EBA Fortifications in Field A (1968).

Photo from The Taanach Excavations archives and first published in Lapp (1969: 7). Note the fortification wall in center and the different trajectories of earlier (B) and later (A) phases. Visible in the lower left center of the photograph (C) is the footing of a room or "tower" abutting the earlier fortification wall (B). 
W 57) and continued with L 44 under the rampart wall (SE 1-27: W 40). W 36 appears to have been faced with plaster on the south side; it was later enlarged and refaced by W 37. Rubble stones initially construed as W 30 covered both W 36 and W 37 and spilled downslope. Over $L 30$ were a series of lenses consisting of $L 25$ under $L 23$ under $L 15 . L 15$ appeared as a sloping, thin line of green or yellow-green huwwar, a continuation of $L 30$ from SE 1-27. Approximately halfway across the square, this huwwar layer disappeared into a tumble of eroded material ( $L 40,38,27,41 A$, and 27$)$. These, in turn, were sealed by a thick layer of white huwwar, presumably the remains of the MBA glacis.

Field A, SW 1-26. Revealed in this square were elements of the second phase enclosure wall (no locus assigned) and inner "tower" (W 174), the third phase "steps" (L 81), and the north wall of the fourth phase "tower" (no locus assigned). The square was probed to bedrock over the course of two seasons and several valuable stratigraphic sequences emerged.

A sequence in the 1963 probe to bedrock involved $L 83,80,79,82,85,86,87$. and 88 . This probe was sunk against the north face of the second phase wall and revealed horizontal layers of huwwar upbuilds, presumably placed at the time of the second phase construction to elevate the area inside the enclosure wall. A second sequence in and around $\mathrm{W} 174$ is critical, yet questionable: verbal descriptions alone fix its position as sub $L 169,170$, and 171 . A third sequence demonstrated that the fourth phase "tower," known elsewhere as a stone scree across the square, had a well-defined north face (W 166). A drawn section reveals yellow huwwar $(L 177)$ abutting what appears to have been the base of this face and topped by a possible use surface ( $L$ 176). A second huwwar layer $(L 173)$ rests above $L 176$, and is, in turn, sealed by $L 171$ 


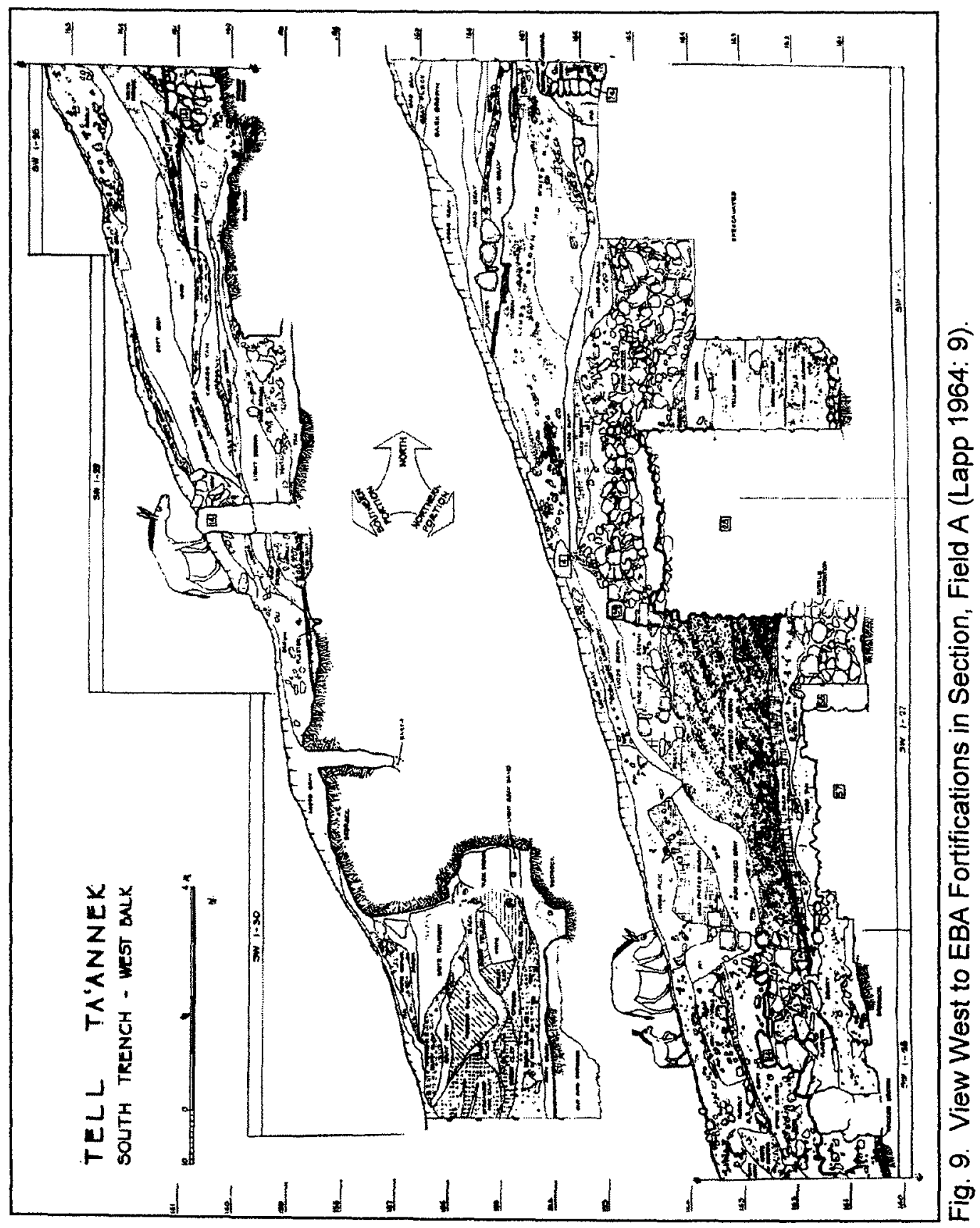


containing evidence of burning. Two more loci ( $L 169$ and 167$)$ cover $L 171$, the last abutting the top of the preserved "tower" surface. This surface and $L 167$ were sealed by a large mixed deposition ( $L$ 151) that interfaced with the MBA strata. Finally, an enigmatic note suggests that a portion of $W 166$ was removed. No section drawing locates this work, but $L$ 166: B 319 apparently contains the ceramic sherds collected in the removal. Similarly, records do not preserve an accurate stratigraphic fix for what Glock believed to be third phase "stairs" ( $L$ 81), associated with a perimeter walkway.

Field A, SW 1-27. Architectural features visible in this square include the first phase enclosure wall ( $L$ 57) and its corresponding "tower" (no locus assigned), the second phase enclosure wall ( $L 28)$, and fragments of the fourth phase "tower" ( $L 4)$.

Loci resting within the walls of the first phase tower may be related to its construction ( $L$ 64), use or reuse ( $L 54,55,56,59,60 ?, 61,62,63$, and 72$)$, and destruction ( $L 51$ ). Leveling efforts ( $L 43,44,48$, and 49 ), initiated at the time of the building of the second phase enclosure wall (W 28) or before the third phase glacis was deposited, sealed all first phase loci. The huwwar glacis itself ( L. 31? and 90) abutted W 28 and trailed massively downslope into SW 1-28. With the exception of a possible surface fragment ( $L$ 40), mixed loci, likely eroded from upslope, appeared above the glacis. A battered line of stones, representing the south line of the fourth phase "tower" (W 4), was present on the crest of W 28.

Field A, SW 1-28. SW 1-28, SW 1-29, and SW 1-30 were not expanded in later seasons from their original width excavated in the 1963 "South Slope" trench. Architecture revealed in SW 1-28 included features associated with the base of the third phase glacis. 
$\mathrm{L} 34,35,36$, and 40 appeared directly above bedrock in this area; a possible plaster fragment sealed $L 36$ and 40 and linked them with the "leveling" actions described above in advance of the third phase glacis construction. Large stones, backed by a considerable amount of medium-sized stones, were located upslope in a series of steps over these loci $(L 14,37,38$, and 39$)$. Presumably, these anchored the third phase glacis, as it dipped and disappeared into them. Sealing these steps, loci described as "soft brown" (L 13), "rocky" (L 32), or as a "rocky scree" (L 30) spilled down into a rising bedrock shelf. Pockets of material were distinguished resting immediately on the shelf's surface ( $L 28$ and 33). Portions of the subsequent MBA glacis ( $L 11$ and 12) were visible over these later loci $(L 13$ and 30$)$, raising the possibility that human, as well as erosive, efforts shifted this EBA material downslope. Stray MBA sherds confirm this proposal.

Field A, SW 1-29. Continuing the "South Trench," SW 1-29 picked up eroded elements from above as well as some in-situ features. Under a bedrock ledge, two EBA loci were preserved ( $L 27$ and 28). Similarly, a large stone cluster ( $L$ 14) partially preserved a plaster floor fragment resting directly on bedrock ( $L$ 22) contained EBA sherds.

Field A, SW 1-30. As in SW 1-29, EBA material was found in a deep bedrock pocket ( $(\mathrm{L} 15)$.

Field A, SW 2-25. A wall fragment (no locus assigned) emerging from this narrow trench was linked to the north face of the fourth phase tower on the basis of alignment and elevation. No surfaces were noted in association with this wall fragment. 
L 230, described as "loose brown," abutted the wall. $L 231$ probed it, and $L 229$ sealed it.

Field A, SW 2-26. Efforts in this square revealed the battered uppermost courses of the second phase enclosure wall (W 72). Many mixed loci lenses were found upslope, on, and downslope from W 72; only two were exclusively EBA ( $L 80$ and 81).

Field A, SW 2-27. All four EBA architectural phases were discovered in this congested square. The first phase enclosure wall ( $W 78)$ continued to emerge beneath the south face of the second phase enclosure wall (W 44?, 88?). A fragment of a possible second "tower" abutting the first phase wall came into view (W 93). Features outside the second phase enclosure wall and associated with the third phase were encountered (W 46 and 48), and the south wall line of the fourth phase "tower" was followed (W 4).

Significant loci begin with the series $L 91$ and 92 , that rested on bedrock and were sealed by a stonefall ( $L 90)$, presumably from the first phase enclosure $W 78$ that they abut. This stonefall $(L 90)$ also covered $W 93$, which may represent the beginning of a second "tower," akin to that revealed in SE 1-27 and SW 1-27. L 90 was, in turn, at least partially topped by $L 89$, which, along with $L 87$ and other first phase elements, was completely sealed by a hard, brown soil locus with ashy deposits ( $L$ 76a).

Resting atop $L$ 76a was more than a meter of green huwwar deposit $(L 75)$. This huwwar abutted the second phase enclosure wall on the north and spilled across the length of the square. Constructed upon the huwwar was a feature described as a cobbled surface, yet depicted on the balk drawing as a wall fragment (W 46). Whether surface or wall, it was associated with loci labeled "soil" (L 85) and "stone" (L 86). 
Between this feature and abutting the second phase wall (W 44 or 88 ?), a sequence of stone steps emerged ( $L 48$, but were apparently excavated as $L 81,82,83 a)$. $L 34,51$, 58 , and 60 topped these stairs in an undetermined fashion, revealing fine ash, burned bones, and burned sherds. A mixed locus ( $L 33$ ) sealed this destruction. Other loci likely associated with the construction, use, and destruction/abandonment of this third phase stepped installation include $L 54,55,56,57,58,59,60,61,62,63$, and 65 .

The fourth phase "tower" wall line (W 4) utilized the second phase enclosure wall as foundation in this square. No surfaces may be assigned to this structure, although soil lenses ( $L 51$ ), some with ashy deposits ( $L 34)$, have washed downslope from its face.

Field A, SW 2-29. Excavations conducted downslope from Area A in SW 2-29 and SW 2-30 revealed several bedrock installations. It is possible that a winepress here may be dated to the EBA. ${ }^{1}$ In SW 2-29, two rectangular basins were discovered, cut into bedrock. The larger, shallow $(10 \mathrm{~cm})$ basin measured approximately 3.10 by $2 \mathrm{~m}$ in size; the smaller, deeper $(70 \mathrm{~cm})$ basin measured ca. 88 by $55 \mathrm{~cm}$. Bored channels connected the two and some plaster lining was found in one of the channels and in the smaller basin. Sealed EBA loci $(L 24,27$, and 28$)$ were excavated from both basins. It is possible, however, that these were infilled at a later date, perhaps, as the excavator suggests, for the construction of an MBA wall ( $L$ 8) located above.

Field A, SW 3-26. Architecture excavated from this square includes the second phase enclosure wall (W 18), a surface associated with the third phase ( $(\mathrm{39})$, and a

${ }^{1}$ Ahlstrom (1978: 19-49) gives details of this press within a larger survey of wine presses and cup-marks in the region between Jenin and Megiddo. 
single wall fragment that may suggest the western limit of the fourth phase "tower" (W 37).

Bedrock was reached south of the second phase enclosure wall (W 18). L 54 and 55 rested on and above bedrock and were sealed by a thick green huwwar (L 52) that abutted $W 18$. Several striated layers covered the huwwar including $L 40,43,41$, $44,42,45,46,50$, and 51 . These may have been sealed in part by a nearly horizontal plaster surface $(L 39)$ that also abutted $W 18$. The position and elevation of this surface invite the suggestion of its continuity with the "stepped" feature of SW 2-27. Mixed loci appear above this plaster. Finally, two probes were executed to discern the make up of W 18 (L 48 and 49).

A western limit to the stony scree associated with the fourth phase tower was identified in the northwest corner of the square (W 37). A probe into the structure itself revealed some sherds corresponding to its construction (W 37: B 106); a small probe was sunk against its west face ( $L$ 47). No corresponding surfaces were noted.

Field A, SW 3-27. Excavation in this square revealed elements of the first phase enclosure wall (W 81) and the third phase revetment with associated "features."

The first phase enclosure wall (W 81), extremely fragmented at this point, rested directly on bedrock. Stone fall ( $L 83$ and 84$)$, a possible secondary wall ( $L$ 85), white huwwar (surface?) ( $L$ 86), and other soil ( $L$ 78) and ashy deposits ( $L$ 82) were found in conjunction with W 81 and were subsequently sealed by the thick green huwwar layer (L 73) associated with the third phase construction. 


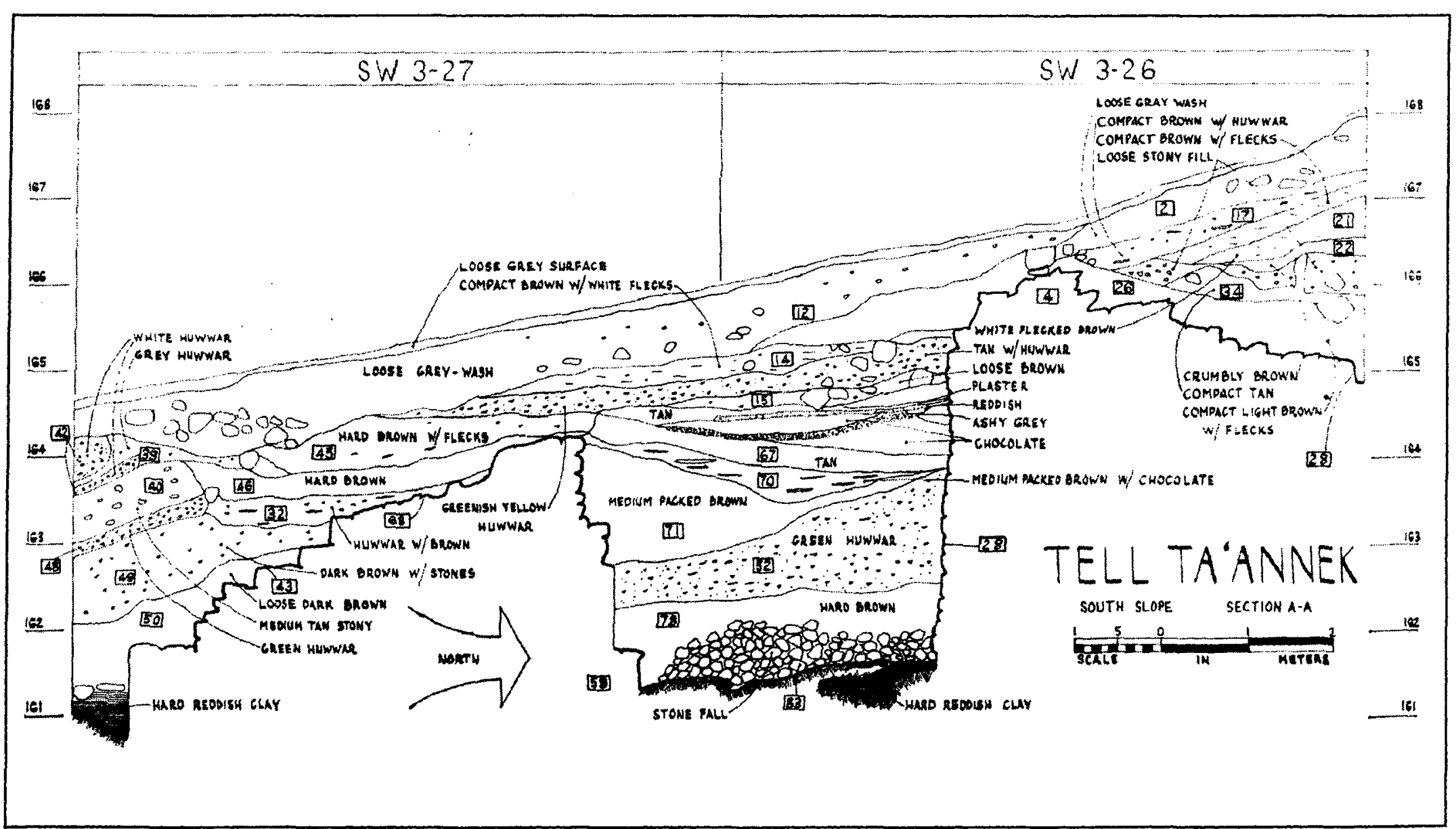

Fig. 10. View West to EBA Fortifications in Section, SW 3-26 and 3-27 (Lapp 1969: 9). 
As elsewhere, the green huwwar ( $L$ 73) sloped down from the second phase enclosure wall and was terminated at a massive revetment system (W 68 and 43). ${ }^{1}$ Above the huwwar rested loci that seemed to thicken and "pool" as they approached the revetment $(L 67,71)$. Other loci that rested above the huwwar include $L 65,70$, and 69 .

No north face for the revetment wall(s) is noted. Loci sealing the downslope side of the revetment wall include $L 51$ (bedrock pocket), and mixed $L 50$ and 49 . Broken against the revetment wall, but picked up further downslope, is huwwar associated with the MBA glacis ( $L$ 48).

Upslope, above the third phase huwwar, several soil loci were noted. At least three of these ( $L 36,64$, and 65$)$ were sealed by an undefined white plaster layer ( $L 62)$ which possibly corresponded with SW 2-27: L 57. Other loci located in the same general context include $L 58,59,60,61,66,67,69,70,71$, and 76 . Resting in sequence immediately above $L 62$ was $L 57,56$, and 54 . The relationship between these loci and $L 24$, labeled an "Early Bronze pavement," cannot be determined. The same is said for other soil layers that are not identified in section drawings or given elevation assignments.

Field A, SW 4-25. This one-by-five-meter probe briefly revealed the stratigraphy along the north face of the second phase wall (W 25), and a trace of the EBA occupation. Only the lowest excavated area is relevant to the present discussion. At least two unidentified "stone complexes" ( $L 27,24$, and 23) emerged upslope and adjacent to the uppermost courses of W 25. These possibly rested on unexcavated surface ( $L$ 26) of semi-compact orange soil. They were sealed by soil $(L 22)$ described as "grey-black" on one occasion and "loose grey" on another. An irregular lens of "loose

${ }^{1} A$ possible foundation trench for $W 68$ was excavated as $L 72$. 
reddish brown" ( $L 21)$ rested upon $L 22$ and was, in turn, sealed by mixed fills $L 20$ and $L 18$, the latter stretching over the uppermost courses of the second phase wall (W 25).

Field A, SW 4-26. The second phase wall continued here as W 8; the third phase revetment continued as Wall 38. Stratified material was excavated from between these two walls. In the lowest areas, dark brown soil with much ash $(L 17,20,21)$ covered the bedrock and, in turn, was itself buried beneath a thick fill of "green" huwwar ( $L$ 18). This huwwar was approximately one meter thick against $W 8$, but gave out slowly, and according to the excavator, did not actually reach revetment $W 38$. Thick soil fills $(L 15,30)$ were, in turn, resting upon the huwwar, and as detailed below, spilled over the revetment W 38 . A sequence of surfaces was superimposed upon these fills. A lower plaster surface was severely broken up, but was preserved sealing against W 8 . Above this were several thin soil layers $(L 31,32,33,34$, and 35$)$ sealed by a better preserved plaster surface ( $L$ 16). This plaster sealed against $\mathrm{W} 8$ and extended southward to a point roughly one meter above extant W 38 . Stone and soil debris accumulated upon this upper plaster $(L 13)$ and finally, insecure fills were excavated from the top of W 8, some with significant EBA remains $(L 24,39,40,41)$.

Field A, SW 4-27. The third phase revetment wall continued here as Wall 24. As elsewhere on the south face, the lowest courses stepped down to bedrock where pockets of dark red brown soil were revealed $(L 28,29)$. Tiers of sloping fill were superimposed, one above the other ( $L 22,26 \mathrm{~A}$, and 27$)$ and sealed by a thick "green" huwwar layer $(L 15)$ that ran towards the south face of the outer revetment wall. Elsewhere the path of the huwwar could be traced easily over the south face, but in SW 4-27, disturbance rendered this effort difficult. However, it does appear that the hard 
brown soil of $L 30$ from SW 6-26 did spill over the revetment wall and continue as $L 22$ (which runs beneath huwwar $L$ 15). This important observation led Glock to suggest that the entire revetment system was eventually buried with soil and huwwar, perhaps in the latest part of Phase 3 or during the construction of the Phase 4 defenses (1969: 13).

Field A, SW 5-26127. ${ }^{1}$ A small portion of the second phase enclosure wall was encountered in the northeast corner of SW 5-26. L 27, "mudbrick" (fall?), was found against the face of W 28 in the lowest excavated area. Adjacent to the mudbrick was a stub of an east faced wall (W 30), which the excavator believes to be a portion of the first phase defenses. ${ }^{2}$ Sealing against $W 28$, against the third phase revetment wall, and over $W 30$ was $L 25$, a possible surface ("medium hard brown"), which, in turn, was sealed by $L 21,22$, and 23 . Lenses of ash and other evidence of burning (charred bone) appeared over and on $L 25$. No mention is made of a foundation trench cut through any of these fills for the third phase revetment wall, raising the question of the priority of $L 21,22,23$, and 25 to the revetment construction. Equally problematic is the sequence of fills deposited above $L 21$ between the revetment wall and $W 28$. The presence of deep intrusive sherds $(L 20,36)$ disallows the easy conclusion that the area between the second and third phase walls filled to the upper courses of the revetment, and suggests that erosive forces may account for as much as half of this excavated fill.

${ }^{1}$ The discussion of SW 5-27 is more readily handled in conjunction with the discussion of SW 5-26. Unless otherwise indicated, all loci references here refer to SW 5-26.

${ }^{2}$ If this is the case, a sharp turn in the first phase Wall 58 would be required to link this stub in SW 5-26 with the preserved portions in SW 3-27. No such turn has been excavated, although it is likely that the perimeter defenses must turn northward to follow the scarp of the tell at some point (Glock 1969: 4). 
As already mentioned, the third phase revetment wall $(L 8,14)$ continued here. Its construction was best delineated in SW 5-27 and SW 6-26. It consisted of an inner wall $(L 8)$ rising approximately $1.5 \mathrm{~m}$ above the level of the outer wall $(L 14)$ that stepped down to bedrock. The core was stone and packed soil. Approximately $24 \mathrm{~m}$ of this structure ran southeast-northwest between SW 3-27 and SW 6-26, following the edge of the slope.

Loci banked down and away from the revetment on the south. A huwwar layer $(L 75=S W 5-27: L 11)$, nearly $40 \mathrm{~cm}$ thick in places, was partially preserved sealing the top of the outer wall and several downslope loci (L 10,12, 13, 15, 16, 17, 31; SW 5-27: $L 13,14,16,19,21,23,24 A$, and 27$)$. Small walls may have helped stabilize the huwwar cover here (SW 5-27: W 18), as elsewhere (SW 6-26: L 35). Above the huwwar, loci are mixed with later material.

Field A, SW 6-26. The third phase revetment wall continued in this square ( $L$ 34). It was founded on the south side upon bedrock or a layer of dark red soil ( $L 30)$ directly upon bedrock. Sealing against the lowest course of the revetment and over other soil loci $(L 38,39)$ in one place was a fill of white huwwar $(L 33,36$, and possibly 37).

Other loci in this square appeared as build-up debris deliberately placed against the downslope face of the revetment. As in SW 5-26127, a huwwar layer ( $L$ 11) sealed the lower portions of these fills $(L 12,13,15,22,24,26,27) .{ }^{1}$ Above the huwwar, late material mixed with the earlier EBA material in sliding washes.

${ }^{1} A$ thin plaster seal may have faced the huwwar. Lapp notes the presence of the plaster in his published report (1969: 10-11), although no mention was made of this in the SW 6-26 field book. 


\section{Field A, Outline by Phase}

Four distinct phases in Field A have been outlined (see Table 2). This construct offers a temporal sequence for the massive fortifications found in the field. Specific fills may be linked to these phases, and suggest, by content or position, a further breakdown of the field into subphases.

A massive enclosure wall with flanking towers characterizes the first phase construction in Field A. Subphase $1 \mathrm{~A}$ is associated with fills preceding construction, while Subphase 1B represents the construction and use phases of the initial fortification wall. Subphase $1 \mathrm{C}$ is associated with the partial destruction of this wall.

The second phase of activity is focused on the reuse and modification of the first phase wall. Here, too, two subphases are proposed. Subphase $2 \mathrm{~A}$ is linked to the modification efforts and reuse of the wall, while Subphase $2 B$ is linked to the destruction and abandonment phase of these modifications

Revetment walls downslope from earlier construction and some isolated features, such as "steps" and a possible "cobbled surface," make up the third phase in Field $A$. The revetment(s) appear to have been refaced and enlarged in time; for the sake of this study, and in light of the piecemeal nature of the evidence, such construction and modifications are lumped together as Subphase $3 \mathrm{~A}$. The destruction and abandonment of these revetments constitute Subphase 3B.

The fourth phase construction in Field $A$ has been identified as a large rectangular platform or "tower." Fills found in association with this platform fall into one of two groups. Materials identified with Subphase $4 \mathrm{~A}$ are associated with the preconstruction, construction, and use of the platform. Materials identified with Subphase 4B suggest the abandonment residues of the platform. 
TABLE 2

FIELD A BY PHASE AND SUBPHASE

Phase 1

Subphase $1 \mathrm{~A}$

Preconstruction

Subphase 1B

Construction/Use

Subphase $1 \mathrm{C}$

Destruction/Abandonment

Phase 2

Subphase 2A

Preconstruction/Construction/Use

Subphase 2B

Destruction/Abandonment

Phase 3

Subphase $3 A$

Preconstruction/Construction/Use

Subphase 3B

Destruction/Abandonment

Phase 4

Subphase 4A

Preconstruction/Construction/Use

Subphase 4B

Destruction 


\section{Stratigraphic Description and Analysis in Field B}

Field B was excavated in the south center of the tell, immediately to the east of Field D. Its eight squares included SW 1-7, 1-8, 1-9, 2-7, 2-8, 3-5, 3-6, and 3-7. Reasons for the selection of this area were linked to Sellin's discovery of a spectacular incense altar nearby; it was hoped that other cultic remains might be revealed. Expansion of the field into squares 1-7, 1-8, and 1-9 revealed a well-stratified development of EBA architectural phases: at one point, the outline of some ten chambers, including domestic artifacts, was uncovered (see Figures 8 and 9). Unfortunately, clarity in SW 2-7, 3-5, 3-6, and 3-7 was more difficult to achieve. The EBA horizon was not reached in 2-8.

\section{Field B, Outline by Square}

Field B, SW 1-7. A portion of two rectangular rooms was recovered in the deepest excavated areas of this square. W 218 (later rebuilt as W 225) runs the distance of the square and is assumed to intersect Wall 214 (later rebuilt as W 201) in the balk, possibly forming the southwest corner of the structure. A narrow gap in W 214 suggests a doorway (L 213). W 224 is bonded to Wall 218 and effectively divides the area into two rooms. All walls are approximately one meter thick and founded upon bedrock.

Resting upon bedrock in the center of the north room were soil loci 222,221 , and 220. $L 220$ could have been the last in a sequence of preconstruction leveling fills, or possibly even a beaten earth floor. It was described as "firm grey," and associated with the lower courses of intersecting Walls 218 and 224 . However, sealing $L 222,221$, and 220 was a thin plaster surface $(L 219=L 111$ of SW 1-8), which extended throughout both rooms in the structure. To the north of "crosswall" W 224, the surface of L 219 ran 


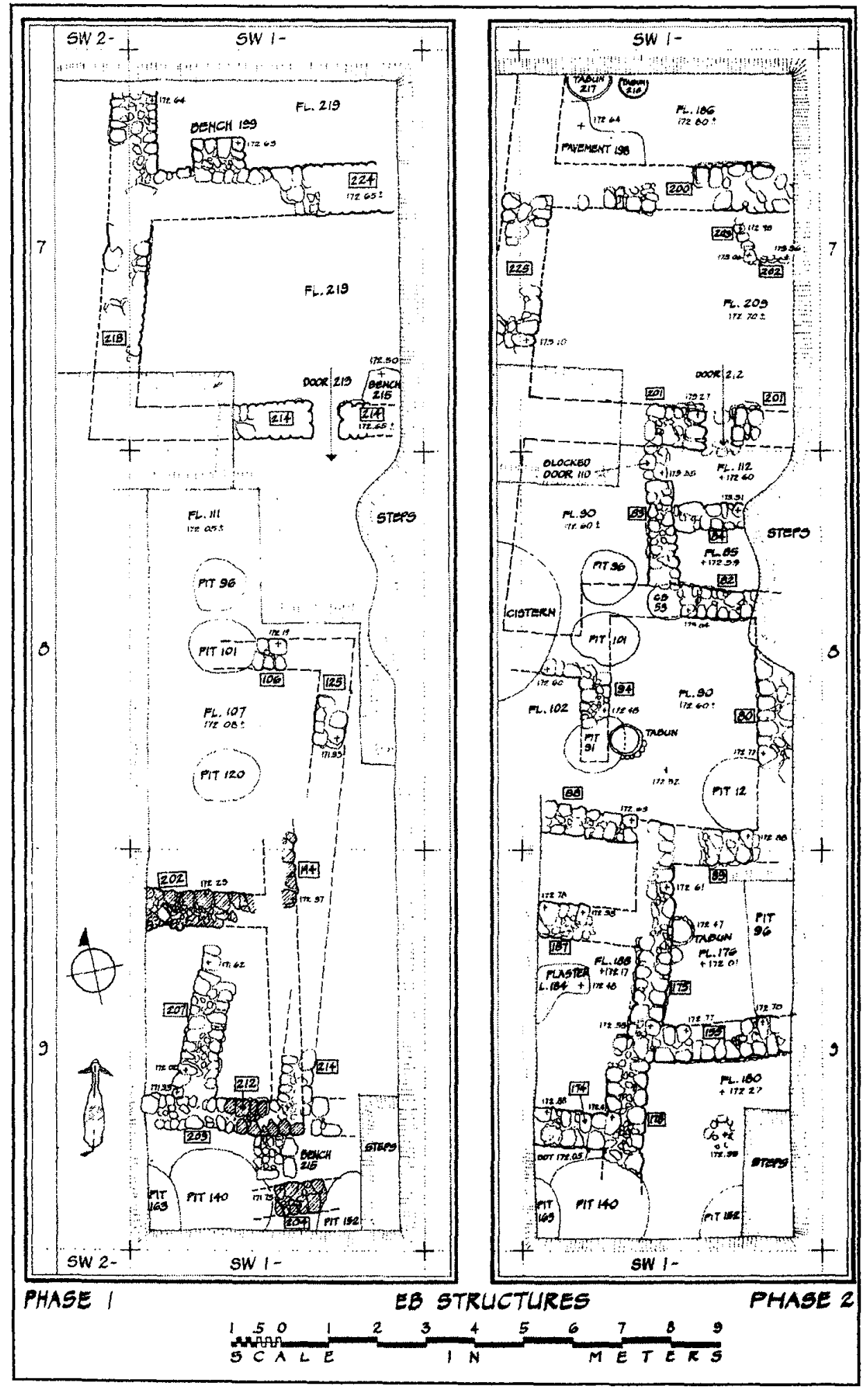

Map 4. Top Plan of EBA Structures in Field B (Lapp 1969: 15) 
over a bench built into the wall ( $L$ 199), confirming its contemporary use. Concurrently, a second bench ( $\mathrm{L} 215)$ was attached to Wall 214. An ashy destruction was noted on the surface of $L 219$. Approximately $30 \mathrm{~cm}$ of soil fill $(L 194$ and 197$)$ accumulated above L 219.

Patches of cobbles ( $L$ 198) were suggestive of a still later surface. Two tabunovens were associated by the excavator with the use phase of this surface $(L 216$ and 217). South of "crosswall" W 224, a second scrap of surface ( $L$ 209) was preserved running under a small square installation ( $L 203$ and 202) whose functions were unclear (possible bin?). Above these installations and smothering even W 200 was a fill of loose brown soil and stones ( $L$ 195) that gave way to, and was eventually considered coterminous with, $L 165$. Fill $L 165$, containing MBA sherds, sealed the EBA stratum across the square.

Field B, SW 1-8. South of the rectangular structure described above was a sequence of fills and floors over bedrock. $L 120,119,117$, and 116 were sealed by surface L 111. Intrusive pits have destroyed the coherency of structural plans at the earliest levels, although wall fragments $L 106$ and $L 125$ suggest their presence. These are buried under fills $L 99,100$, and 109 .

New construction efforts are present in the second phase, south of the rectangular building (in SW 1-8). Walls 82,83 , and 84 join to form an enclosure just south of the doorway of the rectangular building. This resulted in the creation of a narrow "hallway" to gain entrance to the rectangular building and a corresponding adjacent narrow room of an undetermined length. In still a later subphase, this "hallway" was blocked up. Phase 2 floors in this "annex" were preserved $(L 85,90$, and 112) resting upon fills assigned to the Phase 1 abandonment. Intrusive pits again plague the 


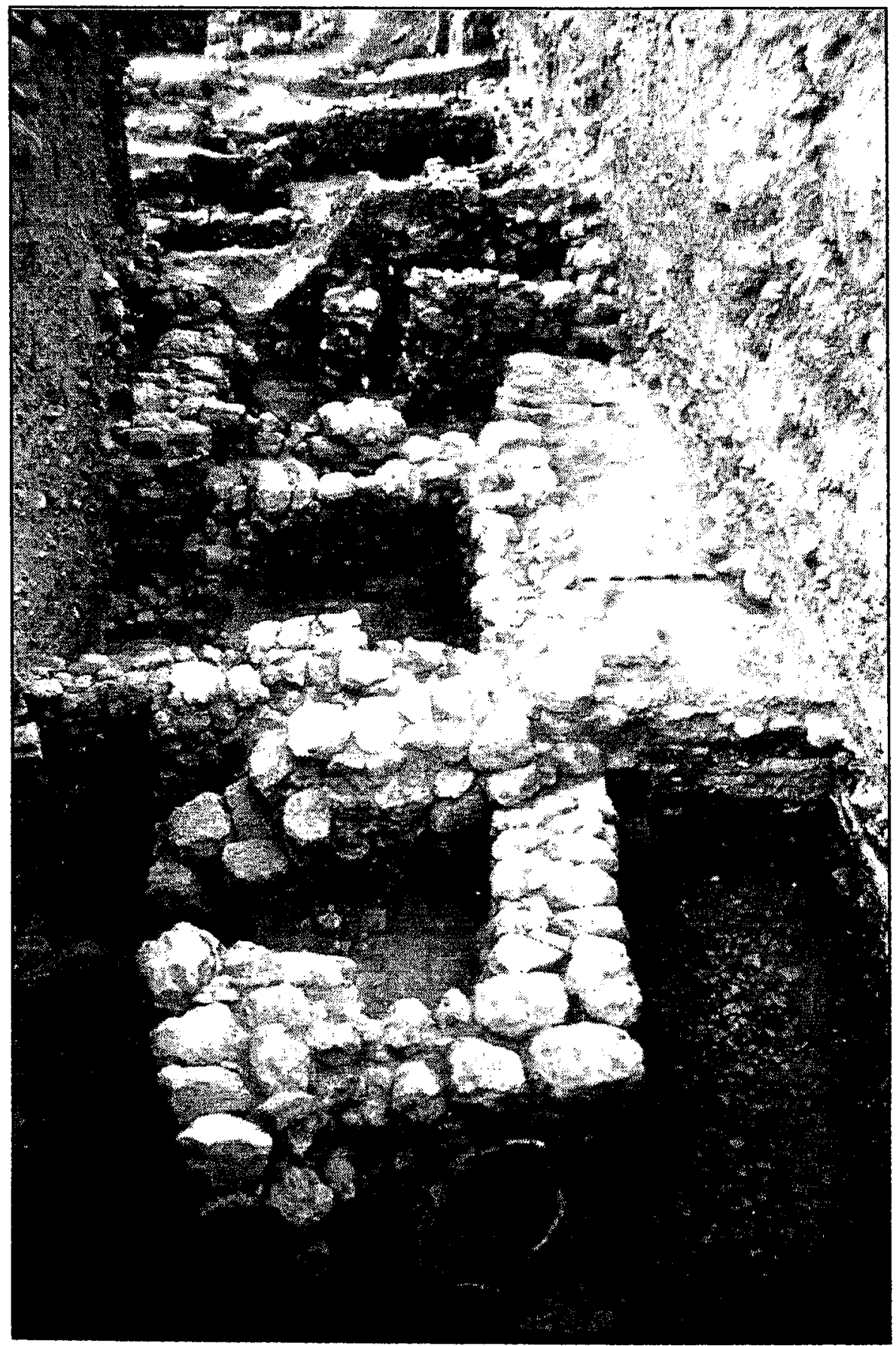

Fig. 11. View North to Phase 1 Domestic Complex in Field $B$ (n.d.). Photograph from The Taanach Excavations archives. 


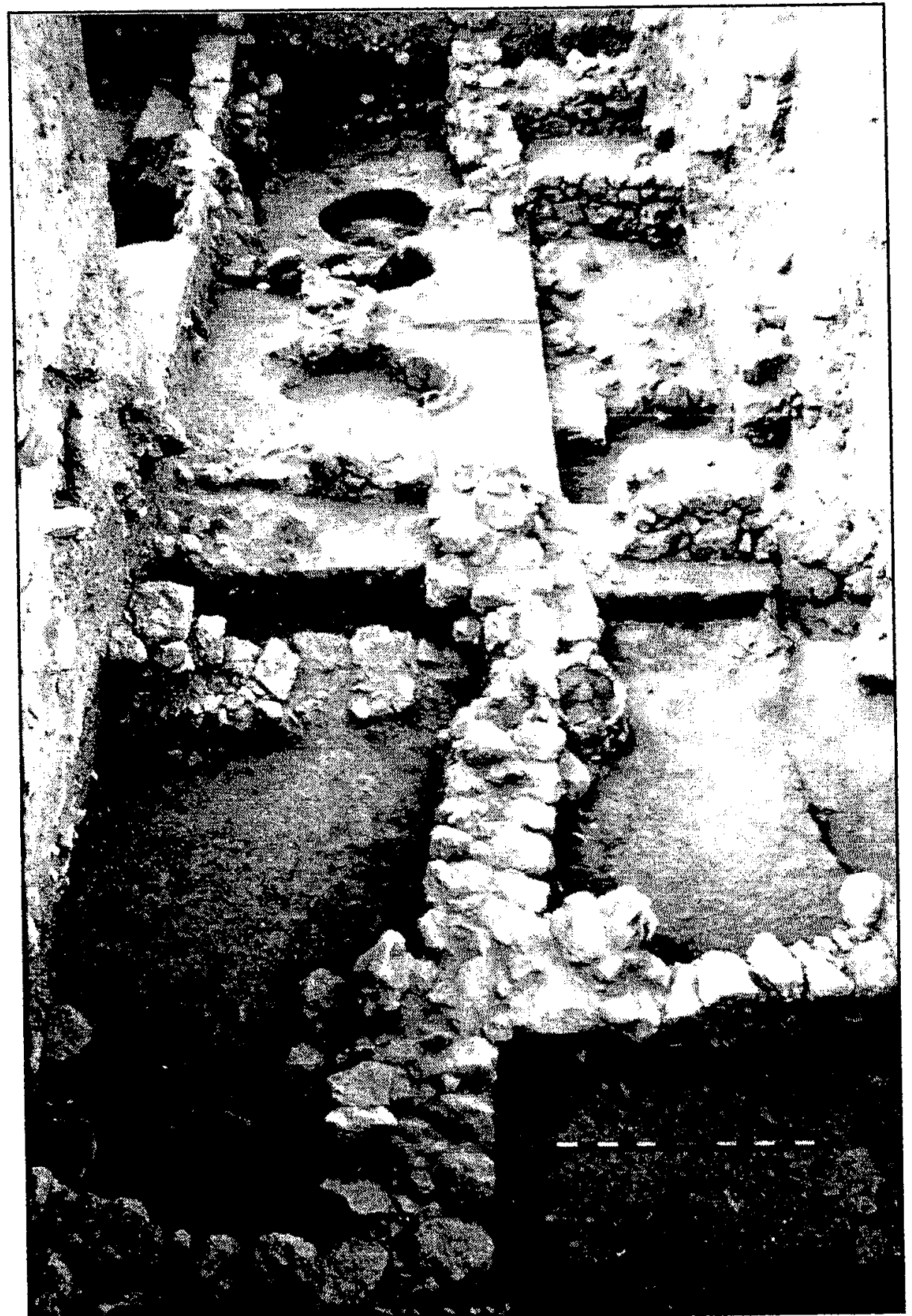

Fig. 12. View North to Phase 2 Domestic Complex in Field B (n.d.). Photograph from The Taanach Excavations archives. 
reconstruction of the southern half of SW 1-8, interrupting more walls ( $L 94,103)$, their associated floor ( $L$ 102), and a tabun ( $L$ 92). Excavations under Floor 102 revealed a sealed soil locus ( $L$ 108) resting between this floor and the debris of the abandonment phase preceding its construction ( $L 109$ ). If any sherds were found in the removal of walls in SW 1-7 and SW 1-8, it was not recorded.

Although separated from SW 1-7: $L 195$ by intrusive pits, it is likely that $L 76$ represents the same post-occupational deposition in SW 1-8. The absence of ashy deposits suggests that the EBA stratum here was abandoned, rather than destroyed.

Field B, SW 1-9. This first EBA phase continued south into SW 1-9, where a complex of walls was encountered. Construction technique appears similar to that of SW $1-7$, however, the overall plan of the area is very unclear due to discontinuities between walls. It is possible that the outline of one room is determined by Walls $202(=217)$ and $212(=\mathrm{L} 209$ ), with a crosswall ( $\mathrm{L} 207)$ creating two smaller rooms, although even this alignment is problematic. Unclear stratigraphy, compounded by a failure to describe all wall junctions, renders phasing statements here as speculative. Still, some secure loci may be identified. $L 216$, described as a "surface," appears sealed by $L 213$, that, in turn, is sealed by $L 197$ and 200 . $L 200$ is also termed a "surface," while $L 197$ is termed "brick rubble." It is possible that L 216 functioned as a use surface for the "narrow room" defined by Walls 207,212 , and 214 , while $L 213$ represents a brief abandonment or perhaps purposive fill anticipating Phase 2 of this area.

Phase 2 in SW $1-9$ is associated with renewed building activity. Some walls are (re)constructed atop the first phase wall lines (Walls 174, 178, and 187); others run in new directions (Wall 89 of SW 1-8, and Wall 155). The result is a series of small rooms or courtyards which more or less share a central north-south dividing wall (Wall 175, 
178). Walls not constructed on the earlier Phase 1 wall lines are founded on soil. In one case, the removal of a wall demonstrated two subphases (Wall 155 and 155a): the earlier subphase sealing soil $L$ 168, and a later subphase sealing soil $L 203$. Floors /surfaces in these enclosures were tentatively located: surface L 176, "firm, brown," rested between Walls 89 (of SW 1-8), 175, and 155; surface $L 188$, identified as a "floor" in the published top plan, yet described as "no real occupation layer" in the locus list (!), was enclosed by Walls 187,175 , and 174 ; and surface $L 180$, "firm dark brown soil," rested between Walls 155 and 178. Two tabuns were noted: one tabun (L 173) was located in association with surface L 176; the second (unnumbered) was associated with L 188.

Field B, SW 2-7. A small section of plaster floor ( L 277) was preserved amid the many pits of this square. Above the plaster, a stony pavement of MBA construction appeared, and below it were EBA fills ( $L 287$ and 288). The assignment of this floor ( $L$ 277 ) is difficult, due to the inexactness of the excavation/recording procedure. EBA materials were found in association with the excavation of $L 277$, but it cannot be ascertained if these materials were above, on, in, or even immediately under the floor. Neither can a Phase 1 or 2 assignment with the SW 1-7/819 series be established. Nonetheless, fills below (L 287 and 288 ) appear secure.

Field B, SW 3-5. In the process of dismantling MBA walls on the last two days of the 1963 season, three sealed EBA loci were encountered. Wall 84 rested upon a soil fill ( $L$ 89); Wall 85 rested upon soil fills as well ( $L 90$ and 94 ). Excavation notes make no mention of a foundation trench. All three of these loci $(L 89,90$, and 94$)$ are judged secure, but their relationship to areas outside the square is unknown. 
Field B, SW 3-6. More than a meter of undisturbed EBA material was revealed in a small, well-defined probe sunk to bedrock in this square during the 1963 effort. Sealed beneath a substantial buff grey fill ( $L 84$ and 85 ) were fills of various textures and consistencies ( $L 86,88,89,90$, and 91 ). This last locus (91) rested on bedrock and contained fragments of white plaster; much ash and cinder were sprinkled in $L 89$ above it. Finally, it is possible that a cistern ( $L 93$ ), located partially in the south balk, may be associated with the EBA use, but the evidence is inconclusive.

Field B, SW 3-7. Preliminary reconstruction efforts within this square failed due to the complexity of the strata and/or the nature of the excavation method. The deepest levels where EBA material rested were seriously disturbed by a sequence of MBA and LBA pits and burials. Plaster fragments ( $L 286, L$ 319) suggest possible EBA use phases, as does a small wall (L. 309) cut by a burial. Much charcoal and ash accompanied associated fills ( $\mathrm{L} 282,283,288,292,294,297,298,300,301,302,303$, $304,313,315,316,318,321,323$, and possibly 269 ), although it was not noted in every case ( $L$ 263, 275, 280, 281, 286, 289, 299, 305, 310, 311, and 317). No secure loci are highlighted here.

\section{Field B, Outline by Phase}

Tracing the development of phases for Field B is only possible in SW 1-71819. These three squares reveal a sequence of activity that may be outlined as two occupational phases separated by a destruction (see Table 3). Subphases $1 \mathrm{~A}$ (preconstruction), 1B (construction/use), and 1C (destruction) may be proposed and associated with the first occupational phase. Subphases $2 \mathrm{~A}$ (preconstruction), $2 \mathrm{~B}$ 
TABLE 3

FIELD B BY PHASE AND SUBPHASE

\section{Phase 1}

Subphase $1 \mathrm{~A}$

Preconstruction

Subphase 1B

Construction/Use

Subphase 1C

Destruction

\section{Phase 2}

Subphase $2 A$

Preconstruction

Subphase 2B

Construction/Use

Subphase 2C

Destruction/Abandonment 
(construction/use), and 2C (destruction/ abandonment) are proposed and associated with the second occupational phase.

Sealed loci from SW 2-7, 3-5, 3-6, and 3-7 have been identified, but cannot be positively linked to the SW 1-7 1819 sequence on the basis of the stratigraphic record alone.

\section{Stratigraphic Description and Analysis in Field C}

Field $C$ incorporated 11 squares of the grid, SW 5-1, 5-2, 5-3, 5-4, 6-1, 6-2, 7-1, 8-1, 9-1, and NW 8-1 and 9-1. These squares were opened in the center of the western side of the tell in order to restudy portions of Sellin's Westburg, here, the "West Building," and, if possible, to discover other administrative elements of the site. In the 1963 season, one area was opened against the "West Building"; a second, narrow (2 m wide) area was positioned inside a nearby Sellin trench to check the section. It was this latter area which reached EBA levels in subsequent seasons. By extending the trench to a length of 15 meters, a small sample of the revealed "inner city" could be linked with the enclosure system on the scarp of the tell.

\section{Field C, Outline by Square}

Field C, SW 6-1 and SW 71819-1. ${ }^{1}$ Features located inside the enclosure system were revealed here and assigned to one of two major construction/use phases.

Beginning on the west end of the trench, a narrow "chamber" or "passage" (one meter) was identified as running between north-south Walls 146 and 147. An unexcavated

'Unless explicitly associated with SW 6-1, all loci in this discussion may be assumed to relate to SW $7 \backslash 819-1$. 
surface ( $L$ 157) was associated with these walls whose lower courses were also unexcavated. A second chamber utilized W 146, as well as Walls $122 \mathrm{~A}, 123,135$ and 146. Construction fill, surfaces ( $L 156,158)$, and a bench $(L 149)$ were associated with this chamber. Two other possible "chambers" were identified upslope where bedrock was struck (SW 6-1: L 206, 207, 208, 210, 211, and Walls 185 and 195), but subsequent robbing and pitting destroyed all direct stratigraphic connections with downslope structures.

These first phase features were modified with time: ${ }^{1}$ Fills were introduced (SW 6-1: L 186, 188, 200); new surfaces were created (SW 6-1: L 182, 187, 189, and 193); possible "bins" were added (SW 6-1: L 179 and 181); and, walls were raised or modified (SW 6-1: W 180 over W 195; SW 7\819-1: W 150 over W 147; W 160, and W 148 were added). More substantial modifications were noted on the western end of the trench where Walls $122 \mathrm{~A}, 123$, and 148 were overbuilt by new walls (122B, 123C, and 139), two enigmatic pedestals were introduced into the center of the modified "chamber," and nearly a meter of fill ( $L$ 127) was topped by huwwar surface, drawn even with the tops of the pedestals ( $L$ 142). ${ }^{2}$ Ultimately, a massive level of ashy destruction debris (SW 6-1: L 167,170 , and 171) $50 \mathrm{~cm}$ deep in places, brought an end to the use of first phase EBA features (see Fig. 13). Broken mud bricks, smashed storage jars, and a basalt grinder were excavated as part of this debris.

According to the later views of Graesser, none of the first EBA phase enclosure systems or defenses were recovered in the SW 7/8/9-1 trench. He argues that the remains of this system are further downslope and suggests that the illustration of

\footnotetext{
${ }^{1}$ Graesser's subphases $A$ and $B$.

${ }^{2}$ Graesser's subphase C.
} 


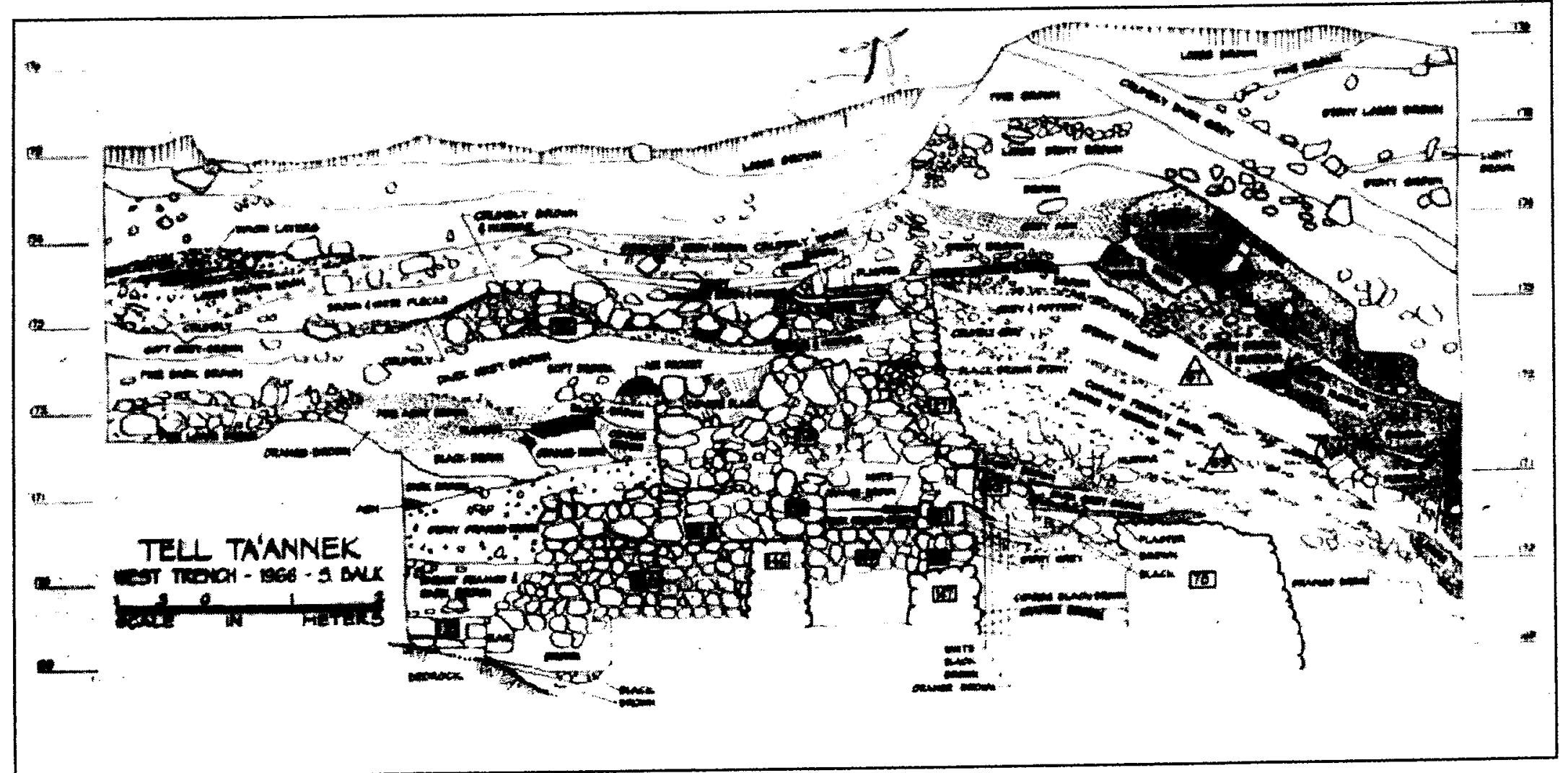

Fig. 13. View South to EBA Fortifications in Section, Field C (Lapp 1967b: 11). 
construction, use, and destruction subphases of the first phase wall must be gathered from the excavation report of NW 9-1. Other views, however, have been voiced. ${ }^{1}$

The area inside of the enclosure system in SW 71819-1 was radically altered in the second EBA phase. Whereas formerly, the area appeared to be filled with a series of chambered structures (residences?), second phase alterations suggest use as an open courtyard, plaza, or esplanade. A series of pavements were laid over the first phase debris that covered all of SW 7-1 and a portion of SW 6-1. (Including fragments, the exposed paved area approximated 33 square meters.) Excavations revealed a prepared surface (SW 6-1: L 162, 163, and 166) and a series of consecutive pavements (SW 6-1: L 155, 123, 121, and 157?). Only one small wall on the east side of the trench could be tied directly to a pavement (SW 6-1: W 115). Connected to it was a line of stones creating a channel (SW 6-1: L 110) and two intersecting walls (SW 6-1: W 145 and 150).

Such simplicity does not extend to a discussion of the second phase enclosure system. A large revetment ( $L 78)$ serves as the beginning point, if in fact it does not belong to the "missing" Phase 1 defenses. It appeared as "battered," without an east face, and therefore designed to retain soil rather than be freestanding. Fills retained by the revetment and eventually sealed by a layer of plaster $(L 79)$ coming downslope off the city wall ( $L 110)$ include $L 145,152,153$, and 155.

The massive EBA city wall ( $L 110$ ) was constructed upon the debris of the first phase, sealing Walls $122 \mathrm{~B}, 139$, and 151 . As elsewhere, it was approximately $4 \mathrm{~m}$ in width, had a rubble core, and, in this case, was preserved to a height of 1 to $1.5 \mathrm{~m}$. As

${ }^{1}$ This does not appear to be the view published in a preliminary report by Lapp (1967b: 12), who interprets W 78 (SW 9-1) and W 59-38-49 in NW 9-1 as the first phase city enclosure system. 


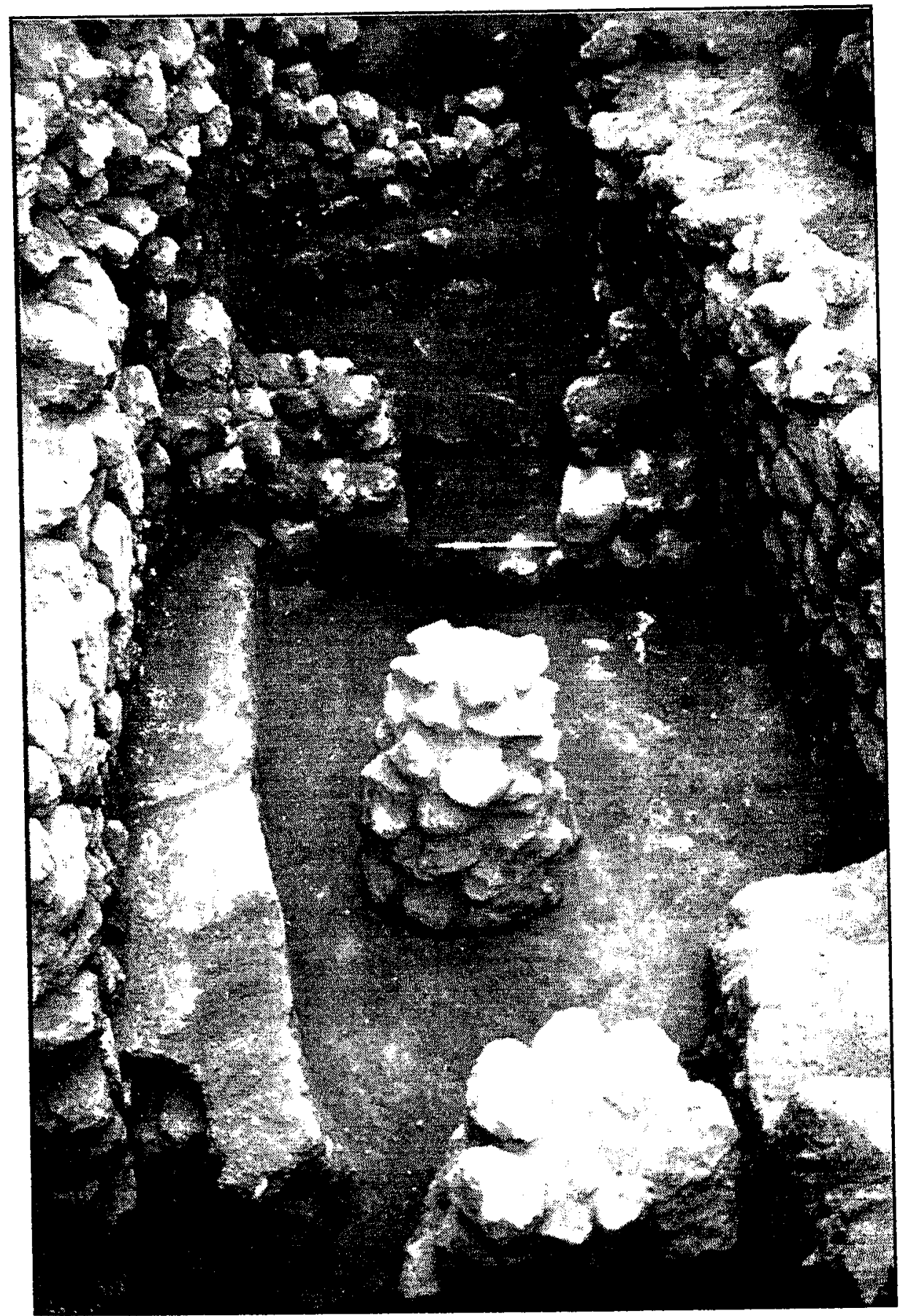

Fig. 14. View to Enigmatic Pedestals in Field C (n.d.).

Photograph from The Taanach Excavations archives. 
in NW 9-1 ( $L 60$ ), a footing ( $L$ 110F) was laid for support and to counter erosive forces. A layer of small stones ( $L 77)$, along with the plaster surface previously described $(L 79)$, linked Wall 110 with the revetment $(L 78)$ below.

The abandonment of Phase 2 occupation is represented by debris collected on the pavement/surface upslope (SW 6-1: L 130, 139, 143, 144, possibly 94). No wash lenses off of Wall 110 were described, although it is likely that these are downslope, represented in part by $L 154$. The absence of ash and the presence of soft, and possibly wind-blown, soil suggest that the site was abandoned, not destroyed, at the end of the second EBA phase.

Field C, NW 9-1. The two major EBA phases identified in "The West Trench" were also identified here. A description of the first phase begins in the deepest excavated levels of this square where soil was found resting on bedrock $(L 51,53,55$, and 56). Upon the soil a thick "wall" (2.85 $\mathrm{m}$ to $3.9 \mathrm{~m})$ was founded, having three elements. The first element was the eastern face ( $L 59)$; the second ran parallel to the first and served as the western face ( $L 49)$. The third ( $L$ 38) may be an internal strengthening diaphragm or crosswall, or even possibly a tower, bonding to $L 59$, but abutting $L 49$ and following it into the balk as a secondary outer face. This last observation raises the possibility of no less than two subphases to this structure. It is proposed that the area between these three "faces" of $L 59,39$, and 49 was filled with rubble and soil $(L 41,42,43,50)$ to form a solid core "wall." This is likely, given the alignment of this composite "wall" with the revetment $(L 78)$ of SW 7/8/9-1 identified 4 meters south.

A second architectural feature was located 1.5 m east of this revetment "wall" of NW 9-1 and was believed to be in phase with it. However, only the west face of Wall 
$30 \mathrm{~A}$ was revealed. It survived at a height of at least $3 \mathrm{~m}$ and its lower courses were unexcavated. The relationship between W 30A to the revetment is unknown, but an unexcavated packed surface ( $L$ 63, 64 $=L 155$ of SW 9-1) suggests a narrow path passed between them. The size and location of these structures on the scarp of the tell are suggestive of defensive purposes, although given the limited sample ( $2 \mathrm{~m}$ trench), it is difficult to determine their exact function or relationship.

The second EBA phase in NW 9-1 witnessed the reuse of the composite "wall" as a revetment (continuing the line of $L 78$ in $S W 7 / 8 / 9-1$ ). Wall 30A was faced by Wall 30 (bringing it into alignment with W 110 of SW 7/8/9-1); fills were introduced between the new face and existing Wall $59(L 62,63)$ and a footing $(L 57,60)$ was added. This second phase defensive structure runs beneath the foundations of Sellin's "West Building."

Field C, Outline by Phase

Stratigraphic conclusions drawn from Field $\mathrm{C}$ must be regarded as exceedingly tentative and await further study. What is proposed aligns the loci of Field $\mathrm{C}$ with the outline clarified elsewhere at Tell Ta'annek (see Table 4). Two major occupational phases appeared here, each demonstrating evidence of reuse and modification. A massive destruction separates these phases in places, while preconstruction fills and fills suggestive of abandonment frame the EBA horizon. These may be outlined in the following sequence: 1A (preconstruction), 1B (construction/use), 1C (reconstruction), 1D (abandonment), 2A(construction), and 2B (destruction). 


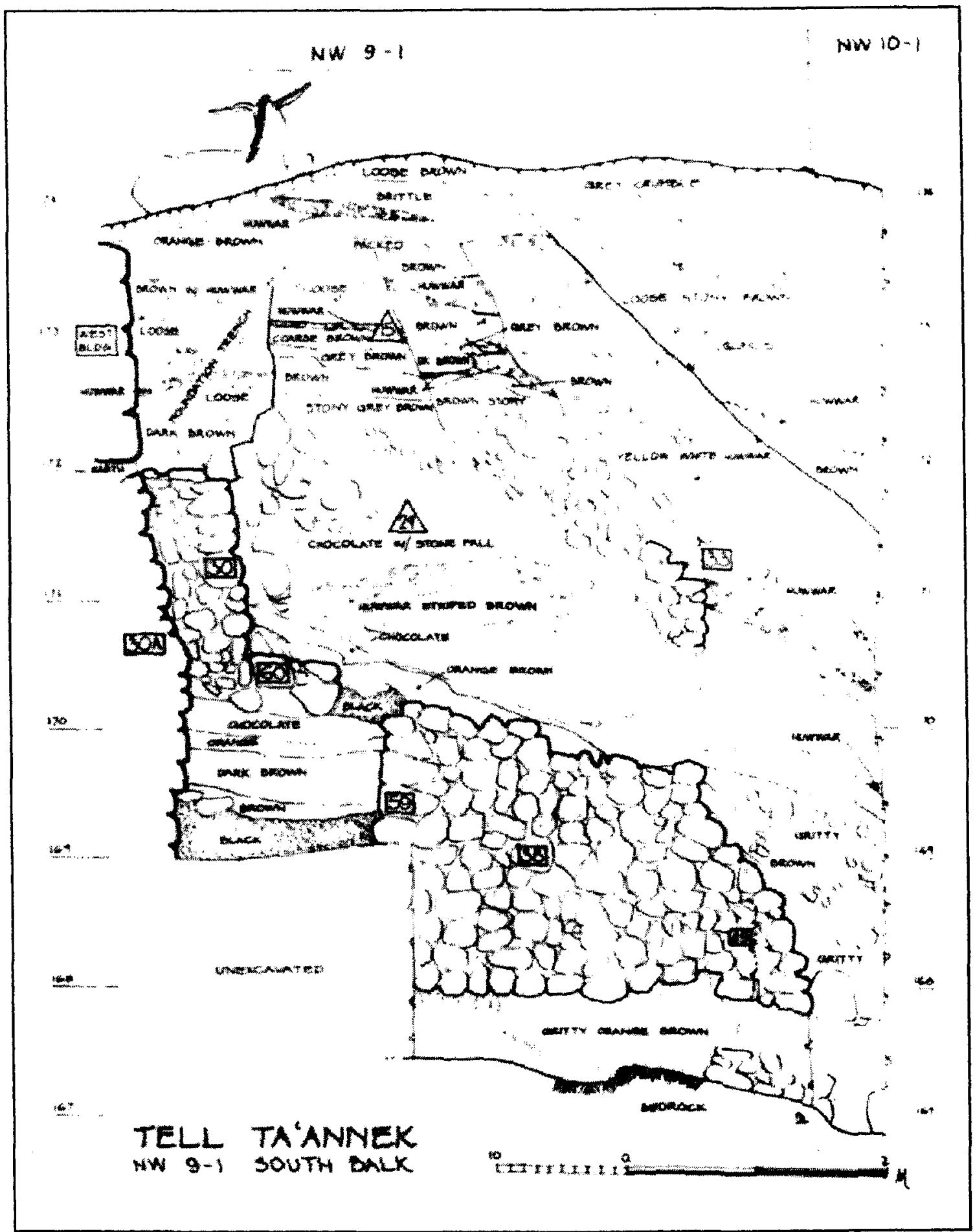

Fig. 15. View South to EBA Fortifications in Section, NW 9-1 (Lapp 1964: 13). 
TABLE 4

FIELD C BY PHASE AND SUBPHASE

\section{Phase 1}

Subphase 1A

Preconstruction

Subphase 1B

Construction/Use

Subphase $1 \mathrm{C}$

Reconstruction

Subphase 1D

Abandonment

Phase 2

Subphase 2A

Construction/Use

Subphase 2B

Destruction 


\section{Stratigraphic Description and Analysis in Field D}

Nine squares compose Field D: SW 4-7, 5-5, 5-6, 5-7, 5-8, 6-5, 6-6, 6-7, and 7-

7. Like Field $B$, these squares were opened with the goal of locating domestic and/or industrial installations within the enclosed area. However, the retrieved EBA sample turned out to be quite small: only in two squares were sealed loci encountered, and these were insufficiently excavated to draw solid conclusions.

\section{Field D, Outline by Square}

Field D, SW 6-7. This square was opened for the purpose of tracing the continuation of LBA remains. However, the removal of several MBA installations and walls revealed fills and washes in the lowest excavated areas. Loci 211,220 , and 243 were excavated beneath Wall 186. Beneath Wall 97 were L 247 and 248. L 250, which was severely pitted and not fully excavated, seems to rest upon an enigmatic surface described as "whitish" at one point and "yellowish" at another. Ashes are noted above this surface.

Beneath a rock pile ( $L$ 249) associated with $L 250$ is a burial suggested by the excavator to be EBA ( $L$ 251). A lack of section plans prevents a positive statement of relationship here. However, the paucity of ceramic remains within the burial (one EBA sherd only) and the presence of a second MBA burial immediately beside it suggest that this, too, is MBA.

Walls 204 (preserved to at least five courses) and 245 form a corner on the east side of the square. Excavations did not reach the lower portions of these walls, but it is likely that these are a part of an EBA structure. The same is true of Wall 235, an ephemeral semicircular stone installation. Soil loci surrounding Wall 235--with the exception of $L 244$ and 246 -were disturbed by later burial activity. In sum: it is 
suggested that Walls $204,245,235$, and the surface (no locus number) represent the latest EBA occupational phase in this area, while $L 211,220,242,243,244,246,247$, 248 , and 250 represent the post-destruction abandonment of this phase.

Field D, SW 7-7. This $3 \times 7 \mathrm{~m}$ trench was excavated to probe the MBllc defenses over and down the western edge of the site. Below the MBA remains were discovered three walls associated with EBA construction.

On the eastern side of SW 7-7, soil depositions rested directly on bedrock; this is best explained as fill anticipating the construction of $\mathrm{W} 171$. The courses of this first phase wall are unspecified, but from a sketch it appears to be approximately $50 \mathrm{~cm}$ in width and runs for some 3 meters in length before disappearing into the balk on the east and under the second phase Wall 152 on the west. The excavator describes a "floor covered with ash" (Hillers n.d.: 8) as part of this first phase (use and destruction?), but fails to indicate its relationship to Wall 171 or its locus number. The best candidate for this "floor" is $L 177$, described as "hard brown with some ash on top." Secure loci here are difficult to identify due to gaps in the excavation method and/or record keeping, but it is possible that $L 170$ is part of a preconstruction subphase for Phase 1 , while the "floor" ( $L$ 177) is witness to its latest use and destruction. Debris accumulating in an abandonment subphase are represented by lenses of ash and stony rubble on the surface of $L 177$ ( $L 169,174$, and possibly 176).

It is suggested here that the contours of fill $L 175$ represent the cutting of a foundation trench into which the massive W 152 was laid. Unfortunately this "trench" is only represented clearly in the south balk drawing, and was not reported as such by the excavator. The exposed section of this unexcavated wall ran north-south through the square, measuring $4 \mathrm{~m}$ in width, and $2 \mathrm{~m}$ in height. According to the excavator, it was 


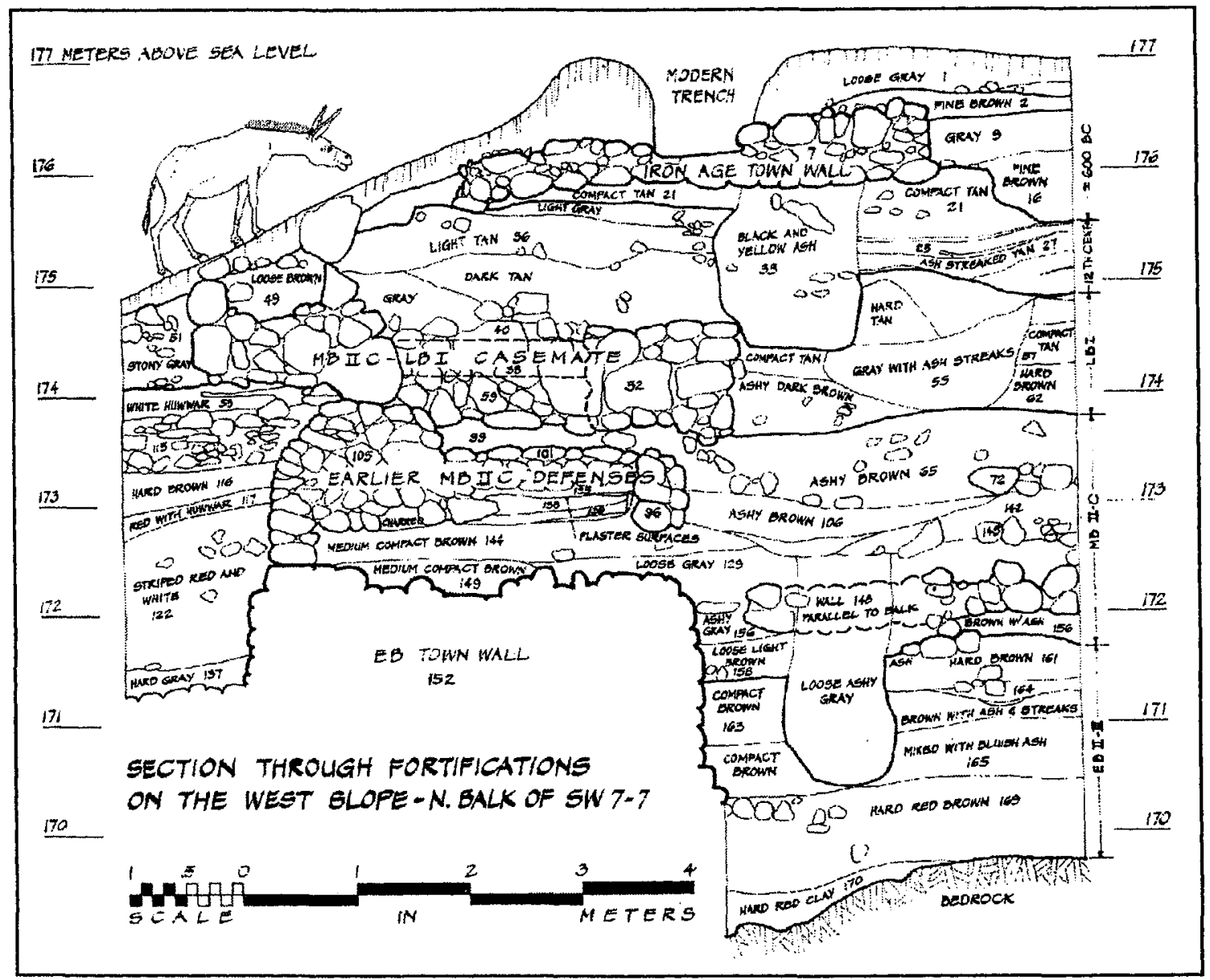

Fig. 16. View to EBA Fortifications in Section, SW 7-7 (Lapp 1969: 17). 
not founded on bedrock but upon undefined soil fills on the inner face and stones on the outer face (Hillers n.d.: 9). W 171 also ran under the inner face of W 152. A use surface outside the defensive wall rested below the excavated levels; efforts to identify such a surface on the inside of the wall are unclear. The solution suggested here is that fill $L 175$, placed into the foundation trench, and the surface of $L 173$, an unidentified pit visible in the south balk, $L 174$, and 169 served as an initial surface, while the horizon composed of $L 163,165,166,168$, and 172 constitute later fills and surface(s) used contemporaneously with W 152.

Additional construction is associated with a small wall (W 140) running parallel to the south face of the square. It appeared for approximately $2 \mathrm{~m}$ in length before cornering at both ends into the south balk. W 140 rested on previously laid surfaces $(L$ 168 and 172); $L$ 161, 163, and 164 may have served as surface(s) used outside the structure and are in phase with it. The south balk section suggests $L 163$ also served as a use surface inside the structure, although no mention is made of this in the field book notes.

The end of the use phase of fortification W 152 is illustrated in the north and south balk sections by fill lenses $(L 149,151,157$, and 153) covering the uppermost courses of W 152 and abutting W 140. The nature of these sediments ("fine grey," "fine brown") argues that wind-blown and washed detritus eventually enveloped portions of these structures before the MBA population overbuilt the area. Other loci containing ash hint at some destruction ( $L 156,162)$. In the MBA, new walls were founded on the uppermost surviving courses of W 140; W 152 likewise anchored a new fortification system. 


\section{Field D, Outline by Phase}

The construction and use phases noted in SW 6-7 are followed by a series of loci suggesting a period of abandonment (see Table 5). Because no ashy destruction is present as follows first phase occupation elsewhere (Fields B and C), it is tentatively suggested that the occupation/use revealed here corresponds to the second phase of Fields $B$ and $C$. If this scenario is correct, the first phase occupation as noted in Fields $B$ and $C$ remains unexcavated in SW 6-7.

In SW 7-7, the full pattern of first phase preconstruction, use, and destruction, second phase use, modification, and abandonment, is present. The massive city enclosure wall is associated here with the beginning of the second phase.

\section{Stratigraphic Description and Analysis in Field E}

Excavations in Field E were conducted in the 1968 season where focus was given to the interior of Sellin's Nordostvorwerk (Sellin 1904: 30-2; Lapp 1969: 39-42; Rast 1978: 41, 44-45). This area was dubbed "Northeast Outwork," or "NEO" for short, and three squares were excavated: NEO 1, NEO 2, and NEO 3. Scatters of EBA pottery were found in mixed fills dating mostly to the Iron Age.

\section{Field E, Outline by Square}

Field E, NEO 2. Only one locus is noted here, $L 35$ from NEO 2. This locus consists of a pocket of red earth over bedrock. $L 35$ rests beneath the lowest courses of the 9th-century "outwork" Wall 7.

\section{Field E, Outline by Phase}

The location and composition of $L 35$ match that of first phase preconstruction leveling fills found elsewhere. 
TABLE 5

FIELD D BY PHASE AND SUBPHASE

Phase 1

Subphase 1A

Preconstruction

Subphase 1B

Construction/Use

Subphase 1C

Destruction

Phase 2

Subphase $2 \mathrm{~A}$

Construction/Use

Subphase 2B

Abandonment 


\section{Summary}

Stratigraphic excavation of Tell Ta'annek revealed extensive residues of a heavily fortified EBA site. More than 400 loci were identified in some 29 squares organized into five fields. Walls, fills, and surfaces, serving in a variety of functions, were brought to light by the original excavators. The "history" of these materials may be presented as a construct of depositional phases that are suggestive of the sequence by which the original inhabitants of Tell Ta'annek modified space and structure to meet contemporary needs. Restudy and synthesis of this depositional history have been attempted here, not for the purpose of presenting a comprehensive stratigraphic report, but for the express purpose of identifying "key" loci for ceramic study.

Summarizing this construct is possible in four fields: $A, B, C$, and D. Fields $A, C$, and $D$ are dominated by the site's defensive structures. In Field A, four major phases of use are evident with destruction debris visible between each major phase.

Preconstruction and abandonment frame the sequence. Fields $C$ and $D$ are less clear, but suggest two major phases of use. Field $B$ uniquely reveals domestic structures. These appear in two major phases, each followed by destruction.

Significantly absent from this chapter is an attempt to link all fields together in a site-wide construct. This is not accidental, but is a direct result of the architectural discontinuities that exist between each of these fields. One begins to sense the limits of stratigraphic analysis and the need for other tools, other data, and other paradigms to meet this need. Fortunately, ceramic materials were saved from many of the excavated loci described in this chapter. It is to these data and to their analysis that we now turn. 
CHAPTER IV

THE EARLY BRONZE AGE HORIZON AT TELL TA'ANNEK:

A CERAMIC ORIENTATION

\section{Introduction}

In order to describe the selected EBA ceramic assemblage from Tell Ta'annek, an electronic database was generated to assist in classifying, searching, and presenting some tens of thousands of informational details. For the sake of the present work, this electronic database has been reduced to the sum of plates in Appendix IV. The purpose of this chapter is not only to orient the reader to that database, noting how it was constructed, but also how it may be activated toward a range of present and future questions. To effect that orientation, the present chapter breaks into two parts. The first part outlines, item by item, the five tiers of information contained in that database. The second part comments specifically on the subject of ceramic forms, touching briefly on issues of typology and technology.

\section{Creating and Reading the Database}

All initial observations of the assemblage were originally recorded on paper data sheets (Fig. 17). In time, these sheets were entered into an electronic format using Microsoft Excel 97. This transfer facilitated searches of various types and allowed for information sharing. All sherd profiles and stances were originally plotted on paper, inked, and later scanned into electronic form where they could be modified and 


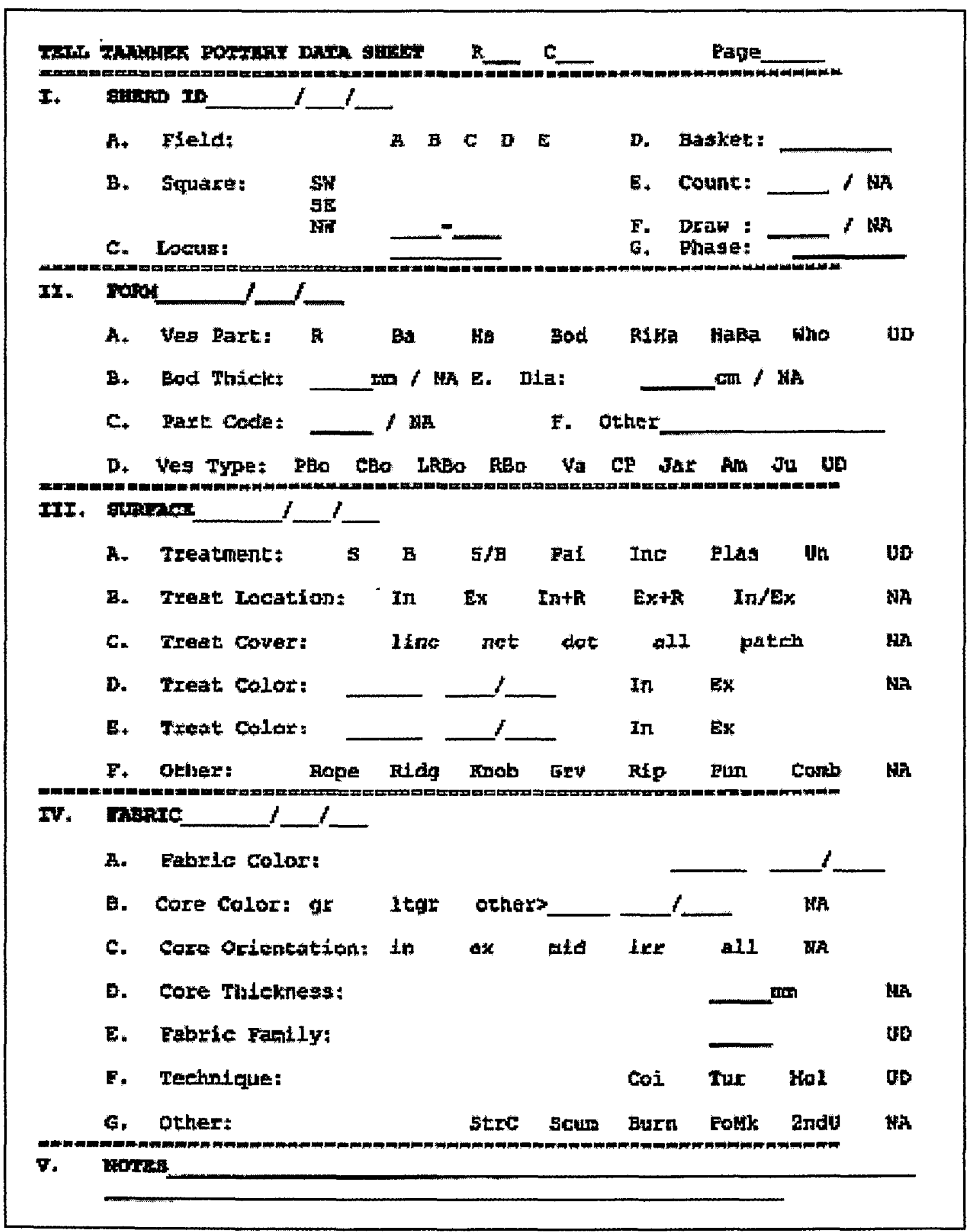

Fig. 17. Worksheet.

This form was developed in the course of the present study to record observations of the EBA ceramic assemblage from Tell Ta'annek. 
expanded using Micrografx Picture Publisher 6.0. These graphic files were ultimately grouped by locus and organized into the presentation viewed in this work using Adobe PageMaker 6.5.

The EBA ceramic database from Tell Ta'annek presented here contains 5 tiers of information. The first tier focuses on the categories of identification, location, and form. The second tier focuses on categories of fabric. The third tier focuses on categories of finish. The fourth tier collects assorted notes. Finally, the fifth tier is composed of illustrations of each sherd. Each of these tiers of information may be further described.

Tier One: Identification, Location, and Form

Seven columns of information are present in the first tier. These include information gathered under the labels of number, registration number, square, locus, vessel, part, body thickness, and diameter.

Number (No): This number provides an identification mark for a given sherd on a given plate. It provides a ready reference for working through all tiers of information and for associating specific data with a specific graphic.

Registration Number (Reg): This number is unique to each sherd. These assignments were made solely for the purposes of the present study and were not a part of the original records of The Taanach Excavations.

Square: This alphanumeric assignment describes the excavation unit where the sherd was found.

Locus: As in the case of square, this assignment locates the findspot of a given sherd within a given square. An index of phased loci by plate assignment is found in 
Appendix I; an index of phased loci by square and field assignment is found in Appendix II.

Vessel: While a variety of labels may be used to describe specific forms, the present work has used labels that are recognized by consensus, i.e., jug, jar, bowl, vat, etc. ${ }^{1}$ The category of "UD," "undefined," is used when no clearly recognizable form was noted.

Part: Because few whole forms were recovered by The Taanach Excavations and because all sherds in this assemblage were broken (and usually sawed) pieces of vessels, each sherd is described along diagnostic lines. In brief, three major groups are suggested: $\operatorname{rim}(R)$, base $(B)$, or handle $(H)$. Each of these was further clustered into groups by shape and assigned a code number. Discussion of these shapes and codes is found below in the second half of this chapter. Beyond rim, base, and handle, other parts which appear in this column include body fragments (BOD), spout (SPT), neck (NECK), or unidentified (UD).

Body Thickness (Body Thick): Sherd thickness was recorded in millimeters and may be used to estimate vessel weight, strength, size, and stability. Recognizing the handmade, and hence, irregular nature of EBA material, the effort was made to measure an "average" body thickness at points distant from intentional buildups near rims, bases, and handles, and by avoiding coil terminus points.

Diameter (Dia): Diameter measurement, with respect to rims and bases, is recorded in centimeters and was estimated using concentric circle chart. Where irrelevant or impossible due to sample size or part, a "No record" $(\mathrm{N})$ is reported.

\footnotetext{
${ }^{1}$ Assistance with these labels was found in Hendrix, Drey, and Storfjell (1996).
} 


\section{Tier Two: Fabric}

The second tier of record is concerned with fabric. Data are organized along lines of fabric color, core orientation, core color, core thickness, and "Fabric Family."

Fabric Color: Determination of fabric color was assigned under natural light using Munsell Soil Color Charts (1994). Samples were drawn from immediately under the surface and well away from the core, which was easily accomplished in the sawn sections. Verbal descriptions, rather than alphanumeric codes, were recorded.

Core Orientation (Core Orient): As an indication of firing dynamics, core orientations are noted and recorded. Within this column, five options are possible. The core could be oriented in the middle (M) of the vessel wall, toward the interior (IN) vessel wall, toward the exterior (EX) vessel wall, irregularly oriented (IRR), or N (not applicable).

Core Color: Where cores were visible, they were judged as grey (G), light grey (LG). If no core was visible, not applicable $(\mathrm{N})$ is recorded.

Core Thickness (Core Thick): Measurement of core thickness is recorded in millimeters, and was measured in a place in the vessel wall judged as average in thickness. Comparison with body thickness figures suggests the extent to which the vessel was throughly fired. As elsewhere, not applicable $(\mathrm{N})$ may also appear.

Fabric Family: Per Glock's study (1975), some sherds were sorted into "fabric families." Where records permit, "fabric families" have been transferred from the Glock records into the database. No attempt has been made to imitate this method of analysis. Sherds not evaluated in the Glock records are recorded as not applicable (N). Additional comments directed toward Glock's analysis are offered in chapter 6. 


\section{Tier Three: Finish}

The third tier of record is concerned with surface finish. Five categories of data are represented: treatment, treatment location, treatment cover, color interior, and color exterior.

Treatment: Slipped finishes (S) are common here, as are slipped and burnished (SB) finishes. Only rarely were surfaces considered painted $(P)$ (usually lines) or (white) washed (W). Incisions (I) typically appear as combing, although some slashes do appear. Where no finish treatment was visible, a not applicable $(\mathrm{N})$ was recorded.

Treatment Location: The location of the treatments described above is suggested. Assignments include: interior (I), exterior $(E)$, rim only $(R)$, interior and rim (IR), exterior and rim (ER), interior and exterior (IE), or not applicable (N).

Treatment Cover: An assessment was made regarding the extent of the surface treatment. If, on the sample, the treatment covered the entire surface, it was judged as all (ALL). Extrapolations to the whole vessel from this assessment must be balanced against sample size (as viewed in the line drawing) and sample location. Other options include a line (LINE), net (NET), irregular or undetermined (IRR), or not applicable (N).

Color Interior: Where colored slips, washes, or paints were detected, a judgment was made of that color using the verbal descriptions found in Munsell Soil Color Charts (1994).

Color Exterior: When color assignment shifted from vessel interior to exterior, a second judgment was made.

\section{Tier Four: Other}

Specific details deemed as significant yet unaddressed in the first three tiers of the database are noted here. Recognition of Metallic Ware (hereafter MW), Khirbet 
Kerak Ware (hereafter KKW), or Grey Burnished Ware (hereafter GBW) traditions is recorded. If none of these are assigned, common ware (hereafter $\mathrm{CW}$ ) may be assumed.

\section{Tier Five: Drawing}

The fifth and final tier of information contained in the data base is a graphic presentation (line drawing) of each sherd. These drawings were produced according to convention, preserving in cross-section the extant profile of the vessel, the thickness of the vessel wall, other associated features, and interior/exterior surface treatment. Slips are indicated by light gray masks; burnishes are indicated by dark gray masks. Various scales of reduction are used to maximize space and are detailed on each plate.

\section{Ceramic Forms: Typology and Technology}

While ultimately serving typological purposes, the effort has been made to organize the EBA ceramic assemblage from Tell $\mathrm{Ta}^{c}$ annek along lines sensitive to manufacturing techniques. However, because this organization is paradigmatic in nature, exceptions are to be tolerated and even expected.

As described above, the majority of saved diagnostics fall into the group of rim $(R)$, base $(B)$, or handle $(H)$. For the sake of classification, each group may be further subdivided and assigned numeric codes as detailed in the first tier of the corpus description under "Part." These assignments require additional clarification and comment.

\section{Rim Assignments}

Approximately 70 percent of the corpus is composed of rim fragments. This group is divided into two groups on the basis of manufacturing technique. The first 
group consists of rims from handmade vessels apparently constructed in a freestanding way using a slab or coil method. The second group consists of rims from handmade vessels apparently constructed by being pressed into shaping dish or mold. In the case of either group, it is possible (and indeed, likely) that a wheel or turntable was used in the finishing process.

Rims from vessels manufactured in a coil or "brim" method may be assigned to one of two groups. In the first group are fragments from neckless, or hole-mouth, forms. In the second group are those that do have a distinct neck between the rim and body wall.

Coil- or brim-made vessels: Neckless bowl and jar rims (Fig. 18). Rim forms R01 through R29 represent aspects of neckless, or hole-mouthed, vessels. These may be termed bowls (open form) or jars (closed form), as defined by Hendrix, Drey, and Storfjell (1996: 45). However, lacking the complete vessels required to make this assignment, a new criterion for objectively distinguishing between "open" and "closed" forms was sought. The resulting effort gaged the external angle of the rim, or, more specifically, the angle between the horizontal line of the rim extension (determined by the sherd stance) and the line running from the outer edge of the sherd lip to a tangent on the sherd body some $7 \mathrm{~cm}$ from its lip. If this angle was more than 40 degrees, the form was judged as "open," and hence, a "bowl" (see Fig. 19a). If this angle was 40 degrees or less, the form was judged as "closed" and hence, a "jar" (See Fig. 19b). 

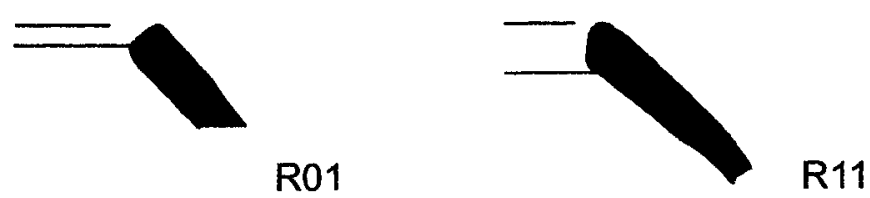

R01

R11
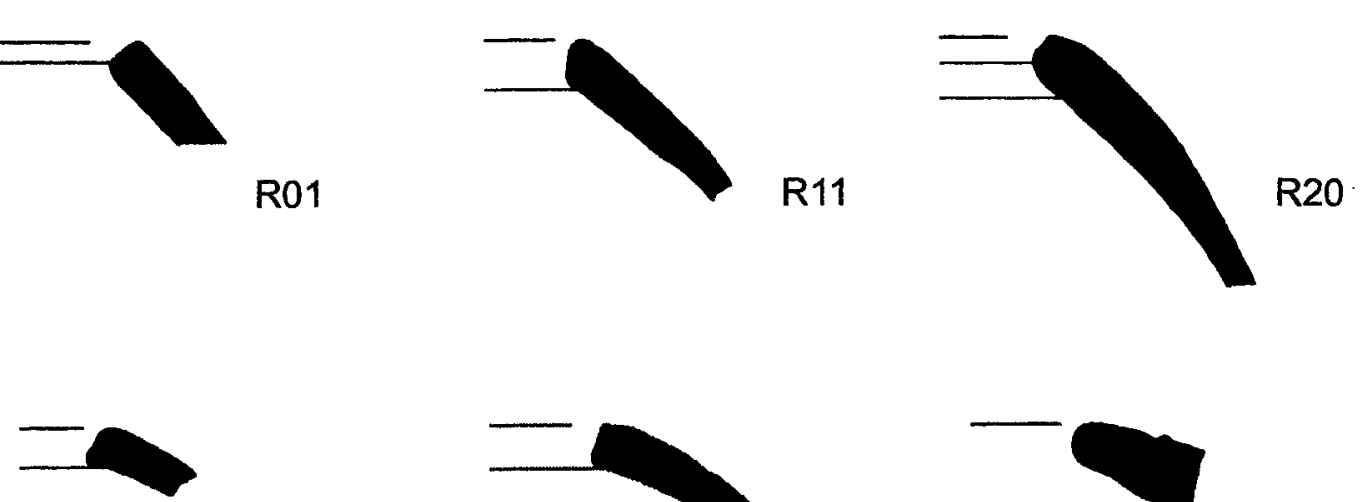

$\mathrm{R} 02$
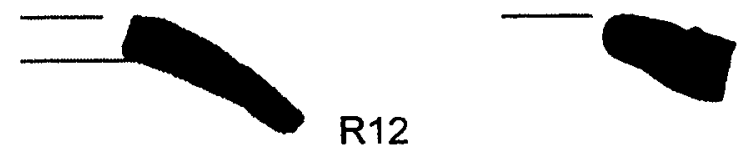

R21

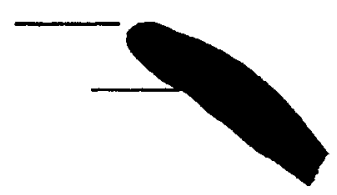

R04
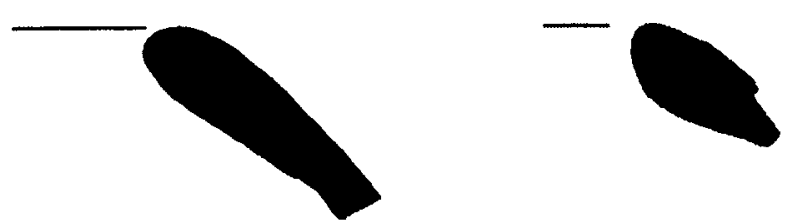

R22

R14
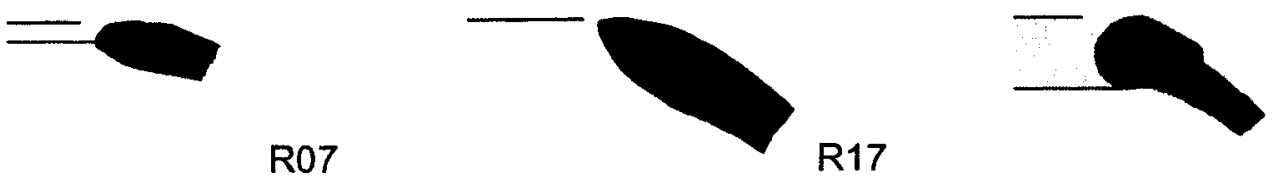

R07

$\mathrm{R} 17$

R28
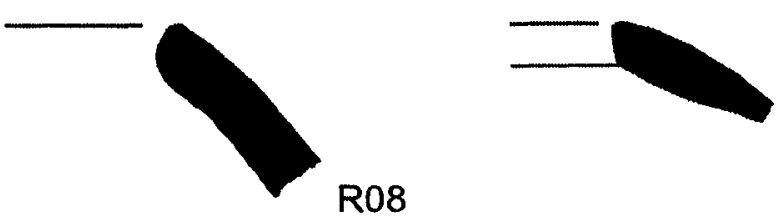

R18
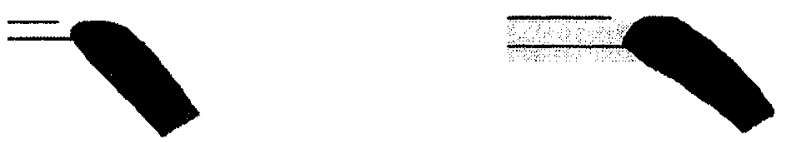

R09

R19

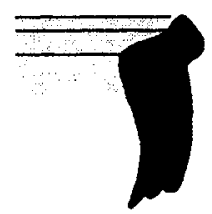

R29

Fig.18. Neckless Vessels: Rim Typological Assignments (R01-R29). 


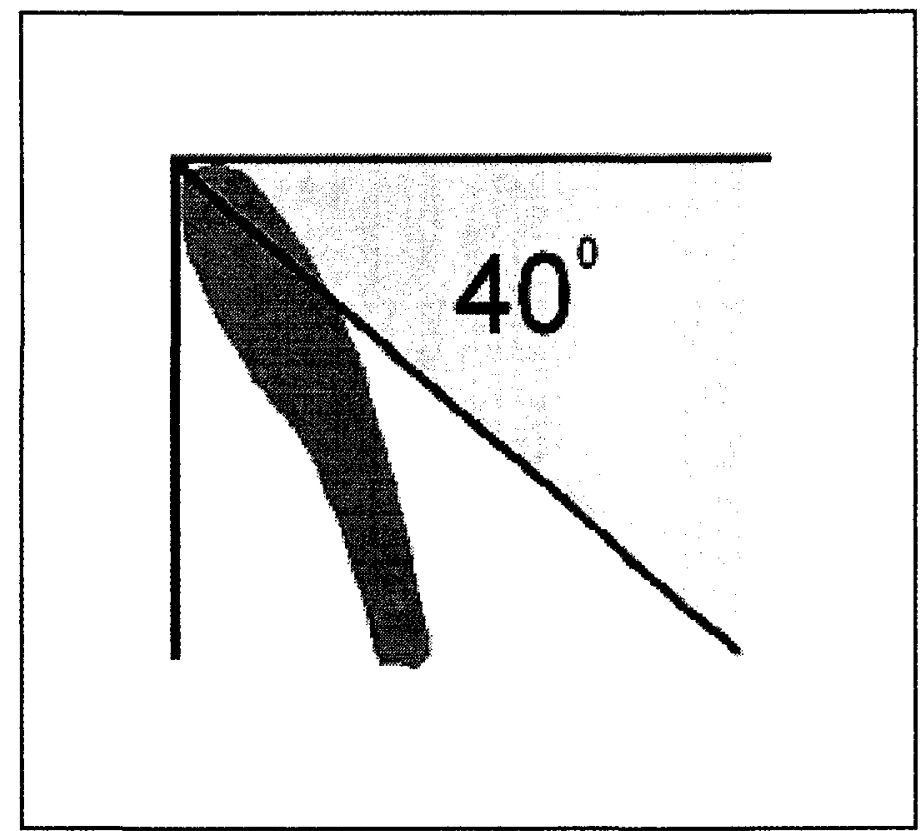

Fig. 19a. Neckless (Holemouth) Bowl Defined. Note how bowls have a rim angle of 40 degrees or more and are considered "open" forms.

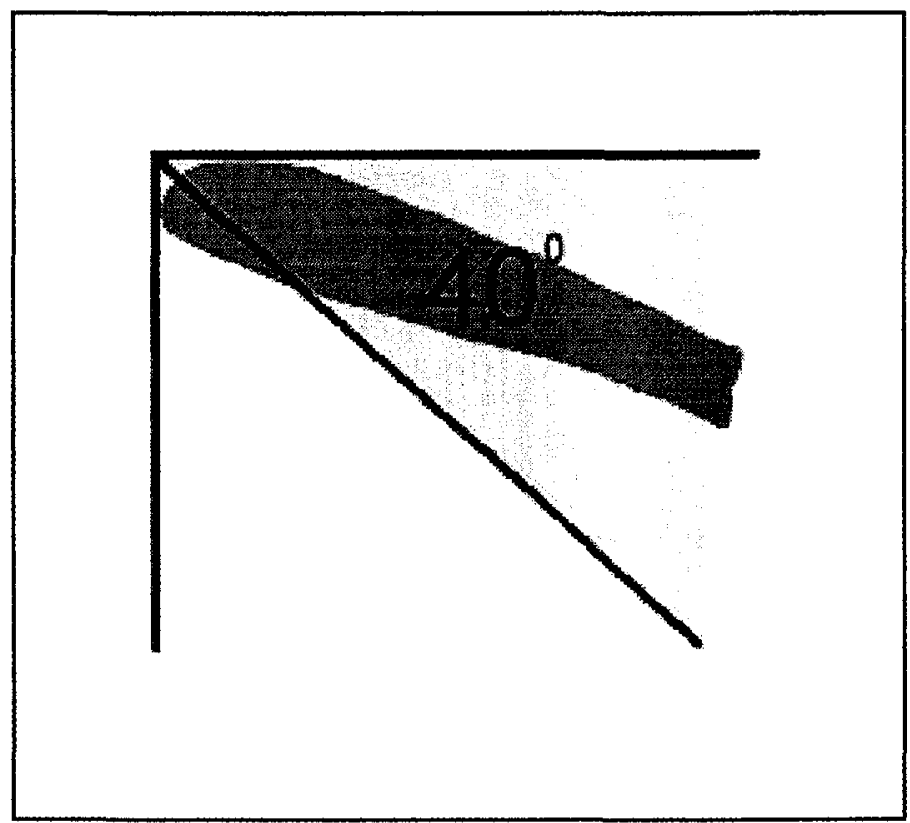

Fig. 19b. Neckless (Holemouth) Jar Defined.

Note how jars have a rim angle of 40 degrees or less and are considered "closed" forms. 
Observations from a technological perspective suggest that these neckless vessels were handmade using a coiling or "brim" method of construction. ${ }^{1}$ "Constrictions," suggestive of joins, are often quite visible, particularly in profile. These vessels are, in the main, unslipped and undecorated, although some red slips, applied decoration, and incisions are noted on the exterior walls. Examination of the interior walls often reveals scraping or smoothing marks executed by a tool, pulled upwards and diagonally across the interior face (more or less 45 degrees) from the base (see Fig. 20). The common orientation of these lines (from lower left to upper right as one faces the hypothetical whole form and puts his/her hand through the vessel's mouth) suggests that the potters used their right hand for this task. Small "dragging" gouges, which frequently pull surface inclusions, hint at sharp edges or corners on the tool. Occasionally such scraping lines run horizontally, or parallel to the base, possibly suggesting the "thinning" of the vessel walls.

Finish marks on the exterior walls are generally much more fine than those on the interior. They often appear as swiping or even as criss-crossing angular courses created as the finger (or cloth or leather tool) of the potter ran rapidly across the slurry of

\footnotetext{
'Voyatzoglou (1974: 20) describes how the potters of Crete build handmade vessels in sections called "brims." She writes "Each stage in the shaping of a jar constitutes one section of the final shape, otherwise known as a brim. When one section is dry enough it is ready to receive the next. Thus every section is based on the preceding section, itself becoming the basis for the next section. It is in this manner that the circular form of the jar is shaped on the turntable; the clay bears the seal of continuous human energy. A large jar is necessarily made of six sections or brims and each brim has its own peculiar name (the 'base,' the 'first brim,' the 'round brim,' the 'straight brim,' the 'big brim,' the 'lip'); each section or brim has its own definite shape. The name of each brim automatically defines the diameter corresponding to each respective level of the jar. A fixed number of coils is necessary for each brim. Consequently, there is a close connection between the quantity of clay coils need and the form of the brim to be made (according to its curve and height). Thus each brim is ahead of the following by about one hour in time and by about $12 \mathrm{~cm}$. of loose clay in height. An additional band called the belt is added where two brims are joined. When the jar finally stands completed on the turntable, handles are attached to it."
} 

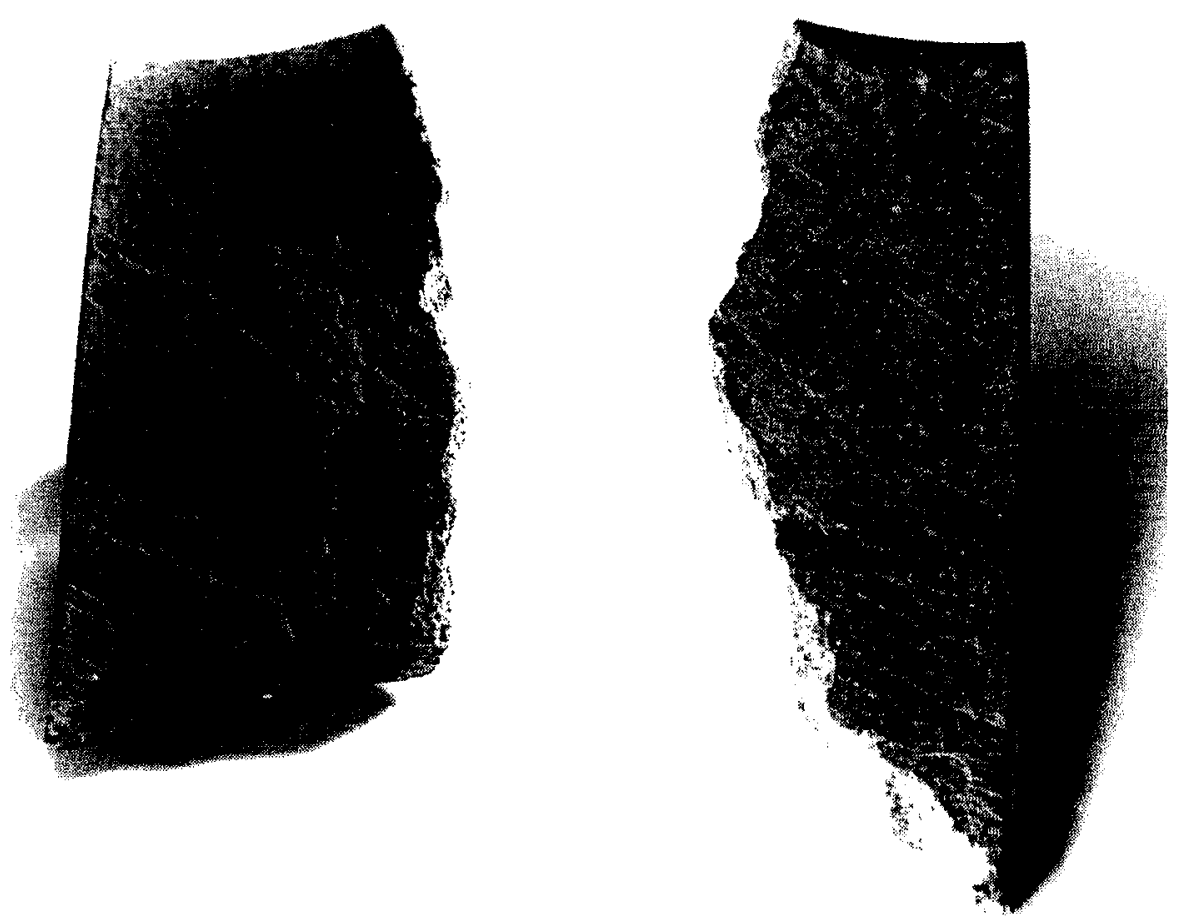

Fig. 20. View to the Interior Wall of Two Holemouth Forms. In both examples (78:3 on left, 129:8 on right) the diagonal marks of interior scraping are clear. 
the pot's surface. Such patterns may be broken by an occasional spout, but always by the lip of the rim, demonstrating that it was the last feature of the vessel to be smoothed. Here, fine lines around the inner and outer circumference of the lip suggest the motion used in the final steps of vessel forming. It is likely that this finish work was done on a turntable or slow wheel-especially given the size of some of these vessels--although it is possible to create a similar effect by hand speed alone.

Sooty burn marks on a vast majority of neckless forms suggest their use in/over an open fire. Clay composition, heavy with calcite inclusions, confirms this aptitude, as does the very simple and unadorned shape. ${ }^{1}$ Convention dictates the identification of this form as the EB "cookpot."

R01. This rim form has a squarish lip; vessel wall shows little or no thickening as it approaches the rim. Fine lines and a very slight concavity on the lip face suggest the lip was formed between the potter's thumb (placed on the lip face) and forefinger (placed on interior wall of mouth).

R02. Like R01, this rim form has a flattened face; however, unlike R01, this form has a greater concavity on the lip face and a protuberance on the underside of the lip; both elements are a result of shaping pressure.

R04. This rim form is characterized by its rounded or "teardrop" lip, with little or no vessel wall thickening.

R07. This form appears as tapered, with little or no thickening in the body wall as it approaches the rim. The rim face is typically a beveled or very thin, flat surface; the taper is brought to a dull point.

${ }^{1} G$. Crowfoot once questioned villagers why they did not decorate cooking pots. The women responded, "What is the use of ornamenting a cooking pot?" (1932: 185). 
R08. This form is beveled from the inside toward the lip, with little or no vessel wall thickening. Fine lines on the rim suggest this bevel was shaped into final form through wet-smoothing.

R09. Like R08, this form is beveled with little or no vessel wall thickening. However, unlike R08, the bevel falls away to the exterior wall of the vessel.

R11. This rim form is characterized by a squared and bulbous lip, the thickness of which is greater than the vessel wall. The variety of stances encountered make difficult any statement concerning the orientation of the lip face; however, in general, it is flat and runs perpendicular to the vessel wall. The formation of many of rims in the series R11-R29 was accomplished by the folding over of the vessel wall while the clay was still wet. In a few sections, this folding is visible due to inclusion or void orientation or large breaks. In many more cases, this conclusion is suggested by measurements which reveal a rim approximately twice the thickness of the vessel wall. After folding, the lip face was pressed square using a combination of pinching and rotational forces. Some "ridges" on the upper and lower corners remain unsmoothed, likely the result of pressure applied on the lip face. Finally, on the vessel interior, finger impressions and tool marks suggest efforts to smooth the folded portion of the rim back into the interior wall.

R12. This rim form exhibits a protuberance on the inner side of the lip as R02. However, the thickness of the rim is considerably greater than the vessel wall; clear evidence of rim folding is present (e.g., 107:7, 184:4). Stance is often nearly upright, with the lip face approaching horizontal. The inner protuberance seems to be the result of pressure applied downwards upon the rim face. In two cases, this excess clay simply "curled" over and was left relatively unfinished; in all other cases, this excess was smoothed into a rounded or angular ledge. 
R14. This rim form is characterized by a rounded or "teardrop" lip. Unlike R04, however, the R14 lip is often bulbous, with a thickness considerably greater than the vessel wall. The formation of these rims was likely accomplished by the folding over of the vessel wall while the clay was still wet. In a few sections, this folding is very visible due to color changes, inclusion or void orientation, or large breaks (e.g., 145:1, 175:2). After folding, efforts to press and smooth the leading edge back into the interior wall of the vessel were successful in varying degrees; in some cases, the transition was rendered smooth and nearly invisible, while in other cases, considerable lumpiness and finger impressions are evident.

R17. This rim form is characterized by a considerable thickening of the vessel wall as it approaches the rim. However, this thickness is beveled on both interior and exterior faces (tapered) to a very thin lip. The form appears as the result of rim folding; voids, inclusions, and efforts to smooth the folded lip into the interior body demonstrate this conclusion. Fine lines on the interior and exterior faces suggest that this beveling/ tapering was done when the vessel walls were still wet and, presumably, rotating on a turntable. A very sharp lip may be seen on some examples $(24: 6,139: 5)$; others have what appears to be an exterior "collar" (24:5).

R18. Like R08, this rim is tapered from the interior face to the lip, but unlike R08, this rim is considerably thicker than the vessel wall. Folding accounts for the thickening as voids, breaks, inclusions, and smoothing on the inner face demonstrate. Fine lines on the rim interior and exterior suggest the final form was wet-smoothed.

R19. This thickened rim is tapered from the exterior face to the lip. Manufacturing notes are the same here as for R18.

R20. This thickened form has a noticeable concavity on its lip face. Familiar signs of rim folding are present here. The smoothing of the lip into the interior vessel 
wall is accomplished with more or less care. The concavity on the lip varies from narrow, where it appears as a line on the lip face (91:10), to wide, where it includes the entire face $(146: 8)$. This concavity may have been created by a tool, fingernail, or, in the larger wider examples, the entire thumb.

$\underline{\mathrm{R} 21}$. This thickened rim appears with an isolated "margin" (ca. $1.5 \mathrm{~cm}$ ) on the exterior face around the mouth. Fine lines suggest that this margin was formed by a tool or fingernail as the vessel was rotated. This margin was worked into the rim from the lip outwards, as tiny, deep grooves as well as splaying clay mark its border with the vessel wall.

R22. This rim is a folded, rounded, or tapered holemouth, with a rope application below the exterior lip. Rope decoration was applied after the shaping of the rim was completed. The impressed "waves" of molding appear to move generally in a left-to-right direction, possibly executed by the thumb of a right-handed potter "pulling" the vessel on a turntable.

R28. This thickened rim form has a raised "collar" on the external face which runs around the vessel mouth. Two examples have distinct "collars"; the "collar" of one appears flattened (87:6), the other (161:3), rounded. The folding of the former is clear; the internal lip of the latter is enigmatic.

R29. This rim form is essentially that of the rolled holemouth, with a built-up squared ridge on its outer lip. This squared ridge was added in application after the rim was folded and smoothed. This form is referred to as a "gutter rim."

Coil- or brim-made vessels: Necked jar rims (Fig. 21). Rim forms R30 through $\mathrm{R} 43$ represent select aspects of necked vessels. These forms are considered "closed" and may or may not have handles. Like neckless or hole-mouthed forms, 


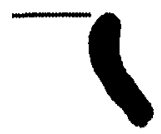

R30

117

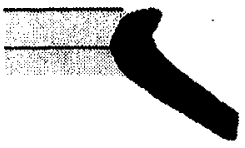

R31

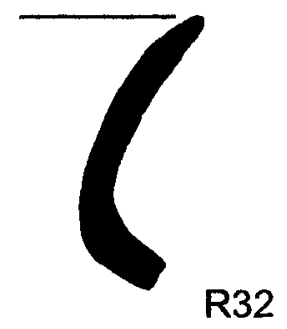

R32

R33
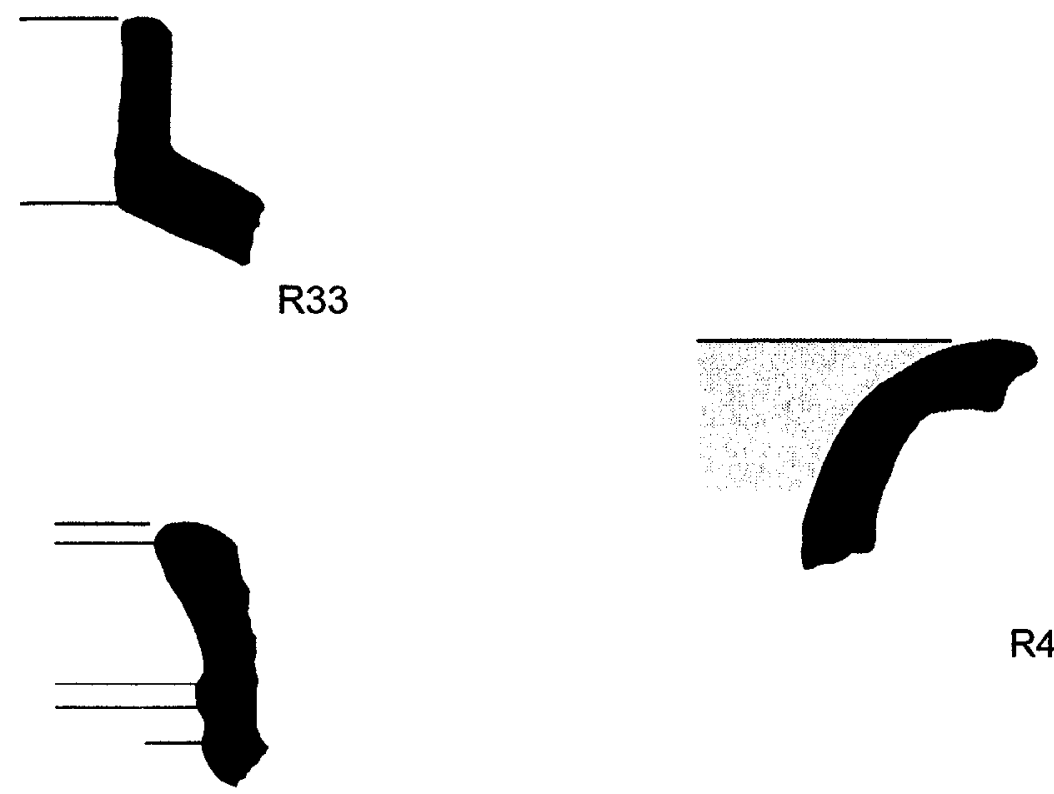

R43

R42

\section{R40}

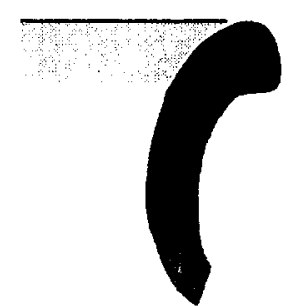


subtle "constrictions" in the body walls suggest that these vessels were coil- or brimmade and efforts to smooth and scape interior and exterior body walls are suggested by lines and smoothing marks. A question remains whether the neck "assemblies" were formed separately and subsequently attached to the body (as is typically the case with "thrown" vessels), or if the effort to build the neck was simply an extension of shaping the vessel walls. In isolated cases, junctures between neck and body are visible (e.g., $60: 8)$. Whatever the case, the neck and rim almost always display a greater attention to detail than do vessel walls.

In an effort to offer an objective description of proportion, a determination of ratio between neck height and mouth diameter was sought. Where the sample size allowed, the vertical distance between the lip and shoulder was estimated; mouth diameters were determined by the use of standard rim charts. Proportional descriptions are as follows: if height was less than 20 percent mouth diameter, the neck was considered very short; if 20 percent to 39 percent, neck was considered short; if 40 percent or more, the neck was considered tall.

R30. This rim form is upright to slightly everted and very short to short in height. Wet-smoothing lines suggest the motion by which the rim was flared and finished and pose a contrast to the crudely executed interior walls. Red slip is present on many, but not all examples.

R31. This rim form is everted or flairing in shape and short in height. The lip curves outwardly and may terminate in a simple tapered fashion, a well-executed bevel, or a bevel with a slight exterior ridge. Some examples of rims in this class appear well shaped and smoothed. Most, however, bear a lumpiness and irregularity that suggests handmade technology. 
R32. This rim form is slightly everted to everted in shape and tall in height. Examples of this class appear handmade with wet-smoothing and red slip on the exterior walls or necks. Interior finish extends no more than a finger's length into the mouth of the vessel, and usually less.

R33. Rims in this class are upright, squared to slightly tapered, and short in height. These forms are handmade, fairly well smoothed, and red-slipped. The term "bow-rim" has been used to describe them (e.g., Braun 1997: 62).

R34. Rims in this class are upright to slightly everted with exterior ribbing. They are short in height. Two subclasses appear in this group. The first is handmade, red slipped, with two or four ribs evenly spaced on the exterior neck. The distance between these ribs is a comfortable finger width and smoothed to a concavity. Wet-smoothing inside the vessel neck extends only the length of a finger. The second subclass within this group appears wheel-finished and has much sharper ribs, likely cut by means of a tool.

R35. Rims in this class are sharply everted to achieve a horizontal attitude which is slightly concave or "channeled." They are very short to short in height. Smoothing lines suggestive of turning are present in every example of this class. The rim is sharply folded in an outward direction and squared. A very slight upturn of the lip creates the "channel" on the horizontal face.

R40. This rim form is thickened and very short to short in height. Voids, inclusions, breaks, and smoothing marks suggest that this rim form was created by folding the lip outward in a rolled fashion to meet the external face. The resulting shape, in section, appears round to triangular. In a few cases, an additional clay build-up may have been added to achieve the desired thickness and shape. 
R42. This rim form is thickened and everted, with an upright squared, to slightly tapered lip. It is short in height. Voids, inclusions, breaks, or smoothing suggest the lip of forms in this class was folded outwardly to meet the exterior wall.

R43. Similar to R42, this rim form is thickened and everted. However, the outer limits of this fold were, in turn, pinched into one or two sharp corners and wet-smoothed. Some examples have an exaggerated, or flairing, upper corner which protrudes beyond the lower corner.

Mold-made vessels: Bowl and platter rims (Fig. 22). ${ }^{1} \mathrm{~A}$ variety of bowls and platters appears in the corpus whose rims may be termed simple, sinuous, or ledgerimmed. It is proposed that these vessels were hand-built and likely constructed in a "shaping dish" or mold. ${ }^{2}$ Bases were either left rough or "textured," as pulled from the mold (or possibly a textile fabric placed between the clay and mold) or finished using a combination of scraping and smoothing actions. ${ }^{3}$ Ledge-rimmed bowls

"Arnold gives considerable attention to the use of the "vertical-half mold" (1985: 202-8). He observes that when compared to traditional coil-made methods, the use of molds decreases the drying time between stages of vessel production, increases overall output, and reduces the motor habits and skills required by the potters themselves. All of these factors indicate mass production and job specialization.

${ }^{2}$ Franken and Kalsbeek have demonstrated the technique for making a vessel in a shaping dish. A textile was used for ease in removing the vessel from the mold (1975: 169). See also Beck (1985: 19-20) for a description of experimental efforts to reproduce EBA ceramic forms.

${ }^{3}$ The presence of the sub-rim concavity is frequently noted but has yet to be adequately explained. This inadequacy is sensed in the choice of language by Philip and Baird (2000: 19) who describe such vessels as "platters with a notch below the rim."

Ceramicist John Landgraft suggested (personal communication, 1997) that this concavity could be the result of the rim being shaped while the base was still in a mold or "half-mold." In this scenario, the rim was attached to that portion of the vessel that extended beyond the mold and the concavity is the result of motion and shaping pressures applied from below. This would explain why the mold marks abruptly end where the "concavity" begins. 

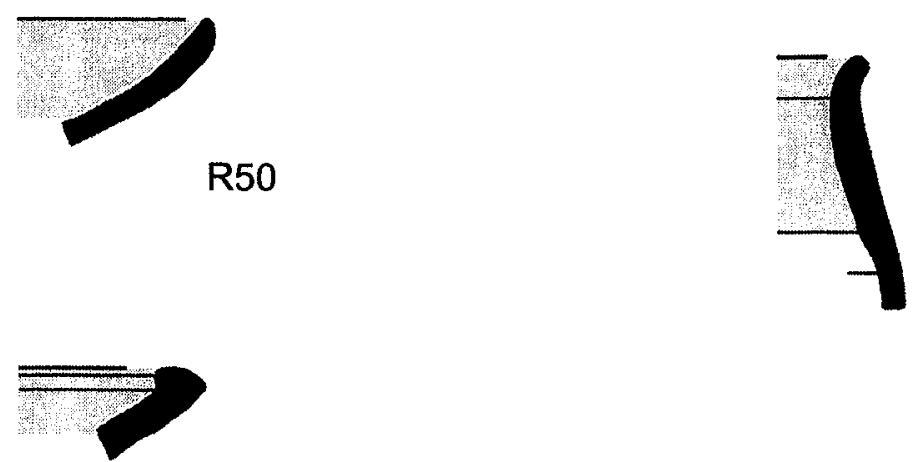

R57

R51
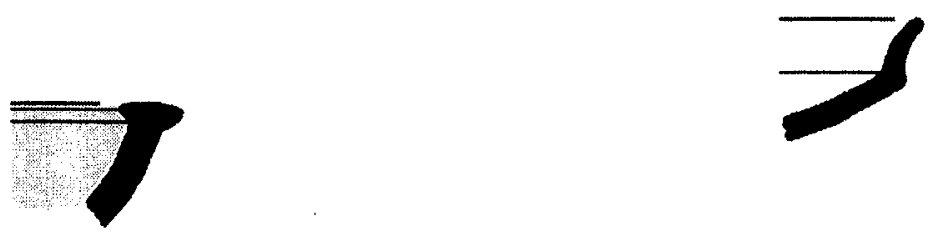

R58

R52

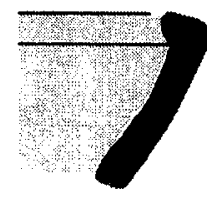

R53
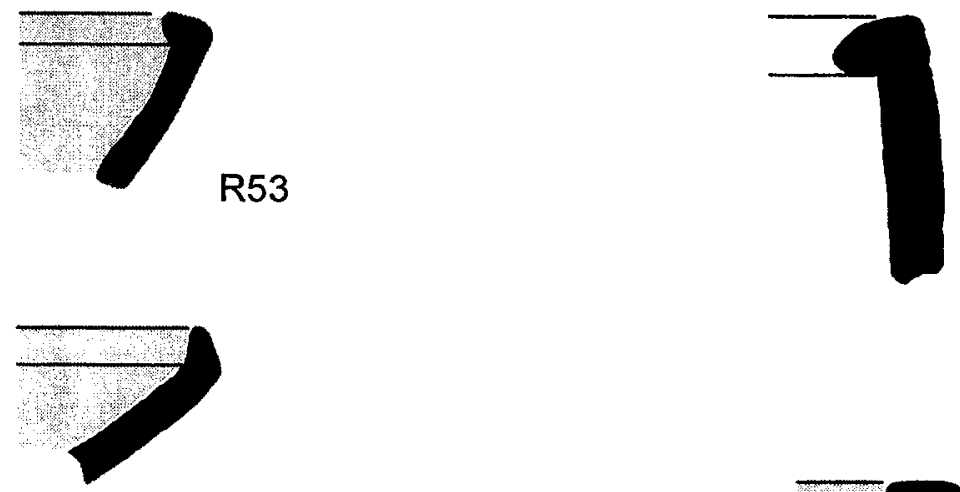

R59

R54
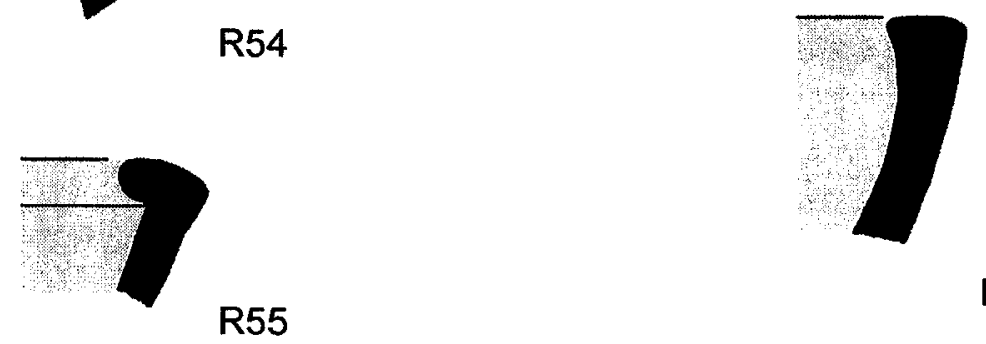

R60

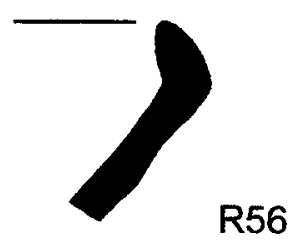

Fig. 22. Bowls and Platters, Rim Typological Assignments (R50 - R60), 
particularly display a slight concavity beneath rim exterior, suggesting construction techniques consistent with large platters (Fig. 23). Fine lines on nearly all rim forms suggest additional attention given to achieve a finish.

R50. Rims assigned to this class have a simple rim with a tapered lip. Both MW and $\mathrm{CW}$ are identified. CW forms are usually red-slipped. That a majority of these examples have burn marks on the lip suggests the use of these simple hemispherical bowls as lamps (Fig. 24).

R51. Rims assigned to this class are sharply inverted with an upper surface that approaches horizontal. Visible marks suggest the lip was folded inwardly and wetsmoothed. Inclusion "drags" suggest direction of motion on specific vessels. Some examples have slight concavity on exterior face immediately below the rim suggestive of the mold or shaping-dish. CW forms are often slipped; both MW and CW forms show burnish on interior face and rim.

R52. This rim has an upper surface that approaches horizontal. However, unlike those in the R51 class, a lip protrudes from both the interior and exterior faces, giving rise to the term, "hammerhead." The interior protrusion is clearly the result of an inward roll or fold. The external protrusion may be a by-product of pressure applied to upper rim face or pressure applied when "pulling" the concavity that appears beneath the rim exterior on some forms. Most of these large bowls are likely mold-made with a poorly finished and "textured" external face.

R53. Rims assigned to this class are inverted to sharply inverted and have no marginal concavity under rim. Stance varies considerably, suggesting some of these forms appeared as deep bowls, while others, particularly those in MW, appeared as broad platters. Evidence of mold-made construction is clearly visible on many forms with irregular scraping/ smoothing on the exterior face. All examples tend to be well 

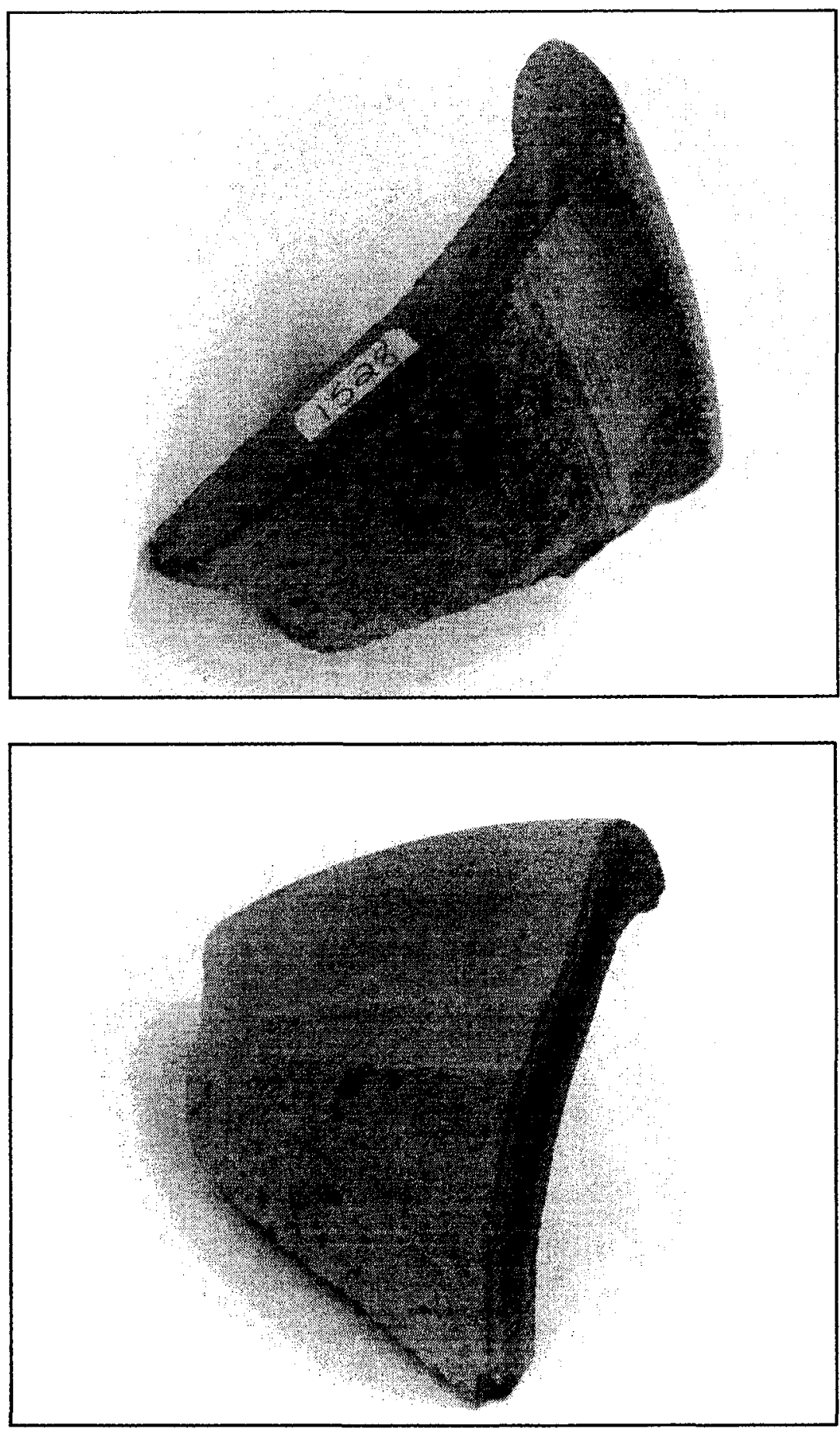

Fig. 23. Concave Margins on Mold-made Vessels. These examples of the exterior face of a platter bowl (above, 155:8) and a ledge-rim bowl (below, 172:3) clearly demonstrate how the smoothed and sometimes concave margin differs dramatically in appearance from the textured, lower, exterior wall. 


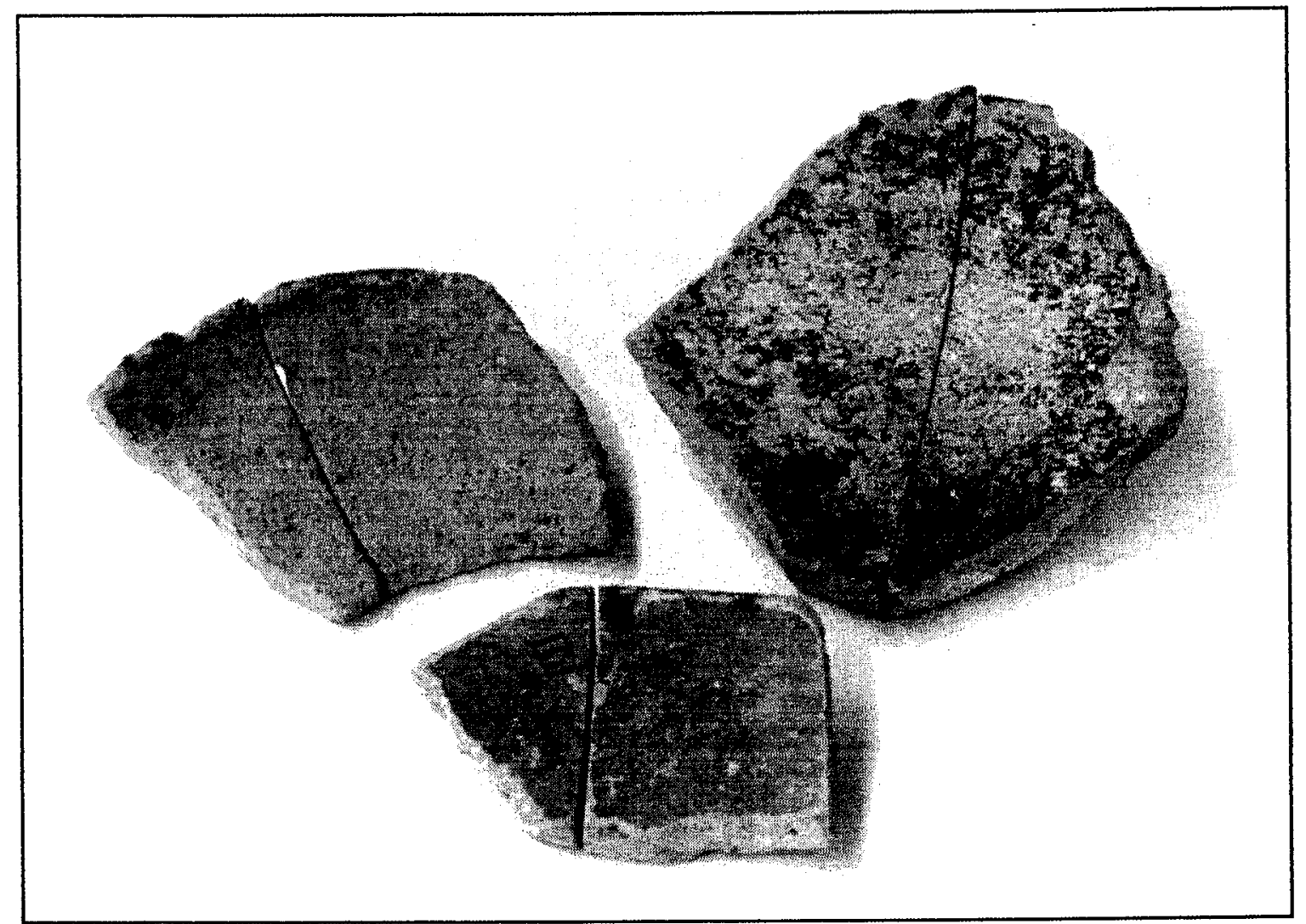

Fig. 24. Bowls with Sooty Rims, likely used as Lamps.

Clockwise from left: 101:2, 90:1, 29:2. 
finished and burnished around the edge of the lip, however. Inclusion and void orientations suggest lip was folded inwardly to meet interior face. Radial burnish may be visible on interior face.

R54. Rims assigned to this class are short, upright, and have no marginal concavity under rim. Construction notes are the same as for R53. Many examples are MW.

R55. Rims assigned to this class are inverted to sharply inverted and have a marginal concavity under rim. This concavity may represent the limits of the mold. The limits of the vessel, however, were built beyond this mold for the purpose of folding the lip. Final efforts to smooth the rim created this concavity below the folded lip but above the original mold.

R56. Rims assigned to this class are short, upright, and have a marginal concavity under rim. The lip fold in these case is less severe than in form R55. Construction notes are the same, however.

R57. A few rims suggest the shape of a mold-made platters which do not clearly fit into established categories. These may have an extremely short lip, a low profile, or even a distinct disk base.

R58. This rim form has a blunt to rounded lip which gives way to the graceful carination of vessels often called "Aphek bowls" or "Beck bowls" (Beck 1985).

Preserved below the carinated "keel" on these forms are the texture and scraping marks consistent with mold-made vessels (Fig. 25). Above the "keel" on the interior and exterior walls are fine lines suggestive of wet-smoothing. Both MW and CW are found. Burn marks confirm the use of some of these bowls as lamps.

R59. These rims are distinguished from the R53-R56 series because of their upright stance. Vessels with this rim may rightly be termed deep ledge-rimmed bowls or 


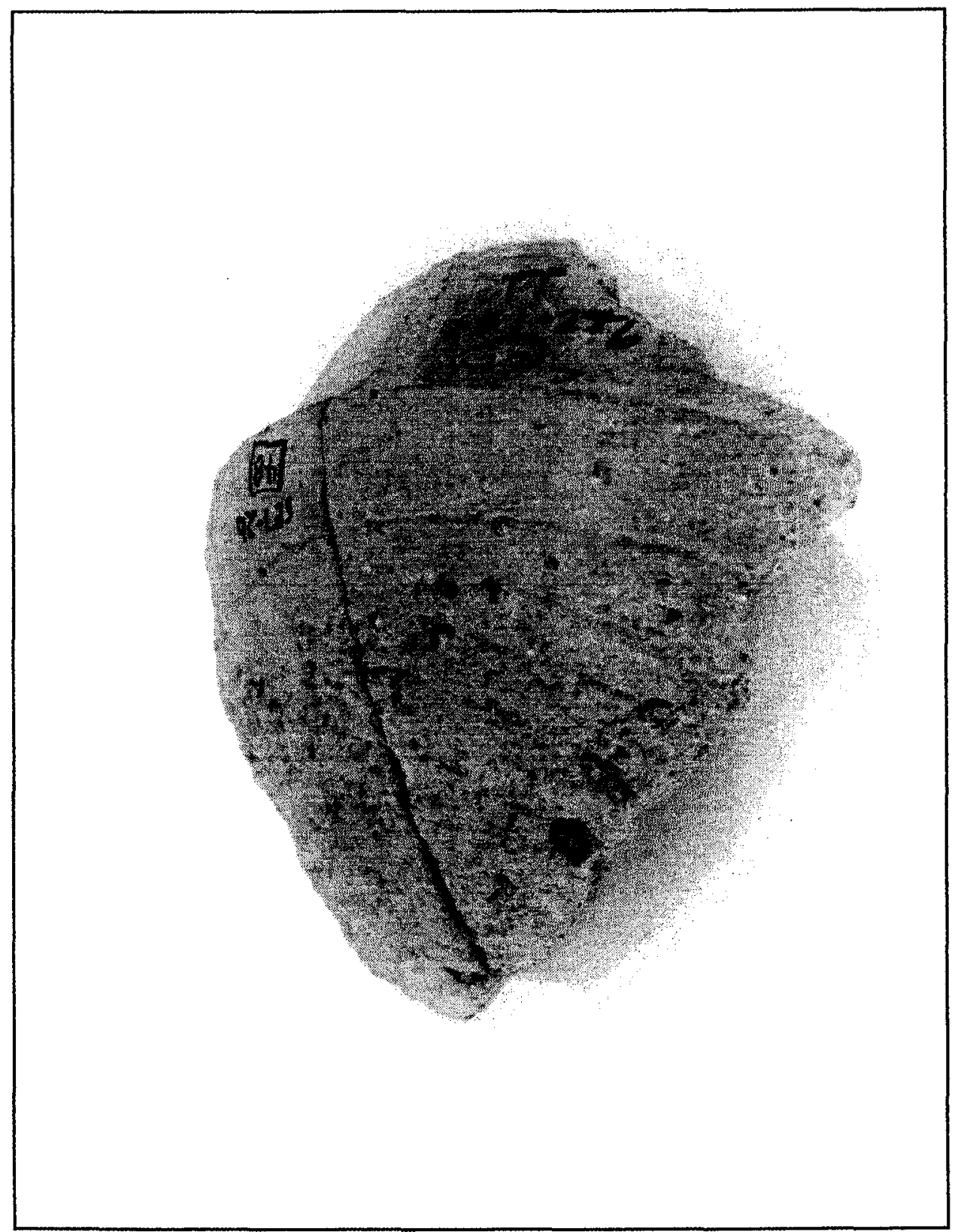

Fig. 25. Exterior Wall and "Keel" of a Carinated Bowl. Contrast the rough base below the "keel" with the smoother finish above (93:4). 
even "vats." Such rims are sharply inverted, with the lip folding to meet the interior vessel face. Finish on these forms ranges from white wash to red slip to unfinished. As elsewhere, greater attention is given to finishing rim and vessel interior. Wall thickness and diameter suggest these vessels were characteristically large.

R60. Like R59 forms, rims of this class are upright and inverted. However, a distinct "ledge" is not visible, as the vessel lip has been folded and smoothed into the interior wall, suggesting a "squarish" profile. Evidence of construction suggests these forms are mold-made; some textures and scrape marks are visible on exterior faces. The external concavity typical of platter construction is also noted here in some examples. Finish techniques vary greatly.

Other. Other rims fall outside the forms described, either due to sample size or unique shape. Among these are the following:

R80. These rims are simple and squared.

R81. These rims are simple and rounded.

R82. These rims are simple and tapered.

\section{Handle Assignments (Fig. 26)}

Approximately 11 percent of the total corpus is composed of handles or handle fragments. Of these, loop handle fragments outnumber ledge-handle fragments at a ratio of nearly three to one. The following descriptions detail handle assignments.

H10. Handles in this set are clearly ledge handles; however, they are too fragmentary to distinguish details.

H11. Ledge handles of this type are simple and plain.

H12. This ledge handle is indented with a thumb or tool, but not significantly pushed up. 

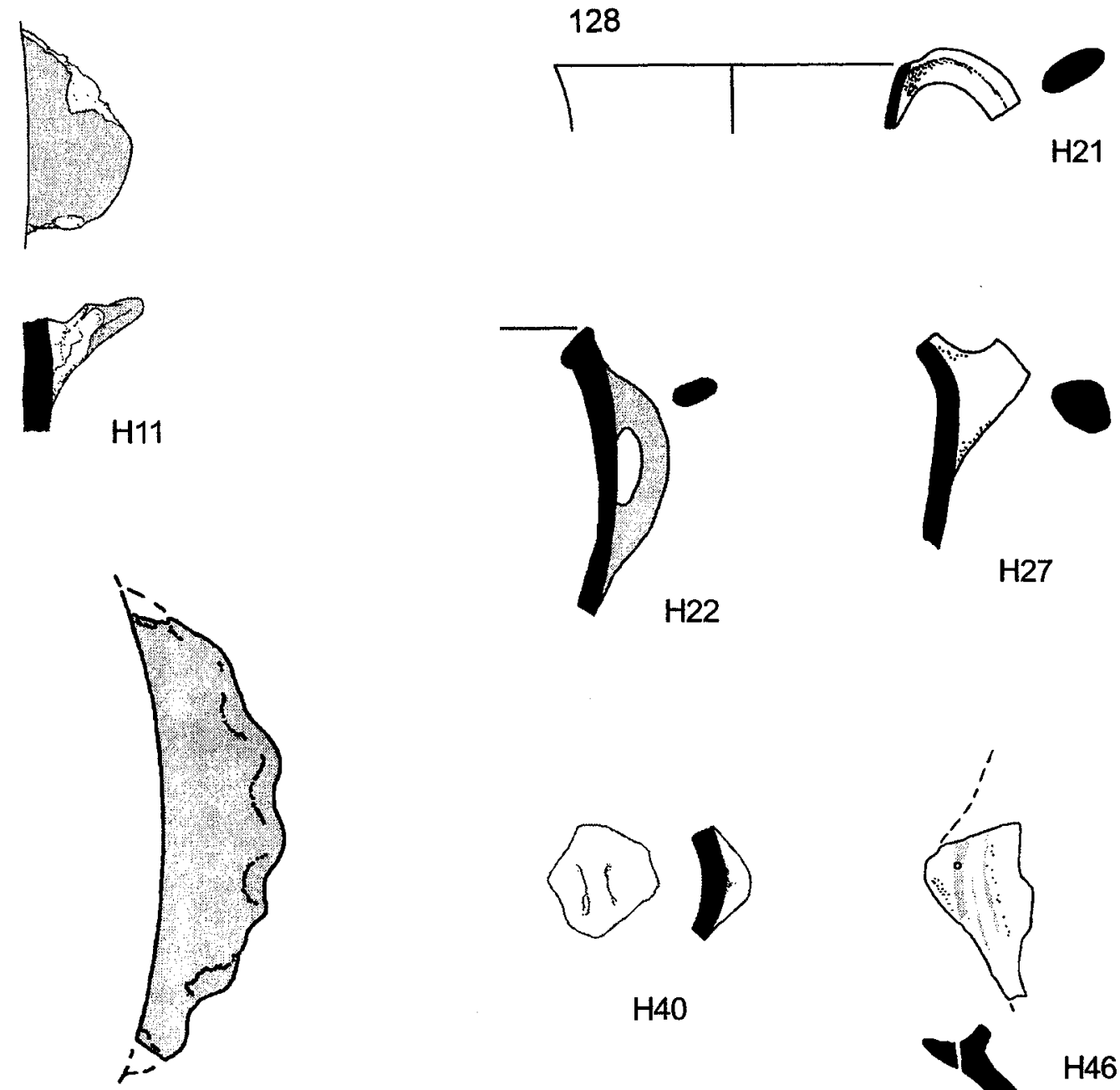

$\mathrm{H} 27$

$\mathrm{H} 22$
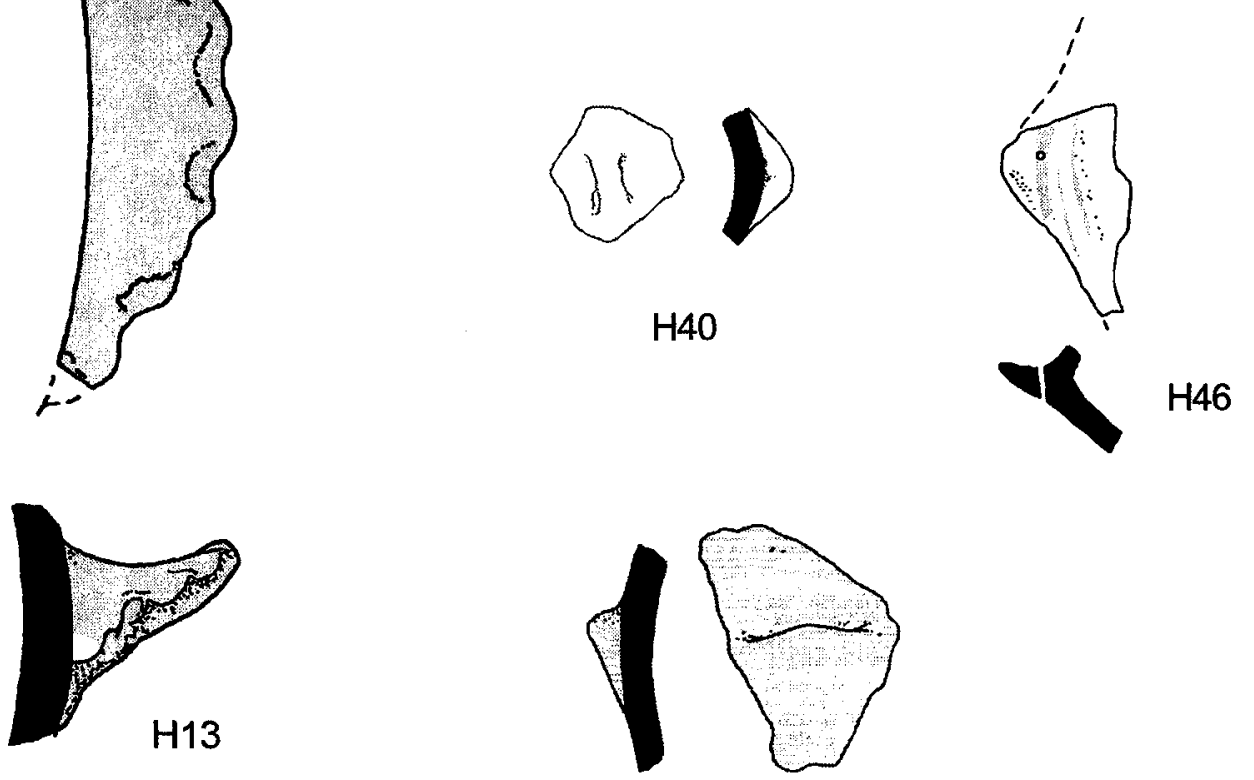

$\mathrm{H} 50$
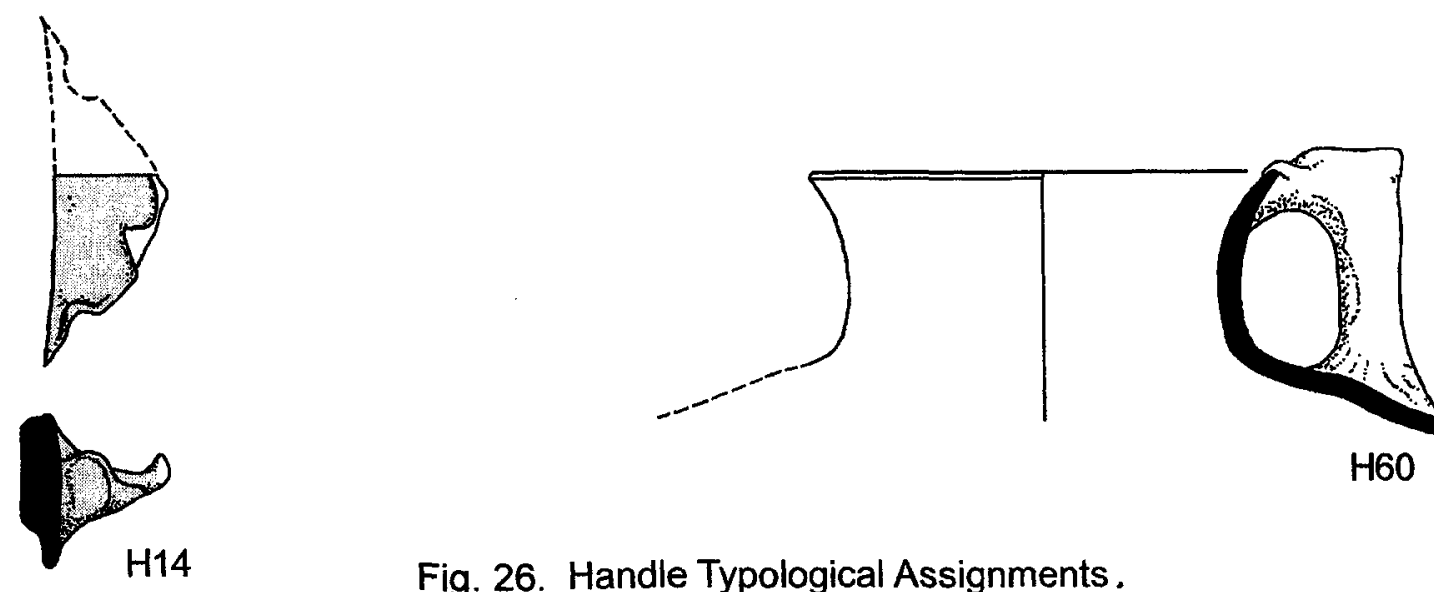

H60

$\mathrm{H} 14$

Fig. 26. Handle Typological Assignments. 
H14. Wavy ledge handles. These handles are not only indented, but pushed up significantly in two or more places.

H20. Handles in this set are loop handles too broken to distinguish details.

H21. Loop handles in this set extend to the vessel rim and may extend above it.

H27. Loop handles in this set extend to the vessel wall.

H40. Loop handles in this set may be vestigial. There is no piercing or opening. Orientation is vertical.

H50. Lug handles in this set may be horizontal or vertical. They are pierced.

H60. Handles in this set are unique in that they involve the rim. One is a ledge $\operatorname{rim}(159: 1)$ and the other is a pillar handle (162:10).

Base Assignments (Fig. 27)

Approximately 10 percent of the total corpus is composed of base or base fragments. More than half of this set may be described as simple, handmade, and flat. The remainder are stump or elevated stump bases. Slight differences suggest the following categories:

B10. Base fragments which appear to be simple and flat, but because of their extremely fragmented nature disallow further description, fall into this group.

B11. Bases assigned to this group are flat and are joined to the vessel wall in a relatively straight juncture. Both inside and outside corners are well defined, with no inner buildup or smoothed slope on the inside corner between base and wall.

Within this group, diameters vary considerably. No mat impressions are noted on base bottom; one possible string cut is visible (see Fig. 28a). Finger impressions inside the base often demonstrate smoothing in circular motions. Exterior finishes, burnish or slip, may or may not extend to cover base. 

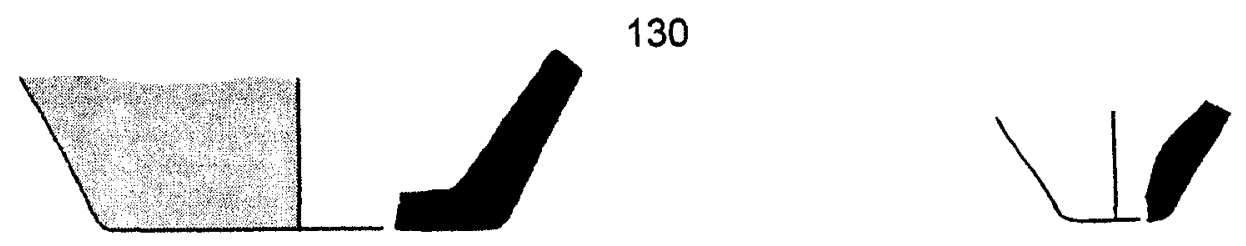

B11

B21
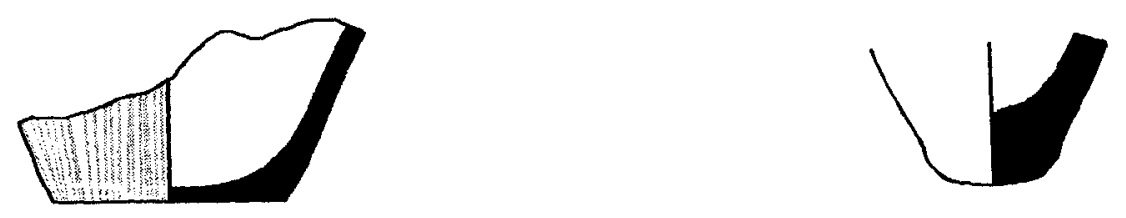

B12

$\mathrm{B} 22$
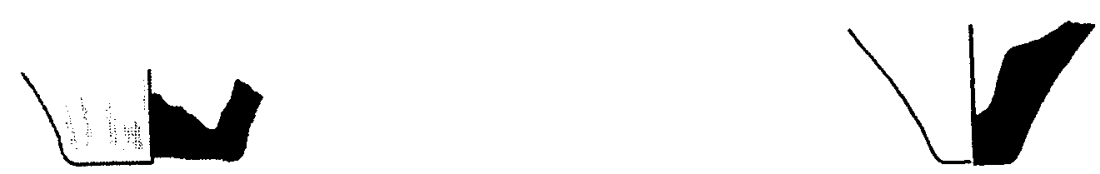

B13

B23

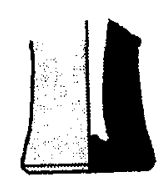

B24

Fig. 27. Base Typological Assignments . 
B12. Bases in this category have a concave juncture between the vessel wall and base proper, with no clear interior corner. In some cases the slope is quite gradual, while in other cases, a noticeable buildup of clay may be seen on the wall interior, that produces a thickened or "step-down" line from wall to base. In either case, the thickness of the wall tends to be greater than the base, sometimes significantly.

This juncture may be the result of an interior buildup of applied clay, or the result of exterior, or constricting, pressure or applied by the hands while the vessel is turned. Franken suggests the former possibility was used in an EBA context:

When large storage jars were produced people needed to make strong large and flat bases. These were made on a flat and porous surface such as a limestone disk. A clay coil was fixed along the edge of the base and pinched up to form the lower part of the wall. Often there was a considerable difference in thickness between base and wall. In order to make both parts stick together, potters often fixed an extra clay coil inside where base and wall joined. The pots were built up in coils to the simple rim without a complex profile. These are the neckless storage jars.

When large concave bases were needed the potters probably used holes in the hard soil. (Homes-Fredericq and Franken 1986: 96)

Attempts to smooth the vessel interior are suggested by lines which pull across the diameter of the base, or lines which suggest circular movement. Lines of unremoved clay surplus hint at a rapid turning.

On the vessel exterior, a small flair, suggestive of hand building from the bottom upwards, may be noted. In some cases, this flair is shaved off. String-cuts are seen (69:5, 157:8). No mat impressions are visible. Vessel finish (slip, burnish, or combing) may or may not extend from wall to base.

B13. This flat base has a convex juncture between base and vessel wall. These bases may not be termed "omphalos" proper, but are likely produced by similar dynamics. Here, it is suggested that such forms are the result of unremoved surplus 


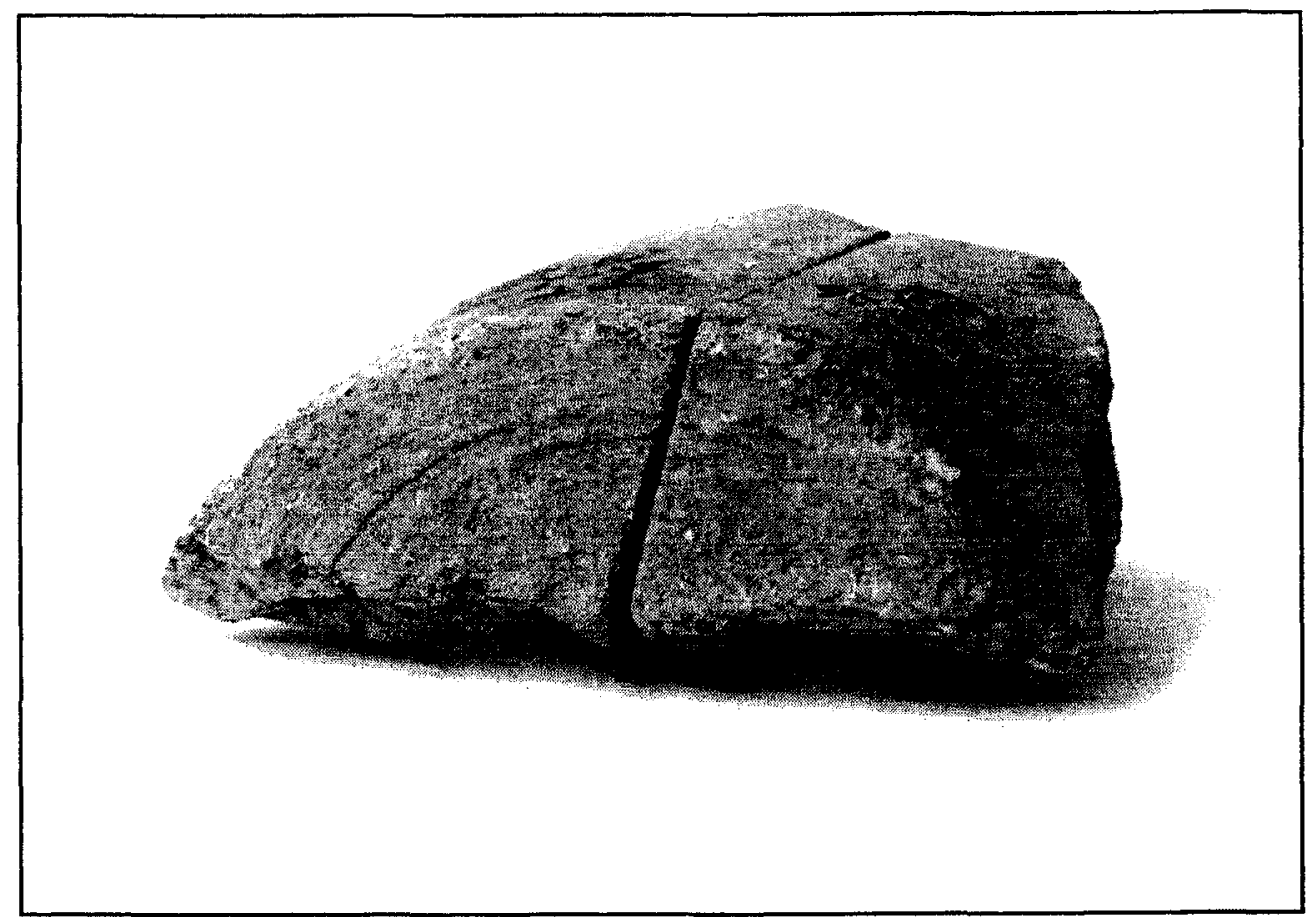

Fig. 28a. A String-cut Base?

Note how this unique example (106:2) displays arching lines that may be evidence of a string cut.

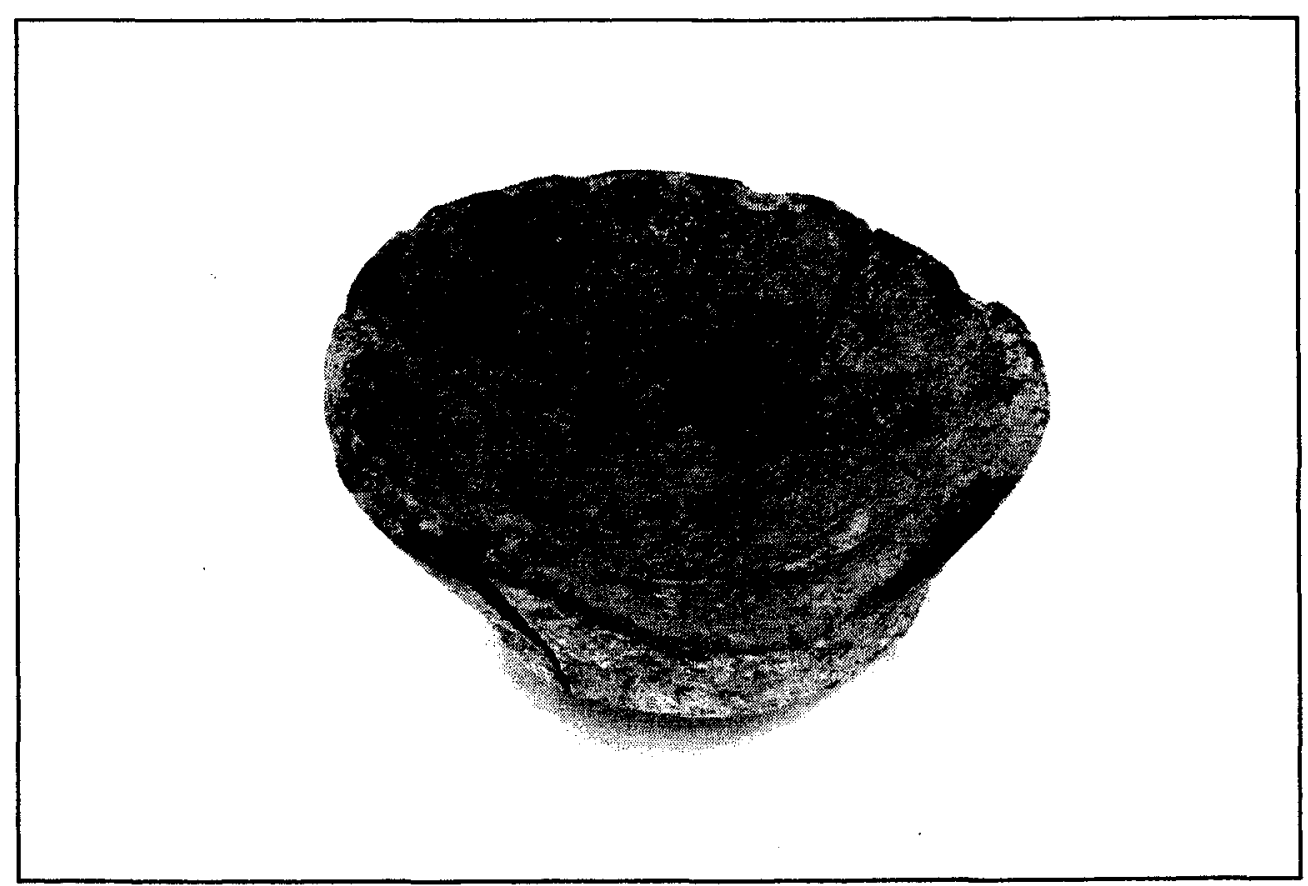

Fig. 28b. Recycling the EBA.

This broken EBA base (not in the study sample) was later reused as a lamp. Note the sooty marks around the break. A similarly burned base (146:5) was found elsewhere in an EB II context. 
clay accumulating on the interior of the vessel. This clay is often "twirled" in such a way as to suggest forming motions (see Fig. 29a and especially Fig. 29b).

B20. Base fragments which appear to be stumped, but because of their extremely fragmented nature disallow further description, fall into this group.

B21. This set of bases is short, squat, and stumped with a base which is thinner or equal to the vessel wall.

Common to $\underline{B 21}, \underline{B 22}, \underline{B 23}$, and $\underline{B 24}$ are significant accumulations of clay on the interior vessel walls, suggestive of external or constricting pressure applied in the forming process. This may also be suggested by the presence of a slight concavity which is visible on the exterior vessel wall in some cases (see Fig. 30a and Fig. 30b). Slips may or may not extend to cover base.

B22. Stumped bases which have a base significantly thicker than the vessel wall fall into this category. For this reason they may be described as slightly elevated and rounded.

B23. This class of base is identical to B22 except the base of the stump is flattened rather than rounded.B24. Stump bases from this set have a flat bottom and are very elevated. A slight flair is visible on the external wall.

\section{Body Sherds}

Approximately 7 percent of the total assemblage consists of body sherds. These are, for the most part, nondescript fragments which represent vessel walls and contribute little information concerning form. Exceptions to this include spouts and (jug) necks, which, for the sake of convenience, are included in this discussion. In the main, it appears that the original excavators chose to save these body sherds because of 


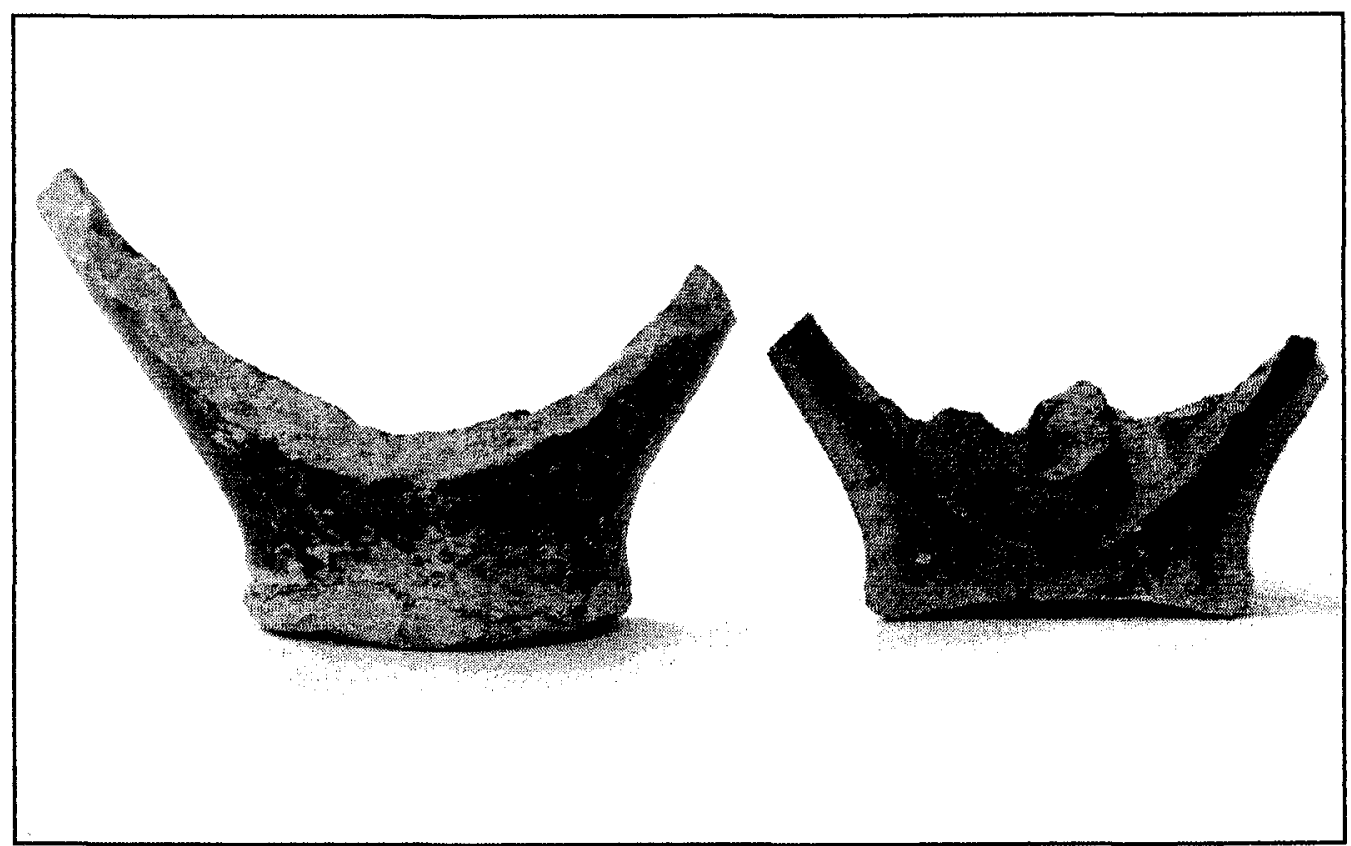

Fig. 29a. A Metallic Ware Jug Base in Section.

Note the surplus clay on the vessel interior of this slightly stumped vessel (69:6).

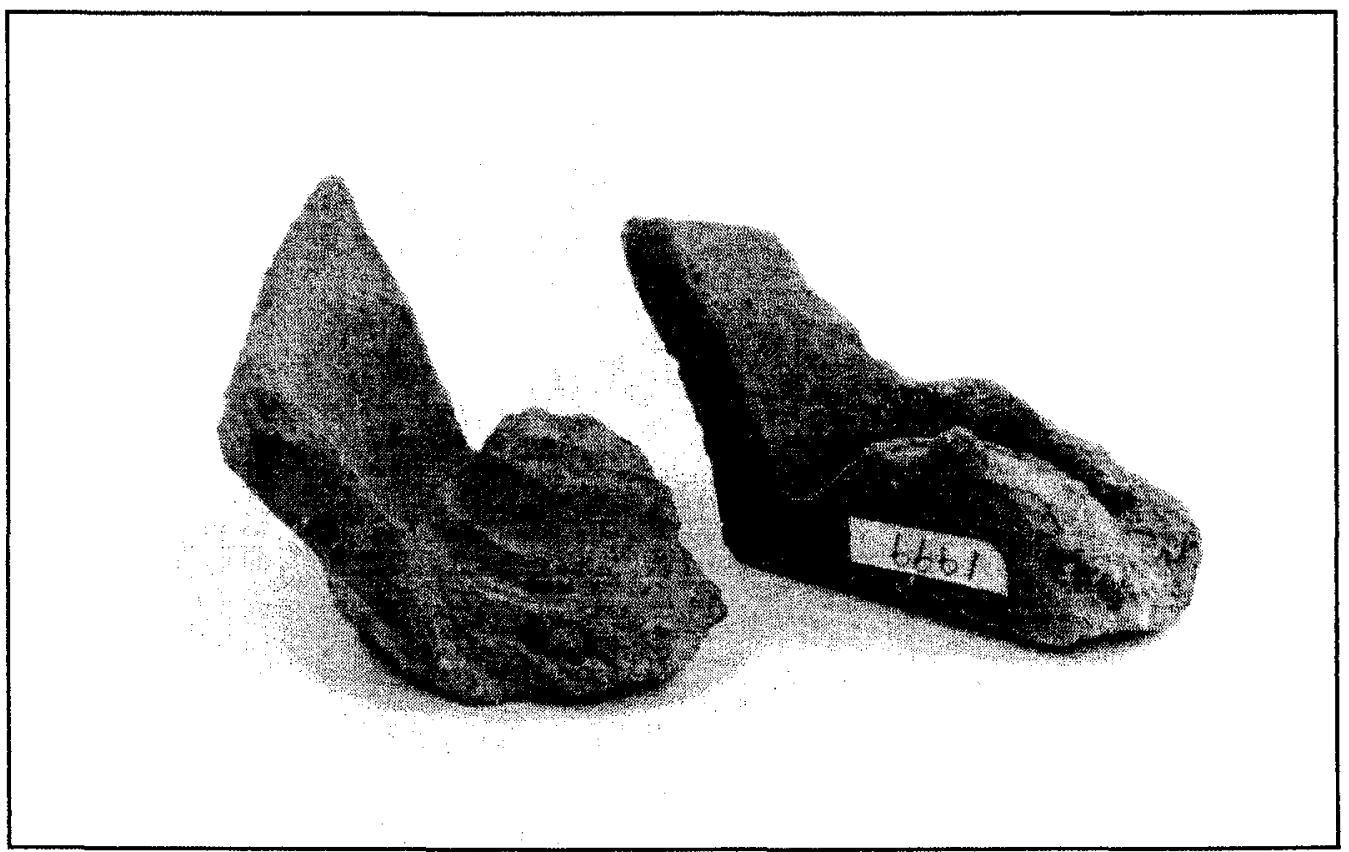

Fig. 29b. Swirling Surplus.

Note how the excess clay on the interior of this cut base is indicative of the motion used to form the vessel (174:2). 


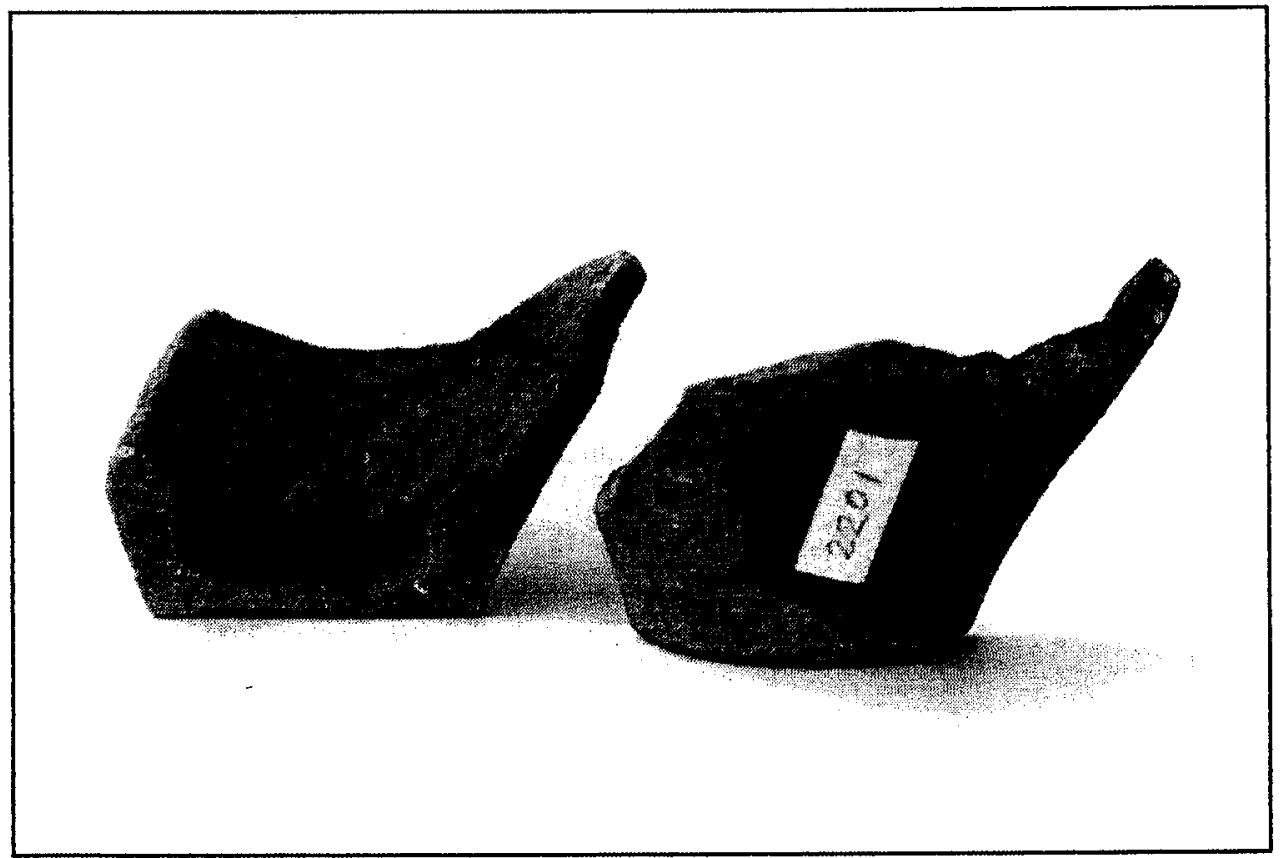

Fig. 30a. More Clay Surplus.

Note how the exterior wall thickens considerably as it approaches the base (146:5).

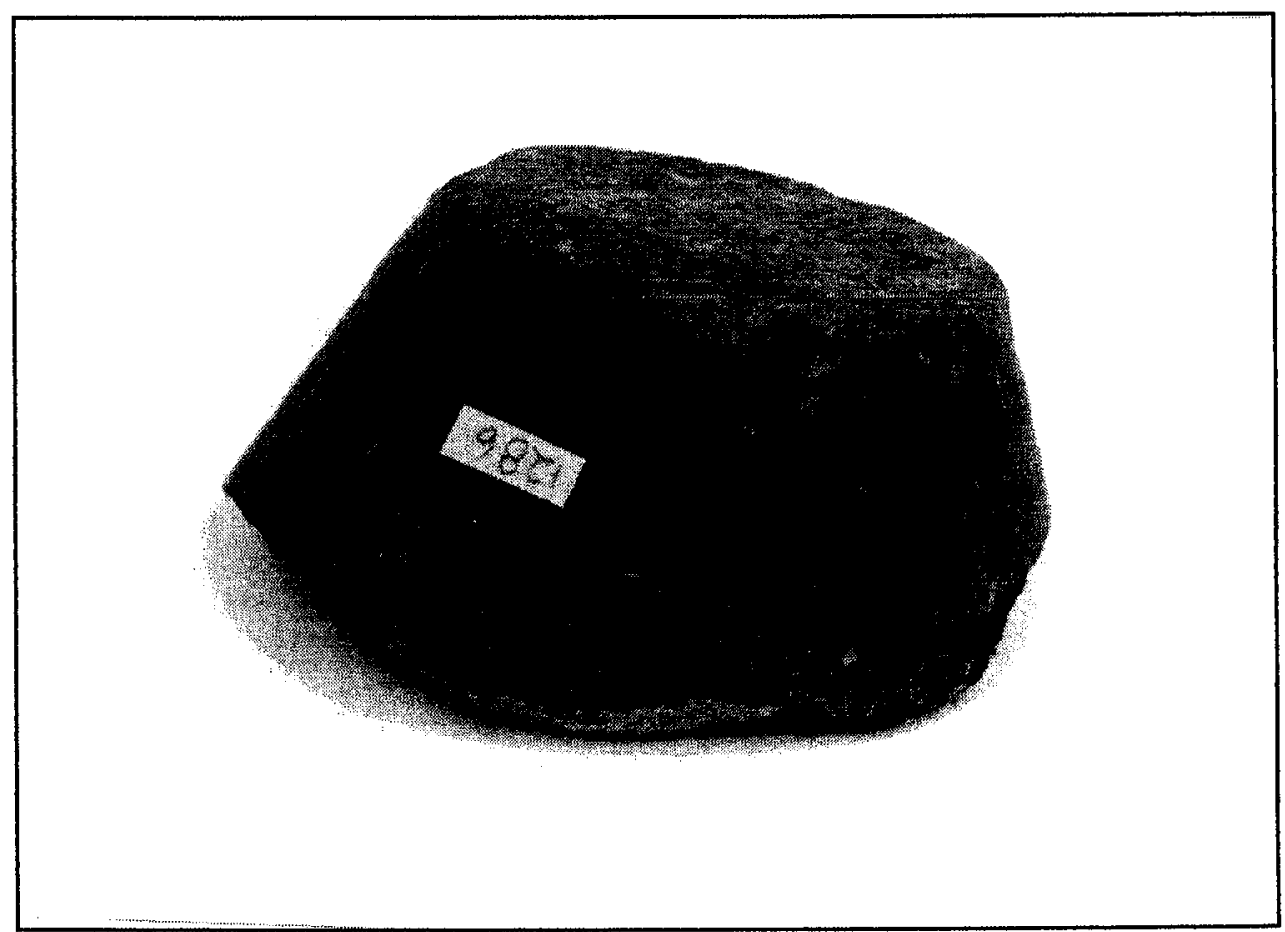

Fig. 30b. A Slight Bulge.

Evident near the junction of the flat base and vessel exterior wall is a slight "bulge," hinting at the join (113:4). 
uniquenesses viewed as significant, mostly relating to fabric or finish (Fig. 31a). As an example, all sherds belonging to the class of KKW were saved, regardless of size. The same is likely true of combed MW (Fig. 31b), GBW, and painted wares (Fig. 32).

\section{Summary}

On the basis of the stratigraphic outline presented in chapter 3, approximately 2,000 sherds were selected to represent the EBA at Tell Ta' annek. No whole vessels are noted; these broken materials are from excavated fills and living surfaces judged to be reasonably secure. The purpose of this chapter has been to provide an orientation to this created assemblage through a narrative of typological and technological observations. A complete presentation of collected data is available in the Pottery Plates of Appendix IV.

Rims, handles, and bases characterize the assemblage and provide a heuristic means by which the material may be organized. While some 40 different rim forms have been identified, it is significant to point out that these represent nuances of relatively simple vessels which fall into two basic categories: those which were handbuilt using coil or brim techniques and those which were formed in or on molds. Proposals have been offered to explain some features of vessel production; however, these are little more than theories based upon preserved signs. Loop handles predominate, as do flat, simple bases. Finally, it is likely that some forms were built by hand, yet finished on a wheel. Distinctions between a slow wheel (turntable or tournette), where access to all "sides" of a vessel is achieved, and a fast wheel, where clay is actually "thrown," are not crisp. 


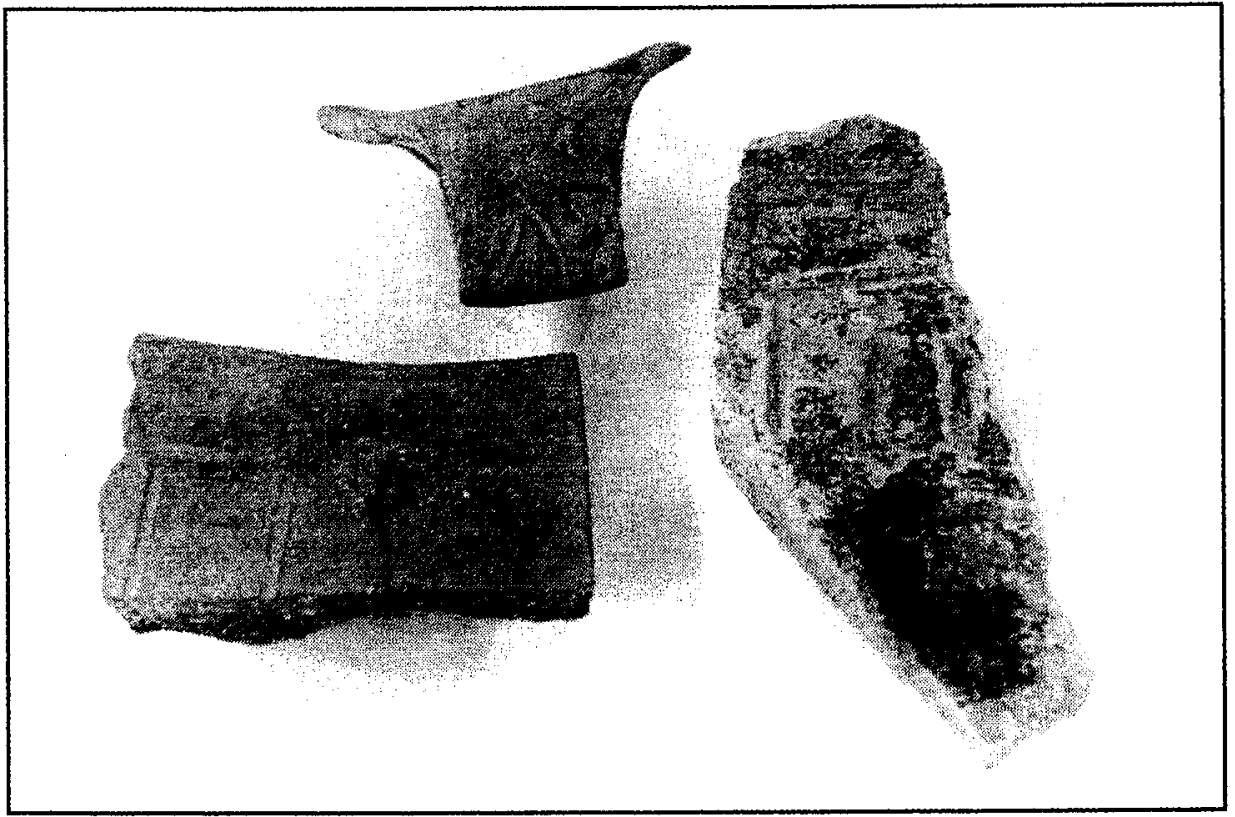

Fig. 31a. Samples of Incisions or Potter's Marks.

Clockwise from top: 29:7, 36:4, 140:4.

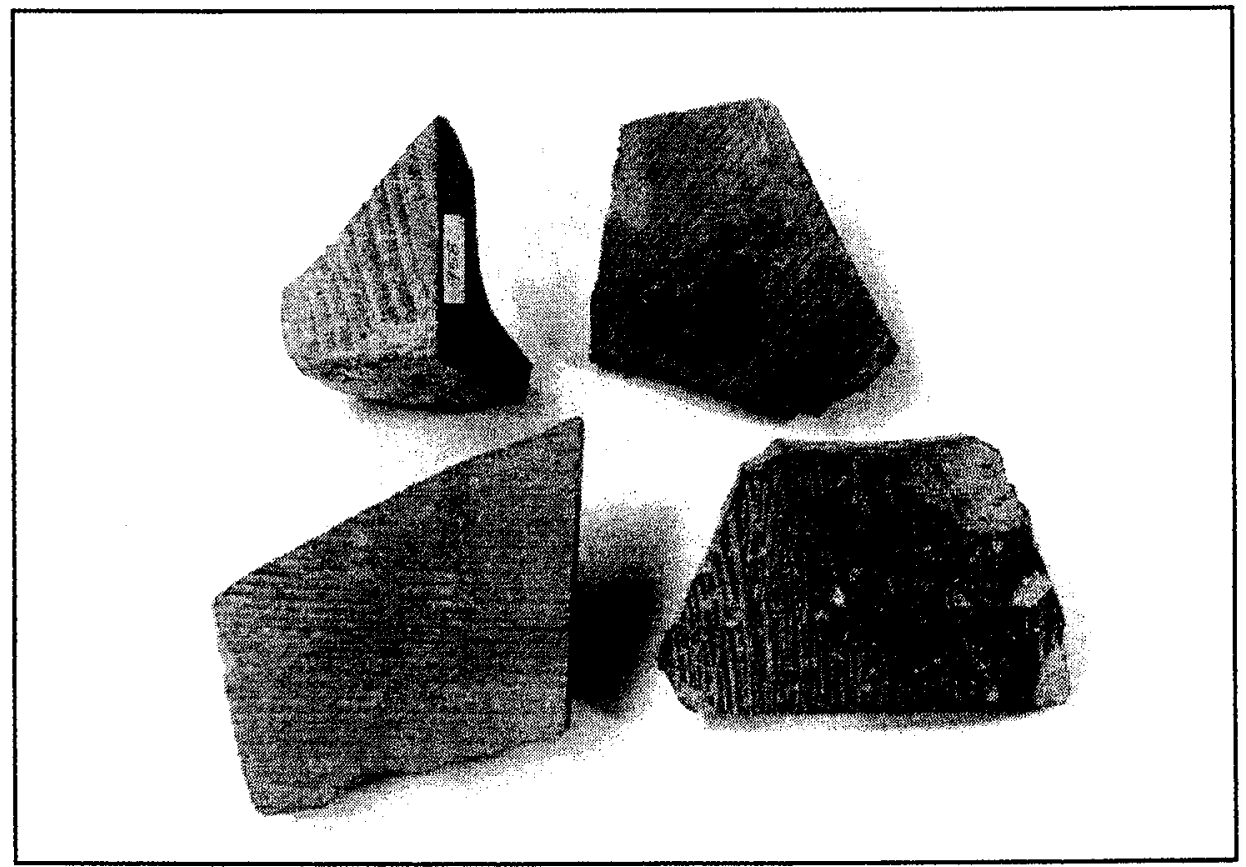

Fig. 31b. Samples of Combed Metallic Ware.

Clockwise from upper left: $33: 8,137: 8,147: 9,33: 10$. 


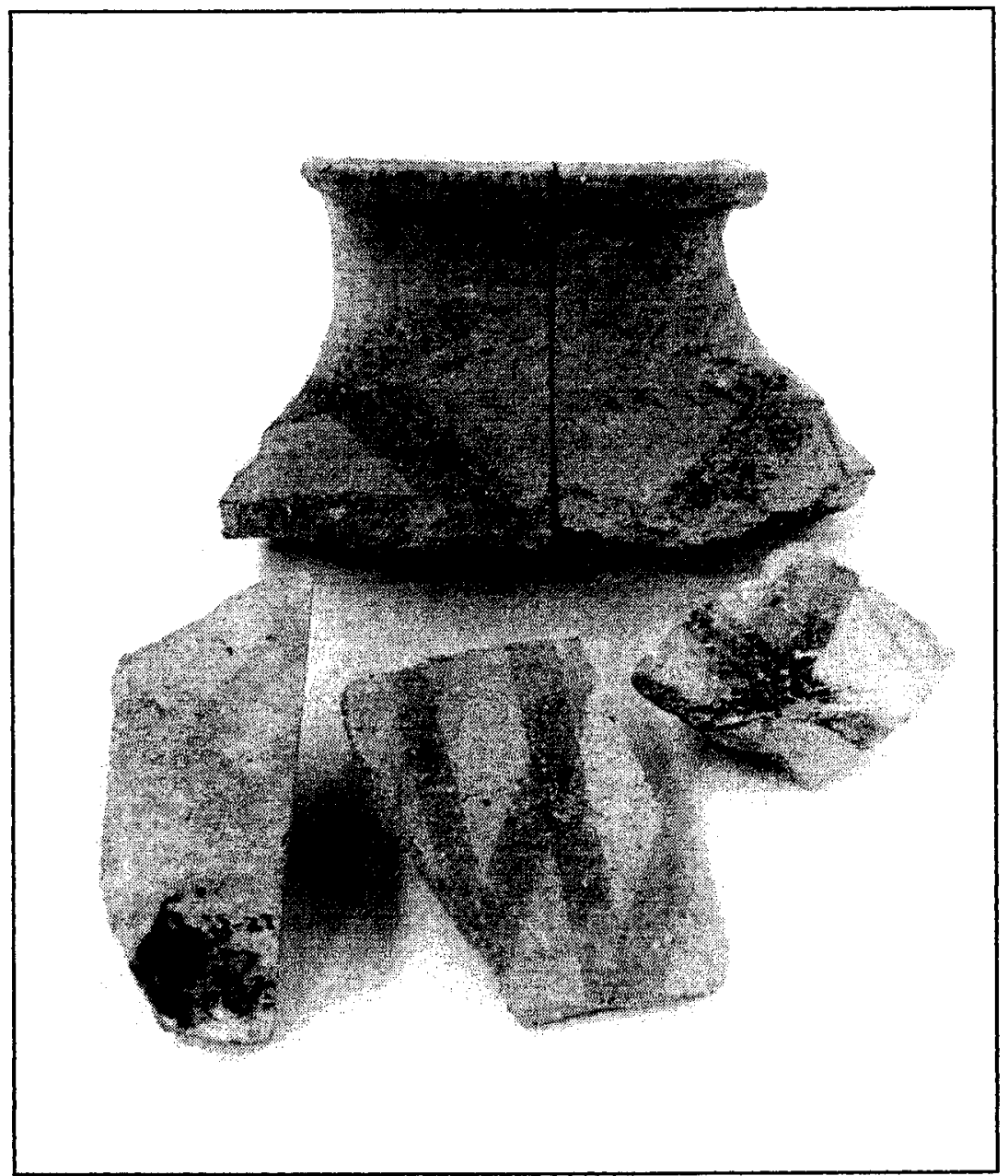

Fig. 32. Samples of Painted Decoration.

Clockwise from top: 142:3, 13:9, 8:6, 51:1. 
By searching the data outlined here and comparing them with previous work in the region, the temporal limits of the EBA horizon at Tell Ta'annek may now be approached. This is, in part, the task of the following chapter. 


\section{CHAPTER V}

\section{THE EARLY BRONZE AGE HORIZON AT TELL TA'ANNEK: A CERAMIC OUTLINE}

\section{Introduction}

Given the processes that shaped the EBA assemblage from Tell Ta'annek described in chapter 2, the stratigraphy from which it was drawn described in chapter 3 , and the categories of data clarified in chapter 4 , the next task becomes that of placing that assemblage into a larger chronological context. This is the primary challenge of the present chapter.

This discussion does not intend to give equal weight to every sherd in the assemblage. Full details may be gained from the plates and descriptions which illustrate and accompany this discussion. Rather, it is intended here to highlight only those significant changes of form, fabric, or finish which are suggestive of developments which may be temporally correlated and help to "fix" the EBA culture of Tell Ta'annek in its regional setting. Two steps are required to reach this goal: first, the ceramic evidence from individual loci are analyzed by field and phase, and second, a site-wide synthesis is offered. 


\section{Analysis by Field and Phase}

\section{Field A, Phase 1A (Plates 1 - 2)}

Analysis and summary (Field A, Phase 1A). Slipped holemouth bowl rims $(1: 1 ; 1: 2)$ in conjunction with handles in the form of a pierced lug $(2: 1)$, a knob $(2: 3)$, a strap (1:6), and a simple ledge (2:4) hint at the EB I residue which is regularly encountered in all fills on Tell Ta'annek. However, the varied and non-discrete nature of the data limits speculation concerning the correspondence between this ethereal presence and Joffe's early and late EB I phases (1993: 39-40), or, more specifically, Braun's three (or possibly four) phases of a "northern EB I sequence" (Braun 1996: 1045). Regardless, a necked jar rim (1:3) is judged to be intrusive.

\section{Field A, Phase $1 B$ (Plates 3 - 8)}

Analysis. Holemouth bowls and jars appear here in a wide variety of shapes and fabrics $(3: 1 ; 3: 3 ; 3: 4 ; 4: 2 ; 4: 3 ; 4: 4 ; 4: 5 ; 4: 9 ; 4: 10 ; 5: 2 ; 5: 3 ; 5: 4 ; 5: 5 ; 5: 6 ; 6: 1 ; 6: 2 ; 6: 3$; $6: 4 ; 7: 3 ; 7: 48: 1 ; 8: 2 ; 8: 3 ; 8: 4)$. While holemouth forms are generally poor chronological indicators, at Tell Ta'annek some trends may be observed. Most of holemouths in this phase are well fired and slipped in various shades of red and reddish-brown. This may be contrasted with holemouth forms from later phases which tend to be unslipped and poorly fired. Such trends have been noted by Esse (1991: 47) and Joffe (2000: 176) and may be taken with other indicators to suggest a basic distinction between EB $\|$ and EB III forms.

A deep bowl with a gutter- or "profiled"-rim (3:2) is paralleled regionally in Late EB I contexts at En Shadud (Braun 1985: Type 6); Tel Qashish (Zukerman 1996: Fig. VIII.10), and Megiddo (Joffe 2000: Fig. 8.4.14 and Fig. 8.5.5) among others. Similarly, a bow-rim pithos (5:7) finds ample representation in EB I contexts (Braun 1996: Table 
VI.D.9), as does a member of the GBW family (4:6) (e.g., Braun 1985: Fig. 19.7, 8). ${ }^{1}$

All bowl fragments are red slipped. Two deep bowls with inverted rims $(5: 8 ; 7: 1)$ could fit anywhere along the EB II-III spectrum. The same is true of jar fragments (7:5; 8:5). Three platter bowl fragments appear $(7: 2 ; 7: 7 ; 7: 8)$, all of which have more in common with EB II-III forms than local Late EB I forms (cf. with Megiddo material in Joffe 2000: Fig. 8.3.17, 18; or Fig. 8.5.3).

All bases are plain, flat, unevenly fired, and nearly uniform in diameter (ca. 18 $\mathrm{cm})$. Two exceptions are noted: the first is a base to a small jug or juglet (3:6), the second may have had a diameter that reached $40 \mathrm{~cm}(8: 8)$. Undoubtedly due to its large size, twine or rope was used during its construction, the imprint of which is still visible (London 1979: 10).

With the exception of one ledge handle (3:9), all handles here are simple loops. While a note of ledge-to-loop ratios is of little statistical value here, it does correspond with a site-wide trend. Such a trend informally underlines the observation that while ledge handle distribution is widespread at EBA sites in the southern Levant, it decreases in North Palestine (Amiran 1969: 40).

Finally, two groups of body sherds are identified. The first group is noted for its fabric, the second for its finish. In the first group are samples of $M W(4: 7 ; 4: 8 ; 7: 6 ; 8: 7)$. Recent work published on MW by Greenberg and Porat (1996) has proposed important definitions of form and fabric for this class of ware. Additionally, spatial and temporal limits of this distinctive ware distribution are offered. It is suggested that MW makes a first, substantial appearance in the EB II and continues, in a lingering way, through EB

${ }^{1}$ While common consensus identifies GBW as a primary EB I indicator, it is recognized that the latest appearances of this tradition are ill defined (Fischer 2000: 225). The same is true of Grain wash/Band slip decoration (Genz 2000; Mazar, ZivEsudri, and Cohen-Weinberger 2000: 267). 
III. Equally important is the analysis which concludes that the site of Tell Ta'annek marks the southern limit of large-scale distribution of this material. These conclusions substantially impact the present study beyond the discussion of body sherds associated with this phase.

In the second group of body sherds here are those with painted decoration. The first is irregularly painted with black lines (3:8) and is too limited in size to offer comment. The second, however, is painted red with a net or cross pattern (8:6). This latter technique of painting in wide, cris-crossing lines is known on jars from local contexts, e.g., at EB II Beth-yerah (Amiran 1969: Photo 53) or at EB III Megiddo (Joffe 2000: Fig. 8.11.15).

Summary (Field A, Phase 1B). EB I residues in this early phase of construction and use in Field A are identified. This is clearly true of exemplars from the GBW tradition (4:6) and the bow-rim jar (5:7). Other indicators, such as the platter bowls and combed MW, however, push for a later, EB II identification for this phase.

\section{Field A, Phase 1C (Plates 9-16)}

Analysis. Only a few holemouths in pink fabric with red slip are noted here (9:1; $9: 2 ; 14: 6 ; 14: 9)$. More prominent are plain, dense, unslipped forms with little or no thickening near the $\operatorname{rim}(10: 2 ; 11: 4 ; 11: 6 ; 11: 7 ; 12: 1 ; 12: 3 ; 12: 4 ; 12: 5 ; 14: 5 ; 14: 7 ; 14: 8$; $14: 10 ; 16: 2 ; 16: 3 ; 16: 4)$. Two anomalies stand out, however: one holemouth has plastic rope decoration near the rim (15:7); a second has a marginal band around the lip (12:2) and has a near-parallel at Megiddo (Joffe 2000: Fig. 8.5:8). Both are likely EB I residues. 
Small bowls with red slip continue $(11: 1 ; 14: 1)$. One large bowl or krater has a rim approaching a "hammer" shape (11:3) and is paralleled by larger forms at EB II-III Qashish (Zukerman 1996: Fig. 41.3; 43.11). A deep bowl in buff fabric appears with a shallow marginal concavity on the exterior face under the rim (11:2). Buff platter bowls with short triangular rims share these qualities and also appear here for the first time $(11: 12 ; 14: 3)$. These are slipped in red on the interior and rim and are irregularly burnished.

Small jars with sinuous necks (13:7) resemble earlier forms as do larger forms with rolled and everted rims $(9: 4 ; 12: 6 ; 13: 1)$. These are all in a pink to buff fabric with red slip. One unslipped form with unique profile does appear (9:3). Two necked jars with everted rims resemble MW forms, but are in "soft" CW fabric.

Represented MW forms include small (13:2) and large $(9: 5 ; 14: 2 ; 13: 13 ; 14: 4)$ platter bowls, deep bowls (13:3), and a necked jar (13:4). These are well burnished.

All bases are flat and are either CW with red slip $(10: 6 ; 13: 11 ; 13: 9 ; 15: 3$, and possibly 15:5) or are MW (11:9).

Loop handles predominate. Some are more rounded in section while others are flattened and approach a "strap"-like form. Other than a single MW loop (15:1), all are red slipped.

Three ledge handles appear in this phase. Two are red slipped (15:4) while the third shows flecks of a white wash (15:2). None are folded or "enveloped." A residual "knob" in GBW is also noted (10:5).

Two body sherds $(11: 10 ; 13: 9)$ are decorated with red cross painting. 
Summary (Field A, Phase 1C). The appearance of round-bottomed platter bowls, MW, and red-slipped MW forms in CW fabrics suggest an EB II context for this subphase. As elsewhere, EB I material is found residually.

\section{Field A, Phase 2A (Plates 17-34)}

Analysis. As in phase 1B, a variety of holemouth rims appears here. Several $(24: 6 ; 30: 8 ; 18: 8)$ closely resemble EB I forms and complicate the analytical task. Still, the obvious shift away from more delicately shaped, red-slipped forms to a thicker, less elegant, and unslipped vessel aligns with EB II tendencies.

Simple hemispherical bowls continue to be red slipped $(24: 1 ; 28: 1 ; 29: 1 ; 29: 2)$, although some MW forms now appear as coeval $(20.1 ; 20: 2)$. The latter are highly burnished, interior and exterior. In addition, a new slightly carinated bowl form appears (32:1). A possible parallel emerges from Phase III at 'Ai (Callaway 1980: Fig. 68.12).

A variety of forms of deep ledge-rim bowls and vats is attested. All are formed from buff to pink $\mathrm{CW}$ fabric; many have rough bases with scrape marks on the exterior wall (e.g., 18:1). Red slip and random burnish marks extend over the interior face and rim in many cases (e.g., 23:4). A pattern of radial burnish on the interior face is visible in select examples $(25: 2 ; 25: 7 ; 25: 8)$. One rim with painted lines is regarded as enigmatic at best, intrusive at worst (24:11).

MW and CW platter bowls exhibit care in manufacture. CW forms are slipped in red and are either pattern burnished or wiped, perhaps in imitation of true MW (20:5; $21: 8 ; 27: 6 ; 30: 2 ; 30: 7 ; 34: 2)$. A shallow marginal concavity under the rim appears and the base appears wet-smoothed and rounded. MW platter bowls are unslipped (or "selfslipped"), burnished, and wiped (26:8; $24: 2 ; 26: 8 ; 28: 7 ; 30: 3 ; 30: 4 ; 30: 6 ; 34: 3 ; 34: 4)$. A marginal concavity under the rim is slight or non-existent. This observation concurs with 
Greenberg's assessment of the EB II assemblage from Tel Dan (1996a: 101); however, unlike the assemblage from Tel Dan, the lip of platter bowls from Tell Ta'annek tends to be short.

Two small jug/jar rims appear (19:6;19:7).

Jars with simple everted necks are primarily formed of pink to buff CW and are unslipped $(17: 1 ; 24: 7)$ or red slipped $(19: 1 ; 29: 8 ; 29: 9 ; 32: 3 ;$ cf. $29: 9$ with Zukerman 1996: Fig. 26:6). GBW persists (32:4), as do larger versions of the CW jar $(25: 14,33: 5$; cf. Zukerman 1996: Fig. 25:3 and 6). A new form at Tell Ta'annek (21:4) appears here, possibly a necked "cookpot" (21:4). If so, this "non-holemouth" form compares to the "short-necked type with an out-turned rim" known from EB II Tel Dan (Greenberg 1996a: 102).

Jars with everted and folded necks appear in MW and in "softer" fabrics. Redslipped, CW forms are more upright and squared $(19: 3 ; 19: 4,22: 3 ; 26: 9 ; 29: 6)$, while MW forms have thin walls and are more splaying and tapered $(26: 12 ; 28: 5 ; 29: 10)$. One rim closely resembles a MW form, but appears here in unslipped buff fabric (19:5).

Similarly, all bases are flat and are formed in MW or in CW. Non-metallic ware forms are red slipped or white washed. In one example, the red slip extends to cover the bottom of the vessel $(33: 9)$. MW bases are combed $(22: 7 ; 33: 8)$ or white washed (19:13). Three short stump bases appear, one in CW (27:4), the other two in MW $(24: 12 ; 31: 4)$.

Loop handles dominate this phase. Nearly all are elliptical in section, nonmetallic, and red slipped. Exceptions in form include one vestigial loop (24:13), and two white-washed ledge handles $(20: 8 ; 34: 1)$. Exceptions in fabric include four MW samples: three loop handles $(23: 6 ; 28: 6$; and $29: 7)$ and, curiously, one ledge (31:7). This latter example is without parallel and defies the "streamlined symmetry and spare 
functionalism" associated with the corpus of MW (Greenberg and Porat 1996: 301).

Saved body sherds are almost all combed MW. Apart from these are undistinguished examples of two body sherds slipped in red $(23: 9 ; 32: 5)$ and an unidentified form (23:7) which could be a MB intrusive. Alternatively, it could be a rare ring base for a bowl. A possible parallel exists for such a ring base in the Proto-Urban stratum at Jericho (Hennessy 1967: PI. II.10).

Summary (Field A, Phase 2A). Trends previously established in Phase IA and B continue here with little or no modifications. Holemouth jar rims appear thick and unslipped. MW and CW platters and jars exist side by side. Stump bases are low and simple. Hence, despite the possibility of early $(E B I)$ and late $(M B)$ intrusives, all indications from this assemblage point to a clear EB II context.

Field A, Phase 2B (Plates 35 - 40)

Analysis. By this phase of development, all red slip is gone from holemouth rims. Only two are decorated; these are white washed $(35: 4 ; 40: 4)$.

Bowls appear in both CW (39:3) and in MW (37:1). A very small body sherd in the KKW tradition also appears here (35:2).

Jars with lightly everted rims are seen (35:5), as is one channel-rim jar which is still fairly squared and upright in stance (38:5). The form of the latter is clearly seen in late EB II contexts, albeit in MW fabric (Greenberg 1996a: 3.26.5 and 3.27.15; Esse 1991: 47). However, the question of the relationship between these MW forms and what appears to be local imitations in common ware may again be raised.

Jars with folded rims are represented in "soft" fabric and in MW. The latter forms are classic EB II in design $(38: 2,4)$, while some buff examples are more flattened and 


\title{
NOTE TO USERS
}

\author{
Page(s) not included in the original manuscript and are \\ unavailable from the author or university. The manuscript \\ was scanned as received.
}

This reproduction is the best copy available.

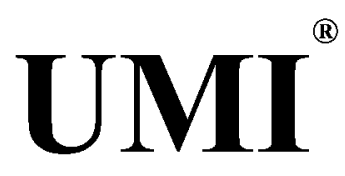


Field A, Phase 3A (Plates 41-79)

Analysis. Several bowls are found here. CW forms are unslipped (41:1;73:1; 76:2), slipped (78:1), burnished (43:2), or slipped and burnished $(66: 1 ; 67: 1 ; 71: 2)$. MW bowls are also attested (67:2) and were used as lamps (46:1). Deep carinated bowls $(52: 1 ; 52: 2 ; 62: 3)$ appear in a reddish brown fabric. These differ, however, from Beck's "deep bowls" or "goblets" (1985: 20-21). One bowl or krater in the KKW tradition (68:7) is noted. Finally, the growing tendency to ignore rough mold marks on the external face is noted in conjunction with a large bowl (70:1). In previous phases, some attempt is made to smooth these out or scrape them off. Here, all such pretense is gone.

Holemouth rims are sooty, numerous, and largely undifferentiated. Few are slipped or decorated; those that are may be EB I residue $(53: 7 ; 56: 3)$.

MW platters continue to appear alongside of "soft" CW platters, albeit in lesser quantity. The MW platters show little change from the previous phase. Most have a slight or no concavity under the $\operatorname{rim}(54: 2 ; 55: 2 ; 62: 7 ; 62: 8 ; 65: 1)$. One, however, shows many characteristics of EB III non-metallic forms including a significant concavity on the exterior face and radial burnish (42:7).

Non-metallic platters here achieve features typically associated with EB III forms (Esse 1991: 47-8; Greenberg 1996a: 103-4). Vessels are red slipped and are burnished in radial and net patterns (e.g., 42:8; 43:7; 48:10; 48:11; 53:10; 61:8; 77:10). Rim shape remains divided between those which are triangular or thickened (e.g., 42:8; 48:10) and those which simply are a carinated extension of the base (e.g., 48:9). The marginal concavity under the rim is present on some samples (e.g., 62:1) and absent on others (e.g., 53:10). As already seen, less effort is now given to smoothing the mold marks 
beneath the marginal concavity (e.g., 64:8; 77:10). This tendency becomes even more clear in the ledge rim bowls of this phase.

Many jars with slightly everted rims appear. All are CW and are fairly evenly divided between those that are unslipped $(41: 7 ; 44: 4 ; 50: 10 ; 52: 4 ; 53: 9 ; 55: 4 ; 58: 5 ; 60: 6$; $60: 8 ; 73: 7)$ and those that are slipped in red $(42: 4 ; 45: 2 ; 57: 2 ; 57: 4 ; 57: 5 ; 58: 6 ; 60: 9$; $63: 9 ; 65: 4 ; 65: 5 ; 65: 6 ; 69: 2 ; 77: 4 ; 77: 5)$. No innovations are readily apparent. A fragment of large GBW vessel (45:1) is considered residual.

Alongside a squared-lip channel rim jar in MW (60:12) is a channel-rim in "soft" fabric with a very tapered lip (76:5). This latter form illustrates in both fabric and shape the direction of channel rim development in the EB III period (cf. Esse 1991: PI. 4:J).

No significant morphological developments in necked jars with folded rims are noted here. The presence of MW, however, diminishes considerably $(52: 6 ; 60: 11$; 69:1). Corresponding in size and shape to the MW are red-slipped CW equivalents $(47: 2 ; 65: 7 ; 66: 5)$. Apart from these, folded rims appear as very blunt $(57: 3 ; 78: 6)$ to blunt $(41: 5 ; 47: 1 ; 57: 3 ; 63: 8 ; 66: 5 ; 78: 8)$ to tapering $(58: 8 ; 63: 6 ; 63: 7 ; 73: 6)$. No extremely flared rims appear as those which are assigned to the mid- to late-EB III stratum at Tel Dan (Greenberg 1996a: 3:34.3). One unique form may be a part of the EB II residue (75:6).

Few examples of MW are found among the ledge-rim bowls $(43: 1 ; 50: 3)$. Redslipped "soft" fabric forms predominate. These assume a variety of profiles. The slipped area includes the interior face and rim, which is often burnished (e.g., 50:1; 53:1; $67: 6)$, sometimes radially $(53: 2 ; 59: 1 ; 67: 10 ; 72: 8)$. On the exterior, a shallow marginal concavity is typical, usually marking the end of the slipped area (e.g., 62:9; 63:1). On larger samples where the area below the marginal concavity is preserved, no effort is made to smooth the obvious mold marks $(67: 10 ; 72: 8)$. 
No developments are noted in the large deep bowls, kraters, or vats $(55: 6 ; 70: 4$; $74: 3 ; 78: 9 ; 78: 10)$.

Flat bases in buff to pink common ware fabrics dominate this phase, although MW is still represented $(75: 8)$. Most striking are the short $(51: 4 ; 55: 5 ; 69: 6 ; 79: 1)$ to elevated $(57: 8 ; 71: 4)$ stump bases that appear here for the first time. While some elevated stump bases appear elsewhere in EB II contexts, they are more commonly fixed to EB III (Esse 1991: 48).

A variety of loop and ledge handles is assigned to this phase. Most are formed in buff to pink common ware fabrics, and in the case of the loop handles, are redslipped. Ledge handles appear as plain (64:3), wavy $(42: 6 ; 58: 9 ; 62: 5)$, or pushed up $(48: 5 ; 62: 4 ; 66: 7)$. One vestigial handle $(51: 8)$, probably from a MW jug, represents a new dynamic, whereas a high-loop cup or mug is residual EB I (Joffe 1993: 66).

A number of combed MW body sherds are a part of this phase $(45: 5 ; 45: 7 ; 45: 9$; $49: 5 ; 61: 6 ; 62: 6 ; 65: 9 ; 66: 8 ; 75: 9 ; 76: 9 ; 77: 8)$. Significant also is the presence of KKW $(52: 3 ; 79: 4)$

Summary (Field A, Phase 3A). EB II traditions remain influential, yet subdued or modified in this phase. Bowls, platters, jars, jugs resemble those in previous phases, yet real differences are noted. Mold-made forms in buff $\mathrm{CW}$ fabrics receive less attention, particularly in the finishing of bases. The appearance of MW diminishes. Channel-rim jars assume a more flaring shape, while elevated and slightly flared jug bases are seen. Finally, KKW continues to appear, albeit in small numbers. Taken as a unit, these tendencies strongly suggest an EB III context for Field A, Phase 3A. 
Field A, Phase 3B (Plates 80 - 87)

Analysis. Holemouth jars are quite undistinguished in this phase. What stands out initially are residual EB I forms $(80: 7,86: 6,87: 6)$.

No true MW platters survive into this phase. Platters which resemble MW have peeling red slips over common ware fabric $(81: 11 ; 87: 3 ; 87: 4 ; 87: 5)$. With the exception of $81: 11$, the exterior wall below the marginal concavity is rough and unfinished. Other platters here are thick, poorly executed, and underfired $(84: 4 ; 84: 6 ; 85: 8)$.

Likewise, ledge-rim bowls follow trends for platters in terms of form and fabric. No MW bowls are found. All are of "soft" buff to pink fabric, are red-slipped, and in the case of some, pattern burnished $(80: 1 ; 82: 1 ; 84: 5 ; 86: 1)$.

One channel-rim jar (80:3) has a tapered lip, as noted previously, a development associated with EB III forms from Beth-yerah (Esse 1982: PI. 9.39).

Several jars with folded, everted rims are a part of this set. One is possibly MW, although it is underfired (80:5).

Three exemplars stand apart from this group of flat bases of $\mathrm{CW}$ fabric. The first is from a small jug or juglet (85:7); the second is from a poorly fired MW jar (84:3). A third base is significant because of string-cut markings. While rare, there is precedence for this in EBA contexts (cf. Greenberg 1996a: Fig. 3:20).

A "vestigial" ledge is preserved on the exterior wall of what appears to be a carinated bowl (86:5). Other handles from this phase are undistinguished loop or ledge.

Combed MW $(87: 9,10)$ and interesting body sherds with plastic molding $(87: 8$, 80:5) are included in this phase. 
Summary (Field A, Phase 3B). Poorly executed platters and ledge-rim bowls, reduced numbers of $\mathrm{MW}$, and a tapered channel-rim all underline an EB III assignment here. Earlier intrusives continue to be seen.

Field A, Phase 4A (Plates 88 - 91)

Analysis and summary (Field A, Phase 4A). Due to the quantity and quality of the ceramic remains from this phase, little may be said by way of innovation. One MW jar rim (90:5) and base (88:6) stands apart from a corpus of "soft" CW forms. A slipped and radially burnished bowl (90:1) fits easily into an EB III context. These indications suggest an EB III assignment for this phase.

Field A, Phase 4B (Plates 92 - 103)

Analysis. A variety of holemouth jars appears here. Esse's observation (1991: 51) from the Beth-yerah materials that the fabric changes from dark and brittle in the earlier part of the EBA to a light buff in the later part of the EBA does not hold true with the Tell Ta'annek corpus. If anything, just the opposite seems to be the case; this is especially true when the EB I sample is included in the discussion. However, Esse's idea (1991: 51) that EB III holemouth rims tend to be more "squared-off" than their EB II counterparts does describe an observable trend $(92: 1 ; 95: 1 ; 95: 5 ; 97: 2 ; 98: 2 ; 98: 3 ; 99: 5$; 103:5)

Significant morphological change is most visible in platter bowls of this phase. First, as an inclination previously described, bases are left textured, unsmoothed, and unslipped. Second, the maintenance of a uniform vessel wall thickness is no longer a concern. Bases become quite thick and heavy below the marginal concavity (e.g., 97:9). Third, while in some cases the size of the rim above the carination is maintained, 
in other cases, it is reduced considerably (e.g., 93:2) or even misshapen according to "MW standards" (e.g., 98:1). The well-established pattern of slip and radial burnish continues to be seen here $(93: 2 ; 96: 2 ; 97: 8 ; 97: 10 ; 97: 11 ; 98: 1 ; 102: 9)$ as does poor firing methods that leave grey cores. A platter with a thickly molded flat base (102:6) finds a smaller near-parallel in the late EB III material from Tel Dan (Greenberg 1996a: 3.33.13), but may also be EB I residue (Joffe 2000: Fig. 8.3.18).

Changes which affected the platters in this phase also impacted ledge-rim bowls, vats, and/or basins. Rough exterior faces are seen (99:11), some bordering on the extreme (94:5). Body thicknesses are uneven. A marginal concavity continues to appear below the rim. Buff ware, red slip, and radial burnish continue without interruption.

A bowl with a rounded carination (94:1) may be consistent with an EB I or an EB III tradition (cf. Zukerman 1996: Fig. 41:2, unslipped), while another with sharp carination (93:4) fits cleanly in a late EB II/early EB III context, given its pink fabric, red slip, and unfinished base. Similarly, a very thin bowl with red slip on its rim and interior fits well into an EB III context (101:4) as do larger forms which are slipped and burnished (100:7; 103:1). Other bowl rims are unslipped, continuously burnished, and bear a resemblance to MW jugs $(93: 3 ; 99: 1 ; 101: 1,3)$.

Conclusions concerning lightly everted rims come with difficultly given the small sample size. Little new appears beyond the straight (99:7; 99:9; cf. Esse 1982: PI. 6:19) or sinuous profiles $(99: 8 ; 101: 6$; cf. Esse 1982: PI. 6:30) of the KKW tradition. One jar rim (96:5) resembles EB I forms, but has EB III parallels in the north (Esse 1982: PI. 8.2; PI. 9:37).

Everted and folded jar rims follow patterns established in the EB II, but, with one exception (96:4), are quite poorly executed. What was once shaped in crisp symmetry 
is now lumpy $(95: 6 ; 99: 6 ; 102: 4)$ and blunted $(95: 10,11)$. No thinned or "feathered" forms associated with the late EB III appear. One exemplar $(95: 8)$ is oddly shaped and may be a late intrusive; only a distant parallel can be found in Stratum XI at Qashish (Zukerman 1996: Fig. 38.27).

Little can be added to the discussion here beyond the presence of a MW jug base (99:10) and a small juglet (103:6).

Ledge and loop handles continue to appear. Only three may be highlighted. The first is in the KKW tradition (95:9) and the second is MW (100:6). These continue to underline an EB III context. The third handle highlighted is in a MW tradition (103:12).

Combed MW body sherds $(95: 7 ; 103: 10 ; 95: 2)$ appear in this phase as does a tiny body sherd in KKW style (undrawn).

Summary (Field A, Phase 4B). This phase demonstrates a clear overlap of the MW tradition and the KKW tradition. The deterioration of the quality platter bowls, ledge-rim bowis and jars is significant. Given the presence of MW and absence of late EB III indicators, an early- to mid-EB III assignment for this phase is suggested.

\section{Field A, Unphased Loci (Plates 104-106)}

Analysis and summary. Most useful indications here include a rather flaring jar rim (105:3), a large platter (106:4) with a degenerate lip and a deep ledge-rimmed bowl or basin (106:5). Comparison with forms from Stratum XV and XIV from Tel Dan suggest a mid- and possibly late-EB III assignment here. 
Field B, Phase 1A (Plates 107 - 108)

Analysis. Holemouth jars and bowls $(107: 1 ; 107: 2 ; 107: 4 ; 107: 6 ; 107: 7)$ are constructed of lightly colored fabric and slipped. These are plain without plastic decoration, and comply with EB I trends described above. Small jar rims $(108: 1,2,3)$ are red-slipped and slightly everted. These likely represent EB I amphoriskoi or "gourd jars" known at En Shadud (Braun 1985: Fig. 20:2, 4), Qashish (Zukerman 1996: Fig. 15.10), Megiddo (Joffe 2000: Fig. 8.1.1), and elsewhere.

Two ledge handles $(108: 5 ; 107: 3)$ and a tiny loop $(108: 6)$ with a possible parallel from Qashish (Zukerman 1996: Fig. 4:11) are present, as is a dark-slipped, wide strap handle (undrawn). The strap handle and base (108:4) are identical in fabric and slip and may come from the same vessel.

A body sherd with dark red slip and another with an elegant rope molding (undrawn) complete the assemblage from this phase.

Summary (Field B, Phase 1A). EB I materials dominate this preconstruction phase in Field B. A single MW platter bowl (107:5) may be intrusive or indicative of latest use (EB II).

Field B, Phase $1 \mathrm{~B}$ (Plate 109)

Analysis and summary (Field B, Phase 1B). The ceramic evidence from this phase is slight but conclusive. A straight-sided jar rim is suggestive of $E B \mid(109: 2)$, while other indicators including MW $(109: 4,6)$ and a sharply carinated bowl with pierced lug handle (109:5; cf. Esse 1991: PI. 1:C and D) point strongly toward EB II. 
Field B, Phase 1C (Plates 110 - 121)

Analysis. A number of holemouth jars appear, all unslipped (except 115:2), and many have a sooty residue on their exterior surface. Profiles vary, although one with a folded rim and squared lip appears frequently $(117: 9 ; 117: 11 ; 117: 12 ; 118: 2 ; 118: 4$; 118:6). Some of these may be from the same vessel. Also noted are a number of folded and rounded rims with rope molding decoration $(115: 1 ; 115: 7 ; 117: 5 ; 117: 8)$. Such decoration begins in the Chalcolithic period but finds continued expression in the EB I, particularly in the early stages in North Palestine (cf. Amiran 1969: 55; Braun 1985: 31; Joffe 1993: 39). One example (118:14) has a spout below the rope molding. A second spout is found on a squared rim, of which little else has been preserved $(116: 8)$

From this phase emerge a cluster of MW vessels. Platters are elegantly shaped and well fired. Some have a slight marginal concavity under the rim $(114: 4 ; 114: 6$; $114: 7 ; 114: 8)$, others do not $(114: 3 ; 114: 5)$. Regardless of the concavity, all exterior walls (bases) and rims are well burnished and the interior faces are wiped. Platters in $\mathrm{CW}$ are clearly imitative: they are slipped in red and burnished and demonstrate the same attention to the exterior wall (base) $(114: 2 ; 116: 1)$. All these fit squarely in an EB Il context as defined by Greenberg and Porat (1996).

Lightly everted jar rims are undistinguished. Most are red- $(118: 13 ; 120: 7)$ or white-slipped (115:4). One GBW rim (117:4) appears, as does an undrawn body sherd of the same tradition. These are viewed here as residual. The same may be said of an isolated bow-rim (112:6) and a possible amphoriskos fragment (120:6).

Folded jar rims fall into three categories. In the first category are buff ware rims with secondary buildup or "wave" on the neck $(111: 7 ; 111: 8)$. These are red-slipped 
and, interestingly, do not appear elsewhere on the site. Possible parallels include an unslipped rim from Qashish (Zukerman 1996: Fig. 52:14). In the second category are variations of a more upright and squared jar rim in buff fabric $(112: 2 ; 118: 10 ; 118: 12)$ which find parallels all along the EB II-III continuum (cf. Amiran 1969: PI. 16:7; Esse 1991: PI. 8:Z). In the third category are MW jar rims $(112: 7 ; 120: 5)$. One such jar rim has punctures around the neck and appears to have had a combed body. A close parallel is identified with the late EB II or early EB III strata at Tel Dan (Greenberg 1996a: Fig. 3.27.12).

Bowls from this phase are formed of "soft" CW $(110: 1 ; 120: 2)$ or MW (111:1). The latter appears rather shallow and may correspond with a "saucer" as defined by Greenberg and Porat (1996: Fig. 1:1). A buff bowl has soot on the rim suggesting use as a lamp (117:1). One tiny fragment may represent the rim of a carinated bowl (119:2). Most interesting is a small simple bowl formed on a flat surface (114:1), a unique form at Tell Ta'annek which finds no immediate parallels. A similarly formed, but much larger "flat platter" emerges in a late EB I context at Megiddo (Joffe 2000: Fig. 8.5.3).

Slipped and unslipped flat bases in buff fabric compose this phase. There is little of note beyond a well-preserved base in a MW tradition (113:4; cf. Esse 1991: Plate 1:Q).

A larger than usual number of ledge handles is associated with this phase. No comments, however, may be offered here by way of development. CW and MW loop handles also appear.

One body sherd in combed MW is noted (121:2).

Summary (Field B, Phase $1 \mathrm{C}$ ). An extraordinary number of sherd fragments associated with the EB I are revealed in fills from this phase. However, the presence of 
developed MW bowls, jars, and platters, together with the slight evidence of a nonmetallic carinated bowl and a MW jug, suggests an EB II context.

Field B, Phase 2B (Plates 122 - 130)

Analysis. Holemouth jars are unslipped, sooty, and largely undifferentiated. Early intrusives are easily identified by their shape, fabric, and slip (122:1; 125:4; $127: 1)$.

The set of everted and folded rims lacks distinctives and could fit easily into an EB II or EB III context. One pithoi rim, however, is worth noting for its unusually large size (126:4). It may be compared with an EB III example from Beth-yerah (Esse 1982: PI. 1:30). Another is likely an early intrusive (130:5).

Evidence of the degeneration of the EB III platter is visible here. Thickened and unfinished bases $(124: 3 ; 130: 13)$, flatter profile rims (123:4), and an overall decrease in technological investment are obvious. However, MW platters persist (125:2; 126:8; 128:2), most likely as residual debris.

A large ledge-rim bowl $(125: 10)$ is witness to the same degenerative dynamics as the platters.

Three KKW rims appear in this phase, two shallow bowls (124:1; one undrawn) and a deep bowl (124:2). Two red-slipped buff bowls are also a part of this phase $(126: 1 ; 129: 2)$. The final example is preserved down to its flat base.

The only exception to simple flat bases here are two very short stump bases $(127: 8 ; 130: 12)$. No tall or flaring stump bases appear in this phase. Two bases in MW $(125: 7 ; 127: 6)$ complete the set.

Handles are divided between ledge and loop. Two loop handles are well fired and are "metallic" in at least a general sense $(124: 6 ; 127: 7)$. One white-washed pierced lug handle (125:9) is likely EB I residual. 
Three other sherds are of interest here. The first appears to be the junction of a twin vessel (122:8), associated in a general way with the whole of the EB I-III spectrum (Amiran 1969: 58). The second is a small "teapot" spout, undoubtedly EB I (Amiran 1969: 43; Joffe 1993: 66 ). The third is a simple base, highlighted here because of its unusually brittle, porous clay (124:8). It is possible that this base is EB IV. Other EB IV sherds, including a fragment from a distinctive four-spouted lamp, were encountered in the Tell Ta'annek corpus in unstratified fills.

Summary (Field B, Phase 2B). Materials here appear mixed, with clear representation from the EB I, EB II, and EB III periods. EB IV evidence is slight at best, and may be disregarded. It therefore appears reasonable to suggest an EB III assignment for the latest use of Field $\mathrm{B}$, Phase $2 \mathrm{~B}$.

\section{Field C, Phase 1A (Plates 131 - 132)}

Analysis. Nearly all holemouth jar rims here are beveled and slipped and correspond to EB I holemouths found elsewhere on the site. Likewise, a slightly everted jar (131:1) may correspond to late EB I jars found commonly at Megiddo (Joffe 2000:

Fig. 8.1.11). A single platter appears (131:6) with a slight lip, but finished on interior and exterior faces. While it is possible to suggest that this is a late EB I form, platters of this type are most commonly associated with EB II-III strata.

Summary (Field C, Phase 1A). Excluding a single platter fragment, all forms appearing here could easily fit into an EB I association. Fills associated with this phase represent the preconstruction context of the structures revealed in Field C. 
Field C, Phase 1B (Plates 133 - 135)

Analysis and summary (Field C, Phase 1B). As above, the small sample, lack of powerful diagnostics, and a lingering EB I presence make definitive statements difficult here. However, four MW sherds $(133: 4,9,135: 3,5)$ along with a carinated bowl (135:1) suggest an EB II context.

Field C, Phase 1C (Plates 136 - 142)

Analysis. Holemouth jars are largely unslipped and of a dense dark fabric hinting at EB II-III; a few may be earlier (140:9; 142:2).

Platters and bowls include a well-burnished exemplar (141:13) and two carinated forms $(139: 1 ; 139: 2)$. Soot marks on the former carinated bowl suggest its use as a lamp.

A spouted holemouth appears (140:5) as does a fragment of a rim-handle $(141: 3)$

Simple and lightly everted jar rims are fairly ubiquitous; fabric and shape suggest one may have served as a necked cookpot (141:6). A close parallel is found in the EB II-early EB III materials from Tel Dan (Greenberg 1996a: 3.28.1). Necked jars with a folded rim are well represented. Two MW jars add to the identification of this phase as EB II. Of these, one (142:3) is particularly unique as it is well-preserved and painted in a pattern of wide red lines, cf. with unpainted, but incised example from Qashish (Zukerman 1996: Fig. 38.16). Apart from these are squared and upright folded rims in poorly fired common ware $(138: 3 ; 139: 9 ; 139: 10 ; 141: 9)$. Those with an extended upper corner are rather rare on this site $(141: 1 ; 141: 4 ; 142: 1)$. One form remains unidentified (138:6). 
All bases are flat and, apart from a variety of finishing techniques, are of little note.

Ledge and loop handles represent this phase. While impressed in various degrees, no wavy ledge handles appear. All are slipped and one approaches a vestigial state (142:7). Among loop handles, most are strap-like. One appears to have been formed as a pierced-lug (142:8).

What appears as a perforated "disk" is likely the join of a small twin vessel (139:14). Such twin vessels find ample representation in EB I-III contexts (e.g., Amiran 1969: PI. 15.11; Callaway 1980: Fig. 127.1; Homes-Fredericq and Franken 1986: No. 114; Esse 1991: PI. 9.A). A single body sherd of combed MW appears (137:8). Two small undrawn body sherds also are found here, one in a GBW tradition, the other decorated in a Grain-wash pattern.

Summary (Field C, Phase 1C). EB I residues continue to appear here as elsewhere. However, latest diagnostics from this phase include MW forms which support an EB II identification.

Field C, Phase 1D (Plates 143 - 142)

Analysis. Holemouth jars are generally in a dark, friable fabric. Three appear to have been slipped $(143: 3 ; 143: 8 ; 146: 8)$; the last has a preserved spout.

One MW platter appears (145:9) alongside a small buff platter well burnished on both interior and exterior faces (143:1). A highly fired carinated bowl is seen (144:4) as is a small fragment of a large ledge-rim bowl. As previously demonstrated, such platters and bowls are common components of EB II assemblages. 
A pithoi with corrugated neck and decorated in a Grain-wash pattern is likely part of the continuing EB I residue (144:3), as is a rail-rim without striations (145:6). Other inverted and everted rims add little to advance the chronological discussion.

All bases are flat and rather evenly divided between those that are slipped and those that are not. One base in common ware resembles a MW jug in form (144:7). Another base (146:5) is highly fired, but poorly preserved and is curious for two reasons. First, "bulging" clay rolls on the interior vessel wall are of technological interest; the applied exterior pressure used to form the base is suggested. Second, burn marks on the uppermost broken edges of the base suggest that the original vessel was broken in antiquity and used secondarily as a lamp.

Two handles here may be MB intrusives (144:5; 144:6); two others in red slip are more appropriate to the EBA. A single, wavy, ledge handle appears (146:3).

As elsewhere, combed MW body sherds are saved (144:8; 144:9; 146:1).

Summary (Field C, Phase 1D). All indications suggest an EB II context for this phase.

\section{Field C, Phase 2A (Plates 147 - 164)}

Analysis. A variety of forms, fabrics, and finishes appears among the holemouth jars from this phase. A high incidence of forms of lightly colored fabric, fairly well-fired, and slip finished is reminiscent of the preconstruction Phase $1 \mathrm{~A}$ of Area A $(148: 3 ; 148: 4 ; 156: 8 ; 160: 7 ; 162: 3 ; 163: 1 ; 164: 2)$. Like that phase, this one is associated with many construction fills. A large EB I residue is therefore expected, as soil and sherds are imported as part of the buildup effort. 
Platters are divided between MW and CW. Ledge-rim bowls are of the latter material. Among the MW platters, all are carefully shaped and burnished. Three possess slight concavities on the exterior face under the rim $(152: 6 ; 155: 7 ; 159: 10)$, four do not $(149: 10 ; 152: 8 ; 160: 1 ; 162: 2)$, and one is indeterminate (147:7). Among CW platters and ledge-rim bowls, all appear to have been red-slipped and burnished on the interior face and rim. Random (157:10), radial (153:2;156:3; 155:8), and net (156:2) patterns are visible. Some efforts to smooth bases of both platters and bowls are detected; additionally some bases are slipped $(150: 8 ; 155: 8 ; 157: 9 ; 158.2 ; 159: 2)$. Such efforts suggest a date of manufacture earlier, rather than later, in the EB IIIIII spectrum. A number of necked jars with everted and folded rims appear. MW forms vary between short (150:3; 159:4) and extended lips (151:7; 161:2). Non-metallic forms fall into sub-groups: some appear to imitate MW in color and in form (150:2; 152:3; 157:5); others have a relatively tall, upright neck and squared rim $(147: 8 ; 155: 2 ; 157: 2 ; 158: 3$; 162:6; cf. Esse 1982: PI. 14:20; Esse 1991: PI. 8.Z); still others are rolled directly from a very short neck $(148: 8 ; 151: 8 ; 151: 9 ; 155: 1 ; 157: 1)$. Members of this latter group (notably 148:8 and 155:1) may represent the category of rail-rim pithos (cf. Joffe 2000: Fig. 8.4.21; Engberg and Shipton 1934: 17, Type 16B-F), although striations visible on the lip and known from many EB I sites (Braun 1996: 199) are notably absent here. Braun (1996: 200) suggests the non-striated form of the rail-rim is late EB I and possibly restricted in distribution to the Jordan and Jezreel valleys. A corrugated neck from a pithos decorated in a Grain-wash pattern is likely EB I (158:4).

A jar with a pillar handle (162:10) could be associated with a late EB I or an EB II context (Joffe 1993: 66; Braun 1996: 222). According to a survey of distribution offered by Braun (1996: Map AJ), this form is more common in the southern Levant, and therefore makes a surprising appearance here. 
Two channel-rim jars appear, with red slip over buff fabric. One has a fairly short lip (152:4); the second is awkwardly large and blunted (152:2).

Simple hemispherical bowls, ledge-rims bowls, and vats are all of common ware fabric. Red slip and burnish are regular features. One large vat (159:1) has a rimhandle as a built-up extension of the exterior lip. As with platters from this same phase, attention in the form of smoothing or slipping is present as far as can be ascertained.

Finally with respect to rim fragments, the presence of three well fired and randomly burnished carinated bowls $(154: 2 ; 154: 5 ; 162: 1)$ is noted.

All bases from this phase are flat and are evenly divided between MW (149:7; $149: 9 ; 152: 5 ; 155: 6 ; 159: 9)$ and CW fabrics $(147: 10 ; 149: 5 ; 149: 6 ; 149: 8 ; 155: 5 ; 159: 11$; 161:4). One MW form is also combed (155:6); size and shape suggest others be identified with MW jugs $(149: 9 ; 157: 8)$. A short stump base (150:5), likely from a small globular jar, is exceptional in this class and finds parallels throughout the EB II-III spectrum (Esse 1991: PI. 8:V; Greenberg 1996a: Fig. 3.34.4).

Only two ledge handles $(157: 4 ; 162: 9)$ appear among this group of loop handles $(149: 3 ; 149: 4 ; 150: 4 ; 154: 9 ; 154: 10 ; 161: 5 ; 163: 7 ; 163: 9 ; 163: 10 ; 164: 6)$. All loop handles are formed of $\mathrm{CW}$ and are red-slipped. One may be identified with a highhandled vessel, or possibly a twin-vessel (163:8).

Among saved body sherds, all are plain (149:2) or combed MW (147:9; 147:11; $150: 6 ; 150: 7 ; 159: 7)$. One preserved fragment consists of the shoulder and lower neck of a MW jug (149:1).

Summary (Field C, Phase 2A). While some fragments here shift uncomfortably between EB II and EB III contexts, (e.g., channel-rims, net burnish on platters and 
bowls, a short stump base), there are no absolutely compelling EB III indicators. It is therefore suggested that this phase be assigned to an EB II context.

Field C, Phase 2B (Plate 165)

Analysis and summary (Field C, Phase 2B). Indicators from this phase are quite mixed. Late diagnostics include two large platters. The first $(165: 8)$ is quite worn, but appears to be poorly fired, with a roughly finished base and diminutive rim. The second (165:9) is better preserved, with a radial burnish over a dark red slip. These are likely EB III.

Field C, Unphased Loci (Plate 166)

Analysis and summary (unphased loci). A single example of $\mathrm{MW}(166: 6)$ is suggestive of an EB II context. No other diagnostics challenge this assignment.

Field D, Phase 1A (Plate 167)

Analysis and summary (Field D, Phase 1A). A single holemouth (167:1) and a flat base (167:2) in red slip suggest a general EB I-III assignment. No further conclusions may be drawn.

Field D, Phase 1B (Plate 168)

Analysis. A externally slipped and burnished bowl (168:1) finds late EB I parallels at Megiddo (Joffe 2000: Fig. 8.3.10 and 11). However, if evaluated on the rim form alone, this bowl could fit anywhere in the EB I-III spectrum.

Red lines painted on the base of a large jar (168:3) appear patterned in a Grainwash style, common to the Jezreel Valley in EB I (Braun 1996: 197-198). 
Summary (Field D, Phase 1B). Only a general EB I-III assignment may be suggested for this poorly attested phase.

\section{Field D, Phase 1C (Plate 169)}

Analysis and summary (Field D, Phase 1C). A single ledge handle is an insufficient chronological indicator. No conclusions may be drawn here.

\section{Field D, Phase 2A (Plates 170 - 178)}

Analysis. Latest-use platters in this phase point towards the end of the EB II-III ceramic spectrum at Tell Ta'annek $(171: 8 ; 171: 10 ; 172: 3174: 11 ; 177: 10)$. Poorly fired $\mathrm{CW}$ forms are irregularly shaped, have rough textured bases, and flattened rims. This trait-list corresponds with EB III trends identified elsewhere (Greenberg 1996a: 103-4). However, some elegant MW (176:5) and non-metallic (171:7) shapes continue to appear.

Round bowls, ledge rim bowls, holemouth jars, jars with lightly everted rims, and jars with folded everted rims from this phase offer little which is chronologically determinative. The presence of bow-rim pithoi $(175: 5 ; 176: 4)$ and a necked jar $(175: 6)$ is considered residual.

With respect to bases, little can be said here beyond the observation that these are divided between a MW jug (174:2), an enormous (?) MW pithos or vat (171:11), a combed vessel (174:3), and a buff vessel (174:4). A worn short stump base (171:5) is well suited to an EB III context (Amiran 1969: PI. 20:14; Greenberg 1997: Fig. III.3.14).

The bulk of the handles that make up this phase are looped. One loop springs from the rim (174:1) while the rest are indeterminate. None appear to be MW. Three ubiquitous ledge handles are also noted $(172: 2 ; 174: 5 ; 174: 6)$. 
A fragment of a neck and upper shoulder from a MW jug (173:10) and a curious form whose stance is questionable at best invite speculation (173:5). Striations on one side (inner?) suggest use as a grater. However, comparison with other possible graters (Greenberg 1996a: Fig. 3.28.13; Zukerman 1996: Fig. 17:4) reveals a different form and pattern. Greenberg has suggested a bed-model (personal communication, 1998). Comparisons may be drawn with furniture models found at Beth-yerah (Esse 1991: PI. 6) and Tel Dan (Greenberg 1996a: Fig. 3.38.12-13).

Summary (Field D, Phase 2A). Despite the obvious lack of KKW, it is proposed that this phase be assigned to the EB III. Other indicators, such as inferences drawn from platter development and the limited presence of MW, support this proposal.

\section{Field D, Phase 2B (Plates 179 - 184)}

Analysis. Simple and ledge-rim bowls make up the largest component of this phase. All are of "soft" CW fabric. Rims and interior faces are slipped and often burnished in horizontal (179:7), vertical $(181: 2 ; 181: 3)$, and diagonal movements (184:2). Rim lips appear flattened at times (179:7; 181:2). Exterior faces are quite textured and unfinished below a margin of smoothing (e.g.,179:1). These trends parallel the development of EB III platter bowls as described above.

In the case of the platters, additional notice is given to flattened lips (183:5), uneven body thickness (184:6), and a poorly executed carination fold (184:3).

Two slightly stumping bases in CW fabric (179:4; 183:8), a flat MW base (180:5), and a possible intrusive (181:5) were saved from this phase. In terms of chronology, these forms provide little information. 
A loop (179:5) and a ledge (182:1) handle are in common ware and are redslipped.

An example of rope molding on an upper shoulder fragment (of a jar?) (180:6) completes the description of this phase.

Summary (Field D, Phase 2B). All indications suggest that this phase be associated with the EB III.

\section{Synthesis}

The preceding discussion highlighted specific ceramic forms, fabrics, and finishes which correlate with developments from other sites in the region. These highlights now lend themselves to positing a site-wide framework for the EBA settlement at Tell Ta'annek.

\section{Stratum I (Early Bronze I)}

Stratigraphy. Residues associated with Stratum I are drawn from the deepest excavated areas in Fields $A$ and $C$. This material rests beneath and adjacent to the first phase fortifications (Subphases A-1A and C-1A). Similarly in Field B, deep fills beneath and adjacent to domestic areas give testimony to the site's earliest inhabitants (Subphase B-1A).

Ceramic inventory. While no architecture corresponding to the EB I period has yet been recovered or recognized, ceramic evidence associated with the period is widespread. Pockets of soil on bedrock in Field A hint at stratified remains, but yield a meager sample for analysis. EB I ceramic materials in subsequent fills offer a more substantial attestation of the period. This unstratified assemblage is large and 
enigmatic, including many aspects of form and ware identified with the EB I in North Palestine. GBW is represented, as are fragments decorated in Grain-wash style. A variety of red-slipped and well-fired holemouth jars is found, some with rope molding. Bow-rim and corrugated-rim pithoi, Gutter-rim (or "profiled") holemouth jars, "Gourd jars" (amphoriskoi), and high-handled cup fragments appear, as do distinctive features such as an occasional "teapot" spout or solid pillar handle. Only future excavation will reveal the nature and extent of this settlement.

\section{Stratum II (Early Bronze II)}

Stratigraphy. Architecture and materials associated with Stratum II are clearly witnessed in Fields A, B, and C. In the fortification systems revealed in Field A, two primary phases of construction and use (Subphases $1 B$ and $2 A$ ) are isolated by two phases of destruction and abandonment (Subphases $1 C$ and $2 B$ ). In Field B, a domestic area is built (Subphase 1B) and destroyed (Subphase 1C). In Field C, initial construction (Subphase $1 \mathrm{~B}$ ) is modified (Subphase $1 \mathrm{C}$ ), seemingly abandoned (Subphase 1D) and rebuilt (Subphase 2A). Evidence is only slight from Field D, but it is possible that here, too, a parallel outline may be suggested of construction (Subphase 1B) and destruction (Subphase 1C).

Ceramic inventory. While vessels in "soft," non-metallic, or CW fabrics account for the majority of the saved assemblage from Stratum II, it is the presence of MW that most clearly suggests an EB II assignment. As Greenberg and Porat (1996: 12) have demonstrated, only in the EB II does the floruit of a "full typological range" occur. At Tell Ta'annek, hemispherical bowls, deep bowls, carinated bowls, and platter bowls in MW are noted, as are jugs and juglets, channeled rim jars, necked jars with everted rims, 
pithoi, and vats. While it is difficult to isolate typological distinctives within the MW of Stratum II, it is clear that the percentage of MW diminishes appreciably when the earlier subphases are compared with the later subphases in Field A.

The quality of craftsmanship appears high throughout Stratum II, even in CW vessels. Careful attention is given to the bases of mold-made forms. Marks suggest scraping and cleaning, and at times such bases are even slipped. Radial, net, and random burnish patterns adorn the inner face of platters, bowls, jugs, juglets, and vats. The stump bases of jugs remain low, jar rims range from the fairly upright and squared to everted. Loop handles clearly outnumber ledge handles. Finally, apart from holemouth jars and bowls and an occasional white-washed jar, red slip is ubiquitous.

\section{Stratum III (Early to Mid- Early Bronze III)}

Stratigraphy. Stratum III is attested in all excavated fields. In Field A, the fortification system was modified (Subphases $3 A$ and $4 A$ ) and destroyed (Subphases $3 B$ and $4 B$ ) in two successive cycles before being abandoned entirely. In Field B, domestic structures were rebuilt (Subphases $2 \mathrm{~A}$ and $2 \mathrm{~B}$ ), following the established lines of Stratum II occupation. These, in turn, were destroyed and abandoned (Subphase 2C). Field C stratigraphy remains troubled, but may be associated with Stratum III in the final use and destruction phases of this area (Subphase 2B). Field D is unique in that the final use phases here (Subphase 2A) give way to abandonment (Subphase 2B), and do not exhibit the destructions witnessed in Fields A-C. The eclipse of settlement at EBA Tell Ta'annek appears to have been dark and prolonged. Not until the next millennium, in the MB IIC, is the site rebuilt by a new generation of settlers. 
Ceramic inventory. While continuing into Stratum III, MW is only lightly attested. Platters, bowls, and jar fragments appear. In most cases, these are identical to Stratum III forms, but in a few examples some degenerative qualities may be found.

In a separate, but much smaller trajectory, $\mathrm{KKW}$ is detected. Unlike MW which seems to have substantially impacted the ceramic inventory of Stratum II, traces of KKW are slight in appearance, repertoire, and influence in Stratum III.

$\mathrm{CW}$ vessels appear in numbers and are largely ubiquitous. As a trend, they tend to be poorly executed and poorly fired when compared to similar forms from Stratum II. Bases are rarely finished; platters are marked by exterior marginal concavities. High, flaring, stump bases appear on jugs. By the closing phase of Field A (Subphase 4B), the trajectory of degeneration is clear. Little attention is given to vessel thickness; awkwardly formed, poorly fired and finished forms dominate the assemblage. However, forms associated with Late EB III contexts are not present (cf. Tel Dan, Strata XIV), suggesting that the demise of settlement at Tell $\mathrm{Ta}^{\mathrm{c}}$ annek may have come earlier, rather than later in the EB III.

\section{Summary}

By isolating the EBA ceramic assemblage of Tell Ta'annek by field and phase, it is possible to present a discrete assemblage that is chronologically sensitive. As an assemblage of fragments drawn from a "living" tell (as opposed to tomb material), it offers enormous potential for advancing the study of EBA ceramics. This task is viewed as particularly acute, given how the monolithic EB II-III "block" continues to resist a finer analysis in the southern Levant.

Such analysis has been conducted and is presented in this chapter. Attention has been given to the categories of form, fabric, and finish, in light of larger EBA trends 
known in North Palestine. It is proposed that the initial settlement residues of Tell Ta'annek be organized into three strata. In the main, continuity, rather than discontinuity, characterizes this sequence. Stratum I, the least known and understood of the three, may be perceived only through the venue of ceramic study, as no associated architectural features were revealed by The Taanach Excavations. Typological study of these ceramics suggests that Stratum I be dated to the EB I. Evidence of the tumultuous period associated with the EB II was found in Stratum II. A particular irony develops out of the tension that may be imagined when one sets the relative stability of ceramic development seen here against a backdrop of fortification building, ashy destructions, and what must have been viewed as a dire period of political instability. Finally, Stratum III witnessed the eclipse of settlement at Tell Ta'annek and may be coordinated with the early to mid- EB III.

As intimated, this arrangement of data prompts many inferences about the nature of ceramic production, trade, and larger lifeway patterns in the EBA. Exploring some of these inferences is the subject of the next chapter and the final task of this work. 


\section{CHAPTER VI}

\section{LOOKING BACK, AROUND, AND FORWARD FROM \\ EARLY BRONZE AGE TELL TA'ANNEK}

\section{Introduction}

The present study has raised a number of issues, conclusions, and questions which require further comment. These are addressed in three concluding thrusts. First, the subject of ceramic fabrics is revisited as part of a brief review and critique of Glock's vision. Second, issues of local production and regional trade are raised with a view to persistent potters and the dynamics of resistance. Third and finally, suggestions for further study are offered in a context of new vistas.

\section{Looking Back from Tell Ta'annek: Glock's "Fabric Families"}

\section{The Agenda}

Within a year of inheriting oversight of The Taanach Excavations in 1970, A. E. Glock was already working to develop new formats for arranging, describing, and presenting ceramic data. This was a necessary step, he believed, as traditional archaeological reports communicated ceramic data in a relatively standard, yet incomplete, manner. The convention focused on profiles of vessel form and shape, critical for the typological work which dominated pottery study in the Levant from the 1930s onward; however, it rarely addressed technological or compositional details. This 
lack was significant for Glock in his quest to understand "the potter as bearer of a craft tradition as well as the role of ceramics as a reflector of the culture of the community" (Glock n.d. f). For him, clues for answering processual, technical, and even sociological questions were being overlooked. In retrospect, this quest for the link between technology and tradition may be viewed as one aspect of a larger attempt to introduce elements of "The New Archaeology" into the study of the Ancient Near East. The push to move ceramic analysis beyond typological and chronological issues may be felt in the work of Glock's immediate contemporaries, including Shepard (1956), Matson (1965), Franken (1969), Bullard (1970), and Rye and Evans (1976), among others.

Fortunately, Glock's journey is well documented through the early 1970 s. A number of unpublished papers, proposals, and correspondences are a part of The Taanach Excavations archives housed at the Palestinian Institute of Archaeology. These culminated in a 1975 Bulletin of the American Schools of Oriental Research article by Glock entitled, "Homo Faber: The Pot and the Potter at Taanach." As described above in chapter 2, some 25,000 potsherds from The Taanach Excavations (including the majority of those published here) were first sorted, sawn, and examined as part of that effort. Key to this agenda was developing criteria for classifying ceramic fragments synchronically by fabric, apart from form. Glock assumed that sets of potsherd fabrics, or "families," as he termed them, shared qualities of likeness that could be detected through a macroscopic observation of a sawn section, noting the nature of clays, inclusions, and voids.

This forward-thinking agenda was reasonable in many respects. Work in the early 1960 s and 1970 s had raised the possibility of detecting and describing unique petrographic "fingerprints" of ceramic ware. Moreover, the promise of identifying the 
material sources for ancient potters was a new and enticing avenue for understanding the potter's "craft tradition" in local and regional contexts.

\section{An Unreached Goal}

Unfortunately, despite an enormous investment of energy, the agenda proposed by Glock for the Tell Ta'annek materials was never realized. Reasons for this are many, and certainly Glock's untimely death played a part. ${ }^{1}$ Still, it is suggested that his agenda ultimately fell short for three reasons.

First, the proposed study was impractical simply from the perspective of time.

This is certainly true when one considers that Glock's plan initiated the sawing of about 25,000 sherds, of which some 6,000 were viewed as stratigraphically significant. All 25,000 sherds were sawn; how many of these were actually examined or sorted is not known. What is known is that the time and energy required to handle and record the data, much less analyze it at the proposed level of detail, could only be accomplished by a trained team of researchers and even this would have required tens of thousands of man-hours.

Second, Glock's agenda assumed that the fabric profile was controlled by the potters. Certainly, many elements of the production process would have been controlled insofar as time, opportunity, and levels of skill allowed. This cannot be denied. In fact, it is likely that "mental templates" or "blends" of clay, temper, and grog types and densities existed for fabric components just as patterns existed for vessel shape. In many cases, such "blends" were tried and tested over the course of generations and were even

${ }^{1}$ For one perspective on the story of Glock's life and contributions, see the essay, "Albert E. Glock (1925-1992): A Remembrance," by Silberman in the Glock Memorial Volume (Kapitan 1999). For a focused investigation into the mystery of his death, see Fox (2001). 
specific to particular vessels destined for a particular use. As an example, a high concentration of large grains of crushed calcite is crucial to provide the expansion and contraction properties for vessels, such as holemouth cookpots, placed on an open fire. Still, the presumption that these variables are constant enough to provide an organizing force, at least in the case of $\mathrm{CW}$, may be questioned. Access to suitable raw materials by EBA potters may not have been regular, and hence not controllable. Less-than-ideal materials were substituted at times (and could be substituted given the fact that most EBA vessels were handmade-not wheelmade-and generally fired at lower temperatures). Add to these variables the different levels of skill attached to particular potters, or even the distinction between vessels produced in household or small-scale context (with less homogenous qualities) and vessels produced in large(r) scale production centers (with more homogenous qualities). In short, it is likely that the degree of control by EBA potters was uneven in time and place. This unevenness may or may not have been noticeable at a glance, but becomes more profound as the scale of examination is magnified.

Third, Glock's agenda was unworkable because it assumed that macroscopic inspection could reveal the nature of ceramic fabrics and facilitate their sorting. Features considered "visible and measurable" included fabric color, type, size and density of non-plastics, and core. These were judged by the naked eye, or by use of a $7 \times$ comparator as proposed and practiced. Such work resulted in a total of 25 EBA, 15 MBA, and 35 LBA basic "Fabric Families," and a proliferation of subfamilies (1975: 15). In order to revisit the validity of these assumptions, a thin-section analysis of samples from 24 of Glock's 25 "Fabric Families" was commissioned by K. Nashef at the Palestinian Institute of Archaeology and conducted by T. Salem. The results are presented in Appendix IV. In short, this microscopic examination suggests that Glock's 
"Fabric Family" sets and subsets be reduced to six major clay groups used in concert with five major groups of additives. A close reading of this new analysis demonstrates that compositional variations exist within a single "family" as proposed by Glock and that the assemblage of additives is diverse and difficult to predict. These three reasons suggest why Glock's proposal for organizing the Bronze Age ceramic assemblage from Tell Ta'annek fell short and that arranging a large assemblage by "Fabric Family" remains a theoretical enterprise.

\section{The Legacy}

While these weaknesses detract from Glock's work only as they relate to a single proposal, his innovative thinking and contribution to the field are not to be ignored. In fact, three examples suggest the impact of his legacy. All are connected, in part, to the building of a heightened awareness towards ceramic technology. The first example may be seen in W. Rast's publication, Taanach I: Studies in the Iron Age Pottery (1978). Here, a very rich description of ceramic fabrics is offered, including cores, colors, and non-plastic inclusions. Additionally, the conventional presentation of ceramic profiles is given a new look: a properly stanced, high-quality photograph of the sherd is inserted into the ink drawing. Additional details not communicated in tabular form are offered via the photograph. Not surprisingly, Glock served as editor for this first volume of The Taanach Excavations final publication series.

A second example of Glock's impact is recognized through the work of an emerging generation of archaeology students who studied with him at Birzeit University. The work of M. G. H. Ziadeh, H. Salem, T. Salem, N. Jelal, and M. Muqbil, among others, continues to be seen. Their original thinking rests, in part, upon foundations of cultural tradition and change established by Glock. 
A third and final example of Glock's impact may be gathered from a Memorial Volume recently published in his honor (Kapitan 1999). Focused studies by colleagues and former students in this work highlight issues that touch upon Glock's interests in many ways.

\section{Looking Around from Tell Ta'annek: Persistent Potters and the Dynamics of Resistance}

The conservative nature of the potting tradition has been frequently discussed in Old and New World archaeological contexts (e.g., Voyatzoglou 1974: 24; Franken 1982: 142; Wood 1990: 85-6). Reasons offered to explain this conservatism are typically linked to minimizing the risk of failure (Arnold 1985: 229-30), although functional requirements and cultural conformity must also play a role (Wood 1990: 58) as do issues of technology.

Understanding this conservatism is significant for the present study, as stability, rather than change, dominates the EBA ceramic inventory from Tell Ta'annek. This has been demonstrated here in virtually every category of CW: holemouth (or neckless) jars and bowls, hemispherical bowls, platter bowls, carinated bowls, jugs, and vats. In many cases, isolating the subtle features that suggest categories of temporal sensitivities (e.g., late EB I, early EB III, etc.) remains a difficult, if not impossible task.

The same could be said of other sites in EBA North Palestine, particularly when examining EB II-III assemblages. One need only to survey the limited publications from sites such as Megiddo, 'Affula, Tel Qashish, Beth-shan, Beth-yerah, Hazor, Dan, and Qishyon, among others, to sense this difficulty.

Fortunately, steps toward resolving this impasse continue to be made, not on the basis of common ware alone, but by viewing this ware in conjunction with that which is 
strikingly new or "disruptive" in the EB II-III ceramic inventory: Metallic Ware (MW) and Khirbet Kerak Ware (KKW). Proposals for these ceramic classes suggest that neither tradition was indigenous to the Jezreel Valley, but associated with the larger movements of people-groups (Esse and Hopke 1986: 327-8, 332; Greenberg and Porat 1996: 20). ${ }^{1}$ This is a beginning point for placing Tell Ta'annek in the larger context of EBA North Palestine.

\section{Tell Ta'annek, Early Bronze II, and Metallic Ware}

The Numbers. From a ceramic perspective, it is difficult to underestimate the influence of MW in EB II North Palestine. Greenberg and Porat (1996: 11) have gathered the limited data to build an impressive case for MW production and distribution. Petrographic study indicates the geological provenance for MW fabric is centered in outcrops of the Lower Cretaceous Hatira formation in the Anti-Lebanon range. From this center, the distribution of MW radiates outwardly. In some sites, MW dominates "to such an extent that it is difficult to identify any local industries (with the exception of cooking-pot manufacture) within a radius of some $30 \mathrm{~km}$ " (Greenberg and Porat 1996: 19). At Tel Dan, Rosh-haniqra, and Me 'ona, for example, MW accounts for more than 85 percent of the relevant assemblages. Elsewhere, these percentages shift, decreasing generally as one moves away from the proposed source region. At sites relatively near Tell Ta'annek such as Tel Qashish, Qiryat Ata, Qishyon, and Beth-yerah (Khirbet Kerak), however, MW still accounts for 50 percent or more of informal sherd counts. It appears that the Jezreel Valley formed a southern distribution limit for MW, as only isolated finds are documented beyond it to the south.

${ }^{1}$ This is not to say that neither was imitated in local technique. For imitation MW, see below. For imitation KKW, see Esse 1991: 52 and Mazar, Ziv-Esudri, and CohenWeinberger 2000: 262. 
Given the methods by which the ceramic assemblage from Tell Ta'annek was shaped, it is difficult to invest much weight into statistical conclusions. Still, raw counts remain informative and suggestive. Of the total phased EB II-III assemblage analyzed in this study, approximately 11 percent is MW (Table 6). This number, however, is raised to 17 percent, if all holemouth vessels (jars and bowls) are eliminated from the larger set. ${ }^{1}$ Isolating the EB II (Stratum II) from EB III (Stratum III) assemblage and eliminating the holemouths may also prove informative. This effort raises the frequency of MW within the EB II sample still higher to 20 percent. When effected within the EB III sample alone, the frequency drops back down to 12 percent. Such data may be arranged to support many inferences. Three are offered here, beginning with the least speculative.

A Metallic Ware curve. First, it may be inferred that Tell Ta'annek fits into the larger pattern of appearance, floruit, and decline of MW. Little can be made of the EB I material in the assemblage, but it is clear that MW is introduced in moderate quantity into the EB II stratum. The term moderate is significant, as reports have hinted that Tell Ta'annek is the southernmost EB II site reporting "large quantities of Metallic Ware" (Greenberg and Porat 1996: 11, cf. Esse 1982: 213-7). Compared to figures of 50 percent (or more) reported for other EBA assemblages in North Palestine, the 20 percent figure for Stratum II may hardly be considered overwhelming. Still, it must be remembered that Tell Ta'annek represents the edge of a meaningful distribution limit: "no site south of the Jezreel Valley has produced anything more than isolated vessels in

${ }^{1}$ The rationale for this rests in the fact that the fabric of MW is not suited for the tasks typically associated with holemouth vessels (i.e., the direct heat of a cooking fire) and therefore would never be used (or substituted) for a holemouth bowl or jar.

It is also necessary to eliminate the holemouths to fairly compare data here with those presented by Greenberg and Porat (1996), as seen below. 
TABLE 6

METALLIC WARE IN THE TELL TA'ANNEK

ASSEMBLAGE BY STRATUM

\begin{tabular}{|c|c|c|c|c|c|}
\hline \multicolumn{6}{|c|}{ STRATUM II (EB II) } \\
\hline $\begin{array}{l}4: 7 \\
7: 6 \\
8: 7 \\
9: 5 \\
11: 9 \\
13: 2 \\
13: 3 \\
13: 4 \\
13: 13 \\
14: 2 \\
14: 4 \\
18: 10 \\
19: 5 \\
19: 14 \\
19: 15 \\
19: 16 \\
20: 1 \\
20: 2 \\
21: 7\end{array}$ & $\begin{array}{l}22: 7 \\
24: 2 \\
24: 12 \\
26: 8 \\
26: 12 \\
28: 5 \\
28: 6 \\
28: 7 \\
29: 7 \\
30: 3 \\
30: 4 \\
30: 6 \\
31: 3 \\
31: 4 \\
31: 7 \\
32: 6 \\
33: 8 \\
33: 10 \\
33: 12\end{array}$ & $\begin{array}{l}34: 3 \\
34: 4 \\
35: 6 \\
37: 1 \\
38: 2 \\
38: 4 \\
38: 9 \\
38: 10 \\
40: 1 \\
107: 5 \\
109: 4 \\
109: 5 \\
109: 6 \\
110: 2 \\
111: 1 \\
112: 1 \\
112: 7 \\
112: 8 \\
113: 5\end{array}$ & $\begin{array}{l}114: 3 \\
114: 4 \\
114: 5 \\
114: 6 \\
114: 7 \\
114: 8 \\
117: 3 \\
120: 1 \\
120: 5 \\
121: 2 \\
133: 4 \\
133: 6 \\
133: 9 \\
135: 5 \\
136: 4 \\
136: 5 \\
136: 9 \\
137: 8 \\
139: 3\end{array}$ & $\begin{array}{l}142: 3 \\
144: 8 \\
144: 9 \\
145: 9 \\
146: 1 \\
147: 11 \\
149: 1 \\
149: 2 \\
149: 7 \\
149: 9 \\
149: 10 \\
150: 3 \\
150: 6 \\
150: 7 \\
151: 7 \\
152: 5 \\
152: 6 \\
154: 2 \\
154: 5\end{array}$ & $\begin{array}{l}155: 4 \\
155: 6 \\
155: 7 \\
157: 8 \\
159: 4 \\
159: 6 \\
159: 7 \\
159: 10 \\
159: 9 \\
160: 1 \\
161: 2 \\
162: 1 \\
162: 2 \\
163: 4\end{array}$ \\
\hline \multicolumn{6}{|c|}{ STRATUM III (EB III) } \\
\hline $\begin{array}{l}41: 9 \\
41: 11 \\
42: 7 \\
43: 1 \\
44: 6 \\
45: 5 \\
45: 7 \\
45: 9\end{array}$ & $\begin{array}{l}46: 1 \\
47: 3 \\
47: 7 \\
49: 5 \\
49: 8 \\
50: 3 \\
50: 4 \\
51: 8\end{array}$ & $\begin{array}{l}52: 6 \\
54: 2 \\
55: 2 \\
58: 11 \\
60: 11 \\
60: 12 \\
61: 4\end{array}$ & $\begin{array}{l}61: 6 \\
62: 6 \\
62: 7 \\
62: 8 \\
65: 1 \\
65: 7 \\
65: 8\end{array}$ & $\begin{array}{l}65: 9 \\
66: 8 \\
67: 2 \\
69: 1 \\
75: 9 \\
76: 8 \\
76: 9\end{array}$ & $\begin{array}{l}84: 3 \\
88: 6 \\
90: 5 \\
95: 2 \\
95: 7 \\
103: 10 \\
103: 12\end{array}$ \\
\hline \multicolumn{6}{|c|}{ UNPHASED } \\
\hline $\begin{array}{l}125: 2 \\
125: 7\end{array}$ & $\begin{array}{l}126: 5 \\
126: 8\end{array}$ & $\begin{array}{l}127: 4 \\
127: 7\end{array}$ & $\begin{array}{l}128: 2 \\
166: 6\end{array}$ & $\begin{array}{l}171: 11 \\
174: 9\end{array}$ & $\begin{array}{l}176: 3 \\
176: 5 \\
180: 5\end{array}$ \\
\hline
\end{tabular}


Metallic Ware" (Greenberg and Porat 1996: 11). Reasons for this will be surmised in a moment, but as a beginning point, two basic facts are clear: Tell Ta'annek is at least $100 \mathrm{~km}$ distant from the region where MW was likely produced, and, ethnographic parallels suggest that while $100 \mathrm{~km}$ is a distant stretch, it is a reasonable distance for the operation of ceramic distribution systems in a pre-industrial peasant society (Wood 1990: 60-70). Hence, if there is any surprise connected to the appearance of MW at Tell Ta'annek, it is not a question of timing, but of frequency. Why is there not more MW at Tell Ta'annek? Is the explanation rooted in sheer distance from the source region, or is there something else?

With respect to the issue of abatement of MW, Greenberg and Porat have suggested that "at sites with EB III occupation, the relative quantity of Metallic Ware is drastically reduced" (1996: 12). Here, little adjustment is offered. Tell Ta'annek certainly evidences EB III occupation. Furthermore, when comparing the appearance of MW from Stratum II (EB II) with Stratum III (EB III), there is a reduction of some 60 percent in total sherd counts (excluding all holemouths). Even within a limited sample, this would seem to qualify as a "drastic" drop. Hence, while total occurrences are smaller than expected, Tell Ta'annek fits into the larger known pattern of appearance, floruit, and decline of MW. This first inference is essential for the building of a second.

The end of the line. It may be argued on the basis of the MW distribution and frequency that Tell Ta'annek was positioned on the fringe of a powerful system of distribution. That such a system existed is without question. ${ }^{1}$ The sheer numbers of MW enveloping such a large region attest to the fact that this is no isolated or accidental

${ }^{1} \mathrm{H}$. Pirenne (1937: 219) suggests, "It is not the existence of trade and commerce which requires examination, but their scale and nature." 
feature. In fact, it may be suggested that this is a purposive, mass-produced commodity on a scale that is relatively unmatched in the whole of the Levantine Bronze Age.

Greenberg's "colonizing process" (Greenberg and Porat 1996: 20) is a reasonable step for understanding the social matrix of this phenomenon; ${ }^{1}$ the innundation of MW may be accounted for by an influx of new people with new technology. ${ }^{2}$ As such it may be described as an imported, rather than an indigenous, development. The process of abatement, however, appears more complex, as the "competition and regional disintegration" (Greenberg 2000: 194) associated with MW sites may be linked to forces detected in the EB III that are even larger than North Palestine. Other unanswered questions involve the basic identity of the "colonizers," the direction from which they came, motive for the moving and "colonizing" this particular area, the variations of MW intensity within North Palestine, or, perhaps most vexing, the reality of a "MW culture" with explicit material correlates that go beyond one particular technology or type of pottery. Such questions are always easier to ask than answer, and ultimately it must be remembered that the process of MW production and distribution is a phenomenon without a recognized EB I antecedent, without a recognized EB II-III parallel, and without a recognized EB IV legacy!

The core region where MW was produced is located on the slopes of the AntiLebanon range (Greenberg and Porat 1996: 18-9). Centralized workshops powered by

'Boardman has recently written, "The word "colony," like polis, has acquired an almost mystic meaning in modern scholarship, effectively categorizing what was in fact a very diverse phenomenon and excluding other enterprises in which people traveled and settled far from home" (2001: 39). How Greenberg intends "colonizing process" to be understood here is not made explicit and demands further attention.

${ }^{2} \mathrm{~A}$ dismissive response to Greenberg here on the grounds that it suggests a "pots to people" seems faddish. We await Joffe's forthcoming article which presents an alternative "scenario of mutually reinforcing ceramic and commodity exchange" (Dessel and Joffe 2000: 43). 
specialized labor manufactured and controlled this process. Such conclusions are based on geological survey, limited survey work, and inference. Unfortunately, as long as the tension of current political realities is maintained in this region, many questions of provenance and distribution patterns will continue to go unanswered. In the meantime, other angles of thought may take advantage of what information is available.

Wood has sketched a general model for diffusion as he considers the movement of ceramic wares from workshop to market, to itinerant merchants, to household (1990: 74-7). Considerable ethnographic data are mustered to support this model. While many aspects of Wood's discussion are beyond the scope of this work, his presentation of the "itinerant merchant" may be most relevant. This becomes clear when one considers the observation of Hodder and Orton (1976: 57) that markets will not likely be sustained when separated by distances greater than $10 \mathrm{~km}$ (cf. Wood 1990: 73). On the other hand, a merchant wisely positions himself between the producer and the consumer and plies his wares along major roadways. Little imagination is needed to picture such an operative, traveling by foot or pack animal, transporting quantities of MW from workshops or markets to local villages.

The position of Tell Ta'annek lends itself to such musing. "Backed" into the hills of Samaria, yet "facing" the open Jezreel Valley and astride the southernmost road in the valley, the inhabitants of the site could easily be networked into patterns of interaction in North Palestine. In fact, the map of principal sites with MW composited by Greenberg and Porat (1996: 11) reveals a settlement string following the principal roadway southeast from the Plain of Acco, under the shoulder of the Carmel ridge, and into the Jezreel. This string veers inland to Qiryat Ata, Tel Qashish, Tel Yoqneam, Megiddo, and ends at Tell Ta'annek. The raw distances between these sites vary slightly, but in the main, each is evenly spaced with an average separation of less than 
$10 \mathrm{~km}$. The additional observation that MW percentages drop with distance as one moves south along this road (and away from the area of production) may even be tentatively supported, although full publication is needed for confirmation. At Qiryat Ata and Tel Qashish, MW constitutes a significant percentage of the relevant ceramic corpora, perhaps exceeding 50 percent (Greenberg and Porat 1996: 11). On the other hand, there is a "relative dearth" of MW at Megiddo (Joffe 2000: 183) that continues to demand explanation. ${ }^{1}$ Finally, at route's end is Tell Ta'annek, with a MW sample weighing in at 20 percent, as reported above.

The notion that Tell Ta'annek was located on the fringe of a system of MW distribution supplied by itinerant merchants may also be supported when a closer look is given to the repertoire of MW forms found on the site. Recognized vessel types that appear within the assemblage include platter bowls, necked jars, carinated bowls, ledgerimmed bowls, channeled-rim bowls, simple bowls, and jugs. When this list is compared to an inventory of principal MW forms compiled by Greenberg and Porat (1996: 6), it becomes clear that many of known MW vessel types are accounted for at Tell Ta'annek. However, not all types are recognized. Notably absent are small and large vats and small, squat jars. ${ }^{2}$ Also worth noting is the fact that recognized forms do

'The poor showing of MW at Megiddo is termed "remarkable" by the excavator (Joffe 2000: 183) and is a part of the larger challenge of separating EB II from EB III at this controversial site. Kenyon (1958) was convinced that Megiddo was only lightly populated in this period, a conclusion that Esse suggests may simply be a result of a limited sample (1991: 74).

Recent excavations at Megiddo have expanded this sample considerably. However, while refinements have clarified the late EB I presence (Level J-5) and early EB III presence (Level J-6), there remains little else between (Joffe, personal communication). Not only is the expected MW inventory missing, so are other diagnostic EB II forms. It may be that Kenyon was right after all.

${ }^{2}$ These may be present in body fragments, but unrecognized. Many combed body fragments are present, however, and these may be from large jars or vats. 
not appear with equal frequencies. ${ }^{1}$ By far, the most persistent MW fragment is the platter bowl, which, by itself, accounts for nearly 30 percent of the entire MW sample. Other kinds of bowls bring this number up to 37 percent. Closed forms include necked jars with everted and folded lips, accounting for 18 percent of the sample, and jugs and juglets which represent about 3 percent of the total. Unidentified handles, bases, and body fragments account for the balance.

As open vessels would be a poor choice for commodity containers, it is logical to suggest that many, if not all, of these MW forms, were imported not because of products they contained, but because of their innate value as commodities. All indications--the clay used to produce MW, the high temperatures which fired it, and the high standards of quality evinced by the ware, the uniformity of shape, the range of vessel types-suggest a superior product. This becomes obvious when MW vessels are aligned with comparable $\mathrm{CW}$ vessels. In fact, it is highly likely that some $\mathrm{CW}$ vessels were red slipped and burnished in a deliberate effort to imitate MW. ${ }^{2}$ This "desirability factor" may account, in part, for the wide diffusion of MW and would have had profound consequences for local potting traditions and their producers. Undoubtedly, some

${ }^{1} \mathrm{MW}$ platter-bowls and jars/pithoi dominate the assemblages elsewhere. Compare these figures to samples totaled from Tel Dan, Tel Te'o, Tel Qashish, Tel Yoqne'am, Hazor, Gamla, Rosh-haniqra, and Beth-yerah by Greenberg and Porat (1996: 14).

${ }^{2}$ This is clearly seen in the example of platter bowls. Compare $\mathrm{CW}$ examples (e.g., 144:2; 116:1) with MW examples from the same stratum and phase (e.g., 144:3-8; 120:1). Other examples should be surveyed as well.

It appears that local potters were unable to obtain the clays necessary to form MW vessels, much less the high firing temperatures which give $M W$ its distinctive look and feel. In compensation, CW platter bowls (with gray cores suggestive of lower firing temperatures) were slipped in red and burnished. Close inspection distinguishes the MW from the common ware; however, this may be the only option for those who could not afford the "real thing," but nonetheless, wanted its "feel" or "portrayal." 
degree of status was attached to MW in some places. At the level of household, popular MW platter bowls found application in the presenting and consuming of food, contexts ripe for the display of economic or social status. Similarly, burn marks on the edge of small MW bowls suggest their use as lamps: once again, an example of a vessel in a very visible or "public" context. Bowls and platter bowls would likely have been a favorite among merchants also. Such forms easily "nest" one inside the other and transport in quantity more easily than closed vessels.

Such means of ceramic distribution tailor neatly into larger discussions of EB II dynamics. Mention may be made of the lack of pre-urban settlements in North Palestine, the sudden appearance and rapid expansion of EB II settlements connected with MW, and the new economic opportunities associated with these settlers or colonists (Esse 1991: 103-116, 175; Joffe 1993: 82-83; Greenberg and Porat 1996: 19-21). ${ }^{1}$ If, in truth, the presence of MW signals not only the arrival of "newfangled pots," but the potent arrival of new traditions, economy, people, and indeed, a new society, how might this have been received by those who witnessed the arrival? This question sets the stage for a third inference concerning Tell Ta'annek, EB II, and MW.

Persistent potters. It is proposed here that the original inhabitants of Tell Ta'annek were not core participants in this MW enterprise. Distance and sherd counts alone might demonstrate this, but even more could be adduced. In fact, if pockets of early material recovered by The Taanach Excavations are truly suggestive of a more substantial EB I settlement (and only additional excavations will establish this), it appears that Tell Ta'annek was continuously settled from the EB I through mid-EB III

${ }^{1}$ Arnold (1985: 199-201) has outlined the relationship between population pressure and craft specialization as it may be applied in the context of ceramic production. 
periods. This places Tell Ta'annek in a select group of sites which survived the transition from EB I to EB II, a feat that many of her nearest neighbors, including Megiddo, 'Affula, and Tell Qishyon, did not achieve.' These folk, it is reasoned here, were in place before the arrival of MW and its associated dynamics: this thread must be woven together with others. It has been proposed that the sources of MW were distant, that the producers of MW represent a new social entity, that a powerful trade network was required for MW distribution, that itinerant merchants may account for ware transport, and that MW was a valuable commodity. Understanding this combination of factors establishes a context for local response(s).

Greenberg (2000: 197) has recently stressed how the uniformity of ceramic assemblages at EB II MW sites may be suggestive of a larger egalitarian ideal: "pots may have been perceived as merely functional means to attain a collective goal." Whether or not this was true in the center of the MW distribution area may be discussed elsewhere. It is unlikely that this was true on the fringe. At Tell Ta'annek, MW and CW bowls, platters, and jars rest side by side in the same phase and stratum. The stark contrast that this presents cannot be missed. Unfortunately, beyond the exposure of defensive systems (that, incidentally, speak powerfully to this point), little horizontal exposure is revealed on the tell, especially in domestic areas, making it difficult to isolate other material correlates that might suggest social stratification. It may be inferred, however, given the quality of $\mathrm{MW}$, its imported distance, and even its repertoire

${ }^{1}$ The forces which seem to be operating here are complex and poorly understood. On one hand, the largest trends suggest that the total number of sites in the southern Levant was significantly reduced in the EB II, when compared to the total number of EB I sites. However, in select regions, such as arid zones, or in the Golan where $M W$ is found, site numbers increased. This drive to abandon old sites and build new ones, however, must be set in a context of population agglomeration, a trend that continues from the EB I to the EB III. For discussion of the data and problems in their interpretation, see Joffe (1993: 73-9). 
of "functionally visible" vessels, as discussed above. That such wares would be more valuable than locally produced common wares underlines one possible response: $\mathrm{MW}$ was a prestige or luxury item.

Such an identification underlines the conclusion that EB II society at Tell Ta'annek was ranked, and likely along kinship lines. Joffe (1993: 84) has identified two sets of elites in the EB II: urban and rural. Could it be possible that his "rural elites" were associated with the population at Tell Ta'annek and visible through MW residues? While the issues of ruralism and urbanism are enormous and go well beyond the scope of this work, it may be valuable to connect Joffe's observations concerning the "rural component" or "peasantry" with an EBA winepress to the south of Field A. Not surprisingly, Joffe assigns such "peasantry" to the "production of Mediterranean crops" and the "rural elites" to the role of "agricultural producers" (1993: 85).

Additional layers of interpretation may be added to the MW presence as other variables are explored. Examples of such variables include ethnicity and local perception of the MW producers/distributors, the relationship between "rural" and "urban elites," larger regional alliances, trade guilds, and the extent to which MW was really viewed as symbolic of other constructs--e.g., elitist-common, cosmopolitan-"country bumpkin," fancy-dull, formal-informal, etc. (cf. Joffe 1993: 82-6). Particularly enticing is a question that requires a return for a closer look at the $\mathrm{Tell} \mathrm{Ta}^{\mathrm{c}}$ annek stratigraphy. Could the EB II fortifications at Tell Ta'annek be viewed not as another product of the "MW culture," but as a response to it? It is unlikely that a positive answer to this question has the power to explain the larger trajectory of fortification building that continued across the entire Levant into the EB III, but it may have been one of many factors. In the end, what might have been a luxury item to some, must have been a dark omen to others. 
Little speculation is needed to recognize the individual who would have been most threatened by the arrival of MW: the local potter. Even if the proposed MW "colonists" prove to be unfounded, the unified MW market posed real economic dangers to any number of local workshops. CW producers could not match MW producers in technique, output (if the standardization of MW is indicative of mass production), or access to raw materials. Attempts to imitate MW were unconvincing. Production and exchange ventures were developed with points as far away as Egypt and coastal Syria, leaving a "trail" of MW clues (Esse 1991: 104-5). With the total suffocation of local traditions imminent, the larger mystery may ultimately boil down to this: Whose persistence would prevail? Would it be that of a relatively large-scale, technologically advanced industry, or would it be that of a small-scale, traditional workshop?

The attractions of $\mathrm{CW}$ over MW are not obvious. Examples from Tell Ta'annek represent a complete inventory of vessels from small bowls to large pithoi. These are handmade, but wheel-finished at times; vessels tend to be thick, poorly fired with grey cores, red slipped, and formed from fabric that ranges from pink to reddish brown in color. The repertoire of standard forms suggests either a limited number of workshops, or, more likely, a "mental" template informed by local traditions. That this template is only general in nature, however, is suggested by irregularities in vessel size and shape. Regardless, there is nothing to suggest that $\mathrm{CW}$ vessels were any more or less efficient than MW, and therefore may be considered equally suited from a functional perspective. ${ }^{1}$

${ }^{1}$ Perhaps in the case of large vessels, wall thickness would have made common ware heavier than its MW equivalent, and therefore more difficult to use.

Of course, holemouth jars and bowls are here considered $\mathrm{CW}$, but are uniquely tasked in a way not imitated by any MW vessel. 
These comments give way to the obvious: While pottery workshops have not been identified in the near vicinity of Tell $\mathrm{Ta}^{\mathrm{c}}$ annek, it is assumed that $\mathrm{CW}$ was produced locally. As a local commodity, it would have been, by definition itself, more accessible and affordable than MW. Add to this an (archaeologically evasive) sense of loyalty--either to particular individuals, to kin-groups, to local heritage or tradition-and the attraction of common ware begins to accumulate. Any number of distant (e.g., "image of limited good") ${ }^{1}$ or modern (e.g., "Made in the USA," "Buy union") analogies may be projected to even suggest that MW was shunned or avoided by some circles for ideological reasons. Seen in this way, it may be that $\mathrm{CW}$ appealed to the conservatism that is frequently attached to rural life. Such "dynamics of resistance," however covert, are very real, and may help explain the persistence of a local ceramic industry in and around EB II Tell Ta'annek. ${ }^{2}$

\section{Tell Ta'annek, Early Bronze III, and Khirbet Kerak Ware}

The numbers. It is difficult to underestimate the influence of $\mathrm{KKW}$ for the study of EB III North Palestine. Sensuously open forms and an unmistakable finish make $\mathrm{KKW}$ easy to recognize and perhaps the most significant diagnostic feature associated with EB III assemblages. Like MW, KKW is also common in North Palestine. De Vaux observes "there are traces of it on almost all the sites of the plain of Esdraelon (Jezreel)

${ }^{1}$ This "image of limited good" is an attitude documented in a pottery-making community of Tzintzuntzan, Mexico, by Wolf (1955). In this view, personal advancement only comes at the expense of others. Such attitudes place sanctions on deviation or innovation and inhibit material or social change.

${ }^{2}$ Arnold (1985: 221-4) outlines four barriers that explain why ceramic innovations may not be accepted in a given place: (1) the habit patterns or skills of the potters themselves, (2) the organizational patterns of pottery making (which include gender roles), (3) the economic marginality of potters (inability to upgrade equipment), and (4) the attitudes of the society in which the potter works. 
and further north. South of the Plain of Esdraelon (Jezreel) it is rare" (1971: 213).

However, unlike MW, the diffusion of KKW appears ultimately wider, pressing south (to the Shephelah) and north (to Anatolia). ${ }^{1}$ Ironically, while it has attracted many commentators (Hennessy 1967: 75-84; Amiran 1969: 68-70; Esse and Hopke 1986: 328-332; Esse 1991: 51-53; Burney 1989; Leonard 1992: 50-55), Dessel and Joffe still claim that it "remains one of the least studied ceramic types in the Levant" (2000:43). Obviously, there is much to be learned about this exceptional tradition.

Many EB III sites in the vicinity of Tell Ta'annek are significantly impacted by the presence of $\mathrm{KKW}$. Unfortunately, much of this material remains unpublished and an inclusive regional synthesis has yet to be produced. Esse's (1991) general survey of 11 sites may be the most complete to date. Apart from his work, excavators from Bethshan report that KKW accounts for an enormous 58 percent of the EB III assemblage there (Mazar, Ziv-Esudri, and Cohen-Weinberger 2000: 262). Leonard calls KKW a "striking feature" at Tell Esh-Shuneh (1992: 50), while Greenberg (1997: 183-93; 2000: 189) fills in the details of Hazor's "Khirbet Kerak phase" (Yadin's Stratum XX) where KKW accounts for between 25 and 33 percent of saved diagnostics, and the "Post Khirbet Kerak" (Yadin's Stratum XIX) phase, where the appearance of KKW shrinks to only about 10 percent.

Other prominent EB III sites appear to be relatively unaffected by $\mathrm{KKW}$. At Tel Dan, for example, only small quantities are reported (Greenberg 1996a: 103). A similar situation is found in Megiddo, where Joffe (2000: 184) reports

${ }^{1}$ Burney (1989) surveys the evidence of the diffusion of KKW from central Anatolia to the Amuq plain and other points south. He embraces an explanation rooted in migration or invasion over one that is rooted in long-distance trade. This sentiment appears consensual (Amiran 1969: 74-5; Yakar 1989). 
very little of this type was found... either in the renewed excavations or by the Oriental Institute excavators. . . . The vessels found in the renewed Megiddo excavations consist of a few sinuous-sided bowls, while the few buff-coloured sherds probably derive from poorly documented Khirbet Kerak imitations of local forms, such as holemouth jars.

This assessment corresponds with the evidence from Tell Ta'annek, where perhaps 50 total KKW sherds were identified from all fills associated with the entire Bronze Age corpus. When narrowing the field to only those loci selected for the present study, the number is further reduced to only 9 sherds, a negligible 1 percent of the EB III assemblage (Table 7).

A mesh. Little can be inferred from this trace element, especially given the incomplete regional data concerning KKW distribution. What is clear is that large statements of presence, such as the association of KKW with North Palestine, must be used cautiously. These are only true at the level of quick generalization, and that a finer level of examination is needed in conjunction with more complex models of explanation. It also seems clear at this preliminary stage to suggest that a diffusion pattern of KKW in North Palestine is analogous to a "mesh" or "net" with knotted lines of irregular intensity interrupted by "holes" of absence. ${ }^{1}$ In the case of Tell Ta'annek (and Megiddo as well), KKW as an imported product, idea, or tradition seemingly slipped by and around the site.

Persistent potters. What can be made of this evidence? Greenberg (2000: 191-7) has offered the clearest interpretation on this to date. He sees a distinct contrast

'Philip and Baird (2000: 16-7) use the term "mesh" to describe the distribution of MW. It is contended here that this term is appropriate for discussing KKW patterns, where the "lines" and "holes" are even more pronounced. 
TABLE 7

KHIRBET KERAK WARE IN THE TELL TA'ANNEK ASSEMBLAGE BY STRATUM

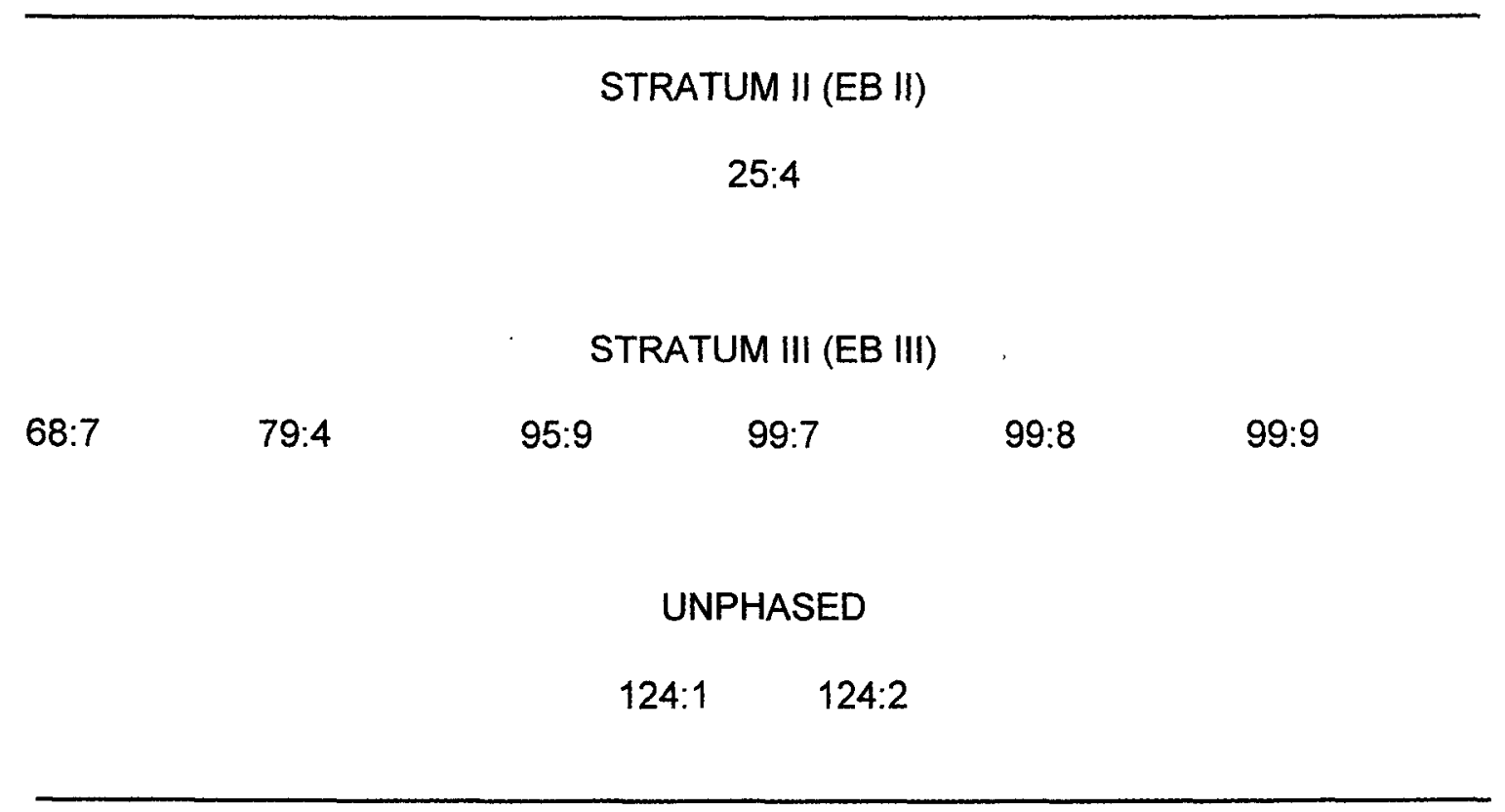


in North Palestine between the EB II and EB III periods based, in part, upon the ceramic evidence. As previously suggested, he interprets the uniformity of MW in EB II as indicative of a more unified, centralized, and perhaps egalitarian-minded society. This is set in contrast with evidence from the EB III that suggests a more localized, fragmented, and autonomous society, suffering, in part, from "internal contradictions and plurality" (2000: 197).

It is difficult to support or challenge this view on the basis of the ceramic assemblage from Tell Ta'annek alone. What is clear from this study is that in the EB III, when KKW was seriously impacting the assemblages of neighboring sites, Tell Ta'annek was almost completely unaffected; it was removed, if not indifferent, to this dynamic. In fact, given the numbers, an alternative trajectory suggests that even the presence of lingering MW forms played a larger role at EB III Tell Ta'annek than any $\mathrm{KKW}$ influence. If $\mathrm{KKW}$ was viewed as the new symbol of prestige, it never caught on. If this ceramic tradition is a product of a newly arrived people-group, they chose to live elsewhere. If networks of trade were rerouted in the valley, Tell Ta'annek was out of the loop. Such observations are particularly perplexing when it is remembered that 'Affula, where KKW left a powerful imprint (Sukenik 1948: Pls. X, XI), is visible from the brow of the tell.

Equally visible is the complete dominance of CW in Tell Ta'annek's EB III assemblage. Ubiquitous, practical, and unassuming, the repertoire of $\mathrm{CW}$ forms, as well as the techniques for shaping them, changes little from traditions previously established in EB II. While it is highly unlikely that the systems of production, distribution, and consumption of MW and KKW were the same, it is suggested here that the larger population of Tell Ta'annek did not fully embrace either. A preference for 
local wares over more expensive or more exotic forms hints at a rural conservatism that is consistent with the site's location.

\section{Looking Forward from Tell Ta'annek: New Vistas}

Archaeological investigations by The Taanach Excavations conducted under the direction of Paul Lapp revealed many aspects of a complex tell in the context of North Palestine. The preserved records from these investigations have proved sufficient to isolate, organize, and describe a sample of the EBA residue. As an important segment of that sample is ceramic in nature, effort has been directed toward retrieving a discrete assemblage that is stratigraphically sensitive. This retrieval has been presented here as useful for ordering claims about chronology, technology, and, to a lesser extent, systems of diffusion and exchange.

Not surprisingly, while the purpose of this study has been to present a view to the distant past in one small part of the world, a by-product has been a demonstration of how little about that past is actually known. This is particularly true when focus is turned to EBA Palestine and Tell Ta'annek in particular. Hence, proposals for future study are grouped into four clusters by way of conclusion.

First, continued attention must be given toward understanding the dynamic processes, both human and natural, which account for the creation of tell sites. Excavation techniques and recording procedures must match the complexity of deposition and be clear enough to allow for reconstruction. At Tell Ta'annek, EBA materials were drawn from the lowest levels of deep trenches; consequently, access to this material was limited and was complicated (and compromised, at times) by overburdens of later debris. The material revealed in these deep trenches was almost 
always associated with defensive structures: only in Field B was a sample of EBA residential structures encountered. One cannot help but wonder how this particular fact has skewed the ceramic sample and the conclusions drawn here. Another unanswered question concerns the nature and extent of the EB I presence on the site. Given the substantial EB I remains at nearby Megiddo and Jenin (personal communication, $H$. Salem), the southern Jezreel Valley appears to have been an animated landscape. How to understand the eclipse at EB I Megiddo over and against the resilience of EB I Tell Ta'annek is not known. Obviously, a full study of the EBA stratigraphy of Tell Ta 'annek is urgently needed.

Second, while some typological developments within the class of $\mathrm{CW}$ have been made more explicit and will be helpful for informing a relative ceramic chronology in North Palestine, isolating EB II from EB III on the basis of CW alone still remains a challenge. MW and $\mathrm{KKW}$ continue to serve as indispensable chronological tools. While work with MW has been advanced as of late, it would seem that further investigation into the areas of modern Lebanon and Syria will be necessary to identify specific production centers and a more complete pattern of diffusion. The same may be true of KKW, although revisiting excavated data within North Palestine may be a simpler starting point. It should be noted here as well that new radiocarbon evidence needs to be gathered and evaluated as one way to "control" relative chronologies in a time and place lacking written records.

Third, Glock's emphases on ceramic technology and "fabric families" demand additional attention. Modern trends away from a classificatory approach to ceramic studies recognize the limits of the paradigm introduced to EBA study by Wright. However, ceramic study within a context that is more sensitive to the technology of "pot making" is already opening new avenues for critical thinking. The recruitment of 
practicing potters for the study of ceramic technology is needed if the subtle signs of manufacturing, such as the concavity beneath the rims of platter-bowls, are to find explanation. Similarly, additional petrographic study of "Common Ware" is needed to determine just how local this material really is.

Fourth and finally, just as the recognized limits of ceramic typology have been sensed in the last decade or two, so, too, have the limits of positing deeper social realities based solely upon the ceramic evidence. To describe the EBA residents of Tell $\mathrm{Ta}$ 'annek as conservative ruralists, as has been suggested here, is a hypothesis in need of critique. Is it really fair to infer an analogous relationship between ceramic diversity and society? Why should a simple pot necessarily suggest a simple man, much less a simple society? In the end, it may be the modern specialist who is engaged in simple activities; the ancients may have preferred to invest their energies elsewhere. 


\section{APPENDIX 1}

\section{INDEX TO PHASED LOCI BY PLATE ASSIGNMENT}

The following index presents individual squares and loci arranged chronologically by phase. Individual locus (L.) assignments are keyed to the plates (PI.) in Appendix IV.

Field A, Phase 1A

SE 1-26

L. 53 PI. 1

SE 1-28

$$
\text { L. } 39 \text { Pl. } 1
$$

Field A, Phase 1B

SE 1-27

L. 56 PI. 3

SW 1-27
L. 54 PI. 3
L. 55 PI. 4
L. 56 PI. 4
L. 60 PI. 4
L. 62 PI. 5
L. 63 PI. 6
L. 64 PI. 6
L. 72 PI. 6

SW 1-29

L. 28 PI. 7

SW 2-27

SW 4-27

L. 91 PI. 8

L. 28 PI. 8

Field A, Phase $1 \mathrm{C}$

SE 1-27

L. 54 PI. 9

SE 1-27

L. 51 PI. 10

L. 52 PI. 10

L. 53 PI. 10

SW 1-28

L. 33 PI. 11

L. 40 PI. 11
SW 2-27
L. 87 PI. 11

L. 90 PI. 12

SW 3-27
L. 83
PI. 13
L. 84 PI. 12

SW 4-26

SW 5-26

L. 21 PI. 14, 15

L. 38 PI. 16

Field A, Phase 2A

SE 1-26

L. 47 PI. 17

SW 1-26

L. 36 PI. 17

L. 79 PI. 18, 19

L. 82 PI. 20

L. 85 PI. 20

L. 87 PI. 21

SW 1-27

L. 43 PI. 22

L. 44 PI. 23

L. 48 PI. 22

L. 49 PI. 24

L. 87 PI. 22

SW 1-28

SW 2-27

L. 30 PI. 25

L. 18 PI. 26, 27

L. $76 \mathrm{~A}$ PI 28

SW 3-26

L. 48 PI. 26, 27

SW 3-27

L. 78 PI. 26,27 
SW 4-26

SW 5-26
L. 17 PI. $29,30,31$
L. 19 PI. 32
L. 20 PI. 33,34

L. 28 PI. 32

Field A, Phase 2B

SE 1-26

SW 4-25

$$
\text { L. } 49 \text { PI } 35
$$

$\begin{array}{ll}\text { L. } 20 & \text { PI. } 36\end{array}$

L. 22 PI. 36

SW 5-26
L. 21 PI. 37, 38
L. 22 PI. 36
L. 23 PI. 39, 40

Field A, Phase $3 A$

SE 1-27
L. 40 PI. 41
L. 48 PI. 42

$\begin{array}{ll}\text { L. } 50 & \text { PI. } 41\end{array}$

SE 1-28

L. 34 PI. 43

L. 35 PI. 44

L. 44 PI. 44

SW 1-27

L. 27 PI. 45

L. 40 PI. 45

L. 70 PI. 45

L. 90 PI. 46, 47

SW 1-28

L. 14 PI. 48

L. 28 PI. 48

L. 35 PI. 48

L. 36 PI. 49

L. 38 PI. 49

SW 2-27

L. 14 PI. 50

L. 17 PI. 50, 51

L. 46 PI. 51

L. 55 PI. 52

L. 57 PI. 52

L. 62 PI. 52

L. 63 PI. 52

L. 65 PI. 52

L. 66 PI. 52

L. $67 \mathrm{PI} .52$
SW 3-26
L. 75 PI. 53, 54
L. $78 \mathrm{~A} \mathrm{PI.} 56,57$
L. 79 PI. 55
L. 80 PI. 55
L. 83 PI. 56, 57

SW 3-27

L. 39 PI. 56, 57
L. 24 PI. 56, 57
L. 72 PI. 58
L. 73 PI. 58

SW 4-26

L. 15 PI. 59, 60, 61

L. 18 PI. 62

L. 30 PI. 63, 64

L. 31 PI. 65

L. 35 PI. 65

SW 4-27

L. 15 PI. 66

L. 22 PI. 67, 68, 69, 70

L. $26 \mathrm{~A} \mathrm{PI} .66$

L. 27 PI. $67,68,69,70$

SW 5-26

L. 12 PI. 66

L. 13 PI. 71

L. 16 PI. 71

SW 5-27

L. 13 PI. 72

L. 14 PI. 72

L. 16 PI. 73, 74

L. 19 PI. 75

L. 21 PI. 75

L. 23 PI. 76

L. 27 PI. 75

SW 6-26
L. 22 PI. 77
L. 24 PI. 77
L. 26 PI. 77
L. 27 PI. 78,79
L. 29 PI. 78
L. 36 PI. 78
L. 38 PI. 78
L. 42 PI. 78,79
L. 43 PI. 78,79
L. 44 PI. 78
L. 48 PI. 78 
Field A, Phase 3B

SE 1-28

$\begin{aligned} \text { L. } 28 & \text { PI. } 80 \\ \text { L. } 31 & \text { PI. } 80 \\ \text { SW 1-28 } & \\ \text { L. } 13 & \text { PI. } 81 \\ \text { SW 2-27 } & \\ \text { L. } 33 & \text { PI. } 82 \\ \text { L. } 58 & \text { PI. } 82 \\ \text { SW 3-27 } & \\ \text { L. } 49 & \text { PI. } 83,84 \\ \text { L. } 50 & \text { PI. } 85 \\ \text { L. } 65 & \text { PI. } 83 \\ \text { L. } 67 & \text { PI. } 86 \\ \text { L. } 69 & \text { Pl. } 87 \\ \text { L. } 70 & \text { PI. } 87\end{aligned}$

Field A, Phase 4A

SE 1-28
L. 15 PI. 88
L. 23 PI. 88
L. 25 PI. 88
L. 26 PI. 89

SW 1-26

L. 166 PI. 89

L. 177 PI. 89

SW 1-27

$$
\text { L. } 4 \text { PI. } 90
$$

L. 230 PI. 90

SW 3-26

$$
\begin{array}{ll}
\text { L. } 37 & \text { PI. } 91 \\
\text { L. } 47 & \text { PI. } 91
\end{array}
$$

SE 1-26

$$
\begin{array}{ll}
\text { L. } 46 & \text { PI. } 92 \\
\text { L. } 48 & \text { PI. 93, 94, 95 }
\end{array}
$$

SE 1-28

$$
\text { L. } 27 \text { PI. 96, } 97
$$

Field A, Phase 4B

SW 1-26
L. 155 PI. 98
L. $158 \mathrm{PI} .98$
L. 160 PI. 99
L. 163 PI. 99
L. 167 PI. 99
L. 169 PI. 100
L. 170 PI. 101

SW 2-26

$$
\text { L. } 80 \text { PI. } 101
$$

SW 2-27

L. 81 PI. 102

L. 34 PI. 101

L. 51 PI. 102

SW 3-27
L. 56 PI. 103
L. 57 PI. 103

Field A, Unphased SW 7-26
L. 8 PI. 104
L. 12 PI. 105, 106

Field $B$, Phase $1 \mathrm{~A}$

SW 1-7

$$
\text { L. } 222 \text { PI. } 108
$$

SW 1-8

$$
\begin{aligned}
& \text { L. } 116 \text { Pl. } 107 \\
& \text { L. } 117 \text { Pl. } 107 \\
& \text { L. } 119 \text { PI. } 108
\end{aligned}
$$

Field $B$, Phase 1B

SW 1-7

$$
\text { L. } 219 \text { PI. } 109
$$

Field B, Phase 1C SW 1-7

L. 189 PI. 110

L. 194 PI. 111, 112, 113,

SW 1-8

$$
114
$$

L. $100 \mathrm{PI} .115$

L. 109 PI. 115

SW 1-9

L. 121 PI. 116

L. 201 PI. 117, 118, 119

L. 213 PI. 120,121

Field $B$, Phase 2B

SW 1-7

SW 1-8

$$
\text { L. } 202 \text { PI. } 122
$$

L. 216 PI. 122

$$
\begin{array}{ll}
\text { L. } 90 & \text { PI. } 122 \\
\text { L. } 92 & \text { PI. } 122 \\
\text { L. } 102 & \text { PI. } 123
\end{array}
$$

SW 1-9

L. 155 PI. 124

L. 168 PI. 124 
L. $172 \mathrm{PI} .130$

L. 173 PI. 128

L. 175 PI. 129

L. 176 PI. 129

L. 178 PI. 125

L. $180 \mathrm{PI} .125$

L. 187 PI. 125

L. 188 PI. 126

L. 203 PI. 127

Field C, Phase 1A

NW 9-1
L. 51 PI. 131, 132
L. 53 PI. 131, 132
L. 55 PI. 131

Field C, Phase 1B

SW 6-1

L. 208 PI. 134

L. 210 PI. 134

SW 9-1

L. 156 PI. 135

L. 157 PI. 135

NW 9-1

L. 64 PI. 133

Field C, Phase 1C

SW 6-1

L. 179 PI. 138

L. $186 \mathrm{PI} .138$

L. 187 PI. 138

L. 189 PI. 139

SW 9-1

L. 193 PI. 139

L. 127 PI. 140,141

L. $139 \mathrm{PI} .142$

L. 142 PI. 142

NW 9-1$$
\text { L. } 41 \text { PI. } 136
$$

L. 42 PI. 137

L. 43 PI. 137

Field C, Phase 1D

SW 6-1
L. 167 PI. 143, 144
L. 170 PI. 145,146
L. 171 PI. 145

Field C, Phase 2A

SW 6-1

L. 115 PI. 150

L. 121 PI. 151, 152

L. 123 PI. 153

L. 155 PI. 154, 155

L. 162 PI. 156, 157

L. 163 PI. 158

L. 166 PI. 159

SW 9-1

L. 110 PI. 160,161

L. 145 PI. 162

L. 152 PI. 163

L. 153 PI. 163

L. 155 PI. 164

NW 9-1
L. 30 PI. 147
L. 57 PI. 147
L. 60 PI. 147
L. 62 PI. 147
L. 63 PI. 148, 149

Field C, Phase 2B

SW 6-1

SW 9-1

L. 94 PI. 165

L. $130 \mathrm{PI} .165$

L. 144 PI. 165

L. 154 PI. 165

Field C, Unphased

NW 9-1

$$
\text { L. } 47 \text { PI. } 166
$$

Field D, Phase $1 \mathrm{~A}$

SW 7-7

L. 170 PI. 167

Field D, Phase 1B

SW 7-7

L. 177 PI. 168

Field D, Phase $1 C$ SW 7-7

L. 176 PI. 169

Field D, Phase 2A

SW 7-7

L. 161 PI. 171 

L. 163 PI. 171
L. $164 \mathrm{PI} .172$
L. 166 PI. 173,174
L. $168 \mathrm{PI} .175$
L. $169 \mathrm{PI} .175$
L. 172 PI. 176
L. 173 PI. 177
L. 174 PI. 177
L. 175 PI. 178

Field D, Phase 2B

SW 6-7

L. $220 \mathrm{PI} .179$

L. $243 \mathrm{PI} .179$

L. $244 \mathrm{PI} .179$

L. 246 PI. 179

SW 7-7

L. $149 \mathrm{PI} 180$

L. 151 PI. 180

L. 153 PI. 181,182

L. $157 \mathrm{PI} .183,184$ 


\section{APPENDIX $\|$}

\section{INDEX TO PHASED LOCI BY SQUARE}

AND FIELD ASSIGNMENT

Field A

SE 1-26: $\quad 46,47,48,49,53,54$

SE 1-27: $\quad 54,40,48,50,56$

SE 1-28: $\quad 15,23,25,26,27,28,31,34,35,36,39,44$

SW 1-26: $\quad 79,82,85,87,155,158,160,163,166,167,169,170,177$

SW 1-27: $\quad 4,27,40,43,44,48,49,51,52,53,54,55,56,60,62,63,64,70$, $72,87,90,230$

SW 1-28: $\quad 13,14,28,30,33,35,36,38,40$

SW 1-29: $\quad 28$

SW 2-26: $\quad 80,81$

SW 2-27: $\quad 14,17,18,33,34,46,51,55,57,58,62,63,65,66,67,75,78 \mathrm{~A}$, $79,80,83,76 \mathrm{~A}, 87,90,91$

SW 3-26: $\quad 37,39,47,48$

SW 3-27: $\quad 24,49,50,56,57,65,67,69,70,72,73,78,83,84$

SW 4:25: $\quad 20,22$

SW 4-26: $\quad 15,17,18,19,20,21,30,31,35$

SW 4-27: $\quad 15,22,28,26 \mathrm{~A}, 27$

SW 5-26: $\quad 12,13,16,21,22,23,28,38$

SW 5-27: $\quad 13,14,16,19,21,23,27$

205 


\section{6}

SW 6-26: $\quad 22,24,26,27,29,36,38,42,43,44,48$

Field B

SW 1-7: $\quad 189,194,202,216,219,222$

SW 1-8: $\quad 90,92,100,102,109,116,117,119,121$

SW 1-9: $\quad 155,168,172,173,175,176,178,180,187,188,201,203,213$

Field C

NW 9-1: $\quad 30,41,42,43,51,53,55,57,60,62,63,64$

SW 6-1: $\quad 94,115,121,123,130,144,155,162,163,166,167,170,171$, $179,186,187,189,193,208,210$

SW 7/8/9-1: $110,127,139,142,145,152,153,156,157$

Field D

SW 6-7: $\quad 220,243,244,246$

SW 7-7: $\quad 149,151,153,157,170,176,161,163,164,166,168,169,172$, $173,174,175,177$ 
APPENDIX III

\section{A PETROGRAPHIC ANALYSIS OF SAMPLES FROM THE EARLY BRONZE AGE ASSEMBLAGE OF TELL TA' ANNEK \\ Tahani Salem, Palestinian Institute of Archaeology with Mark Ziese, Cincinnati Bible Seminary}

\section{Introduction}

This report summarizes the results of a petrological analysis of 56 thin sections cut from selected samples of the EBA corpus from Tell Ta'annek. These thin sections represent 24 of 25 "Fabric Families" as determined by A. Glock (1975) and described in preliminary fashion in his study, "Homo Faber: The Pot and the Potter at Taanach." The ceramic samples analyzed here were originally selected in conjunction with that study and thin samples were prepared under Glock's supervision. However, no complete report of conclusions from this effort could be found. Therefore, in order to revisit discussion of Glock's "fabric families" and to provide a sample analysis of EBA ceramic fabrics presented in the present study, a new analysis was commissioned by Khaled Nashef, director of the Palestinian Institute of Archaeology. Tahani Salem, staff member of the Palestinian Institute of Archaeology conducted the essential analysis, while Mark Ziese assisted by locating the materials and helping shape the report.

\section{Method}

All thin sections were examined using a petrographic microscope. Magnifications used were $\times 63, \times 160$, and $\times 250$. Readings were recorded and are presented in tabular form for ease in comparison and classification. 


\section{The Data}

The following table offers initial observations by identifying visible minerals and their percentage intensities. Intensities reported in bold typeface represent materials considered to be additives, while intensities reported in non-bold typeface represent naturally occurring minerals.

The first major block of columns (left side of table) contains three columns referencing the thin section sample number, the identification number (used in the context of the Ziese's work) and Glock's "Fabric Family" assignment, respectively.

To the right of these, the next major block of columns reports on the nature and size of the clay background, making note of the presence of allochems, mica, quartz, feldspar, hematite, and others. Numbers represent estimated percentages with respect to the area or intensity of clay only and not with respect to the whole of the thin section.

The third block of columns reports the percentage of intensities with respect to the whole of the thin section. All of these are non-plastics such as limestone, gabbro, chert, quartz, feldspar, hematite, calcite, mica or pyroxene. However, the presence and intensities of grog and of fabric voids are also noted. In a few cases (in the feldspar and hematite columns), a mineral name alone, or a number with the mineral name is offered. This suggests the source of the mineral, i.e. that listed mineral is within, or mixed with the category of non-plastics.

Finally, it is here noted that in many cases two or three samples from each of Glock's "Fabric Families" are represented in this analysis. However, no thin section sample was located from Glock's "Family 14." This omission is unfortunate, as this "family" is typically associated with Khirbet Kerak Ware. 


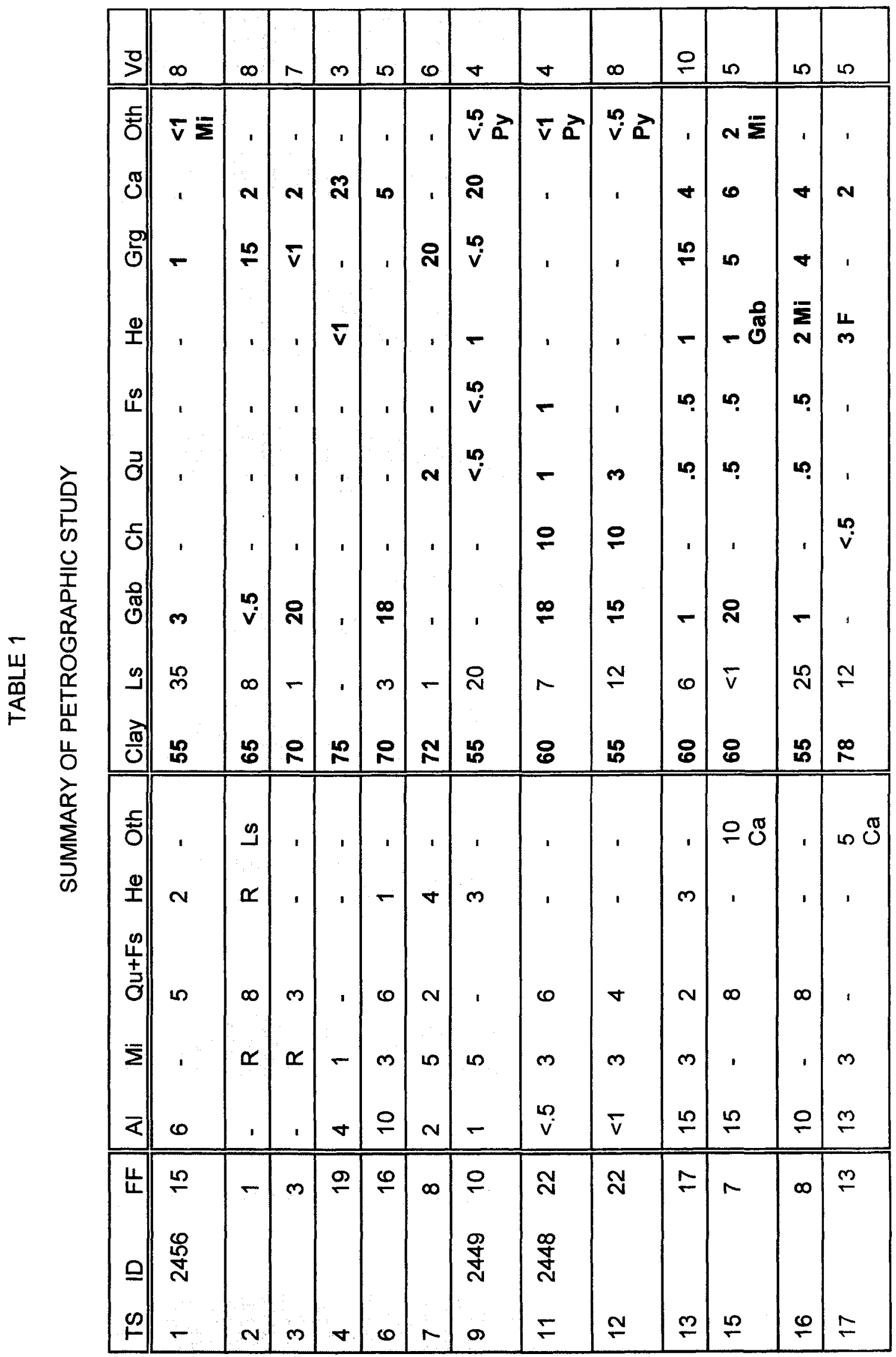




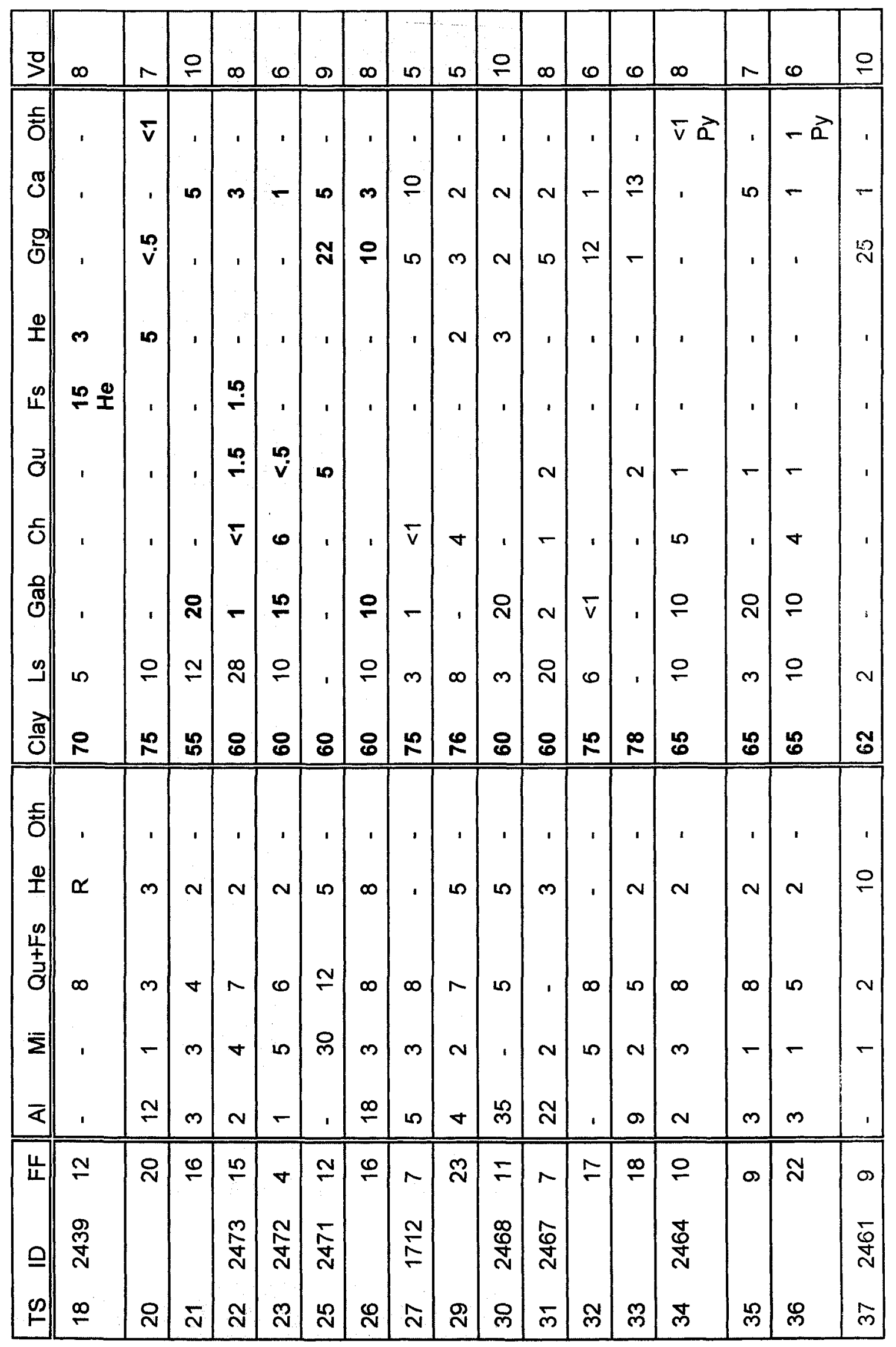




\begin{tabular}{|c|c|c|c|c|c|c|c|c|c|c|c|c|c|c|c|c|c|}
\hline$\frac{7}{3}$ & $\infty$ & $\sigma$ & 으 & 10 & $\checkmark$ & $N$ & 우 & N & $\infty$ & $\infty$ & 우 & 0 & 10 & $\infty$ & $\nabla$ & 10 & $\nabla$ \\
\hline 今 & 1 & ' & $-\bar{\Sigma}$ & I & 1 & 1 & I & I & 1 & $-\Sigma$ & ' & 1 & 1 & ' & 1 & 1 & ' \\
\hline$\stackrel{\pi}{\mathcal{O}}$ & $\nabla$ & $N$ & $\infty$ & I & $r$ & 10 & 10 & $N$ & 10 & $\mathscr{N}$ & $N$ & 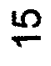 & $\nabla$ & $N$ & م & ㅇ & $m$ \\
\hline$\overline{0}$ & $\stackrel{\sim}{\sim}$ & $\stackrel{2}{\sim}$ & $\sigma$ & ' & $r$ & ' & $\forall$ & $\infty$ & ' & ' & $\stackrel{n}{2}$ & $\bar{v}$ & ' & ' & $\bar{v}$ & ' & , \\
\hline$\stackrel{0}{I}$ & $r$ & I & - & I & $\tau$ & $N$ & $\begin{array}{l}\frac{0}{\mathbb{0}} \\
\mathbb{0}\end{array}$ & ' & ' & $m$ & ' & ' & ' & ర్ల & $m$ & $m$ & 0 \\
\hline$\stackrel{\infty}{\sim}$ & $6 ?$ & 1 & ' & ' & $\infty$ & ' & $\bar{v}$ & 1 & ' & I & $r$ & $r$ & ' & in & ' & 1 & 1 \\
\hline $\overrightarrow{\mathrm{O}} \|$ & 0 & $\bar{v}$ & $r$ & - & $\mathbb{N}$ & , & $\bar{v}$ & $r$ & ما & ' & $r$ & $r$ & $r$ & $\stackrel{0}{v}$ & $\bar{v}$ & . & $N$ \\
\hline$\frac{c}{u}$ & . & I & $\bar{v}$ & 10 & v? & $r$ & ' & I & 10 & ' & ' & ' & ' & ' & ' & 1 & 1 \\
\hline ல] & ' & ' & $\stackrel{\infty}{\leftarrow}$ & 으 & , & $m$ & 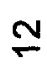 & - & 요 & I & ' & ' & $\stackrel{n}{\leftarrow}$ & 음 & $m$ & 1 & 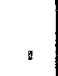 \\
\hline 9 & $r$ & L & $N$ & $\stackrel{\circ}{\circ}$ & $m$ & ㅇ & $m$ & ㅇ & $\nabla$ & $\nabla$ & 10 & $N$ & $\nabla$ & $r$ & 오 & 으 & $\stackrel{\sim}{\sim}$ \\
\hline$\frac{\pi}{0}$ & 8 & 웅 & 8 & 요 & 8 & ச & ๑ี & 8 & 象 & 우 & 里 & $\stackrel{n}{N}$ & R & $R$ & ஜ̊ & $\boldsymbol{0}$ & 8 \\
\hline ક્| & 1 & 1 & I & 1 & 1 & $\frac{n}{10}$ & 1 & 1 & 1 & , & 1 & I & $\frac{0}{v}$ & $\frac{n}{v}$ & 1 & 1 & ' \\
\hline$\stackrel{\oplus}{I} \|$ & $\infty$ & 1 & $N$ & ' & $\boldsymbol{x}$ & $N$ & I & 10 & $\nabla$ & $\mathbf{N}$ & $\propto$ & 1 & , & $\propto$ & $m$ & $m$ & $\simeq$ \\
\hline$\stackrel{+}{\vec{a}}$ & $\stackrel{n}{\sim}$ & $\stackrel{\sim}{N}$ & $\stackrel{\infty}{\sim}$ & 10 & 1 & $\infty$ & m & 0 & $\nabla$ & $N$ & $\stackrel{N}{\sim}$ & $\forall$ & 으 & 으 & 1 & 1 & ما \\
\hline$\Sigma$ & ' & 0 & $\widetilde{x}$ & $m$ & 요 & $N$ & $N$ & $r$ & $\mathbf{v}$ & $m$ & 10 & ' & $m$ & $\alpha$ & - & $m$ & $\simeq$ \\
\hline $\bar{\alpha}$ & $\bar{v}$ & $r$ & $N$ & $m$ & ' & $N$ & $\stackrel{N}{\sim}$ & $m$ & $N$ & ' & I & $N$ & $m$ & , & 움 & 1 & $\bar{v}$ \\
\hline 岌 & $\omega$ & 0 & $m$ & $\stackrel{m}{N}$ & $m$ & $N$ & $\forall$ & $\stackrel{10}{\circ}$ & $\omega$ & $\bar{N}$ & $\infty$ & n & $N$ & 10 & $\stackrel{\sigma}{\underline{\sigma}}$ & $\approx$ & $\stackrel{N}{\sim}$ \\
\hline$\underline{\underline{Q}}$ & 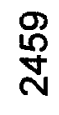 & & $\underset{\sim}{\stackrel{N}{N}}$ & $\stackrel{\infty}{\frac{\mathscr{V}}{\sim}}$ & & & & & & 원 & \begin{tabular}{l}
$\mathscr{O}$ \\
$\stackrel{\infty}{+}$ \\
\} & 市 & & & 号 & & \\
\hline$\stackrel{\infty}{\circ}$ & 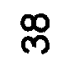 & ్ㅛ & 암 & $\forall$ & $\underset{F}{\Psi}$ & $\stackrel{m}{q}$ & $y$ & \& & 寸 & $\stackrel{\infty}{\text { ㇒ }}$ & 용 & $\overline{10}$ & ชิ & గి & षั & 员 & ஜ \\
\hline
\end{tabular}
\end{tabular}




\begin{tabular}{|c|c|c|c|c|c|c|c|c|c|c|c|c|c|c|c|c|c|}
\hline TS ID & $\mathrm{FF}$ & $\mathrm{Al}$ & $\mathrm{Mi}$ & $\mathrm{Qu}+\mathrm{Fs}$ & $\mathrm{He}$ & Oth & Clay & Ls & Gab & $\mathrm{Ch}$ & $\mathrm{Qu}$ & $\mathrm{Fs}$ & $\mathrm{He}$ & Grg & $\mathrm{Ca}$ & Oth & $\mathrm{Vd}$ \\
\hline 89 & 25 & - & 1 & 4 & 3 & - & 70 & 4 & - & - & $<1$ & 1 & - & 18 & 2 & - & 6 \\
\hline 90 & 25 & 3 & 3 & 6 & 3 & - & 60 & $\mathrm{Ca}$ & - & - & 1 & 1 & 2 & 1 & $\begin{array}{l}25 \\
L\end{array}$ & - & 8 \\
\hline 91 & 24 & 2 & 5 & 6 & - & $5 \mathrm{Ls}$ & 60 & 15 & 10 & 5 & 2 & - & - & 2 & 2 & $\begin{array}{l}1 \\
\text { Py }\end{array}$ & 5 \\
\hline 92 & 24 & - & 4 & 6 & - & - & 58 & 15 & 10 & 6 & 1 & 1 & - & - & - & $\begin{array}{l}1 \\
\mathrm{Mi}\end{array}$ & 8 \\
\hline 93 & 1 & 2 & 5 & 4 & 1 & - & 70 & 15 & - & - & - & - & - & 8 & 1 & - & 5 \\
\hline 94 & 18 & 1 & 2 & 10 & 4 & - & 60 & 20 & 5 & $<1$ & $<.5$ & - & 1 & 2 & 3 & - & 8 \\
\hline 95 & 21 & 1 & 4 & 7 & 3 & - & 75 & 5 & 1 & .5 & .5 & - & - & 12 & 2 & - & 4 \\
\hline 96 & 20 & 3 & 2 & 4 & 2 & - & 70 & 2 & - & - & 1 & - & $<1$ & 18 & 5 & - & 4 \\
\hline 97 & 11 & - & 15 & 2 & 10 & - & 68 & 5 & $<.5$ & - & - & - & Grg & 15 & 4 & - & 8 \\
\hline
\end{tabular}

Key Terms and Abbreviations

$\begin{array}{ll}\text { Al } & \begin{array}{l}\text { Allochems (microfossils and } \\ \text { subshells) }\end{array} \\ \mathrm{Ca} & \text { Calcite } \\ \mathrm{Ch} & \text { Chert } \\ \mathrm{Fs} & \text { Feldspar } \\ \mathrm{Gab} & \text { Gabbro } \\ \mathrm{Grg} & \text { Grog } \\ \mathrm{He} & \text { Hematite } \\ \mathrm{L} & \text { Lime } \\ \mathrm{Ls} & \text { Limestone }\end{array}$

$\begin{array}{ll}\text { Mi } & \text { Mica } \\ \text { Oth } & \text { Other } \\ \text { Py } & \text { Pyroxene } \\ \text { Qu } & \text { Quartz } \\ \text { R } & \text { Rich, or rich with } \\ \text { Vd } & \text { Voids }\end{array}$




\section{Analysis}

Mineral and fossil (foraminifera) particles may be classified into one of two groups as a result of thin section analysis: those occurring naturally in clay and those that are added by potters. Naturally occurring particles may be further divided into groups according grain size. One group, which may be termed "small," has grain sizes which range from silt- to clay-sized grains. These are often composed of mica, quartz, feldspar and some hematite. A second group, which may be termed "large" has grain sizes which range from sand-sized to approximately 30 square $\mathrm{mm}$. These naturally appearing particles are easily distinguished by shape from particles considered as additives. Weathering effects are telling: minerals which form part of the clay background are often rounded with no or little cleavage.

Mineral and fossil particles that do not occur naturally, but are added by potters included calcite, grog, gabbro, hematite, and a few appearances of feldspar and quartz. Unlike naturally occurring minerals, the shapes of these additives are angular and have perfect to good cleavages. The effects of crushing are obvious. These grains can dominate the thin section and appear as sand-sized grains and larger.

The following discussion isolates minerals and fossils which occur naturally from a discussion of those which occur as additives.

\section{Naturally Occurring Mineral and Fossil Particles}

Of the mineral and fossil particles which occur naturally, limestone is most frequently encountered. Limestone is identified in 95 percent of all thin sections, 66 percent show intensities $>4$ percent. After limestone are quartz and feldspar. These are identified in 88 percent of the sample, with 73 percent measuring intensities $>4$ percent. Mica exists in 88 percent of the sample, 34percent having intensities $>4$ 
percent. Hematite exists in 71 percent of all thin sections, with 30 percent having intensities $>4$ percent. Finally, allochems are identified in 75 percent of the sample with 29 percent having intensities $>4$ percent. Samples which have a measurable level $c^{5}$ richness or intensity are detailed in Table 2.

TABLE 2

THIN SECTION SAMPLE CLUSTERS BY NATURALLY OCCURRING MINERALS AND FOSSILS

\begin{tabular}{|l|l|l|}
\hline $\begin{array}{l}\text { Naturally Occurring } \\
\text { Mineral and Fossils }\end{array}$ & Intensity & Thin Section Sample \\
\hline \hline \multirow{4}{*}{ Lime } & $>10 \%$ & $\begin{array}{l}1,9,12,16,17,20,21,22,23,26,31, \\
34,36,41,43,46,54,55,91,92,93,94\end{array}$ \\
\cline { 2 - 3 } & $>4 \%$ & $\begin{array}{l}2,11,13,18,29,32,39,47,48,50,52, \\
89,95,97\end{array}$ \\
\hline \hline \multirow{2}{*}{$\begin{array}{l}\text { Quartz and } \\
\text { Feldspar }\end{array}$} & $>10 \%$ & $25,38,39,40,50,52,53,94$ \\
\cline { 2 - 3 } & $>4 \%$ & $\begin{array}{l}1,2,6,11,12,15,16,18,21,22,23,26, \\
27,29,30,32,33,34,35,36,41,43,46, \\
47,51,56,89,90,91,92,93,95,96\end{array}$ \\
\hline \hline \multirow{2}{*}{ Mica } & $>10 \%$ & $2,3,25,40,42,53,56,97$ \\
\hline \hline \multirow{2}{*}{ Hematite } & $>4 \%$ & $7,9,22,23,32,39,50,91,92,93,95$ \\
\cline { 2 - 4 } & $>10 \%$ & $2,18,37,42,50,53,56,97$ \\
\cline { 2 - 3 } & $>4 \%$ & $7,20,25,26,29,30,38,46,47,94$ \\
\hline \multirow{2}{*}{ Allochems } & $>10 \%$ & $6,13,15,16,17,20,26,30,31,44,54$ \\
\cline { 2 - 3 } & $>4 \%$ & $1,4,27,29,33$ \\
\hline
\end{tabular}


While this level of analysis is helpful, it is incomplete. Note that many samples contain more than one or two minerals within the range of given intensities. Therefore a more inclusive system of classification must take into account clusters of mineral intensities. Hence, the following six groups are discerned and arranged in Table 3.

TABLE 3

THIN SECTION SAMPLE CLUSTERS BY MAJOR CLAY GROUPS

\begin{tabular}{|c|c|c|}
\hline Group & Major Components & Thin Section Sample \\
\hline \multirow[t]{4}{*}{1} & Carbonate, Quartz, and Feldspar & $\begin{array}{l}1,6,11,12,15,16,21,27,33 \\
24,26,41,43,89\end{array}$ \\
\hline & $\begin{array}{l}\text { Carbonate, Quartz, Feldspar, and } \\
\text { Hematite }\end{array}$ & $18,26,29,30,46,47,48,94$ \\
\hline & Carbonate, Quartz, Feldspar, and Mica & $22,23,32,39,91,92,93,95$ \\
\hline & $\begin{array}{l}\text { Carbonate, Quartz, Feldspar, Hematite, } \\
\text { and Mica }\end{array}$ & $2,50,56$ \\
\hline \multirow[t]{3}{*}{2} & Hematite and Mica & 7,42 \\
\hline & Hematite, Mica, Quartz, and Feldspar & 25,53 \\
\hline & Hematite, Mica, and Carbonate & 97 \\
\hline \multirow[t]{3}{*}{3} & Carbonate & $4,13,17,31,44,54,55$ \\
\hline & Carbonate and Mica & 9 \\
\hline & Carbonate and Hematite & 20 \\
\hline \multirow[t]{3}{*}{4} & Quartz and Feldspar & $35,51,52,90,96$ \\
\hline & Quartz, Feldspar, and Hematite & 38 \\
\hline & Quartz, Feldspar, and Mica & 40 \\
\hline 5 & Hematite & 37 \\
\hline 6 & Mica & 3 \\
\hline
\end{tabular}




\section{Mineral and Fossil Particles Appearing as Additives}

Of the minerals and fossils which occur as additives, calcite is the most common, present in 73 percent of all thin sections. Gabbro and grog follow, appearing in 45 percent and 43 percent of the sample respectively. Chert is identified in 16 percent, quartz in 14 percent and feldspar is seen in 5 percent of all thin sections. Accordingly, the following 5 groups may be clustered on the basis of additives (Table 4).

TABLE 4

THIN SECTION SAMPLE CLUSTERS BY ADDITIVE

\begin{tabular}{|l|l|l|}
\hline Group & Particle & Thin Section Sample \\
\hline \hline \multirow{2}{*}{2} & Calcite & $4,9,33,43,48,51,54,55,90$ \\
\hline \hline \multirow{3}{*}{2} & Gabbro & $1,3,21,30,53,94$ \\
\cline { 2 - 3 } & Gabbro and Calcite & $6,35,40,47,52$ \\
\cline { 2 - 3 } & Gabbro and Chert & $11,12,23,34,36,41,91,92$ \\
\cline { 2 - 3 } & Gabbro and Grog & $15,26,44$ \\
\hline \hline \multirow{3}{*}{3} & Grog & $2,7,31,32,37,39,46,50,89,93,95$ \\
\cline { 2 - 3 } & Grog and Calcite & $13,16,25,27,38,96,97$ \\
\hline \hline \multirow{2}{*}{4} & Feldspar, Quartz, and/or Chert & $18,22,29,42$ \\
\hline \hline \multirow{2}{*}{5} & Hematite & $17,20,56$ \\
\hline \hline
\end{tabular}


Some correspondences between major clay groups and groups of additives may be noted. As an example, gabbro additives are frequently found in a clay matrix of quartz and feldspar. Similarly, grog is often used as an additive to the carbonate, quartz, and feldspar clay group. However, for the most part, linkages are difficult to isolate and nearly impossible to predict given the limits of the sample.

\section{A Note on Firing}

It is well known that firing process has a profound affect on the nature of ceramic fabrics. Minerals subjected to the high temperatures associated with kilns may change or decompose, e.g. note how the calcite additive in Thin Section 90 has altered to lime. However, apart from Metallic Ware vessels, such changes are rare in the ceramic fabric of this sample. Most calcite crystals are not substantially altered, suggesting that the firing temperatures here did not typically exceed 700 degrees $\mathrm{c}$.

\section{Conclusion}

Thin section analysis suggests that the EBA corpus from Tell Ta'annek is composed from several clay sources with different additives. This analysis identifies six major groups or "families" of clay which may be further broken down into subgroups. Similarly, five "families" of additives are clear. Direct correspondences between clay "families" and additive "families" are difficult to identify on the basis of this sample. 


\section{APPENDIX IV}

\section{PLATES}




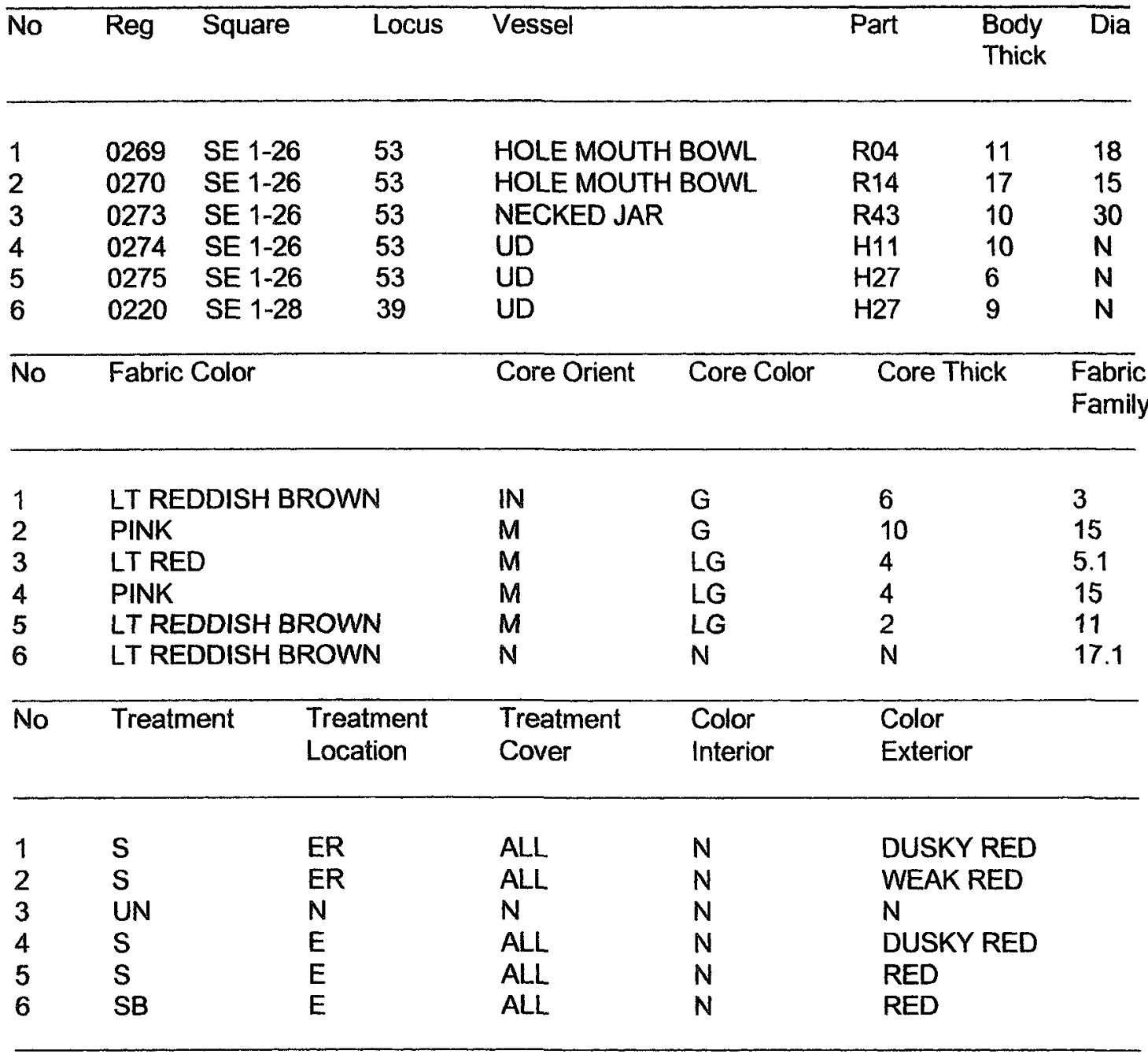

Other

1 Surface burn visible.

2 Surface burn visible.

3 Sample too small to confirm stance or diameter; possibly intrusive.

PLATE 1. FIELD A. PHASE 1A (EB I). 

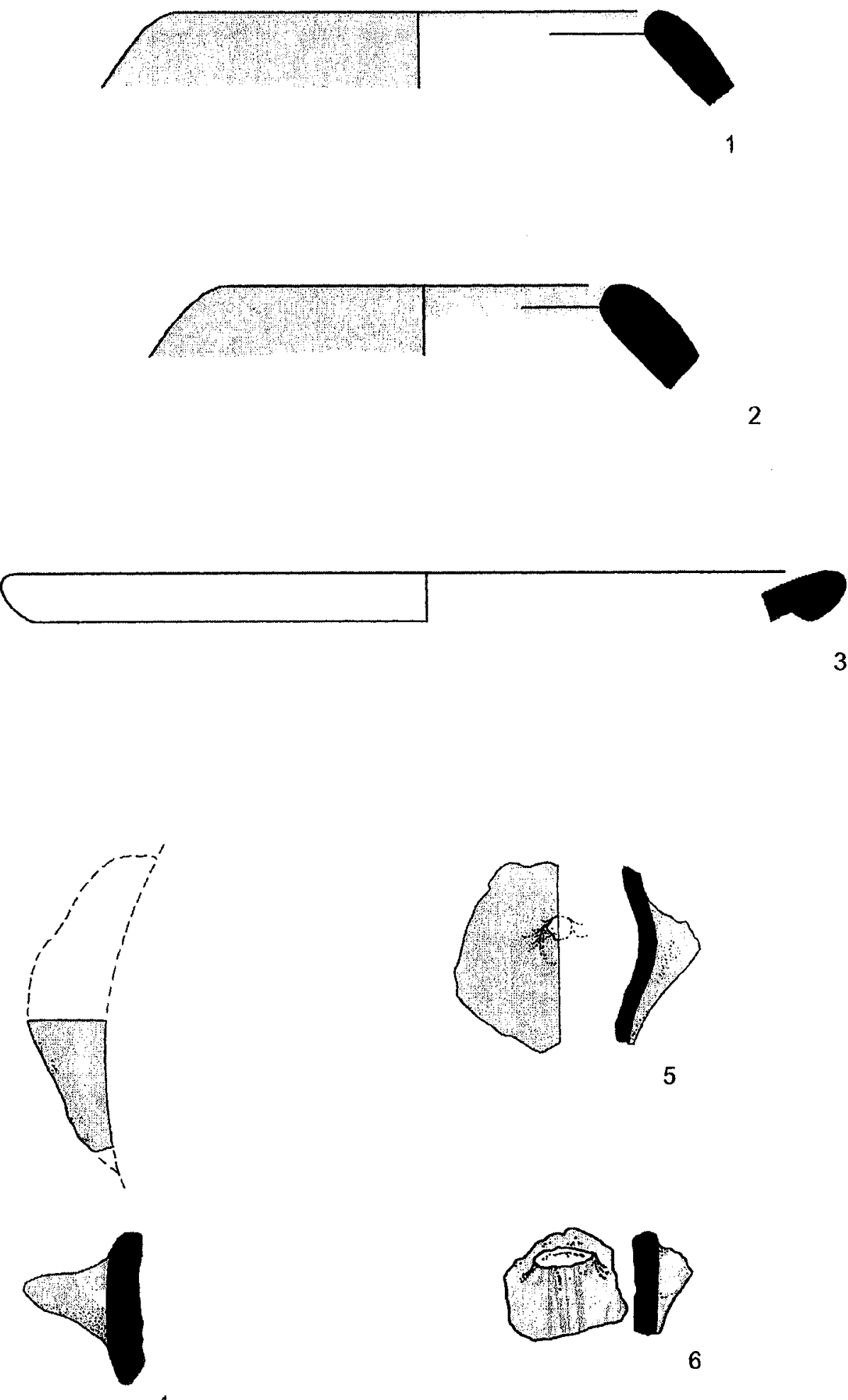

4

PLATE 1(CONT.).

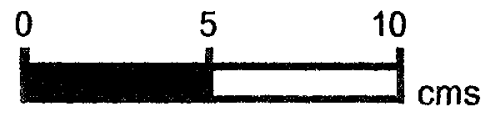


221

\begin{tabular}{llllllll}
\hline No & Reg & Square & Locus & Vessel & Part & $\begin{array}{c}\text { Body } \\
\text { Thick }\end{array}$ & Dia \\
\hline 1 & 0266 & SE 1-26 & 054 & HOLE MOUTH BOWL & R14 & 14 & 26 \\
2 & 0267 & SE 1-26 & 054 & UD & H20 & N & N \\
3 & 0268 & SE 1-26 & 054 & UD & H10 & 9 & N
\end{tabular}

\begin{tabular}{lllll}
\hline No Fabric Color & Core Orient Core Color Core Thick Fabric
\end{tabular}

$\begin{array}{llllll}1 & \text { WEAK RED } & \text { M } & \text { LG } & 7 & 6 \\ 2 & \text { PINK } & \text { IRR } & G & \text { N } & 18 \\ 3 & \text { LTREDDISH BROWN } & \text { IN } & \text { G } & 5 & 18\end{array}$

\begin{tabular}{llllll}
\hline No & Treatment & $\begin{array}{l}\text { Treatment } \\
\text { Location }\end{array}$ & $\begin{array}{l}\text { Treatment } \\
\text { Cover }\end{array}$ & $\begin{array}{l}\text { Color } \\
\text { interior }\end{array}$ & $\begin{array}{l}\text { Color } \\
\text { Exterior }\end{array}$ \\
\hline 1 & UN & $N$ & N & $N$ & N \\
2 & S & E & ALL & $N$ & RED \\
3 & S & E & ALL & N & LT RED \\
\hline
\end{tabular}

\section{Other}

1 Very unevenly formed and smoothed.

3 Portion of ledge/lug handle partially preserved.

PLATE 2. FIELD A. PHASE 1A.(LATE EB I). 

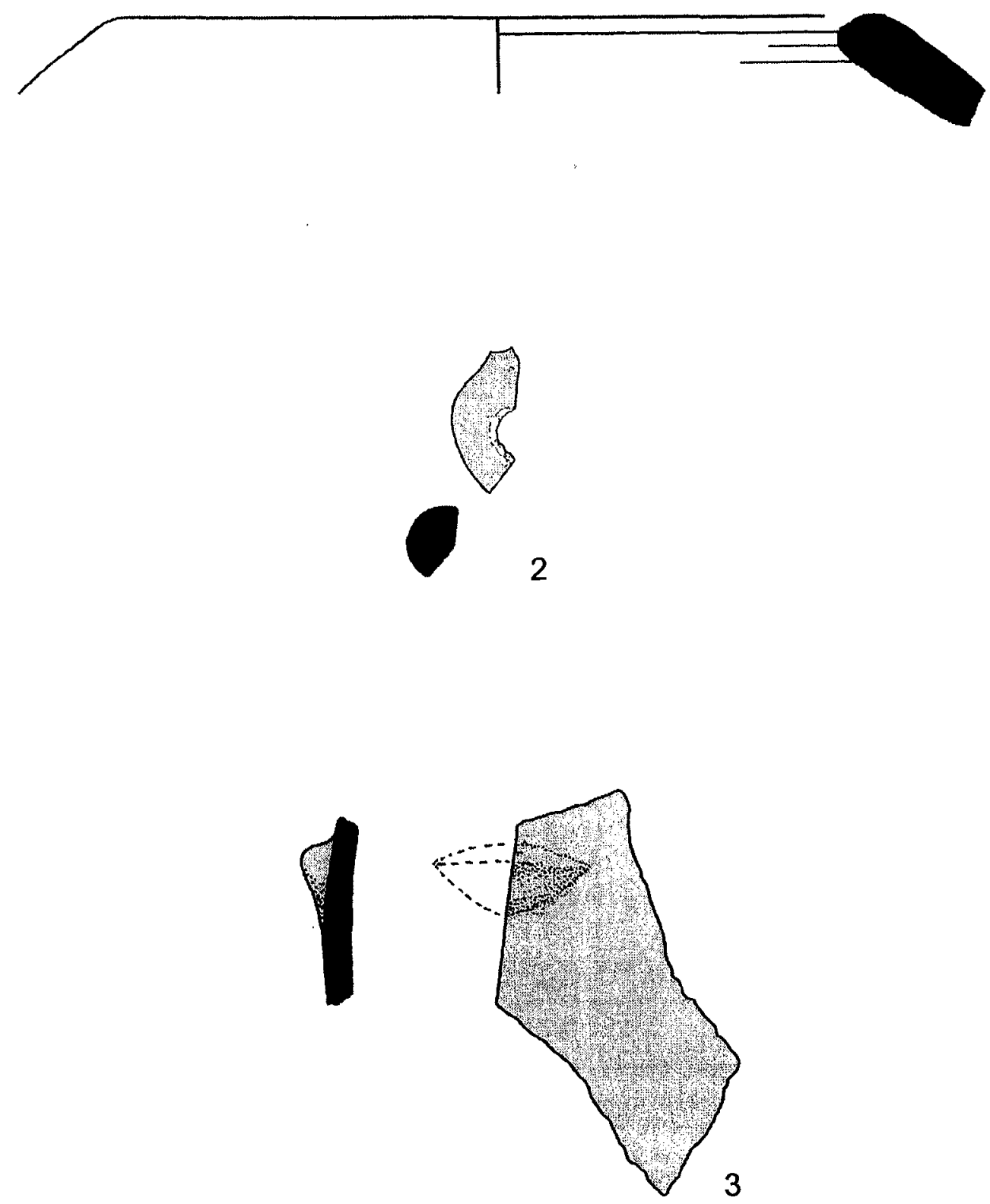

PLATE 2 (CONT.).

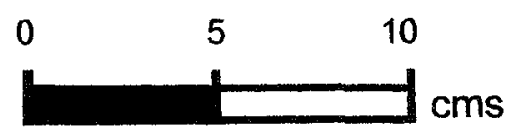


223

\begin{tabular}{llllllll}
\hline No & Reg & Square & Locus & Vessel & Part & $\begin{array}{l}\text { Body } \\
\text { Thick }\end{array}$ & Dia \\
\hline 1 & & & & & & & \\
2 & 0072 & SE 1-27 & 56 & HOLE MOUTH BOWL & R19 & 12 & 12 \\
3 & 0451 & SW 1-27 & 54 & GUTTER-RIM BOWL & R29 & 13 & N \\
4 & 0450 & SW 1-27 & 54 & HOLE MOUTH JAR & R04 & 12 & 30 \\
5 & 0452 & SW 1-27 & 54 & HOLE MOUTH JAR & R11 & 7 & 30 \\
6 & 0074 & SE 1-27 & 56 & UD & B10 & 14 & 16 \\
7 & 0073 & SE 1-27 & 56 & JUG(LET)? & B23 & 5 & 2 \\
8 & 0453 & SW 1-27 & 54 & UD & H20 & N & N \\
9 & 0455 & SW 1-27 & 54 & UD & BOD & 7 & N \\
& 0454 & SW 1-27 & 54 & UD & H14 & 9 & N
\end{tabular}

\begin{tabular}{|c|c|c|c|}
\hline $\begin{array}{ll}\text { No } & \text { Fabric Color }\end{array}$ & Core Orient & Core Color & Core Thick \\
\hline
\end{tabular}

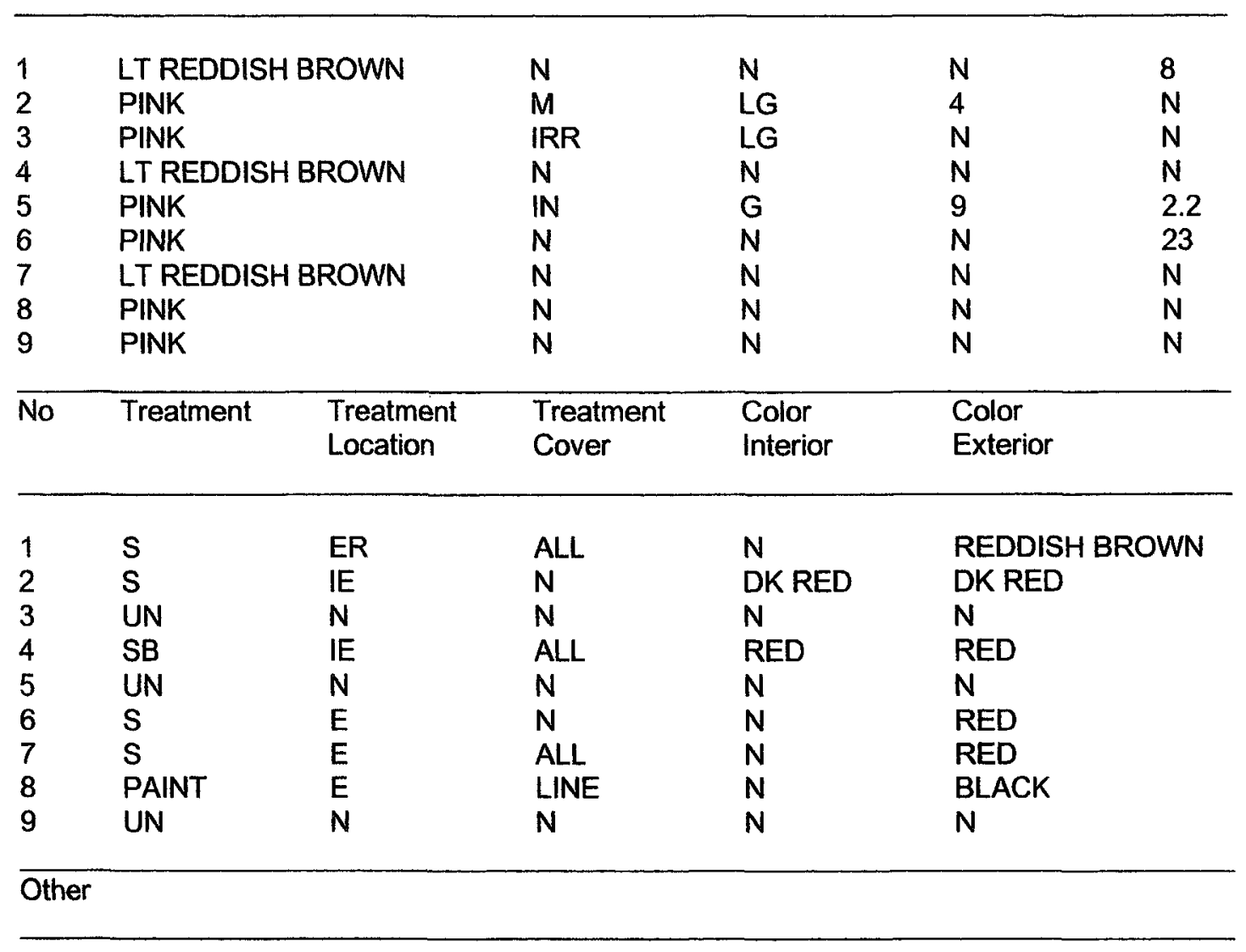

1 Sample too small to confirm stance or diameter.

2 Sample too small to confirm stance or diameter.

PLATE 3. FIELD A. PHASE 1B (EARLY EB II). 

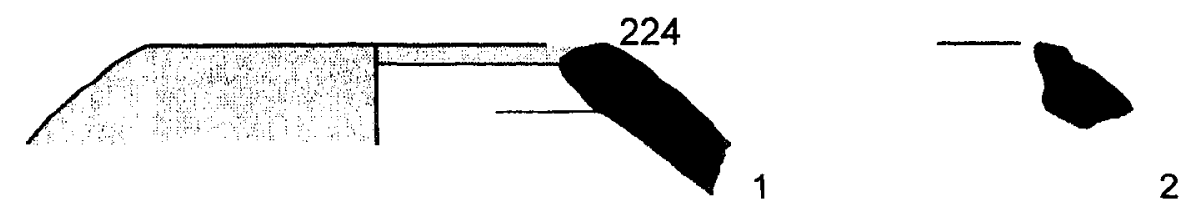

2

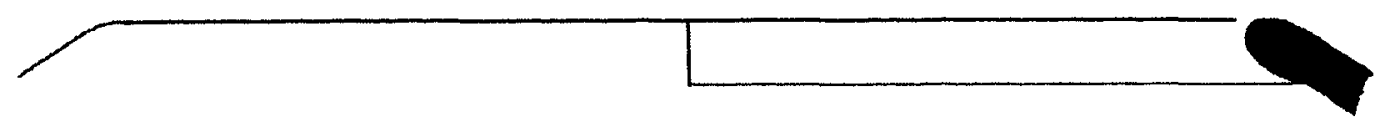

3
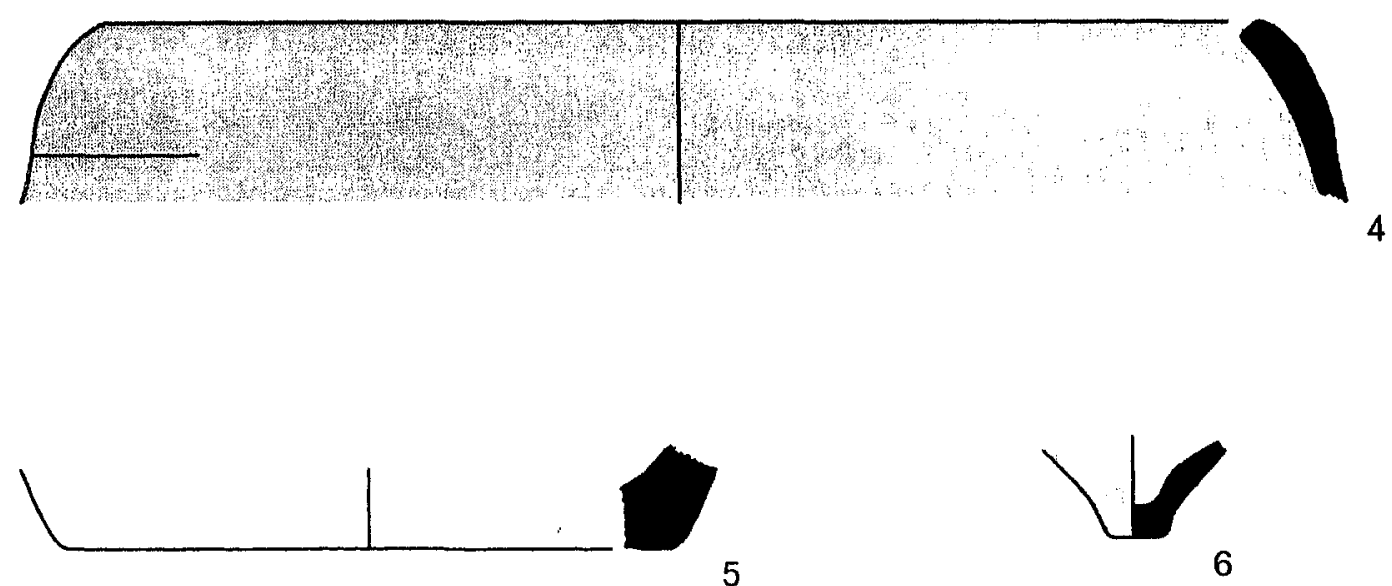

5

6

目
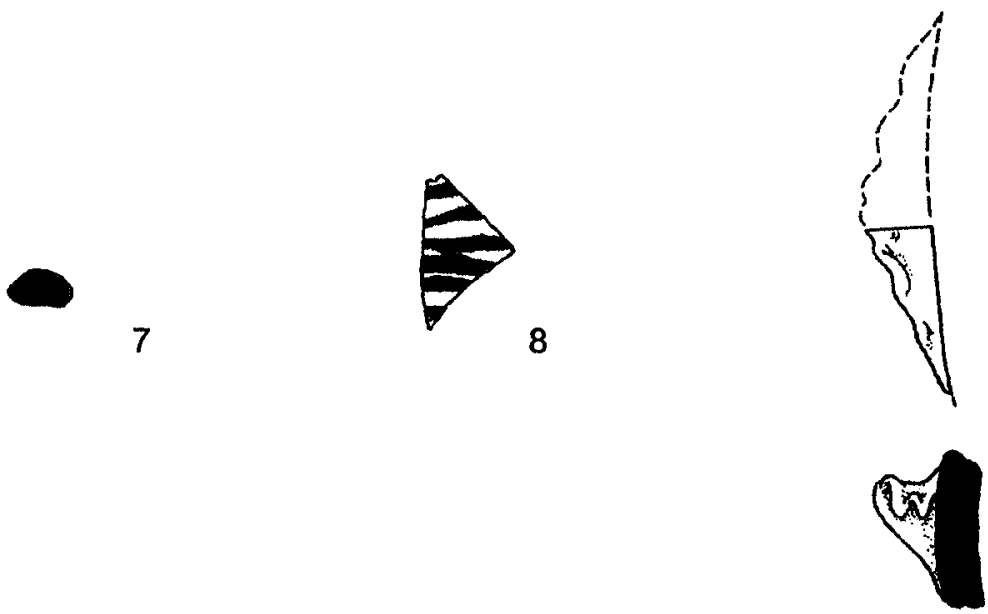

9

PLATE 3 (CONT.).

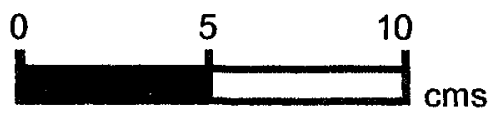




\begin{tabular}{llllllll}
\hline No & Reg & Square & Locus & Vessel & Part & $\begin{array}{l}\text { Body } \\
\text { Thick }\end{array}$ & Dia \\
\hline 1 & & & & & & & \\
1 & 0387 & SW 1-27 & 60 & BOWL & R50 & 6 & 10 \\
2 & 0459 & SW 1-27 & 55 & HOLE MOUTH JAR & R19 & 10 & 30 \\
3 & 0457 & SW 1-27 & 55 & HOLE MOUTH JAR & R04 & 14 & 25 \\
4 & 0390 & SW 1-27 & 60 & HOLE MOUTH JAR & R04 & 9 & 18 \\
5 & 0460 & SW 1-27 & 56 & HOLE MOUTH BOWL & R19 & 14 & 30 \\
6 & 0388 & SW 1-27 & 60 & NECKED JAR & R31 & 7 & 20 \\
7 & 0386 & SW 1-27 & 60 & UD & BOD & 7 & N \\
8 & 0389 & SW 1-27 & 60 & UD & BOD & 4 & N \\
9 & 0456 & SW 1-27 & 55 & HOLE MOUTH BOWL & R19 & 12 & 48 \\
10 & 0458 & SW 1-27 & 55 & HOLE MOUTH BOWL & R28 & 8 & 50 \\
\hline No & Fabric Color & & Core Orient Core Color & Core Thick & Fabric \\
& & & & & & & Family
\end{tabular}

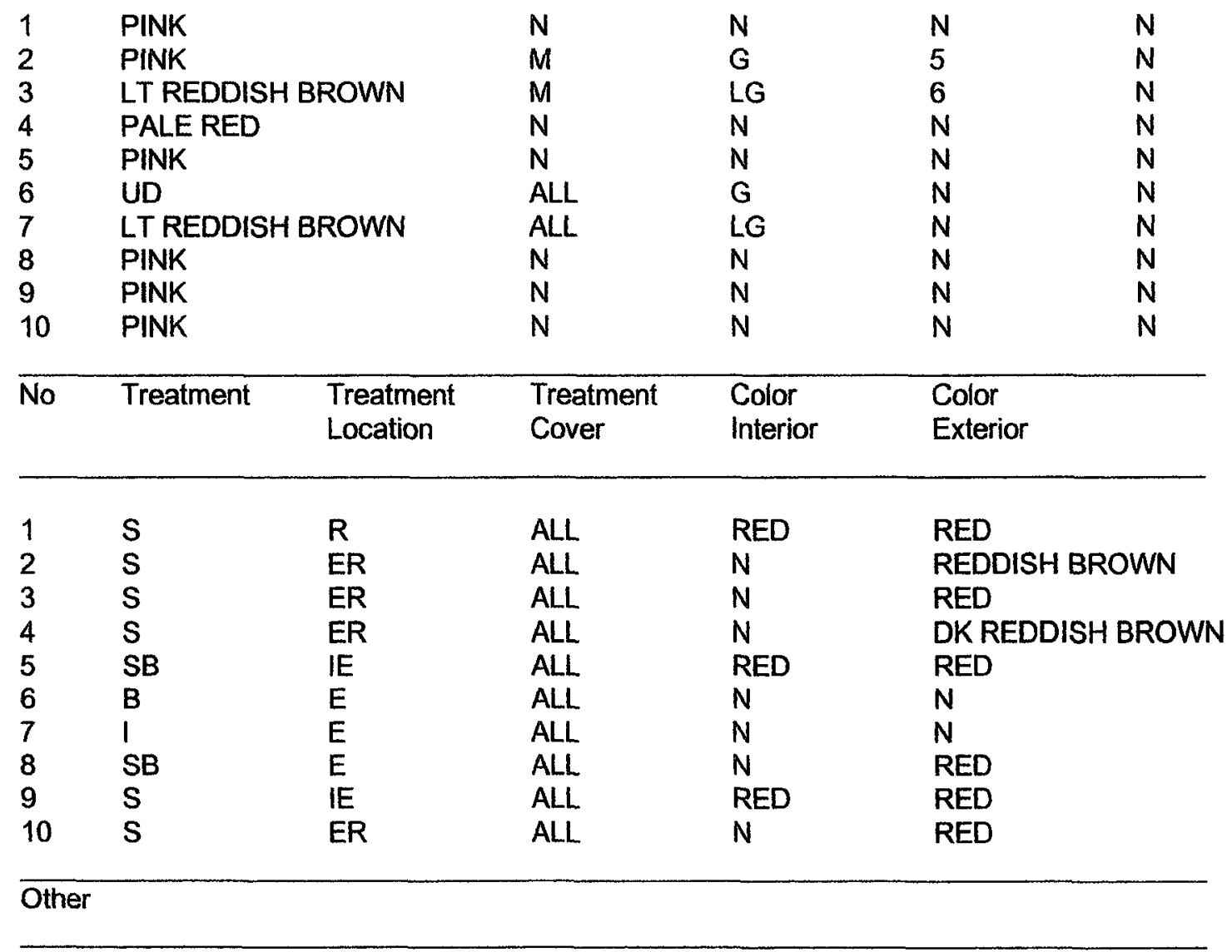

$\begin{array}{ll}6 & \text { Grey Burnished Ware. } \\ 7 & \text { Combed Metallic Ware. }\end{array}$

PLATE 4. FIELD A. PHASE 1B (EARLY EB II). 

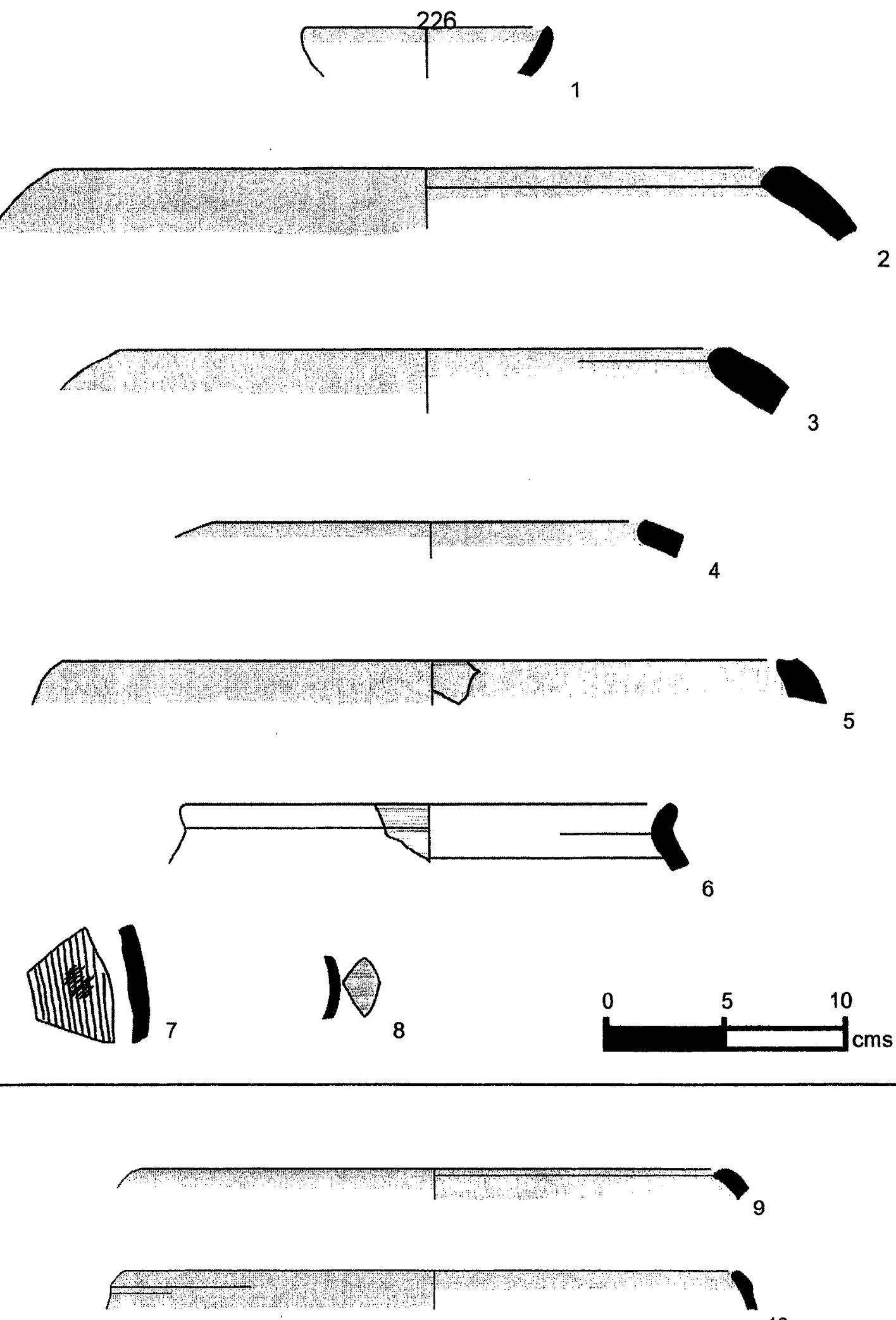

10

PLATE 4 (CONT.).

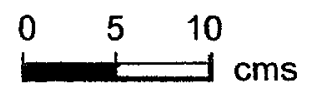




\begin{tabular}{|c|c|c|c|c|c|c|c|}
\hline No & $\operatorname{Reg}$ & Square & Locus & Vessel & Part & $\begin{array}{l}\text { Body } \\
\text { Thick }\end{array}$ & $\overline{\mathrm{Dia}}$ \\
\hline 1 & 0409 & SW 1-27 & 62 & BOWL & R50 & 5 & 14 \\
\hline 2 & 0397 & SW 1-27 & 62 & HOLE MOUTH JAR & R17 & 8 & 16 \\
\hline 3 & 0399 & SW 1-27 & 62 & HOLE MOUTH JAR & $\mathrm{R} 07$ & 12 & 24 \\
\hline 4 & 0398 & SW 1-27 & 62 & HOLE MOUTH JAR & R19 & 13 & 18 \\
\hline 5 & 0394 & SW 1-27 & 62 & HOLE MOUTH JAR & R14 & 14 & 18 \\
\hline 6 & 0393 & SW 1-27 & 62 & HOLE MOUTH BOWL & R09 & 12 & 28 \\
\hline 7 & 0396 & SW 1-27 & 62 & BOW RIM JAR & R33 & 12 & 28 \\
\hline 8 & 0395 & SW 1-27 & 62 & LEDGE RIM BOWL & R53 & 12 & 32 \\
\hline 9 & 0402 & SW 1-27 & 62 & UD & R82 & 8 & 12 \\
\hline 10 & 0407 & SW 1-27 & 62 & UD & $\mathrm{B} 12$ & 12 & 16 \\
\hline 11 & 0404 & SW 1-27 & 62 & UD & $\mathrm{H} 20$ & 9 & $\mathbf{N}$ \\
\hline 12 & 0403 & SW 1-27 & 62 & UD & $\mathrm{H} 20$ & $\mathrm{~N}$ & $N$ \\
\hline 13 & 0406 & SW 1-27 & 62 & UD & $\mathrm{H} 2 \mathrm{O}$ & 6 & $\mathbf{N}$ \\
\hline 14 & 0405 & SW 1-27 & 62 & UD & $\mathrm{H} 20$ & $\mathbf{N}$ & $\mathbf{N}$ \\
\hline No & Fab & & & ore Color & & & $\begin{array}{l}\text { Fabric } \\
\text { Family }\end{array}$ \\
\hline
\end{tabular}

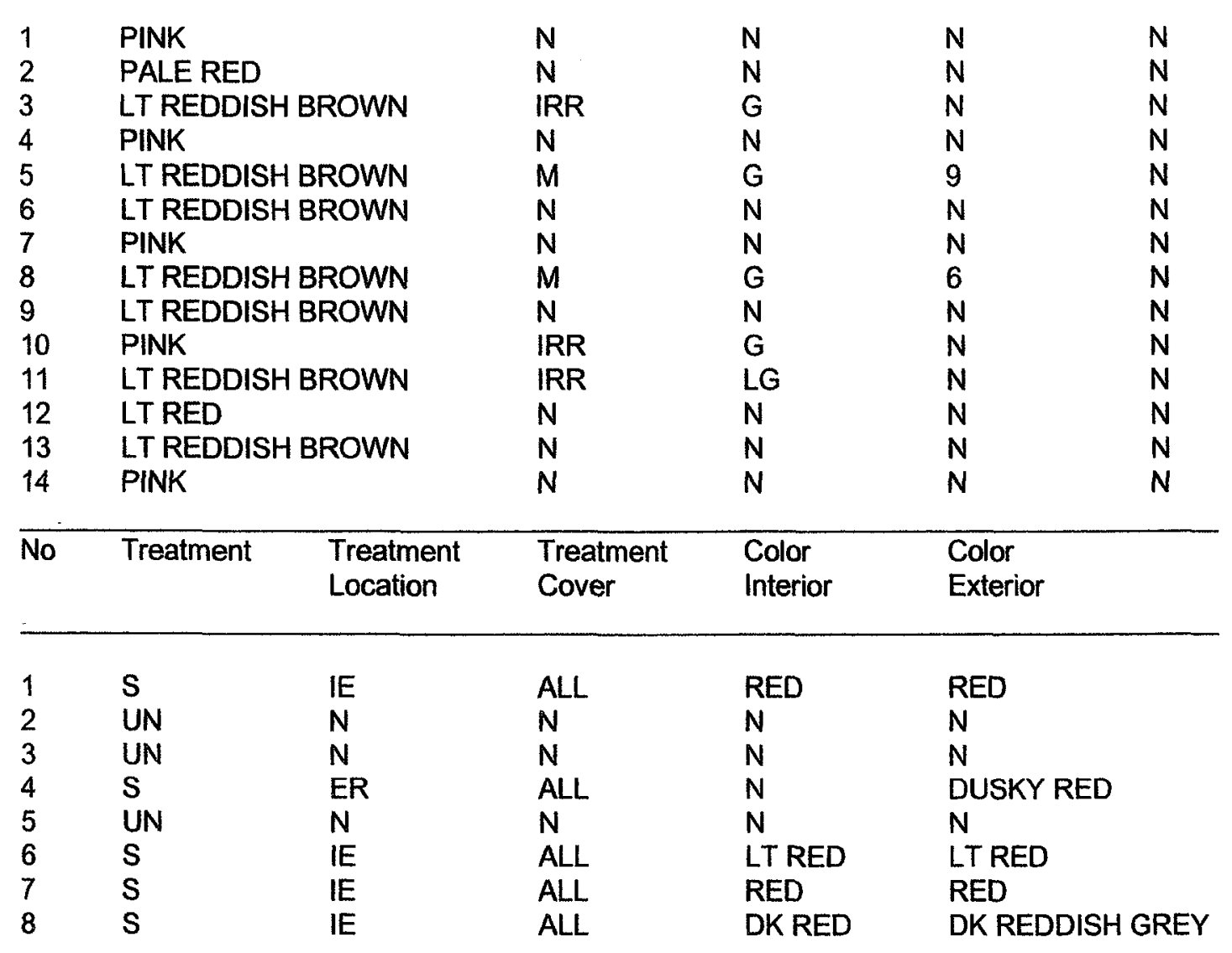

PLATE 5. FIELD A. PHASE 1B (EARLY EB II). 
228

\begin{tabular}{llllll}
\hline No & Treatment & $\begin{array}{l}\text { Treatment } \\
\text { Location }\end{array}$ & $\begin{array}{l}\text { Treatment } \\
\text { Cover }\end{array}$ & $\begin{array}{l}\text { Color } \\
\text { interior }\end{array}$ & $\begin{array}{l}\text { Color } \\
\text { Exterior }\end{array}$ \\
\hline 9 & S & ER & ALL & N & RED \\
10 & S & E & ALL & N & RED \\
11 & S & E & ALL & N & DK RED \\
12 & S & E & ALL & N & DK RED \\
13 & S & E & ALL & N & RED \\
14 & S & E & ALL & N & DK RED \\
\hline Other & & & & \\
\hline
\end{tabular}

1 Burn on lip suggests use as a lamp; sample too small to confirm stance or diameter.

$2 \quad$ Lines of rim smoothing visible on interior and exterior.

3 Surface burn visible.

4 Two horizontal slashes/punch marks on shoulder.

8 Surface burn visible; very weathered.

11 Incised lines radiate out from handle to body wall.

PLATE 5 (CONT.). 

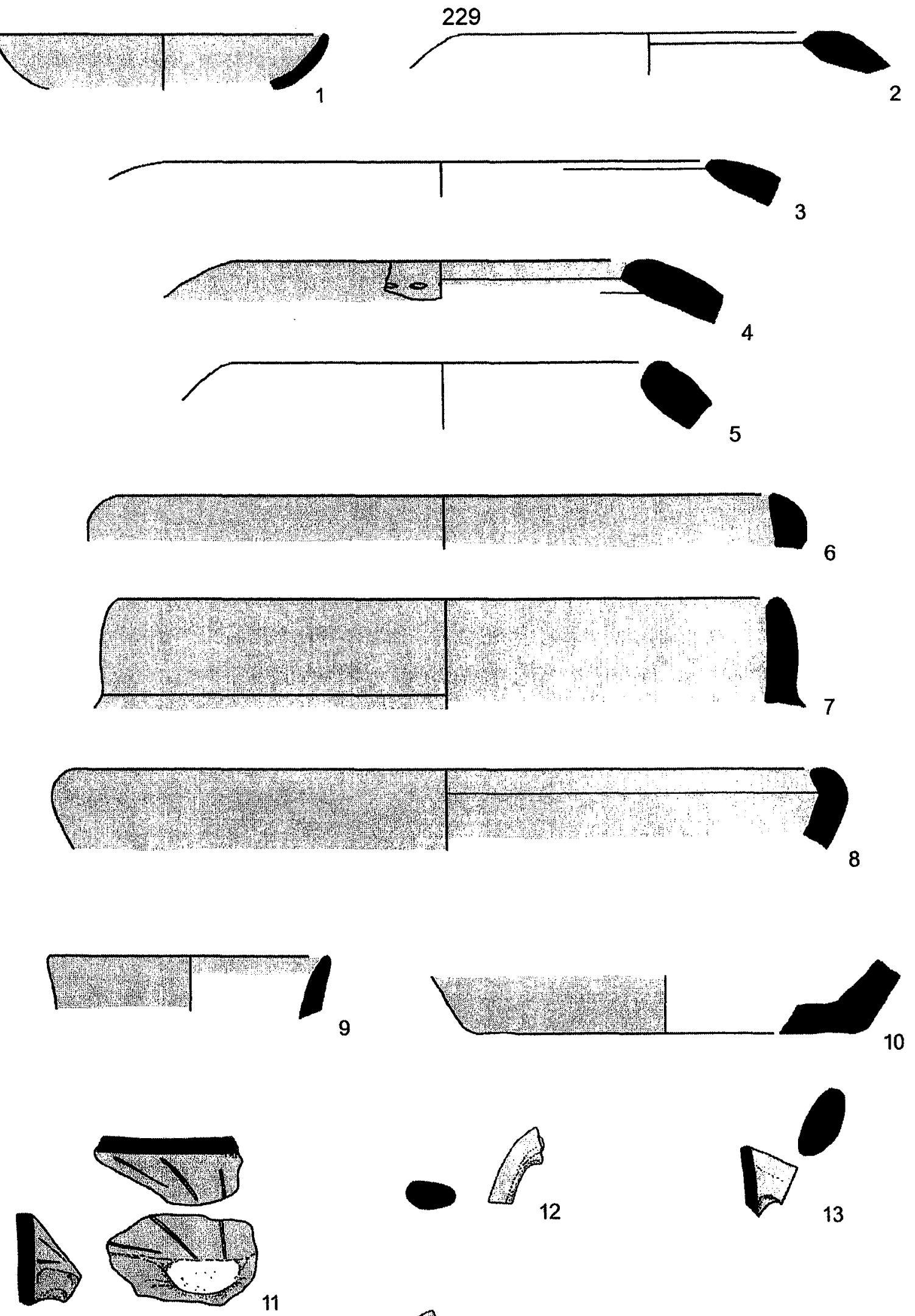

PLATE 5 (CONT.).

11 
230

\begin{tabular}{llllllll}
\hline No & Reg & Square & Locus & Vessel & Part & $\begin{array}{c}\text { Body } \\
\text { Thick }\end{array}$ & Dia \\
& & & & & & & \\
1 & 0382 & SW 1-27 & 63 & HOLE MOUTH JAR & R07 & 10 & 10 \\
2 & 0438 & SW 1-27 & 72 & HOLE MOUTH JAR & R14 & 11 & 18 \\
3 & 0428 & SW 1-27 & 64 & HOLE MOUTH JARIBOWL & R14 & 10 & 30 \\
4 & 0429 & SW 1-27 & 64 & HOLE MOUTH BOWL & R07 & 10 & 30 \\
5 & 0431 & SW 1-27 & 64 & UD & B12 & 12 & 20 \\
6 & 0384 & SW 1-27 & 63 & UD & B12 & 12 & 18 \\
7 & 0430 & SW 1-27 & 64 & UD & H20 & 7 & N \\
8 & 0383 & SW 1-27 & 63 & VAT & R10 & 11 & 38
\end{tabular}

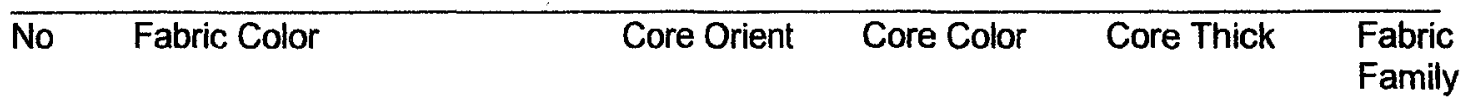

\begin{tabular}{|c|c|c|c|c|c|c|}
\hline 1 & \multicolumn{2}{|c|}{ WEAK RED } & $M$ & G & 5 & $N$ \\
\hline 2 & \multicolumn{2}{|c|}{ LT REDDISH BROWN } & M & G & 7 & $N$ \\
\hline 3 & \multicolumn{2}{|l|}{ PINK } & $\mathrm{N}$ & $\mathbf{N}$ & $\mathbf{N}$ & $\mathbf{N}$ \\
\hline 4 & \multicolumn{2}{|c|}{ LT REDDISH BROWN } & $\mathrm{N}$ & $\mathrm{N}$ & $\mathrm{N}$ & $\mathrm{N}$ \\
\hline 5 & \multicolumn{2}{|c|}{ WEAK RED } & $\mathbb{N}$ & G & 8 & $\mathbf{N}$ \\
\hline 6 & \multicolumn{2}{|c|}{ LT REDDISH BROWN } & $\mathbb{N}$ & G & 9 & $\mathrm{~N}$ \\
\hline 7 & \multicolumn{2}{|c|}{ LT BROWN } & $\mathbf{N}$ & $N$ & $\mathrm{~N}$ & $\mathrm{~N}$ \\
\hline 8 & \multicolumn{2}{|c|}{ LT REDDISH BROWN } & $\mathbf{N}$ & $\mathbf{N}$ & $N$ & $N$ \\
\hline No & Treatment & $\begin{array}{l}\text { Treatment } \\
\text { Location }\end{array}$ & $\begin{array}{l}\text { Treatment } \\
\text { Cover }\end{array}$ & & & $\begin{array}{l}\text { Color } \\
\text { Exterior }\end{array}$ \\
\hline 1 & UN & $N$ & $N$ & $\mathrm{~N}$ & & $\mathrm{~N}$ \\
\hline 2 & UN & $\mathrm{N}$ & $\mathrm{N}$ & $\mathbf{N}$ & & $\mathrm{N}$ \\
\hline 3 & UN & IR & $\mathrm{N}$ & & & $\mathbf{N}$ \\
\hline 4 & $\mathrm{~S}$ & $E$ & ALL & $\mathrm{N}$ & & DUSKY RED \\
\hline 5 & UN & $\mathrm{N}$ & $\mathrm{N}$ & $\mathrm{N}$ & & $\mathbf{N}$ \\
\hline 6 & UN & $N$ & $\mathbf{N}$ & $\mathrm{N}$ & & $\mathbf{N}$ \\
\hline 7 & SB & $\mathrm{E}$ & $A L L$ & $\mathrm{~N}$ & & DK RED \\
\hline 8 & $\mathbf{S}$ & ER & ALL & $\mathrm{N}$ & & RED \\
\hline
\end{tabular}

Other

1 Surface burn visible.

6 Surface burn visible.

PLATE 6. FIELD A. PHASE 1B (EARLY EB II). 

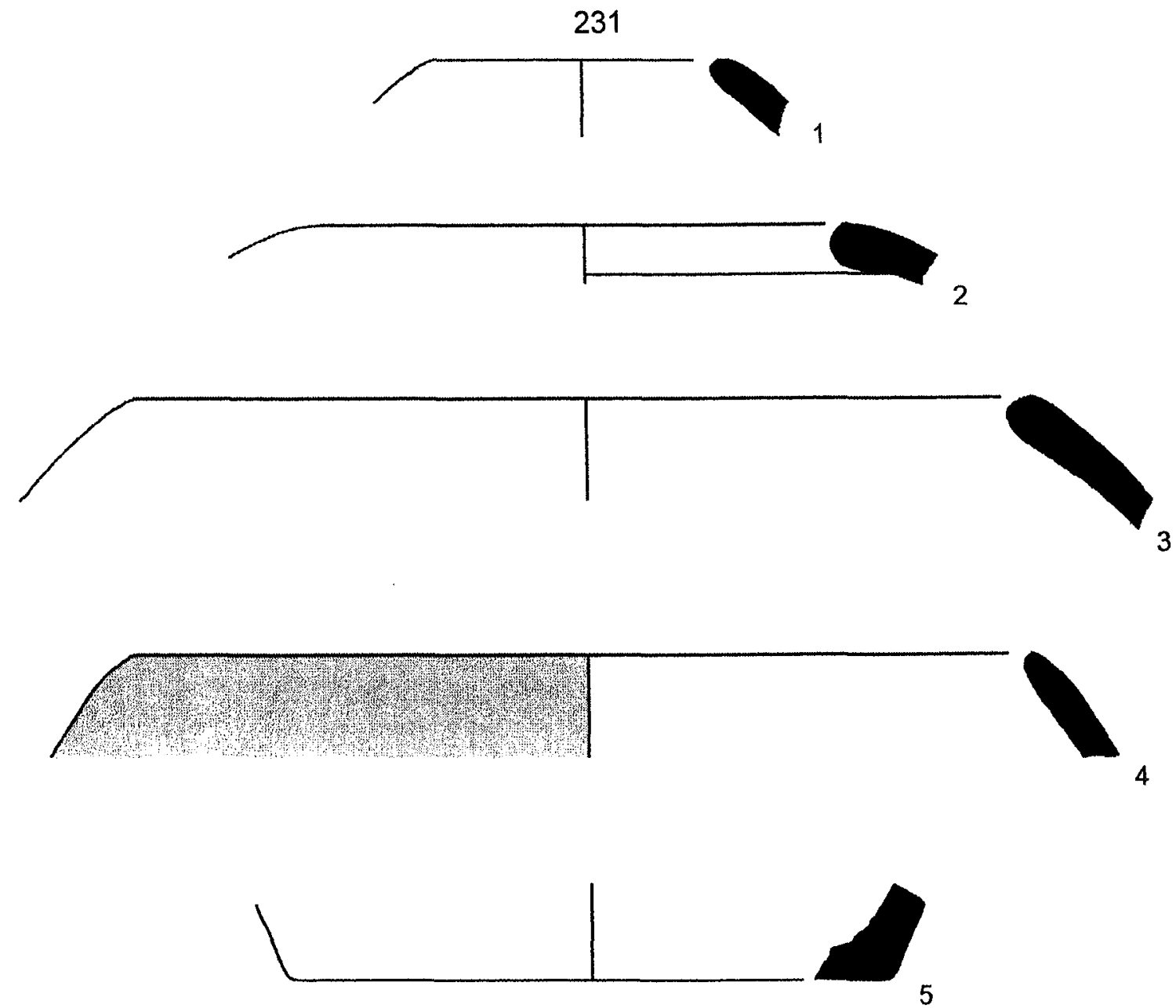

5

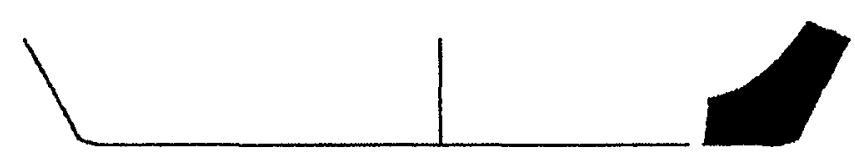

6

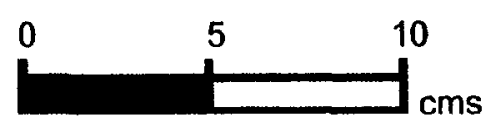

PLATE 6 (CONT.).

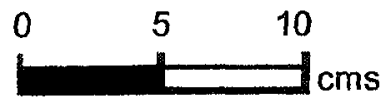




\begin{tabular}{|c|c|c|c|c|c|c|c|}
\hline No & Reg & Square & Locus & Vessel & Part & $\begin{array}{l}\text { Body } \\
\text { Thick }\end{array}$ & $\overline{\text { Dia }}$ \\
\hline 1 & 0586 & SW 1-29 & 28 & LEDGE RIM BOWL & R51 & 12 & 38 \\
\hline 2 & 0589 & SW 1-29 & 28 & PLATTER BOWL & R56 & 10 & 30 \\
\hline 3 & 0585 & SW 1-29 & 28 & HOLE MOUTH JAR & R08 & 15 & 16 \\
\hline 4 & 2250 & SW 1-29 & 28 & HOLE MOUTH JARIBOWL & R02 & $\mathrm{N}$ & $\mathrm{N}$ \\
\hline 5 & 0588 & SW 1-29 & 28 & NECKED JAR & R32 & 13 & 15 \\
\hline 6 & 0590 & SW $1-29$ & 28 & UD & BOD & 9 & $\mathbf{N}$ \\
\hline 7 & 0587 & SW $1-29$ & 28 & LEDGE RIM BOWL & R57 & 16 & 40 \\
\hline 8 & 2251 & SW $1-29$ & 28 & PLATTER BOWL & R56 & 8 & 50 \\
\hline
\end{tabular}

\begin{tabular}{|c|c|c|c|c|c|c|c|}
\hline 1 & & & & & & \\
\hline \multicolumn{6}{|c|}{ LT REDDISH BROWN } & & \\
\hline 3 & \multicolumn{2}{|c|}{ LT REDDISH BROWN } & $M$ & $\mathrm{G}$ & 7 & & 2.1 \\
\hline \multirow{2}{*}{$\begin{array}{l}4 \\
5\end{array}$} & \multicolumn{2}{|c|}{ REDDISH BROWN } & EX & $\mathbf{G}$ & $\mathrm{N}$ & & $\mathbf{N}$ \\
\hline & \multicolumn{2}{|c|}{ LT REDDISH BROWN } & $M$ & G & 4 & & 21 \\
\hline 3 & \multicolumn{2}{|c|}{ LT RED } & $\mathrm{N}$ & $N$ & $\mathrm{~N}$ & & 10.2 \\
\hline & \multicolumn{2}{|l|}{ PINK } & $\mathbf{M}$ & LG & 8 & & 15 \\
\hline 8 & \multicolumn{2}{|l|}{ LT BROWN } & IRR & LG & $N$ & & $N$ \\
\hline No & Treatment & $\begin{array}{l}\text { Treatment } \\
\text { Location }\end{array}$ & $\begin{array}{l}\text { Treatment } \\
\text { Cover }\end{array}$ & \multicolumn{2}{|l|}{$\begin{array}{l}\text { Color } \\
\text { Interior }\end{array}$} & $\begin{array}{l}\text { Color } \\
\text { Exterio }\end{array}$ & \\
\hline 1 & $\mathrm{~s}$ & IE & ALL & RED & & RED & \\
\hline 2 & SB & IR & ALL & DK RED & & $\mathrm{N}$ & \\
\hline 3 & UN & $\mathbf{N}$ & $\mathrm{N}$ & $\mathbf{N}$ & & $\mathrm{N}$ & \\
\hline 4 & UN & $\mathbf{N}$ & $\mathbf{N}$ & $\mathbf{N}$ & & $\mathbf{N}$ & \\
\hline 5 & $\mathbf{S}$ & ER & ALL & $\mathbf{N}$ & & RED & \\
\hline 6 & UN & $\mathrm{N}$ & $\mathrm{N}$ & $\mathrm{N}$ & & $\mathrm{N}$ & \\
\hline 7 & $\mathrm{~S}$ & IR & $A L L$ & DKRED & BROWN & $\mathbf{N}$ & \\
\hline 8 & SB & IR & ALL & RED & & $\mathbf{N}$ & \\
\hline
\end{tabular}

\section{Other}

3 Surface burn visible.

4 Sample too small to confirm stance or diameter.

$6 \quad$ Combed Metallic Ware.

8 Radial burnish over slip; wheel burnish on rim; sample too small to confirm stance or diameter.

PLATE 7. FIELD A. PHASE 1B (EARLY EB II). 
233
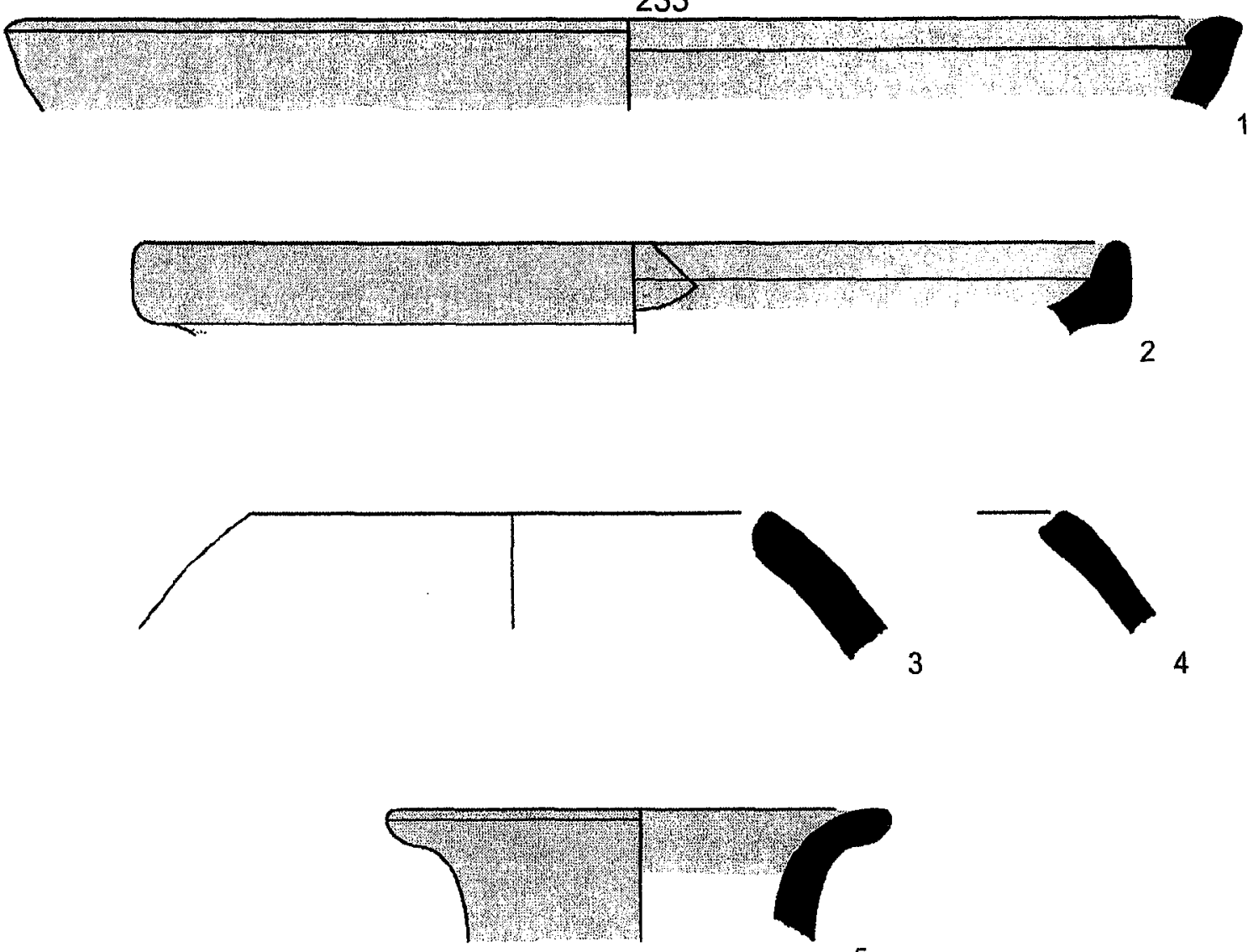

5
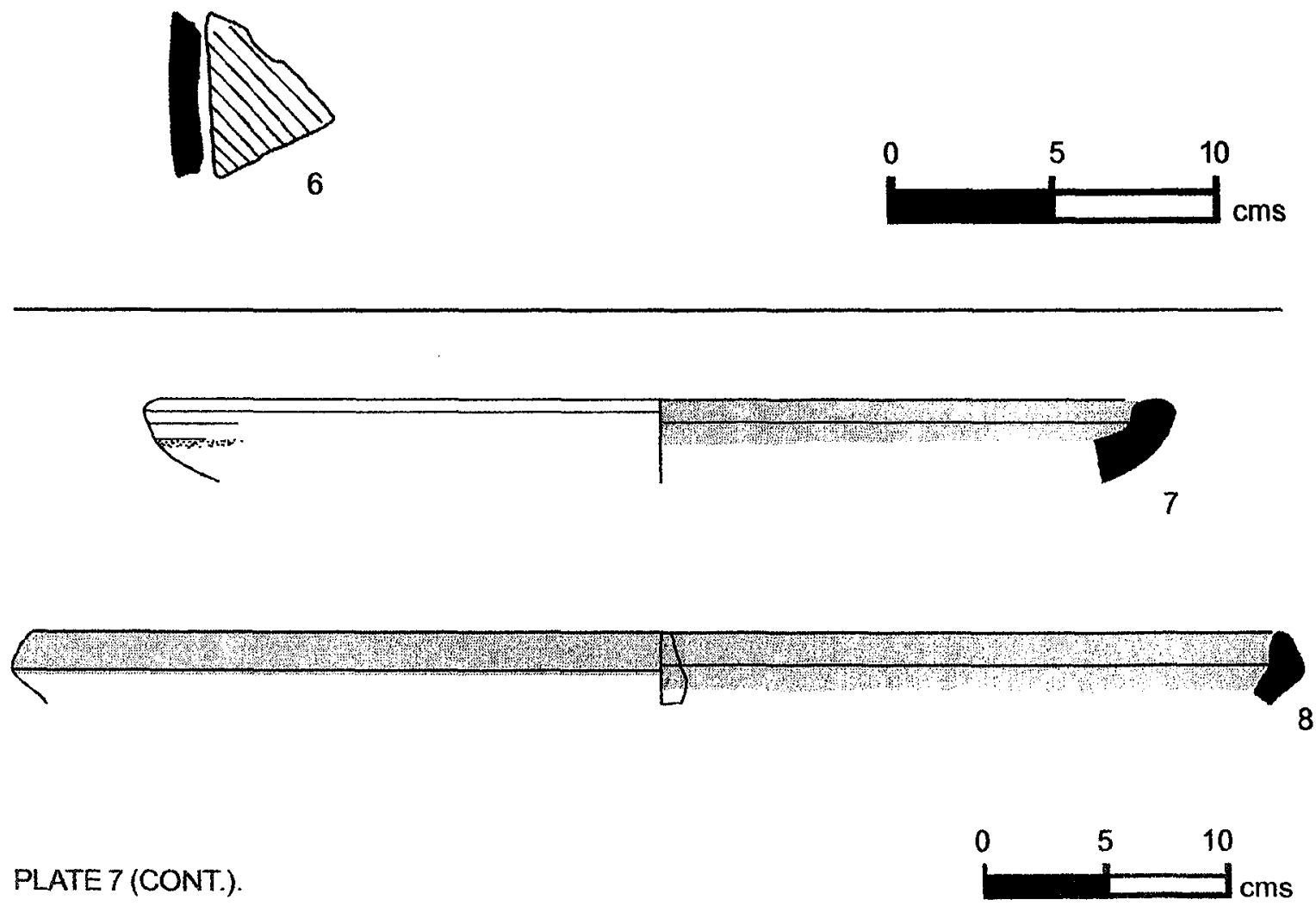

Reproduced with permission of the copyright owner. Further reproduction prohibited without permission. 


\begin{tabular}{llllllll}
\hline No & Reg & Square & Locus & Vessel & Part & $\begin{array}{l}\text { Body } \\
\text { Thick }\end{array}$ & Dia \\
\hline 1 & 0710 & SW 2-27 & 91 & HOLE MOUTH BOWL & R11 & 10 & 20 \\
2 & 0711 & SW 2-27 & 91 & HOLE MOUTH JAR & R11 & 10 & 18 \\
3 & 1034 & SW 4-27 & 28 & HOLE MOUTH BOWL & R11 & 8 & 22 \\
4 & 1035 & SW 4-27 & 28 & HOLE MOUTH JAR & R09 & 9 & 12 \\
5 & 1036 & SW 4-27 & 28 & NECKED JAR & R42 & 12 & 16 \\
6 & 1037 & SW 4-27 & 28 & UD & BOD & 7 & N \\
7 & 2314 & SW 4-27 & 28 & UD & BOD & 6 & N \\
8 & 0712 & SW 2-27 & 91 & UD & B12 & 12 & 40 \\
\hline No & Fabric Color & & Core Orient Core Color & Core Thick & Fabric \\
& & & & & & &
\end{tabular}

\begin{tabular}{|c|c|c|c|c|c|c|}
\hline 1 & \multicolumn{2}{|l|}{ PALE RED } & $\mathbf{N}$ & $\mathrm{N}$ & $\mathrm{N}$ & 8 \\
\hline 2 & \multicolumn{2}{|l|}{ LT RED } & M & G & $\mathrm{N}$ & $\mathrm{N}$ \\
\hline 3 & \multicolumn{2}{|c|}{ LT REDDISH BROWN } & EX & $\mathbf{G}$ & 5 & 5.1 \\
\hline 4 & \multicolumn{2}{|c|}{ WEAK RED } & M & G & 6 & $\mathbf{N}$ \\
\hline 5 & \multicolumn{2}{|l|}{ PINK } & $\mathrm{N}$ & $\mathbf{N}$ & $\mathrm{N}$ & 23 \\
\hline 6 & \multicolumn{2}{|c|}{ LT REDDISH BROWN } & $\mathrm{N}$ & $\mathrm{N}$ & $\mathrm{N}$ & 8 \\
\hline 7 & \multicolumn{2}{|l|}{ RED } & $\mathrm{N}$ & $\mathbf{N}$ & $\mathrm{N}$ & $\mathrm{N}$ \\
\hline 8 & \multicolumn{2}{|l|}{ PALE RED } & $M$ & $\mathbf{G}$ & $\mathrm{N}$ & 6 \\
\hline No & Treatment & $\begin{array}{l}\text { Treatment } \\
\text { Location }\end{array}$ & $\begin{array}{l}\text { Treatment } \\
\text { Cover }\end{array}$ & $\begin{array}{l}\text { Color } \\
\text { Interior }\end{array}$ & $\begin{array}{l}\text { Color } \\
\text { Exterior }\end{array}$ & \\
\hline 1 & UN & $\mathrm{N}$ & $\mathrm{N}$ & $\mathrm{N}$ & $\mathrm{N}$ & \\
\hline 2 & $\mathbf{S}$ & ER & ALL & $\mathrm{N}$ & RED & \\
\hline 3 & UN & $\mathrm{N}$ & $\mathbf{N}$ & $\mathbf{N}$ & $\mathbf{N}$ & \\
\hline 4 & UN & $\mathbf{N}$ & $\mathbf{N}$ & $\mathrm{N}$ & $\mathbf{N}$ & \\
\hline 5 & $\mathbf{s}$ & ER & ALL & $N$ & LT RED & \\
\hline 6 & PAINT & $E$ & NET & $N$ & RED & \\
\hline 7 & 1 & $\mathrm{E}$ & ALL & $\mathbf{N}$ & $\mathrm{N}$ & \\
\hline 8 & 1 & $E$ & LINE & $\mathbf{N}$ & $\mathrm{N}$ & \\
\hline
\end{tabular}

Other

$6 \quad$ Net painting.

7 Combed Metallic Ware.

8 Impression visible on exterior wall, made by rope when forming?

PLATE 8. FIELD A. PHASE 1B (EARLY EB II). 

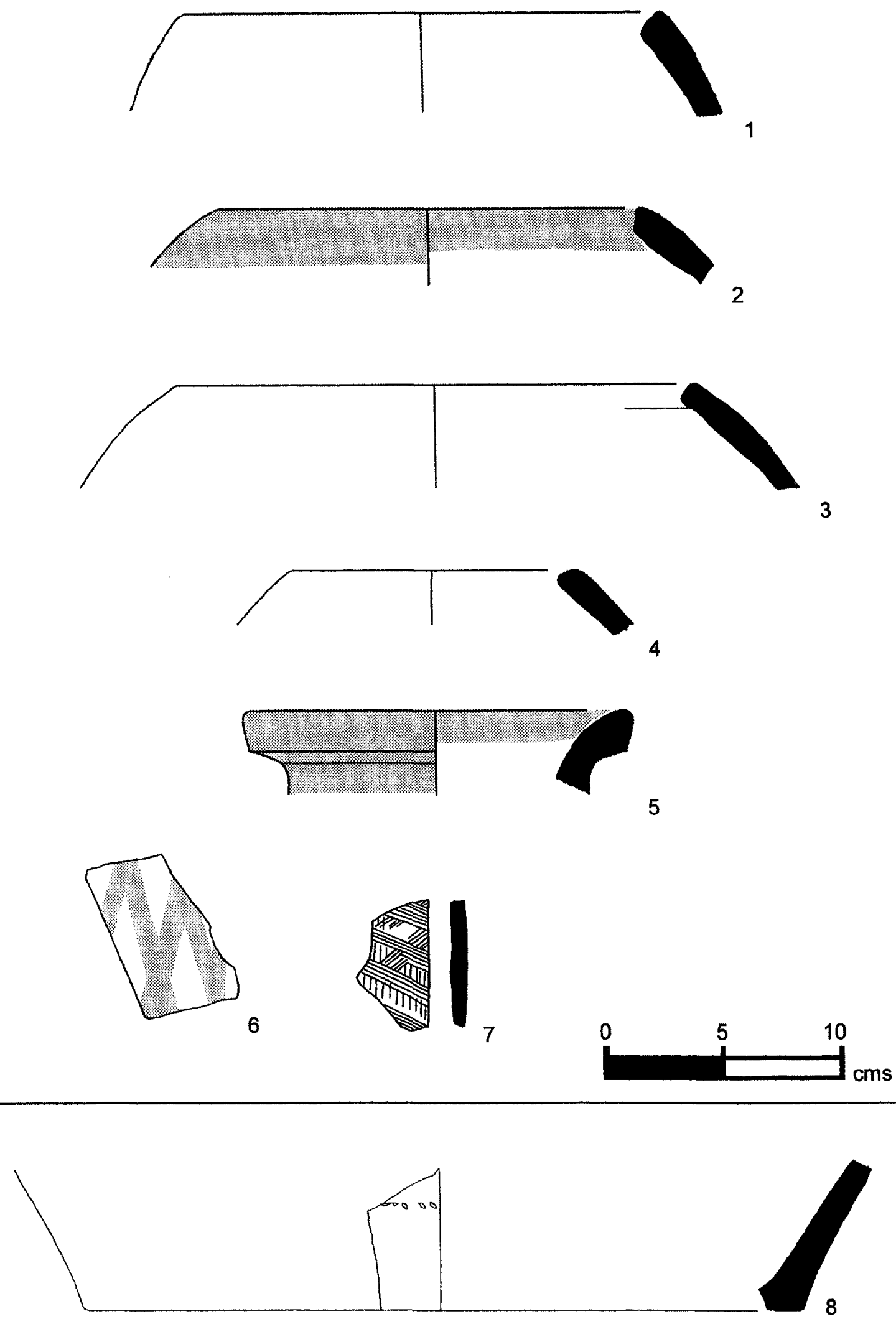

PLATE 8 (CONT.).

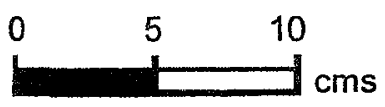



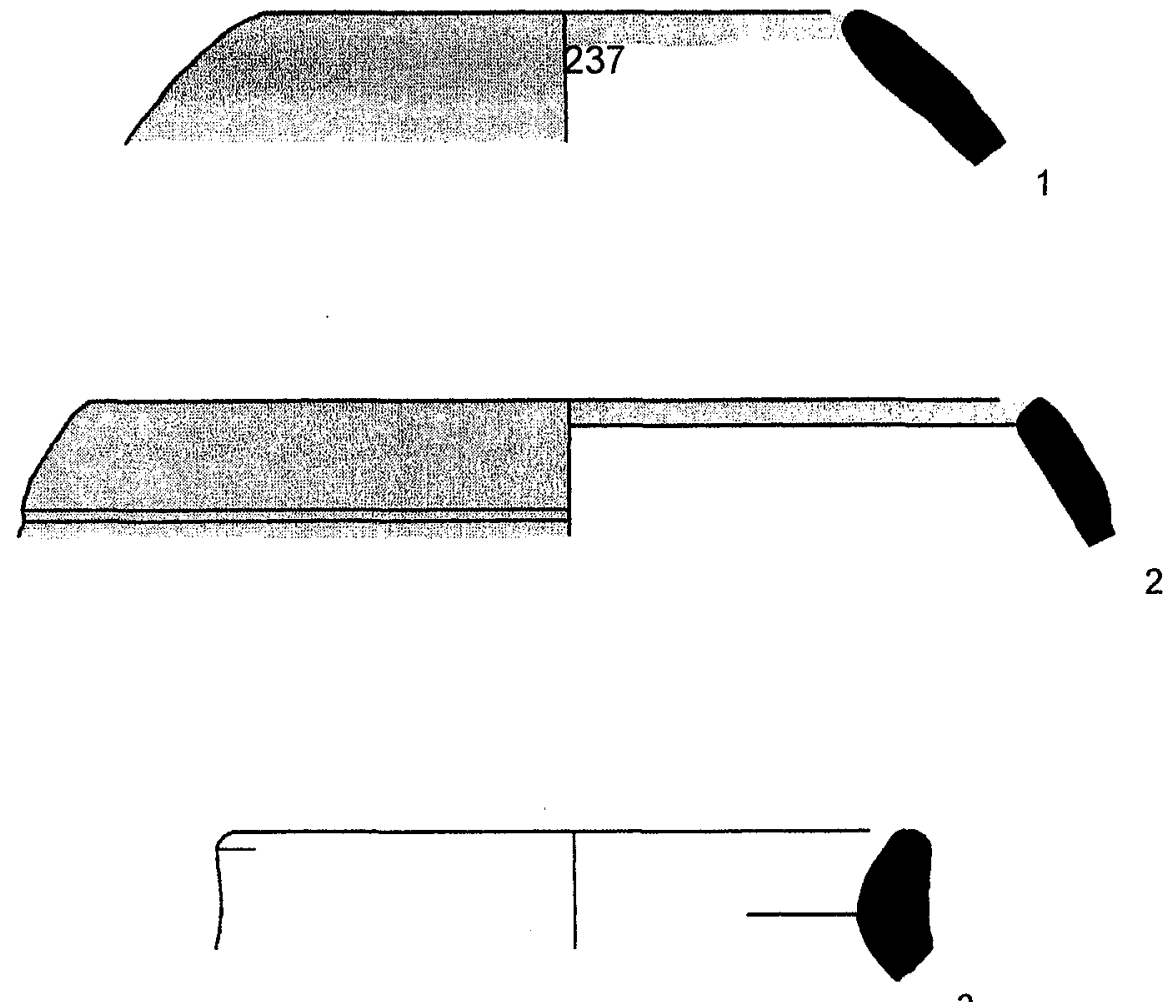

3

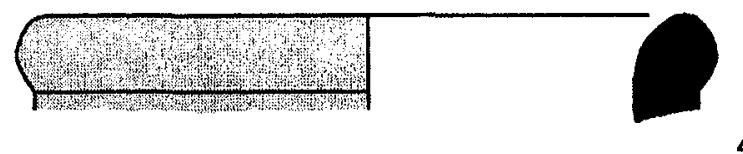

4
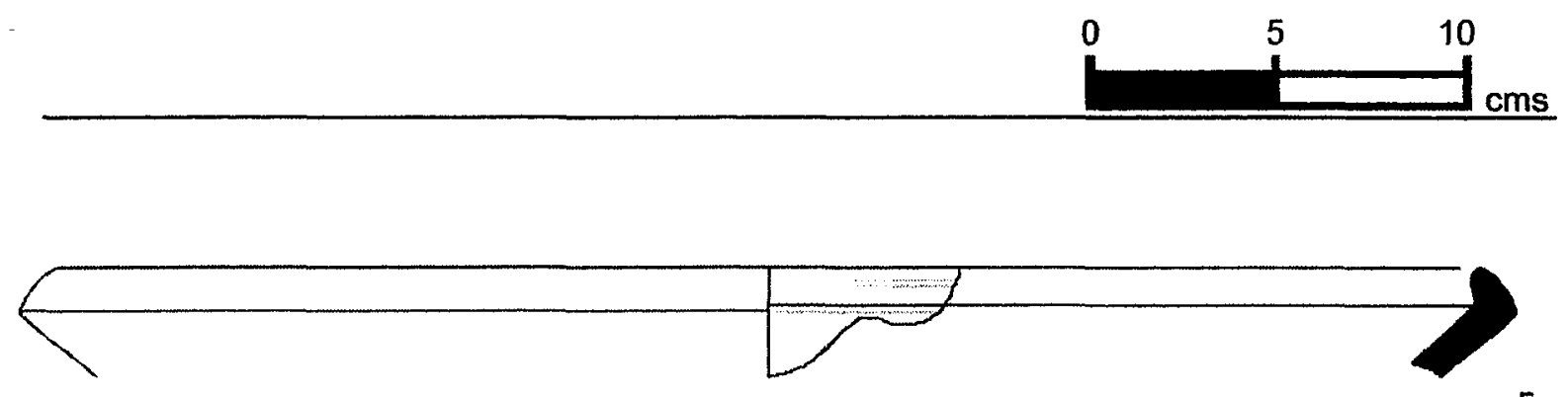

PLATE 9 (CONT.).

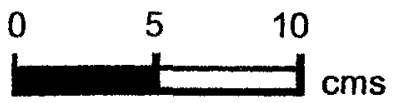


238

\begin{tabular}{llllllll}
\hline No & Reg & Square & Locus & Vessel & Part & $\begin{array}{c}\text { Body } \\
\text { Thick }\end{array}$ & Dia \\
\hline 1 & 0447 & SW 1-27 & 53 & BOWL & R82 & 5 & 22 \\
2 & 0446 & SW 1-27 & 53 & HOLE MOUTH BOWL & R20 & N & 20 \\
3 & 0448 & SW 1-27 & 53 & UD & R00 & N & N \\
4 & 0466 & SW 1-27 & 51 & UD & BOD & 10 & N \\
5 & 0465 & SW 1-27 & 51 & UD & H50 & 8 & N \\
6 & 0464 & SW 1-27 & 52 & UD & B12 & 8 & 7
\end{tabular}

\begin{tabular}{lllll}
\hline No Fabric Color & Core Orient & Core Color & Core Thick & Fabric \\
& & & Family
\end{tabular}

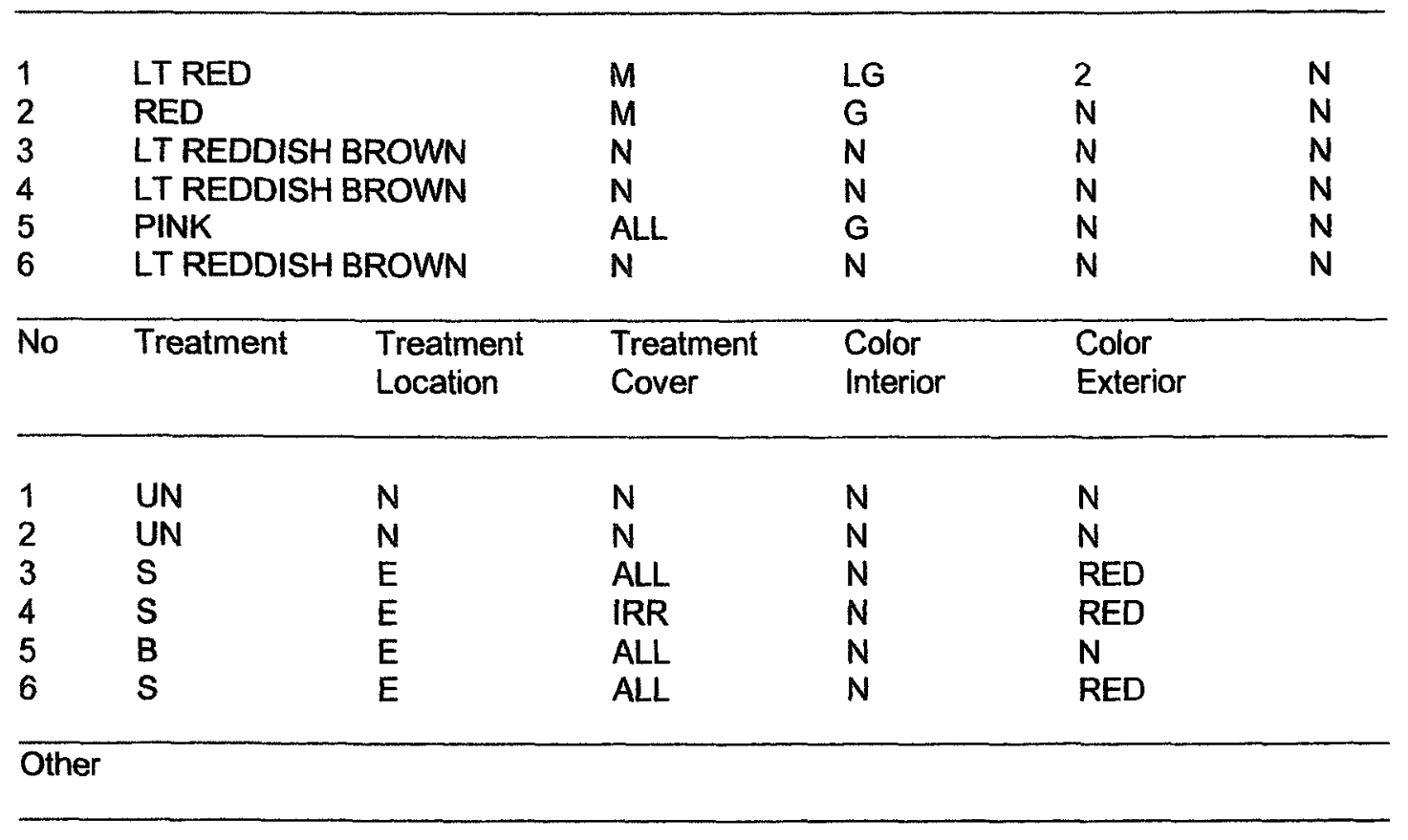

2 Poorly fired.

3 Sample too small to confirm stance or diameter.

5 Gray Burnished Ware.

PLATE 10. FIELD A. PHASE 1C (EB II). 

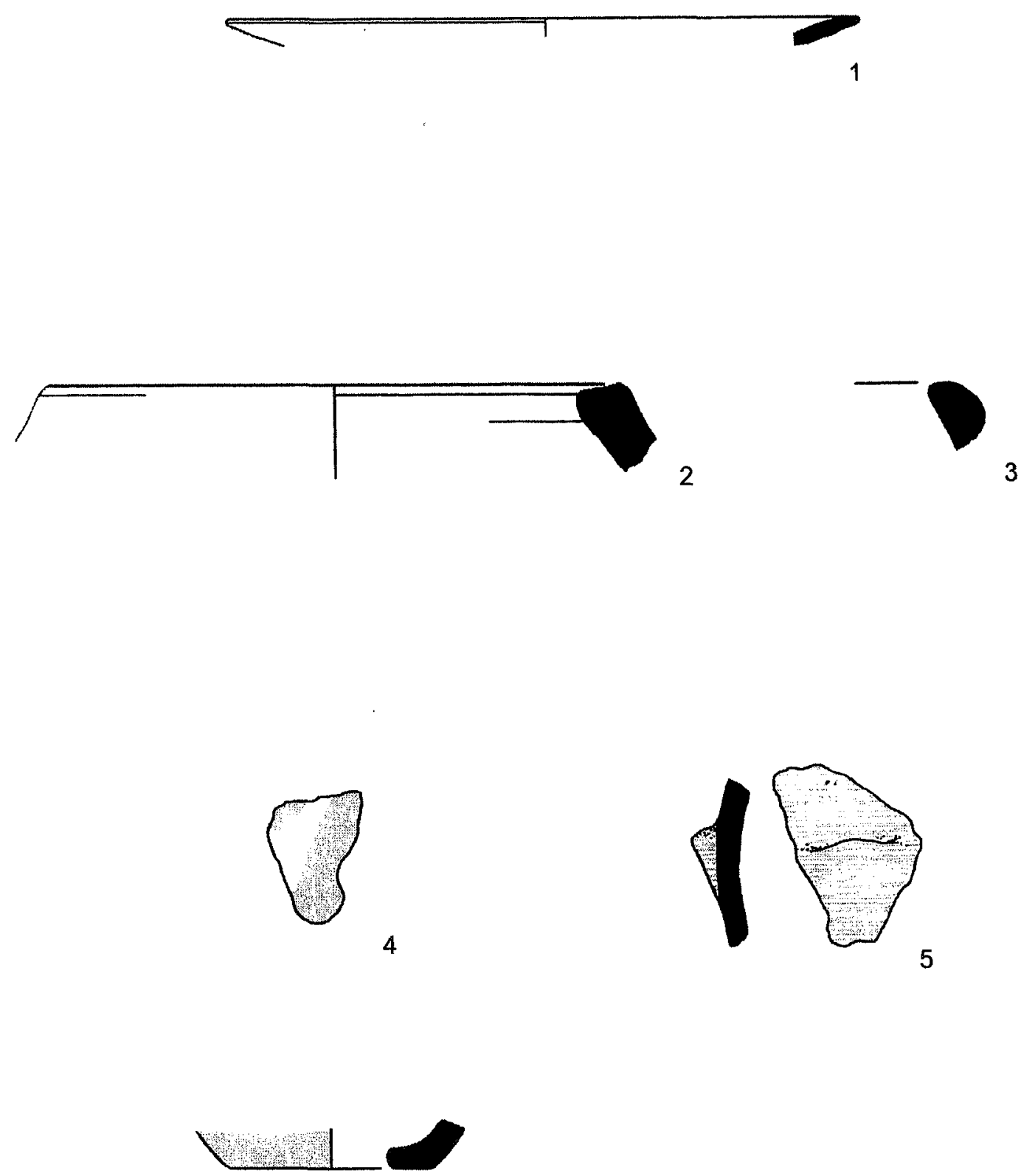

6

PLATE 10 (CONT.).

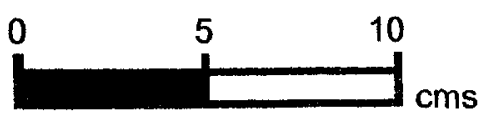




\begin{tabular}{|c|c|c|c|c|c|c|c|}
\hline No & $\operatorname{Reg}$ & Square & Locus & Vessel & Part & $\begin{array}{l}\text { Body } \\
\text { Thick }\end{array}$ & $\overline{\mathrm{Dia}}$ \\
\hline 1 & 0614 & SW 1-28 & 33 & BOWL & R50 & 4 & 20 \\
\hline 2 & 0610 & SW 1-28 & 33 & LEDGE RIM BOWL & R55 & 11 & 25 \\
\hline 3 & 0714 & SW 2-27 & 87 & LEDGE RIM BOWL & R52 & 11 & 34 \\
\hline 4 & 0611 & SW $1-28$ & 33 & HOLE MOUTH BOWL & R11 & 8 & 18 \\
\hline 5 & 2323 & SW 2-27 & 87 & NECKED JAR & R30 & 6 & $\mathbf{N}$ \\
\hline 6 & 0609 & SW 1-28 & 33 & HOLE MOUTH JAR & R18 & 6 & 16 \\
\hline 7 & 0612 & SW 1-28 & 33 & HOLE MOUTH BOWL & RO4 & 8 & 15 \\
\hline 8 & 0608 & SW $1-28$ & 33 & NECKED JAR & R43 & 9 & 12 \\
\hline 9 & 0713 & SW 2-27 & 87 & UD & B11 & 7 & 8 \\
\hline 10 & 2315 & SW 1-28 & 33 & UD & $B O D$ & 6 & $\mathbf{N}$ \\
\hline 11 & 0621 & SW 1-28 & 40 & UD & BOD & 6 & $\mathbf{N}$ \\
\hline 12 & 0613 & SW 1-28 & 33 & LEDGE RIM BOWL & R53 & 12 & 42 \\
\hline
\end{tabular}

\begin{tabular}{|c|c|c|c|c|c|c|}
\hline 1 & \multicolumn{2}{|l|}{ PINK } & $N$ & $\mathrm{~N}$ & $N$ & $\mathrm{~N}$ \\
\hline 2 & \multicolumn{2}{|l|}{ PINK } & $\mathbf{M}$ & LG & 3 & $\mathbf{N}$ \\
\hline 3 & \multicolumn{2}{|l|}{ PINK } & $\mathbf{N}$ & $\mathrm{N}$ & $\mathbf{N}$ & 23 \\
\hline 4 & \multicolumn{2}{|c|}{ LT REDDISH BROWN } & $\mathbf{M}$ & $\mathbf{G}$ & 3 & $\mathrm{~N}$ \\
\hline 5 & \multicolumn{2}{|l|}{ PINK } & $\mathrm{N}$ & $\mathrm{N}$ & $\mathrm{N}$ & $\mathbf{N}$ \\
\hline 6 & \multicolumn{2}{|c|}{ WEAK RED } & $\mathbf{N}$ & $\mathrm{N}$ & $\mathbf{N}$ & $\mathrm{N}$ \\
\hline 7 & \multicolumn{2}{|c|}{ LT REDDISH BROWN } & EX & LG & 5 & $\mathbf{N}$ \\
\hline 8 & \multicolumn{2}{|l|}{ PINK } & $\mathrm{N}$ & $\mathrm{N}$ & $\mathrm{N}$ & $\mathrm{N}$ \\
\hline 9 & \multicolumn{2}{|l|}{ LT RED } & $\mathrm{N}$ & $\mathrm{N}$ & $\mathrm{N}$ & 12.3 \\
\hline 10 & \multicolumn{2}{|l|}{ PINK } & $\mathrm{N}$ & $\mathbf{N}$ & $\mathbf{N}$ & $\mathrm{N}$ \\
\hline 11 & \multicolumn{2}{|c|}{ LT REDDISH BROWN } & $\mathbf{N}$ & $\mathrm{N}$ & $\mathrm{N}$ & 16 \\
\hline 12 & \multicolumn{2}{|c|}{ PINK } & $\mathbf{N}$ & $\mathrm{N}$ & $\mathrm{N}$ & $\mathrm{N}$ \\
\hline No & Treatment & $\begin{array}{l}\text { Treatment } \\
\text { Location }\end{array}$ & $\begin{array}{l}\text { Treatment } \\
\text { Cover }\end{array}$ & $\begin{array}{l}\text { Color } \\
\text { Interior }\end{array}$ & $\begin{array}{l}\text { Color } \\
\text { Exterior }\end{array}$ & \\
\hline 1 & $S$ & $\mathbb{I R}$ & ALL & RED & $\mathbf{N}$ & \\
\hline 2 & SB & IE & ALL & RED & RED & \\
\hline 3 & $\mathbf{S}$ & $\mathbb{E}$ & ALL & RED & BLACK & \\
\hline 4 & UN & $\mathbf{N}$ & $\mathbf{N}$ & $\mathbf{N}$ & $\mathbf{N}$ & \\
\hline 5 & $\mathbf{S}$ & $E$ & ALL & $\mathbf{N}$ & RED & \\
\hline 6 & UN & $\mathrm{N}$ & $\mathrm{N}$ & $\mathrm{N}$ & $\mathrm{N}$ & \\
\hline 7 & UN & $\mathbf{N}$ & $\mathbf{N}$ & $\mathrm{N}$ & $\mathrm{N}$ & \\
\hline 8 & UN & $N$ & $\mathbf{N}$ & $N$ & $N$ & \\
\hline 9 & B & $\mathbf{E}$ & ALL & $\mathbf{N}$ & $\mathrm{N}$ & \\
\hline
\end{tabular}

PLATE 11. FIELD A. PHASE 1C (EB II). 
241

\begin{tabular}{llllll}
\hline No & Treatment & $\begin{array}{l}\text { Treatment } \\
\text { Location }\end{array}$ & $\begin{array}{l}\text { Treatment } \\
\text { Cover }\end{array}$ & $\begin{array}{l}\text { Color } \\
\text { Interior }\end{array}$ & $\begin{array}{l}\text { Color } \\
\text { Exterior }\end{array}$ \\
\hline 10 & PAINT & E & NET & N & RED \\
11 & S & E & ALL & N & RED \\
12 & SB & IR & ALL & RED & RED \\
\hline
\end{tabular}

2 Radial burnish over slip on interior face; rim well burnished; exterior face is wetsmoothed, slipped, and irregularly burnished; shallow concavity under rim.

3 Interior face and rim are slipped and burnished in red, strokes are heavy enough to give a corrugated effect; black with speaks of red appear on exterior face, however, no burnish is visible.

$7 \quad$ Lines on interior face suggest rim shaping and body scraping.

9 Metallic Ware.

PLATE 11 (CONT.). 

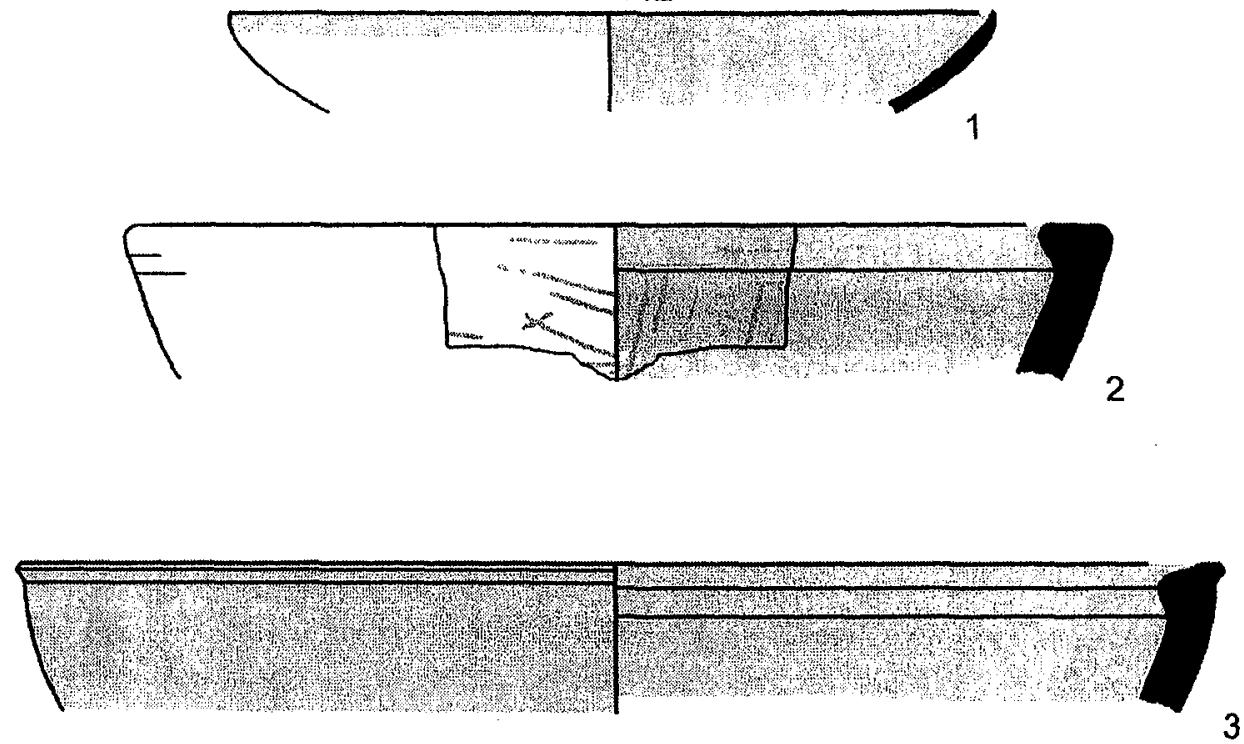

3
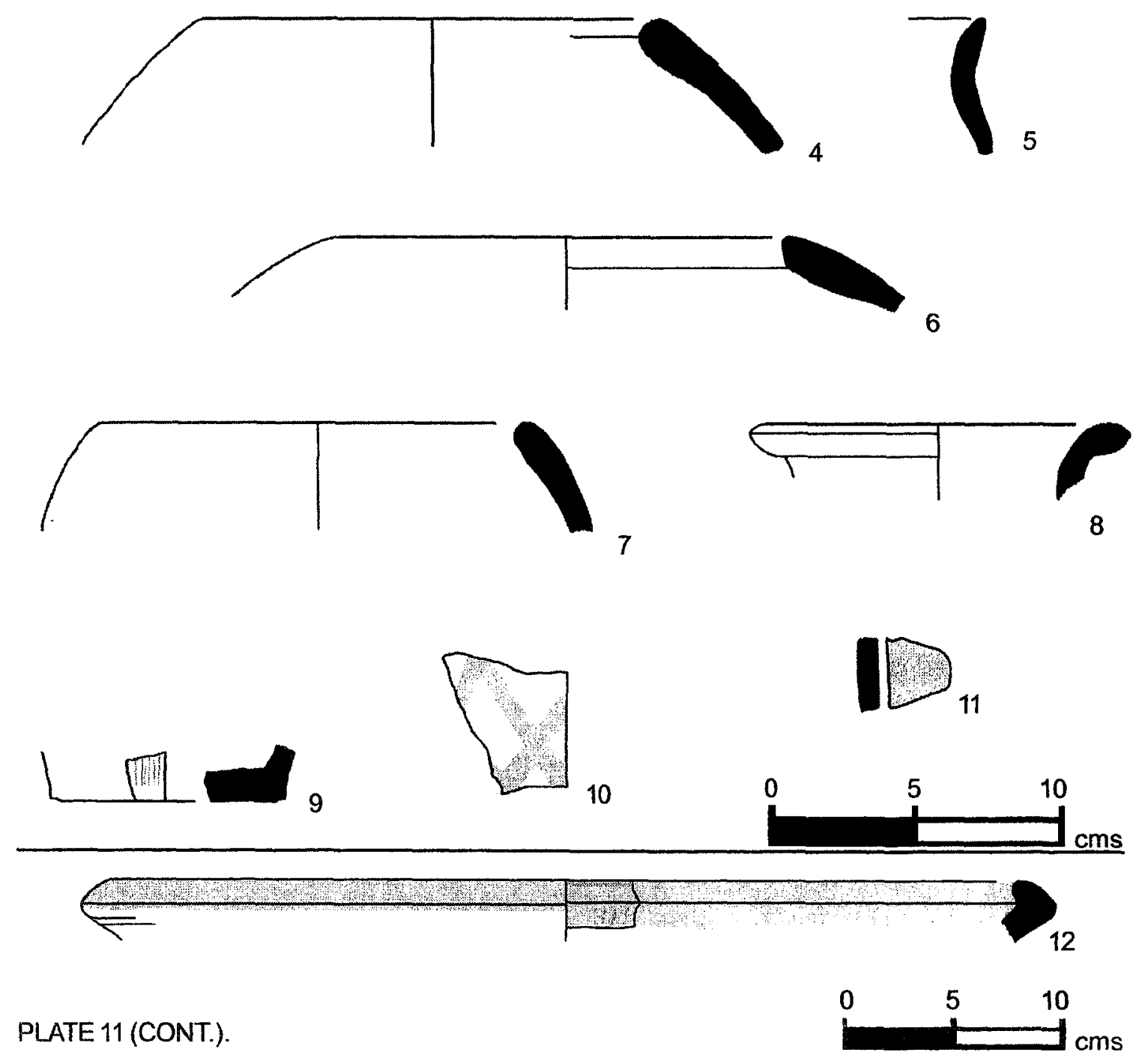
243

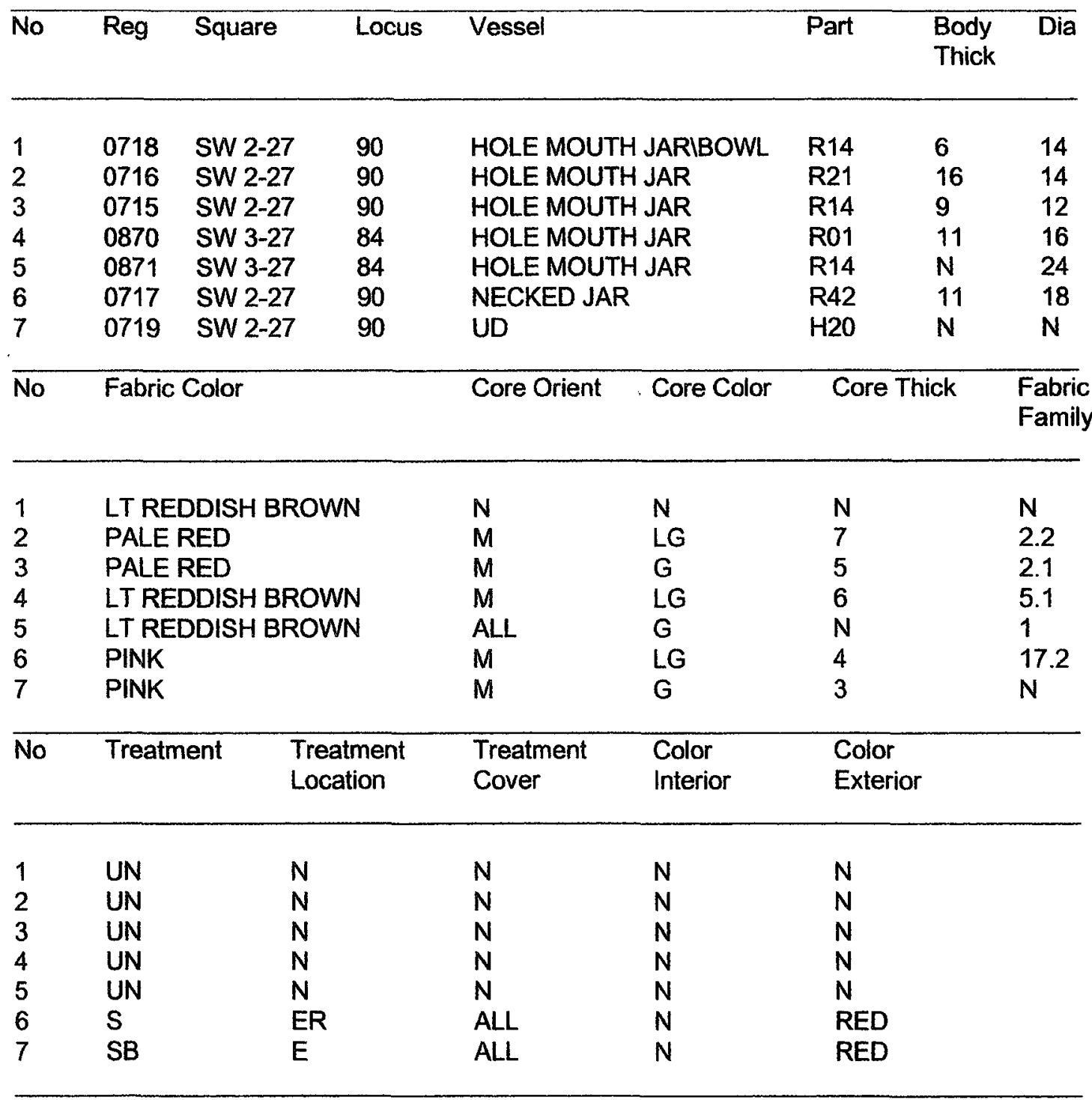

Other

1 Sample too small to confirm stance or diameter.

2 "Margin" on rim appears wet-turned; splaying clay forms small ridge.

$6 \quad$ Also Fabric Family 23.

7 Sample too small to confirm stance or diameter. Undrawn.

PLATE 12. FIELD A. PHASE 1C (EB II). 

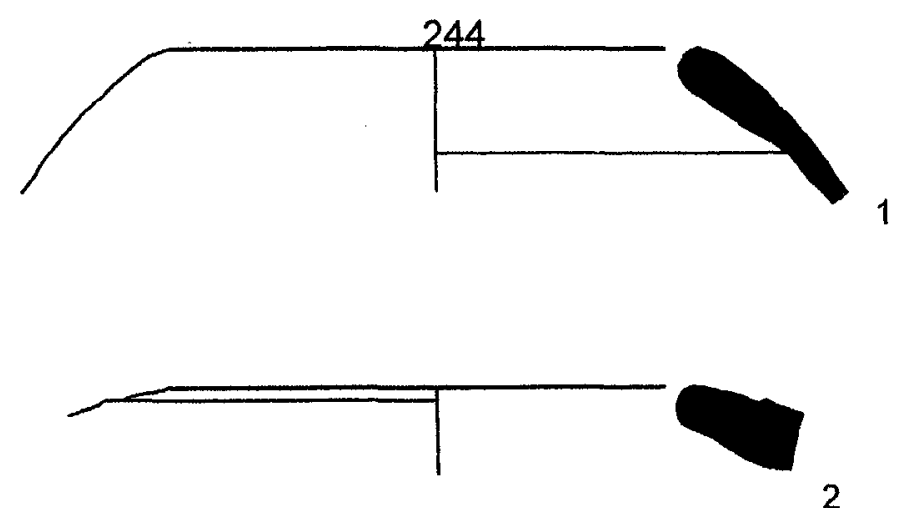

2
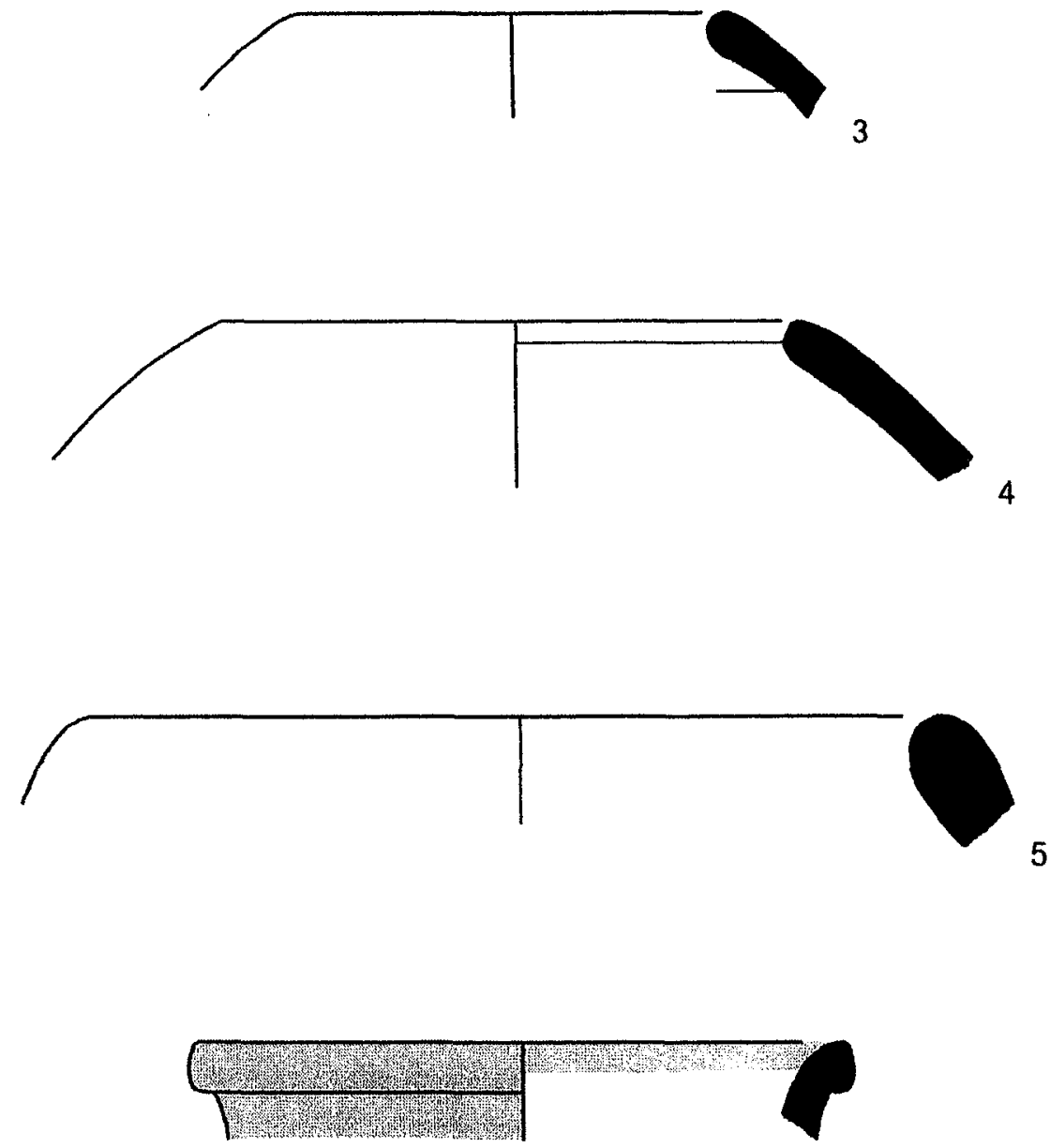

PLATE 12 (CONT.).

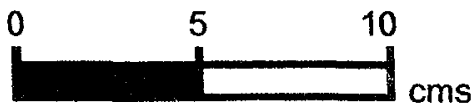


245

\begin{tabular}{|c|c|c|c|c|c|c|c|}
\hline No & Reg & Square & Locus & Vessel & Part & $\begin{array}{l}\text { Body } \\
\text { Thick }\end{array}$ & $\overline{\text { Dia }}$ \\
\hline 1 & 0859 & SW 3-27 & 83 & NECKED JAR & R42 & 15 & 18 \\
\hline 2 & 2420 & SW 3-27 & 83 & PLATTER BOWL & R53 & 7 & $N$ \\
\hline 3 & 2432 & SW 3-27 & 83 & LEDGE RIM BOWL & R51 & 7 & $N$ \\
\hline 4 & 2437 & SW 3-27 & 83 & NECKED JAR & R43 & 5 & 14 \\
\hline 5 & 0861 & SW 3-27 & 83 & NECKED JAR & R43 & 6 & 14 \\
\hline 6 & 0867 & SW 3-27 & 83 & UD & $\mathrm{H} 2 \mathrm{O}$ & 7 & $\mathbf{N}$ \\
\hline 7 & 0860 & SW 3-27 & 83 & NECKED JAR & R32 & 5 & 6 \\
\hline 8 & 0863 & SW 3-27 & 83 & UD & $\mathrm{H} 2 \mathrm{O}$ & $N$ & $N$ \\
\hline 9 & 0869 & SW 3-27 & 83 & UD & B12 & 8 & 8 \\
\hline 10 & 0866 & SW 3-27 & 83 & UD & $\mathrm{H} 27$ & $\mathbf{N}$ & $\mathbf{N}$ \\
\hline 11 & 0868 & SW 3-27 & 83 & UD & $\mathrm{B} 11$ & 8 & 10 \\
\hline 12 & 0862 & SW 3-27 & 83 & UD & $\mathrm{H} 21$ & $\mathrm{~N}$ & $\mathbf{N}$ \\
\hline 13 & 2422 & SW 3-27 & 83 & PLATTER BOWL & R53 & 8 & 38 \\
\hline
\end{tabular}

\begin{tabular}{llll}
\hline No Fabric Color & Core Orient Core Color Core Thick $\begin{array}{l}\text { Fabric } \\
\text { Family }\end{array}$
\end{tabular}

$\begin{array}{llllll}1 & \text { LTREDDISH BROWN } & \text { M } & \text { G } & 7 & \text { N } \\ 2 & \text { RED } & N & N & N & N \\ 3 & \text { RED } & N & N & N & \text { N } \\ 4 & \text { RED } & N & N & N & \text { N } \\ 5 & \text { LTREDDISH BROWN } & \text { M } & \text { LG } & 3 & 8 \\ 6 & \text { LTRED } & N & N & N & 17.1 \\ 7 & \text { LTBROWN } & N & N & N & 24 \\ 8 & \text { PINK } & N & N & N & 2.3 \\ 9 & \text { PINK } & \text { N } & \text { G } & 4 & 11 \\ 10 & \text { PINK } & \text { IRR } & \text { LG } & \text { N } & 17.1 \\ 11 & \text { PINK } & \text { IN } & \text { LG } & 5 & 18 \\ 12 & \text { LTRED } & \text { IRR } & \text { G } & \text { N } & 9.1 \\ 13 & \text { RED } & \text { N } & \text { G } & 3 & \text { N }\end{array}$

\begin{tabular}{|c|c|c|c|c|c|}
\hline No & Treatment & $\begin{array}{l}\text { Treatment } \\
\text { Location }\end{array}$ & $\begin{array}{l}\text { Treatment } \\
\text { Cover }\end{array}$ & $\begin{array}{l}\text { Color } \\
\text { interior }\end{array}$ & $\begin{array}{l}\text { Color } \\
\text { Exterior }\end{array}$ \\
\hline
\end{tabular}

$\begin{array}{llllll}1 & \text { S } & \text { IR } & \text { N } & \text { RED } & \text { N } \\ 2 & \text { B } & \text { IR } & \text { ALL } & \text { N } & \text { N } \\ 3 & \text { B } & \text { IE } & \text { ALL } & \text { N } & \text { N } \\ 4 & \text { UN } & \text { N } & \text { N } & \text { N } & \text { N } \\ 5 & \text { B } & \text { ER } & \text { ALL } & \text { N } & \text { RED } \\ 6 & \text { S } & \text { E } & \text { ALL } & \text { N } & \text { RED } \\ 7 & \text { S } & \text { E } & \text { ALL } & \text { N } & \text { RED } \\ 8 & \text { S } & \text { E } & \text { ALL } & \text { N } & \text { DK RED } \\ 9 & \text { PAINT } & \text { E } & \text { NET } & \text { N } & \text { UD } \\ 10 & \text { S } & \text { E } & \text { ALL } & \text { N } & \text { DUSKY RED }\end{array}$

PLATE 13. FIELD A. PHASE 1C (EB II). 
246

\begin{tabular}{llllll}
\hline No & Treatment & $\begin{array}{l}\text { Treatment } \\
\text { Location }\end{array}$ & $\begin{array}{l}\text { Treatment } \\
\text { Cover }\end{array}$ & $\begin{array}{l}\text { Color } \\
\text { Interior }\end{array}$ & $\begin{array}{l}\text { Color } \\
\text { Exterior }\end{array}$ \\
\hline 11 & $\mathrm{~S}$ & $\mathrm{E}$ & $\mathrm{ALL}$ & $\mathrm{N}$ & RED \\
12 & $\mathrm{~S}$ & $\mathrm{E}$ & $\mathrm{ALL}$ & $\mathrm{N}$ & DK RED \\
13 & $\mathrm{~B}$ & $\mathrm{R}$ & $\mathrm{ALL}$ & $\mathrm{N}$ & $\mathrm{N}$ \\
& & & & \\
\hline
\end{tabular}

2 Metallic Ware.

3 Metallic Ware.

4 Metallic Ware.

13 Metallic Ware.

PLATE 13 (CONT.). 


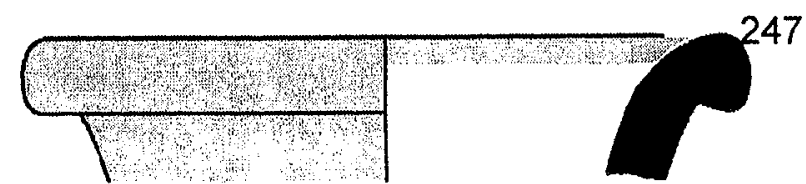

1
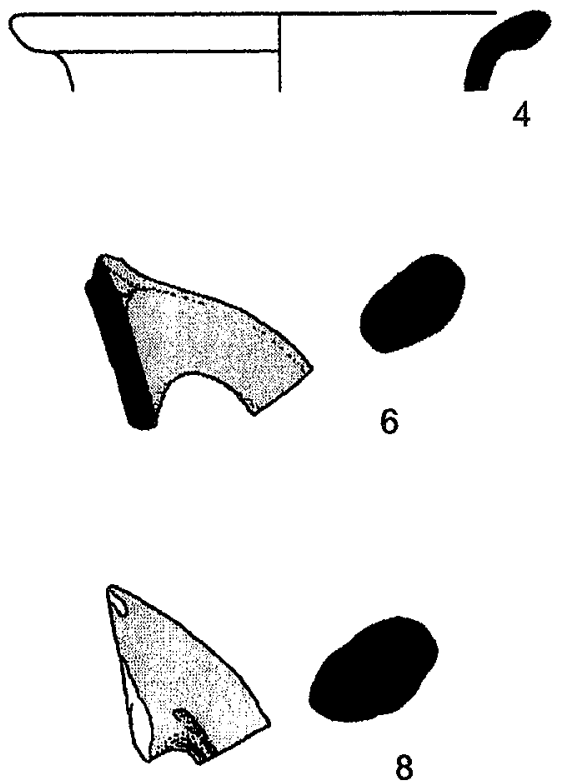

10
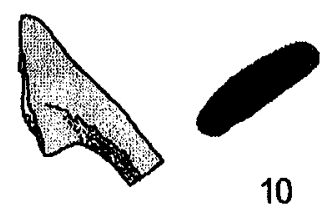

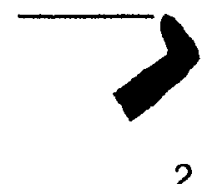

2
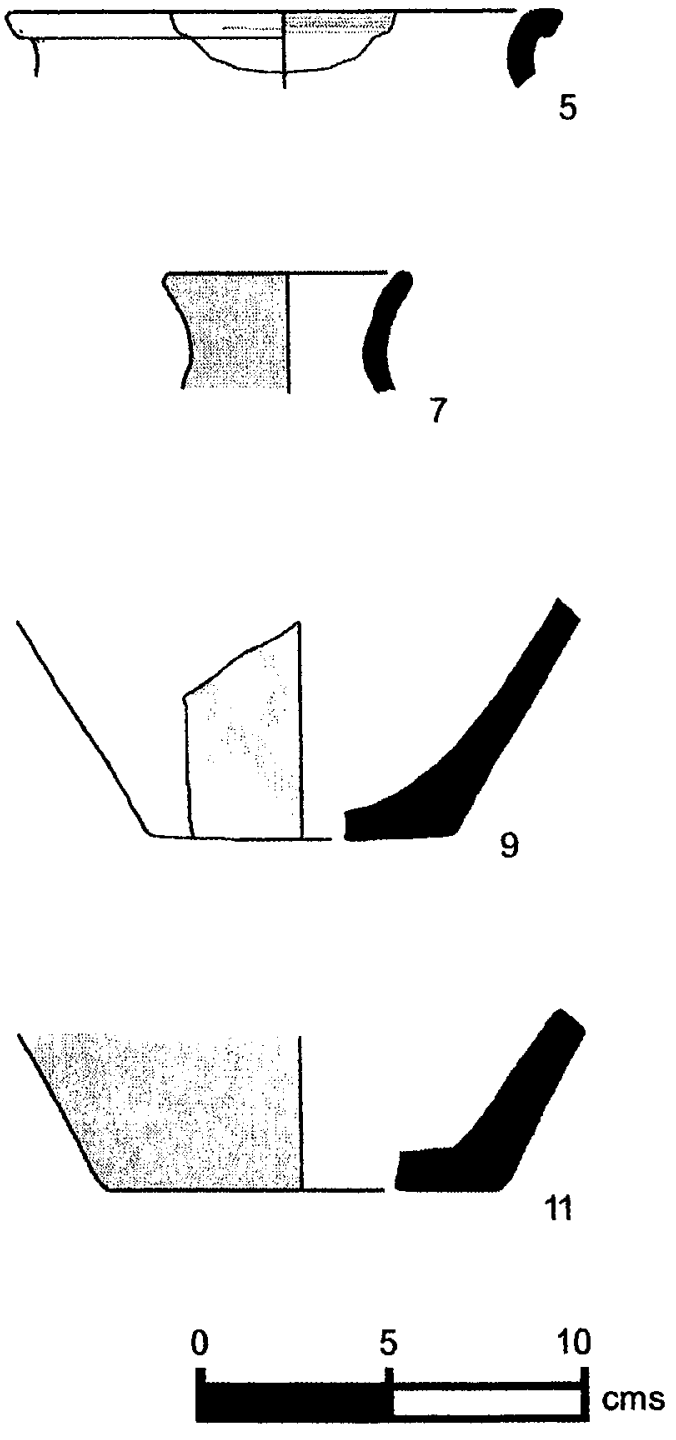

12

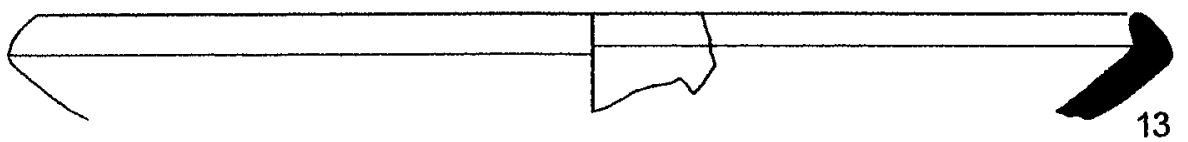

PLATE 13 (CONT.)

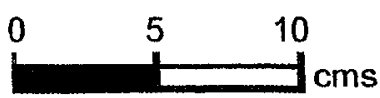




\begin{tabular}{llllllll}
\hline No & Reg & Square & Locus & Vessel & Part & $\begin{array}{c}\text { Body } \\
\text { Thick }\end{array}$ & Dia \\
\hline & & & & & & & \\
1 & 0973 & SW 4-26 & 21 & BOWL & R50 & 7 & 22 \\
2 & 2415 & SW 4-26 & 21 & PLATTER BOWL & R55 & N & N \\
3 & 0972 & SW 4-26 & 21 & PLATTER BOWL & R56 & 9 & 30 \\
4 & 2427 & SW 4-26 & 21 & PLATTER BOWL & R53 & N & N \\
5 & 0970 & SW 4-26 & 21 & HOLE MOUTH JAR & R11 & 13 & 26 \\
6 & 0971 & SW 4-26 & 21 & HOLE MOUTH BOWL & R01 & 11 & 30 \\
7 & 0969 & SW 4-26 & 21 & HOLE MOUTH BOWL & R14 & 12 & 22 \\
8 & 0968 & SW 4-26 & 21 & HOLE MOUTH JAR & R01 & 11 & 15 \\
9 & 0980 & SW 4-26 & 21 & HOLE MOUTH JAR & R14 & 10 & 12 \\
10 & 0974 & SW 4-26 & 21 & HOLE MOUTH JAR & R20 & 14 & 22 \\
\hline No & Fabric Color & & Core Orient Core Color & Core Thick & Fabric \\
& & & & & & & Family
\end{tabular}

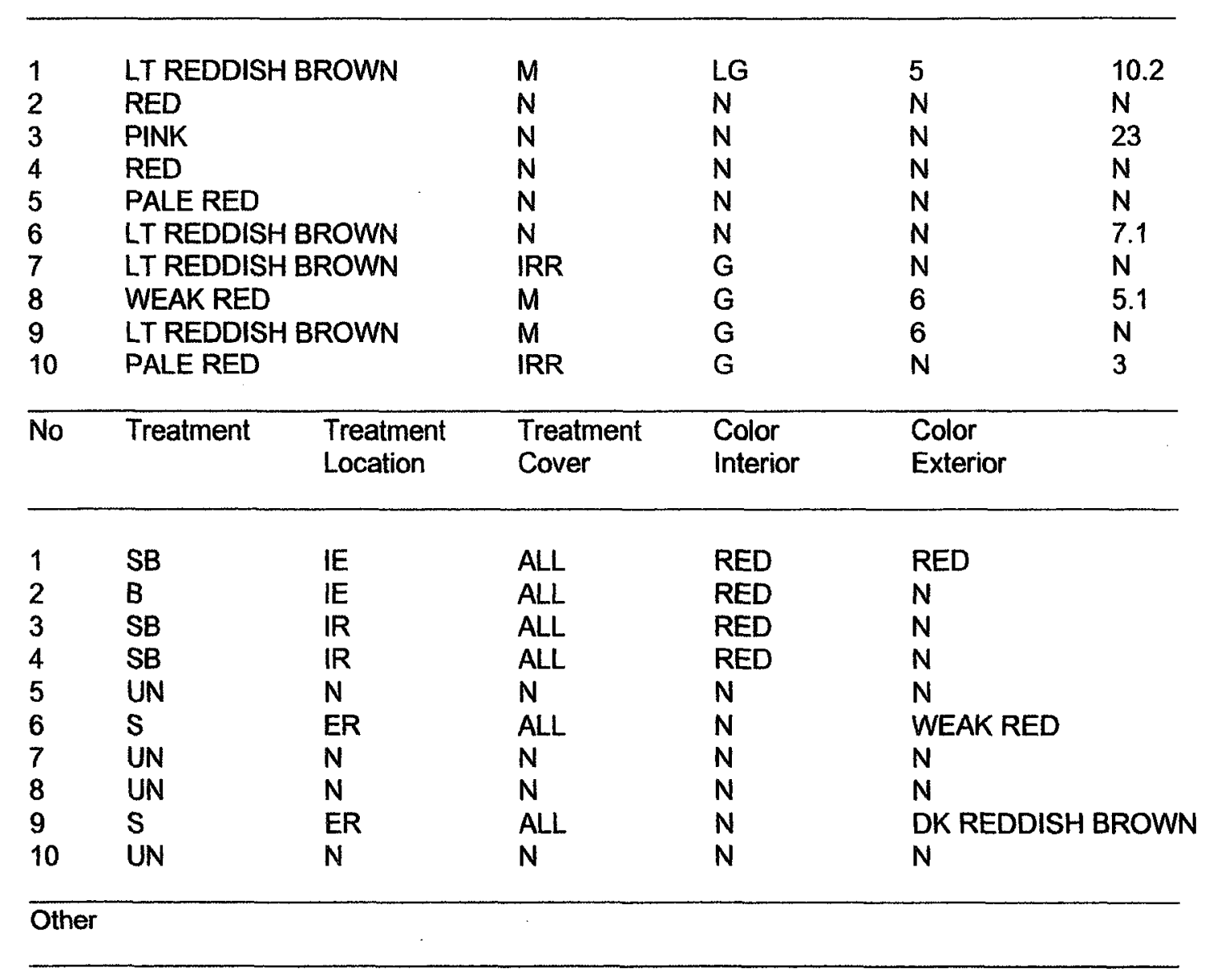

2 Metallic Ware; marginal concavity under rim; sample too small to confirm stance or diameter.

PLATE 14. FIELD A. PHASE 1C (EB II). 
Other

$3 \quad$ Very weathered; surface burn visible.

$4 \quad$ Metallic Ware.

8 Fine lines on rim suggest finishing motion; surface burn visible.

9 Single incision on shoulder.

10 Surface burn visible.

PLATE 14 (CONT.).

Reproduced with permission of the copyright owner. Further reproduction prohibited without permission. 

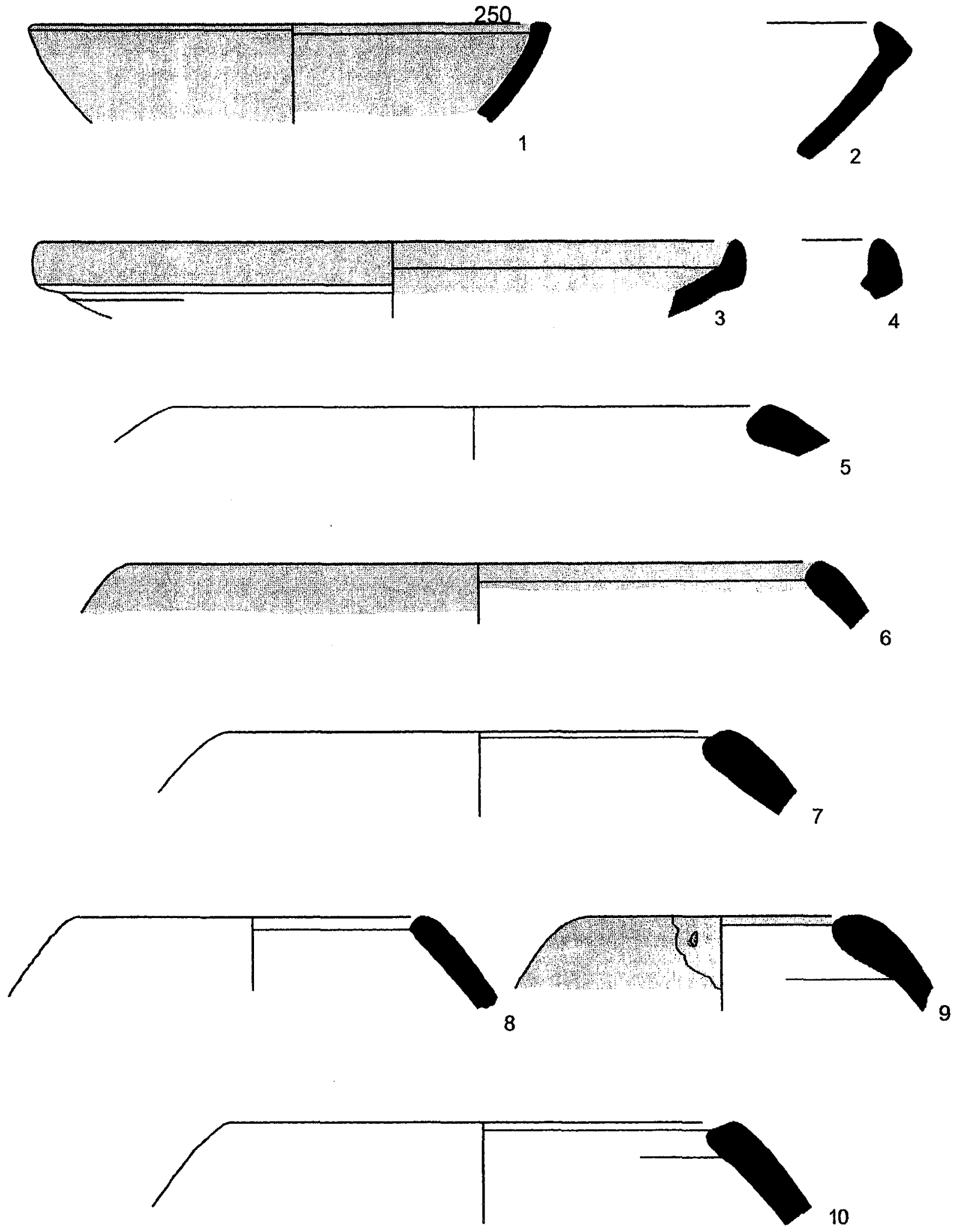

PLATE 14 (CONT.).

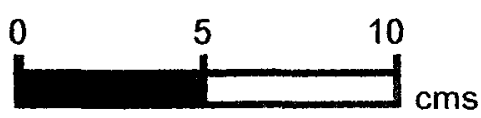




\begin{tabular}{lllllllll}
\hline No & Reg & Square & Locus & Vessel & Part & $\begin{array}{l}\text { Body Dia } \\
\text { Thick }\end{array}$ \\
\hline 1 & & & & & & H20 & $\mathrm{N}$ & $\mathrm{N}$ \\
2 & 0975 & SW 4-26 & 21 & UD & $H 12$ & 8 & $\mathrm{~N}$ \\
3 & 0977 & SW 4-26 & 21 & UD & B12 & 8 & 8 \\
4 & 0981 & SW 4-26 & 21 & UD & H14 & 7 & $\mathrm{~N}$ \\
5 & 0978 & SW 4-26 & 21 & UD & B12 & 11 & 18 \\
6 & 0979 & SW 4-26 & 21 & UD & H20 & 8 & $\mathrm{~N}$ \\
7 & 0976 & SW 4-26 & 21 & UD & R22 & 10 & 36
\end{tabular}

\begin{tabular}{lllll}
\hline No Fabric Color & Core Orient Core Color Core Thick & Fabric \\
& & & Family
\end{tabular}

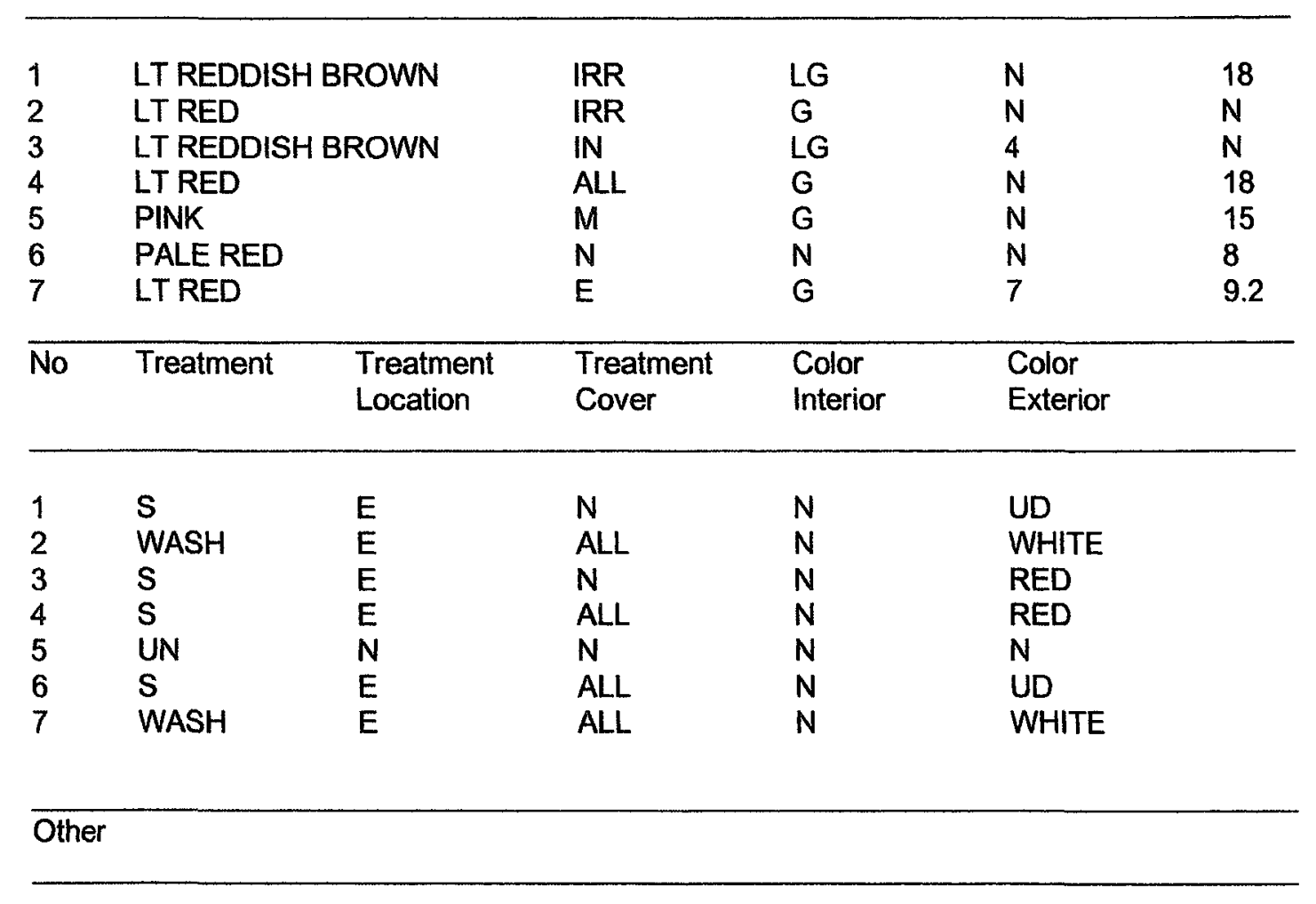

$7 \quad$ Rope molding.

PLATE 15. FIELD A. PHASE 1C (EB II). 

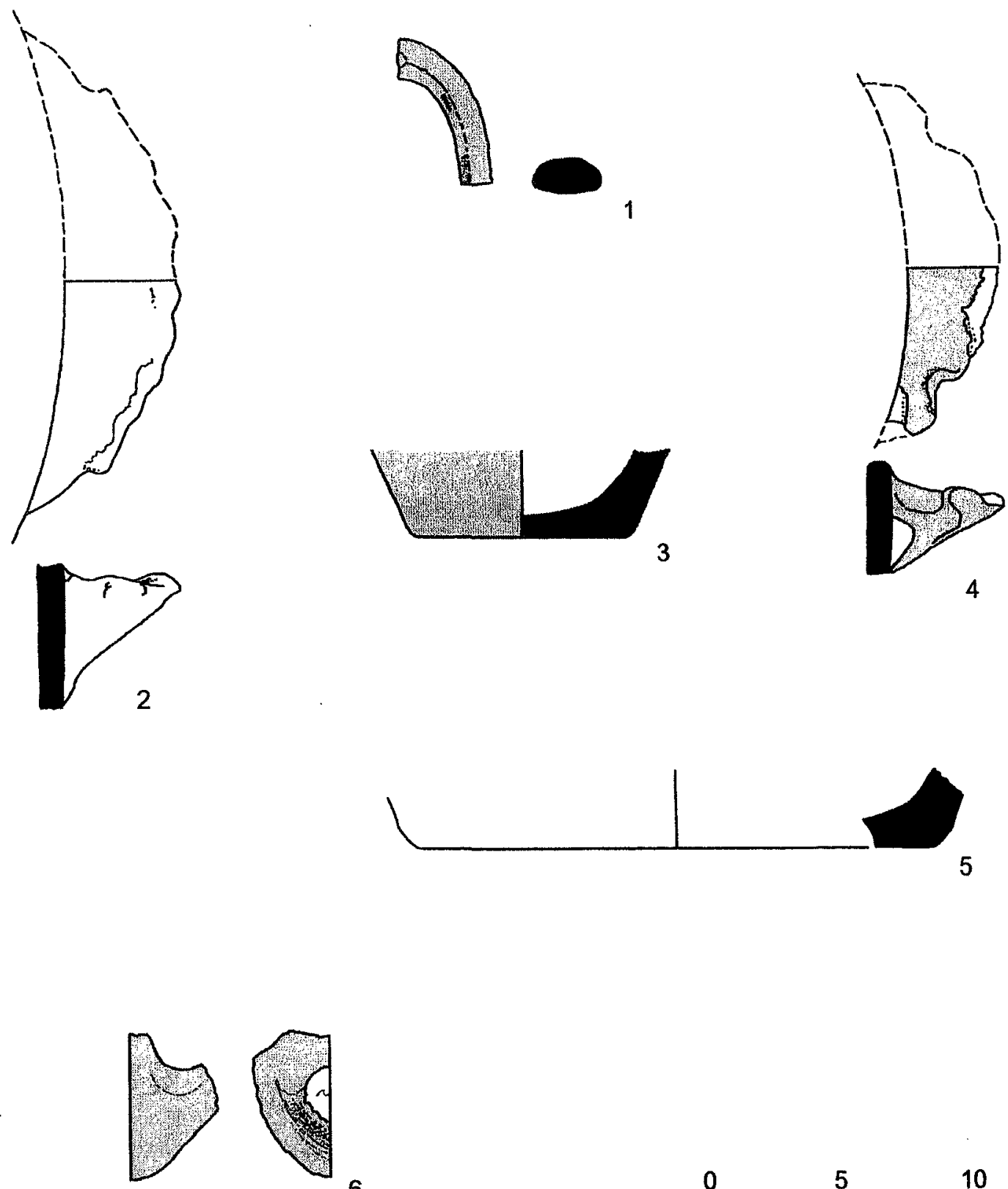

6
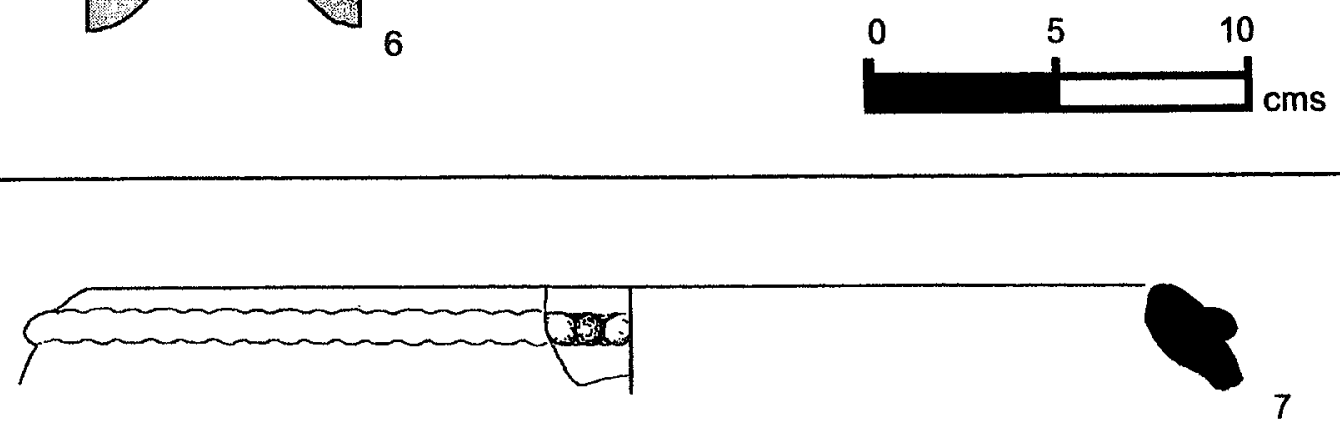

PLATE 15 (CONT.).

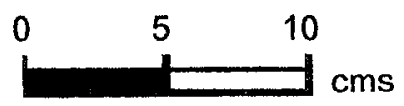




\begin{tabular}{llllllll}
\hline No & Reg & Square & Locus & Vessel & Part & $\begin{array}{c}\text { Body } \\
\text { Thick }\end{array}$ & Dia \\
\hline & & & & & & & \\
1 & 1148 & SW 5-26 & 38 & LEDGE RIM BOWL & R53 & 13 & 30 \\
2 & 1152 & SW 5-26 & 38 & HOLE MOUTH JARIBOWL & R19 & 11 & 20 \\
3 & 1151 & SW 5-26 & 38 & HOLE MOUTH JAR & R01 & 11 & 16 \\
4 & 1150 & SW 5-26 & 38 & HOLE MOUTH JARIBOWL & R11 & 18 & 28 \\
5 & 1153 & SW 5-26 & 38 & PLATTER BOWL & R56 & 10 & 41
\end{tabular}

\begin{tabular}{llll}
\hline No Fabric Color & Core Orient Core Color Core Thick Fabric \\
& & Family
\end{tabular}

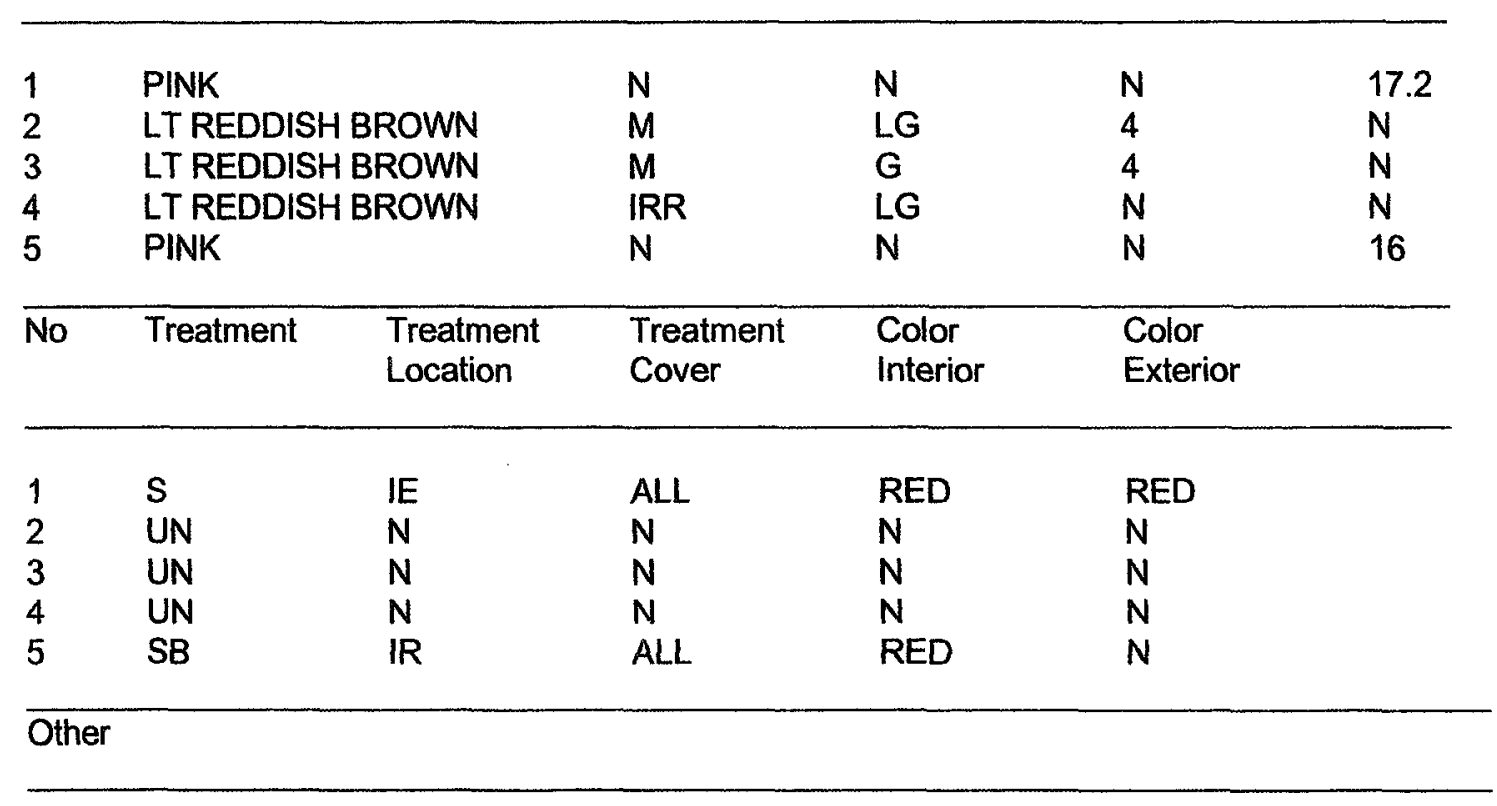

2 Sample too small to confirm stance or diameter.

$4 \quad$ Sample too small to confirm stance or diameter.

5 Radially burnished over slip on interior face; rough surface of base is burnished, after wetsmoothing of marginal concavity.

PLATE 16. FIELD A. PHASE 1C (EB II). 


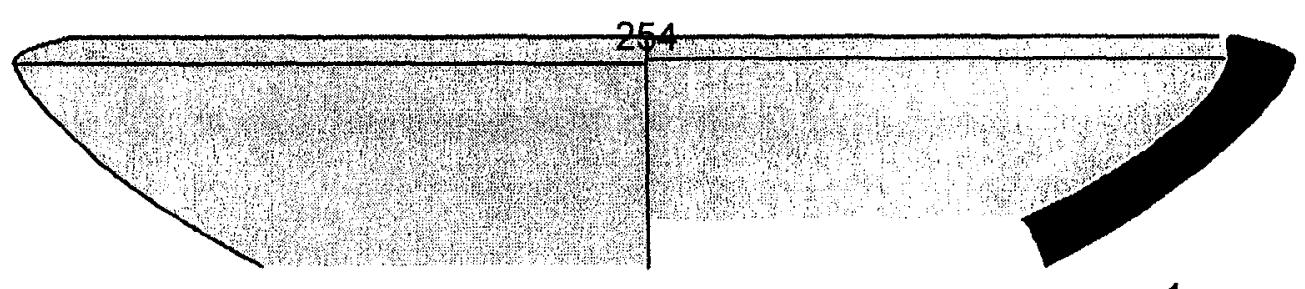

1

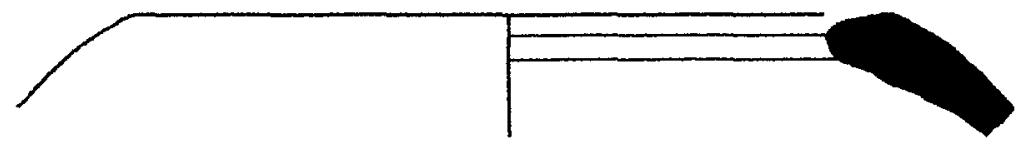

2

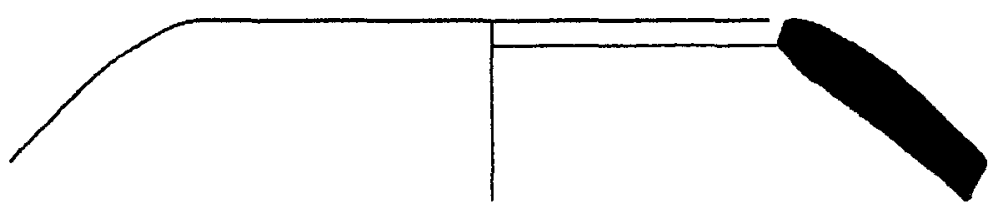

3
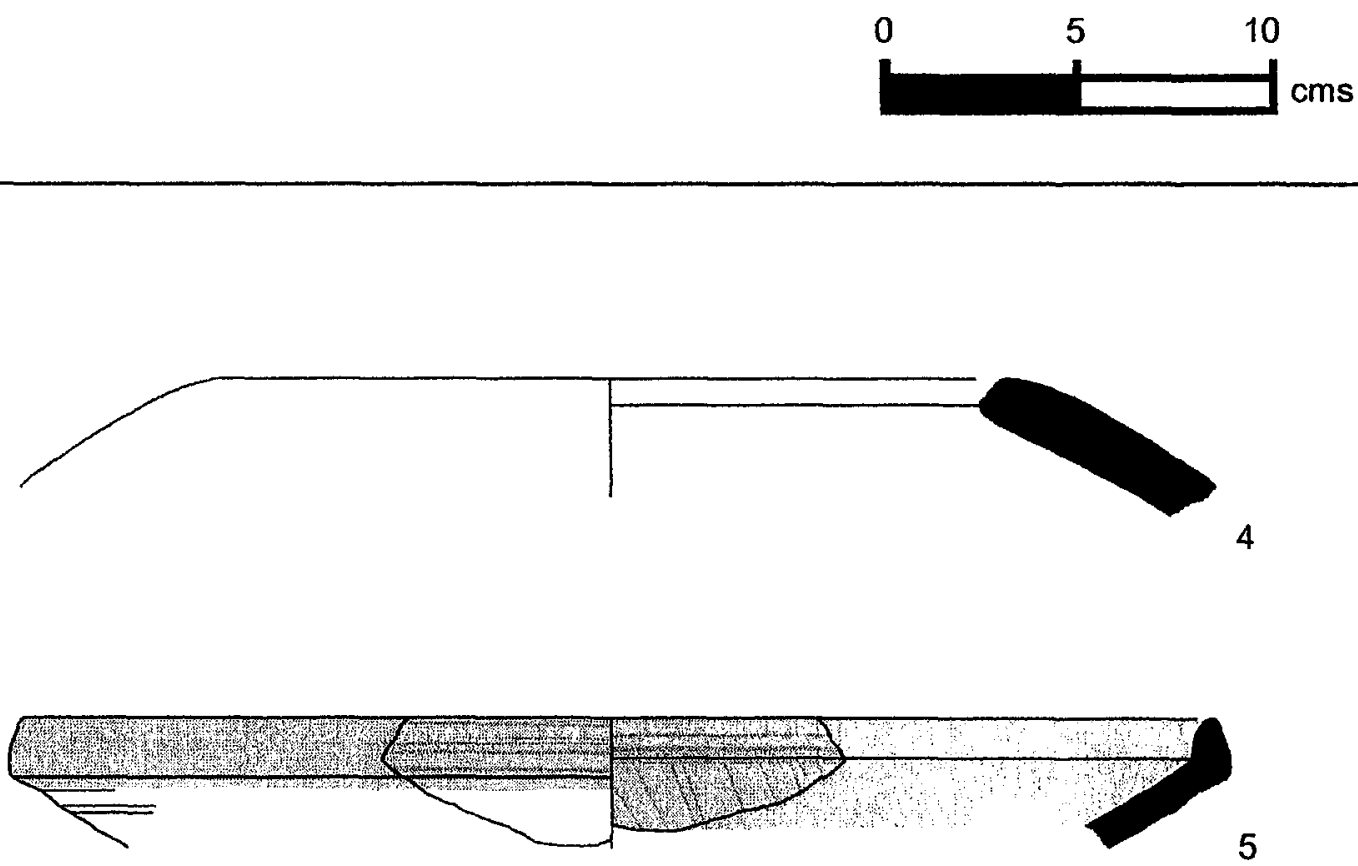

5

PLATE 16(CONT.).

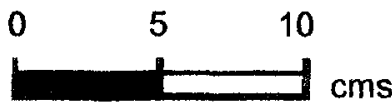


255

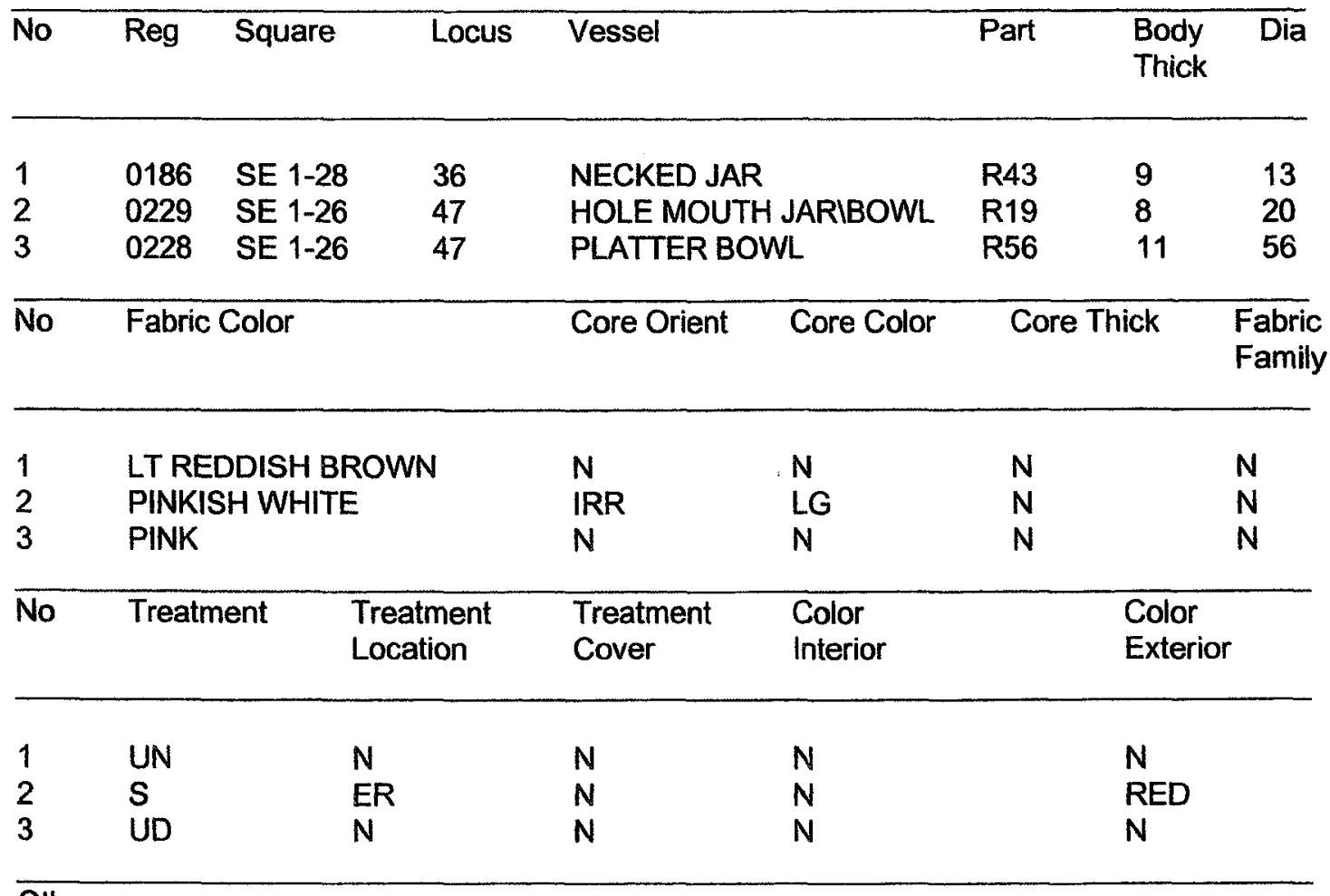

Other

2 Sample too small to confirm stance or diameter.

3 Weathered.

PLATE 17. FIELD A. PHASE 2A (EB II). 


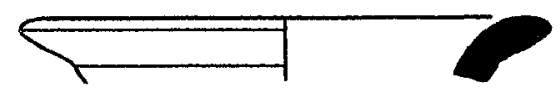

1

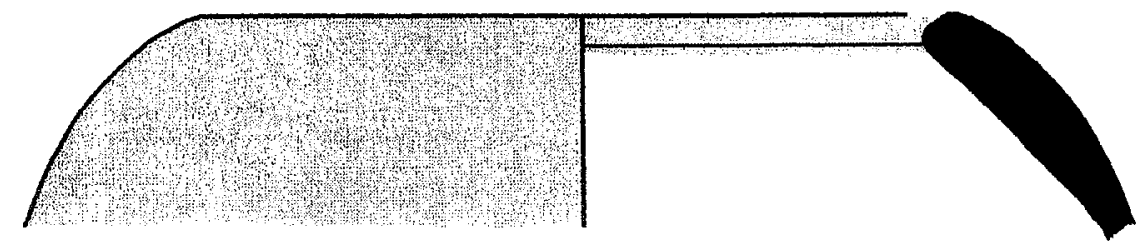

2

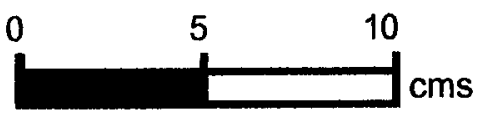

3

PLATE 17 (CONT.).

$\longrightarrow \mathrm{cms}$ 


\begin{tabular}{llllllll}
\hline No & Reg & Square & Locus & Vessel & Part & $\begin{array}{l}\text { Body } \\
\text { Thick }\end{array}$ & Dia \\
\hline & & & & & & & \\
1 & 0295 & SW 1-26 & 79 & LEDGE RIM BOWL & R51 & 11 & 30 \\
2 & 2076 & SW 1-26 & 79 & HOLE MOUTH BOWL & R22 & 8 & 25 \\
3 & 2080 & SW 1-26 & 79 & HOLE MOUTH BOWL & R14 & 11 & 26 \\
4 & 0339 & SW 1-26 & 79 & HOLE MOUTH JAR & R19 & 10 & 20 \\
5 & 2081 & SW 1-26 & 79 & HOLE MOUTH BOWL & R01 & 15 & 20 \\
6 & 0293 & SW 1-26 & 79 & HOLE MOUTH BOWL & R14 & 8 & 18 \\
7 & 2077 & SW 1-26 & 79 & HOLE MOUTH BOWL & R14 & 9 & 11 \\
8 & 2086 & SW 1-26 & 79 & HOLE MOUTH BOWL & R04 & 13 & 15 \\
9 & 0333 & SW 1-26 & 79 & HOLE MOUTH BOWL & R14 & 10 & 14 \\
10 & 2429 & SW 1-26 & 79 & PLATTER BOWL & R53 & N & N \\
\hline
\end{tabular}

\begin{tabular}{llllll}
\hline No & Fabric Color & Core Orient & Core Color & Core Thick & Fabric \\
& & & & Family
\end{tabular}

\begin{tabular}{|c|c|c|c|c|c|c|}
\hline 1 & \multicolumn{2}{|c|}{ LT REDDISH BROWN } & $\mathbf{N}$ & $\mathbf{N}$ & $\mathbf{N}$ & 23 \\
\hline 2 & \multicolumn{2}{|c|}{ LT RED } & IRR & G & $\mathrm{N}$ & $N$ \\
\hline 3 & \multicolumn{2}{|l|}{ LT RED } & $N$ & $\mathrm{~N}$ & $\mathbf{N}$ & $N$ \\
\hline 4 & \multicolumn{2}{|c|}{ LT REDDISH BROWN } & $N$ & $N$ & $N$ & $N$ \\
\hline 5 & \multicolumn{2}{|c|}{ WEAK RED } & EX & G & 12 & $N$ \\
\hline 6 & \multicolumn{2}{|c|}{ LT REDDISH BROWN } & IRR & LG & $\mathbf{N}$ & 2.2 \\
\hline 7 & \multicolumn{2}{|c|}{ WEAK RED } & IRR & $\mathrm{G}$ & $N$ & $\mathrm{~N}$ \\
\hline 8 & \multicolumn{2}{|c|}{ REDDISH BROWN } & $M$ & G & 4 & 1 \\
\hline 9 & \multicolumn{2}{|c|}{ LT REDDISH BROWN } & $M$ & G & 7 & 2.1 \\
\hline 10 & \multicolumn{2}{|c|}{ RED } & $\ddot{N}$ & $N$ & $\mathrm{~N}$ & $\mathrm{~N}$ \\
\hline No & Treatment & $\begin{array}{l}\text { Treatment } \\
\text { Location }\end{array}$ & $\begin{array}{l}\text { Treatment } \\
\text { Cover }\end{array}$ & $\begin{array}{l}\text { Color } \\
\text { Interior }\end{array}$ & $\begin{array}{l}\text { Color } \\
\text { Exterior }\end{array}$ & \\
\hline 1 & SB & $\mathbb{I R}$ & ALL & RED & $\mathbf{N}$ & \\
\hline 2 & WASH & ER & $N$ & $N$ & WHITE & \\
\hline 3 & UN & $\mathbf{N}$ & $\mathrm{N}$ & $\mathbf{N}$ & $\mathbf{N}$ & \\
\hline 4 & UN & $N$ & $N$ & $N$ & $N$ & \\
\hline 5 & UN & $N$ & $\mathbf{N}$ & $\mathbf{N}$ & $\mathbf{N}$ & \\
\hline 6 & UN & $\mathbf{N}$ & $\mathbf{N}$ & $\mathbf{N}$ & $\mathbf{N}$ & \\
\hline 7 & UN & $N$ & $N$ & $\mathrm{~N}$ & $N$ & \\
\hline 8 & UN & $\mathbf{N}$ & $N$ & $\mathbf{N}$ & $N$ & \\
\hline 9 & UN & $\mathbf{N}$ & $N$ & $\mathrm{~N}$ & $\mathrm{~N}$ & \\
\hline 10 & B & IR & ALL & $\ddot{N}$ & $N$ & \\
\hline
\end{tabular}

PLATE 18. fiELD A. PHASE 2A (EB II). 
Other

$5 \quad$ Surface burn visible.

$7 \quad$ Surface burn visible.

8 Surface burn visible.

10 Sample too small to confirm stance or diameter; Metallic Ware.

PLATE 18 (CONT.).

Reproduced with permission of the copyright owner. Further reproduction prohibited without permission. 

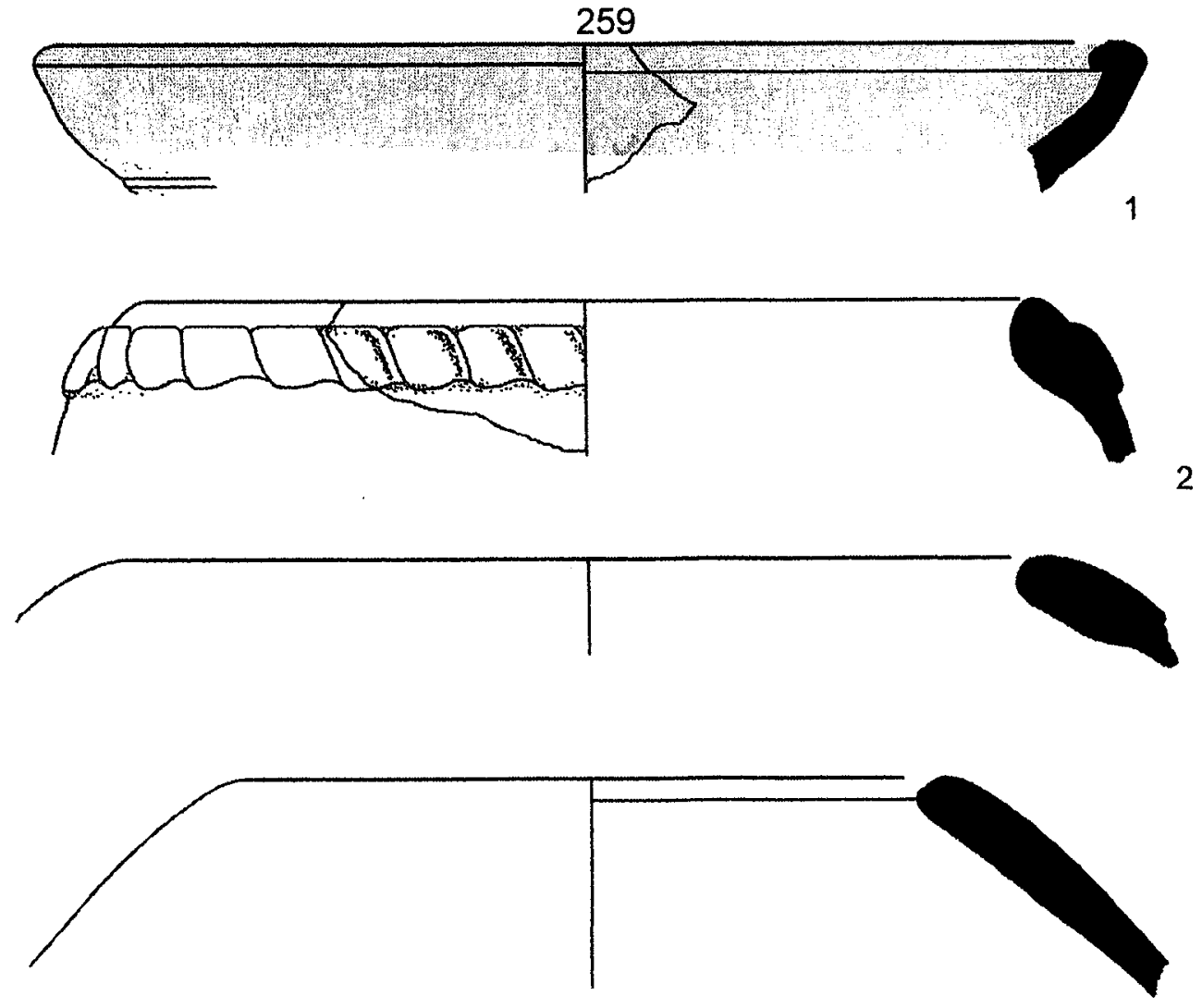

4
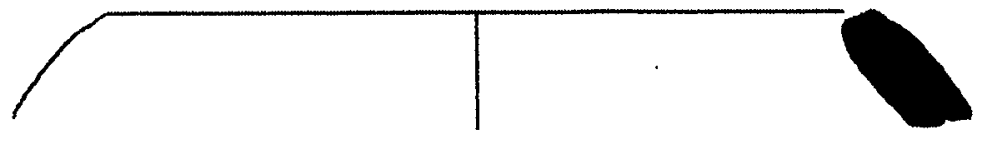

5
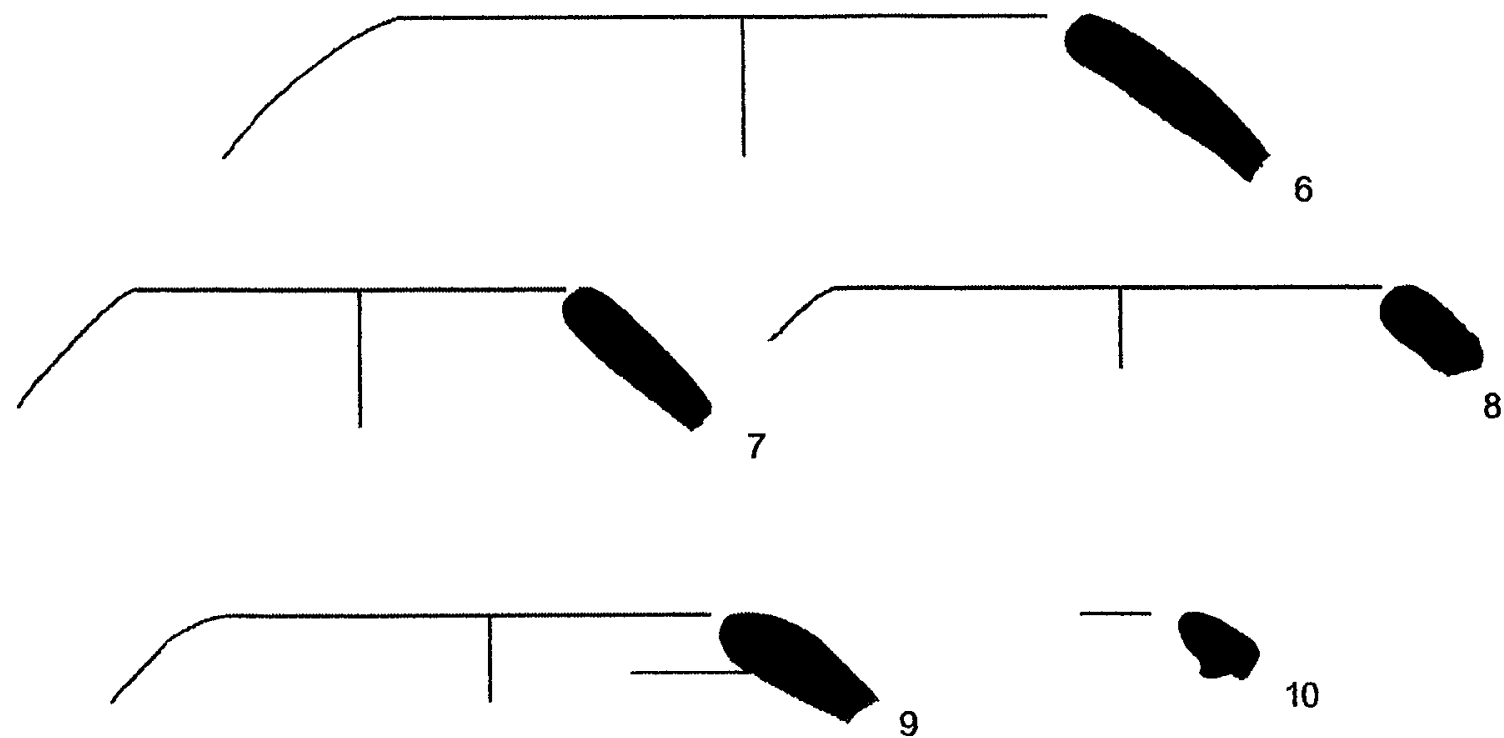

PLATE 18 (CONT.).

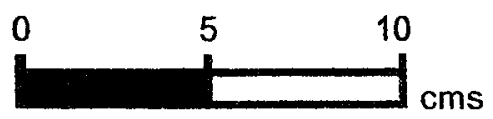




\begin{tabular}{|c|c|c|c|c|c|c|c|}
\hline No & $\operatorname{Reg}$ & Square & Locus & Vessel & Part & $\begin{array}{l}\text { Body } \\
\text { Thick }\end{array}$ & Dia \\
\hline 1 & 2083 & SW 1-26 & 79 & NECKED JAR & R30 & 6 & 12 \\
\hline 2 & 0335 & SW 1-26 & 79 & NECKED JAR & R30 & 7 & 11 \\
\hline 3 & 0287 & SW 1-26 & 79 & NECKED JAR & $\mathrm{R} 43$ & 11 & 16 \\
\hline 4 & 0286 & SW 1-26 & 79 & NECKED JAR & R43 & 10 & $\mathbf{N}$ \\
\hline 5 & 0334 & SW 1-26 & 79 & NECKED JAR & $\mathrm{R} 43$ & 10 & 18 \\
\hline 6 & 2082 & SW 1-26 & 79 & JUG & R32 & 9 & 5 \\
\hline 7 & 0294 & SW 1-26 & 79 & JUG & $\mathrm{R} 82$ & 6 & 4 \\
\hline 8 & 0336 & SW 1-26 & 79 & UD & $\mathrm{H} 27$ & 6 & $N$ \\
\hline 9 & 0340 & SW 1-26 & 79 & UD & $\mathrm{H} 20$ & 6 & $N$ \\
\hline 10 & 0296 & SW 1-26 & 79 & UD & $\mathrm{H} 20$ & 8 & $\mathbf{N}$ \\
\hline 11 & 2087 & SW 1-26 & 79 & UD & $\mathrm{B} 12$ & 13 & 6 \\
\hline 12 & 2085 & SW 1-26 & 79 & UD & $\mathrm{B} 12$ & 8 & 10 \\
\hline 13 & 2088 & SW 1-26 & 79 & UD & B12 & 9 & $N$ \\
\hline 14 & 0341 & SW 1-26 & 79 & UD & BOD & 10 & $\mathbf{N}$ \\
\hline 15 & 0297 & SW 1-26 & 79 & UD & BOD & 12 & $\mathbf{N}$ \\
\hline 16 & 0338 & SW 1-26 & 79 & UD & $\mathrm{BOD}$ & 7 & $\mathbf{N}$ \\
\hline
\end{tabular}

\begin{tabular}{|c|c|c|c|c|}
\hline$\overline{\text { No }}$ & Fabric Color & Core Orient & Core Color & Core Thick \\
\hline
\end{tabular}

\begin{tabular}{|c|c|c|c|c|c|c|}
\hline 1 & \multicolumn{2}{|l|}{ PINK } & $\mathrm{N}$ & $\mathrm{N}$ & $\mathrm{N}$ & $N$ \\
\hline 2 & \multicolumn{2}{|c|}{ LT REDDISH BROWN } & $\mathrm{N}$ & $\mathbf{N}$ & $\mathrm{N}$ & 23 \\
\hline 3 & \multicolumn{2}{|c|}{ LT REDDISH BROWN } & $M$ & G & 6 & 10.1 \\
\hline 4 & \multicolumn{2}{|c|}{ LT REDDISH BROWN } & $M$ & G & 5 & 9.1 \\
\hline 5 & \multicolumn{2}{|c|}{ REDDISH YELLOW } & $M$ & LG & 4 & 8 \\
\hline 6 & \multicolumn{2}{|l|}{ LT RED } & $\mathrm{N}$ & $\mathbf{N}$ & $\mathrm{N}$ & $N$ \\
\hline 7 & \multicolumn{2}{|c|}{ LT REDDISH BROWN } & $N$ & $\mathrm{~N}$ & $\mathbf{N}$ & 24 \\
\hline 8 & \multicolumn{2}{|c|}{ PINKISH GREY } & $M$ & LG & $\mathbf{N}$ & 17.2 \\
\hline 9 & \multicolumn{2}{|c|}{ PINK } & $\mathrm{N}$ & $\mathrm{N}$ & $\mathrm{N}$ & 22 \\
\hline 10 & \multicolumn{2}{|l|}{ PINK } & IRR & LG & $\mathbf{N}$ & 17.1 \\
\hline 11 & \multicolumn{2}{|l|}{ LT RED } & IRR & LG & $\mathrm{N}$ & $\mathrm{N}$ \\
\hline 12 & \multicolumn{2}{|l|}{ PINK } & $\mathbf{N}$ & $\mathbf{N}$ & $\mathrm{N}$ & $\mathbf{N}$ \\
\hline 13 & \multicolumn{2}{|l|}{ LTRED } & $M$ & $\mathbf{G}$ & $\mathrm{N}$ & $\mathbf{N}$ \\
\hline 14 & \multicolumn{2}{|l|}{ LTRED } & $\mathbf{N}$ & $\mathbf{G}$ & 8 & 9.1 \\
\hline 15 & \multicolumn{2}{|l|}{ LT RED } & ALL & $\mathbf{G}$ & $\mathbf{N}$ & 12.2 \\
\hline 16 & \multicolumn{2}{|l|}{ RED } & $\mathrm{N}$ & $\mathbf{N}$ & $\mathbf{N}$ & 12.3 \\
\hline No & Treatment & $\begin{array}{l}\text { Treatment } \\
\text { Location }\end{array}$ & $\begin{array}{l}\text { Treatment } \\
\text { Cover }\end{array}$ & $\begin{array}{l}\text { Color } \\
\text { interior }\end{array}$ & $\begin{array}{l}\text { Color } \\
\text { Exterior }\end{array}$ & \\
\hline 1 & $S$ & $E$ & ALL & $N$ & LT RED & \\
\hline 2 & $\mathbf{S}$ & ER & ALL & $\mathbf{N}$ & RED & \\
\hline 3 & $\mathrm{~S}$ & ER & ALL & $\mathbf{N}$ & RED & \\
\hline 4 & $\mathrm{~S}$ & ER & ALL & $\mathrm{N}$ & RED & \\
\hline
\end{tabular}

PLATE 19. FIELD A. PHASE 2A (EB II). 
261

\begin{tabular}{llllll}
\hline No & Treatment & $\begin{array}{l}\text { Treatment } \\
\text { Location }\end{array}$ & $\begin{array}{l}\text { Treatment } \\
\text { Cover }\end{array}$ & $\begin{array}{l}\text { Color } \\
\text { Interior }\end{array}$ & $\begin{array}{l}\text { Color } \\
\text { Exterior }\end{array}$ \\
\hline 5 & UN & N & N & N & N \\
6 & UN & N & N & N & N \\
7 & SB & E & ALL & N & RED \\
8 & SB & E & ALL & N & WEAK RED \\
9 & UN & N & N & N & N \\
10 & S & E & ALL & N & RED \\
11 & B & E & ALL & N & N \\
12 & SB & E & ALL & N & RED \\
13 & WASH & E & ALL & N & WHITE \\
14 & I & E & ALL & N & N \\
15 & I & E & ALL & N & N \\
16 & I & E & ALL & N & N \\
\hline Other & & & & \\
\hline
\end{tabular}

4 Lines and voids in break suggest rim folding; sample too small to confirm stance or diameter.

13 Sample too small to confirm stance or diameter.

14 Combed Metallic Ware.

15 Combed Metallic Ware.

16 Combed Metallic Ware.

PLATE 19 (CONT.). 

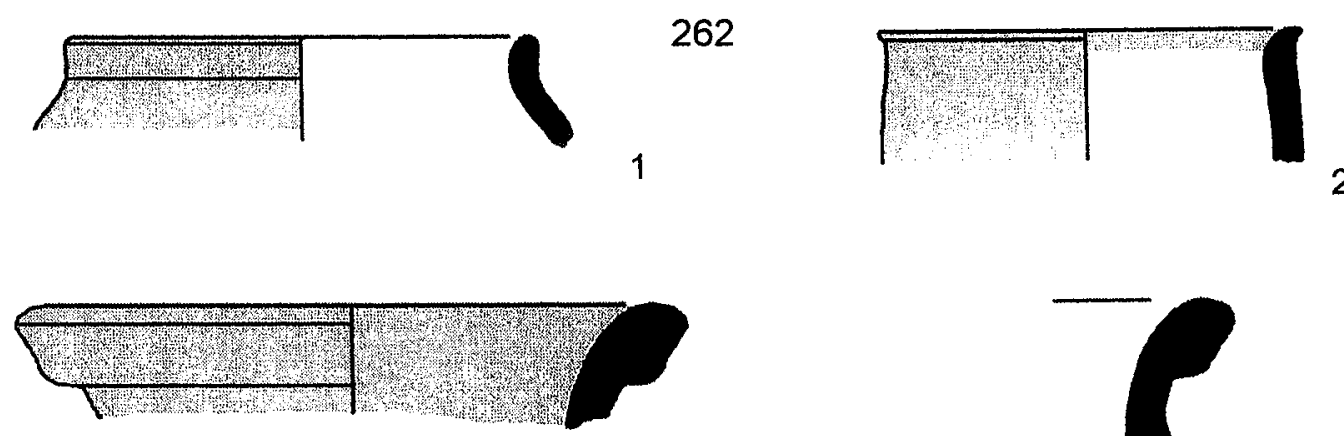

3
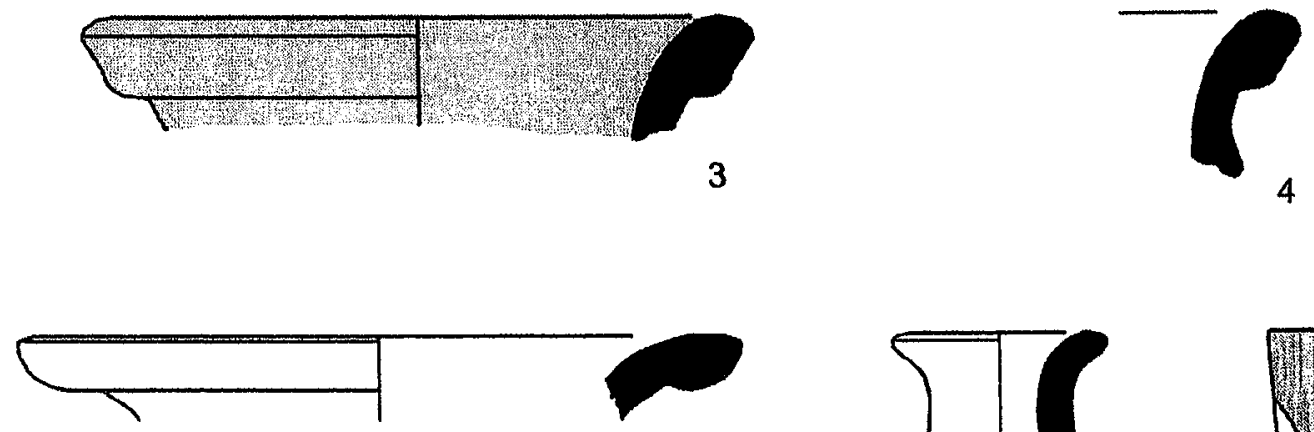

5
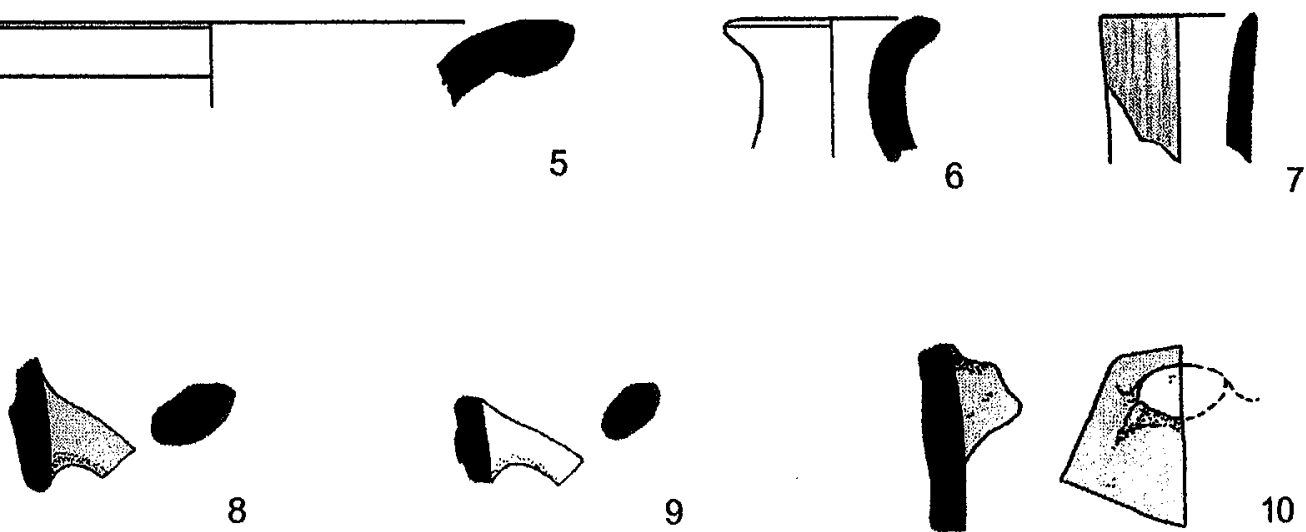

9
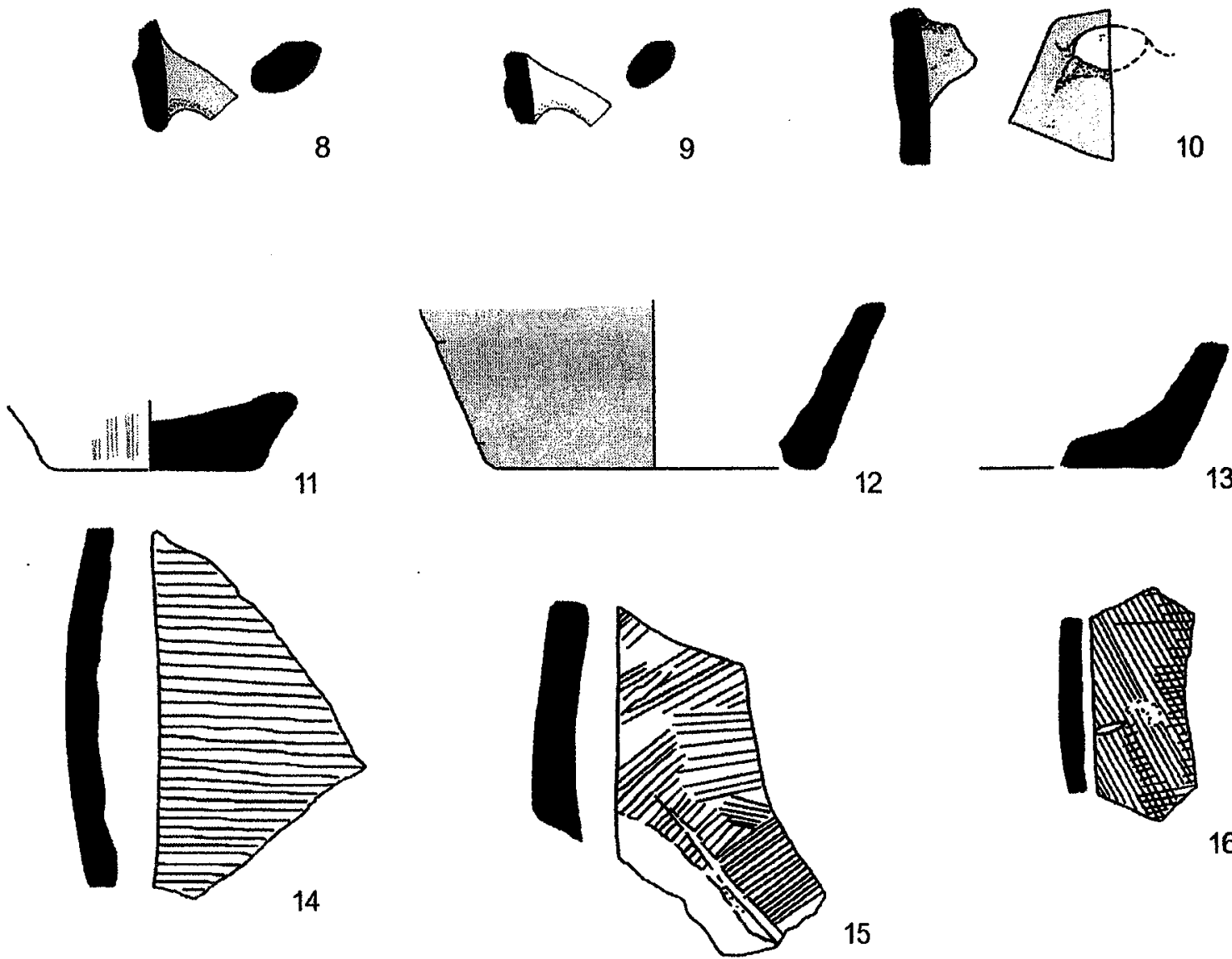

PLATE 19 (CONT.).

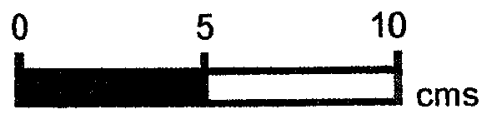




\begin{tabular}{llllllll}
\hline No & Reg & Square & Locus & Vessel & Part & $\begin{array}{l}\text { Body } \\
\text { Thick }\end{array}$ \\
\hline & & & & Dia \\
1 & 0330 & SW 1-26 & 85 & BOWL & R50 & 6 & 20 \\
2 & 0317 & SW 1-26 & 82 & BOWL & R50 & 6 & 20 \\
3 & 0316 & SW 1-26 & 82 & LEDGE RIM BOWL & R53 & 12 & 35 \\
4 & 0319 & SW 1-26 & 82 & LEDGE RIM BOWL & R51 & 9 & 24 \\
5 & 2417 & SW 1-26 & 82 & PLATTER BOWL & R55 & 6 & N \\
6 & 2282 & SW 1-26 & 85 & HOLE MOUTH JAR & R14 & N & 20 \\
7 & 0315 & SW 1-26 & 82 & HOLE MOUTH BOWL & R14 & 9 & 15 \\
8 & 0318 & SW 1-26 & 82 & UD H & H14 & 8 & N \\
9 & 2283 & SW 1-26 & 85 & HOLE MOUTH BOWL & R09 & 12 & 16 \\
\hline No & Fabric Color & & Core Orient Core Color & Core Thick & Fabric \\
& & & & & & & Family
\end{tabular}

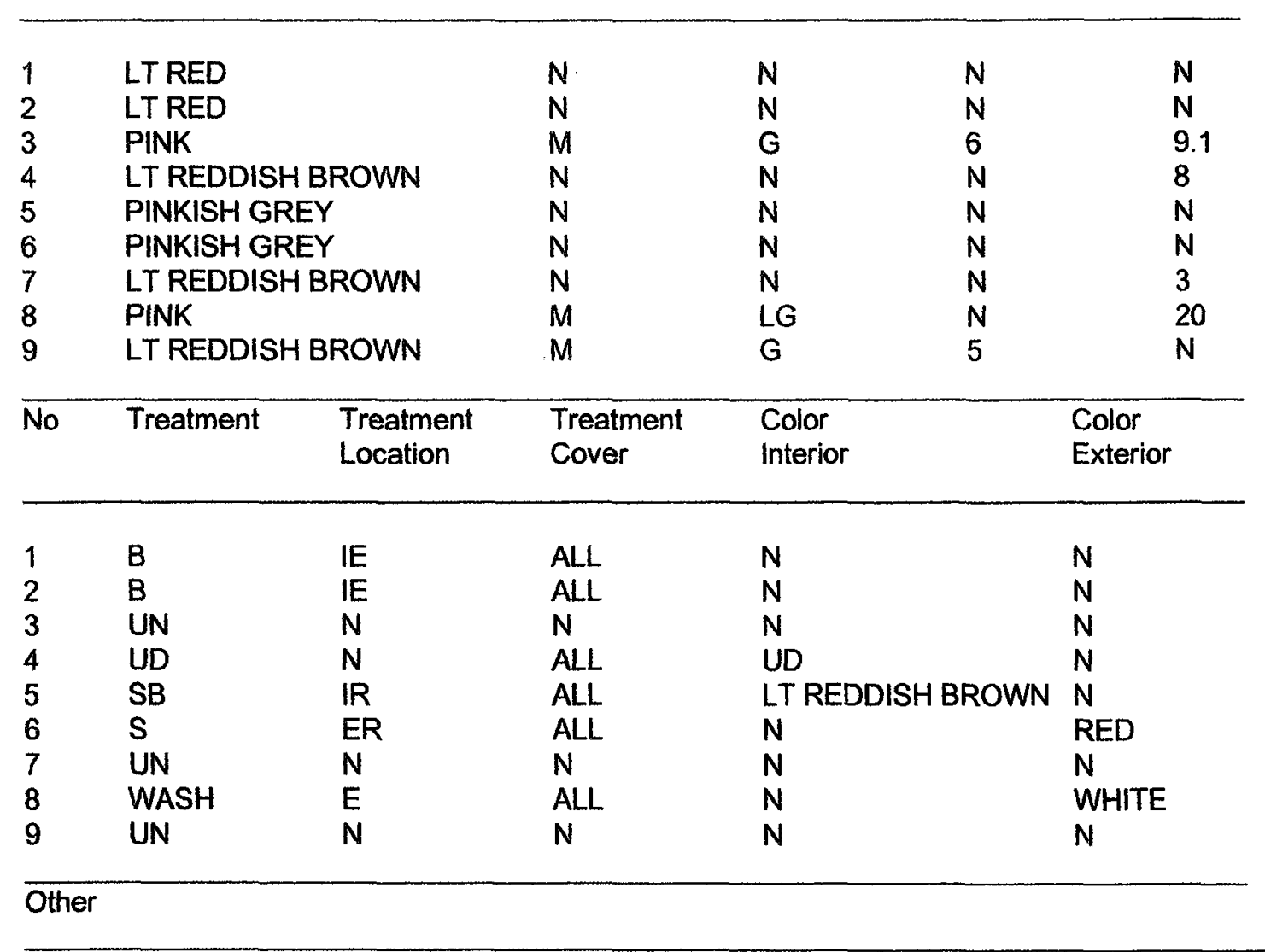

$\begin{array}{ll}1 & \text { Metallic Ware. } \\ 2 & \text { Metallic Ware. } \\ 5 & \text { Sample too small to confirm stance or diameter. }\end{array}$

PLATE 20. FIELD A. PHASE 2A (EB II). 

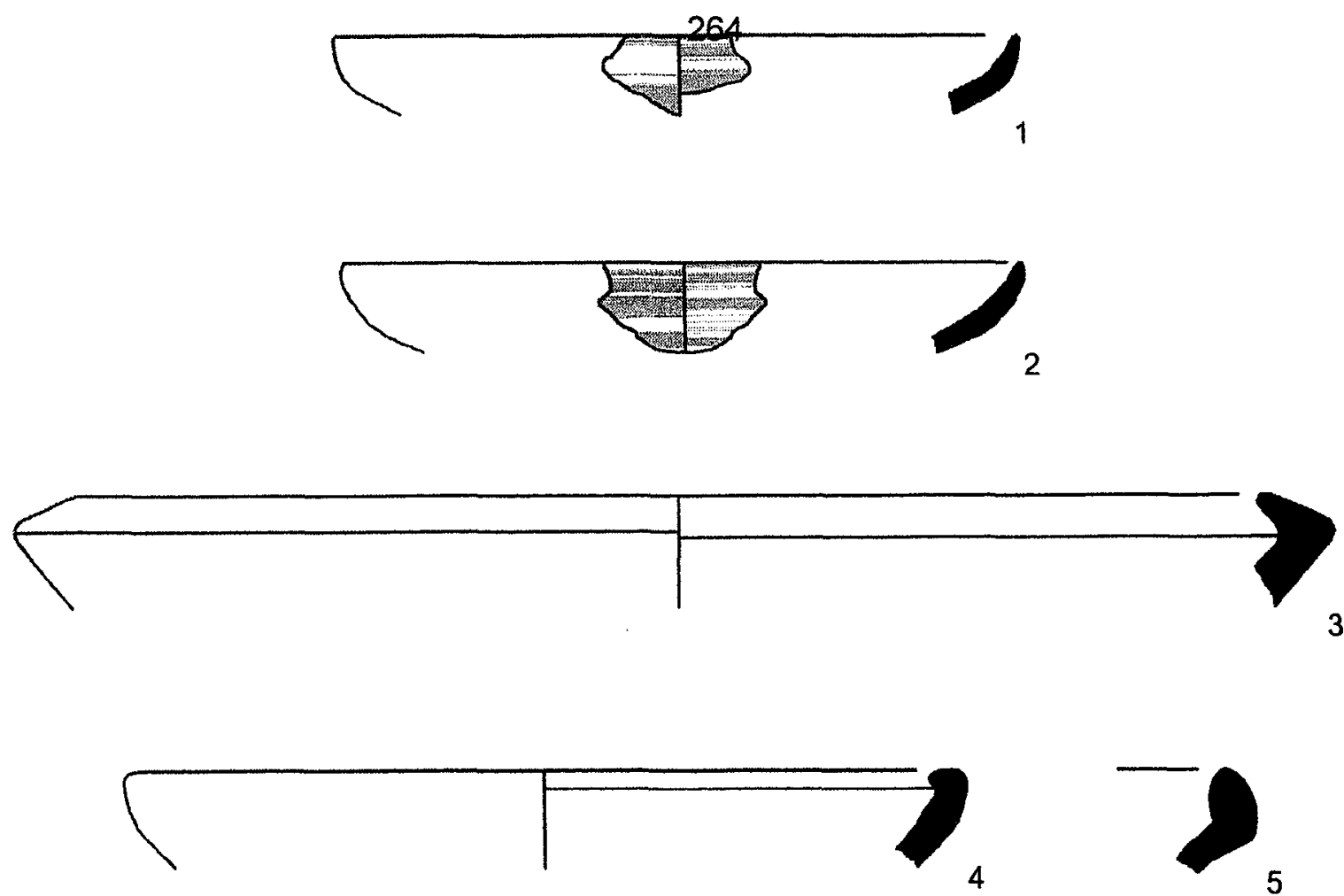

6
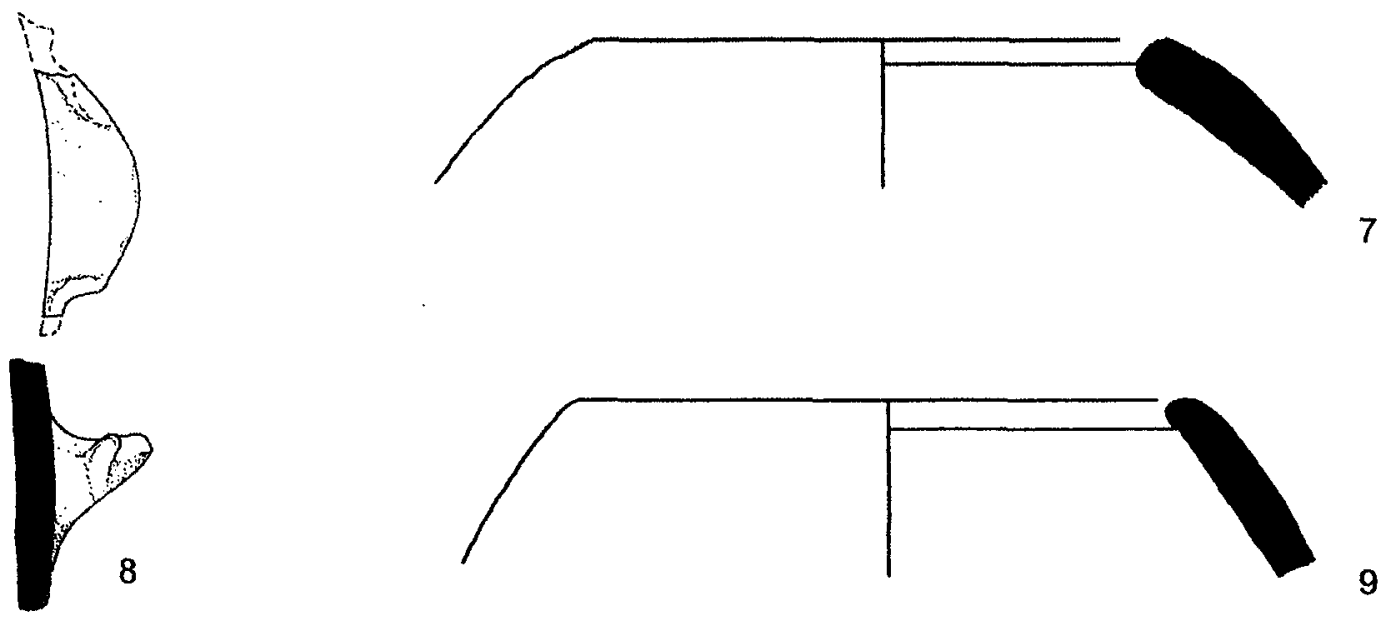

PLATE 20 (CONT.).

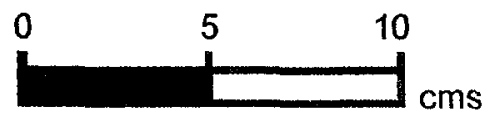


265

\begin{tabular}{llllllll}
\hline No & Reg & Square & Locus & Vessel & Part & $\begin{array}{l}\text { Body } \\
\text { Thick }\end{array}$ & Dia \\
\hline & & & & & & & \\
1 & 0323 & SW 1-26 & 87 & PLATTER BOWL & R19 & 11 & 35 \\
2 & 0329 & SW 1-26 & 87 & HOLE MOUTH JAR & R19 & 12 & 18 \\
3 & 0324 & SW 1-26 & 87 & HOLE MOUTH JARIBOWL & R14 & 10 & 14 \\
4 & 0322 & SW 1-26 & 87 & NECKED JAR & R31 & 14 & 18 \\
5 & 0325 & SW 1-26 & 87 & UD & H27 & 9 & N \\
6 & 0326 & SW 1-26 & 87 & UD & H20 & 8 & N \\
7 & 0328 & SW 1-26 & 87 & UD & BOD & 4 & N \\
8 & 0321 & SW 1-26 & 87 & PLATTER BOWL & R18 & N & 45
\end{tabular}

\begin{tabular}{lllll}
\hline No Fabric Color & Core Orient & Core Color & Core Thick & $\begin{array}{l}\text { Fabric } \\
\text { Family }\end{array}$ \\
\hline
\end{tabular}

\begin{tabular}{|c|c|c|c|c|c|c|}
\hline 1 & \multicolumn{2}{|l|}{ PINK } & $M$ & LG & 7 & 10.1 \\
\hline 2 & \multicolumn{2}{|l|}{ PINK } & M & G & 7 & $\mathrm{~N}$ \\
\hline 3 & \multicolumn{2}{|l|}{ PALE RED } & $\mathbf{M}$ & LG & 6 & \\
\hline 4 & \multicolumn{2}{|l|}{ PINK } & $\mathbf{M}$ & G & 9 & 23 \\
\hline 5 & \multicolumn{2}{|l|}{ LT RED } & $\mathbf{M}$ & G & 5 & 9.1 \\
\hline 6 & \multicolumn{2}{|c|}{ LT REDDISH BROWN } & $\mathrm{N}$ & $\mathrm{N}$ & $\mathrm{N}$ & 7.1 \\
\hline 7 & \multicolumn{2}{|l|}{ RED } & $\mathrm{N}$ & $\mathbf{N}$ & $\mathrm{N}$ & 12.1 \\
\hline 8 & \multicolumn{2}{|c|}{ LT REDDISH BROWN } & $\mathbf{N}$ & $N$ & N & 25.1 \\
\hline No & Treatment & $\begin{array}{l}\text { Treatment } \\
\text { Location }\end{array}$ & $\begin{array}{l}\text { Treatment } \\
\text { Cover }\end{array}$ & $\begin{array}{l}\text { Color } \\
\text { Interior }\end{array}$ & $\begin{array}{l}\text { Color } \\
\text { Exterior }\end{array}$ & \\
\hline 1 & S & ER & UD & RED & $N$ & \\
\hline 2 & $\mathbf{s}$ & ER & ALL & $\mathrm{N}$ & RED & \\
\hline 3 & $\mathrm{~s}$ & ER & ALL & $\mathrm{N}$ & BLACK & \\
\hline 4 & $\mathrm{~s}$ & ER & $\mathrm{N}$ & $\mathrm{N}$ & $\mathrm{N}$ & \\
\hline 5 & S & $E$ & ALL & $\mathrm{N}$ & LT RED & \\
\hline 6 & $S$ & $\mathrm{E}$ & ALL & $N$ & RED & \\
\hline 7 & 1 & $\mathrm{E}$ & ALL & $\mathrm{N}$ & $\mathrm{N}$ & \\
\hline 8 & SB & IE & ALL & RED & N & \\
\hline
\end{tabular}

1 Surface burn visible.

3 Sample too small to confirm stance or diameter.

7 Combed Metallic Ware.

PLATE 21. FIELD A. PHASE 2A (EB II). 

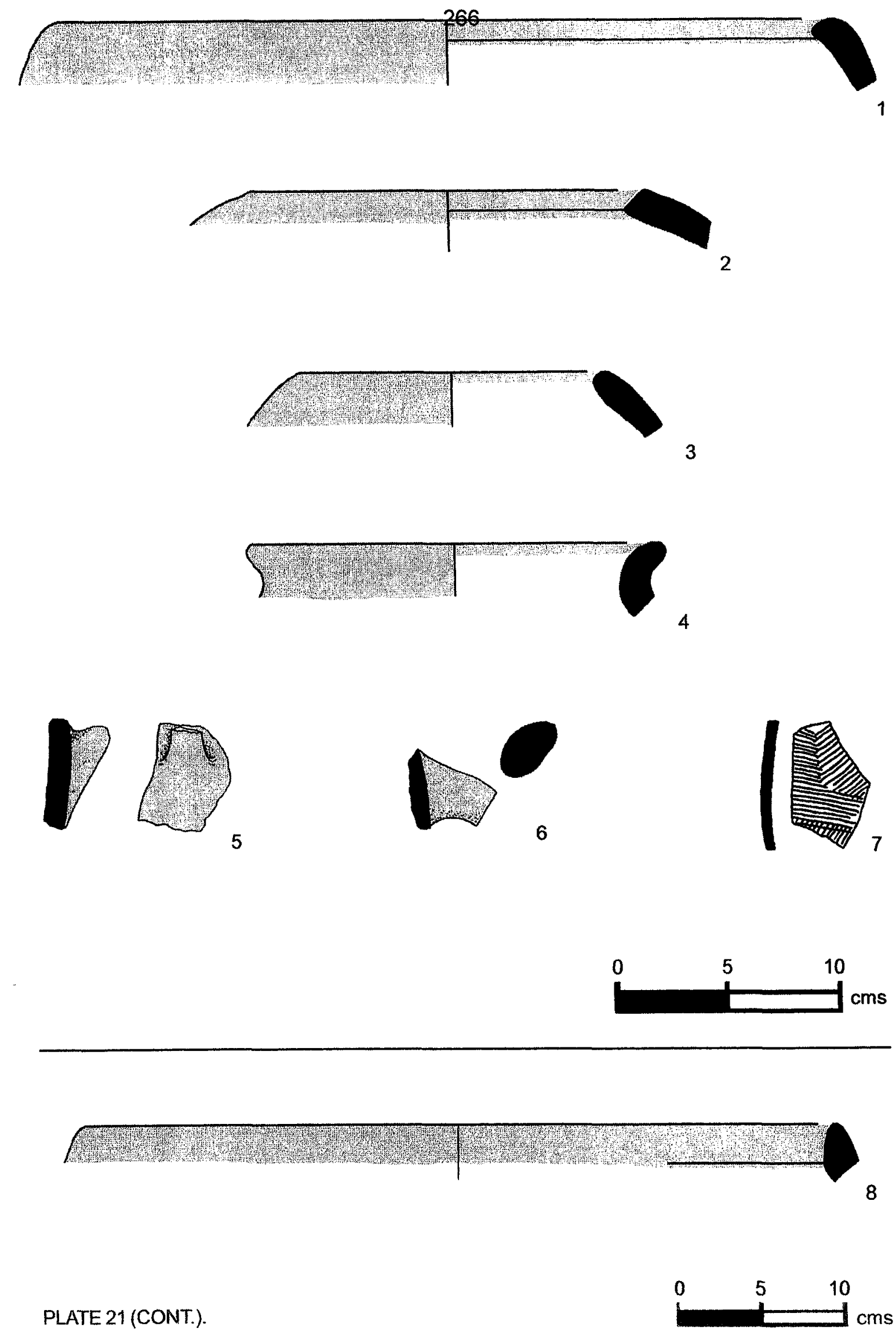
267

\begin{tabular}{llllllll}
\hline No & Reg & Square & Locus & Vessel & $\begin{array}{l}\text { Part } \\
\text { Thick }\end{array}$ & Body & Dia \\
\hline 1 & 0449 & SW 1-27 & 43 & HOLE MOUTH JAR & R19 & 13 & 20 \\
2 & 0441 & SW 1-27 & 43 & HOLE MOUTH BOWL & R18 & 8 & N \\
3 & 0424 & SW 1-27 & 48 & NECKED JAR & R43 & 15 & 18 \\
4 & 2459 & SW 1-27 & 43 & HOLE MOUTH JAR & R14 & 13 & N \\
5 & 0425 & SW 1-27 & 48 & UD & B12 & 14 & 14 \\
6 & 0442 & SW 1-27 & 43 & UD & H20 & 10 & N \\
7 & 0426 & SW 1-27 & 48 & UD & B12 & 8 & 15 \\
8 & 0443 & SW 1-27 & 43 & UD & H20 & N & N \\
9 & 0327 & SW 1-27 & 87 & UD & B12 & 13 & 20 \\
10 & 0423 & SW 1-27 & 48 & HOLE MOUTH BOWL & R14 & 18 & 36 \\
& & & & & & &
\end{tabular}

\begin{tabular}{lllll}
\hline No Fabric Color & Core Orient & Core Color & Core Thick & Fabric \\
Family
\end{tabular}

\begin{tabular}{|c|c|c|c|c|c|c|}
\hline 1 & \multicolumn{2}{|c|}{ WEAK RED } & M & G & 6 & 2.2 \\
\hline 2 & \multicolumn{2}{|c|}{ LT REDDISH BROWN } & IRR & G & $\mathrm{N}$ & 2.2 \\
\hline 3 & \multicolumn{2}{|c|}{ LT REDDISH BROWN } & M & G & 8 & $\mathbf{N}$ \\
\hline 4 & \multicolumn{2}{|c|}{ LT REDDISH BROWN } & M & G & 6 & 6 \\
\hline 5 & \multicolumn{2}{|c|}{ PINK } & $N$ & $\mathrm{~N}$ & $\mathrm{~N}$ & $\mathrm{~N}$ \\
\hline 6 & \multicolumn{2}{|l|}{ LT RED } & IRR & G & $\mathbf{N}$ & 18 \\
\hline 7 & \multicolumn{2}{|l|}{ LTRED } & $\mathbf{N}$ & G & 4 & $\mathbf{N}$ \\
\hline 8 & \multicolumn{2}{|c|}{ LT REDDISH BROWN } & $M$ & LG & $\mathrm{N}$ & 23 \\
\hline 9 & \multicolumn{2}{|c|}{ PINKISH WHITE } & $\mathrm{N}$ & $\mathrm{N}$ & $\mathbf{N}$ & 19 \\
\hline 10 & \multicolumn{2}{|c|}{ PALE RED } & $\mathrm{N}$ & LG & 9 & $N$ \\
\hline No & Treatment & $\begin{array}{l}\text { Treatment } \\
\text { Location }\end{array}$ & $\begin{array}{l}\text { Treatment } \\
\text { Cover }\end{array}$ & $\begin{array}{l}\text { Color } \\
\text { Interior }\end{array}$ & $\begin{array}{l}\text { Color } \\
\text { Exterior }\end{array}$ & \\
\hline 1 & UN & $\mathrm{N}$ & $\mathrm{N}$ & $\mathrm{N}$ & $\mathrm{N}$ & \\
\hline 2 & $\mathbf{S}$ & ER & ALL & $\mathrm{N}$ & RED & \\
\hline 3 & $\mathrm{~S}$ & $E$ & ALL & $\mathrm{N}$ & RED & \\
\hline 4 & UN & $\mathbf{N}$ & $\mathrm{N}$ & $\mathbf{N}$ & $\mathrm{N}$ & \\
\hline 5 & s & $E$ & ALL & $\mathbf{N}$ & DUSKY RED & \\
\hline 6 & $\mathbf{S}$ & $\mathrm{E}$ & ALL & $\mathbf{N}$ & RED & \\
\hline 7 & 1 & $E$ & ALL & $\mathrm{N}$ & $\mathrm{N}$ & \\
\hline 8 & $\mathbf{S}$ & $E$ & ALL & $\mathrm{N}$ & RED & \\
\hline 9 & $\mathbf{s}$ & $E$ & ALL & $\mathrm{N}$ & RED & \\
\hline 10 & UN & $\mathrm{N}$ & $\mathrm{N}$ & $\mathrm{N}$ & $\mathrm{N}$ & \\
\hline
\end{tabular}

2 Sample too small to confirm stance or diameter.

4 Sample too small to confirm stance or diameter; thin section sample 38.

7 Combed Metallic Ware.

PLATE 22. FIELD A. PHASE 2A (EB II). 

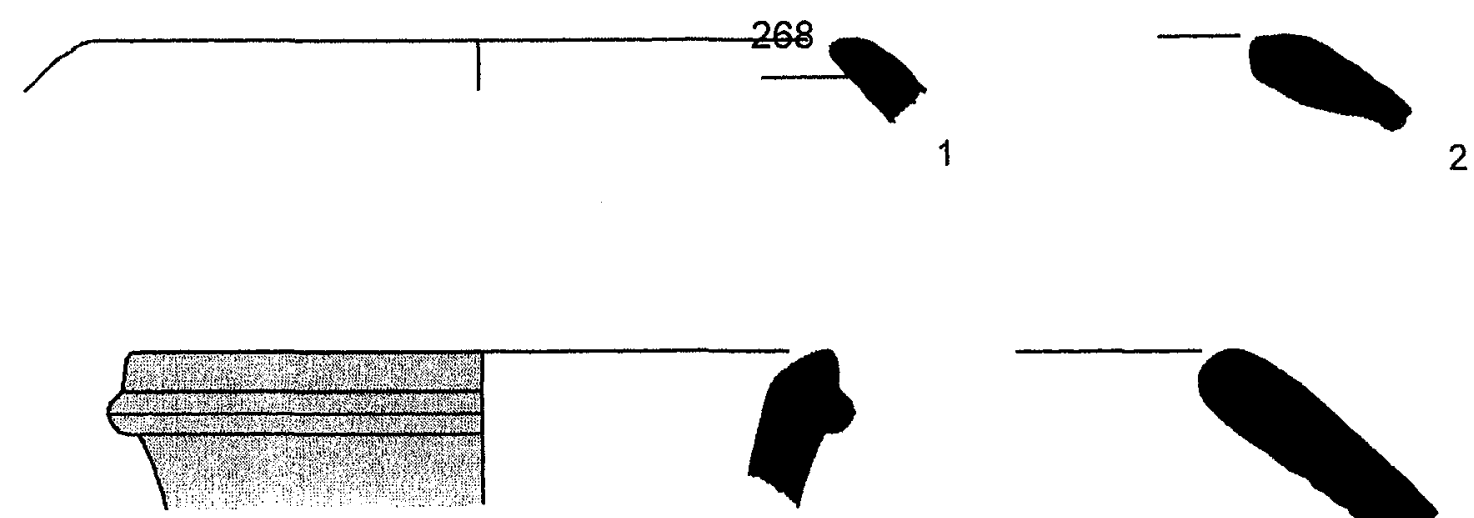

3
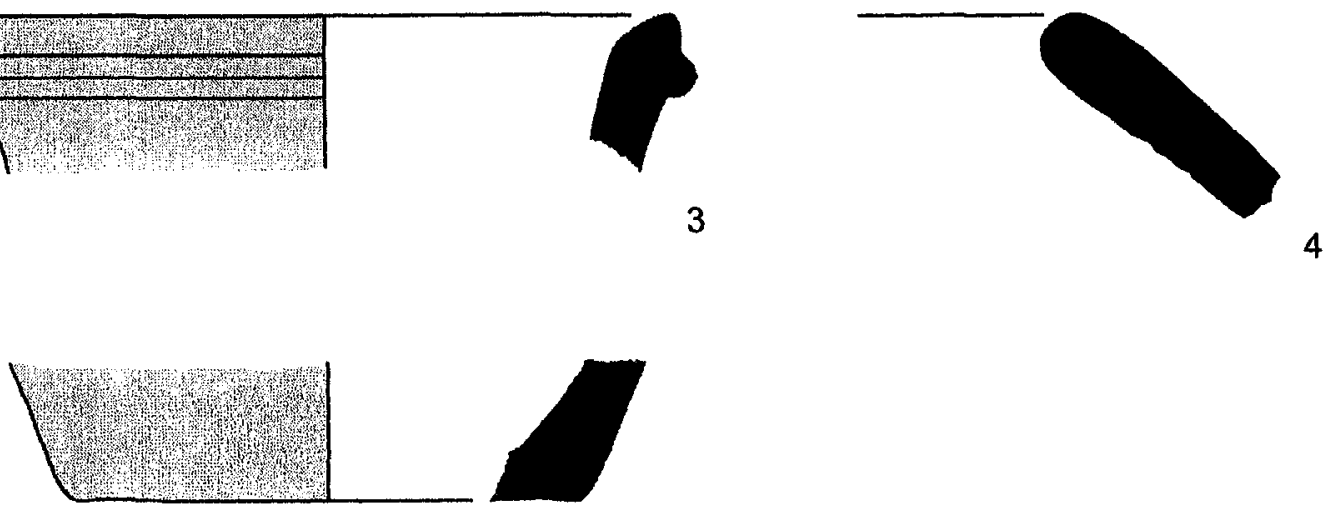

5
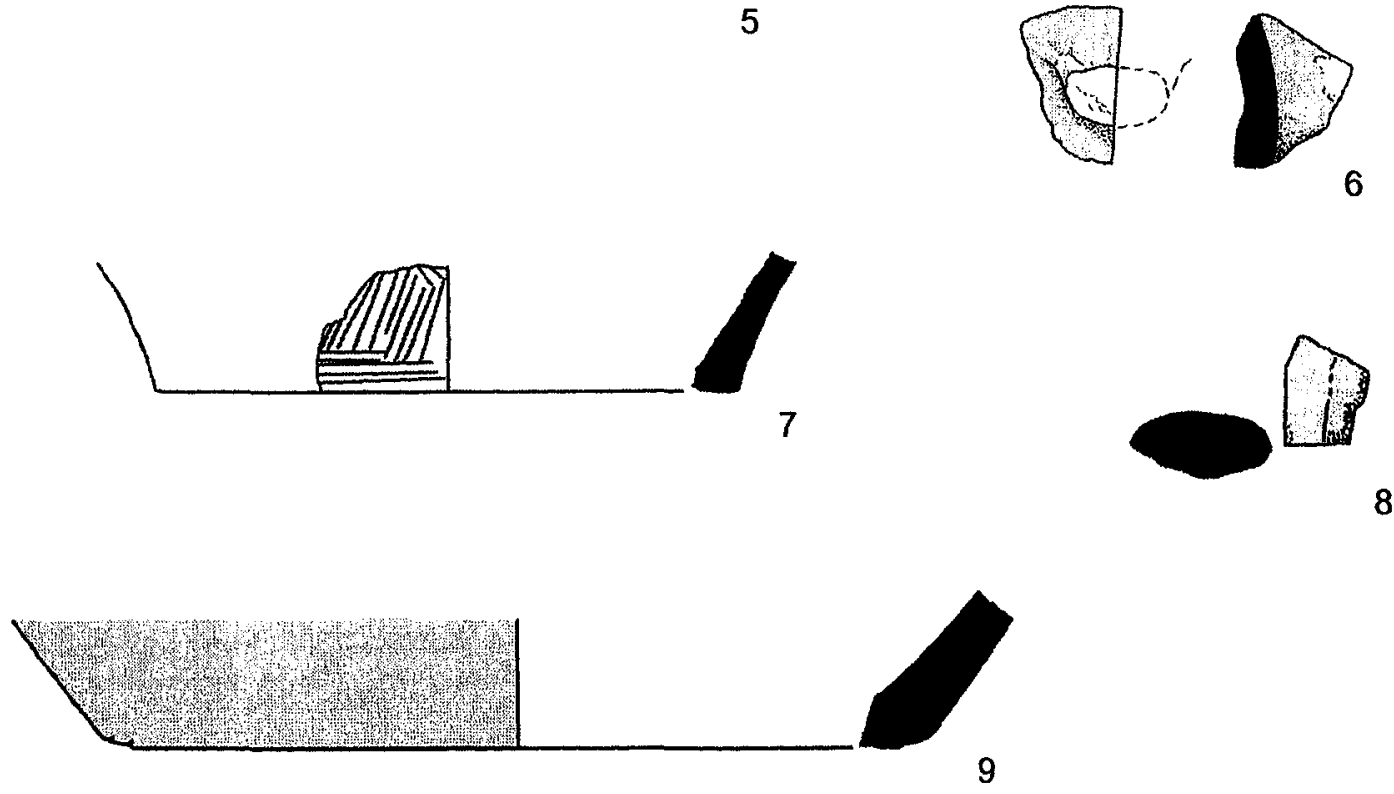

9

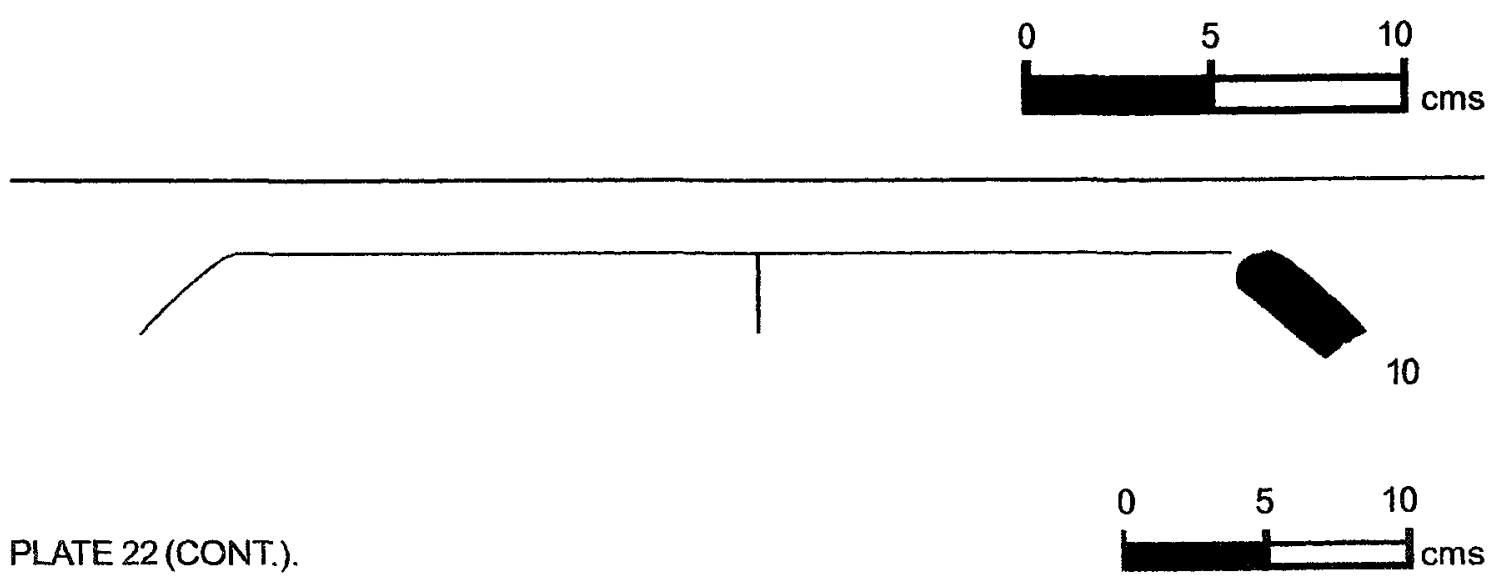




\begin{tabular}{llllllll}
\hline No & Reg & Square & Locus & Vessel & Part & $\begin{array}{c}\text { Body } \\
\text { Thick }\end{array}$ & Dia \\
& & & & & & & \\
\hline & & & & & & & \\
1 & 0414 & SW 1-27 & 44 & HOLE MOUTH JAR & R21 & 19 & 26 \\
2 & 0410 & SW 1-27 & 44 & HOLE MOUTH JAR & R14 & 10 & 25 \\
3 & 0411 & SW 1-27 & 44 & HOLE MOUTH JAR & R18 & 12 & 18 \\
4 & 0413 & SW 1-27 & 44 & LEDGE RIM BOWL & R51 & 8 & 32 \\
5 & 0412 & SW 1-27 & 44 & UD & R81 & 6 & 8 \\
6 & 0415 & SW 1-27 & 44 & UD & H20 & N & N \\
7 & 0416 & SW 1-27 & 44 & UD & B00 & 7 & N \\
8 & 0418 & SW 1-27 & 44 & UD & B12 & 9 & 12 \\
9 & 0421 & SW 1-27 & 44 & UD & BOD & 8 & N \\
10 & 0417 & SW 1-27 & 44 & UD & B12 & 13 & 11 \\
11 & 0419 & SW 1-27 & 44 & UD & B12 & 16 & 20
\end{tabular}

\begin{tabular}{llll}
\hline No Fabric Color Core Orient & Core Color & Core Thick & Fabric \\
& & Family
\end{tabular}

\begin{tabular}{|c|c|c|c|c|c|c|}
\hline 1 & \multicolumn{2}{|c|}{ LT REDDISH BROWN } & IRR & G & $\mathrm{N}$ & $\mathrm{N}$ \\
\hline 2 & \multicolumn{2}{|c|}{ PINK } & $\mathrm{N}$ & $\bar{N}$ & $N$ & $N$ \\
\hline 3 & \multicolumn{2}{|l|}{ PINK } & $\mathbf{M}$ & G & $\mathrm{N}$ & $\mathbf{N}$ \\
\hline 4 & \multicolumn{2}{|l|}{ PINK } & IRR & $G$ & $N$ & $\mathrm{~N}$ \\
\hline 5 & \multicolumn{2}{|l|}{ PINK } & $N$ & $N$ & $\mathrm{~N}$ & $\mathrm{~N}$ \\
\hline 6 & \multicolumn{2}{|l|}{ LT RED } & $\mathbf{N}$ & $\mathrm{N}$ & $\mathrm{N}$ & $\mathrm{N}$ \\
\hline 7 & \multicolumn{2}{|c|}{ LT REDDISH BROWN } & $M$ & $G$ & 3 & $N$ \\
\hline 8 & \multicolumn{2}{|c|}{ LT REDDISH BROWN } & $\mathbb{N}$ & G & 7 & $N$ \\
\hline 9 & \multicolumn{2}{|l|}{ PINK } & $M$ & LG & 2 & $\mathrm{~N}$ \\
\hline 10 & \multicolumn{2}{|l|}{ PINK } & $M$ & LG & 7 & $\mathrm{~N}$ \\
\hline 11 & \multicolumn{2}{|c|}{ LT REDDISH BROWN } & $M$ & LG & 13 & $\mathbf{N}$ \\
\hline No & Treatment & $\begin{array}{l}\text { Treatment } \\
\text { Location }\end{array}$ & $\begin{array}{l}\text { Treatment } \\
\text { Cover }\end{array}$ & $\begin{array}{l}\text { Color } \\
\text { Interior }\end{array}$ & & $\begin{array}{l}\text { Color } \\
\text { Exterior }\end{array}$ \\
\hline 1 & $S$ & ER & ALL & $N$ & & RED \\
\hline 2 & $\mathrm{~S}$ & IR & ALL & RED & & $\mathrm{N}$ \\
\hline 3 & UN & $\mathrm{N}$ & $\mathbf{N}$ & $\mathrm{N}$ & & $\mathrm{N}$ \\
\hline 4 & SB & $\mathbb{R}$ & ALL & DK REDI & BROWN & DK REDDISH BROWN \\
\hline 5 & $\mathbf{S}$ & $\mathrm{IE}$ & ALL & RED & & RED \\
\hline 6 & SB & $E$ & ALL & $N$ & & RED \\
\hline 7 & UD & $\mathbf{N}$ & ALL & $N$ & & $\mathrm{~N}$ \\
\hline 8 & UN & $\mathbf{N}$ & $\mathbf{N}$ & $\mathrm{N}$ & & $\mathrm{N}$ \\
\hline 9 & $\mathrm{~S}$ & $E$ & ALL & $\mathrm{N}$ & & VERY DUSKY RED \\
\hline 10 & WASH & $E$ & ALL & $\mathrm{N}$ & & WHITE \\
\hline 11 & $\mathrm{~S}$ & $E$ & ALL & $N$ & & LT RED \\
\hline
\end{tabular}

PLATE 23. FIELD A. PHASE 2A (EB II). 
Other

1 Roughly finished; "margin" on rim is wet-turned.

7 Possibly intrusive.

PLATE 23 (CONT.).

Reproduced with permission of the copyright owner. Further reproduction prohibited without permission. 

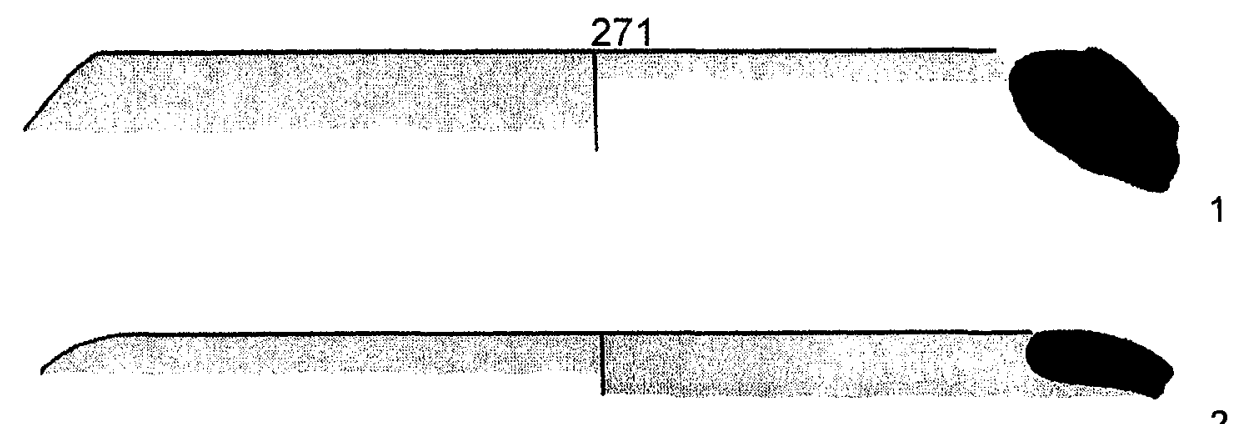

2
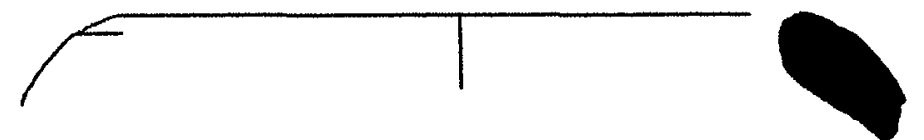

3
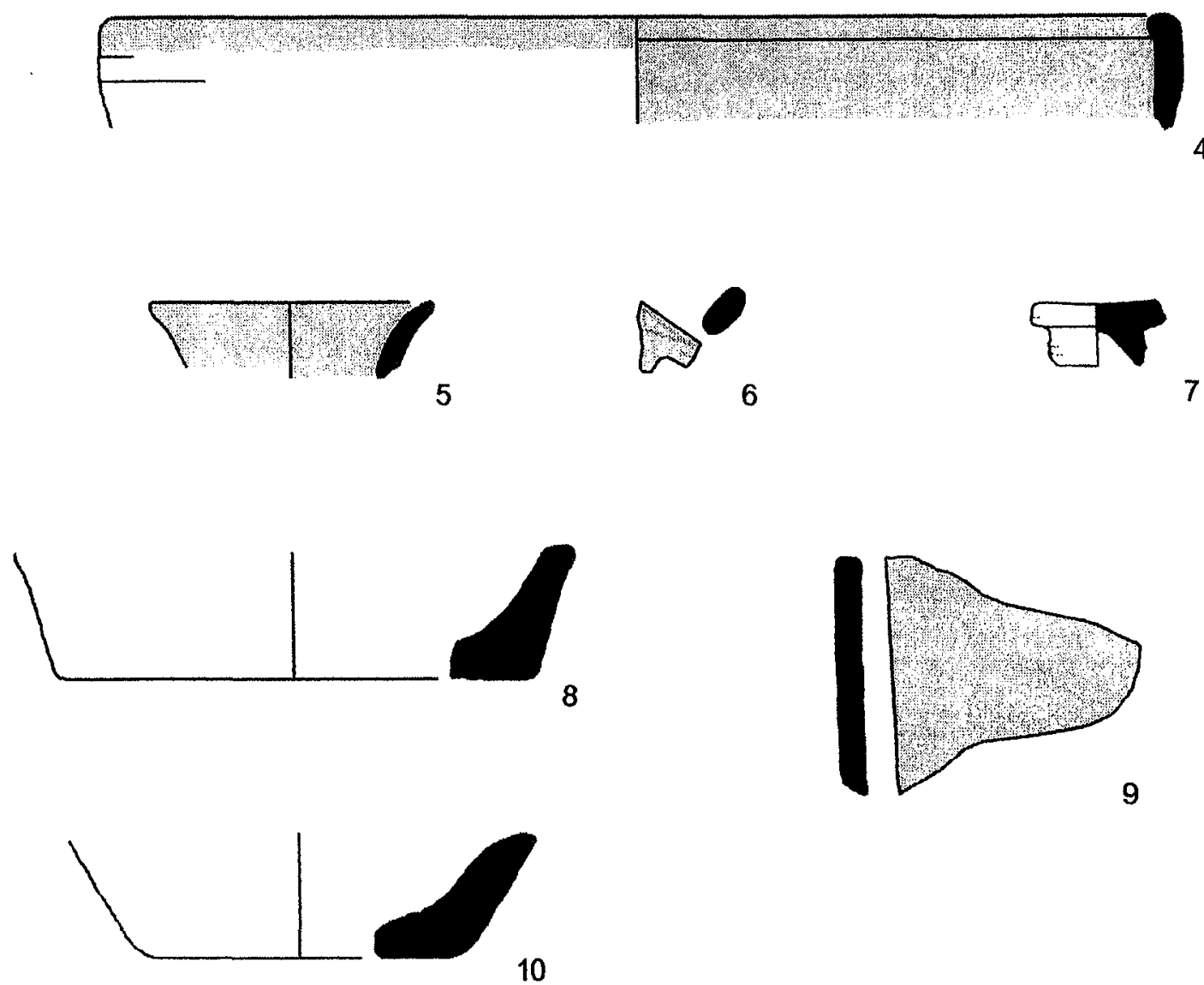

10

PLATE 23 (CONT.).

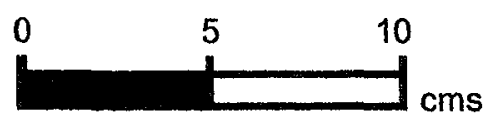


272

\begin{tabular}{llllllll}
\hline No & Reg & Square & Locus & Vessel & Part & $\begin{array}{l}\text { Body } \\
\text { Thick }\end{array}$ & Dia \\
& & & & & & & \\
\hline 1 & 0469 & SW 1-27 & 49 & BOWL & R82 & 5 & 16 \\
2 & 0473 & SW $1-27$ & 49 & PLATTER BOWL & R54 & 12 & 30 \\
3 & 0478 & SW $1-27$ & 49 & HOLE MOUTH BOWL & R14 & 12 & 20 \\
4 & 0477 & SW $1-27$ & 49 & HOLE MOUTH JAR & R17 & N & 18 \\
5 & 0476 & SW $1-27$ & 49 & HOLE MOUTH JAR & R14 & 10 & 16 \\
6 & 0467 & SW $1-27$ & 49 & HOLE MOUTH JAR & R17 & 8 & 15 \\
7 & 0470 & SW 1-27 & 49 & NECKED JAR & R31 & 9 & 13 \\
8 & 0475 & SW $1-27$ & 49 & HOLE MOUTH BOWL & R09 & 13 & 18 \\
9 & 0468 & SW 1-27 & 49 & HOLE MOUTH JAR & R02 & 12 & N \\
10 & 0471 & SW 1-27 & 49 & HOLE MOUTH JAR & R19 & 11 & 15 \\
11 & 0481 & SW 1-27 & 49 & UD & B23 & 4 & 3 \\
12 & 0482 & SW 1-27 & 49 & UD & H40 & 5 & N
\end{tabular}

\begin{tabular}{lllll}
\hline No Fabric Color & Core Orient & Core Color & Core Thick & $\begin{array}{l}\text { Fabric } \\
\text { Family }\end{array}$ \\
& & &
\end{tabular}

\begin{tabular}{|c|c|c|c|c|c|c|}
\hline 1 & \multicolumn{2}{|c|}{ LT REDDISH BROWN } & IRR & LG & $\mathbf{N}$ & $\mathbf{N}$ \\
\hline 2 & \multicolumn{2}{|l|}{ LT RED } & M & LG & 5 & $\mathbf{N}$ \\
\hline 3 & \multicolumn{2}{|l|}{ LT RED } & $M$ & $\mathbf{G}$ & 7 & $\mathbf{N}$ \\
\hline 4 & \multicolumn{2}{|c|}{ REDDISH BROWN } & IRR & G & $\mathbf{N}$ & $\mathbf{N}$ \\
\hline 5 & \multicolumn{2}{|l|}{ PINK } & $M$ & G & 4 & $\mathbf{N}$ \\
\hline 6 & \multicolumn{2}{|c|}{ LT REDDISH BROWN } & $N$ & $\mathrm{~N}$ & $\mathrm{~N}$ & $\mathrm{~N}$ \\
\hline 7 & \multicolumn{2}{|c|}{ LT REDDISH BROWN } & $\mathrm{N}$ & $\mathbf{N}$ & $\mathbf{N}$ & $\mathbf{N}$ \\
\hline 8 & \multicolumn{2}{|c|}{ LT REDDISH BROWN } & $M$ & LG & 7 & $\mathbf{N}$ \\
\hline 9 & \multicolumn{2}{|c|}{ LT REDDISH BROWN } & $M$ & G & 4 & $\mathrm{~N}$ \\
\hline 10 & \multicolumn{2}{|l|}{ PINK } & $\mathrm{N}$ & $\mathbf{N}$ & $\mathbf{N}$ & $\mathbf{N}$ \\
\hline 11 & \multicolumn{2}{|l|}{ LT RED } & $\mathrm{N}$ & $\mathbf{N}$ & $\mathbf{N}$ & $\mathbf{N}$ \\
\hline 12 & \multicolumn{2}{|c|}{ LT REDDISH BROWN } & $N$ & $\mathbf{N}$ & $N$ & $N$ \\
\hline No & Treatment & $\begin{array}{l}\text { Treatment } \\
\text { Location }\end{array}$ & $\begin{array}{l}\text { Treatment } \\
\text { Cover }\end{array}$ & $\begin{array}{l}\text { Color } \\
\text { Interior }\end{array}$ & $\begin{array}{l}\text { Color } \\
\text { Exterior }\end{array}$ & \\
\hline 1 & s & IE & ALL & RED & RED & \\
\hline 2 & UN & $N$ & $\mathrm{~N}$ & $\mathrm{~N}$ & $\mathbf{N}$ & \\
\hline 3 & UN & $\mathrm{N}$ & $\mathrm{N}$ & $\mathbf{N}$ & $\mathbf{N}$ & \\
\hline 4 & UN & $\mathbf{N}$ & $\mathbf{N}$ & $\mathrm{N}$ & $\mathbf{N}$ & \\
\hline 5 & $\mathbf{s}$ & ER & ALL & $\mathrm{N}$ & RED & \\
\hline 6 & s & ER & ALL & $\mathrm{N}$ & RED & \\
\hline 7 & UN & $N$ & $\mathbf{N}$ & $\mathrm{N}$ & $N$ & \\
\hline 8 & $\mathbf{s}$ & ER & ALL & $N$ & RED & \\
\hline 9 & $s$ & ER & ALL & $N$ & LT RED & \\
\hline 10 & $S$ & ER & $\mathrm{ALL}$ & $\mathbf{N}$ & LT RED & \\
\hline
\end{tabular}

PLATE 24. FIELD A. PHASE 2A (EB II). 
273

\begin{tabular}{llllll}
\hline No & Treatment & $\begin{array}{l}\text { Treatment } \\
\text { Location }\end{array}$ & $\begin{array}{l}\text { Treatment } \\
\text { Cover }\end{array}$ & $\begin{array}{l}\text { Color } \\
\text { Interior }\end{array}$ & $\begin{array}{l}\text { Color } \\
\text { Exterior }\end{array}$ \\
\hline 11 & B & E & ALL & $\mathrm{N}$ & $\mathrm{N}$ \\
12 & UN & $\mathrm{N}$ & $\mathrm{N}$ & $\mathrm{N}$ & $\mathrm{N}$ \\
\hline
\end{tabular}

Other

1 Surface burn visible.

2 Surface burn visible; Metallic Ware.

9 Sample too small to confirm stance or diameter.

11 Metallic Ware.

PLATE 24 (CONT.). 

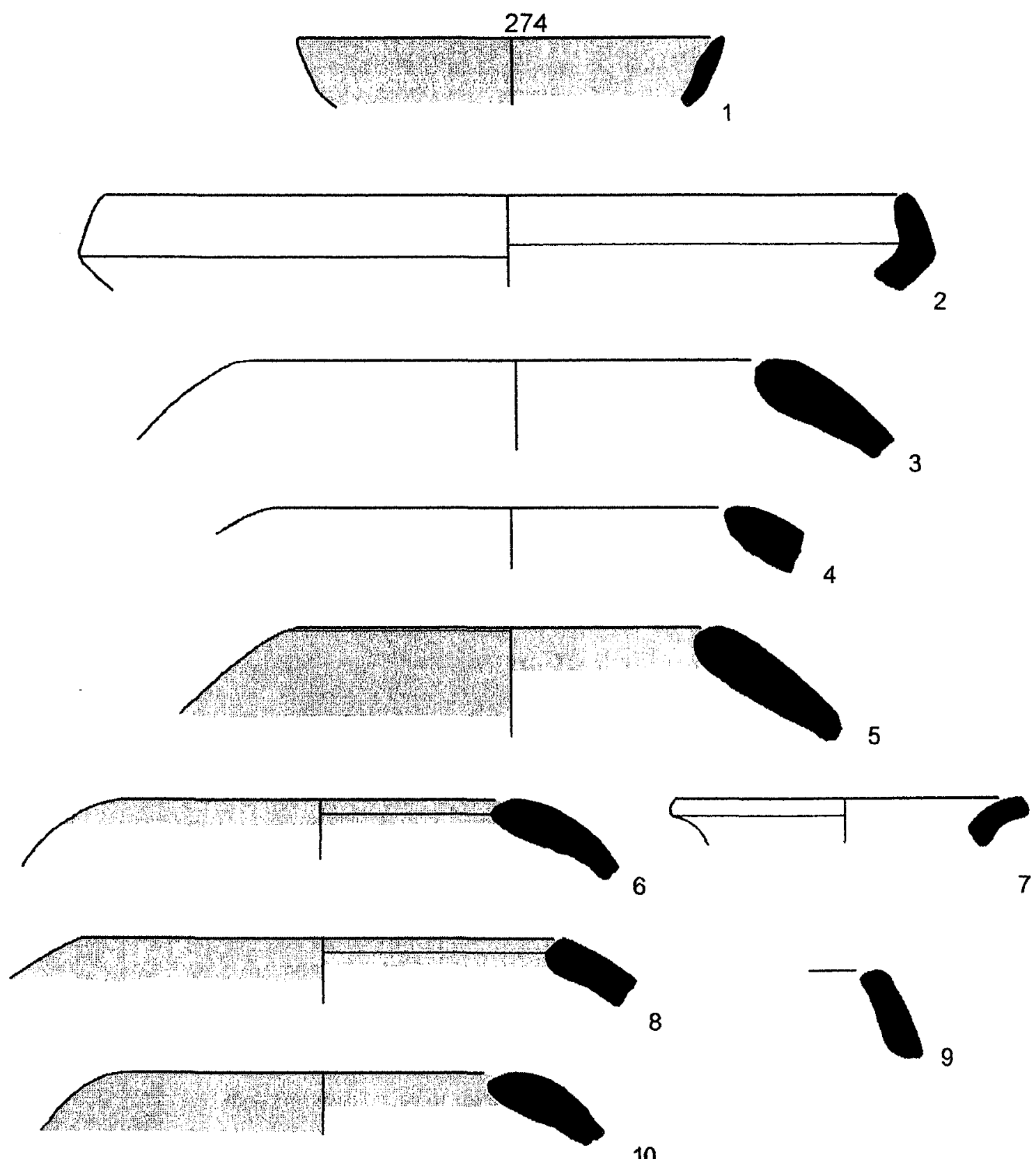

10
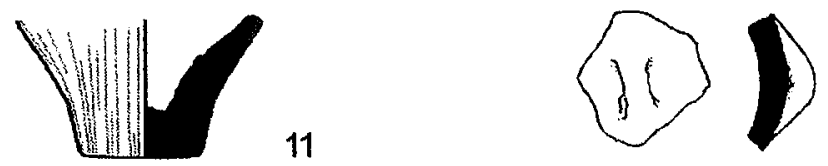

12

PLATE 24 (CONT.).

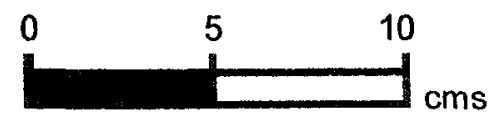


275

\begin{tabular}{llllllll}
\hline No & Reg & Square & Locus & Vessel & Part & $\begin{array}{l}\text { Body } \\
\text { Thick }\end{array}$ & Dia \\
& & & & & & & \\
1 & 0556 & SW 1-28 & 30 & LEDGE RIM BOWL & $R 56$ & 13 & $\mathrm{~N}$ \\
2 & 0560 & SW 1-28 & 30 & LEDGE RIM BOWL & $R 51$ & 19 & $\mathrm{~N}$ \\
3 & 0559 & SW 1-28 & 30 & HOLE MOUTH BOWL & $R 01$ & 8 & $\mathrm{~N}$ \\
4 & 2160 & SW 1-28 & 30 & NECKED JAR & R30 & 5 & $\mathrm{~N}$ \\
5 & 0557 & SW 1-28 & 30 & LEDGE RIM BOWL & R51 & 7 & 38 \\
6 & 0564 & SW 1-28 & 30 & LEDGE RIM BOWL & R51 & 9 & 32 \\
7 & 1844 & SW 1-28 & 30 & LEDGE RIM BOWL & R60 & 11 & $\mathrm{~N}$ \\
8 & 0563 & SW 1-28 & 30 & LEDGE RIM BOWL & R55 & 11 & 28 \\
9 & 0562 & SW 1-28 & 30 & LEDGE RIM BOWL & R53 & 13 & $\mathrm{~N}$ \\
10 & 0593 & SW 1-28 & 30 & HOLE MOUTH BOWL & R11 & 9 & 10 \\
11 & 0565 & SW 1-28 & 30 & HOLE MOUTH JAR & R01 & 11 & 14 \\
12 & 0561 & SW 1-28 & 30 & LEDGE RIM BOWL & R51 & 12 & 38 \\
13 & 0567 & SW 1-28 & 30 & UD & H20 & 7 & $\mathrm{~N}$ \\
14 & 0558 & SW 1-28 & 30 & NECKED JAR & R31 & 13 & 22 \\
15 & 0566 & SW 1-28 & 30 & UD & H20 & 10 & $\mathrm{~N}$ \\
\hline No & Fabric Color & & Core Orient Core Color & Core Thick & Fabric \\
& & & & & & & Family
\end{tabular}

\begin{tabular}{|c|c|c|c|c|c|c|}
\hline 1 & \multirow{2}{*}{\multicolumn{2}{|c|}{$\begin{array}{l}\text { LT BROWN } \\
\text { PINK }\end{array}$}} & $\mathrm{N}$ & $\mathrm{N}$ & $\mathrm{N}$ & 24 \\
\hline 2 & & & $M$ & LG & 5 & 15 \\
\hline 3 & \multicolumn{2}{|c|}{ WEAK RED } & $M$ & LG & 3 & 5.1 \\
\hline 4 & \multicolumn{2}{|l|}{ UD } & ALL & $\mathbf{G}$ & $\mathrm{N}$ & $\mathbf{N}$ \\
\hline 5 & \multicolumn{2}{|l|}{ PINK } & $\mathbf{N}$ & $\mathrm{N}$ & $\mathrm{N}$ & 24 \\
\hline 6 & \multicolumn{2}{|c|}{ LT REDDISH BROWN } & $\mathbf{N}$ & $\mathbf{N}$ & $\mathrm{N}$ & 24 \\
\hline 7 & \multicolumn{2}{|l|}{ PINK } & $M$ & LG & 4 & $\mathbf{N}$ \\
\hline 8 & \multicolumn{2}{|l|}{ PINK } & $\mathbf{M}$ & $\mathbf{G}$ & 5 & 21 \\
\hline 9 & \multicolumn{2}{|l|}{ PINK } & IN & LG & 7 & 8 \\
\hline 10 & \multicolumn{2}{|c|}{ WEAK RED } & $\mathbf{N}$ & $\mathrm{N}$ & $\mathrm{N}$ & $\mathrm{N}$ \\
\hline 11 & \multicolumn{2}{|c|}{ LTREDDISH BROWN } & IRR & G & $\mathrm{N}$ & 4 \\
\hline 12 & \multicolumn{2}{|l|}{ PINK } & $M$ & LG & 3 & 23 \\
\hline 13 & \multicolumn{2}{|l|}{ LT RED } & IRR & LG & $\mathrm{N}$ & 23 \\
\hline 14 & \multicolumn{2}{|l|}{ PINK } & M & G & 7 & 18 \\
\hline 15 & \multicolumn{2}{|c|}{ LT REDDISH BROWN } & $\mathbf{N}$ & $\mathrm{N}$ & N & 23 \\
\hline No & Treatment & $\begin{array}{l}\text { Treatment } \\
\text { Location }\end{array}$ & $\begin{array}{l}\text { Treatment } \\
\text { Cover }\end{array}$ & $\begin{array}{l}\text { Color } \\
\text { Interior }\end{array}$ & $\begin{array}{l}\text { Color } \\
\text { Exterior }\end{array}$ & \\
\hline 1 & SB & $\mathbb{I R}$ & NET & DK REDDISH & $\mathbf{N}$ & \\
\hline 2 & SB & $\mathbf{I R}$ & ALL & DK REDDISH & $\mathbf{N}$ & \\
\hline 3 & UN & $\mathrm{N}$ & $\mathbf{N}$ & $\mathrm{N}$ & $\mathrm{N}$ & \\
\hline 4 & SB & IE & ALL & BLACK & REDDISH & LOW \\
\hline 5 & UD & $\mathrm{N}$ & $\mathbf{N}$ & $N$ & $N$ & \\
\hline 6 & UD & $\mathrm{N}$ & $\mathbf{N}$ & $\mathrm{N}$ & $\mathrm{N}$ & \\
\hline
\end{tabular}

PLATE 25. FIELD A. PHASE 2A (EB II). 


\begin{tabular}{llllll}
\hline No & Treatment & $\begin{array}{l}\text { Treatment } \\
\text { Location }\end{array}$ & $\begin{array}{l}\text { Treatment } \\
\text { Cover }\end{array}$ & $\begin{array}{l}\text { Color } \\
\text { Interior }\end{array}$ & $\begin{array}{l}\text { Color } \\
\text { Exterior }\end{array}$ \\
\hline 7 & S & IE & ALL & RED & RED \\
8 & SB & IR & ALL & YELLOWISH RED & N \\
9 & S & E & ALL & N & LIGHT RED \\
10 & UN & N & N & N & N \\
11 & UN & N & N & N & N \\
12 & SB & IR & ALL & RED & N \\
13 & UN & N & N & N & N \\
14 & S & ER & ALL & N & LT REDDISH BROWN \\
15 & SB & E & ALL & N & DK RED \\
\hline
\end{tabular}

\section{Other}

1 Sample too small to confirm stance or diameter; net burnish over slip.

2 Sample too small to confirm stance or diameter; radially burnished on interior face.

3 Sample too small to confirm stance or diameter; surface burn visible.

4 Sample too small to confirm stance or diameter; Khirbet Kerak Ware.

6 Weathered.

7 Radially burnished; sample too small to confirm stance or diameter.

8 Radially burnished.

9 Sample too small to confirm stance or diameter.

10 Surface burn visible; fine lines on interior/exterior suggest motion used to finish rim.

11 Surface burn visible; fine lines on interior/exterior suggest motion used to finish rim.

PLATE 25 (CONT.). 

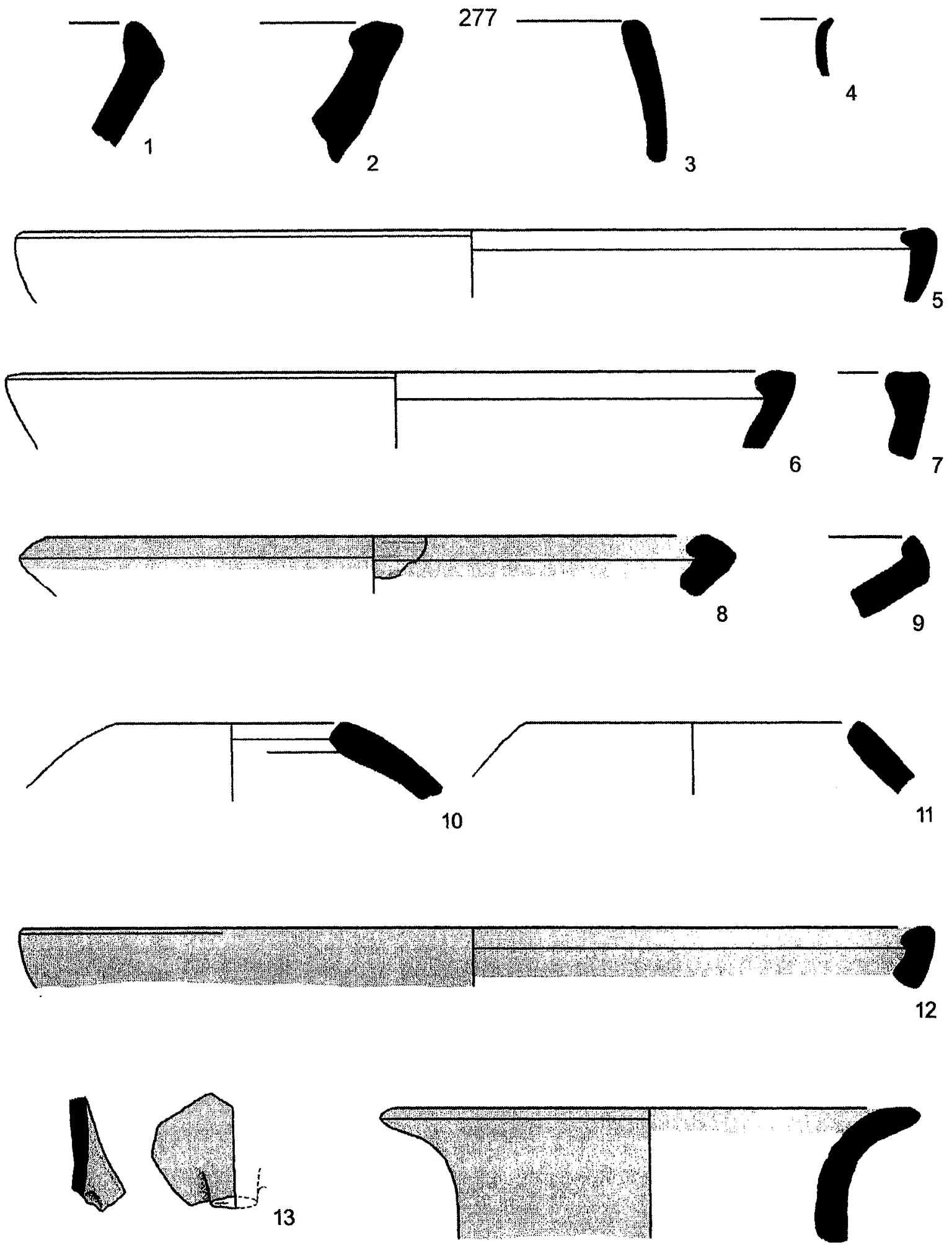

14

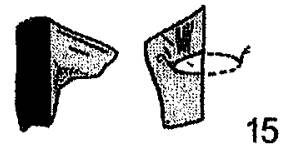

PLATE 25 (CONT.).

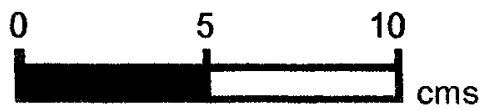




\begin{tabular}{llllllll}
\hline No & Reg & Square & Locus & Vessel & Part & $\begin{array}{l}\text { Body } \\
\text { Thick }\end{array}$ & Dia \\
& & & & & & & \\
\hline & 0752 & SW 3-26 & 48 & HOLE MOUTH BOWL & R09 & 11 & 13 \\
2 & 0627 & SW 2-27 & 18 & HOLE MOUTH BOWL & R01 & 11 & 12 \\
3 & 0852 & SW 3-27 & 78 & HOLE MOUTH JAR & R14 & 13 & 20 \\
4 & 0849 & SW 3-27 & 78 & HOLE MOUTH JAR & R07 & 9 & 12 \\
5 & 0850 & SW 3-27 & 78 & HOLE MOUTH JAR & R14 & 12 & 22 \\
6 & 2290 & SW 3-27 & 78 & HOLE MOUTH JAR & R14 & 11 & 20 \\
7 & 0848 & SW 3-27 & 78 & HOLE MOUTH JAR & R12 & 17 & 22 \\
8 & 2413 & SW 3-27 & 78 & PLATTER BOWL & R55 & 10 & N \\
9 & 0626 & SW 2-27 & 18 & NECKED JAR & R42 & 10 & 15 \\
10 & 0851 & SW 3-27 & 78 & NECKED JAR & R40 & 9 & 16 \\
11 & 0854 & SW 3-27 & 78 & NECKED JAR & R42 & 13 & 14 \\
12 & 0628 & SW 2-27 & 18 & NECKED JAR & R43 & 6 & 12 \\
\hline No & Fabric Color & & Core Orient Core Color & Core Thick & Fabric \\
& & & & & & & Family
\end{tabular}

\begin{tabular}{|c|c|c|c|c|c|c|}
\hline 1 & \multicolumn{2}{|l|}{ WEAK RED } & IRR & G & $\mathbf{N}$ & 5.1 \\
\hline 2 & \multicolumn{2}{|l|}{ LT RED } & IRR & $\mathbf{G}$ & $N$ & 9.1 \\
\hline 3 & \multicolumn{2}{|c|}{ LT REDDISH BROWN } & IRR & LG & $\mathrm{N}$ & 1 \\
\hline 4 & \multicolumn{2}{|c|}{ LT REDDISH BROWN } & $M$ & LG & 3 & 2.2 \\
\hline 5 & \multicolumn{2}{|l|}{ WEAK RED } & $E$ & G & 7 & 1 \\
\hline 6 & \multicolumn{2}{|c|}{ REDDISH BROWN } & $M$ & G & 5 & $\mathbf{N}$ \\
\hline 7 & \multicolumn{2}{|c|}{ LT REDDISH BROWN } & ALL & G & $\mathrm{N}$ & 1 \\
\hline 8 & \multicolumn{2}{|l|}{ LTRED } & $N$ & $N$ & $N$ & $\mathbf{N}$ \\
\hline 9 & \multicolumn{2}{|l|}{ PINK } & $M$ & $\mathbf{G}$ & 7 & 18 \\
\hline 10 & \multicolumn{2}{|c|}{ LT REDDISH BROWN } & $\mathbf{N}$ & $\mathbf{N}$ & $\mathbf{N}$ & 7.1 \\
\hline 11 & \multicolumn{2}{|c|}{ PINK } & $\mathrm{N}$ & $\mathbf{N}$ & $\mathrm{N}$ & $\mathbf{N}$ \\
\hline 12 & \multicolumn{2}{|l|}{ LT RED } & $N$ & $N$ & $N$ & 12.1 \\
\hline No & Treatment & $\begin{array}{l}\text { Treatment } \\
\text { Location }\end{array}$ & $\begin{array}{l}\text { Treatment } \\
\text { Cover }\end{array}$ & $\begin{array}{l}\text { Color } \\
\text { Interior }\end{array}$ & $\begin{array}{l}\text { Color } \\
\text { Exterior }\end{array}$ & \\
\hline 1 & UN & $N$ & $N$ & $N$ & $N$ & \\
\hline 2 & UN & $\mathbf{N}$ & $\mathbf{N}$ & $\mathbf{N}$ & $\mathbf{N}$ & \\
\hline 3 & UN & $\mathbf{N}$ & $\mathbf{N}$ & $\mathbf{N}$ & $\mathbf{N}$ & \\
\hline 4 & UN & $N$ & $\mathbf{N}$ & $N$ & $\mathbf{N}$ & \\
\hline 5 & UN & $\mathbf{N}$ & $\mathbf{N}$ & $\mathbf{N}$ & $\mathbf{N}$ & \\
\hline 6 & UN & $\mathbf{N}$ & $\mathbf{N}$ & $\mathbf{N}$ & $\mathbf{N}$ & \\
\hline 7 & UN & $\mathbf{N}$ & $\mathbf{N}$ & $N$ & $\mathbf{N}$ & \\
\hline 8 & SB & $\mathbb{I R}$ & ALL & RED & $\mathbf{N}$ & \\
\hline 9 & $\mathrm{~s}$ & ER & ALL & $N$ & RED & \\
\hline 10 & $\mathbf{S}$ & IE & ALL & DUSKY RED & DUSKY RED & \\
\hline 11 & $\mathbf{S}$ & ER & ALL & $\mathbf{N}$ & RED & \\
\hline 12 & UN & $\mathbf{N}$ & $\mathbf{N}$ & $\mathbf{N}$ & $\mathbf{N}$ & \\
\hline
\end{tabular}

PLATE 26. FIELD A. PHASE 2A (EB II). 
Other

1 Sample too small to confirm stance or diameter; surface burn visible.

3 Fine marks on exterior lip show angular, smoothing motions; surface burn visible.

5 Surface burn visible.

8 Metallic Ware.

12 Metallic Ware.

PLATE 26 (CONT.).

Reproduced with permission of the copyright owner. Further reproduction prohibited without permission. 

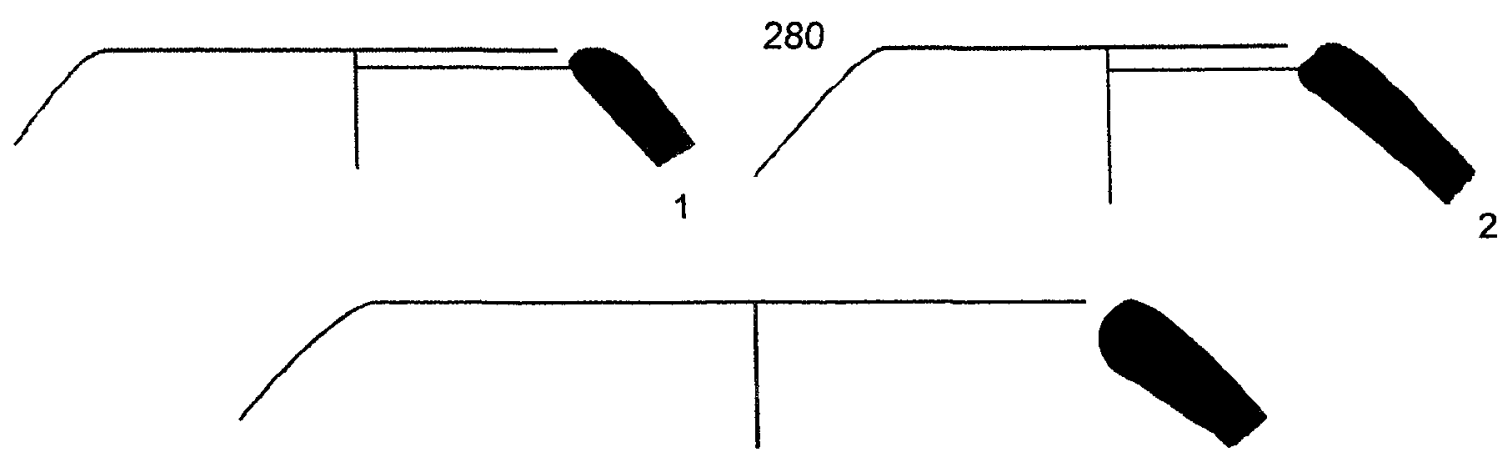

3
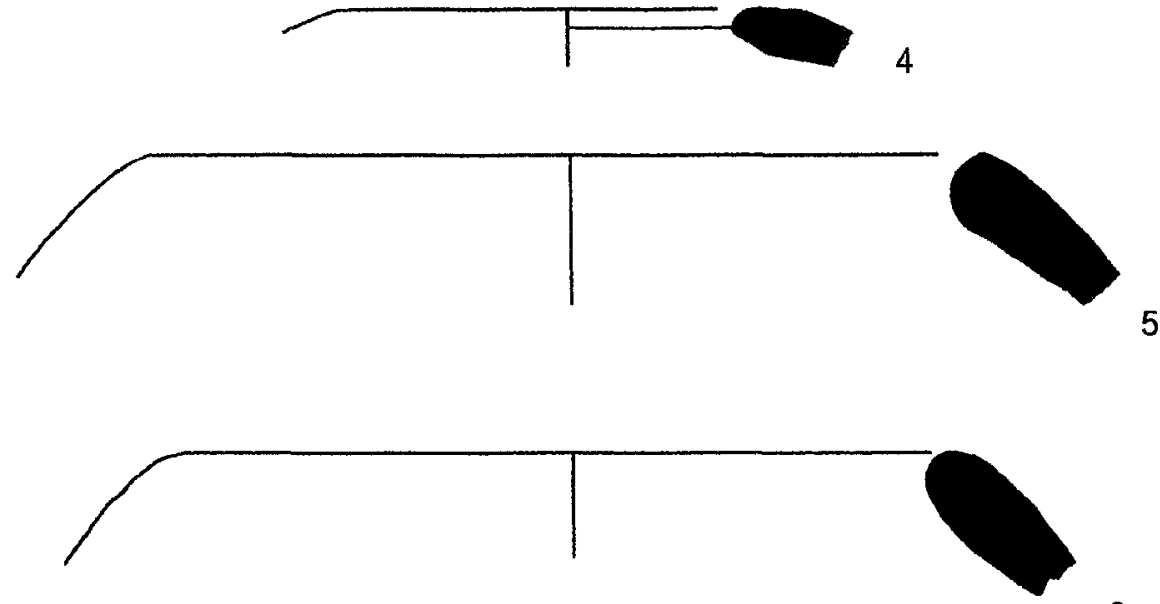

6
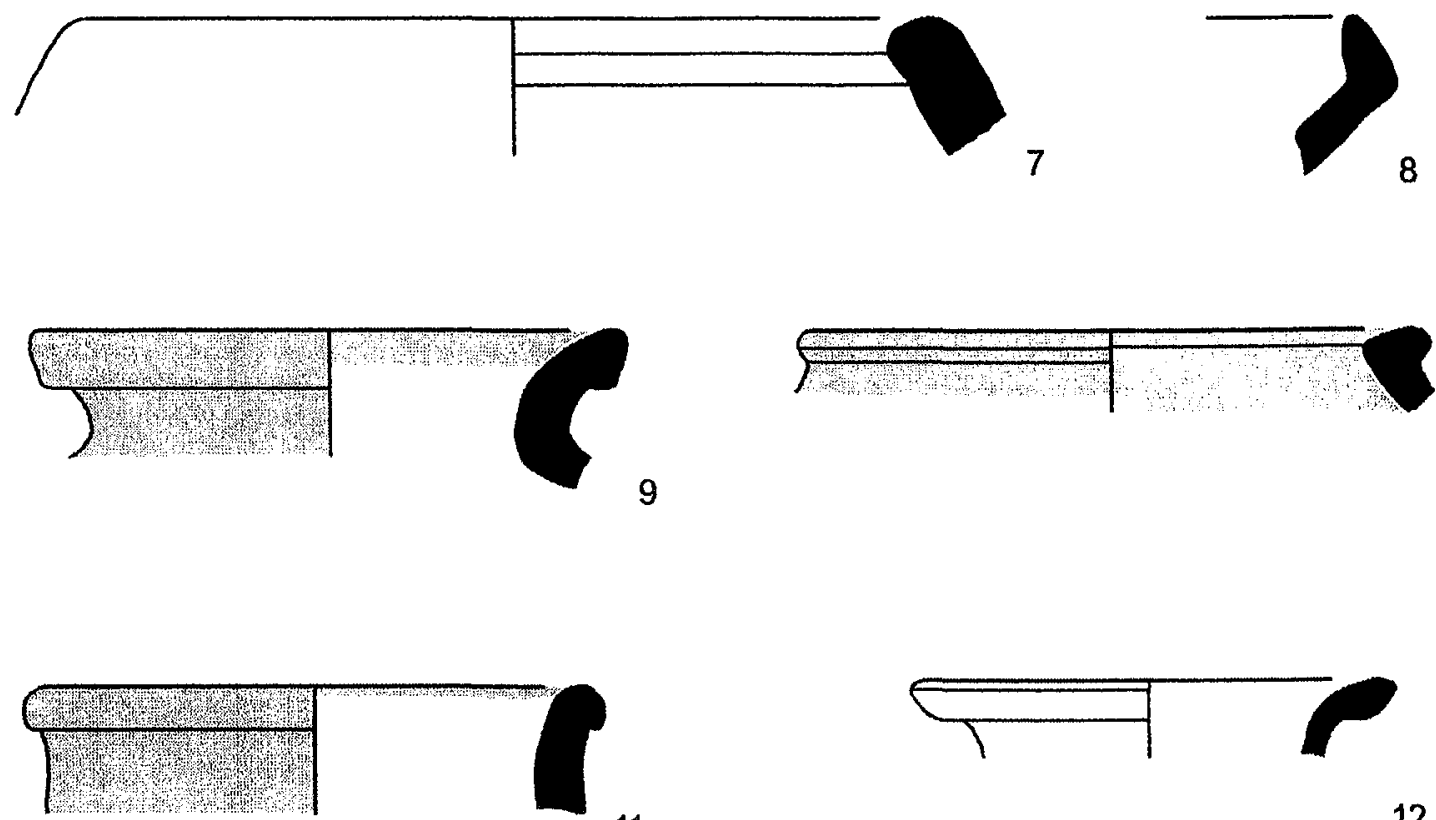

PLATE 26 (CONT.).

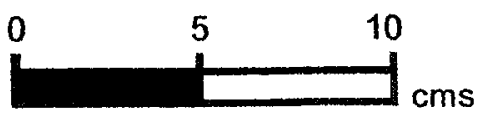




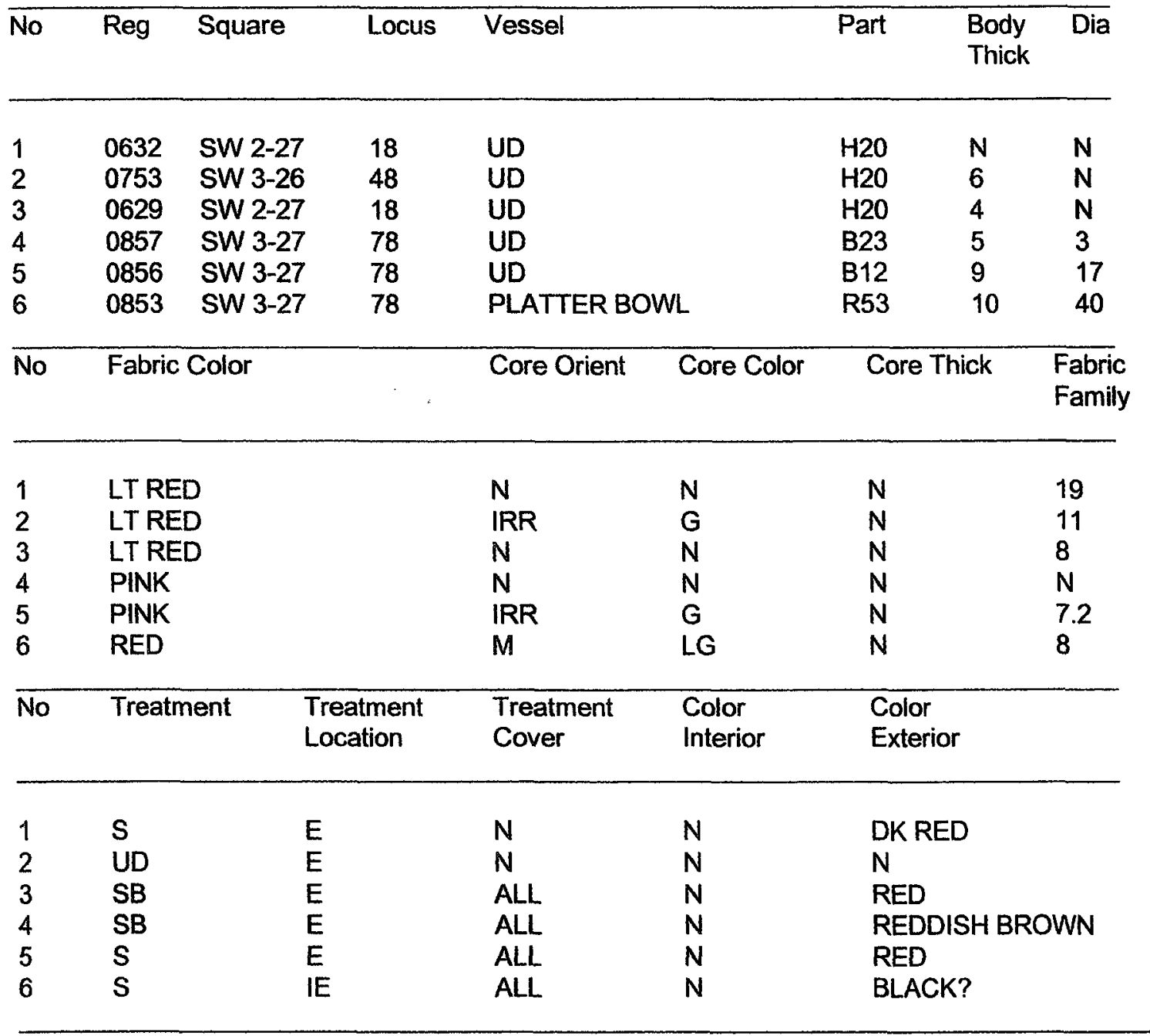

Other

3 A single red line (6 $\mathrm{mm}$ wide) runs vertically down interior face.

6 The dark exterior color of this platter is likely the result of burning.

PLATE 27. FIELD A. PHASE 2A (EB II). 

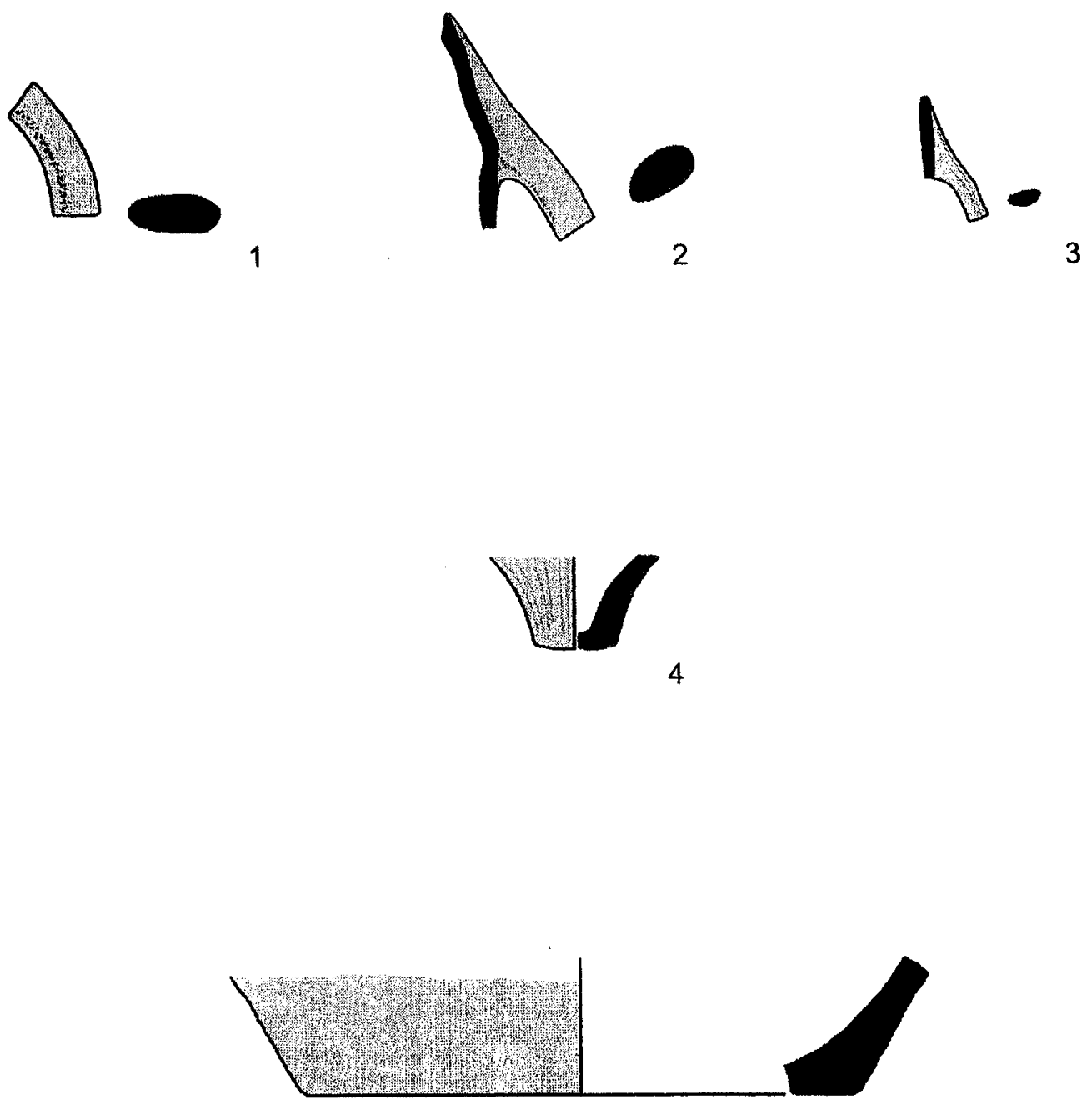

5

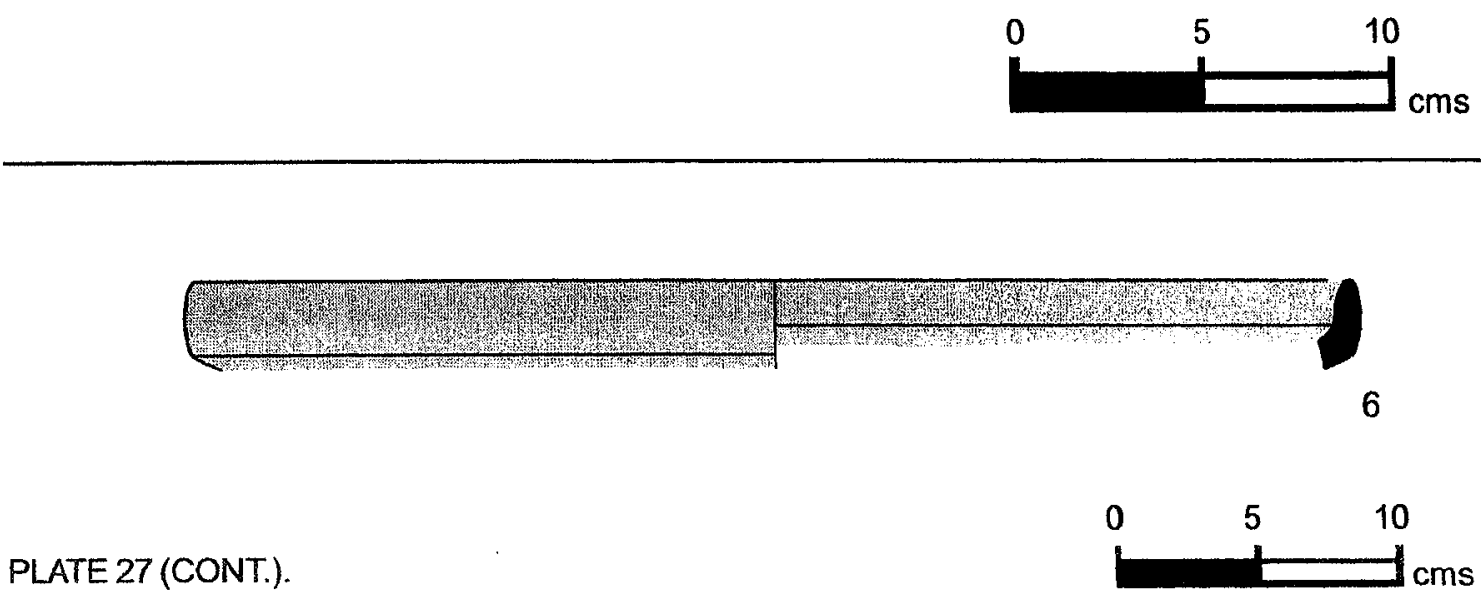




\begin{tabular}{lllllllll}
\hline No & Reg & Square & Locus & Vessel & Part & $\begin{array}{l}\text { Body Dia } \\
\text { Thick }\end{array}$ \\
\hline & & & & & & & & \\
1 & 0738 & SW 2-27 & 76A & BOWL & R50 & 6 & 15 \\
2 & 0743 & SW 2-27 & 76A & HOLE MOUTH BOWL & R14 & 8 & 20 \\
3 & 0736 & SW 2-27 & 76A & HOLE MOUTH JAR & R18 & 8 & 18 \\
4 & 0739 & SW 2-27 & 76A & HOLE MOUTH JAR/BOWL & R07 & 9 & 10 \\
5 & 0742 & SW 2-27 & 76A & CHANNELED RIM JAR & R35 & 8 & 13 \\
6 & 0740 & SW 2-27 & 76A & UD & H20 & 6 & N \\
7 & 0741 & SW 2-27 & 76A & PLATTER BOWL & R53 & 8 & 38 \\
\hline No & Fabric Color & & Core Orient Core Color & Core Thick & Fabric \\
& & & & & & & & Family
\end{tabular}

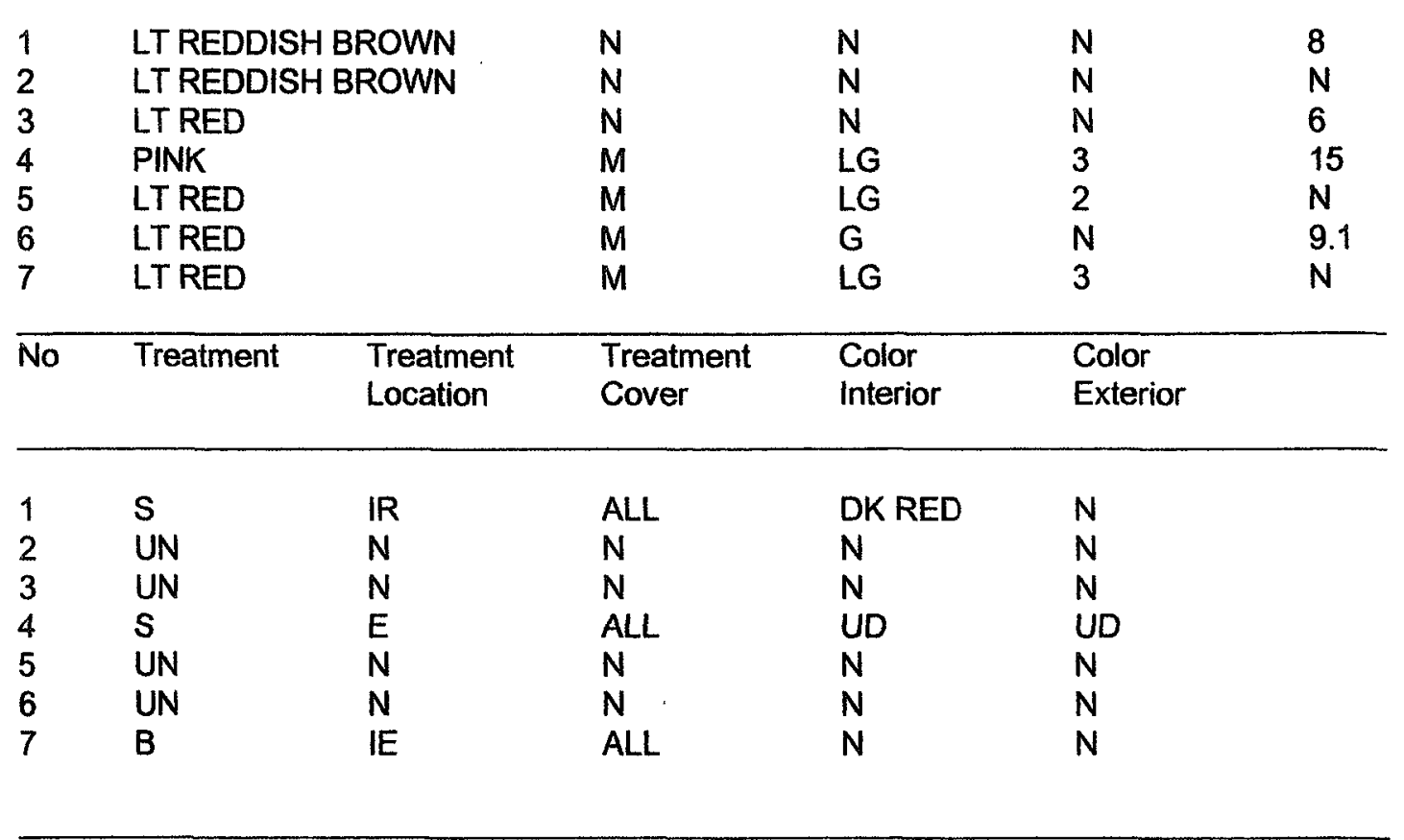

\section{Other}

1 Surface burn visible; exterior face very rough.

3 Features in break reveal rim folding; marks on interior face show fold-smoothing.

$4 \quad$ Surface burn visible; sample too small to confirm stance or diameter.

5 Metallic Ware.

$6 \quad$ Metallic Ware.

7 Metallic Ware.

PLATE 28. FIELD A. PHASE 2A (EB II). 

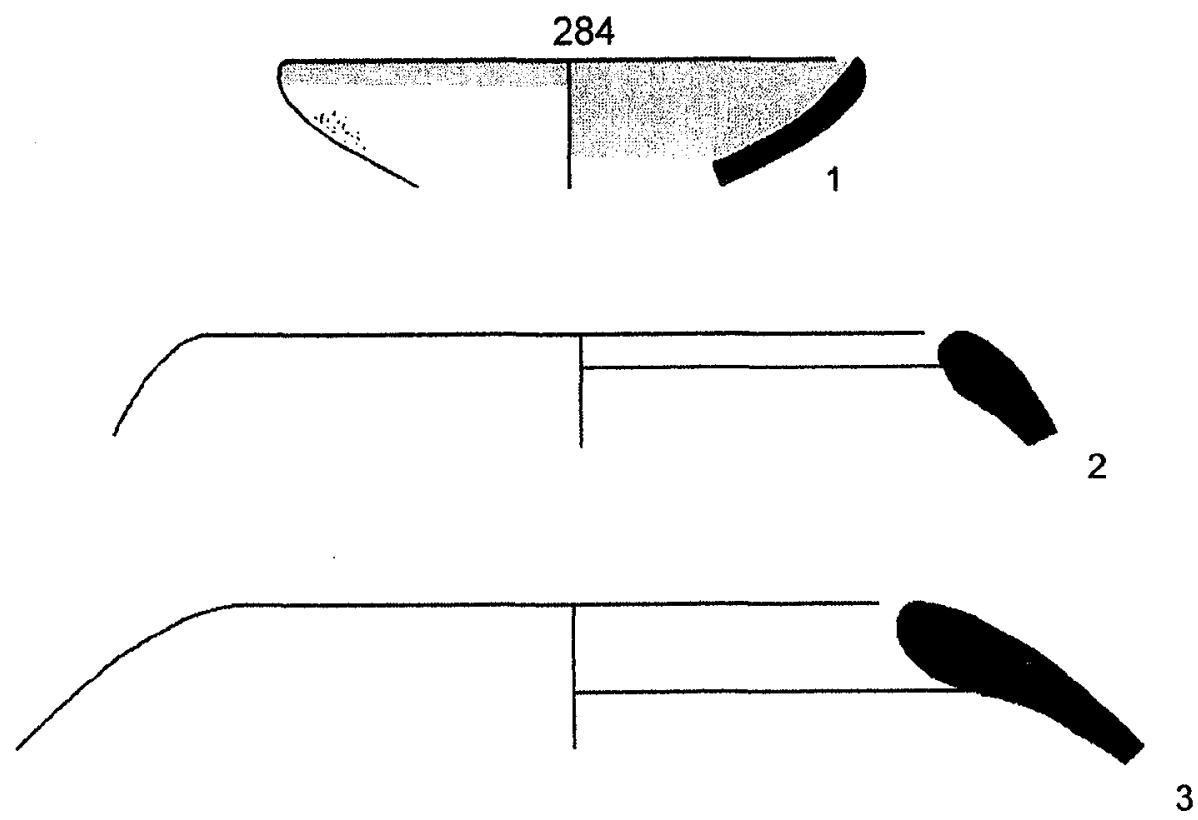

3
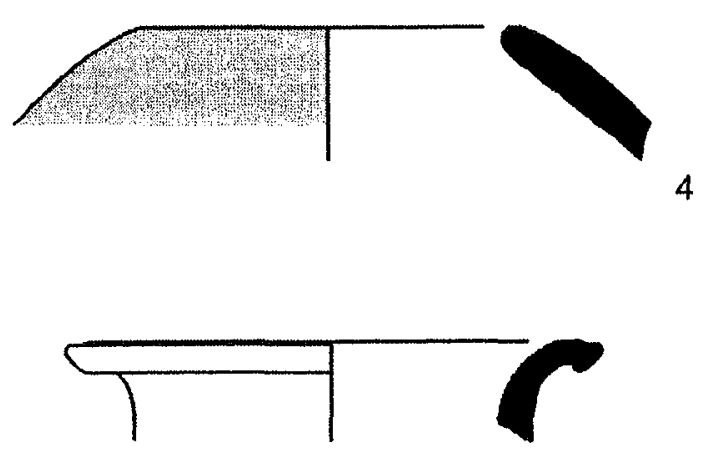

5

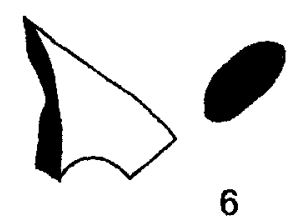

6
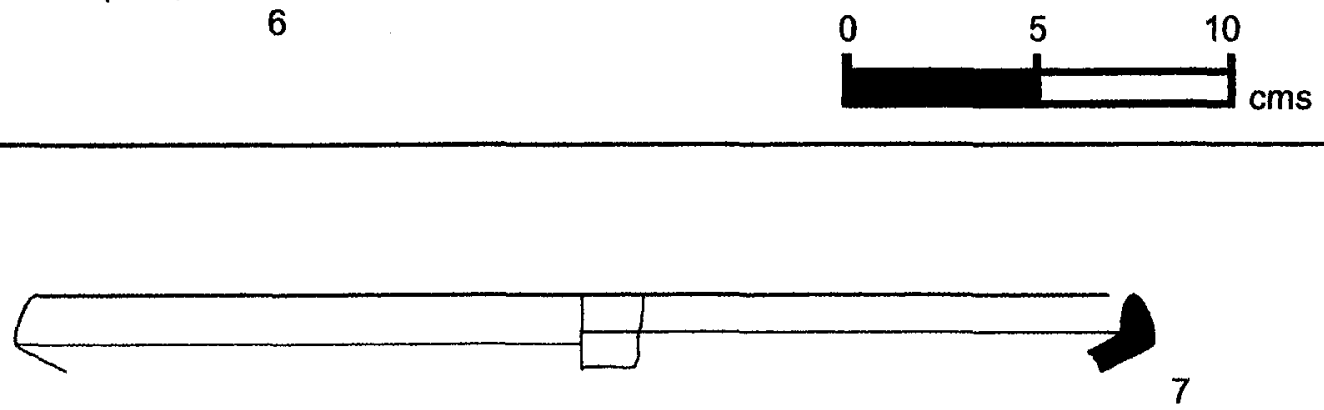

PLATE 28 (CONT.).

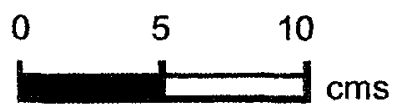




\begin{tabular}{|c|c|c|c|c|c|c|c|}
\hline No & Reg & Square & Locus & Vessel & Part & $\begin{array}{l}\text { Body } \\
\text { Thick }\end{array}$ & Dia \\
\hline 1 & 1001 & SW 4-26 & 17 & BOWL & $\mathrm{R} 50$ & 7 & 19 \\
\hline 2 & 1005 & SW 4-26 & 17 & BOWL & $\mathrm{R} 50$ & 5 & $\mathbf{N}$ \\
\hline 3 & 1023 & SW 4-26 & 17 & HOLE MOUTH JAR & R04 & 16 & 20 \\
\hline 4 & 1007 & SW 4-26 & 17 & HOLE MOUTH BOWL & R01 & 15 & 20 \\
\hline 5 & 1006 & SW 4-26 & 17 & HOLE MOUTH BOWL & R04 & 11 & 18 \\
\hline 6 & 1002 & SW 4-26 & 17 & NECKED JAR & $\mathrm{R} 42$ & 8 & 18 \\
\hline 7 & 1008 & SW 4-26 & 17 & UD & $\mathrm{H} 21$ & 4 & 11 \\
\hline 8 & 0998 & SW 4-26 & 17 & NECKED JAR & R30 & 5 & 12 \\
\hline 9 & 1000 & SW 4-26 & 17 & NECKED JAR. & R31 & 6 & 8 \\
\hline 10 & 1003 & SW 4-26 & 17 & NECKED JAR & $\mathrm{R} 43$ & 7 & 12 \\
\hline No & $F$ & lor & & Core Orient & & & $\begin{array}{l}\text { Fabric } \\
\text { Family }\end{array}$ \\
\hline
\end{tabular}

\begin{tabular}{|c|c|c|c|c|c|c|}
\hline 1 & \multirow{2}{*}{\multicolumn{2}{|c|}{$\begin{array}{l}\text { LT REDDISH BROWN } \\
\text { PINK }\end{array}$}} & $\mathrm{N}$ & $\mathrm{N}$ & $\mathrm{N}$ & 24 \\
\hline 2 & & & $\mathbf{N}$ & $\mathrm{N}$ & $\mathrm{N}$ & 23 \\
\hline 3 & \multicolumn{2}{|c|}{ PALE RED } & M & LG & 4 & $N$ \\
\hline 4 & \multicolumn{2}{|c|}{ LT REDDISH BROWN } & IRR & LG & N & 5.1 \\
\hline 5 & \multicolumn{2}{|c|}{ REDDISH BROWN } & $\mathbf{M}$ & G & 7 & 3 \\
\hline 6 & \multicolumn{2}{|c|}{ LT REDDISH BROWN } & $\mathrm{N}$ & $\mathrm{N}$ & $\mathrm{N}$ & 19 \\
\hline 7 & \multicolumn{2}{|c|}{ REDDISH BROWN } & IRR & $\mathbf{G}$ & $\mathbf{N}$ & 12.2 \\
\hline 8 & \multicolumn{2}{|c|}{ LT BROWN } & $\mathrm{N}$ & $\mathrm{N}$ & $\mathrm{N}$ & 24 \\
\hline 9 & \multicolumn{2}{|c|}{ LT REDDISH BROWN } & $\mathrm{N}$ & $\mathrm{N}$ & $\mathrm{N}$ & 23 \\
\hline 10 & \multicolumn{2}{|c|}{ RED } & M & LG & 3 & 9.1 \\
\hline No & Treatment & $\begin{array}{l}\text { Treatment } \\
\text { Location }\end{array}$ & $\begin{array}{l}\text { Treatment } \\
\text { Cover }\end{array}$ & $\begin{array}{l}\text { Color } \\
\text { Interior }\end{array}$ & $\begin{array}{l}\text { Color } \\
\text { Exterior }\end{array}$ & \\
\hline 1 & $\mathrm{~s}$ & IE & ALL & LT RED & LT RED & \\
\hline 2 & S & IR & ALL & RED & $N$ & \\
\hline 3 & UN & $\mathrm{N}$ & $\mathrm{N}$ & $\mathrm{N}$ & $\mathrm{N}$ & \\
\hline 4 & UN & $\mathbf{N}$ & $N$ & $N$ & $N$ & \\
\hline 5 & UN & $\mathrm{N}$ & $N$ & $\mathrm{~N}$ & $N$ & \\
\hline 6 & $s$ & IE & ALL & RED & RED & \\
\hline 7 & UN & $\mathbf{N}$ & $\mathbf{N}$ & $N$ & $\mathbf{N}$ & \\
\hline 8 & $\mathrm{~S}$ & ER & ALL & $\mathbf{N}$ & LT RED & \\
\hline 9 & $\mathbf{S}$ & ER & ALL & $\mathbf{N}$ & LT RED & \\
\hline 10 & UN & $\mathbf{N}$ & $\mathbf{N}$ & $\mathbf{N}$ & $\mathbf{N}$ & \\
\hline
\end{tabular}

PLATE 29. FIELD A. PHASE 2A (EB II). 
Other

2 Burn on lip suggest use as lamp; sample too small to confirm stance or diameter.

3 Sample too small to confirm stance or diameter.

5 Potter's mark visible.

$6 \quad$ Features in break suggest rim folding.

7 Two slash marks on handle shoulder; Metallic Ware.

PLATE 29 (CONT.). 

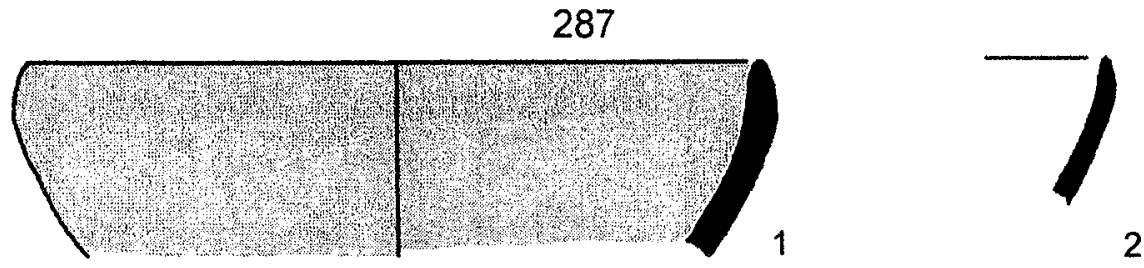

2

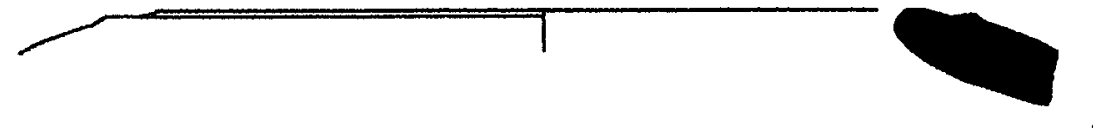

3
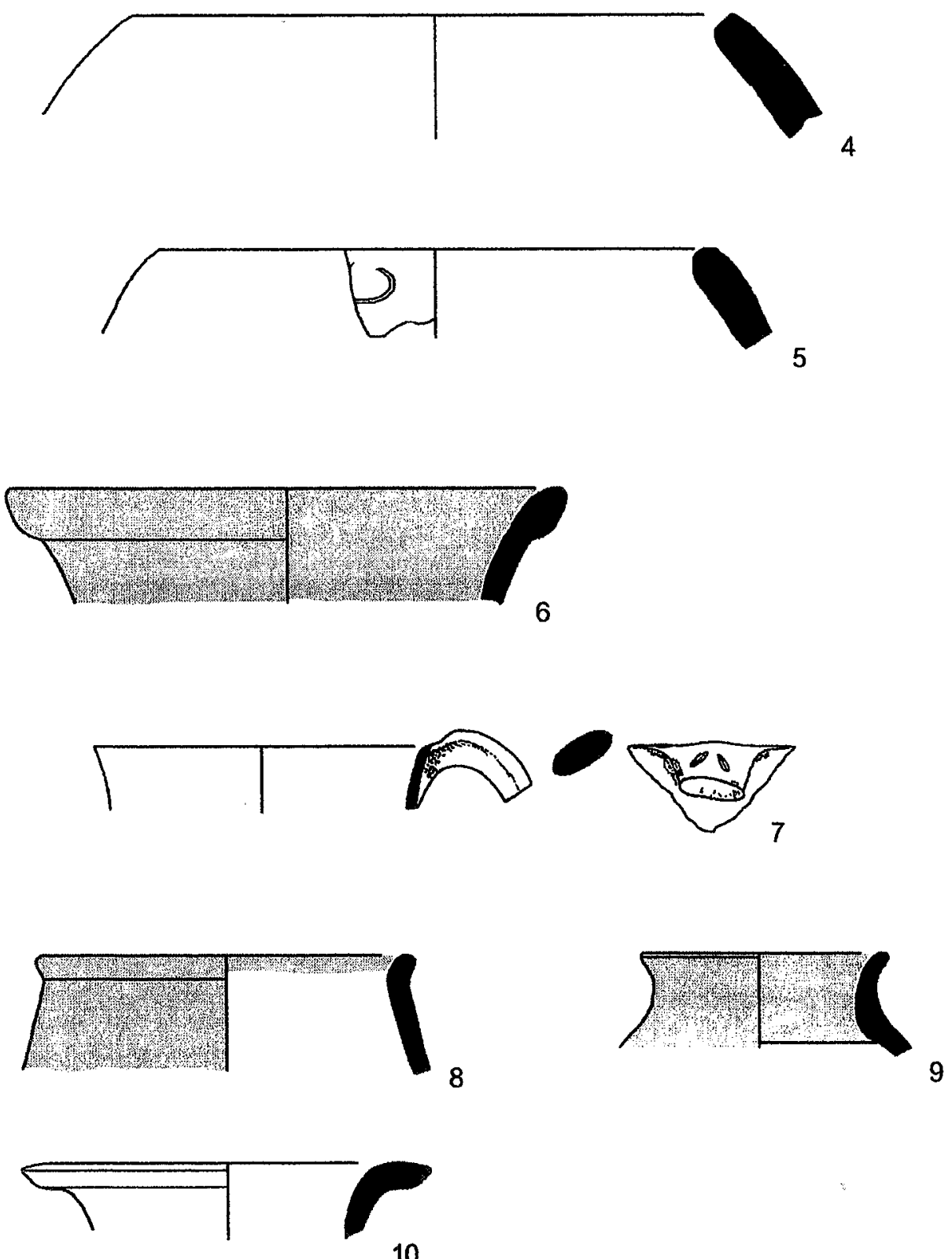

10

PLATE 29 (CONT.).

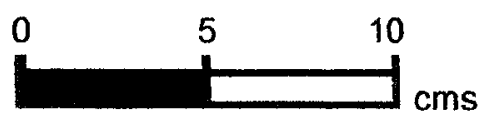




No Reg Square Locus Vessel $\quad$ Part $\begin{aligned} & \text { Body Dia } \\ & \text { Thick }\end{aligned}$

\begin{tabular}{llllllll}
\hline 1 & 1019 & SW 4-26 & 17 & HOLE MOUTH BOWL & R11 & 9 & 40 \\
2 & 1027 & SW 4-26 & 17 & PLATTER BOWL & R56 & 9 & 45 \\
3 & 1025 & SW 4-26 & 17 & PLATTER BOWL & R56 & 9 & 42 \\
4 & 1026 & SW 4-26 & 17 & PLATTER BOWL & R53 & 8 & 46 \\
5 & 0997 & SW 4-26 & 17 & LEDGE RIM BOWL & R55 & 9 & 40 \\
6 & 1013 & SW 4-26 & 17 & PLATTER BOWL & R53 & 9 & 49 \\
7 & 1024 & SW 4-26 & 17 & PLATTER BOWL & R56 & 7 & 50 \\
8 & 1004 & SW 4-26 & 17 & HOLE MOUTH BOWL & R11 & 7 & 48
\end{tabular}

\begin{tabular}{lllll}
\hline No Fabric Color & Core Orient & Core Color Core Thick & Fabric \\
& & & Family
\end{tabular}

\begin{tabular}{|c|c|c|c|c|c|c|}
\hline 1 & \multicolumn{2}{|c|}{ LT REDDISH BROWN } & $M$ & LG & 5 & $\mathbf{N}$ \\
\hline 2 & \multicolumn{2}{|c|}{ LT REDDISH BROWN } & $\mathbf{N}$ & $\mathbf{N}$ & $N$ & $N$ \\
\hline 3 & \multicolumn{2}{|l|}{ RED } & $N$ & $N$ & $N$ & $N$ \\
\hline 4 & \multicolumn{2}{|l|}{ LT RED } & $N$ & $N$ & $N$ & $\mathbf{N}$ \\
\hline 5 & \multicolumn{2}{|l|}{ LT BROWN } & $\mathbf{N}$ & $N$ & $N$ & 24 \\
\hline 6 & \multicolumn{2}{|l|}{ LT RED } & $\mathbf{M}$ & $N$ & 4 & 12.2 \\
\hline 7 & \multicolumn{2}{|c|}{ LT REDDISH BROWN } & $\mathbf{N}$ & $N$ & $\mathbf{N}$ & $\mathbf{N}$ \\
\hline 8 & \multicolumn{2}{|c|}{ LT RED } & $M$ & $G$ & 4 & 11 \\
\hline$\overline{\text { No }}$ & Treatment & $\begin{array}{l}\text { Treatment } \\
\text { Location }\end{array}$ & $\begin{array}{l}\text { Treatment } \\
\text { Cover }\end{array}$ & $\begin{array}{l}\text { Color } \\
\text { Interior }\end{array}$ & $\begin{array}{l}\text { Color } \\
\text { Exterior }\end{array}$ & \\
\hline 1 & $S$ & ER & ALL & $N$ & UD & \\
\hline 2 & SB & $\mathbb{R}$ & ALL & RED & $N$ & \\
\hline$\overline{3}$ & SB & IE & $A L L$ & RED & $N$ & \\
\hline 4 & SB & $\mathbb{R}$ & ALL & RED & $N$ & \\
\hline 5 & UD & $\mathbf{N}$ & $N$ & $N$ & $N$ & \\
\hline 6 & SB & IR & ALL & DK RED & $N$ & \\
\hline 7 & SB & IR & ALL & RED & $N$ & \\
\hline 8 & $\mathrm{~s}$ & ER & ALL & $N$ & DUSKY RED & \\
\hline
\end{tabular}

2 Sample too small to confirm stance or diameter; fine lines suggest motion used to finish rim.

3 Surface burn visible; sample too small to confirm stance or diameter; Metallic Ware.

$4 \quad$ Metallic Ware.

$5 \quad$ Hole $(6 \mathrm{~mm})$ bored through vessel wall immediately below rim.

6 Surface burn visible; Metallic Ware.

PLATE 30. FIELD A. PHASE 2A (EB II). 

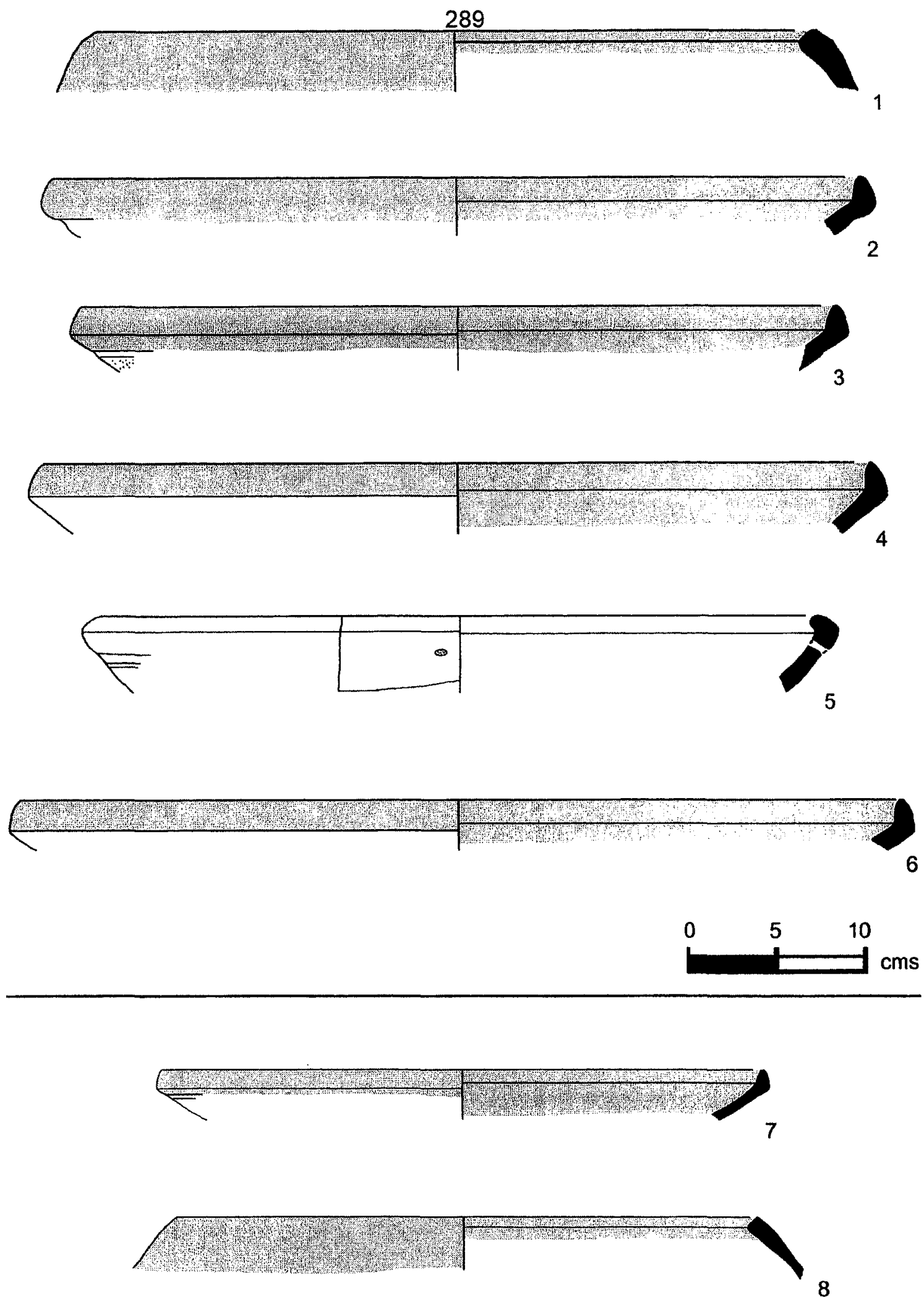

PLATE 30 (CONT.). 


\begin{tabular}{lllllllll}
\hline No & Reg & Square & Locus & Vessel & Part & $\begin{array}{l}\text { Body } \\
\text { Thick }\end{array}$ & Dia \\
\hline 1 & 1016 & SW 4-26 & 17 & UD & B12 & 10 & 18 \\
2 & 1017 & SW 4-26 & 17 & UD & B35 & 6 & 6 \\
3 & 1015 & SW 4-26 & 17 & UD & B12 & 5 & 4 \\
4 & 1014 & SW 4-26 & 17 & JUG & B23 & 7 & 3 \\
5 & 1010 & SW 4-26 & 17 & UD & H20 & N & N \\
6 & 1011 & SW 4-26 & 17 & UD & H14 & 8 & N \\
7 & 1012 & SW 4-26 & 17 & UD & H27 & 3 & N \\
8 & 1009 & SW 4-26 & 17 & JUG & & & & \\
\hline
\end{tabular}

\begin{tabular}{lllll}
\hline No Fabric Color & Core Orient & Core Color & Core Thick & Fabric \\
& & & Family
\end{tabular}

\begin{tabular}{|c|c|c|c|c|c|c|}
\hline 1 & \multicolumn{2}{|l|}{ PINK } & ALL & $G$ & $N$ & 11 \\
\hline 2 & \multicolumn{2}{|l|}{ PINK } & $\mathbb{N}$ & LG & 3 & 17.1 \\
\hline 3 & \multicolumn{2}{|l|}{ LT RED } & $N$ & $\mathbf{N}$ & $\mathrm{N}$ & 12.1 \\
\hline 4 & \multicolumn{2}{|l|}{ RED } & $N$ & $\mathbf{N}$ & $\mathbf{N}$ & 12.1 \\
\hline 5 & \multicolumn{2}{|l|}{ PINK } & IRR & $G$ & $N$ & 11 \\
\hline 6 & \multicolumn{2}{|l|}{ PINK } & IRR & $G$ & $\mathbf{N}$ & 17.1 \\
\hline 7 & \multicolumn{2}{|l|}{ LT RED } & $\mathbf{N}$ & $\mathbf{N}$ & $\mathbf{N}$ & 12.3 \\
\hline 8 & \multicolumn{2}{|c|}{ LT REDDISH BROWN } & $N$ & $N$ & $N$ & 25.1 \\
\hline No & Treatment & $\begin{array}{l}\text { Treatment } \\
\text { Location }\end{array}$ & $\begin{array}{l}\text { Treatment } \\
\text { Cover }\end{array}$ & $\begin{array}{l}\text { Color } \\
\text { Interior }\end{array}$ & $\begin{array}{l}\text { Color } \\
\text { Exterior }\end{array}$ & \\
\hline 1 & $S$ & $E$ & ALL & $N$ & DUSKY RED & \\
\hline 2 & $S$ & $E$ & ALL & $N$ & DUSKY RED & \\
\hline 3 & UN & $\mathbf{N}$ & $N$ & $N$ & $N$ & \\
\hline 4 & SB & $E$ & $A L L$ & $N$ & RED & \\
\hline 5 & $S$ & $E$ & ALL & $\mathrm{N}$ & RED & \\
\hline 6 & SB & $E$ & $A L L$ & $N$ & DUSKY RED & \\
\hline 7 & UN & $N$ & $N$ & $N$ & $\mathrm{~N}$ & \\
\hline 8 & SB & $E$ & ALL & $\mathbf{N}$ & RED & \\
\hline
\end{tabular}

$\begin{array}{ll}3 & \text { Metallic Ware. } \\ 4 & \text { Metallic Ware. } \\ 7 & \text { Metallic Ware. }\end{array}$

PLATE 31. FIELD A. PHASE 2A (EB II). 

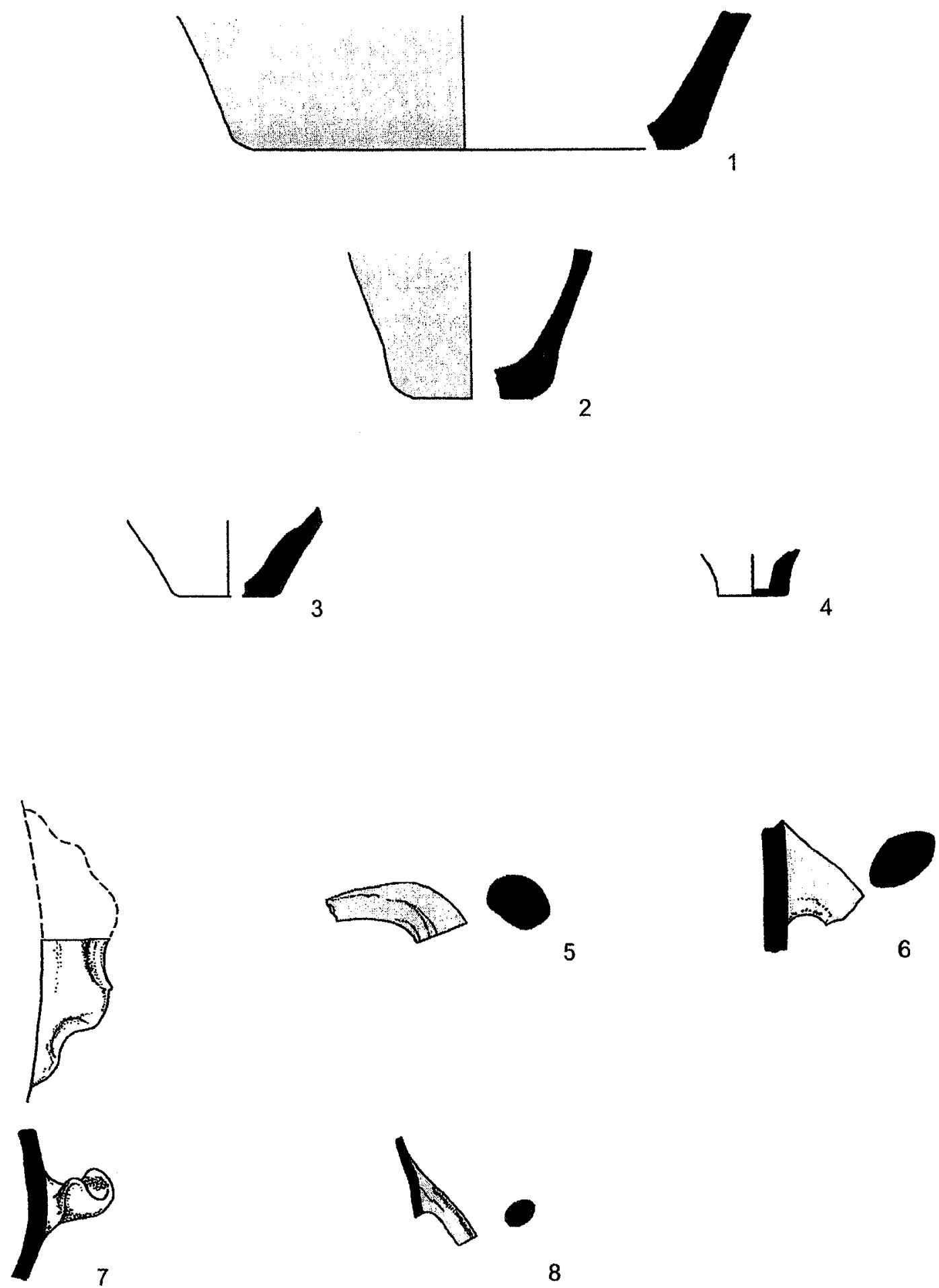

PLATE 31 (CONT.).

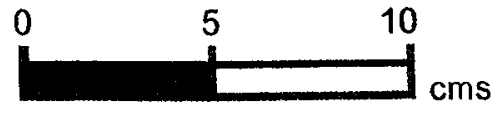




\begin{tabular}{llllllll}
\hline No & Reg & Square & Locus & Vessel & Part & $\begin{array}{l}\text { Body } \\
\text { Thick }\end{array}$ & Dia \\
\hline 1 & 0951 & SW 4-26 & 19 & CARINATED BOWL & R58 & 4 & 18 \\
2 & 1106 & SW 5-26 & 28 & HOLE MOUTH JAR & R17 & 14 & 25 \\
3 & 0947 & SW 4-26 & 19 & NECKED JAR & R32 & 7 & 12 \\
4 & 0948 & SW 4-26 & 19 & SINUOUS SIDED BOWL & R81 & 7 & 15 \\
5 & 0949 & SW 4-26 & 19 & UD & BOD & 9 & N \\
6 & 1107 & SW 5-26 & 28 & UD & BOD & 12 & N \\
7 & 0946 & SW 4-26 & 19 & LEDGE RIM BOWL & R55 & 7 & 38
\end{tabular}

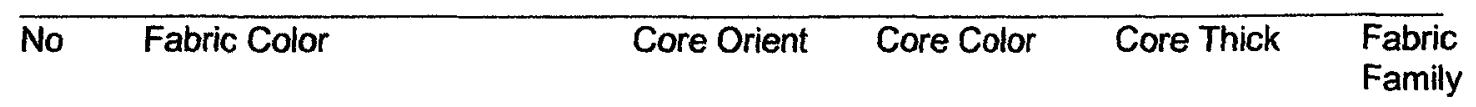

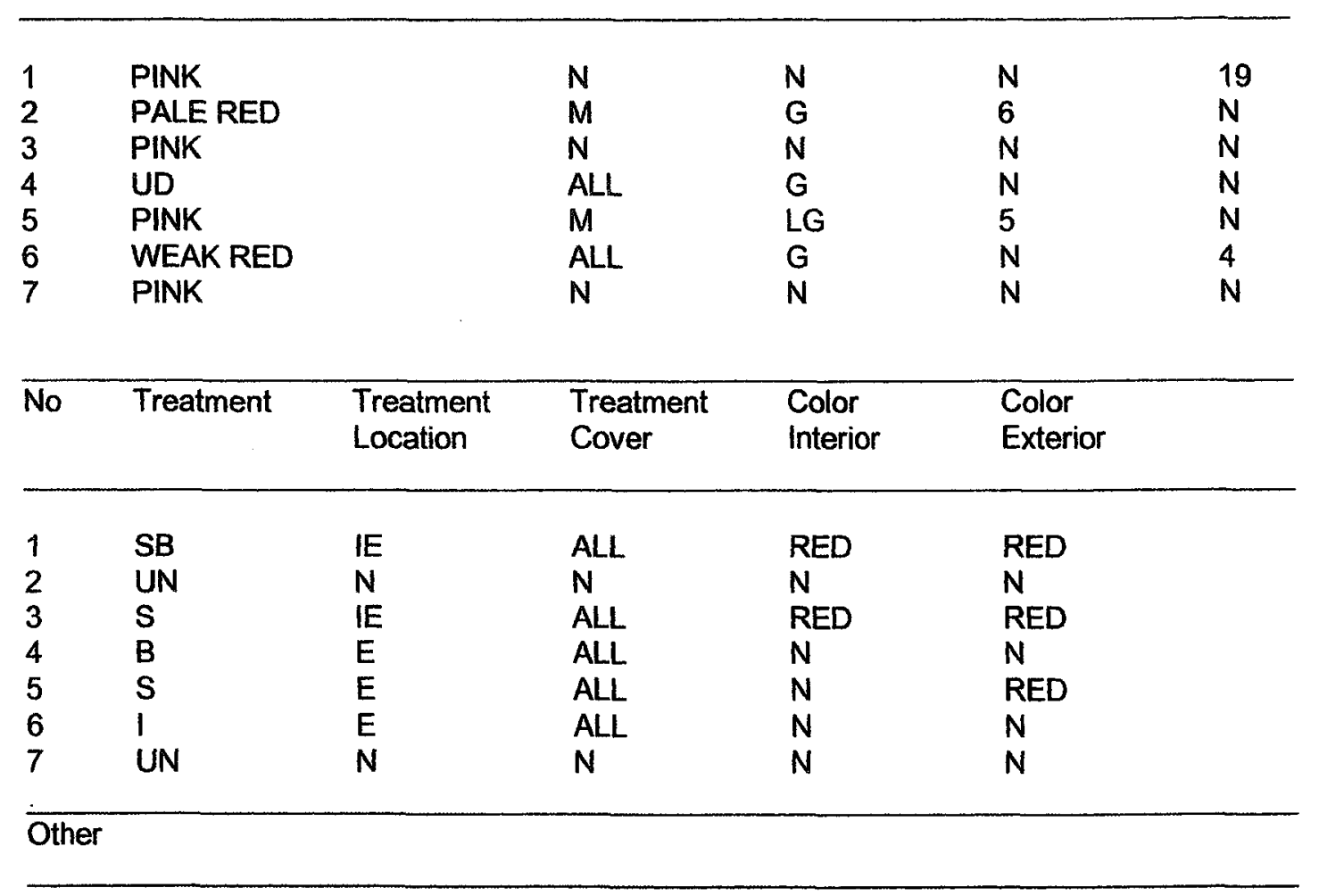

1 Interior face somewhat smoothed, few lines visible; exterior face above keel is wetsmoothed; exterior face below keel is scraped.

3 Wet-smoothing visible on interior/exterior faces.

4 Possible Grey Burnished Ware; interior and exterior faces very smooth, exterior surface, lustrous; the beginning of a plastic application (handle?) visible on break.

6 Combed Metallic Ware

7 Well weathered.

PLATE 32. FIELD A. PHASE 2A (EB II). 


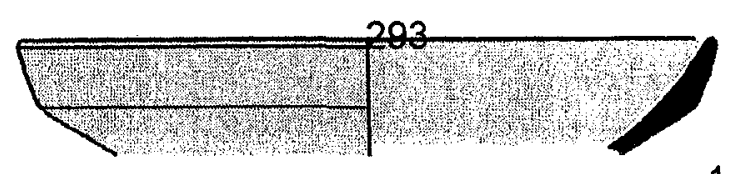

1
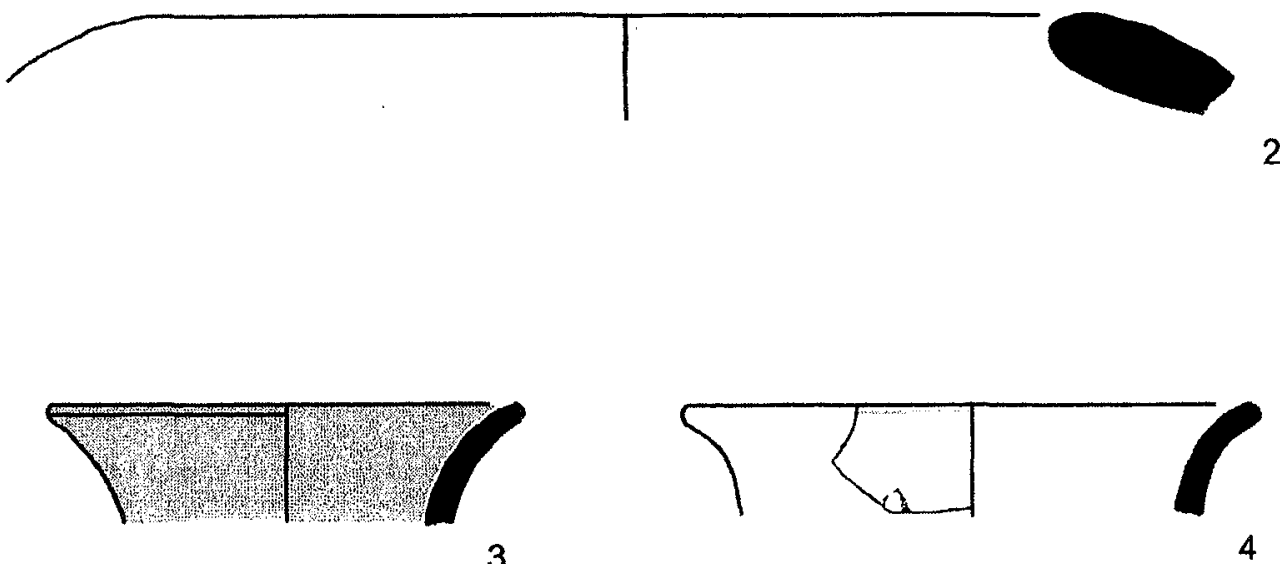

3

4

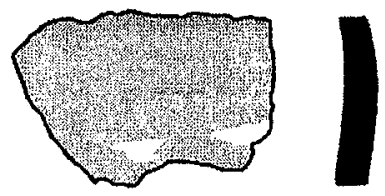

5
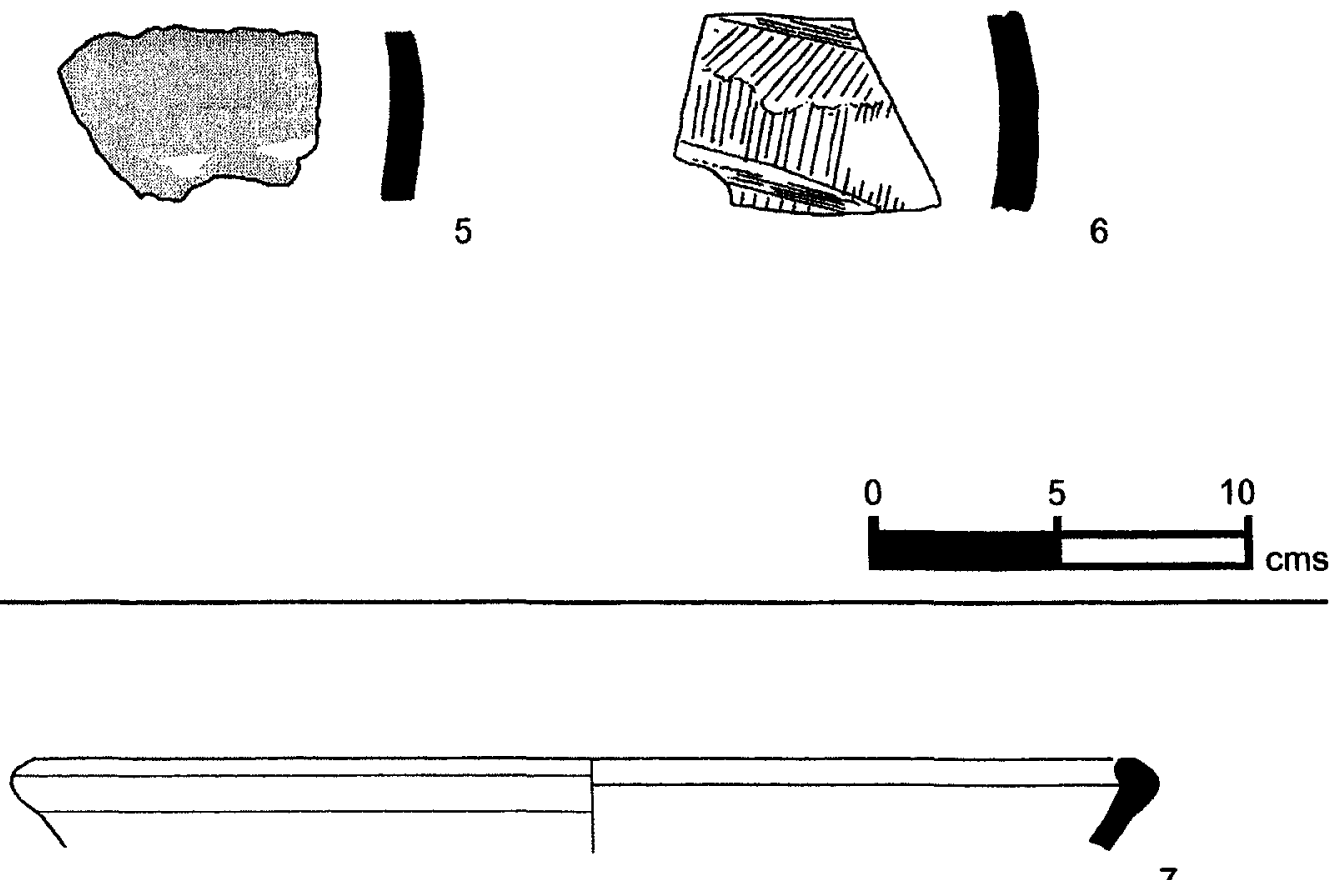

7

PLATE 32 (CONT.).

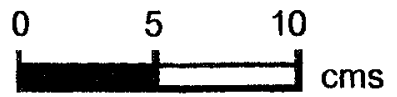




\begin{tabular}{llllllll}
\hline No & Reg & Square & Locus & Vessel & Part & $\begin{array}{l}\text { Body } \\
\text { Thick }\end{array}$ & Dia \\
& & & & & & & \\
1 & 0962 & SW 4-26 & 20 & HOLE MOUTH JAR/BOWL & R14 & 8 & 16 \\
2 & 2298 & SW 4-26 & 20 & HOLE MOUTH JAR/BOWL & R11 & N & N \\
3 & 0964 & SW 4-26 & 20 & HOLE MOUTH JAR/BOWL & R01 & 13 & 15 \\
4 & 0966 & SW 4-26 & 20 & HOLE MOUTH JAR & R11 & 15 & 14 \\
5 & 0954 & SW 4-26 & 20 & NECKED JAR & R31 & 14 & 26 \\
6 & 0950 & SW 4-26 & 20 & UD & R82 & 7 & 14 \\
7 & 0953 & SW 4-26 & 20 & SINUOUS SIDED BOWL & R81 & 7 & 12 \\
8 & 0958 & SW 4-26 & 20 & UD & B12 & 13 & 24 \\
9 & 0957 & SW 4-26 & 20 & UD & B12 & 9 & 16 \\
10 & 0960 & SW 4-26 & 20 & UD & BOD & 11 & N \\
11 & 0955 & SW 4-26 & 20 & UD & H20 & 10 & N \\
12 & 0959 & SW 4-26 & 20 & UD & BOD & 5 & N
\end{tabular}

\begin{tabular}{lllll}
\hline No Fabric Color & Core Orient Core Color Core Thick & $\begin{array}{l}\text { Fabric } \\
\text { Family }\end{array}$
\end{tabular}

\begin{tabular}{|c|c|c|c|c|c|c|}
\hline 1 & \multirow{2}{*}{\multicolumn{2}{|c|}{$\begin{array}{l}\text { LT REDDISH BROWN } \\
\text { LT REDDISH BROWN }\end{array}$}} & IRR & G & $\mathbf{N}$ & $\mathrm{N}$ \\
\hline 2 & & & $\mathbf{N}$ & $\mathrm{N}$ & $\mathbf{N}$ & $\mathbf{N}$ \\
\hline 3 & \multicolumn{2}{|c|}{ WEAK RED } & M & G & 6 & $\mathrm{~N}$ \\
\hline 4 & \multicolumn{2}{|c|}{ LT REDDISH BROWN } & $\mathbf{N}$ & $\mathrm{N}$ & $\mathrm{N}$ & $\mathrm{N}$ \\
\hline 5 & \multicolumn{2}{|c|}{ LT RED } & $M$ & G & 8 & 2.2 \\
\hline 6 & \multicolumn{2}{|c|}{ LT REDDISH BROWN } & N & $N$ & $\mathbf{N}$ & 22 \\
\hline 7 & \multicolumn{2}{|c|}{ LT REDDISH BROWN } & N & N & $N$ & 8 \\
\hline 8 & \multicolumn{2}{|c|}{ LT RED } & $\mathbf{N}$ & $\mathrm{N}$ & $\mathbf{N}$ & 13.1 \\
\hline 9 & \multicolumn{2}{|l|}{ LT RED } & IN & $\mathbf{G}$ & 7 & 9.1 \\
\hline 10 & \multicolumn{2}{|l|}{ LTRED } & IN & G & 9 & 9.1 \\
\hline 11 & \multicolumn{2}{|l|}{ PINK } & IRR & LG & $\mathrm{N}$ & 17.1 \\
\hline 12 & \multicolumn{2}{|l|}{ PINK } & $N$ & $N$ & $N$ & $\mathbf{N}$ \\
\hline No & Treatment & $\begin{array}{l}\text { Treatment } \\
\text { Location }\end{array}$ & $\begin{array}{l}\text { Treatment } \\
\text { Cover }\end{array}$ & $\begin{array}{l}\text { Color } \\
\text { Interior }\end{array}$ & $\begin{array}{l}\text { Color } \\
\text { Exterior }\end{array}$ & \\
\hline 1 & UN & $\mathbf{N}$ & N & $\mathbf{N}$ & $N$ & \\
\hline 2 & UN & $\mathbf{N}$ & $\mathbf{N}$ & $\mathbf{N}$ & $\mathrm{N}$ & \\
\hline 3 & UN & $\mathbf{N}$ & $\mathbf{N}$ & $N$ & $N$ & \\
\hline 4 & UN & $\mathbf{N}$ & $\mathbf{N}$ & $\mathbf{N}$ & $N$ & \\
\hline 5 & UN & $\mathrm{N}$ & $\mathbf{N}$ & $\mathrm{N}$ & $\mathbf{N}$ & \\
\hline 6 & $\mathrm{~S}$ & ER & ALL & $\mathbf{N}$ & LT RED & \\
\hline 7 & $\mathrm{~s}$ & $\mathrm{IE}$ & ALL & RED & RED & \\
\hline 8 & 1 & $E$ & ALL & $\mathbf{N}$ & $\mathbf{N}$ & \\
\hline 9 & S & $E$ & ALL & $\mathbf{N}$ & RED & \\
\hline 10 & 1 & $E$ & ALL & $\mathbf{N}$ & $\mathbf{N}$ & \\
\hline 11 & SB & $\mathrm{E}$ & ALL & $\mathbf{N}$ & RED & \\
\hline 12 & Si & $E$ & ALL & $\mathbf{N}$ & LT RED & \\
\hline
\end{tabular}

PLATE 33. FIELD A. PHASE 2A (EB II). 
Other

1 Sample too small to confirm stance or diameter.

2 Sample too small to confirm stance or diameter.

3 Sample too small to confirm stance or diameter.

8 Combed Metallic Ware.

10 Combed Metallic Ware.

12 Combed Metallic Ware.

PLATE 33 (CONT.).

Reproduced with permission of the copyright owner. Further reproduction prohibited without permission. 

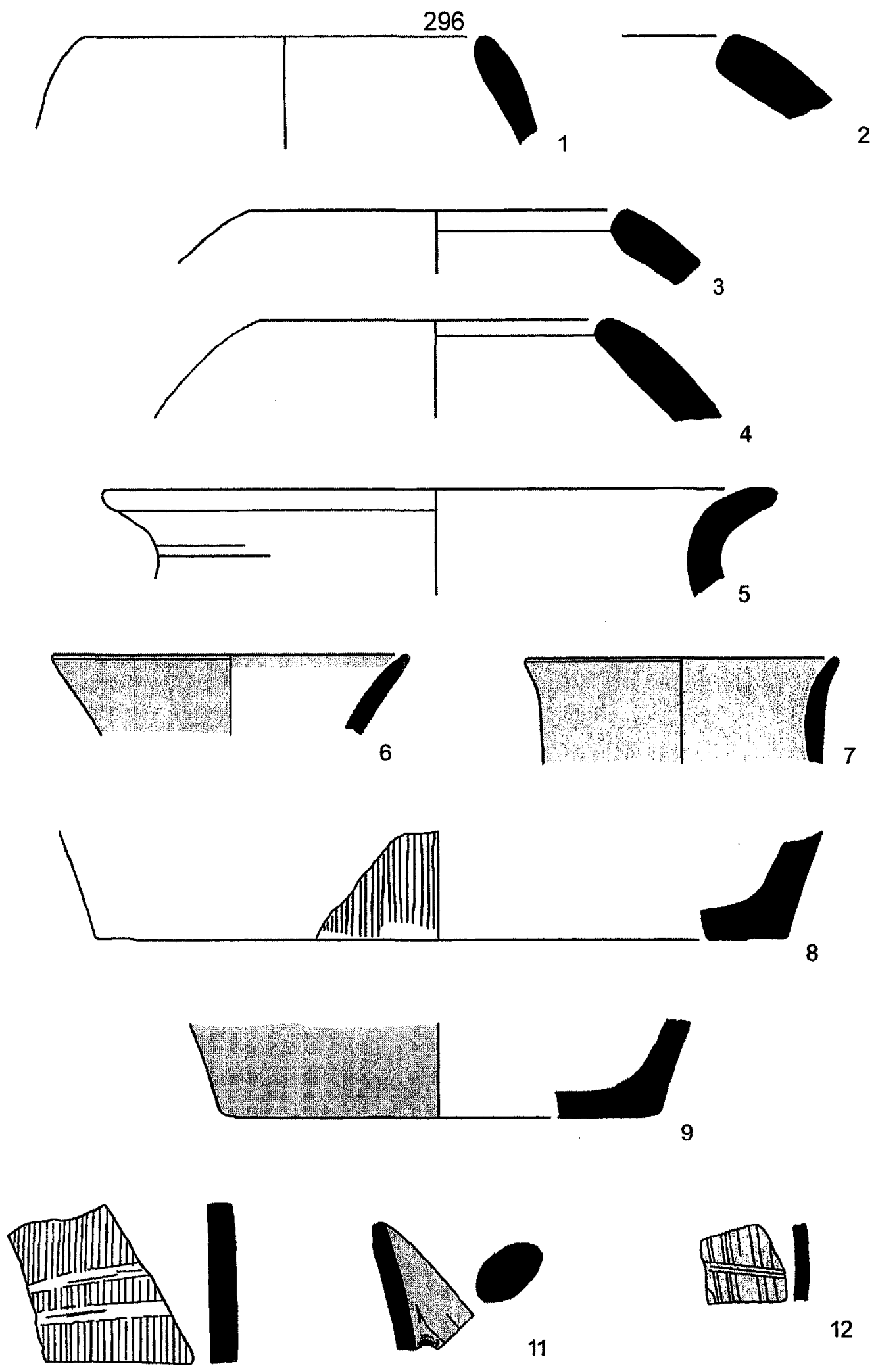

10

11

12

PLATE 33 (CONT.).

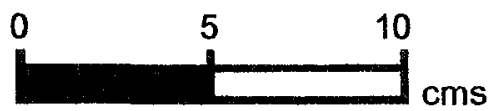


297

\begin{tabular}{lllllllll}
\hline No & Reg & Square & Locus & Vessel & Part & $\begin{array}{c}\text { Body } \\
\text { Thick }\end{array}$ & Dia \\
\hline 1 & 0956 & SW 4-26 & 20 & UD & H10 & 9 & N \\
2 & 0963 & SW 4-26 & 20 & PLATTER BOWL & R56 & 9 & 46 \\
3 & 0952 & SW 4-26 & 20 & PLATTER BOWL & R53 & 8 & 40 \\
4 & 0961 & SW 4-26 & 20 & PLATTER BOWL & R53 & 9 & 38
\end{tabular}

\begin{tabular}{lllll}
\hline No Fabric Color & Core Orient Core Color Core Thick $\begin{array}{l}\text { Fabric } \\
\text { Family }\end{array}$
\end{tabular}

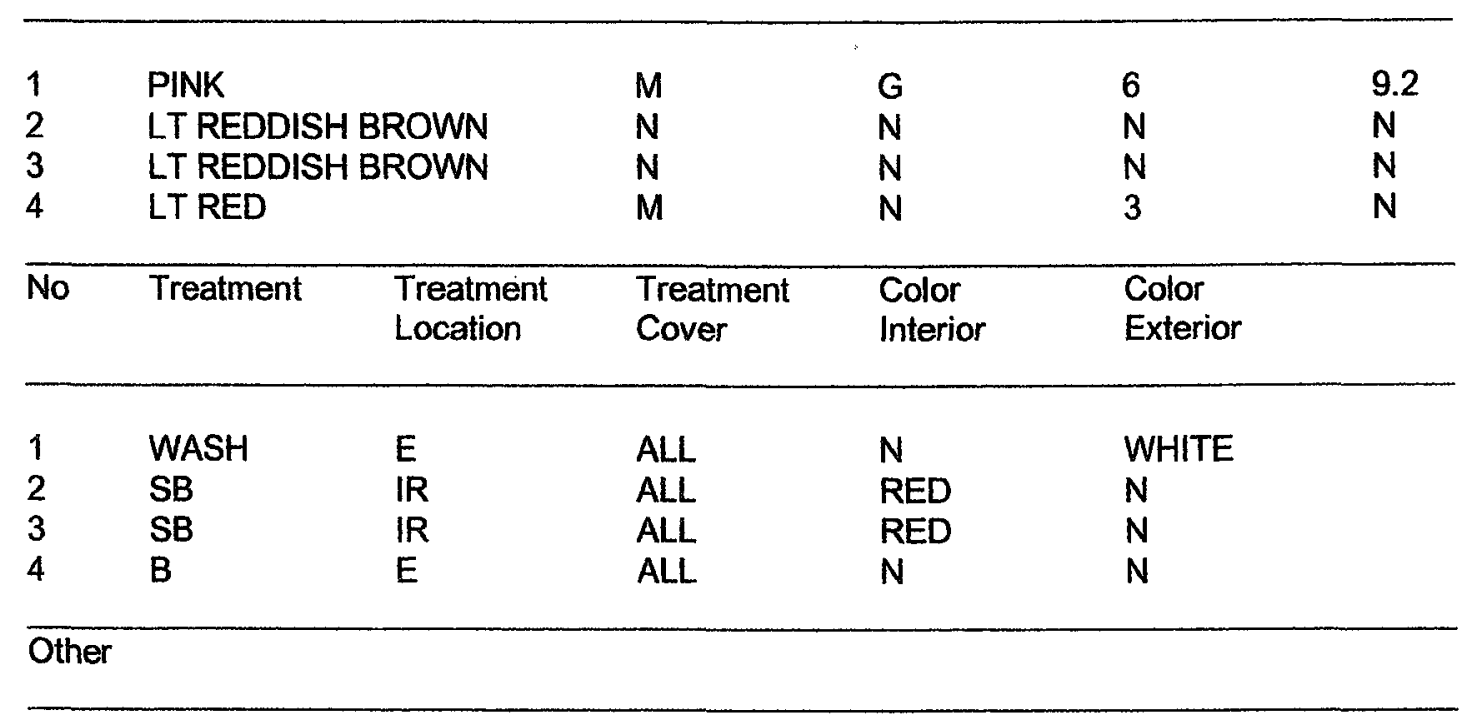

2 Sample too small to confirm stance or diameter.

3 Metallic Ware.

4 Metallic Ware.

PLATE 34. FIELD A. PHASE 2A (EB II). 


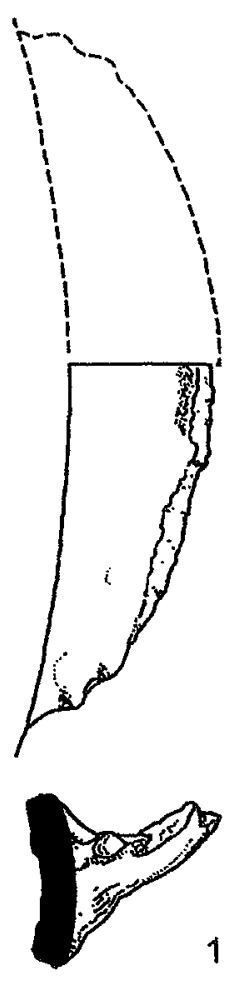

298

1
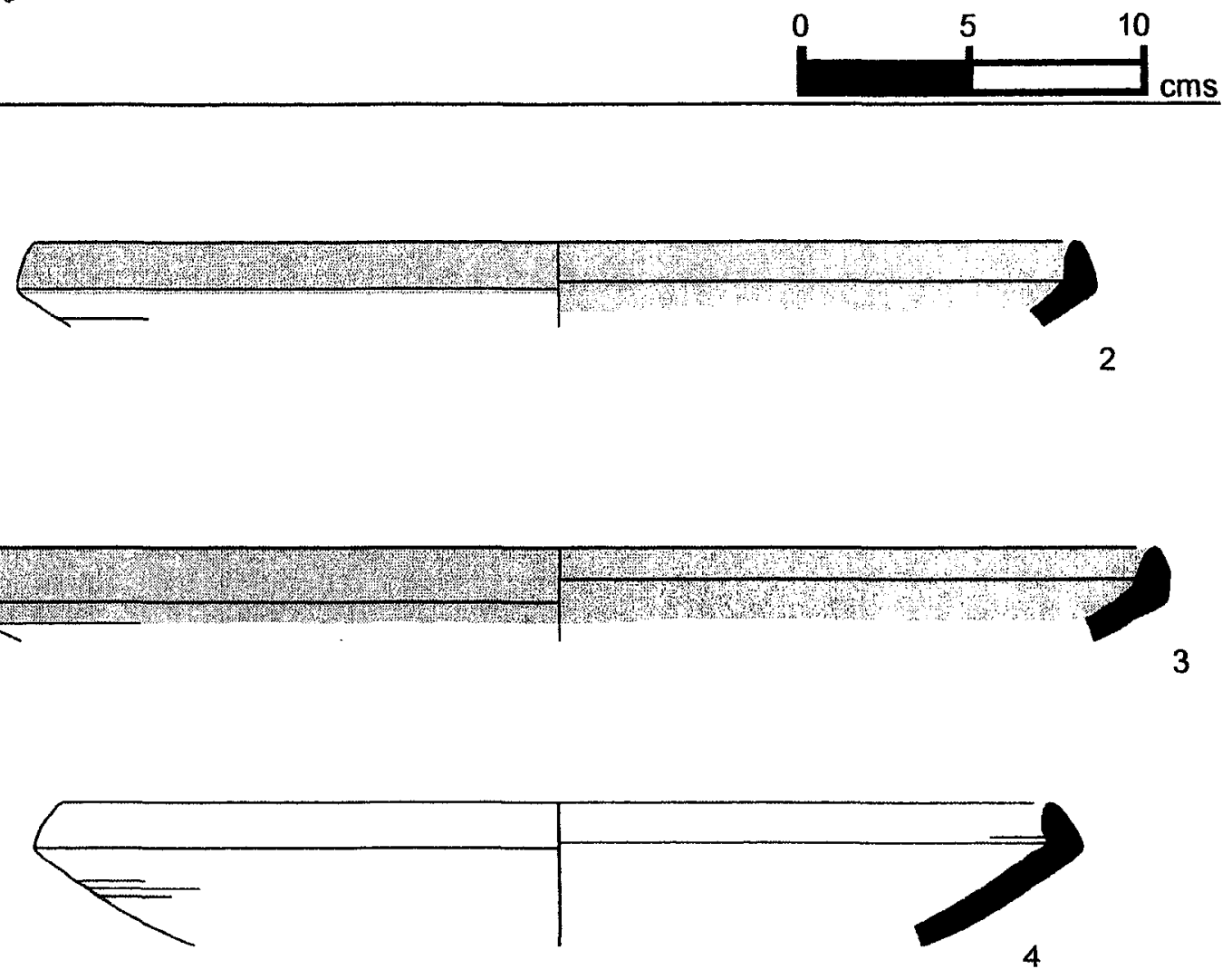

PLATE 34 (CONT.).

$\begin{array}{lll}0 & 5 & 10\end{array}$

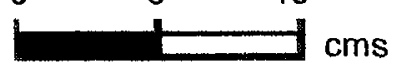




\begin{tabular}{|c|c|c|c|c|c|c|c|}
\hline No & $\operatorname{Reg}$ & Square & Locus & Vessel & Part & $\begin{array}{l}\text { Body } \\
\text { Thick }\end{array}$ & Dia \\
\hline 1 & 0281 & SE 1-26 & 49 & PLATTER BOWL & R53 & 14 & 30 \\
\hline 2 & 0282 & SE 1-26 & 49 & BOWL & $\mathrm{R} 82$ & 5 & 18 \\
\hline 3 & 0277 & SE $1-26$ & 49 & HOLE MOUTH JAR & $\mathrm{R} 11$ & 12 & 15 \\
\hline 4 & 0278 & SE 1-26 & 49 & HOLE MOUTH BOWL & R14 & 12 & 20 \\
\hline 5 & 0279 & SE 1-26 & 49 & NECKED JAR & R31 & 7 & 15 \\
\hline 6 & 0280 & SE 1-26 & 49 & PLATTER BOWL & R55 & 10 & 45 \\
\hline
\end{tabular}

\begin{tabular}{lllll}
\hline No Fabric Color & Core Orient & Core Color & Core Thick & Fabric \\
& & & Family
\end{tabular}

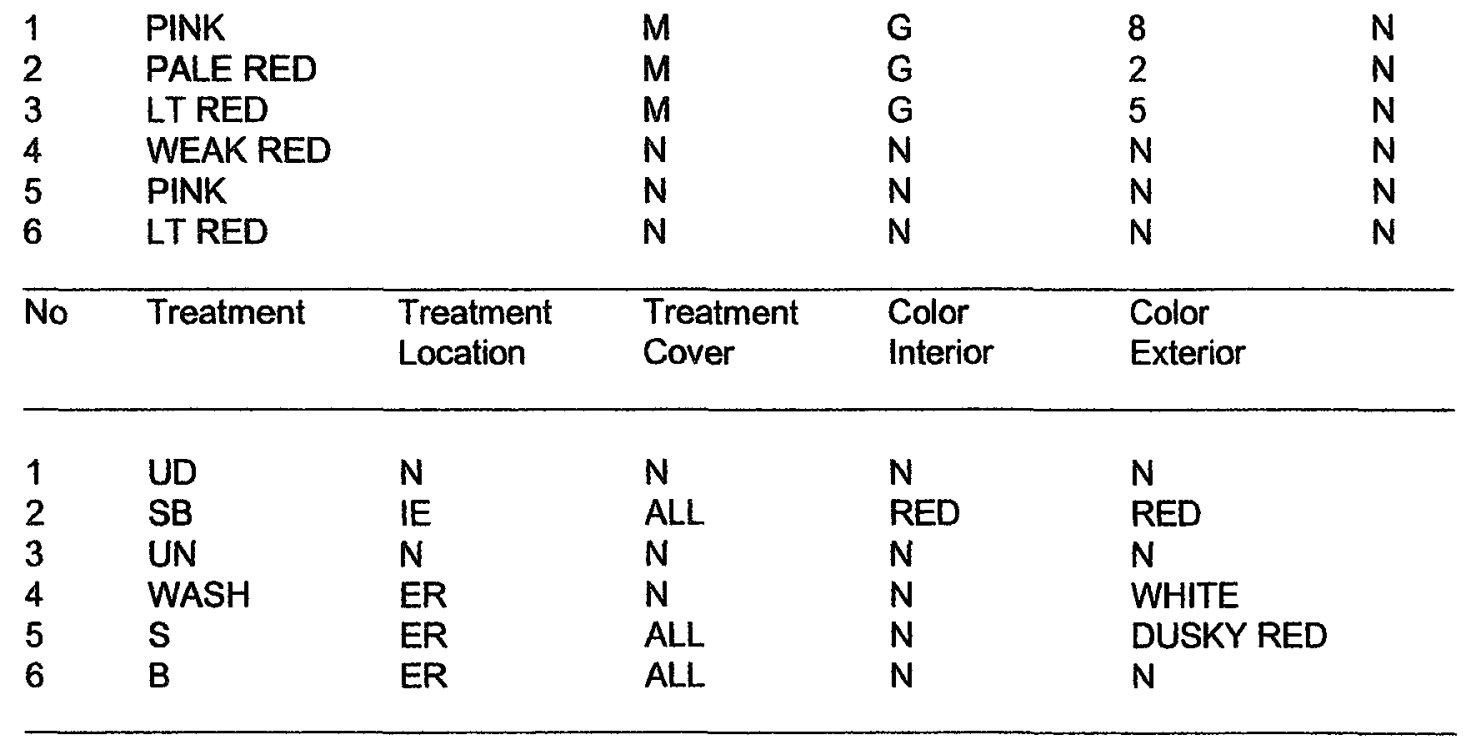

Other

1 Wet-smoothed marginal band appears on exterior face.

$2 \quad$ Khirbet Kerak Ware.

3 Surface burn visible.

6 Wheel burnish on rim circumference; exterior face has wet-smoothed marginal band; Metallic Ware.

PLATE 35. FIELD A. PHASE 2B (LATE EB II). 

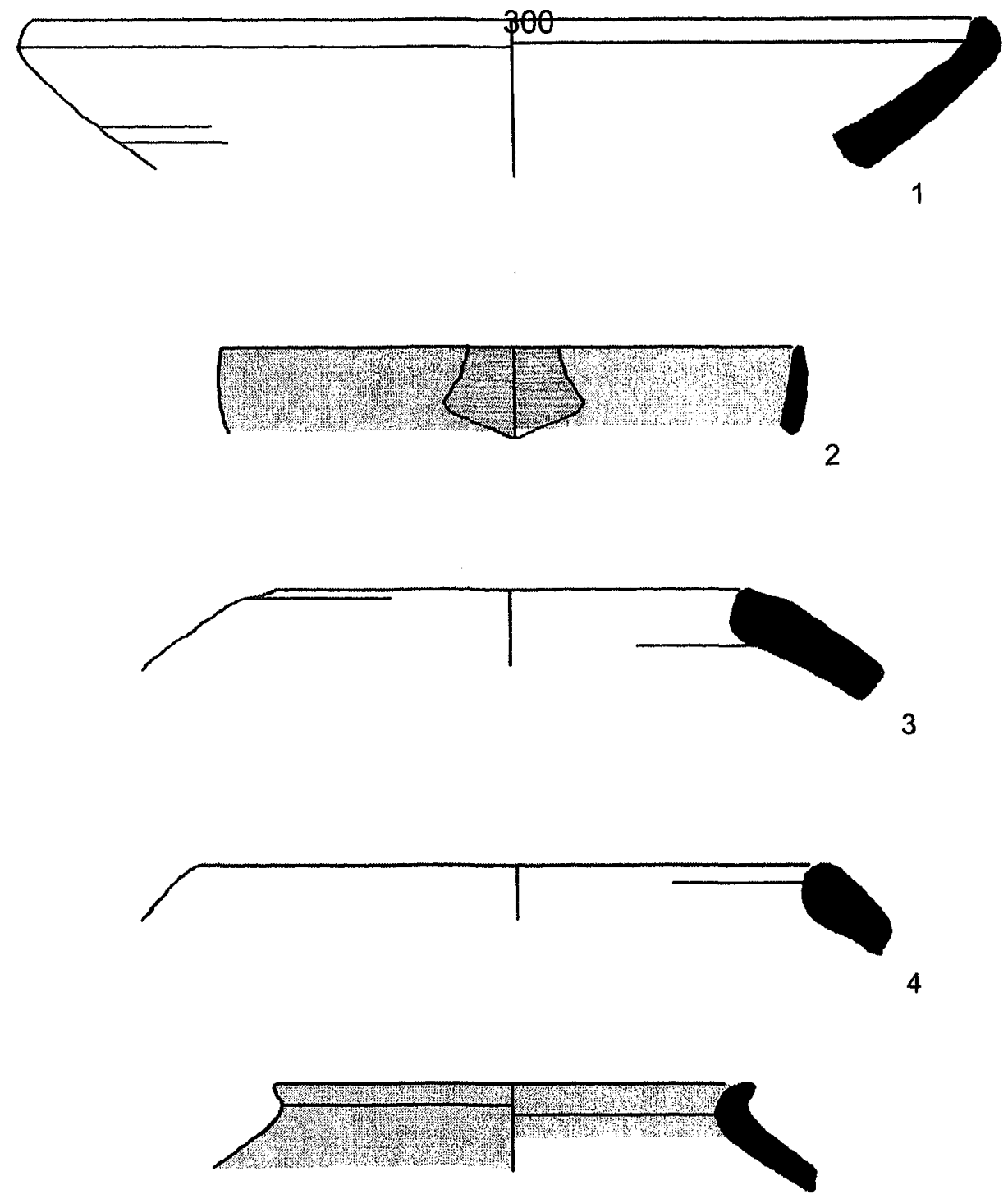

5
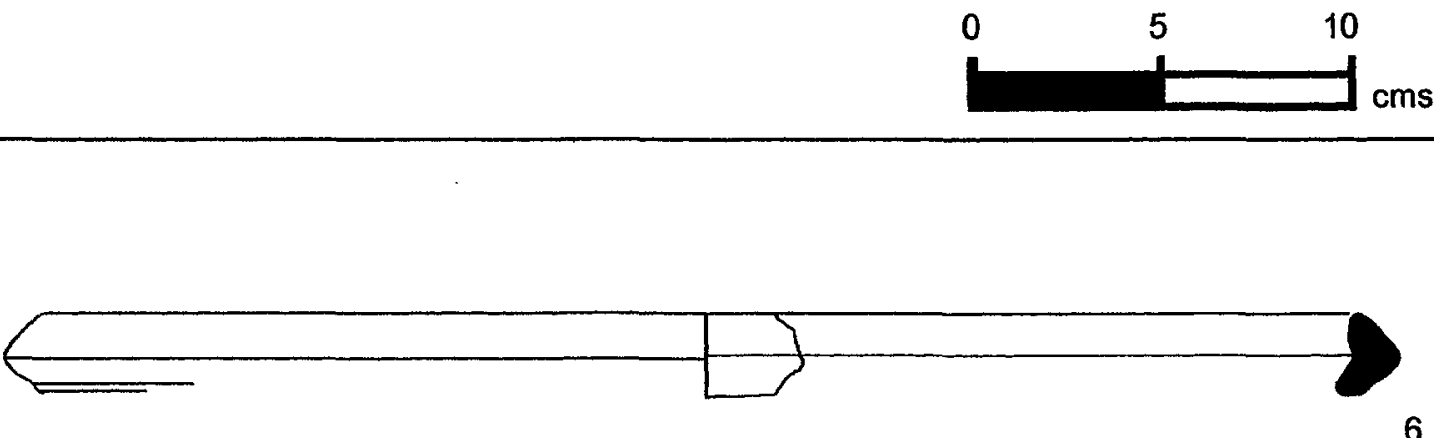

PLATE 35 (CONT.).

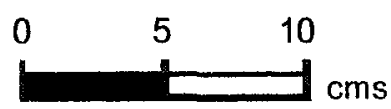


301

\begin{tabular}{llllllll}
\hline No & Reg & Square & Locus & Vessel & Part & $\begin{array}{l}\text { Body } \\
\text { Thick }\end{array}$ & Dia \\
\hline 1 & 0906 & SW 4-25 & 20 & LEDGE RIM BOWL & R51 & 10 & 35 \\
2 & 1109 & SW 5-26 & 22 & HOLE MOUTH JAR & R01 & 13 & 16 \\
3 & 0903 & SW 4-25 & 22 & HOLE MOUTH JAR & R04 & 14 & 16 \\
4 & 1110 & SW 5-26 & 22 & UD & BOD & 12 & N \\
5 & 0902 & SW 4-25 & 22 & JUG & B23 & 8 & 4 \\
6 & 1108 & SW 5-26 & 22 & PLATTER BOWL & R56 & 10 & 42 \\
7 & 0905 & SW 4-25 & 20 & LEDGE RIM BOWL & R51 & 10 & 45 \\
8 & 0900 & SW 4-25 & 22 & PLATTER BOWL & R53 & 11 & 50
\end{tabular}

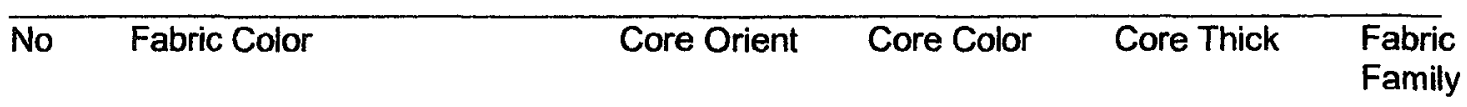

\begin{tabular}{|c|c|c|c|c|c|c|}
\hline 1 & \multicolumn{2}{|c|}{ PINKISH GREY } & $N$ & $N$ & $\mathrm{~N}$ & $\mathrm{~N}$ \\
\hline 2 & \multicolumn{2}{|c|}{ PALE RED } & IN & LG & 6 & 5.1 \\
\hline 3 & \multicolumn{2}{|c|}{ LT REDDISH BROWN } & IRR & $\mathrm{G}$ & $\mathrm{N}$ & $\mathrm{N}$ \\
\hline 4 & \multicolumn{2}{|c|}{ PINK } & $M$ & $\mathbf{G}$ & 7 & 8 \\
\hline 5 & \multicolumn{2}{|l|}{ LT RED } & $\mathbf{M}$ & LG & 2 & 7.2 \\
\hline 6 & \multicolumn{2}{|c|}{ LT REDDISH BROWN } & $\mathbf{N}$ & $N$ & $\mathrm{~N}$ & 24 \\
\hline 7 & \multicolumn{2}{|c|}{ PINK } & $N$ & N & $\mathrm{N}$ & $\mathrm{N}$ \\
\hline 8 & \multicolumn{2}{|c|}{ LT REDDISH BROWN } & $\mathbf{N}$ & $N$ & $\mathbf{N}$ & 8 \\
\hline No & Treatment & $\begin{array}{l}\text { Treatment } \\
\text { Location }\end{array}$ & $\begin{array}{l}\text { Treatment } \\
\text { Cover }\end{array}$ & $\begin{array}{l}\text { Color } \\
\text { Interior }\end{array}$ & $\begin{array}{l}\text { Color } \\
\text { Exterior }\end{array}$ & \\
\hline 1 & UN & $N$ & $N$ & $N$ & $N$ & \\
\hline 2 & UN & $N$ & $N$ & $N$ & $\mathbf{N}$ & \\
\hline 3 & UN & $N$ & $N$ & $\mathbf{N}$ & $\mathrm{N}$ & \\
\hline 4 & $\mathrm{~s}$ & $E$ & ALL & $\mathbf{N}$ & LT RED & \\
\hline 5 & SB & $\bar{E}$ & $A L L$ & $\mathbf{N}$ & RED & \\
\hline 6 & $\mathrm{SB}$ & $\mathbb{R}$ & $\mathrm{ALL}$ & RED & $\mathrm{N}$ & \\
\hline 7 & SB & IR & $A L L$ & RED & $\mathrm{N}$ & \\
\hline 8 & SB & 1 & $\mathrm{ALL}$ & RED & $N$ & \\
\hline
\end{tabular}

3 Surface burn visible.

4 Potter's mark visible.

7 Tight radial burnish on interior face; deep turning grooves on exterior face; inclusion drag marks on exterior suggest rotation in counter-clockwise direction.

PLATE 36. FIELD A. PHASE 2B (LATE EB II). 

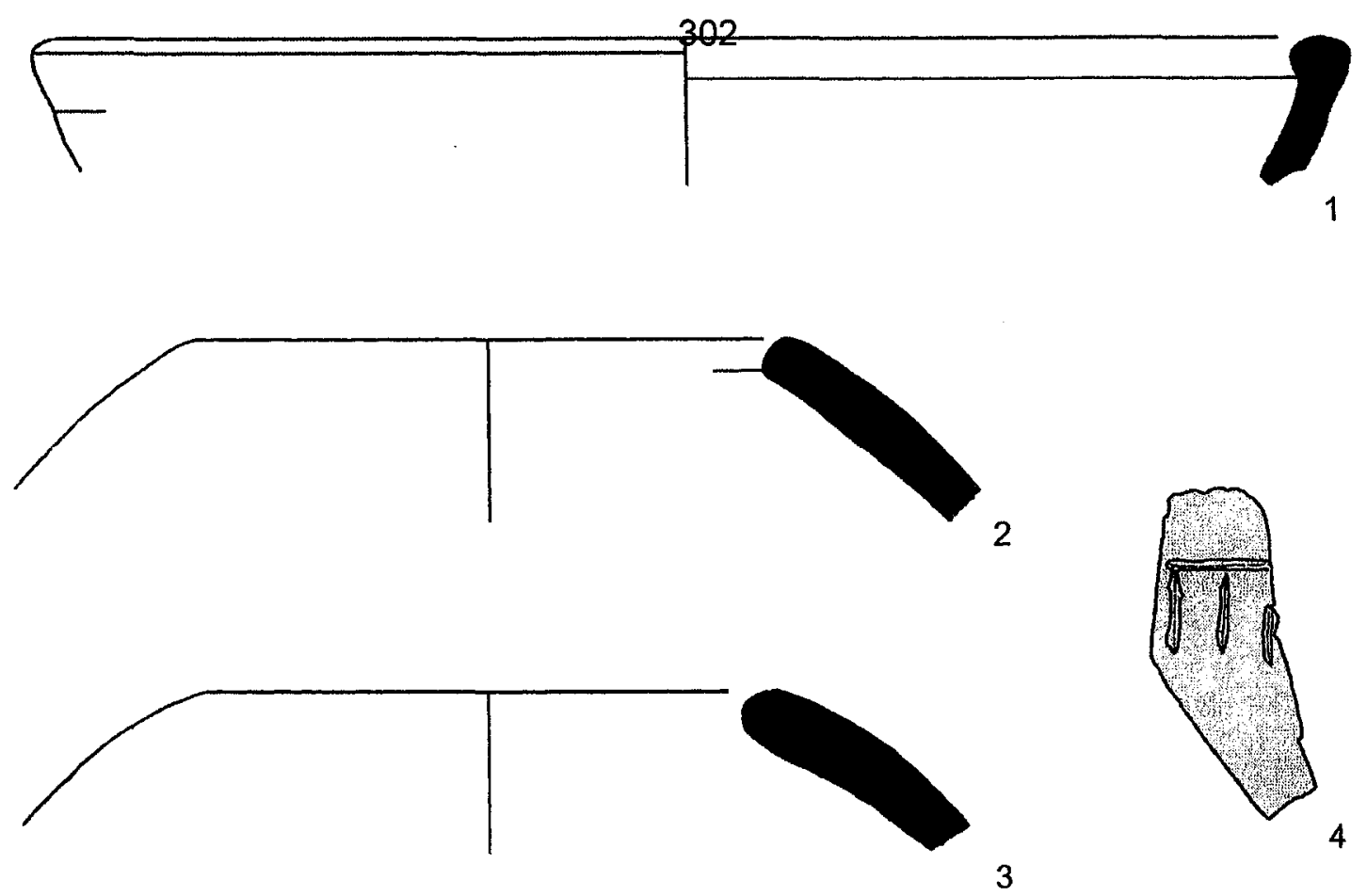

3

5
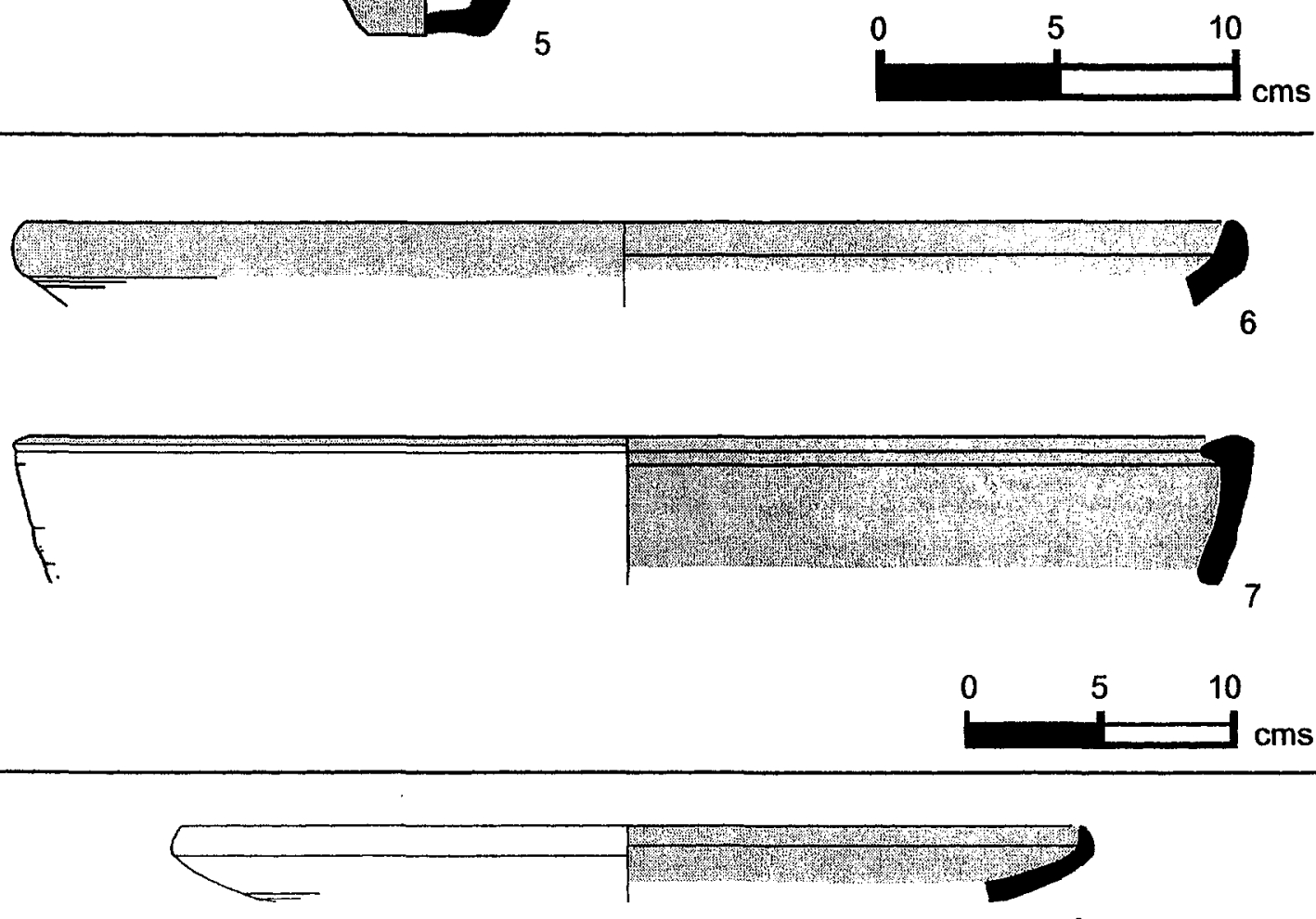

8

PLATE 36 (CONT.).

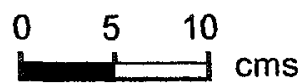




\begin{tabular}{llllllll}
\hline No & Reg & Square & Locus & Vessel & Part & $\begin{array}{c}\text { Body } \\
\text { Thick }\end{array}$ & Dia \\
\hline & & & & & & & \\
1 & 1095 & SW 5-26 & 21 & BOWL & R50 & 8 & 36 \\
2 & 1085 & SW 5-26 & 21 & LEDGE RIM BOWL & R53 & 9 & 32 \\
3 & 1083 & SW 5-26 & 21 & LEDGE RIM BOWL & R53 & 7 & 26 \\
4 & 1089 & SW 5-26 & 21 & PLATTER BOWL & R57 & 15 & 25 \\
5 & 1092 & SW 5-26 & 21 & HOLE MOUTH JAR & R11 & 6 & 20 \\
6 & 1086 & SW 5-26 & 21 & HOLE MOUTH BOWL & R11 & 12 & 18 \\
7 & 1103 & SW 5-26 & 21 & HOLE MOUTH JAR/BOWL & R04 & 15 & N \\
8 & 0996 & SW 5-26 & 21 & HOLE MOUTH BOWL & R11 & 7 & 12 \\
9 & 1091 & SW 5-26 & 21 & UD & R82 & 7 & 4 \\
\hline No & Fabric Color & & Core Orient Core Color & Core Thick & Fabric \\
& & & & & & & Family
\end{tabular}

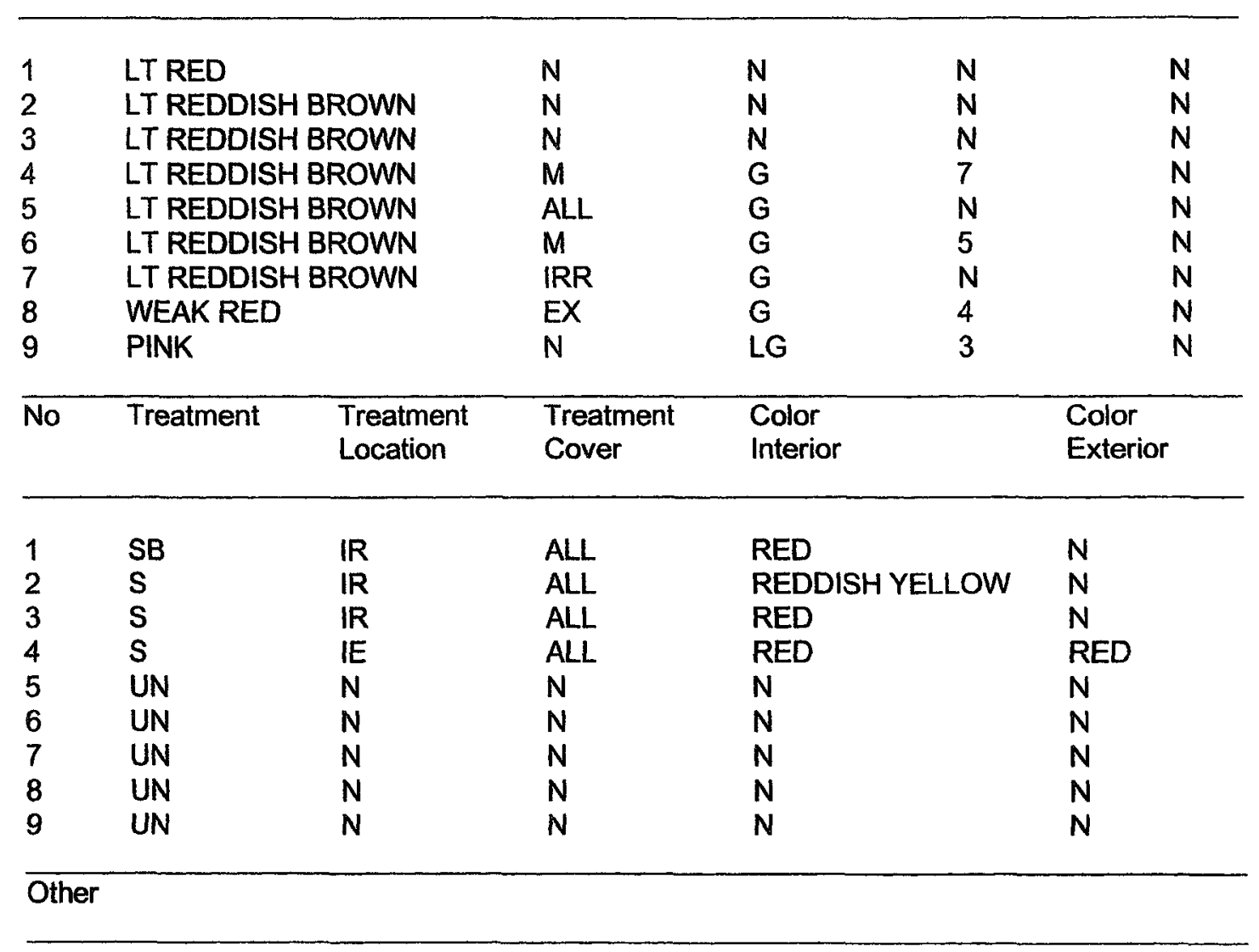

$1 \quad$ Sample too small to confirm stance or diameter; Metallic Ware.

3 Rim is wheel burnished; radial burnish lines visible on interior wall; burn marks on rim suggest use as lamp?

$5 \quad$ Marks on interior show wall scraping and rim finish.

7 Sample too small to confirm stance or diameter.

8 Potter's mark visible.

9 Sample too small to confirm stance or diameter; deep groove cut into interior face.

PLATE 37. FIELD A. PHASE 2B (LATE EB II). 
304
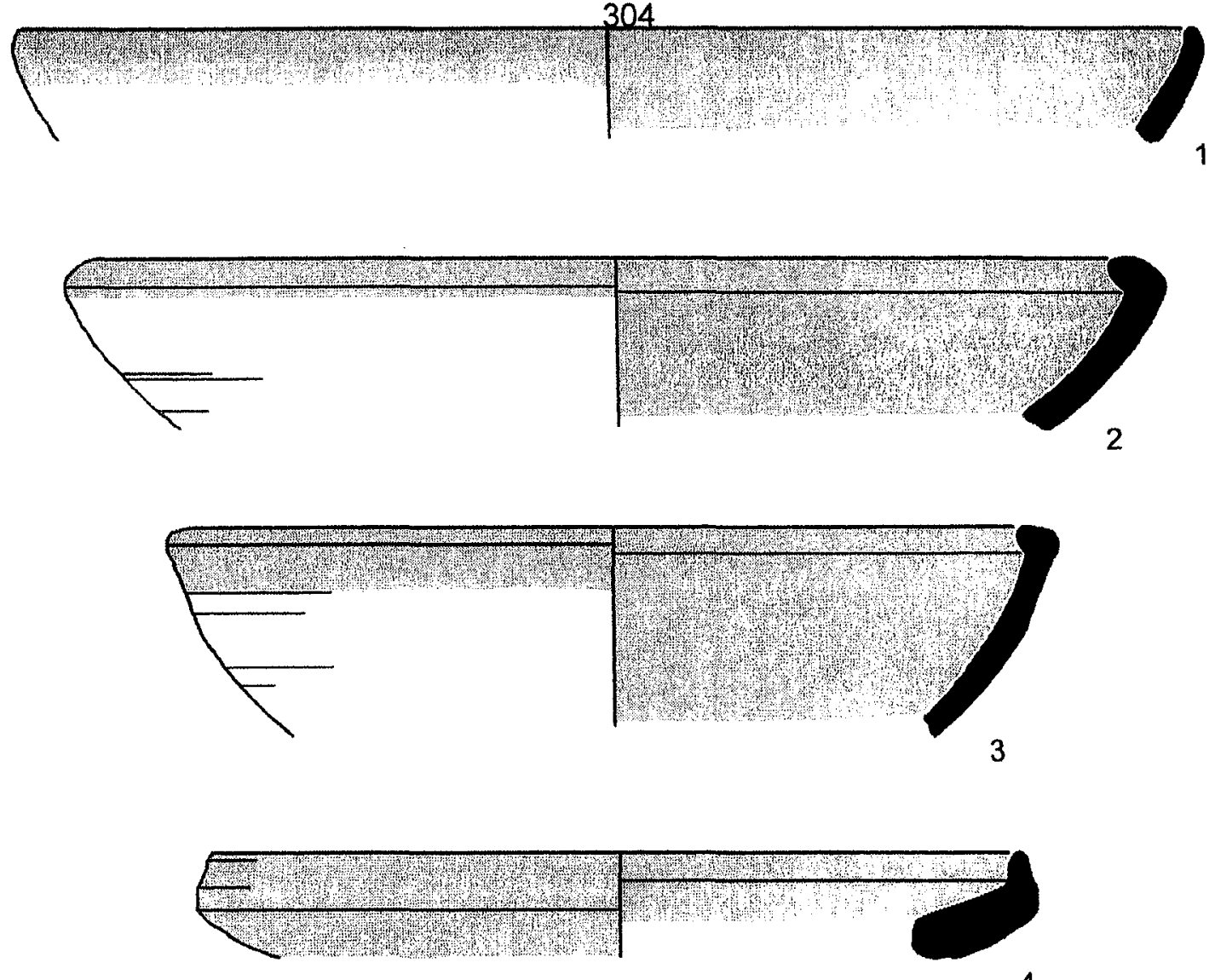

4
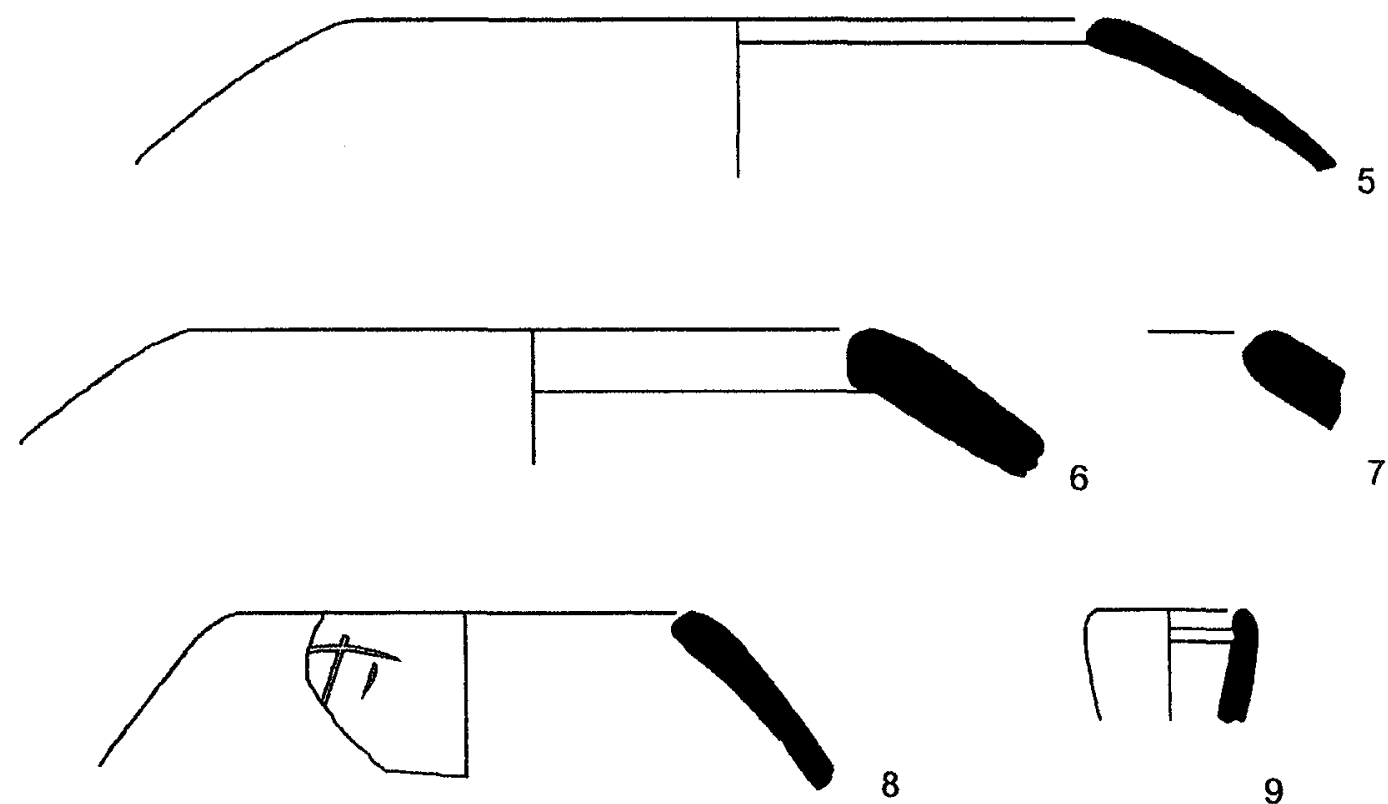

8

9

PLATE 37 (CONT.).

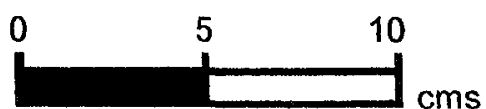


305

\begin{tabular}{llllllll}
\hline No & Reg & Square & Locus & Vessel & Part & $\begin{array}{c}\text { Body } \\
\text { Thick }\end{array}$ & Dia \\
& & & & & & & \\
\hline & & & & & & & \\
1 & 1094 & SW 5-26 & 21 & NECKED JAR & R31 & 9 & 26 \\
2 & 1090 & SW 5-26 & 21 & NECKED JAR & R43 & 6 & 14 \\
3 & 1084 & SW 5-26 & 21 & NECKED JAR & R42 & 12 & 18 \\
4 & 1088 & SW 5-26 & 21 & NECKED JAR & R43 & 7 & 14 \\
5 & 1093 & SW 5-26 & 21 & CHANNELED RIM JAR & R35 & 9 & 12 \\
6 & 1082 & SW 5-26 & 21 & NECKED JAR & R32 & 12 & 20 \\
7 & 2497 & SW 5-26 & 21 & NECKED JAR & R43 & 9 & N \\
8 & 1102 & SW 5-26 & 21 & NECKED JAR & R43 & 12 & N \\
9 & 1099 & SW 5-26 & 21 & UD & B12 & 11 & 24 \\
10 & 1100 & SW 5-26 & 21 & UD & B12 & 11 & 22 \\
11 & 1098 & SW 5-26 & 21 & UD & H20 & 10 & N \\
12 & 1096 & SW 5-26 & 21 & UD & H21 & N & N \\
13 & 1097 & SW 5-26 & 21 & UD & H20 & N & N \\
14 & 1081 & SW 5-26 & 21 & PLATTER BOWL & R56 & 9 & 40
\end{tabular}

\begin{tabular}{llllll}
\hline No & Fabric Color & Core Orient & Core Color & Core Thick & Fabric \\
& & & Family
\end{tabular}

\begin{tabular}{|c|c|c|c|c|c|c|}
\hline 1 & \multicolumn{2}{|c|}{ PINKISH GREY } & $\mathbf{N}$ & $N$ & $N$ & $\mathbf{N}$ \\
\hline 2 & \multicolumn{2}{|l|}{ PALE RED } & IRR & G & $\mathbf{N}$ & $\mathrm{N}$ \\
\hline 3 & \multicolumn{2}{|c|}{ LT REDDISH BROWN } & $\mathbf{M}$ & LG & 4 & $\mathrm{~N}$ \\
\hline 4 & \multicolumn{2}{|l|}{ LT RED } & $\mathbf{N}$ & $\mathbf{N}$ & $\mathbf{N}$ & $\mathrm{N}$ \\
\hline 5 & \multicolumn{2}{|l|}{ PINK } & $\mathbf{N}$ & $\mathbf{N}$ & $\mathbf{N}$ & $\mathrm{N}$ \\
\hline 6 & \multicolumn{2}{|c|}{ LT REDDISH BROWN } & M & G & 6 & $N$ \\
\hline 7 & \multicolumn{2}{|l|}{ PINK } & $\mathrm{N}$ & $\mathrm{N}$ & $\mathrm{N}$ & $\mathrm{N}$ \\
\hline 8 & \multicolumn{2}{|c|}{ LT REDDISH BROWN } & $\mathbf{M}$ & LG & 3 & $\mathrm{~N}$ \\
\hline 9 & \multicolumn{2}{|c|}{ LT REDDISH BROWN } & IN & G & 7 & $\mathrm{~N}$ \\
\hline 10 & \multicolumn{2}{|l|}{ LT RED } & $\mathbb{N}$ & $\mathbf{G}$ & 8 & $\mathrm{~N}$ \\
\hline 11 & \multicolumn{2}{|l|}{ PINK } & $\mathbf{M}$ & LG & $\mathrm{N}$ & $\mathbf{N}$ \\
\hline 12 & \multicolumn{2}{|c|}{ LT REDDISH BROWN } & $M$ & LG & $\mathrm{N}$ & $\mathbf{N}$ \\
\hline 13 & \multicolumn{2}{|c|}{ PINK } & $M$ & $\mathbf{G}$ & $\mathrm{N}$ & $\mathbf{N}$ \\
\hline 14 & \multicolumn{2}{|l|}{ PINK } & $\mathbf{N}$ & $\mathbf{N}$ & $\mathbf{N}$ & $\mathbf{N}$ \\
\hline No & Treatment & $\begin{array}{l}\text { Treatment } \\
\text { Location }\end{array}$ & $\begin{array}{l}\text { Treatment } \\
\text { Cover }\end{array}$ & $\begin{array}{l}\text { Color } \\
\text { Interior }\end{array}$ & $\begin{array}{l}\text { Color } \\
\text { Exterior }\end{array}$ & \\
\hline 1 & UN & $\mathbf{N}$ & $\mathbf{N}$ & $\mathbf{N}$ & $\mathbf{N}$ & \\
\hline 2 & UN & $\mathrm{N}$ & $\mathbf{N}$ & $\mathbf{N}$ & $\mathrm{N}$ & \\
\hline 3 & $\mathbf{S}$ & ER & ALL & $N$ & LT RED & \\
\hline 4 & UN & $\mathbf{N}$ & $\mathbf{N}$ & $\mathbf{N}$ & $\mathbf{N}$ & \\
\hline 5 & $\mathbf{S}$ & ER & ALL & $\mathbf{N}$ & LT RED & \\
\hline 6 & $\mathrm{~s}$ & $\mathrm{IE}$ & ALL & RED & RED & \\
\hline 7 & UN & $\mathbf{N}$ & $\mathbf{N}$ & $\mathbf{N}$ & $\mathbf{N}$ & \\
\hline 8 & WASH & ER & ALL & $\mathbf{N}$ & WHITE & \\
\hline
\end{tabular}

PLATE 38. FIELD A. PHASE 2B (LATE EB II). 
306

\begin{tabular}{llllll}
\hline No & Treatment & $\begin{array}{l}\text { Treatment } \\
\text { Location }\end{array}$ & $\begin{array}{l}\text { Treatment } \\
\text { Cover }\end{array}$ & $\begin{array}{l}\text { Color } \\
\text { Interior }\end{array}$ & $\begin{array}{l}\text { Color } \\
\text { Exterior }\end{array}$ \\
\hline 9 & 1 & E & ALL & $\mathrm{N}$ & $\mathrm{N}$ \\
10 & 1 & $\mathrm{E}$ & ALL & $\mathrm{N}$ & $\mathrm{N}$ \\
11 & $\mathrm{~S}$ & $\mathrm{E}$ & $\mathrm{ALL}$ & $\mathrm{N}$ & VERY DK GREY \\
12 & SB & $\mathrm{E}$ & ALL & $\mathrm{N}$ & DK RED \\
13 & SB & $\mathrm{E}$ & ALL & $\mathrm{N}$ & RED \\
14 & SB & IR & ALL & RED & N \\
\hline
\end{tabular}

1 Grey Burnished Ware.

2 Metallic Ware?

4 Metallic Ware.

7 Sample too small to confirm stance or diameter.

8 Sample too small to confirm stance or diameter.

9 Combed Metallic Ware.

10 Combed Metallic Ware.

14 Net burnish on slipped interior face; marginal concavity under rim appears executed in a wet-smoothing action pressed into the scraped base; dragged inclusions suggest base scraping done in a clockwise motion.

PLATE 38 (CONT.). 

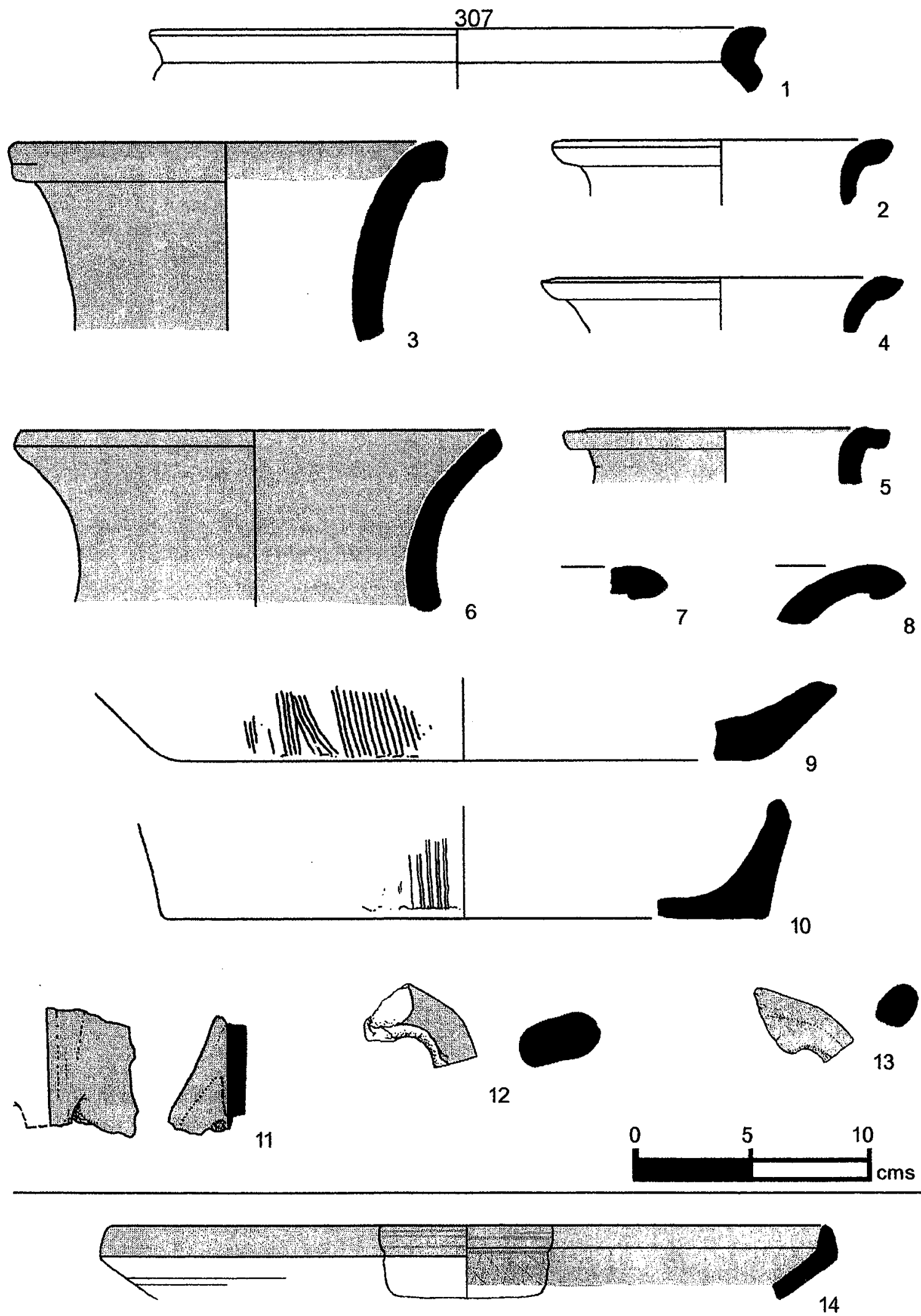

PLATE 38 (CONT.).

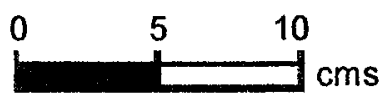




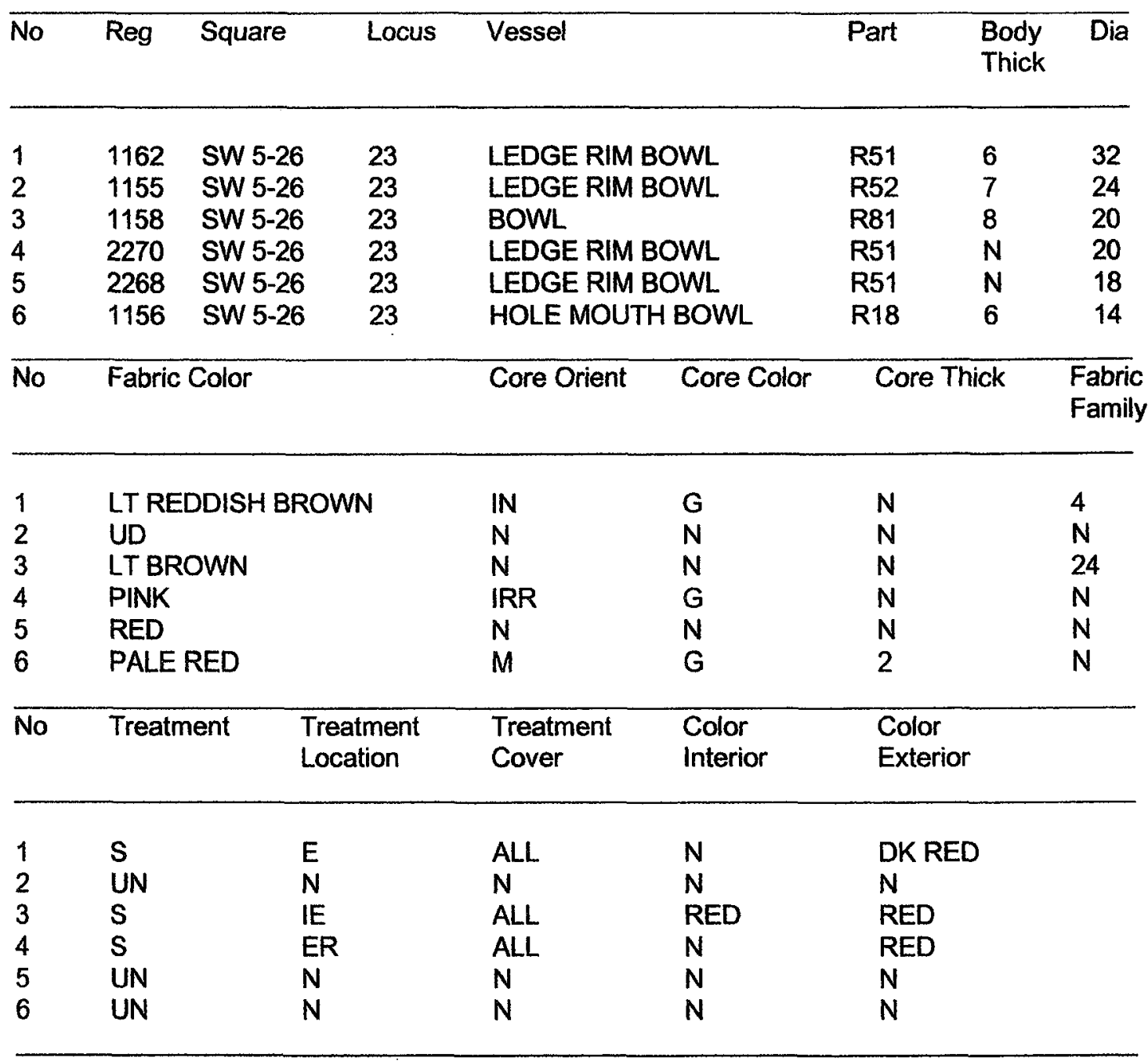

\section{Other}

$1 \quad$ Also $\mathrm{H} 22$; interior face very weathered; slight concavity under rim on exterior face; haphazardly scraped and smoothed; vertical loop handle attached below rim; joints beveled and smoothed; many large inclusions in fabric.

3 Sherd appears gray to black in color and rough in texture; horizontal lines mark both the interior face and the area directly under the rim on exterior face; a broad set of diagonal lines suggest a single swipe which marred the rim and the exterior body.

5 Sample too small to confirm stance or diameter.

6 Sample too small to confirm stance or diameter.

PLATE 39. FiELD A. PHASE 2B (LATE EB II). 

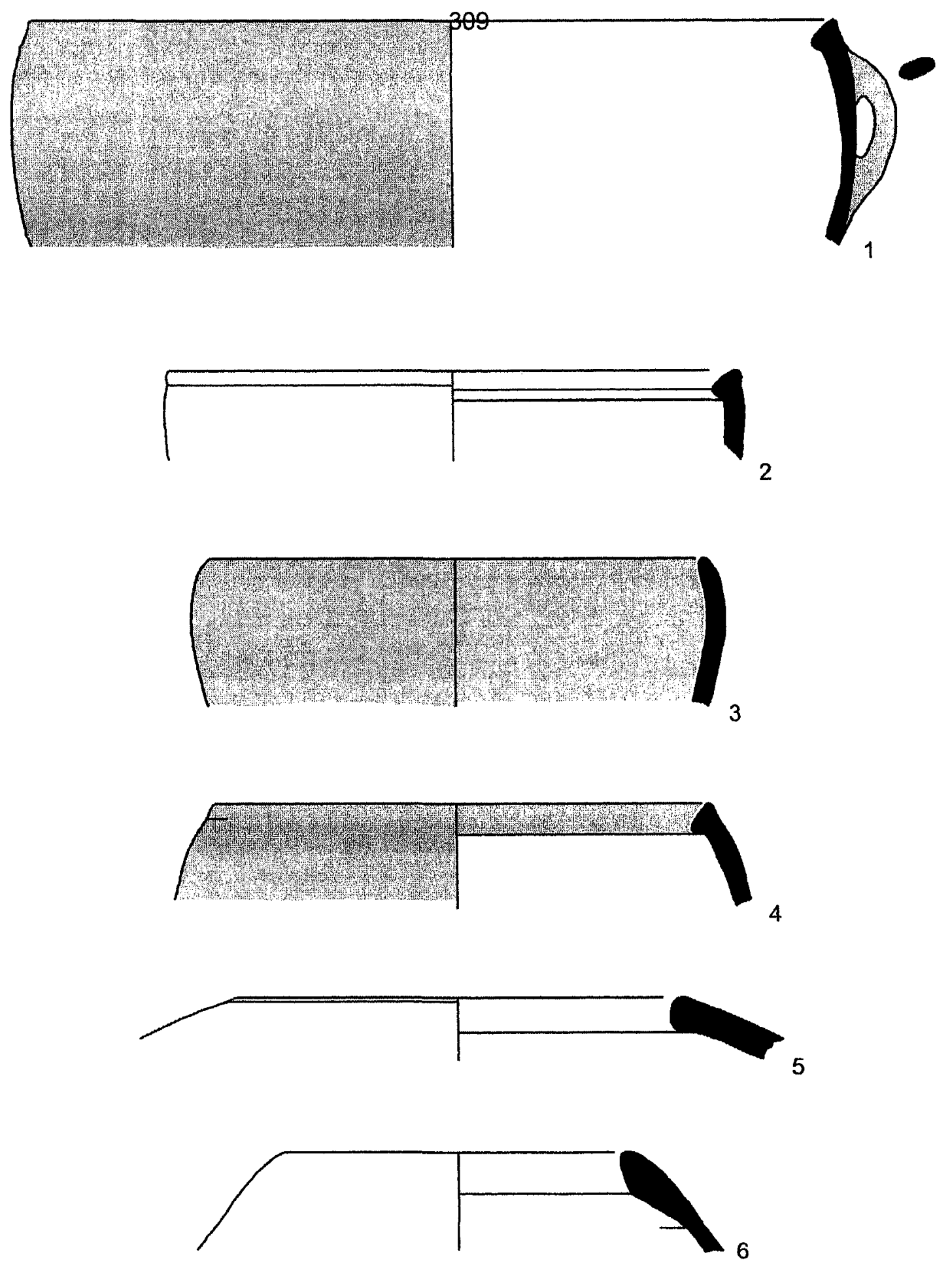

PLATE 39 (CONT.).

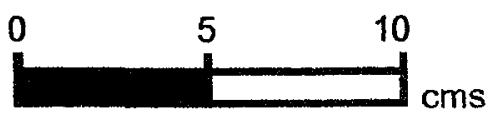




\begin{tabular}{llllllll}
\hline No & Reg & Square & Locus & Vessel & Part & $\begin{array}{l}\text { Body } \\
\text { Thick }\end{array}$ & Dia \\
\hline 1 & 2267 & SW 5-26 & 23 & NECKED JAR & R43 & N & 20 \\
2 & 2269 & SW 5-26 & 23 & NECKED JAR & R42 & N & 20 \\
3 & 1163 & SW 5-26 & 23 & UD & BOD & N & N \\
4 & 1159 & SW 5-26 & 23 & HOLE MOUTH JAR & R22 & 5 & 32 \\
5 & 1157 & SW 5-26 & 23 & PLATTER BOWL & R56 & 10 & 40 \\
6 & 1161 & SW 5-26 & 23 & PLATTER BOWL & R53 & 9 & 50 \\
7 & 2327 & SW 5-26 & 23 & LEDGE RIM BOWL & R51 & 11 & 42
\end{tabular}

\begin{tabular}{lllll}
\hline No Fabric Color & Core Orient Core Color Core Thick & Fabric \\
& & & Family
\end{tabular}

\begin{tabular}{llllll}
\hline & & & & \\
1 & LTREDDISH BROWN & $\mathrm{M}$ & $\mathrm{G}$ & $\mathrm{N}$ & $\mathrm{N}$ \\
2 & LTRED & $\mathrm{N}$ & $\mathrm{N}$ & $\mathrm{N}$ & $\mathrm{N}$ \\
3 & PINK & $\mathrm{M}$ & $\mathrm{G}$ & 2 & 7.2 \\
4 & LTRED & $\mathrm{M}$ & $\mathrm{G}$ & $\mathrm{N}$ & 9.2 \\
5 & REDDISH GREY & $\mathrm{N}$ & $\mathrm{N}$ & $\mathrm{N}$ & $\mathrm{N}$ \\
6 & LTREDDISH BROWN & $\mathrm{N}$ & $\mathrm{N}$ & $\mathrm{N}$ & 24 \\
7 & PINK & $\mathrm{N}$ & $\mathrm{N}$ & $\mathrm{N}$ & $\mathrm{N}$ \\
\hline No & Treatment & Treatment & Treatment & Color & Color \\
& & Location & Cover & Interior & Exterior \\
\end{tabular}

\begin{tabular}{llllll}
1 & N & $N$ & $N$ & $N$ & $N$ \\
2 & UN & $N$ & $N$ & $N$ & $N$ \\
3 & PAINT & E & LINE & N & RED \\
4 & WASH & E & ALL & N & WHITE \\
5 & SB & IR & N & RED & N \\
6 & SB & IR & ALL & RED & N \\
7 & SB & IE & ALL & LT RED & LT RED \\
\hline
\end{tabular}

\footnotetext{
1 Metallic Ware; sample too small to confirm stance or diameter.

4 Lime wash on exterior; rope application is pulled to the right.

5 Bored hole appears in break, ca. $4 \mathrm{~mm}$ in diameter.

$7 \quad$ Hole (about $3 \mathrm{~mm}$ dia.) bored immediately under rim.
}

PLATE 40. FIELD A. PHASE 2B (LATE EB II). 

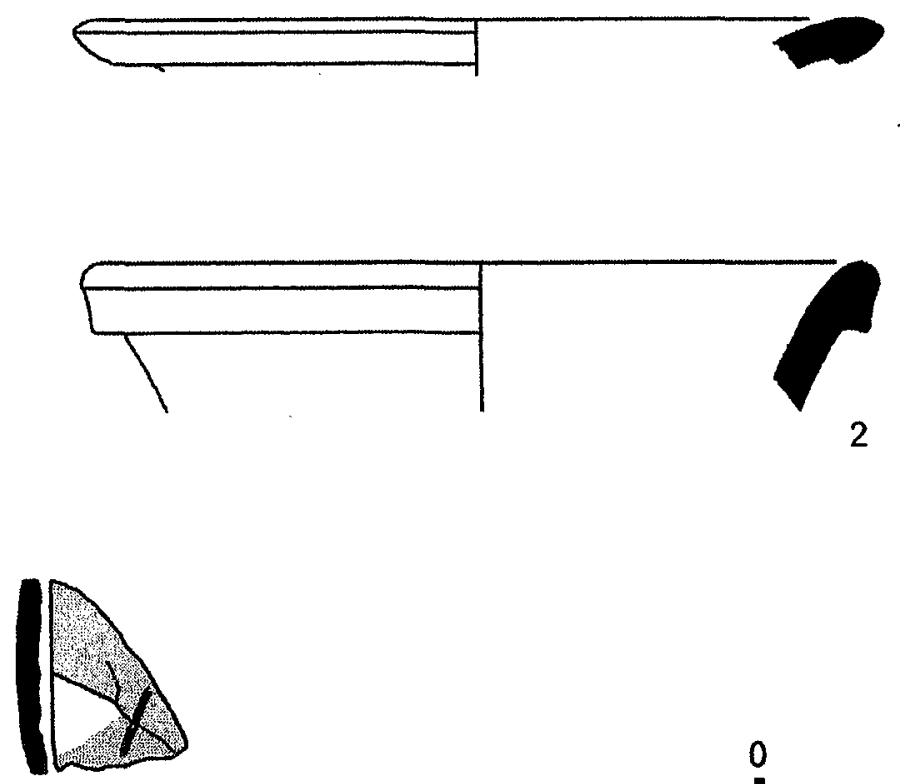

3
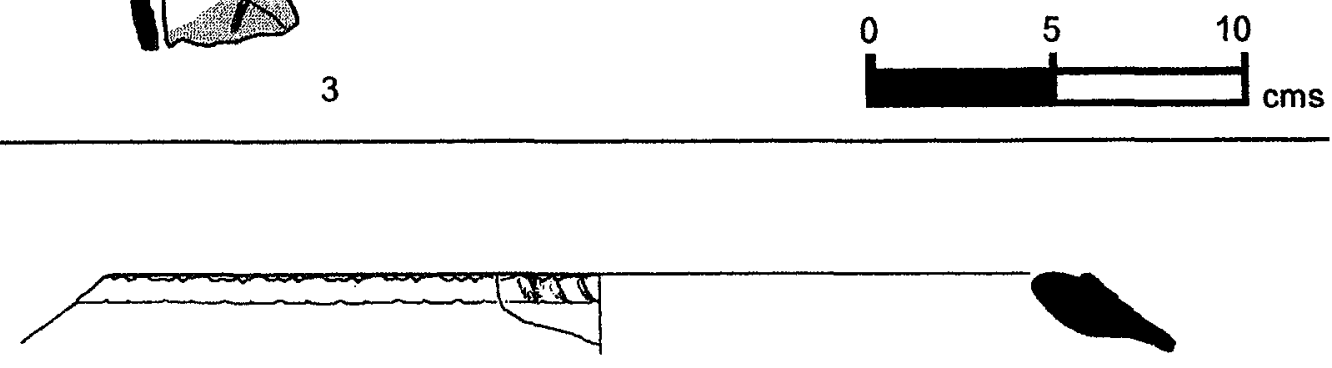

4

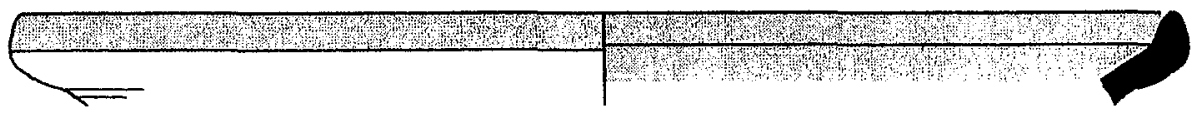

5

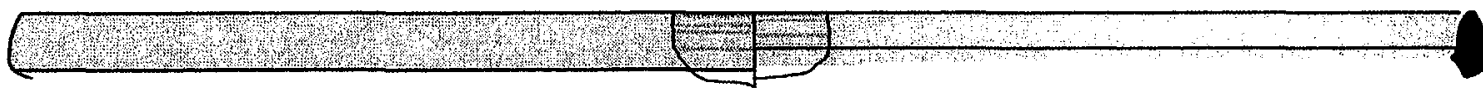

PLATE 40 (CONT).

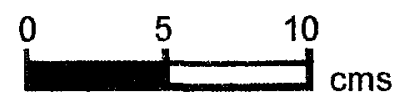


312

\begin{tabular}{llllllll}
\hline No & Reg & Square & Locus & Vessel & Part & $\begin{array}{l}\text { Body } \\
\text { Thick }\end{array}$ & Dia \\
& & & & & & & \\
1 & 0060 & SE 1-27 & 50 & BOWL & R50 & 8 & 15 \\
2 & 0042 & SE 1-27 & 40 & PLATTER BOWL & R00 & 9 & 30 \\
3 & 0044 & SE 1-27 & 40 & UD & R04 & 12 & 18 \\
4 & 0057 & SE 1-27 & 50 & HOLE MOUTH JAR & R01 & 14 & 18 \\
5 & 0059 & SE 1-27 & 50 & HOLE MOUTH JAR & R01 & 10 & 15 \\
6 & 0046 & SE 1-27 & 40 & NECKED JAR & R42 & 12 & 20 \\
7 & 0058 & SE 1-27 & 50 & NECKED JAR & R31 & 8 & 10 \\
8 & 0045 & SE 1-27 & 40 & UD & B12 & 11 & 16 \\
9 & 0043 & SE 1-27 & 40 & UD & H20 & 8 & N \\
10 & 0061 & SE 1-27 & 50 & UD & H27 & 6 & N \\
11 & 0062 & SE 1-27 & 50 & UD & H27 & 8 & N \\
\hline No & Fabric Color & & Core Orient Core Color & Core Thick & Fabric \\
& & & & & & & Family
\end{tabular}

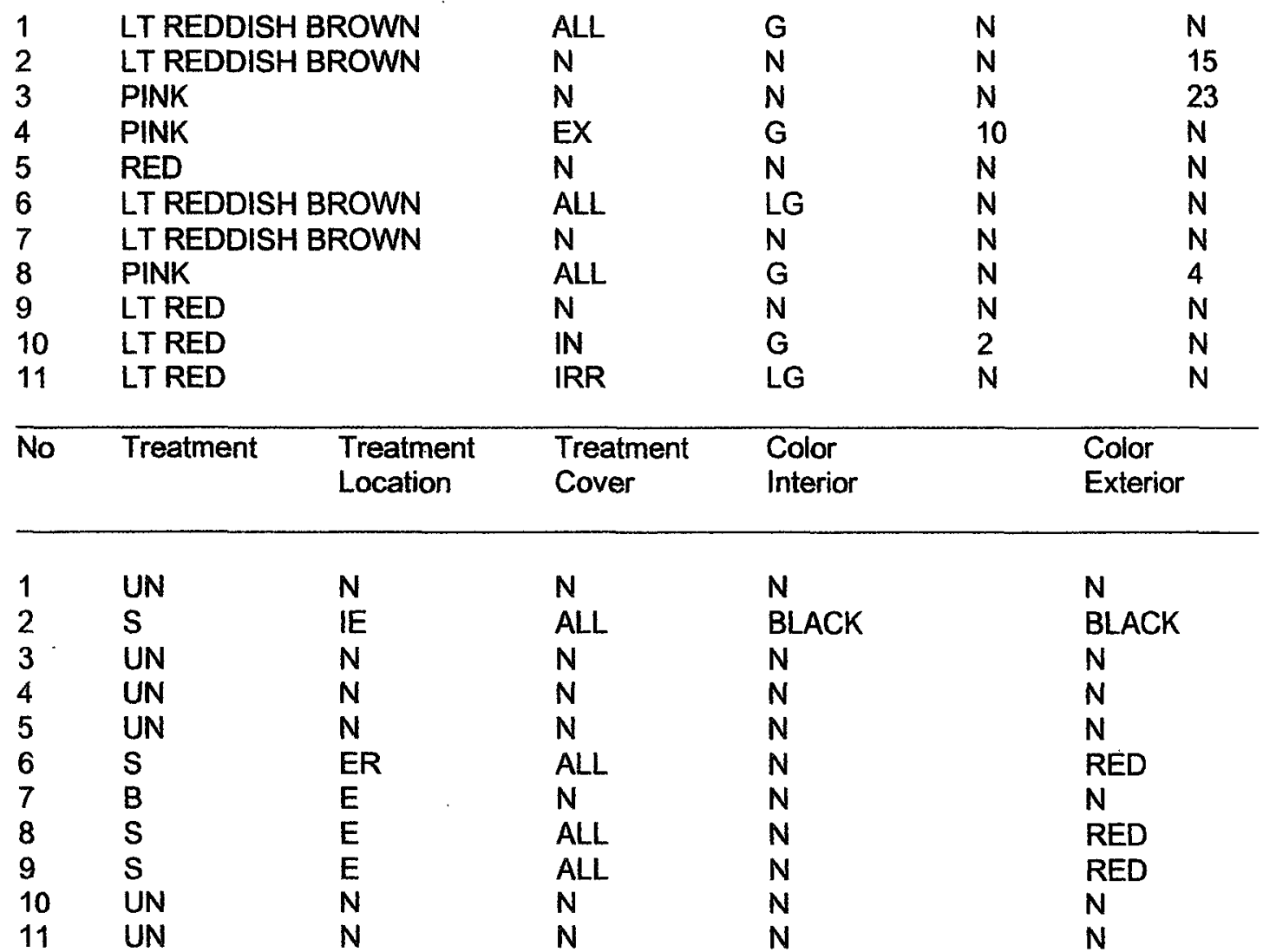

PLATE 41. FIELD A. PHASE 3A (EB III). 
313

Other

1 Fine lines on rim show finishing motion.

9 Vertical incisions on handle; Metallic Ware.

11 Metallic Ware.

PLATE 41 (CONT.).

Reproduced with permission of the copyright owner. Further reproduction prohibited without permission. 

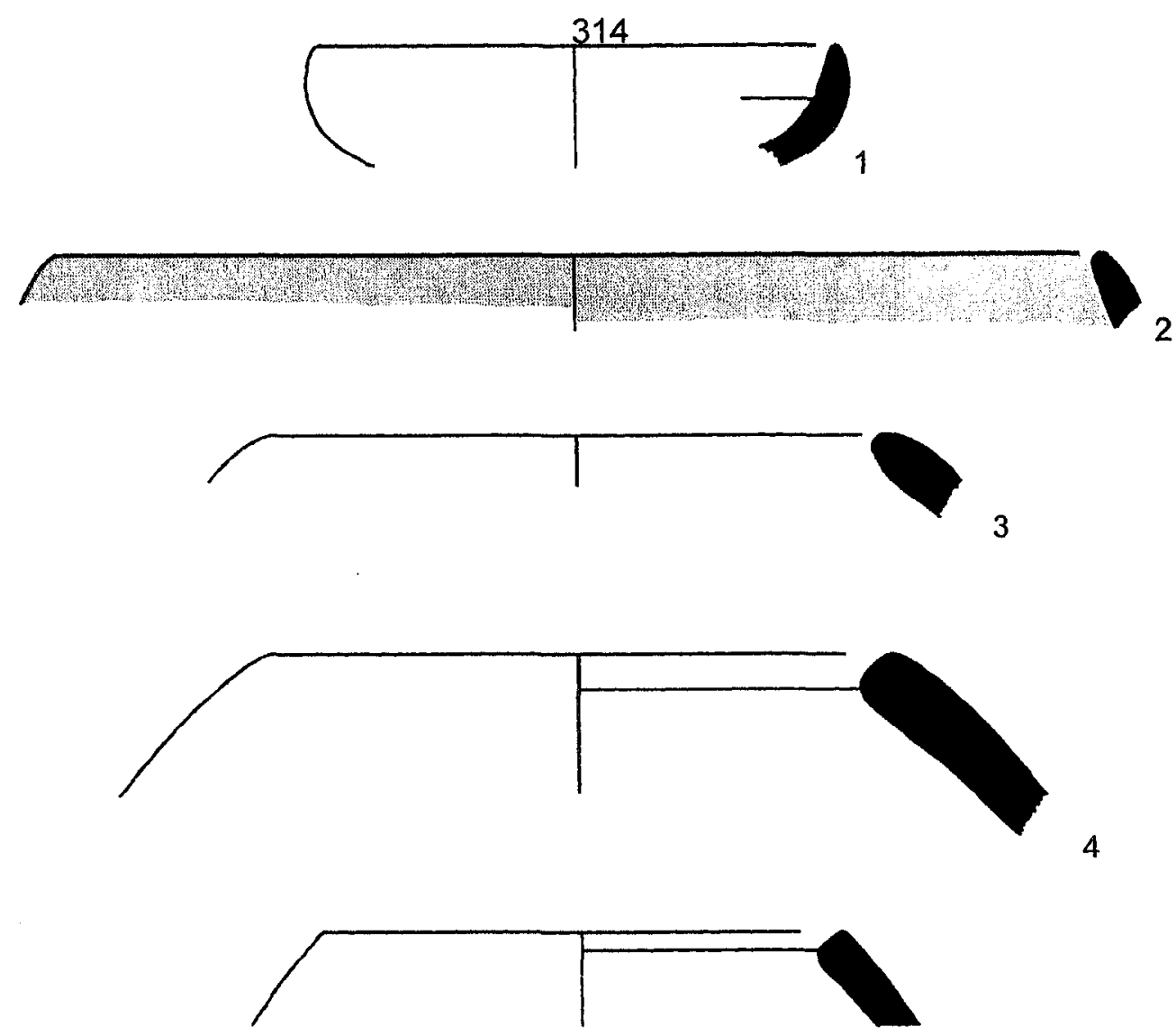

5
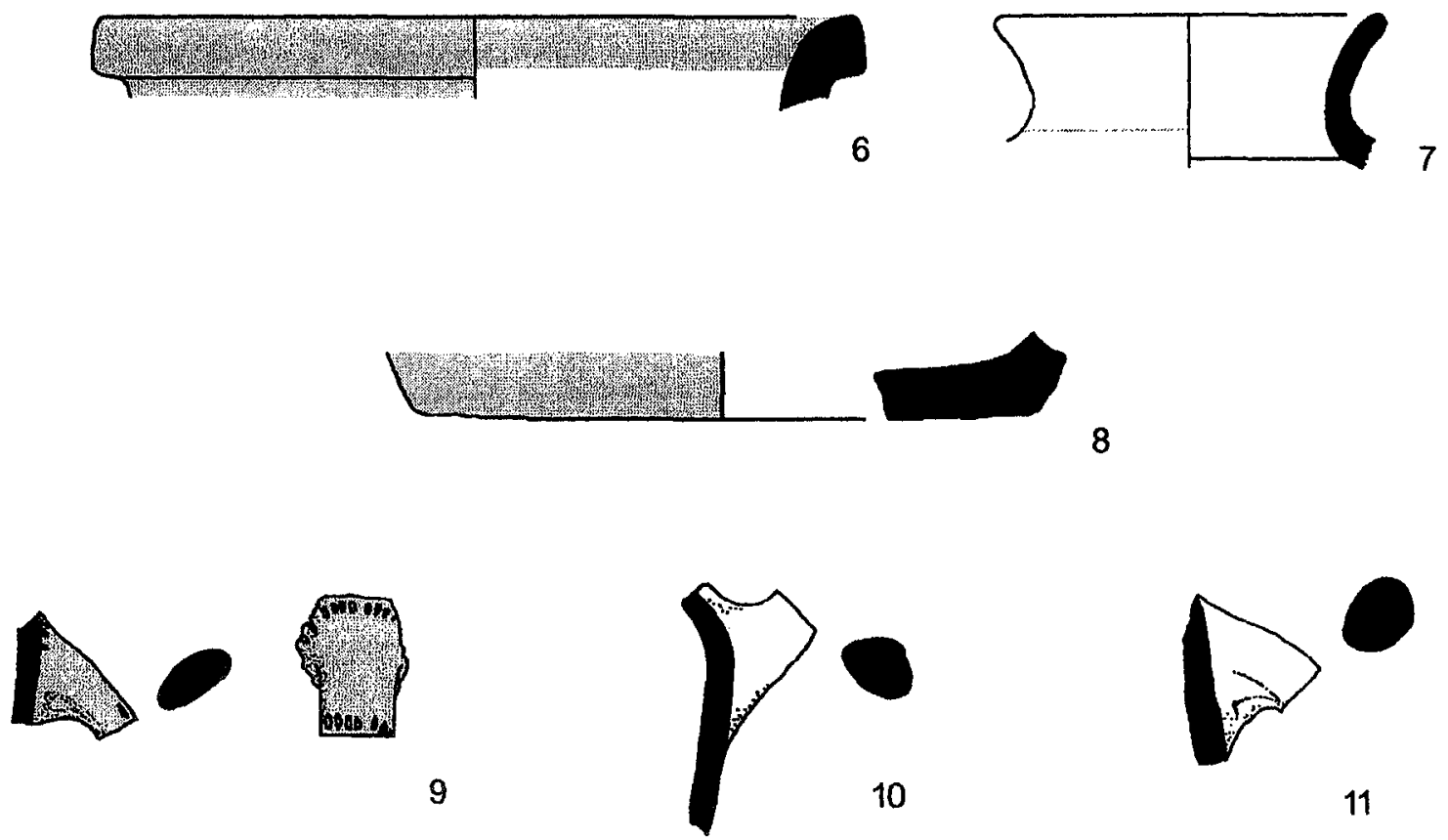

9

10

11

PLATE 41 (CONT.).

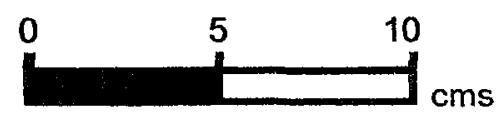




\begin{tabular}{|c|c|c|c|c|c|c|c|}
\hline$\overline{\text { No }}$ & Reg & Square & Locus & Vessel & Part & $\begin{array}{l}\text { Body } \\
\text { Thick }\end{array}$ & $\overline{\text { Dia }}$ \\
\hline 1 & 0048 & SE $1-27$ & 48 & HOLE MOUTH JAR & R04 & 10 & 12 \\
\hline 2 & 0050 & SE $1-27$ & 48 & HOLE MOUTH JAR & R14 & 9 & 15 \\
\hline 3 & 0051 & SE 1-27 & 48 & HOLE MOUTH BOWL & R14 & 12 & 20 \\
\hline 4 & 0049 & SE $1-27$ & 48 & NECKED JAR & R31 & 9 & 14 \\
\hline 5 & 0052 & SE 1-27 & 48 & JUG & R82 & 6 & 6 \\
\hline 6 & 0055 & SE $1-27$ & 48 & UD & $\mathrm{H} 12$ & 9 & $\mathbf{N}$ \\
\hline 7 & 0054 & SE $1-27$ & 48 & PLATTER BOWL & R55 & 12 & 48 \\
\hline 8 & 0053 & SE 1-27 & 48 & PLATTER BOWL & R56 & 8 & 36 \\
\hline
\end{tabular}

\begin{tabular}{|c|c|c|c|c|c|c|}
\hline 1 & \multicolumn{2}{|c|}{ REDDISH BROWN } & ALL & G & $\mathrm{N}$ & $\mathbf{N}$ \\
\hline 2 & \multicolumn{2}{|l|}{ PINK } & EX & G & 7 & $\mathbf{N}$ \\
\hline 3 & \multicolumn{2}{|c|}{ LT REDDISH BROWN } & ALL & G & $\mathbf{N}$ & $\mathrm{N}$ \\
\hline 4 & \multicolumn{2}{|c|}{ PINK } & M & G & 5 & $\mathrm{~N}$ \\
\hline 5 & \multicolumn{2}{|l|}{ PALE RED } & $\mathrm{N}$ & $\mathbf{N}$ & $\mathbf{N}$ & $\mathrm{N}$ \\
\hline 6 & \multicolumn{2}{|c|}{ LT REDDISH BROWN } & $\mathrm{N}$ & $\mathrm{N}$ & $\mathrm{N}$ & $\mathrm{N}$ \\
\hline 7 & \multicolumn{2}{|l|}{ LT RED } & $\mathbf{N}$ & $\mathrm{N}$ & $\mathrm{N}$ & $\mathbf{N}$ \\
\hline 8 & \multicolumn{2}{|l|}{ PINK } & $\mathbf{N}$ & $\mathrm{N}$ & $\mathbf{N}$ & N \\
\hline No & Treatment & $\begin{array}{l}\text { Treatment } \\
\text { Location }\end{array}$ & $\begin{array}{l}\text { Treatment } \\
\text { Cover }\end{array}$ & $\begin{array}{l}\text { Color } \\
\text { Interior }\end{array}$ & $\begin{array}{l}\text { Color } \\
\text { Exterior }\end{array}$ & \\
\hline 1 & UN & $\mathbf{N}$ & $\mathbf{N}$ & $\mathbf{N}$ & $\mathbf{N}$ & \\
\hline 2 & UN & $\mathbf{N}$ & $N$ & $\mathbf{N}$ & $\mathrm{N}$ & \\
\hline 3 & UN & $\mathbf{N}$ & $N$ & $N$ & $N$ & \\
\hline 4 & $\mathbf{S}$ & IE & ALL & RED & RED & \\
\hline 5 & B & $E$ & ALL & $\mathbf{N}$ & $\mathbf{N}$ & \\
\hline 6 & $\mathbf{S}$ & $E$ & ALL & $\mathrm{N}$ & RED & \\
\hline 7 & B & IR & $\mathrm{ALL}$ & $\mathbf{N}$ & $\mathbf{N}$ & \\
\hline 8 & SB & $I E$ & ALL & RED & $\mathbf{N}$ & \\
\hline
\end{tabular}

\footnotetext{
1 Surface burn visible.

2 Surface burn visible; lines on interior/exterior show rim smoothing.

$3 \quad$ Surface burn visible.

7 Exterior face has good examples of marks suggested of dry scraping; marks on marginal band suggests wet-smoothing; rim is wheel burnished while interior face is radially burnished; Metallic Ware.

8 Radial burnish over slip on interior face; slight concavity.
}

PLATE 42. FIELD A. PHASE 3A (EB III). 

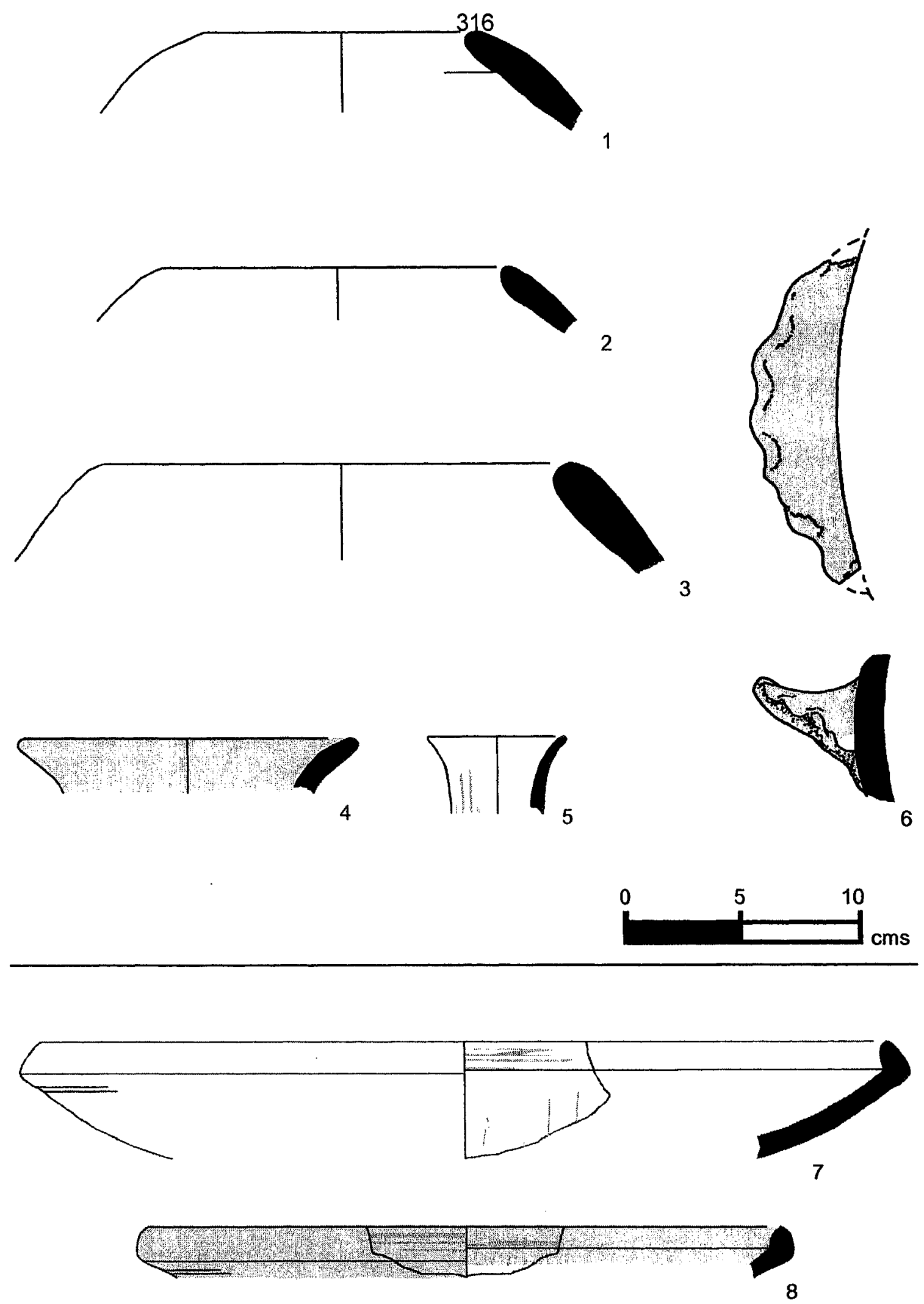

PLATE 42 (CONT.).

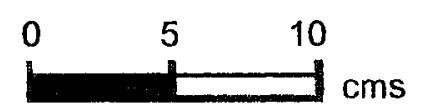


317

\begin{tabular}{llllllll}
\hline No & Reg & Square & Locus & Vessel & Part & $\begin{array}{l}\text { Body } \\
\text { Thick }\end{array}$ & Dia \\
\hline 1 & & & & & & & \\
2 & 0174 & SE 1-28 & 34 & LEDGE RIM BOWL & R51 & 9 & 30 \\
3 & 0178 & SE 1-28 & 34 & BOWL & R50 & 8 & 22 \\
4 & 0182 & SE 1-28 & 34 & HOLE MOUTH JAR & R02 & 12 & 15 \\
5 & 0175 & SE 1-28 & 34 & HOLE MOUTH BOWL & R04 & 11 & 14 \\
6 & 0176 & SE 1-28 & 34 & HOLE MOUTH JARIBOWL & R01 & 12 & N \\
& 0179 & SE 1-28 & 34 & PLATTER BOWL & R56 & 7 & 50
\end{tabular}

\begin{tabular}{lllll}
\hline No Fabric Color Core Orient Core Color Core Thick & $\begin{array}{l}\text { Fabric } \\
\text { Family }\end{array}$ \\
& & & \\
& &
\end{tabular}

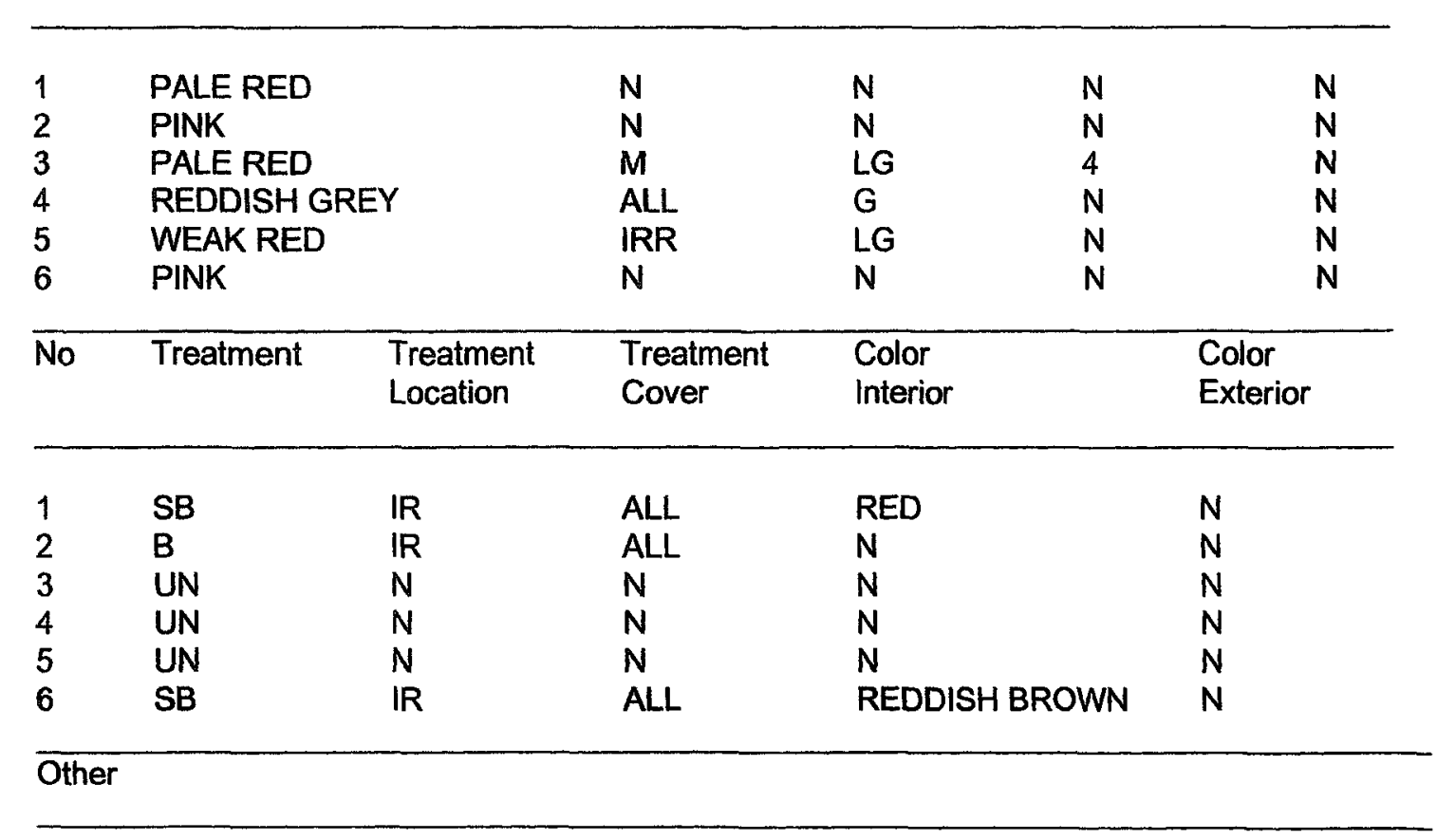

1 Burnish appears as radial scribbles on interior face; rim is well burnished; upper exterior face is wet-smoothed, while two deep scrape marks appear on lower exterior face; Metallic Ware.

2 Horizontal burnish on interior face; exterior is wet-smoothed.

4 Marks on rim interior show finishing motion; marks on body interior show horizontal tool scraping.

5 Sample too small to confirm stance or diameter.

PLATE 43. FIELD A. PHASE 3A (EB III). 


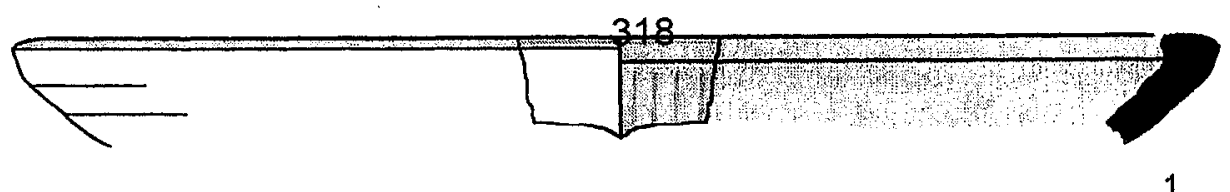

1
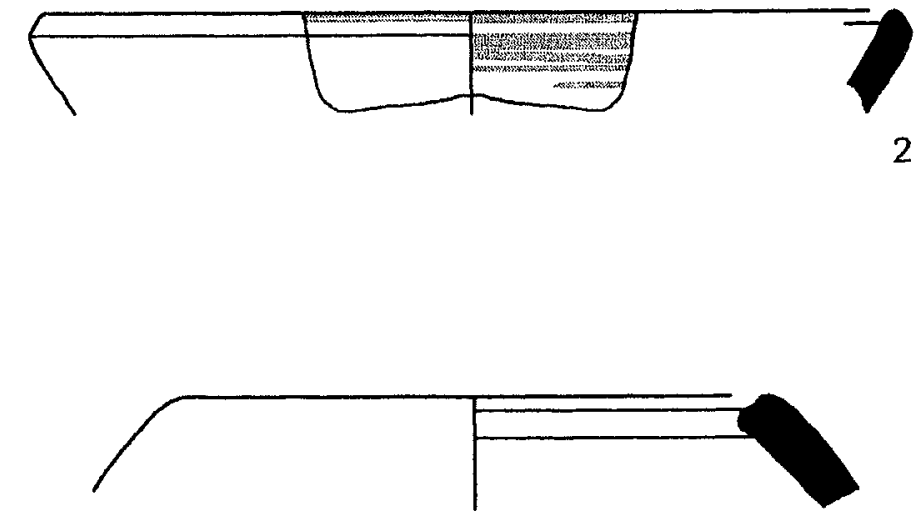

3
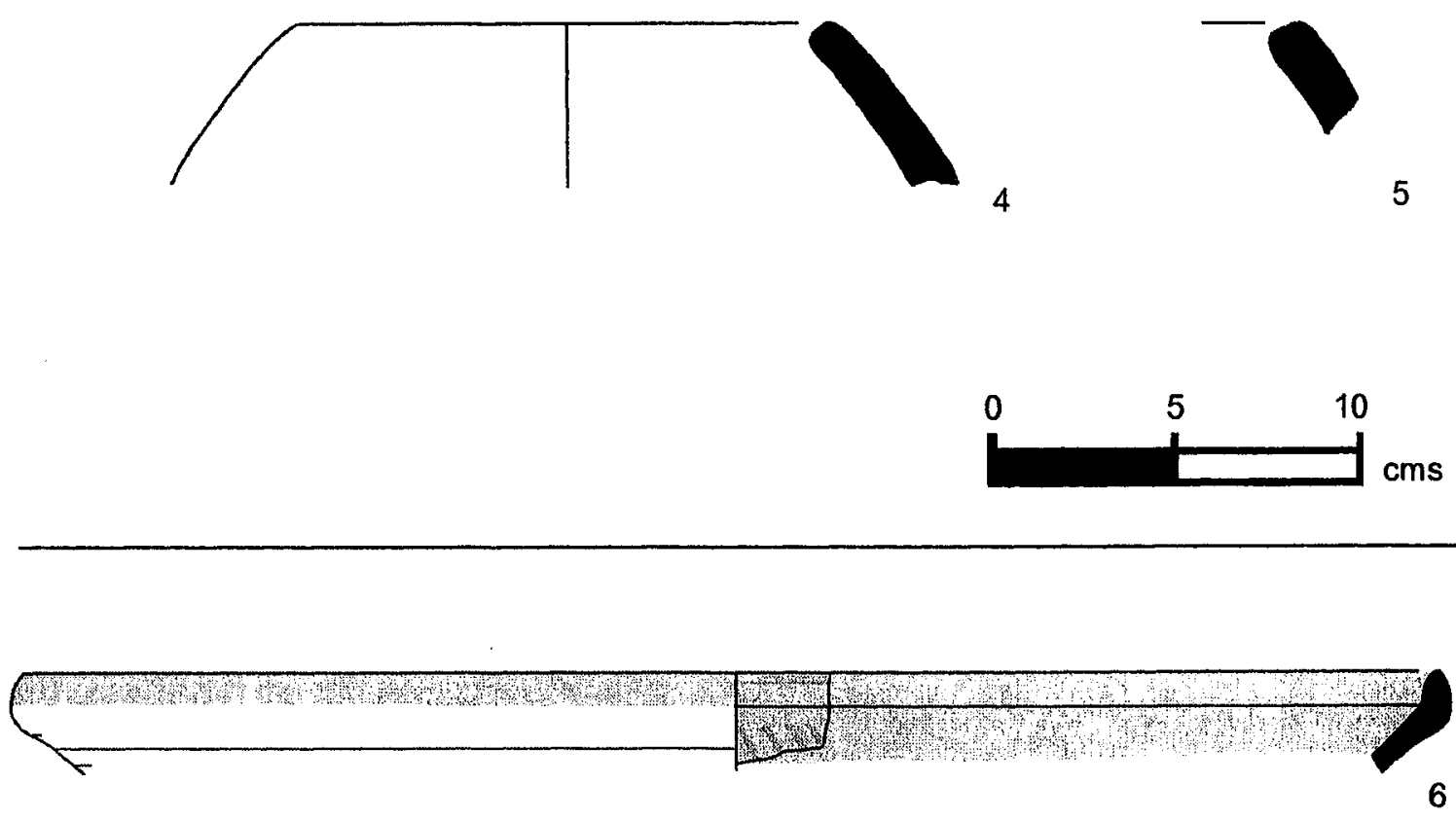

PLATE 43 (CONT.).

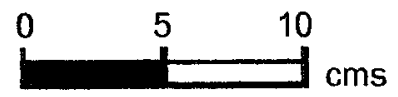


319

\begin{tabular}{llllllll}
\hline No & Reg & Square & Locus & Vessel & Part & $\begin{array}{l}\text { Body } \\
\text { Thick }\end{array}$ & Dia \\
\hline 1 & 0194 & SE 1-28 & 44 & HOLE MOUTH BOWL & R07 & 12 & 16 \\
2 & 0185 & SE 1-28 & 35 & HOLE MOUTH JAR & R01 & 13 & 15 \\
3 & 0208 & SE 1-28 & 44 & HOLE MOUTH JAR & R11 & 15 & 15 \\
4 & 0209 & SE 1-28 & 44 & NECKED JAR & R31 & 17 & 20 \\
5 & 0214 & SE 1-28 & 44 & NECKED JAR & R32 & 10 & 10 \\
6 & 0193 & SE 1-28 & 44 & PLATTER BOWL & R53 & 12 & 45
\end{tabular}

\begin{tabular}{llll}
\hline No Fabric Color Core Orient Core Color Core Thick Fabric & $\begin{array}{l}\text { Family } \\
\text { Fan }\end{array}$
\end{tabular}

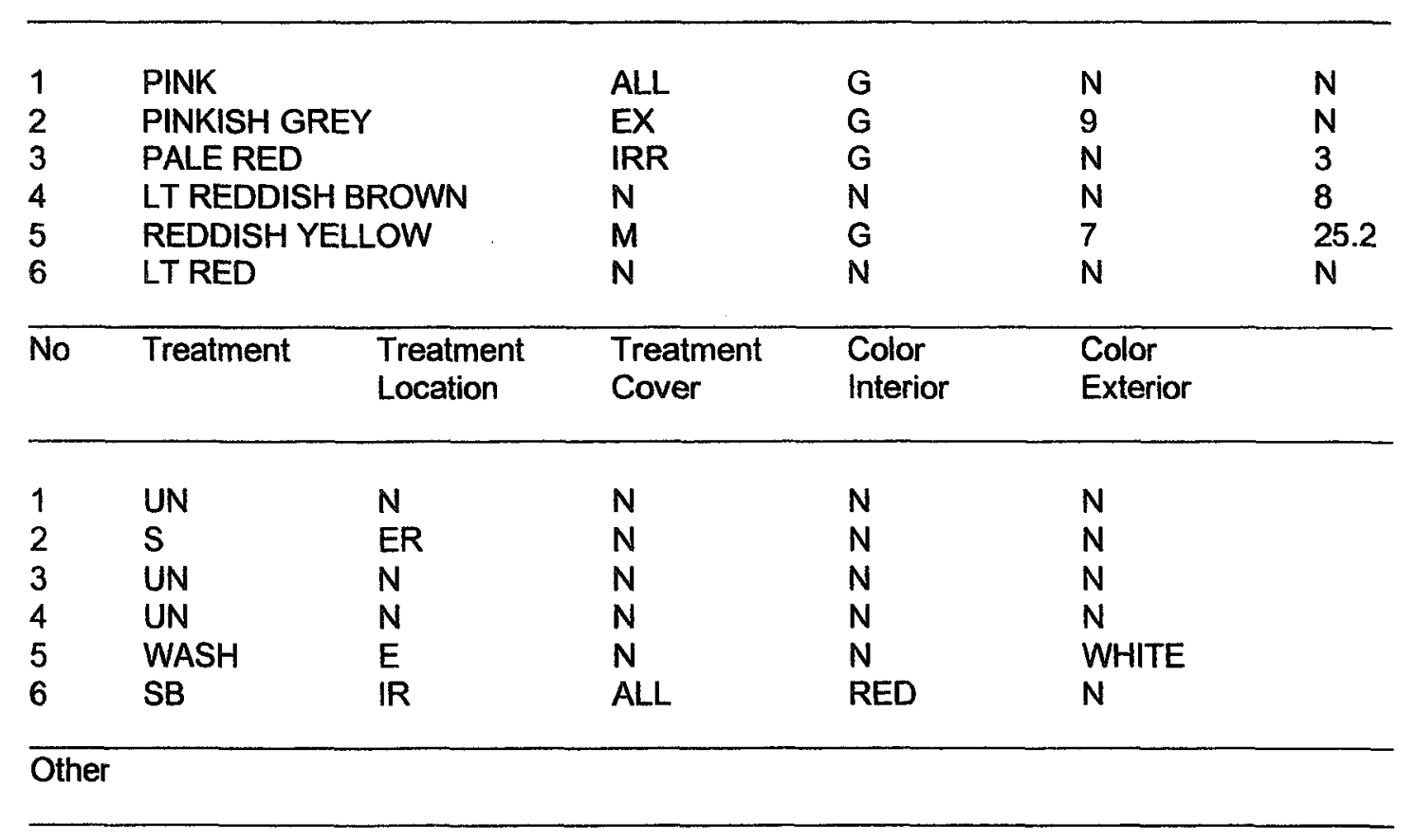

$6 \quad$ Metallic Ware

PLATE 44. FIELD A. PHASE 3A (EB III). 


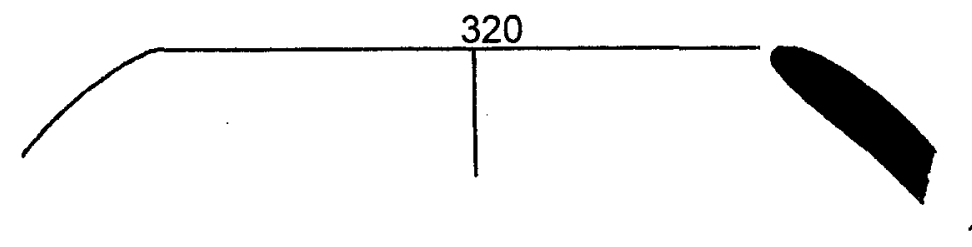

1
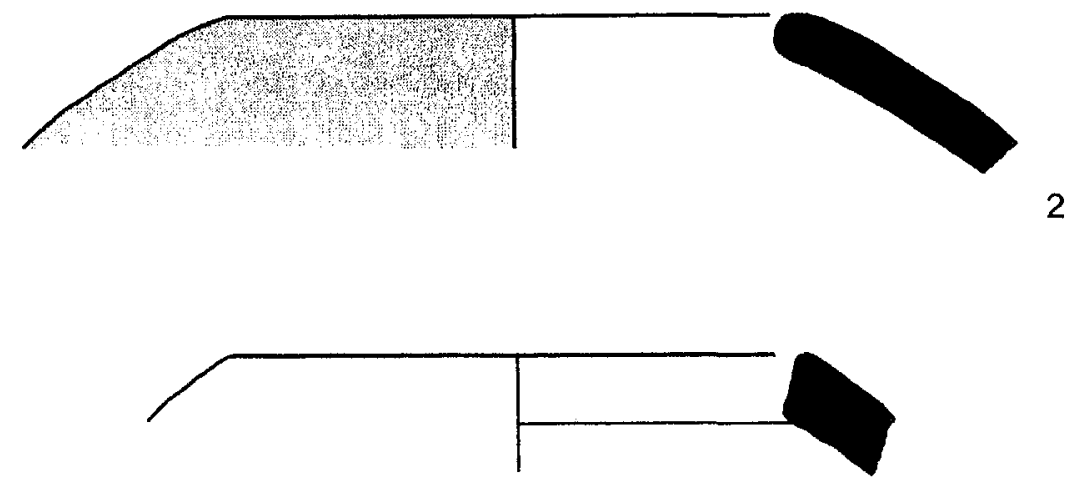

3

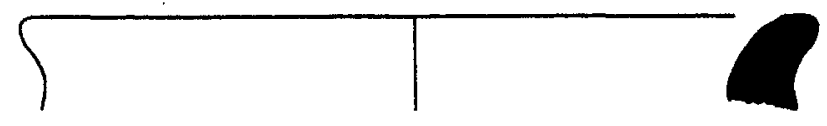

4

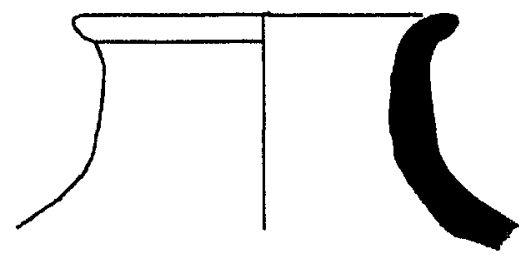

5
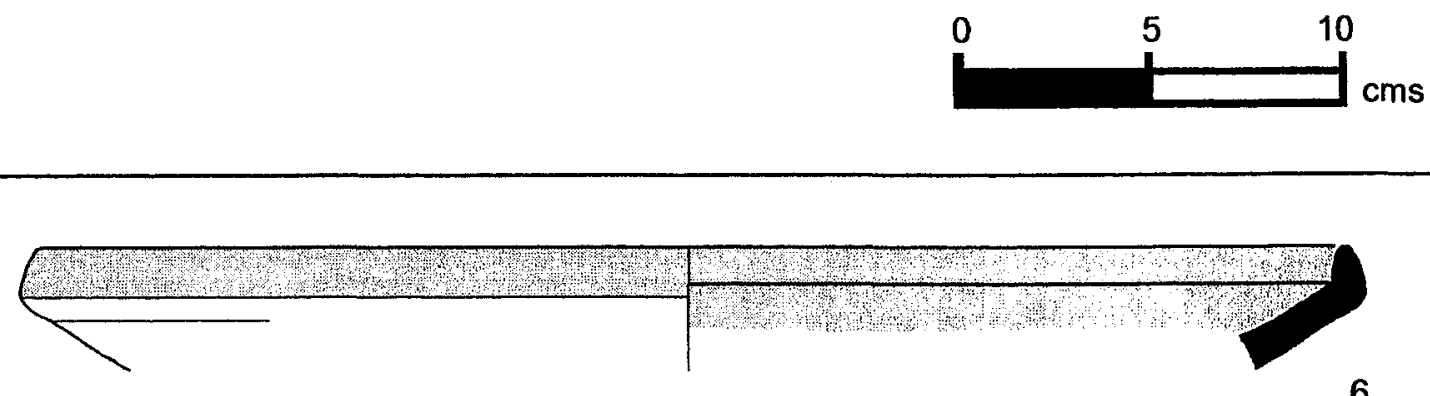

PLATE 44 (CONT.).

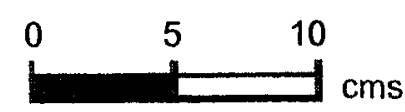




\begin{tabular}{lllllllll}
\hline No & Reg & Square & Locus & Vessel & Part & Body & $\begin{array}{c}\text { Dia } \\
\text { Thick }\end{array}$ \\
\hline & & & & & & & & \\
1 & 0520 & SW 1-27 & 40 & UD & R00 & 10 & 34 \\
2 & 0433 & SW 1-27 & 70 & NECKED JAR & R31 & 10 & 20 \\
3 & 0435 & SW 1-27 & 70 & UD & B12 & 12 & 11 \\
4 & 0486 & SW 1-27 & 27 & UD & B12 & 17 & 17 \\
5 & 0521 & SW 1-27 & 40 & UD & BOD & 7 & $\mathrm{~N}$ \\
6 & 0436 & SW 1-27 & 70 & UD & BOD & 8 & N \\
7 & 0487 & SW 1-27 & 27 & UD & BOD & 6 & N \\
8 & 0434 & SW 1-27 & 70 & UD & H10 & 10 & N \\
9 & 0437 & SW 1-27 & 70 & UD & BOD & 13 & N \\
10 & 0432 & SW 1-27 & 70 & HOLE MOUTH JAR & R02 & 11 & 40 \\
\hline No & Fabric Color & & Core Orient Core Color & Core Thick & Fabric \\
& & & & & & & Family
\end{tabular}

\begin{tabular}{|c|c|c|c|c|c|c|}
\hline 1 & \multicolumn{2}{|l|}{ LT BROWN } & $N$ & $\mathrm{~N}$ & $\mathrm{~N}$ & $\mathbf{N}$ \\
\hline 2 & \multicolumn{2}{|l|}{ PINK } & $M$ & LG & 4 & 17.2 \\
\hline 3 & \multicolumn{2}{|l|}{ PINK } & $\mathbf{M}$ & $\mathbf{G}$ & 6 & 21 \\
\hline 4 & \multicolumn{2}{|l|}{ PINK } & IN & LG & 14 & $N$ \\
\hline 5 & \multicolumn{2}{|l|}{ PALE RED } & $\mathbf{N}$ & $\mathbf{N}$ & $\mathbf{N}$ & $\mathbf{N}$ \\
\hline 6 & \multicolumn{2}{|c|}{ LT REDDISH BROWN } & $N$ & $\mathrm{~N}$ & $N$ & 8 \\
\hline 7 & \multicolumn{2}{|l|}{ RED } & $\mathbb{I N}$ & LG & 3 & 8 \\
\hline 8 & \multicolumn{2}{|l|}{ PALE RED } & IN & G & 4 & 2.2 \\
\hline 9 & \multicolumn{2}{|l|}{ PINK } & IN & G & 9 & 18 \\
\hline 10 & \multicolumn{2}{|l|}{ LT RED } & $M$ & LG & 4 & 15 \\
\hline$\overline{\text { No }}$ & Treatment & $\begin{array}{l}\text { Treatment } \\
\text { Location }\end{array}$ & $\begin{array}{l}\text { Treatment } \\
\text { Cover }\end{array}$ & $\begin{array}{l}\text { Color } \\
\text { Interior }\end{array}$ & $\begin{array}{l}\text { Color } \\
\text { Exterior }\end{array}$ & \\
\hline 1 & UN & $N$ & $N$ & $N$ & $\mathbf{N}$ & \\
\hline 2 & $S$ & ER & ALL & $\mathbf{N}$ & DUSKY RED & \\
\hline 3 & UN & $\mathbf{N}$ & $\mathrm{N}$ & $\mathbf{N}$ & $N$ & \\
\hline 4 & SB & $\mathrm{E}$ & ALL & $\mathbf{N}$ & RED & \\
\hline 5 & 1 & $E$ & ALL & $\mathbf{N}$ & $\mathbf{N}$ & \\
\hline 6 & B & $E$ & ALL & $\mathbf{N}$ & RED & \\
\hline 7 & $i$ & $E$ & ALL & $N$ & $\mathbf{N}$ & \\
\hline 8 & $\mathrm{~s}$ & $E$ & ALL & $\mathbf{N}$ & RED & \\
\hline 9 & 1 & $E$ & ALL & $\mathbf{N}$ & LT RED & \\
\hline 10 & SB & ER & $\mathrm{ALL}$ & $\mathbf{N}$ & RED & \\
\hline
\end{tabular}

PLATE 45. FIELD A. PHASE 3A (EB III). 
Other

$1 \quad$ Grey Burnished Ware?

5 Combed Metallic Ware.

7 Combed Metallic Ware.

9 Combed Metallic Ware.

PLATE 45 (CONT.). 

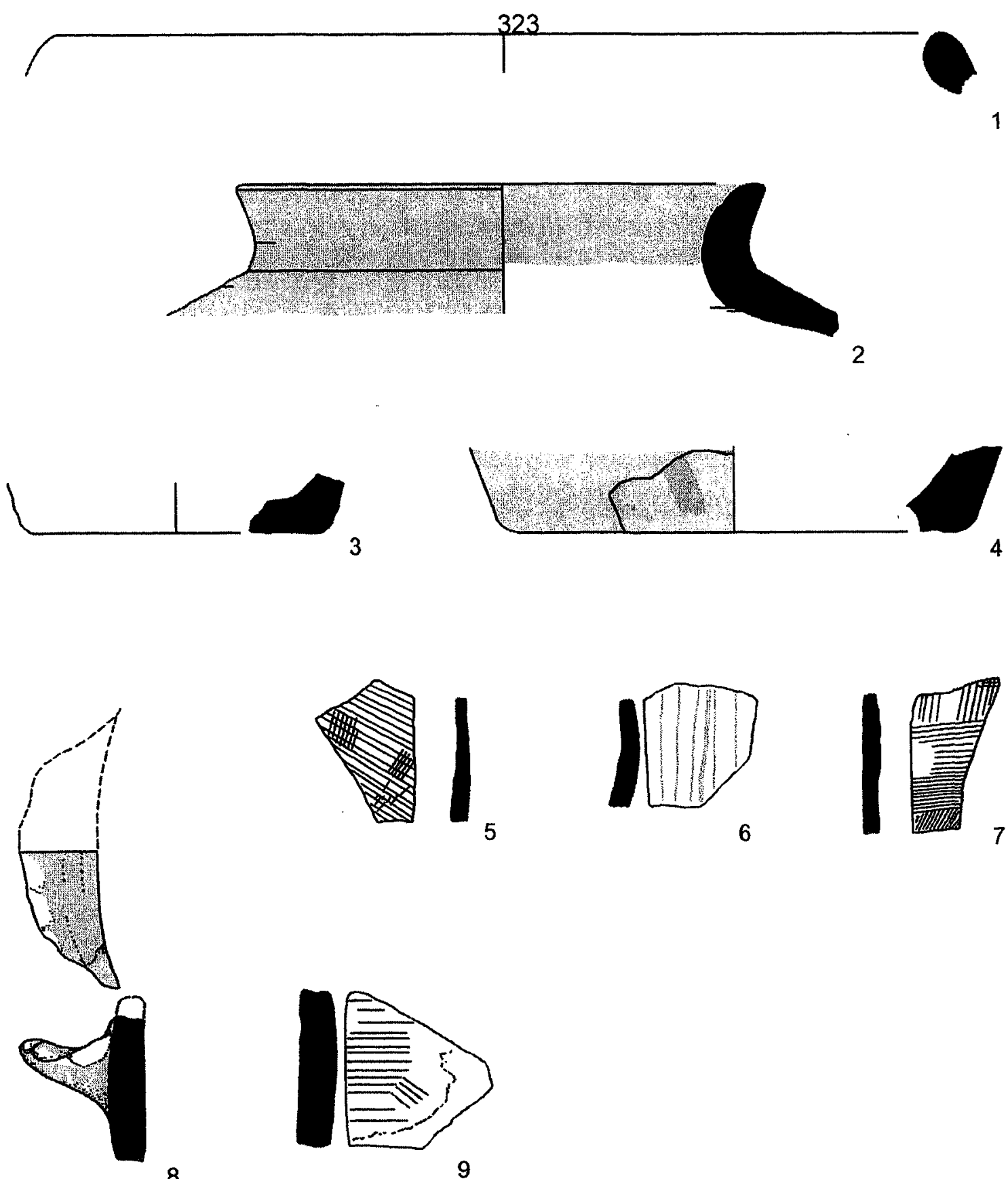

8

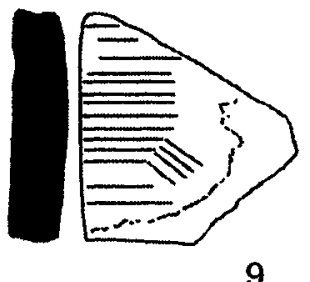

9

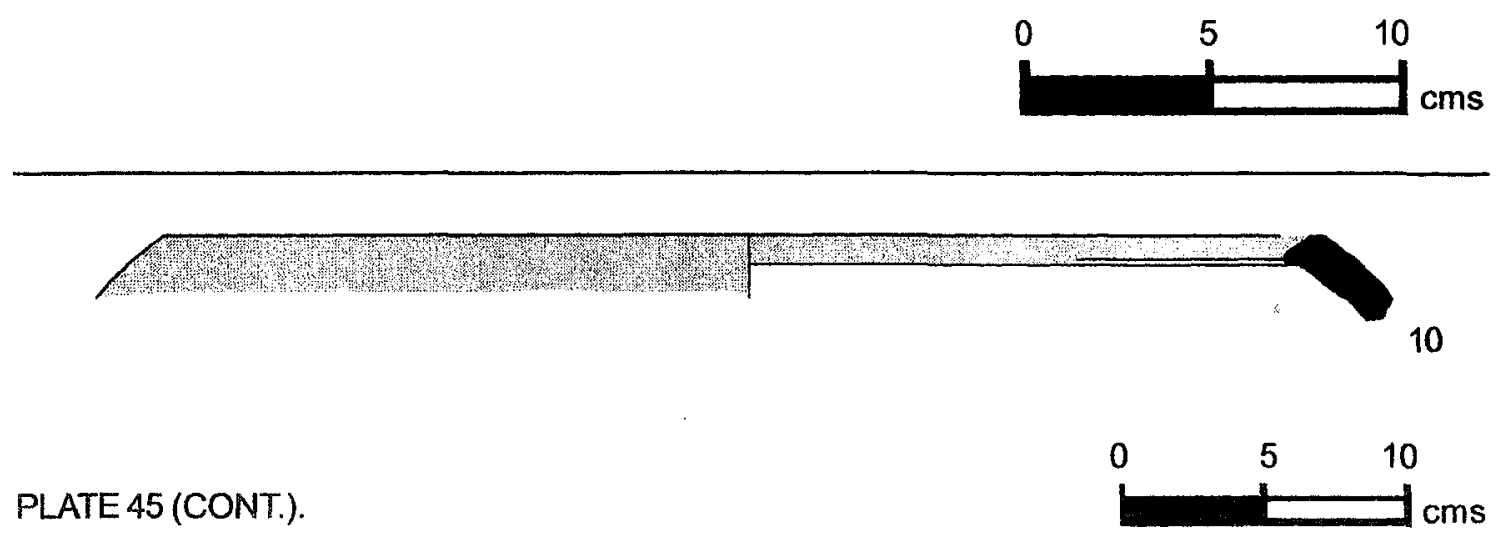




\begin{tabular}{lllllll}
\hline No & Reg Square & Locus & Vessel & Part & Body & Dia \\
& & & Thick
\end{tabular}

\begin{tabular}{llllllll}
\hline 1 & 0523 & SW 1-27 & 90 & BOWL & R50 & 7 & 20 \\
2 & 0525 & SW 1-27 & 90 & BOWL & R50 & 6 & 20 \\
3 & 0532 & SW 1-27 & 90 & PLATTER BOWL & R56 & 7 & 30 \\
4 & 0535 & SW 1-27 & 90 & HOLE MOUTH JAR & R02 & 14 & 20 \\
5 & 0526 & SW 1-27 & 90 & HOLE MOUTH JAR & R11 & 23 & 20 \\
6 & 0540 & SW 1-27 & 90 & HOLE MOUTH JAR & R11 & 11 & 15 \\
7 & 0539 & SW 1-27 & 90 & HOLE MOUTH JAR & R12 & 8 & 14 \\
8 & 0538 & SW 1-27 & 90 & HOLE MOUTH JAR & R22 & 8 & 14 \\
9 & 0527 & SW 1-27 & 90 & HOLE MOUTH BOWL & R19 & 8 & 20 \\
10 & 0541 & SW 1-27 & 90 & HOLE MOUTH JAR & R01 & 10 & 14 \\
11 & 0522 & SW 1-27 & 90 & HOLE MOUTH JAR & R17 & 11 & 12 \\
12 & 0534 & SW 1-27 & 90 & HOLE MOUTH JAR & R18 & 7 & 13 \\
\hline No & Fabric Color & & Core Orient Core Color & Core Thick & Fabric \\
& & & & & & Family
\end{tabular}

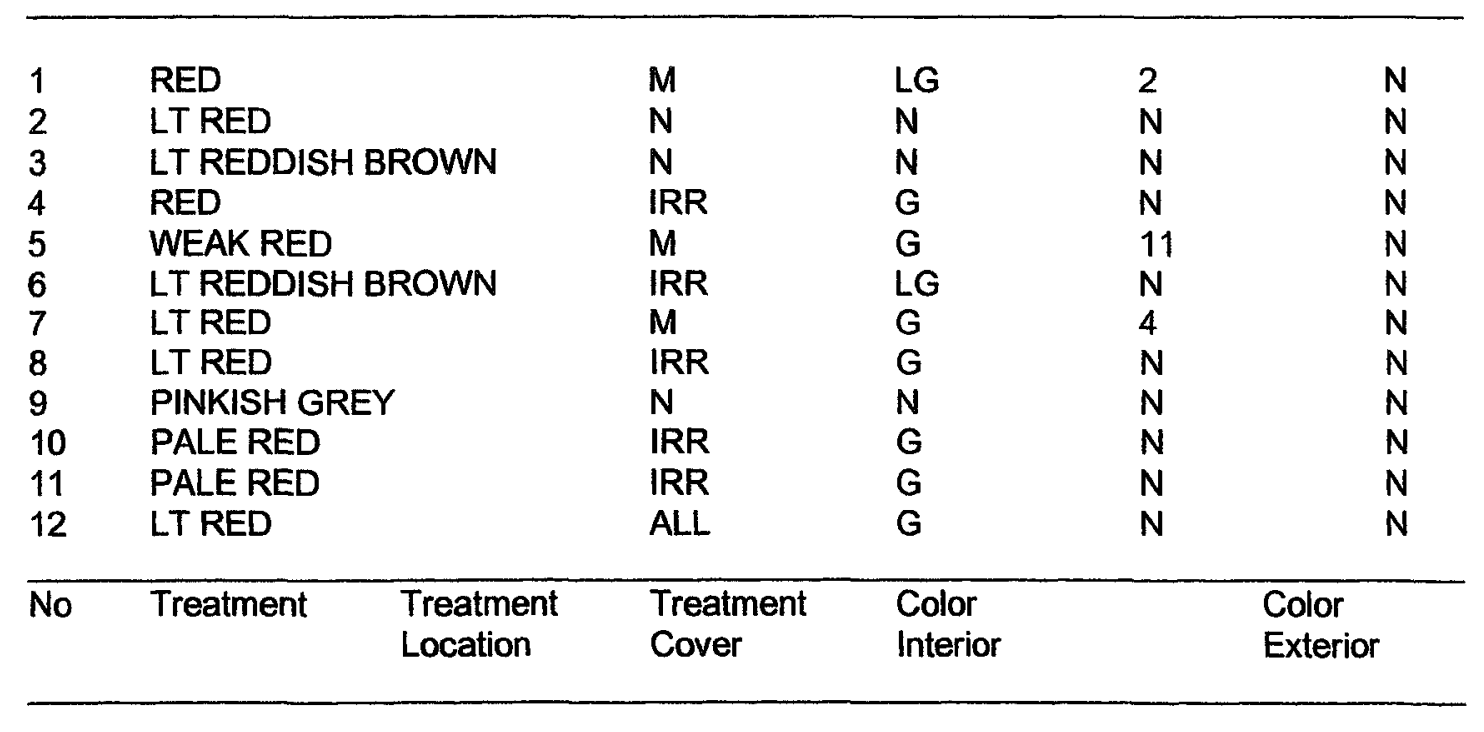

$\begin{array}{llllll}1 & \text { B } & \text { IE } & \text { ALL } & \text { N } & \text { N } \\ 2 & \text { SB } & \text { IR } & \text { ALL } & \text { RED } & \text { N } \\ 3 & \text { B } & \text { IE } & \text { ALL } & \text { N } & \text { N } \\ 4 & \text { WASH } & \text { I } & \text { ALL } & \text { PINKISH WHITE } & \text { N } \\ 5 & \text { UN } & \text { N } & \text { N } & \text { N } & \text { N } \\ 6 & \text { UN } & \text { N } & \text { N } & \text { N } & \text { N } \\ 7 & \text { UN } & \text { N } & \text { N } & \text { N } & \text { GREY } \\ 8 & \text { WASH } & \text { E } & \text { N } & \text { N } & \text { RED } \\ 9 & \text { S } & \text { ER } & \text { ALL } & \text { N } & \text { N } \\ 10 & \text { UN } & \text { N } & \text { N } & \text { N } & \text { N } \\ 11 & \text { UN } & \text { N } & \text { N } & \text { N } & \text { N } \\ 12 & \text { UN } & \text { N } & \text { N } & \text { N } & \end{array}$

PLATE 46. FIELD A. PHASE 3A (EB III). 
Other

$1 \quad$ Burn on rim suggests use as lamp; Metallic Ware; surface burn visible.

3 Possible radial wipe on interior face; rim circumference is burnished; exterior concavity is visible and well burnished.

$7 \quad$ Marks on rim show finishing motion.

8 Rope molding pulled to the right, or counterclockwise around rim.

PLATE 46 (CONT.). 

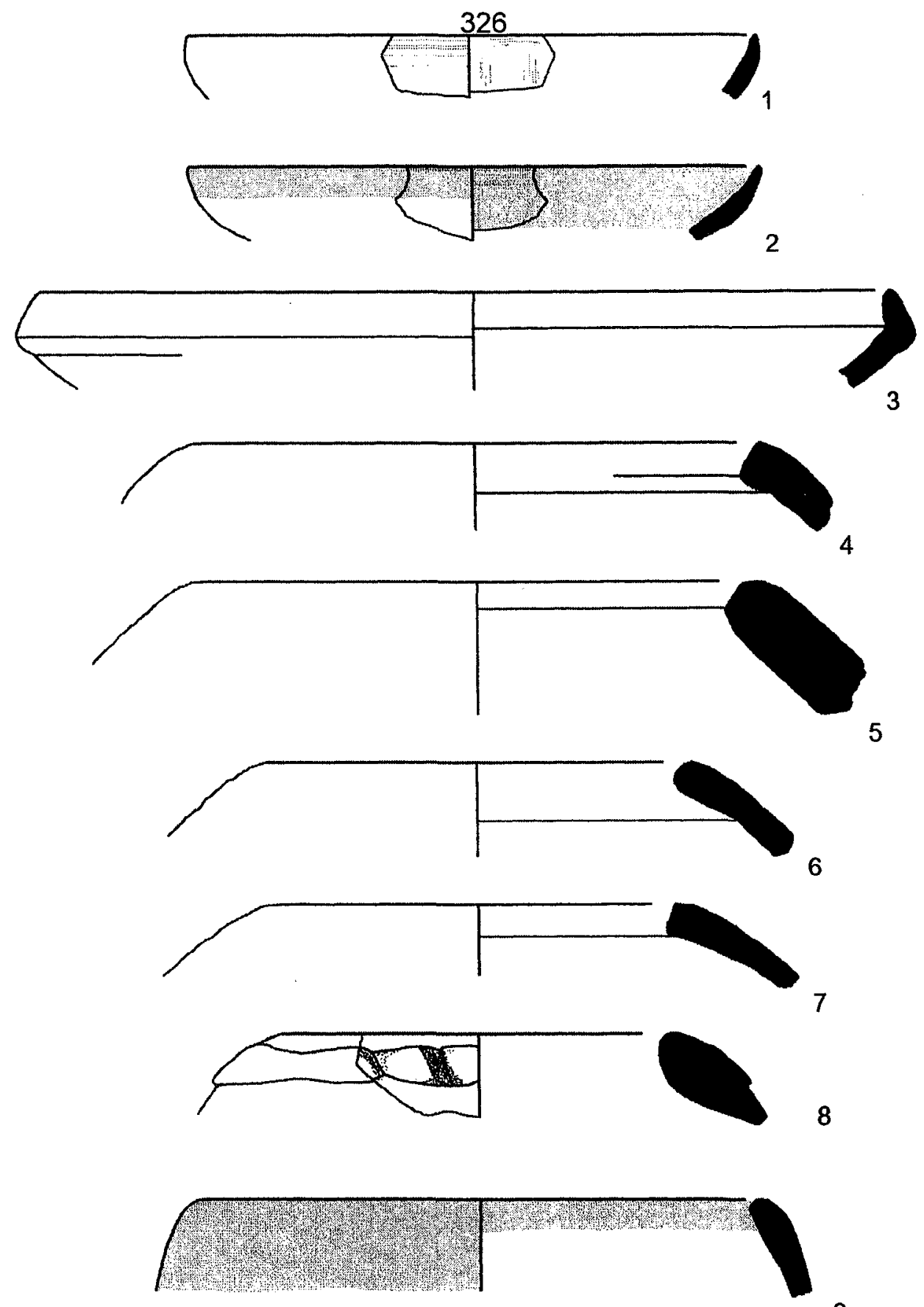

9
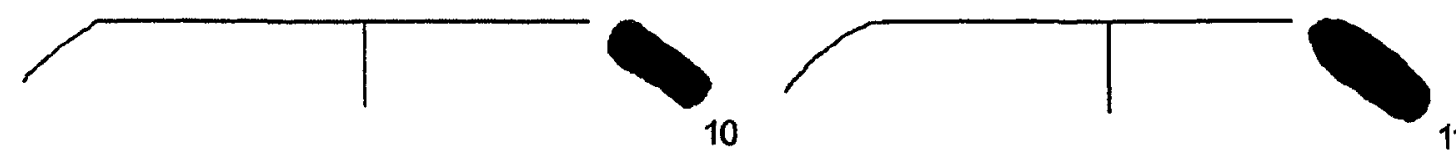

11

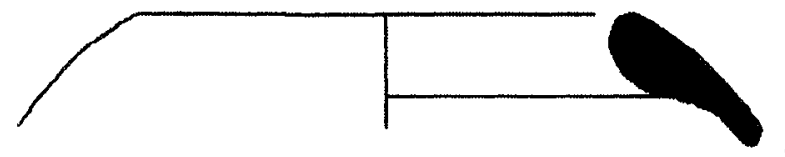

12

PLATE 46 (CONT.).

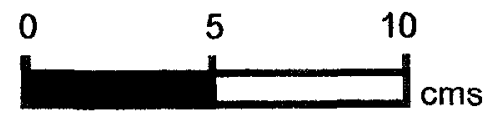


327

\begin{tabular}{llllllll}
\hline No & Reg & Square & Locus & Vessel & Part & $\begin{array}{l}\text { Body } \\
\text { Thick }\end{array}$ & Dia \\
\hline & & & & & & & \\
1 & 0524 & SW 1-27 & 90 & NECKED JAR & R42 & 10 & 20 \\
2 & 0533 & SW 1-27 & 90 & NECKED JAR & R43 & 7 & 14 \\
3 & 0545 & SW 1-27 & 90 & UD & B12 & 15 & 12 \\
4 & 0543 & SW 1-27 & 90 & UD & B11 & 8 & 15 \\
5 & 0544 & SW 1-27 & 90 & UD & B12 & 15 & 22 \\
6 & 0531 & SW 1-27 & 90 & UD & H27 & 8 & N \\
7 & 0529 & SW 1-27 & 90 & UD & H27 & N & N \\
8 & 0530 & SW 1-27 & 90 & UD & H20 & 7 & N \\
9 & 0528 & SW 1-27 & 90 & UD & H20 & N & N \\
10 & 0536 & SW 1-27 & 90 & HOLE MOUTH BOWL & R04 & 11 & 52 \\
\hline
\end{tabular}

\begin{tabular}{lllll}
\hline No Fabric Color & Core Orient & Core Color & Core Thick & Fabric \\
Family
\end{tabular}

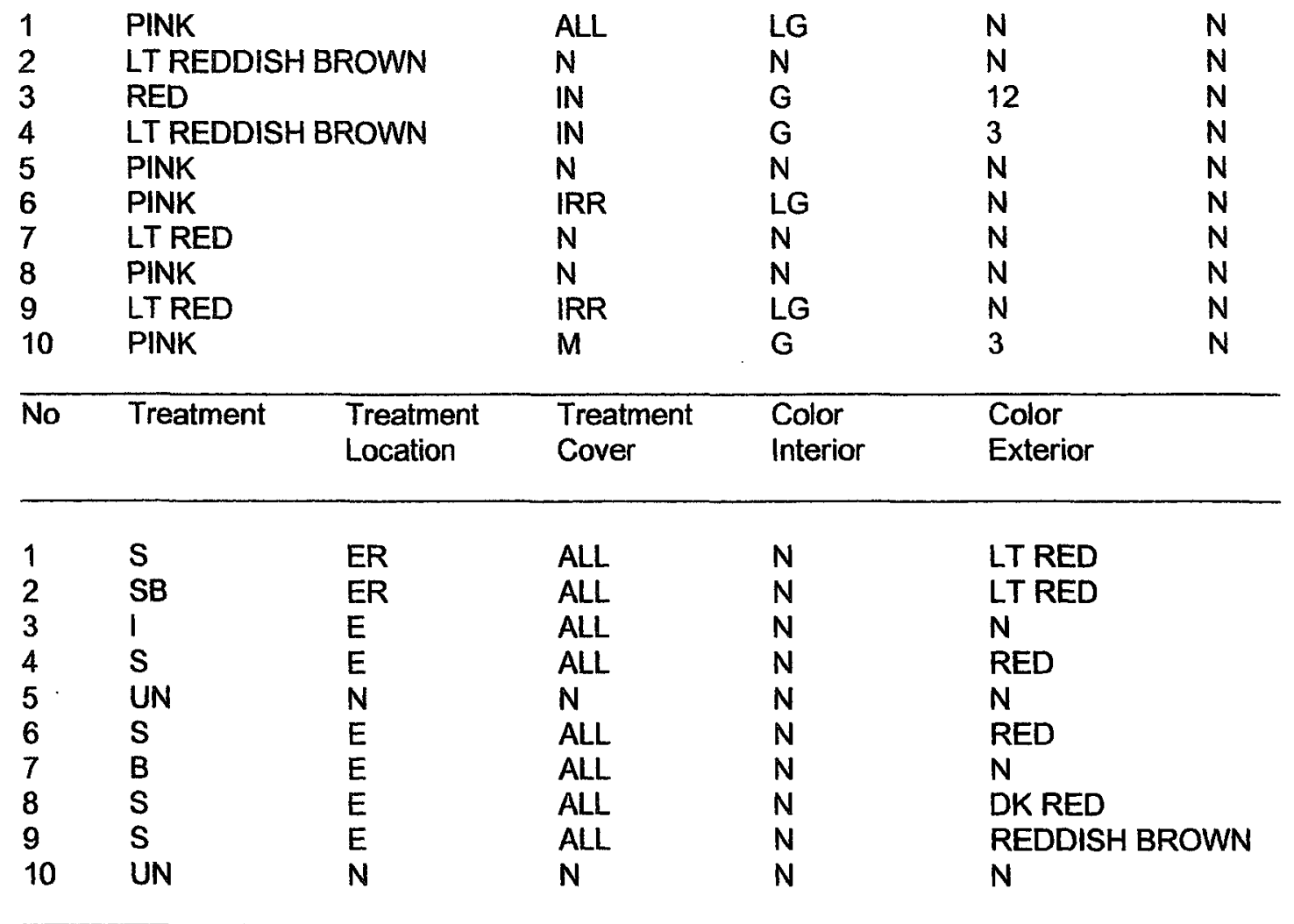

\section{Other}

1 Void in section suggest rim folding from interior to exterior.

3 Combed Metalic Ware.

$7 \quad$ Metallic Ware.

PLATE 47. FIELD A. PHASE 3A (EB III). 
328
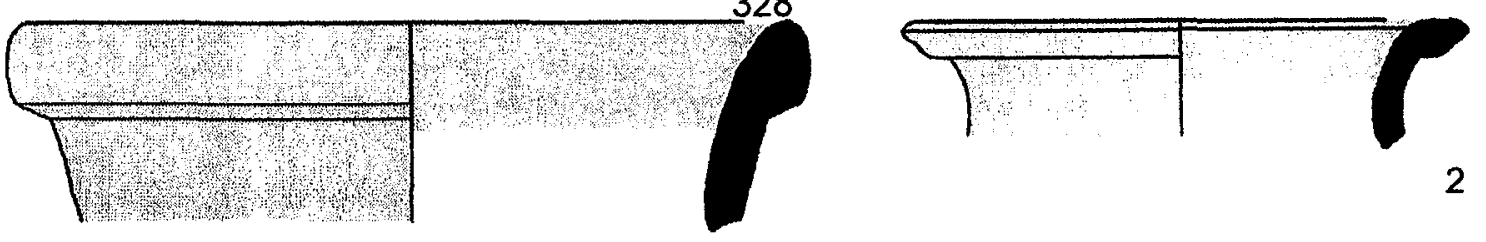

1
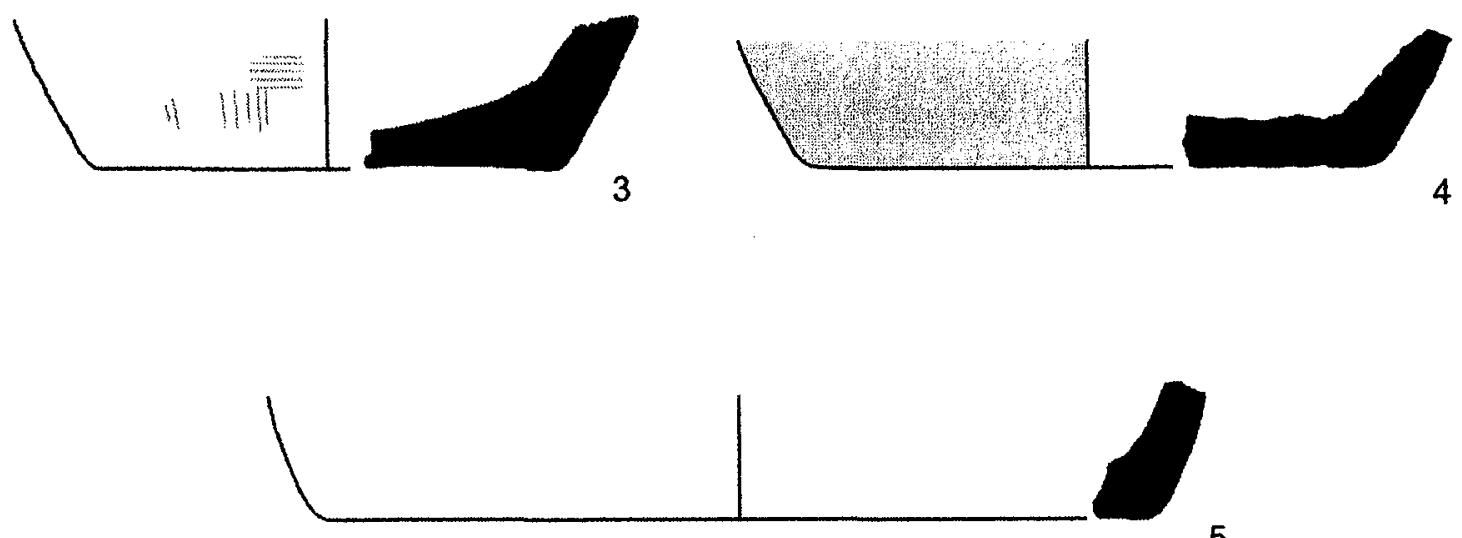

5
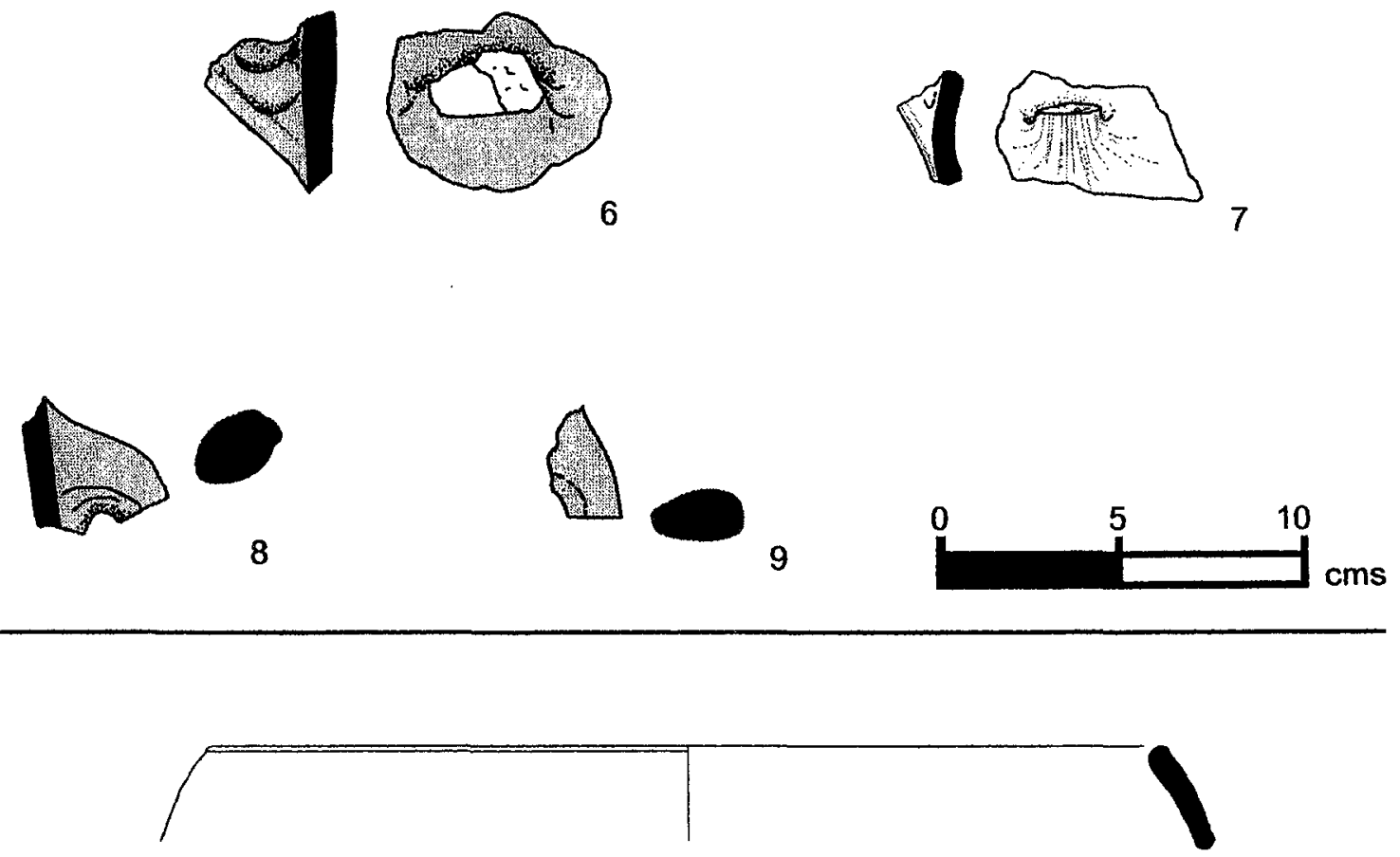

10

PLATE 47 (CONT). 


\begin{tabular}{llllllll}
\hline No & Reg & Square & Locus & Vessel & Part & $\begin{array}{l}\text { Body } \\
\text { Thick }\end{array}$ & Dia \\
\hline & & & & & & & \\
1 & 0570 & SW 1-28 & 14 & HOLE MOUTH JAR & R18 & 15 & 18 \\
2 & 2313 & SW 1-28 & 28 & HOLE MOUTH BOWL & R01 & 6 & 12 \\
3 & 2224 & SW 1-28 & 28 & VAT & R52 & 15 & N \\
4 & 0554 & SW 1-28 & 35 & HOLE MOUTH BOWL & R07 & 10 & 12 \\
5 & 0555 & SW 1-28 & 35 & UD & H14 & 8 & N \\
6 & 0571 & SW 1-28 & 14 & HOLE MOUTH BOWL & R01 & 14 & 20 \\
7 & 0617 & SW 1-28 & 28 & UD & B12 & 10 & 9 \\
8 & 2222 & SW 1-28 & 28 & UD & B12 & 10 & N \\
9 & 2223 & SW 1-28 & 28 & LEDGE RIM BOWL & R53 & 12 & 40 \\
10 & 0569 & SW 1-28 & 14 & LEDGE RIM BOWL & R52 & 9 & 46 \\
11 & 0568 & SW 1-28 & 14 & LEDGE RIM BOWL & R55 & 8 & 38 \\
\hline No & Fabric Color & & Core Orient Core Color & Core Thick & Fabric \\
& & & & & & Family \\
\end{tabular}

\begin{tabular}{|c|c|c|c|c|c|c|}
\hline 1 & \multicolumn{2}{|l|}{ LT RED } & $\mathbf{M}$ & $\mathbf{G}$ & 6 & $\mathrm{~N}$ \\
\hline 2 & \multicolumn{2}{|c|}{ LT REDDISH BROWN } & $\mathbf{E}$ & G & 3 & $\mathrm{~N}$ \\
\hline 3 & \multicolumn{2}{|c|}{ PINK } & ALL & $\mathbf{G}$ & $\mathbf{N}$ & $\mathrm{N}$ \\
\hline 4 & \multicolumn{2}{|l|}{ WEAK RED } & $M$ & $\mathrm{G}$ & 4 & 2.2 \\
\hline 5 & \multicolumn{2}{|c|}{ LT REDDISH BROWN } & IRR & $\mathbf{G}$ & $\mathbf{N}$ & 9.1 \\
\hline 6 & \multicolumn{2}{|c|}{ LT REDDISH BROWN } & IRR & LG & $\mathbf{N}$ & $\mathrm{N}$ \\
\hline 7 & \multicolumn{2}{|c|}{ LT RED } & $\mathbf{N}$ & $N$ & $N$ & 6 \\
\hline 8 & \multicolumn{2}{|c|}{ LT REDDISH BROWN } & $N$ & $\mathrm{~N}$ & $\mathrm{~N}$ & $\mathrm{~N}$ \\
\hline 9 & \multicolumn{2}{|l|}{ PINK } & $\mathbf{N}$ & $\mathbf{N}$ & $\mathbf{N}$ & $\mathrm{N}$ \\
\hline 10 & \multicolumn{2}{|c|}{ LT REDDISH BROWN } & $\mathbf{N}$ & $\mathrm{N}$ & $\mathrm{N}$ & $\mathrm{N}$ \\
\hline 11 & \multicolumn{2}{|l|}{ PINK } & $N$ & $\mathbf{N}$ & $N$ & $N$ \\
\hline No & Treatment & $\begin{array}{l}\text { Treatment } \\
\text { Location }\end{array}$ & $\begin{array}{l}\text { Treatment } \\
\text { Cover }\end{array}$ & $\begin{array}{l}\text { Color } \\
\text { Interior }\end{array}$ & $\begin{array}{l}\text { Color } \\
\text { Exterior }\end{array}$ & \\
\hline 1 & $S$ & ER & $\mathbf{N}$ & $\mathbf{N}$ & DK RED & \\
\hline 2 & UN & $\mathbf{N}$ & $\mathrm{N}$ & $\mathbf{N}$ & $\mathrm{N}$ & \\
\hline 3 & UN & $\mathbf{N}$ & $\mathbf{N}$ & $\mathbf{N}$ & $\mathbf{N}$ & \\
\hline 4 & UN & $\mathbf{N}$ & $\mathbf{N}$ & $\mathbf{N}$ & $\mathrm{N}$ & \\
\hline 5 & UN & $\mathbf{N}$ & $\mathbf{N}$ & $N$ & $N$ & \\
\hline 6 & UN & $\mathbf{N}$ & $\mathbf{N}$ & $\mathrm{N}$ & $\mathrm{N}$ & \\
\hline 7 & UN & $\mathbf{N}$ & $\mathrm{N}$ & $\mathbf{N}$ & $N$ & \\
\hline 8 & UN & $\mathbf{N}$ & $\mathrm{N}$ & $N$ & $\mathrm{~N}$ & \\
\hline 9 & SB & IR & ALL & DKRED & $N$ & \\
\hline 10 & $\mathrm{~B}$ & IR & ALL & $N$ & $N$ & \\
\hline 11 & SB & IR & ALL & RED & $\mathrm{N}$ & \\
\hline
\end{tabular}

PLATE 48. FIELD A. PHASE 3A (EB III). 


\section{Other}

3 Sample too small to confirm stance or diameter.

6 Surface burn visible; swipe marks on exterior suggest motion used to finish rim.

8 Sample too small to confirm stance or diameter.

9 Sample too small to confirm stance or diameter.

10 Fine lines of wet-smoothing appear on interior and exterior faces; a few specks suggest parallel lines in black paint.

PLATE 48 (CONT.). 

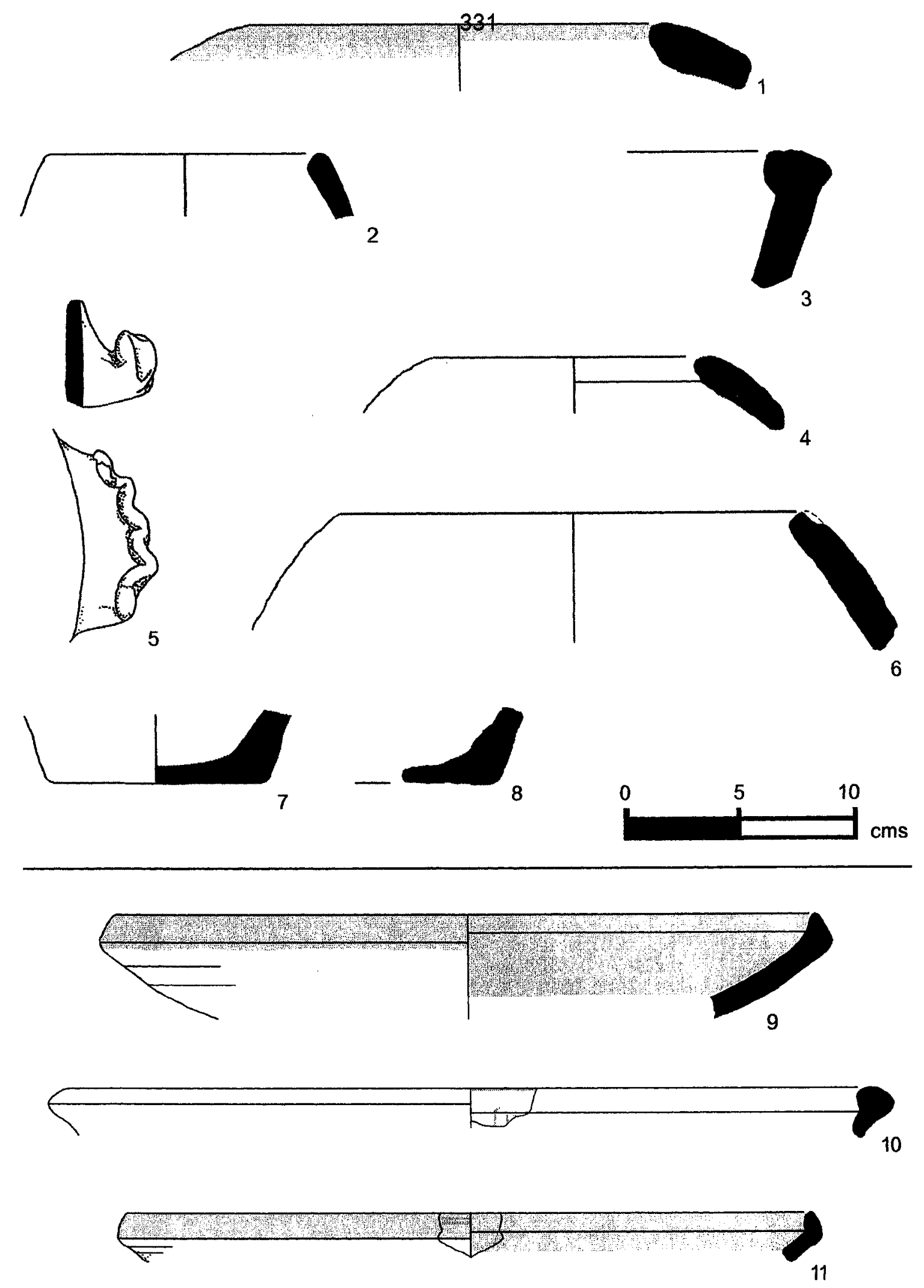

PLATE 48 (CONT.).

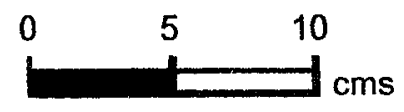




\begin{tabular}{llllllll}
\hline No & Reg & Square & Locus & Vessel & Part & $\begin{array}{l}\text { Body } \\
\text { Thick }\end{array}$ & Dia \\
\hline 1 & 0550 & SW 1-28 & 36 & PLATTER BOWL & R56 & 10 & 30 \\
2 & 0624 & SW 1-28 & 38 & HOLE MOUTH BOWL & R19 & 9 & 32 \\
3 & 0615 & SW 1-28 & 36 & HOLE MOUTH JAR & R14 & 9 & 16 \\
4 & 0546 & SW 1-28 & 38 & HOLE MOUTH JAR & R01 & 9 & 18 \\
5 & 0552 & SW 1-28 & 36 & UD & BOD & 6 & N \\
6 & 0548 & SW 1-28 & 36 & HOLE MOUTH JARIBOWL & R14 & 16 & 20 \\
7 & 0549 & SW 1-28 & 36 & UD & B12 & 15 & 28 \\
8 & 0622 & SW 1-28 & 38 & UD & B12 & 9 & 25 \\
9 & 0553 & SW 1-28 & 36 & PLATTER BOWL & BOD & 11 & N \\
10 & 0551 & SW 1-28 & 36 & UD & H20 & 6 & N
\end{tabular}

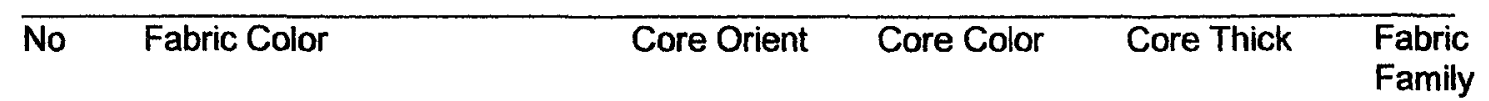

\begin{tabular}{|c|c|c|c|c|c|c|}
\hline 1 & \multicolumn{2}{|c|}{ LT REDDISH BROWN } & ALL & LG & $\mathbf{N}$ & 4 \\
\hline 2 & \multicolumn{2}{|l|}{ LTRED } & $A L L$ & $\mathbf{G}$ & $\mathrm{N}$ & 2.2 \\
\hline 3 & \multicolumn{2}{|c|}{ LT REDDISH BROWN } & $A L L$ & LG & $\mathrm{N}$ & $\mathrm{N}$ \\
\hline 4 & \multicolumn{2}{|c|}{ WEAK RED } & IRR & $\mathrm{G}$ & $N$ & 5.1 \\
\hline 5 & \multicolumn{2}{|l|}{ RED } & $M$ & G & 3 & 12.2 \\
\hline 6 & \multicolumn{2}{|c|}{ LTREDDISH BROWN } & $M$ & $\mathbf{G}$ & 10 & 1 \\
\hline 7 & \multicolumn{2}{|c|}{ LT RED } & IN & G & 8 & 7.2 \\
\hline 8 & \multicolumn{2}{|l|}{ RED } & $M$ & $\mathbf{G}$ & 3 & 12.2 \\
\hline 9 & \multicolumn{2}{|l|}{ PINK } & $\mathrm{N}$ & $\mathrm{N}$ & $\mathbf{N}$ & 20 \\
\hline 10 & \multicolumn{2}{|l|}{ PINK } & $\mathbf{N}$ & $\mathrm{N}$ & $\mathrm{N}$ & 23 \\
\hline No & Treatment & $\begin{array}{l}\text { Treatment } \\
\text { Location }\end{array}$ & $\begin{array}{l}\text { Treatment } \\
\text { Cover }\end{array}$ & $\begin{array}{l}\text { Color } \\
\text { Interior }\end{array}$ & $\begin{array}{l}\text { Color } \\
\text { Exterior }\end{array}$ & \\
\hline 1 & B & IR & ALL & $\mathbf{N}$ & & \\
\hline 2 & UN & $N$ & $N$ & $\mathrm{~N}$ & $\mathrm{~N}$ & \\
\hline 3 & UN & $\mathrm{N}$ & $\mathbf{N}$ & $\mathbf{N}$ & $\mathrm{N}$ & \\
\hline 4 & UN & $N$ & $N$ & $\mathbf{N}$ & $\mathbf{N}$ & \\
\hline 5 & 1 & $E$ & ALL & $\mathbf{N}$ & $\mathbf{N}$ & \\
\hline 6 & UN & $\mathbf{N}$ & $\mathbf{N}$ & $\mathbf{N}$ & $\mathbf{N}$ & \\
\hline 7 & $\mathbf{s}$ & $E$ & ALL & $\mathrm{N}$ & RED & \\
\hline 8 & $\mathbf{S}$ & $E$ & $\mathbf{N}$ & $\mathbf{N}$ & RED & \\
\hline 9 & SB & 1 & ALL & RED & $\mathbf{N}$ & \\
\hline 10 & $\mathbf{s}$ & $\mathbf{E}$ & ALL & $\mathbf{N}$ & DK RED & \\
\hline
\end{tabular}

PLATE 49. FIELD A. PHASE 3A (EB III). 
Other

1 Radially burnished.

2 Features in break suggest rim folding; sample too small to confirm stance or diameter.

3 Fine exterior lines show rim smoothing.

$4 \quad$ Marks on interior and exterior show motion used to finish rim.

$5 \quad$ Combed Metallic Ware.

6 Sample too small to confirm stance or diameter.

8 Metallic Ware.

PLATE 49 (CONT.). 

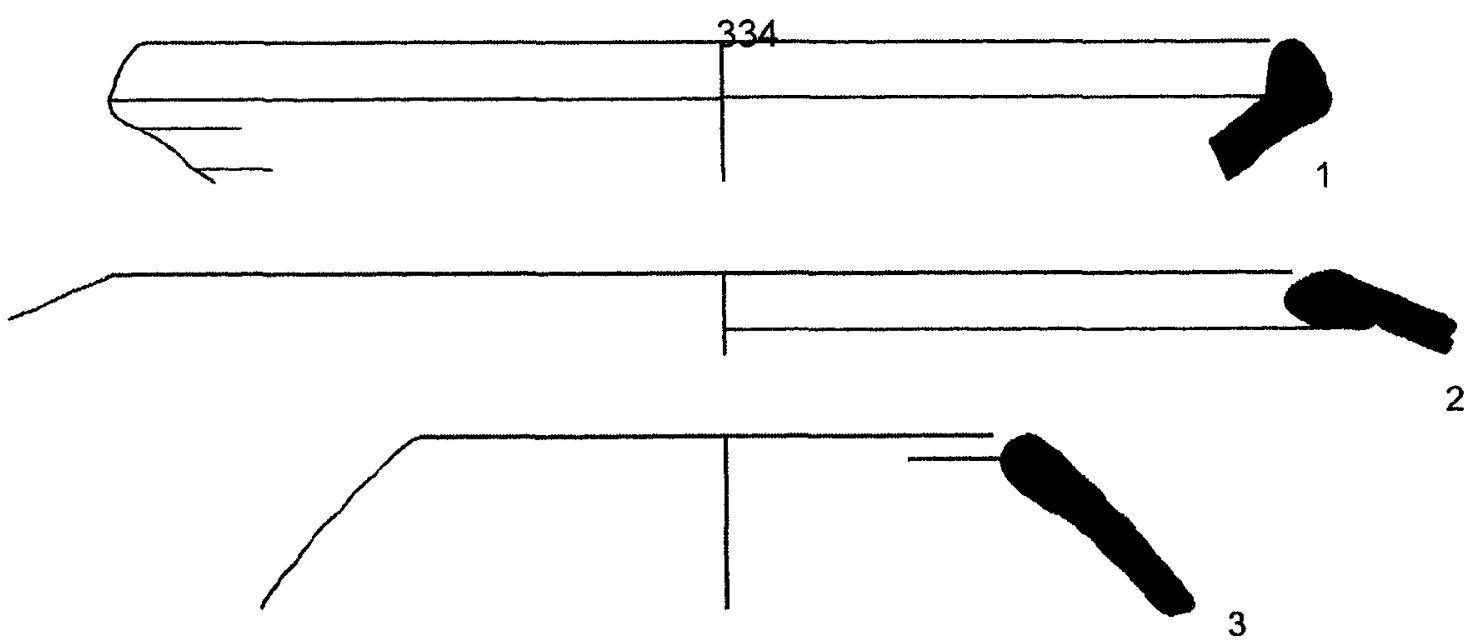

2
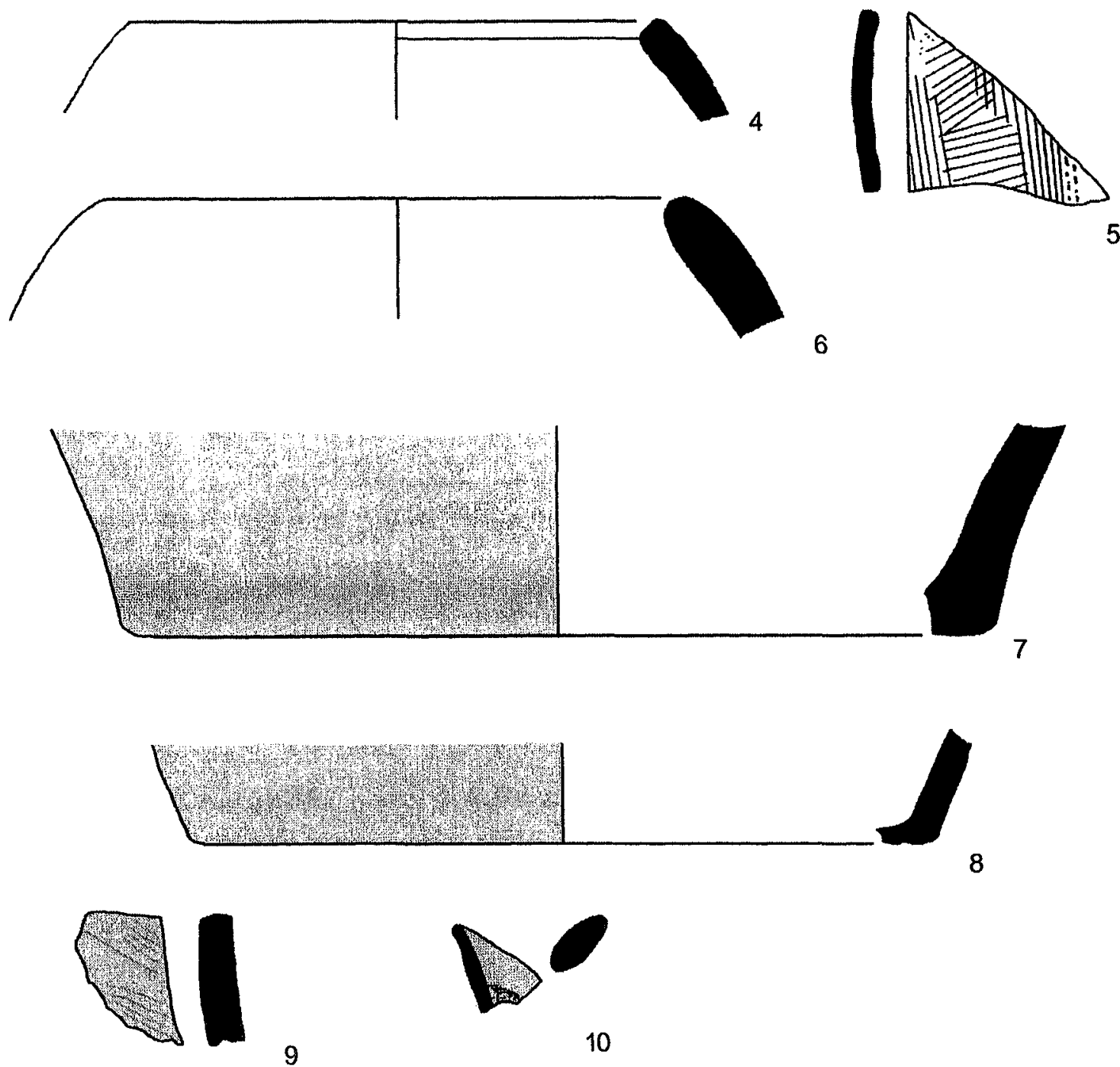

PLATE 49 (CONT.).

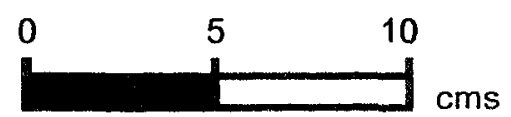




\begin{tabular}{llllllll}
\hline No & Reg & Square & Locus & Vessel & Part & $\begin{array}{l}\text { Body } \\
\text { Thick }\end{array}$ & Dia \\
\hline & & & & & & & \\
1 & 0639 & SW 2-27 & 17 & LEDGE RIM BOWL & R51 & 7 & 26 \\
2 & 0640 & SW 2-27 & 17 & PLATTER BOWL & R51 & 8 & $\mathrm{~N}$ \\
3 & 2433 & SW 2-27 & 17 & LEDGE RIM BOWL & R51 & 8 & $\mathrm{~N}$ \\
4 & 0652 & SW 2-27 & 17 & PLATTER BOWL & R53 & 10 & $\mathrm{~N}$ \\
5 & 0638 & SW 2-27 & 17 & PLATTER BOWL & R53 & 10 & 25 \\
6 & 0631 & SW 2-27 & 17 & HOLE MOUTH JAR & R19 & 13 & 30 \\
7 & 0665 & SW 2-27 & 14 & HOLE MOUTH JAR & R01 & 12 & 14 \\
8 & 0655 & SW 2-27 & 17 & HOLE MOUTH JAR & R14 & 11 & $\mathrm{~N}$ \\
9 & $\mathbf{0 6 3 0}$ & SW 2-27 & 17 & NECKED JAR & R43 & 11 & 20 \\
10 & 0644 & SW 2-27 & 17 & NECKED JAR & R31 & 12 & 25 \\
11 & 0636 & SW 2-27 & 17 & LEDGE RIM BOWL & R80 & 8 & 30 \\
12 & 0666 & SW 2-27 & 14 & HOLE MOUTH JAR/BOWL & R20 & 10 & 35
\end{tabular}

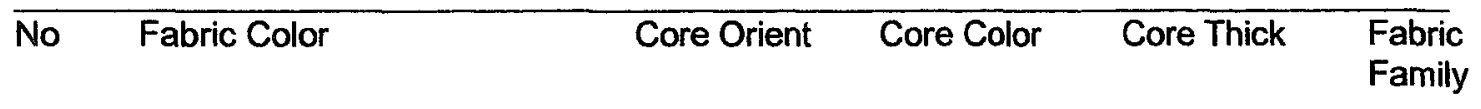

\begin{tabular}{|c|c|c|c|c|c|c|}
\hline 1 & \multicolumn{2}{|l|}{ PINK } & $\mathbf{N}$ & $\mathbf{N}$ & $\mathbf{N}$ & 23 \\
\hline 2 & \multicolumn{2}{|l|}{ PINK } & $\mathbf{N}$ & $N$ & $\mathrm{~N}$ & $\mathbf{N}$ \\
\hline 3 & \multicolumn{2}{|l|}{ RED } & $\mathrm{N}$ & $\mathrm{N}$ & $\mathrm{N}$ & $\mathrm{N}$ \\
\hline 4 & \multicolumn{2}{|l|}{ RED } & $\mathbf{N}$ & $\mathbf{N}$ & $\mathrm{N}$ & $\mathrm{N}$ \\
\hline 5 & \multicolumn{2}{|l|}{ PINK } & $\mathbf{N}$ & $N$ & $\mathrm{~N}$ & 17.1 \\
\hline 6 & \multicolumn{2}{|l|}{ PALE RED } & $\mathbf{M}$ & G & 7 & 2.2 \\
\hline 7 & \multicolumn{2}{|c|}{ WEAK RED } & IRR & $\mathbf{G}$ & $\mathrm{N}$ & 5.1 \\
\hline 8 & \multicolumn{2}{|c|}{ PALE RED } & $M$ & $\mathbf{G}$ & 5 & $\mathrm{~N}$ \\
\hline 9 & \multirow{2}{*}{\multicolumn{2}{|c|}{ LT REDDISH BROWN }} & ALL & LG & $N$ & 22 \\
\hline 10 & & PALE RED & $M$ & LG & 4 & 10.1 \\
\hline 11 & \multicolumn{2}{|c|}{ LT REDDISH BROWN } & $\mathbf{N}$ & $\mathrm{N}$ & $\mathrm{N}$ & 23 \\
\hline 12 & \multicolumn{2}{|c|}{ LT REDDISH BROWN } & $\mathbf{N}$ & $\mathbf{N}$ & $N$ & $\vec{N}$ \\
\hline$\overline{\text { No }}$ & Treatment & $\begin{array}{l}\text { Treatment } \\
\text { Location }\end{array}$ & $\begin{array}{l}\text { Treatment } \\
\text { Cover }\end{array}$ & $\begin{array}{l}\text { Color } \\
\text { Interior }\end{array}$ & $\begin{array}{l}\text { Color } \\
\text { Exterior }\end{array}$ & \\
\hline 1 & $\mathbf{S}$ & $\mathbb{R}$ & ALL & DK RED & $\mathbf{N}$ & \\
\hline 2 & $\mathbf{S}$ & $\mathbb{I R}$ & ALL & RED & $\mathbf{N}$ & \\
\hline 3 & B & IE & ALL & $\mathbf{N}$ & $\mathrm{N}$ & \\
\hline 4 & B & $\mathrm{IE}$ & ALL & $\mathbf{N}$ & $\mathrm{N}$ & \\
\hline 5 & SB & $\mathbb{I R}$ & ALL & RED & $N$ & \\
\hline 6 & $\mathbf{S}$ & ER & ALL & $\mathbf{N}$ & RED & \\
\hline 7 & UN & $N$ & $\mathbf{N}$ & $\mathbf{N}$ & $\mathrm{N}$ & \\
\hline 8 & UN & $\mathbf{N}$ & $\mathbf{N}$ & $\mathbf{N}$ & $\mathbf{N}$ & \\
\hline 9 & $\mathbf{s}$ & ER & ALL & $\mathbf{N}$ & RED & \\
\hline 10 & UN & $N$ & $N$ & $\mathbf{N}$ & $N$ & \\
\hline 11 & $\mathrm{~s}$ & ER & ALL & $\mathrm{N}$ & DK RED & \\
\hline 12 & $\mathrm{~S}$ & ER & ALL & $\mathbf{N}$ & RED & \\
\hline
\end{tabular}

PLATE 50. FIELD A. PHASE 3A (EB III). 


\section{Other}

2 Sample too small to confirm stance or diameter.

3 Sample too small to confirm stance or diameter; Metallic Ware.

4 Sample too small to confirm stance or diameter; Metallic Ware.

7 Surface burn visible; sample too small to confirm stance or diameter.

10 Surface burn visible.

12 Sample too small to confirm stance or diameter.

PLATE 50 (CONT.). 

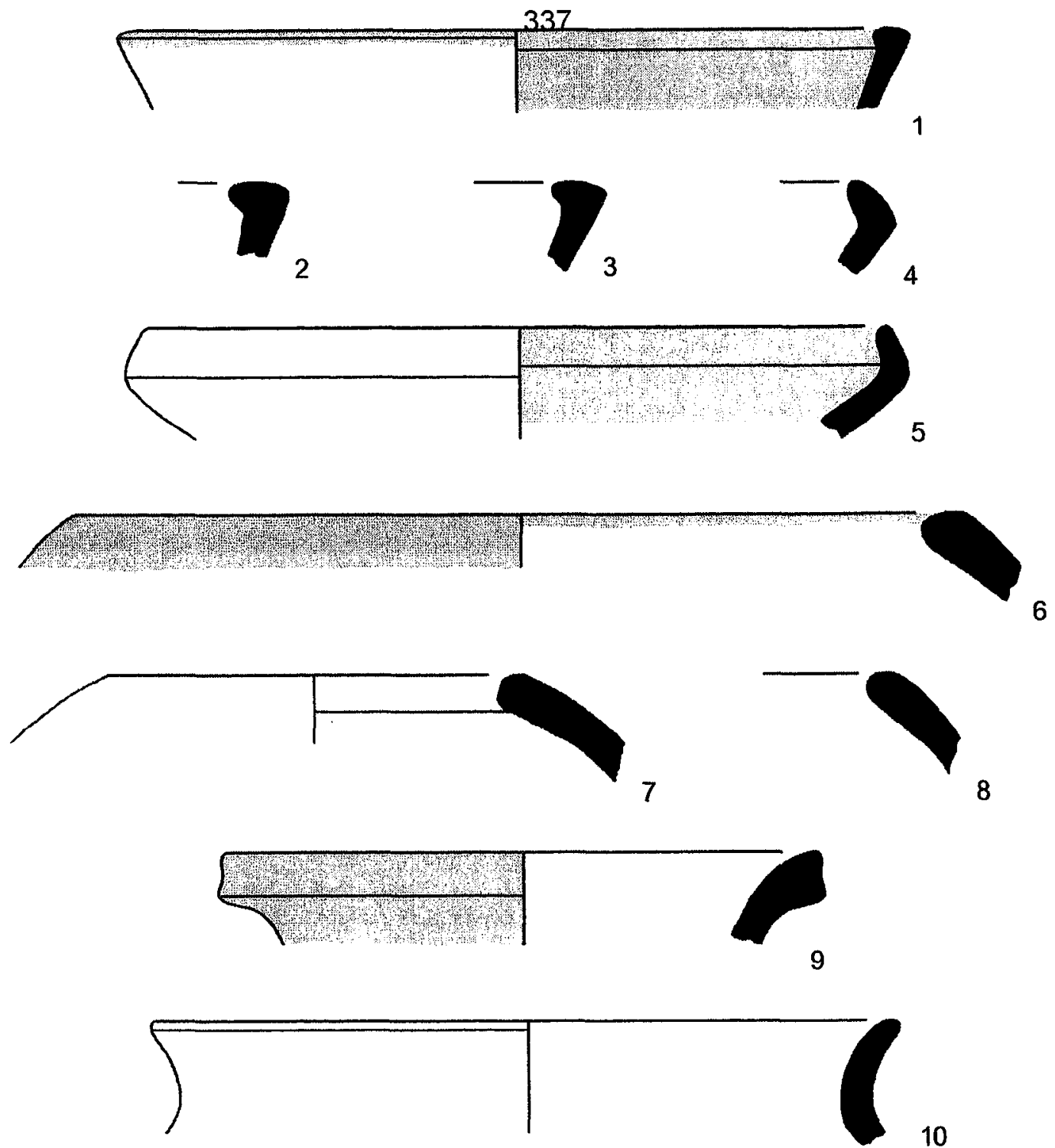

10
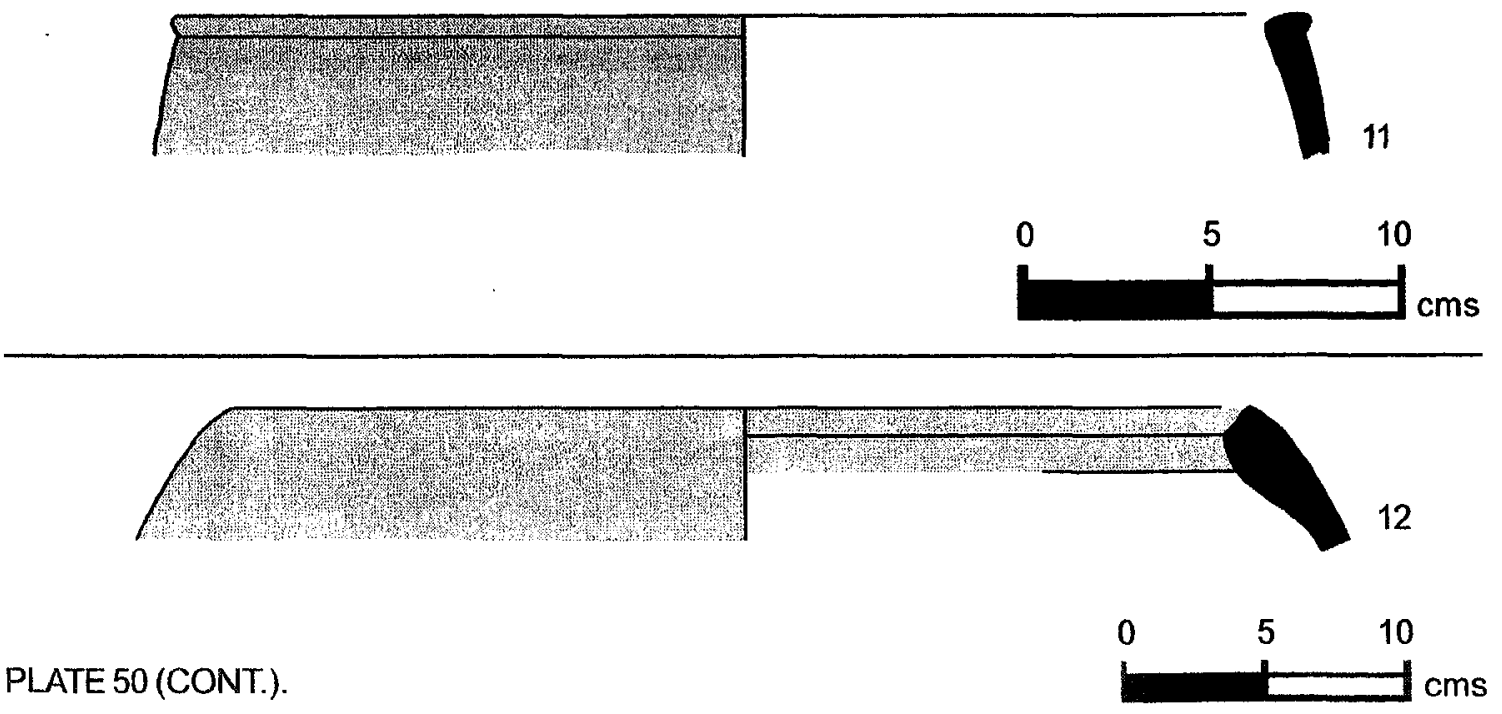


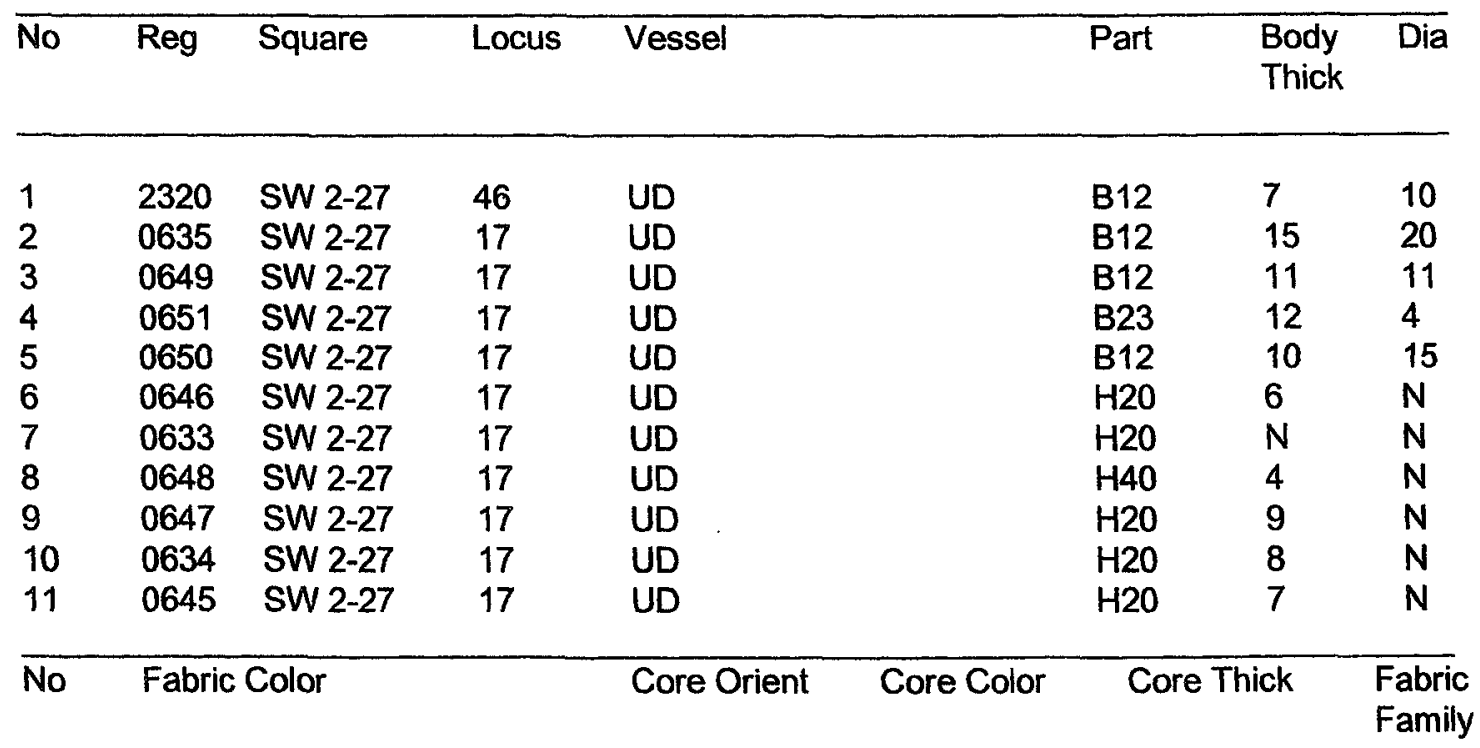

\begin{tabular}{|c|c|c|c|c|c|c|}
\hline 1 & \multicolumn{2}{|l|}{ PINK } & M & $\mathbf{N}$ & 3 & $\mathrm{~N}$ \\
\hline 2 & \multicolumn{2}{|l|}{ RED } & $\mathbf{M}$ & $\mathbf{G}$ & 10 & 17.2 \\
\hline 3 & \multicolumn{2}{|c|}{ LT REDDISH BROWN } & $\mathbf{M}$ & G & 5 & 11 \\
\hline 4 & \multicolumn{2}{|c|}{ LT REDDISH BROWN } & IN & LG & 7 & 17.2 \\
\hline 5 & \multicolumn{2}{|l|}{ LT RED } & M & LG & 4 & $N$ \\
\hline 6 & \multicolumn{2}{|l|}{ PINK } & $N$ & $N$ & $N$ & 16 \\
\hline 7 & \multicolumn{2}{|l|}{ PINK } & $M$ & LG & $\mathrm{N}$ & 20 \\
\hline 8 & \multirow{2}{*}{\multicolumn{2}{|c|}{ LT REDDISH BROWN }} & $N$ & $N$ & $N$ & 7.1 \\
\hline 9 & & PINK & IRR & G & $\mathrm{N}$ & 21 \\
\hline 10 & \multicolumn{2}{|l|}{ LT RED } & $M$ & LG & $\mathbf{N}$ & 13.1 \\
\hline 11 & \multicolumn{2}{|c|}{ LT REDDISH BROWN } & $N$ & $\mathbf{N}$ & $\mathbf{N}$ & 22 \\
\hline No & Treatment & $\begin{array}{l}\text { Treatment } \\
\text { Location }\end{array}$ & $\begin{array}{l}\text { Treatment } \\
\text { Cover }\end{array}$ & $\begin{array}{l}\text { Color } \\
\text { Interior }\end{array}$ & $\begin{array}{l}\text { Color } \\
\text { Exterior }\end{array}$ & \\
\hline 1 & PAINT & $E$ & NET & $\mathbf{N}$ & LT RED & \\
\hline 2 & $\mathrm{~S}$ & $E$ & $N$ & $N$ & RED & \\
\hline 3 & $\mathrm{~S}$ & $E$ & ALL & $\mathbf{N}$ & PALE RED & \\
\hline 4 & SB & $E$ & ALL & $\mathbf{N}$ & $\mathrm{N}$ & \\
\hline 5 & B & $E$ & $N$ & $\mathbf{N}$ & $N$ & \\
\hline 6 & $S$ & $E$ & ALL & $\mathbf{N}$ & RED & \\
\hline 7 & SB & $E$ & ALL & $\mathbf{N}$ & RED & \\
\hline 8 & SB & $E$ & $\mathrm{~N}$ & $\mathrm{~N}$ & LT RED & \\
\hline 9 & SB & $E$ & ALL & $\mathrm{N}$ & RED & \\
\hline 10 & $\mathbf{S}$ & $E$ & ALL & $\mathbf{N}$ & RED & \\
\hline 11 & $\mathrm{~S}$ & $\mathbf{E}$ & $\mathrm{ALL}$ & $N$ & DK RED & \\
\hline
\end{tabular}

PLATE 51. FIELD A. PHASE 3A (EB III). 
Other

$1 \quad$ Painted lines extend over vessel base.

PLATE 51 (CONT.).

Reproduced with permission of the copyright owner. Further reproduction prohibited without permission. 


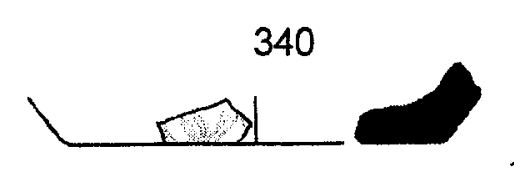

1
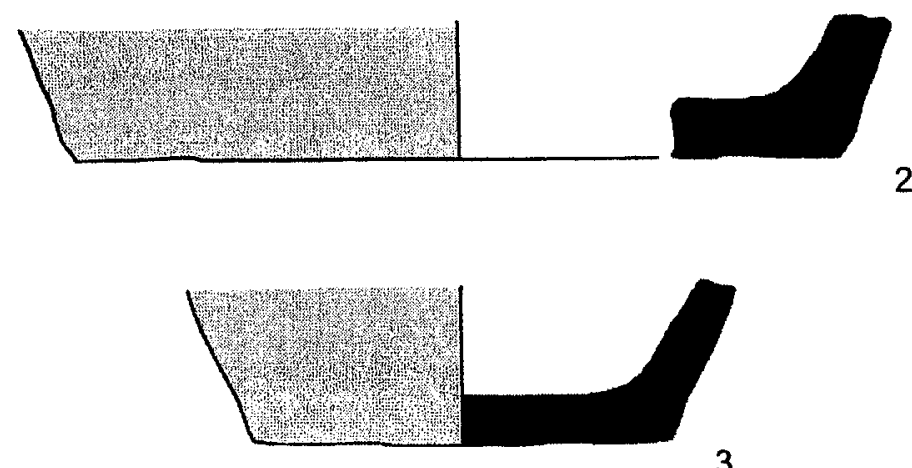

2
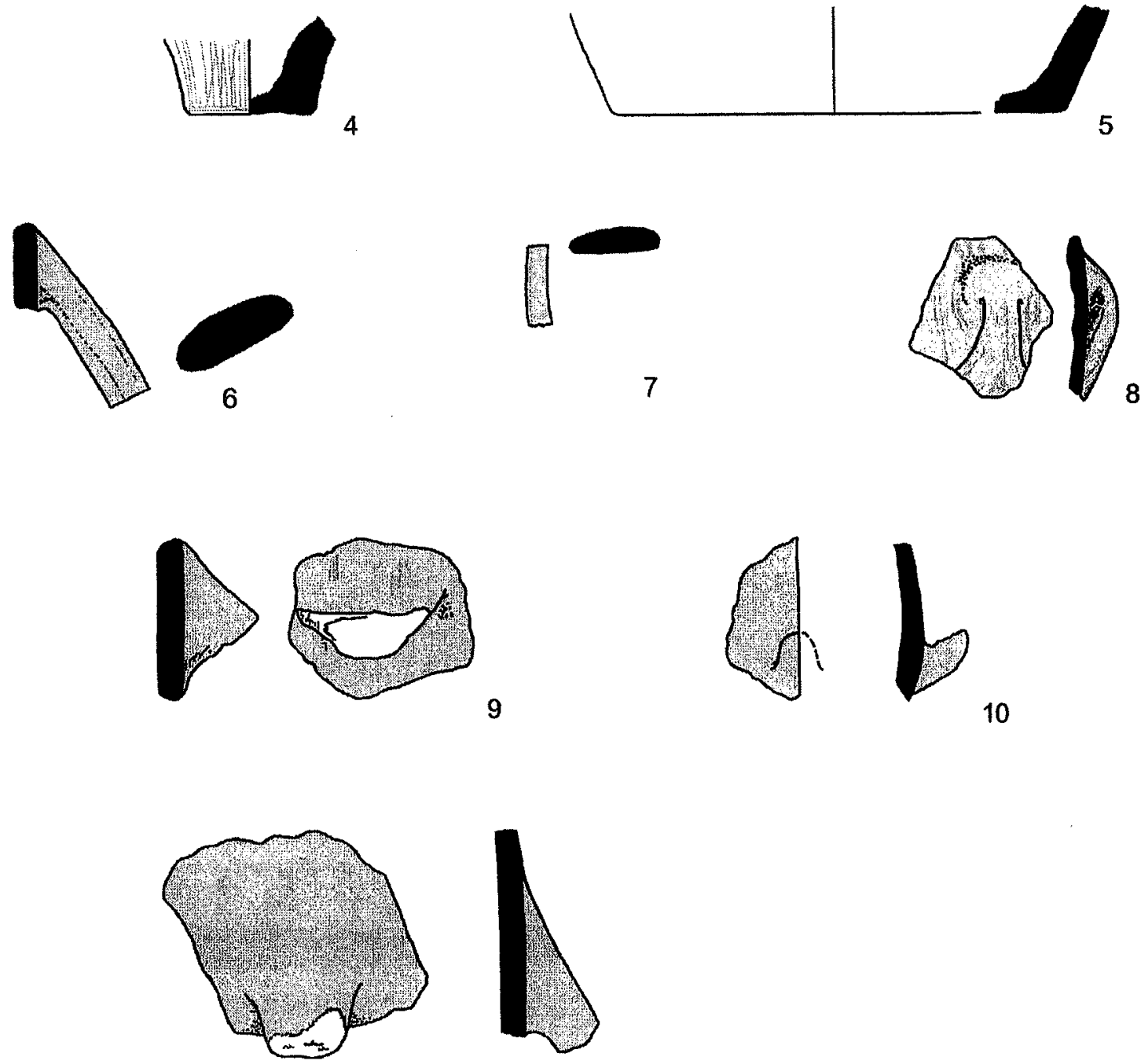

11

PLATE 51 (CONT.).

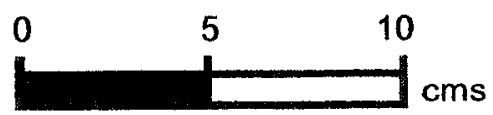




\begin{tabular}{llllllll}
\hline No & Reg & Square & Locus & Vessel & Part & $\begin{array}{l}\text { Body } \\
\text { Thick }\end{array}$ & Dia \\
& & & & & & & \\
1 & 0702 & SW 2-27 & 65 & CARINATED BOWL & R58 & 5 & 8 \\
2 & 0678 & SW 2-27 & 55 & CARINATED BOWL & R58 & 5 & 10 \\
3 & 0697 & SW 2-27 & 66 & BOWL & R82 & 5 & N \\
4 & 0696 & SW 2-27 & 66 & NECKED JAR & R31 & 15 & 20 \\
5 & 0707 & SW 2-27 & 62 & NECKED JAR & R31 & 7 & 10 \\
6 & 0668 & SW 2-27 & 57 & NECKED JAR & R43 & 7 & 12 \\
7 & 0699 & SW 2-27 & 65 & HOLE MOUTH JAR & R02 & 16 & 22 \\
8 & 0679 & SW 2-27 & 55 & UD & B12 & 11 & 20 \\
9 & 0706 & SW 2-27 & 63 & UD & B11 & 7 & 10 \\
10 & 0680 & SW 2-27 & 55 & UD & BOD & 6 & N \\
11 & 0669 & SW 2-27 & 57 & UD & B10 & 7 & 4 \\
12 & 0698 & SW 2-27 & 67 & PLATTER BOWL & R55 & 11 & 45 \\
\hline No & Fabric Color & & Core Orient Core Color & Core Thick & Fabric \\
& & & & & & & Family
\end{tabular}

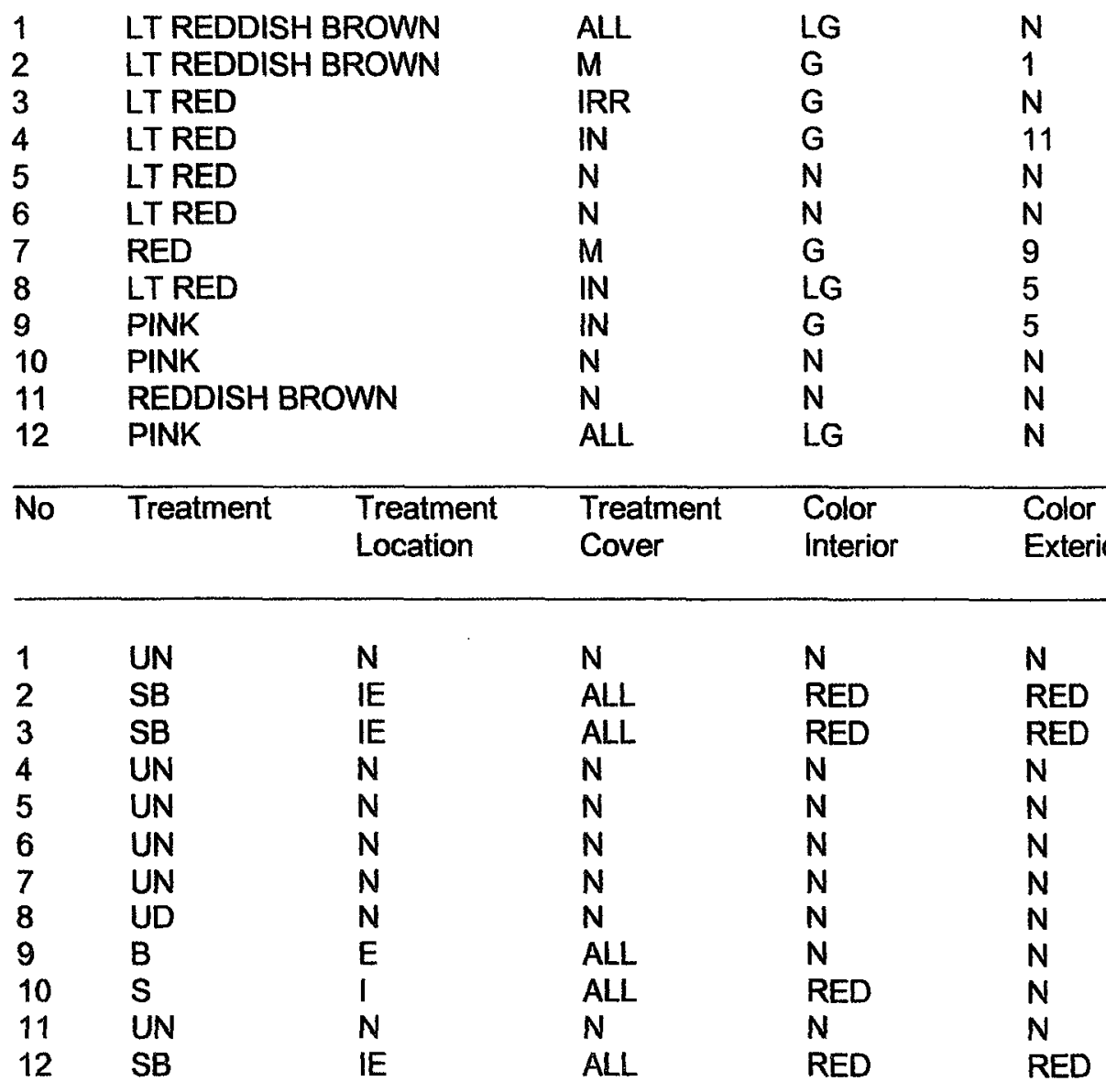

PLATE 52. FIELD A. PHASE 3A (EB III). 
Other

3 Sample too small to confirm stance or diameter; Khirbet Kerak Ware.

6 Metallic Ware.

10 Potter's mark.

11 Sample too small to confirm stance or diameter.

PLATE 52 (CONT.). 


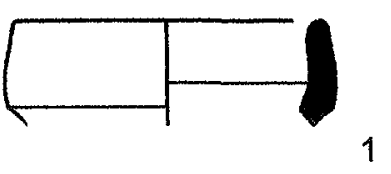

1
343

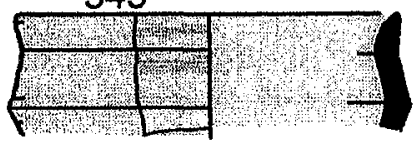

2
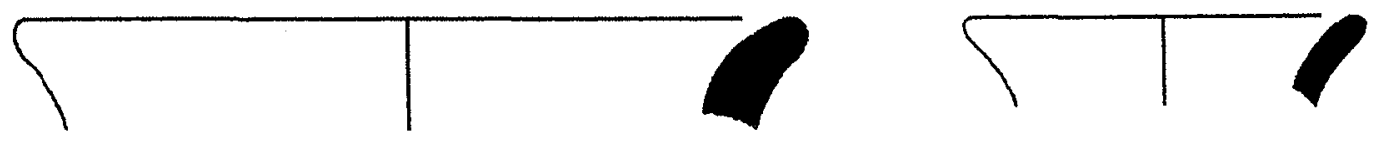

4

5
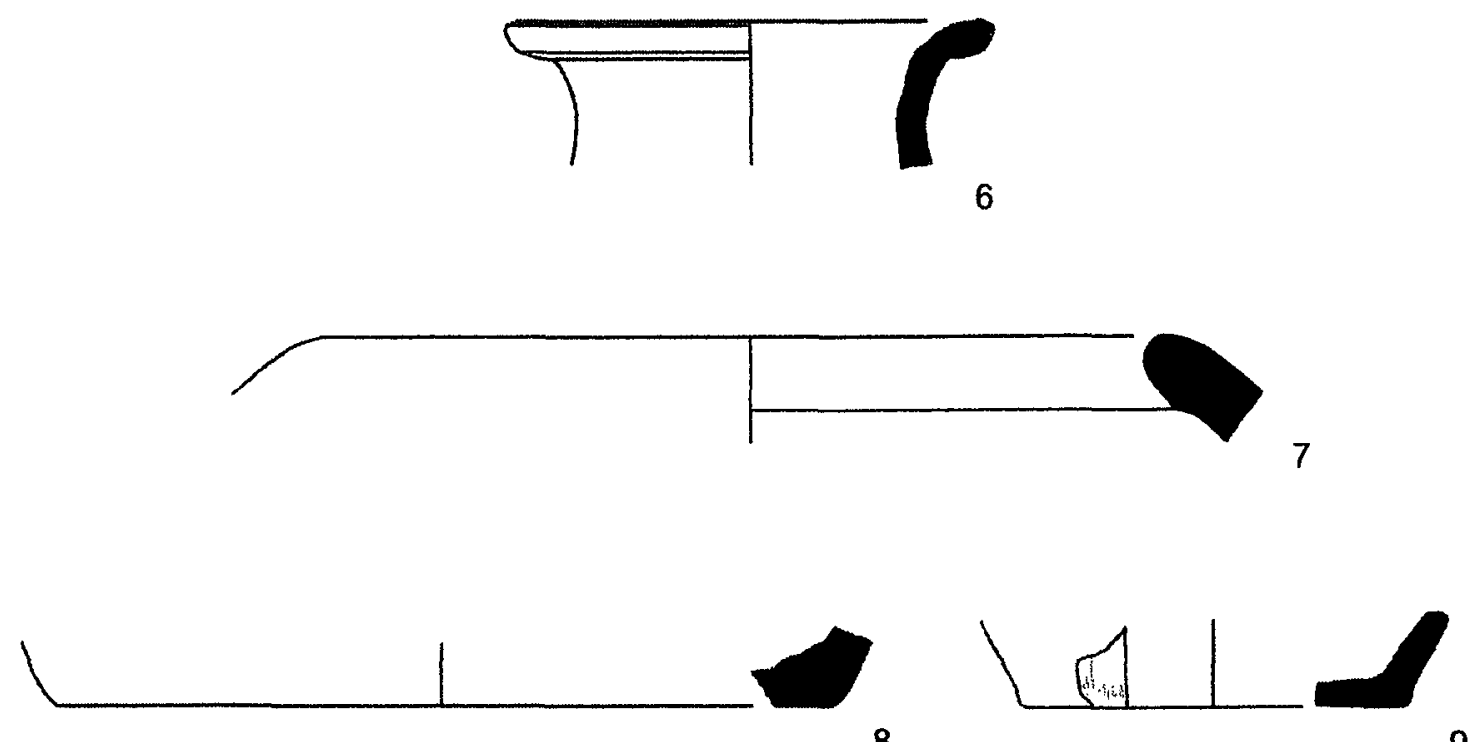

9
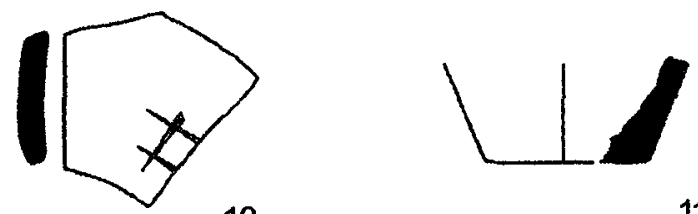

11
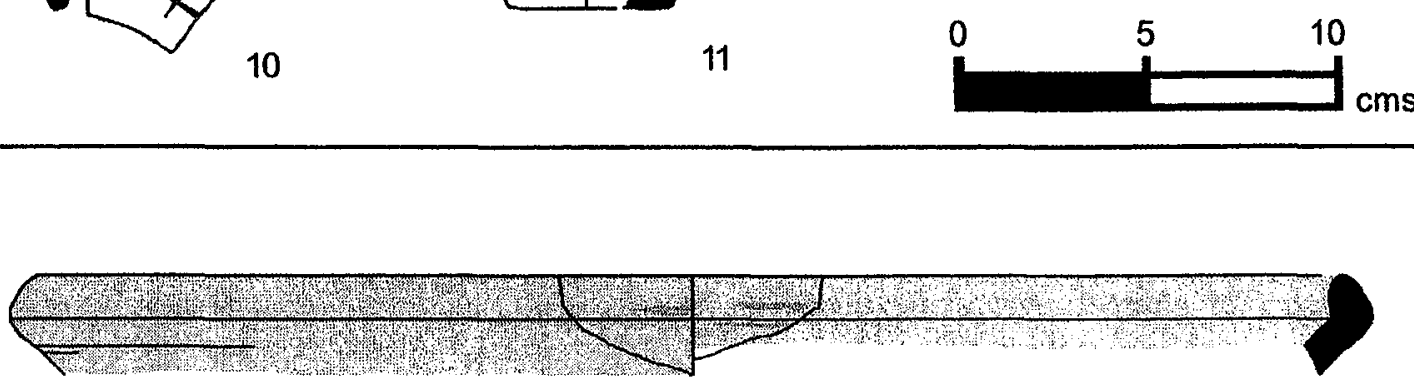

PLATE 52 (CONT.).

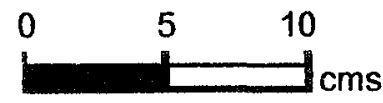


344

\begin{tabular}{llllllll}
\hline No & Reg & Square & Locus & Vessel & Part & $\begin{array}{l}\text { Body } \\
\text { Thick }\end{array}$ & Dia \\
& & & & & & & \\
1 & 0685 & SW 2-27 & 75 & LEDGE RIM BOWL & R51 & 7 & 12 \\
2 & 0683 & SW 2-27 & 75 & LEDGE RIM BOWL & R60 & 10 & 22 \\
3 & 0689 & SW 2-27 & 75 & HOLE MOUTH JAR/BOWL & R11 & 9 & 20 \\
4 & 0692 & SW 2-27 & 75 & HOLE MOUTH BOWL & R04 & 12 & 16 \\
5 & 2297 & SW 2-27 & 75 & HOLE MOUTH JAR & R01 & 16 & N \\
6 & 0688 & SW 2-27 & 75 & HOLE MOUTH JAR & R19 & 8 & 14 \\
7 & 0684 & SW 2-27 & 75 & HOLE MOUTH JAR & R19 & 14 & 11 \\
8 & 0690 & SW 2-27 & 75 & NECKED JAR & R32 & 9 & 12 \\
9 & 0686 & SW 2-27 & 75 & NECKED JAR & R30 & 8 & 12 \\
10 & 0682 & SW 2-27 & 75 & PLATTER BOWL & R53 & 8 & 40
\end{tabular}

\begin{tabular}{lllll}
\hline No Fabric Color & Core Orient & Core Color & Core Thick & $\begin{array}{l}\text { Fabric } \\
\text { Family }\end{array}$ \\
& & & &
\end{tabular}

\begin{tabular}{|c|c|c|c|c|c|c|}
\hline 1 & LT REDDIS & ROWN & $N$ & $N$ & $N$ & 23 \\
\hline 2 & LT REDDIS & ROWN & M & LG & 3 & 23 \\
\hline 3 & LT REDDIS & ROWN & $N$ & $\mathrm{~N}$ & $\mathrm{~N}$ & 10.1 \\
\hline 4 & WEAK RED & & M & G & $N$ & $N$ \\
\hline 5 & LT REDDIS & ROWN & G & $M$ & 7 & $N$ \\
\hline 6 & WEAK RED & & $N$ & $N$ & $N$ & 3 \\
\hline 7 & LT REDDIS & ROWN & $M$ & $\mathbf{G}$ & 7 & 15 \\
\hline 8 & PINK & & $\mathrm{N}$ & $\mathbf{N}$ & $\mathbf{N}$ & 15 \\
\hline 9 & PINK & & $N$ & $\mathbf{N}$ & $\mathrm{N}$ & 23 \\
\hline 10 & PINK & & $\mathrm{N}$ & $\mathrm{N}$ & $\mathrm{N}$ & 25.1 \\
\hline No & Treatment & $\begin{array}{l}\text { Treatment } \\
\text { Location }\end{array}$ & $\begin{array}{l}\text { Treatment } \\
\text { Cover }\end{array}$ & $\begin{array}{l}\text { Color } \\
\text { Interior }\end{array}$ & $\begin{array}{l}\text { Color } \\
\text { Exterior }\end{array}$ & \\
\hline 1 & S & IR & ALL & RED & $N$ & \\
\hline 2 & SB & IR & ALL & RED & RED & \\
\hline 3 & UN & $N$ & $N$ & $N$ & $N$ & \\
\hline 4 & UN & $N$ & $N$ & $N$ & $\mathrm{~N}$ & \\
\hline 5 & UN & UN & $\mathrm{N}$ & $N$ & $N$ & \\
\hline 6 & UN & $\mathbf{N}$ & $\mathbf{N}$ & $\mathbf{N}$ & $N$ & \\
\hline 7 & $\mathbf{S}$ & ER & ALL & $\mathbf{N}$ & RED & \\
\hline 8 & S & IE & ALL & LT RED & LT RED & \\
\hline 9 & UN & $N$ & $N$ & N & $N$ & \\
\hline 10 & SB & IE & ALL & RED & RED & \\
\hline
\end{tabular}

PLATE 53. FIELD A. PHASE 3A (EB III). 
Other

2 Interior face is radially burnished; rim is well burnished; upper portion of exterior face is wet-smoothed and burnished; lower portion of exterior face is haphazardly scraped; very slight concavity under rim.

3 Radially burnished on exterior face; base smoothed and slipped.

$4 \quad$ Sample too small to confirm stance or diameter.

5 Surface burn visible.

6 Sample too small to confirm stance or diameter; two preserved puncture marks.

PLATE 53 (CONT.).

Reproduced with permission of the copyright owner. Further reproduction prohibited without permission. 

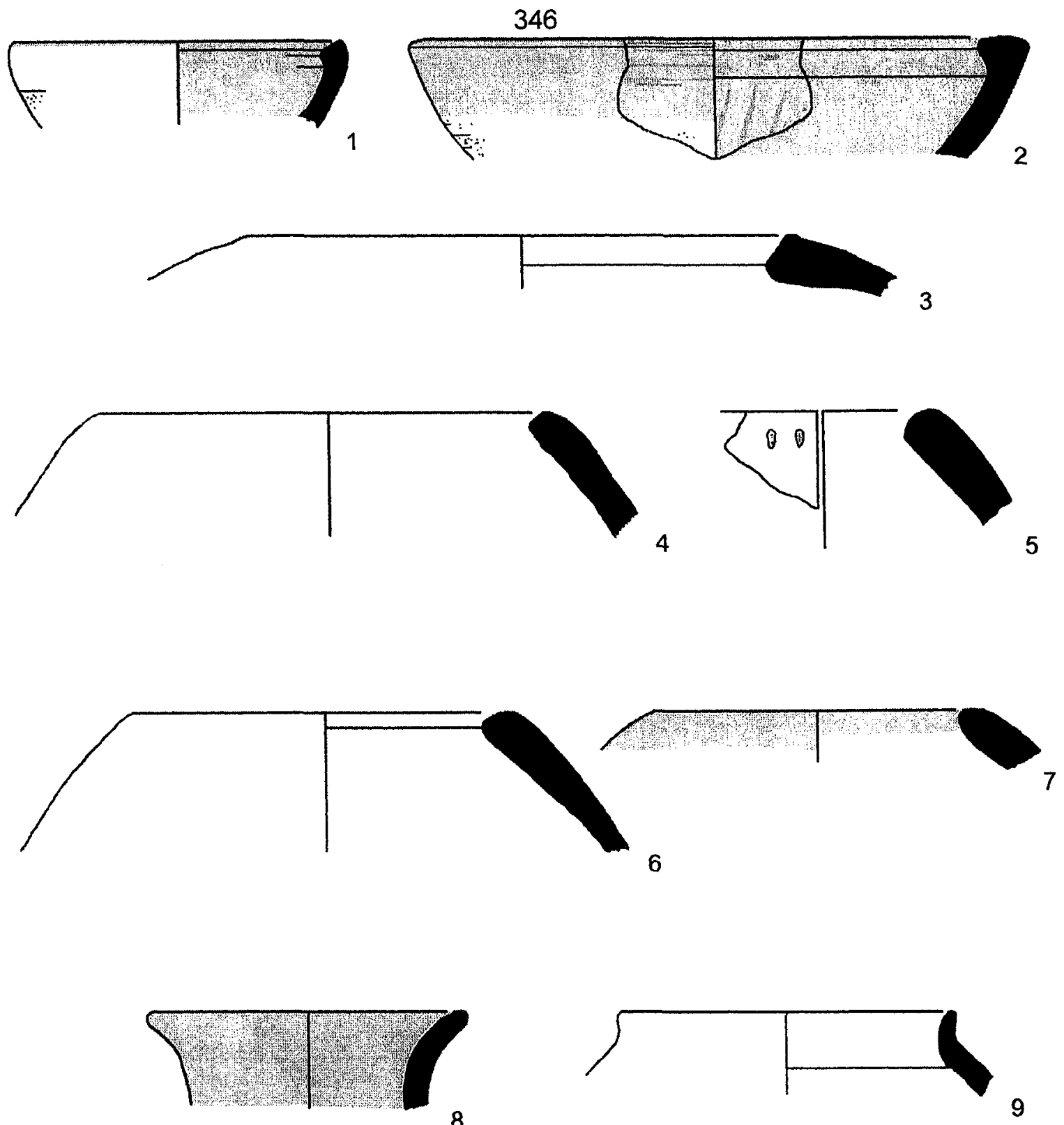

8
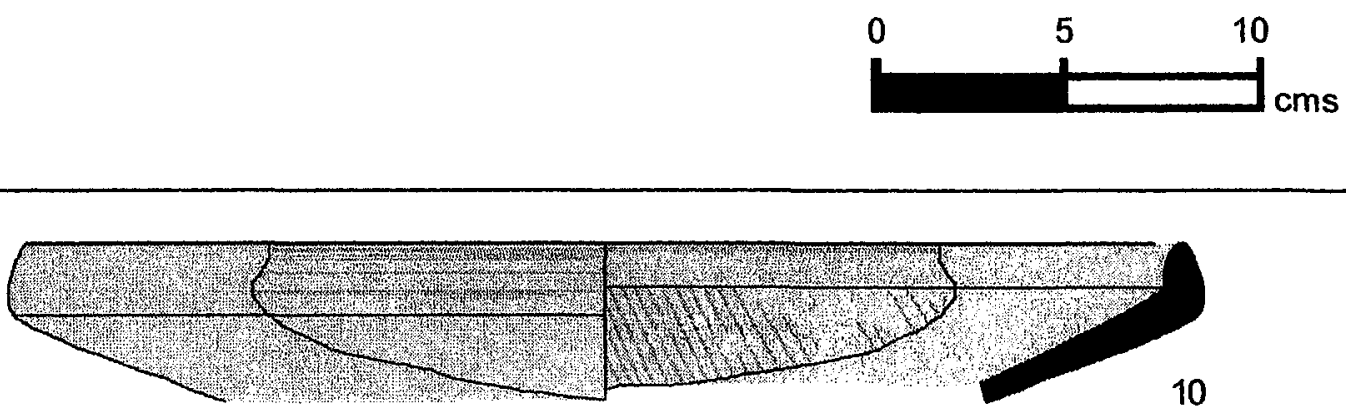

PLATE 53 (CONT.).

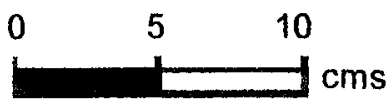


347

\begin{tabular}{llllllll}
\hline No & Reg & Square & Locus & Vessel & Part & $\begin{array}{c}\text { Body } \\
\text { Thick }\end{array}$ & Dia \\
\hline 1 & 0695 & SW 2-27 & 75 & UD & R60 & 11 & 42 \\
2 & 0693 & SW 2-27 & 75 & PLATTER BOWL & R53 & 9 & 42 \\
3 & 0687 & SW 2-27 & 75 & LEDGE RIM BOWL & R52 & 9 & 40 \\
4 & 0694 & SW 2-27 & 75 & HOLE MOUTH JAR/BOWL & R60 & 11 & 54
\end{tabular}

\begin{tabular}{llll}
\hline No Fabric Color Core Orient Core Color Core Thick & Fabric \\
Family
\end{tabular}

\begin{tabular}{llllll}
\hline 1 & PINK & M & G & 7 & $N$ \\
2 & LTRED & N & LG & $N$ & $N$ \\
3 & PINK & N & N & $N$ & 23 \\
4 & LTREDDISH BROWN & EX & G & 4 & $N$
\end{tabular}

\begin{tabular}{llllll}
\hline No & Treatment & $\begin{array}{l}\text { Treatment } \\
\text { Location }\end{array}$ & $\begin{array}{l}\text { Treatment } \\
\text { Cover }\end{array}$ & $\begin{array}{l}\text { Color } \\
\text { Interior }\end{array}$ & $\begin{array}{l}\text { Color } \\
\text { Exterior }\end{array}$ \\
\hline 1 & SB & IR & ALL & N & DUSKY RED \\
2 & SB & IR & ALL & RED & RED \\
3 & S & IR & ALL & RED & N \\
4 & S & ER & ALL & N & WEAK RED
\end{tabular}

Other

1 Sample too small to confirm stance or diameter.

2 Metallic Ware.

3 Rim is rolled inward, lip is not always brought flush against interior face; interior face and rim are slipped, while only the rim appears burnished; exterior face is wet-smoothed with some signs of scraping below.

4 Sample too small to confirm stance or diameter; vestigial handle or knob appears on exterior face below rim.

PLATE 54. FIELD A. PHASE 3A (EB III). 

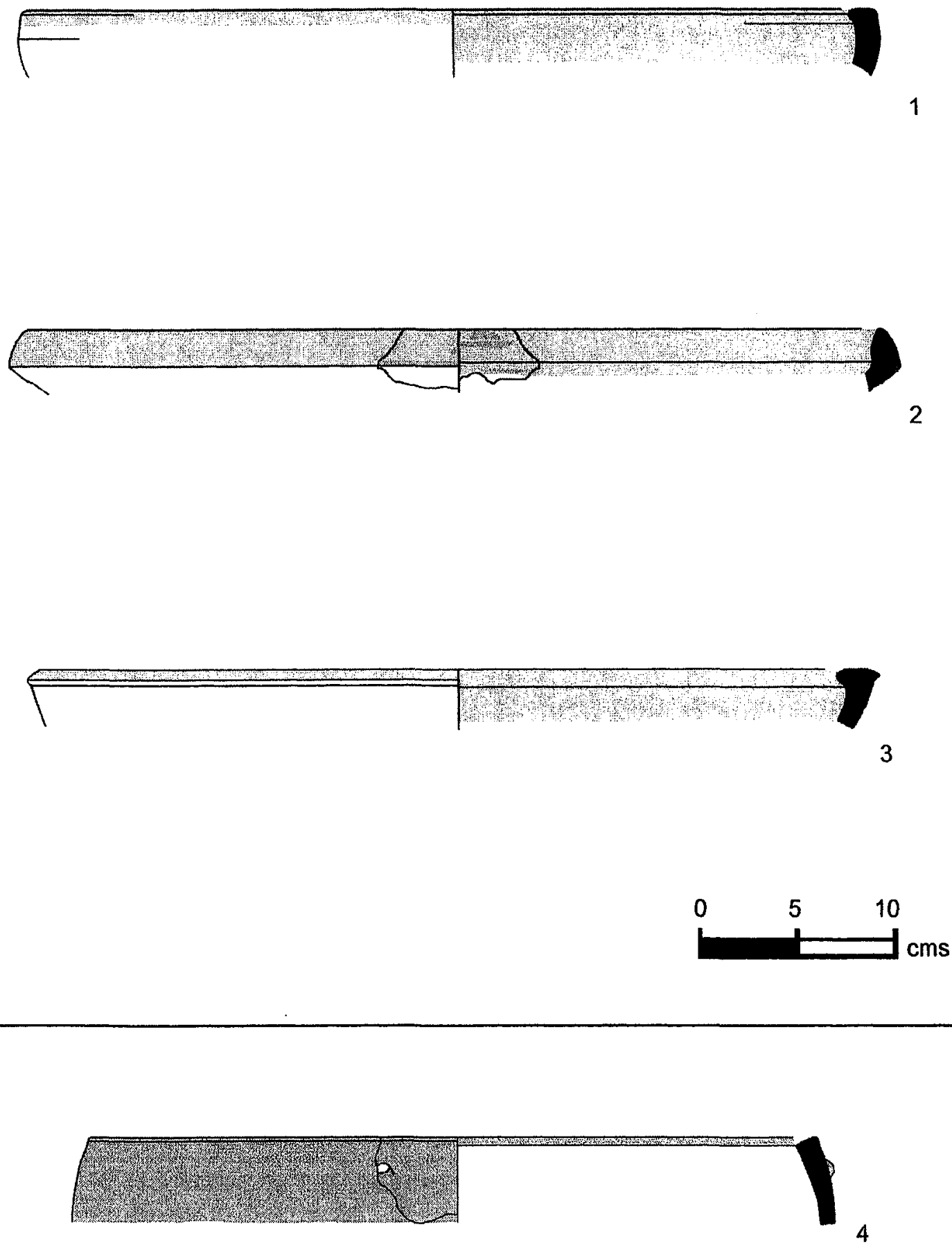

PLATE 54 (CONT.). 


\begin{tabular}{llllllll}
\hline No & Reg & Square & Locus & Vessel & Part & $\begin{array}{l}\text { Body } \\
\text { Thick }\end{array}$ & Dia \\
\hline & & & & & & & \\
1 & 0751 & SW 2-27 & 79 & BOWL & R50 & 7 & 16 \\
2 & 0725 & SW 2-27 & 80 & CARINATED BOWL & R49 & 6 & 30 \\
3 & 0723 & SW 2-27 & 80 & HOLE MOUTH BOWL & R14 & 9 & 14 \\
4 & 0724 & SW 2-27 & 80 & NECKED JAR & R32 & 9 & 12 \\
5 & 0749 & SW 2-27 & 79 & UD & B23 & 9 & 2 \\
6 & 0747 & SW 2-27 & 79 & LEDGE RIM BOWL & R52 & 11 & 50 \\
7 & 0750 & SW 2-27 & 79 & LEDGE RIM BOWL & R53 & 12 & 40 \\
8 & 0748 & SW 2-27 & 79 & LEDGE RIM BOWL & R53 & 12 & 38
\end{tabular}

\begin{tabular}{|c|c|c|c|}
\hline No $\quad$ Fabric Color & Core Orient & Core Color & Core Thick \\
\hline
\end{tabular}

\begin{tabular}{|c|c|c|c|c|c|c|}
\hline 1 & \multirow{2}{*}{\multicolumn{2}{|c|}{$\begin{array}{l}\text { LT REDDISH BROWN } \\
\text { LT RED }\end{array}$}} & $N$ & $N$ & $N$ & $N$ \\
\hline 2 & & & $\mathrm{~N}$ & $\mathrm{~N}$ & $\mathrm{~N}$ & $\mathrm{~N}$ \\
\hline 3 & \multicolumn{2}{|c|}{ REDDISH BROWN } & $\mathrm{N}$ & $\mathrm{N}$ & $\mathrm{N}$ & 5.1 \\
\hline 4 & \multicolumn{2}{|c|}{ PINK } & $\mathrm{N}$ & $N$ & $\mathrm{~N}$ & 10.2 \\
\hline 5 & \multicolumn{2}{|l|}{ PINK } & $\mathbf{N}$ & $\mathbf{N}$ & $\mathrm{N}$ & 24 \\
\hline 7 & \multicolumn{2}{|l|}{ LT RED } & $M$ & LG & 5 & 7.1 \\
\hline 8 & \multicolumn{2}{|l|}{ PINK } & $M$ & LG & 5 & $N$ \\
\hline 9 & \multicolumn{2}{|l|}{ PINK } & $M$ & $\mathrm{G}$ & 9 & $\mathrm{~N}$ \\
\hline$\overline{\text { No }}$ & Treatment & $\begin{array}{l}\text { Treatment } \\
\text { Location }\end{array}$ & $\begin{array}{l}\text { Treatment } \\
\text { Cover }\end{array}$ & $\begin{array}{l}\text { Color } \\
\text { Interior }\end{array}$ & & \\
\hline 1 & UN & $\mathbf{N}$ & $\mathbf{N}$ & $\mathbf{N}$ & $\mathbf{N}$ & \\
\hline 2 & UN & $N$ & $N$ & $N$ & $\mathrm{~N}$ & \\
\hline 3 & UN & $\mathbf{N}$ & $\mathbf{N}$ & $N$ & $\mathrm{~N}$ & \\
\hline 4 & UD & $\mathbf{N}$ & $\mathbf{N}$ & $\mathbf{N}$ & $\mathbf{N}$ & \\
\hline 5 & $\mathbf{S}$ & $E$ & ALL & $\mathbf{N}$ & & \\
\hline 7 & SB & $\mathrm{IE}$ & ALL & DK RED & & \\
\hline 8 & $S$ & ER & ALL & $\mathbf{N}$ & & BROWN \\
\hline 9 & $\mathbf{S}$ & IR & ALL & $\mathrm{N}$ & & \\
\hline
\end{tabular}

\section{Other}

1 Soot on rim suggests use as lamp; sample too small to confirm stance or diameter.

2 Metallic Ware.

3 Surface burn visible.

5 Square number questionable; may be SW 3-27.

6 Interior face and rim are slipped and burnished; upper exterior face wet-smoothed with rim; lower exterior face irregularly finished, very lightly "textured" and slipped.

$7 \quad$ Sample too small to confirm stance or diameter.

8 Very weathered.

PLATE 55. FIELD A. PHASE 3A (EB III). 

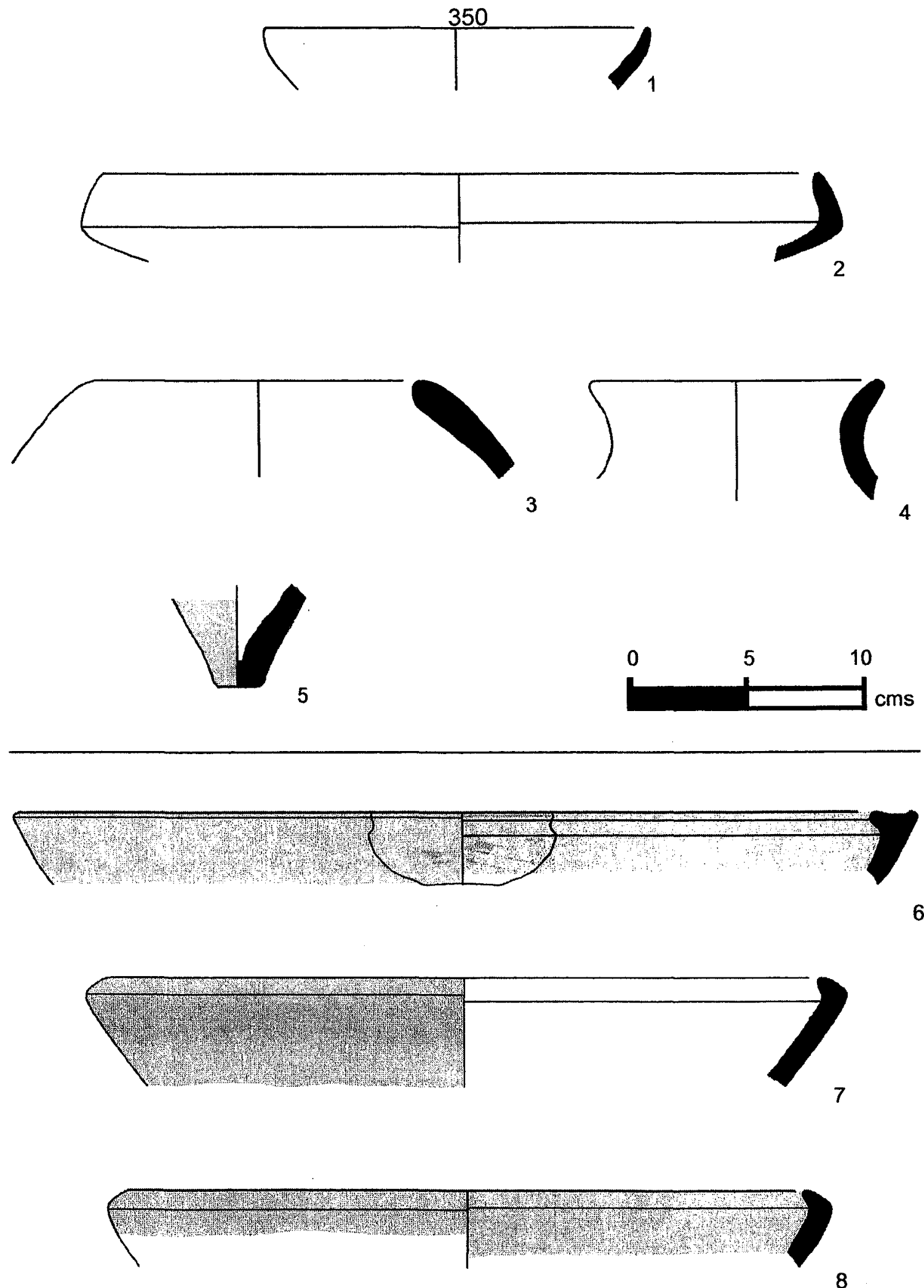

8

PLATE 55 (CONT).

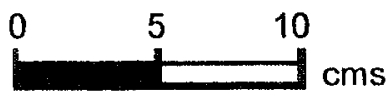




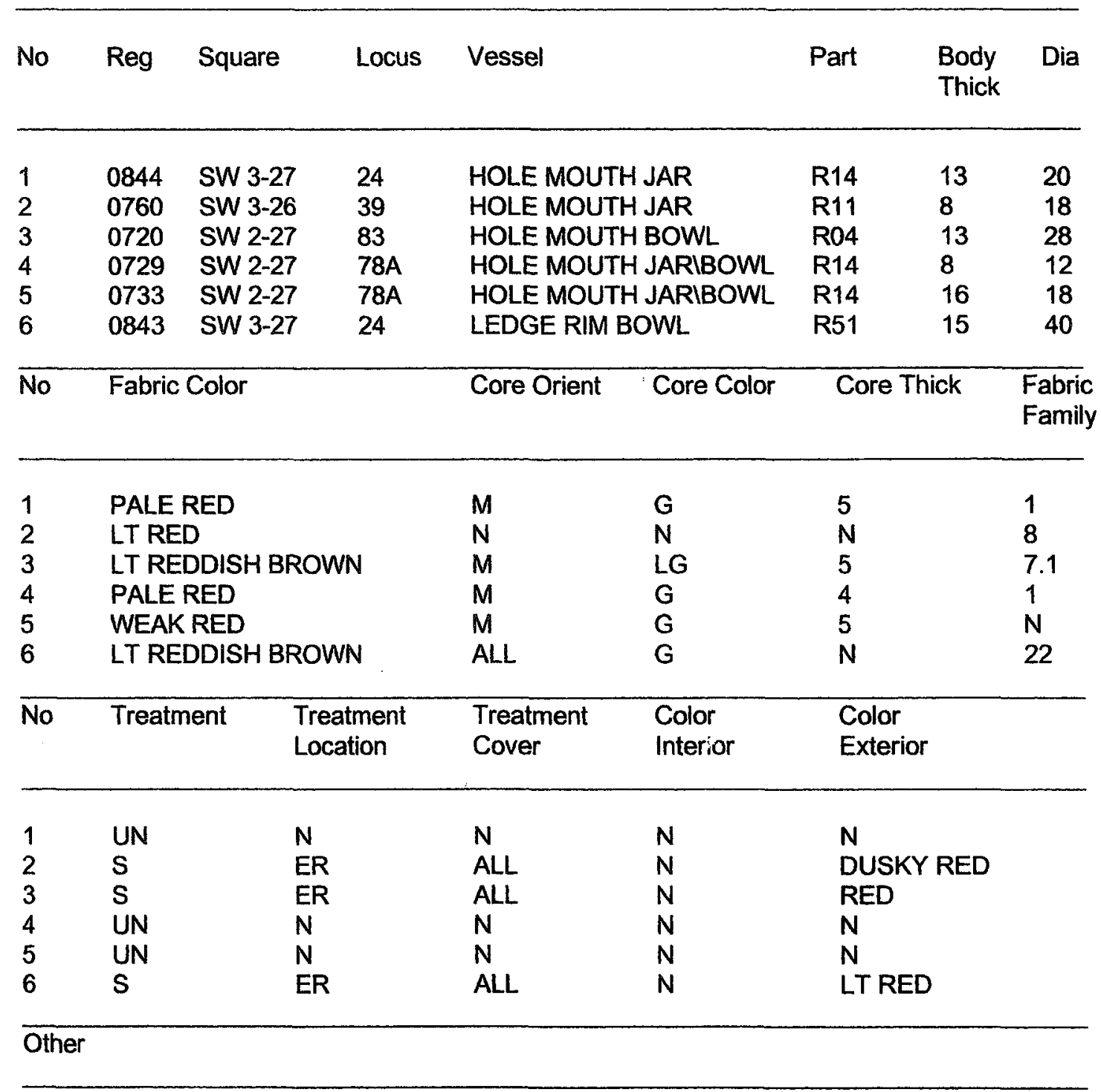

2 Also in Fabric Family 5.1. Swipe marks suggest motion to finish rim.

4 Sample too small to confirm stance or diameter.

5 Burn visible on exterior surface; sample too small to confirm stance or diameter.

6 Interior face is weathered; rim is well burnished; exterior face is uneven, smoothing lines near rim, deep scrape lines below.

PLATE 56. FIELD A. PHASE 3A (EB III). 

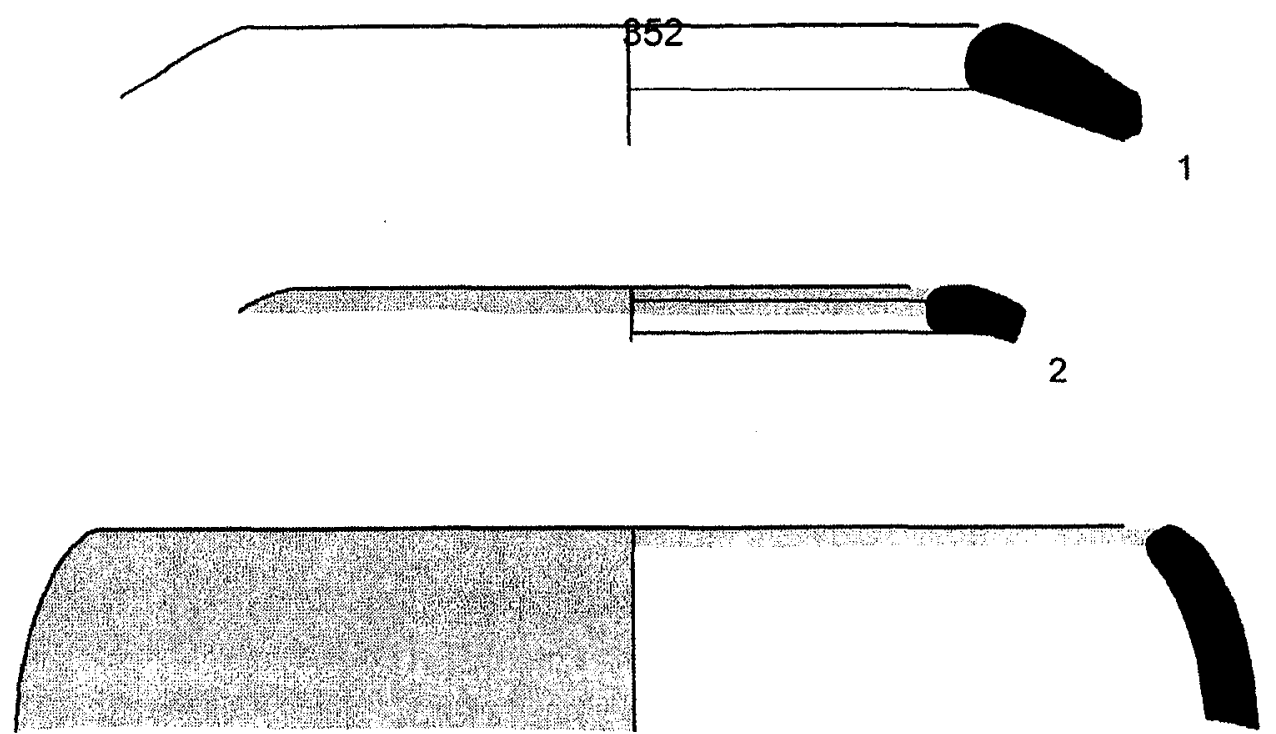

3
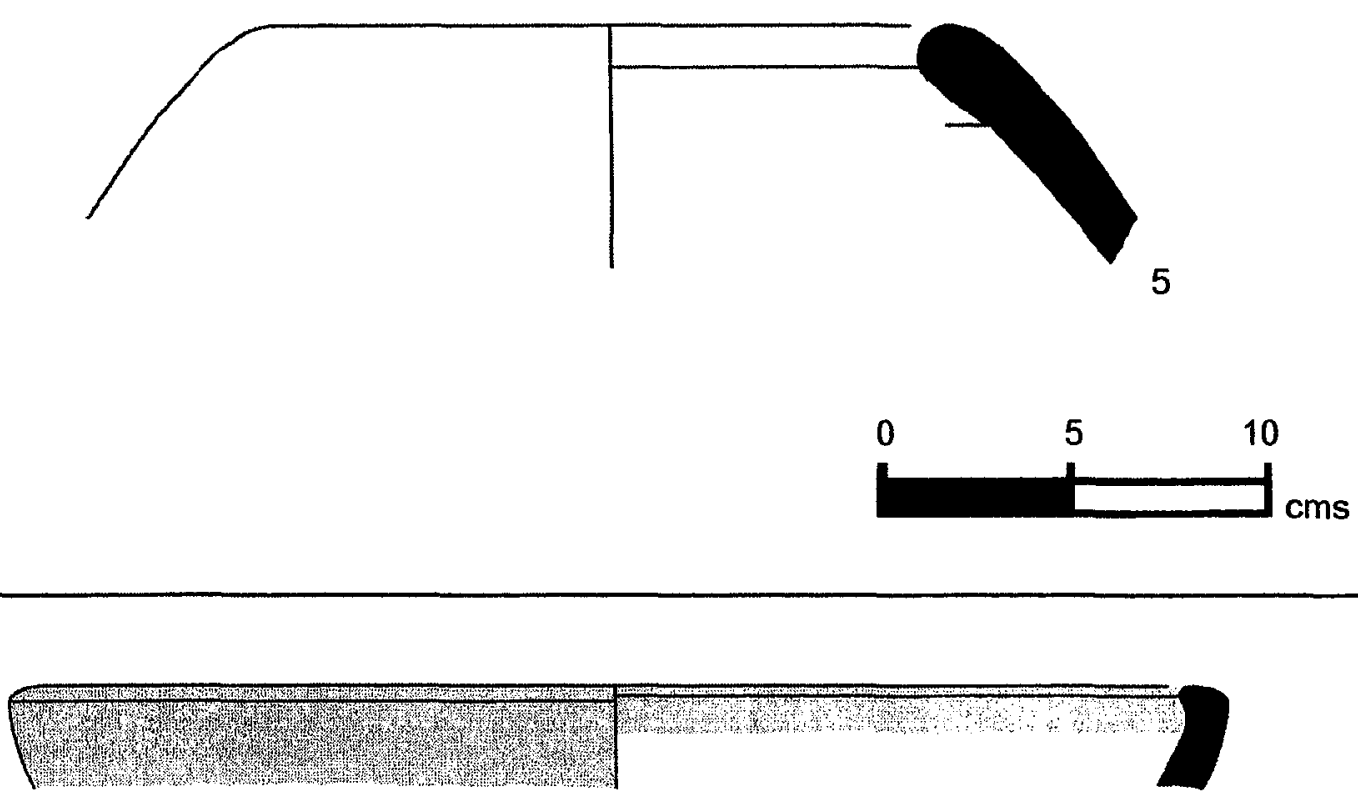

6

PLATE 56 (CONT.).

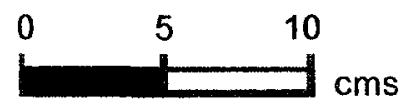




\begin{tabular}{|c|c|c|c|c|c|c|c|}
\hline No & Reg & Square & Locus & Vessel & Part & $\begin{array}{l}\text { Body } \\
\text { Thick }\end{array}$ & Dia \\
\hline 1 & 0759 & SW 3-26 & 39 & NECKED JAR & R33 & 15 & 20 \\
\hline 2 & 0845 & SW 3-27 & 24 & NECKED JAR & R31 & 5 & 10 \\
\hline 3 & 0721 & SW 2-27 & 83 & NECKED JAR & R42 & 12 & 20 \\
\hline 4 & 0730 & SW 2-27 & $78 A$ & NECKED JAR & R31 & 9 & 12 \\
\hline 5 & 0728 & SW 2-27 & $78 A$ & NECKED JAR & R31 & 7 & 15 \\
\hline 6 & 0846 & SW 3-27 & 24 & UD & B12 & 14 & 12 \\
\hline 7 & 0731 & SW 2-27 & $78 A$ & UD & $\mathrm{B} 12$ & 10 & 18 \\
\hline 8 & 0732 & SW 2-27 & $78 A$ & UD & $\mathrm{B} 24$ & 9 & 3 \\
\hline 9 & 0722 & SW 2-27 & 83 & UD & $\mathrm{H} 20$ & $\mathbf{N}$ & $\mathbf{N}$ \\
\hline
\end{tabular}

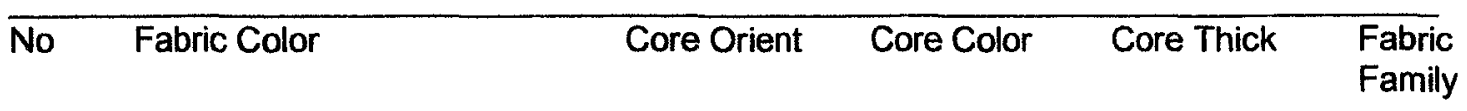

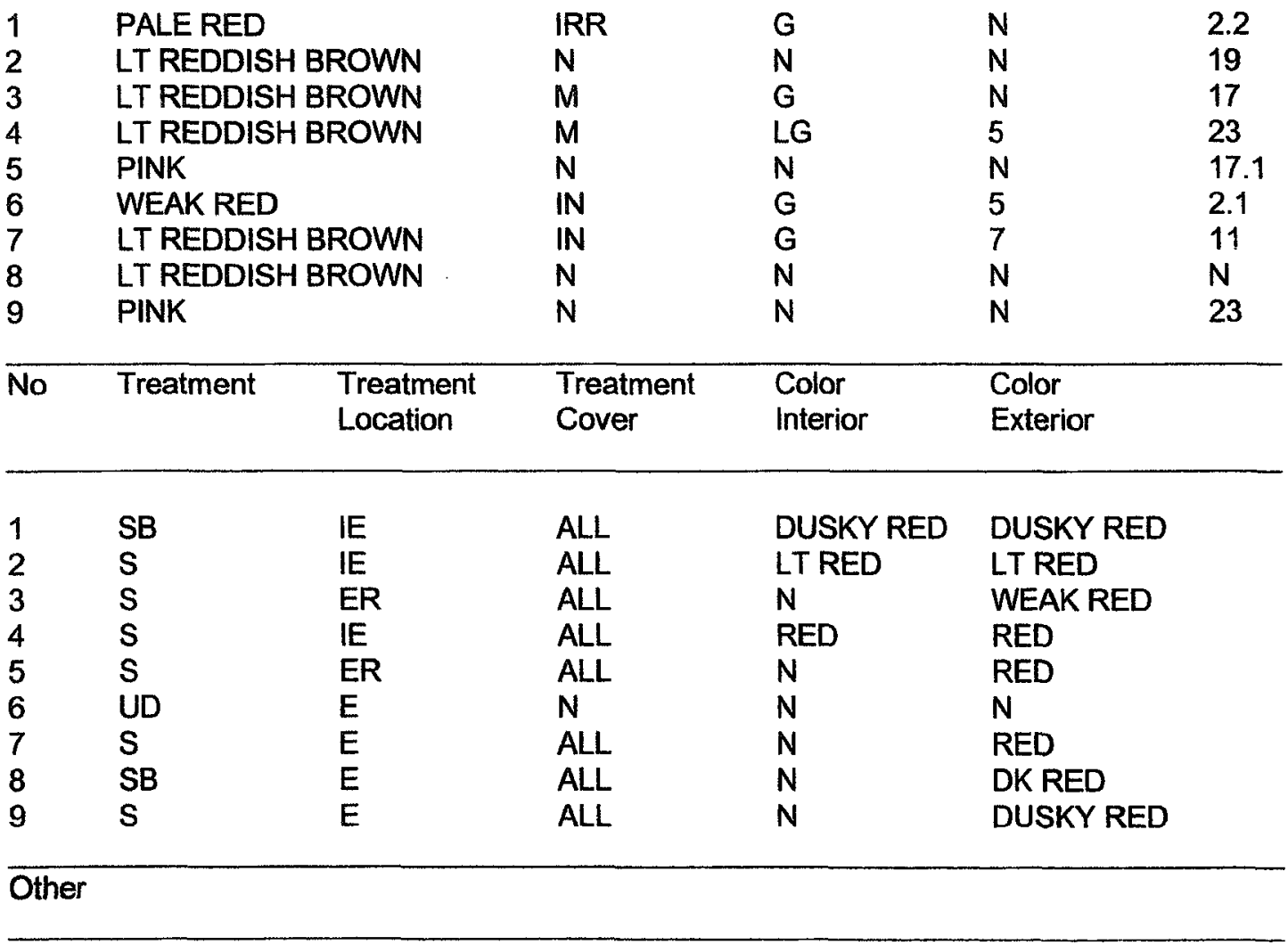

2 Sample too small to confirm stance or diameter.

3 Also in Fabric Family 17.1.

5 Fine lines of smoothing around neck exterior.

PLATE 57. FIELD A. PHASE 3A (EB III). 

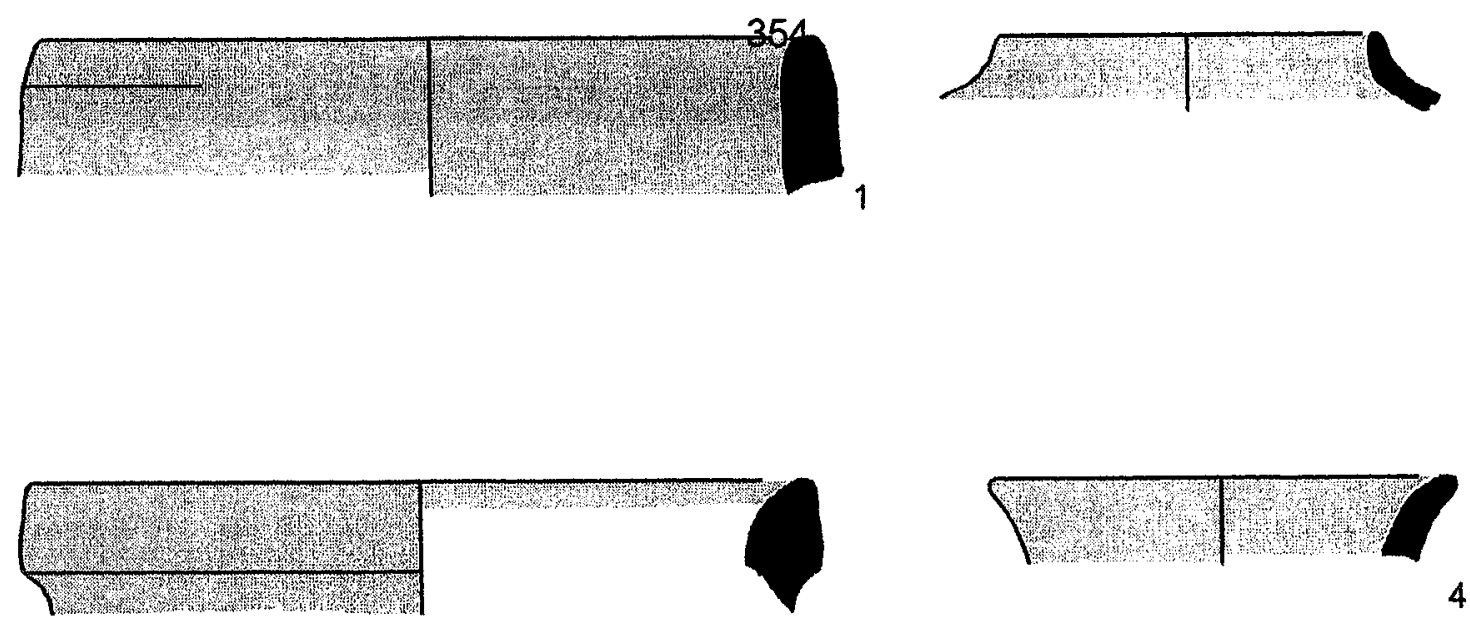

3
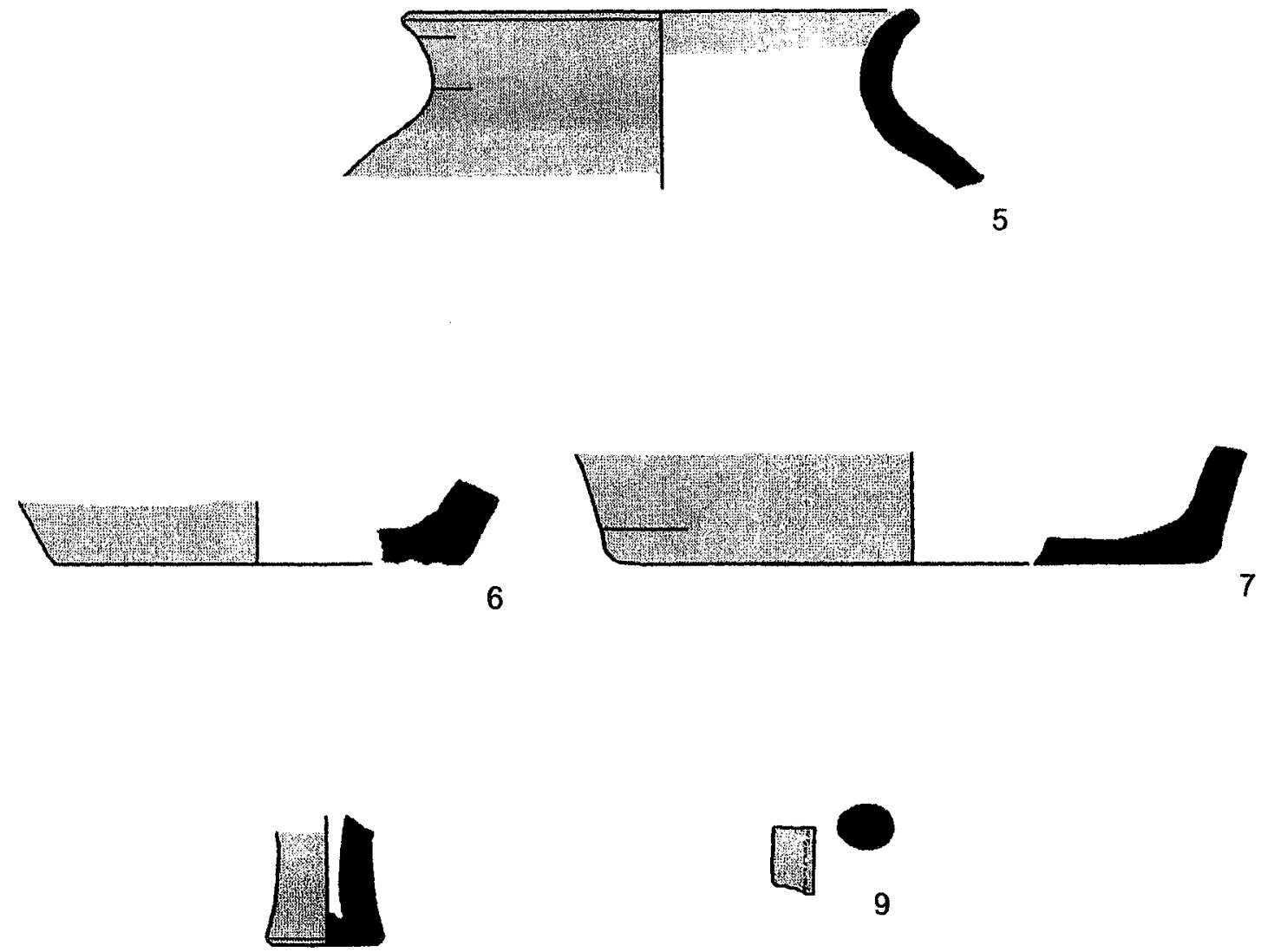

8

PLATE 57 (CONT.).

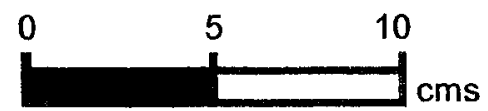




\begin{tabular}{llllllll}
\hline No & Reg & Square & Locus & Vessel & Part & $\begin{array}{l}\text { Body } \\
\text { Thick }\end{array}$ & Dia \\
\hline & & & & & & & \\
1 & 0799 & SW 3-27 & 73 & LEDGE RIM BOWL & R80 & 9 & 16 \\
2 & 0804 & SW 3-27 & 73 & HOLE MOUTH JAR & R22 & 7 & 24 \\
3 & 0801 & SW 3-27 & 73 & HOLE MOUTH BOWL & R22 & 7 & 22 \\
4 & 0797 & SW 3-27 & 72 & HOLE MOUTH BOWL & R11 & 10 & 20 \\
5 & 2328 & SW 3-27 & 73 & NECKED JAR & R30 & 4 & N \\
6 & 0800 & SW 3-27 & 73 & NECKED JAR & R30 & 9 & N \\
7 & 0805 & SW 3-27 & 73 & UD & H27 & 11 & N \\
8 & 0803 & SW 3-27 & 73 & NECKED JAR & R43 & 10 & 20 \\
9 & 0798 & SW 3-27 & 72 & UD & H12 & 6 & N \\
10 & 0806 & SW 3-27 & 73 & UD & H27 & 10 & N \\
11 & 0802 & SW 3-27 & 73 & UD & B12 & 8 & 16 \\
\end{tabular}

\begin{tabular}{lllll}
\hline No Fabric Color & Core Orient & Core Color & Core Thick & $\begin{array}{l}\text { Fabric } \\
\text { Family }\end{array}$
\end{tabular}

\begin{tabular}{|c|c|c|c|c|c|c|}
\hline 1 & \multirow{2}{*}{\multicolumn{2}{|c|}{$\begin{array}{l}\text { PINK } \\
\text { PALE RED }\end{array}$}} & $M$ & LG & 2 & 20 \\
\hline 2 & & & $M$ & LG & 3 & 7.2 \\
\hline 3 & \multicolumn{2}{|l|}{$\begin{array}{l}\text { PALLE RED } \\
\text { LTRED }\end{array}$} & IRR & $\mathrm{G}$ & $N$ & 9.2 \\
\hline 4 & \multicolumn{2}{|c|}{ LT REDDISH BROWN } & $M$ & G & 4 & 1 \\
\hline 5 & \multicolumn{2}{|c|}{ PINK } & $\mathrm{N}$ & $\mathbf{N}$ & $\mathbf{N}$ & $\mathrm{N}$ \\
\hline 6 & \multicolumn{2}{|l|}{ LTRED } & ALL & $G$ & $N$ & 17.1 \\
\hline 7 & \multicolumn{2}{|l|}{ LT RED } & $M$ & $\mathbf{G}$ & 5 & 7.1 \\
\hline 8 & \multicolumn{2}{|l|}{ PINK } & $M$ & LG & 5 & 7.2 \\
\hline 9 & \multicolumn{2}{|c|}{ LT REDDISH BROWN } & IRR & LG & $\mathbf{N}$ & $\mathbf{N}$ \\
\hline 10 & \multicolumn{2}{|c|}{ PINK } & $M$ & LG & 2 & 17.2 \\
\hline 11 & \multicolumn{2}{|l|}{ LT RED } & IRR & LG & $\bar{N}$ & 8 \\
\hline No & Treatment & $\begin{array}{l}\text { Treatment } \\
\text { Location }\end{array}$ & $\begin{array}{l}\text { Treatment } \\
\text { Cover }\end{array}$ & $\begin{array}{l}\text { Color } \\
\text { Interior }\end{array}$ & $\begin{array}{l}\text { Color } \\
\text { Exterior }\end{array}$ & \\
\hline 1 & SB & ER & ALL & $\mathbf{N}$ & RED & \\
\hline 2 & $\mathbf{S}$ & ER & ALL & $\mathbf{N}$ & RED & \\
\hline 3 & WASH & $E$ & $N$ & $N$ & WHITE & \\
\hline 4 & UN & $\mathbf{N}$ & $N$ & $N$ & $N$ & \\
\hline 5 & UN & $\mathbf{N}$ & $\mathbf{N}$ & $\mathbf{N}$ & $N$ & \\
\hline 6 & $\mathrm{~s}$ & IE & ALL & RED & RED & \\
\hline 7 & $\mathbf{S}$ & $E$ & ALL & $\mathbf{N}$ & RED & \\
\hline 8 & $\mathrm{~s}$ & ER & ALL & $N$ & RED & \\
\hline 9 & UN & $\mathbf{N}$ & $\mathbf{N}$ & $\mathbf{N}$ & $\mathrm{N}$ & \\
\hline 10 & $S$ & $E$ & ALL & $\mathbf{N}$ & RED & \\
\hline 11 & UN & $\mathbf{N}$ & $N$ & $N$ & $N$ & \\
\hline
\end{tabular}

PLATE 58. FIELD A. PHASE 3A (EB III). 
Other

$5 \quad$ Vestigal handle on exterior wall.

$6 \quad$ Also in Fabric Families 17.2 and 18; vestigial ledge handle on exterior shoulder; short vertical incisions in margin around mouth.

11 Metallic Ware.

PLATE 58 (CONT.). 


\section{7}

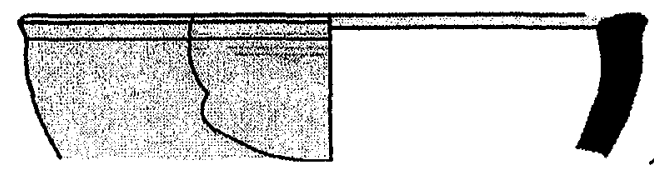

1
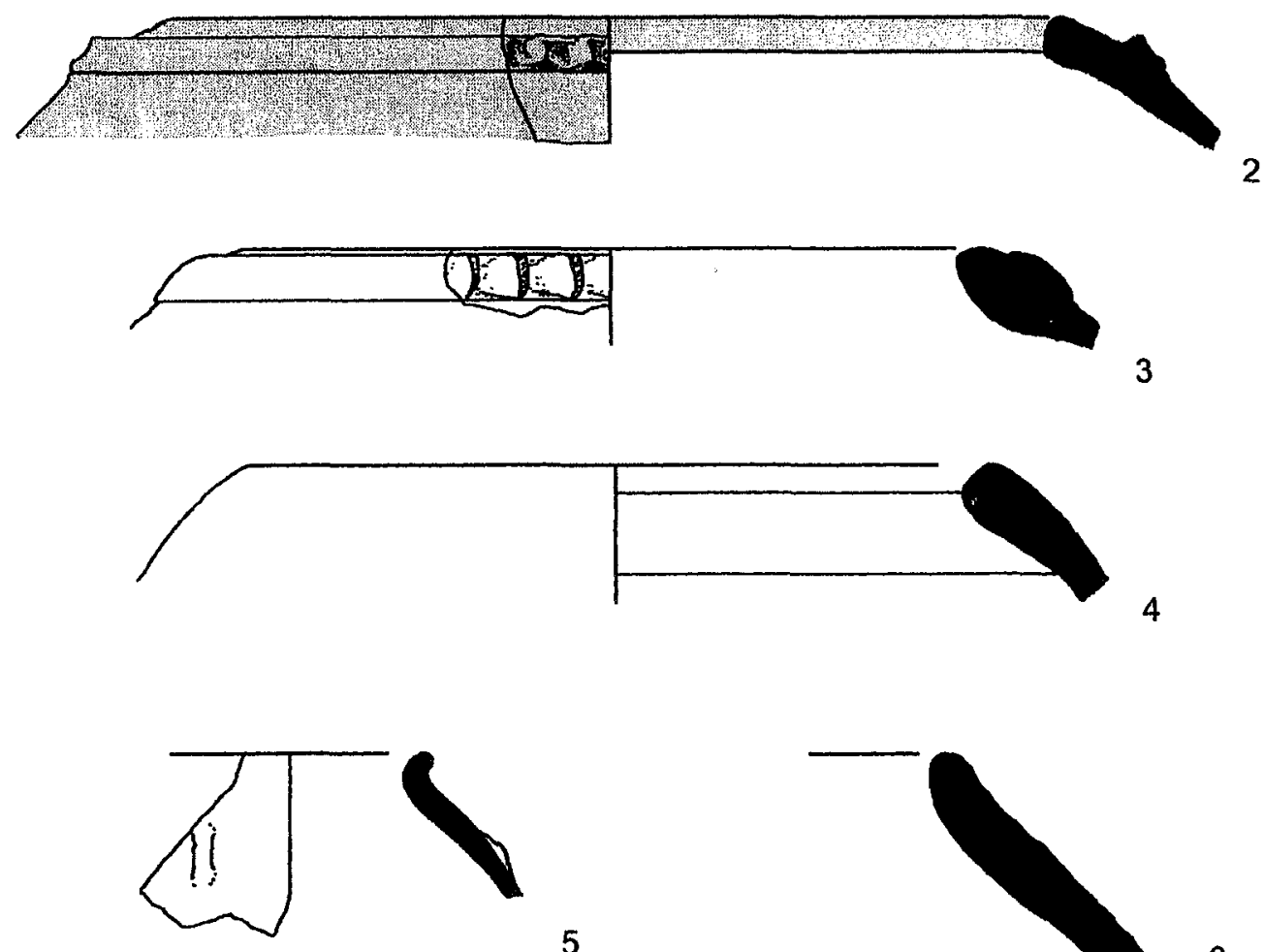

5
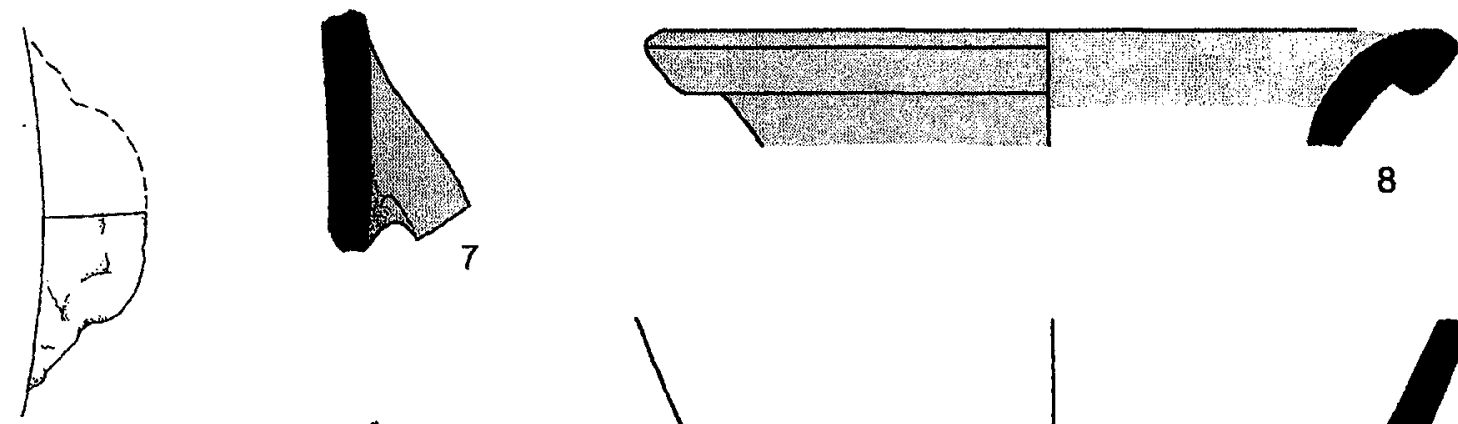

8
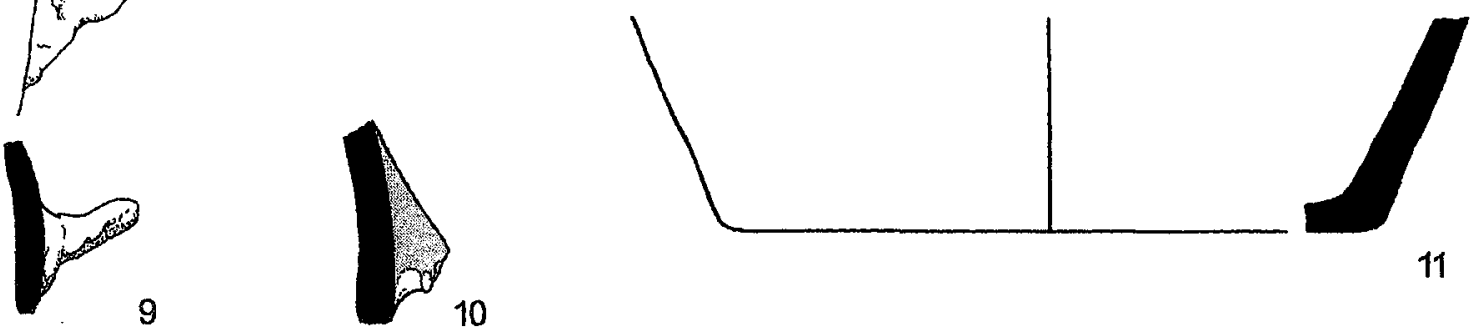

10

PLATE 58 (CONT.).

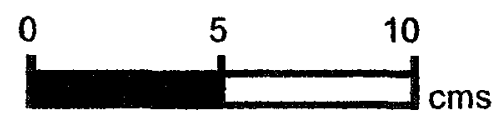




\begin{tabular}{|c|c|c|c|c|c|c|c|}
\hline No & $\operatorname{Reg}$ & Square & Locus & Vessel & Part & $\begin{array}{l}\text { Body } \\
\text { Thick }\end{array}$ & $\overline{\text { Dia }}$ \\
\hline 1 & 0911 & SW 4-26 & 15 & LEDGE RIM BOWL & R53 & 7 & 26 \\
\hline 2 & 0931 & SW 4-26 & 15 & LEDGE RIM BOWL & R53 & 7 & 20 \\
\hline 3 & 0936 & SW 4-26 & 15 & LEDGE RIM BOWL & R53 & 7 & 18 \\
\hline 4 & 0909 & SW 4-26 & 15 & HOLE MOUTH JAR & $\mathrm{R} 21$ & 12 & 22 \\
\hline 5 & 0921 & SW 4-26 & 15 & HOLE MOUTH BOWL. & $\mathrm{R} 14$ & 8 & $N$ \\
\hline 6 & 0918 & SW 4-26 & 15 & HOLE MOUTH JAR & $\mathrm{R} 14$ & $\mathbf{N}$ & 20 \\
\hline 7 & 0916 & SW 4-26 & 15 & HOLE MOUTH JAR & $\mathrm{R} 14$ & 14 & 20 \\
\hline 8 & 0919 & SW 4-26 & 15 & HOLE MOUTH JAR & R04 & 17 & $\mathbf{N}$ \\
\hline 9 & 0912 & SW 4-26 & 15 & HOLE MOUTH BOWL & R08 & 10 & 16 \\
\hline 10 & 0937 & SW 4-26 & 15 & HOLE MOUTH BOWL & $\mathrm{R} 17$ & 9 & $\mathbf{N}$ \\
\hline 11 & 0935 & SW 4-26 & 15 & HOLE MOUTH BOWL & $\mathrm{R} 20$ & 8 & 16 \\
\hline 12 & 0933 & SW 4-26 & 15 & HOLE MOUTH JAR & R14 & 9 & $N$ \\
\hline 13 & 0927 & SW 4-26 & 15 & HOLE MOUTH JAR & R02 & 9 & 15 \\
\hline
\end{tabular}

\begin{tabular}{|c|c|c|c|c|c|c|c|}
\hline 1 & \multicolumn{2}{|l|}{ PINK } & $N$ & $N$ & $N$ & & $N$ \\
\hline 2 & \multicolumn{2}{|l|}{ PINK } & $\mathrm{N}$ & $N$ & $\mathrm{~N}$ & & $N$ \\
\hline 3 & \multicolumn{2}{|l|}{ PINK } & $N$ & $N$ & $N$ & & $\mathbf{N}$ \\
\hline 4 & \multicolumn{2}{|l|}{ PINK } & $M$ & G & 6 & & $N$ \\
\hline 5 & \multicolumn{2}{|l|}{ PINK } & ALL & $\mathbf{G}$ & $N$ & & $N$ \\
\hline 6 & \multicolumn{2}{|c|}{ LT REDDISH BROWN } & IRR & LG & $N$ & & $N$ \\
\hline 7 & \multicolumn{2}{|c|}{ LT REDDISH BROWN } & $\mathbf{N}$ & $N$ & $\mathbf{N}$ & & $\mathbf{N}$ \\
\hline 8 & \multicolumn{2}{|l|}{ PINK } & IRR & G & $\mathrm{N}$ & & $\mathbf{N}$ \\
\hline 9 & \multicolumn{2}{|c|}{ PALE RED } & IRR & G & $N$ & & $\mathbf{N}$ \\
\hline 10 & \multicolumn{2}{|c|}{ LT REDDISH BROWN } & IRR & G & $\mathbf{N}$ & & $\mathbf{N}$ \\
\hline 11 & \multicolumn{2}{|c|}{ PINK } & IRR & LG & $\mathrm{N}$ & & $N$ \\
\hline 12 & \multicolumn{2}{|c|}{ LT REDDISH BROWN } & ALL & $\mathbf{G}$ & $\mathbf{N}$ & & $\mathbf{N}$ \\
\hline 13 & \multicolumn{2}{|c|}{ LT REDDISH BROWN } & IRR & $\mathbf{G}$ & $N$ & & N \\
\hline No & Treatment & $\begin{array}{l}\text { Treatment } \\
\text { Location }\end{array}$ & $\begin{array}{l}\text { Treatment } \\
\text { Cover }\end{array}$ & $\begin{array}{l}\text { Color } \\
\text { Interior }\end{array}$ & & $\begin{array}{l}\text { Color } \\
\text { Exterior }\end{array}$ & \\
\hline 1 & SB & IR & ALL & RED & & $N$ & \\
\hline 2 & SB & IR & $\mathrm{ALL}$ & RED & & $N$ & \\
\hline 3 & SB & IR & ALL & REDDIS & DWN & $N$ & \\
\hline 4 & UN & $\mathbf{N}$ & $\mathbf{N}$ & $N$ & & $\mathbf{N}$ & \\
\hline 5 & UN & $N$ & $N$ & $\mathrm{~N}$ & & $N$ & \\
\hline 6 & UN & $\mathbf{N}$ & $\mathbf{N}$ & $\ddot{N}$ & & $N$ & \\
\hline 7 & $S$ & ER & $A L L$ & $N$ & & RED & \\
\hline 8 & UN & $\mathbf{N}$ & $\mathbf{N}$ & $\mathrm{N}$ & & $N$ & \\
\hline 9 & UN & $\mathbf{N}$ & $N$ & $\mathbf{N}$ & & $\mathbf{N}$ & \\
\hline 10 & $S$ & ER & ALL & $\mathrm{N}$ & & RED & \\
\hline
\end{tabular}

PLATE 59. FIELD A. PHASE 3A (EB III). 
359

\begin{tabular}{llllll}
\hline No & Treatment & $\begin{array}{l}\text { Treatment } \\
\text { Location }\end{array}$ & $\begin{array}{l}\text { Treatment } \\
\text { Cover }\end{array}$ & $\begin{array}{l}\text { Color } \\
\text { Interior }\end{array}$ & $\begin{array}{l}\text { Color } \\
\text { Exterior }\end{array}$ \\
\hline 11 & UN & $\mathrm{N}$ & $\mathrm{N}$ & $\mathrm{N}$ & $\mathrm{N}$ \\
12 & UN & $\mathrm{N}$ & $\mathrm{N}$ & $\mathrm{N}$ & $\mathrm{N}$ \\
13 & UN & $\mathrm{N}$ & $\mathrm{N}$ & $\mathrm{N}$ & $\mathrm{N}$ \\
\hline
\end{tabular}

\section{Other}

$1 \quad$ Margin of wet smoothing visible on exterior wall below rim.

3 Radial burnish over slip on interior face; exterior face is wet-smoothed.

5 Sample too small to confirm stance or diameter.

6 Surface burn visible.

8 Sample too small to confirm stance or diameter.

9 Rim smoothing and wall scraping visible on interior; surface burn visible.

10 Sample too small to confirm stance or diameter.

11 Surface burn visible.

12 Sample too small to confirm stance or diameter; surface burn visible.

13 Surface burn visible; marks on rim show finish motion.

PLATE 59 (CONT.). 

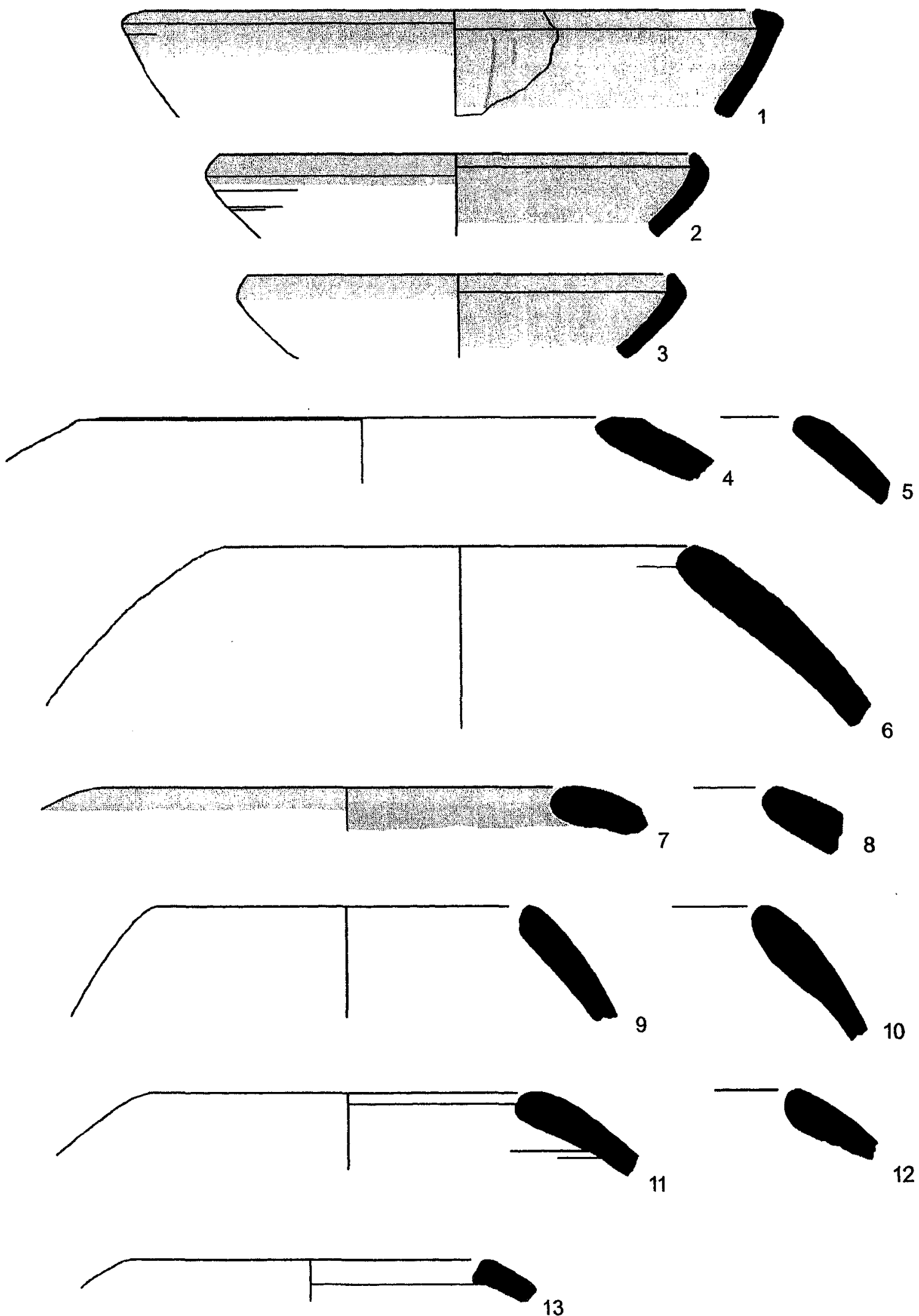

13

PLATE 59 (CONT.).

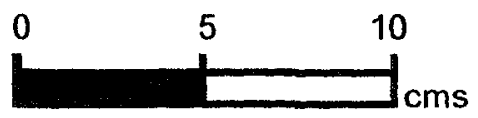




\begin{tabular}{llllllll}
\hline No & Reg & Square & Locus & Vessel & Part & $\begin{array}{l}\text { Body } \\
\text { Thick }\end{array}$ & Dia \\
& & & & & & & \\
1 & 0922 & SW 4-26 & 15 & HOLE MOUTH BOWL & R07 & 8 & 10 \\
2 & 0910 & SW 4-26 & 15 & UD & R14 & 11 & 30 \\
3 & 0920 & SW 4-26 & 15 & HOLE MOUTH JAR & R04 & 10 & 10 \\
4 & 0938 & SW 4-26 & 15 & HOLE MOUTH BOWL & R04 & 15 & 26 \\
5 & 0917 & SW 4-26 & 15 & NECKED JAR & R32 & 10 & 20 \\
6 & 0913 & SW 4-26 & 15 & NECKED JAR & R32 & 14 & 14 \\
7 & 0926 & SW 4-26 & 15 & NECKED JAR & R31 & 10 & 16 \\
8 & 0925 & SW 4-26 & 15 & NECKED JAR & R31 & 8 & 15 \\
9 & 0924 & SW 4-26 & 15 & NECKED JAR & R31 & 8 & 12 \\
10 & 0908 & SW 4-26 & 15 & NECKED JAR & R31 & 15 & 20 \\
11 & 0923 & SW 4-26 & 15 & NECKED JAR & R43 & 8 & 13 \\
12 & 0928 & SW 4-26 & 15 & CHANNELED RIM JAR & R35 & 7 & 12 \\
\hline No & Fabric Color & & Core Orient Core Color & Core Thick & Fabric \\
& & & & & & Family \\
& & & & & &
\end{tabular}

\begin{tabular}{|c|c|c|c|c|c|c|}
\hline 1 & \multicolumn{2}{|l|}{ PINK } & N & $\mathrm{N}$ & $\mathrm{N}$ & $N$ \\
\hline 2 & \multicolumn{2}{|l|}{ PINK } & $M$ & G & 3 & $\mathbf{N}$ \\
\hline 3 & \multicolumn{2}{|c|}{ LT REDDISH BROWN } & $\mathbb{N}$ & G & 7 & $\mathbf{N}$ \\
\hline 4 & \multicolumn{2}{|c|}{ PALE RED } & M & G & 6 & $N$ \\
\hline 5 & \multicolumn{2}{|l|}{ LTRED } & $\mathbf{M}$ & G & 5 & $N$ \\
\hline 6 & \multicolumn{2}{|l|}{ LT RED } & IN & G & 11 & $\mathbf{N}$ \\
\hline 7 & \multicolumn{2}{|l|}{ PINK } & $\mathbf{M}$ & G & 5 & $\mathbf{N}$ \\
\hline 8 & \multicolumn{2}{|l|}{ PINK } & M & LG & 2 & $\mathbf{N}$ \\
\hline 9 & \multirow{2}{*}{\multicolumn{2}{|c|}{$\begin{array}{l}\text { LT RED } \\
\text { LT REDDISH BROWN }\end{array}$}} & $M$ & G & 2 & $\mathbf{N}$ \\
\hline 10 & & & $M$ & $\mathbf{G}$ & 9 & $\mathbf{N}$ \\
\hline 11 & \multicolumn{2}{|l|}{ LT RED } & $\mathbf{N}$ & $\mathbf{N}$ & $\mathbf{N}$ & $\mathrm{N}$ \\
\hline 12 & \multicolumn{2}{|c|}{ LT REDDISH BROWN } & $N$ & $\mathbf{N}$ & $\mathbf{N}$ & $\mathrm{N}$ \\
\hline$\overline{\text { No }}$ & Treatment & $\begin{array}{l}\text { Treatment } \\
\text { Location }\end{array}$ & $\begin{array}{l}\text { Treatment } \\
\text { Cover }\end{array}$ & $\begin{array}{l}\text { Color } \\
\text { Interior }\end{array}$ & $\begin{array}{l}\text { Color } \\
\text { Exterior }\end{array}$ & \\
\hline 1 & $\mathbf{S}$ & ER & ALL & $\mathbf{N}$ & DUSKY RED & \\
\hline 2 & $\mathbf{S}$ & ER & ALL & $\mathbf{N}$ & RED & \\
\hline 3 & UN & $\mathbf{N}$ & $\mathbf{N}$ & $\mathbf{N}$ & $\mathbf{N}$ & \\
\hline 4 & UN & $\mathrm{N}$ & $\mathbf{N}$ & $\mathbf{N}$ & $\mathbf{N}$ & \\
\hline 5 & SB & ER & ALL & $\mathbf{N}$ & DK RED & \\
\hline 6 & UN & $\mathrm{N}$ & $\mathbf{N}$ & $\mathbf{N}$ & $\mathrm{N}$ & \\
\hline 7 & $\mathbf{S}$ & IE & ALL & DK RED & DK RED & \\
\hline 8 & UN & $\mathbf{N}$ & $\mathbf{N}$ & $\mathbf{N}$ & $\mathbf{N}$ & \\
\hline 9 & $\mathrm{~S}$ & ER & ALL & $\mathbf{N}$ & RED & \\
\hline 10 & $\mathbf{s}$ & $E$ & ALL & $\mathrm{N}$ & RED & \\
\hline 11 & UN & $\mathbf{N}$ & $\mathbf{N}$ & $N$ & $\mathbf{N}$ & \\
\hline 12 & UN & $\mathrm{N}$ & $\mathbf{N}$ & $\mathbf{N}$ & $N$ & \\
\hline
\end{tabular}

PLATE 60. FIELD A. PHASE 3A (EB III). 


\section{Other}

2 Sample too small to confirm stance or diameter.

3 Surface burn visible.

4 Sample too small to confirm stance or diameter.

5 Roughly finished.

11 Metallic Ware.

12 Metallic Ware.

PLATE 60 (CONT.). 


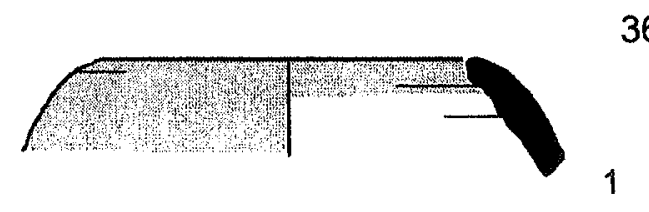

363

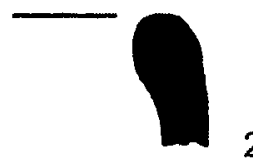

2

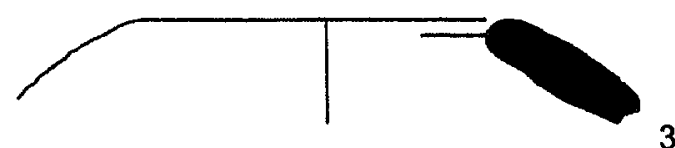

3
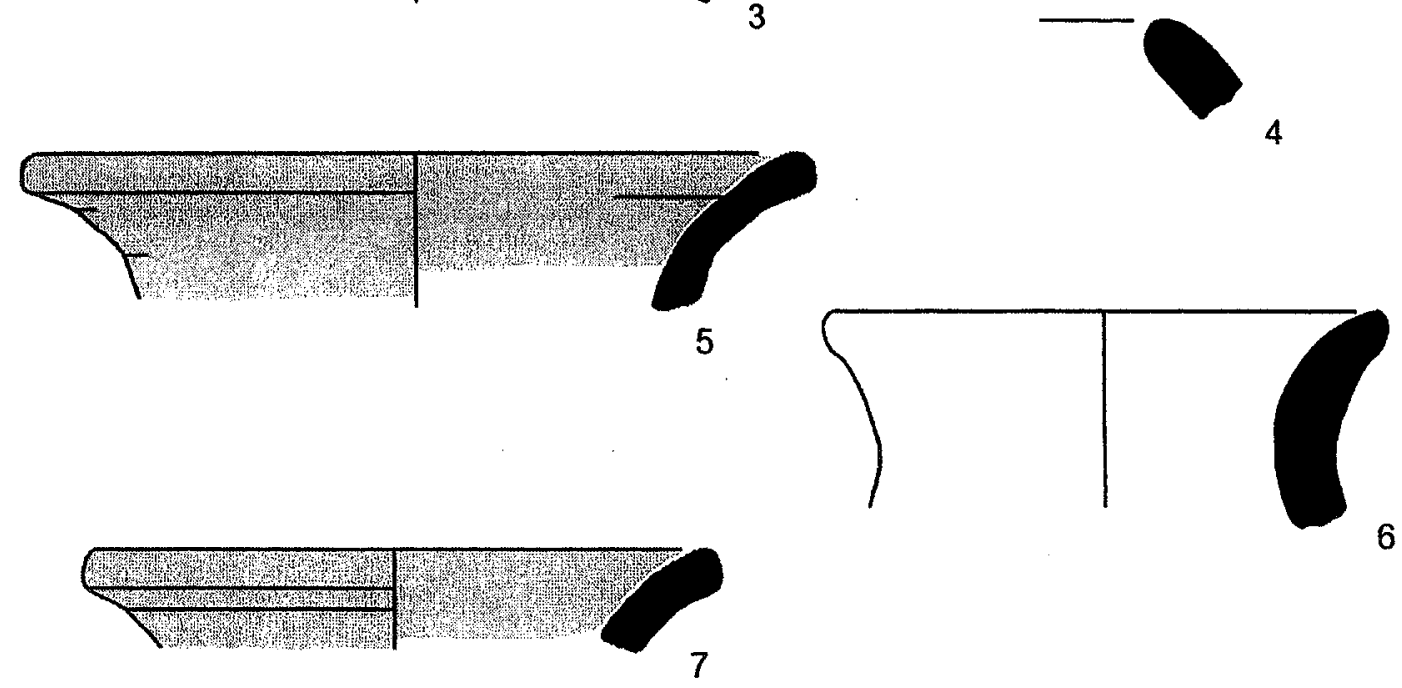

7
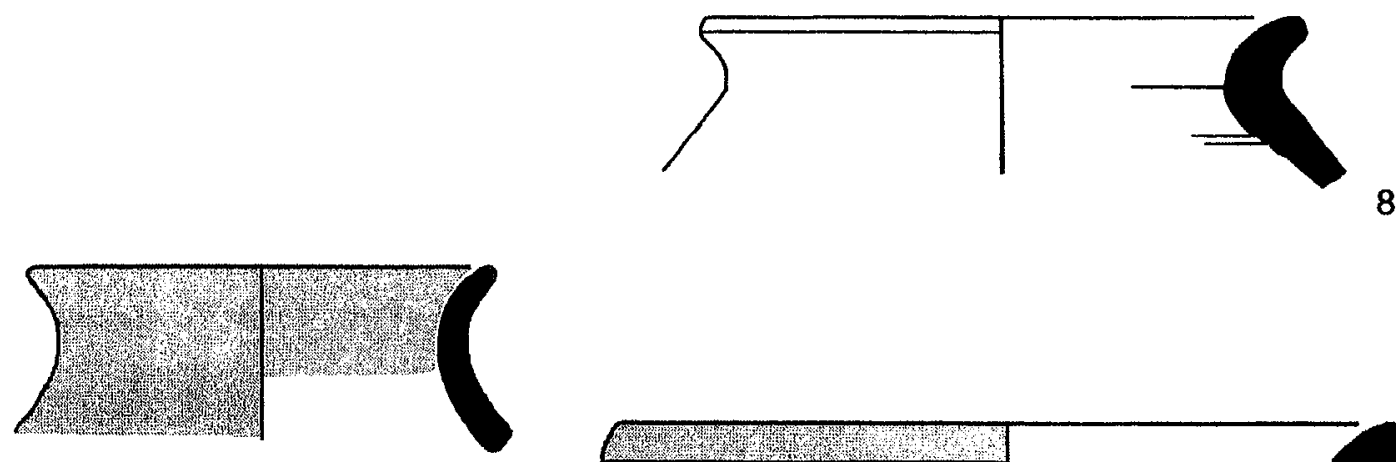

9
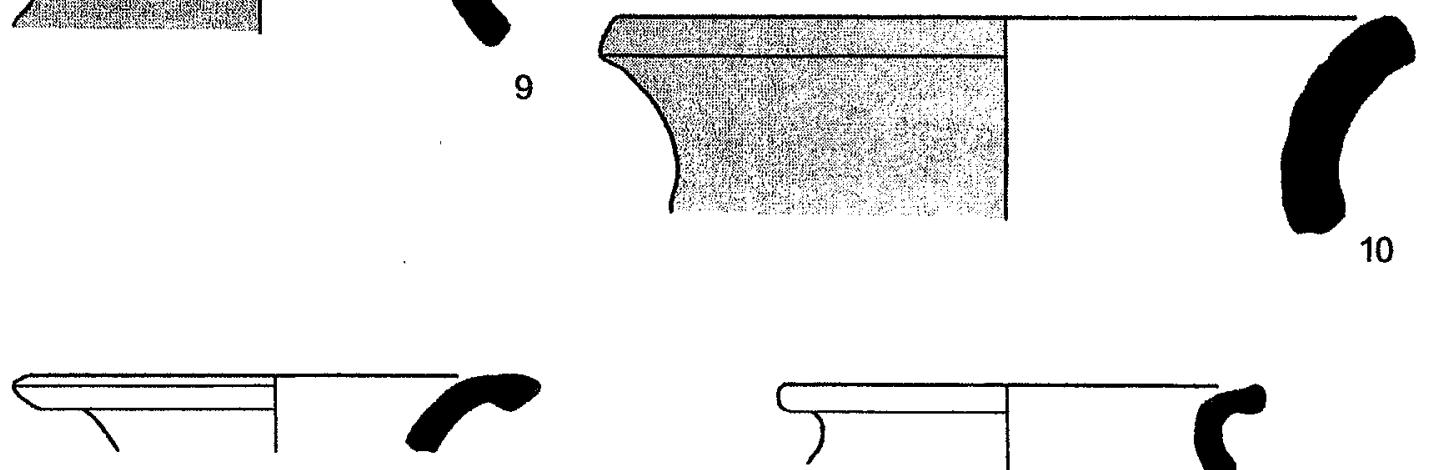

11

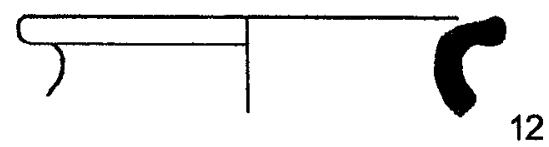

PLATE 60 (CONT.).

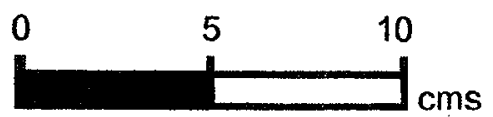




\begin{tabular}{llllllll}
\hline No & Reg & Square & Locus & Vessel & Part & $\begin{array}{l}\text { Body } \\
\text { Thick }\end{array}$ & Dia \\
\hline 1 & & & & & & & \\
\hline & 0914 & SW 4-26 & 15 & HOLE MOUTH JAR & R21 & 13 & 10 \\
2 & 0939 & SW 4-26 & 15 & LEDGE RIM BOWL & R83 & 14 & 30 \\
3 & 0943 & SW 4-26 & 15 & UD & B12 & 13 & 18 \\
4 & 0942 & SW 4-26 & 15 & UD & B11 & 8 & 19 \\
5 & 0941 & SW 4-26 & 15 & UD & B12 & 5 & 15 \\
6 & 0944 & SW 4-26 & 15 & UD & BOD & 10 & N \\
7 & 0940 & SW 4-26 & 15 & UD & H20 & 7 & N \\
8 & 0934 & SW 4-26 & 15 & PLATTER BOWL & R56 & 8 & 40 \\
9 & 0930 & SW 4-26 & 15 & HOLE MOUTH BOWL & R21 & 9 & 42 \\
\hline No & Fabric Color & & Core Orient Core Color & Core Thick & Fabric \\
& & & & & & & Family \\
\end{tabular}

$\begin{array}{llllll}1 & \text { LT REDDISH BROWN } & \text { ALL } & \text { G } & \text { N } & \text { N } \\ 2 & \text { PINK } & \text { M } & \text { G } & 11 & \text { N } \\ 3 & \text { PINK } & \text { M } & \text { LG } & 4 & \text { N } \\ 4 & \text { LTRED } & \text { N } & \text { N } & \text { N } & \text { N } \\ 5 & \text { PINK } & \text { IRR } & \text { G } & \text { N } & \text { N } \\ 6 & \text { REDDISH YELLOW } & \text { N } & \text { G } & 8 & \text { N } \\ 7 & \text { PINK } & \text { IRR } & \text { LG } & \text { N } & \text { N } \\ 8 & \text { LT BROWN } & \text { N } & \text { N } & \text { N } & \text { N } \\ 9 & \text { PINK } & \text { IRR } & \text { G } & \text { N } & \text { N }\end{array}$

\begin{tabular}{lllll}
\hline No Treatment & $\begin{array}{l}\text { Treatment } \\
\text { Location }\end{array}$ & $\begin{array}{l}\text { Treatment } \\
\text { Cover }\end{array}$ & $\begin{array}{l}\text { Color } \\
\text { Interior }\end{array}$ & $\begin{array}{l}\text { Color } \\
\text { Exterior }\end{array}$ \\
\hline
\end{tabular}

$\begin{array}{llllll}1 & \text { UN } & \text { N } & \text { N } & N & \text { N } \\ 2 & \text { S } & \text { ER } & \text { ALL } & \text { N } & \text { RED } \\ 3 & \text { S } & \text { E } & \text { N } & \text { N } & \text { WEAK RED } \\ 4 & \text { UN } & \text { N } & \text { N } & \text { N } & \text { N } \\ 5 & \text { SB } & \text { E } & \text { ALL } & N & \text { RED } \\ 6 & 1 & \text { E } & \text { ALL } & N & N \\ 7 & \text { S } & \text { E } & \text { ALL } & \text { N } & \text { RED } \\ 8 & \text { SB } & \text { IR } & \text { ALL } & \text { WEAKRED } & \text { N } \\ 9 & \text { S } & \text { ER } & \text { ALL } & \text { N } & \text { DUSKY RED }\end{array}$

PLATE 61. FIELD A. PHASE 3A (EB III). 
Other

1 "Margin" on rim is wet-turned; fingernailtool marks visible in groove.

2 Flattened rim protrudes slightly on exterior side; horizontal smoothing marks visible on interiorlexterior of rim; interior face is diagonally smoothed.

$4 \quad$ Metallic Ware.

6 Combed Metallic Ware.

8 Net burnish over slip on interior face; wet-smoothed concavity is very slight.

9 "Margin" on rim is well smoothed.

PLATE 61 (CONT.). 
366
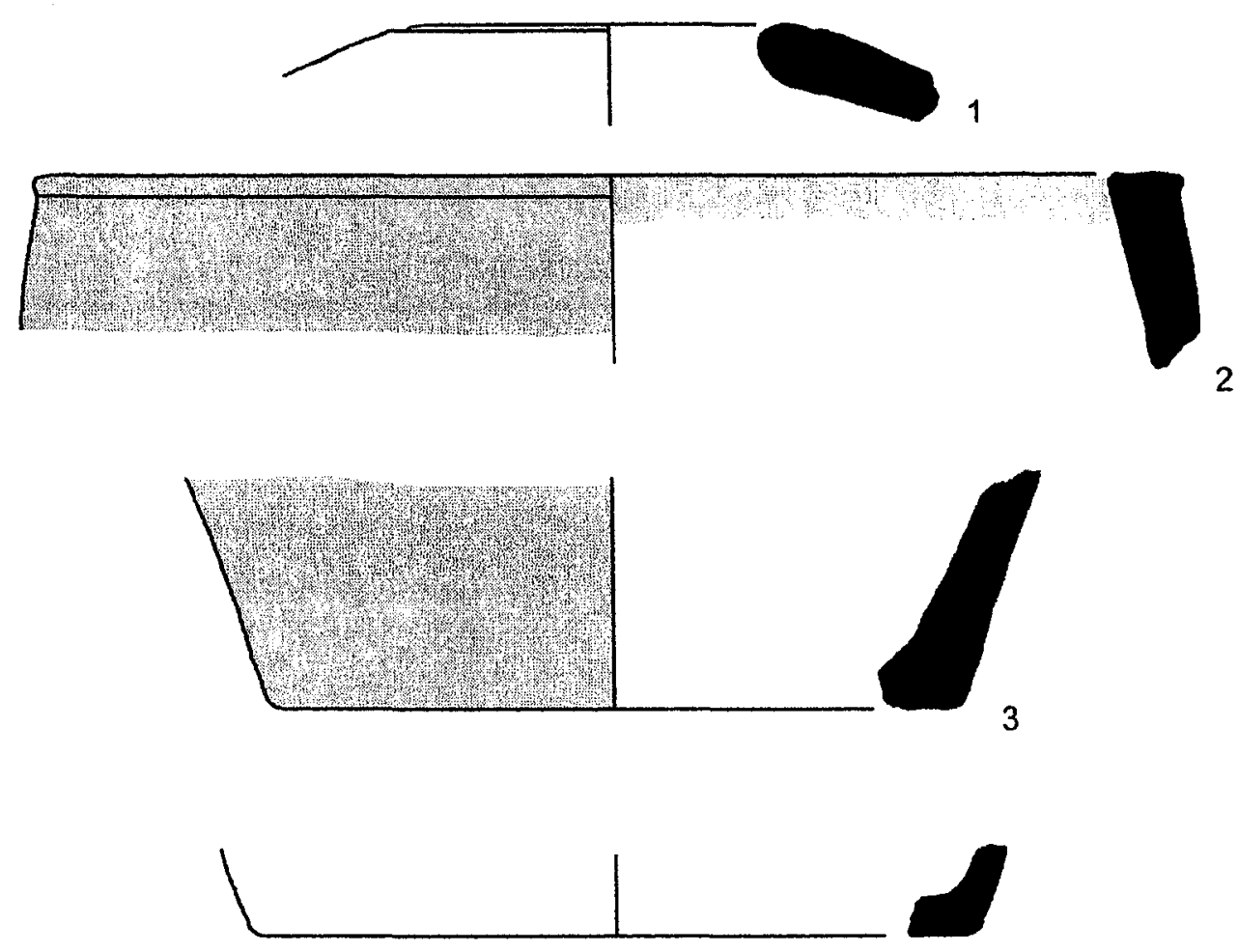

4
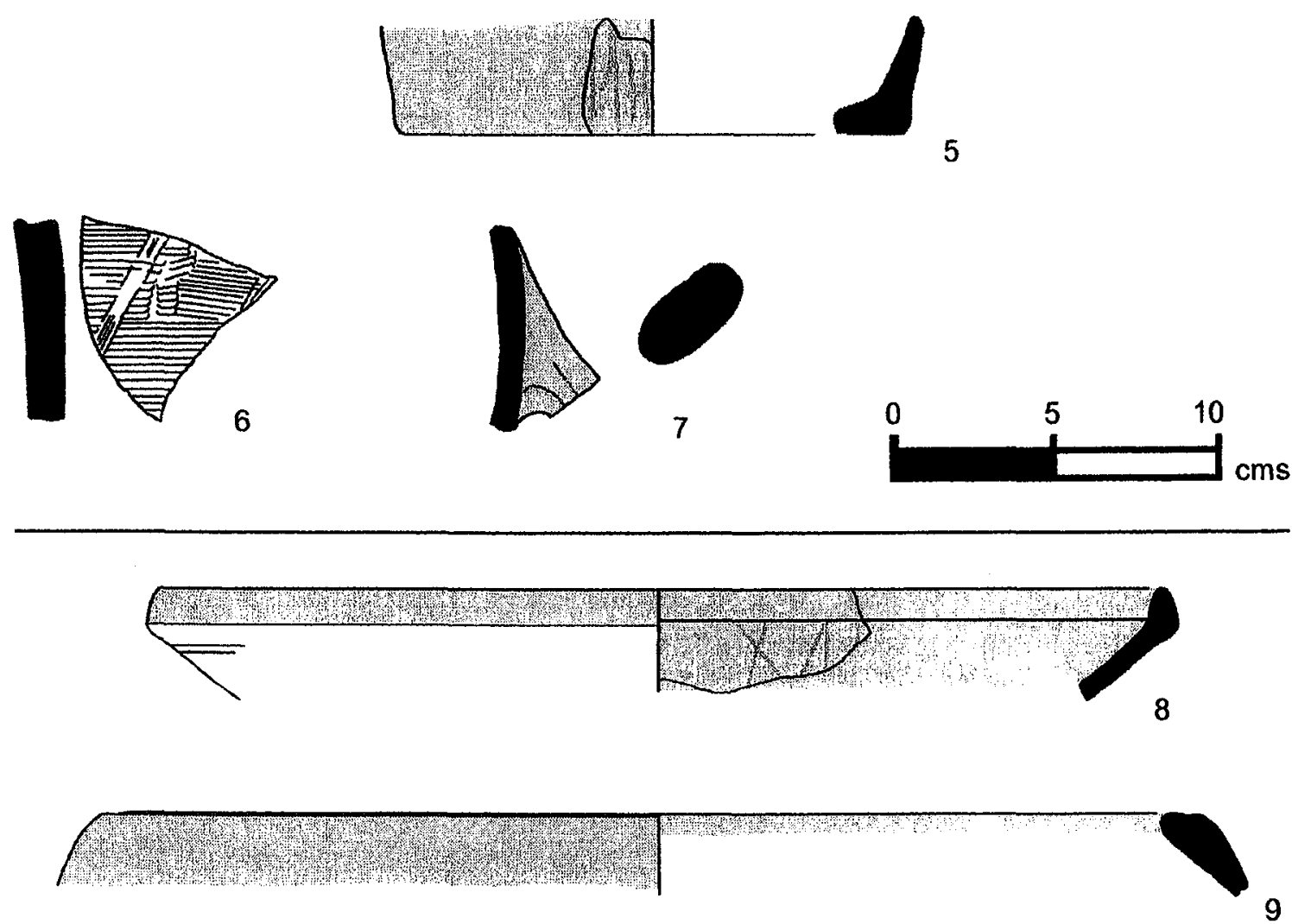

PLATE 61 (CONT.).

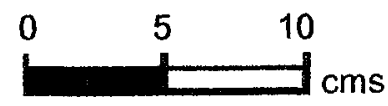




\begin{tabular}{llllllll}
\hline No & Reg & Square & Locus & Vessel & Part & $\begin{array}{l}\text { Body } \\
\text { Thick }\end{array}$ & Dia \\
& & & & & & & \\
1 & 0984 & SW 4-26 & 18 & PLATTER BOWL & R56 & 7 & 36 \\
2 & 0989 & SW 4-26 & 18 & HOLE MOUTH BOWL & R22 & 7 & 30 \\
3 & 0990 & SW 4-26 & 18 & BOWL & R81 & 7 & 12 \\
4 & 0993 & SW 4-26 & 18 & UD & H10 & 9 & $N$ \\
5 & 0994 & SW 4-26 & 18 & UD & H14 & N & N \\
6 & 0995 & SW 4-26 & 18 & UD & BOD & 7 & N \\
7 & 0985 & SW 4-26 & 18 & PLATTER BOWL & R53 & 9 & 45 \\
8 & 0986 & SW 4-26 & 18 & PLATTER BOWL & R53 & 9 & 43 \\
9 & 0988 & SW 4-26 & 18 & LEDGE RIM BOWL & R55 & 10 & 40 \\
10 & 0991 & SW 4-26 & 18 & HOLE MOUTH JAR & R14 & 14 & 38 \\
11 & 0987 & SW 4-26 & 18 & HOLE MOUTH BOWL & R18 & 8 & 30
\end{tabular}

\begin{tabular}{lllll}
\hline No Fabric Color & Core Orient & Core Color Core Thick & Fabric \\
& & & Family
\end{tabular}

\begin{tabular}{|c|c|c|c|c|c|c|}
\hline 1 & \multicolumn{2}{|c|}{ LT REDDISH BROWN } & $N$ & $\mathbf{N}$ & $\mathrm{N}$ & $\mathbf{N}$ \\
\hline 2 & \multicolumn{2}{|l|}{ LT RED } & $\mathbb{N}$ & $\mathbf{G}$ & 4 & $\mathbf{N}$ \\
\hline 3 & \multicolumn{2}{|c|}{ LT REDDISH BROWN } & $\mathbf{N}$ & $\mathbf{N}$ & $\mathbf{N}$ & $\mathbf{N}$ \\
\hline 4 & \multicolumn{2}{|c|}{ LT REDDISH BROWN } & $M$ & G & 5 & $N$ \\
\hline 5 & \multicolumn{2}{|c|}{ LT REDDISH BROWN } & IRR & LG & $\mathbf{N}$ & $\mathbf{N}$ \\
\hline 6 & \multicolumn{2}{|l|}{ RED } & $\mathbf{M}$ & $\mathbf{G}$ & 3 & 12.2 \\
\hline 7 & \multicolumn{2}{|l|}{ LT RED } & $\mathbf{N}$ & $\mathrm{N}$ & $\mathrm{N}$ & $\mathbf{N}$ \\
\hline 8 & \multicolumn{2}{|l|}{ RED } & $\mathbf{M}$ & LG & 2 & $\mathrm{~N}$ \\
\hline 9 & \multicolumn{2}{|c|}{ LT REDDISH BROWN } & $\mathbf{N}$ & $\mathbf{N}$ & $\mathbf{N}$ & $\mathrm{N}$ \\
\hline 10 & \multirow{2}{*}{\multicolumn{2}{|c|}{$\begin{array}{l}\text { LT REDDISH BROWN } \\
\text { PINK }\end{array}$}} & $M$ & G & 12 & $\mathbf{N}$ \\
\hline 11 & & & $M$ & $\mathbf{G}$ & 5 & $\mathrm{~N}$ \\
\hline No & Treatment & $\begin{array}{l}\text { Treatment } \\
\text { Location }\end{array}$ & $\begin{array}{l}\text { Treatment } \\
\text { Cover }\end{array}$ & $\begin{array}{l}\text { Color } \\
\text { Interior }\end{array}$ & $\begin{array}{l}\text { Color } \\
\text { Exterior }\end{array}$ & \\
\hline 1 & B & IR & ALL & RED & $N$ & \\
\hline 2 & UN & $N$ & $\mathbf{N}$ & $N$ & $\mathbf{N}$ & \\
\hline 3 & $\mathbf{S}$ & IE & ALL & LT RED & $\mathrm{N}$ & \\
\hline 4 & WASH & $E$ & ALL & $\mathrm{N}$ & WHITE & \\
\hline 5 & $\mathrm{~S}$ & $E$ & $\mathbf{N}$ & $N$ & RED & \\
\hline 6 & I & $E$ & ALL & $\mathbf{N}$ & $\mathbf{N}$ & \\
\hline 7 & SB & IE & ALL & $N$ & $N$ & \\
\hline 8 & B & IE & ALL & $N$ & $N$ & \\
\hline 9 & SB & IR & ALL & RED & $\mathbf{N}$ & \\
\hline 10 & UN & $\mathbf{N}$ & $N$ & $N$ & $N$ & \\
\hline 11 & UD & $N$ & $\mathbf{N}$ & $\mathbf{N}$ & $\mathbf{N}$ & \\
\hline
\end{tabular}

PLATE 62. FIELD A. PHASE 3A (EB III). 
Other

6 Combed Metallic Ware.

7 Metallic Ware; faint radial wipe on platter face.

8 Metallic Ware; radial wipe on platter face.

9 Margin of wet-smoothing visible on exterior face.

11 Portion of potter's mark preserved on shoulder.

PLATE 62 (CONT.). 


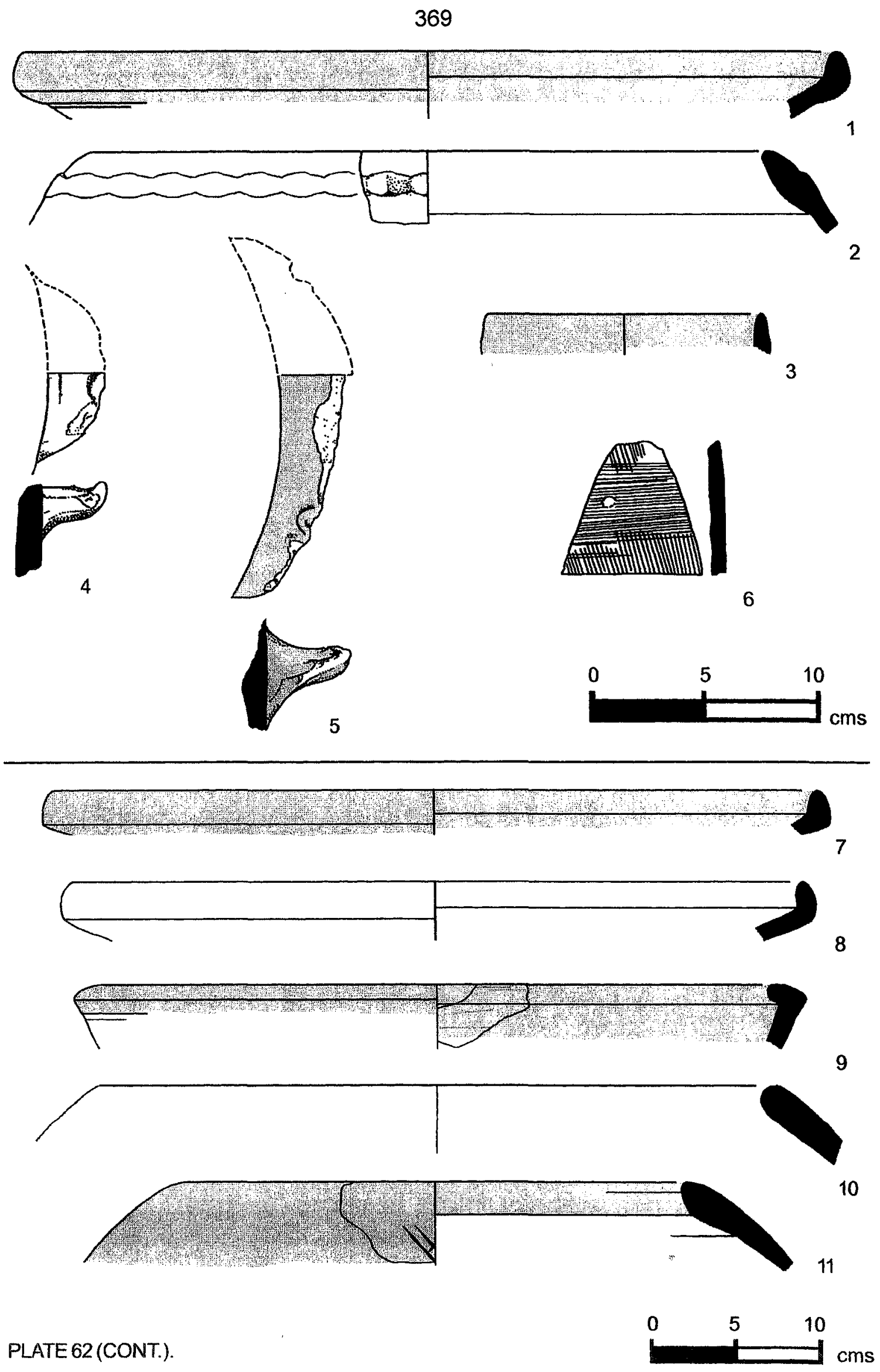




\begin{tabular}{llllllll}
\hline No & Reg & Square & Locus & Vessel & Part & $\begin{array}{c}\text { Body } \\
\text { Thick }\end{array}$ & $\begin{array}{c}\text { Dia } \\
\end{array}$ \\
& & & & & & & \\
1 & 0882 & SW 4-26 & 30 & LEDGE RIM BOWL & R53 & 8 & 32 \\
2 & 0887 & SW 4-26 & 30 & PLATTER BOWL & R53 & 7 & 18 \\
3 & 0879 & SW 4-26 & 30 & HOLE MOUTH JAR & R14 & 12 & 30 \\
4 & 0884 & SW 4-26 & 30 & HOLE MOUTH BOWL & R21 & 10 & 30 \\
5 & 0885 & SW 4-26 & 30 & HOLE MOUTH BOWL & R04 & 13 & 15 \\
6 & 0890 & SW 4-26 & 30 & NECKED JAR & R43 & 11 & 24 \\
7 & 0880 & SW 4-26 & 30 & NECKED JAR & R43 & 14 & 20 \\
8 & 0881 & SW 4-26 & 30 & NECKED JAR & R42 & 9 & 20 \\
9 & 0891 & SW 4-26 & 30 & SINUOUS SIDED BOWL & R81 & 6 & 14
\end{tabular}

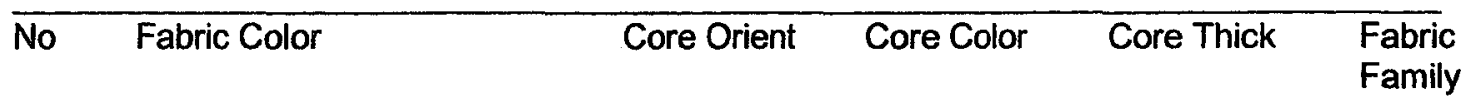

\begin{tabular}{|c|c|c|c|c|c|c|}
\hline 1 & \multicolumn{2}{|c|}{ PINK } & N & $\mathbf{N}$ & $N$ & $\mathbf{N}$ \\
\hline 2 & \multicolumn{2}{|c|}{ PINKISH GREY } & $\mathrm{N}$ & $\mathrm{N}$ & $\mathbf{N}$ & $\mathbf{N}$ \\
\hline 3 & \multicolumn{2}{|c|}{ LT REDDISH BROWN } & ALL & G & $\mathrm{N}$ & $\mathbf{N}$ \\
\hline 4 & \multicolumn{2}{|l|}{ LT RED } & $M$ & $\mathbf{G}$ & 4 & $N$ \\
\hline 5 & \multicolumn{2}{|c|}{ LT REDDISH BROWN } & M & G & 8 & $\mathbf{N}$ \\
\hline 6 & \multicolumn{2}{|c|}{ REDDISH YELLOW } & $M$ & $\mathbf{G}$ & 6 & $N$ \\
\hline 7 & \multicolumn{2}{|c|}{ LT BROWN } & IN & LG & 9 & $N$ \\
\hline 8 & \multicolumn{2}{|l|}{ PINK } & $M$ & $\mathbf{G}$ & 4 & $N$ \\
\hline 9 & \multicolumn{2}{|l|}{ PINK } & $\mathrm{N}$ & $N$ & $N$ & $N$ \\
\hline No & Treatment & $\begin{array}{l}\text { Treatment } \\
\text { Location }\end{array}$ & $\begin{array}{l}\text { Treatment } \\
\text { Cover }\end{array}$ & $\begin{array}{l}\text { Color } \\
\text { Interior }\end{array}$ & $\begin{array}{l}\text { Color } \\
\text { Exterior }\end{array}$ & \\
\hline 1 & $\mathbf{S}$ & $\mathbb{R}$ & ALL & RED & RED & \\
\hline 2 & $\mathrm{~S}$ & IE & ALL & RED & RED & \\
\hline 3 & UN & $\mathbf{N}$ & $\mathbf{N}$ & $\mathbf{N}$ & $\mathrm{N}$ & \\
\hline 4 & UN & $\mathrm{N}$ & $\mathrm{N}$ & $\mathbf{N}$ & $\mathbf{N}$ & \\
\hline 5 & UN & $N$ & $\mathrm{~N}$ & $\mathbf{N}$ & $N$ & \\
\hline 6 & UN & $\mathbf{N}$ & $\mathrm{N}$ & $\mathbf{N}$ & $N$ & \\
\hline 7 & UN & $\mathbf{N}$ & $\mathrm{N}$ & $\mathbf{N}$ & $\mathbf{N}$ & \\
\hline 8 & $\mathbf{S}$ & ER & ALL & $\mathbf{N}$ & DK RED & \\
\hline 9 & $\mathrm{~s}$ & $\mathrm{IE}$ & ALL & LT RED & LT RED & \\
\hline
\end{tabular}

\section{Other}

\footnotetext{
1 Interior face is well weathered; exterior face shows wet-smoothed marginal band.

3 Surface burn visible.

$5 \quad$ Surface burn visible.

$6 \quad$ Features in break suggests rim folding.

8 Features in break suggests rim folding.
}

PLATE 63. FIELD A. PHASE 3A (EB III). 


\section{1}
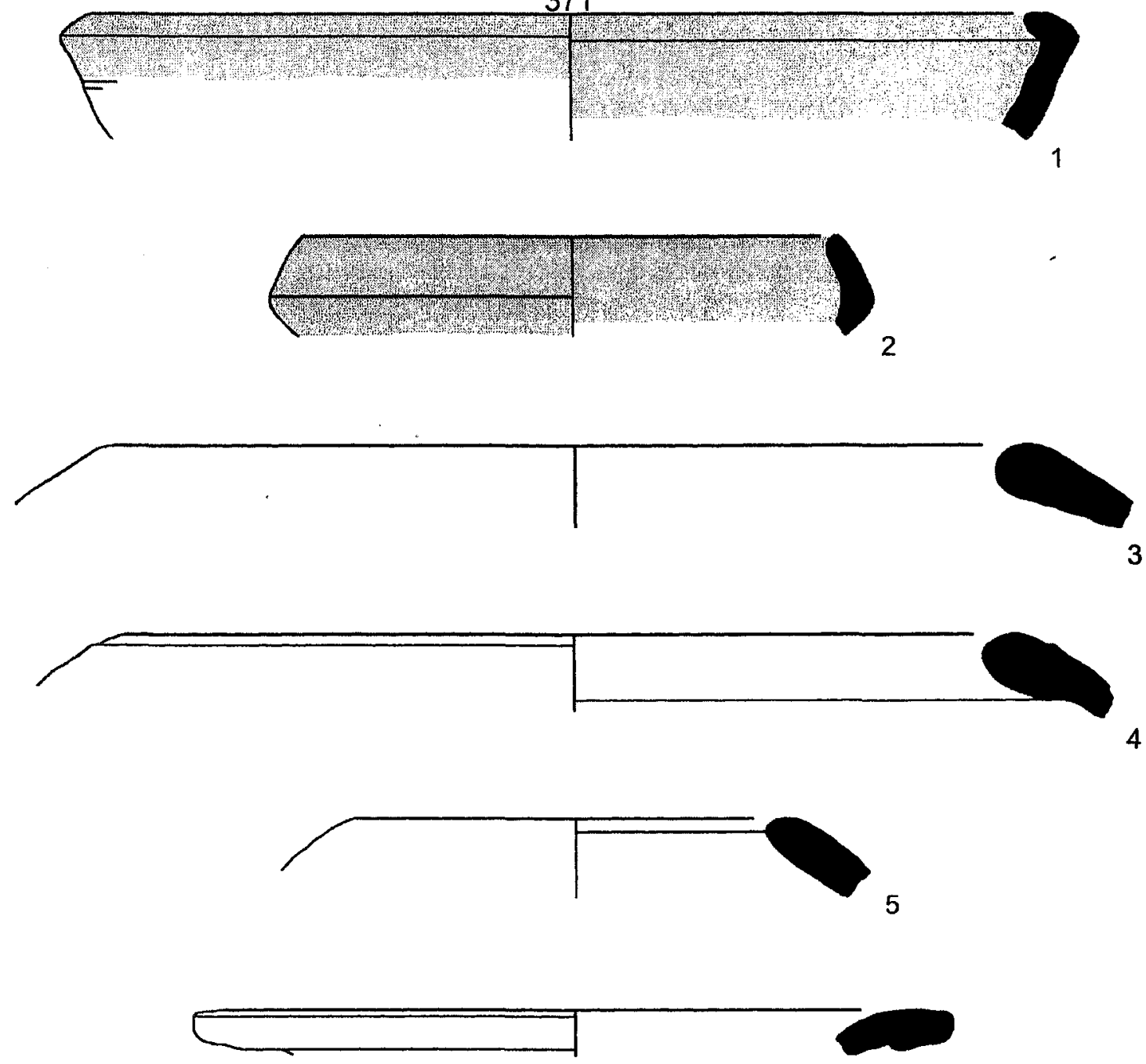

6
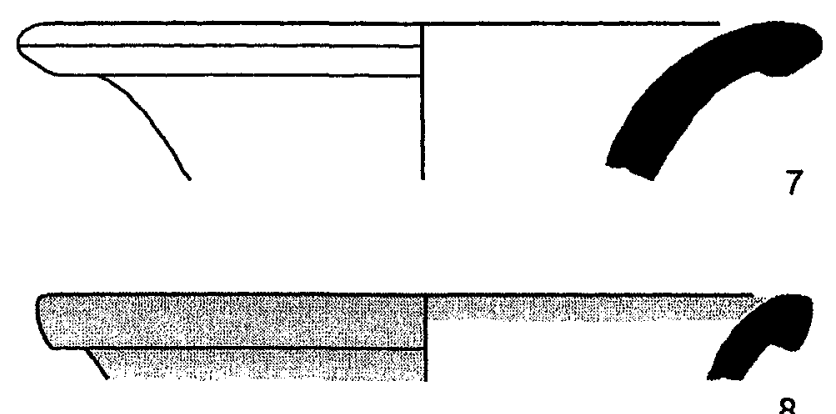

8

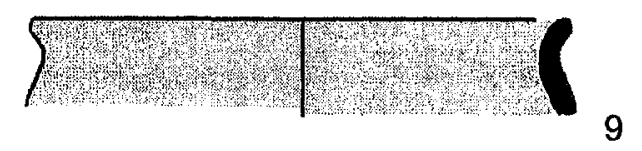

PLATE 63 (CONT.).

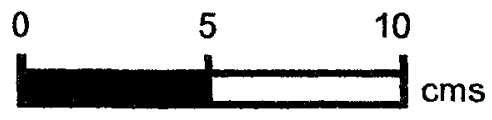




\begin{tabular}{llllllll}
\hline No & Reg & Square & Locus & Vessel & Part & $\begin{array}{l}\text { Body } \\
\text { Thick }\end{array}$ & Dia \\
\hline & & & & & & & \\
1 & 0897 & SW 4-26 & 30 & UD & B12 & 13 & 18 \\
2 & 0899 & SW 4-26 & 30 & UD & B11 & 9 & 13 \\
3 & 0893 & SW 4-26 & 30 & UD & H11 & 9 & $\mathrm{~N}$ \\
4 & 0898 & SW 4-26 & 30 & UD & B11 & 8 & 6 \\
5 & 0895 & SW 4-26 & 30 & UD & H20 & N & N \\
6 & 0894 & SW 4-26 & 30 & LEDGE RIM BOWL & R60 & 12 & 45 \\
7 & 0883 & SW 4-26 & 30 & LEDGE RIM BOWL & R51 & 12 & 45 \\
8 & 0892 & SW 4-26 & 30 & PLATTER BOWL & R56 & 10 & 42 \\
9 & 2078 & SW 4-26 & 30 & HOLE MOUTH BOWL & R11 & 10 & 50
\end{tabular}

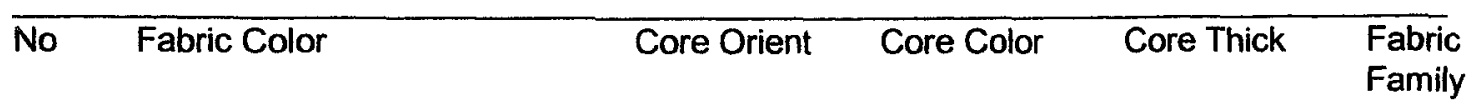

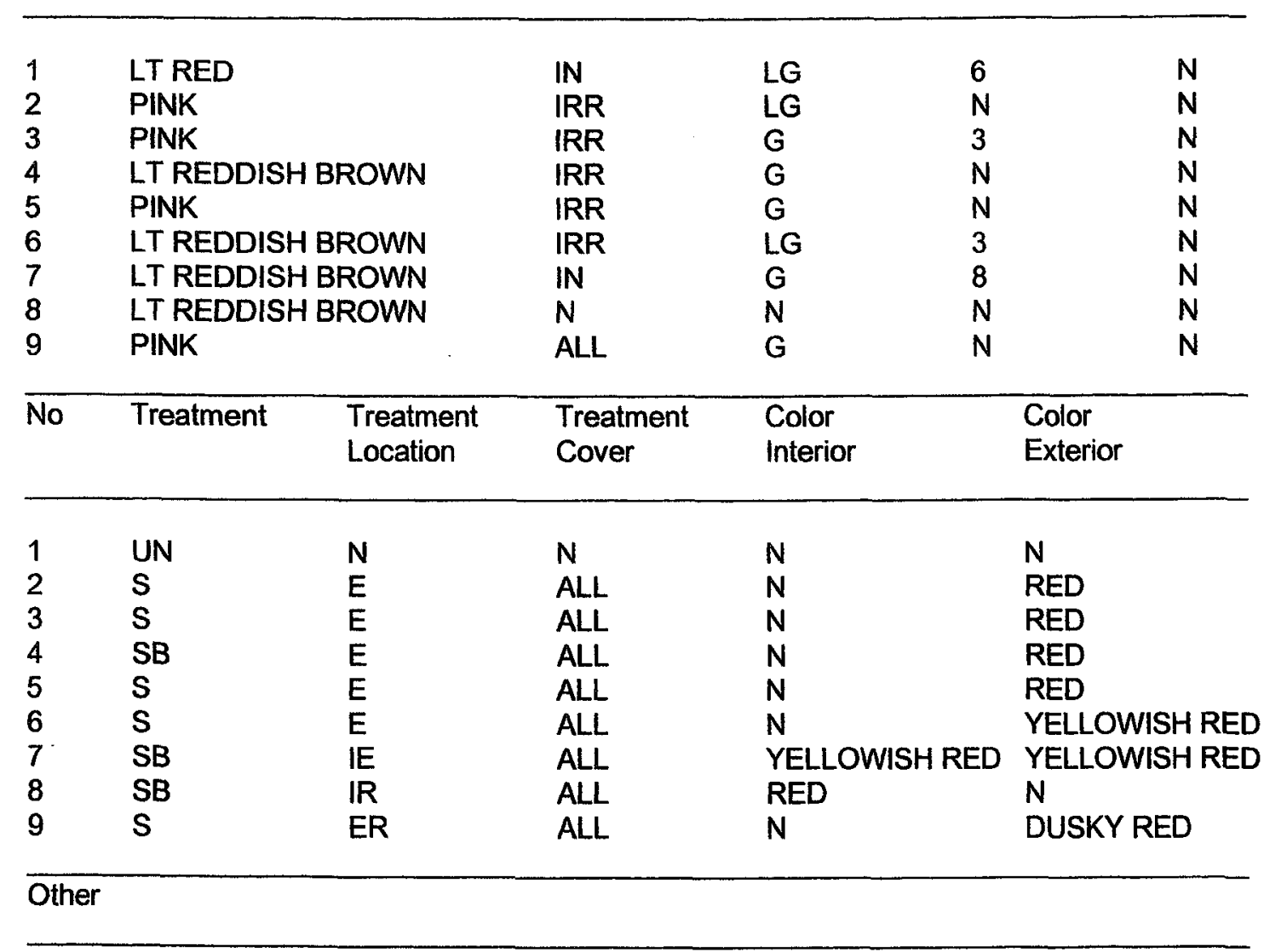

$7 \quad$ Surface burn visible; pattern burnish on interior face; rim well burnished; two wetsmoothed grooves on rim exterior; exterior surface, uneven, "textured."

8 Base appears burnished; concavity under rim has "doubled" look with small, center ridge.

PLATE 64. FIELD A. PHASE IIIA (EB III). 

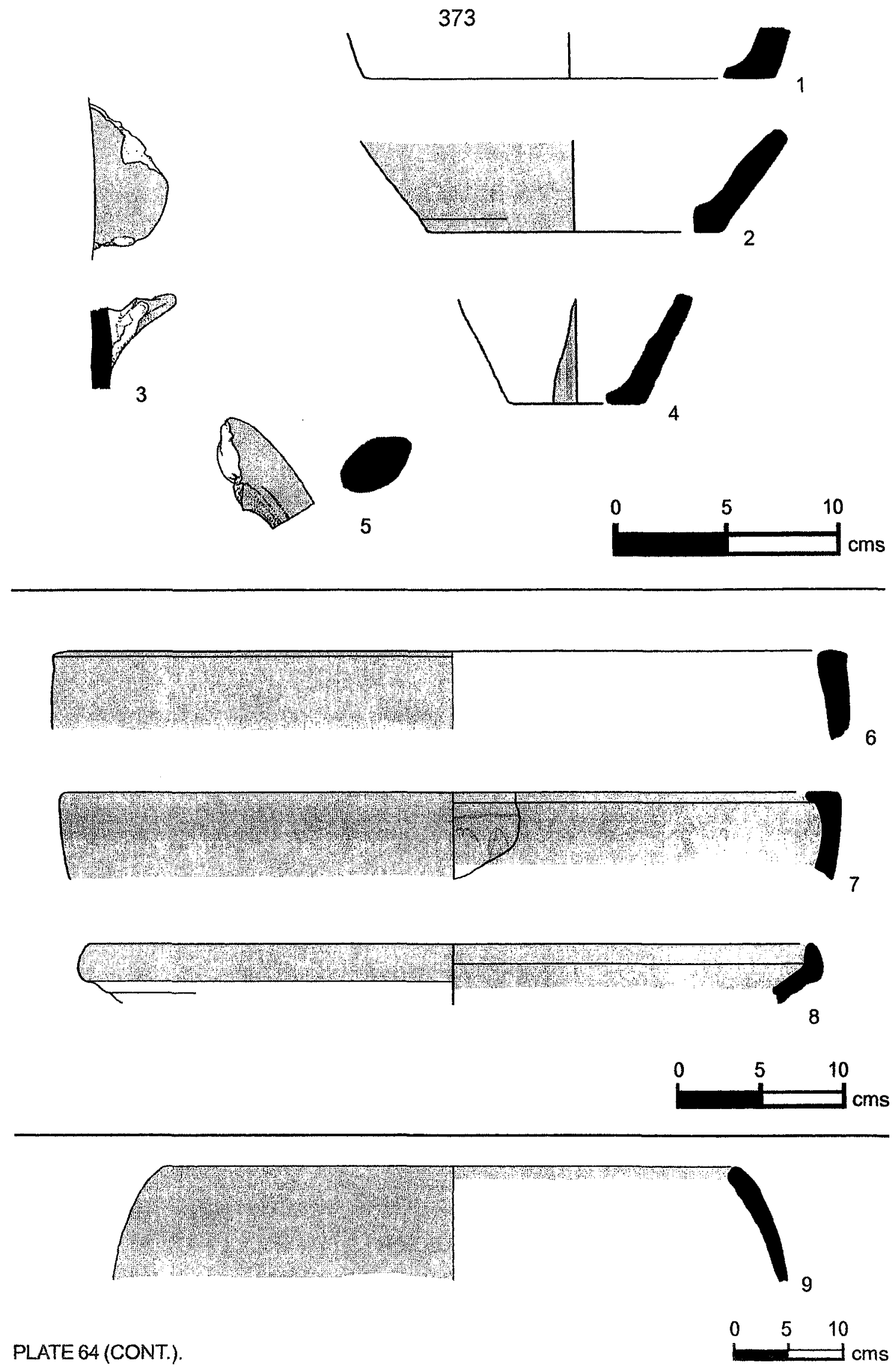
374

\begin{tabular}{llllllll}
\hline No & Reg & Square & Locus & Vessel & Part & $\begin{array}{l}\text { Body } \\
\text { Thick }\end{array}$ & Dia \\
\hline 1 & 0874 & SW 4-26 & 31 & PLATTER BOWL & R53 & 9 & 30 \\
2 & 0877 & SW 4-26 & 31 & HOLE MOUTH JAR & R17 & 14 & 20 \\
3 & 0873 & SW 4-26 & 31 & HOLE MOUTH JAR & R11 & 10 & 20 \\
4 & 0872 & SW 4-26 & 31 & NECKED JAR & R30 & 8 & 14 \\
5 & 1029 & SW 4-26 & 35 & NECKED JAR & R30 & 7 & 12 \\
6 & 1028 & SW 4-26 & 35 & NECKED JAR & R39 & 14 & 30 \\
7 & 0875 & SW 4-26 & 31 & NECKED JAR & R43 & 10 & 20 \\
8 & 1031 & SW 4-26 & 35 & UD & B12 & 18 & 28 \\
9 & 1033 & SW 4-26 & 35 & UD & BOD & 9 & N \\
10 & 0876 & SW 4-26 & 31 & HOLE MOUTH BOWL & R14 & 10 & 40
\end{tabular}

\begin{tabular}{lllll}
\hline No Fabric Color & Core Orient & Core Color & Core Thick & $\begin{array}{l}\text { Fabric } \\
\text { Family }\end{array}$ \\
\hline
\end{tabular}

\begin{tabular}{|c|c|c|c|c|c|c|}
\hline 1 & \multicolumn{2}{|l|}{ LT RED } & $N$ & $\mathrm{~N}$ & $\mathrm{~N}$ & $\mathrm{~N}$ \\
\hline 2 & \multicolumn{2}{|c|}{ LT REDDISH BROWN } & $\mathrm{N}$ & $\mathbf{N}$ & $N$ & $\mathbf{N}$ \\
\hline 3 & \multicolumn{2}{|l|}{ PALE RED } & $\mathbf{M}$ & $\mathbf{G}$ & 4 & $\mathbf{N}$ \\
\hline 4 & \multicolumn{2}{|l|}{ PALE RED } & IRR & G & $\mathbf{N}$ & $\mathbf{N}$ \\
\hline 5 & \multicolumn{2}{|l|}{ PINK } & $\mathrm{N}$ & $\mathrm{N}$ & $\mathbf{N}$ & 23 \\
\hline 6 & \multicolumn{2}{|c|}{ LT REDDISH BROWN } & $\mathbf{M}$ & LG & 5 & 23 \\
\hline 7 & \multicolumn{2}{|l|}{ LT RED } & M & G & 6 & $\mathbf{N}$ \\
\hline 8 & \multicolumn{2}{|l|}{ PINK } & $\mathbb{N}$ & G & 11 & 17.1 \\
\hline 9 & \multicolumn{2}{|c|}{$\begin{array}{l}\text { LT REDDISH BROWN } \\
\text { LT REDDISH BROWN }\end{array}$} & $\mathrm{M}$ & $\mathbf{G}$ & 3 & $\mathbf{N}$ \\
\hline 10 & LT REDDIS & ROWN & $\mathbf{M}$ & LG & 4 & $\mathrm{~N}$ \\
\hline No & Treatment & $\begin{array}{l}\text { Treatment } \\
\text { Location }\end{array}$ & $\begin{array}{l}\text { Treatment } \\
\text { Cover }\end{array}$ & $\begin{array}{l}\text { Color } \\
\text { Interior }\end{array}$ & $\begin{array}{l}\text { Color } \\
\text { Exterior }\end{array}$ & \\
\hline 1 & B & IR & ALL & $\mathrm{N}$ & $\mathrm{N}$ & \\
\hline 2 & UN & $\mathrm{N}$ & $\mathbf{N}$ & $\mathrm{N}$ & $\mathbf{N}$ & \\
\hline 3 & UN & $\mathbf{N}$ & $\mathbf{N}$ & $\mathrm{N}$ & $\mathbf{N}$ & \\
\hline 4 & $S$ & ER & ALL & $\mathrm{N}$ & RED & \\
\hline 5 & $\mathrm{~s}$ & ER & ALL & RED & RED & \\
\hline 6 & SB & IE & ALL & $\mathbf{N}$ & RED & \\
\hline 7 & UN & $\mathbf{N}$ & $\mathbf{N}$ & $\mathbf{N}$ & $\mathbf{N}$ & \\
\hline 8 & $\mathbf{S}$ & E & ALL & $\mathbf{N}$ & DK REL & BROWN \\
\hline 9 & SI & E & ALL & $\mathbf{N}$ & RED & \\
\hline 10 & $\mathbf{S}$ & $E$ & ALL & $\mathbf{N}$ & RED & \\
\hline
\end{tabular}

PLATE 65. FIELD A. PHASE 3A (EB III). 
Other

1 Metallic Ware.

2 Rim may be folded (R17) but sample to small to judge.

8 Metallic Ware.

9 Combed Metallic Ware.

PLATE 65. (CONT.). 

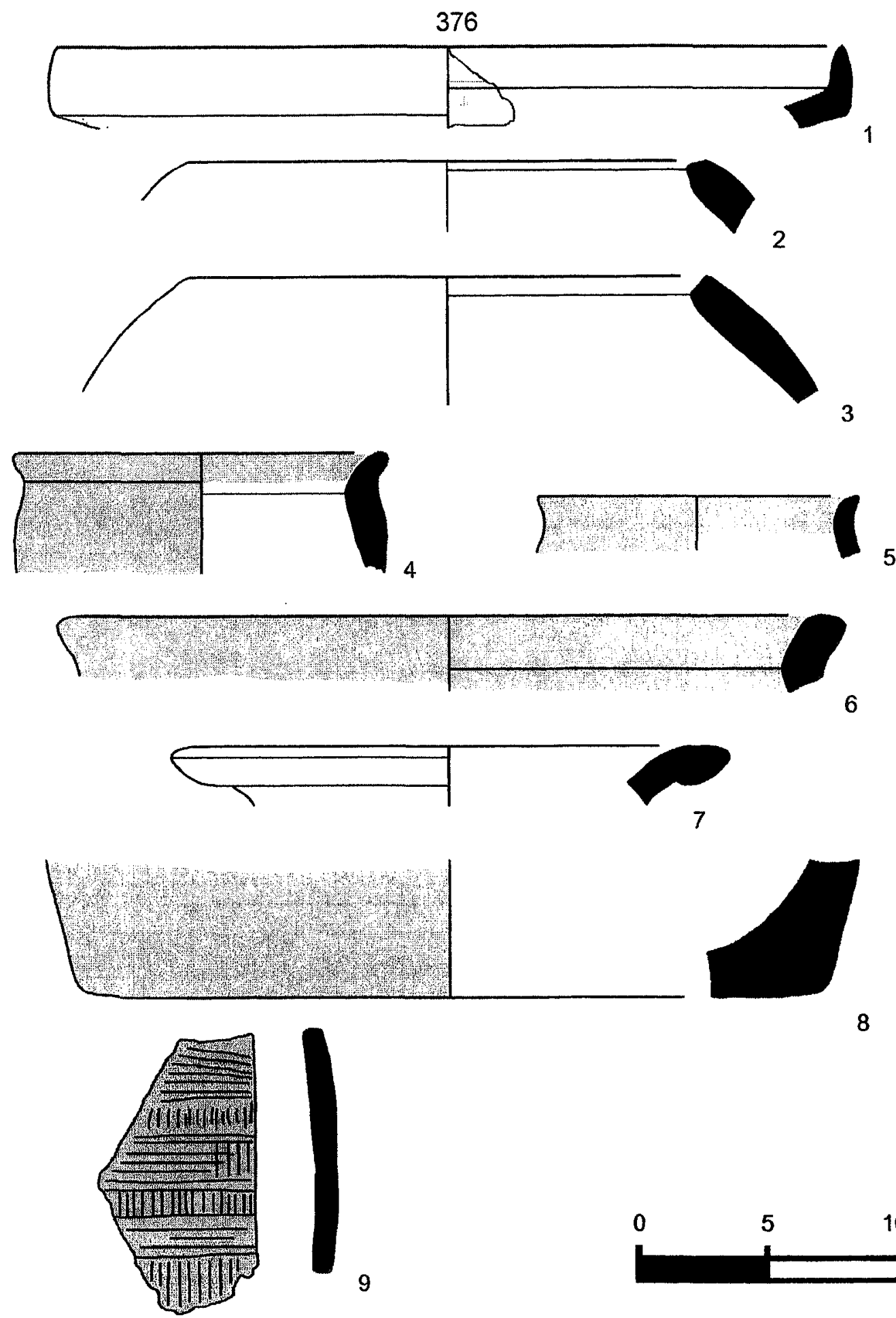

8
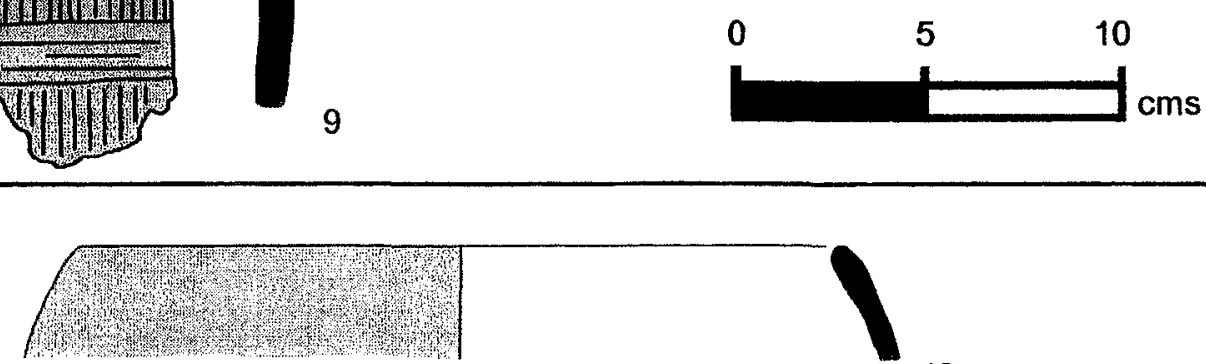

PLATE 65 (CONT.).

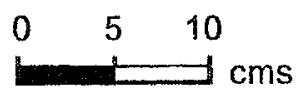




\begin{tabular}{llllllll}
\hline No & Reg & Square & Locus & Vessel & Part & $\begin{array}{l}\text { Body } \\
\text { Thick }\end{array}$ & Dia \\
\hline 1 & & & & & & & \\
2 & 1120 & SW 5-26 & 12 & BOWL & R50 & 7 & 25 \\
3 & 1119 & SW 5-26 & 12 & HOLE MOUTH JAR & R19 & 15 & 20 \\
4 & 1118 & SW 5-26 & 12 & HOLE MOUTH JAR & R04 & 14 & 16 \\
5 & 1056 & SW 4-27 & 15 & NECKED JAR & R31 & 9 & 14 \\
6 & 1038 & SW 4-27 & $26 A$ & NECKED JAR & R43 & 8 & 10 \\
7 & 1058 & SW 4-27 & 15 & NECKED JAR & R31 & 7 & 11 \\
8 & 1121 & SW 5-26 & 12 & UD & H14 & 8 & N \\
9 & 1039 & SW 4-27 & $26 A$ & UD & BOD & 7 & N \\
& 1040 & SW 4-27 & 26A & PLATTER BOWL & R56 & 8 & 60
\end{tabular}

\begin{tabular}{lllll}
\hline No Fabric Color & Core Orient Core Color Core Thick & $\begin{array}{l}\text { Fabric } \\
\text { Family }\end{array}$ \\
& & &
\end{tabular}

\begin{tabular}{|c|c|c|c|c|c|c|}
\hline 1 & \multicolumn{2}{|l|}{ LT RED } & $\mathbf{N}$ & $N$ & $N$ & 8 \\
\hline 2 & \multicolumn{2}{|l|}{ RED } & $A L L$ & G & $\mathrm{N}$ & 4 \\
\hline 3 & \multicolumn{2}{|l|}{ PALE RED } & IRR & LG & $\mathrm{N}$ & 5.1 \\
\hline 4 & \multicolumn{2}{|l|}{ LT RED } & EX & G & 5 & $N$ \\
\hline 5 & \multicolumn{2}{|c|}{ LT REDDISH BROWN } & $N$ & $N$ & $N$ & 23 \\
\hline 6 & \multicolumn{2}{|c|}{ LT REDDISH BROWN } & $M$ & G & 3 & $N$ \\
\hline 7 & \multicolumn{2}{|l|}{ LT RED } & IRR & LG & $N$ & 23 \\
\hline 8 & \multicolumn{2}{|l|}{ LT RED } & $\mathrm{N}$ & $\mathrm{N}$ & $\mathbf{N}$ & 12.1 \\
\hline 9 & \multicolumn{2}{|l|}{ LT RED } & $N$ & $\mathrm{~N}$ & $\mathbf{N}$ & $N$ \\
\hline No & Treatment & $\begin{array}{l}\text { Treatment } \\
\text { Location }\end{array}$ & $\begin{array}{l}\text { Treatment } \\
\text { Cover }\end{array}$ & $\begin{array}{l}\text { Color } \\
\text { Interior }\end{array}$ & $\begin{array}{l}\text { Color } \\
\text { Exterior }\end{array}$ & \\
\hline 1 & SB & $\mathbb{R}$ & ALL & RED & $\mathbf{N}$ & \\
\hline 2 & UN & $\mathrm{N}$ & $N$ & $N$ & $N$ & \\
\hline 3 & UN & $\mathbf{N}$ & $N$ & $N$ & $N$ & \\
\hline 4 & UN & $\mathbf{N}$ & $N$ & $\mathbf{N}$ & $\mathbf{N}$ & \\
\hline 5 & $\mathrm{~s}$ & ER & ALL & $\mathbf{N}$ & RED & \\
\hline 6 & UN & $\mathrm{N}$ & $N$ & $N$ & $N$ & \\
\hline 7 & WASH & $E$ & $\mathrm{~N}$ & $N$ & WHITE & \\
\hline 8 & 1 & $E$ & ALL & $N$ & $\mathbf{N}$ & \\
\hline 9 & UD & $N$ & $\mathbf{N}$ & $N$ & $N$ & \\
\hline
\end{tabular}

$4 \quad$ Surface burn visible.

8 Combed Metallic Ware.

PLATE 66. Field A. PHASE 3A (EB III). 

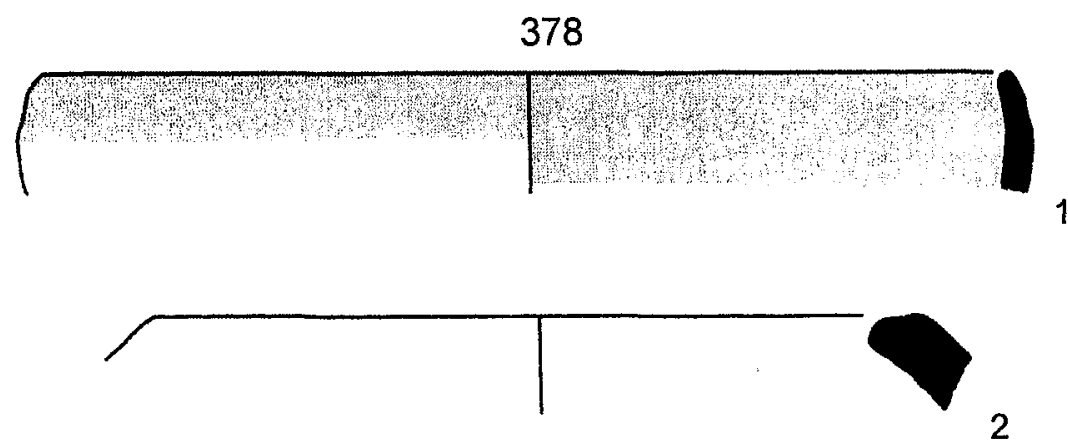

2
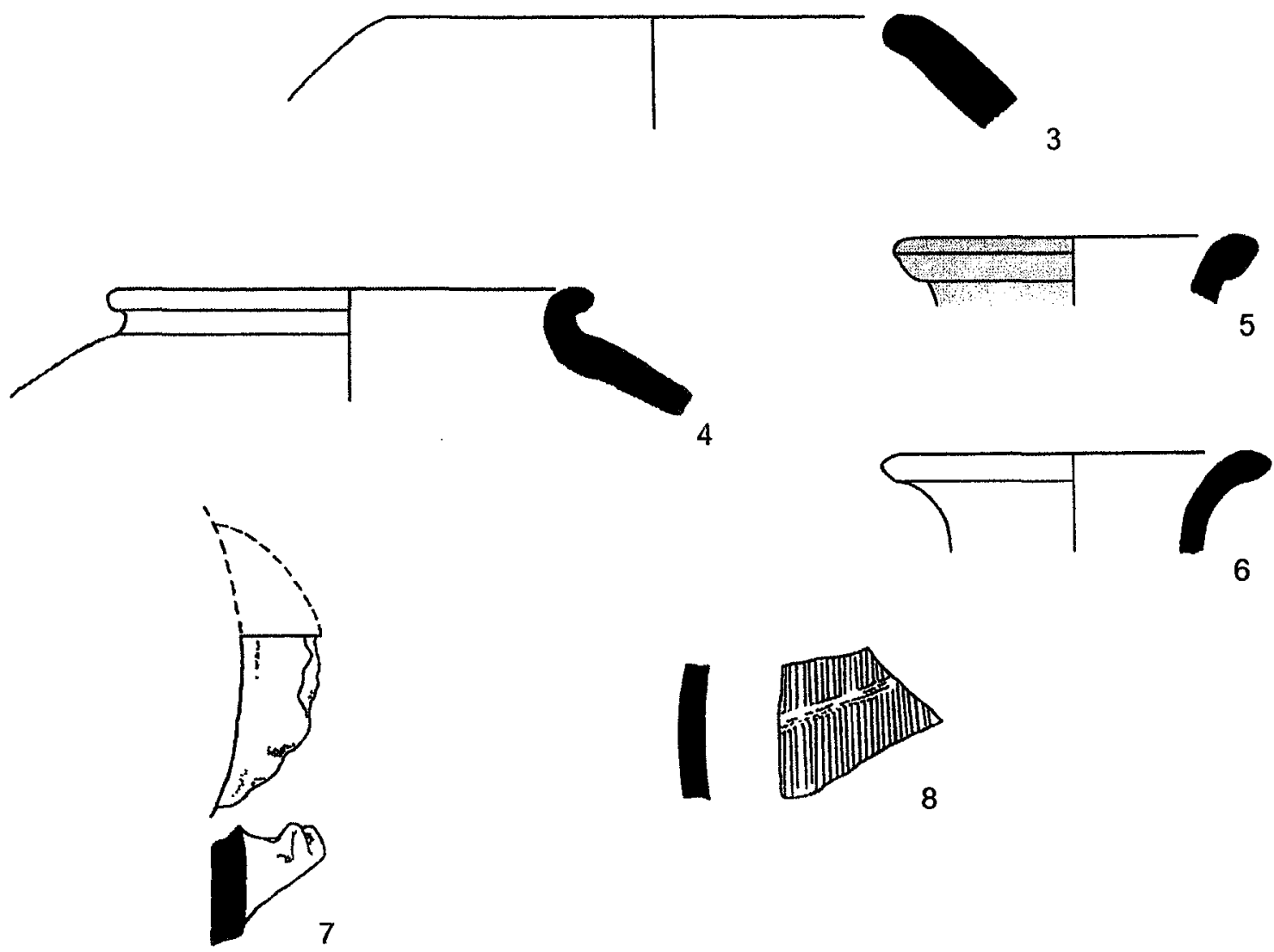

8

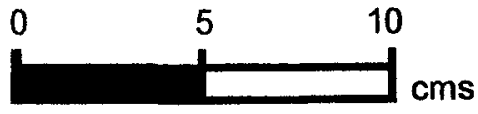

PLATE 66 (CONT.).

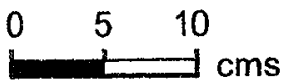




\begin{tabular}{llllllll}
\hline No & Reg & Square & Locus & Vessel & Part & $\begin{array}{l}\text { Body } \\
\text { Thick }\end{array}$ & Dia \\
& & & & & & & \\
1 & 1050 & SW 4-27 & 27 & BOWL & R50 & 5 & 17 \\
2 & 1044 & SW 4-27 & 27 & BOWL & R50 & 6 & 15 \\
3 & 1068 & SW 4-27 & 22 & BOWL & R50 & 9 & 30 \\
4 & 1079 & SW 4-27 & 22 & BOWL & R50 & 6 & N \\
5 & 1072 & SW 4-27 & 22 & BOWL & R80 & 11 & 33 \\
6 & 1067 & SW 4-27 & 22 & LEDGE RIM BOWL & R51 & 6 & 19 \\
7 & 1064 & SW 4-27 & 22 & HOLE MOUTH JARIBOWL & R02 & 12 & 20 \\
8 & 1052 & SW 4-27 & 27 & LEDGE RIM BOWL & R51 & 8 & 17 \\
9 & 1073 & SW 4-27 & 22 & LEDGE RIM BOWL & R51 & 10 & 26 \\
10 & 1045 & SW 4-27 & 27 & LEDGE RIM BOWL & R53 & 10 & 28
\end{tabular}

\begin{tabular}{lllll}
\hline No Fabric Color & Core Orient & Core Color Core Thick & Fabric \\
& & & Family
\end{tabular}

\begin{tabular}{|c|c|c|c|c|c|c|}
\hline 1 & \multicolumn{2}{|c|}{ LT REDDISH BROWN } & $\mathrm{N}$ & $\mathrm{N}$ & $\mathbf{N}$ & $\mathrm{N}$ \\
\hline 2 & \multicolumn{2}{|l|}{ LT RED } & $\mathrm{N}$ & $\mathrm{N}$ & N & $\mathbf{N}$ \\
\hline 3 & \multicolumn{2}{|l|}{ PINK } & ALL & LG & $\mathrm{N}$ & $\mathrm{N}$ \\
\hline 4 & \multicolumn{2}{|l|}{ PINK } & $\mathrm{N}$ & $\mathbf{N}$ & $\mathbf{N}$ & $\mathbf{N}$ \\
\hline 5 & \multicolumn{2}{|l|}{ RED } & $A L L$ & G & $\mathrm{N}$ & $N$ \\
\hline 6 & \multicolumn{2}{|l|}{ PINK } & $\mathbf{N}$ & $\mathbf{N}$ & $\mathbf{N}$ & $\mathbf{N}$ \\
\hline 7 & \multicolumn{2}{|l|}{ PINK } & $N$ & $\mathrm{~N}$ & $N$ & $N$ \\
\hline 8 & \multicolumn{2}{|c|}{ LT REDDISH BROWN } & $\mathrm{N}$ & $\mathrm{N}$ & $\mathrm{N}$ & $\mathbf{N}$ \\
\hline 9 & \multicolumn{2}{|c|}{ PINK } & $N$ & $\mathrm{~N}$ & $\mathrm{~N}$ & $\mathrm{~N}$ \\
\hline 10 & \multicolumn{2}{|l|}{ PINK } & $M$ & LG & 5 & N \\
\hline No & Treatment & $\begin{array}{l}\text { Treatment } \\
\text { Location }\end{array}$ & $\begin{array}{l}\text { Treatment } \\
\text { Cover }\end{array}$ & $\begin{array}{l}\text { Color } \\
\text { Interior }\end{array}$ & $\begin{array}{l}\text { Color } \\
\text { Exterior }\end{array}$ & \\
\hline 1 & S & IR & ALL & LT RED & $N$ & \\
\hline 2 & B & IE & ALL & $N$ & $\mathbf{N}$ & \\
\hline$\overline{3}$ & UD & $N$ & $N$ & $N$ & $N$ & \\
\hline 4 & $\mathrm{~s}$ & IE & ALL & RED & RED & \\
\hline 5 & SB & IE & ALL & DK RED & $\mathbf{N}$ & \\
\hline 6 & SB & IR & ALL & RED & $N$ & \\
\hline 7 & $\mathbf{S}$ & IE & ALL & LT RED & LT RED & \\
\hline 8 & SB & IE & ALL & RED & RED & \\
\hline 9 & B & 1 & ALL & $\mathrm{N}$ & $\mathbf{N}$ & \\
\hline 10 & SB & IR & ALL & RED & $\mathbf{N}$ & \\
\hline
\end{tabular}

PLATE 67. FIELD A. PHASE 3A (EB III). 


\section{Other}

2 Metallic Ware.

3 Very weathered.

$4 \quad$ Burn visible on surface.

6 Burnish on rim; possible radial burnish lines over slip.

7 Sample too small to confirm stance or diameter.

10 Radial burnish over red slip on interior face.

PLATE 67 (CONT.). 

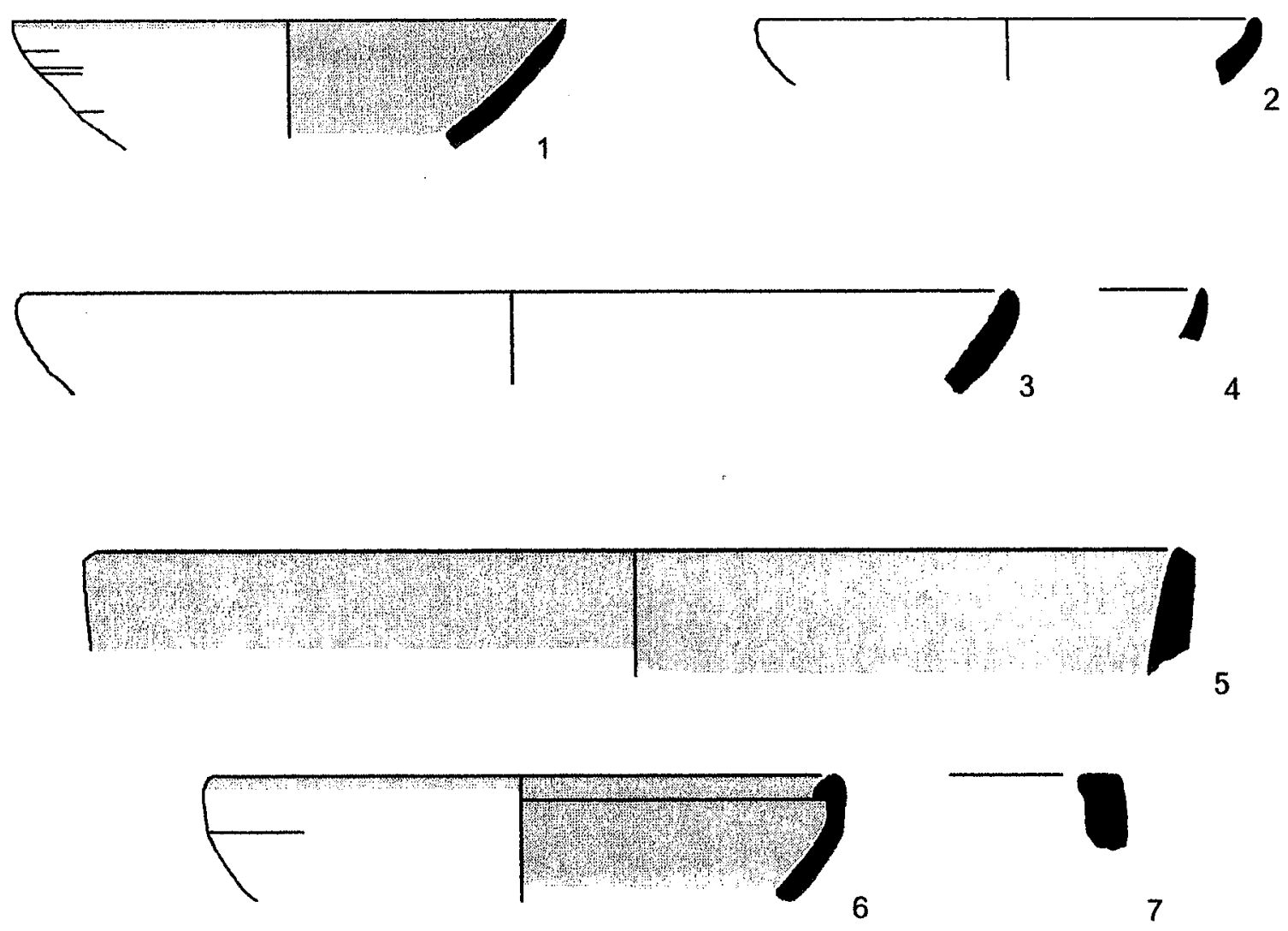

8
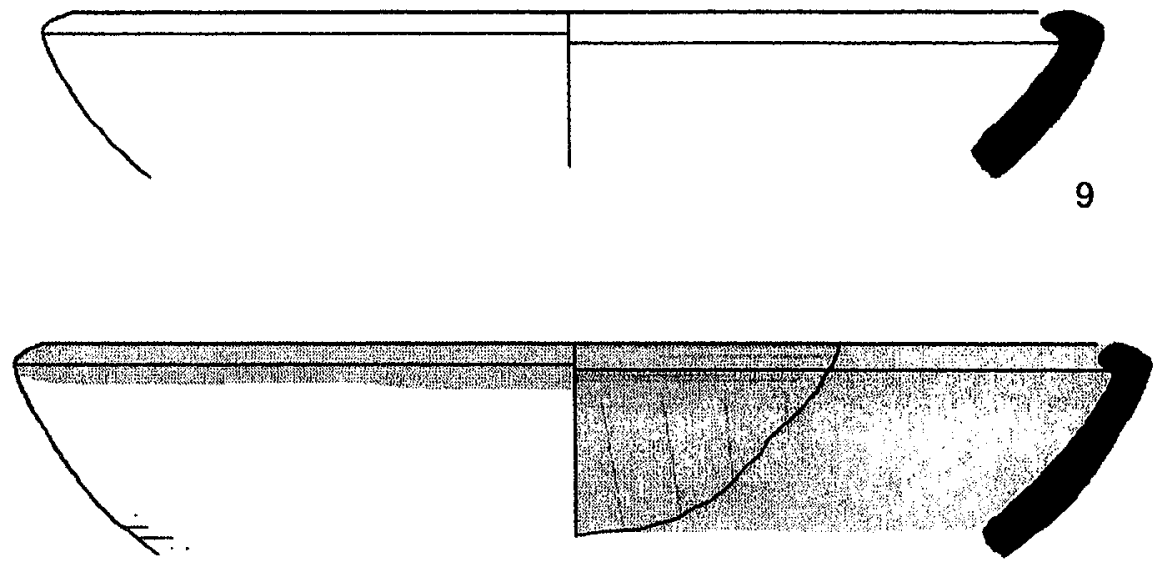

10

PLATE 67 (CONT.).

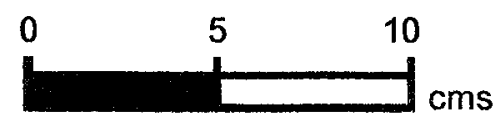




\begin{tabular}{llllllll}
\hline No & Reg & Square & Locus & Vessel & Part & $\begin{array}{l}\text { Body } \\
\text { Thick }\end{array}$ & $\begin{array}{c}\text { Dia } \\
\end{array}$ \\
& & & & & & & \\
1 & 1070 & SW 4-27 & 22 & HOLE MOUTH JAR & R04 & 12 & 12 \\
2 & 1071 & SW 4-27 & 22 & HOLE MOUTH BOWL & R04 & 12 & 14 \\
3 & 1074 & SW 4-27 & 22 & HOLE MOUTH BOWL & R01 & 14 & 20 \\
4 & 1046 & SW 4-27 & 27 & HOLE MOUTH BOWL & R01 & 9 & 13 \\
5 & 1049 & SW 4-27 & 27 & HOLE MOUTH BOWL & R01 & 9 & 12 \\
6 & 1051 & SW 4-27 & 27 & HOLE MOUTH BOWL & R02 & 10 & 20 \\
7 & 1048 & SW 4-27 & 27 & HOLE MOUTH BOWL & R59 & 9 & N \\
8 & 1043 & SW 4-27 & 27 & HOLE MOUTH JAR & R01 & 12 & 15
\end{tabular}

\begin{tabular}{lllll}
\hline No Fabric Color & Core Orient & Core Color Core Thick & $\begin{array}{l}\text { Fabric } \\
\text { Family }\end{array}$
\end{tabular}

\begin{tabular}{|c|c|c|c|c|c|c|}
\hline $\begin{array}{l}1 \\
2\end{array}$ & \multicolumn{2}{|c|}{$\begin{array}{l}\text { LT REDDISH BROWN } \\
\text { PAIF RFD }\end{array}$} & $\begin{array}{l}\text { IRR } \\
\text { IRR }\end{array}$ & $\begin{array}{l}L G \\
G\end{array}$ & $\begin{array}{l}\mathbf{N} \\
\mathbf{N}\end{array}$ & $\begin{array}{l}N \\
N\end{array}$ \\
\hline 3 & \multicolumn{2}{|l|}{ PINK } & IRR & $\mathbf{G}$ & $N$ & $\mathbf{N}$ \\
\hline 4 & \multicolumn{2}{|l|}{ PALE RED } & IRR & $\mathbf{G}$ & $N$ & $\mathbf{N}$ \\
\hline 5 & \multicolumn{2}{|l|}{ PALE RED } & IRR & $\mathbf{G}$ & $\mathbf{N}$ & $\mathbf{N}$ \\
\hline 6 & \multicolumn{2}{|l|}{ PALE RED } & $\mathbf{N}$ & $\mathbf{N}$ & $\mathbf{N}$ & $\mathbf{N}$ \\
\hline 7 & \multicolumn{2}{|l|}{ PALE RED } & M & $\mathbf{G}$ & 7 & $\mathbf{N}$ \\
\hline 8 & \multicolumn{2}{|l|}{ PALE RED } & EX & $\mathbf{G}$ & 6 & $N$ \\
\hline No & Treatment & $\begin{array}{l}\text { Treatment } \\
\text { Location }\end{array}$ & $\begin{array}{l}\text { Treatment } \\
\text { Cover }\end{array}$ & $\begin{array}{l}\text { Color } \\
\text { Interior }\end{array}$ & $\begin{array}{l}\text { Color } \\
\text { Exterior }\end{array}$ & \\
\hline 1 & $\mathrm{~S}$ & ER & $A L L$ & $\mathbf{N}$ & RED & \\
\hline 2 & UN & $\mathbf{N}$ & $N$ & $\mathbf{N}$ & $\mathbf{N}$ & \\
\hline 3 & UN & $\mathbf{N}$ & $N$ & $N$ & $N$ & \\
\hline 4 & UN & $\mathbf{N}$ & $N$ & $\mathbf{N}$ & $\mathbf{N}$ & \\
\hline 5 & UN & $N$ & $N$ & $N$ & $N$ & \\
\hline 6 & UN & $\mathbf{N}$ & $N$ & $N$ & N & \\
\hline 7 & SB & IR & ALL & $\mathbf{N}$ & RED & \\
\hline 8 & UN & $N$ & $\mathbf{N}$ & $\mathbf{N}$ & $\mathbf{N}$ & \\
\hline & & & & & & \\
\hline
\end{tabular}

\footnotetext{
3 Surface burn visible.

$4 \quad$ Swipes on Interior and exterior show motion used in finishing rim.

5 Interior face and rim well smoothed; wet-smoothed marginal band slightly visible on rim exterior, while lower portion of exterior face appears more "textured;" entire exterior face scarred with small, haphazard wipe and scrape lines.

7 Sample too small to confirm stance or diameter; two holes ( $3 \mathrm{~mm}$ diameter) bored through wall below rim; Khirbet Kerak Ware.

8 Surface burn visible; swipe marks suggest motion used to finish rim.
}

PLATE 68. FIELD A. PHASE 3A (EB III). 


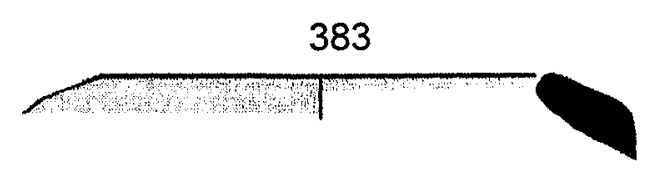

1
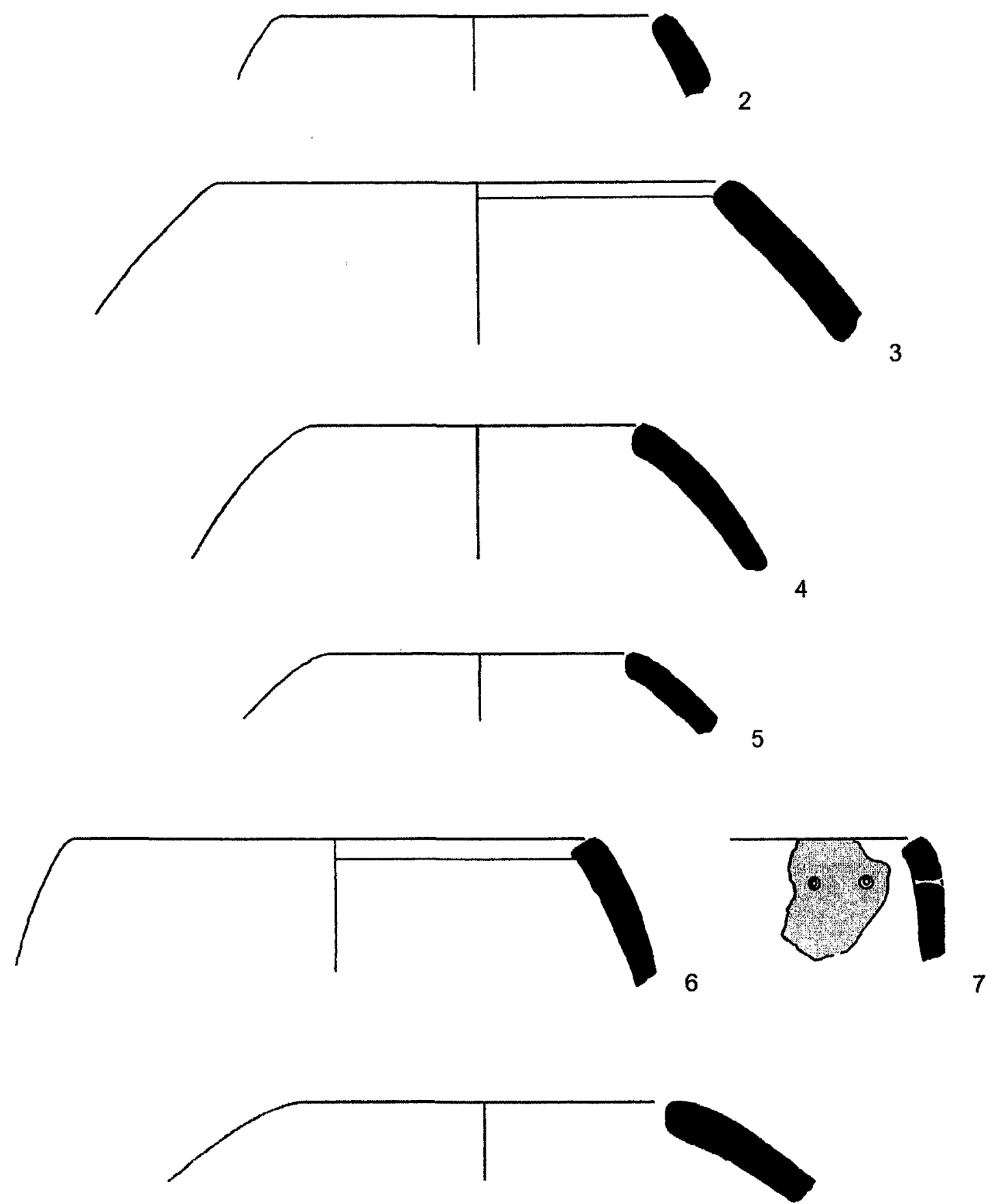

8

PLATE 68 (CONT.).

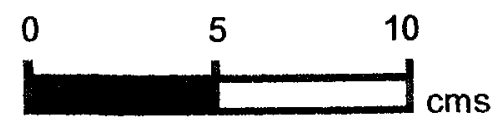


384

\begin{tabular}{llllllll}
\hline No & Reg & Square & Locus & Vessel & Part & $\begin{array}{c}\text { Body } \\
\text { Thick }\end{array}$ & Dia \\
\hline 1 & 1066 & SW 4-27 & 22 & NECKED JAR & R43 & 11 & 25 \\
2 & 1065 & SW 4-27 & 22 & NECKED JAR & R30 & 11 & 16 \\
3 & 1078 & SW 4-27 & 22 & UD & B12 & 11 & 20 \\
4 & 1077 & SW 4-27 & 22 & UD & B11 & 8 & 9 \\
5 & 1075 & SW 4-27 & 22 & UD & B12 & 9 & 7 \\
6 & 1053 & SW 4-27 & 27 & JUG & B12 & 7 & 15
\end{tabular}

\begin{tabular}{lllll}
\hline No Fabric Color & Core Orient & Core Color & Core Thick & Fabric \\
& & & Family
\end{tabular}

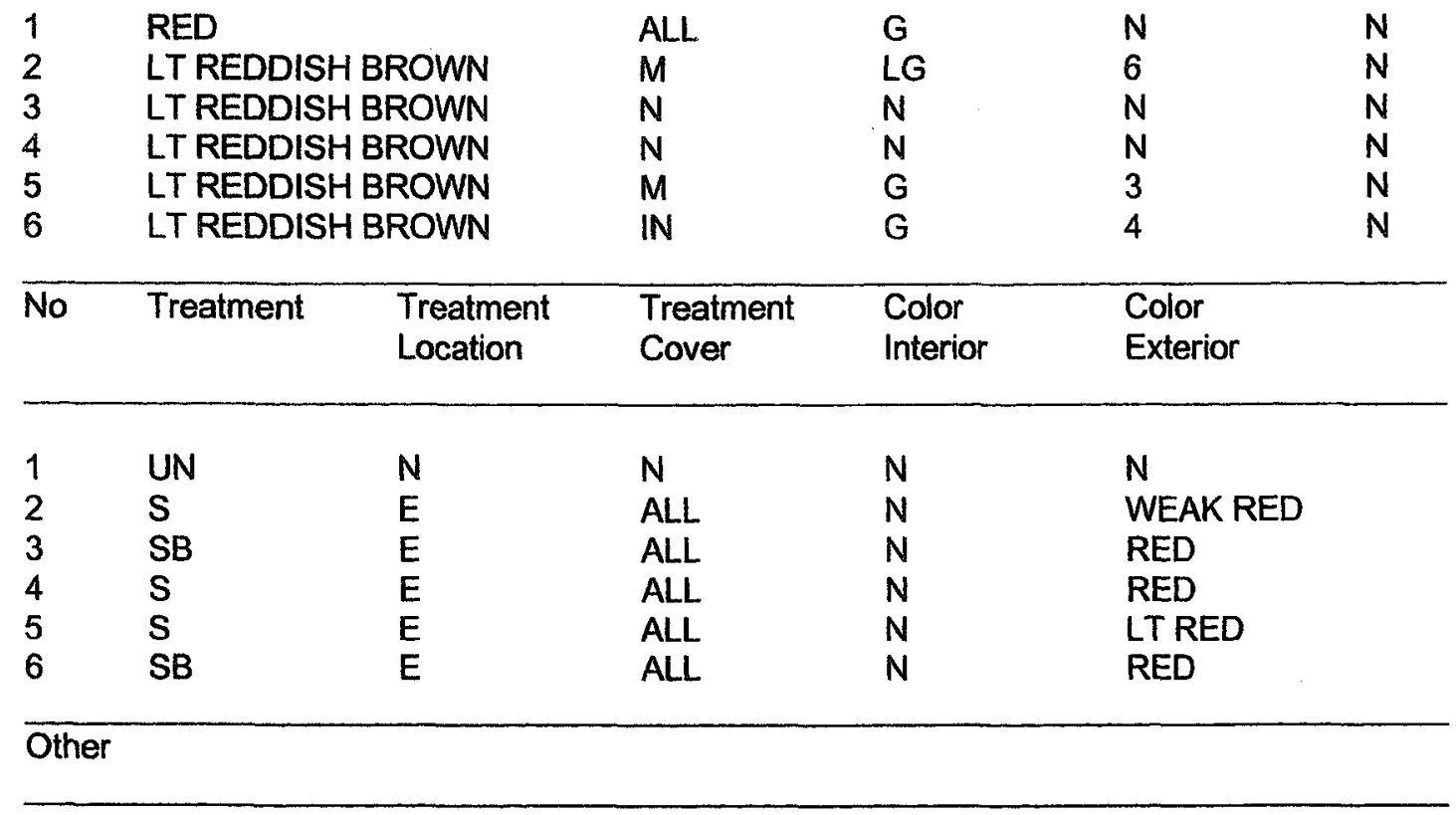

$1 \quad$ Metallic Ware.

$5 \quad$ String cut base.

PLATE 69. FIELD A. PHASE 3A (EB III). 

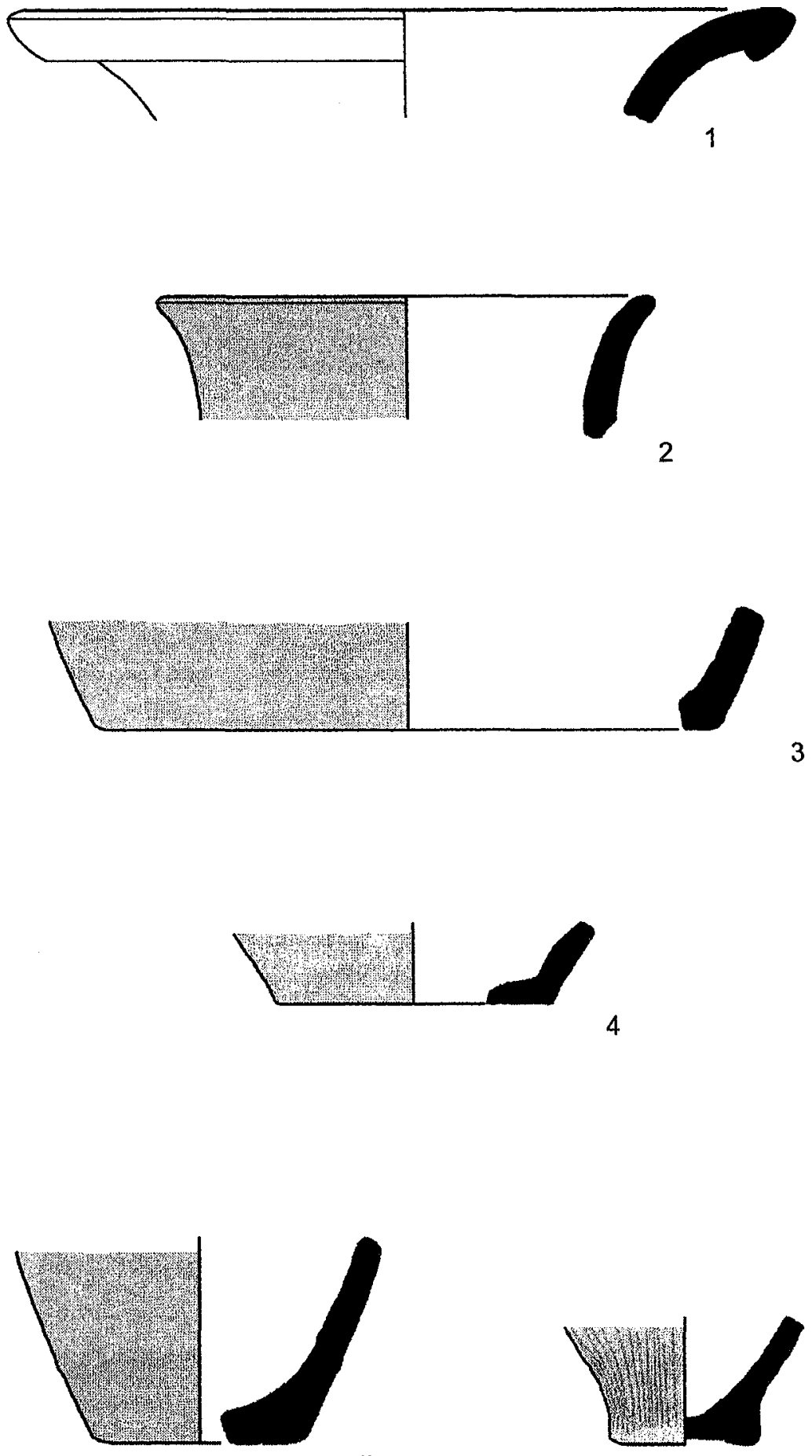

6

PLATE 69 (CONT.).

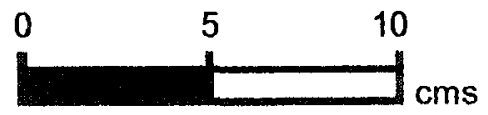


386

\begin{tabular}{llllllll}
\hline No & Reg & Square & Locus & Vessel & Part & $\begin{array}{c}\text { Body } \\
\text { Thick }\end{array}$ & \begin{tabular}{c} 
Dia \\
\hline 1
\end{tabular} \\
\hline 1041 & SW 4-27 & 27 & BOWL & R50 & 19 & 48 \\
2 & 1042 & SW 4-27 & 27 & LEDGE RIM BOWL & R52 & 9 & 38 \\
3 & 1069 & SW 4-27 & 22 & LEDGE RIM BOWL & R55 & 13 & 50 \\
4 & 1047 & SW 4-27 & 27 & LEDGE RIM BOWL & R60 & 11 & 48
\end{tabular}

\begin{tabular}{lllll}
\hline No Fabric Color & Core Orient & Core Color Core Thick & Fabric \\
& & & & \\
& Family
\end{tabular}

\begin{tabular}{|c|c|c|c|c|c|c|}
\hline $\begin{array}{l}1 \\
2 \\
3 \\
4\end{array}$ & $\begin{array}{l}\text { PINK } \\
\text { PINK } \\
\text { PINK } \\
\text { PINK }\end{array}$ & & $\begin{array}{l}M \\
N \\
\text { IRR } \\
\text { EX }\end{array}$ & $\begin{array}{l}\text { LG } \\
N \\
L G \\
L G\end{array}$ & $\begin{array}{l}8 \\
N \\
5 \\
10\end{array}$ & $\begin{array}{l}N \\
N \\
N \\
N\end{array}$ \\
\hline No & Treatment & $\begin{array}{l}\text { Treatment } \\
\text { Location }\end{array}$ & $\begin{array}{l}\text { Treatment } \\
\text { Cover }\end{array}$ & $\begin{array}{l}\text { Color } \\
\text { Interior }\end{array}$ & $\begin{array}{l}\text { Color } \\
\text { Exterior }\end{array}$ & \\
\hline $\begin{array}{l}1 \\
2 \\
3 \\
4\end{array}$ & $\begin{array}{l}\text { SB } \\
S \\
\text { SB } \\
S\end{array}$ & $\begin{array}{l}\text { IR } \\
\text { IR } \\
\text { IR } \\
\text { ER }\end{array}$ & $\begin{array}{l}\text { ALL } \\
A L L \\
A L L \\
A L L\end{array}$ & $\begin{array}{l}\text { RED } \\
\text { RED } \\
\text { RED } \\
N\end{array}$ & $\begin{array}{l}N \\
N \\
N \\
\text { RED }\end{array}$ & \\
\hline
\end{tabular}

1 Interior and upper exterior surface appears smooth, slipped, and possibly burnished; lower portion of exterior surface reveals many scrape marks, some horizontal, some diagonal; scraping appears to have been done subsequent to smoothing of upper exterior surface.

2 Lines of wet-smoothing mark interior and exterior face.

3 Radial burnish on platter face; wheel burnish around circumference.

$4 \quad$ Very slight concavity under rim on ext face; sherd well weathered.

PLATE 70. FIELD A. PHASE 3A (EB III). 

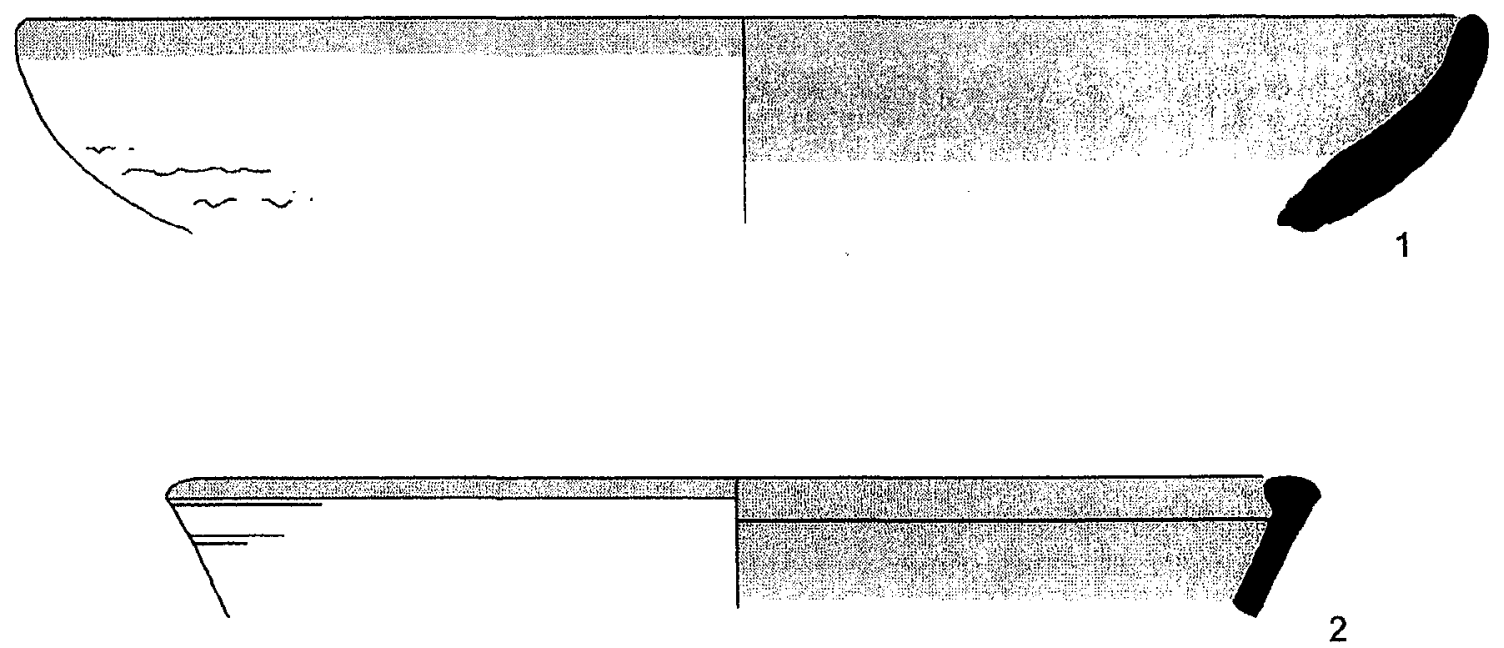

2
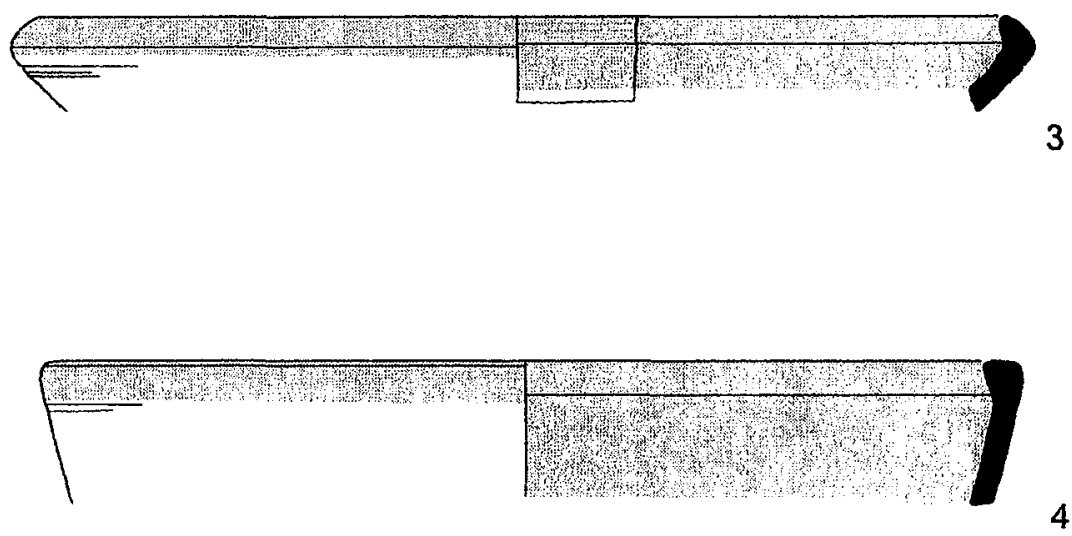

PLATE 70 (CONT).

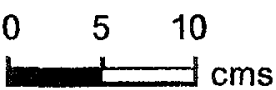




\begin{tabular}{llllllll}
\hline No & Reg & Square & Locus & Vessel & Part & $\begin{array}{c}\text { Body } \\
\text { Thick }\end{array}$ & $\begin{array}{c}\text { Dia } \\
\text { n }\end{array}$ \\
& & & & & & & \\
1 & 1111 & SW 5-26 & 16 & HOLE MOUTH JAR & R01 & 12 & 12 \\
2 & 1117 & SW 5-26 & 13 & BOWL & R81 & 9 & N \\
3 & 1115 & SW 5-26 & 13 & LEDGE RIM BOWL & R53 & 9 & 30 \\
4 & 1116 & SW 5-26 & 13 & JUG & B24 & 8 & 5 \\
5 & 1166 & SW 5-26 & 16 & NECKED JAR & R31 & 9 & 10 \\
6 & 1113 & SW 5-26 & 13 & LEDGE RIM BOWL & R53 & 10 & 38 \\
7 & 1112 & SW 5-26 & 16 & LEDGE RIM BOWL & R51 & 13 & 46
\end{tabular}

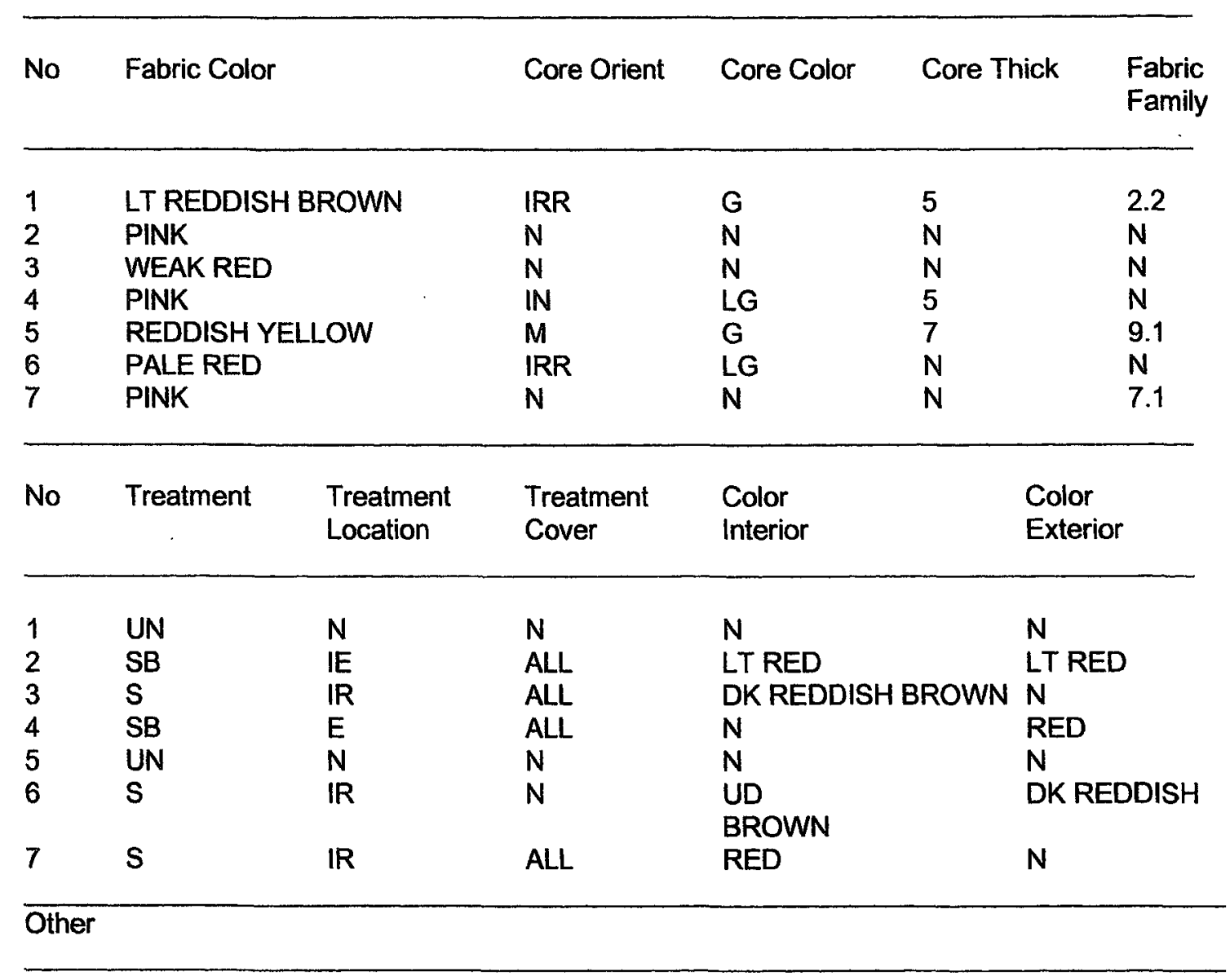

2 Sample too small to confirm stance or diameter.

PLATE 71. FIELD A. PHASE 3A (EB III). 

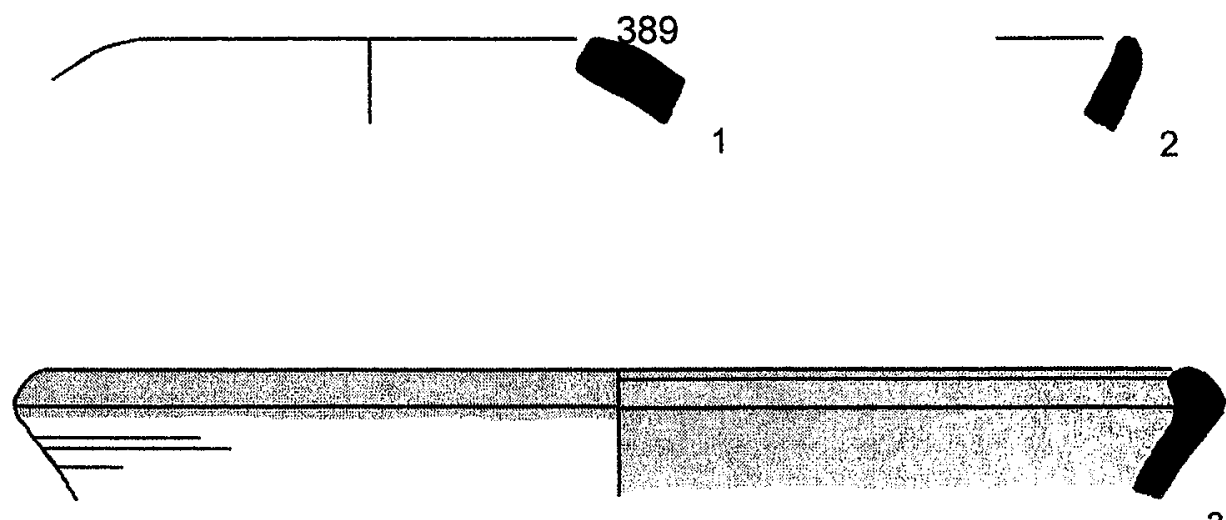

3
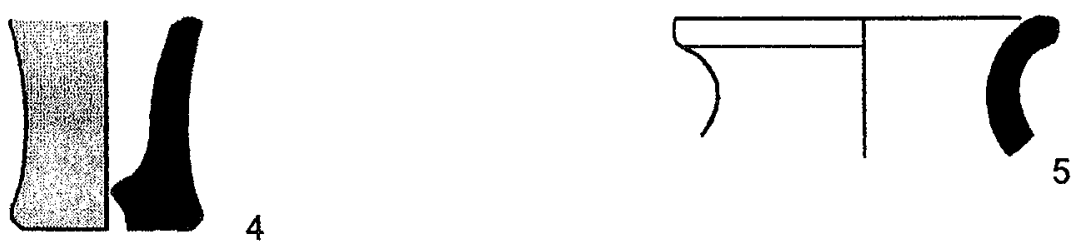

4
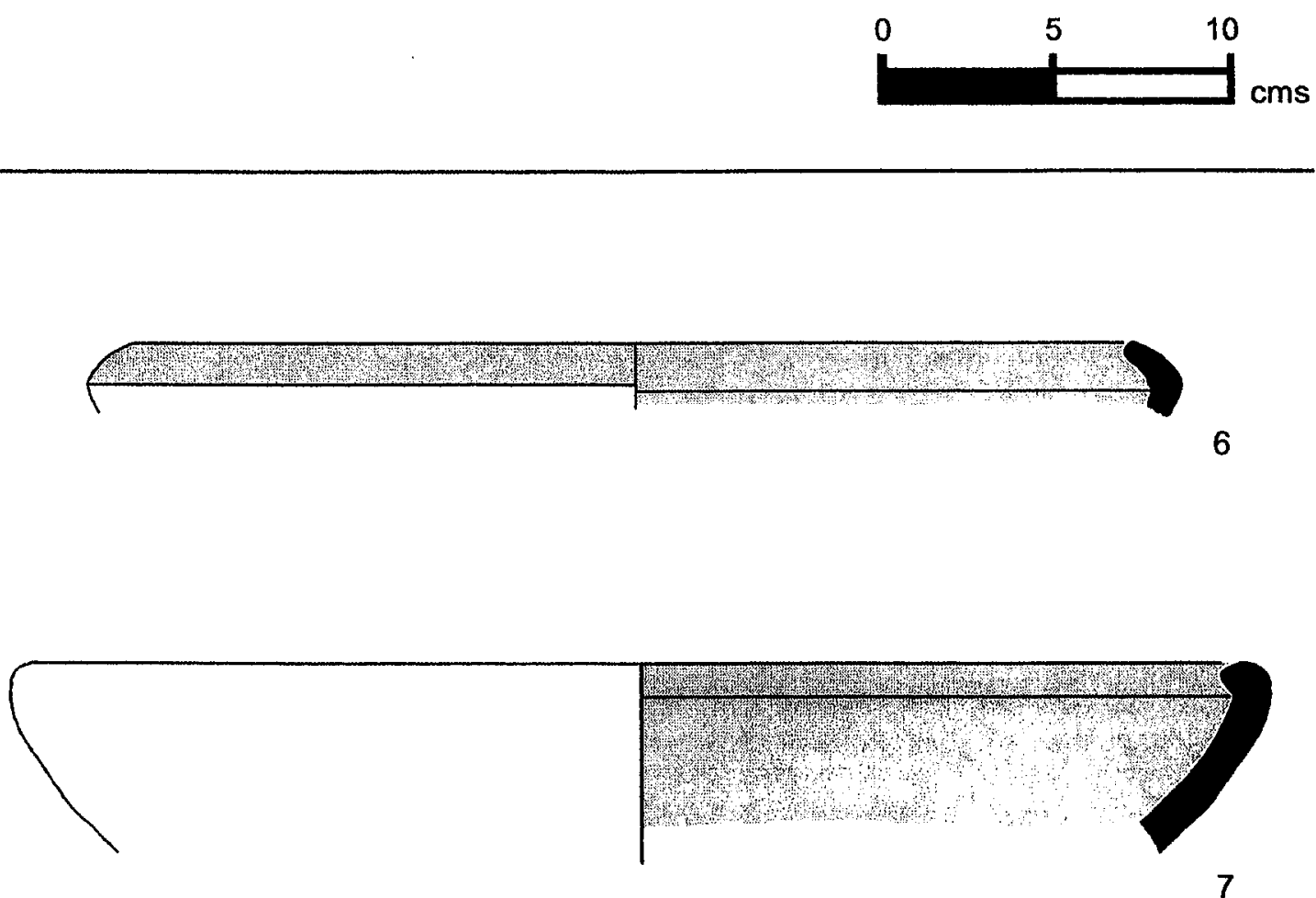

7

PLATE 71 (CONT.).

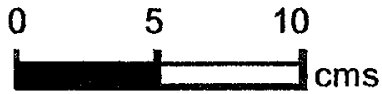




\begin{tabular}{llllllll}
\hline No & Reg & Square & Locus & Vessel & Part & $\begin{array}{c}\text { Body } \\
\text { Thick }\end{array}$ & Dia \\
\hline 1 & 1182 & SW 5-27 & 14 & PLATTER BOWL & R55 & 13 & 36 \\
2 & 1181 & SW 5-27 & 14 & HOLE MOUTH BOWL & R12 & 10 & 30 \\
3 & 1187 & SW 5-27 & 13 & HOLE MOUTH JAR & R04 & 16 & 20 \\
4 & 1185 & SW 5-27 & 13 & HOLE MOUTH BOWL & R01 & 11 & 15 \\
5 & 1180 & SW 5-27 & 14 & HOLE MOUTH BOWL & R12 & 10 & 14 \\
6 & 1184 & SW 5-27 & 13 & LEDGE RIM BOWL & R51 & 9 & 20 \\
7 & 1186 & SW 5-27 & 13 & LEDGE RIM BOWL & R51 & 13 & 40 \\
8 & 1178 & SW 5-27 & 14 & LEDGE RIM BOWL & R51 & 12 & 40 \\
\hline No & Fabric Color & \multicolumn{7}{c}{ Core Orient Core Color } & Core Thick & Fabric \\
& & & & & & Family
\end{tabular}

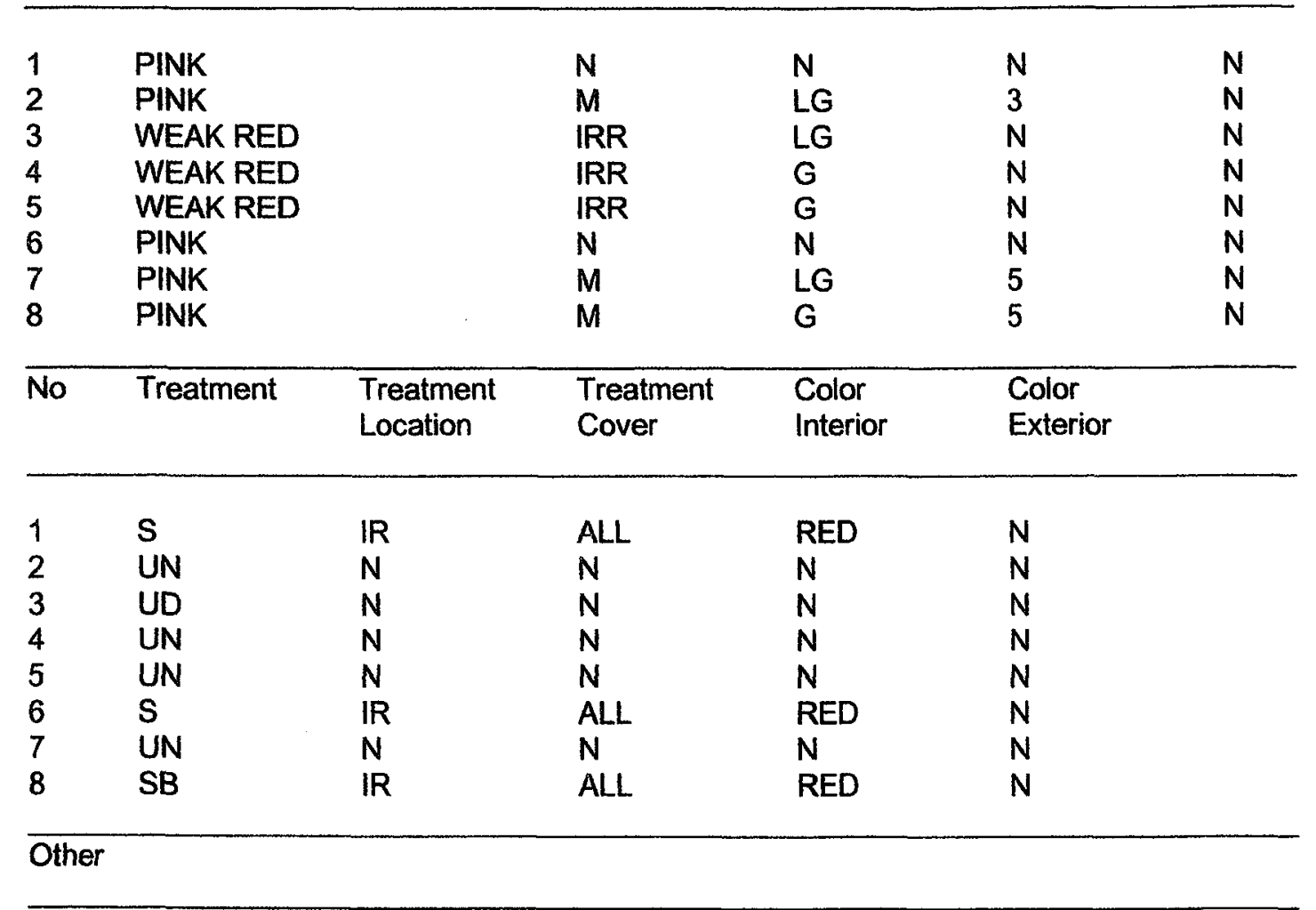

3 Sample too small to confirm stance or diameter.

4 Sample too small to confirm stance or diameter; surface burn visible; finish marks visible on interior face.

$5 \quad$ Surface burn visible.

6 Sample too small to confirm stance or diameter.

8 Marginal band very distinct.

PLATE 72. FIELD A. PHASE 3A (EB III). 

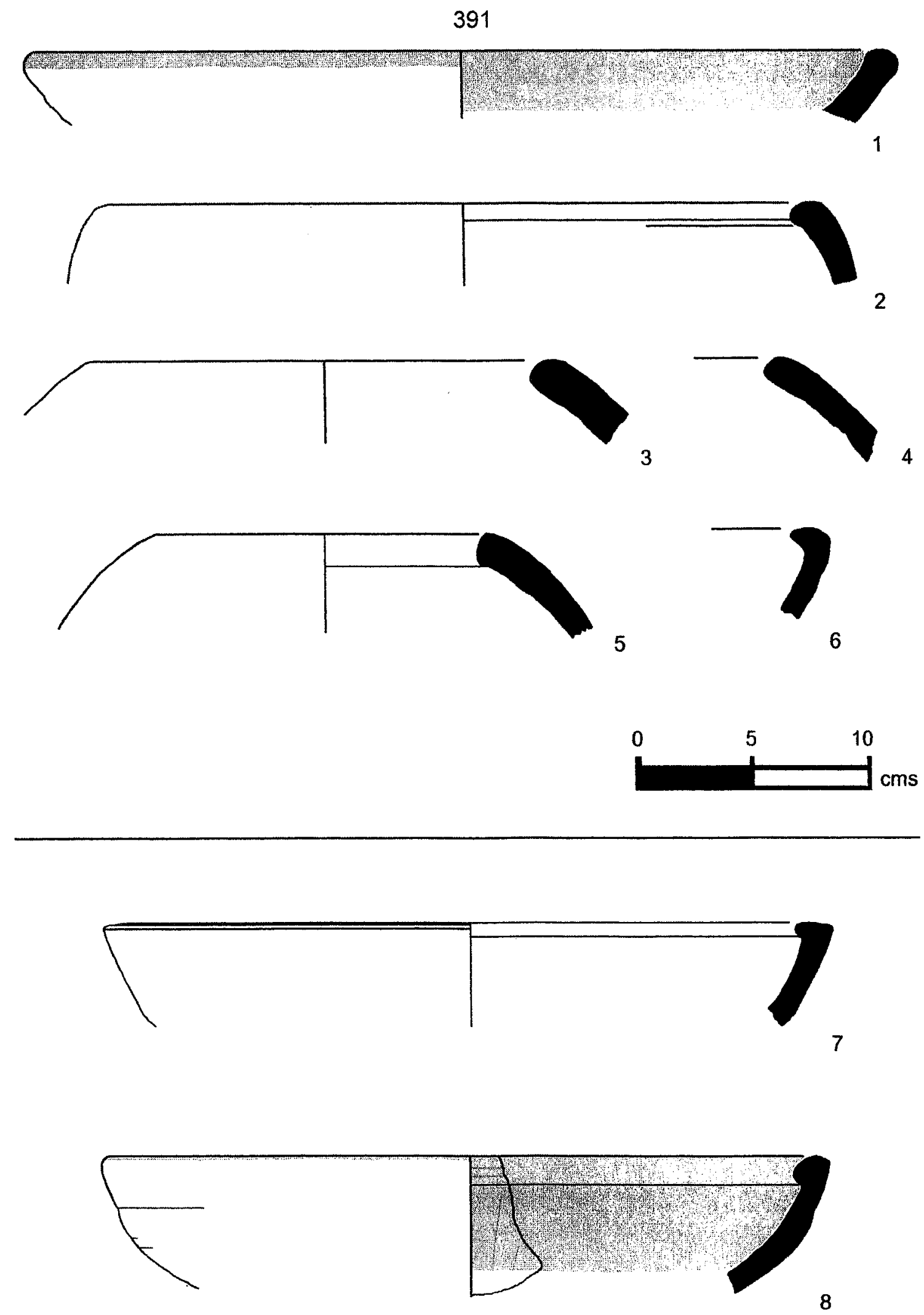

PLATE 72(CONT.).

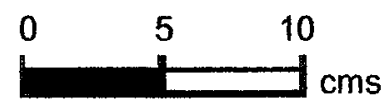


392

\begin{tabular}{llllllll}
\hline No & Reg & Square & Locus & Vessel & Part & $\begin{array}{c}\text { Body } \\
\text { Thick }\end{array}$ & Dia \\
\hline & & & & & & & \\
1 & 1170 & SW 5-27 & 16 & BOWL & R50 & 5 & 24 \\
2 & 2271 & SW 5-27 & 16 & HOLE MOUTH JARIBOWL & R02 & N & 30 \\
3 & 1174 & SW 5-27 & 16 & HOLE MOUTH JAR & R01 & 13 & 20 \\
4 & 1169 & SW 5-27 & 16 & HOLE MOUTH JAR & R04 & 5 & 7 \\
5 & 1167 & SW 5-27 & 16 & HOLE MOUTH BOWL & R04 & 9 & 13 \\
6 & 1168 & SW 5-27 & 16 & NECKED JAR & R43 & 14 & 26 \\
7 & 1175 & SW 5-27 & 16 & NECKED JAR & R31 & 9 & 12 \\
\hline No & Fabric Color & & Core Orient Core Color & Core Thick & Fabric \\
& & & & & & Family
\end{tabular}

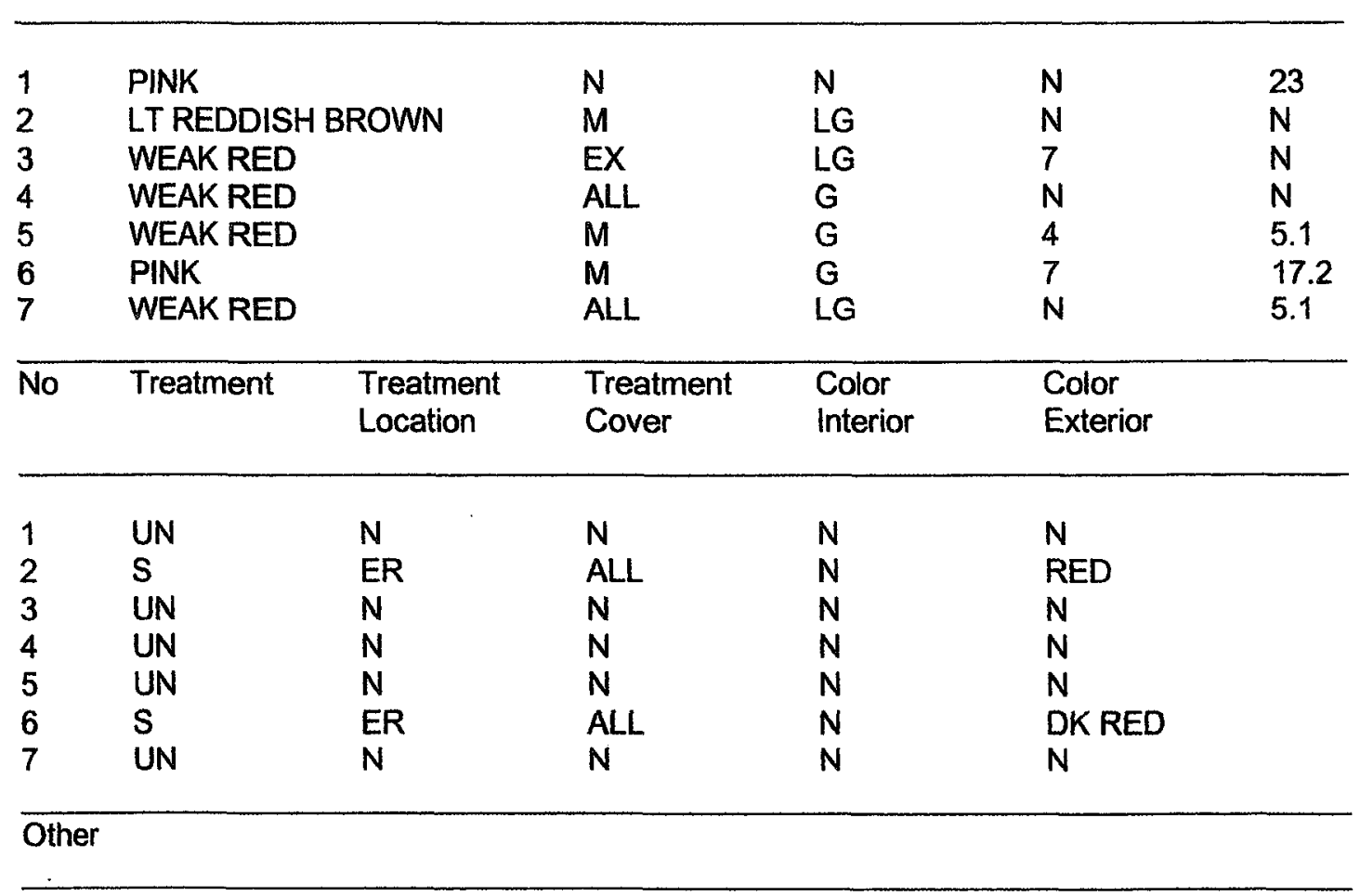

2 Sample too small to confirm stance or diameter.

3 Sample too small to confirm stance or diameter; surface burn visible.

5 Surface burn visible.

PLATE 73. FIELD A. PHASE 3A (EB III). 


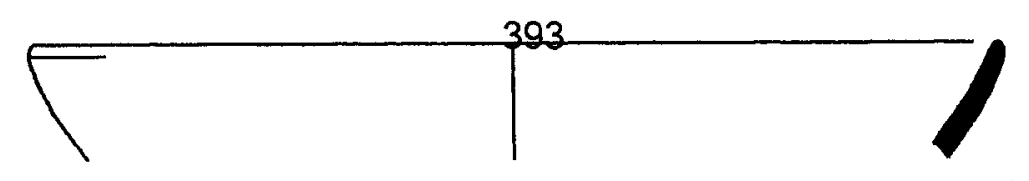

1
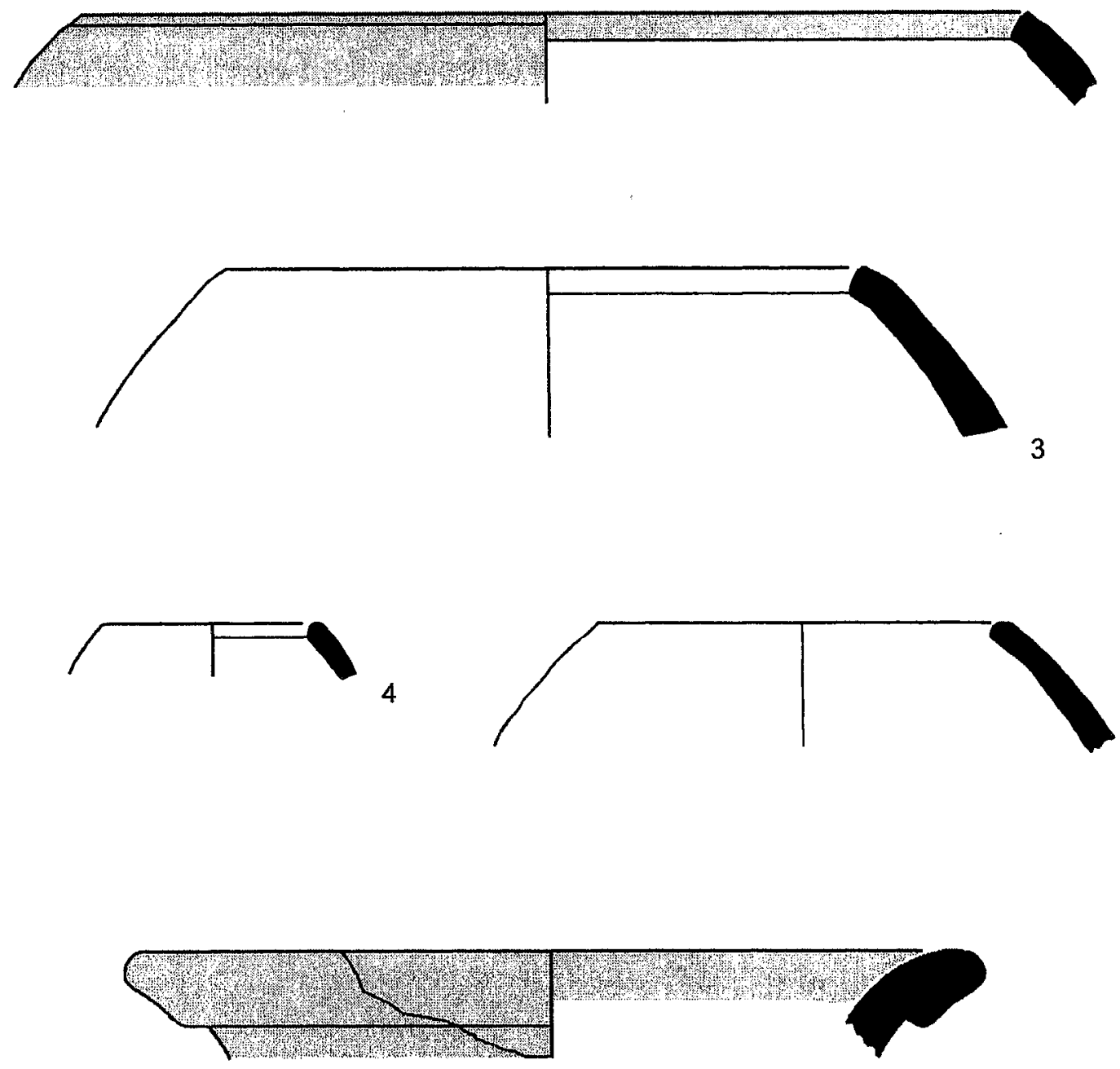

6

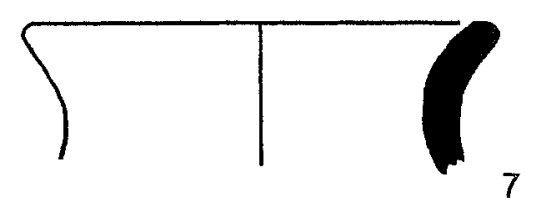

PLATE73(CONT.).

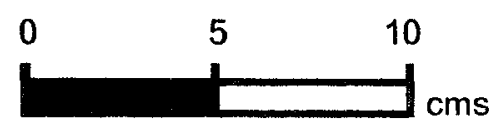


394

\begin{tabular}{|c|c|c|c|c|c|c|c|c|c|}
\hline$\overline{\text { No }}$ & $\operatorname{Reg}$ & \multicolumn{2}{|c|}{ Square } & Locus & \multicolumn{2}{|l|}{ Vessel } & Part & \multicolumn{2}{|c|}{$\begin{array}{l}\text { Body } \\
\text { Thick }\end{array}$} \\
\hline 1 & 1172 & \multicolumn{2}{|c|}{ SW 5-27 } & 16 & \multicolumn{2}{|l|}{ UD } & B11 & 8 & 18 \\
\hline 2 & 2275 & \multicolumn{2}{|c|}{ SW 5-27 } & 16 & \multicolumn{2}{|l|}{ UD } & B12 & $N$ & 18 \\
\hline 3 & 1171 & & & 16 & \multicolumn{2}{|c|}{ LEDGE RIM BOWL } & R51 & 9 & 42 \\
\hline No & \multicolumn{4}{|c|}{ Fabric Color } & Core Orient & Core Color & \multicolumn{2}{|c|}{ Core Thick } & Fabric \\
\hline 1 & \multirow{3}{*}{\multicolumn{4}{|c|}{$\begin{array}{l}\text { LT REDDISH BROWN } \\
\text { LT BROWN } \\
\text { LT REDDISH BROWN }\end{array}$}} & $\mathbf{N}$ & $\mathbf{N}$ & $N$ & & 8 \\
\hline 2 & & & & & $\mathbf{N}$ & $\mathbf{N}$ & $N$ & & $\mathbf{N}$ \\
\hline 3 & & & & & $\mathbb{N}$ & $\mathbf{N}$ & $\mathbf{N}$ & & $\mathbf{N}$ \\
\hline No & \multicolumn{2}{|c|}{ Treatment } & \multicolumn{2}{|c|}{$\begin{array}{l}\text { Treatment } \\
\text { Location }\end{array}$} & $\begin{array}{l}\text { Treatment } \\
\text { Cover }\end{array}$ & $\begin{array}{l}\text { Color } \\
\text { Interior }\end{array}$ & \multicolumn{2}{|c|}{$\begin{array}{l}\text { Color } \\
\text { Exterior }\end{array}$} & \\
\hline 1 & UN & & $\mathrm{N}$ & & $N$ & $\mathbf{N}$ & $\mathbf{N}$ & & \\
\hline 2 & UN & & $\mathrm{N}$ & & $\mathbf{N}$ & $\mathrm{N}$ & $\mathbf{N}$ & & \\
\hline 3 & B & & IE & & ALL & $\mathrm{N}$ & $N$ & & \\
\hline
\end{tabular}

Other

2 Sample too small to confirm stance or diameter.

3 Exterior concavity possibly formed as a result of pressure applied in rim folding.

PLATE 74. FIELD A. PHASE 3A (EB III). 

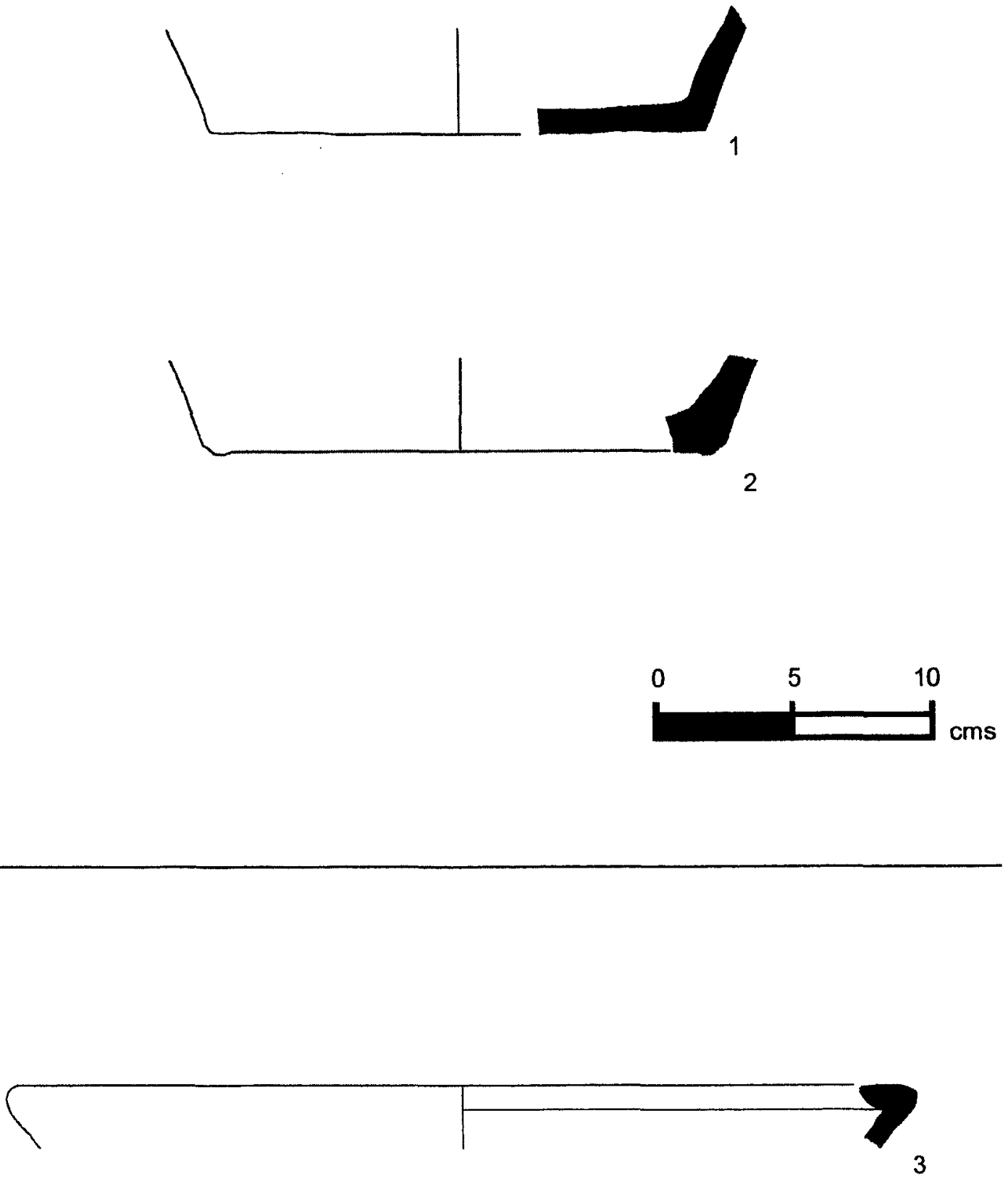

3

PLATE 74 (CONT.).

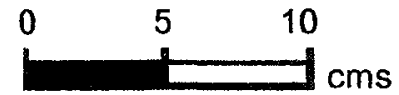




\begin{tabular}{llllllll}
\hline No & Reg & Square & Locus & Vessel & Part & $\begin{array}{l}\text { Body } \\
\text { Thick }\end{array}$ & $\begin{array}{l}\text { Dia } \\
\end{array}$ \\
\hline & & & & & & & \\
1 & 2266 & SW 5-27 & 21 & HOLE MOUTH JAR & R04 & 8 & 7 \\
2 & 1137 & SW 5-27 & 21 & HOLE MOUTH JAR & R01 & 10 & 12 \\
3 & 1141 & SW 5-27 & 19 & HOLE MOUTH JARIBOWL & R14 & 9 & 20 \\
4 & 1143 & SW 5-27 & 27 & HOLE MOUTH JAR & R19 & 8 & 15 \\
5 & 1144 & SW 5-27 & 27 & HOLE MOUTH BOWL & R01 & 12 & 14 \\
6 & 1145 & SW 5-27 & 27 & PLATTER BOWL & R00 & 7 & 36 \\
7 & 1140 & SW 5-27 & 19 & UD & B12 & 6 & 20 \\
8 & 1139 & SW 5-27 & 21 & UD & B12 & 19 & 14 \\
9 & 1146 & SW 5-27 & 27 & UD & BOD & 7 & N
\end{tabular}

\begin{tabular}{llll}
\hline No Fabric Color Core Orient & Core Color Core Thick & Fabric \\
Family
\end{tabular}

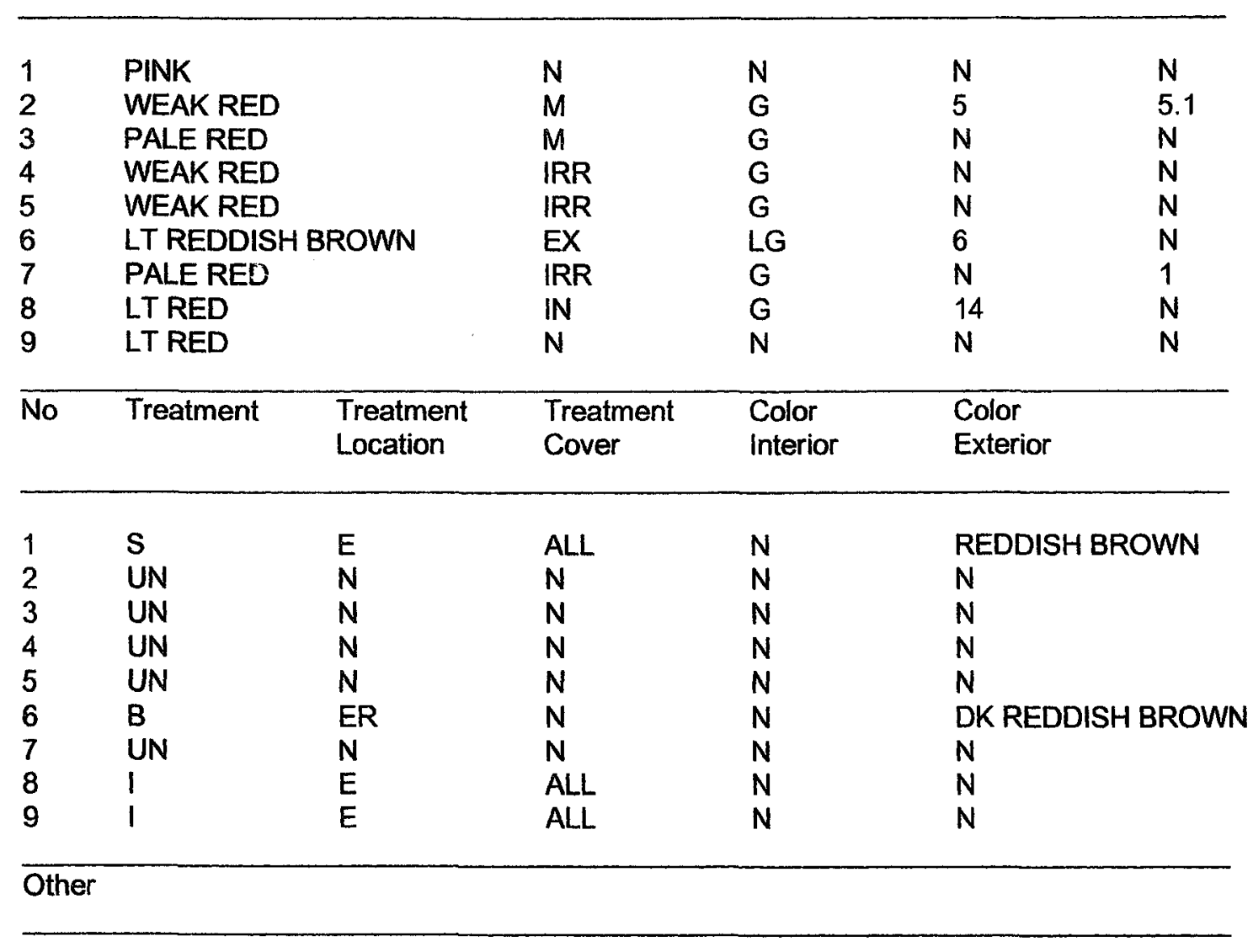

\footnotetext{
1 Sample too small to confirm stance or diameter.

2 Surface burn visible; fine lines suggest motion used to finish rim.

3 Sample too small to confirm stance or diameter.

5 Surface burn visible.

8 Combed Metallic Ware.

9 Combed Metallic Ware.
}

PLATE 75. FIELD A. PHASE 3A (EB III). 

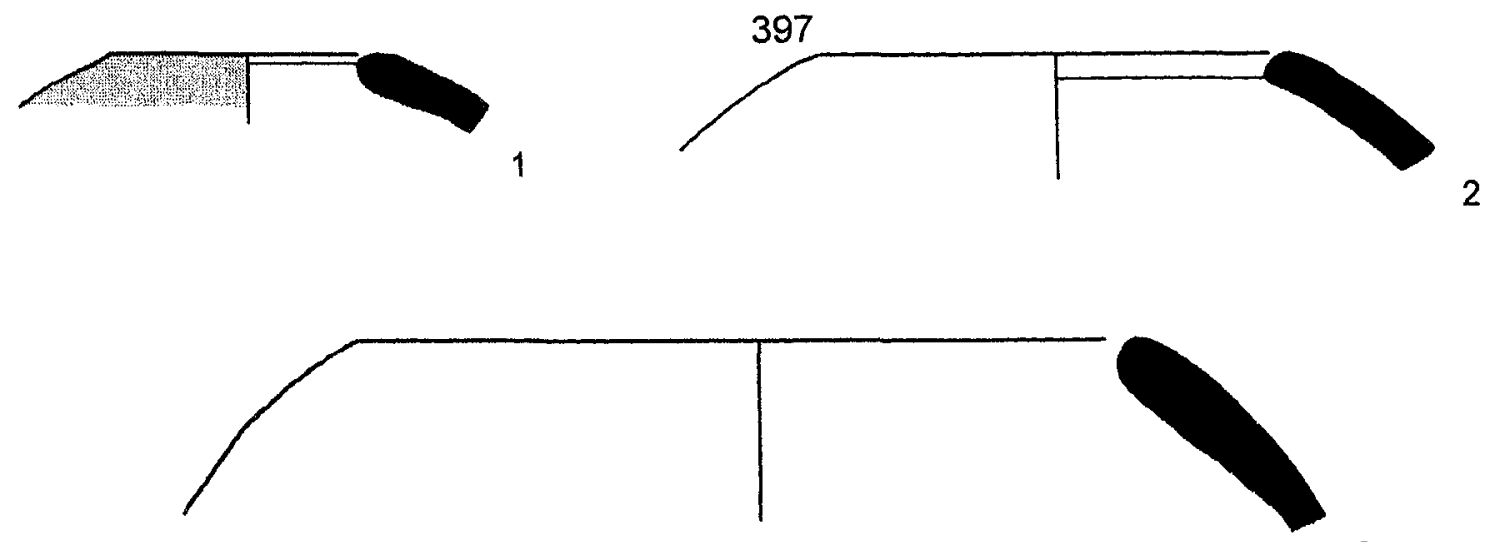

3
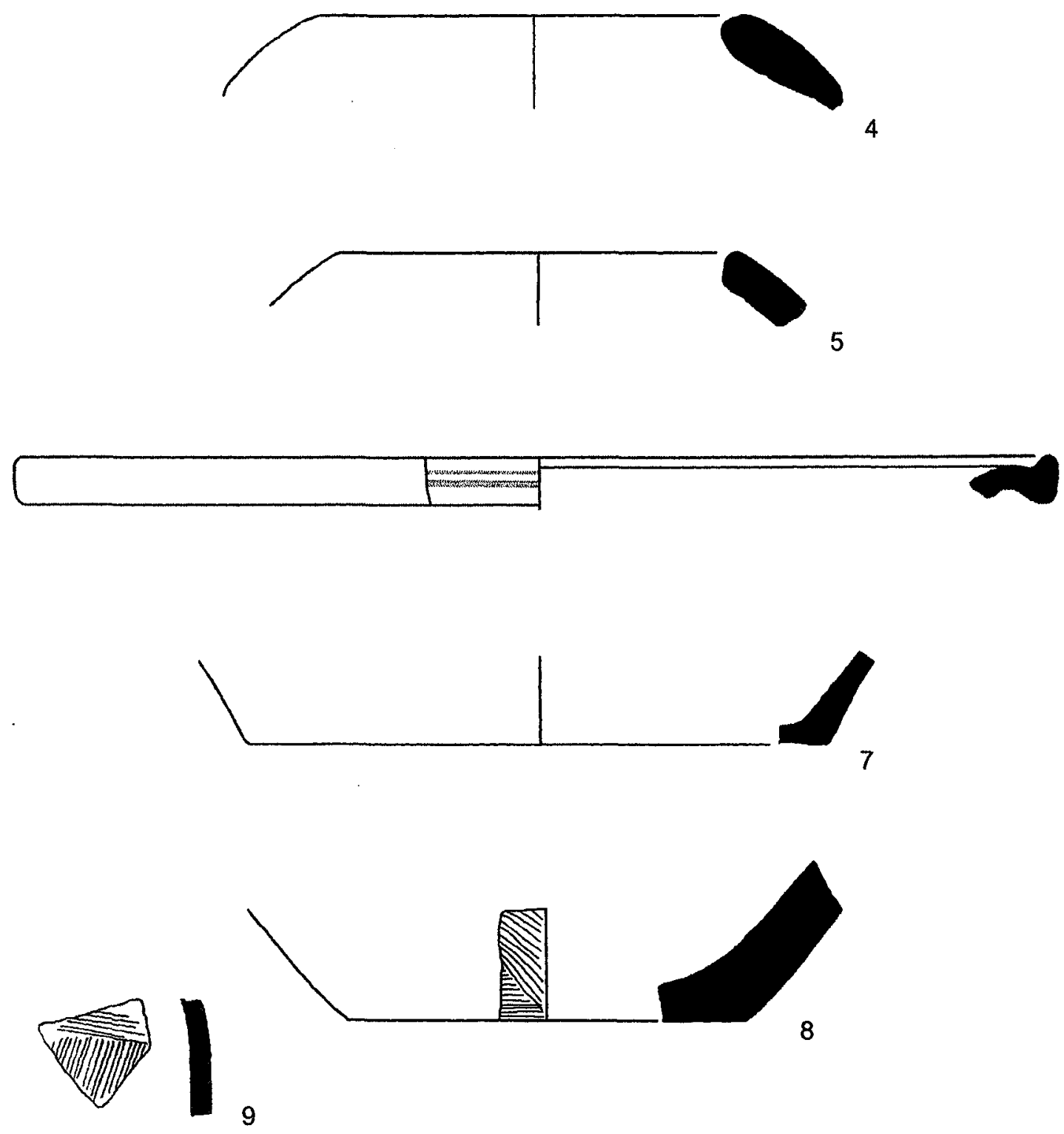

PLATE 75 (CONT.).

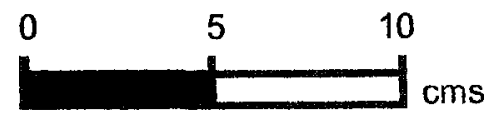


398

\begin{tabular}{llllllll}
\hline No & Reg & Square & Locus & Vessel & Part & $\begin{array}{c}\text { Body } \\
\text { Thick }\end{array}$ & Dia \\
\hline & & & & & & & \\
1 & 1123 & SW 5-27 & 23 & BOWL & R53 & 7 & 18 \\
2 & 1124 & SW 5-27 & 23 & BOWL & R50 & 8 & 12 \\
3 & 1130 & SW 5-27 & 23 & HOLE MOUTH JARIBOWL & R04 & 17 & 15 \\
4 & 1122 & SW 5-27 & 23 & NECKED JAR & R42 & 11 & 22 \\
5 & 1125 & SW 5-27 & 23 & CHANNELED RIM JAR & R35 & 8 & 10 \\
6 & 1129 & SW 5-27 & 23 & UD & B12 & 8 & 22 \\
7 & 1128 & SW 5-27 & 23 & UD & B11 & 7 & 6 \\
8 & 1127 & SW 5-27 & 23 & UD & B12 & 8 & 15 \\
9 & 1131 & SW 5-27 & 23 & UD & BOD & 8 & N \\
\hline No & Fabric Color & & Core Orient Core Color & Core Thick & Fabric \\
& & & & & & & Family
\end{tabular}

\begin{tabular}{|c|c|c|c|c|c|c|}
\hline 1 & \multicolumn{2}{|c|}{ LT REDDISH BROWN } & $M$ & G & 5 & $\mathbf{N}$ \\
\hline 2 & \multicolumn{2}{|c|}{ PALE RED } & IRR & $\mathbf{G}$ & $N$ & $\mathrm{~N}$ \\
\hline 3 & \multicolumn{2}{|c|}{ LT REDDISH BROWN } & $\mathbf{M}$ & G & 7 & $\mathrm{~N}$ \\
\hline 4 & \multicolumn{2}{|c|}{ LT RED } & ALL & G & $N$ & N \\
\hline 5 & \multicolumn{2}{|c|}{ LT REDDISH BROWN } & $\mathbf{N}$ & $\mathrm{N}$ & $\mathbf{N}$ & $\mathrm{N}$ \\
\hline 6 & \multicolumn{2}{|c|}{ PALE RED } & ALL & $\mathbf{G}$ & $N$ & $N$ \\
\hline 7 & \multicolumn{2}{|c|}{ LT REDDISH BROWN } & $\mathbf{N}$ & $\mathrm{N}$ & $\mathbf{N}$ & $\mathbf{N}$ \\
\hline 8 & \multicolumn{2}{|l|}{ LT RED } & $N$ & $\mathrm{~N}$ & $\mathrm{~N}$ & $\mathrm{~N}$ \\
\hline 9 & \multicolumn{2}{|l|}{ PINK } & $\mathrm{N}$ & $\mathrm{N}$ & $\mathrm{N}$ & $\mathbf{N}$ \\
\hline No & Treatment & $\begin{array}{l}\text { Treatment } \\
\text { Location }\end{array}$ & $\begin{array}{l}\text { Treatment } \\
\text { Cover }\end{array}$ & $\begin{array}{l}\text { Color } \\
\text { Interior }\end{array}$ & $\begin{array}{l}\text { Color } \\
\text { Exterior }\end{array}$ & \\
\hline 1 & B & IE & ALL & $\mathrm{N}$ & $\mathrm{N}$ & \\
\hline 2 & UD & $N$ & $\mathbf{N}$ & $N$ & $N$ & \\
\hline 3 & $\mathrm{~S}$ & ER & ALL & $\mathbf{N}$ & WEAK RED & \\
\hline 4 & $\mathrm{~S}$ & ER & ALL & $\mathrm{N}$ & RED & \\
\hline 5 & $\mathrm{~S}$ & ER & UD & $\mathbf{N}$ & RED & \\
\hline 6 & UN & $\mathbf{N}$ & $\mathbf{N}$ & $\mathbf{N}$ & $\mathrm{N}$ & \\
\hline 7 & B & $E$ & ALL & $\mathbf{N}$ & $\mathrm{N}$ & \\
\hline 8 & UD & $N$ & $\mathbf{N}$ & $N$ & $N$ & \\
\hline 9 & 1 & $E$ & ALL & $N$ & $N$ & \\
\hline
\end{tabular}

\section{Other}

1 Surface burn visible; soot on lip suggests use as lamp; random burnish on interior face.

3 Sample too small to confirm stance or diameter.

8 Metallic Ware.

9 Combed Metallic Ware.

PLATE 76. FIELD A. PHASE 3A (EB III). 

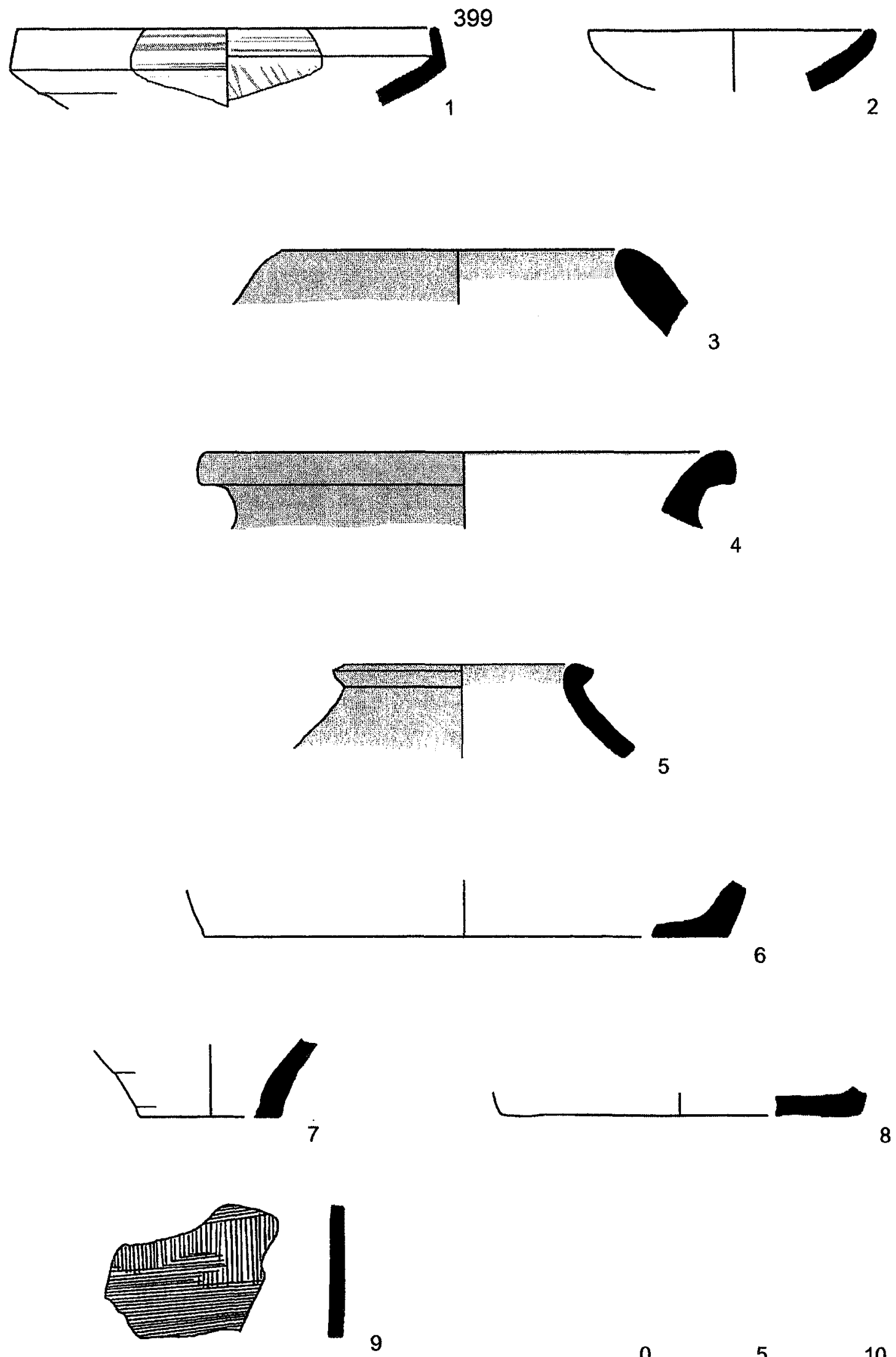

PLATE 76 (CONT.).

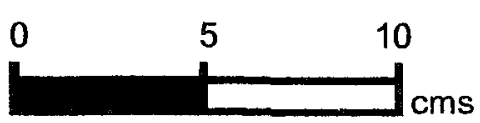




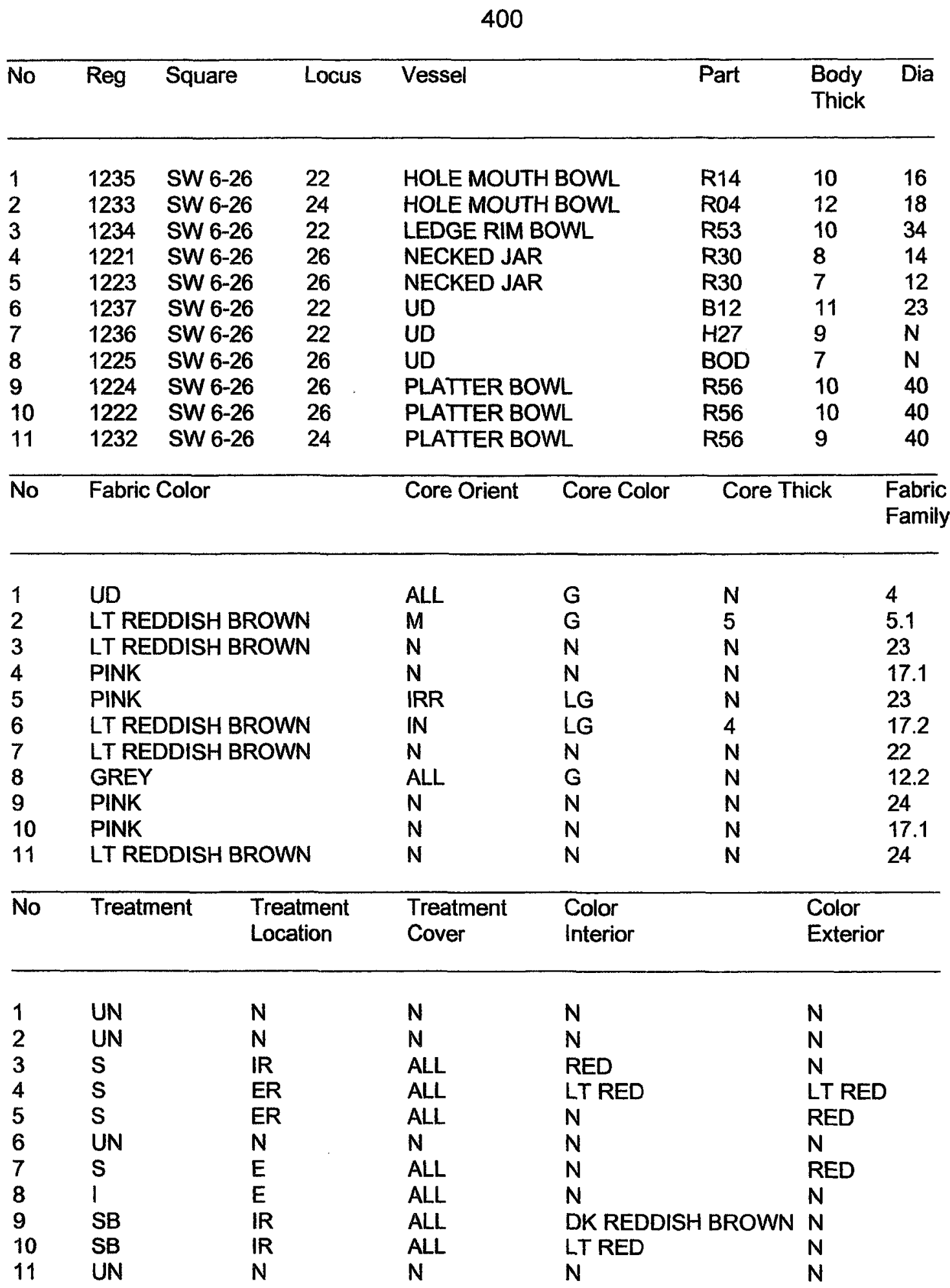

PLATE 77. FIELD A. PHASE 3A (EB III). 


\section{Other}

1 Sample too small to confirm stance or diameter.

2 Sample too small to confirm stance or diameter; surface burn visible.

3 Sample too small to confirm stance or diameter.

5 Coil marks visible on interior wall.

8 Combed.

9 Radial burnish on interior face.

10 Features in break suggest rim-foldings; wet-smoothing in the marginal concavity under rim has smeared some gouges from base scraping.

11 Concavity under rim is very faint.

PLATE 77 (CONT.). 

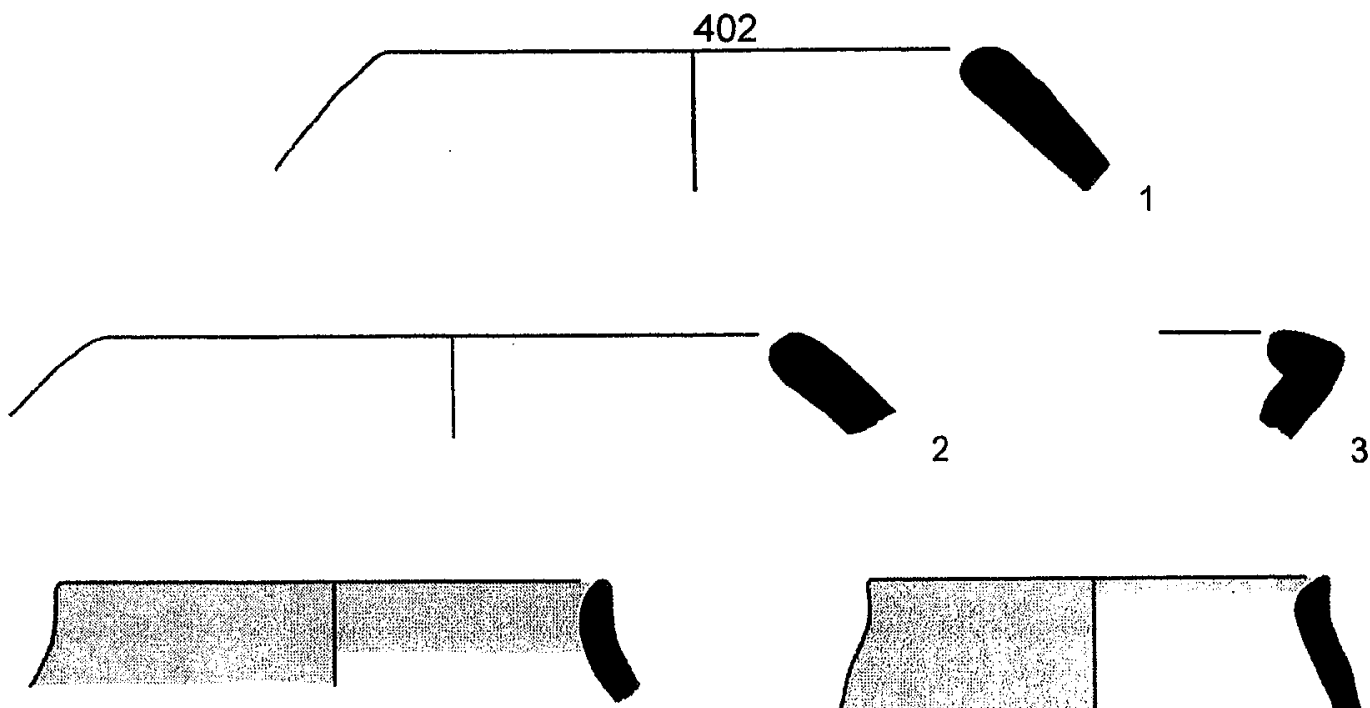

4
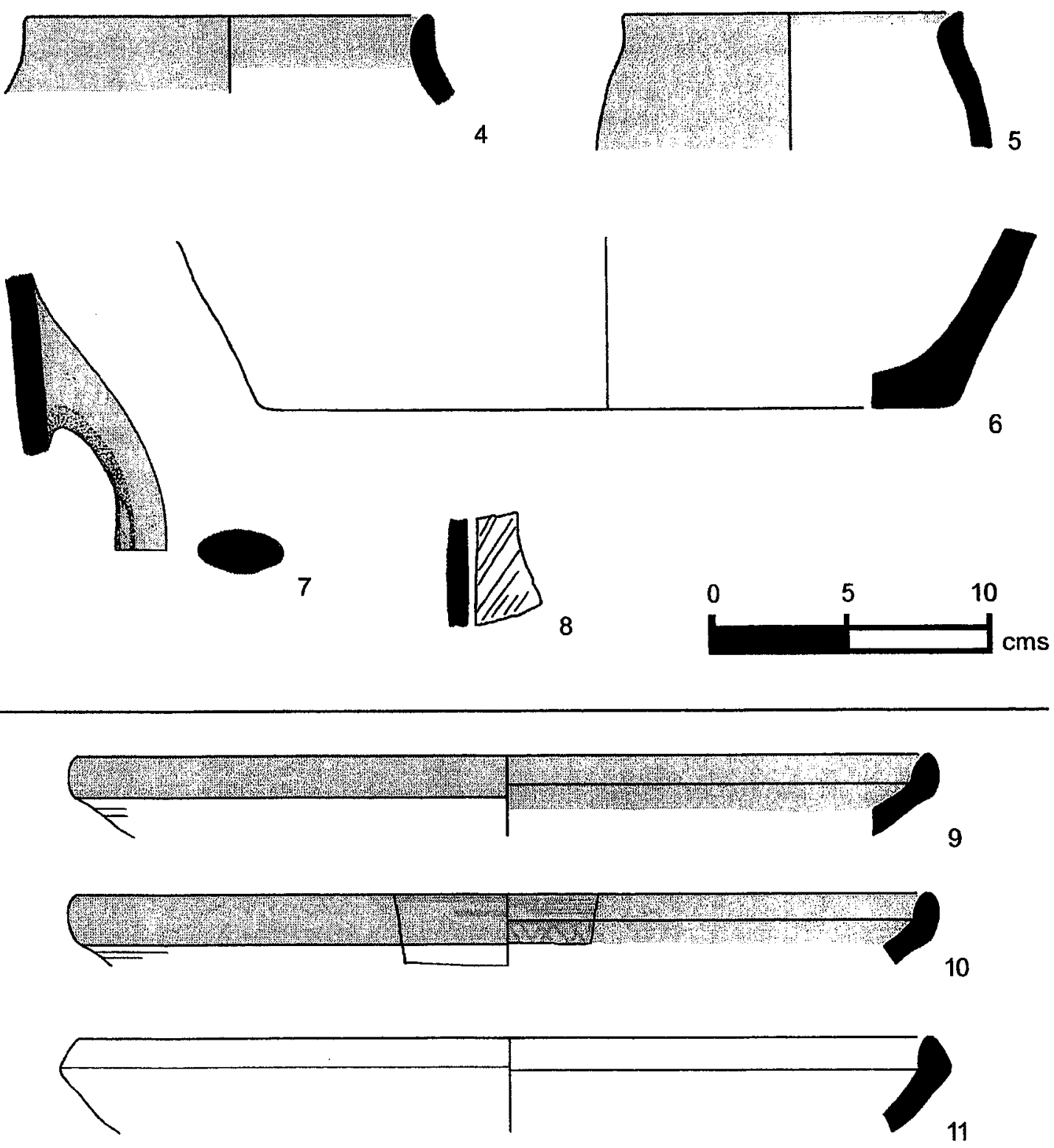

PLATE 77 (CONT.).

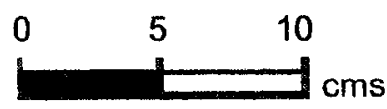


403

\begin{tabular}{llllllll}
\hline No & Reg & Square & Locus & Vessel & Part & $\begin{array}{c}\text { Body } \\
\text { Thick }\end{array}$ & Dia \\
& & & & & & & \\
& & & & & R50 & 8 & 16 \\
1 & 1229 & SW 6-26 & 36 & BOWL & R81 & 6 & 12 \\
2 & 1214 & SW 6-26 & 44 & UD & R04 & 11 & 18 \\
3 & 1227 & SW 6-26 & 42 & HOLE MOUTH BOWL & R04 & 14 & 18 \\
4 & 1215 & SW 6-26 & 43 & HOLE MOUTH BOWL & R00 & 10 & 25 \\
5 & 1218 & SW 6-26 & 38 & HOLE MOUTH JAR & R42 & 14 & 18 \\
6 & 1216 & SW 6-26 & 43 & NECKED JAR & R51 & 15 & N \\
7 & 2324 & SW 6-26 & 43 & VAT & R42 & 14 & 20 \\
8 & 1219 & SW 6-26 & 29 & NECKED JAR & R60 & 9 & N \\
9 & 2312 & SW 6-26 & 27 & LEDGE RIM BOWL & R60 & 13 & 35 \\
10 & 1226 & SW 6-26 & 48 & LEDGE RIM BOWL & & & \\
\hline No & Fabric Color & & Core Orient Core Color & Core Thick & Fabric \\
& & & & & & & Family
\end{tabular}

\begin{tabular}{|c|c|c|c|c|c|c|}
\hline 1 & & $\mathbf{N}$ & $\mathbf{N}$ & $\mathbf{N}$ & 23 \\
\hline 2 & \multicolumn{2}{|c|}{$\begin{array}{l}\text { LT REDDISH BROWN } \\
\text { LT RED }\end{array}$} & $\mathbf{N}$ & $\mathbf{N}$ & $N$ & 22 \\
\hline 3 & \multicolumn{2}{|c|}{ LT REDDISH BROWN } & EX & G & 8 & 5.1 \\
\hline 4 & \multicolumn{2}{|c|}{ WEAK RED } & IRR & $\mathbf{G}$ & $\mathrm{N}$ & 5.1 \\
\hline 5 & \multicolumn{2}{|l|}{ PINK } & $M$ & LG & 6 & 10.1 \\
\hline 6 & \multicolumn{2}{|l|}{ LT RED } & $\mathbf{N}$ & $\mathrm{N}$ & $\mathrm{N}$ & $\mathbf{N}$ \\
\hline 7 & \multicolumn{2}{|l|}{ PINK } & $\mathrm{N}$ & $\mathbf{N}$ & $N$ & $\mathrm{~N}$ \\
\hline 8 & \multicolumn{2}{|c|}{ LT REDDISH BROWN } & ALL & $G$ & $\mathbf{N}$ & 4 \\
\hline 9 & \multicolumn{2}{|c|}{ PINK } & $\mathrm{N}$ & $\mathrm{N}$ & $\mathbf{N}$ & $\mathrm{N}$ \\
\hline 10 & \multicolumn{2}{|l|}{ PINK } & $\mathbf{N}$ & $\mathbf{N}$ & $\mathbf{N}$ & 16 \\
\hline No & Treatment & $\begin{array}{l}\text { Treatment } \\
\text { Location }\end{array}$ & $\begin{array}{l}\text { Treatment } \\
\text { Cover }\end{array}$ & $\begin{array}{l}\text { Color } \\
\text { Interior }\end{array}$ & $\begin{array}{l}\text { Color } \\
\text { Exterior }\end{array}$ & \\
\hline 1 & $\mathbf{S}$ & $\mathrm{E}$ & ALL & $\mathrm{N}$ & RED & \\
\hline 2 & UN & $\mathbf{N}$ & $N$ & $\mathbf{N}$ & $N$ & \\
\hline 3 & UN & $\mathbf{N}$ & $\mathbf{N}$ & $\mathbf{N}$ & $\mathbf{N}$ & \\
\hline 4 & UN & $N$ & $\mathbf{N}$ & $\mathbf{N}$ & $\mathbf{N}$ & \\
\hline 5 & $\mathbf{S}$ & $\mathrm{IE}$ & ALL & DUSKY RED & DUSKY RED & \\
\hline 6 & UN & $\mathbf{N}$ & $\mathbf{N}$ & $\mathbf{N}$ & $\mathbf{N}$ & \\
\hline 7 & $\mathrm{~S}$ & $\mathbb{R}$ & ALL & LT RED & $\mathbf{N}$ & \\
\hline 8 & $\mathrm{~S}$ & ER & $\mathbf{N}$ & $N$ & RED & \\
\hline 9 & $\mathrm{~S}$ & $\mathrm{IE}$ & ALL & RED & RED & \\
\hline 10 & SB & IE & ALL & LT RED & LT RED & \\
\hline
\end{tabular}

PLATE 78. FIELD A. PHASE 3A (EB III). 


\section{Other}

2 Also $\mathrm{H} 21$.

3 Interior lines show rim shaping and body scraping.

4 Surface burn visible.

7 Sample too small to confirm stance or diameter.

9 Sample too small to confirm stance or diameter.

10 Radial burnish on interior face; circumference of rim well burnished; lines of wet smoothing visible on exterior face.

PLATE 78 (CONT.). 

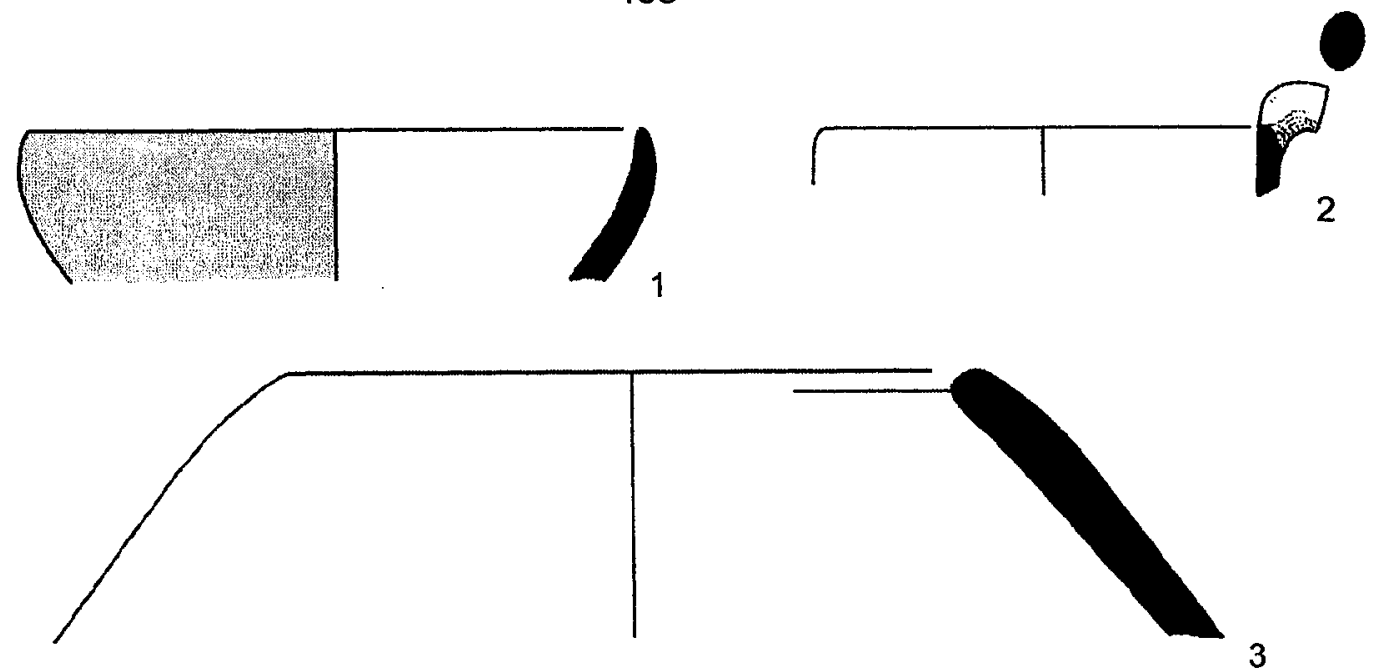

3
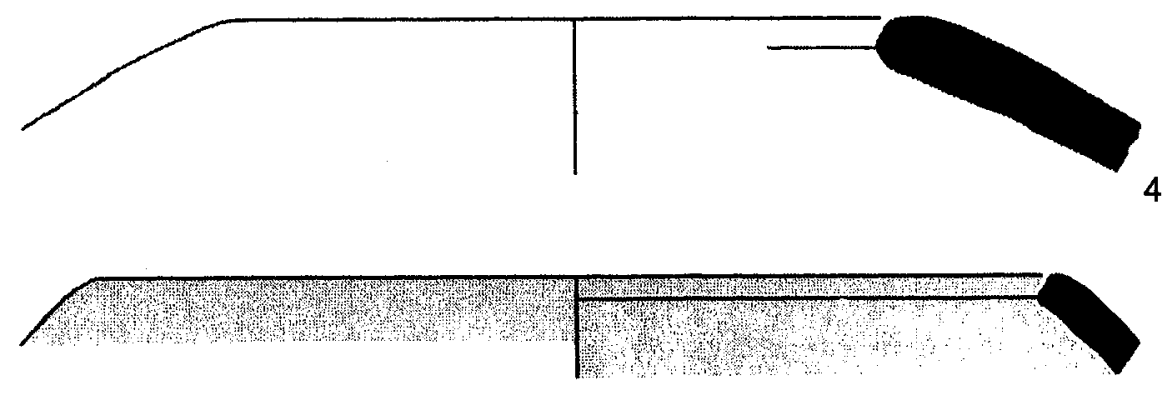

5
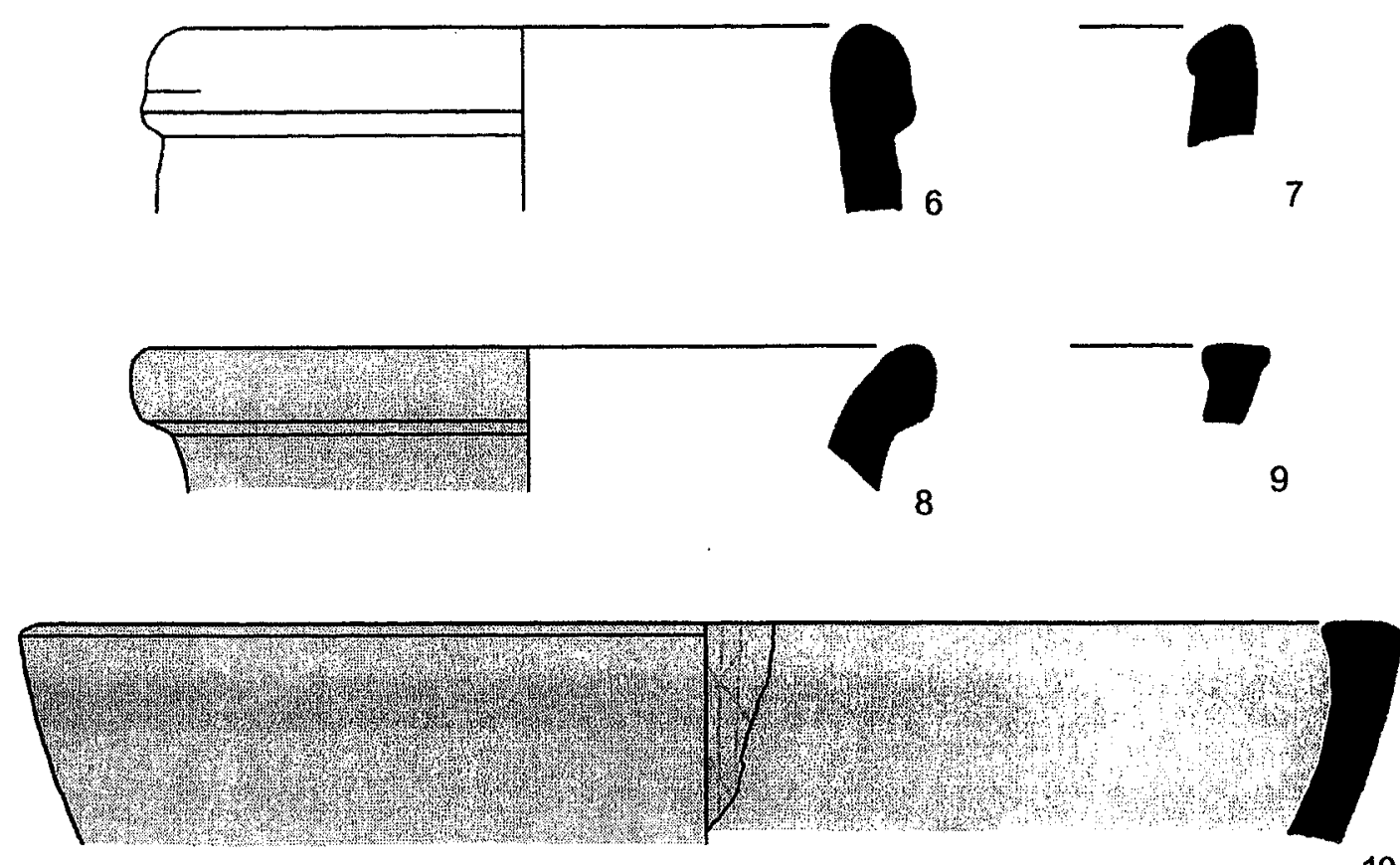

PLATE 78 (CONT.).

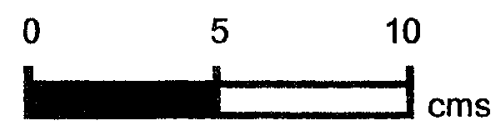


406

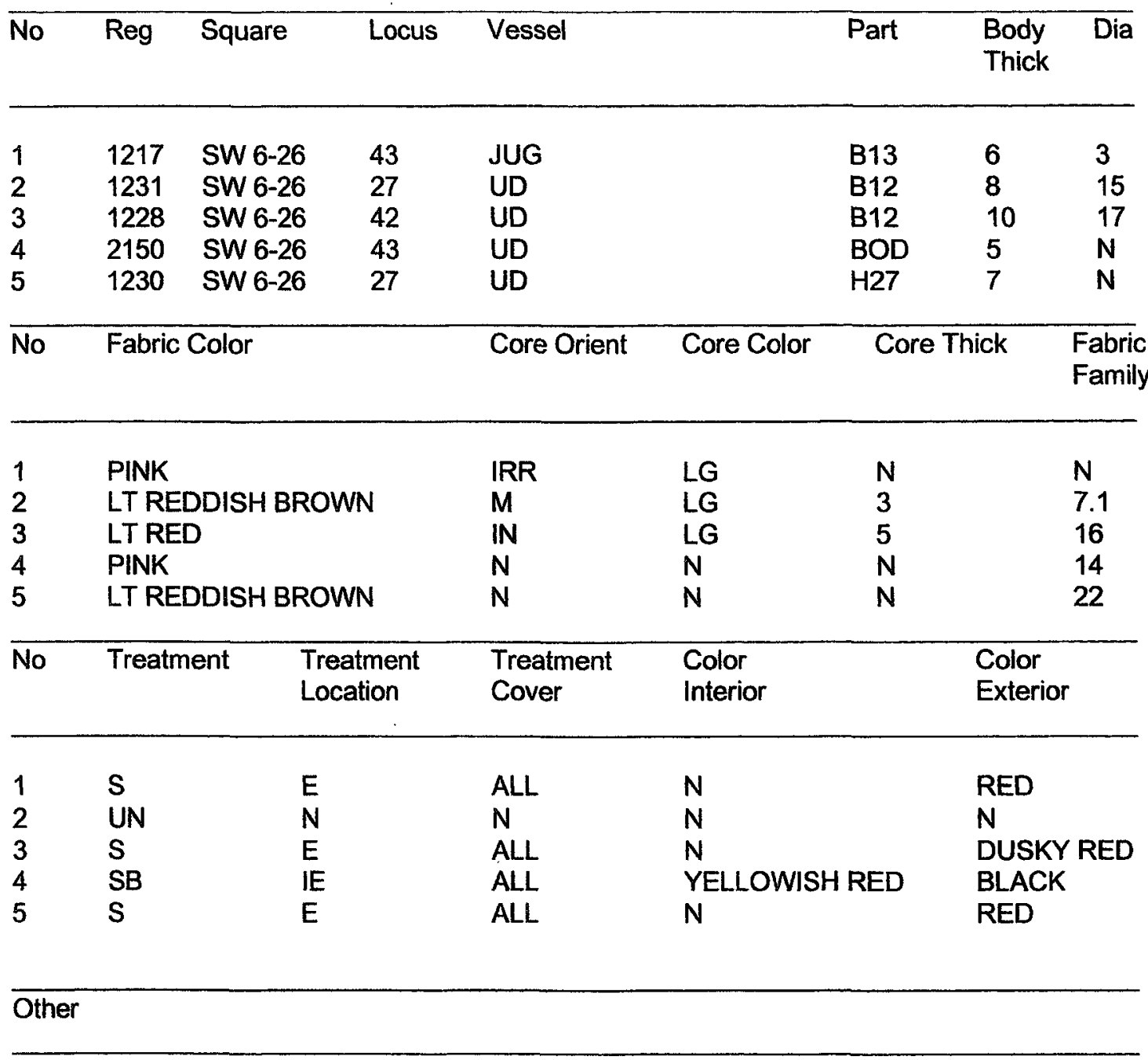

$4 \quad$ Khirbet Kerak Ware.

PLATE 79. FIELD A. PHASE 3A (EB III). 


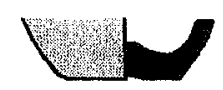

1
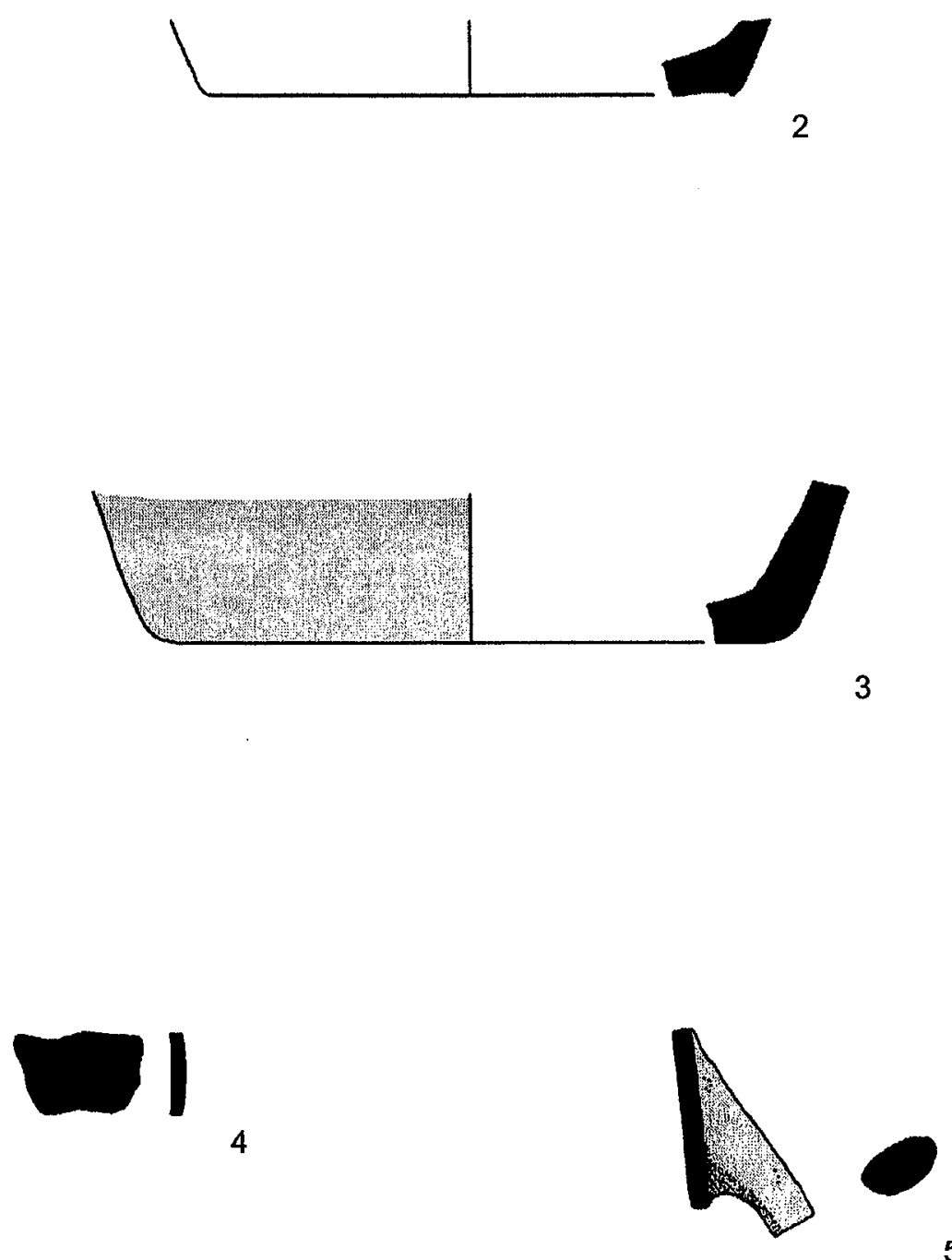

5

PLATE 79(CONT.).

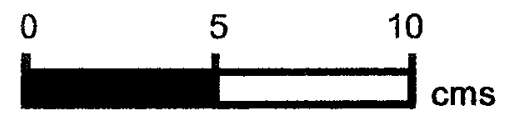




\begin{tabular}{llllllll}
\hline No & Reg & Square & Locus & Vessel & Part & $\begin{array}{l}\text { Body } \\
\text { Thick }\end{array}$ & Dia \\
\hline 1 & 0169 & SE 1-28 & 28 & LEDGE RIM BOWL & R51 & 7 & 26 \\
2 & 0170 & SE 1-28 & 28 & LEDGE RIM BOWL & R51 & 6 & 25 \\
3 & 0167 & SE 1-28 & 28 & CHANNELED RIM JAR & R35 & 6 & 9 \\
4 & 0196 & SE 1-28 & 31 & HOLE MOUTH BOWL & R01 & 10 & 21 \\
5 & 0173 & SE 1-28 & 31 & UD & B12 & 8 & 12 \\
6 & 0166 & SE 1-28 & 28 & LEDGE RIM BOWL & R51 & 16 & 40 \\
7 & 0168 & SE 1-28 & 28 & LEDGE RIM BOWL & R60 & 14 & 50
\end{tabular}

\begin{tabular}{lllll}
\hline No Fabric Color & Core Orient & Core Color & Core Thick & Fabric \\
& & & Family
\end{tabular}

\begin{tabular}{|c|c|c|c|c|c|c|c|}
\hline $\begin{array}{l}1 \\
2 \\
3 \\
4 \\
5 \\
6 \\
7\end{array}$ & \multicolumn{2}{|c|}{$\begin{array}{l}\text { LT REDDISH BROWN } \\
\text { LT RED } \\
\text { LT REDDISH BROWN } \\
\text { WEAK RED } \\
\text { LT REDDISH BROWN } \\
\text { LT REDDISH BROWN } \\
\text { PINK }\end{array}$} & $\begin{array}{l}N \\
\text { IRR } \\
N \\
\text { IRR } \\
N \\
N \\
\text { IN }\end{array}$ & $\begin{array}{l}N \\
G \\
N \\
G \\
N \\
N \\
G\end{array}$ & $\begin{array}{l}N \\
N \\
N \\
N \\
N \\
N \\
7\end{array}$ & & $\begin{array}{l}N \\
N \\
N \\
5.1 \\
23 \\
N \\
N\end{array}$ \\
\hline No & Treatment & $\begin{array}{l}\text { Treatment } \\
\text { Location }\end{array}$ & $\begin{array}{l}\text { Treatment } \\
\text { Cover }\end{array}$ & $\begin{array}{l}\text { Color } \\
\text { Interior }\end{array}$ & & $\begin{array}{l}\text { Color } \\
\text { Exterio }\end{array}$ & \\
\hline $\begin{array}{l}1 \\
2 \\
3 \\
4 \\
5 \\
6\end{array}$ & $\begin{array}{l}\text { SB } \\
B \\
\text { SB } \\
\text { UN } \\
S \\
\text { SB } \\
\text { SB }\end{array}$ & $\begin{array}{l}\text { IR } \\
R \\
\text { ER } \\
N \\
\text { E } \\
\text { IR } \\
\text { IR }\end{array}$ & $\begin{array}{l}\text { ALL } \\
\text { ALL } \\
\text { ALL } \\
N \\
\text { ALL } \\
\text { ALL } \\
\text { ALL }\end{array}$ & $\begin{array}{l}\text { DK RED } \\
N \\
N \\
N \\
N \\
\text { RED } \\
\text { RED }\end{array}$ & & $\begin{array}{l}N \\
N \\
\text { RED } \\
N \\
\text { UD } \\
N \\
N\end{array}$ & \\
\hline
\end{tabular}

1 Some burnish over slip fragments on interior face, possibly with radial orientation; wetsmoothing lines on exterior face.

2 Label difficulties here, possibly from SW 1-28.

4 Sample too small to confirm stance or diameter.

6 Deep horizontal lines and gouges visible on interior/exterior faces; inclusion drags

7 Horizontal smoothing/scraping lines visible on interior/exterior faces.

PLATE 80. FIELD A. PHASE 3B (EB III). 

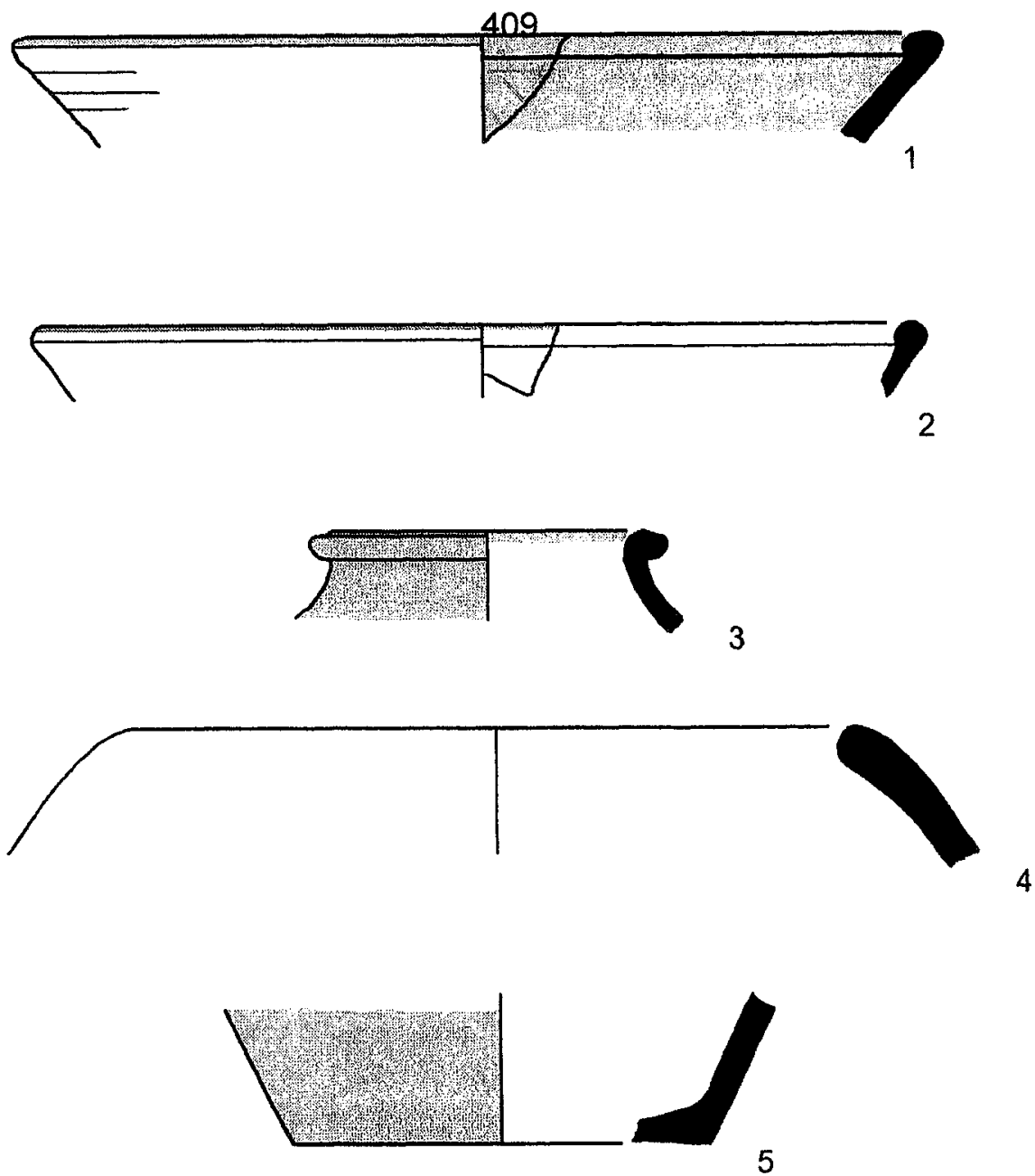

5
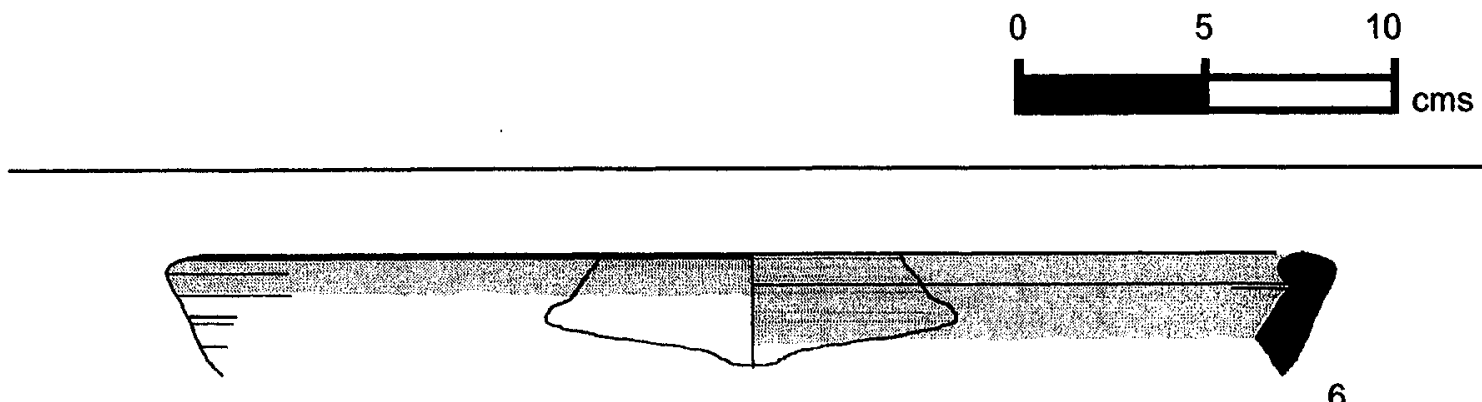

6
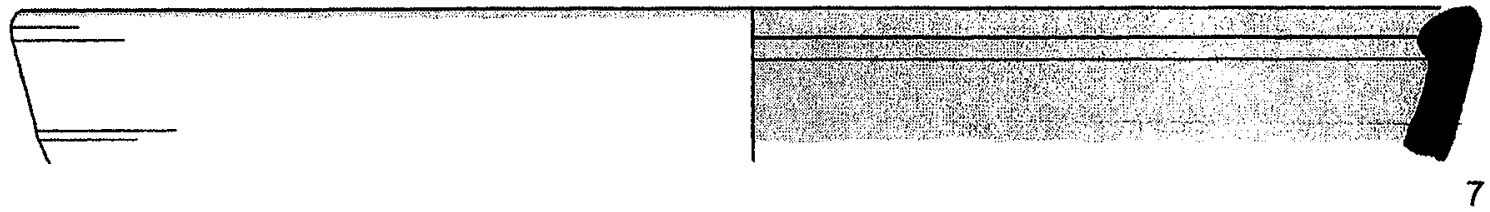

PLATE 80 (CONT.).

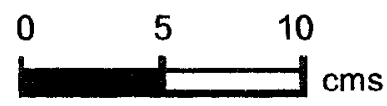




\begin{tabular}{llllllll}
\hline No & Reg & Square & Locus & Vessel & Part & $\begin{array}{l}\text { Body } \\
\text { Thick }\end{array}$ & Dia \\
& & & & & & & \\
1 & 0574 & SW 1-28 & 13 & HOLE MOUTH BOWL & R04 & 11 & 15 \\
2 & 0620 & SW 1-28 & 13 & HOLE MOUTH BOWL & R14 & 11 & 10 \\
3 & 0577 & SW 1-28 & 13 & HOLE MOUTH JAR & R12 & 12 & 15 \\
4 & 0579 & SW 1-28 & 13 & UD & H20 & N & N \\
5 & 0573 & SW 1-28 & 13 & NECKED JAR & R43 & 12 & 28 \\
6 & 0572 & SW 1-28 & 13 & LEDGE RIM BOWL & R51 & 15 & 26 \\
7 & 0576 & SW 1-28 & 13 & GUTTER RIM BOWL & R29 & 8 & 28 \\
8 & 0578 & SW 1-28 & 13 & HOLE MOUTH JAR & R01 & 13 & 20 \\
9 & 0580 & SW 1-28 & 13 & UD & H20 & 7 & N \\
10 & 0581 & SW 1-28 & 13 & UD & B12 & 14 & 14 \\
11 & 0575 & SW 1-28 & 13 & PLATTER BOWL & R53 & 8 & 45 \\
\hline No & Fabric Color & & Core Orient Core Color & Core Thick & Fabric \\
& & & & & & & Family
\end{tabular}

\begin{tabular}{|c|c|c|c|c|c|}
\hline 1 & \multicolumn{2}{|l|}{ PINK } & ALL & $G$ & $N$ \\
\hline 2 & & IRR & $\mathbf{G}$ & $\mathrm{N}$ \\
\hline 3 & \multirow{2}{*}{\multicolumn{2}{|c|}{$\begin{array}{l}\text { LTRED } \\
\text { PALERED }\end{array}$}} & $M$ & LG & $\mathrm{N}$ \\
\hline 4 & & & $\mathbf{M}$ & G & $\mathrm{N}$ \\
\hline 5 & \multicolumn{2}{|l|}{ LT RED } & IRR & LG & $N$ \\
\hline 6 & \multicolumn{2}{|l|}{ PINK } & $M$ & LG & 4 \\
\hline 7 & \multicolumn{2}{|c|}{ REDDISH GREY } & ALL & LG & $\mathbf{N}$ \\
\hline 8 & \multicolumn{2}{|l|}{ WEAK RED } & $\mathbf{N}$ & $\mathbf{N}$ & $N$ \\
\hline 9 & \multicolumn{2}{|l|}{ LT RED } & $N$ & $\mathbf{N}$ & $\mathbf{N}$ \\
\hline 10 & \multicolumn{2}{|l|}{ PINK } & IN & $\mathbf{G}$ & 9 \\
\hline 11 & \multicolumn{2}{|l|}{ PALE RED } & IRR & LG & $N$ \\
\hline No & Treatment & $\begin{array}{l}\text { Treatment } \\
\text { Location }\end{array}$ & $\begin{array}{l}\text { Treatment } \\
\text { Cover }\end{array}$ & $\begin{array}{l}\text { Color } \\
\text { Interior }\end{array}$ & $\begin{array}{l}\text { Color } \\
\text { Exterior }\end{array}$ \\
\hline 1 & UN & $N$ & $\mathbf{N}$ & $\mathbf{N}$ & $N$ \\
\hline 2 & UN & $N$ & $N$ & $N$ & $N$ \\
\hline 3 & UN & $N$ & $\mathrm{~N}$ & $\mathbf{N}$ & $N$ \\
\hline 4 & UN & $N$ & $\mathbf{N}$ & $\mathbf{N}$ & $\mathbf{N}$ \\
\hline 5 & UN & $\mathbf{N}$ & $\mathbf{N}$ & $\mathbf{N}$ & $\mathrm{N}$ \\
\hline 6 & $\mathrm{~S}$ & IE & ALL & WEAK RED & WEAK RED \\
\hline 7 & SB & ER & ALL & $\mathbf{N}$ & BLACK \\
\hline 8 & UN & $\mathrm{N}$ & $\mathbf{N}$ & $\mathbf{N}$ & $N$ \\
\hline 9 & UN & $\mathrm{N}$ & $\mathbf{N}$ & $\mathbf{N}$ & $\mathbf{N}$ \\
\hline 10 & $\mathrm{~S}$ & E & ALL & $N$ & DK RED \\
\hline 11 & B & IE & ALL & DK RED & DK RED \\
\hline
\end{tabular}

PLATE 81. FIELD A. PHASE 3B (EB III). 
Other

1 Surface burn visible.

2 Label problems, square/locus of this sherd is uncertain.

6 Well weathered.

8 Surface burn visible.

PLATE 81 (CONT.). 

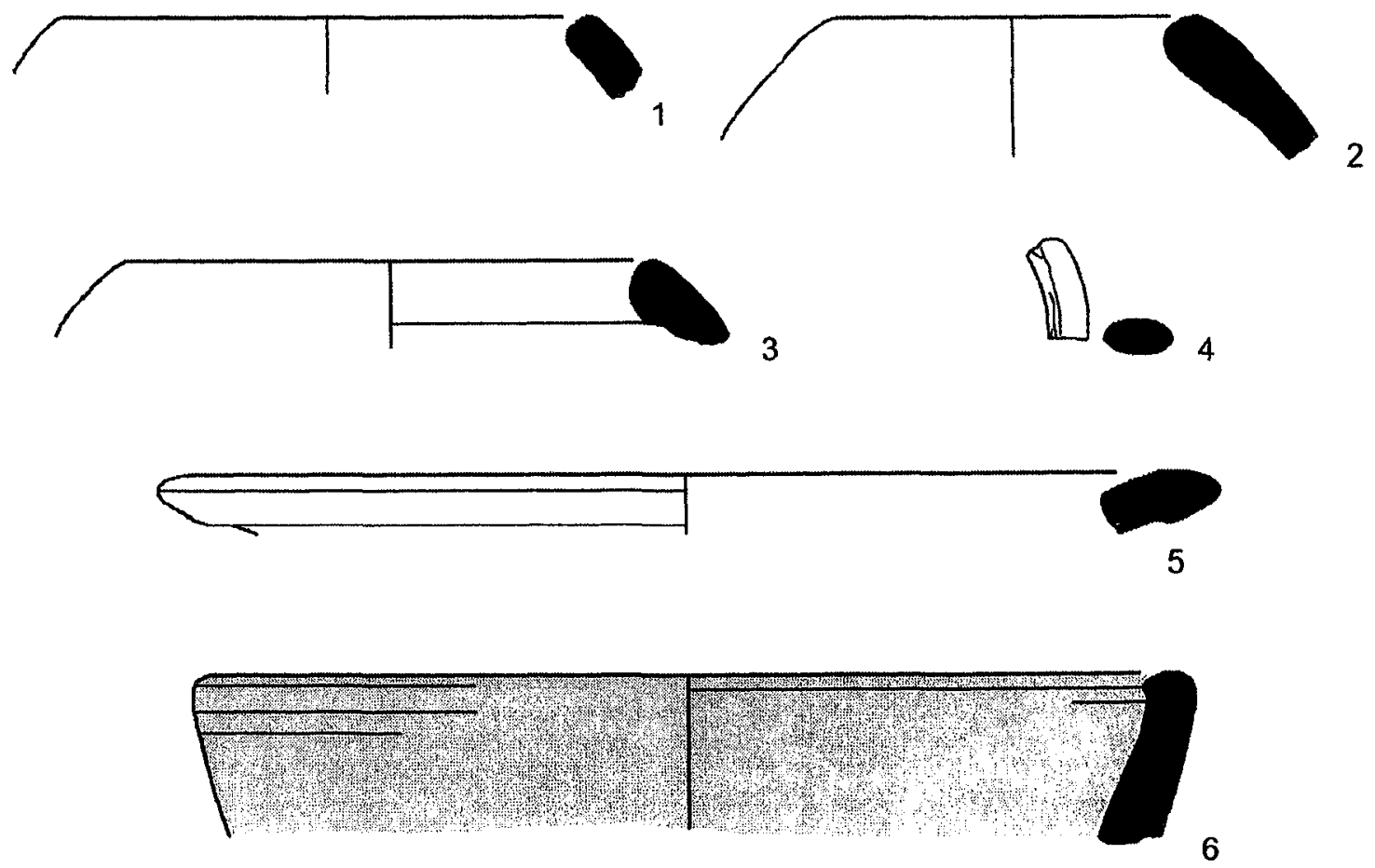

6
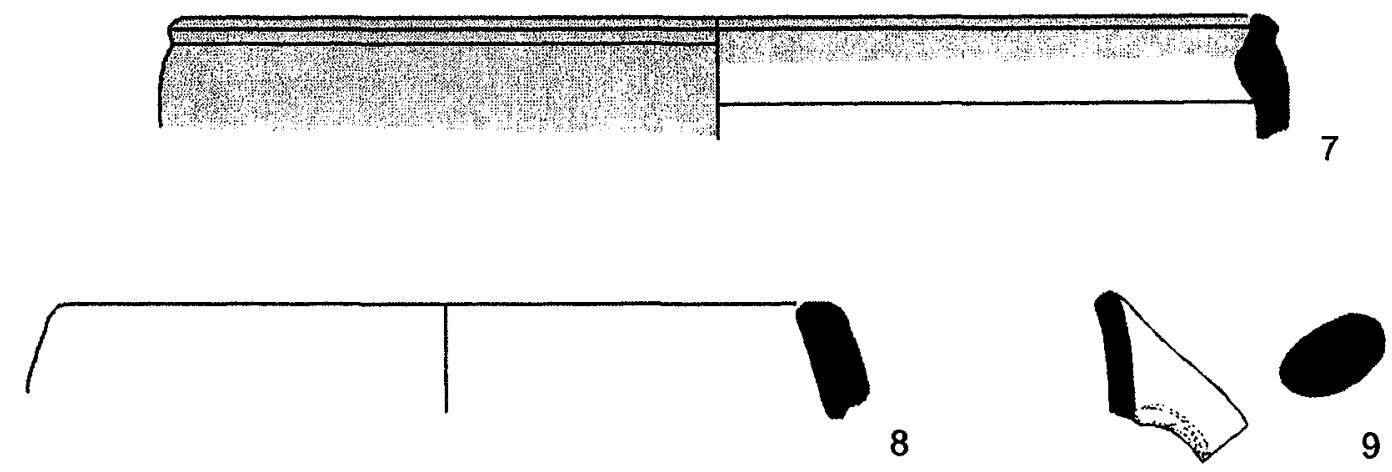

10
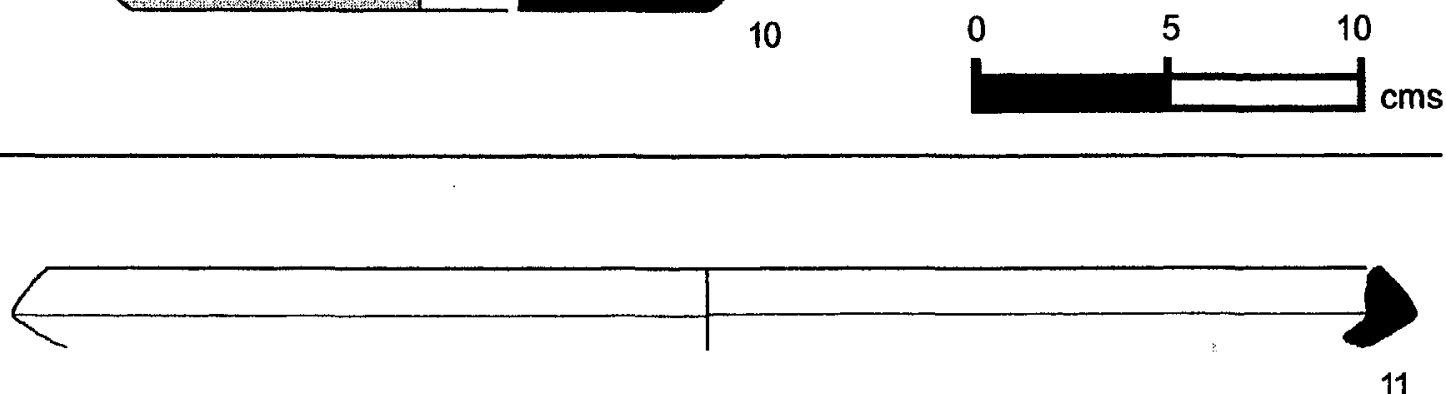

PLATE 81 (CONT.).

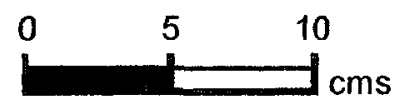




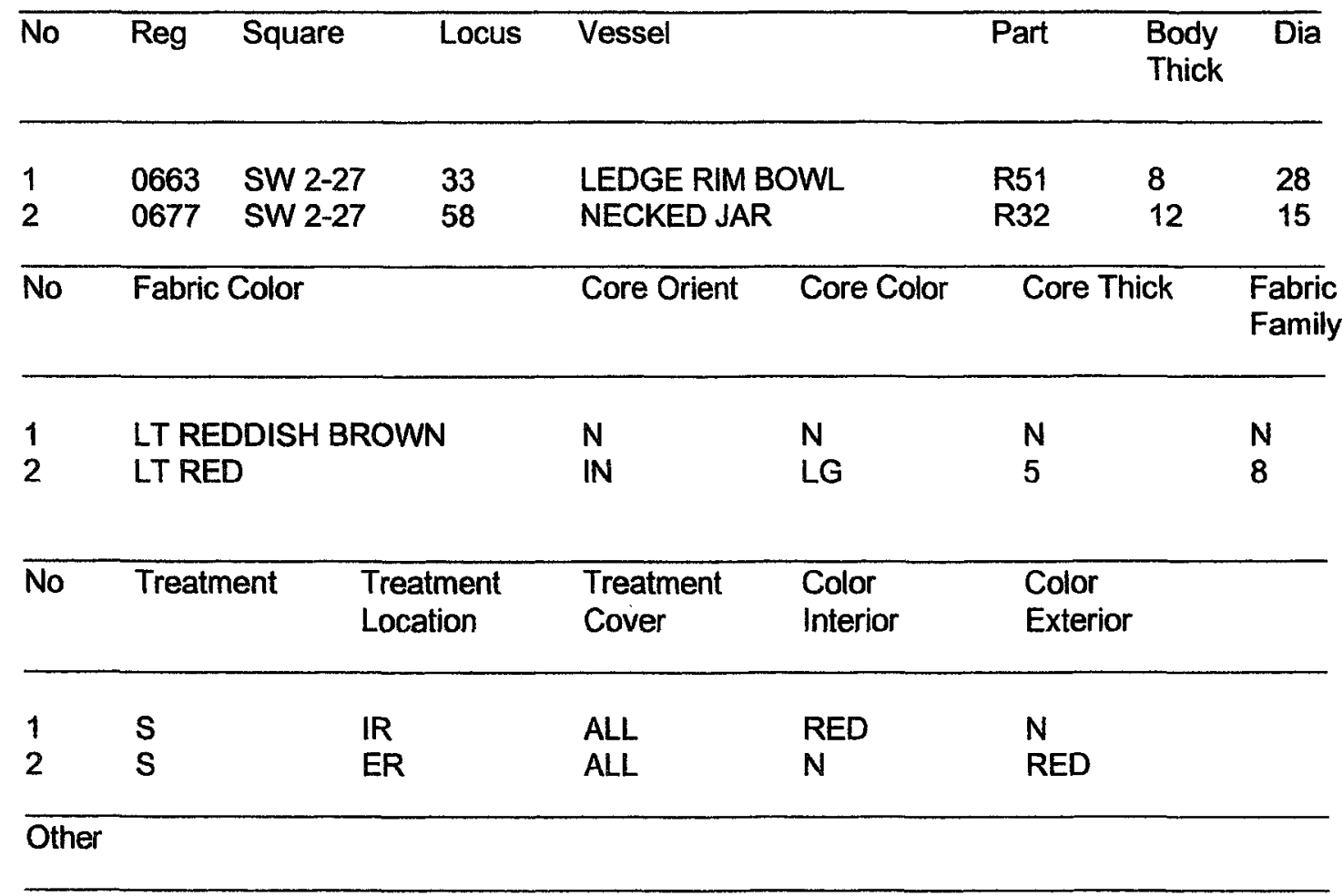

1 Interior face and rim well burnished; wet-smoothing lines visible on external face.

PLATE 82. FIELD A. PHASE 3B (EB III). 


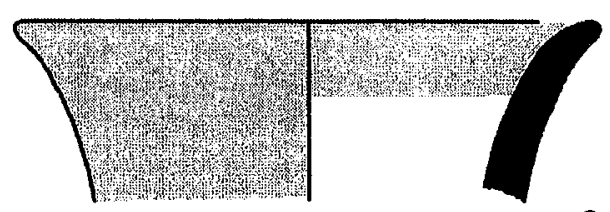

2

PLATE 82 (CONT.).

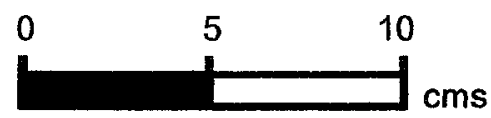




\begin{tabular}{llllllll}
\hline No & Reg & Square & Locus & Vessel & Part & $\begin{array}{c}\text { Body } \\
\text { Thick }\end{array}$ & Dia \\
\hline 1 & 0818 & SW 3-27 & 49 & LEDGE RIM BOWL & R60 & 14 & 38 \\
2 & 0821 & SW 3-27 & 49 & HOLE MOUTH JAR & R11 & 11 & 22 \\
3 & 0826 & SW 3-27 & 49 & HOLE MOUTH JAR & R01 & 16 & 20 \\
4 & 0824 & SW 3-27 & 49 & HOLE MOUTH JAR & R04 & N & 15 \\
5 & 0819 & SW 3-27 & 49 & NECKED JAR & R31 & 5 & 13 \\
6 & 0820 & SW 3-27 & 49 & NECKED JAR & R31 & 11 & 18 \\
7 & 0823 & SW 3-27 & 49 & NECKED JAR & R43 & 9 & 15 \\
8 & 0790 & SW 3-27 & 65 & NECKED JAR & R43 & 6 & 12 \\
9 & 0825 & SW 3-27 & 49 & UD & H27 & 5 & N
\end{tabular}

\begin{tabular}{lllll}
\hline No Fabric Color & Core Orient & Core Color & Core Thick & $\begin{array}{l}\text { Fabric } \\
\text { Family }\end{array}$ \\
\hline
\end{tabular}

\begin{tabular}{|c|c|c|c|c|c|c|}
\hline 1 & \multirow{2}{*}{\multicolumn{2}{|c|}{$\begin{array}{l}\text { LT REDDISH BROWN } \\
\text { PALE RED }\end{array}$}} & $\mathbf{N}$ & $\mathbf{N}$ & $\mathbf{N}$ & $\mathbf{N}$ \\
\hline 2 & & & IRR & G & $\mathbf{N}$ & $\mathbf{N}$ \\
\hline 3 & \multicolumn{2}{|c|}{ WEAK RED } & IRR & G & $\mathrm{N}$ & $\mathbf{N}$ \\
\hline 4 & \multicolumn{2}{|c|}{ WEAK RED } & $E$ & $\mathbf{G}$ & $\mathbf{N}$ & $\mathbf{N}$ \\
\hline 5 & \multicolumn{2}{|l|}{ PINK } & $\mathbf{N}$ & $\mathbf{N}$ & $\mathrm{N}$ & $\mathbf{N}$ \\
\hline 6 & \multicolumn{2}{|c|}{ LT REDDISH BROWN } & IRR & $\mathbf{G}$ & $N$ & N \\
\hline 7 & \multicolumn{2}{|c|}{ LT REDDISH BROWN } & $\mathbf{N}$ & $\mathbf{N}$ & $\mathrm{N}$ & $\mathbf{N}$ \\
\hline 8 & \multicolumn{2}{|l|}{ PINK } & $\mathrm{N}$ & $\mathrm{N}$ & $\mathrm{N}$ & $\mathrm{N}$ \\
\hline 9 & \multicolumn{2}{|l|}{ RED } & IRR & G & $\mathrm{N}$ & $\mathbf{N}$ \\
\hline No & Treatment & $\begin{array}{l}\text { Treatment } \\
\text { Location }\end{array}$ & $\begin{array}{l}\text { Treatment } \\
\text { Cover }\end{array}$ & $\begin{array}{l}\text { Color } \\
\text { Interior }\end{array}$ & $\begin{array}{l}\text { Color } \\
\text { Exterior }\end{array}$ & \\
\hline 1 & $\mathbf{S}$ & IR & ALL & RED & $\mathbf{N}$ & \\
\hline 2 & UN & $\mathrm{N}$ & $\mathrm{N}$ & $\mathrm{N}$ & $\mathbf{N}$ & \\
\hline 3 & UN & $N$ & $\mathbf{N}$ & $\mathrm{N}$ & $\mathbf{N}$ & \\
\hline 4 & UN & $N$ & $N$ & $N$ & $\mathbf{N}$ & \\
\hline 5 & B & ER & ALL & $\mathrm{N}$ & $\mathbf{N}$ & \\
\hline 6 & UD & $\mathrm{N}$ & $\mathbf{N}$ & $\mathbf{N}$ & $\mathbf{N}$ & \\
\hline 7 & $\mathbf{S}$ & $\mathbb{E}$ & ALL & RED & RED & \\
\hline 8 & $\mathrm{~S}$ & $\mathbb{I R}$ & $A L L$ & LT RED & LT RED & \\
\hline 9 & UN & $\mathbf{N}$ & $\mathbf{N}$ & $\mathrm{N}$ & $\mathrm{N}$ & \\
\hline
\end{tabular}

\section{Other}

2 Surface burn visible.

$4 \quad$ Surface burn visible.

6 Surface burn visible.

PLATE 83. FIELD A. PHASE 3B (EB III). 

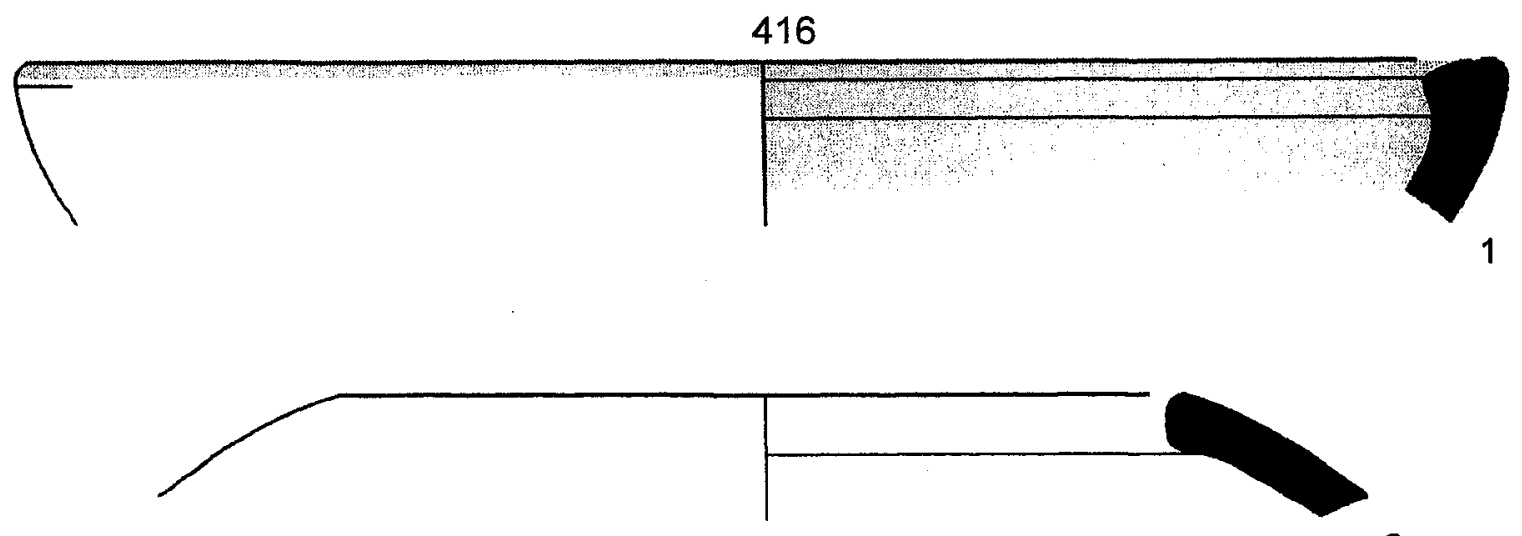

2
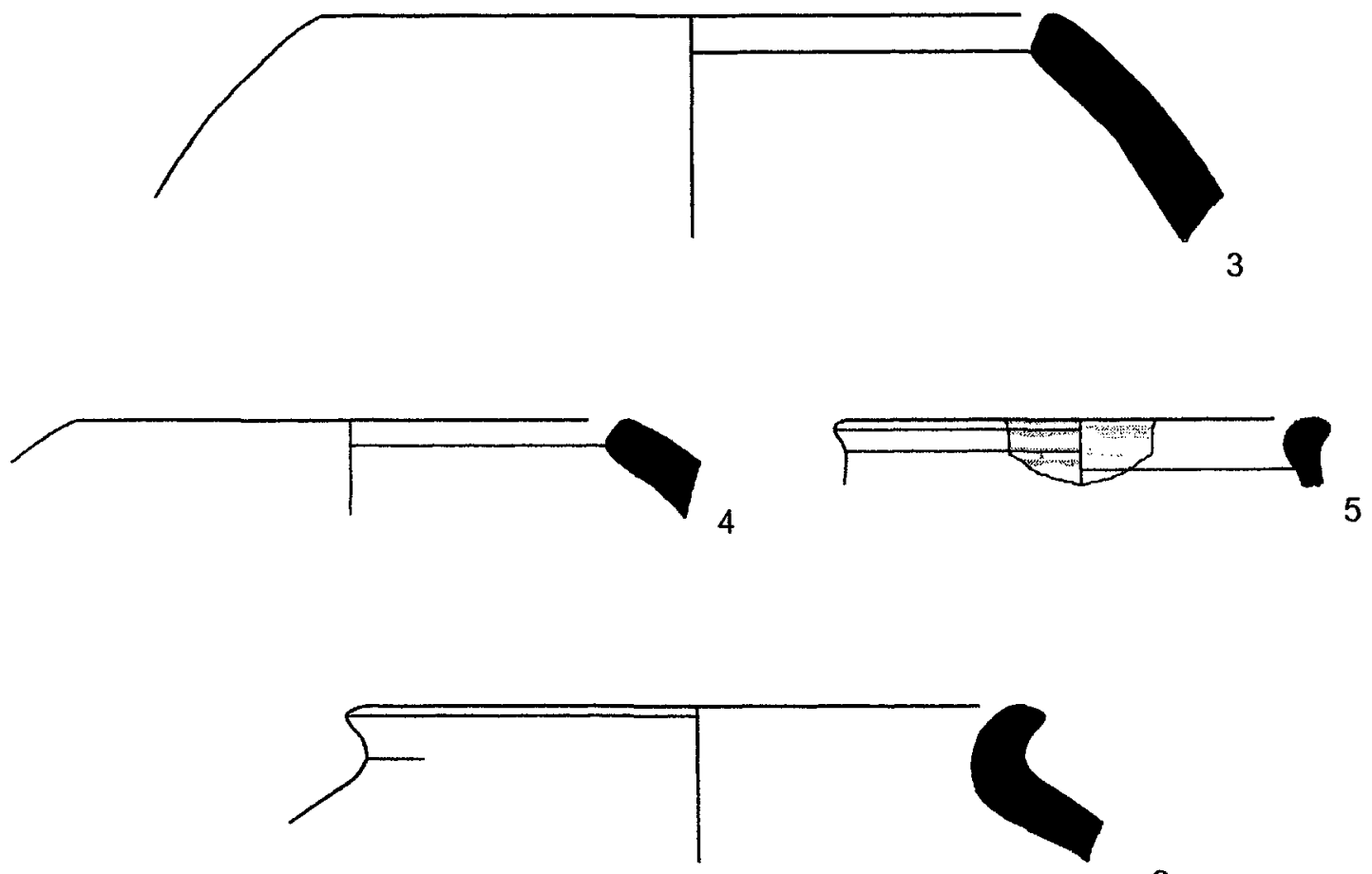

6
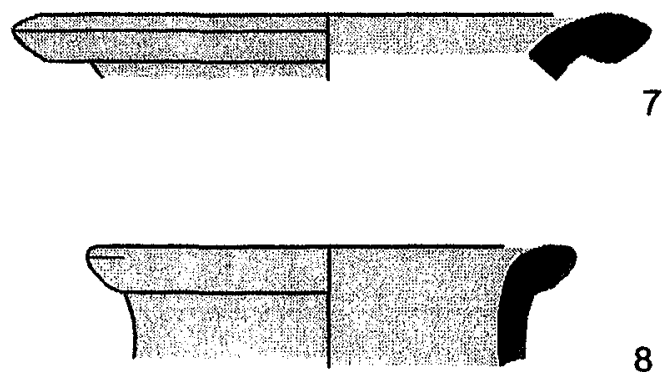

7

PLATE 83 (CONT.).

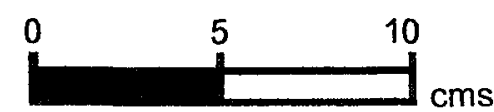




\begin{tabular}{llllllll}
\hline No & Reg & Square & Locus & Vessel & Part & $\begin{array}{l}\text { Body } \\
\text { Thick }\end{array}$ & Dia \\
\hline 1 & 0828 & SW 3-27 & 49 & UD & B12 & 15 & 26 \\
2 & 0827 & SW 3-27 & 49 & UD & B12 & 6 & 6 \\
3 & 0829 & SW 3-27 & 49 & UD & B12 & 11 & 15 \\
4 & 0822 & SW 3-27 & 49 & PLATTER BOWL & R56 & 12 & 43 \\
5 & 0816 & SW 3-27 & 49 & LEDGE RIM BOWL & R53 & 14 & 38 \\
6 & 0817 & SW 3-27 & 49 & PLATTER BOWL & R56 & 16 & 56
\end{tabular}

\begin{tabular}{llccc}
\hline No Fabric Color & Core Orient & Core Color & Core Thick & $\begin{array}{l}\text { Fabric } \\
\text { Family }\end{array}$ \\
\hline
\end{tabular}

\begin{tabular}{|c|c|c|c|c|c|c|}
\hline $\begin{array}{l}1 \\
2 \\
3 \\
4 \\
5 \\
6\end{array}$ & $\begin{array}{l}\text { LT RED } \\
\text { LT REDDIS } \\
\text { LT RED } \\
\text { LT REDDIS } \\
\text { LT REDDIS } \\
\text { LT RED }\end{array}$ & $\begin{array}{l}\text { ROWN } \\
\text { ROWN } \\
\text { ROWN }\end{array}$ & $\begin{array}{l}A L L \\
M \\
A L L \\
N \\
M \\
M\end{array}$ & $\begin{array}{l}\text { LG } \\
G \\
G \\
N \\
G \\
L G\end{array}$ & $\begin{array}{l}N \\
2 \\
N \\
N \\
6 \\
4\end{array}$ & $\begin{array}{l}N \\
N \\
N \\
N \\
N \\
N\end{array}$ \\
\hline$\overline{\text { No }}$ & Treatment & $\begin{array}{l}\text { Treatment } \\
\text { Location }\end{array}$ & $\begin{array}{l}\text { Treatment } \\
\text { Cover }\end{array}$ & $\begin{array}{l}\text { Color } \\
\text { Interior }\end{array}$ & $\begin{array}{l}\text { Color } \\
\text { Exterior }\end{array}$ & \\
\hline $\begin{array}{l}1 \\
2 \\
3 \\
4 \\
5 \\
6\end{array}$ & $\begin{array}{l}\text { WASH } \\
\text { UN } \\
\text { UN } \\
\text { SB } \\
\text { SB } \\
\text { UN }\end{array}$ & $\begin{array}{l}E \\
N \\
N \\
I R \\
I R \\
N\end{array}$ & $\begin{array}{l}A L L \\
N \\
N \\
A L L \\
N \\
N\end{array}$ & $\begin{array}{l}N \\
N \\
N \\
\text { RED } \\
\text { RED } \\
N\end{array}$ & $\begin{array}{l}\text { WHITE } \\
N \\
N \\
N \\
N \\
N\end{array}$ & \\
\hline
\end{tabular}

Other

2 String-cut base.

3. Metallic Ware.

4 Very fine lines on base suggest wiping, some small concavities persist; on interior face, lines of radial burnish are evenly spaced.

PLATE 84. FIELD A. PHASE 3B (EB III). 

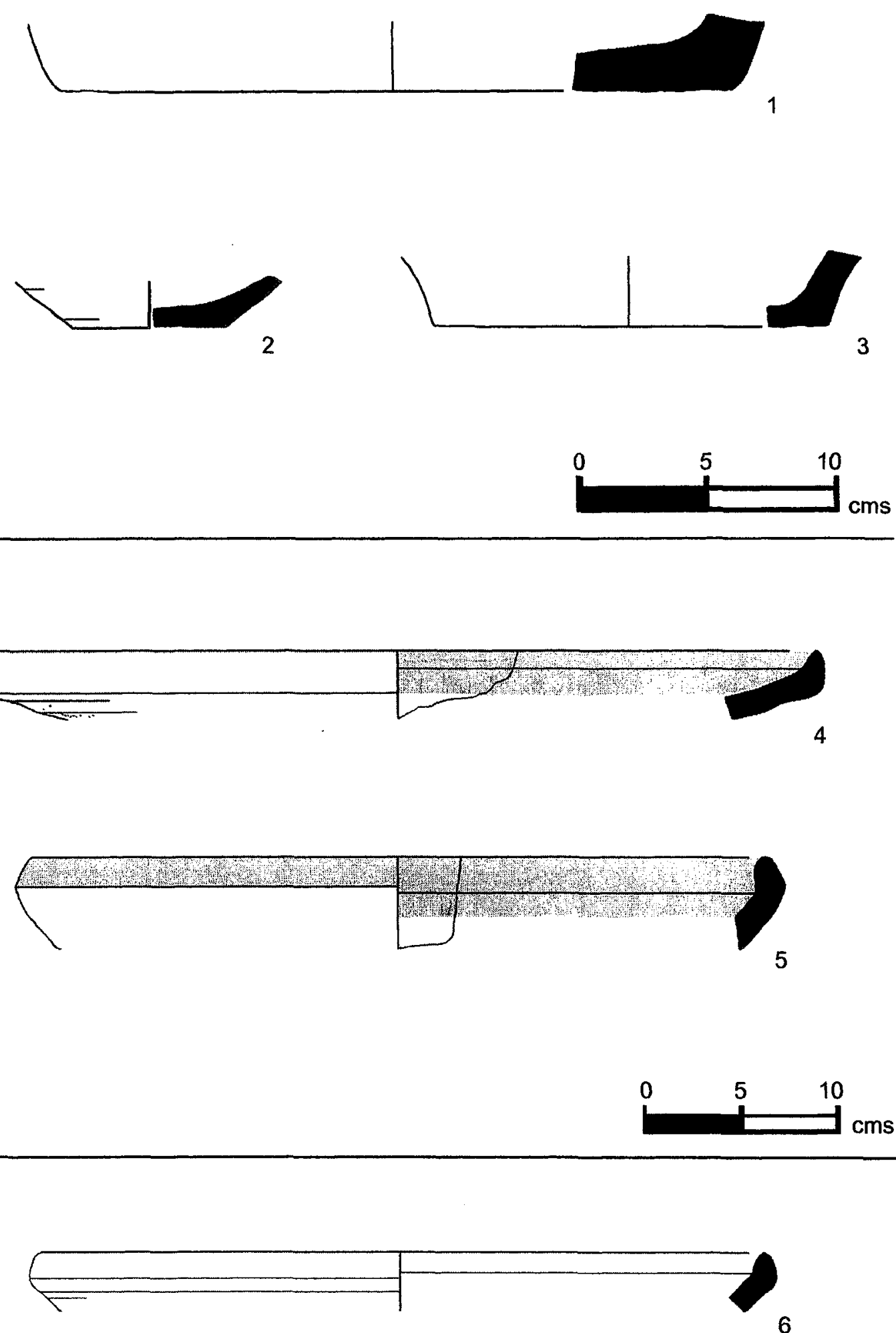

6

PLATE 84 (CONT.).

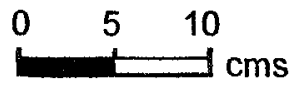


419

\begin{tabular}{llllllll}
\hline No & Reg & Square & Locus & Vessel & Part & $\begin{array}{l}\text { Body } \\
\text { Thick }\end{array}$ & Dia \\
\hline 1 & & & & & & & \\
2 & 0808 & SW 3-27 & 50 & LEDGE RIM BOWL & R51 & 8 & 25 \\
3 & 0810 & SW 3-27 & 50 & HOLE MOUTH BOWL & R11 & 9 & 18 \\
4 & 0812 & SW 3-27 & 50 & HOLE MOUTH JAR & R19 & 10 & 20 \\
5 & 0811 & SW 3-27 & 50 & HOLE MOUTH BOWL & R01 & 8 & 18 \\
6 & 0809 & SW 3-27 & 50 & UD & B12 & 10 & 20 \\
7 & 0814 & SW 3-27 & 50 & UD & H27 & 8 & N \\
8 & 0815 & SW 3-27 & 50 & JUG & B21 & 7 & 2 \\
& 0813 & SW 3-27 & 50 & PLATTER BOWL & R56 & 13 & 58
\end{tabular}

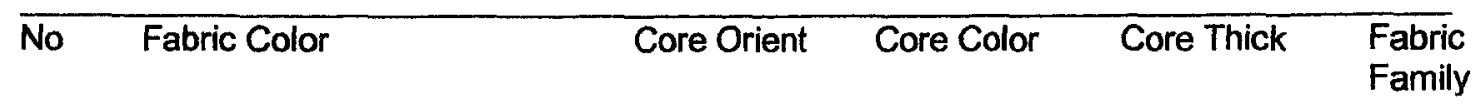

\begin{tabular}{|c|c|c|c|c|c|c|}
\hline $\begin{array}{l}1 \\
2 \\
3 \\
4 \\
5 \\
6 \\
7 \\
8\end{array}$ & $\begin{array}{l}\text { PINK } \\
\text { LT REDDIS } \\
\text { PALE RED } \\
\text { REDDISH } \\
\text { LT RED } \\
\text { LT RED } \\
\text { PINK } \\
\text { LT REDDIS }\end{array}$ & $\begin{array}{l}\text { ROWN } \\
\text { WN } \\
\text { ROWN }\end{array}$ & $\begin{array}{l}N \\
\text { IRR } \\
M \\
\text { IRR } \\
\text { IRR } \\
N \\
N \\
\text { ALL }\end{array}$ & $\begin{array}{l}N \\
G \\
G \\
G \\
L G \\
N \\
N \\
G\end{array}$ & $\begin{array}{l}N \\
N \\
5 \\
N \\
N \\
N \\
N \\
N\end{array}$ & $\begin{array}{l}N \\
N \\
N \\
N \\
N \\
N \\
N \\
N\end{array}$ \\
\hline$\overline{\text { No }}$ & Treatment & $\begin{array}{l}\text { Treatment } \\
\text { Location }\end{array}$ & $\begin{array}{l}\text { Treatment } \\
\text { Cover }\end{array}$ & $\begin{array}{l}\text { Color } \\
\text { Interior }\end{array}$ & $\begin{array}{l}\text { Color } \\
\text { Exterior }\end{array}$ & \\
\hline $\begin{array}{l}1 \\
2 \\
3 \\
4 \\
5 \\
6 \\
7 \\
8\end{array}$ & $\begin{array}{l}\text { UN } \\
\text { UN } \\
\text { UN } \\
\text { UN } \\
\text { UN } \\
\text { UN } \\
\text { UN } \\
\text { B }\end{array}$ & $\begin{array}{l}N \\
N \\
N \\
N \\
N \\
N \\
N \\
I R\end{array}$ & $\begin{array}{l}N \\
N \\
N \\
N \\
N \\
N \\
N \\
N\end{array}$ & $\begin{array}{l}N \\
N \\
N \\
N \\
N \\
N \\
N \\
N\end{array}$ & $\begin{array}{l}N \\
N \\
N \\
N \\
N \\
N \\
N \\
N\end{array}$ & \\
\hline
\end{tabular}

1 Smoothing lines around break on exterior wall suggest the presence of a loop/lug handle, now broken.

PLATE 85. FIELD A. PHASE 3B (EB III). 

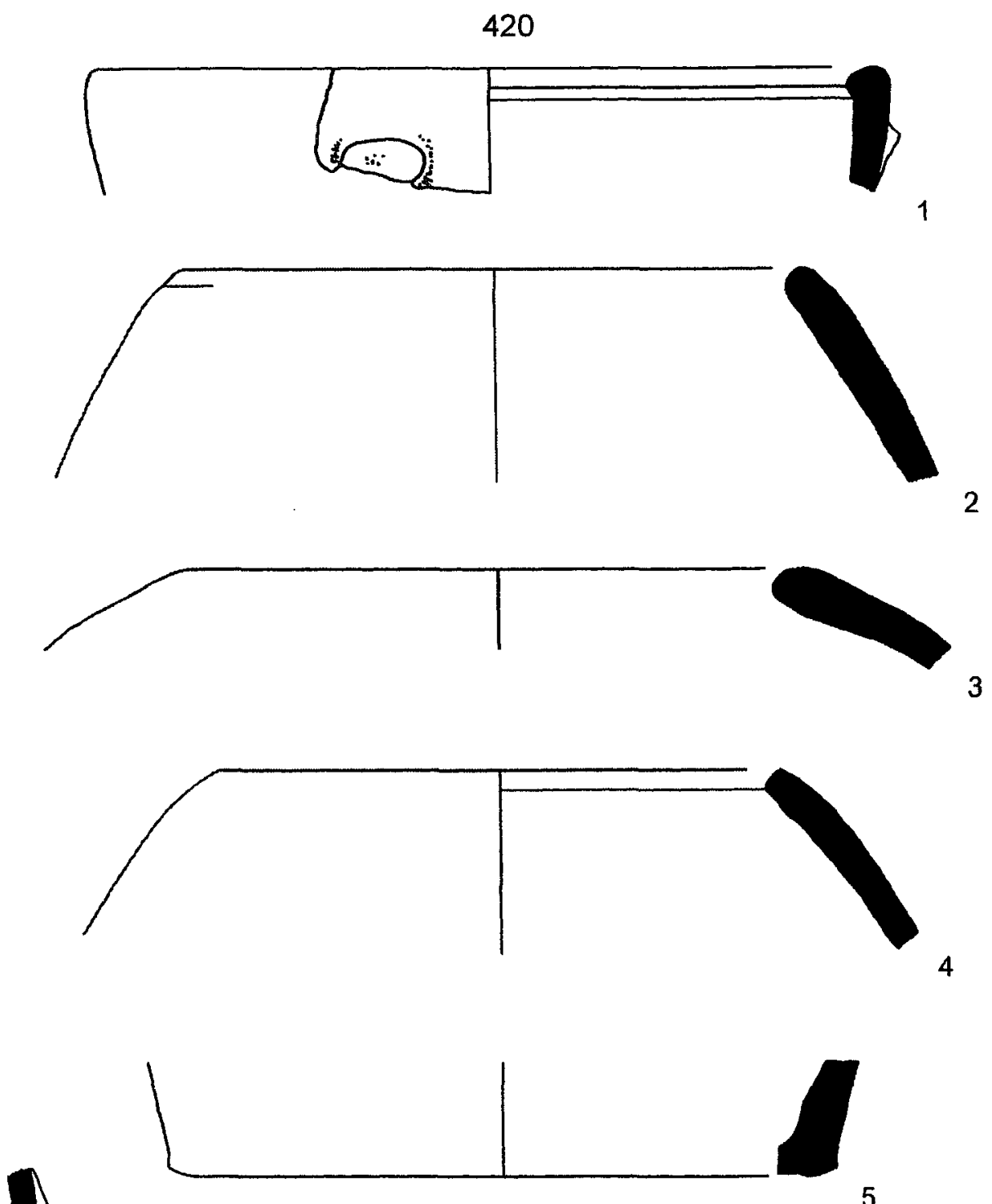

5

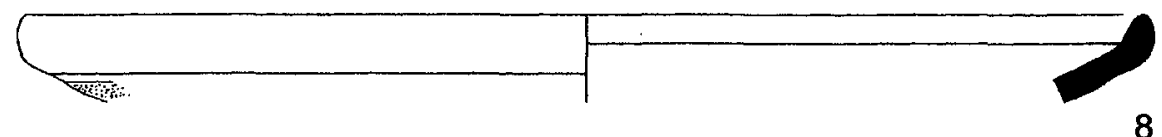

8

PLATE 85 (CONT.).

$0 \quad 5 \quad 10$

$\mathrm{cms}$ 


\begin{tabular}{llllllll}
\hline No & Reg & Square & Locus & Vessel & Part & $\begin{array}{c}\text { Body } \\
\text { Thick }\end{array}$ & Dia \\
\hline & & & & & & & \\
1 & 0775 & SW 3-27 & 67 & LEDGE RIM BOWL & R51 & 8 & 32 \\
2 & 0778 & SW 3-27 & 67 & HOLE MOUTH BOWL & R20 & 7 & 16 \\
3 & 2326 & SW 3-27 & 67 & HOLE MOUTH BOWL & R18 & 7 & N \\
4 & 0777 & SW 3-27 & 67 & HOLE MOUTH JAR & R21 & 9 & 14 \\
5 & 0780 & SW 3-27 & 67 & UD & R81 & 6 & 15 \\
6 & 0784 & SW 3-27 & 67 & HOLE MOUTH JAR & R20 & 10 & 16 \\
7 & 2321 & SW 3-27 & 67 & HOLE MOUTH JAR & R14 & 9 & 18 \\
8 & 0781 & SW 3-27 & 67 & NECKED JAR & R31 & 14 & 18 \\
9 & 0776 & SW 3-27 & 67 & NECKED JAR & R31 & 11 & 13 \\
10 & 0774 & SW 3-27 & 67 & NECKED JAR & R43 & 11 & 18 \\
11 & 2307 & SW 3-27 & 67 & NECKED JAR & R31 & 8 & 16 \\
12 & 0782 & SW 3-27 & 67 & JUG & B23 & 9 & 5 \\
13 & 0783 & SW 3-27 & 67 & JUG & B12 & 8 & 6
\end{tabular}

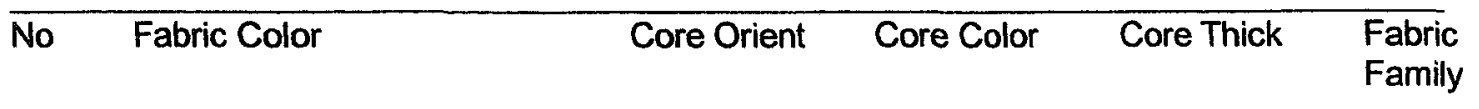

\begin{tabular}{|c|c|c|c|c|c|c|}
\hline 1 & \multicolumn{2}{|c|}{ REDDISH GREY } & ALL & G & $\mathbf{N}$ & 4 \\
\hline 2 & \multicolumn{2}{|c|}{ WEAK RED } & IRR & $\mathbf{G}$ & $\mathrm{N}$ & 5.1 \\
\hline 3 & \multicolumn{2}{|c|}{ LT REDDISH BROWN } & $M$ & $\mathrm{G}$ & 2 & $N$ \\
\hline 4 & \multicolumn{2}{|c|}{ WEAK RED } & ALL & $\mathbf{G}$ & $\bar{N}$ & $\mathbf{N}$ \\
\hline 5 & \multicolumn{2}{|l|}{ PINK } & $N$ & $N$ & $\mathbf{N}$ & 23 \\
\hline 6 & \multicolumn{2}{|l|}{ PALE RED } & IRR & LG & $N$ & 10.1 \\
\hline 7 & \multicolumn{2}{|c|}{ LT REDDISH BROWN } & M & $\mathbf{G}$ & 5 & $N$ \\
\hline 8 & \multicolumn{2}{|l|}{ LT RED } & $\mathbf{M}$ & $\mathbf{G}$ & 9 & 1 \\
\hline 9 & \multicolumn{2}{|l|}{ PALE RED } & $M$ & G & 5 & 15 \\
\hline 10 & \multicolumn{2}{|l|}{ PINK } & $N$ & $N$ & $\mathbf{N}$ & 19 \\
\hline 11 & \multicolumn{2}{|c|}{ LT REDDISH BROWN } & M & $\mathbf{G}$ & 5 & $N$ \\
\hline 12 & \multicolumn{2}{|c|}{ LT REDDISH BROWN } & IN & LG & 4 & 22 \\
\hline 13 & \multicolumn{2}{|c|}{ LT REDDISH BROWN } & IRR & LG & $N$ & 23 \\
\hline No & Treatment & $\begin{array}{l}\text { Treatment } \\
\text { Location }\end{array}$ & $\begin{array}{l}\text { Treatment } \\
\text { Cover }\end{array}$ & $\begin{array}{l}\text { Color } \\
\text { Interior }\end{array}$ & $\begin{array}{l}\text { Color } \\
\text { Exterior }\end{array}$ & \\
\hline 1 & SB & IR & ALL & WEAK RED & $\mathbf{N}$ & \\
\hline 2 & UN & $\mathrm{N}$ & $N$ & $N$ & $\mathbf{N}$ & \\
\hline 3 & UN & $N$ & $N$ & $\mathrm{~N}$ & $N$ & \\
\hline 4 & UN & $\mathbf{N}$ & $\mathbf{N}$ & $\mathbf{N}$ & $\mathbf{N}$ & \\
\hline 5 & SB & ER & ALL & $N$ & RED & \\
\hline 6 & UN & $\mathrm{N}$ & $N$ & $\mathbf{N}$ & $\mathbf{N}$ & \\
\hline 7 & UN & $\mathrm{N}$ & $\mathbf{N}$ & $\mathbf{N}$ & $\mathbf{N}$ & \\
\hline 8 & UN & $\mathbf{N}$ & $\mathbf{N}$ & $\mathbf{N}$ & $\mathbf{N}$ & \\
\hline 9 & UN & $\mathbf{N}$ & $N$ & $N$ & $N$ & \\
\hline 10 & $\mathbf{S}$ & ER & ALL & $\mathbf{N}$ & RED & \\
\hline
\end{tabular}

PLATE 86. FIELD A. PHASE 3B (EB III). 
422

\begin{tabular}{llllll}
\hline No & Treatment & $\begin{array}{l}\text { Treatment } \\
\text { Location }\end{array}$ & $\begin{array}{l}\text { Treatment } \\
\text { Cover }\end{array}$ & $\begin{array}{l}\text { Color } \\
\text { Interior }\end{array}$ & $\begin{array}{l}\text { Color } \\
\text { Exterior }\end{array}$ \\
\hline 11 & UN & N & N & N & N \\
12 & S & E & ALL & N & RED \\
13 & S & E & ALL & N & BLACK \\
\hline
\end{tabular}

\section{Other}

1 Interior face has lines of burnish in net pattern over slip; rim appears wheel burnished.

3 Sample too small to confirm stance or diameter.

5 Also $\mathrm{H} 50$.

PLATE 86 (CONT.). 
423
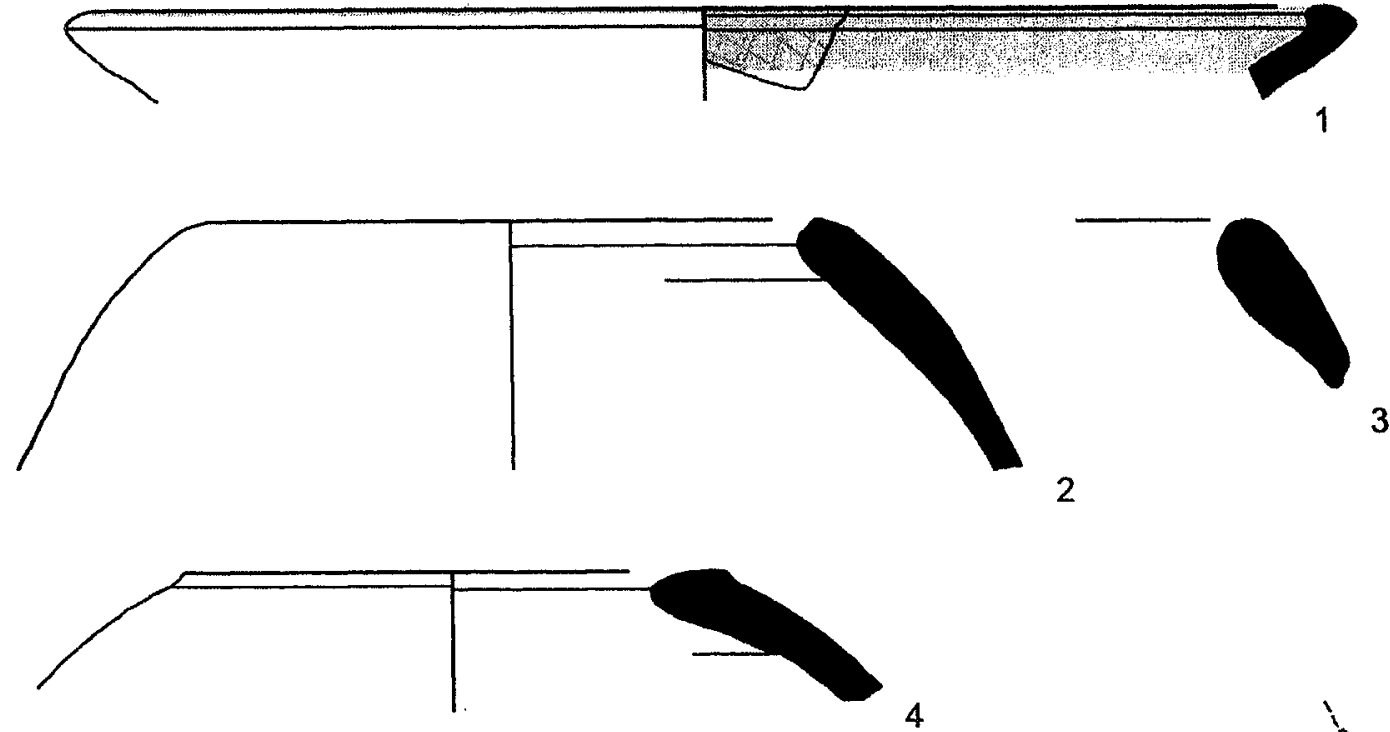

4
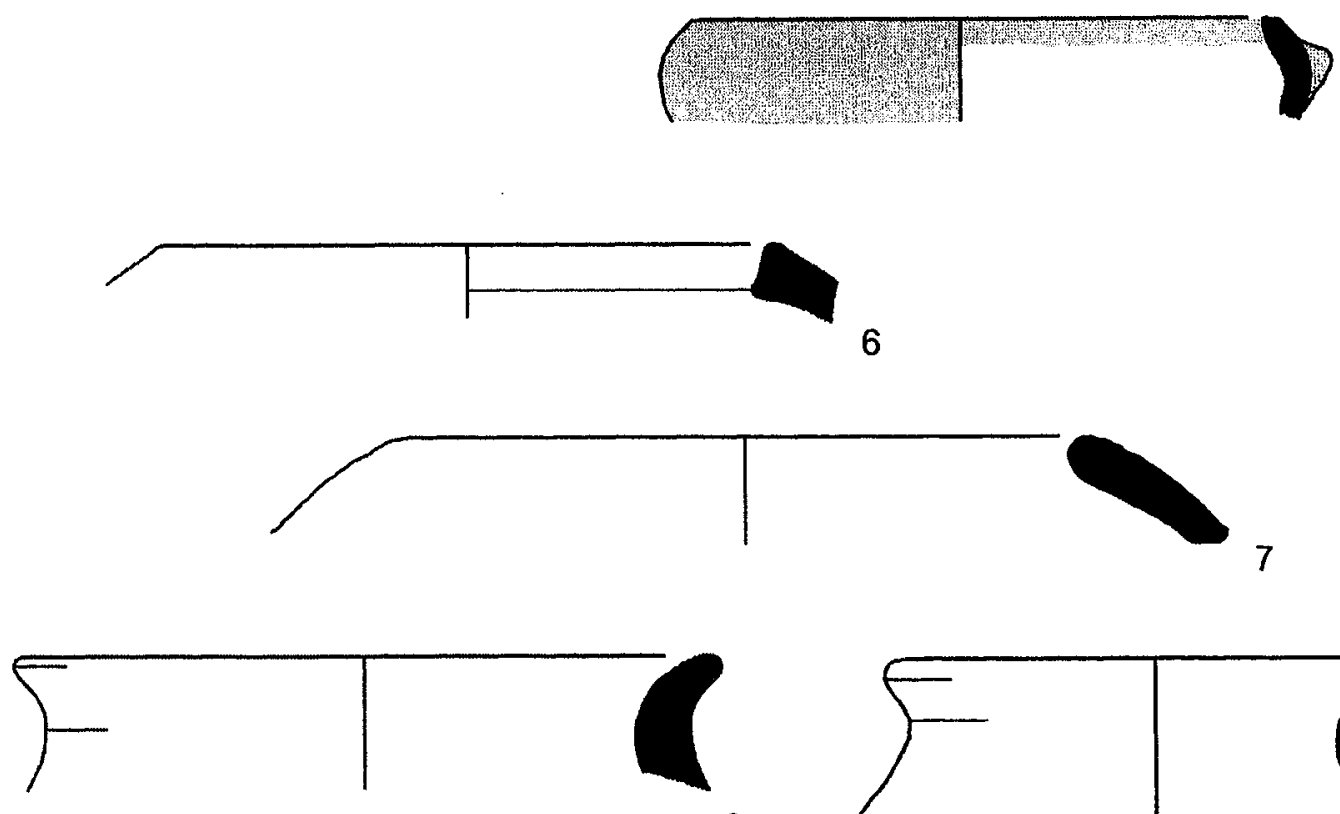

8
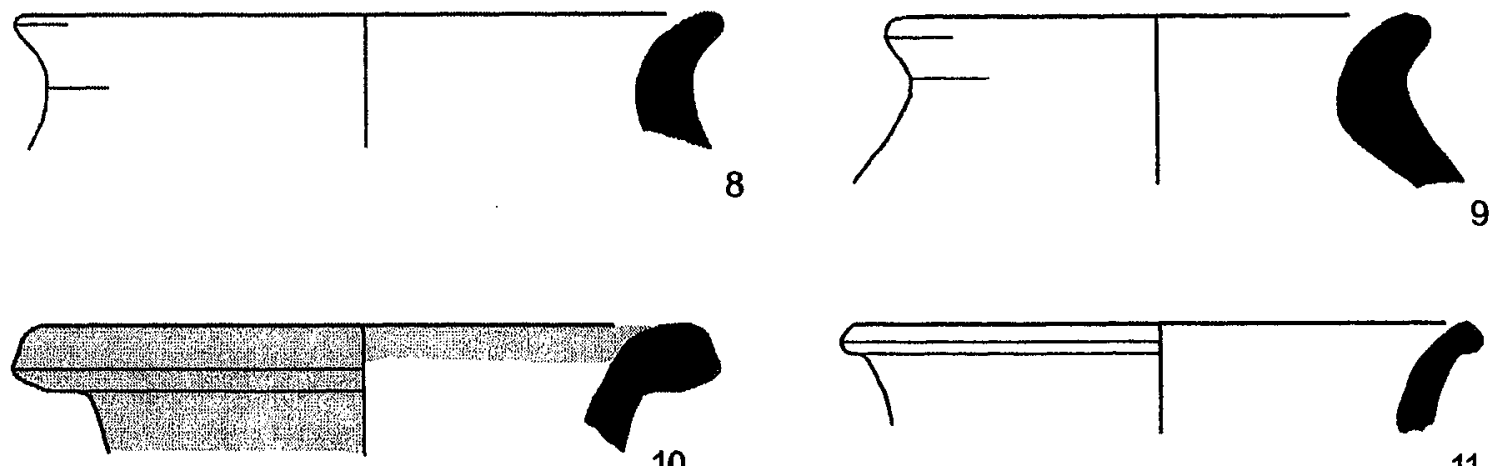

11
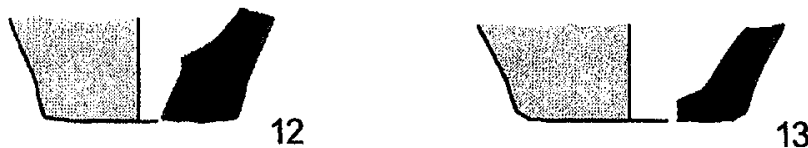

13

PLATE 86 (CONT.).

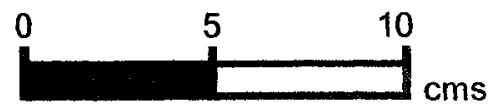




\begin{tabular}{llllllll}
\hline No & Reg & Square & Locus & Vessel & Part & $\begin{array}{c}\text { Body } \\
\text { Thick }\end{array}$ & Dia \\
\hline & & & & & & & \\
1 & 0770 & SW 3-27 & 69 & NECKED JAR & R00 & 14 & 32 \\
2 & 0792 & SW 3-27 & 70 & NECKED JAR & R31 & 14 & 20 \\
3 & 2414 & SW 3-27 & 70 & PLATTER BOWL & R71 & N & N \\
4 & 2416 & SW 3-27 & 70 & PLATTER BOWL & R56 & 7 & $\mathrm{~N}$ \\
5 & 2419 & SW 3-27 & 70 & PLATTER BOWL & R56 & 8 & $\mathrm{~N}$ \\
6 & 0771 & SW 3-27 & 69 & HOLE MOUTH JAR & R28 & 8 & 18 \\
7 & 0772 & SW 3-27 & 69 & UD & H14 & 8 & $\mathrm{~N}$ \\
8 & 0793 & SW 3-27 & 70 & UD & BOD & 9 & $\mathrm{~N}$ \\
9 & 0773 & SW 3-27 & 69 & UD & BOD & 10 & $\mathrm{~N}$ \\
10 & 0794 & SW 3-27 & 70 & UD & BOD & 11 & $\mathrm{~N}$
\end{tabular}

\begin{tabular}{lllll}
\hline No Fabric Color & Core Orient & Core Color & Core Thick & Fabric \\
& & Family
\end{tabular}

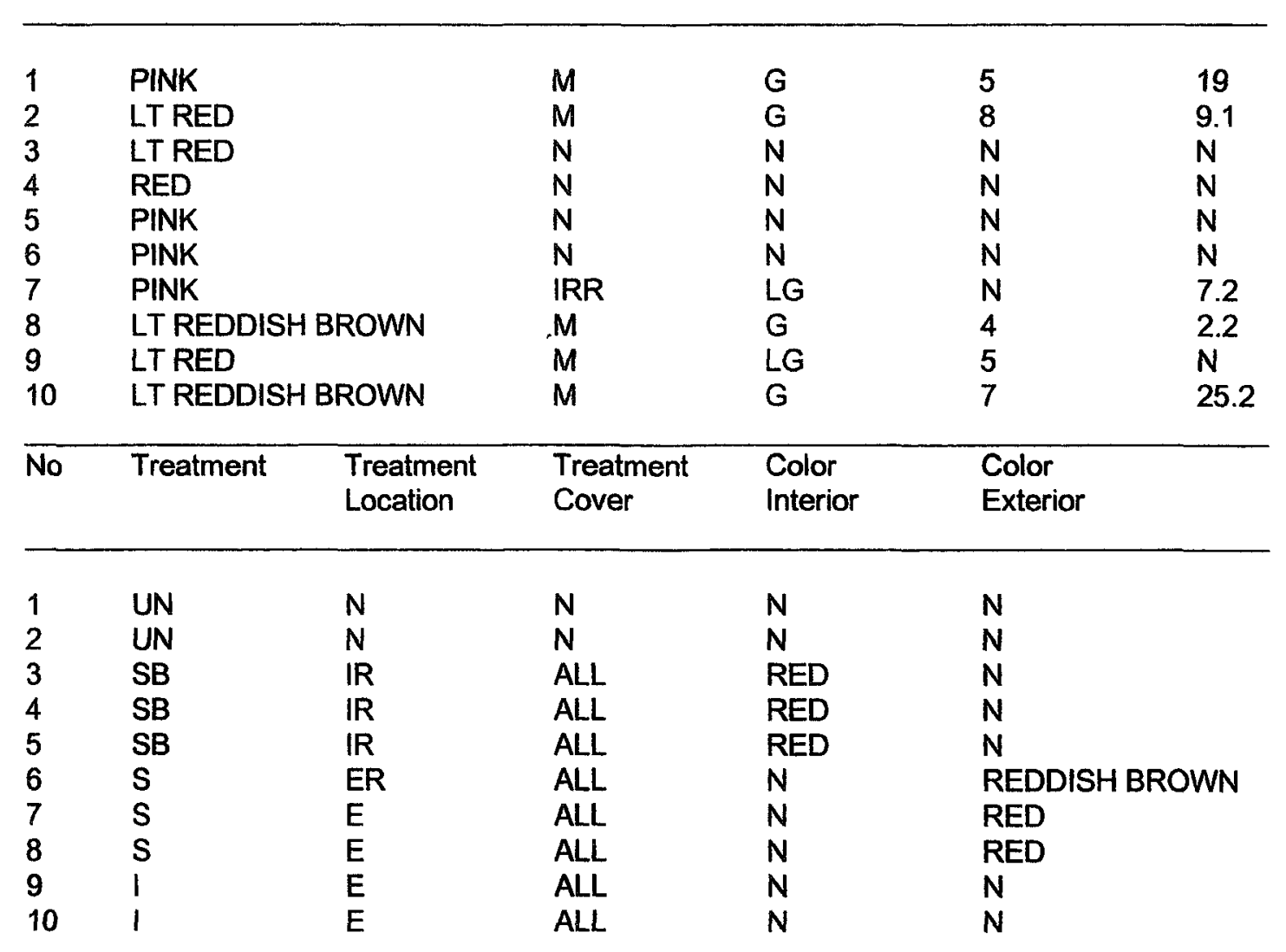

PLATE 87. FIELD A. PHASE 3B (EB III). 
Other

1 Possibly intrusive.

3 Sample too small to confirm stance or diameter.

4 Sample too small to confirm stance or diameter.

5 Sample too small to confirm stance or diameter.

9 Combed.

10 Combed.

PLATE 87 (CONT.).

Reproduced with permission of the copyright owner. Further reproduction prohibited without permission. 

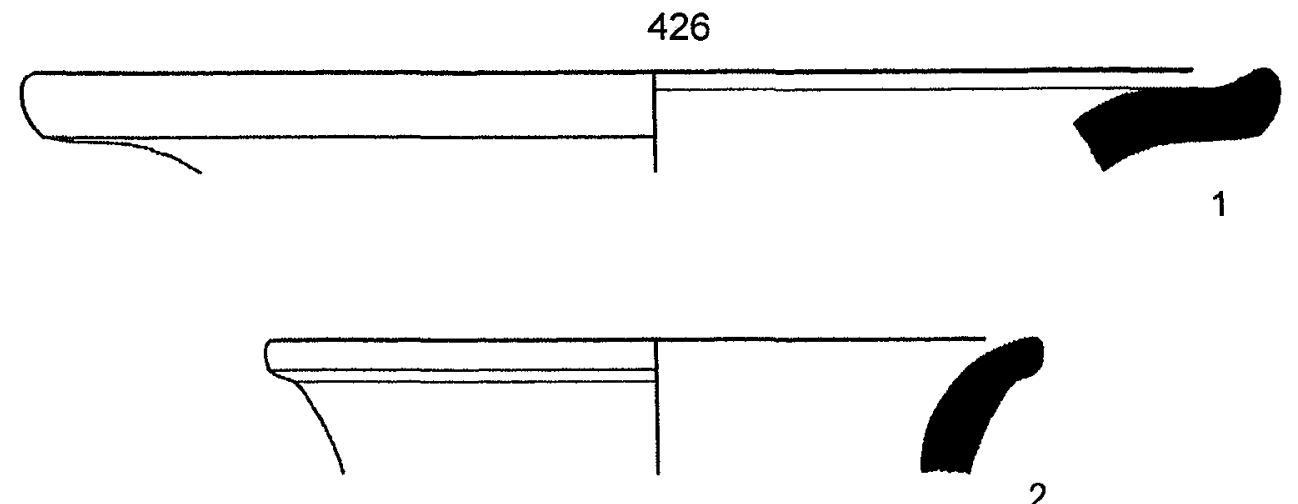

2
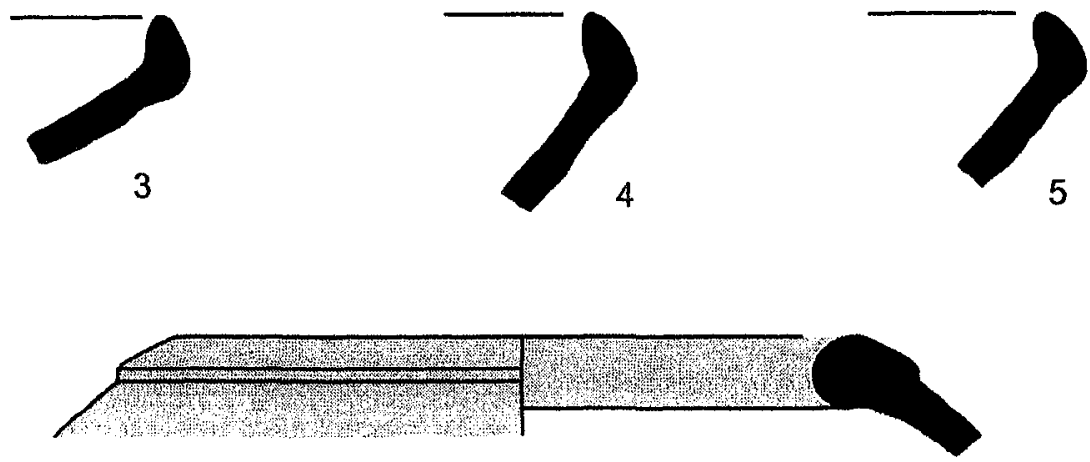

6
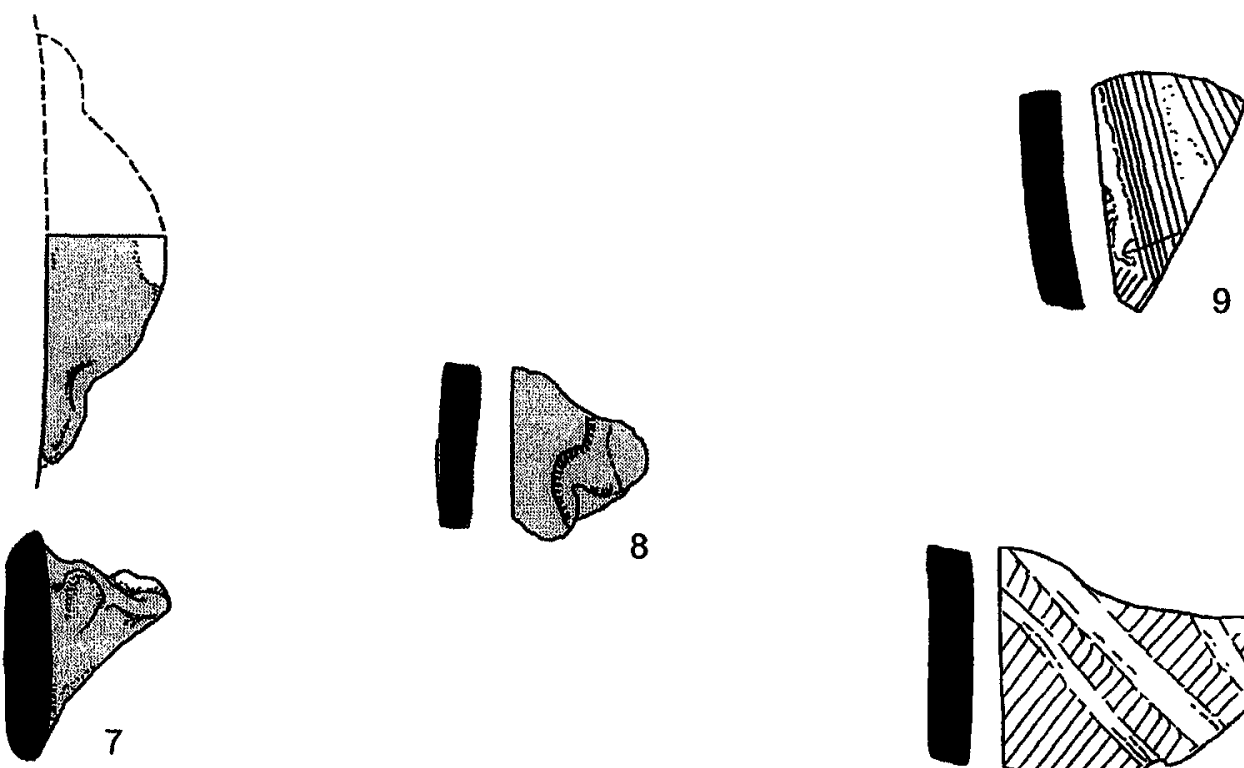

PLATE 87 (CONT.).
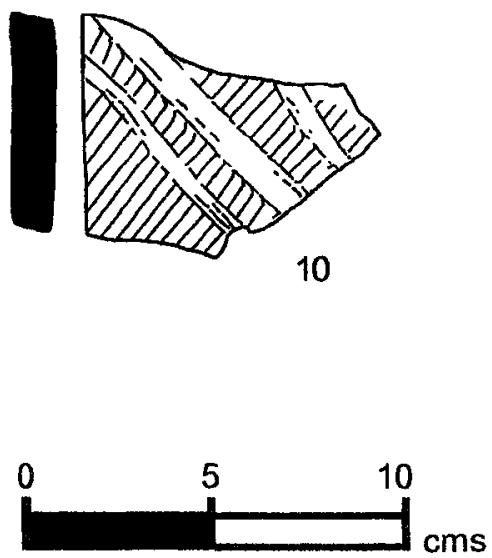


\begin{tabular}{llllllll}
\hline No & Reg & Square & Locus & Vessel & Part & $\begin{array}{l}\text { Body } \\
\text { Thick }\end{array}$ & Dia \\
\hline & & & & & & & \\
1 & 0212 & SE 1-28 & 15 & HOLE MOUTH BOWL & R02 & 12 & 15 \\
2 & 0183 & SE 1-28 & 25 & HOLE MOUTH JAR & R08 & 14 & 22 \\
3 & 0184 & SE 1-28 & 25 & NECKED JAR & R42 & 12 & 20 \\
4 & 0213 & SE 1-28 & 15 & UD & B11 & 12 & 20 \\
5 & 0218 & SE 1-28 & 23 & UD & B12 & 12 & 20 \\
6 & 0211 & SE 1-28 & 25 & UD & B12 & 9 & 18 \\
7 & 0217 & SE 1-28 & 23 & UD & H20 & 10 & N \\
8 & 0215 & SE 1-28 & 23 & PLATTER BOWL & R56 & N & 58
\end{tabular}

\begin{tabular}{lllll}
\hline No & Fabric Color & Core Orient & Core Color Core Thick & Fabric \\
& & & Family
\end{tabular}

\begin{tabular}{|c|c|c|c|c|c|c|}
\hline $\begin{array}{l}1 \\
2 \\
3 \\
4 \\
5 \\
6 \\
7 \\
8\end{array}$ & \multicolumn{2}{|c|}{$\begin{array}{l}\text { WEAK RED } \\
\text { REDDISH GREY } \\
\text { PINK } \\
\text { LT REDDISH BROWN } \\
\text { PINK } \\
\text { LT RED } \\
\text { PINK } \\
\text { PINKISH GREY }\end{array}$} & $\begin{array}{l}\text { IRR } \\
N \\
N \\
M \\
\mathbb{N} \\
N \\
\mathbb{N} \\
M\end{array}$ & $\begin{array}{l}\text { LG } \\
N \\
N \\
L G \\
L G \\
N \\
G \\
\text { LG }\end{array}$ & $\begin{array}{l}N \\
N \\
N \\
6 \\
10 \\
N \\
7 \\
N\end{array}$ & $\begin{array}{l}N \\
N \\
11 \\
N \\
N \\
12.1 \\
N \\
N\end{array}$ \\
\hline$\overline{\text { No }}$ & Treatment & $\begin{array}{l}\text { Treatment } \\
\text { Location }\end{array}$ & $\begin{array}{l}\text { Treatment } \\
\text { Cover }\end{array}$ & $\begin{array}{l}\text { Color } \\
\text { Interior }\end{array}$ & $\begin{array}{l}\text { Color } \\
\text { Exterior }\end{array}$ & \\
\hline $\begin{array}{l}1 \\
2 \\
3 \\
4 \\
5 \\
6 \\
7 \\
7 \\
8\end{array}$ & $\begin{array}{l}\text { UN } \\
\text { UN } \\
\text { SB } \\
\text { UN } \\
\text { S } \\
\text { UN } \\
\text { SB } \\
\text { SB }\end{array}$ & $\begin{array}{l}N \\
N \\
E R \\
N \\
E \\
N \\
E \\
I E\end{array}$ & $\begin{array}{l}N \\
N \\
A L L \\
N \\
A L L \\
N \\
\text { ALL } \\
\text { ALL }\end{array}$ & $\begin{array}{l}N \\
N \\
N \\
N \\
N \\
N \\
N \\
\text { DUSKY RED }\end{array}$ & $\begin{array}{l}N \\
N \\
\text { RED } \\
N \\
\text { RED } \\
N \\
\text { RED } \\
N\end{array}$ & \\
\hline
\end{tabular}

$\begin{array}{ll}3 & \text { Also in Fabric Families } 22 \text { and } 23 . \\ 6 & \text { Metallic Ware. }\end{array}$

PLATE 88. FIELD A. PHASE 4A (EB III). 

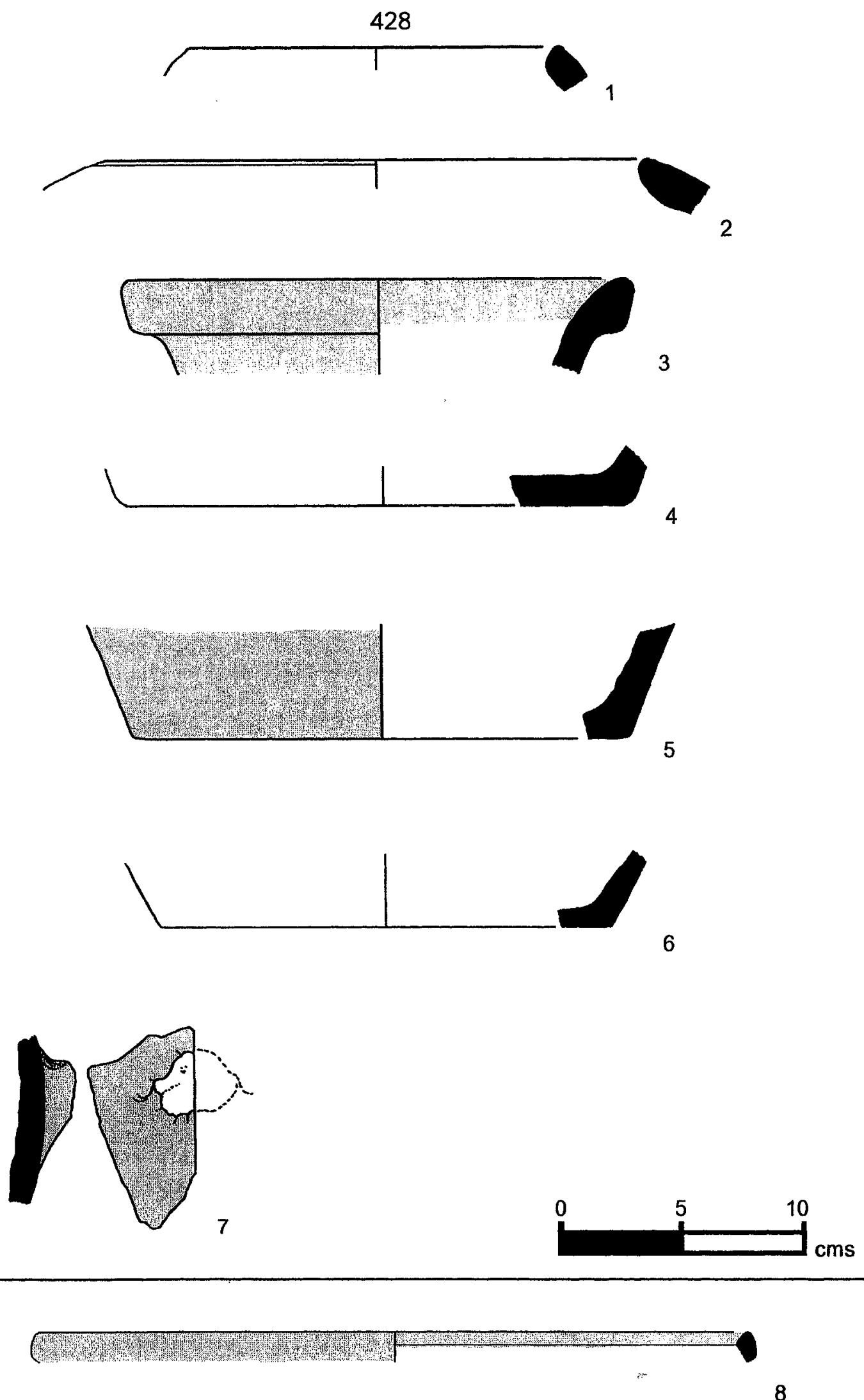

PLATE 88 (CONT.).

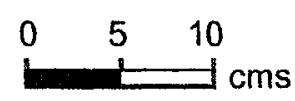




\begin{tabular}{llllllll}
\hline No & Reg & Square & Locus & Vessel & Part & $\begin{array}{c}\text { Body } \\
\text { Thick }\end{array}$ & Dia \\
\hline 1 & 0352 & SW 1-26 & 177 & HOLE MOUTH JAR & R14 & 13 & 18 \\
2 & 0351 & SW 1-26 & 177 & HOLE MOUTH BOWL & R07 & 10 & 14 \\
3 & 0298 & SW 1-26 & 166 & NECKED JAR & R31 & 8 & 20 \\
4 & 0210 & SE 1-28 & 26 & NECKED JAR & R43 & 11 & 20 \\
5 & 2239 & SE 1-28 & 26 & UD & B12 & N & N \\
6 & 0353 & SW 1-26 & 177 & UD & H20 & 8 & N \\
7 & 0354 & SW 1-26 & 177 & UD & H27 & 5 & N \\
8 & 0192 & SE 1-28 & 26 & PLATTER BOWL & R56 & 11 & 42 \\
& & & & Core Orient Core Color & Core Thick & Fabric \\
No & Fabric Color & & & & & Family
\end{tabular}

\begin{tabular}{|c|c|c|c|c|c|c|}
\hline 1 & \multicolumn{2}{|l|}{ RED } & IRR & G & $\mathrm{N}$ & 2.1 \\
\hline 2 & \multicolumn{2}{|l|}{ LT RED } & $M$ & LG & 5 & 1 \\
\hline 3 & \multicolumn{2}{|l|}{ PINK } & M & G & 2 & 2.2 \\
\hline 4 & \multicolumn{2}{|l|}{ LT RED } & $M$ & G & 7 & $\mathrm{~N}$ \\
\hline 5 & \multicolumn{2}{|l|}{ PINK } & $\mathbf{N}$ & $\mathbf{N}$ & $\mathbf{N}$ & $\mathbf{N}$ \\
\hline 6 & \multicolumn{2}{|l|}{ LT RED } & $M$ & LG & $\mathbf{N}$ & $\mathrm{N}$ \\
\hline 7 & \multicolumn{2}{|c|}{ LT REDDISH BROWN } & $M$ & LG & $\mathbf{N}$ & $N$ \\
\hline 8 & \multicolumn{2}{|c|}{ REDDISH YELLOW } & $\mathrm{N}$ & $N$ & $N$ & 24 \\
\hline No & Treatment & $\begin{array}{l}\text { Treatment } \\
\text { Location }\end{array}$ & $\begin{array}{l}\text { Treatment } \\
\text { Cover }\end{array}$ & $\begin{array}{l}\text { Color } \\
\text { Interior }\end{array}$ & & \\
\hline 1 & UN & $\mathrm{N}$ & $\mathrm{N}$ & $\mathrm{N}$ & $\mathbf{N}$ & \\
\hline 2 & UN & $\mathbf{N}$ & $\mathrm{N}$ & $\mathbf{N}$ & $\mathbf{N}$ & \\
\hline 3 & UN & $N$ & $N$ & $N$ & $N$ & \\
\hline 4 & UN & $\mathbf{N}$ & $\mathrm{N}$ & $\mathrm{N}$ & $\mathrm{N}$ & \\
\hline 5 & $S$ & $E$ & ALL & $N$ & & WN \\
\hline 6 & $S$ & $E$ & ALL & $N$ & UL & \\
\hline 7 & UN & $N$ & $N$ & $\mathrm{~N}$ & $\mathrm{~N}$ & \\
\hline 8 & UN & $\mathbf{N}$ & $\mathbf{N}$ & $\mathbf{N}$ & $\mathbf{N}$ & \\
\hline
\end{tabular}

5 Sample too small to confirm stance or diameter.

8 Weathered.

PLATE 89. FIELD A. PHASE 4A (EB III). 

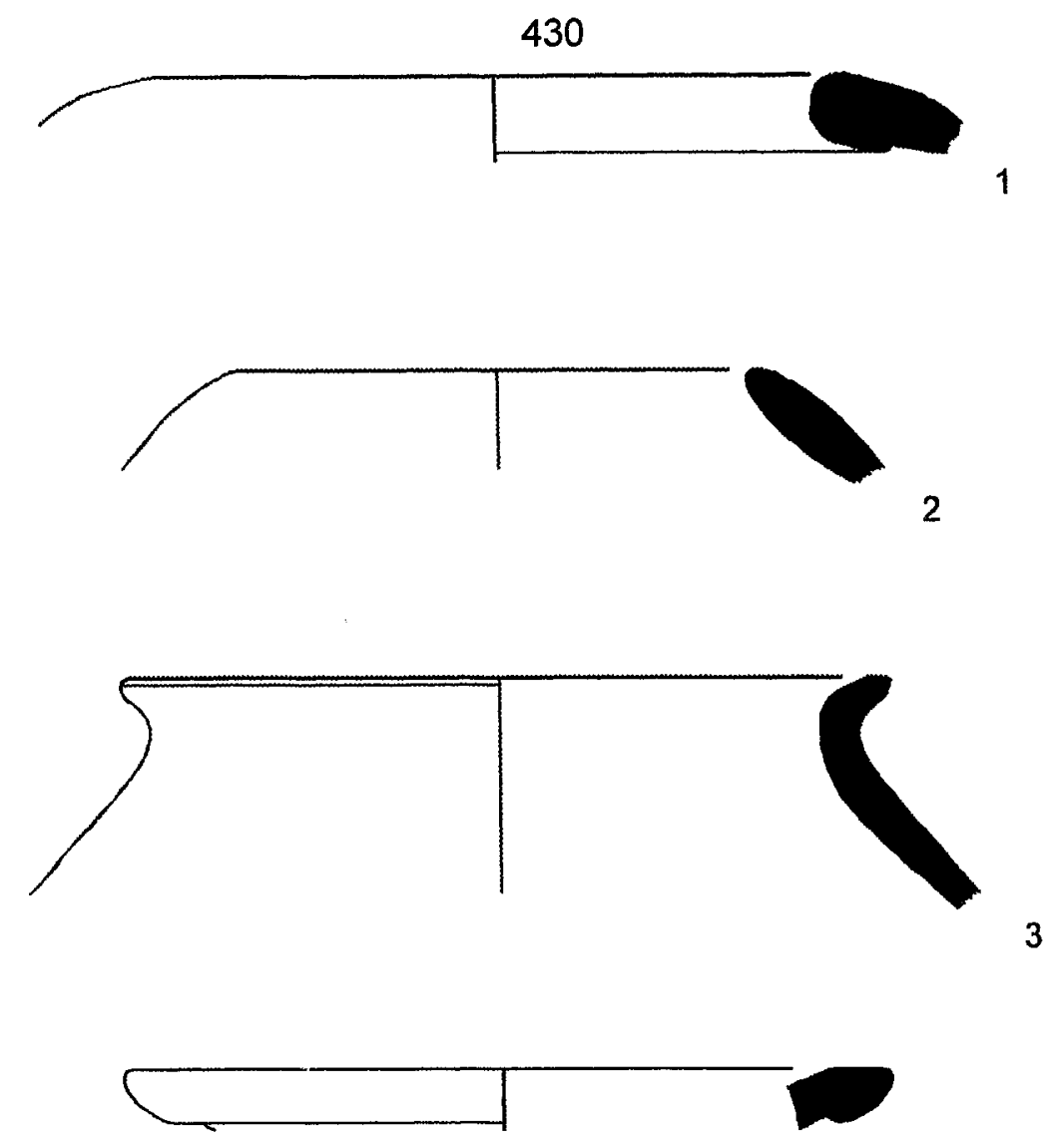

4
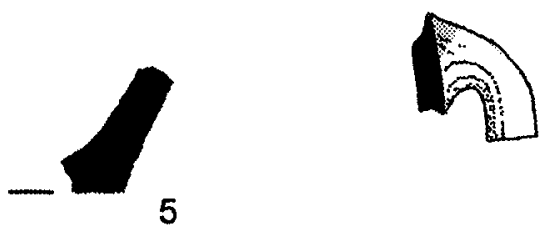

5

6
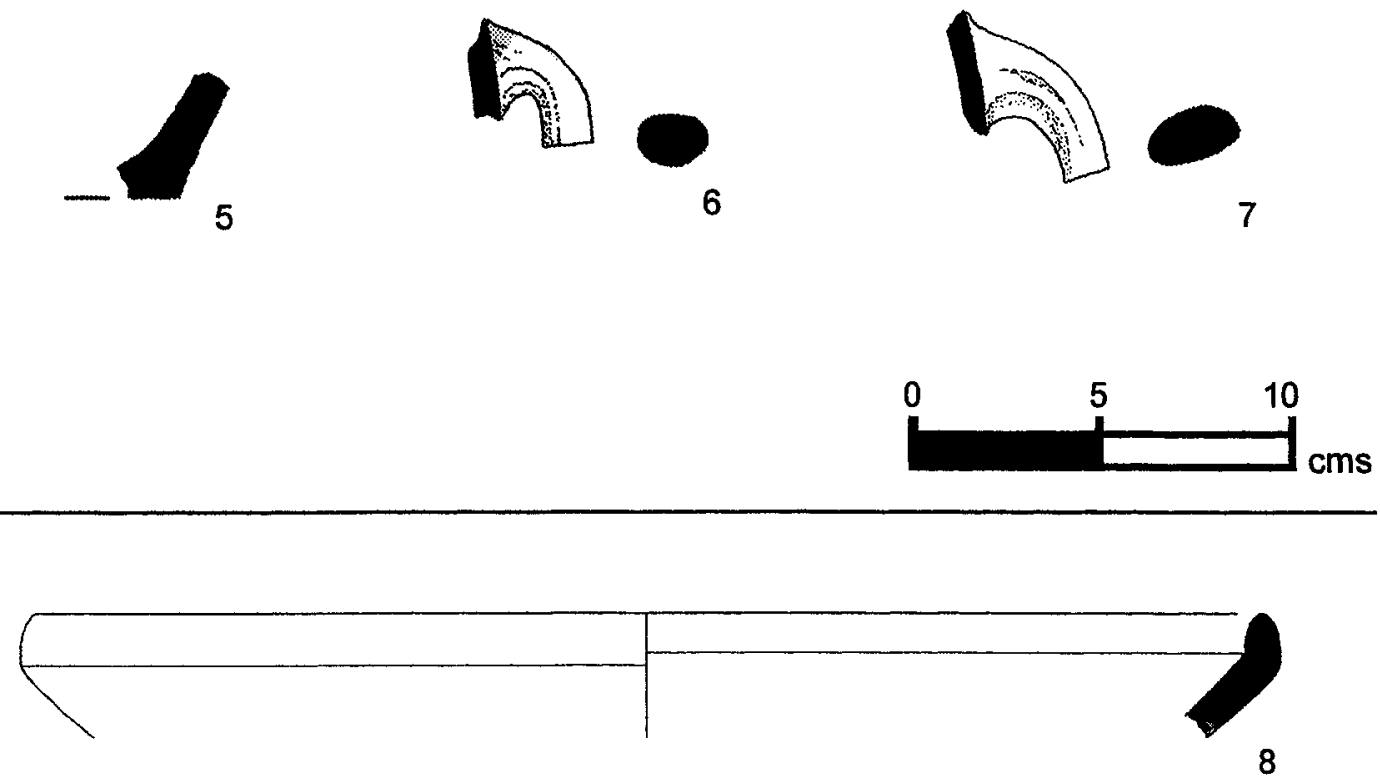

PLATE 89 (CONT.).

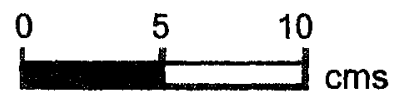




\begin{tabular}{llllllll}
\hline No & Reg & Square & Locus & Vessel & Part & $\begin{array}{c}\text { Body } \\
\text { Thick }\end{array}$ & Dia \\
\hline & & & & & & & \\
1 & 0599 & SW 1-27 & 230 & BOWL & R50 & 9 & 18 \\
2 & 2253 & SW 1-27 & 230 & LEDGE RIM BOWL & R52 & 8 & 36 \\
3 & 0600 & SW 1-27 & 230 & HOLE MOUTH JAR & R01 & 8 & 14 \\
4 & 2252 & SW 1-27 & 230 & NECKED JAR & R31 & 7 & 12 \\
5 & 0485 & SW 1-27 & 4 & NECKED JAR & R43 & 6 & 10 \\
6 & 0484 & SW 1-27 & 4 & UD & H27 & 9 & N
\end{tabular}

\begin{tabular}{lllll}
\hline No Fabric Color & Core Orient & Core Color & Core Thick & Fabric \\
& & & Family
\end{tabular}

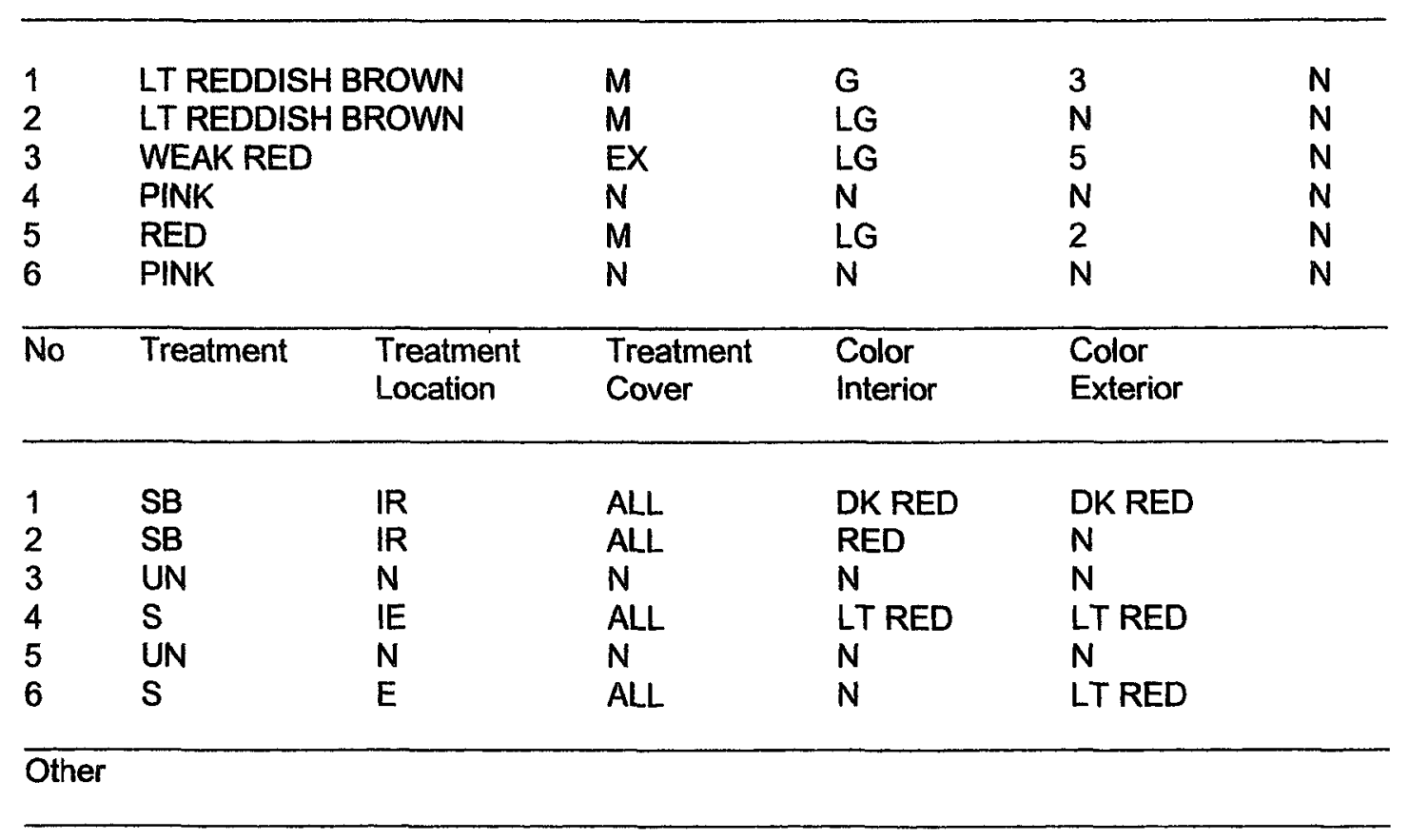

1 Burn on rim suggests use as a lamp; radially burnished.

2 Interior face and rim well burnished; slight concavity under rim on unfinished exterior face; sample too small to confirm stance or diameter.

4 Sample too small to confirm stance or diameter.

5 Metallic Ware.

PLATE 90. FIELD A. PHASE 4A (EB III). 
432
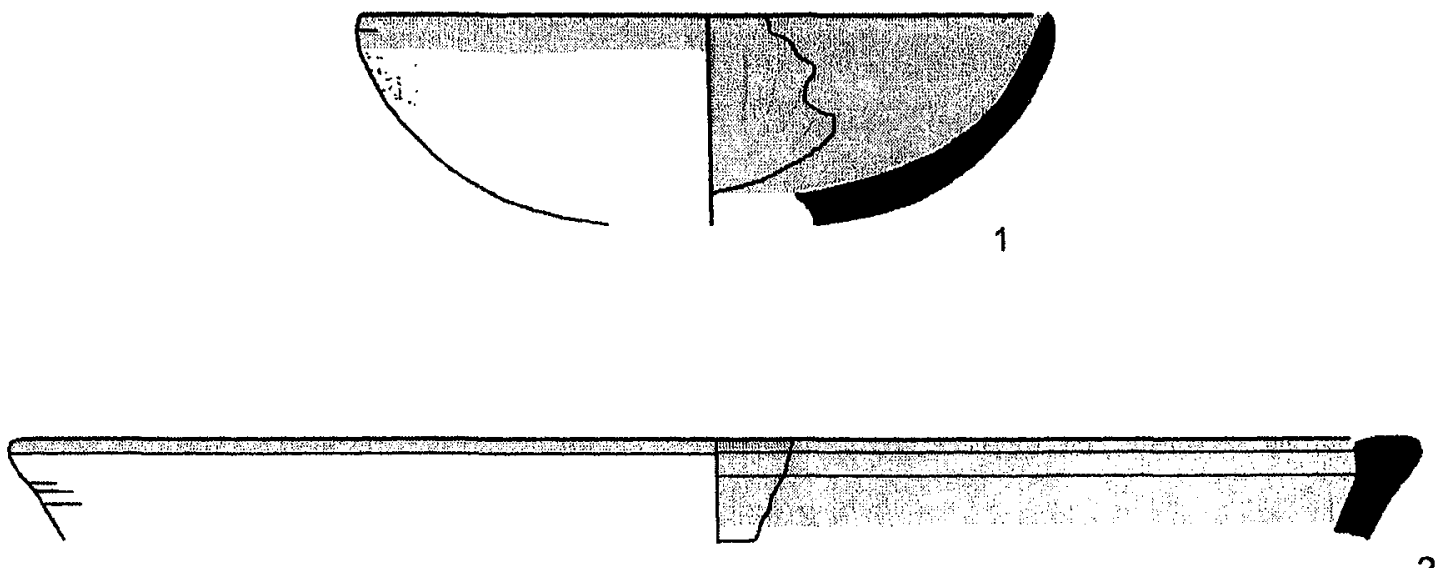

2
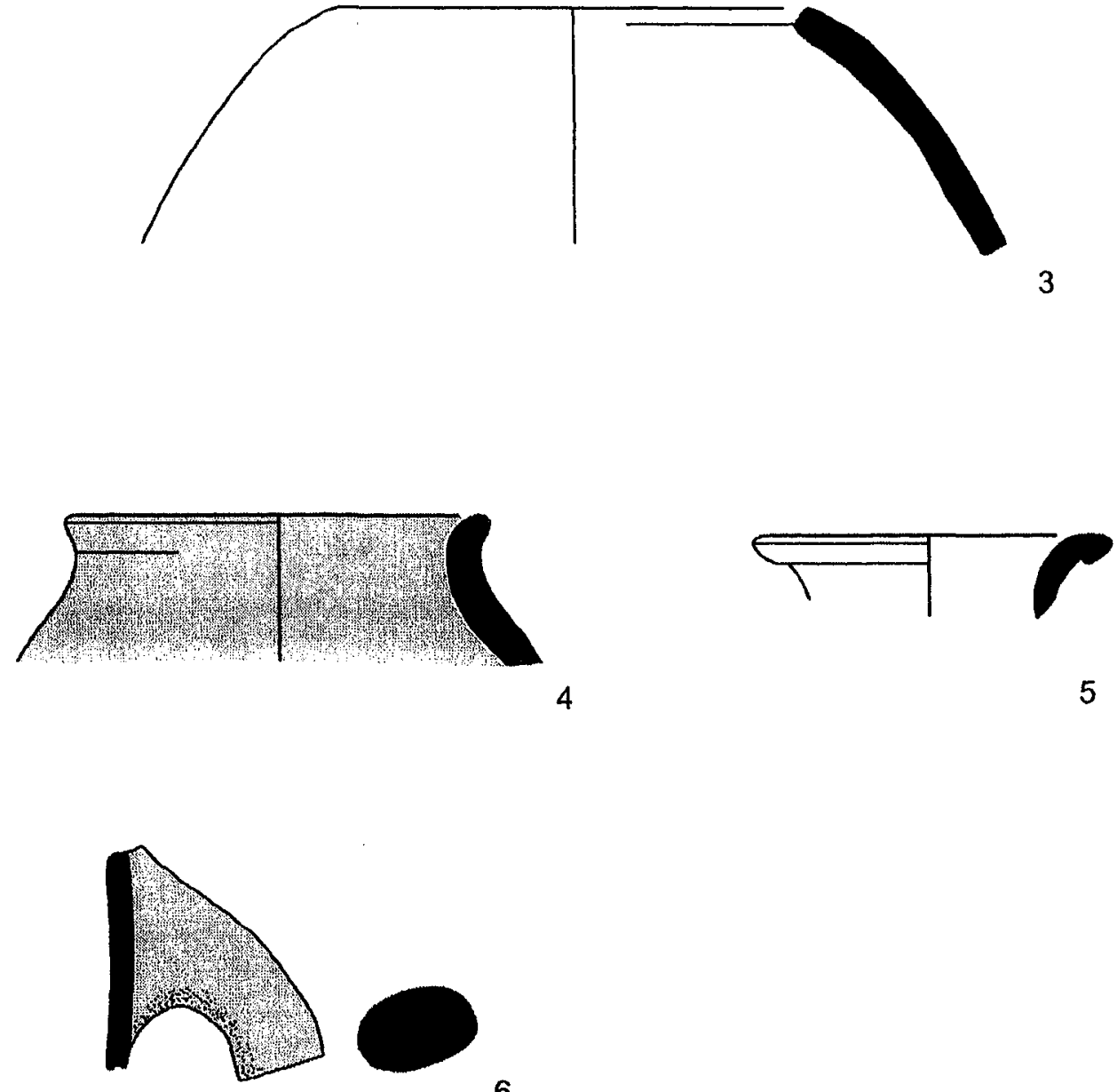

6

PLATE 90 (CONT.).

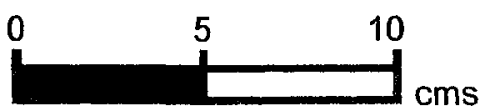




\begin{tabular}{llllllll}
\hline No & Reg & Square & Locus & Vessel & Part & $\begin{array}{c}\text { Body } \\
\text { Thick }\end{array}$ & $\begin{array}{c}\text { Dia } \\
\end{array}$ \\
& & & & & & & \\
\hline 1 & 0765 & SW 3-26 & 37 & BOWL & R50 & 6 & 16 \\
2 & 0764 & SW 3-26 & 37 & HOLE MOUTH JAR & R02 & 9 & 13 \\
3 & 0768 & SW 3-26 & 37 & HOLE MOUTH BOWL & R14 & 14 & 20 \\
4 & 0763 & SW 3-26 & 37 & HOLE MOUTH JAR & R04 & 11 & 16 \\
5 & 0756 & SW 3-26 & 47 & HOLE MOUTH JAR & R02 & 12 & 14 \\
6 & 0755 & SW 3-26 & 47 & HOLE MOUTH JAR & R08 & 12 & 18 \\
7 & 0766 & SW 3-26 & 37 & NECKED JAR & R31 & 7 & 15 \\
8 & 0757 & SW 3-26 & 47 & UD & H14 & 9 & N \\
9 & 0754 & SW 3-26 & 47 & NECKED JAR & R81 & 6 & 13 \\
10 & 0767 & SW 3-26 & 37 & HOLE MOUTH JAR & R20 & 21 & 40
\end{tabular}

\begin{tabular}{lllll}
\hline No Fabric Color & Core Orient & Core Color & Core Thick & Fabric \\
& & & Family
\end{tabular}

\begin{tabular}{|c|c|c|c|c|c|c|}
\hline 1 & \multirow{2}{*}{\multicolumn{2}{|c|}{$\begin{array}{l}\text { PINK } \\
\text { WEAK RED }\end{array}$}} & $\mathbf{N}$ & $\mathrm{N}$ & $\mathrm{N}$ & $\mathbf{N}$ \\
\hline 2 & & & IRR & G & $\mathrm{N}$ & $\mathrm{N}$ \\
\hline 3 & & $M$ & $\mathbf{G}$ & 8 & $\mathbf{N}$ \\
\hline 4 & \multicolumn{2}{|l|}{ WEAK RED } & $M$ & $G$ & 7 & $N$ \\
\hline 5 & \multicolumn{2}{|l|}{ WEAK RED } & IRR & G & $\mathbf{N}$ & $\mathbf{N}$ \\
\hline 6 & \multicolumn{2}{|l|}{ PALE RED } & $N$ & $\mathbf{N}$ & $N$ & $\mathrm{~N}$ \\
\hline 7 & \multicolumn{2}{|l|}{ PINK } & $\mathbf{N}$ & $\mathbf{N}$ & $N$ & $\mathrm{~N}$ \\
\hline 8 & \multicolumn{2}{|l|}{ PINK } & IRR & LG & $N$ & $N$ \\
\hline 9 & \multicolumn{2}{|l|}{ PINK } & $\mathbf{N}$ & $\mathbf{N}$ & $\mathbf{N}$ & $\mathrm{N}$ \\
\hline 10 & \multicolumn{2}{|c|}{ REDDISH GREY } & IRR & $\mathbf{G}$ & $N$ & $N$ \\
\hline No & Treatment & $\begin{array}{l}\text { Treatment } \\
\text { Location }\end{array}$ & $\begin{array}{l}\text { Treatment } \\
\text { Cover }\end{array}$ & $\begin{array}{l}\text { Color } \\
\text { Interior }\end{array}$ & $\begin{array}{l}\text { Color } \\
\text { Exterior }\end{array}$ & \\
\hline 1 & SB & IE & $A L L$ & RED & RED & \\
\hline 2 & UN & $N$ & $\mathbf{N}$ & $\mathbf{N}$ & $N$ & \\
\hline 3 & UN & $\mathbf{N}$ & $N$ & $N$ & $N$ & \\
\hline 4 & UN & $\mathbf{N}$ & $\mathbf{N}$ & $\mathbf{N}$ & $\mathrm{N}$ & \\
\hline 5 & UN & $N$ & $\mathbf{N}$ & $\mathbf{N}$ & $N$ & \\
\hline 6 & UN & $N$ & $\mathbf{N}$ & $\mathbf{N}$ & $N$ & \\
\hline 7 & B & $\mathbb{I E}$ & ALL & $\mathbf{N}$ & $\mathrm{N}$ & \\
\hline 8 & $\mathrm{~S}$ & $E$ & ALL & $\mathbf{N}$ & RED & \\
\hline 9 & $\mathbf{S}$ & $\mathbf{I R}$ & ALL & LT RED & $\mathrm{N}$ & \\
\hline 10 & UN & $N$ & $\mathbf{N}$ & $\mathbf{N}$ & $N$ & \\
\hline
\end{tabular}

PLATE 91. FIELD A. PHASE 4A (EB III). 
Other

2 Surface burn visible.

$4 \quad$ Surface burn visible.

5 Marks on interior face show finish motion along rim and lower diagonal scraping; surface burn visible.

6 Surface burn visible.

10 Concavity on lip is thin and shallow.

PLATE 91 (CONT.). 

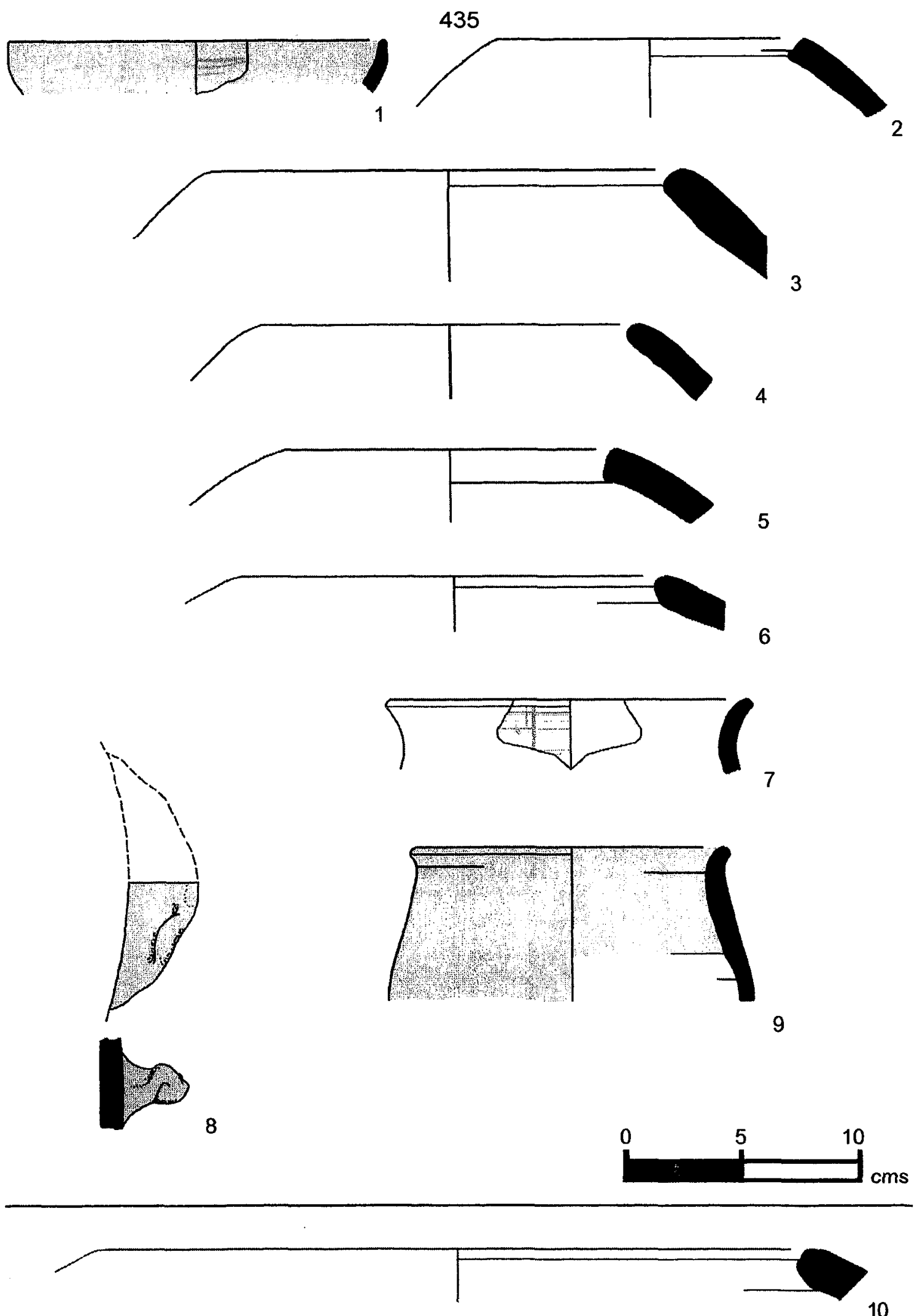

PLATE 91 (CONT.).

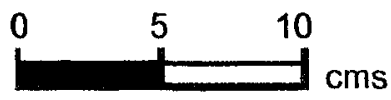




\begin{tabular}{llllllll}
\hline No & Reg & Square & Locus & Vessel & Part & $\begin{array}{c}\text { Body } \\
\text { Thick }\end{array}$ & Dia \\
\hline 1 & 0232 & SE 1-26 & 46 & HOLE MOUTH JAR & R01 & 12 & 19 \\
2 & 0231 & SE 1-26 & 46 & HOLE MOUTH JAR & R11 & 15 & 18 \\
3 & 0233 & SE 1-26 & 46 & NECKED JAR & R43 & 8 & 10 \\
4 & 0234 & SE 1-26 & 46 & UD & H20 & 7 & N
\end{tabular}

\begin{tabular}{lllll}
\hline No Fabric Color & Core Orient & Core Color & Core Thick & $\begin{array}{l}\text { Fabric } \\
\text { Family }\end{array}$
\end{tabular}

\begin{tabular}{llllll}
\hline 1 & LT REDDISH BROWN & EX & G & 8 & 2.1 \\
2 & LT REDDISH BROWN & M & G & 8 & 2.1 \\
3 & LTREDDISH BROWN & N & N & N & 23 \\
4 & PINK & M & G & 4 & N \\
\hline No & Treatment & Treatment & Treatment & Color & Color \\
& & Location & Cover & Interior & Exterior \\
\hline 1 & UN & N & N & N & N \\
2 & UN & N & N & N & N \\
3 & S & ER & ALL & N & RED \\
4 & SB & E & ALL & N & RED \\
\hline Other & & & & & \\
\hline
\end{tabular}

2 Possible potter's mark on shoulder.

PLATE 92. FIELD A. PHASE 4B (EB III). 

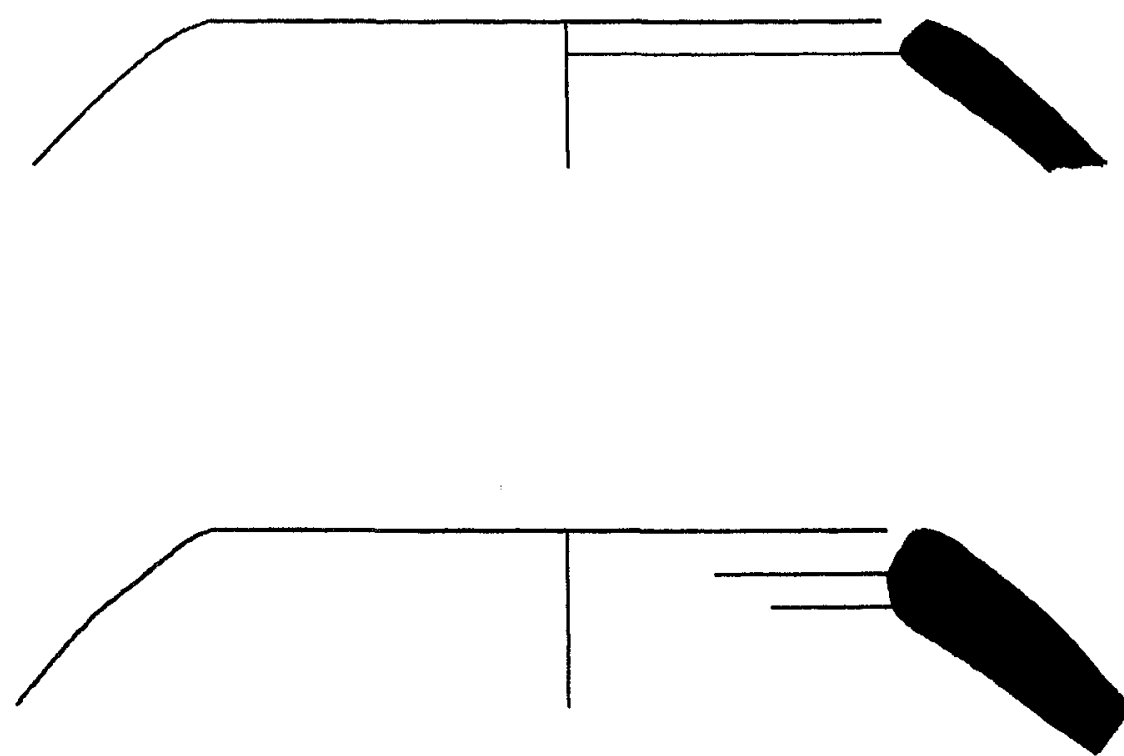

2
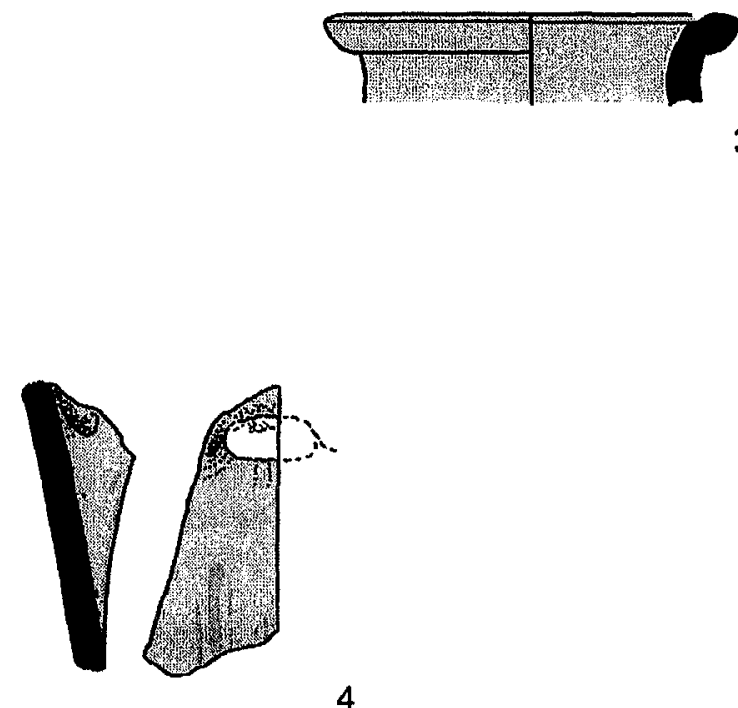

4

PLATE 92 (CONT.).

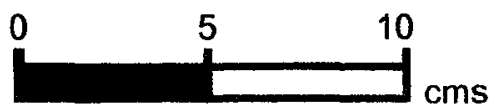




\begin{tabular}{llllll}
\hline No Reg Square & Locus & Vessel & Part & $\substack{\text { Body } \\
\text { Thick }}$ & Dia
\end{tabular}

\begin{tabular}{llllllll}
\hline 1 & 0261 & SE 1-26 & 48 & LEDGE RIM BOWL & R51 & 11 & 36 \\
2 & 0259 & SE 1-26 & 48 & PLATTER BOWL & R56 & 14 & 30 \\
3 & 0245 & SE 1-26 & 48 & PLATTER BOWL & R50 & 7 & 18 \\
4 & 0244 & SE 1-26 & 48 & CARINATED BOWL & R58 & 7 & 16 \\
5 & 2242 & SE 1-26 & 48 & LEDGE RIM BOWL & R51 & 9 & 24 \\
6 & 0235 & SE 1-26 & 48 & LEDGE RIM BOWL & R51 & 10 & 35 \\
7 & 0243 & SE 1-26 & 48 & HOLE MOUTH BOWL & R04 & 14 & 25 \\
8 & 0237 & SE 1-26 & 48 & HOLE MOUTH JAR & R01 & 11 & 15 \\
9 & 0250 & SE 1-26 & 48 & HOLE MOUTH JARIBOWL & R11 & 12 & 18 \\
10 & 0242 & SE 1-26 & 48 & HOLE MOUTH BOWL & R14 & 7 & 15
\end{tabular}

\begin{tabular}{llllll}
\hline No Fabric Color & Core Orient & Core Color & Core Thick & Fabric \\
& & & Family
\end{tabular}

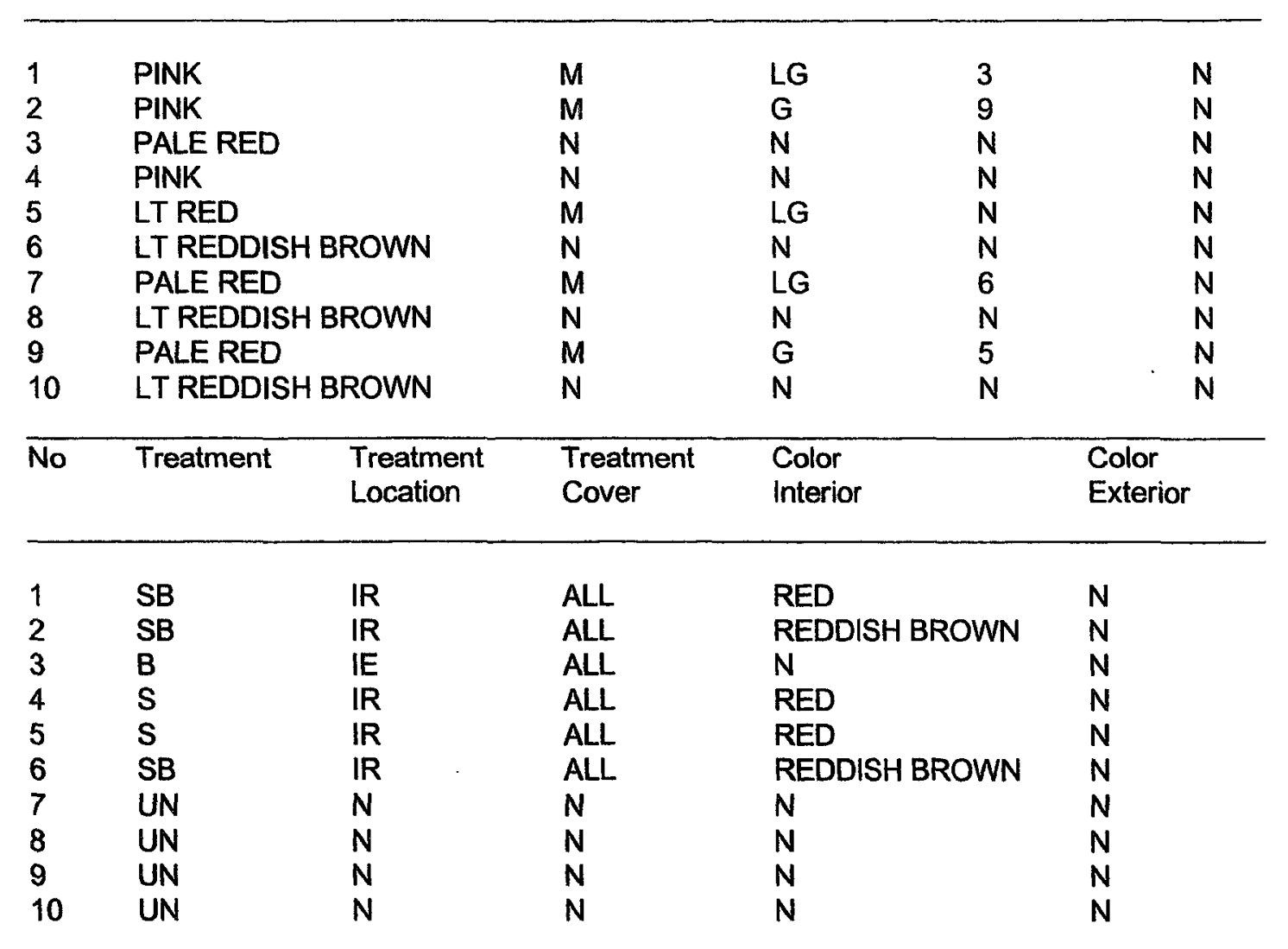

PLATE 93. FIELD A. PHASE 4B (EB III). 
Other

$1 \quad$ Radial burnish on interior face; exterior face is uneven, "textured."

2 Marginal concavity appears to "step down" from rim to base; textured base has many small concavities but few scraped lines; radial burnish on interior face.

4 Interior face is slightly uneven, some finger marks; rim interior and exterior marked by fine lines suggestive of wet-smoothing; area immediately below keel smoothed with only a few tool marks; beyond this margin, area of base is extremely "textured" with haphazard scraping.

6 Upper exterior face marked by margin of fine lines and slight concavity; lower exterior face appears scraped in clockwise direction (from inclusion drags); smoothing lines are, at times, obliterated by scraping.

9 Sample is too small to confirm stance or diameter; surface burn visible.

PLATE 93 (CONT.). 

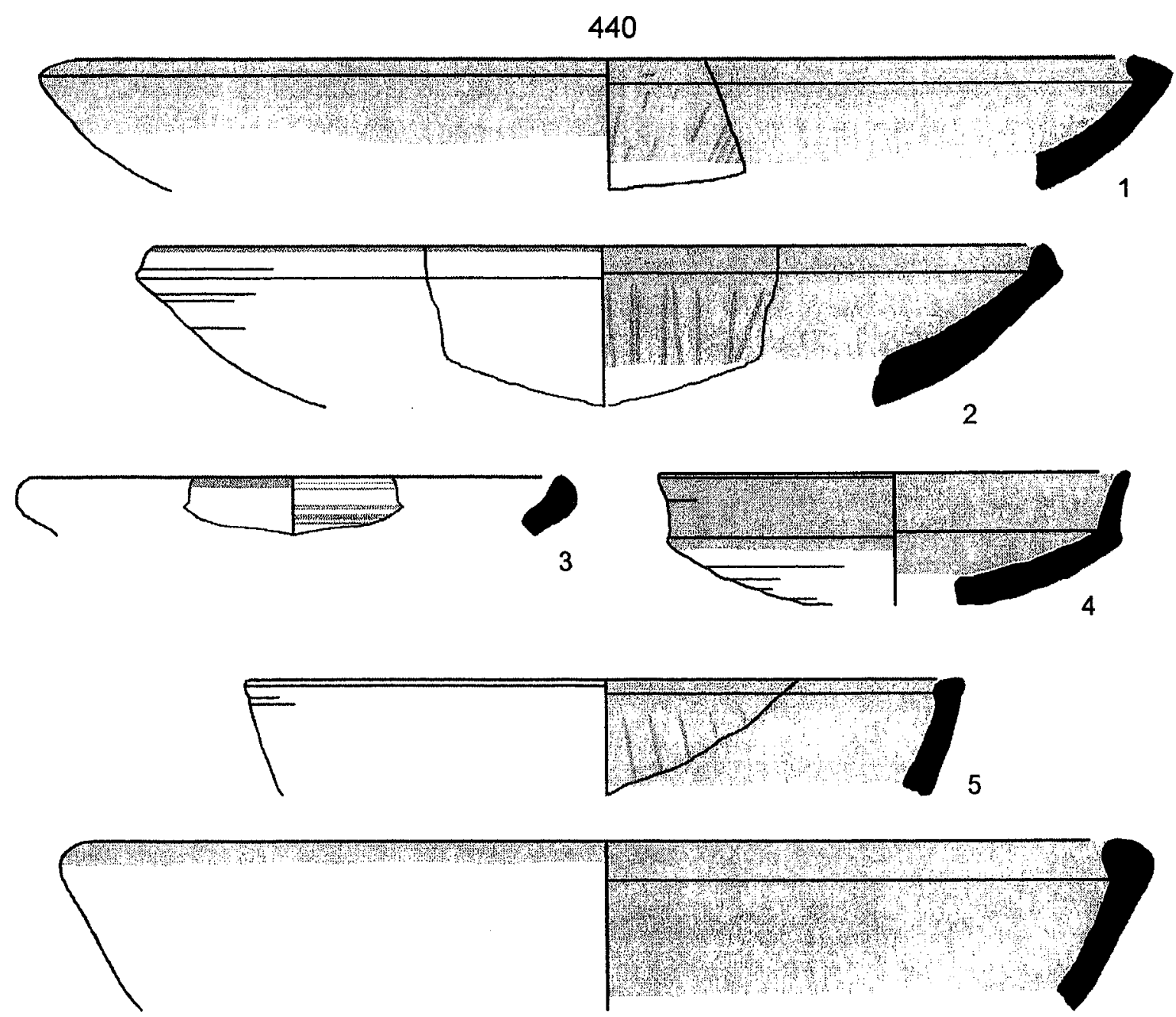

6
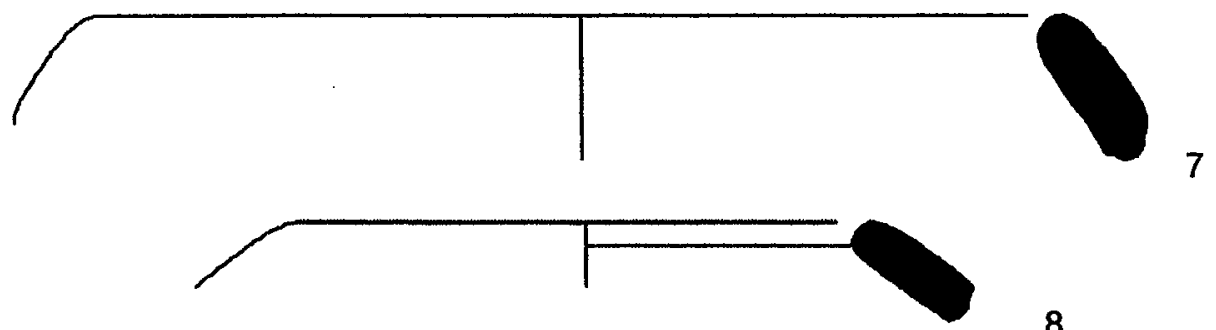

8
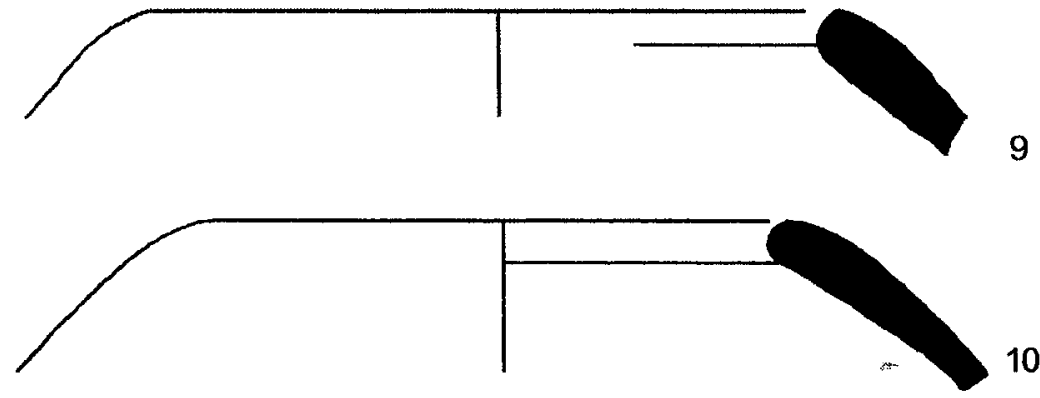

PLATE 93 (CONT).

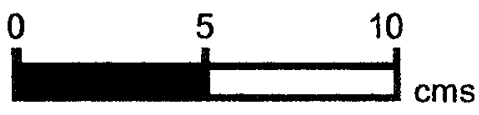




\begin{tabular}{llllllll}
\hline No & Reg & Square & Locus & Vessel & Part & $\begin{array}{c}\text { Body } \\
\text { Thick }\end{array}$ & $\begin{array}{c}\text { Dia } \\
\text { n }\end{array}$ \\
\hline 1 & 0240 & SE 1-26 & 48 & CARINATED BOWL & R58 & 10 & 30 \\
2 & 0258 & SE 1-26 & 48 & LEDGE RIM BOWL & R59 & 10 & 38 \\
3 & 0260 & SE 1-26 & 48 & LEDGE RIM BOWL & R53 & 14 & 38 \\
4 & 0239 & SE 1-26 & 48 & LEDGE RIM BOWL & R52 & 16 & 54 \\
5 & 0253 & SE 1-26 & 48 & LEDGE RIM BOWL & R59 & 9 & 26
\end{tabular}

\begin{tabular}{lllll}
\hline No Fabric Color & Core Orient & Core Color & Core Thick & Fabric \\
& & & Family
\end{tabular}

\begin{tabular}{|c|c|c|c|c|c|c|c|}
\hline $\begin{array}{l}1 \\
2 \\
3 \\
4 \\
5\end{array}$ & $\begin{array}{l}\text { PINK } \\
\text { PINK } \\
\text { PINK } \\
\text { PINK } \\
\text { LT REDDIS }\end{array}$ & ROWN & $\begin{array}{l}M \\
\text { IRR } \\
M \\
M \\
N\end{array}$ & $\begin{array}{l}\text { LG } \\
\text { LG } \\
G \\
\text { LG } \\
N\end{array}$ & $\begin{array}{l}3 \\
N \\
6 \\
4 \\
N\end{array}$ & & $\begin{array}{l}N \\
N \\
N \\
N \\
N\end{array}$ \\
\hline No & Treatment & $\begin{array}{l}\text { Treatment } \\
\text { Location }\end{array}$ & $\begin{array}{l}\text { Treatment } \\
\text { Cover }\end{array}$ & $\begin{array}{l}\text { Color } \\
\text { Interior }\end{array}$ & & $\begin{array}{l}\text { Color } \\
\text { Exterior }\end{array}$ & \\
\hline $\begin{array}{l}1 \\
2 \\
3 \\
4 \\
5\end{array}$ & $\begin{array}{l}S \\
S \\
S B \\
S \\
\text { UN }\end{array}$ & $\begin{array}{l}\text { IE } \\
\text { IR } \\
\text { IR } \\
\text { IR } \\
\text { N }\end{array}$ & $\begin{array}{l}A L L \\
A L L \\
A L L \\
A L L \\
N\end{array}$ & $\begin{array}{l}\text { RED } \\
\text { DK REDDISH } \\
\text { RED } \\
\text { DUSKY RED } \\
\text { N }\end{array}$ & BROWN & $\begin{array}{l}\text { RED } \\
N \\
N \\
N \\
N\end{array}$ & \\
\hline
\end{tabular}

\section{Other}

1 "Loosely carinated."

2 Burn?

3 Margin of wet-smoothing above dry scraping visible on exterior wall; possibly radially burnished.

$4 \quad$ Unique form; ridge; fine horizontal lines of smoothing, slip, and burnishing appear on interior face and rim; exterior face appears as series of descending ridges, which are wet-smoothed.

$5 \quad$ Irregular pattern of wet-smoothing on interior face; rim smoothed evenly and horizontally; stance questionable; Undrawn.

PLATE 94. FIELD A. PHASE 4B (EB III). 


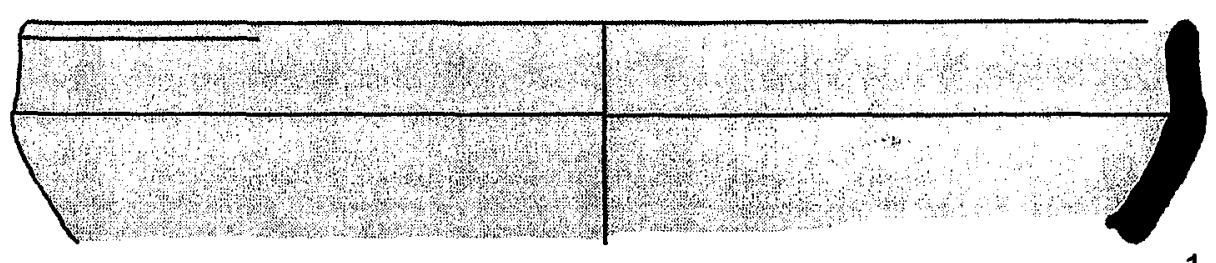

1
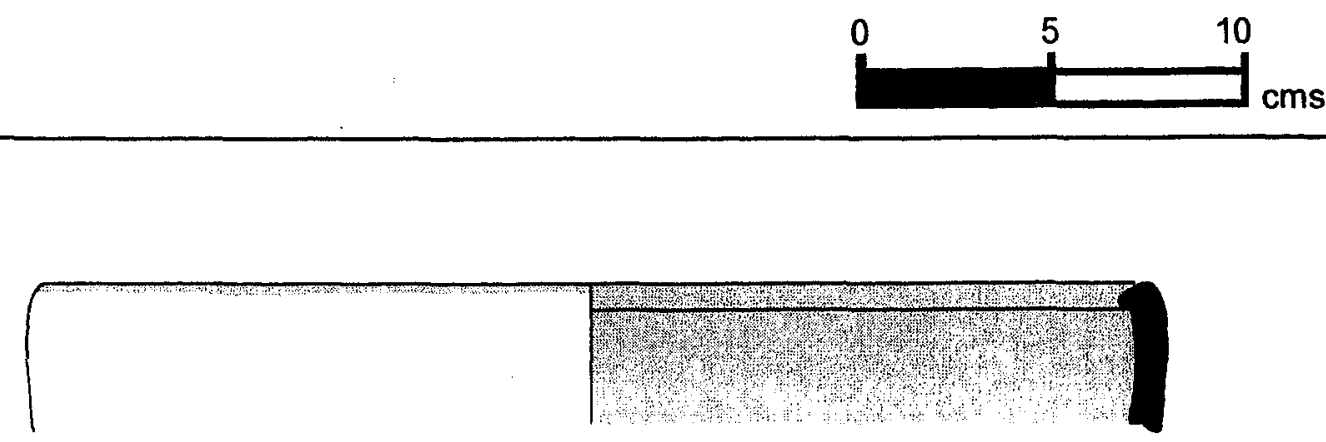

2

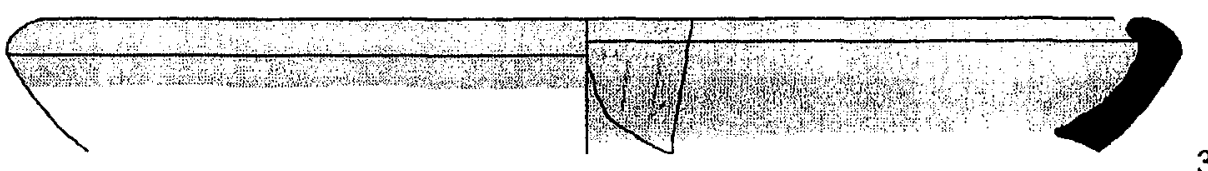

3
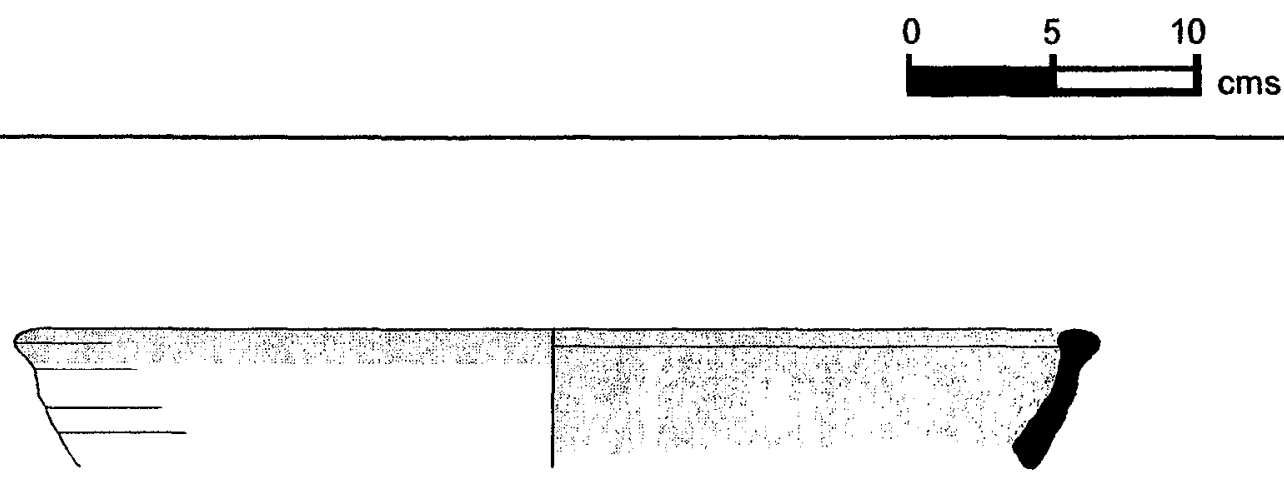

4

PLATE 94 (CONT.).

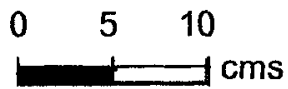


443

\begin{tabular}{llllllll}
\hline No & Reg & Square & Locus & Vessel & Part & $\begin{array}{l}\text { Body } \\
\text { Thick }\end{array}$ & Dia \\
& & & & & & & \\
\hline 1 & 0238 & SE 1-26 & 48 & HOLE MOUTH JAR & R20 & 13 & 15 \\
2 & 2287 & SE 1-26 & 48 & UD & BOD & 6 & $\mathrm{~N}$ \\
3 & 0252 & SE 1-26 & 48 & HOLE MOUTH JAR & R04 & 13 & 12 \\
4 & 0256 & SE 1-26 & 48 & UD & BOD & 12 & $\mathrm{~N}$ \\
5 & 0248 & SE 1-26 & 48 & HOLE MOUTH JAR & R19 & 15 & 15 \\
6 & 0247 & SE 1-26 & 48 & NECKED JAR & R43 & 14 & 16 \\
7 & 0255 & SE 1-26 & 48 & UD & BOD & 8 & N \\
8 & 0246 & SE 1-26 & 48 & NECKED JAR & R00 & 8 & 19 \\
9 & 2175 & SE 1-26 & 48 & UD & H20 & N & N \\
10 & 0249 & SE 1-26 & 48 & NECKED JAR & R31 & 11 & 20 \\
11 & 0236 & SE 1-26 & 48 & NECKED JAR & R31 & 11 & 24 \\
12 & 0262 & SE 1-26 & 48 & UD & B11 & 9 & 14 \\
13 & 0257 & SE 1-26 & 48 & UD & H12 & 8 & $N$ \\
14 & 0263 & SE 1-26 & 48 & UD & B12 & 11 & 13
\end{tabular}

\begin{tabular}{lllll}
\hline No Fabric Color & Core Orient Core Color Core Thick & Fabric \\
& & & Family
\end{tabular}

\begin{tabular}{|c|c|c|c|c|c|c|}
\hline 1 & \multicolumn{2}{|l|}{ PINK } & IRR & $\mathbf{G}$ & $\mathrm{N}$ & $\mathbf{N}$ \\
\hline 2 & \multicolumn{2}{|l|}{ PINK } & $\mathbb{N}$ & G & 3 & $\mathrm{~N}$ \\
\hline 3 & \multicolumn{2}{|l|}{ WEAK RED } & IRR & LG & $\mathbf{N}$ & $\mathbf{N}$ \\
\hline 4 & \multicolumn{2}{|l|}{ GREY } & IRR & LG & $\mathbf{N}$ & $\mathbf{N}$ \\
\hline 5 & \multicolumn{2}{|l|}{ PINK } & $\mathrm{N}$ & $\mathrm{N}$ & $\mathrm{N}$ & $\mathrm{N}$ \\
\hline 6 & \multicolumn{2}{|l|}{ PINK } & M & LG & 7 & $\mathbf{N}$ \\
\hline 7 & \multicolumn{2}{|l|}{ PINK } & IN & LG & 5 & $\mathbf{N}$ \\
\hline 8 & \multicolumn{2}{|l|}{ PINK } & M & G & 2 & $\mathbf{N}$ \\
\hline 9 & \multicolumn{2}{|l|}{ UD } & ALL & $\mathbf{G}$ & $\mathbf{N}$ & $\mathbf{N}$ \\
\hline 10 & \multicolumn{2}{|c|}{ LT REDDISH BROWN } & $\mathbf{N}$ & $\mathbf{N}$ & $\mathbf{N}$ & $\mathbf{N}$ \\
\hline 11 & \multicolumn{2}{|l|}{ PINK } & $N$ & $\mathbf{N}$ & $\mathrm{N}$ & $\mathrm{N}$ \\
\hline 12 & \multicolumn{2}{|l|}{ PINK } & $\mathrm{N}$ & $\mathbf{N}$ & $N$ & $\mathbf{N}$ \\
\hline 13 & \multicolumn{2}{|l|}{ PINK } & IRR & G & $\mathbf{N}$ & $\mathbf{N}$ \\
\hline 14 & \multicolumn{2}{|c|}{ LT REDDISH BROWN } & M & $\mathbf{G}$ & 5 & $N$ \\
\hline No & Treatment & $\begin{array}{l}\text { Treatment } \\
\text { Location }\end{array}$ & $\begin{array}{l}\text { Treatment } \\
\text { Cover }\end{array}$ & $\begin{array}{l}\text { Color } \\
\text { Interior }\end{array}$ & $\begin{array}{l}\text { Color } \\
\text { Exterior }\end{array}$ & \\
\hline 1 & UN & $\mathbf{N}$ & $N$ & $\mathbf{N}$ & $N$ & \\
\hline 2 & UN & $\mathrm{N}$ & $\mathbf{N}$ & $\mathbf{N}$ & $\mathrm{N}$ & \\
\hline 3 & UN & $\mathbf{N}$ & $\mathbf{N}$ & $\mathbf{N}$ & $\mathbf{N}$ & \\
\hline 4 & $\mathbf{s}$ & $E$ & ALL & $\mathbf{N}$ & RED & \\
\hline 5 & $\mathbf{S}$ & ER & ALL & $\mathbf{N}$ & RED & \\
\hline 6 & UN & $N$ & $\mathbf{N}$ & $\mathbf{N}$ & $\mathrm{N}$ & \\
\hline 7 & 1 & $E$ & ALL & $\mathbf{N}$ & $\mathrm{N}$ & \\
\hline 8 & UN & $\mathbf{N}$ & $\mathbf{N}$ & $\mathbf{N}$ & $\mathbf{N}$ & \\
\hline
\end{tabular}

PLATE 95. FIELD A. PHASE 4B (EB III). 
444

\begin{tabular}{llllll}
\hline No & Treatment & $\begin{array}{l}\text { Treatment } \\
\text { Location }\end{array}$ & $\begin{array}{l}\text { Treatment } \\
\text { Cover }\end{array}$ & $\begin{array}{l}\text { Color } \\
\text { Interior }\end{array}$ & $\begin{array}{l}\text { Color } \\
\text { Exterior }\end{array}$ \\
\hline 9 & SB & E & ALL & N & STRONG BROWN \\
10 & UD & IE & ALL & RED & RED \\
11 & S & IE & ALL & N & RED \\
12 & S & E & ALL & N & RED \\
13 & S & E & ALL & N & RED \\
14 & S & E & ALL & N & DUSKY RED \\
\hline
\end{tabular}

\section{Other}

2 Rope molding; Metallic Ware.

7 Combed Metallic Ware.

8 Fine lines of wet-smoothing are visible on interior and exterior bases. Intrusive.

9 Khirbet Kerak Ware.

PLATE 95 (CONT.). 

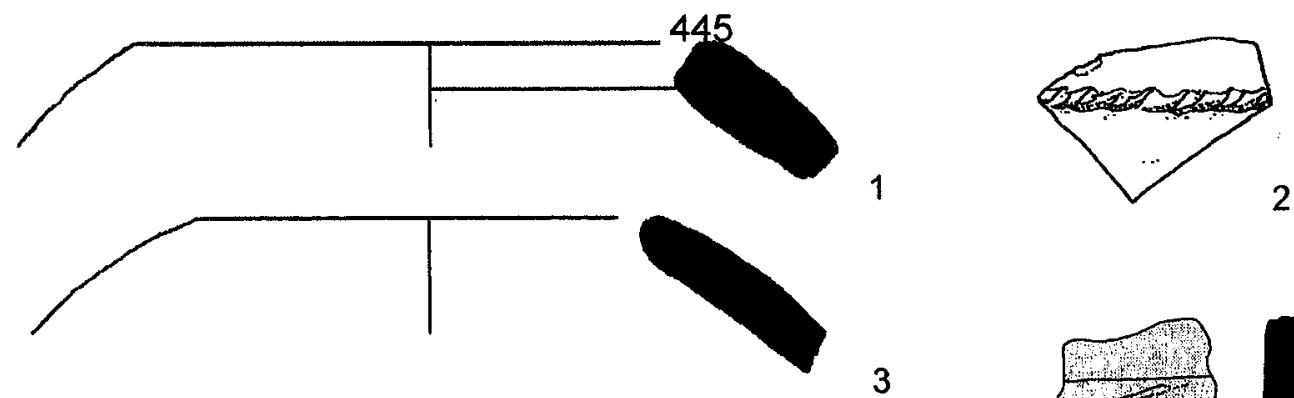

2
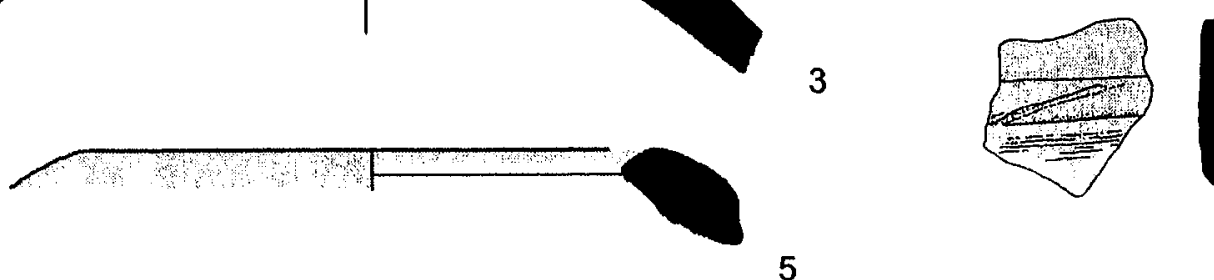

4
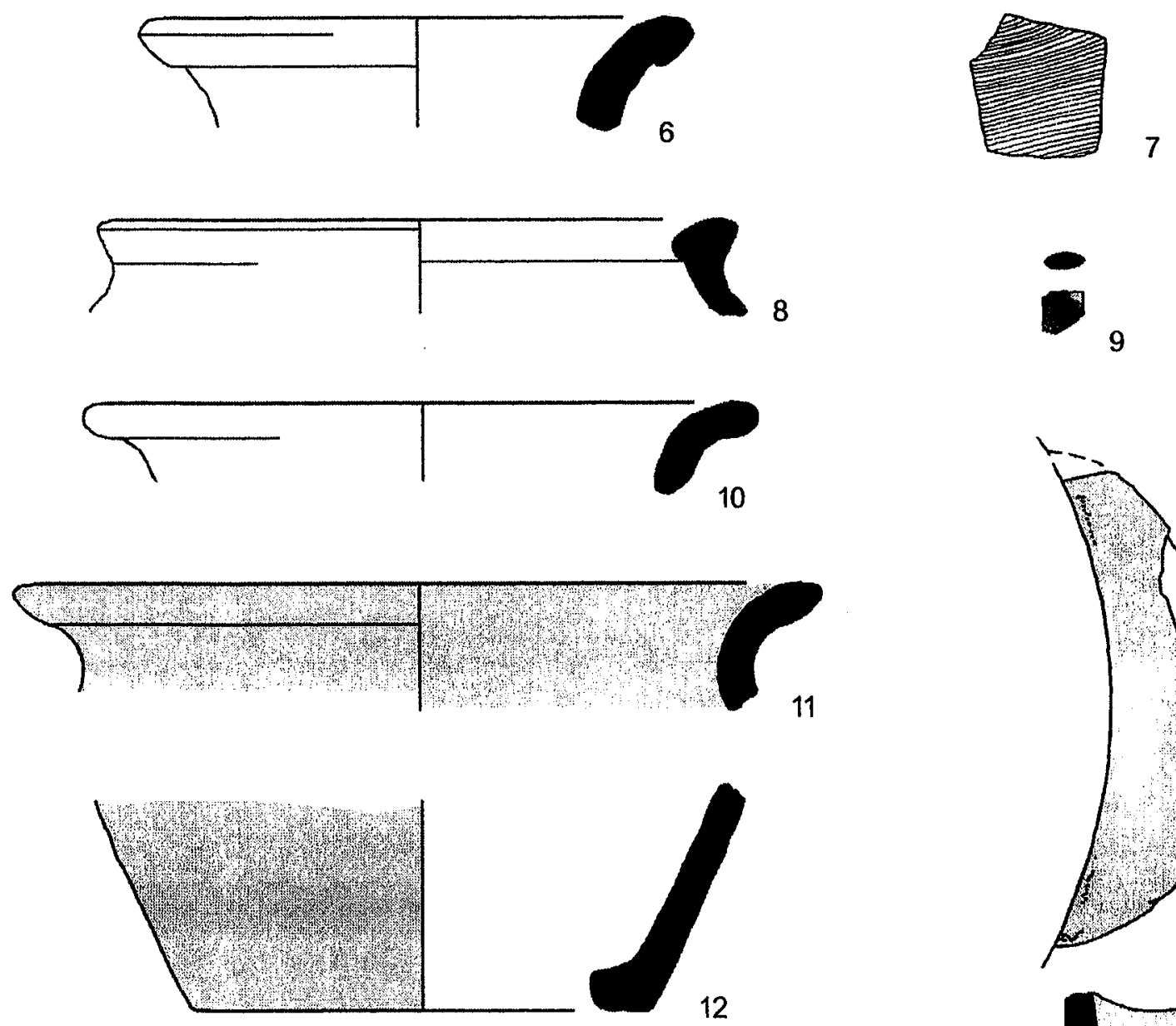

1
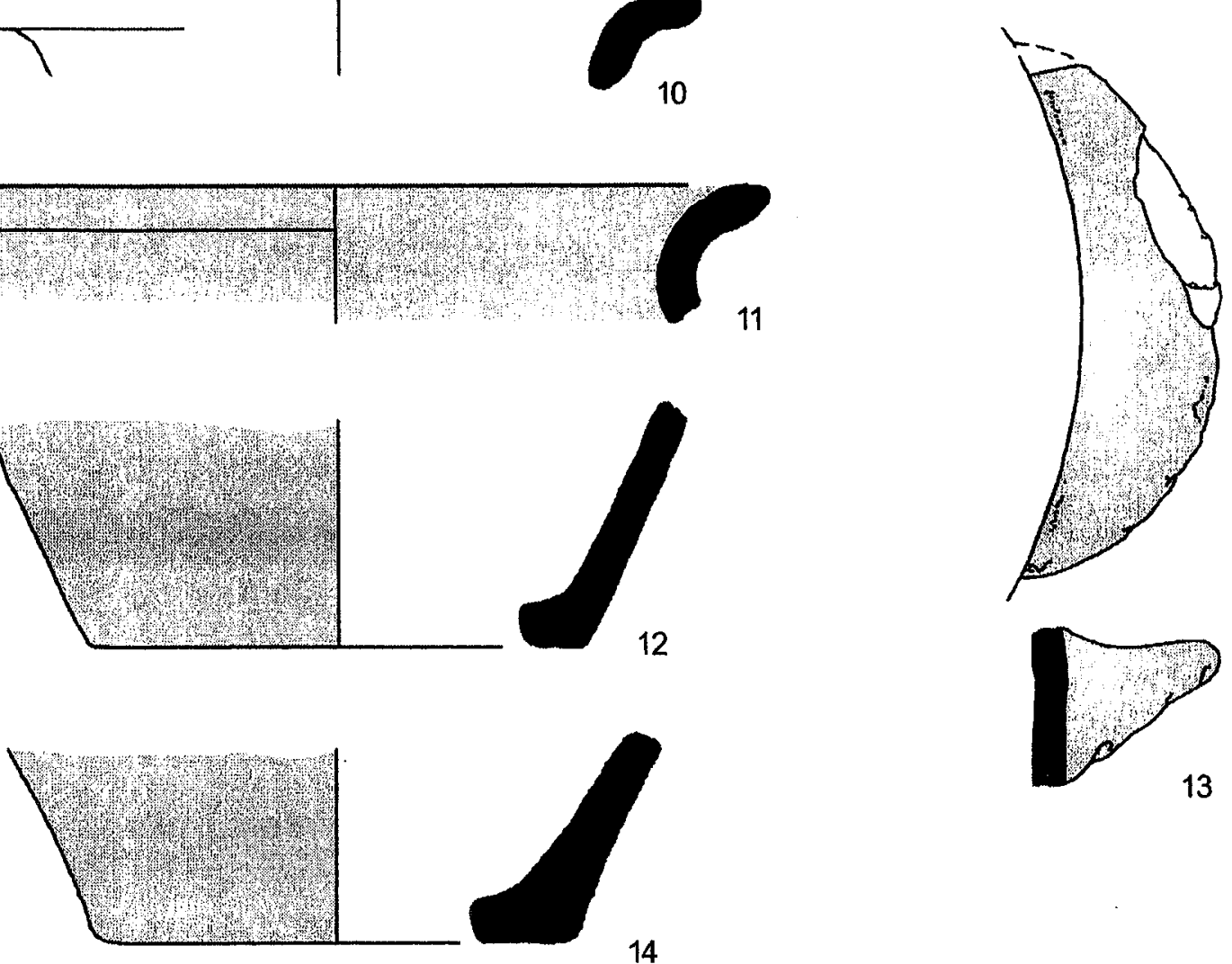

PLATE 95 (CONT.).

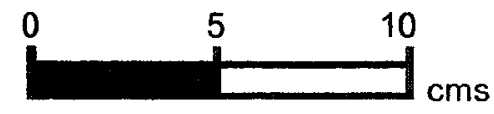




\begin{tabular}{lllllllll}
\hline No & Reg & Square & Locus & Vessel & Part & $\begin{array}{l}\text { Body } \\
\text { Thick }\end{array}$ & Dia \\
& & & & & & & \\
\hline & 0188 & SE 1-28 & 27 & LEDGE RIM BOWL & R60 & 12 & 18 \\
2 & 2228 & SE 1-28 & 27 & PLATTER BOWL & R54 & 7 & 25 \\
3 & 2237 & SE 1-28 & 27 & PLATTER BOWL & R53 & 7 & 32 \\
4 & 0199 & SE 1-28 & 27 & NECKED JAR & R43 & 8 & 28 \\
5 & 0195 & SE 1-28 & 27 & NECKED JAR & R32 & 8 & 14 \\
6 & 2449 & SE 1-28 & 27 & NECKED JAR & R40 & 15 & N \\
7 & 0224 & SE 1-28 & 27 & UD & H20 & 13 & N \\
8 & 0206 & SE 1-28 & 27 & UD & H27 & 8 & N \\
9 & 0207 & SE 1-28 & 27 & UD & H14 & 9 & N \\
10 & 0200 & SE 1-28 & 27 & UD & B12 & 13 & 15 \\
\hline No & Fabric Color & & Core Orient Core Color & Core Thick & Fabric \\
& & & & & & & Family
\end{tabular}

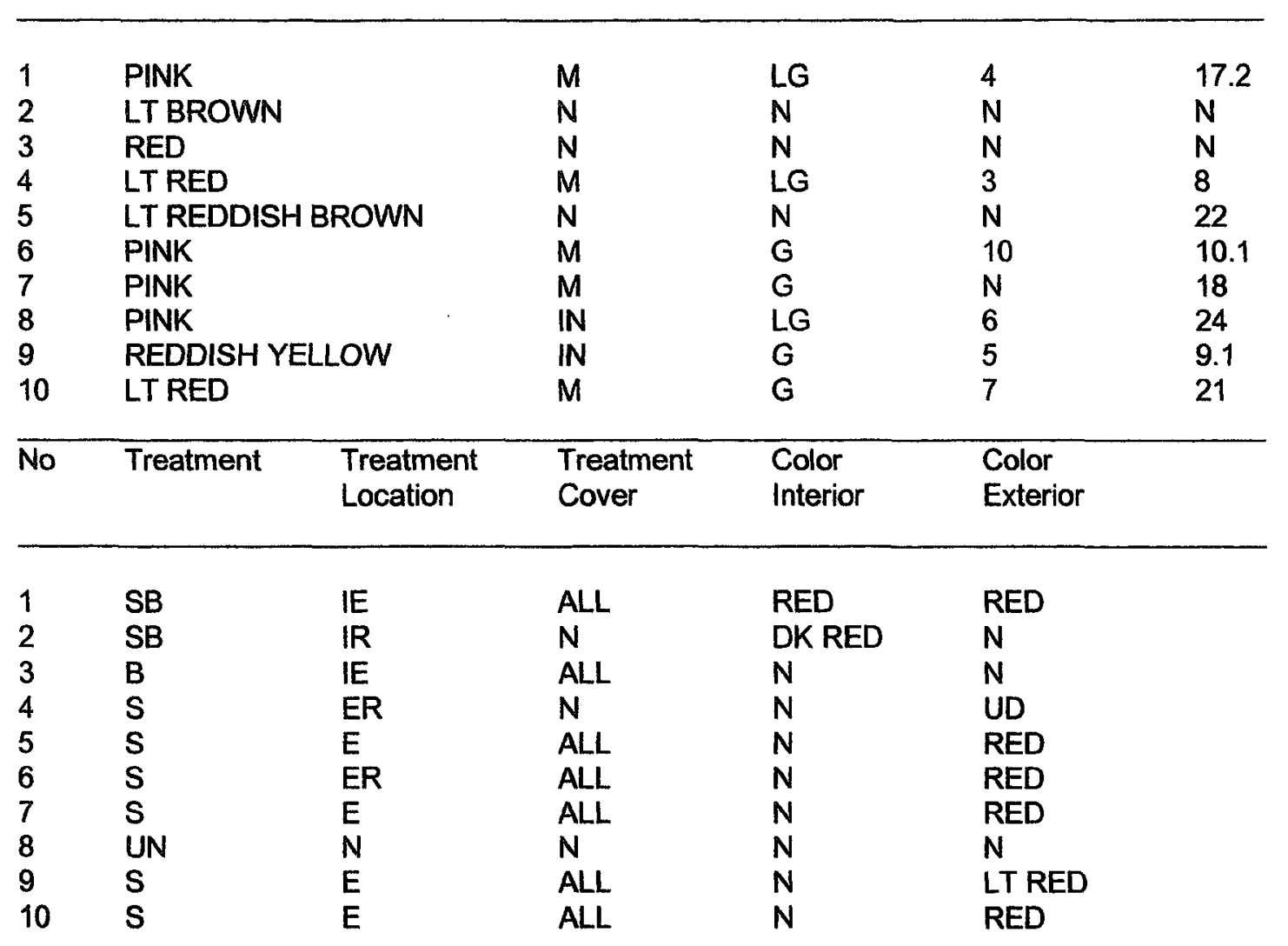

PLATE 96. FIELD A. PHASE 4B (EB III). 
Other

1 Possible radial burnish over slip on interior face; rim, well burnished; exterior face is unevenly smoothed with a very slight concavity under rim.

2 Sample too small to confirm stance or diameter.

$4 \quad$ Slip appears to cover only lip face; features in break suggest rim folding, smoothing.

6 Sample too small to confirm stance or diameter; thin section sample 9.

$7 \quad$ Vertical slashes on handle.

PLATE 96 (CONT.). 

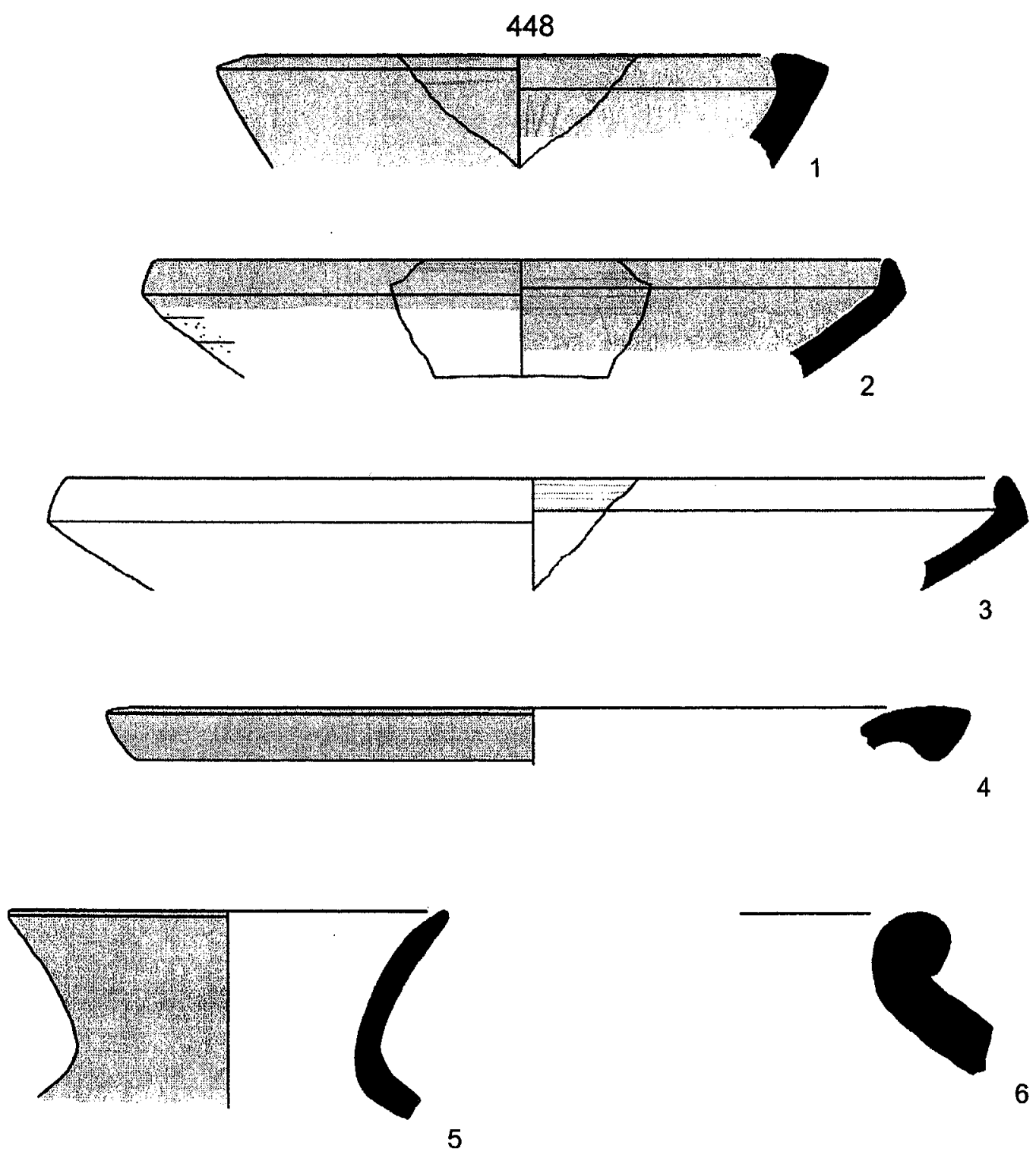

5
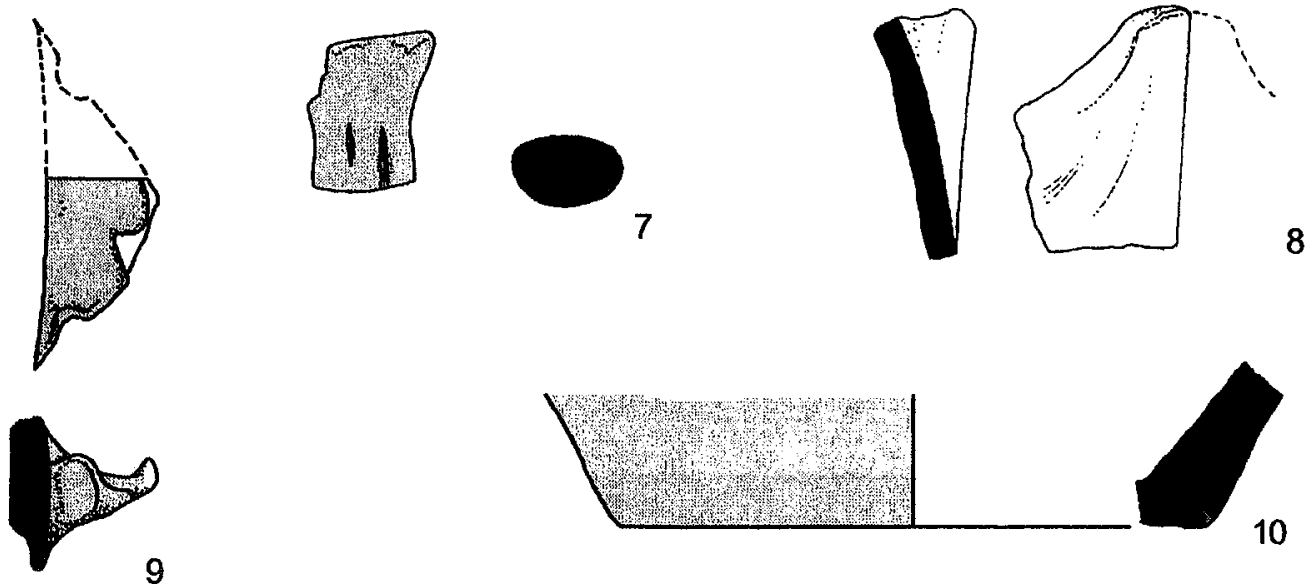

9

10

PLATE 96 (CONT.).

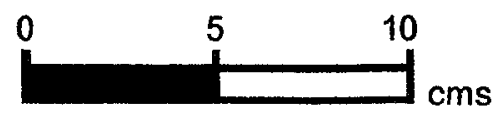




\begin{tabular}{llllllll}
\hline No & Reg & Square & Locus & Vessel & Part & $\begin{array}{l}\text { Body } \\
\text { Thick }\end{array}$ & Dia \\
\hline 1 & 0198 & SE 1-28 & 27 & HOLE MOUTH BOWL & R02 & 9 & 12 \\
2 & 0222 & SE 1-28 & 27 & HOLE MOUTH BOWL & R11 & 11 & 12 \\
3 & 2226 & SE 1-28 & 27 & HOLE MOUTH JARIBOWL & R04 & 14 & 15 \\
4 & 2232 & SE 1-28 & 27 & HOLE MOUTH JARIBOWL & R11 & N & N \\
5 & 2231 & SE 1-28 & 27 & HOLE MOUTH JARIBOWL & R09 & N & N \\
6 & 2233 & SE 1-28 & 27 & HOLE MOUTH JARIBOWL & R04 & N & 15 \\
7 & 2472 & SE 1-28 & 27 & PLATTER BOWL & R56 & 12 & N \\
8 & 0202 & SE 1-28 & 27 & PLATTER BOWL & R56 & 10 & 38 \\
9 & 0201 & SE 1-28 & 27 & PLATTER BOWL & R56 & 14 & 50 \\
10 & 0203 & SE 1-28 & 27 & PLATTER BOWL & R55 & 11 & 45 \\
11 & 0204 & SE 1-28 & 27 & PLATTER BOWL & R56 & 10 & 40
\end{tabular}

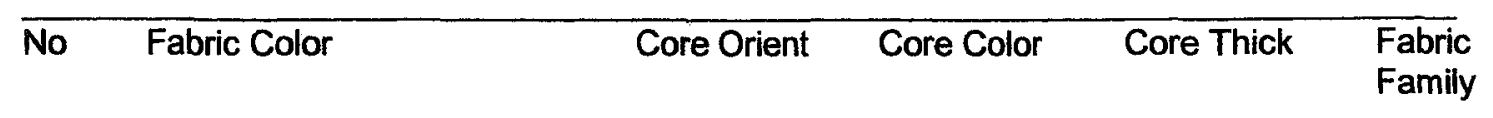

\begin{tabular}{|c|c|c|c|c|c|c|c|}
\hline 1 & \multirow{2}{*}{\multicolumn{2}{|c|}{ REDDISH BROWN }} & ALL & G & $N$ & & 4 \\
\hline 2 & & & $\mathbf{M}$ & G & 5 & & $\mathbf{N}$ \\
\hline 3 & & IRR & $\mathbf{G}$ & $\mathbf{N}$ & & $\mathbf{N}$ \\
\hline 4 & \multicolumn{2}{|c|}{$\begin{array}{l}\text { REDDISH BROWN } \\
\text { LT REDDISH BROWN }\end{array}$} & $M$ & $\mathbf{G}$ & $\mathbf{N}$ & & $\mathbf{N}$ \\
\hline 5 & \multicolumn{2}{|c|}{ REDDISH BROWN } & $\mathbf{N}$ & $\mathrm{N}$ & $\mathrm{N}$ & & $N$ \\
\hline 6 & \multicolumn{2}{|l|}{ BROWN } & $M$ & G & $\mathrm{N}$ & & $\mathbf{N}$ \\
\hline 7 & \multicolumn{2}{|c|}{ LT REDDISH BROWN } & $\mathrm{N}$ & $\mathbf{N}$ & $\mathbf{N}$ & & 4 \\
\hline 8 & \multicolumn{2}{|c|}{ PINK } & $\mathrm{N}$ & $\mathbf{N}$ & $\mathrm{N}$ & & $\mathrm{N}$ \\
\hline 9 & \multicolumn{2}{|c|}{ LT REDDISH BROWN } & $\mathrm{N}$ & $\mathrm{N}$ & $\mathrm{N}$ & & 24 \\
\hline 10 & \multicolumn{2}{|c|}{ PINK } & $\mathrm{N}$ & $N$ & $N$ & & 23 \\
\hline 11 & \multicolumn{2}{|l|}{ LT BROWN } & N & $\mathbf{N}$ & $N$ & & $\mathrm{~N}$ \\
\hline$\overline{N o}$ & Treatment & $\begin{array}{l}\text { Treatment } \\
\text { Location }\end{array}$ & $\begin{array}{l}\text { Treatment } \\
\text { Cover }\end{array}$ & $\begin{array}{l}\text { Color } \\
\text { Interior }\end{array}$ & & $\begin{array}{l}\text { Color } \\
\text { Exterio }\end{array}$ & \\
\hline 1 & UN & $\mathrm{N}$ & $\mathbf{N}$ & $\mathbf{N}$ & & $\mathbf{N}$ & \\
\hline 2 & UN & $\mathrm{N}$ & $\mathrm{N}$ & $\mathbf{N}$ & & $\mathrm{N}$ & \\
\hline 3 & UN & $\mathrm{N}$ & $\mathbf{N}$ & $\mathrm{N}$ & & $\mathbf{N}$ & \\
\hline 4 & UN & $\mathbf{N}$ & $\mathbf{N}$ & $\mathbf{N}$ & & $\mathbf{N}$ & \\
\hline 5 & UN & $\mathrm{N}$ & $N$ & $\mathbf{N}$ & & $\mathbf{N}$ & \\
\hline 6 & UN & $N$ & $\mathbf{N}$ & $\mathbf{N}$ & & $\mathbf{N}$ & \\
\hline 7 & SB & IR & ALL & REDDI & JWN & $\mathbf{N}$ & \\
\hline 8 & SB & $\mathbb{R}$ & ALL & RED & & $\mathbf{N}$ & \\
\hline 9 & UD & $\mathrm{N}$ & $\mathbf{N}$ & $\mathbf{N}$ & & $\mathbf{N}$ & \\
\hline 10 & SB & IR & ALL & RED & & $\mathbf{N}$ & \\
\hline 11 & SB & IR & ALL & DK REI & & $\mathbf{N}$ & \\
\hline
\end{tabular}

PLATE 97. FIELD A. PHASE 4B (EB III). 
Other

3 Sample too small to confirm stance or diameter.

4 Sample too small to confirm stance or diameter.

5 Sample too small to confirm stance or diameter; surface burn visible.

6 Surface burn visible; sample too small to confirm stance or diameter.

7 Thin section sample 23; sample too small to confirm stance or diameter.

8 Slip appears to have been applied in a large circular motion, parallel to vessel rim; burnish on interior face is carefully executed in a pattern of diagonal and horizontal motions; base is roughly burnished, but unslipped.

9 Marks on exterior face show dry scraping; a wet-smoothed marginal band appears under rim; weathered.

10 Radial burnish on platter face; wheel burnish on rim; on exterior face is an excellent example of the dry scraped base and wet-smoothed margin.

11 Faint marks a wet-smoothed marginal concavity below rim; possible net burnish on interior face.

PLATE 97 (CONT.). 

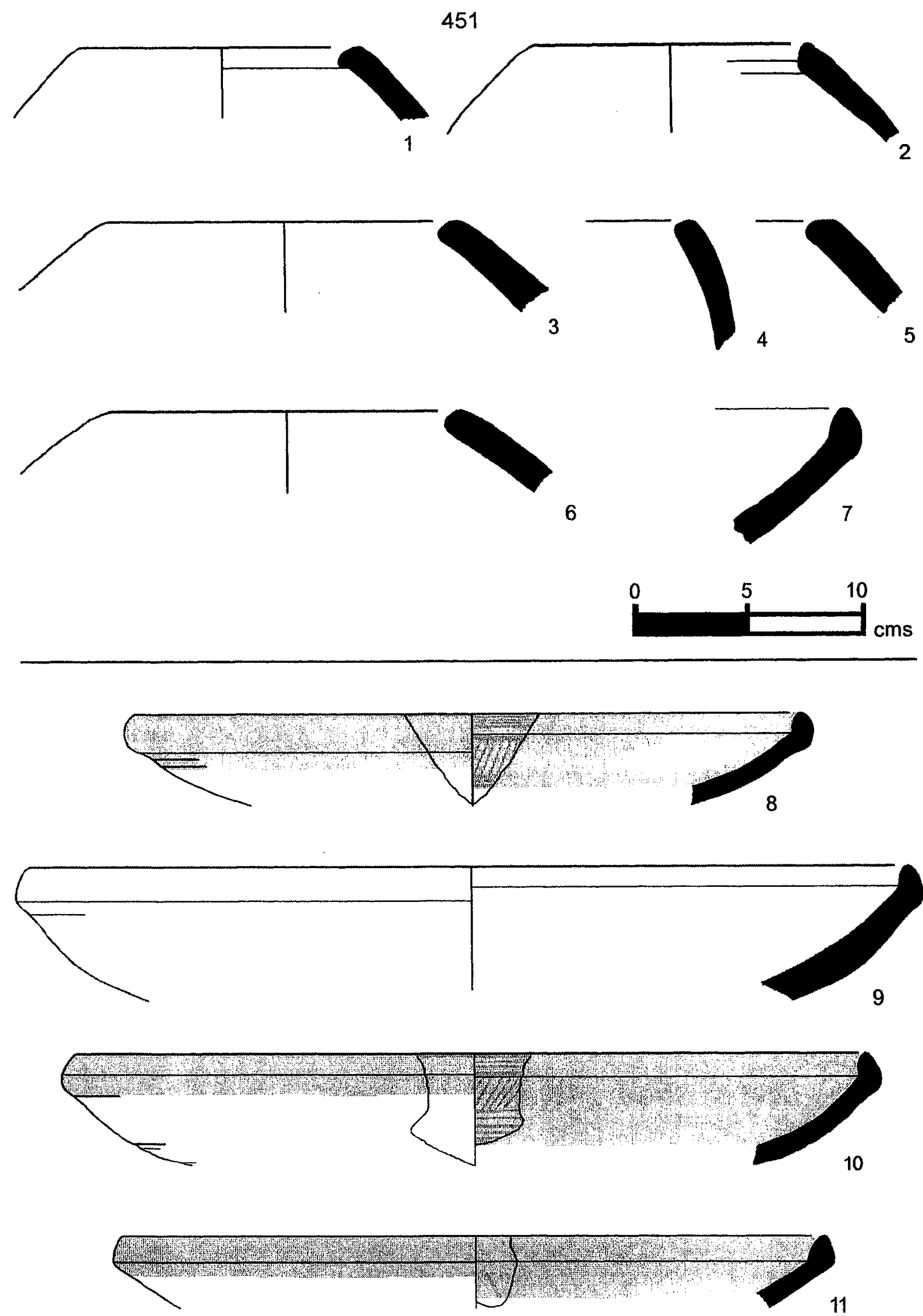

PLATE 97 (CONT.).

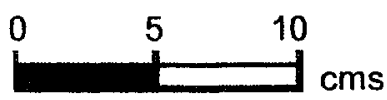




\begin{tabular}{llllllll}
\hline No & Reg & Square & Locus & Vessel & Part & $\begin{array}{c}\text { Body } \\
\text { Thick }\end{array}$ & Dia \\
& & & & & & & \\
1 & 0348 & SW 1-26 & 155 & PLATTER BOWL & R56 & 12 & 36 \\
2 & 0304 & SW 1-26 & 155 & HOLE MOUTH JAR & R02 & 12 & 18 \\
3 & 0305 & SW 1-26 & 155 & HOLE MOUTH JARIBOWL & R11 & 9 & 14 \\
4 & 0347 & SW 1-26 & 155 & NECKED JAR & R31 & 6 & 10 \\
5 & 0349 & SW 1-26 & 155 & UD & H27 & 8 & N \\
6 & 0292 & SW 1-26 & 158 & UD & B10 & 16 & 7 \\
7 & 0350 & SW 1-26 & 155 & UD & B12 & 9 & 7 \\
8 & 0346 & SW 1-26 & 155 & PLATTER BOWL & R53 & 13 & 42 \\
\hline No & Fabric Color & & Core Orient Core Color & Core Thick & Fabric \\
& & & & & & Family
\end{tabular}

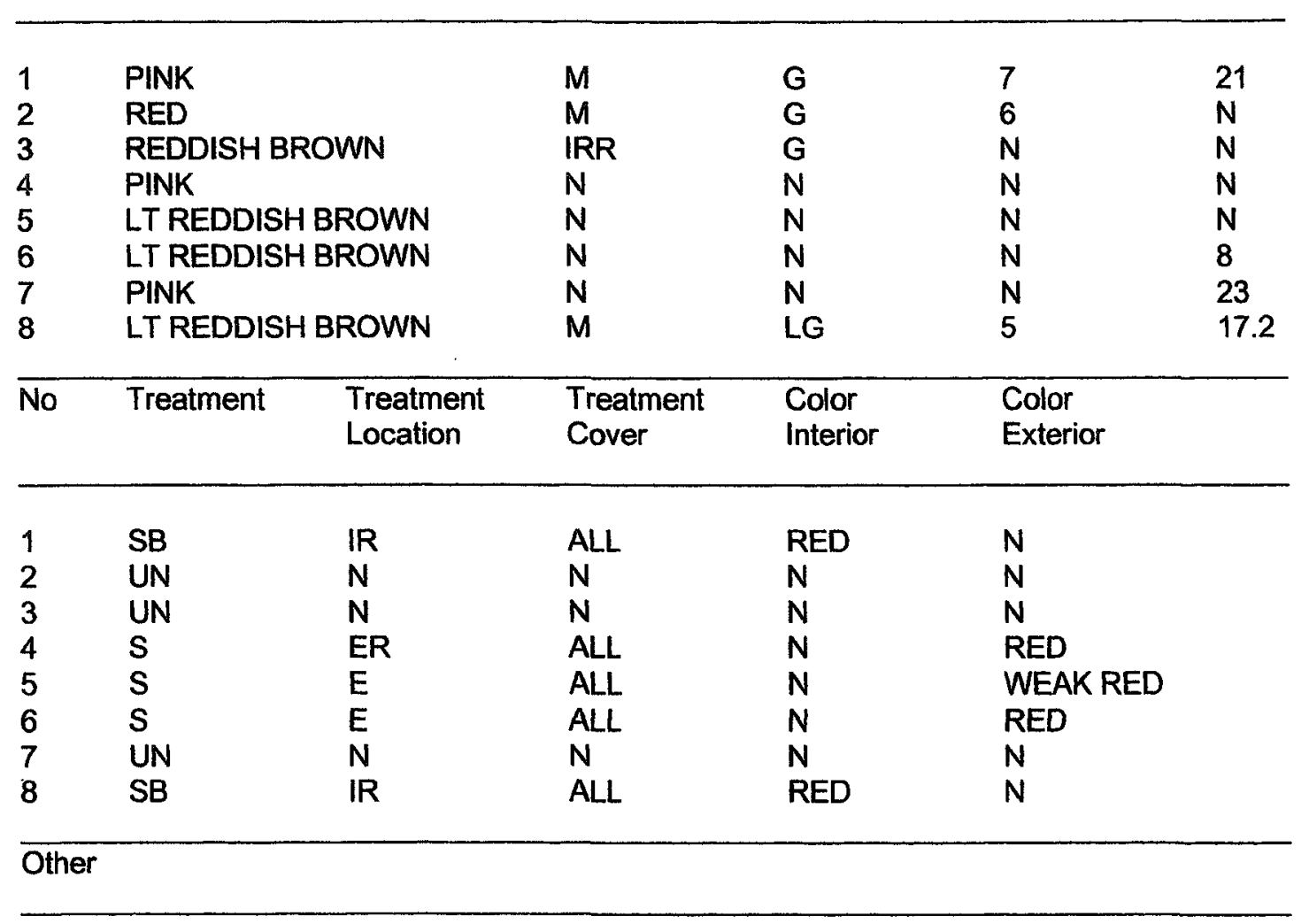

1 Radial burnish over red slip.

2 Surface burn visible.

3 Surface burn visible; sample too small to confirm stance or diameter.

$7 \quad$ Omphalos in interior.

PLATE 98. FIELD A. PHASE 4B (EB III). 

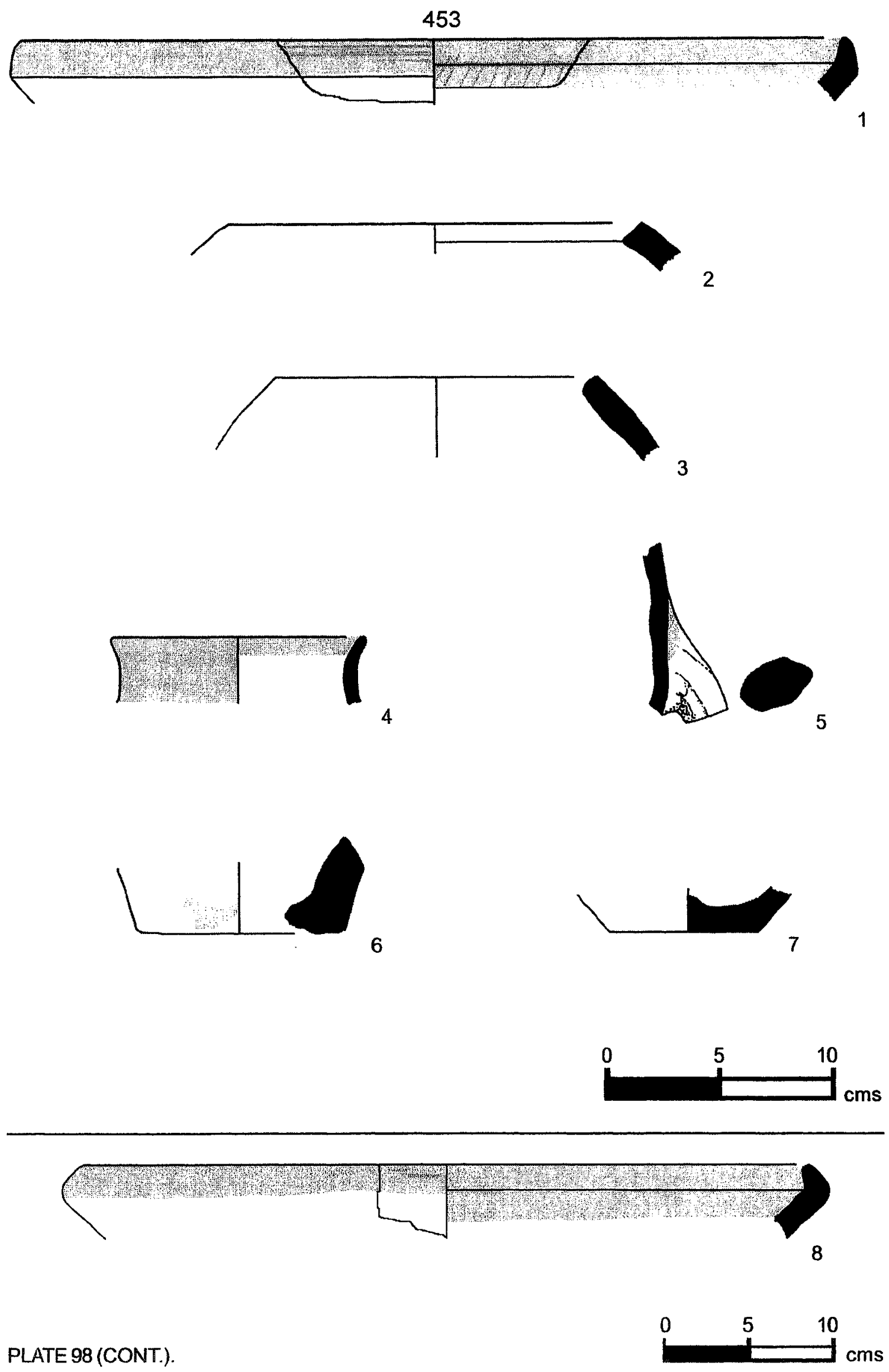


\begin{tabular}{lllllllll}
\hline No & Reg & Square & Locus & Vessel & Part & $\begin{array}{l}\text { Body } \\
\text { Thick }\end{array}$ & Dia \\
\hline & & & & & & & \\
1 & 0299 & SW 1-26 & 167 & BOWL & R50 & 5 & 13 \\
2 & 0288 & SW 1-26 & 160 & LEDGE RIM BOWL & R53 & 10 & 21 \\
3 & 2246 & SW 1-26 & 167 & HOLE MOUTH JARIBOWL & R01 & N & 15 \\
4 & 2244 & SW 1-26 & 167 & NECKED JAR & R31 & N & 11 \\
5 & 2247 & SW 1-26 & 167 & HOLE MOUTH JARIBOWL & R01 & 8 & 14 \\
6 & 0300 & SW 1-26 & 167 & NECKED JAR & R43 & 9 & 13 \\
7 & 2162 & SW 1-26 & 160 & UD & R82 & 6 & 16 \\
8 & 0342 & SW 1-26 & 163 & CARINATED BOWL & R81 & 4 & 8 \\
9 & 2161 & SW 1-26 & 160 & UD & R82 & 5 & 16 \\
10 & 0302 & SW 1-26 & 167 & JUG & B13 & 9 & 6 \\
11 & 0301 & SW 1-26 & 167 & LEDGE RIM BOWL & R59 & 9 & 58 \\
\hline No & Fabric Color & & Core Orient Core Color & Core Thick & Fabric \\
& & & & & & & Family
\end{tabular}

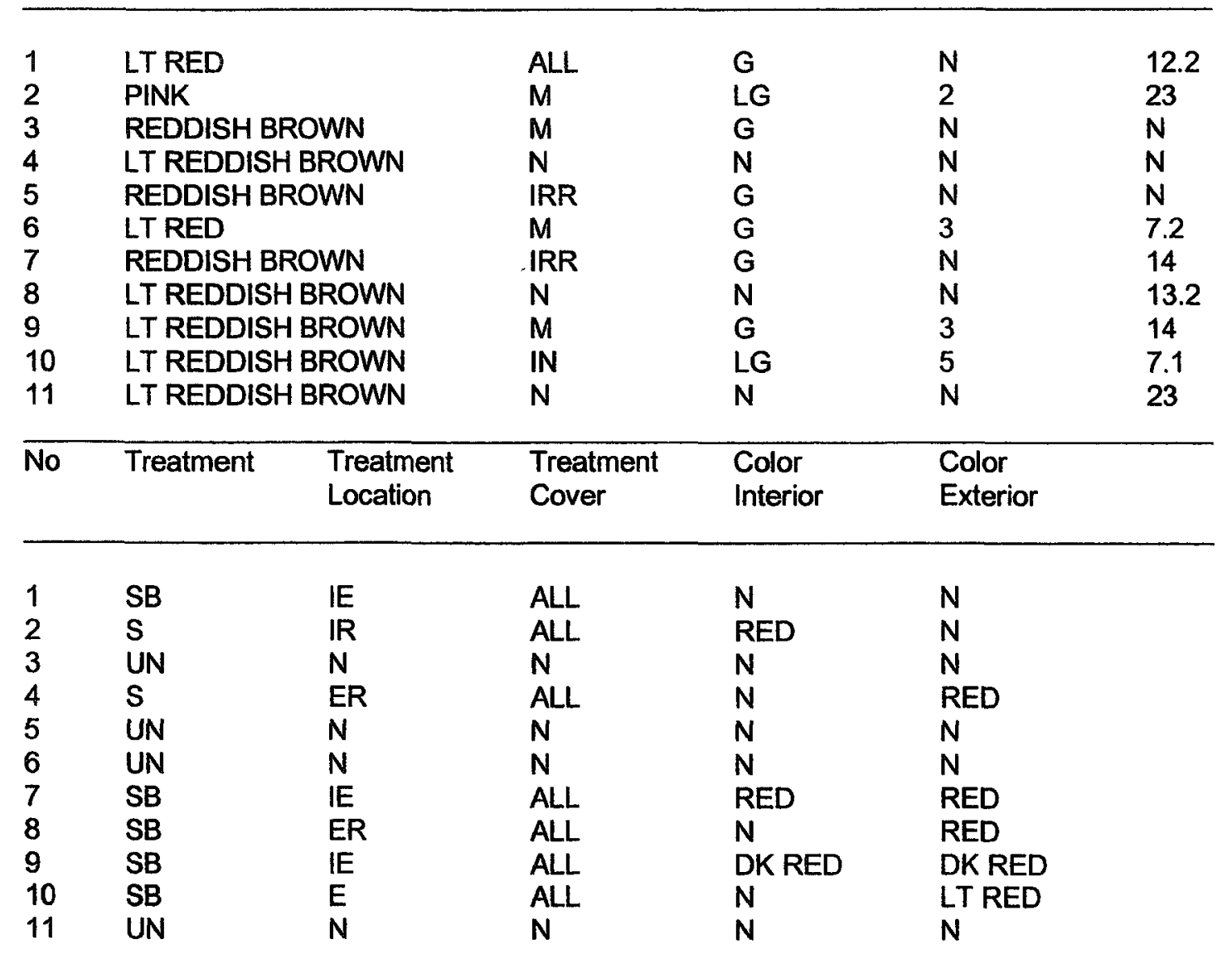

PLATE 99. FIELD A. PHASE IVB (EB III). 


\section{Other}

$1 \quad$ Double groove inside rim interior.

3 Sample too small to confirm stance or diameter; surface burn visible.

5 Sample too small to confirm stance or diameter.

$7 \quad$ Khirbet Kerak Ware.

8 Khirbet Kerak Ware.

$9 \quad$ Khirbet Kerak Ware.

PLATE 99 (CONT.). 

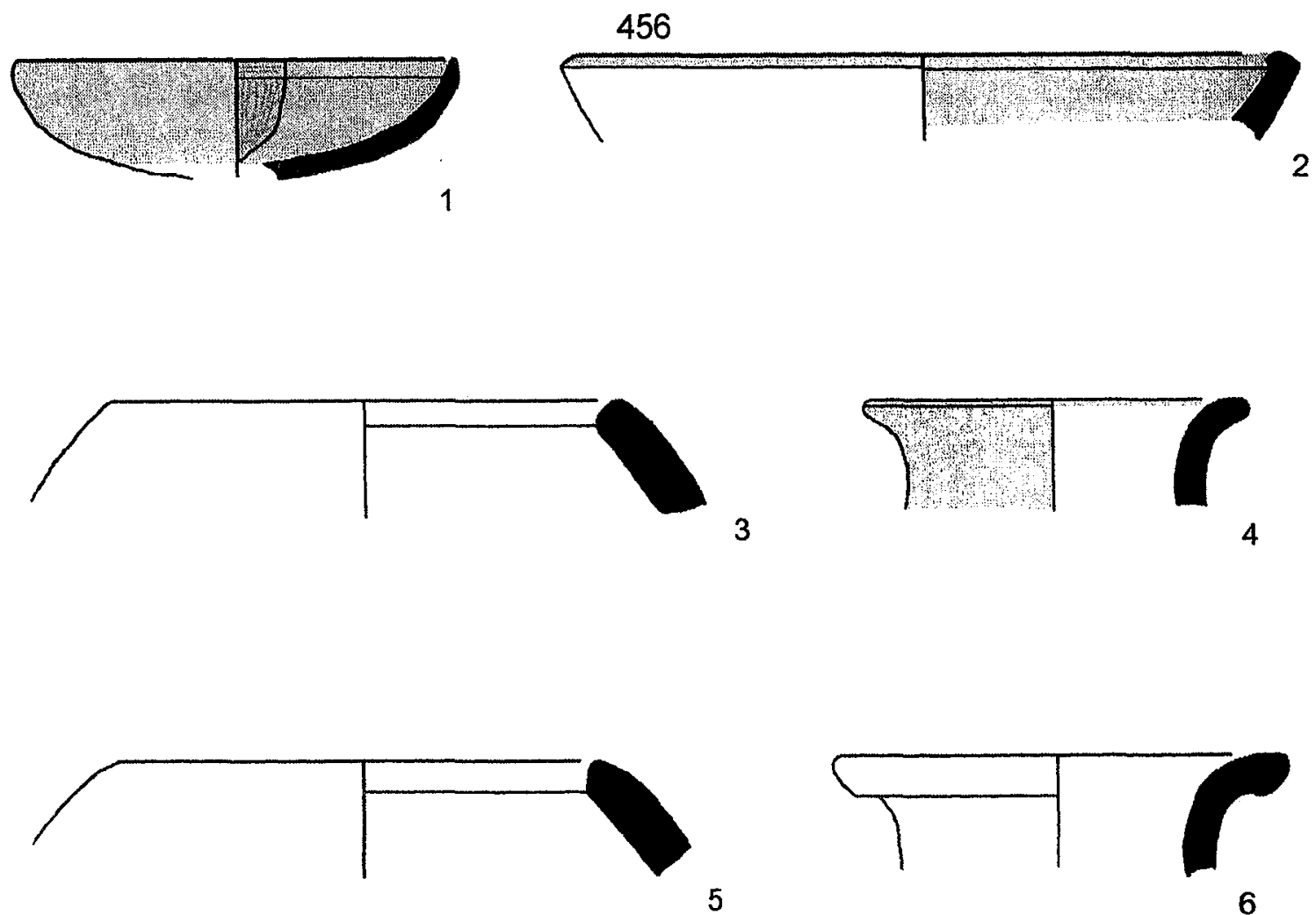

5

6
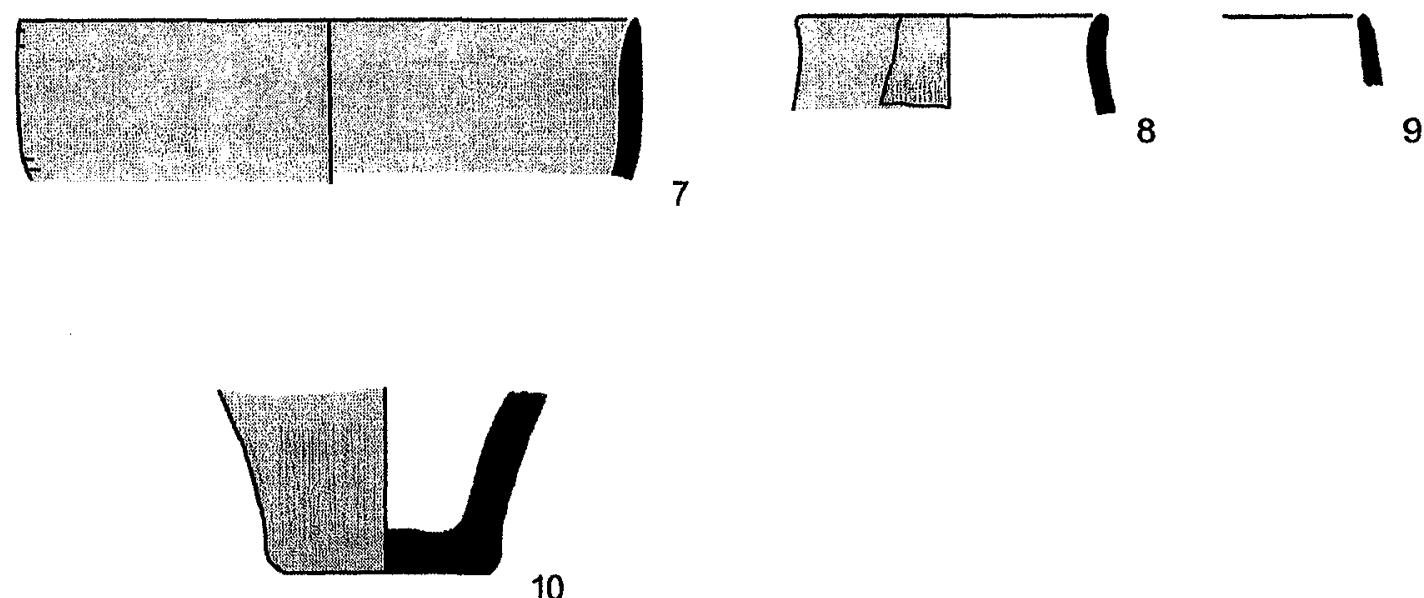

10
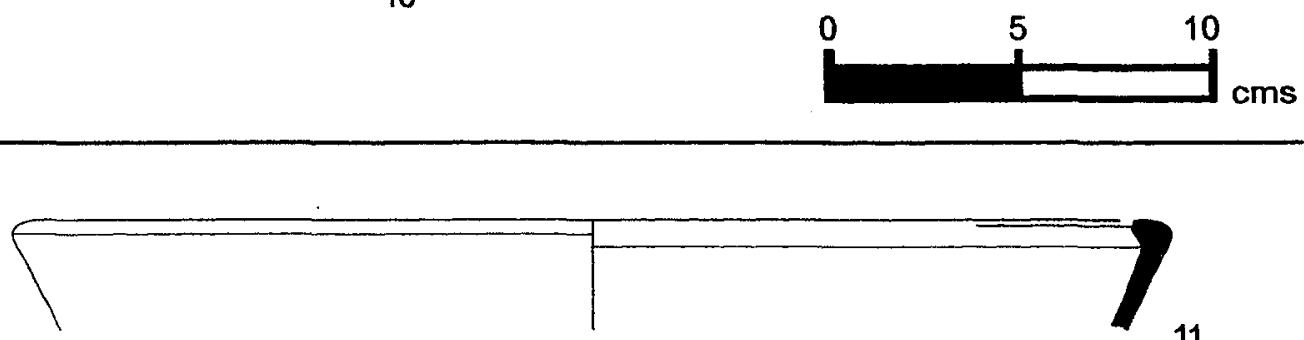

PLATE 99 (CONT.). 


\begin{tabular}{|c|c|c|c|c|c|c|c|}
\hline No & Reg & Square & Locus & Vessel & Part & $\begin{array}{l}\text { Body } \\
\text { Thick }\end{array}$ & $\overline{\text { Dia }}$ \\
\hline 1 & 0356 & SW 1-26 & 169 & NECKED JAR & R31 & 8 & 16 \\
\hline 2 & 0363 & SW 1-26 & 169 & NECKED JAR & R31 & 10 & 14 \\
\hline 3 & 0357 & SW $1-26$ & 169 & NECKED JAR & R42 & 9 & 20 \\
\hline 4 & 0358 & SW 1-26 & 169 & NECKED JAR & R42 & 12 & 18 \\
\hline 5 & 0362 & SW 1-26 & 169 & NECKED JAR & R43 & 7 & 12 \\
\hline 6 & 0364 & SW 1-26 & 169 & JUG & $\mathrm{H} 2 \mathrm{O}$ & 6 & $\mathbf{N}$ \\
\hline 7 & 0360 & SW 1-26 & 169 & BOWL & R50 & 14 & 38 \\
\hline 8 & 0361 & SW 1-26 & 169 & PLATTER BOWL & R54 & 11 & 45 \\
\hline
\end{tabular}

\begin{tabular}{|c|c|c|c|c|c|c|}
\hline 1 & \multicolumn{2}{|c|}{ LT REDDISH BROWN } & $M$ & $\mathbf{G}$ & 4 & N \\
\hline 2 & \multicolumn{2}{|c|}{ LT RED } & $M$ & G & 4 & $\mathbf{N}$ \\
\hline 3 & \multicolumn{2}{|l|}{ PINK } & ALL & G & $\mathrm{N}$ & $\mathbf{N}$ \\
\hline 4 & \multicolumn{2}{|l|}{ PINK } & $\mathbf{N}$ & $\mathbf{N}$ & $\mathbf{N}$ & $\mathbf{N}$ \\
\hline 5 & \multicolumn{2}{|c|}{ LT REDDISH BROWN } & IRR & G & $\mathrm{N}$ & $\mathrm{N}$ \\
\hline 6 & \multicolumn{2}{|c|}{ PINK } & $\mathbf{N}$ & $\mathbf{N}$ & $\mathbf{N}$ & $\mathbf{N}$ \\
\hline 7 & \multicolumn{2}{|l|}{ PINK } & $\mathbf{N}$ & $\mathbf{N}$ & N & $\mathbf{N}$ \\
\hline 8 & \multicolumn{2}{|l|}{ LTRED } & $\mathbf{N}$ & $\mathbf{N}$ & $N$ & $\mathrm{~N}$ \\
\hline No & Treatment & $\begin{array}{l}\text { Treatment } \\
\text { Location }\end{array}$ & $\begin{array}{l}\text { Treatment } \\
\text { Cover }\end{array}$ & $\begin{array}{l}\text { Color } \\
\text { Interior }\end{array}$ & $\begin{array}{l}\text { Color } \\
\text { Exterior }\end{array}$ & \\
\hline 1 & WASH & ER & ALL & $\mathbf{N}$ & GREYWHITE & \\
\hline 2 & UN & $N$ & $\mathbf{N}$ & $\mathrm{N}$ & & \\
\hline 3 & UN & $\mathrm{N}$ & $\mathrm{N}$ & $\mathbf{N}$ & $\mathbf{N}$ & \\
\hline 4 & $S$ & ER & ALL & $N$ & RED & \\
\hline 5 & UN & $N$ & $N$ & $N$ & $N$ & \\
\hline 6 & SB & $E$ & ALL & $\mathbf{N}$ & DK RED & \\
\hline 7 & SB & IE & PATCH & RED & RED & \\
\hline 8 & SB & IR & ALL & RED & $\mathbf{N}$ & \\
\hline
\end{tabular}

\footnotetext{
1 Surface burn visible.

$4 \quad$ Features in break suggest rim folding.

$7 \quad$ Fine turning lines visible on interiorlexterior rim; patterns of horizontalldiagonal slip lines on interior face; upper exterior face is wet-smoothed, slip, and burnished; lower exterior face appears scraped.

8 Very weathered.
}

PLATE 100. FIELD A. PHASE 4B (EB III). 

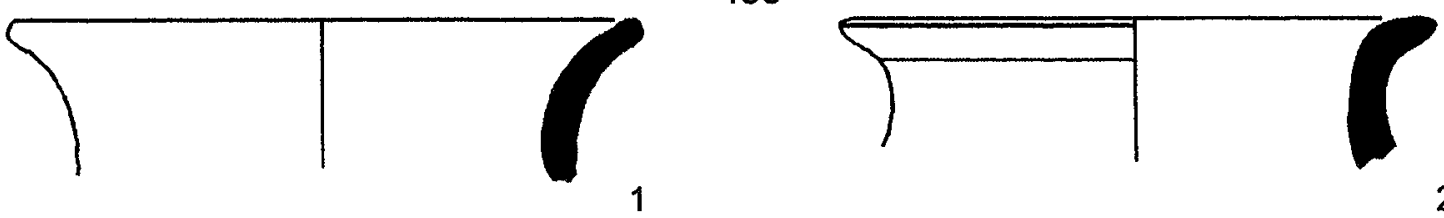

2

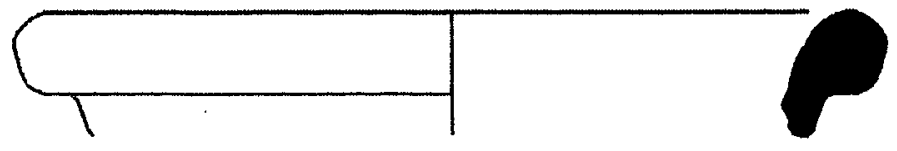

3
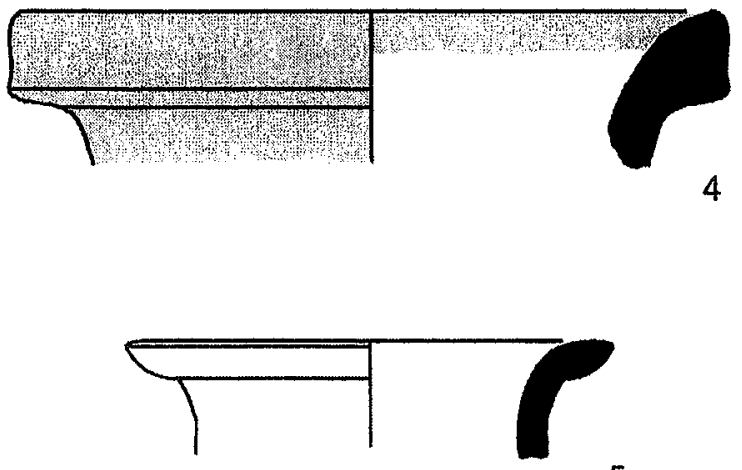

5

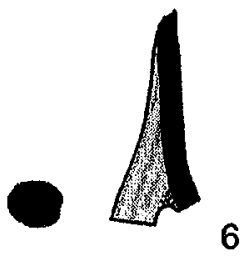

6
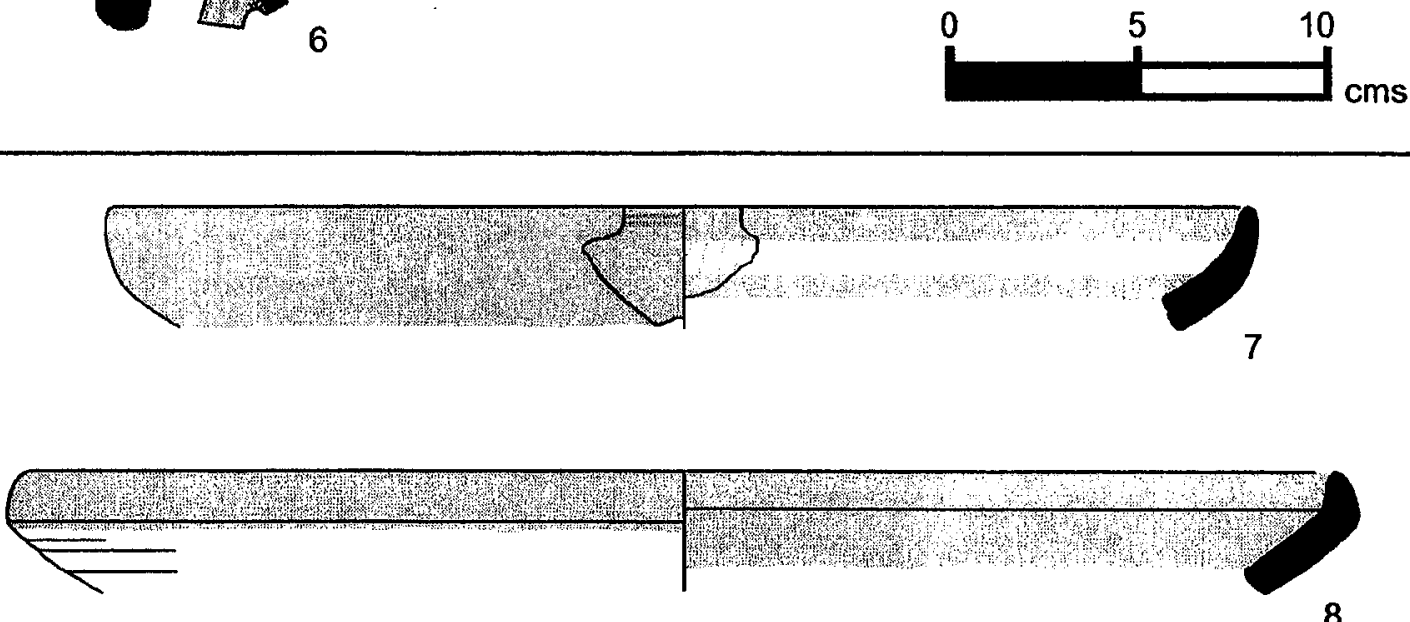

8

PLATE 100 (CONT.).

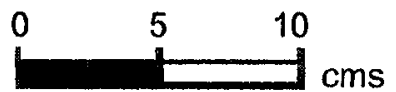




\begin{tabular}{llllllll}
\hline No & Reg & Square & Locus & Vessel & Part & $\begin{array}{l}\text { Body } \\
\text { Thick }\end{array}$ & Dia \\
\hline & & & & & & & \\
1 & 0369 & SW 1-26 & 170 & BOWL & R50 & 6 & 20 \\
2 & 2264 & SW 2-27 & 34 & BOWL & R50 & 5 & 10 \\
3 & 0366 & SW 1-26 & 170 & BOWL & R50 & 6 & 19 \\
4 & 2265 & SW 2-27 & 34 & BOWL & R50 & N & N \\
5 & 0365 & SW 1-26 & 170 & NECKED JAR & R31 & 10 & 24 \\
6 & 0602 & SW 2-26 & 80 & SINUOUS SIDED JAR & R81 & 6 & 8 \\
7 & 0660 & SW 2-27 & 34 & HOLE MOUTH BOWL & R11 & 8 & 17 \\
8 & 0368 & SW 1-26 & 170 & HOLE MOUTH JARIBOWL & R09 & 14 & 18 \\
9 & 0367 & SW 1-26 & 170 & LEDGE RIM BOWL & R51 & 11 & 48
\end{tabular}

\begin{tabular}{llll}
\hline No Fabric Color Core Orient Core Color Core Thick Fabric & Family
\end{tabular}

\begin{tabular}{|c|c|c|c|c|c|c|}
\hline $\begin{array}{l}1 \\
2 \\
3 \\
4 \\
5 \\
6 \\
7 \\
8 \\
9\end{array}$ & $\begin{array}{l}\text { LT REDDIS } \\
\text { LT REDDISI } \\
\text { PINK } \\
\text { LT RED } \\
\text { LT REDDIS } \\
\text { UD } \\
\text { PALE RED } \\
\text { RED } \\
\text { LT RED }\end{array}$ & $\begin{array}{l}\text { 3ROWN } \\
\text { BROWN } \\
\text { BROWN }\end{array}$ & $\begin{array}{l}N \\
N \\
N \\
N \\
A L L \\
A L L \\
N \\
M \\
M\end{array}$ & $\begin{array}{l}N \\
N \\
N \\
N \\
G \\
G \\
N \\
L G \\
G\end{array}$ & $\begin{array}{l}N \\
N \\
N \\
N \\
N \\
N \\
N \\
6 \\
5\end{array}$ & $\begin{array}{l}N \\
N \\
20 \\
N \\
1 \\
N \\
N \\
N \\
9.1\end{array}$ \\
\hline No & Treatment & $\begin{array}{l}\text { Treatment } \\
\text { Location }\end{array}$ & $\begin{array}{l}\text { Treatment } \\
\text { Cover }\end{array}$ & $\begin{array}{l}\text { Color } \\
\text { Interior }\end{array}$ & $\begin{array}{l}\text { Color } \\
\text { Exterior }\end{array}$ & \\
\hline $\begin{array}{l}1 \\
2 \\
3 \\
4 \\
5 \\
6 \\
7 \\
8 \\
9\end{array}$ & $\begin{array}{l}S B \\
S \\
S \\
S \\
U N \\
S B \\
U N \\
U N \\
B\end{array}$ & $\begin{array}{l}\text { IE } \\
R \\
\text { I } \\
\text { IR } \\
N \\
\text { IE } \\
N \\
N \\
R\end{array}$ & $\begin{array}{l}\text { ALL } \\
\text { ALL } \\
\text { ALL } \\
\text { ALL } \\
N \\
A L L \\
N \\
N \\
\text { ALL }\end{array}$ & $\begin{array}{l}\text { LT RED } \\
\text { RED } \\
\text { RED } \\
\text { RED } \\
N \\
\text { RED } \\
N \\
N \\
N\end{array}$ & $\begin{array}{l}N \\
N \\
N \\
N \\
N \\
R E D \\
N \\
N \\
N\end{array}$ & \\
\hline
\end{tabular}

\footnotetext{
2 Burn on rim suggest use as lamp; well weathered.

4 Sample too small to confirm stance or diameter.

5 Thick, deep, horizontally oriented tool marks on interior face.

7 Two vertical slashes on shoulder, potter's mark?

8 Sample too small to confirm stance or diameter.
}

PLATE 101. FIELD A. PHASE 4B (EB III). 

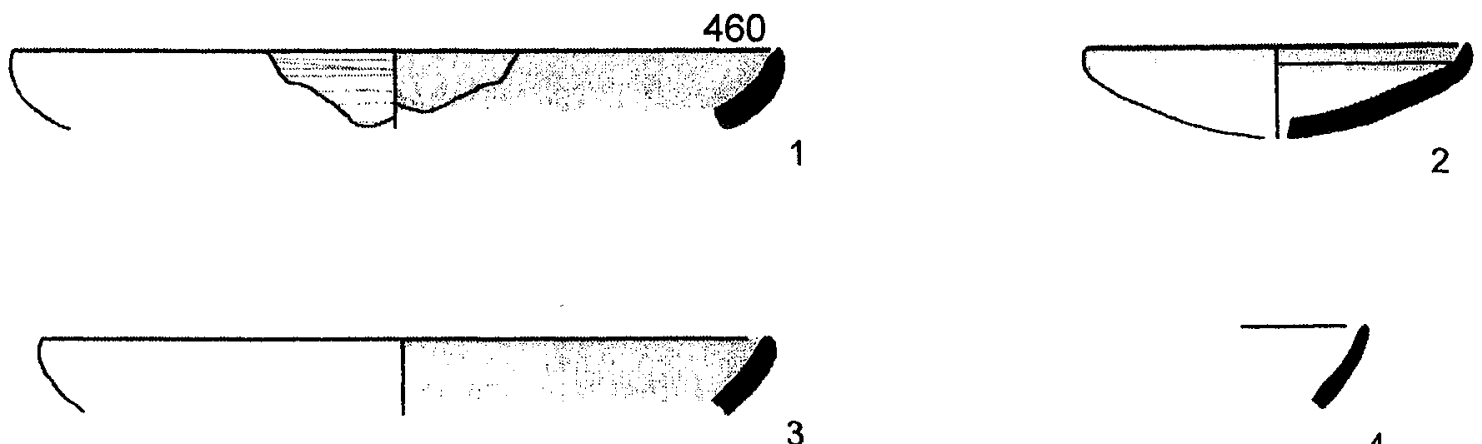

4
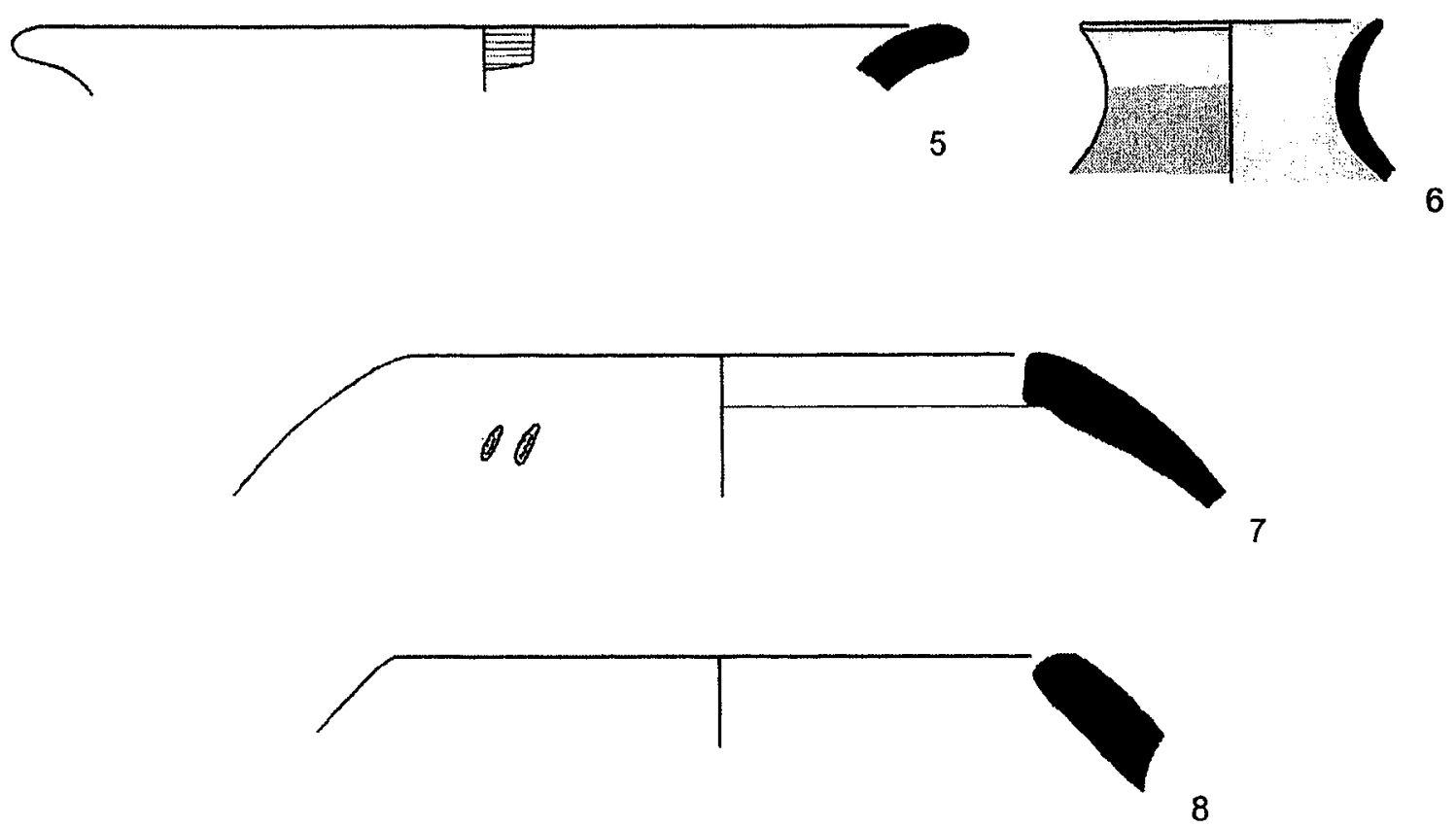

8
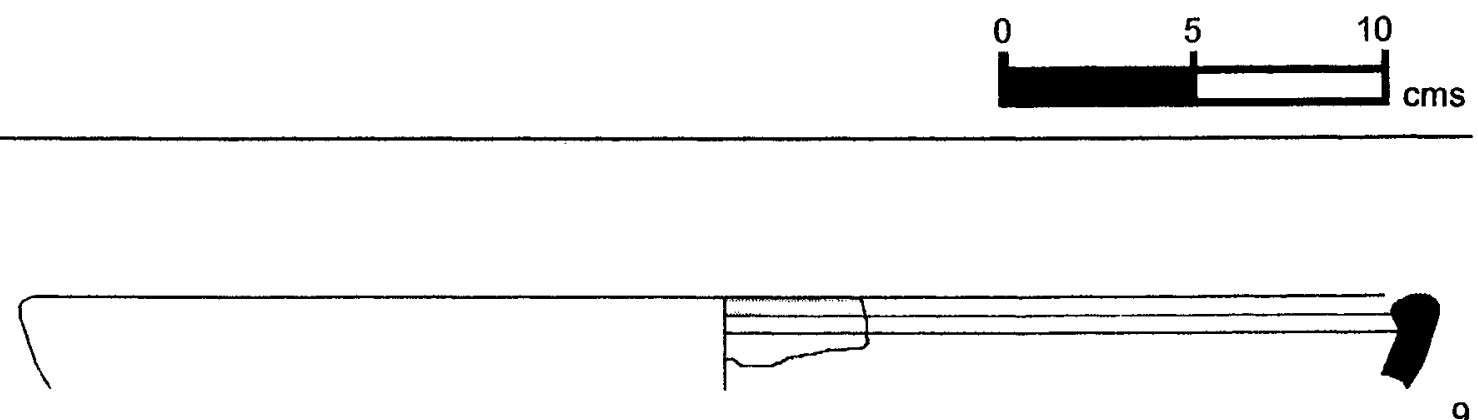

PLATE 101 (CONT.).

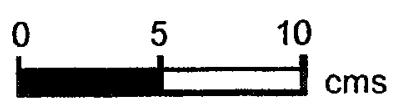




\begin{tabular}{|c|c|c|c|c|c|c|c|}
\hline$\overline{\text { No }}$ & Reg & Square & Locus & Vessel & Part & $\begin{array}{l}\text { Body } \\
\text { Thick }\end{array}$ & $\overline{\text { Dia }}$ \\
\hline 1 & 0675 & SW 2-27 & 51 & HOLE MOUTH JARIBOWL & R04 & 15 & 16 \\
\hline 2 & 0604 & SW 2-26 & 81 & HOLE MOUTH JAR & R01 & 11 & 12 \\
\hline 3 & 0606 & SW 2-26 & 81 & HOLE MOUTH JAR & R01 & 11 & 18 \\
\hline 4 & 0673 & SW 2-27 & 51 & NECKED JAR & R43 & 8 & 13 \\
\hline 5 & 0674 & SW 2-27 & 51 & UD & BOD & 6 & $\mathbf{N}$ \\
\hline 6 & 0605 & SW 2-26 & 81 & PLATTER BOWL & R57 & 14 & 34 \\
\hline 7 & 0607 & SW 2-26 & 81 & UD & B12 & 5 & 9 \\
\hline 8 & 0603 & SW 2-26 & 81 & PLATTER BOWL & R56 & 12 & 40 \\
\hline 9 & 0671 & SW 2-27 & 51 & PLATTER BOWL & R56 & 16 & 40 \\
\hline 10 & 0672 & SW 2-27 & 51 & PLATTER BOWL & R56 & 13 & 54 \\
\hline
\end{tabular}

\begin{tabular}{|c|c|c|c|c|c|c|}
\hline 2 & WEAK RED & PALE RED & M & $\begin{array}{l}N \\
G\end{array}$ & $\begin{array}{l}N \\
7\end{array}$ & $\begin{array}{l}N \\
N\end{array}$ \\
\hline 3 & \multicolumn{2}{|l|}{ PALE RED } & IRR & G & $\mathrm{N}$ & $N$ \\
\hline 4 & \multicolumn{2}{|l|}{ PALE RED } & IRR & LG & $N$ & 4 \\
\hline 5 & \multicolumn{2}{|l|}{ PINK } & $\mathrm{N}$ & $\bar{N}$ & $\mathrm{~N}$ & 13.2 \\
\hline 6 & \multicolumn{2}{|l|}{ PINK } & IRR & $\mathbf{G}$ & $N$ & $N$ \\
\hline 7 & \multicolumn{2}{|l|}{ PINK } & ALL & $G$ & $N$ & $N$ \\
\hline 8 & \multicolumn{2}{|c|}{ LT REDDISH BROWN } & IRR & $G$ & $N$ & $N$ \\
\hline 9 & \multicolumn{2}{|l|}{ PINK } & $\mathbb{I N}$ & LG & 4 & 12.1 \\
\hline 10 & \multicolumn{2}{|l|}{ PINK } & $\mathbf{N}$ & $N$ & $N$ & $N$ \\
\hline No & Treatment & $\begin{array}{l}\text { Treatment } \\
\text { Location }\end{array}$ & $\begin{array}{l}\text { Treatment } \\
\text { Cover }\end{array}$ & $\begin{array}{l}\text { Color } \\
\text { Interior }\end{array}$ & $\begin{array}{l}\text { Color } \\
\text { Exterior }\end{array}$ & \\
\hline 1 & UN & $N$ & $N$ & $N$ & $N$ & \\
\hline 2 & UN & $\mathbf{N}$ & $\mathrm{N}$ & $\mathrm{N}$ & $\mathbf{N}$ & \\
\hline 3 & UN & $N$ & $\mathbf{N}$ & $\mathbf{N}$ & $\mathbf{N}$ & \\
\hline 4 & UN & $\mathbf{N}$ & $\mathrm{N}$ & $\mathbf{N}$ & $\mathbf{N}$ & \\
\hline 5 & $\mathbf{S}$ & 1 & ALL & DK RED & $\mathbf{N}$ & \\
\hline 6 & UN & $\mathbf{N}$ & $N$ & $\mathbf{N}$ & $\mathbf{N}$ & \\
\hline 7 & $S$ & $E$ & $\mathrm{~N}$ & $N$ & RED & \\
\hline 8 & SB & IR & ALL & RED & $\mathbf{N}$ & \\
\hline 9 & SB & $\mathbb{R} \mathbf{R}$ & ALL & RED & $\mathrm{N}$ & \\
\hline 10 & $\mathrm{~s}$ & IR & $A L L$ & RED & $\mathbf{N}$ & \\
\hline
\end{tabular}

PLATE 102. FIELD A. PHASE 4B (EB III). 


\section{Other}

1 Sample too small to confirm stance or diameter.

6 Also B50.

8 Slip color changes from rim to center on interior face; radial burnish over slip; faint concavity under rim.

$9 \quad$ Loose "net"-like burnish on interior face.

PLATE 102 (CONT.). 

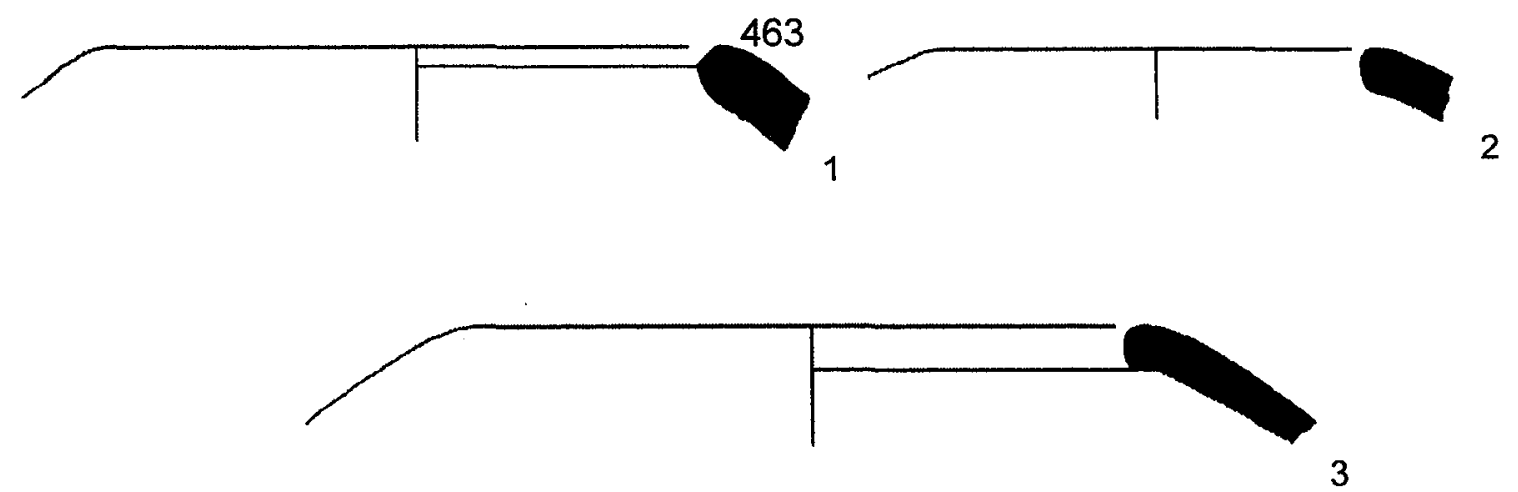

3

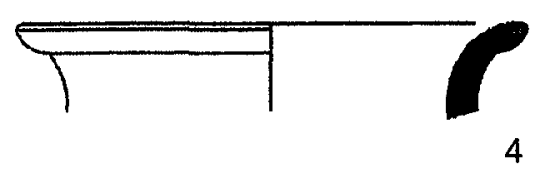

4
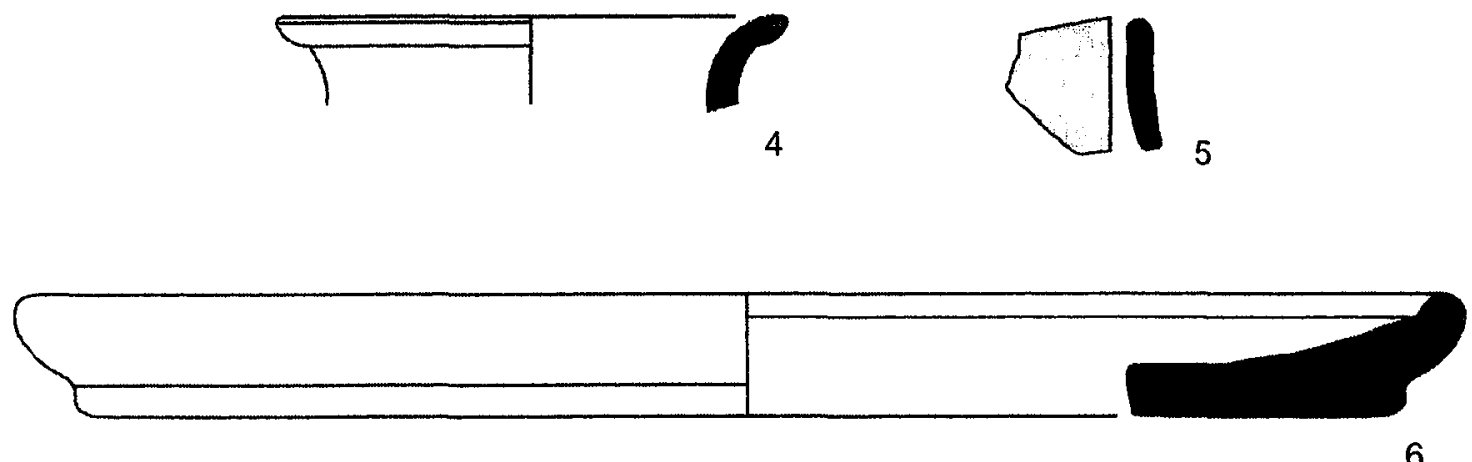

6
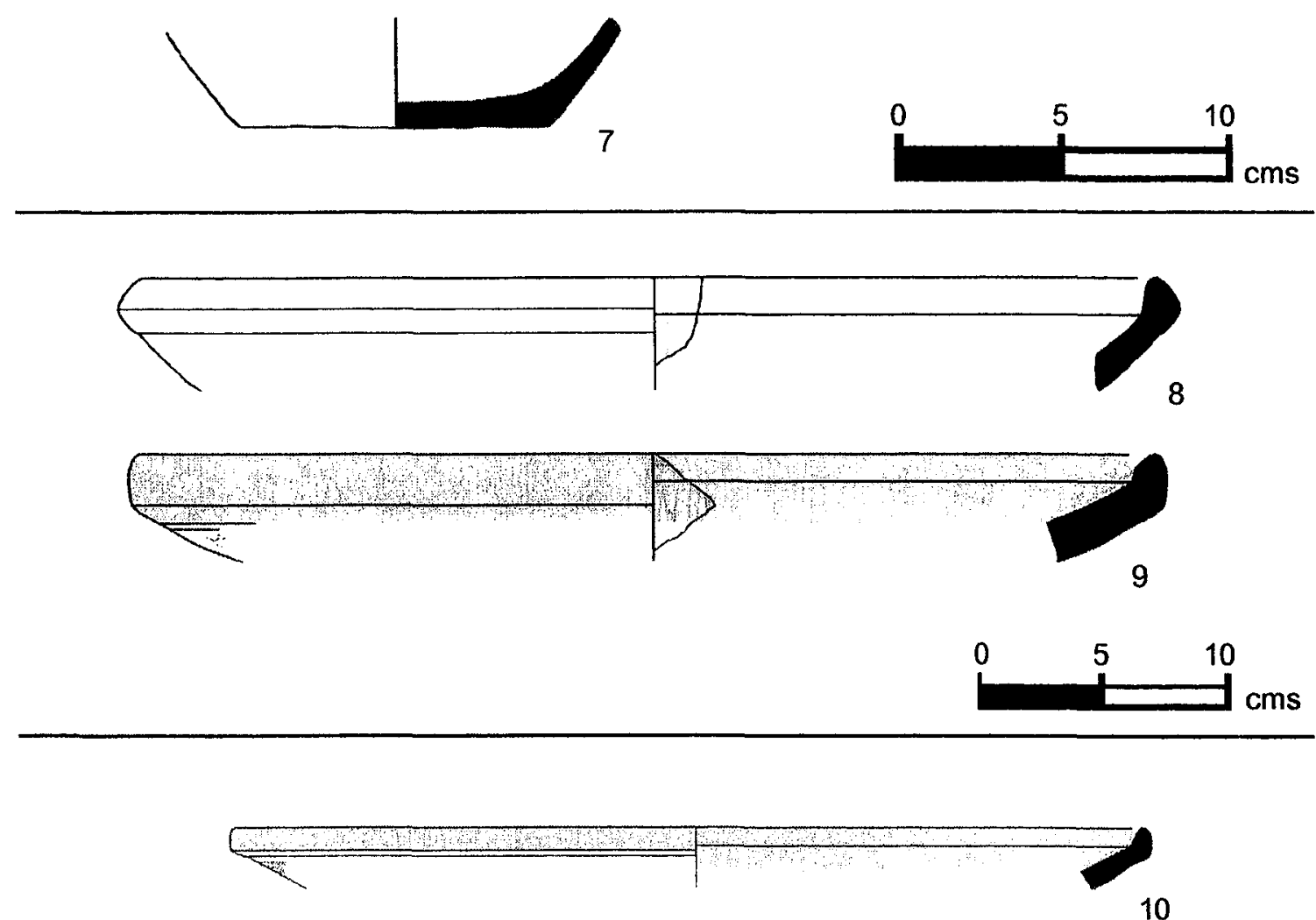

PLATE 102 (CONT.). 


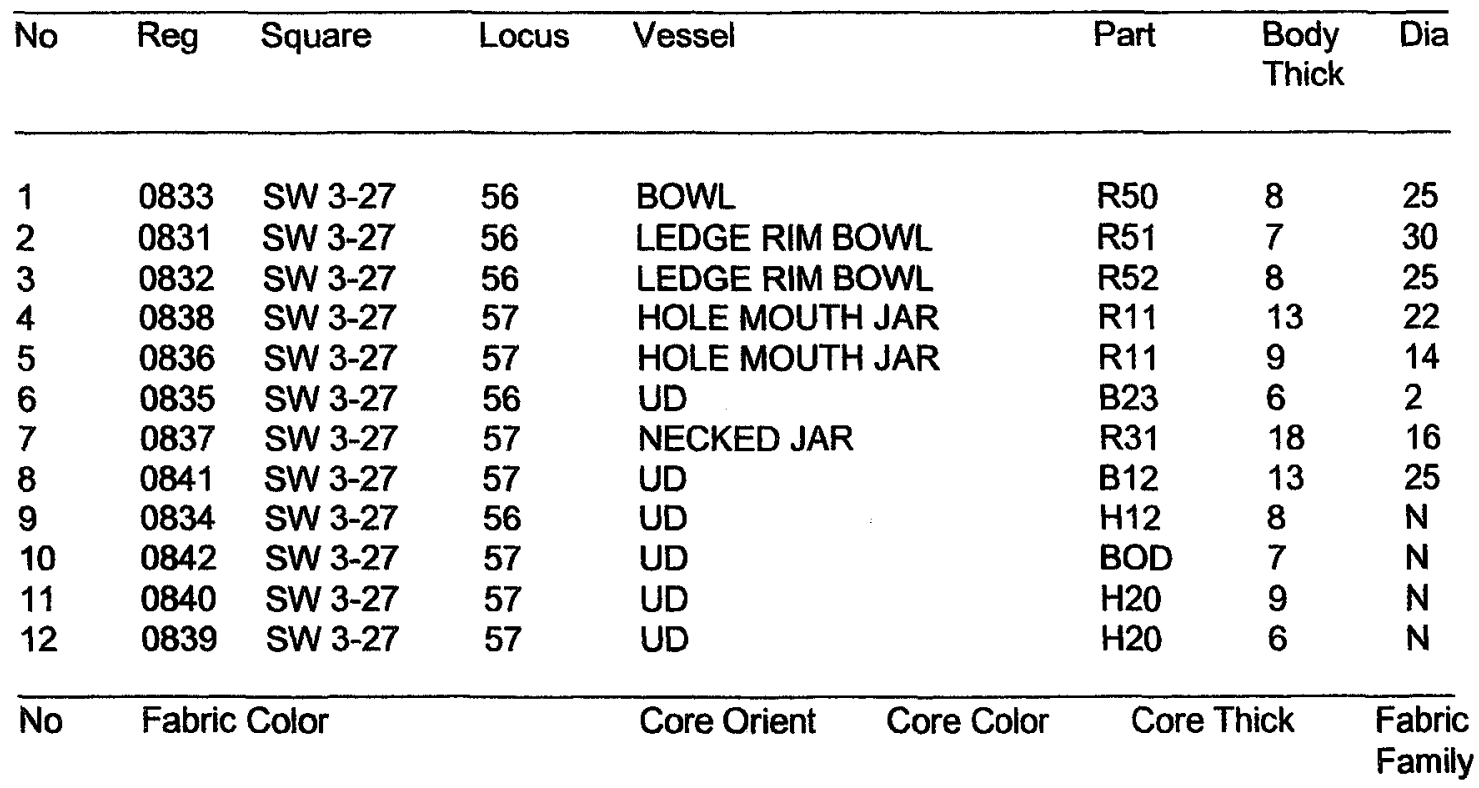

\begin{tabular}{|c|c|c|c|c|c|c|}
\hline 1 & \multicolumn{2}{|c|}{ LT REDDISH BROWN } & $M$ & LG & 2 & 17.2 \\
\hline 2 & \multicolumn{2}{|l|}{ PINK } & $\mathrm{N}$ & $N$ & $\mathrm{~N}$ & 24 \\
\hline 3 & \multicolumn{2}{|l|}{ PINK } & $\mathbf{N}$ & $\mathbf{N}$ & $N$ & 24 \\
\hline 4 & \multicolumn{2}{|l|}{ LT RED } & IRR & G & $\mathrm{N}$ & 1 \\
\hline 5 & \multicolumn{2}{|l|}{ WEAK RED } & IRR & LG & $\mathbf{N}$ & 5.1 \\
\hline 6 & \multicolumn{2}{|l|}{ PINK } & $N$ & $N$ & $\mathbf{N}$ & 23 \\
\hline 7 & \multicolumn{2}{|c|}{ LT REDDISH BROWN } & $M$ & LG & 9 & 15 \\
\hline 8 & \multicolumn{2}{|c|}{ LT REDDISH BROWN } & 1 & LG & 6 & 6 \\
\hline 9 & \multicolumn{2}{|l|}{ LT RED } & IRR & $\mathbf{G}$ & $\mathrm{N}$ & 9.2 \\
\hline 10 & \multicolumn{2}{|l|}{ LT RED } & $N$ & $\mathbf{N}$ & $\mathrm{N}$ & 13.1 \\
\hline 11 & \multicolumn{2}{|c|}{ REDDISH YELLOW } & IRR & $\mathbf{G}$ & $\mathbf{N}$ & 21 \\
\hline 12 & \multicolumn{2}{|c|}{ LT RED } & $\mathbf{N}$ & $\mathbf{N}$ & $N$ & 12.1 \\
\hline No & Treatment & $\begin{array}{l}\text { Treatment } \\
\text { Location }\end{array}$ & $\begin{array}{l}\text { Treatment } \\
\text { Cover }\end{array}$ & $\begin{array}{l}\text { Color } \\
\text { Interior }\end{array}$ & $\begin{array}{l}\text { Color } \\
\text { Exterior }\end{array}$ & \\
\hline 1 & SB & $\mathbf{I E}$ & ALL & RED & RED & \\
\hline 2 & $\mathbf{S}$ & IE & ALL & LT RED & LT RED & \\
\hline 3 & SB & IE & ALL & RED & RED & \\
\hline 4 & UN & $\mathbf{N}$ & $\mathrm{N}$ & $\mathbf{N}$ & $\mathrm{N}$ & \\
\hline 5 & UN & $\mathbf{N}$ & $\mathbf{N}$ & $\mathbf{N}$ & $N$ & \\
\hline 6 & $\mathrm{~S}$ & $\mathrm{E}$ & ALL & $N$ & RED & \\
\hline 7 & $\mathbf{S}$ & ER & ALL & $\mathbf{N}$ & RED & \\
\hline 8 & UN & $\mathbf{N}$ & $\mathbf{N}$ & $\mathbf{N}$ & $\mathbf{N}$ & \\
\hline 9 & WASH & $E$ & ALL & $\mathbf{N}$ & WHITE & \\
\hline 10 & 1 & $E$ & ALL & $\mathbf{N}$ & $\mathbf{N}$ & \\
\hline 11 & $\mathbf{S}$ & $E$ & ALL & $\mathbf{N}$ & BLACK & \\
\hline 12 & UN & $N$ & $\mathbf{N}$ & $\mathbf{N}$ & $\mathbf{N}$ & \\
\hline
\end{tabular}

PLATE 103. FIELD A. PHASE 4B (EB III). 
Other

3 Interior face is wet-smoothed in various direction, scrape lines immediately under rim are visible on exterior face; very weathered.

$5 \quad$ Surface burn visible.

10 Combed Metallic Ware.

12 Metallic Ware.

PLATE 103 (CONT.). 

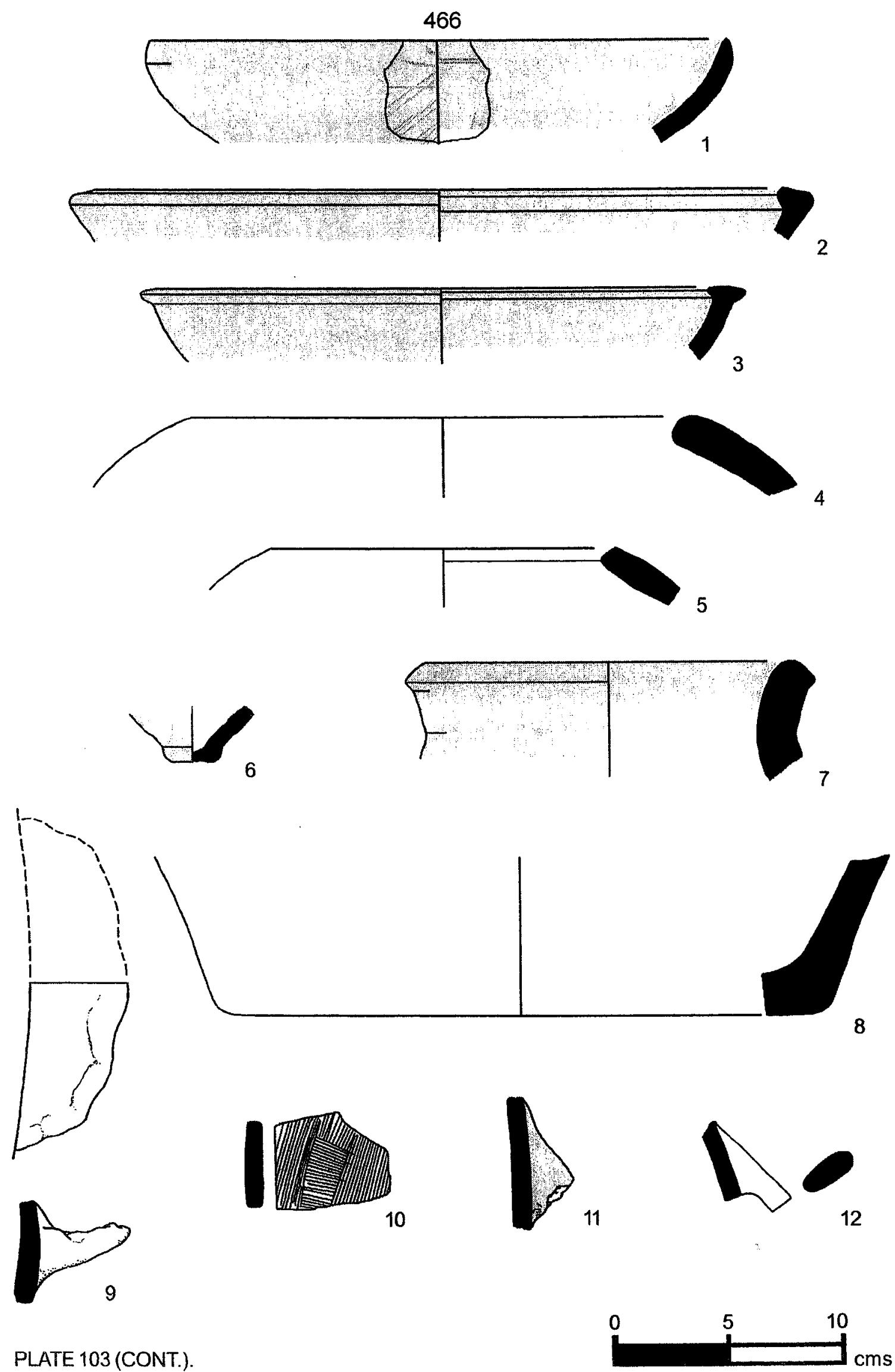


\begin{tabular}{|c|c|c|c|c|c|c|c|c|}
\hline & $\operatorname{Reg}$ & Square & Locus & \multicolumn{2}{|l|}{ Vessel } & Part & \multicolumn{2}{|c|}{$\begin{array}{l}\text { Body } \\
\text { Thick }\end{array}$} \\
\hline $\begin{array}{l}1 \\
2 \\
3 \\
4\end{array}$ & $\begin{array}{l}1195 \\
1196 \\
1197 \\
1194\end{array}$ & $\begin{array}{l}\text { SW } 7-26 \\
\text { SW } 7-26 \\
\text { SW } 7-26 \\
\text { SW } 7-26\end{array}$ & $\begin{array}{l}8 \\
8 \\
8 \\
8\end{array}$ & $\begin{array}{l}\text { LEDGE RIM } \\
\text { HOLE MOU } \\
\text { UD } \\
\text { PLATTER B }\end{array}$ & $\begin{array}{l}\text { JAR } \\
\text { JAR }\end{array}$ & $\begin{array}{l}\text { R51 } \\
\text { R14 } \\
\text { B13 } \\
\text { R53 }\end{array}$ & $\begin{array}{l}5 \\
8 \\
6 \\
10\end{array}$ & $\begin{array}{l}20 \\
32 \\
5 \\
40\end{array}$ \\
\hline No & Fabric & Color & & Core Orient & Core Color & Co & ick & $\begin{array}{l}\text { Fabric } \\
\text { Family }\end{array}$ \\
\hline $\begin{array}{l}1 \\
2 \\
3 \\
4\end{array}$ & $\begin{array}{l}\text { REDD } \\
\text { LT RE } \\
\text { PINK } \\
\text { WEAK }\end{array}$ & $\begin{array}{l}\text { SH BROV } \\
\text { DDISH BR } \\
\text { RED }\end{array}$ & $\begin{array}{l}\text { NN } \\
\text { ROWN }\end{array}$ & $\begin{array}{l}N \\
\text { IRR } \\
N \\
M\end{array}$ & $\begin{array}{l}N \\
L G \\
N \\
G\end{array}$ & $\begin{array}{l}N \\
N \\
N \\
4\end{array}$ & & $\begin{array}{l}N \\
N \\
N \\
N\end{array}$ \\
\hline$\overline{\text { No }}$ & Treatr & lent & $\begin{array}{l}\text { Treatment } \\
\text { Location }\end{array}$ & $\begin{array}{l}\text { Treatment } \\
\text { Cover }\end{array}$ & $\begin{array}{l}\text { Color } \\
\text { Interior }\end{array}$ & & & \\
\hline $\begin{array}{l}1 \\
2 \\
3 \\
4\end{array}$ & $\begin{array}{l}S \\
\text { UN } \\
\text { UN } \\
B\end{array}$ & & $\begin{array}{l}\text { IR } \\
N \\
N \\
\text { IE }\end{array}$ & $\begin{array}{l}\text { ALL } \\
N \\
N \\
\text { ALL }\end{array}$ & $\begin{array}{l}\text { LT RED } \\
N \\
N \\
N\end{array}$ & $\begin{array}{l}N \\
N \\
N \\
N\end{array}$ & & \\
\hline
\end{tabular}

\section{Other}

2 Pronounced finger marks on lip.

4 Wheel burnish along rim:

PLATE 104. FIELD A. UNPHASED (EB III). 


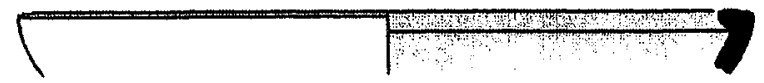

1
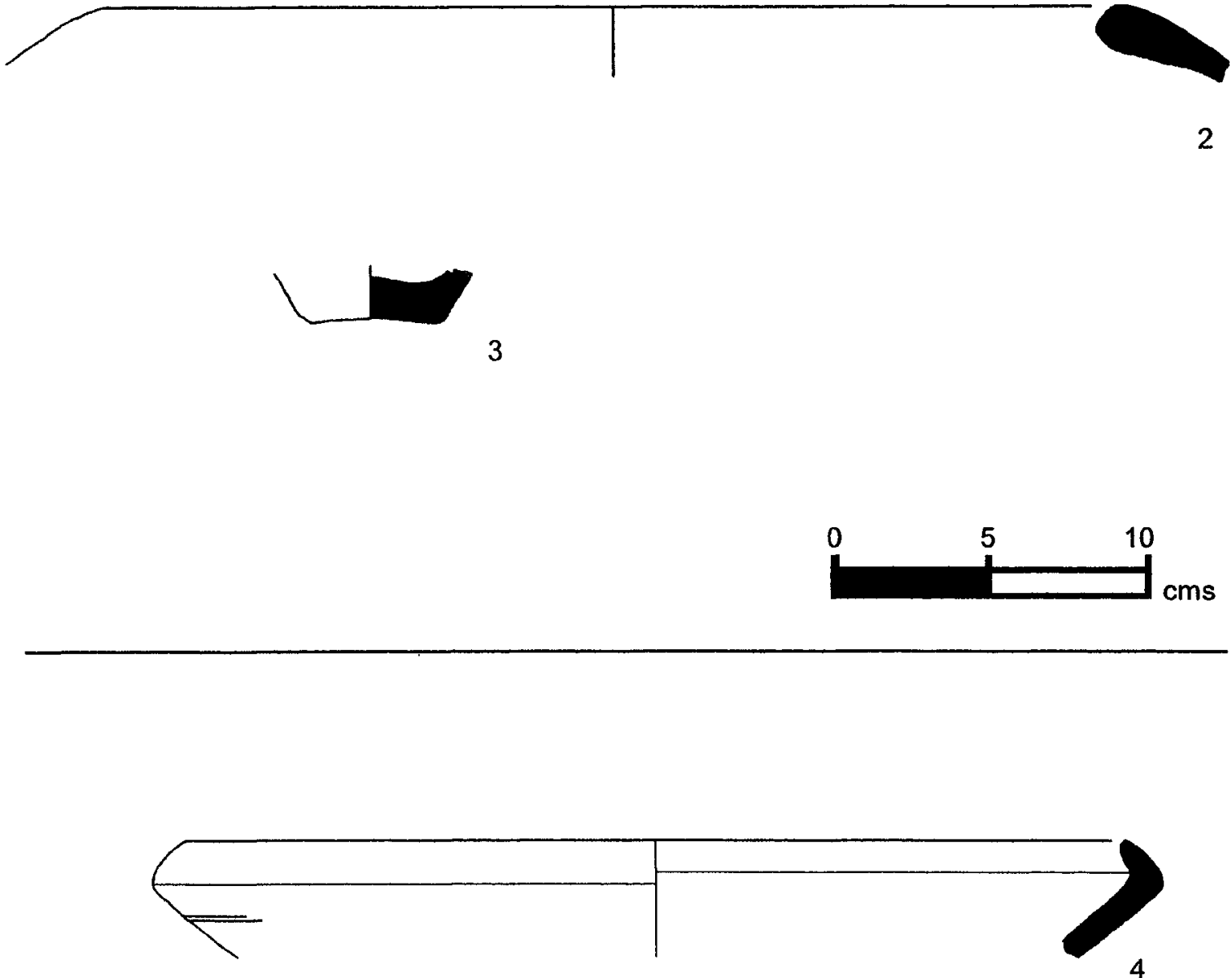

PLATE 104 (CONT.).

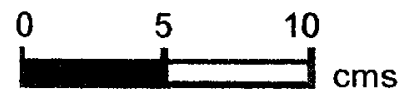




\begin{tabular}{llllllll}
\hline No & Reg & Square & Locus & Vessel & Part & $\begin{array}{c}\text { Body } \\
\text { Thick }\end{array}$ & Dia \\
& & & & & & & \\
1 & 1199 & SW 7-26 & 12 & BOWL & R81 & 5 & 20 \\
2 & 1206 & SW 7-26 & 12 & LEDGE RIM BOWL & R53 & 12 & 26 \\
3 & 1201 & SW 7-26 & 12 & NECKED JAR & R43 & 13 & 20 \\
4 & 1202 & SW 7-26 & 12 & NECKED JAR & R81 & 5 & 10 \\
5 & 1198 & SW 7-26 & 12 & NECKED JAR & R31 & 9 & 12 \\
6 & 1208 & SW 7-26 & 12 & NECKED JAR & R42 & 6 & 11 \\
7 & 1207 & SW 7-26 & 12 & HOLE MOUTH BOWL & R04 & 10 & 20 \\
8 & 1209 & SW 7-26 & 12 & HOLE MOUTH JAR & R04 & 13 & 15 \\
9 & 1205 & SW 7-26 & 12 & HOLE MOUTH JAR & R04 & 12 & 16
\end{tabular}

\begin{tabular}{lllll}
\hline No Fabric Color & Core Orient & Core Color & Core Thick & Fabric \\
Family
\end{tabular}

\begin{tabular}{|c|c|c|c|c|c|c|}
\hline 1 & \multicolumn{2}{|l|}{ PALE RED } & $M$ & G & 2 & $\mathbf{N}$ \\
\hline 2 & \multicolumn{2}{|l|}{ PINK } & $\mathrm{N}$ & $\mathrm{N}$ & $\mathrm{N}$ & $\mathrm{N}$ \\
\hline 3 & \multicolumn{2}{|c|}{ LT REDDISH BROWN } & $M$ & LG & 6 & $\mathbf{N}$ \\
\hline 4 & \multicolumn{2}{|l|}{ LT RED } & $M$ & $\mathbf{G}$ & 4 & $\mathbf{N}$ \\
\hline 5 & \multicolumn{2}{|l|}{ PINK } & $M$ & G & 4 & $N$ \\
\hline 6 & \multicolumn{2}{|l|}{ LT RED } & $N$ & $\mathrm{~N}$ & $N$ & $\mathbf{N}$ \\
\hline 7 & \multicolumn{2}{|c|}{ LT REDDISH BROWN } & $\mathrm{N}$ & $\mathrm{N}$ & $\mathrm{N}$ & $\mathrm{N}$ \\
\hline 8 & \multicolumn{2}{|c|}{ PINK } & $\mathbf{N}$ & $\mathrm{N}$ & $\mathrm{N}$ & $\mathrm{N}$ \\
\hline 9 & \multicolumn{2}{|c|}{ LT REDDISH BROWN } & $\mathbf{M}$ & $\mathbf{G}$ & 7 & $\mathbf{N}$ \\
\hline No & Treatment & $\begin{array}{l}\text { Treatment } \\
\text { Location }\end{array}$ & $\begin{array}{l}\text { Treatment } \\
\text { Cover }\end{array}$ & $\begin{array}{l}\text { Color } \\
\text { Interior }\end{array}$ & $\begin{array}{l}\text { Color } \\
\text { Exterior }\end{array}$ & \\
\hline 1 & $\mathrm{~s}$ & IR & ALL & DK RED & $\mathrm{N}$ & \\
\hline 2 & SB & IR & ALL & RED & $\mathrm{N}$ & \\
\hline 3 & WASH & ER & ALL & $\mathbf{N}$ & WHITE & \\
\hline 4 & S & IE & ALL & RED & RED & \\
\hline 5 & $\mathbf{S}$ & $E$ & ALL & $\mathbf{N}$ & RED & \\
\hline 6 & UN & $\mathbf{N}$ & $\mathrm{N}$ & $\mathbf{N}$ & $\mathrm{N}$ & \\
\hline 7 & UN & $N$ & $\mathbf{N}$ & $N$ & $\mathrm{~N}$ & \\
\hline 8 & UN & $\mathbf{N}$ & $\mathbf{N}$ & $\mathbf{N}$ & $\mathrm{N}$ & \\
\hline 9 & UN & $\mathrm{N}$ & $\mathbf{N}$ & $\mathbf{N}$ & $\mathrm{N}$ & \\
\hline
\end{tabular}

1 Burn on rim suggests use as lamp.

2 Radial burnish over red slip on interior face; margin of wet-smoothing visible above dry scraping on exterior face.

$9 \quad$ Surface burn visible.

PLATE 105. FIELD A. UNPHASED (EB III). 

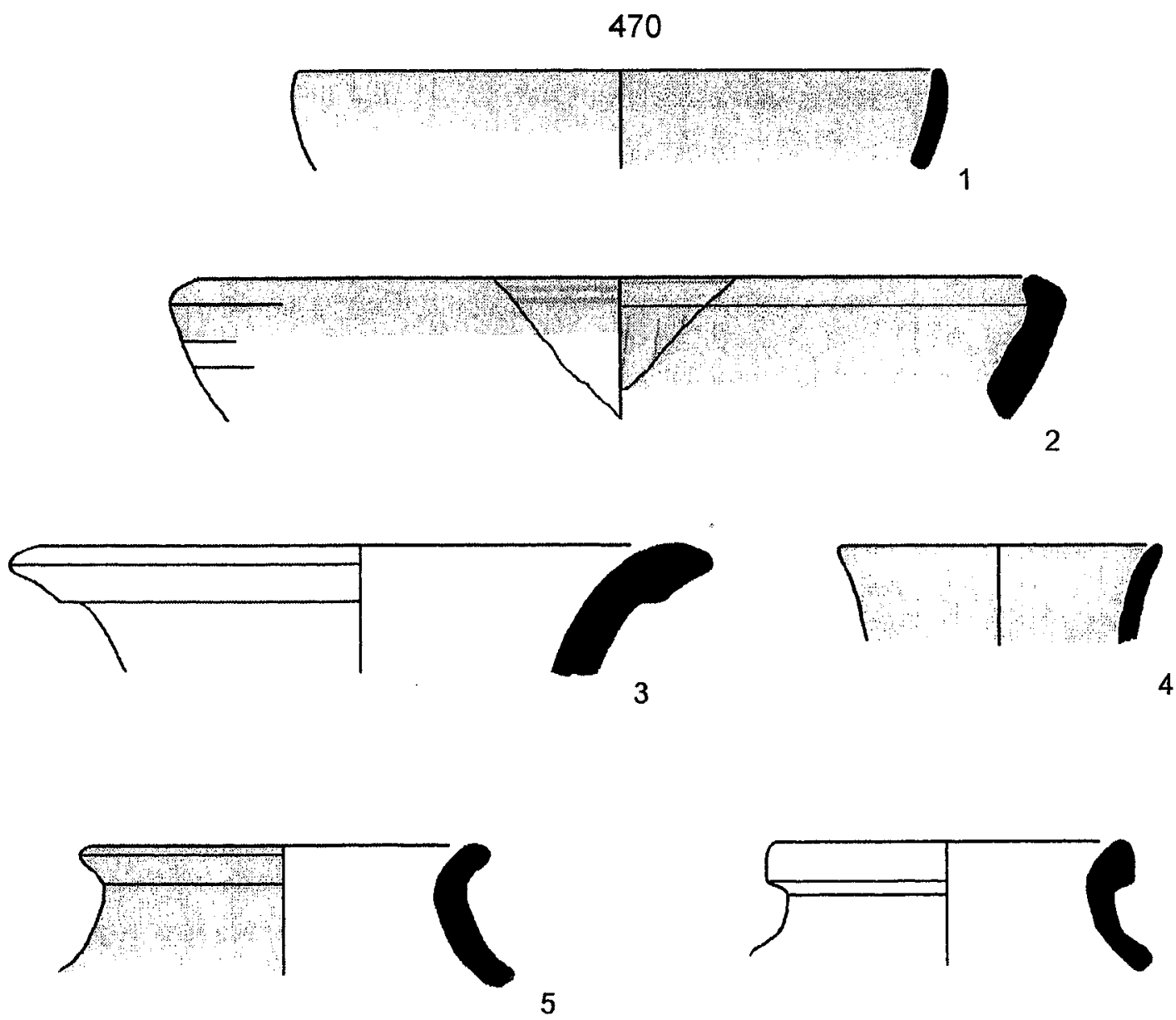

5

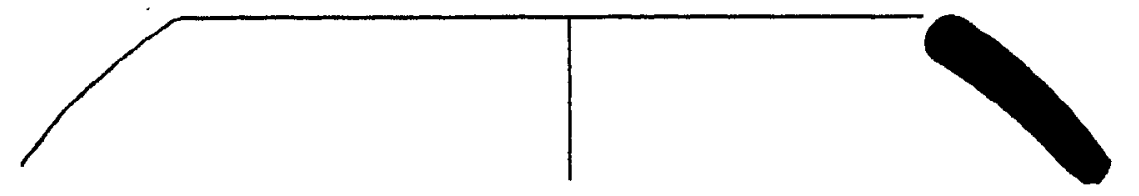

7
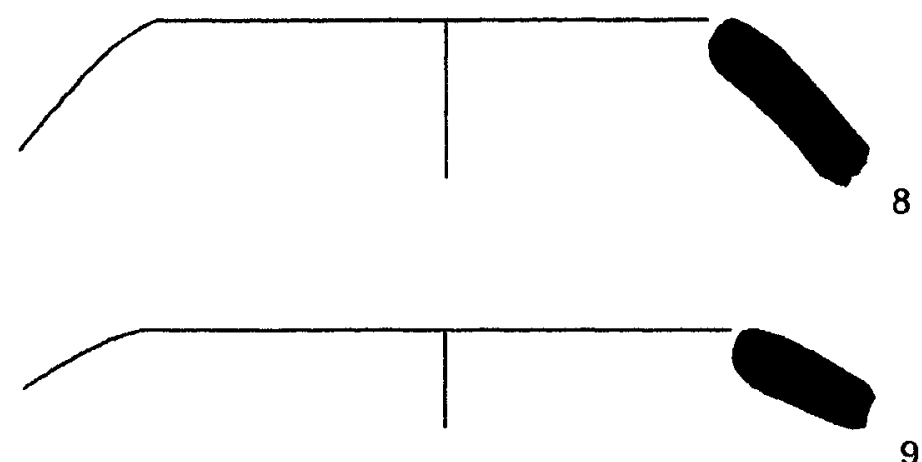

PLATE 105 (CONT.).

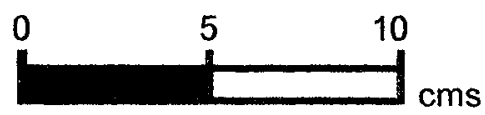




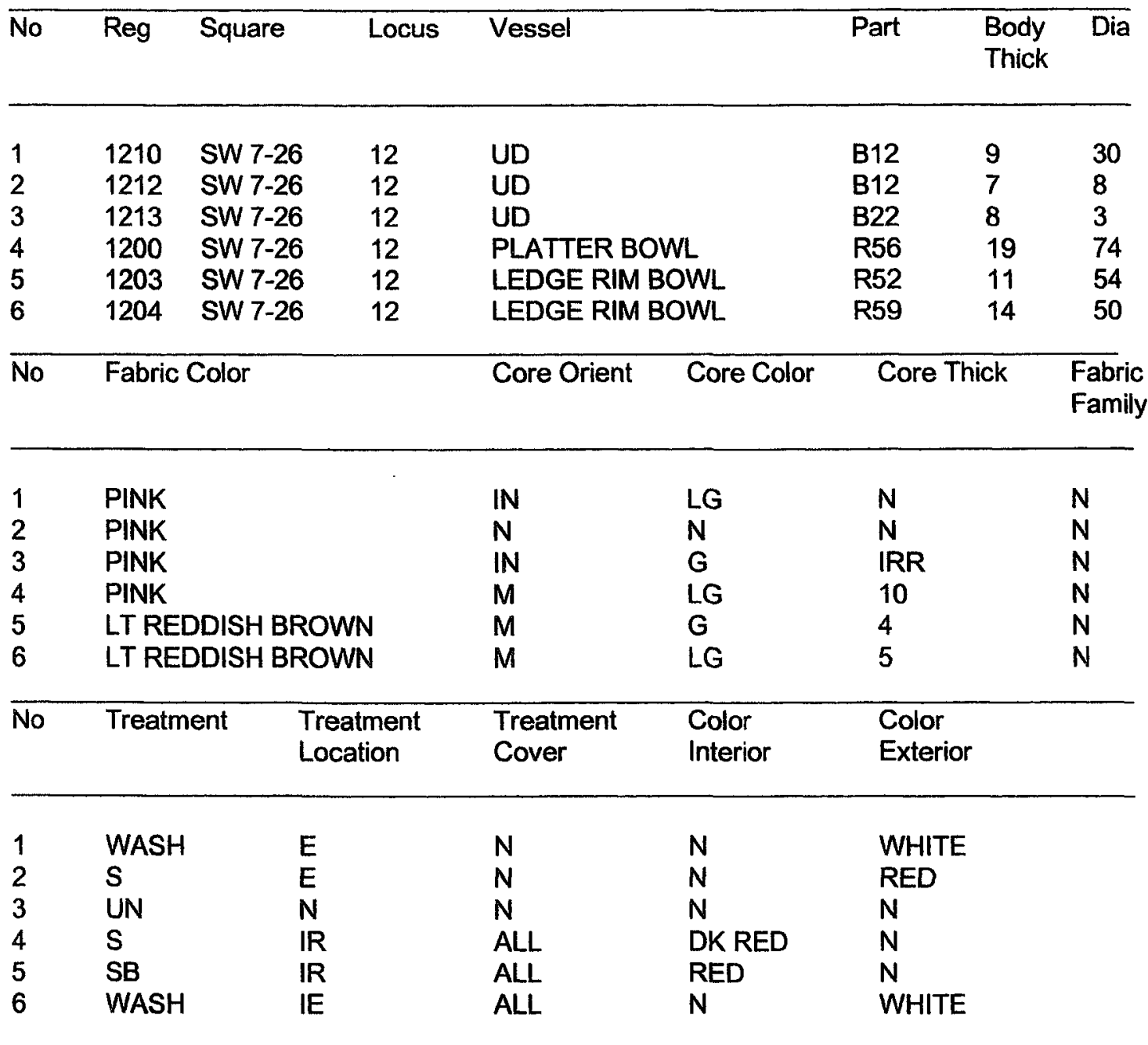

Other

2 String cut base.

5 Rim lip folded inwardly and well burnished; radial burnish over slip on interior face; exterior face is irregular and "textured," with horizontal and diagonal scrape marks.

PLATE 106. FIELD A. UNPHASED (EB III). 
472
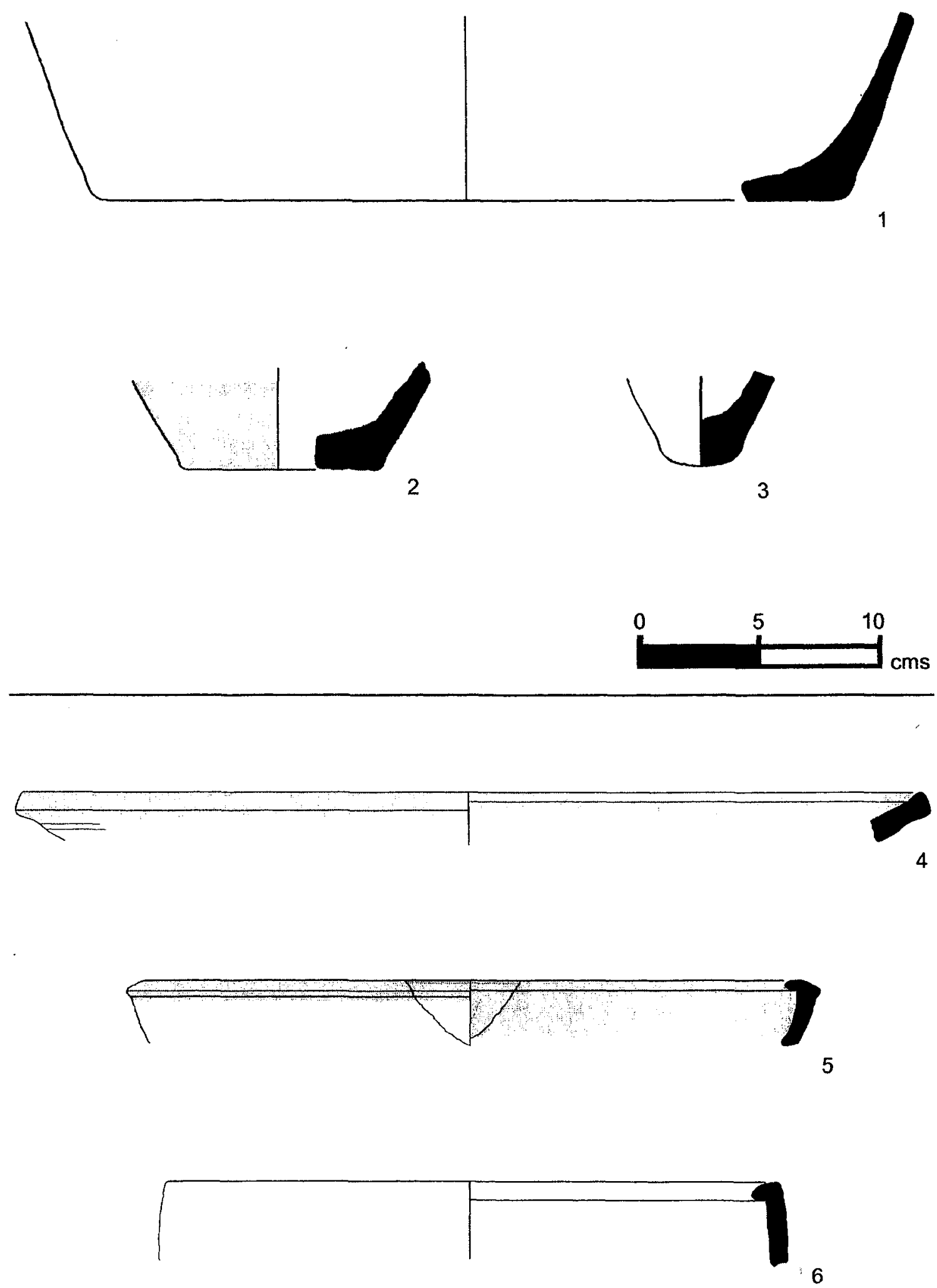

PLATE 106 (CONT.). 


\begin{tabular}{llllllll}
\hline No & Reg & Square & Locus & Vessel & Part & $\begin{array}{l}\text { Body } \\
\text { Thick }\end{array}$ & Dia \\
\hline 1 & 2215 & SW 1-8 & 116 & HOLE MOUTH JAR & R14 & 8 & 22 \\
2 & 2217 & SW 1-8 & 116 & HOLE MOUTH JAR & R14 & 22 & 16 \\
3 & 1475 & SW 1-8 & 117 & UD & H12 & 9 & N \\
4 & 1474 & SW 1-8 & 117 & HOLE MOUTH BOWL & R11 & 11 & 40 \\
5 & 2218 & SW 1-8 & 116 & PLATTER BOWL & R53 & N & 44 \\
6 & 2216 & SW 1-8 & 116 & HOLE MOUTH BOWL & R04 & 10 & 45 \\
7 & 1473 & SW 1-8 & 117 & HOLE MOUTH BOWL & R12 & 14 & 50 \\
\hline No & Fabric Color & & Core Orient Core Color & Core Thick & Fabric \\
& & & & & & &
\end{tabular}

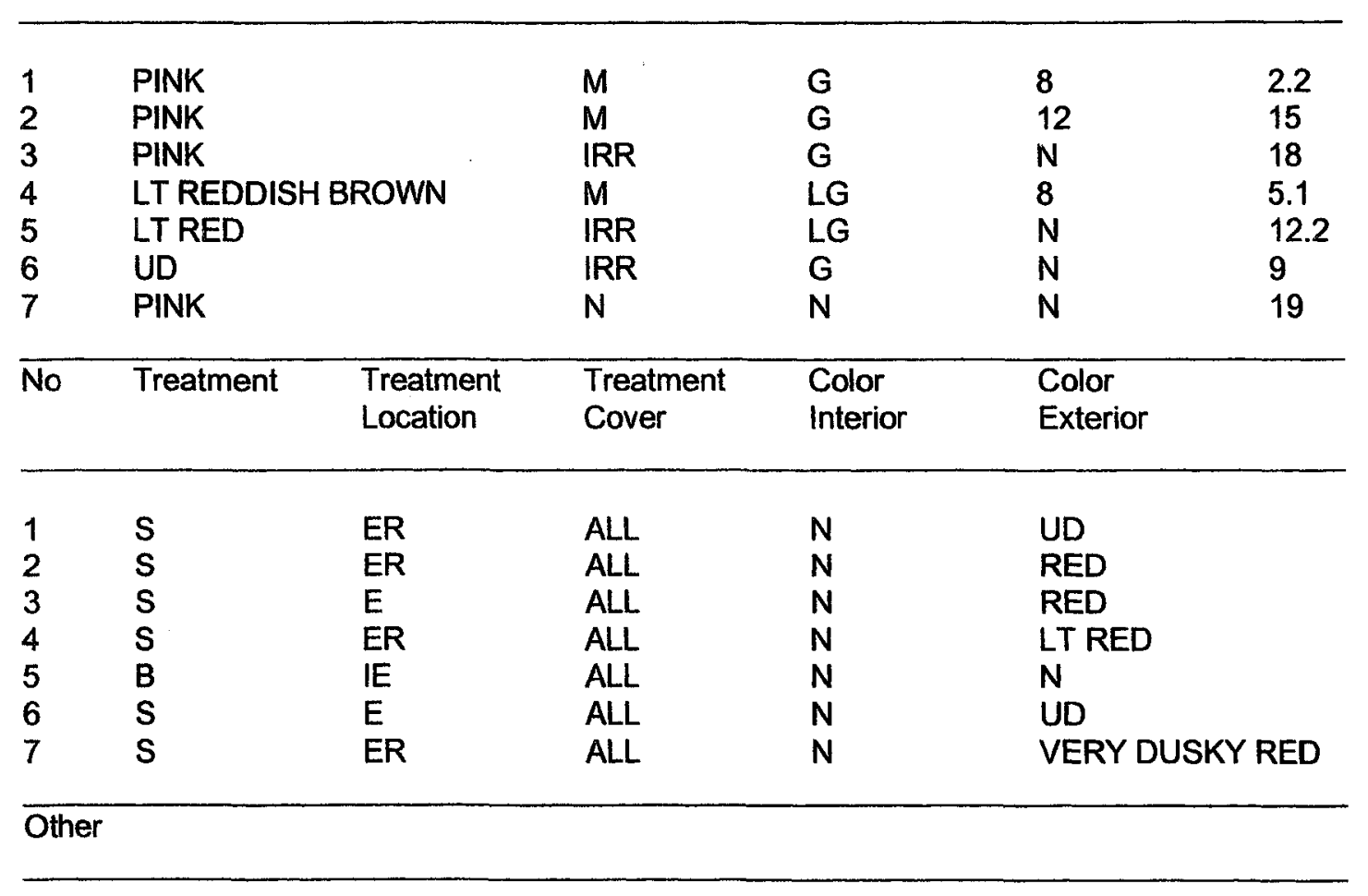

1 Void in break suggests rim folding.

5 Metallic Ware.

$6 \quad$ Also in Fabric Family 3; hole bored through body wall just below rim.

7 Very irregularly formed; surface burn visible.

PLATE 107. FIELD B. PHASE 1A (LATE EB I - EARLY EB II). 

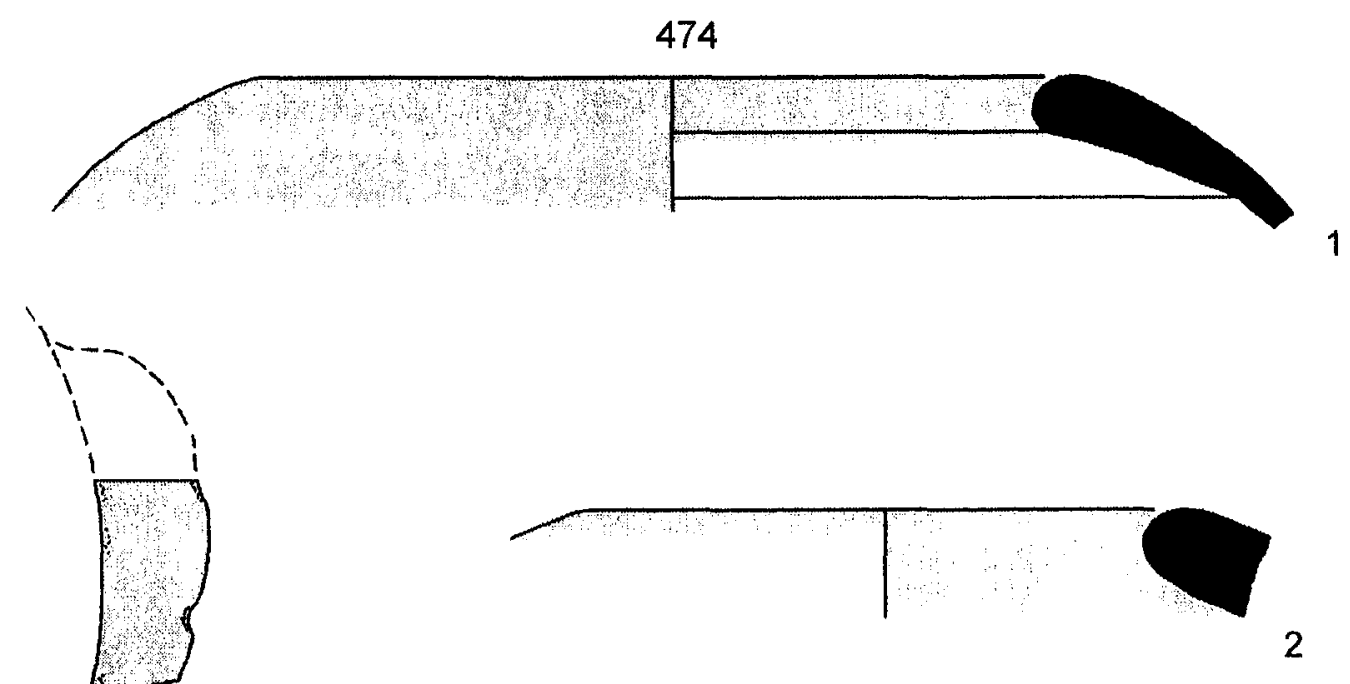

.
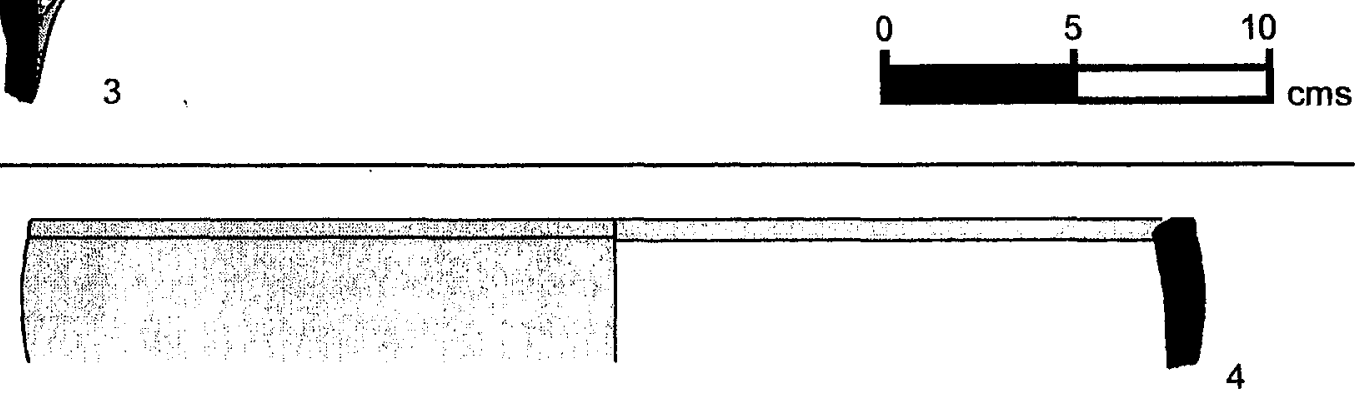

4

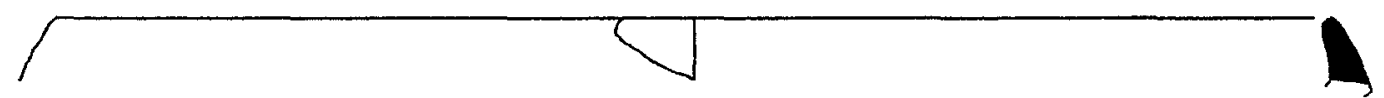

5
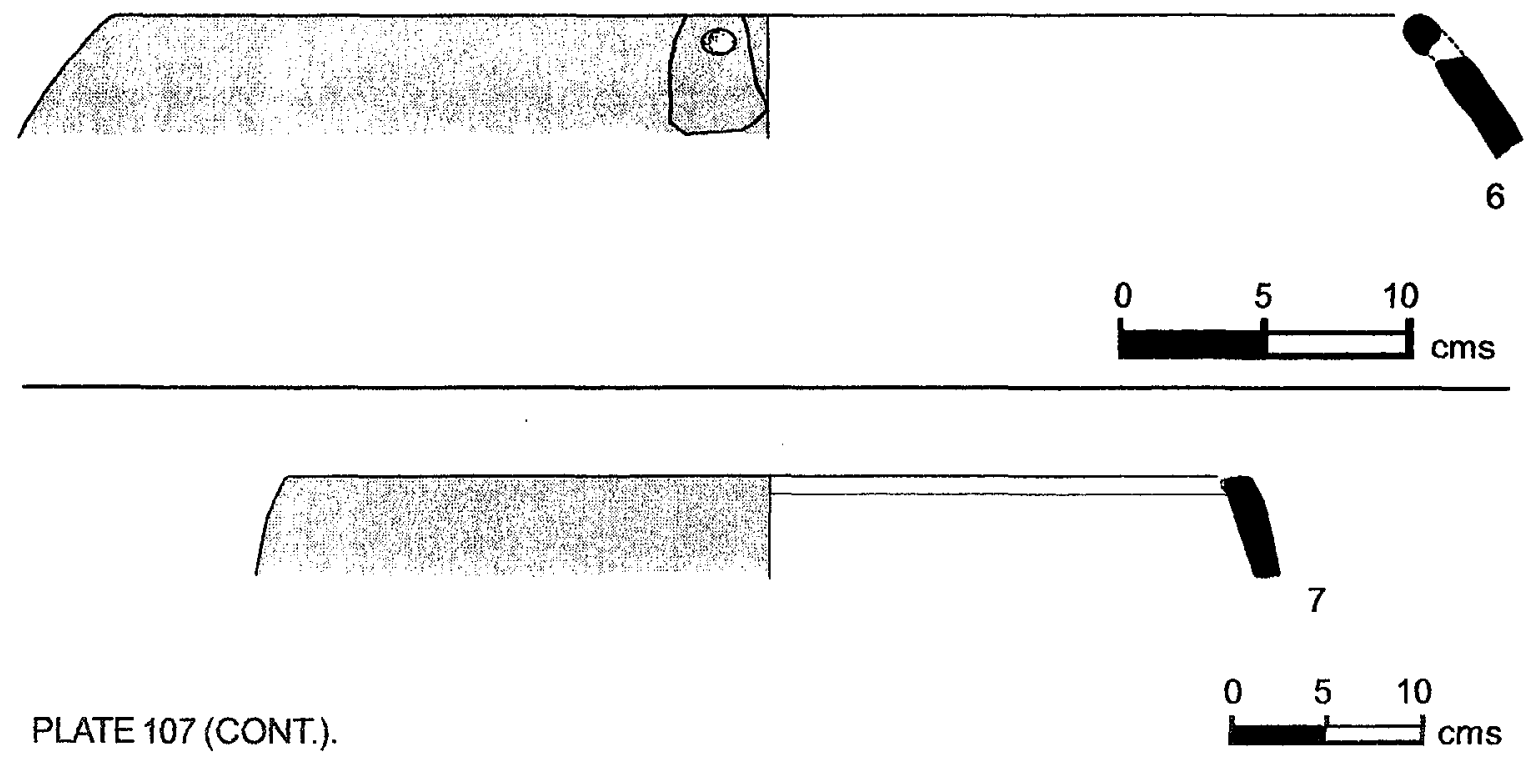
475

\begin{tabular}{llllllll}
\hline No & Reg & Square & Locus & Vessel & Part & $\begin{array}{l}\text { Body } \\
\text { Thick }\end{array}$ & $\begin{array}{c}\text { Dia } \\
1\end{array}$ \\
\hline & 1469 & SW 1-8 & 119 & NECKED JAR & R31 & 10 & 12 \\
2 & 1472 & SW 1-8 & 119 & NECKED JAR & R31 & 8 & 12 \\
3 & 1470 & SW 1-8 & 119 & NECKED JAR & R32 & 10 & N \\
4 & 2214 & SW 1-8 & 119 & UD & B22 & 9 & 3 \\
5 & 1471 & SW 1-8 & 119 & UD & H12 & 10 & N \\
6 & 1331 & SW 1-7 & 222 & UD & H27 & 6 & N
\end{tabular}

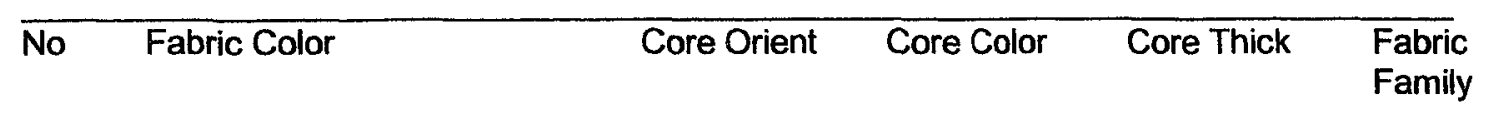

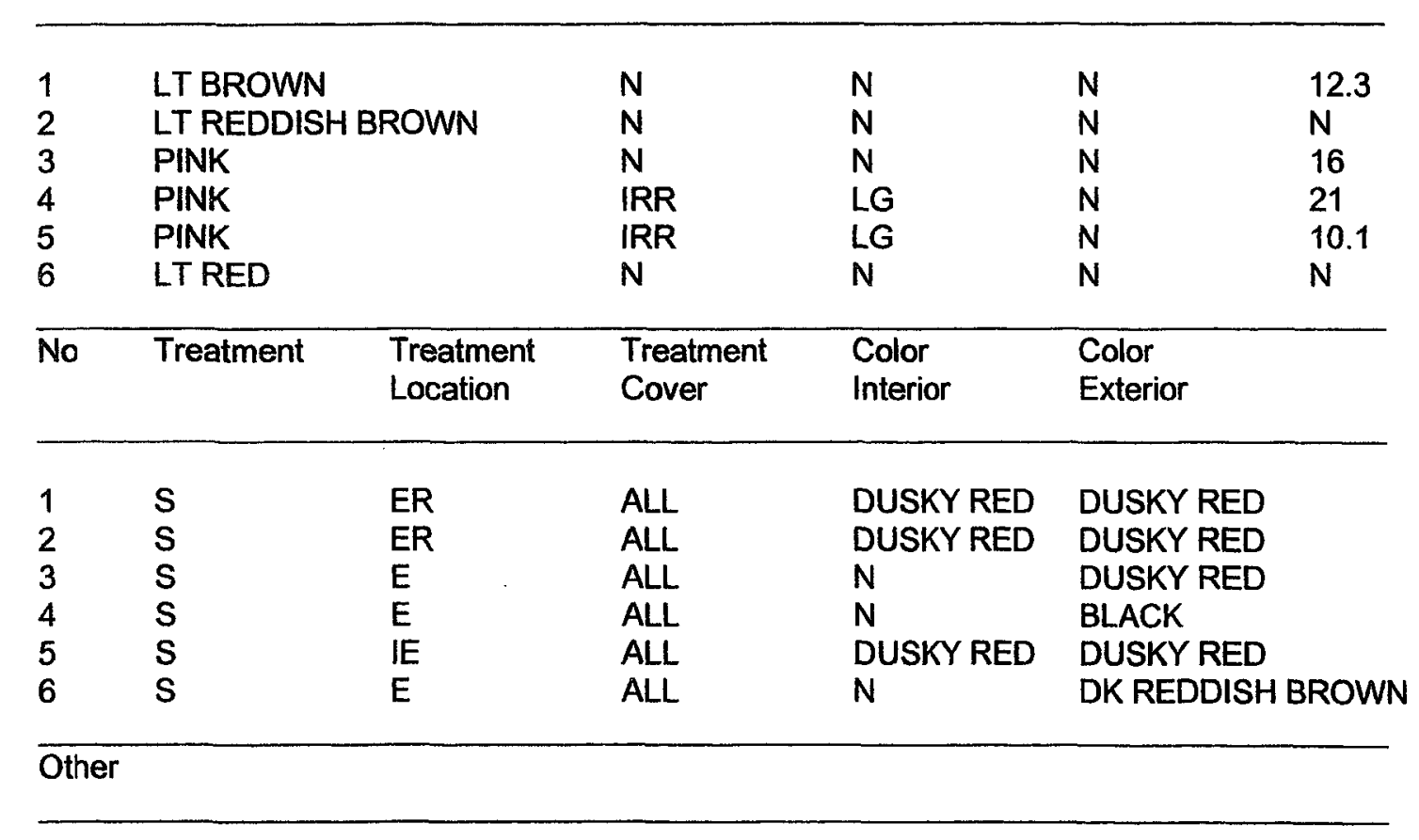

$\begin{array}{ll}1 & \text { Also in Fabric Family } 4 . \\ 3 & \text { Sample too small to confirm stance or diameter. } \\ 5 & \text { Also in Fabric Family } 11 .\end{array}$

PLATE 108. FIELD B. PHASE 1A (LATE EB I - EARLY EB II). 


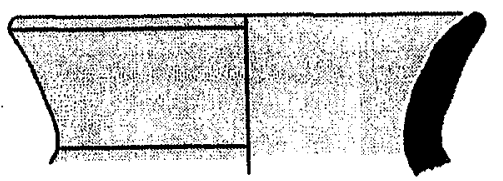

1
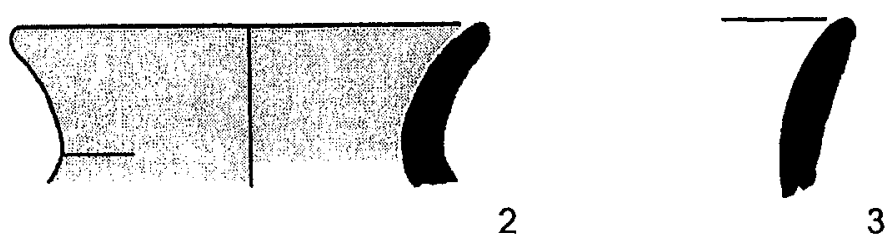

3

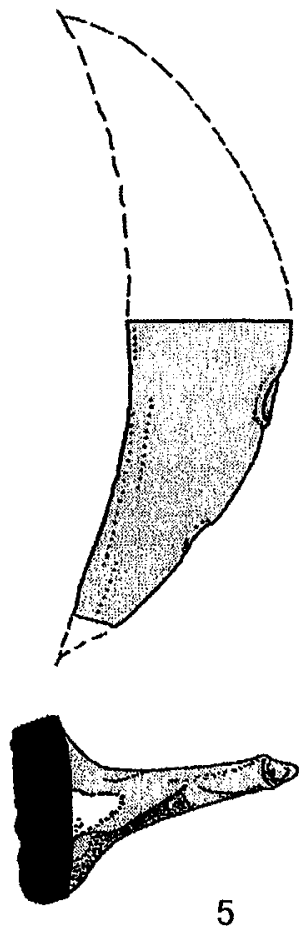

PLATE 108 (CONT.).
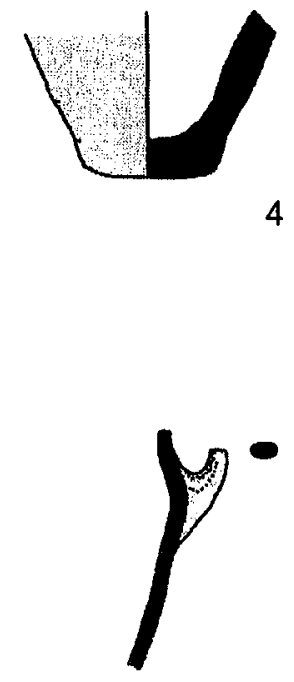

6

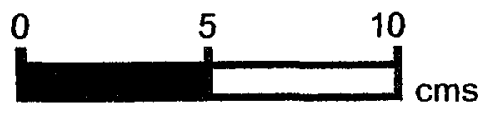




\begin{tabular}{llllllll}
\hline No & Reg & Square & Locus & Vessel & Part & $\begin{array}{c}\text { Body } \\
\text { Thick }\end{array}$ & Dia \\
\hline 1 & 1297 & SW 1-7 & 219 & HOLE MOUTH BOWL & R01 & 15 & 20 \\
2 & 1298 & SW $1-7$ & 219 & NECKED JAR & R81 & 11 & 12 \\
3 & 1296 & SW $1-7$ & 219 & NECKED JAR & R43 & 10 & 20 \\
4 & 1299 & SW $1-7$ & 219 & CHANNELED RIM JAR & R35 & 7 & 10 \\
5 & 1300 & SW 1-7 & 219 & UD & H46 & 6 & N \\
6 & 1302 & SW 1-7 & 219 & UD & H20 & 6 & N
\end{tabular}

\begin{tabular}{lllll}
\hline No Fabric Color & Core Orient & Core Color & Core Thick & Fabric \\
& & & Family
\end{tabular}

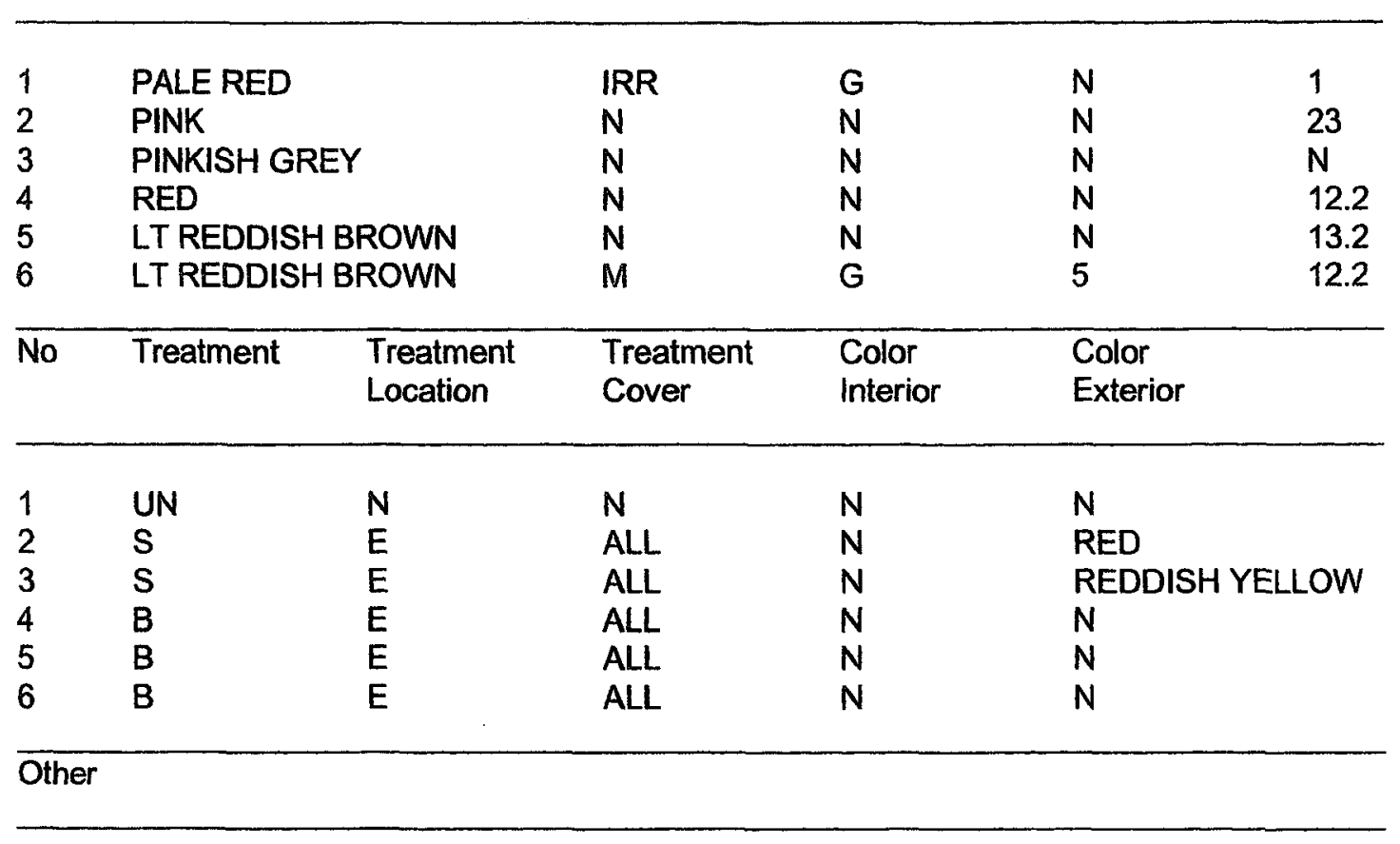

1. Surface burn visible.

3 Features in break suggest rim folding.

$4 \quad$ Also in Fabric Family 12; Metallic Ware.

5 Lug handle is pierced; Metallic Ware.

6 Metallic Ware.

PLATE 109. FIELD B. PHASE 1B (LATE EB I - EARLY EB II). 

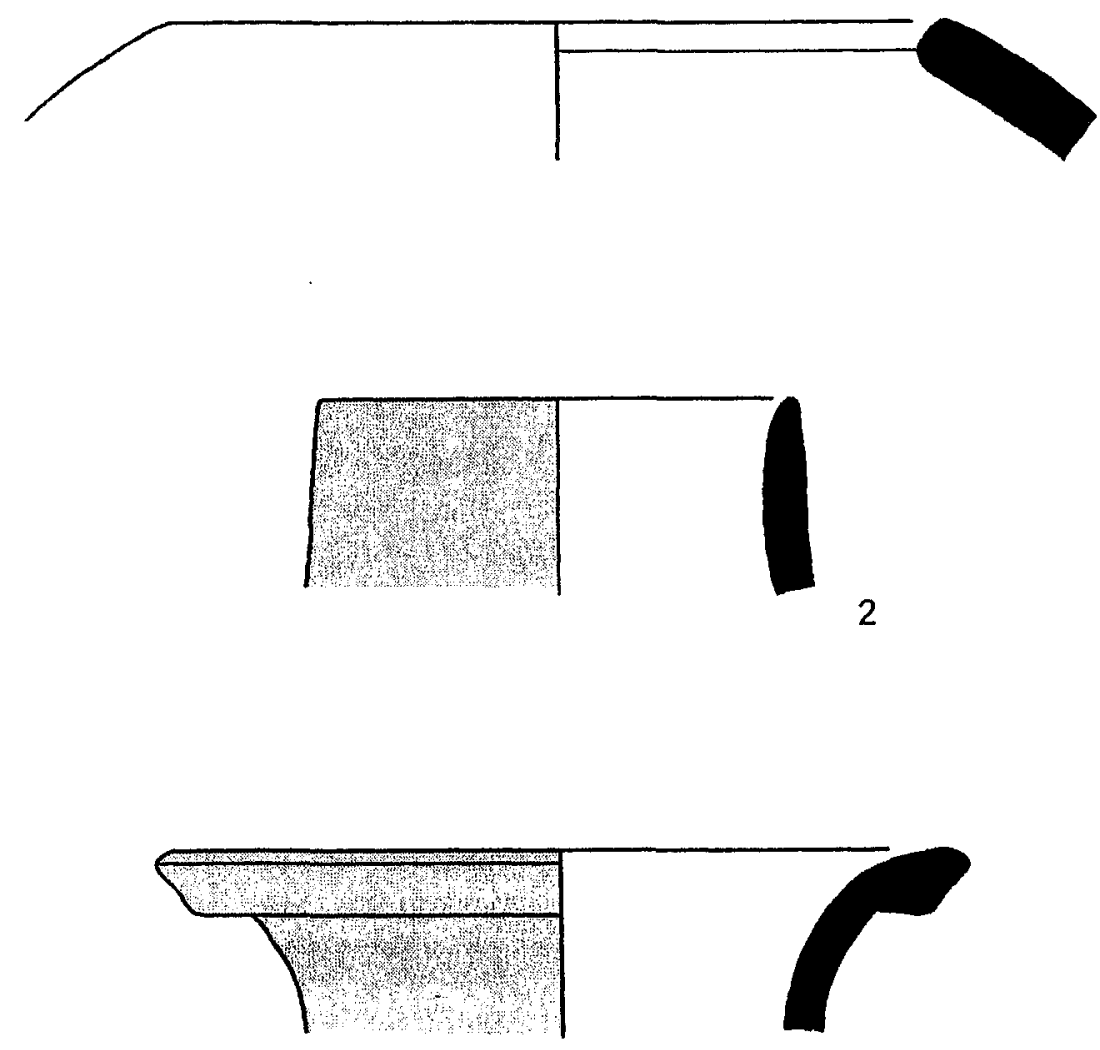

3
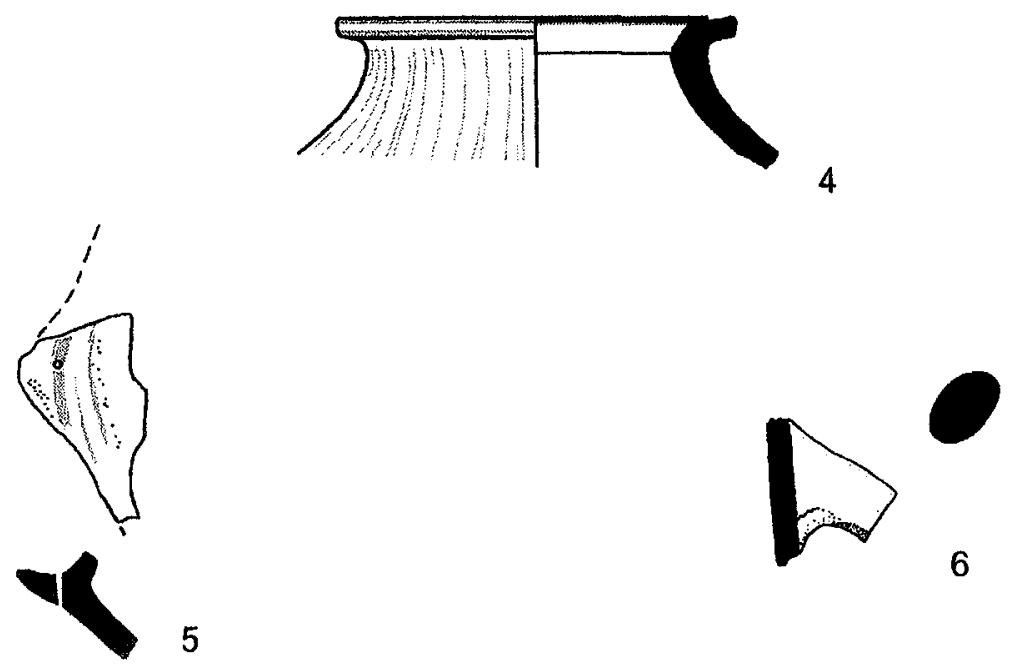

PLATE 109 (CONT.).

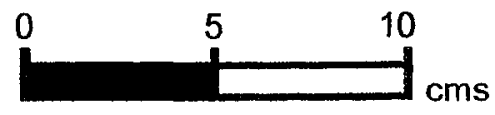


479

\begin{tabular}{lllllllll}
\hline No & Reg & Square & Locus & Vessel & Part & $\begin{array}{l}\text { Body } \\
\text { Thick }\end{array}$ & Dia \\
\hline & & & & & & & \\
1 & 1253 & SW $1-7$ & 189 & BOWL & R50 & 6 & 17 \\
2 & 1252 & SW $1-7$ & 189 & NECKED JAR & R32 & 10 & 19 \\
3 & 1255 & SW $1-7$ & 189 & UD & B12 & 10 & 25 \\
4 & 1254 & SW $1-7$ & 189 & UD & H14 & 9 & N
\end{tabular}

\begin{tabular}{lllll}
\hline No Fabric Color & Core Orient & Core Color & Core Thick & Fabric \\
& & & Family
\end{tabular}

\begin{tabular}{|c|c|c|c|c|c|c|}
\hline $\begin{array}{l}1 \\
2 \\
3 \\
4\end{array}$ & $\begin{array}{l}\text { PINK } \\
\text { LT RED } \\
\text { LT RED } \\
\text { LT RED }\end{array}$ & & $\begin{array}{l}\mathbf{N} \\
\mathrm{N} \\
\text { IN } \\
\text { IRR }\end{array}$ & $\begin{array}{l}N \\
N \\
G \\
G\end{array}$ & $\begin{array}{l}N \\
N \\
6 \\
N\end{array}$ & $\begin{array}{l}N \\
N \\
N \\
N\end{array}$ \\
\hline$\overline{\text { No }}$ & Treatment & $\begin{array}{l}\text { Treatment } \\
\text { Location }\end{array}$ & $\begin{array}{l}\text { Treatment } \\
\text { Cover }\end{array}$ & $\begin{array}{l}\text { Color } \\
\text { Interior }\end{array}$ & $\begin{array}{l}\text { Color } \\
\text { Exterior }\end{array}$ & \\
\hline $\begin{array}{l}1 \\
2 \\
3 \\
4\end{array}$ & $\begin{array}{l}S \\
\text { UN } \\
S \\
\text { UN }\end{array}$ & $\begin{array}{l}\text { IR } \\
N \\
E \\
N\end{array}$ & $\begin{array}{l}A L L \\
N \\
A L L \\
N\end{array}$ & $\begin{array}{l}\text { RED } \\
N \\
N \\
N\end{array}$ & $\begin{array}{l}\mathbf{N} \\
\mathbf{N} \\
\text { WEAK RED } \\
\mathbf{N}\end{array}$ & \\
\hline
\end{tabular}

2 Metallic Ware.

PLATE 110. FIELD B. PHASE 1C (LATE EB I - EARLY EB II). 

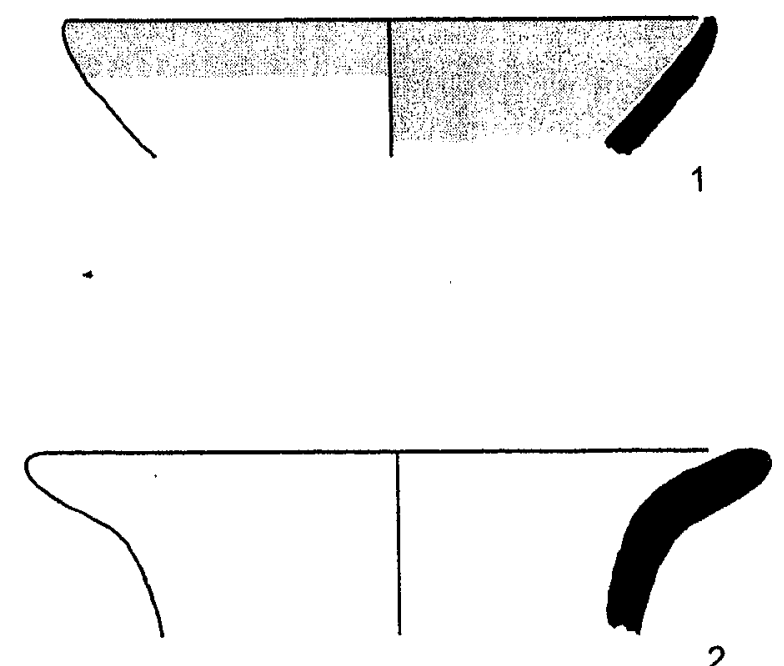

2
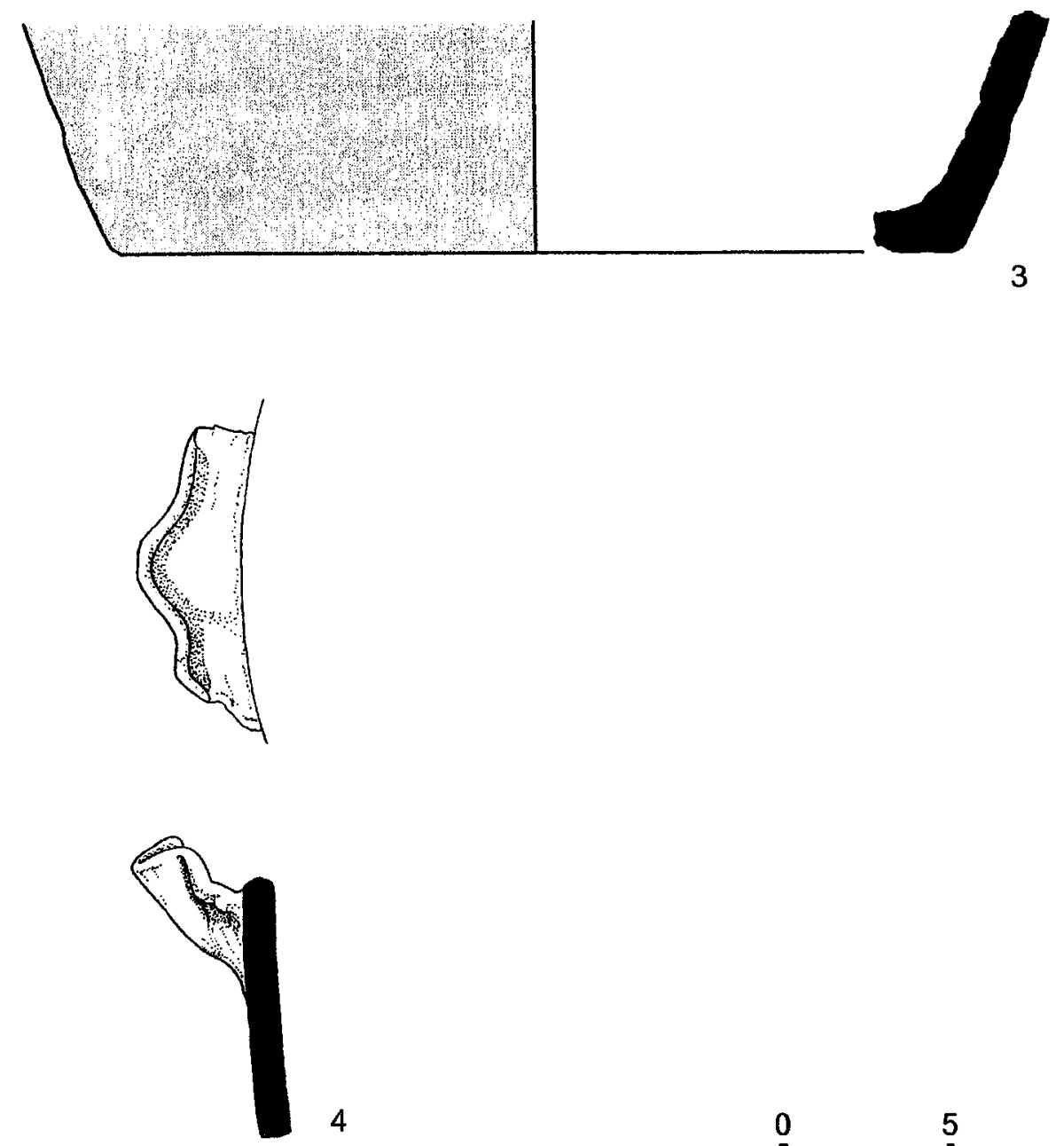

PLATE 110 (CONT.).

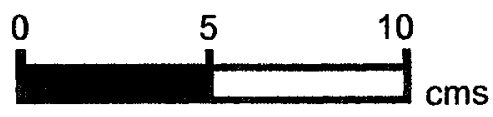




\begin{tabular}{llllllll}
\hline No & Reg & Square & Locus & Vessel & Part & $\begin{array}{c}\text { Body } \\
\text { Thick }\end{array}$ & Dia \\
\hline & & & & & & & \\
1 & 1261 & SW 1-7 & 194 & BOWL & R50 & 8 & 32 \\
2 & 1274 & SW 1-7 & 194 & HOLE MOUTH BOWL & R14 & 9 & 21 \\
3 & 1277 & SW 1-7 & 194 & HOLE MOUTH JAR & R14 & 9 & 18 \\
4 & 1276 & SW 1-7 & 194 & HOLE MOUTH JARIBOWL & R18 & 8 & 15 \\
5 & 1271 & SW 1-7 & 194 & HOLE MOUTH BOWL & R11 & 6 & 15 \\
6 & 1273 & SW 1-7 & 194 & NECKED JAR & R30 & 5 & 13 \\
7 & 1257 & SW 1-7 & 194 & NECKED JAR & R34 & 14 & 15 \\
8 & 1268 & SW 1-7 & 194 & NECKED JAR & R34 & 9 & 20 \\
\hline No & Fabric Color & & Core Orient Core Color & Core Thick & Fabric \\
& & & & &
\end{tabular}

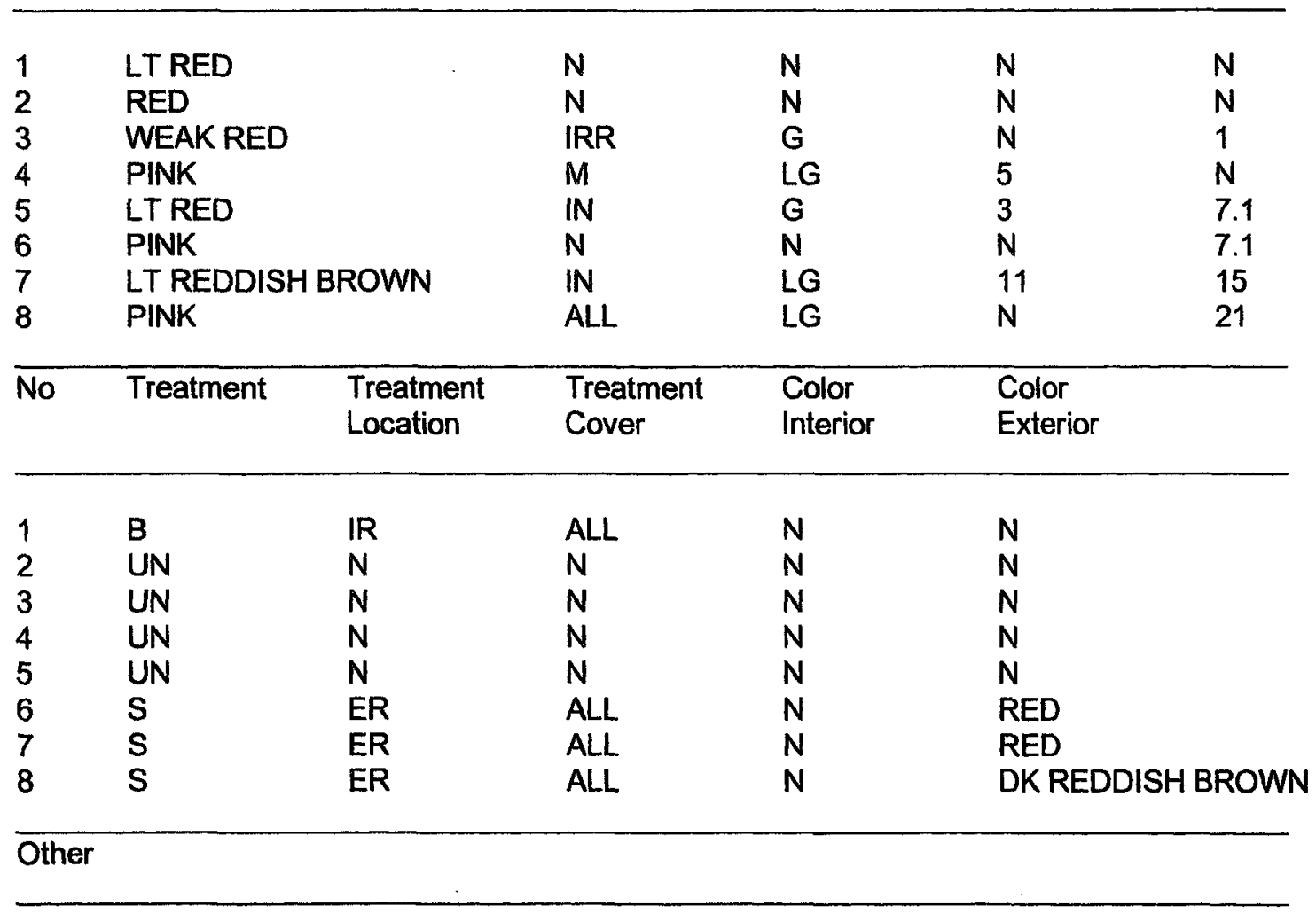

$1 \quad$ Metallic Ware.

3 Surface burn visible.

7 Features in break suggest mid-rim ridge added as an application and smoothed.

8 Features in break suggest mid-rim ridge added as an application and smoothed.

PLATE 111. FIELD B. PHASE 1C (LATE EB I - EARLY EB II). 


\section{2}
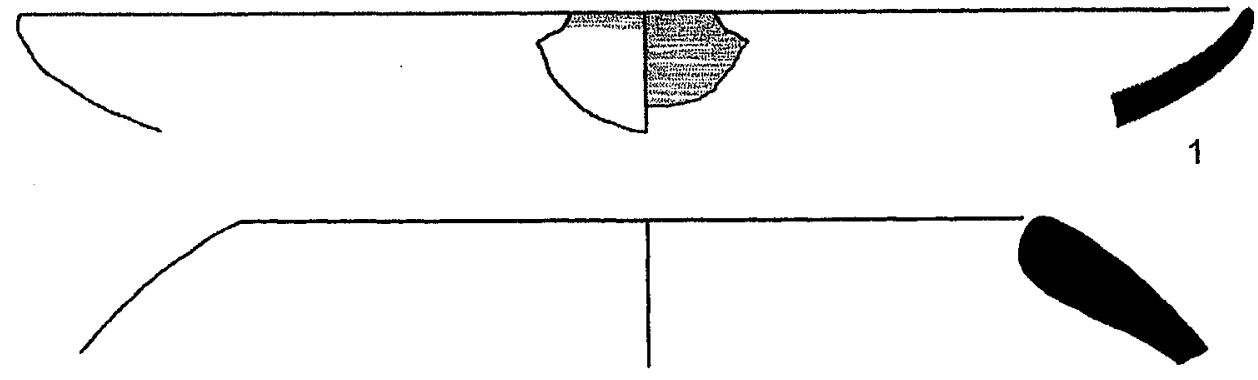

2

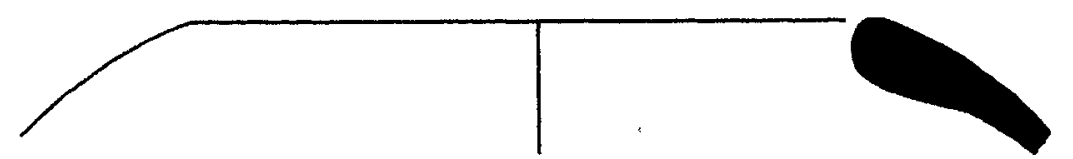

3

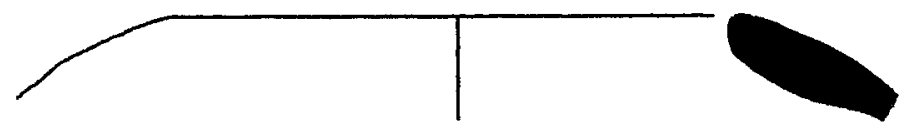

4

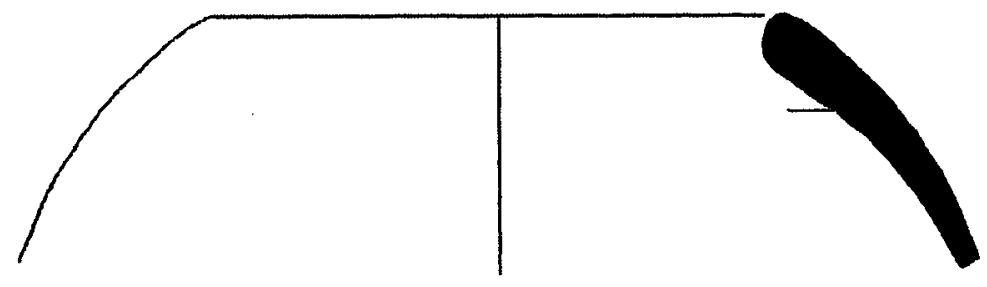

5
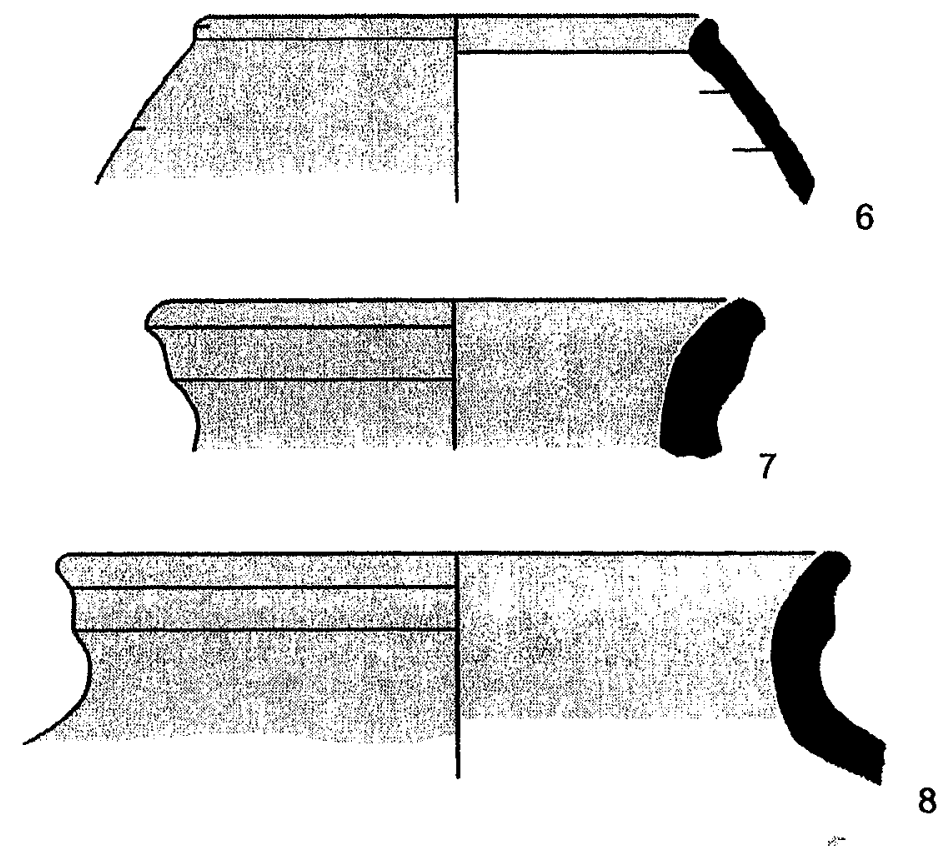

PLATE 111 (CONT.).

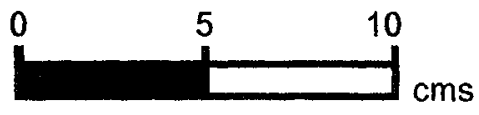




\begin{tabular}{llllllll}
\hline No & Reg & Square & Locus & Vessel & Part & $\begin{array}{l}\text { Body } \\
\text { Thick }\end{array}$ & Dia \\
\hline & & & & & & & \\
1 & 1256 & SW 1-7 & 194 & NECKED JAR & R31 & 9 & 14 \\
2 & 1270 & SW 1-7 & 194 & NECKED JAR & R42 & 11 & 18 \\
3 & 1272 & SW 1-7 & 194 & NECKED JAR & R31 & 6 & 13 \\
4 & 1278 & SW 1-7 & 194 & NECKED JAR & R30 & 10 & 15 \\
5 & 1287 & SW 1-7 & 194 & NECKED JAR & R30 & 7 & 15 \\
6 & 1264 & SW 1-7 & 194 & BOW RIM JAR & R33 & 17 & 20 \\
7 & 1260 & SW 1-7 & 194 & NECKED JAR & R43 & 8 & 24 \\
8 & 1259 & SW 1-7 & 194 & NECKED JAR & R43 & 6 & 9
\end{tabular}

\begin{tabular}{lllll}
\hline No Fabric Color Core Orient & Core Color Core Thick & $\begin{array}{l}\text { Fabric } \\
\text { Family }\end{array}$
\end{tabular}

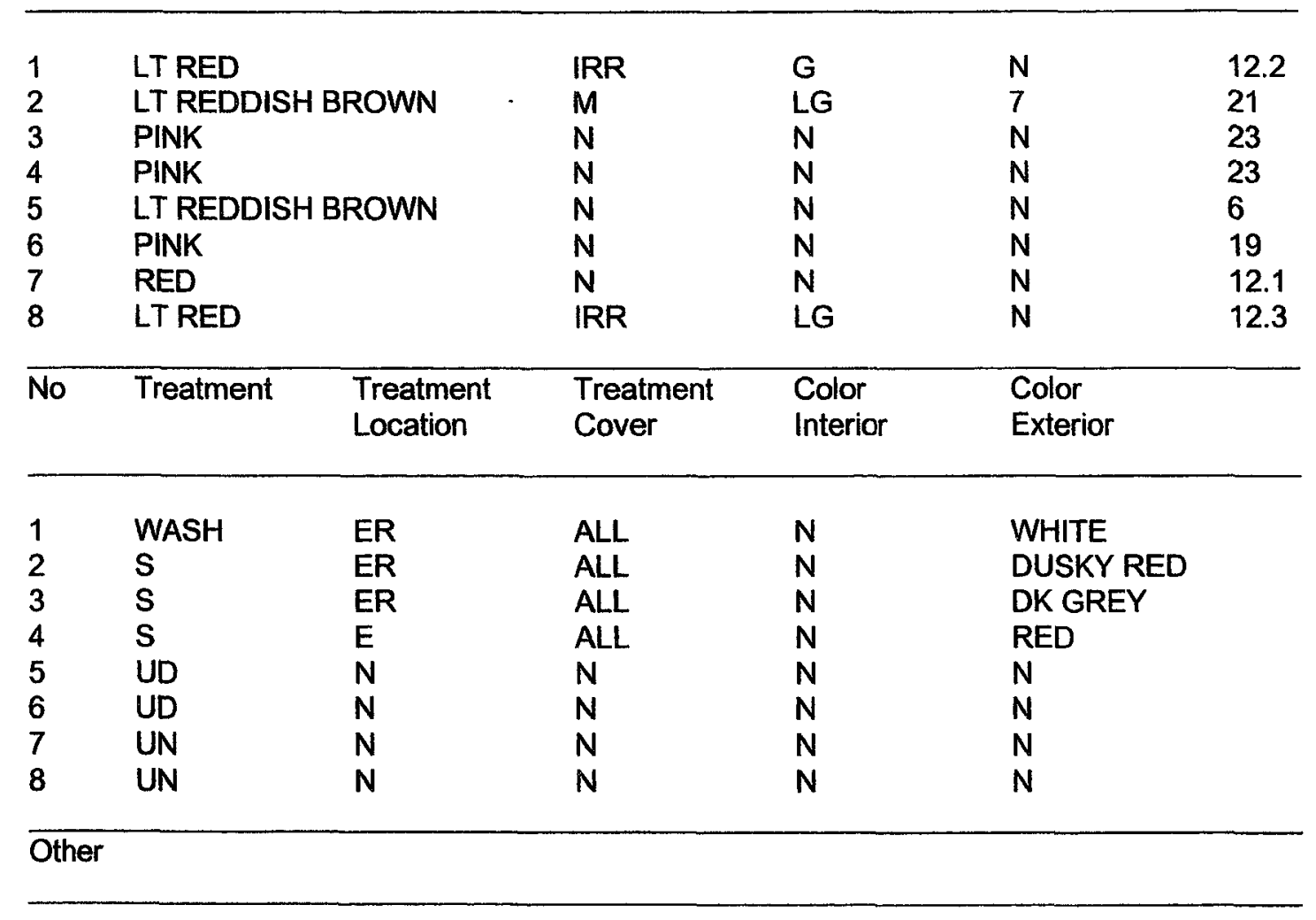

$\begin{array}{ll}1 & \text { Metallic Ware. } \\ 7 & \text { Metallic Ware. } \\ 8 & \text { Punctured margin on neck; combed Metallic Ware. }\end{array}$

PLATE 112. FIELD B. PHASE 1C (LATE EB I - EARLY EB II). 

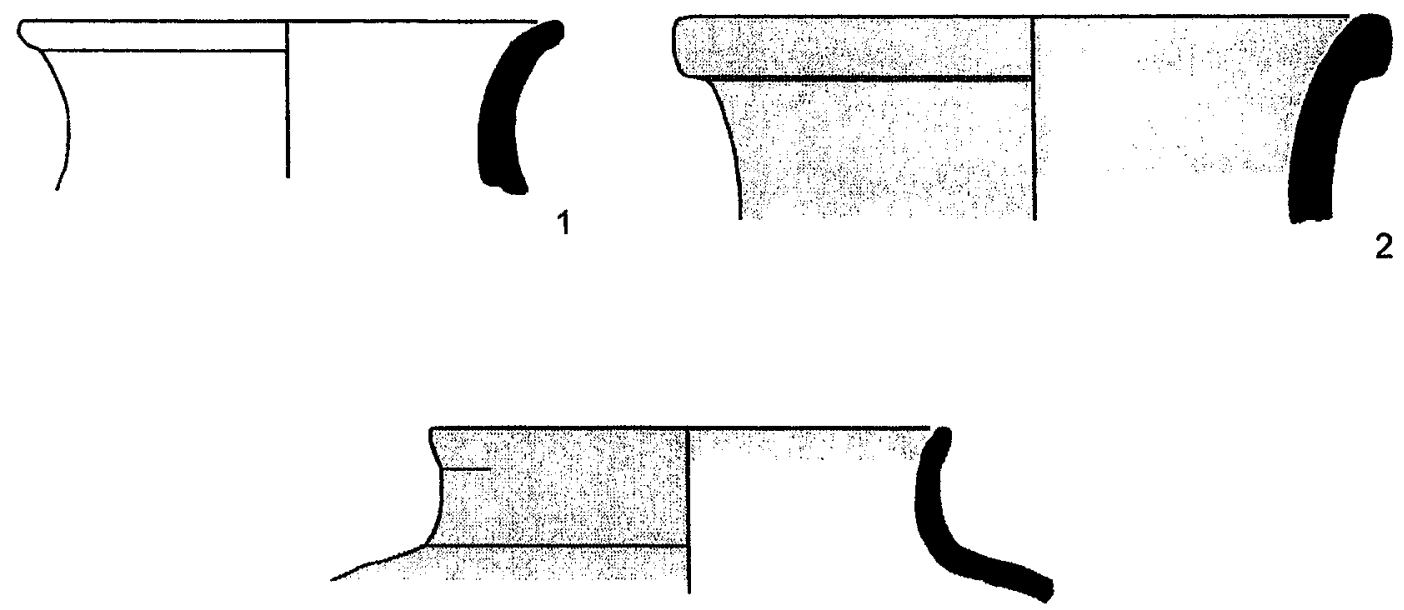

3
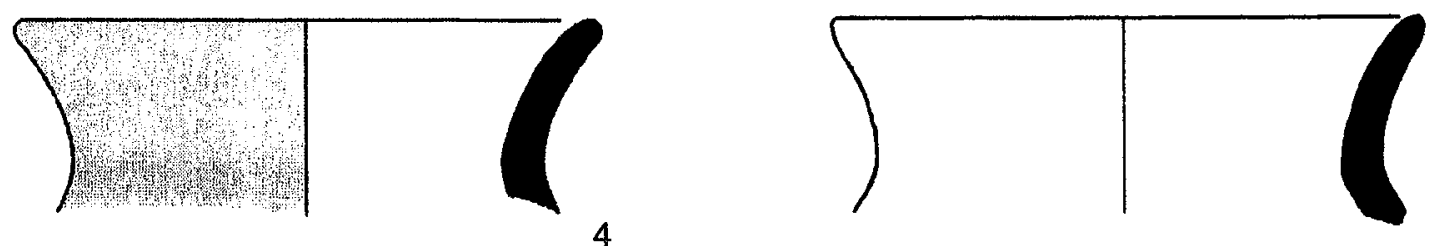

4

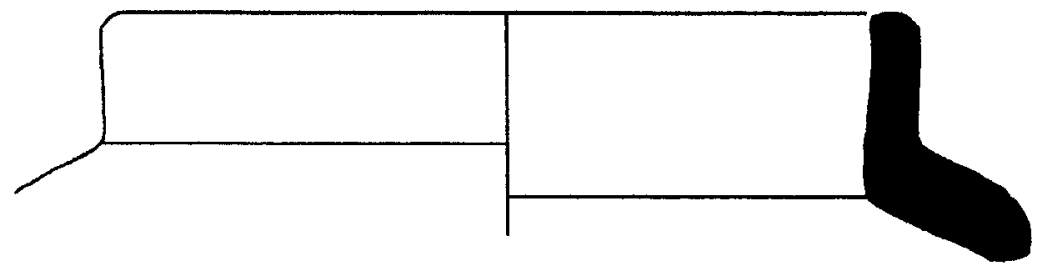

6
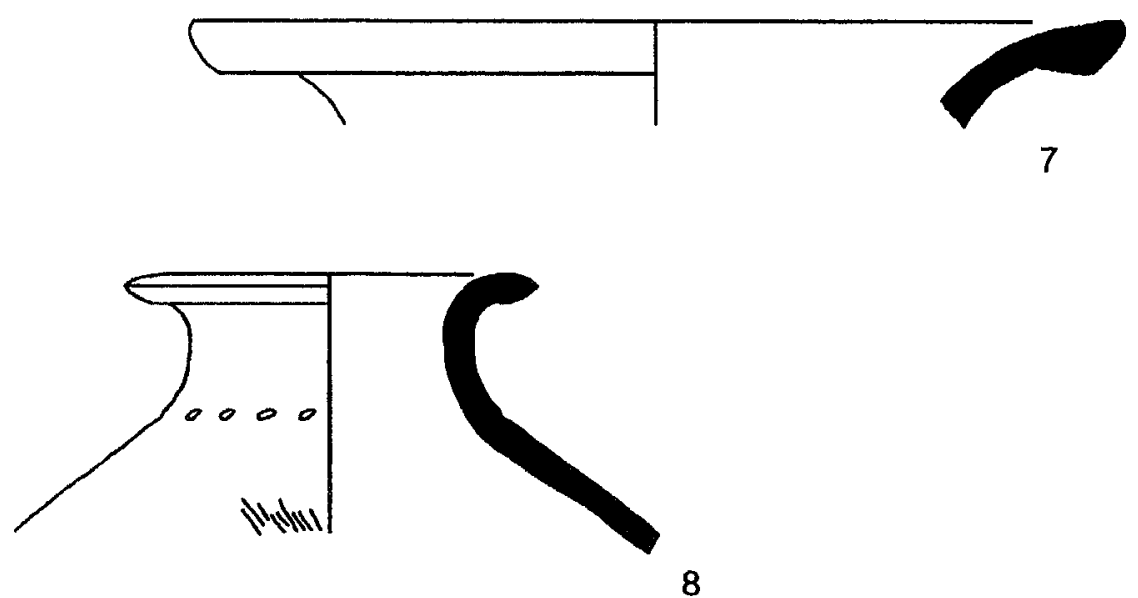

PLATE 112 (CONT.).

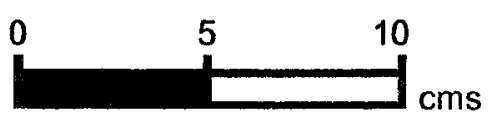




\begin{tabular}{lllllllll}
\hline No & Reg & Square & Locus & Vessel & Part & $\begin{array}{c}\text { Body } \\
\text { Thick }\end{array}$ & Dia \\
\hline 1 & 1285 & SW 1-7 & 194 & UD & H12 & 7 & N \\
2 & 1280 & SW 1-7 & 194 & UD & H20 & 8 & N \\
3 & 1281 & SW 1-7 & 194 & UD & H12 & 14 & N \\
4 & 1286 & SW 1-7 & 194 & JUG & B12 & 5 & 7 \\
5 & 1283 & SW 1-7 & 194 & JUG & H27 & 4 & N \\
6 & 1266 & SW 1-7 & 194 & UD & H20 & 6 & N
\end{tabular}

\begin{tabular}{lllll}
\hline No & Fabric Color & Core Orient & Core Color Core Thick & $\begin{array}{c}\text { Fabric } \\
\text { Family }\end{array}$ \\
\end{tabular}

\begin{tabular}{|c|c|c|c|c|c|c|}
\hline $\begin{array}{l}1 \\
2 \\
3 \\
4 \\
5 \\
6\end{array}$ & $\begin{array}{l}\text { LT RED } \\
\text { PINK } \\
\text { PINK } \\
\text { LT RED } \\
\text { LT RED } \\
\text { PINK }\end{array}$ & & $\begin{array}{l}\text { IRR } \\
\text { N } \\
\text { IRR } \\
N \\
N \\
\text { IRR }\end{array}$ & $\begin{array}{l}\text { LG } \\
N \\
L G \\
N \\
N \\
L G\end{array}$ & $\begin{array}{l}N \\
N \\
N \\
N \\
N \\
N\end{array}$ & $\begin{array}{l}9.2 \\
N \\
19 \\
12.1 \\
N \\
N\end{array}$ \\
\hline No & Treatment & $\begin{array}{l}\text { Treatment } \\
\text { Location }\end{array}$ & $\begin{array}{l}\text { Treatment } \\
\text { Cover }\end{array}$ & $\begin{array}{l}\text { Color } \\
\text { Interior }\end{array}$ & $\begin{array}{l}\text { Color } \\
\text { Exterior }\end{array}$ & \\
\hline $\begin{array}{l}1 \\
2 \\
3 \\
4 \\
5 \\
6\end{array}$ & $\begin{array}{l}\text { WASH } \\
\text { S } \\
\text { S } \\
\text { B } \\
\text { B } \\
\text { S }\end{array}$ & $\begin{array}{l}E \\
E \\
E \\
E \\
E \\
E\end{array}$ & $\begin{array}{l}\text { ALL } \\
\text { ALL } \\
\text { ALL } \\
\text { ALL } \\
\text { ALL } \\
\text { ALL }\end{array}$ & $\begin{array}{l}N \\
N \\
N \\
N \\
N \\
N\end{array}$ & $\begin{array}{l}\text { WHITE } \\
\text { DUSKY RED } \\
\text { RED } \\
\mathbf{N} \\
\mathrm{N} \\
\text { DK REDDISH }\end{array}$ & BROWN \\
\hline
\end{tabular}

$4 \quad$ Metallic Ware.

5 Metallic Ware.

PLATE 113. FIELD B. PHASE 1C (LATE EB I - EARLY EB II). 

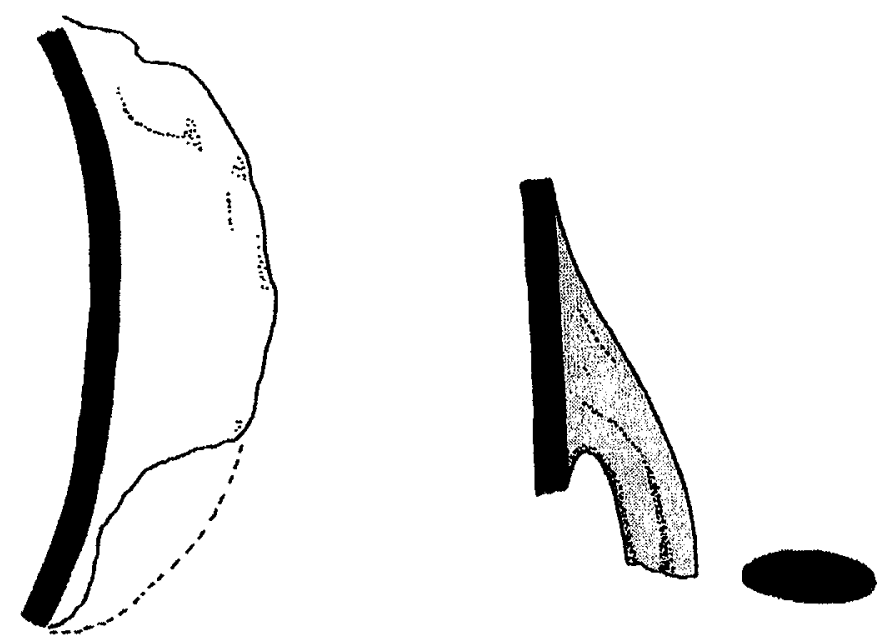

2
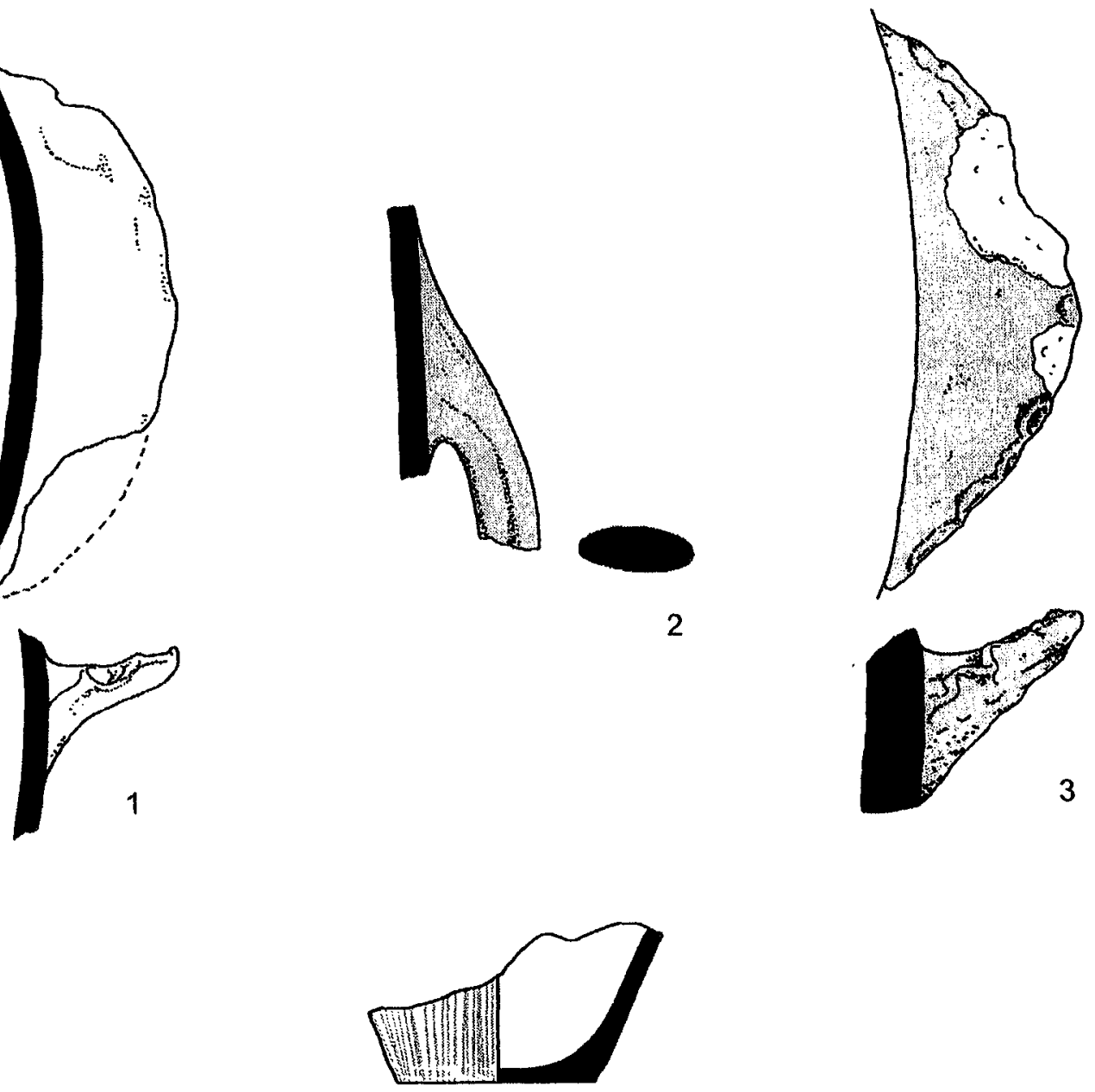

4
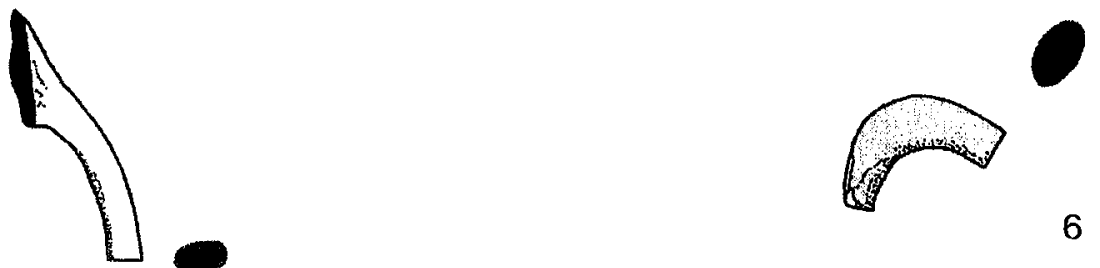

5

PLATE 113 (CONT.).

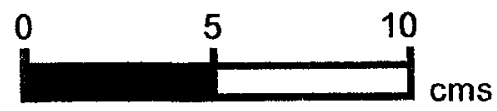




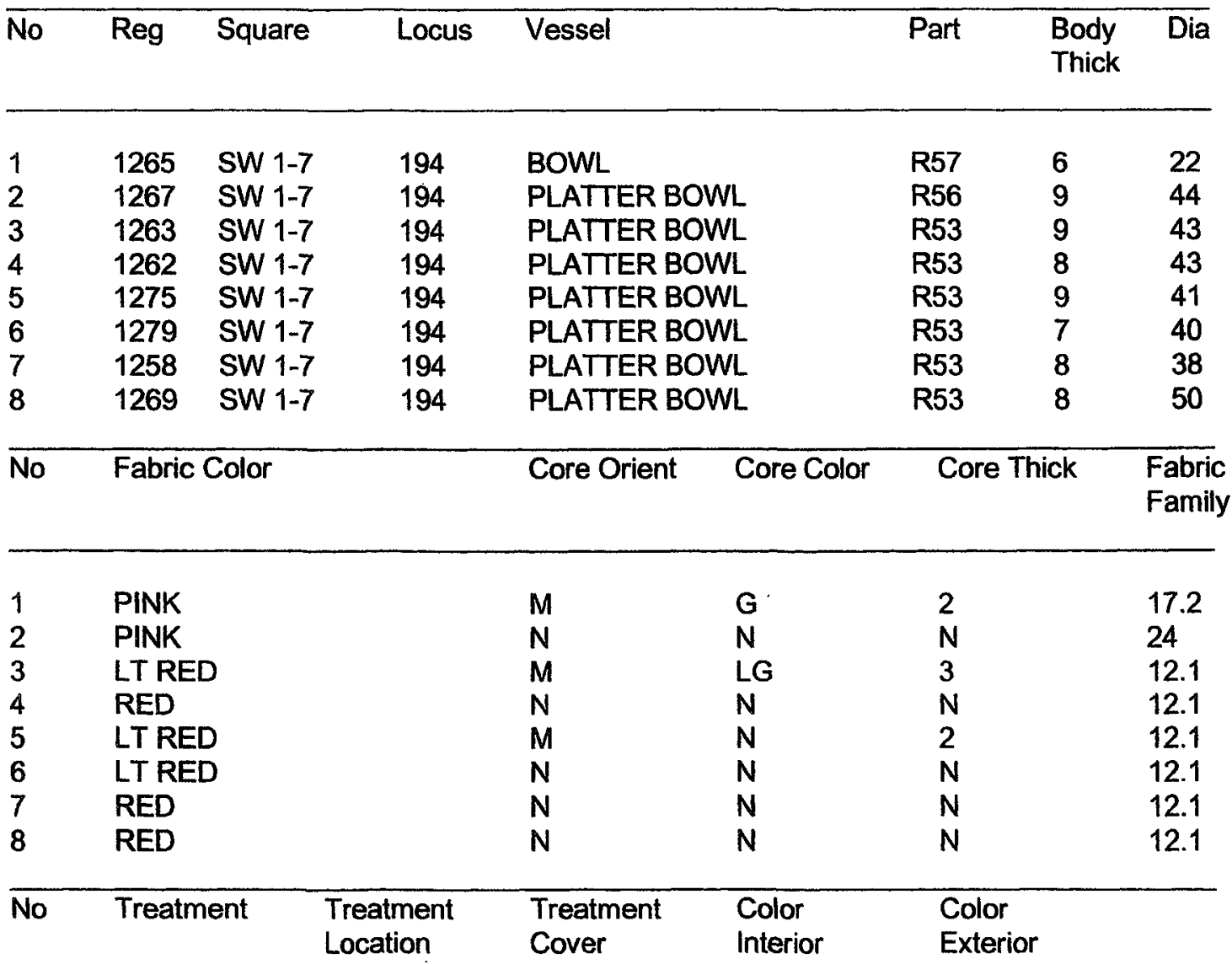

\begin{tabular}{llllll}
\hline 1 & S & E & ALL & N & RED \\
2 & S & IR & ALL & RED & N \\
3 & B & IR & ALL & N & N \\
4 & B & IR & ALL & N & N \\
5 & B & IR & ALL & N & N \\
6 & B & IR & ALL & N & N \\
7 & B & IE & ALL & N & N \\
8 & B & IE & ALL & N & N \\
\hline
\end{tabular}

1 Surface burn visible.

2 Very weathered; traces of burnished slip visible on interior face.

3 Metallic Ware.

4 Exterior face is well burnished, including concavity; rim shows marks of wheel burnish and face appears to be radially wiped; Metallic Ware.

$5 \quad$ Metallic Ware.

6 Exterior face is well burnished, including concavity; Thin section sample 14; Metallic Ware.

7 Metallic Ware.

8 Exterior face is well burnished, including concavity; interior face has fine lines suggestive of radial wiping; Metallic Ware.

PLATE 114. FIELD B. PHASE 1C (LATE EB I - EARLY EB II). 

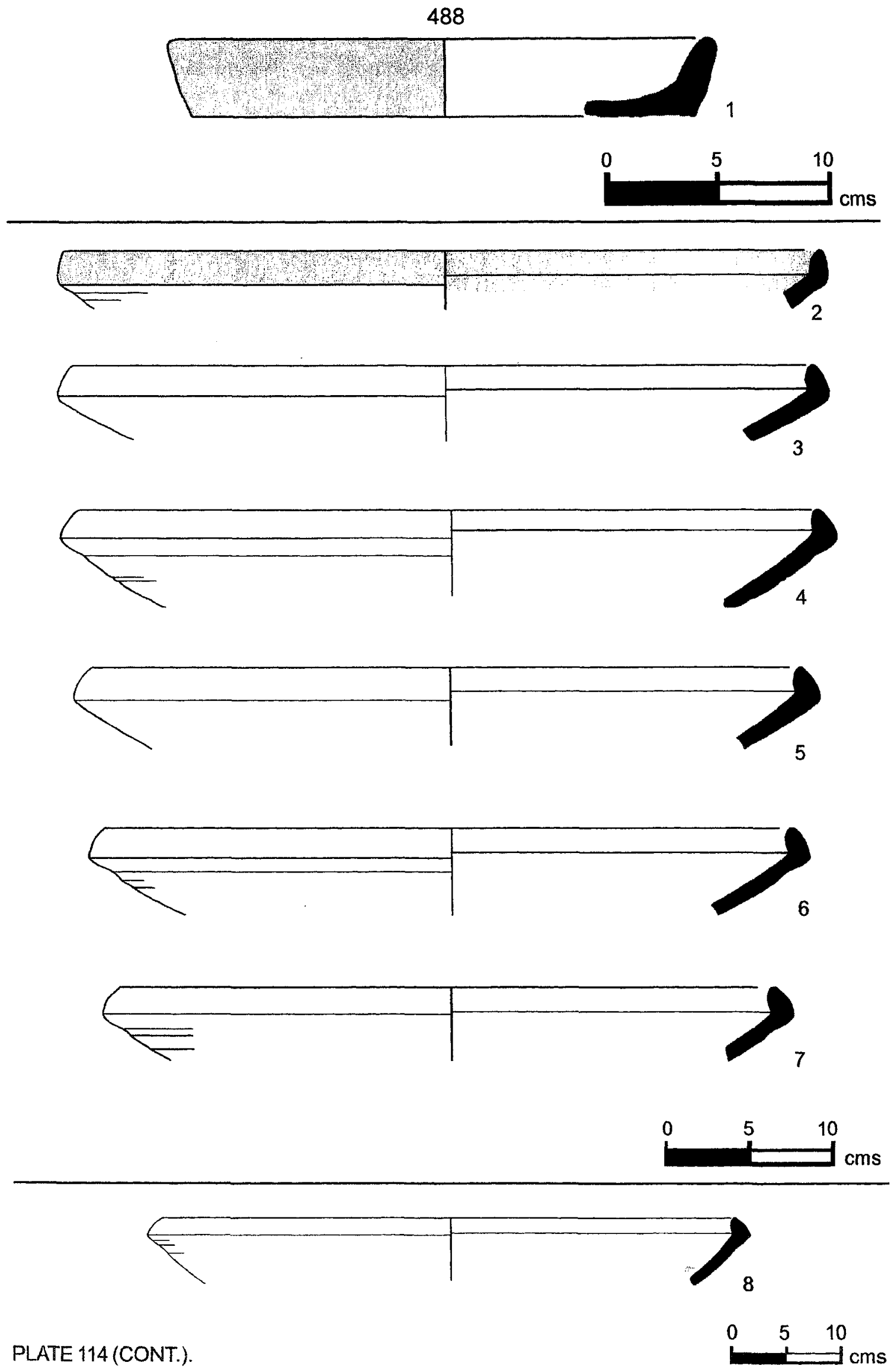


\begin{tabular}{llllllll}
\hline No & Reg & Square & Locus & Vessel & Part & $\begin{array}{c}\text { Body } \\
\text { Thick }\end{array}$ & $\begin{array}{c}\text { Dia } \\
\end{array}$ \\
& & & & & & & \\
1 & 1408 & SW 1-8 & 100 & HOLE MOUTH BOWL & R22 & 6 & 24 \\
2 & 1410 & SW 1-8 & 100 & HOLE MOUTH JAR & R14 & 8 & 18 \\
3 & 1407 & SW 1-8 & 109 & LEDGE RIM BOWL & R51 & 5 & 14 \\
4 & 1406 & SW 1-8 & 109 & NECKED JAR & R31 & 10 & N \\
5 & 2325 & SW 1-8 & 109 & PLATTER BOWL & R56 & 13 & N \\
6 & 1411 & SW 1-8 & 100 & UD & H10 & 6 & N \\
7 & 1409 & SW 1-8 & 100 & HOLE MOUTH BOWL & R22 & 7 & 32
\end{tabular}

\begin{tabular}{lllll}
\hline No Fabric Color & Core Orient & Core Color & Core Thick & Fabric \\
Family
\end{tabular}

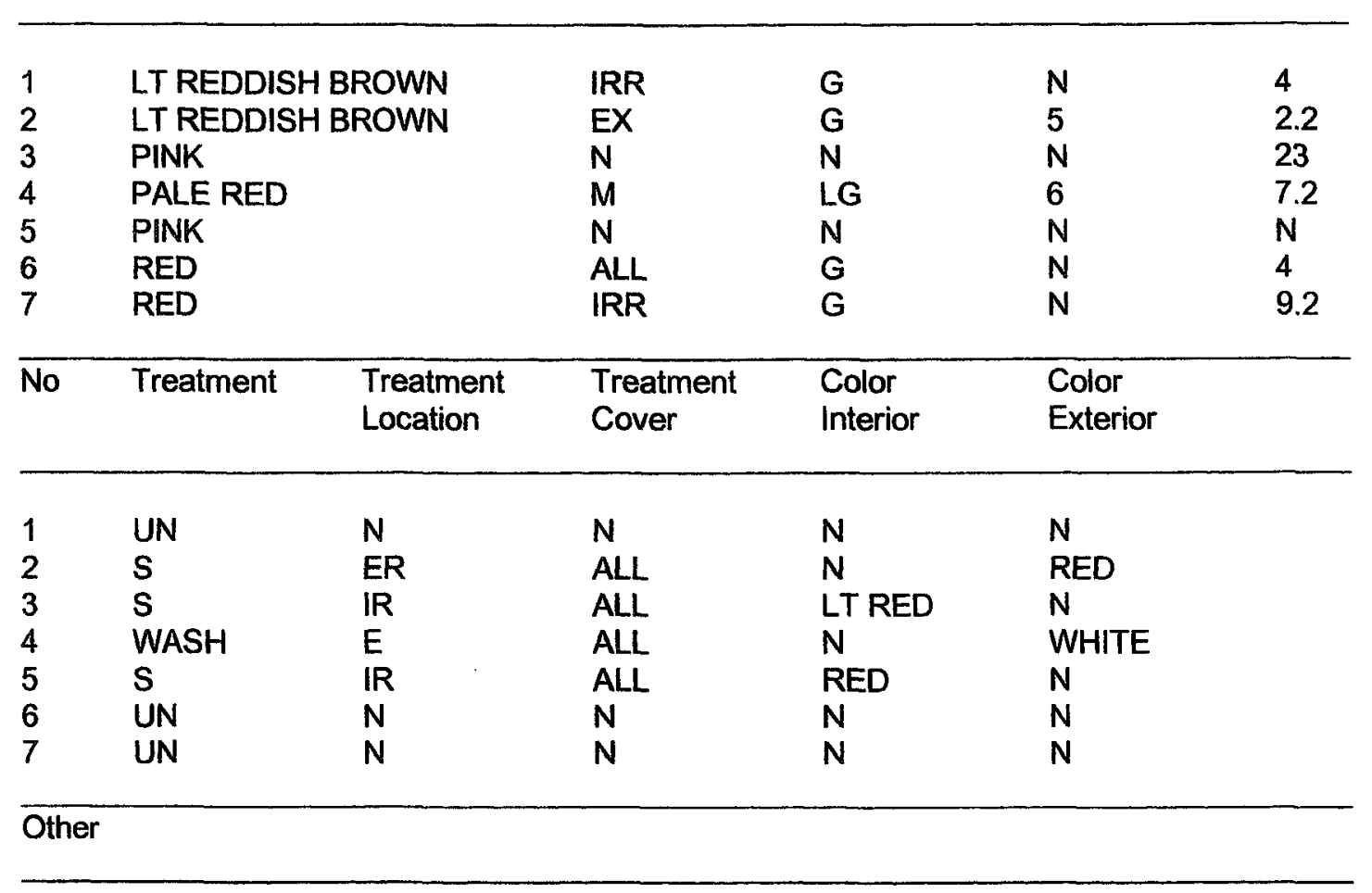

1 Surface burn visible.

2 Surface burn visible.

3 Lines of wet-smoothing appear on exterior face.

4 Sample too small to confirm stance or diameter.

5 Sample too small to confirm stance or diameter.

6 Surface burn visible.

PLATE 115. FIELD B. PHASE 1C (LATE EB I - EARLY EB II). 


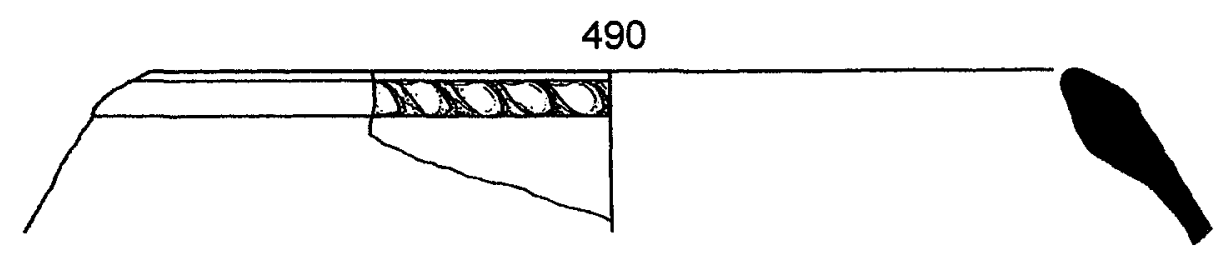

1
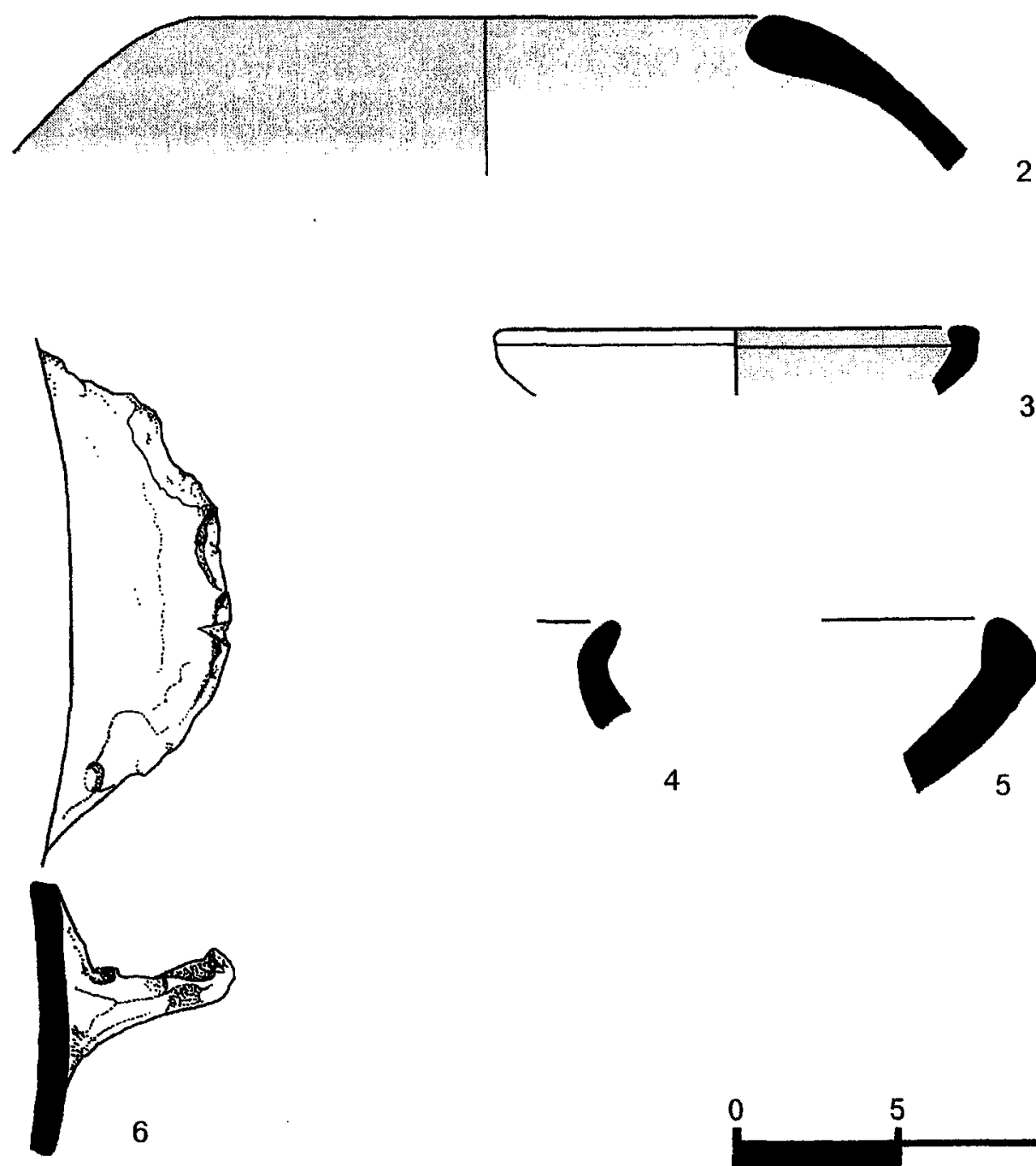

4
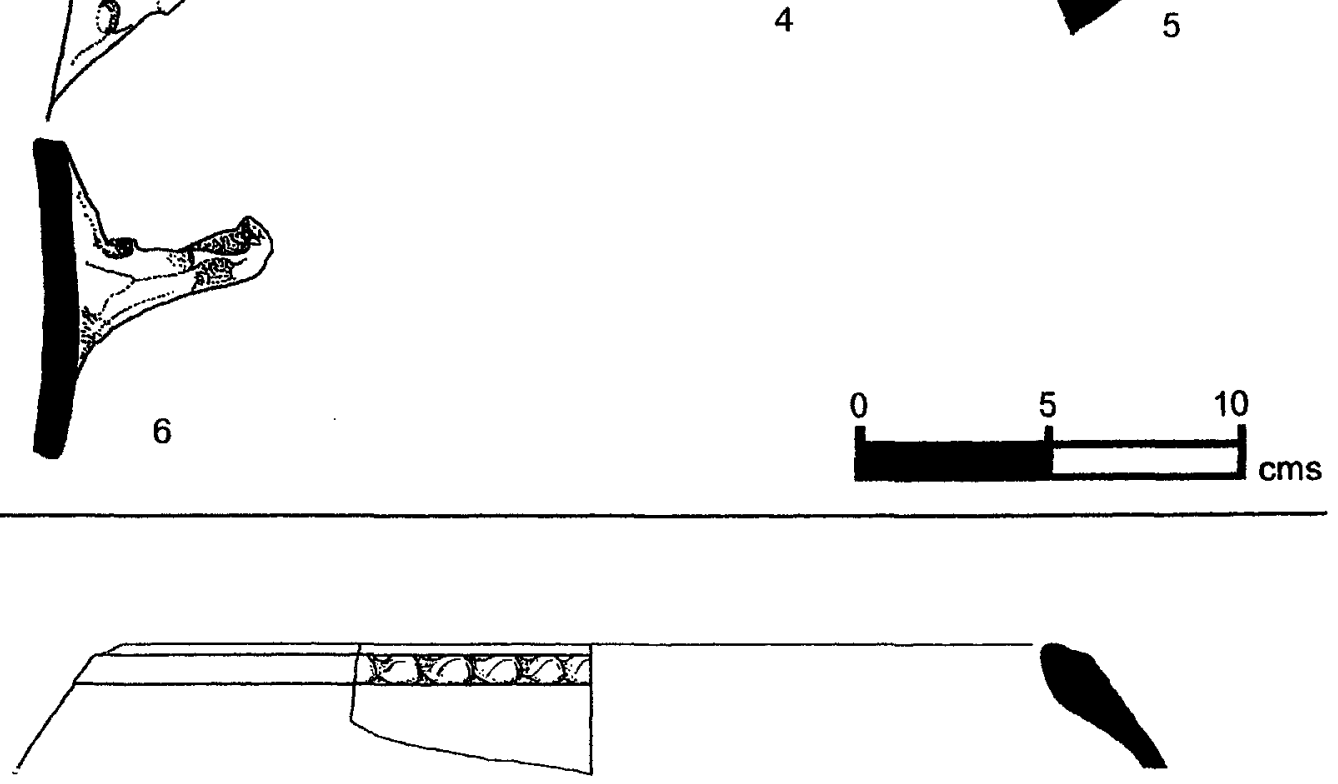

PLATE 115 (CONT.).

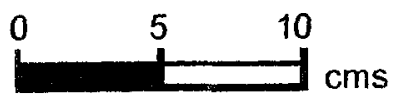




\begin{tabular}{llllllll}
\hline No & Reg & Square & Locus & Vessel & Part & $\begin{array}{l}\text { Body } \\
\text { Thick }\end{array}$ & Dia \\
\hline 1 & 1395 & SW 1-8 & 121 & PLATTER BOWL & R53 & 11 & 30 \\
2 & 1397 & SW 1-8 & 121 & HOLE MOUTH JAR & R14 & 8 & 30 \\
3 & 1402 & SW 1-8 & 121 & HOLE MOUTH JAR & R01 & 10 & 18 \\
4 & 1403 & SW 1-8 & 121 & HOLE MOUTH BOWL & R11 & 9 & 20 \\
5 & 1394 & SW 1-8 & 121 & HOLE MOUTH BOWL & R11 & 10 & 18 \\
6 & 1404 & SW 1-8 & 121 & UD & H27 & 9 & N \\
7 & 1396 & SW 1-8 & 121 & NECKED JAR & R31 & 10 & 18 \\
8 & 1401 & SW 1-8 & 121 & UD & SPT & 16 & N \\
9 & 1398 & SW 1-8 & 121 & UD & H27 & 7 & N \\
10 & 1405 & SW 1-8 & 121 & UD & B12 & 6 & 6 \\
11 & 1399 & SW 1-8 & 121 & UD & B11 & 6 & 9
\end{tabular}

\begin{tabular}{lllll}
\hline No Fabric Color & Core Orient Core Color Core Thick & Fabric \\
& & Family
\end{tabular}

\begin{tabular}{|c|c|c|c|c|c|c|}
\hline 1 & \multicolumn{2}{|l|}{ PINK } & $M$ & LG & 4 & 7.1 \\
\hline 2 & \multicolumn{2}{|c|}{ LT REDDISH BROWN } & IRR & G & $\mathbf{N}$ & 1 \\
\hline 3 & \multicolumn{2}{|c|}{ LT REDDISH BROWN } & IRR & $\mathbf{G}$ & $N$ & $N$ \\
\hline 4 & \multicolumn{2}{|c|}{ PALE RED } & IRR & LG & $\mathbf{N}$ & $N$ \\
\hline 5 & \multicolumn{2}{|c|}{ WEAK RED } & $M$ & $\mathbf{G}$ & 3 & 3 \\
\hline 6 & \multicolumn{2}{|c|}{ PINK } & IRR & LG & $N$ & $\mathbf{N}$ \\
\hline 7 & \multicolumn{2}{|c|}{ LT REDDISH BROWN } & $\mathrm{N}$ & $\mathbf{N}$ & $N$ & 15 \\
\hline 8 & \multicolumn{2}{|l|}{ PINK } & $\mathbf{N}$ & $\mathbf{N}$ & $\mathbf{N}$ & 17.1 \\
\hline 9 & \multicolumn{2}{|l|}{ PINK } & $\mathbf{N}$ & $\mathbf{N}$ & $\mathbf{N}$ & 7.1 \\
\hline 10 & \multicolumn{2}{|l|}{ PINK } & $\mathrm{N}$ & $\mathbf{N}$ & $\mathbf{N}$ & $\mathbf{N}$ \\
\hline 11 & \multicolumn{2}{|c|}{ LT REDDISH BROWN } & $M$ & $\mathbf{G}$ & 2 & 7 \\
\hline No & Treatment & $\begin{array}{l}\text { Treatment } \\
\text { Location }\end{array}$ & $\begin{array}{l}\text { Treatment } \\
\text { Cover }\end{array}$ & $\begin{array}{l}\text { Color } \\
\text { Interior }\end{array}$ & $\begin{array}{l}\text { Color } \\
\text { Exterior }\end{array}$ & \\
\hline 1 & SB & IE & ALL & RED & RED & \\
\hline 2 & UN & $\mathbf{N}$ & $N$ & $N$ & $N$ & \\
\hline 3 & UN & $\mathbf{N}$ & $\mathbf{N}$ & $\mathbf{N}$ & $\mathbf{N}$ & \\
\hline 4 & UN & $\mathbf{N}$ & $\mathbf{N}$ & $N$ & $N$ & \\
\hline 5 & UN & $N$ & $\mathbf{N}$ & $\mathbf{N}$ & $\mathbf{N}$ & \\
\hline 6 & $\mathbf{S}$ & $E$ & ALL & $\mathbf{N}$ & PALE RED & \\
\hline 7 & UN & $N$ & $\mathbf{N}$ & $N$ & $\mathbf{N}$ & \\
\hline 8 & UN & $\mathrm{N}$ & $\mathbf{N}$ & $\mathrm{N}$ & $\mathrm{N}$ & \\
\hline 9 & $\mathbf{s}$ & $E$ & ALL & $\mathbf{N}$ & RED & \\
\hline 10 & SB & $E$ & ALL & $\mathbf{N}$ & RED & \\
\hline 11 & $\mathbf{S}$ & $E$ & ALL & $\mathbf{N}$ & LT RED & \\
\hline
\end{tabular}

PLATE 116. FIELD B. PHASE 1C (LATE EB I - EARLY EB II). 
Other

1 Radial burnish over red slip on interior face; wheel burnish around rim circumference; random burnish on base; also in Fabric Family 20.

2 Surface burn visible.

3 Surface burn visible.

$4 \quad$ Surface burn visible.

$5 \quad$ Surface burn visible.

7 Fragment of potter's mark preserved.

8 Spout immediately below rim; outside diameter, $3 \mathrm{~cm}$; inside diameter $1.6 \mathrm{~cm}$; spout length $2 \mathrm{~cm}$.

11 Also in Fabric Family 11.

PLATE 116 (CONT.). 

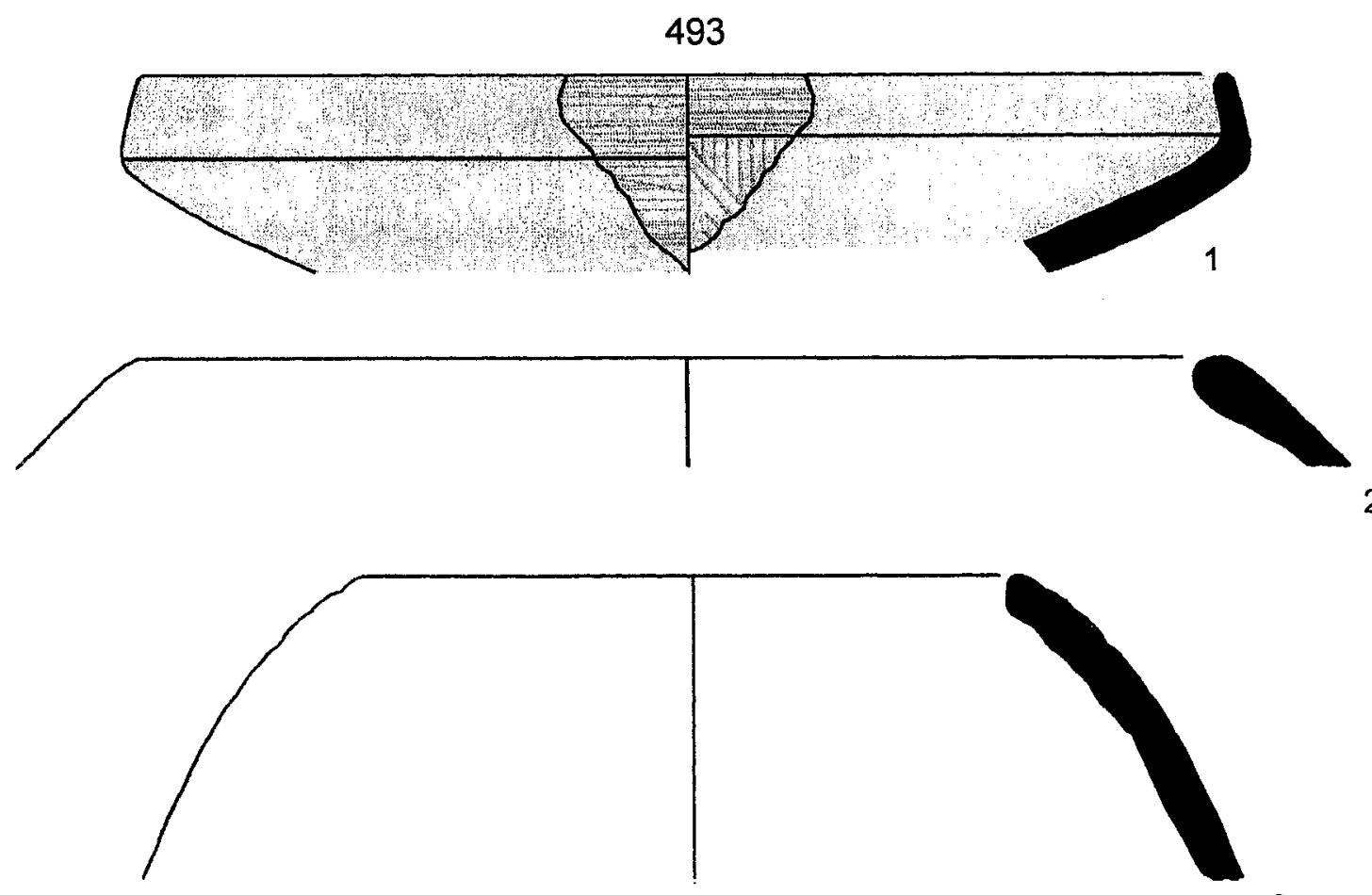

3
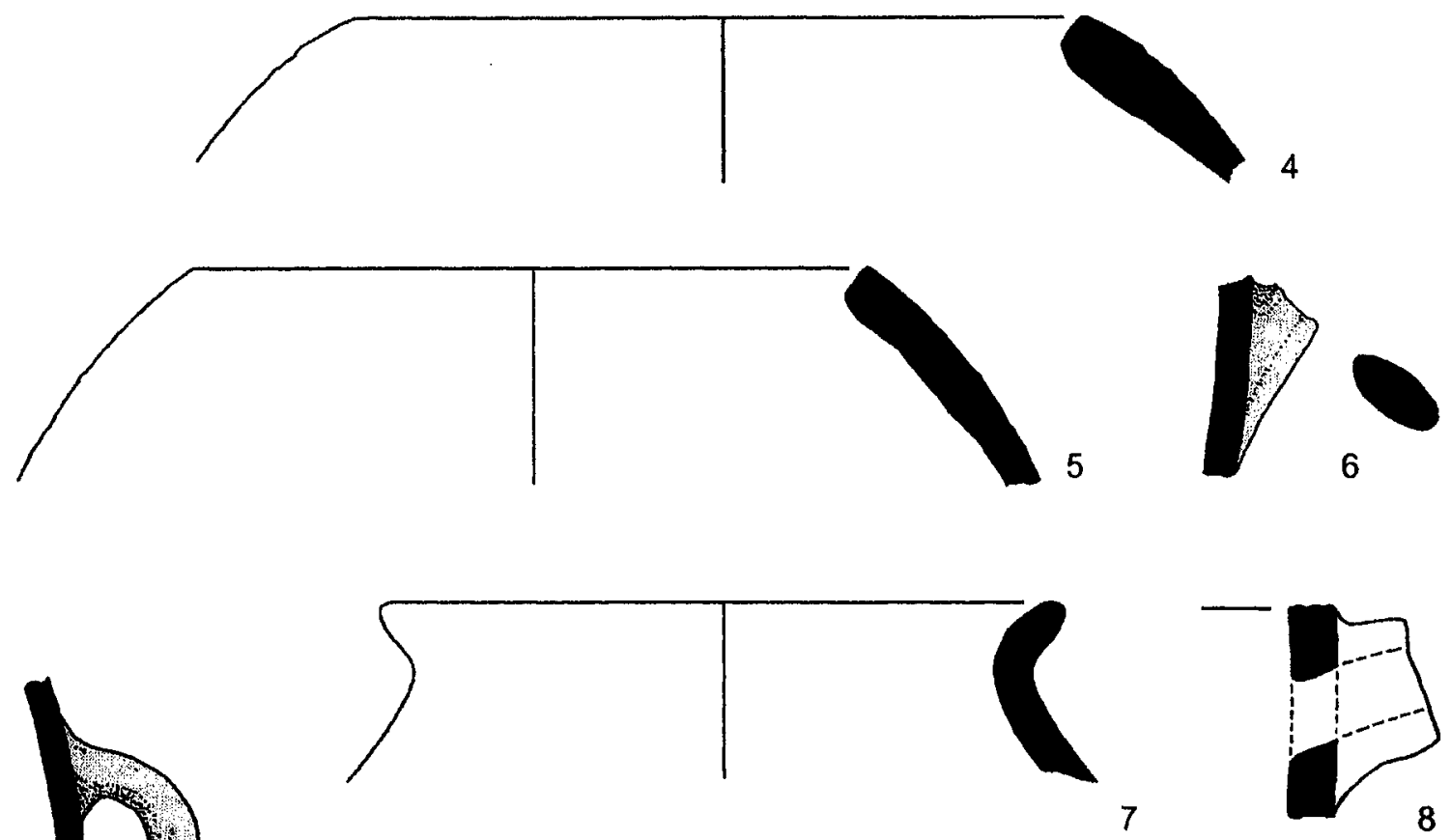

PLATE 116 (CONT.).
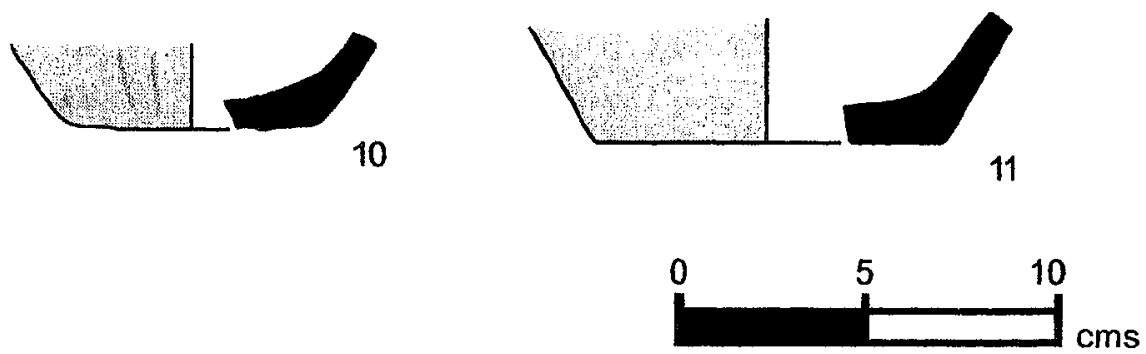


\begin{tabular}{|c|c|c|c|c|c|c|c|}
\hline No & $\operatorname{Reg}$ & Square & Locus & Vessel & Part & $\begin{array}{l}\text { Body } \\
\text { Thick }\end{array}$ & $\overline{D i a}$ \\
\hline 1 & 2364 & SW 1-9 & 201 & BOWL & R81 & $\mathbf{N}$ & 14 \\
\hline 2 & 2346 & SW 1-9 & 201 & NECKED JAR & R42 & 6 & $\mathbf{N}$ \\
\hline 3 & 2421 & SW 1-9 & 201 & PLATTER BOWL & R53 & 7 & $\mathbf{N}$ \\
\hline 4 & 2058 & SW 1-9 & 201 & UD & ROO & $\mathbf{N}$ & $\mathrm{N}$ \\
\hline 5 & 2352 & SW 1-9 & 201 & HOLE MOUTH BOWL & R22 & 8 & $\mathbf{N}$ \\
\hline 6 & 2048 & SW 1-9 & 201 & HOLE MOUTH JAR & R14 & $\mathbf{N}$ & 13 \\
\hline 7 & 2049 & SW 1-9 & 201 & HOLE MOUTH JAR & R14 & $\mathbf{N}$ & 12 \\
\hline 8 & 2066 & SW 1-9 & 201 & HOLE MOUTH JARIBOWL & R22 & 7 & 30 \\
\hline 9 & 2055 & SW 1-9 & 201 & HOLE MOUTH BOWL & R11 & 9 & 24 \\
\hline 10 & 2064 & SW 1-9 & 201 & HOLE MOUTH JARIBOWL & R14 & 8 & 18 \\
\hline 11 & 2065 & SW 1-9 & 201 & HOLE MOUTH BOWL & $\mathrm{R} 11$ & 7 & 18 \\
\hline 12 & 2358 & SW 1-9 & 201 & HOLE MOUTH JAR & R11 & 7 & 14 \\
\hline 13 & 2060 & SW 1-9 & 201 & HOLE MOUTH JAR & R21 & 7 & 16 \\
\hline
\end{tabular}

\begin{tabular}{|c|c|c|c|c|c|c|}
\hline 1 & \multicolumn{2}{|c|}{ LT REDDISH BROWN } & IRR & G & $\mathbf{N}$ & $\mathbf{N}$ \\
\hline 2 & \multicolumn{2}{|l|}{ PINK } & $\mathbf{N}$ & $\mathbf{N}$ & $\mathbf{N}$ & $\mathrm{N}$ \\
\hline 3 & \multicolumn{2}{|l|}{ RED } & $\mathrm{N}$ & $\mathbf{N}$ & $\mathbf{N}$ & $\mathbf{N}$ \\
\hline 4 & \multicolumn{2}{|c|}{ LT REDDISH BROWN } & $\mathbf{N}$ & $\mathrm{N}$ & $\mathbf{N}$ & $\mathrm{N}$ \\
\hline 5 & \multicolumn{2}{|c|}{ PINKISH GREY } & $E$ & $\mathbf{G}$ & IRR & $\mathbf{N}$ \\
\hline 6 & \multicolumn{2}{|c|}{ REDDISH BROWN } & IRR & LG & $\mathrm{N}$ & $\mathrm{N}$ \\
\hline 7 & \multicolumn{2}{|c|}{ REDDISH BROWN } & IRR & LG & $\mathbf{N}$ & $N$ \\
\hline 8 & \multicolumn{2}{|c|}{ LT REDDISH BROWN } & IRR & $G$ & $\mathbf{N}$ & $N$ \\
\hline 9 & \multicolumn{2}{|c|}{ LT RED } & $\mathbf{N}$ & $\mathbf{N}$ & $\mathbf{N}$ & $\mathbf{N}$ \\
\hline 10 & \multicolumn{2}{|l|}{ WEAK RED } & $\mathbf{N}$ & $\mathbf{N}$ & $\mathbf{N}$ & $\mathbf{N}$ \\
\hline 11 & \multicolumn{2}{|c|}{ REDDISH BROWN } & $\mathbf{N}$ & $\mathbf{N}$ & $\mathrm{N}$ & $\mathbf{N}$ \\
\hline 12 & \multicolumn{2}{|c|}{ PINKISH GREY } & $\mathbf{N}$ & $\mathbf{N}$ & $\mathbf{N}$ & $\mathrm{N}$ \\
\hline 13 & \multicolumn{2}{|c|}{ REDDISH YELLOW } & $\mathbf{N}$ & $\mathbf{N}$ & $N$ & $\mathbf{N}$ \\
\hline No & Treatment & $\begin{array}{l}\text { Treatment } \\
\text { Location }\end{array}$ & $\begin{array}{l}\text { Treatment } \\
\text { Cover }\end{array}$ & $\begin{array}{l}\text { Color } \\
\text { Interior }\end{array}$ & $\begin{array}{l}\text { Color } \\
\text { Exterior }\end{array}$ & \\
\hline 1 & $\mathrm{~S}$ & IE & ALL & RED & RED & \\
\hline 2 & $\mathbf{S}$ & ER & ALL & $\mathbf{N}$ & LT RED & \\
\hline 3 & $\mathrm{~B}$ & IR & ALL & $\mathbf{N}$ & $\mathbf{N}$ & \\
\hline 4 & B & IE & ALL & $\mathbf{N}$ & $N$ & \\
\hline 5 & UD & $\mathbf{N}$ & $\mathbf{N}$ & $\mathbf{N}$ & $\mathrm{N}$ & \\
\hline 6 & UN & $\mathrm{N}$ & $N$ & $\mathbf{N}$ & $\mathrm{N}$ & \\
\hline 7 & UN & $\mathbf{N}$ & $\mathbf{N}$ & $\mathbf{N}$ & $\mathbf{N}$ & \\
\hline 8 & UN & $\mathbf{N}$ & $\mathbf{N}$ & $\mathbf{N}$ & $\mathbf{N}$ & \\
\hline 9 & UN & $\mathbf{N}$ & $\mathbf{N}$ & $\mathbf{N}$ & $\mathbf{N}$ & \\
\hline 10 & UN & $\mathbf{N}$ & $\mathbf{N}$ & $\mathbf{N}$ & $\mathbf{N}$ & \\
\hline
\end{tabular}

PLATE 117. FIELD B. PHASE 1C (LATE EB I - EARLY EB II). 


\begin{tabular}{llllll}
\hline No & Treatment & $\begin{array}{l}\text { Treatment } \\
\text { Location }\end{array}$ & $\begin{array}{l}\text { Treatment } \\
\text { Cover }\end{array}$ & $\begin{array}{l}\text { Color } \\
\text { Interior }\end{array}$ & $\begin{array}{l}\text { Color } \\
\text { Exterior }\end{array}$ \\
\hline 11 & UN & $\mathrm{N}$ & $\mathrm{N}$ & $\mathrm{N}$ & $\mathrm{N}$ \\
12 & UN & $\mathrm{N}$ & $\mathrm{N}$ & $\mathrm{N}$ & $\mathrm{N}$ \\
13 & UN & $\mathrm{N}$ & $\mathrm{N}$ & $\mathrm{N}$ & $\mathrm{N}$ \\
\hline
\end{tabular}

$1 \quad$ Also B12; burn on rim suggests use as lamp; mold-marks visible on exterior wall.

2 Sample too small to confirm stance or diameter.

3 Metallic ware; sample too small to confirm stance or diameter.

4 Sample too small to confirm stance or diameter; possibly Grey Burnished Ware.

5 Sample too small to confirm stance or diameter.

8 Sample too small to confirm stance or diameter.

9 Interior lines reveal irregular effort to smooth folded lip; surface burn visible.

10 Surface burn visible.

11 Surface burn visible.

13 "Margin" appears wet-turned, splaying clay forms small ridge; possible (broken) vestigial handle or plastic decoration is located beneath margin.

PLATE 117 (CONT.). 

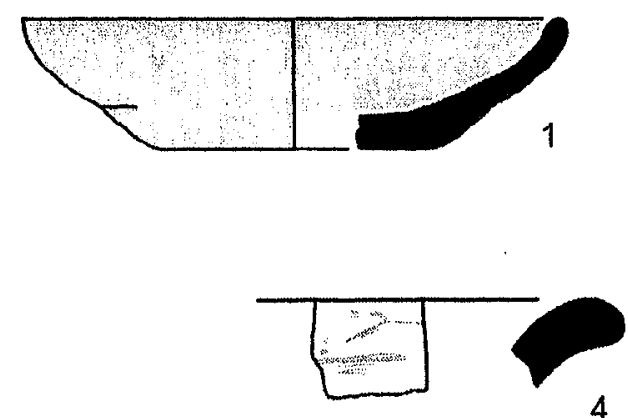
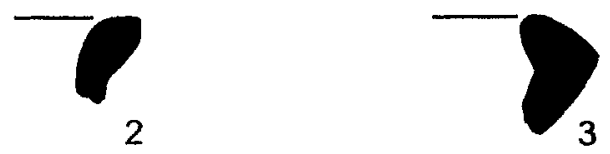

3

6
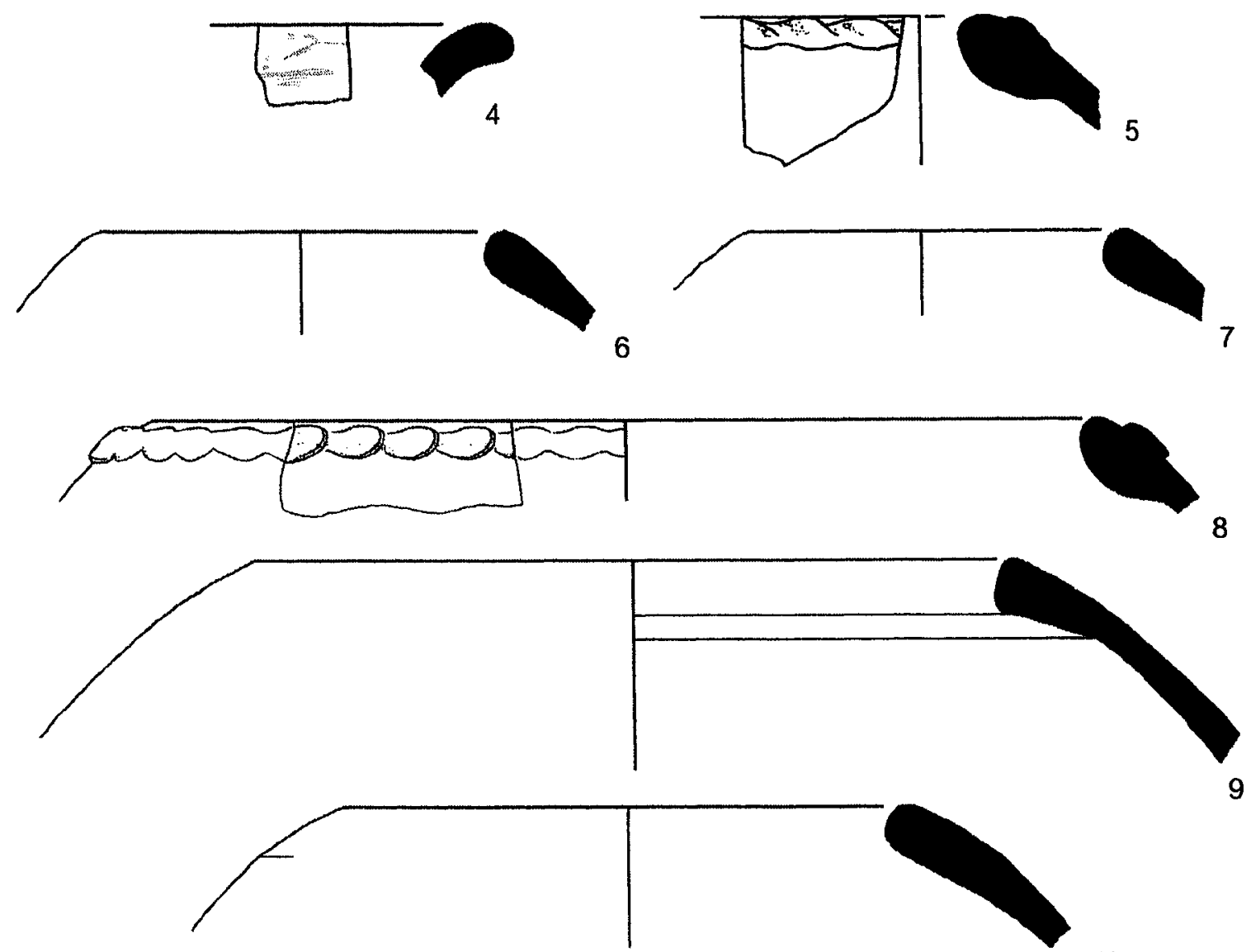

10

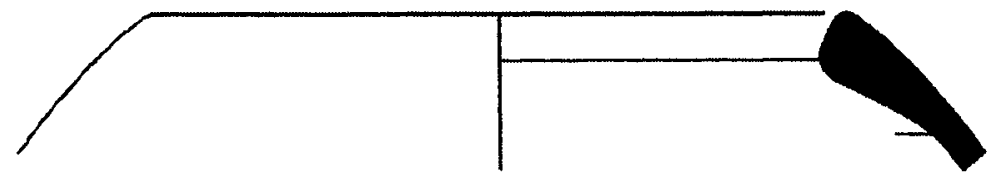

11
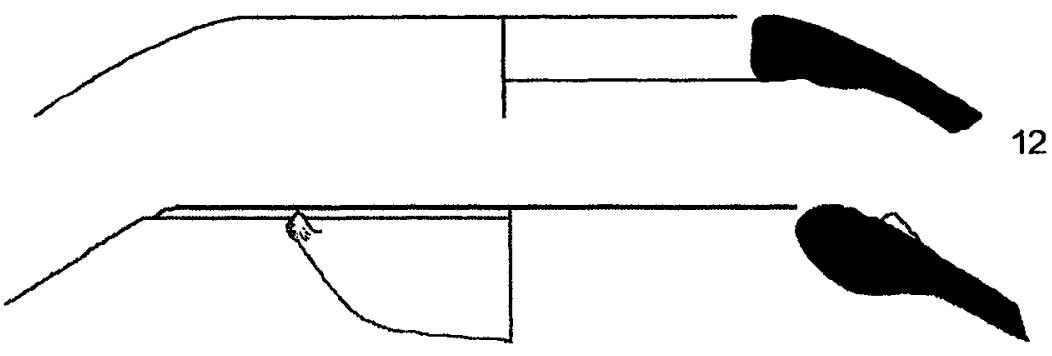

PLATE 117 (CONT.).

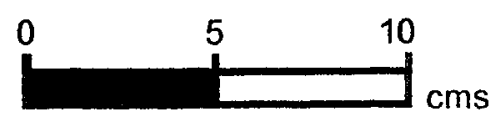




\begin{tabular}{|c|c|c|c|c|c|c|c|}
\hline No & Reg & Square & Locus & Vessel & Part & $\begin{array}{l}\text { Body } \\
\text { Thick }\end{array}$ & $\overline{\text { Dia }}$ \\
\hline 1 & 2062 & SW 1-9 & 201 & HOLE MOUTH BOWL & R14 & 4 & 10 \\
\hline 2 & 2068 & SW 1-9 & 201 & HOLE MOUTH JAR & R11 & $N$ & $\mathbf{N}$ \\
\hline 3 & 2367 & SW 1-9 & 201 & HOLE MOUTH JARIBOWL & R14 & 5 & 12 \\
\hline 4 & 2056 & SW 1-9 & 201 & HOLE MOUTH JARIBOWL & R11 & 9 & $\mathbf{N}$ \\
\hline 5 & 2392 & SW 1-9 & 201 & HOLE MOUTH JAR & R14 & 6 & 12 \\
\hline 6 & 2368 & SW 1-9 & 201 & HOLE MOUTH JAR & R11 & $\mathbf{N}$ & $\mathbf{N}$ \\
\hline 7 & 2374 & SW 1-9 & 201 & HOLE MOUTH JAR & R28 & $\mathrm{N}$ & $\mathbf{N}$ \\
\hline 8 & 2057 & SW 1-9 & 201 & HOLE MOUTH BOWL & R11 & 6 & 18 \\
\hline 9 & 2378 & SW 1-9 & 201 & HOLE MOUTH BOWL & R04 & 5 & $\mathbf{N}$ \\
\hline 10 & 2052 & SW 1-9 & 201 & NECKED JAR & R42 & 55 & 18 \\
\hline 11 & 2053 & SW 1-9 & 201 & NECKED JAR & R31 & $\mathbf{N}$ & 9 \\
\hline 12 & 2332 & SW 1-9 & 201 & NECKED JAR & R42 & 15 & 18 \\
\hline 13 & 2063 & SW 1-9 & 201 & NECKED JAR & R31 & 10 & 12 \\
\hline 14 & 2350 & SW 1-9 & 201 & HOLE MOUTH BOWL & R22 & 8 & $\mathbf{N}$ \\
\hline
\end{tabular}

\begin{tabular}{lllll}
\hline No Fabric Color & Core Orient & Core Color & Core Thick & $\begin{array}{l}\text { Fabric } \\
\text { Family }\end{array}$ \\
& & & & \\
& &
\end{tabular}

\begin{tabular}{|c|c|c|c|c|c|c|}
\hline 1 & \multicolumn{2}{|l|}{ WEAK RED } & IRR & G & $\mathbf{N}$ & $N$ \\
\hline 2 & \multicolumn{2}{|c|}{ REDDISH BROWN } & $\mathbf{N}$ & $\mathbf{N}$ & $\mathrm{N}$ & $\mathbf{N}$ \\
\hline 3 & \multicolumn{2}{|c|}{ LT REDDISH BROWN } & $\mathbf{N}$ & $N$ & $\mathbf{N}$ & $\mathbf{N}$ \\
\hline 4 & \multicolumn{2}{|l|}{ LT RED } & $\mathbf{N}$ & $\mathbf{N}$ & $\mathbf{N}$ & $\mathbf{N}$ \\
\hline 5 & \multicolumn{2}{|c|}{ LT REDDISH BROWN } & IRR & G & $N$ & N \\
\hline 6 & \multicolumn{2}{|c|}{ REDDISH GREY } & $N$ & $N$ & $N$ & $\mathrm{~N}$ \\
\hline 7 & \multicolumn{2}{|c|}{ PINK } & $N$ & $\mathbf{N}$ & $\mathbf{N}$ & $\mathrm{N}$ \\
\hline 8 & \multicolumn{2}{|l|}{ WEAK RED } & $M$ & $\mathbf{G}$ & $N$ & $\mathrm{~N}$ \\
\hline 9 & \multicolumn{2}{|c|}{ PINKISH GREY } & $N$ & $\mathbf{N}$ & $\mathbf{N}$ & $\mathbf{N}$ \\
\hline 10 & \multicolumn{2}{|c|}{ PINK } & IRR & $\mathbf{G}$ & $\mathbf{N}$ & $\mathrm{N}$ \\
\hline 11 & \multicolumn{2}{|l|}{ WEAK RED } & IRR & $\mathbf{G}$ & $\mathrm{N}$ & $\mathrm{N}$ \\
\hline 12 & \multicolumn{2}{|l|}{ PINK } & $N$ & $\mathbf{N}$ & $\mathbf{N}$ & $\mathbf{N}$ \\
\hline 13 & \multicolumn{2}{|l|}{ PINK } & $\mathbf{N}$ & $\mathrm{N}$ & $\mathbf{N}$ & $\mathbf{N}$ \\
\hline 14 & \multicolumn{2}{|l|}{ PINK } & N & $N$ & $N$ & $\mathrm{~N}$ \\
\hline No & Treatment & $\begin{array}{l}\text { Treatment } \\
\text { Location }\end{array}$ & $\begin{array}{l}\text { Treatment } \\
\text { Cover }\end{array}$ & $\begin{array}{l}\text { Color } \\
\text { Interior }\end{array}$ & $\begin{array}{l}\text { Color } \\
\text { Exterior }\end{array}$ & \\
\hline 1 & UN & $N$ & $\mathbf{N}$ & $\mathbf{N}$ & $N$ & \\
\hline 2 & UN & $N$ & $N$ & $N$ & $\mathbf{N}$ & \\
\hline 3 & UN & $N$ & $\mathrm{~N}$ & $\mathbf{N}$ & $\mathbf{N}$ & \\
\hline 4 & UN & $\mathbf{N}$ & $\mathbf{N}$ & $\mathbf{N}$ & $\mathbf{N}$ & \\
\hline 5 & UN & $N$ & $N$ & $\mathbf{N}$ & $\mathbf{N}$ & \\
\hline 6 & UN & $\mathbf{N}$ & $\mathbf{N}$ & $\mathbf{N}$ & $\mathbf{N}$ & \\
\hline 7 & $\mathrm{~s}$ & $E$ & ALL & $\mathbf{N}$ & LT RED & \\
\hline 8 & UN & $\mathbf{N}$ & $\mathbf{N}$ & $\mathbf{N}$ & $\mathbf{N}$ & \\
\hline
\end{tabular}

PLATE 118. FIELD B. PHASE $1 C$ (LATE EB I - EARLY EB II). 


\begin{tabular}{llllll}
\hline No & Treatment & $\begin{array}{l}\text { Treatment } \\
\text { Location }\end{array}$ & $\begin{array}{l}\text { Treatment } \\
\text { Cover }\end{array}$ & $\begin{array}{l}\text { Color } \\
\text { Interior }\end{array}$ & $\begin{array}{l}\text { Color } \\
\text { Exterior }\end{array}$ \\
\hline 9 & UN & N & N & N & N \\
10 & S & ER & ALL & N & RED \\
11 & UN & N & N & N & N \\
12 & S & ER & ALL & N & RED \\
13 & S & ER & ALL & LT RED & LTRED \\
14 & WASH & IE & ALL & RED & WHITE \\
\hline Other & & & & \\
\hline
\end{tabular}

1 Voids in break suggest rim fold; surface burn visible.

2 Sample too small to confirm stance or diameter; surface burn visible.

4 Sample too small to confirm stance or diameter.

5 Potter's mark.

6 Sample too small to confirm stance or diameter.

7 Sample too small to confirm stance or diameter.

8 Lines on interior/exterior suggest motion used to finish rim; surface burn visible.

9 Sample too small to confirm stance or diameter.

11 Burn visible on all surfaces.

13 Sample too small to confirm stance or diameter.

14 Spout emerges below rope molding.

PLATE 118 (CONT.). 

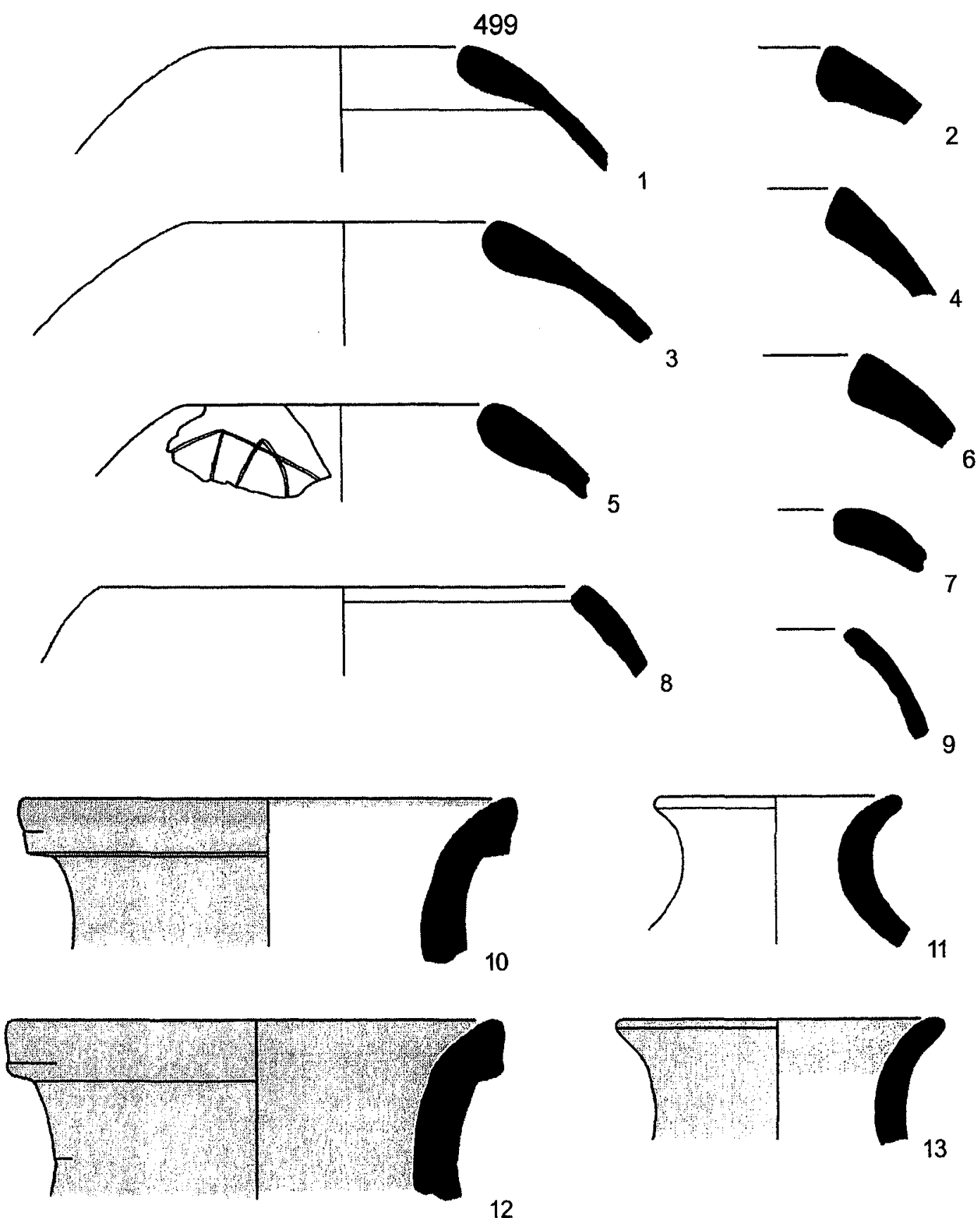

12
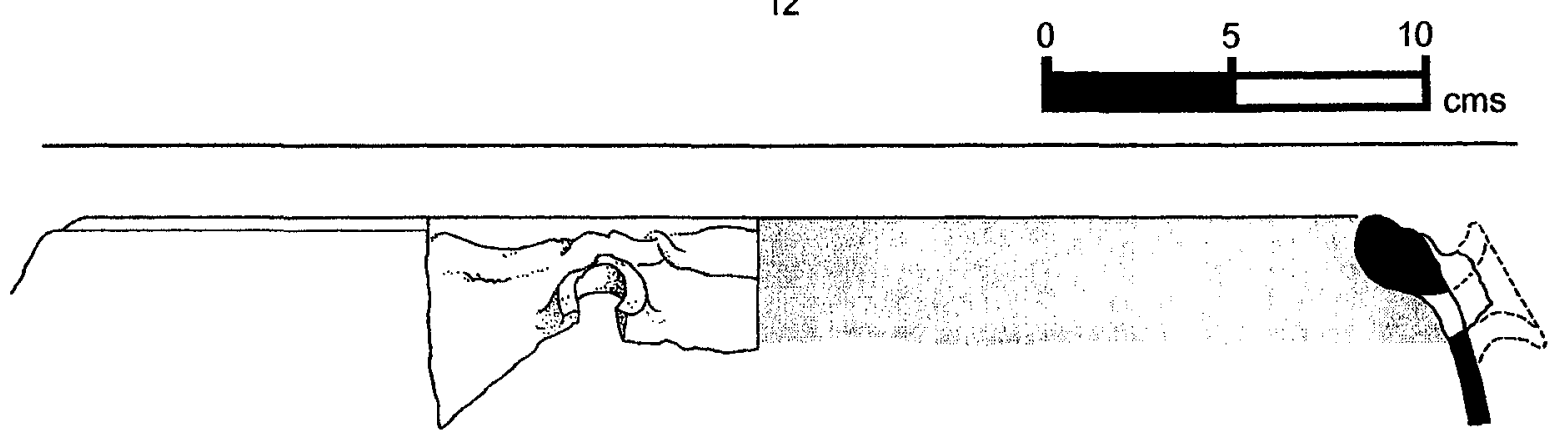

14

PLATE 118 (CONT.)

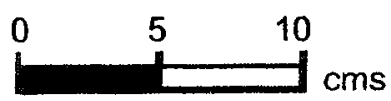




\begin{tabular}{lllllllll}
\hline No & Reg & Square & Locus & Vessel & Part & $\begin{array}{c}\text { Body } \\
\text { Thick }\end{array}$ & Dia \\
\hline 1 & 2362 & SW 1-9 & 201 & UD & R82 & 2 & UD \\
2 & 2348 & SW $1-9$ & 201 & CARINATED BOWL & R58 & N & N \\
3 & 2360 & SW $1-9$ & 201 & UD & B12 & N & 18 \\
4 & 2047 & SW $1-9$ & 201 & UD & B12 & 15 & 16 \\
5 & 2054 & SW $1-9$ & 201 & UD & B11 & N & N \\
6 & 2050 & SW 1-9 & 201 & UD & B12 & N & N \\
7 & 2331 & SW 1-9 & 201 & UD & H12 & 8 & N \\
8 & 2353 & SW 1-9 & 201 & UD & H12 & 7 & N
\end{tabular}

\begin{tabular}{lllll}
\hline No Fabric Color & Core Orient & Core Color & Core Thick & Fabric \\
& & & & Family
\end{tabular}

\begin{tabular}{|c|c|c|c|c|c|c|}
\hline $\begin{array}{l}1 \\
2 \\
3 \\
4 \\
5 \\
6 \\
7 \\
8\end{array}$ & \multicolumn{2}{|c|}{$\begin{array}{l}\text { REDDISH BROWN } \\
\text { PINK } \\
\text { REDDISH BROWN } \\
\text { LT BROWN } \\
\text { WEAK RED } \\
\text { RED } \\
\text { LT REDDISH BROWN } \\
\text { LT REDDISH BROWN }\end{array}$} & $\begin{array}{l}N \\
M \\
N \\
\text { ALL } \\
\text { ALL } \\
\text { IN } \\
N \\
\text { IRR }\end{array}$ & $\begin{array}{l}N \\
G \\
N \\
G \\
L G \\
L G \\
N \\
G\end{array}$ & $\begin{array}{l}N \\
N \\
N \\
N \\
N \\
N \\
N \\
N\end{array}$ & $\begin{array}{l}N \\
N \\
N \\
2.2 \\
N \\
N \\
N \\
N\end{array}$ \\
\hline$\overline{\text { No }}$ & Treatment & $\begin{array}{l}\text { Treatment } \\
\text { Location }\end{array}$ & $\begin{array}{l}\text { Treatment } \\
\text { Cover }\end{array}$ & $\begin{array}{l}\text { Color } \\
\text { Interior }\end{array}$ & $\begin{array}{l}\text { Color } \\
\text { Exterior }\end{array}$ & \\
\hline $\begin{array}{l}1 \\
2 \\
3 \\
4 \\
5 \\
6 \\
7 \\
8\end{array}$ & $\begin{array}{l}S \\
S \\
\text { UN } \\
\text { UN } \\
\text { UN } \\
\text { UN } \\
S \\
S\end{array}$ & $\begin{array}{l}E \\
\text { IE } \\
N \\
N \\
N \\
N \\
E \\
E\end{array}$ & $\begin{array}{l}\text { ALL } \\
\text { ALL } \\
N \\
N \\
N \\
N \\
\text { ALL } \\
\text { ALL }\end{array}$ & $\begin{array}{l}N \\
N \\
N \\
N \\
N \\
N \\
N \\
N\end{array}$ & $\begin{array}{l}\text { RED } \\
\text { RED } \\
N \\
N \\
N \\
N \\
\text { RED } \\
\text { RED }\end{array}$ & \\
\hline
\end{tabular}

1 Tiny hole (dia. $1 \mathrm{~mm}$ ) penetrates vessel wall; sample too small to confirm stance or diameter.

2 Sample too small to confirm stance or diameter.

$4 \quad$ Surface burn visible.

5 Sample too small to confirm stance or diameter.

6 Sample too small to confirm stance or diameter; a single slash on the exterior wall running parallel to the base may represent a potter's mark.

PLATE 119. FIELD B. PHASE 1C (LATE EB I - EARLY EB II). 

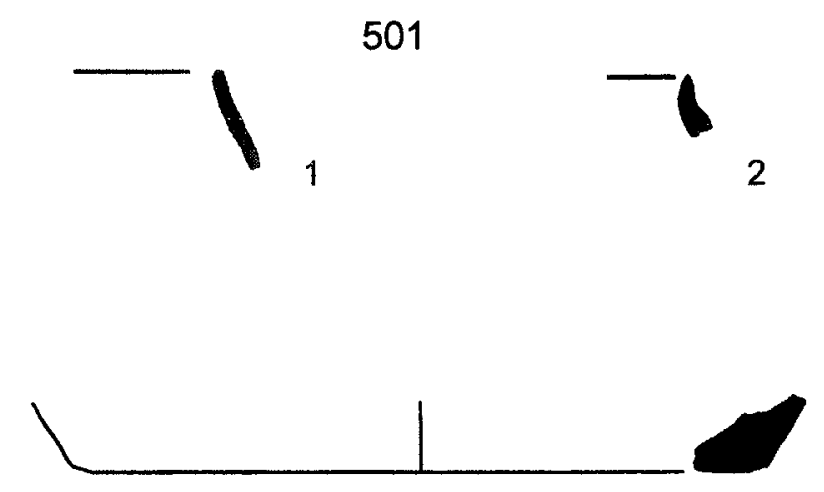

3
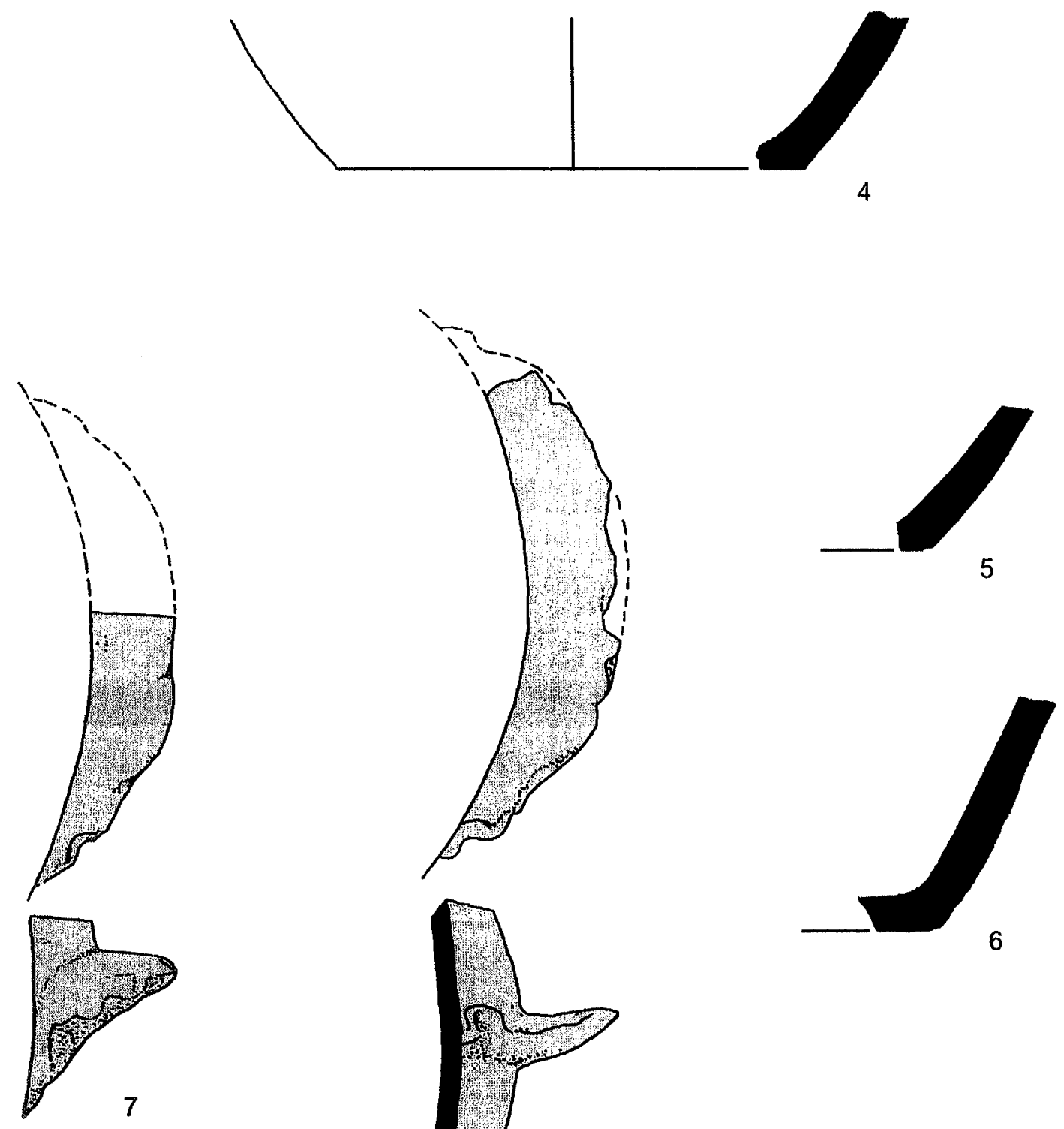

Reproduced with permission of the copyright owner. Further reproduction prohibited without permission. 


\begin{tabular}{llllllll}
\hline No & Reg & Square & Locus & Vessel & Part & $\begin{array}{c}\text { Body } \\
\text { Thick }\end{array}$ & $\begin{array}{c}\text { Dia } \\
\end{array}$ \\
& & & & & & & \\
1 & 1421 & SW 1-9 & 213 & PLATTER BOWL & R53 & 4 & 25 \\
2 & 1425 & SW 1-9 & 213 & BOWL & R82 & 7 & 22 \\
3 & 1423 & SW 1-9 & 213 & HOLE MOUTH BOWL & R14 & 11 & 20 \\
4 & 1431 & SW 1-9 & 213 & HOLE MOUTH JAR & R14 & 8 & 10 \\
5 & 1424 & SW 1-9 & 213 & NECKED JAR & R43 & 8 & 24 \\
6 & 1422 & SW 1-9 & 213 & NECKED JAR & R31 & 10 & 13 \\
7 & 1420 & SW 1-9 & 213 & NECKED JAR & R31 & 12 & 10 \\
8 & 1426 & SW 1-9 & 213 & HOLE MOUTH BOWLNAT & R02 & 11 & 40
\end{tabular}

\begin{tabular}{lllll}
\hline No Fabric Color & Core Orient & Core Color Core Thick & Fabric \\
Family
\end{tabular}

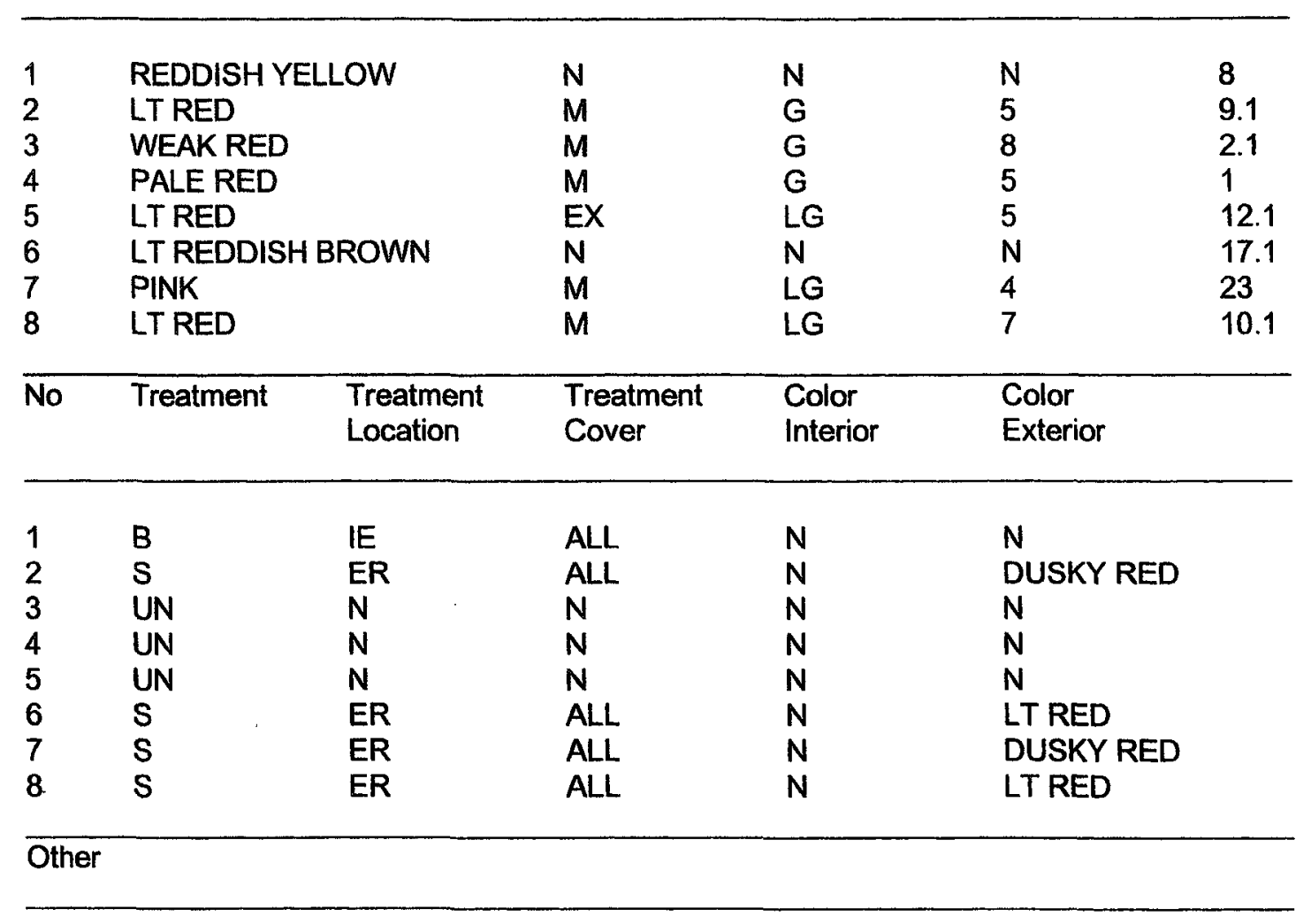

$\begin{array}{ll}1 & \text { Metallic Ware. } \\ 4 & \text { Surface burn visible. } \\ 5 & \text { Metallic Ware. }\end{array}$

PLATE 120. FIELD B. PHASE 1C (LATE EB I - EARLY EB II). 


\section{3}

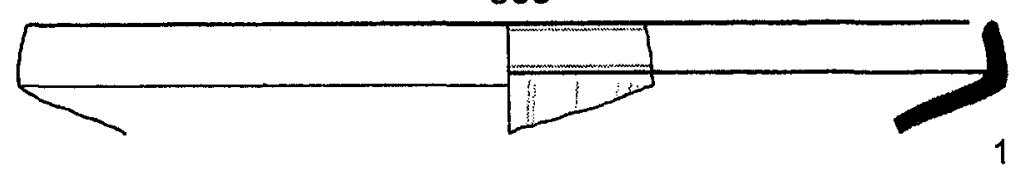

1

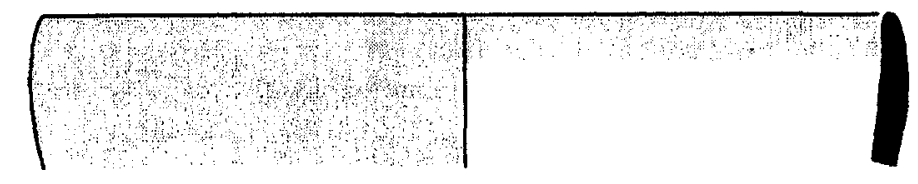

2
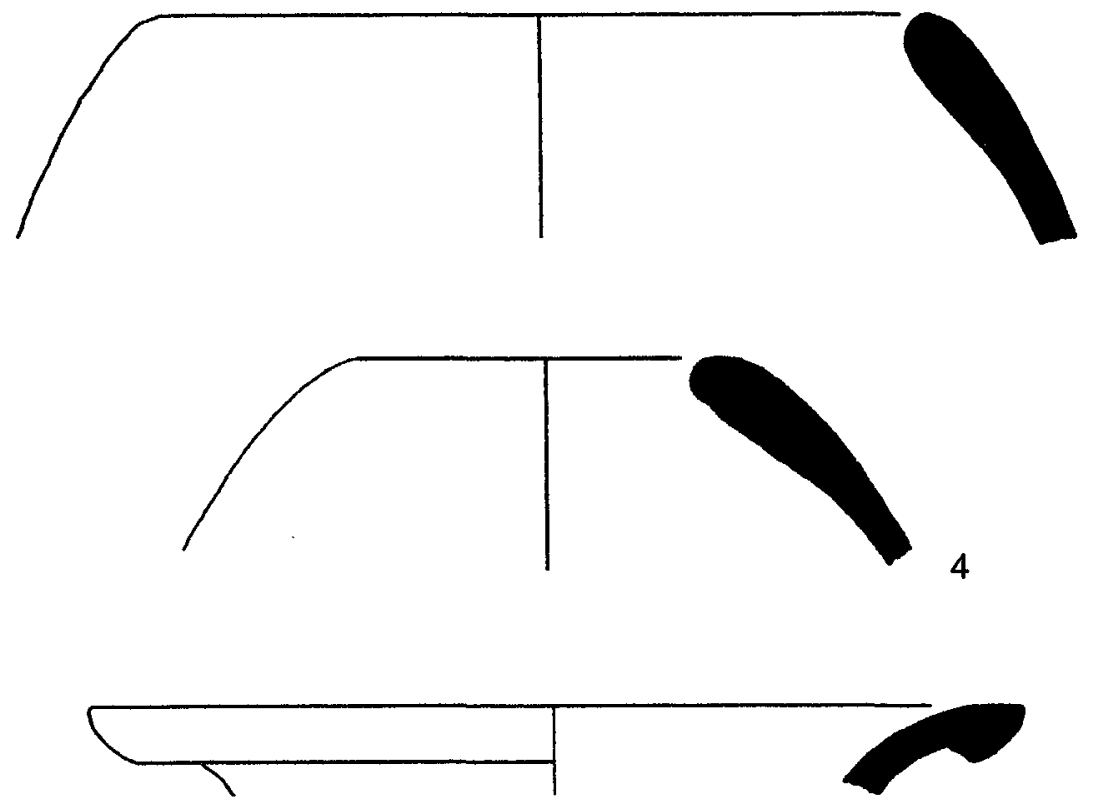

5
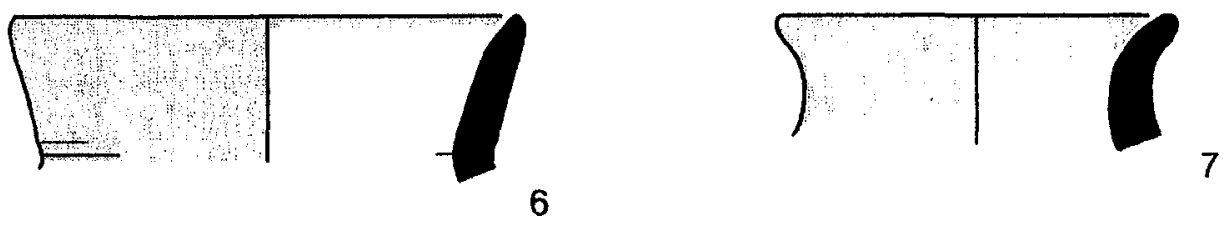

6
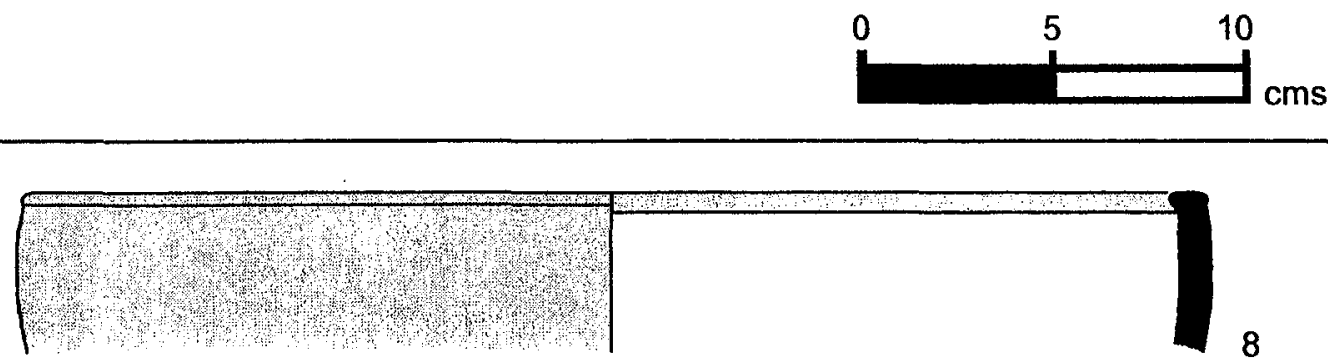

8

PLATE 120 (CONT.).

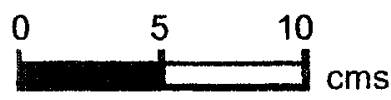




\begin{tabular}{lllllllll}
\hline No & Reg & Square & Locus & Vessel & Part & $\begin{array}{l}\text { Body } \\
\text { Thick }\end{array}$ & Dia \\
\hline 1 & 1427 & SW 1-9 & 213 & UD & H2O & 10 & $\mathrm{~N}$ \\
2 & 1430 & SW 1-9 & 213 & UD & BOD & 6 & $\mathrm{~N}$ \\
3 & 1429 & SW 1-9 & 213 & UD & H10 & 12 & $\mathrm{~N}$ \\
4 & 1432 & SW 1-9 & 213 & UD & H12 & 9 & $\mathrm{~N}$ \\
5 & 1428 & SW 1-9 & 213 & UD & H14 & 11 & $\mathrm{~N}$
\end{tabular}

\begin{tabular}{llll}
\hline No Fabric Color & Core Orient Core Color Core Thick Fabric \\
& & & Family
\end{tabular}

\begin{tabular}{|c|c|c|c|c|c|c|}
\hline $\begin{array}{l}1 \\
2 \\
3 \\
4 \\
5\end{array}$ & $\begin{array}{l}\text { PINK } \\
\text { LT RED } \\
\text { LT RED } \\
\text { PALE RED } \\
\text { LT RED }\end{array}$ & & $\begin{array}{l}\text { IRR } \\
N \\
M \\
\text { IRR } \\
M\end{array}$ & $\begin{array}{l}G \\
N \\
L G \\
G \\
G\end{array}$ & $\begin{array}{l}N \\
N \\
8 \\
N \\
8\end{array}$ & $\begin{array}{l}7.1 \\
12.1 \\
8 \\
9 \\
19\end{array}$ \\
\hline No & Treatment & $\begin{array}{l}\text { Treatment } \\
\text { Location }\end{array}$ & $\begin{array}{l}\text { Treatment } \\
\text { Cover }\end{array}$ & $\begin{array}{l}\text { Color } \\
\text { Interior }\end{array}$ & $\begin{array}{l}\text { Color } \\
\text { Exterior }\end{array}$ & \\
\hline $\begin{array}{l}1 \\
2 \\
3 \\
4 \\
5\end{array}$ & $\begin{array}{l}5 \\
1 \\
5 \\
5 \\
5\end{array}$ & $\begin{array}{l}E \\
E \\
E \\
E \\
E\end{array}$ & $\begin{array}{l}\text { ALL } \\
\text { ALL } \\
\text { ALL } \\
\text { ALL } \\
\text { ALL }\end{array}$ & $\begin{array}{l}N \\
N \\
N \\
N \\
N\end{array}$ & $\begin{array}{l}\text { RED } \\
\text { RED } \\
\text { RED } \\
\text { LT RED } \\
\text { RED }\end{array}$ & \\
\hline
\end{tabular}

2 Combed Metallic Ware; also in Fabric Family 12.3.

$4 \quad$ Also in Fabric Family 9.1.

PLATE 121. FIELD B. PHASE 1C (LATE EB I - EARLY EB II). 

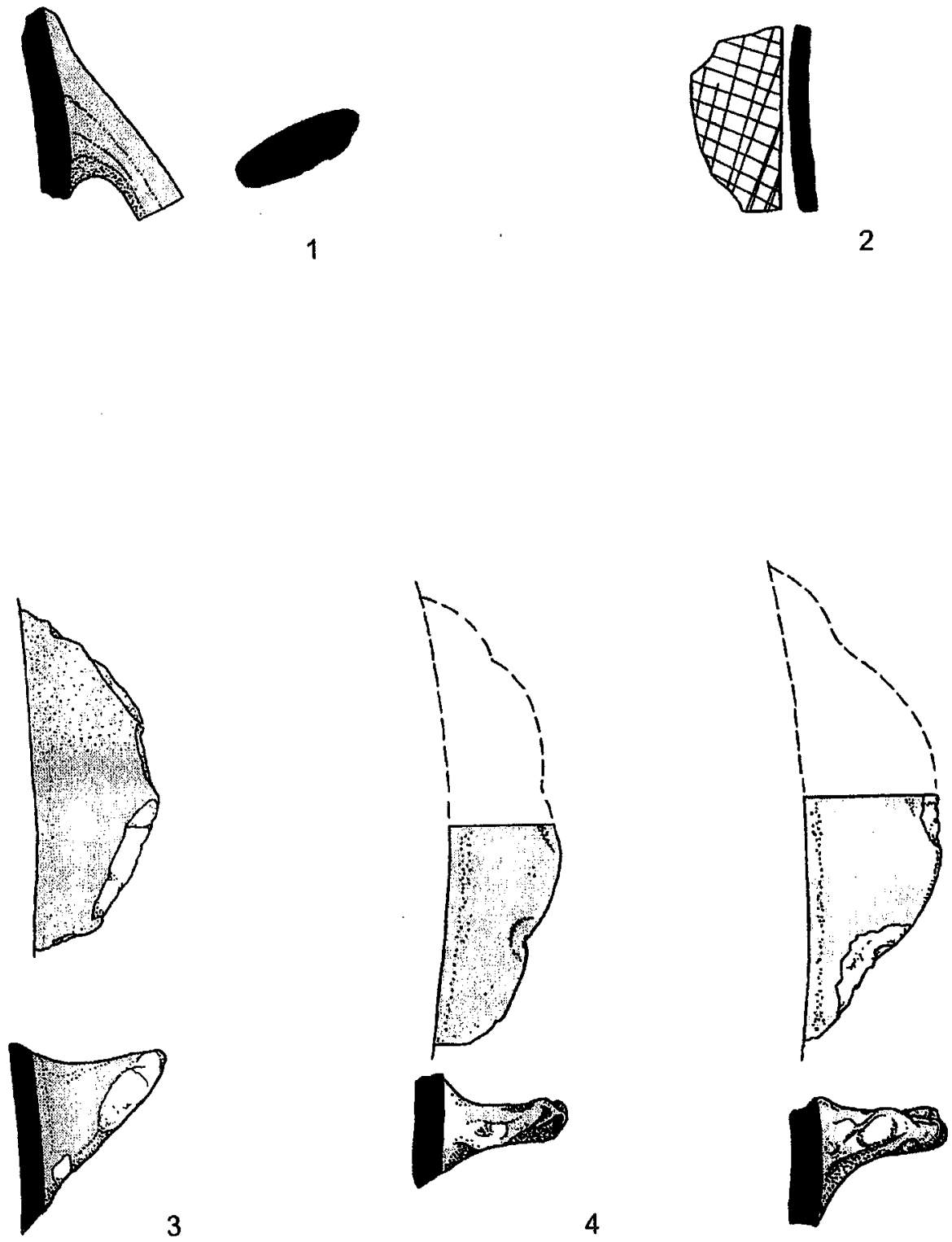

3

4

PLATE 121 (CONT.).

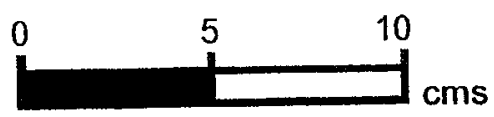




\begin{tabular}{llllllll}
\hline No & Reg & Square & Locus & Vessel & Part & $\begin{array}{l}\text { Body } \\
\text { Thick }\end{array}$ & Dia \\
& & & & & & \\
\hline 1 & 2276 & SW 1-7 & 202 & HOLE MOUTH JARIBOWL & R19 & 12 & 19 \\
2 & 1290 & SW 1-7 & 202 & NECKED JAR & R42 & 9 & 20 \\
3 & 1292 & SW 1-7 & 216 & UD & R30 & 5 & 11 \\
4 & 1465 & SW 1-8 & 92 & UD & H20 & N & N \\
5 & 1467 & SW 1-8 & 90 & LEDGE RIM BOWL & R51 & 8 & 30 \\
6 & 1294 & SW 1-7 & 216 & UD & B12 & 10 & 27 \\
7 & 1293 & SW 1-7 & 216 & UD & H27 & 8 & N \\
8 & 1468 & SW 1-8 & 90 & TWIN VESSEL? & BOD & N & N \\
9 & 1291 & SW 1-7 & 202 & UN & H20 & N & N \\
10 & 1464 & SW 1-8 & 92 & VAT & R52 & 15 & 62
\end{tabular}

\begin{tabular}{lllll}
\hline No Fabric Color & Core Orient & Core Color Core Thick & Fabric \\
& & & Family
\end{tabular}

\begin{tabular}{|c|c|c|c|c|c|c|}
\hline $\begin{array}{l}1 \\
2 \\
3 \\
4 \\
5 \\
6 \\
7 \\
8 \\
9 \\
10\end{array}$ & $\begin{array}{l}\text { PINK } \\
\text { LT BROWN } \\
\text { PINK } \\
\text { LT RED } \\
\text { PINK } \\
\text { LT REDDISI } \\
\text { LT REDDIS } \\
\text { PINK } \\
\text { PINK } \\
\text { LT RED }\end{array}$ & $\begin{array}{l}\text { ROWN } \\
\text { ROWN }\end{array}$ & $\begin{array}{l}\text { N } \\
\text { IRR } \\
\text { N } \\
\text { IRR } \\
M \\
M \\
\text { IRR } \\
N \\
N \\
M\end{array}$ & $\begin{array}{l}N \\
G \\
N \\
\text { LG } \\
G \\
\text { LG } \\
\text { LG } \\
N \\
N \\
\text { LG }\end{array}$ & $\begin{array}{l}N \\
N \\
N \\
N \\
3 \\
3 \\
N \\
N \\
N \\
10\end{array}$ & $\begin{array}{l}N \\
N \\
7.1 \\
7.1 \\
11 \\
7.1 \\
N \\
N \\
9.2 \\
7.1\end{array}$ \\
\hline No & Treatment & $\begin{array}{l}\text { Treatment } \\
\text { Location }\end{array}$ & $\begin{array}{l}\text { Treatment } \\
\text { Cover }\end{array}$ & $\begin{array}{l}\text { Color } \\
\text { Interior }\end{array}$ & $\begin{array}{l}\text { Col } \\
\text { Ext }\end{array}$ & \\
\hline $\begin{array}{l}1 \\
2 \\
3 \\
4 \\
5 \\
6 \\
7 \\
8 \\
9 \\
10\end{array}$ & $\begin{array}{l}\text { S } \\
\text { S } \\
\text { UN } \\
\text { UN } \\
\text { SB } \\
\text { S } \\
\text { UD } \\
\text { S } \\
\text { S } \\
\text { WASH }\end{array}$ & $\begin{array}{l}E R \\
E \\
N \\
N \\
\text { IE } \\
E \\
N \\
E \\
E \\
E R\end{array}$ & $\begin{array}{l}\text { ALL } \\
A L L \\
N \\
N \\
A L L \\
A L L \\
A L L \\
A L L \\
\text { ALL } \\
\text { PAT }\end{array}$ & $\begin{array}{l}N \\
N \\
N \\
N \\
\text { RED } \\
N \\
N \\
N \\
N \\
N\end{array}$ & $\begin{array}{l}\text { RE } \\
\text { RE } \\
N \\
N \\
\text { RE } \\
\text { DK } \\
N \\
\text { RE } \\
\text { RE } \\
\text { Wh }\end{array}$ & BROWN \\
\hline
\end{tabular}

PLATE 122. FIELD B. PHASE 2B (MIXED EB). 
Other

1 Sample too small to determine stance or diameter.

$6 \quad$ Also in Fabric Family 16.

7 Possible twin vessel junction.

8 Interior face is self-slipped and smoothed in horizontal movements; isolated fragments suggest a wash covered the exterior and rim; exterior face is very smooth with few fine horizontal lines.

PLATE 122 (CONT.). 

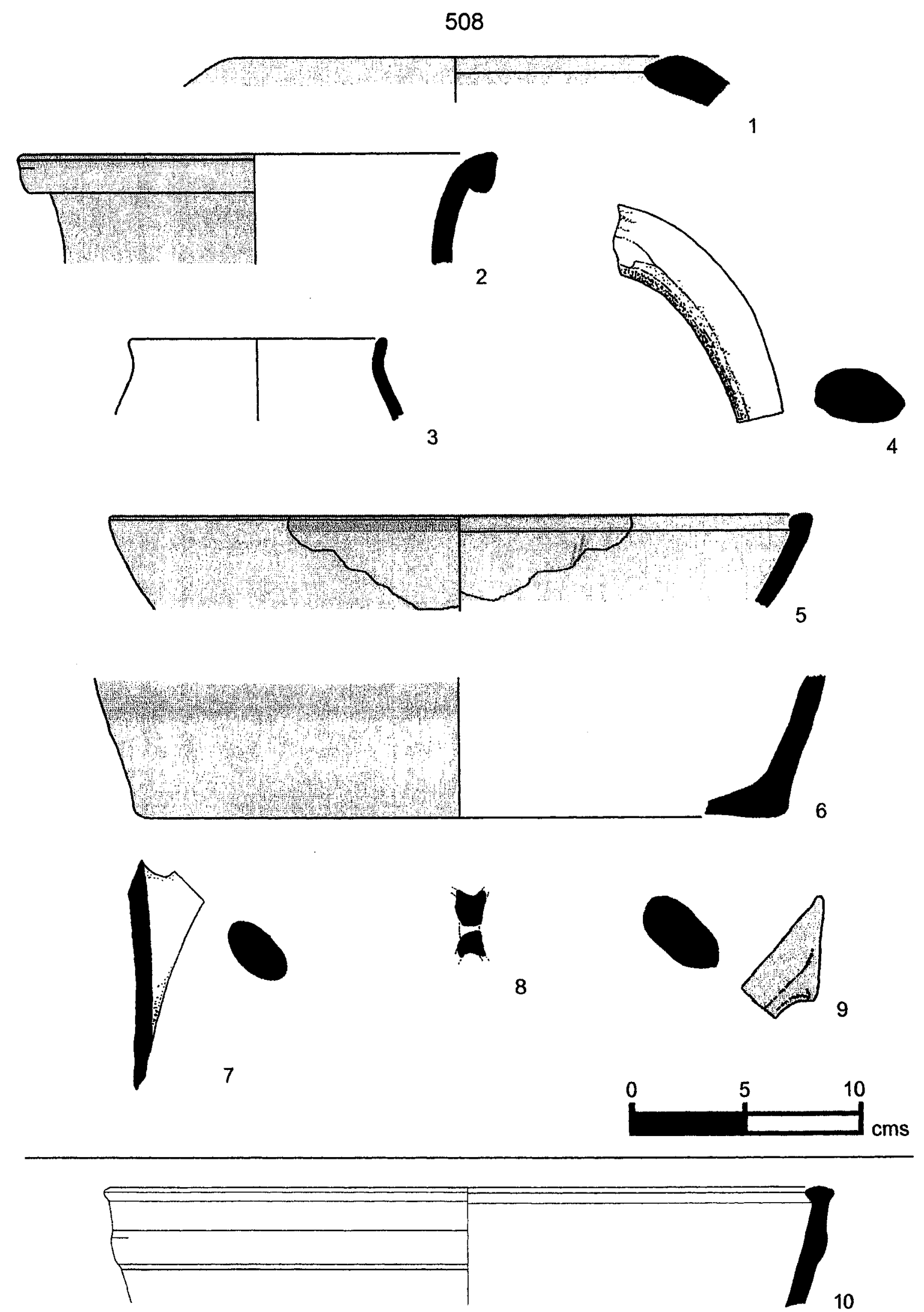

10

PLATE 122(CONT.).

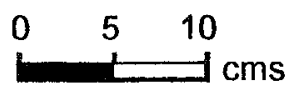




\begin{tabular}{llllllll}
\hline No & Reg & Square & Locus & Vessel & Part & $\begin{array}{c}\text { Body } \\
\text { Thick }\end{array}$ & \begin{tabular}{c} 
Dia \\
\hline
\end{tabular} \\
\hline & 1459 & SW 1-8 & 102 & HOLE MOUTH JAR & R01 & 13 & 20 \\
2 & 1458 & SW 1-8 & 102 & HOLE MOUTH BOWL & R02 & 12 & 18 \\
3 & 1460 & SW 1-8 & 102 & HOLE MOUTH JAR & R01 & 15 & 16 \\
4 & 1461 & SW 1-8 & 102 & PLATTER BOWL & R56 & 15 & 45
\end{tabular}

\begin{tabular}{lllll}
\hline No Fabric Color & Core Orient & Core Color & Core Thick & Fabric \\
Family
\end{tabular}

\begin{tabular}{|c|c|c|c|c|c|c|}
\hline $\begin{array}{l}1 \\
2 \\
3 \\
4\end{array}$ & $\begin{array}{l}\text { LT REDDISH } \\
\text { PALE RED } \\
\text { WEAK RED } \\
\text { PINK }\end{array}$ & BROWN & $\begin{array}{l}M \\
E X \\
E X \\
N\end{array}$ & $\begin{array}{l}L G \\
G \\
G \\
N\end{array}$ & $\begin{array}{l}5 \\
9 \\
11 \\
N\end{array}$ & $\begin{array}{l}\mathbf{N} \\
\mathbf{N} \\
\mathbf{N} \\
\mathbf{N}\end{array}$ \\
\hline No & Treatment & $\begin{array}{l}\text { Treatment } \\
\text { Location }\end{array}$ & $\begin{array}{l}\text { Treatment } \\
\text { Cover }\end{array}$ & $\begin{array}{l}\text { Color } \\
\text { Interior }\end{array}$ & $\begin{array}{l}\text { Color } \\
\text { Exterior }\end{array}$ & \\
\hline
\end{tabular}

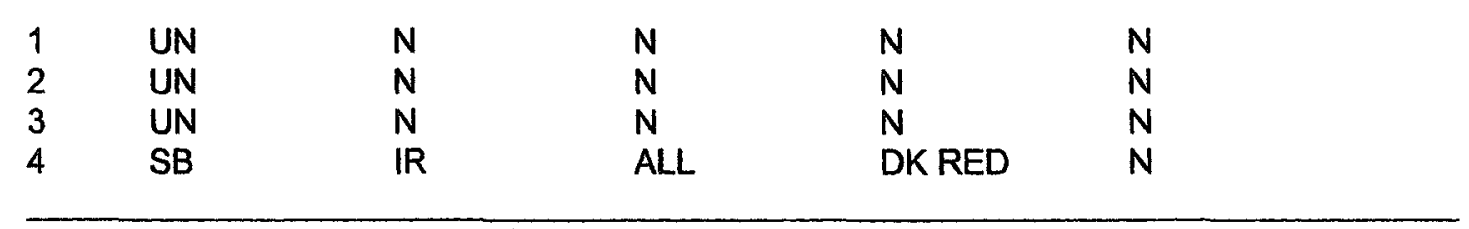

Other

2 Lines on interior/exterior suggest motion used to finish rim; scrape marks on interior.

3 Lines on interior/exterior suggest motion used to finish rim.

$4 \quad$ Faint concavity under rim.

PLATE 123. FIELD B. PHASE 2B (MIXED EB). 

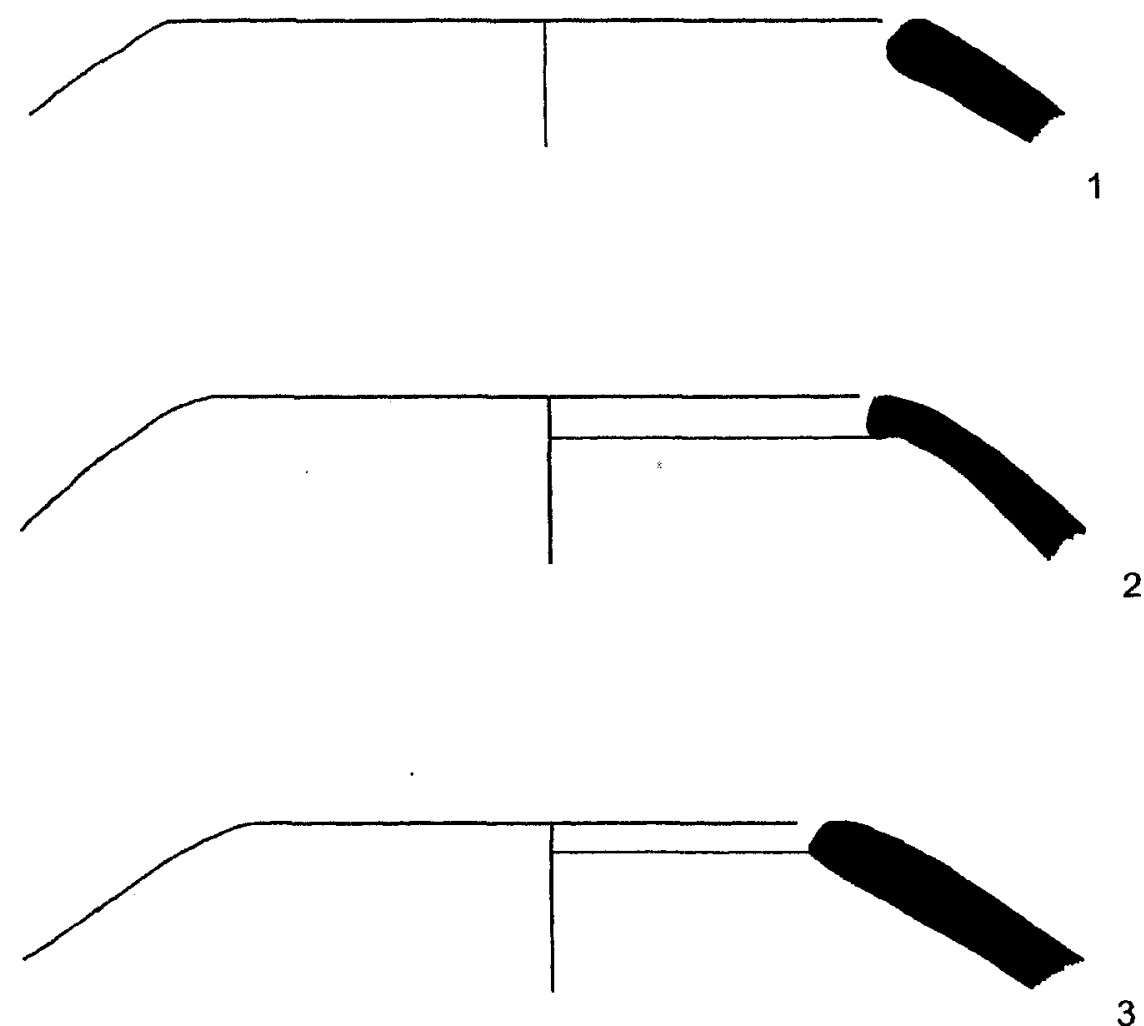

3
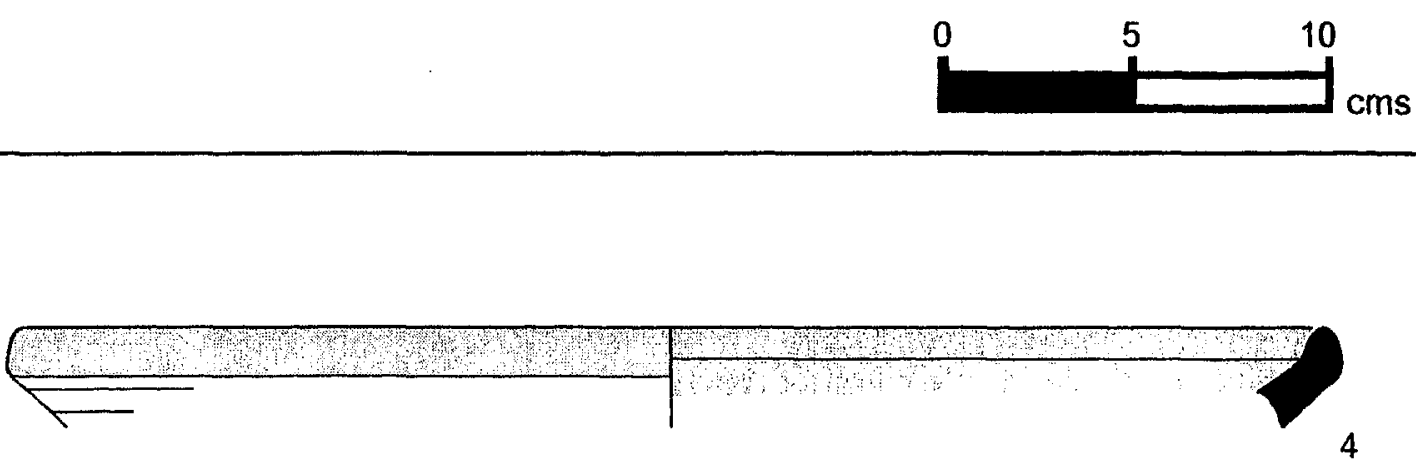

PLATE 123 (CONT.).

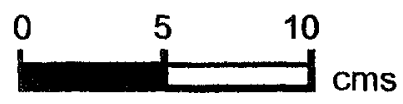




\begin{tabular}{|c|c|c|c|c|c|c|c|}
\hline No & $\operatorname{Reg}$ & Square & Locus & Vessel & Part & $\begin{array}{l}\text { Body } \\
\text { Thick }\end{array}$ & $\overline{\text { Dia }}$ \\
\hline 1 & 2387 & SW $1-9$ & 155 & BOWL & ROO & 5 & $N$ \\
\hline 2 & 2388 & SW 1-9 & 155 & UD & $\mathrm{R} 00$ & 4 & $\mathbf{N}$ \\
\hline 3 & 2389 & SW 1-9 & 155 & LEDGE RIM BOWL & R53 & 15 & $\mathbf{N}$ \\
\hline 4 & 2390 & SW 1-9 & 155 & HOLE MOUTH JAR & R14 & 7 & 12 \\
\hline 5 & 2391 & SW 1-9 & 155 & HOLE MOUTH JAR & $\mathrm{R} 02$ & 10 & $\mathbf{N}$ \\
\hline 6 & 1334 & SW 1-9 & 155 & UD & $\mathrm{H} 27$ & 9 & $\mathbf{N}$ \\
\hline 7 & 1333 & SW 1-9 & 155 & NECKED JAR & R31 & 8 & 13 \\
\hline 8 & 1339 & SW 1-9 & 168 & UD & B12 & 10 & $\mathbf{N}$ \\
\hline 9 & 1341 & SW 1-9 & 168 & UD & B12 & 14 & 8 \\
\hline
\end{tabular}

\begin{tabular}{|c|c|c|c|c|c|c|}
\hline 1 & \multicolumn{2}{|l|}{ LT RED } & ALL & $\mathbf{G}$ & 3 & $\mathbf{N}$ \\
\hline 2 & \multicolumn{2}{|l|}{ UD } & $A L L$ & $\mathbf{G}$ & 4 & $\mathbf{N}$ \\
\hline 3 & \multicolumn{2}{|l|}{ PINK } & $\mathbf{N}$ & $\mathrm{N}$ & $N$ & $\mathbf{N}$ \\
\hline 4 & \multicolumn{2}{|c|}{ LT REDDISH BROWN } & $M$ & $\mathbf{G}$ & 3 & $\mathbf{N}$ \\
\hline 5 & \multicolumn{2}{|c|}{ LT REDDISH BROWN } & $N$ & $\mathrm{~N}$ & $N$ & $\mathrm{~N}$ \\
\hline 6 & \multicolumn{2}{|c|}{ LT REDDISH BROWN } & IRR & G & $\mathbf{N}$ & $\mathbf{N}$ \\
\hline 7 & \multicolumn{2}{|l|}{ PINK } & $N$ & $\mathrm{~N}$ & $\mathbf{N}$ & $\mathrm{N}$ \\
\hline 8 & \multicolumn{2}{|c|}{ PINKISH GREY } & IN & LG & $N$ & $\mathbf{N}$ \\
\hline 9 & \multicolumn{2}{|l|}{ LT RED } & $M$ & $\mathbf{G}$ & 8 & $\mathrm{~N}$ \\
\hline No & Treatment & $\begin{array}{l}\text { Treatment } \\
\text { Location }\end{array}$ & $\begin{array}{l}\text { Treatment } \\
\text { Cover }\end{array}$ & $\begin{array}{l}\text { Color } \\
\text { Interior }\end{array}$ & $\begin{array}{l}\text { Color } \\
\text { Exterior }\end{array}$ & \\
\hline 1 & SB & $\mathrm{IE}$ & ALL & RED & RED & \\
\hline 2 & SB & $\mathrm{IE}$ & ALL & RED & LT RED & \\
\hline 3 & $\mathrm{~S}$ & ER & ALL & RED & $\mathrm{N}$ & \\
\hline 4 & UN & $\mathbf{N}$ & $\mathbf{N}$ & $N$ & $\mathbf{N}$ & \\
\hline 5 & UN & $\mathbf{N}$ & $\mathbf{N}$ & $N$ & $\mathbf{N}$ & \\
\hline 6 & UN & $\mathbf{N}$ & $\mathbf{N}$ & $\mathbf{N}$ & $\mathbf{N}$ & \\
\hline 7 & $\mathrm{~S}$ & ER & ALL & $\mathbf{N}$ & RED & \\
\hline 8 & $\mathrm{~S}$ & $E$ & ALL & $\mathbf{N}$ & LT RED & \\
\hline 9 & UN & $\mathbf{N}$ & $\mathbf{N}$ & $\mathbf{N}$ & $\mathbf{N}$ & \\
\hline
\end{tabular}

$1 \quad$ Khirbet Kerek Ware; burn on rim suggests use as lamp.

2 Khirbet Kerek Ware; a small part of plastic molding is preserved on the exterior face; sample too small to confirm stance or diameter.

3 Sample too small to confirm stance or diameter.

5 Sample too small to confirm stance or diameter.

8 Sample too small to confirm stance or diameter.

PLATE 124. FIELD B. PHASE 2B (MIXED EB). 
512

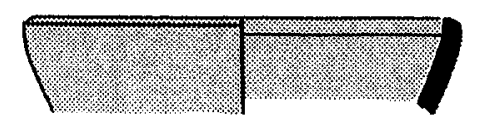

1

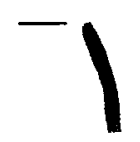

2

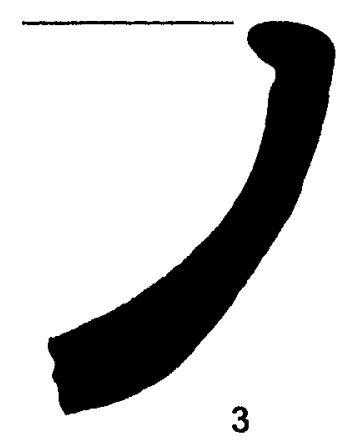

3
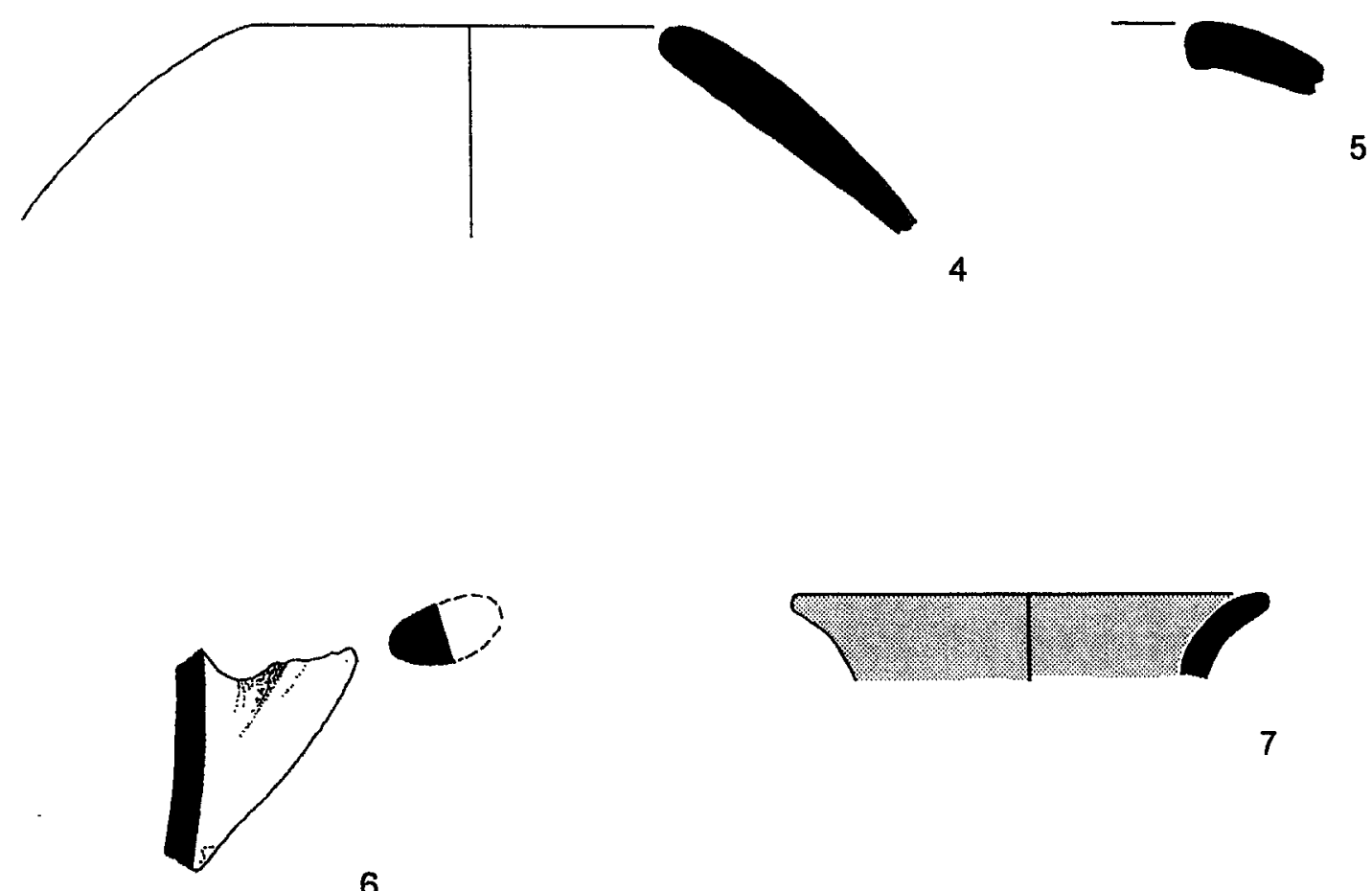

7
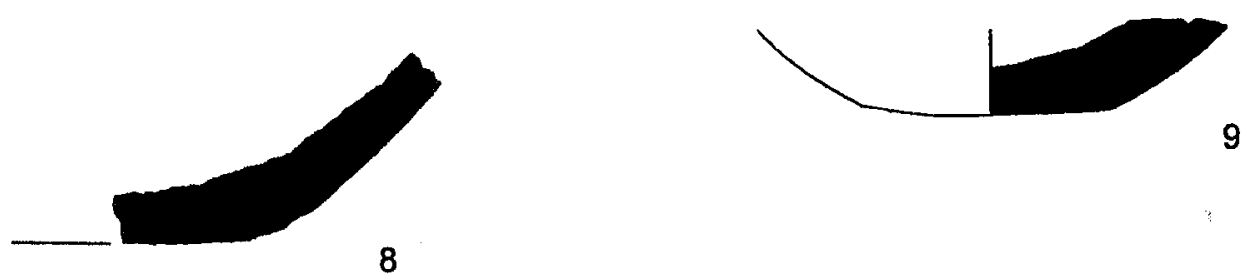

9

PLATE 124 (CONT.).

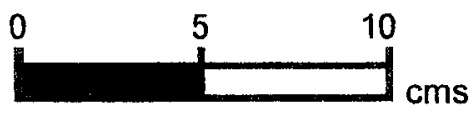




\begin{tabular}{llllllll}
\hline No & Reg & Square & Locus & Vessel & Part & $\begin{array}{c}\text { Body } \\
\text { Thick }\end{array}$ & Dia \\
\hline & & & & & & & \\
1 & 1454 & SW 1-9 & 180 & BOWL & R50 & 6 & N \\
2 & 1453 & SW 1-9 & 180 & PLATTER BOWL & R53 & 11 & N \\
3 & 1447 & SW 1-9 & 178 & HOLE MOUTH BOWL & R19 & 15 & 30 \\
4 & 2339 & SW 1-9 & 180 & HOLE MOUTH JAR & R19 & 9 & N \\
5 & 2341 & SW 1-9 & 180 & HOLE MOUTH JAR & R12 & 6 & N \\
6 & 1444 & SW 1-9 & 187 & UD & SPT & N & N \\
7 & 1451 & SW 1-9 & 180 & JUG & B11 & 8 & 3 \\
8 & 1452 & SW 1-9 & 180 & UD & B12 & 11 & N \\
9 & 2344 & SW 1-9 & 180 & UD & H46 & 11 & N \\
10 & 1445 & SW 1-9 & 187 & LEDGE RIM BOWL & R53 & 17 & 60 \\
\hline No & Fabric Color & & Core Orient Core Color & Core Thick & Fabric \\
& & & & & & Family
\end{tabular}

\begin{tabular}{|c|c|c|c|c|c|c|c|}
\hline $\begin{array}{l}1 \\
2 \\
3 \\
4 \\
5 \\
6 \\
7 \\
8 \\
9 \\
10\end{array}$ & $\begin{array}{l}\text { LT REDDIS } \\
\text { LT RED } \\
\text { LT REDDIS } \\
\text { PINK } \\
\text { LT REDDIS } \\
\text { PINK } \\
\text { LT RED } \\
\text { LT RED } \\
\text { PINK } \\
\text { PINK }\end{array}$ & $\begin{array}{l}\text { ROWN } \\
\text { ROWN } \\
\text { ROWN }\end{array}$ & $\begin{array}{l}N \\
N \\
\text { IRR } \\
N \\
N \\
N \\
N \\
\text { IN } \\
N \\
N\end{array}$ & $\begin{array}{l}N \\
N \\
G \\
N \\
N \\
N \\
N \\
G \\
N \\
N\end{array}$ & $\begin{array}{l}N \\
N \\
N \\
N \\
N \\
N \\
N \\
6 \\
N \\
N\end{array}$ & & $\begin{array}{l}N \\
N \\
N \\
N \\
N \\
N \\
12.1 \\
N \\
N \\
N\end{array}$ \\
\hline$\overline{\text { No }}$ & Treatment & $\begin{array}{l}\text { Treatment } \\
\text { Location }\end{array}$ & $\begin{array}{l}\text { Treatment } \\
\text { Cover }\end{array}$ & $\begin{array}{l}\text { Color } \\
\text { Interior }\end{array}$ & & $\begin{array}{l}\text { Color } \\
\text { Exterior }\end{array}$ & \\
\hline $\begin{array}{l}1 \\
2 \\
3 \\
4 \\
5 \\
6 \\
7 \\
8 \\
9 \\
10\end{array}$ & $\begin{array}{l}\text { UN } \\
\text { UD } \\
\text { UN } \\
\text { S } \\
\text { UN } \\
\text { S } \\
\text { B } \\
\text { UN } \\
\text { WASH } \\
\text { SB }\end{array}$ & $\begin{array}{l}N \\
N \\
N \\
E R \\
N \\
E \\
E \\
N \\
E \\
\text { IR }\end{array}$ & $\begin{array}{l}N \\
N \\
N \\
A L L \\
N \\
A L L \\
A L L \\
N \\
\text { ALL } \\
\text { NET }\end{array}$ & $\begin{array}{l}N \\
N \\
N \\
N \\
N \\
N \\
N \\
N \\
N \\
\text { REDDIS }\end{array}$ & Low & $\begin{array}{l}N \\
N \\
N \\
\text { RED } \\
N \\
\text { RED } \\
N \\
N \\
\text { WHITE } \\
N\end{array}$ & \\
\hline
\end{tabular}

PLATE 125. FIELD B. PHASE 2B (MIXED EB). 
Other

1 Sample too small to confirm stance or diameter; burn on rim suggests use as lamp.

2 Sample too small to confirm stance or diameter; very weathered; Metallic Ware.

4 Sample too small to confirm stance or diameter.

5 Sample too small to confirm stance or diameter.

7 Metallic Ware.

8 Sample too small to confirm stance or diameter.

9 Ledge handle is vertically pierced; the piercing instrument (ca. $3 \mathrm{~mm}$ in dia) was pushed from below handle and dug into the exterior vessel wall above handle.

PLATE 125 (CONT.). 

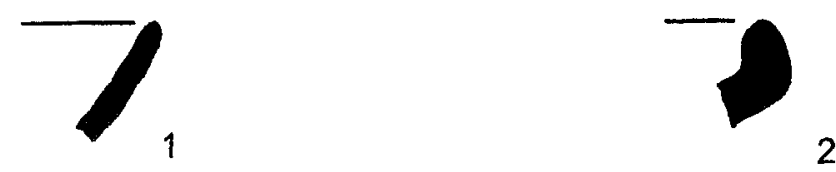

2
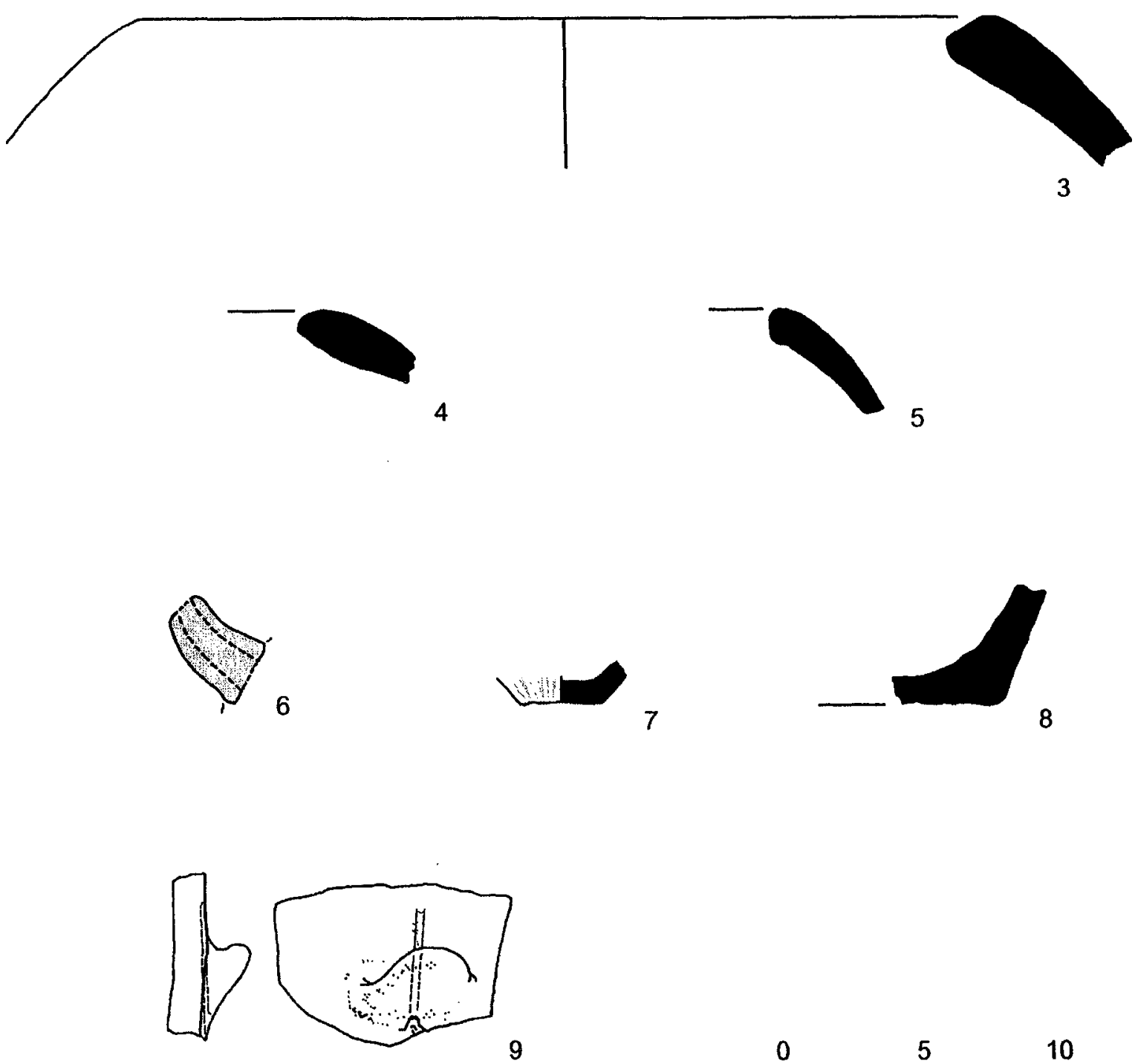

9
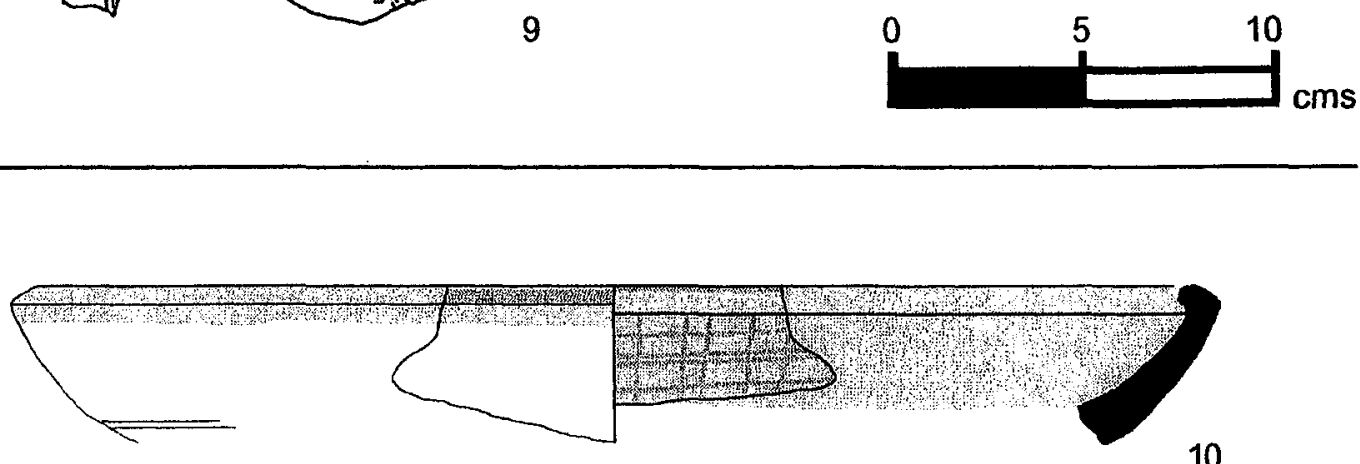

10

PLATE 125 (CONT.).
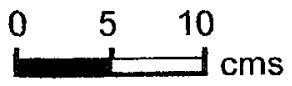


\begin{tabular}{llllllll}
\hline No & Reg & Square & Locus & Vessel & Part & $\begin{array}{l}\text { Body } \\
\text { Thick }\end{array}$ & Dia \\
\hline 1 & 1434 & SW 1-9 & 188 & BOWL & R50 & 5 & 15 \\
2 & 1442 & SW 1-9 & 188 & PLATTER BOWL & R56 & 10 & N \\
3 & 1441 & SW 1-9 & 188 & NECKED JAR & R43 & 15 & 20 \\
4 & 1435 & SW 1-9 & 188 & NECKED JAR & R43 & 7 & 10 \\
5 & 1439 & SW 1-9 & 188 & UD & B11 & 11 & 12 \\
6 & 1438 & SW 1-9 & 188 & UD & B12 & 8 & 13 \\
7 & 1443 & SW 1-9 & 188 & PLATTER BOWL & R53 & 9 & 45 \\
\hline No & Fabric Color & & Core Orient Core Color & Core Thick & Fabric \\
& & & & & & &
\end{tabular}

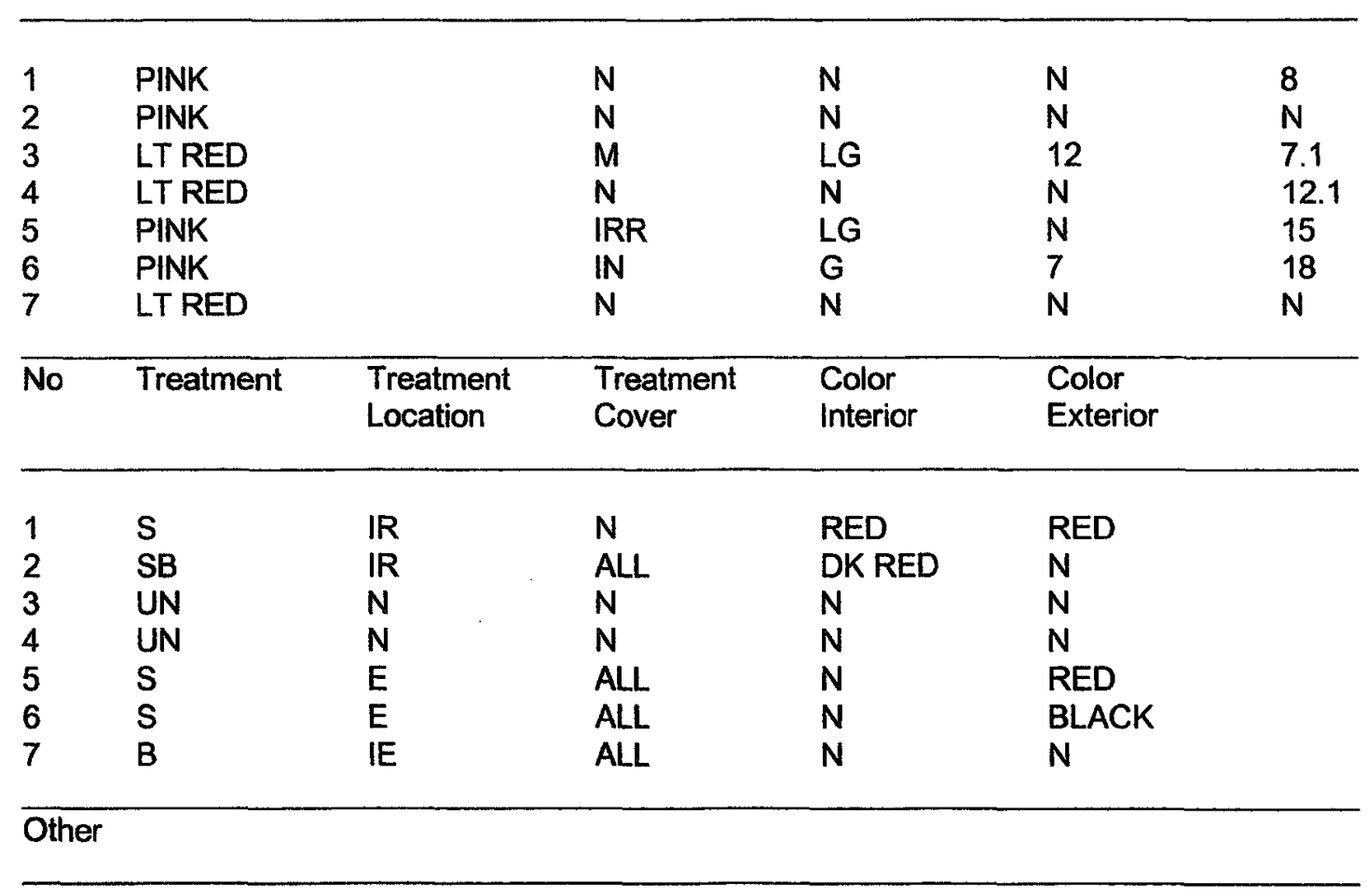

2 Sample too small to confirm stance or diameter.

3 Voids in section suggest rim folding from int to ext.

4 Metallic Ware.

7 Metallic Ware.

PLATE 126. FIELD B. PHASE 2B (MIXED EB). 

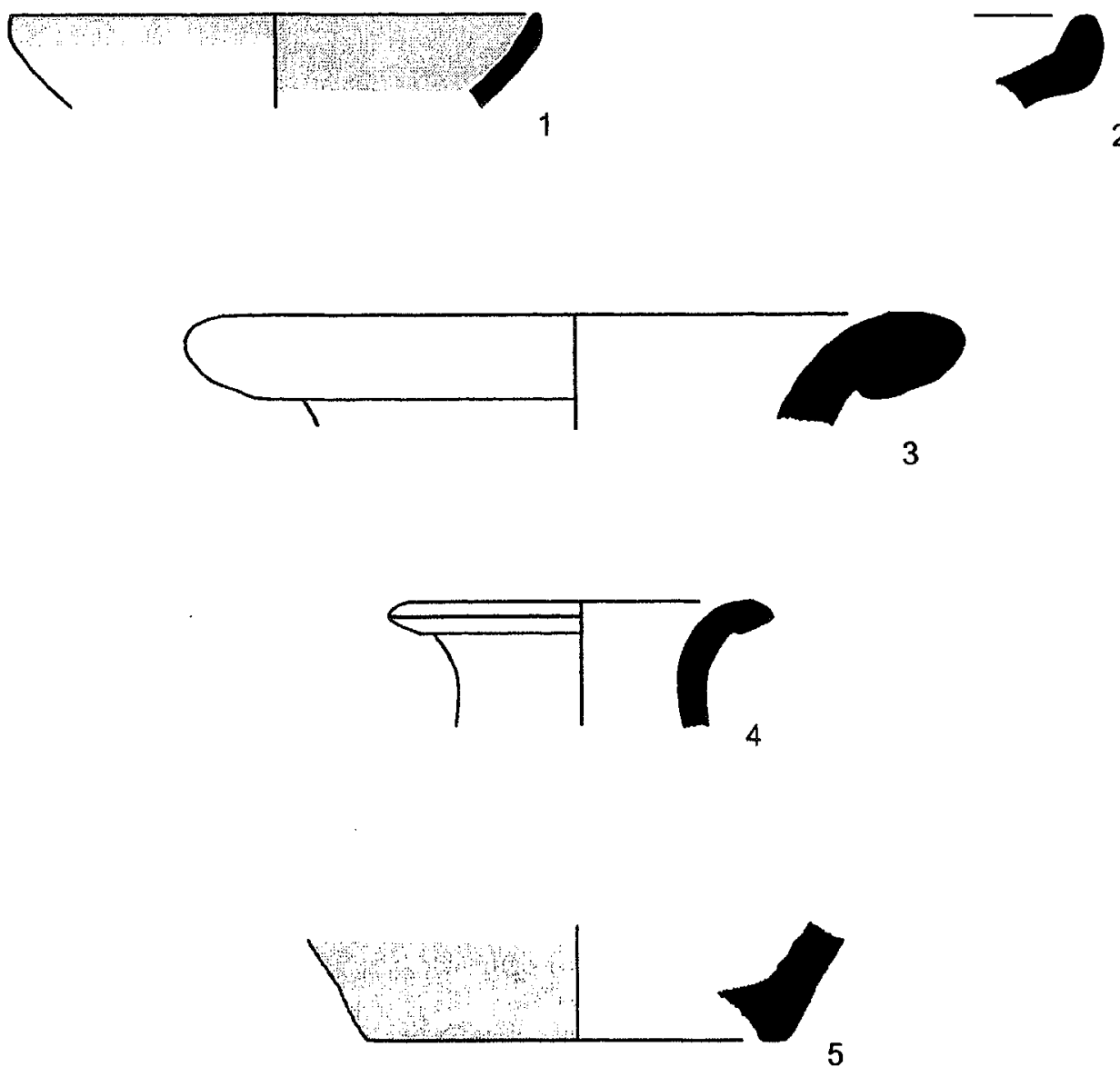

5
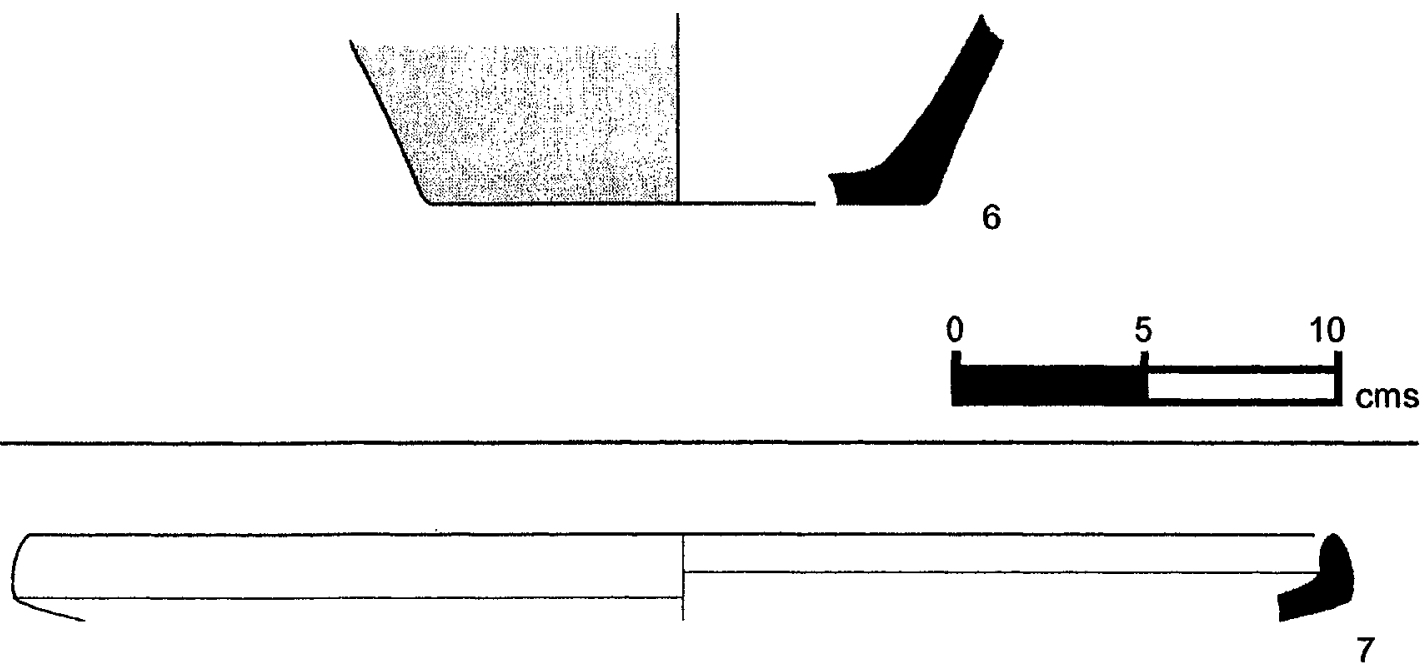

PLATE 126 (CONT.).

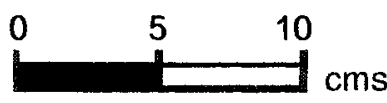




\begin{tabular}{llllllll}
\hline No & Reg & Square & Locus & Vessel & Part & $\begin{array}{c}\text { Body } \\
\text { Thick }\end{array}$ & Dia \\
\hline 1 & 1412 & SW 1-9 & 203 & HOLE MOUTH BOWL & R19 & 10 & 17 \\
2 & 1413 & SW 1-9 & 203 & HOLE MOUTH JAR & R14 & 11 & 13 \\
3 & 2294 & SW 1-9 & 203 & HOLE MOUTH JARIBOWL & R21 & N & N \\
4 & 1414 & SW 1-9 & 203 & NECKED JAR & R43 & 9 & 24 \\
5 & 1417 & SW 1-9 & 203 & UD & B13 & 11 & 12 \\
6 & 1416 & SW 1-9 & 203 & UD & B12 & 7 & 5 \\
7 & 1415 & SW 1-9 & 203 & UD & H27 & 8 & N \\
8 & 1418 & SW 1-9 & 203 & UD & B22 & 9 & 4
\end{tabular}

\begin{tabular}{lllll}
\hline No Fabric Color & Core Orient & Core Color & Core Thick & Fabric \\
Family
\end{tabular}

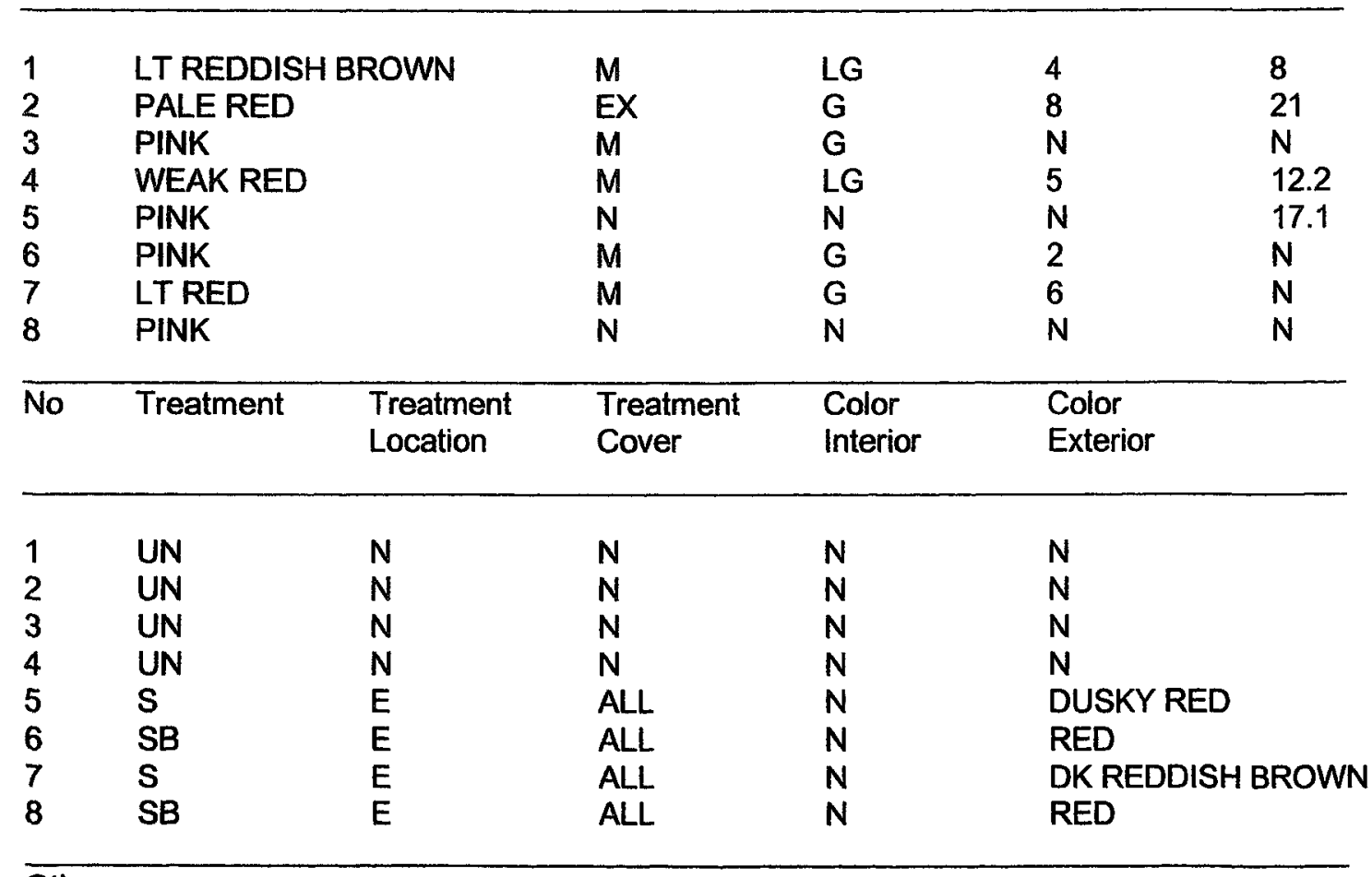

Other

3 Sample too small to confirm stance or diameter.

4 Metallic Ware.

7 Metallic Ware.

PLATE 127. FIELD B. PHASE 2B (MIXED EB). 

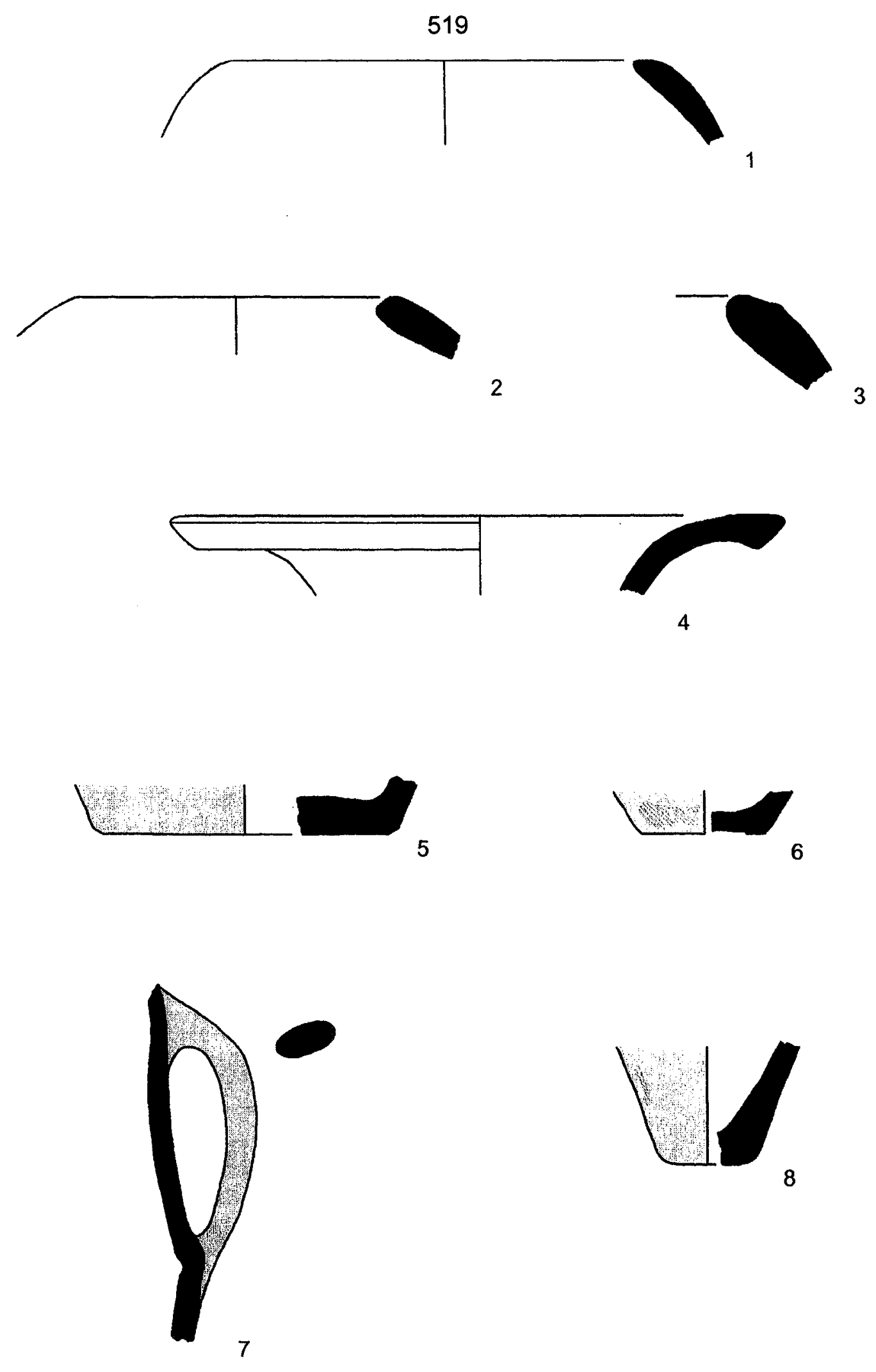

PLATE 127 (CONT.).

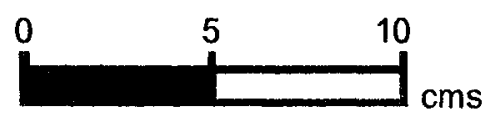




\begin{tabular}{llllllll}
\hline No & Reg & Square & Locus & Vessel & Part & $\begin{array}{l}\text { Body } \\
\text { Thick }\end{array}$ & Dia \\
\hline 1 & 1480 & SW 1-9 & 173 & PLATTER BOWL & R54 & 11 & 30 \\
2 & 1483 & SW 1-9 & 173 & PLATTER BOWL & R53 & 9 & N \\
3 & 1486 & SW 1-9 & 173 & HOLE MOUTH JAR & R01 & 13 & 20 \\
4 & 1488 & SW 1-9 & 173 & HOLE MOUTH JARIBOWL & R01 & 12 & 12 \\
5 & 1487 & SW 1-9 & 173 & NECKED JAR & R31 & 7 & N \\
6 & 1484 & SW 1-9 & 173 & NECKED JAR & R31 & 9 & N \\
7 & 1485 & SW 1-9 & 173 & UD & B12 & 11 & 20 \\
8 & 2410 & SW 1-9 & 173 & VAT & R04 & 11 & 50 \\
\hline
\end{tabular}

No Fabric Color Core Orient $\quad$ Core Color Core Thick $\begin{aligned} & \text { Fabric } \\ & \text { Family }\end{aligned}$

\begin{tabular}{|c|c|c|c|c|c|c|}
\hline $\begin{array}{l}1 \\
2 \\
3 \\
4 \\
5 \\
6 \\
7 \\
8\end{array}$ & $\begin{array}{l}\text { LT REDDIS } \\
\text { RED } \\
\text { RED } \\
\text { PALE RED } \\
\text { LT RED } \\
\text { PINK } \\
\text { PALE RED } \\
\text { PINK }\end{array}$ & 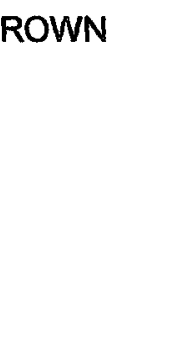 & $\begin{array}{l}M \\
N \\
\text { EX } \\
\text { EX } \\
N \\
M \\
\text { IRR } \\
N\end{array}$ & $\begin{array}{l}\text { LG } \\
N \\
G \\
G \\
N \\
\text { LG } \\
\text { LG } \\
N\end{array}$ & $\begin{array}{l}4 \\
N \\
7 \\
9 \\
N \\
2 \\
N \\
N\end{array}$ & $\begin{array}{l}17.2 \\
N \\
N \\
N \\
N \\
N \\
N \\
N\end{array}$ \\
\hline$\overline{\text { No }}$ & Treatment & $\begin{array}{l}\text { Treatment } \\
\text { Location }\end{array}$ & $\begin{array}{l}\text { Treatment } \\
\text { Cover }\end{array}$ & $\begin{array}{l}\text { Color } \\
\text { Interior }\end{array}$ & $\begin{array}{l}\text { Color } \\
\text { Exterior }\end{array}$ & \\
\hline $\begin{array}{l}1 \\
2 \\
3 \\
4 \\
5 \\
6 \\
7 \\
8\end{array}$ & $\begin{array}{l}S \\
\text { SB } \\
\text { UN } \\
\text { UN } \\
\text { UN } \\
\text { S } \\
\text { UN } \\
\text { UN }\end{array}$ & $\begin{array}{l}\text { IR } \\
\text { IR } \\
N \\
N \\
N \\
\text { ER } \\
N \\
N\end{array}$ & $\begin{array}{l}A L L \\
A L L \\
N \\
N \\
N \\
A L L \\
N \\
N\end{array}$ & $\begin{array}{l}\text { RED } \\
\text { RED } \\
N \\
N \\
N \\
N \\
N \\
N\end{array}$ & $\begin{array}{l}N \\
N \\
N \\
N \\
N \\
D K \text { RED } \\
N \\
N\end{array}$ & \\
\hline
\end{tabular}

\footnotetext{
2 Metallic Ware; sample too small to confirm stance or diameter.

$4 \quad$ Surface burn visible.

5 Sample too small to confirm stance or diameter.

6 Sample too small to confirm stance or diameter.
}

PLATE 128. FIELD B. PHASE 2B (MIXED EB). 
521
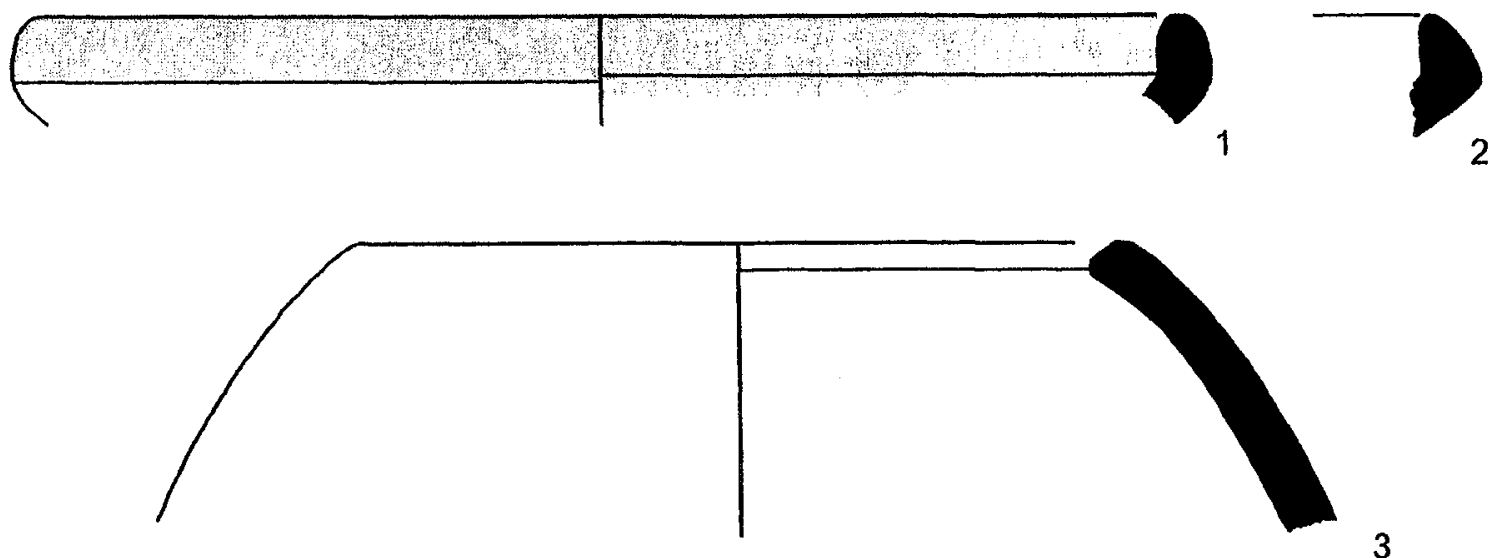

3

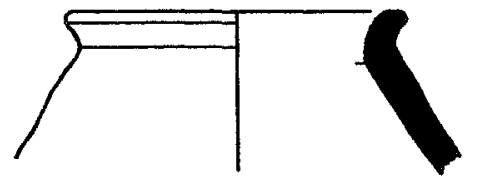

5
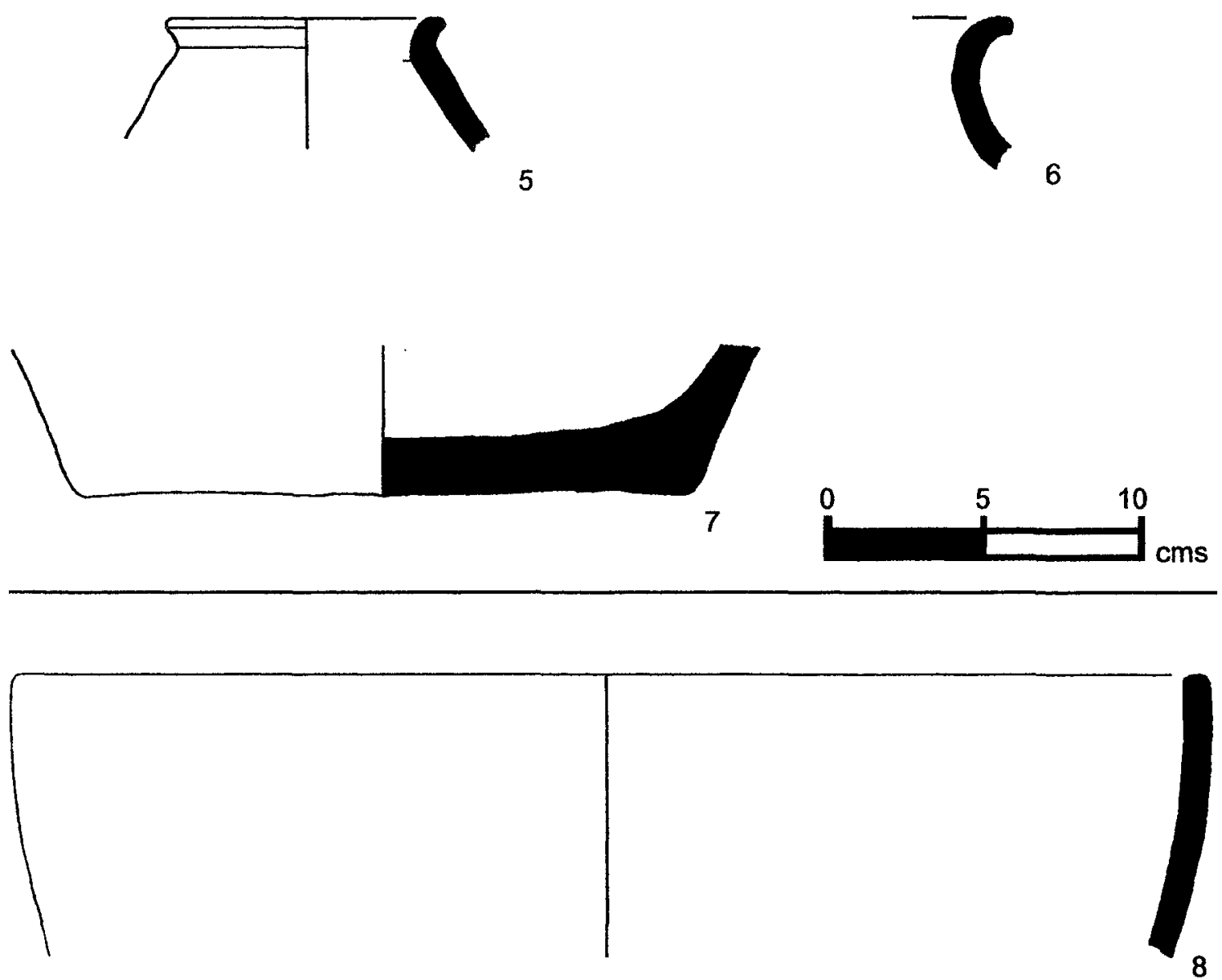

PLATE 128 (CONT.).

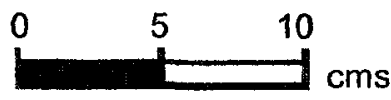


522

\begin{tabular}{llllllll}
\hline No & Reg & Square & Locus & Vessel & Part & $\begin{array}{l}\text { Body } \\
\text { Thick }\end{array}$ & Dia \\
\hline & & & & & & & \\
1 & 1476 & SW 1-9 & 175 & LEDGE RIM BOWL & R51 & 6 & 25 \\
2 & 1457 & SW 1-9 & 176 & BOWL & R50 & 6 & 14 \\
3 & 1456 & SW 1-9 & 176 & LEDGE RIM BOWL & R53 & 16 & 24 \\
4 & 2300 & SW 1-9 & 176 & NECKED JAR & R30 & N & 12 \\
5 & 1479 & SW 1-9 & 175 & LEDGE RIM BOWL & R53 & 12 & N \\
6 & 1478 & SW 1-9 & 175 & NECKED JAR & R42 & 10 & 20 \\
7 & 1477 & SW 1-9 & 175 & JUG & B12 & 7 & 8 \\
8 & 1455 & SW 1-9 & 176 & HOLE MOUTH JAR & R01 & 12 & 28 \\
\hline
\end{tabular}

No Fabric Color Core Orient Core Color Core Thick $\begin{aligned} & \text { Fabric } \\ & \text { Family }\end{aligned}$

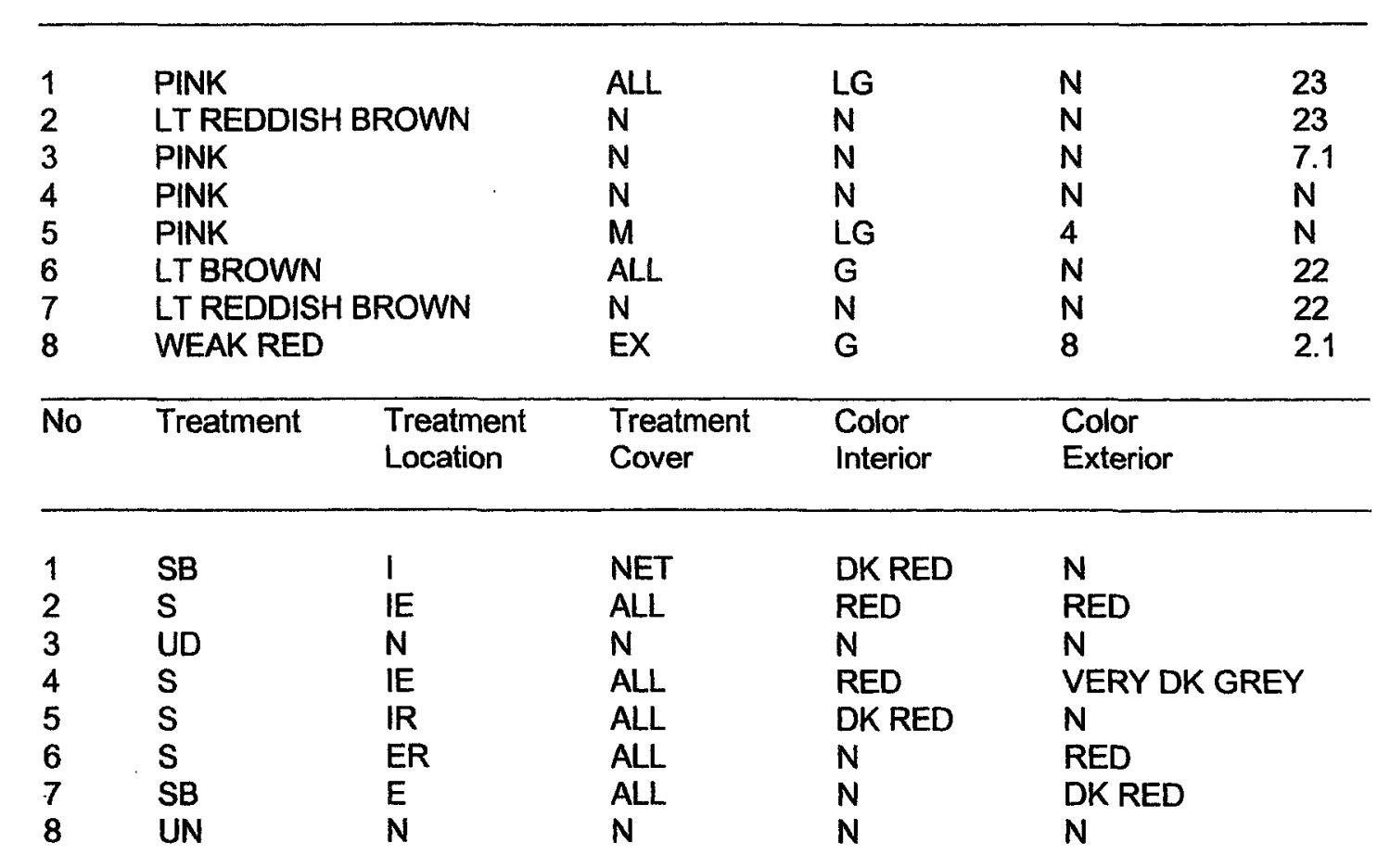

PLATE 129. FIELD B. PHASE 2B (MIXED EB). 
Other

1 Lines on interior/exterior suggest motion used to finish rim; net burnish over slip on interior face.

2 Also B50; burn on rim suggests use as lamp.

3 Very weathered.

5 Sample too small to confirm stance or diameter.

6 Voids in section suggest rim folding from interior to exterior.

8 Surface burn visible.

PLATE 129 (CONT.). 
524
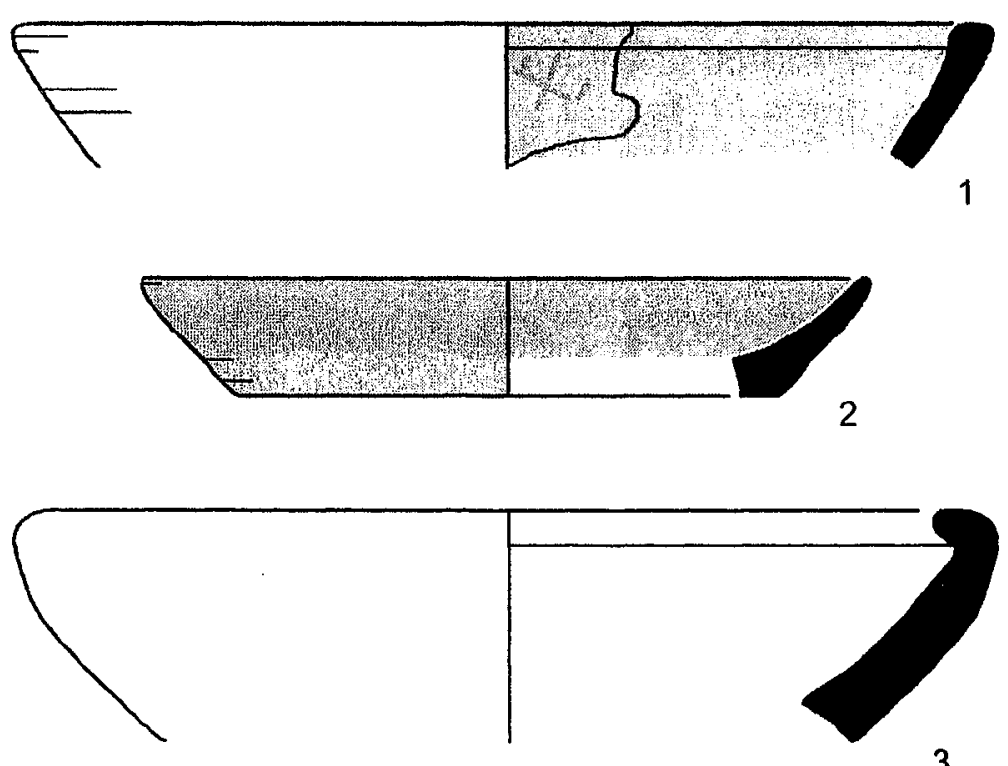

3
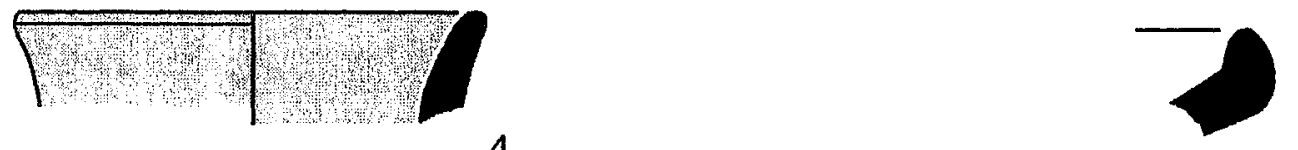

4
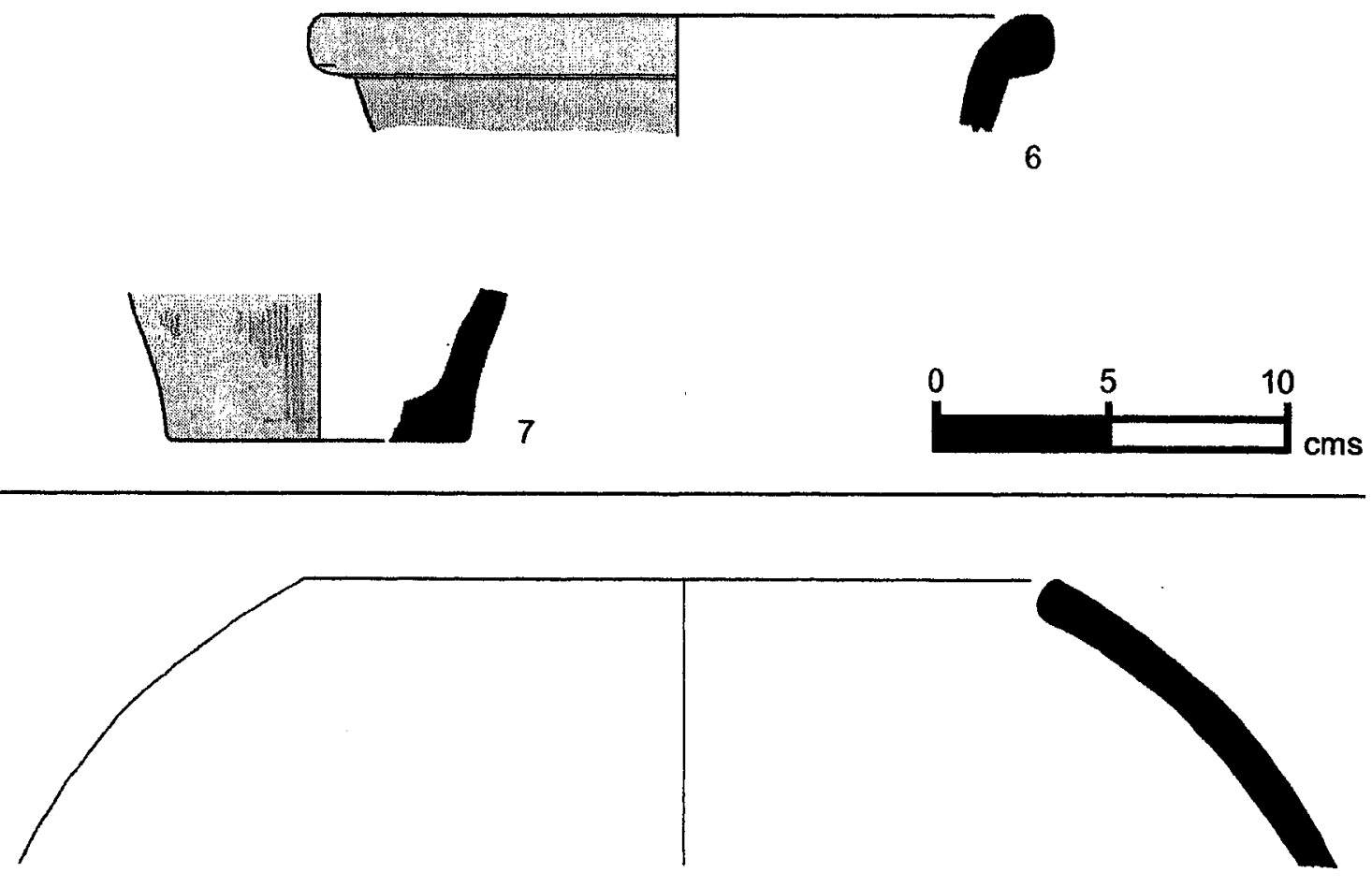

PLATE 129 (CONT.).

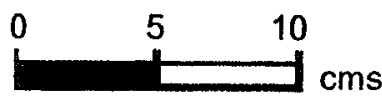




\begin{tabular}{|c|c|c|c|c|c|c|c|}
\hline No & $\operatorname{Reg}$ & Square & Locus & Vessel & Part & $\begin{array}{l}\text { Body } \\
\text { Thick }\end{array}$ & $\overline{\text { Dia }}$ \\
\hline 1 & 1493 & SW 1-9 & 172 & HOLE MOUTH JAR & R01 & 12 & 16 \\
\hline 2 & 2402 & SW 1-9 & 172 & HOLE MOUTH JAR & R14 & $\mathbf{N}$ & 13 \\
\hline 3 & 2281 & SW $1-9$ & 172 & HOLE MOUTH JARIBOWL & R04 & 13 & $\mathbf{N}$ \\
\hline 4 & 2280 & SW 1-9 & 172 & NECKED JAR & R43 & 8 & 22 \\
\hline 5 & 2279 & SW 1-9 & 172 & NECKED JAR & R34 & $\mathrm{N}$ & $\mathbf{N}$ \\
\hline 6 & 1496 & SW 1-9 & 172 & NECKED JAR & R43 & 8 & 22 \\
\hline 7 & 1491 & SW 1-9 & 172 & NECKED JAR & $\mathrm{R} 30$ & 9 & 13 \\
\hline 8 & 2409 & SW 1-9 & 172 & CARINATED BOWL & R58 & $\mathbf{N}$ & $\mathbf{N}$ \\
\hline 9 & 2278 & SW 1-9 & 172 & LEDGE RIM BOWL & $\mathbf{R} 60$ & $\mathbf{N}$ & $\mathbf{N}$ \\
\hline 10 & 1494 & SW 1-9 & 172 & LEDGE RIM BOWL & R60 & 12 & $\mathbf{N}$ \\
\hline 11 & 2400 & SW 1-9 & 172 & UD & $\mathrm{H} 10$ & 6 & $\mathbf{N}$ \\
\hline 12 & 1497 & SW 1-9 & 172 & UD & B23 & 12 & 4 \\
\hline 13 & 1489 & SW 1-9 & 172 & LEDGE RIM BOWL & R51 & 17 & 46 \\
\hline
\end{tabular}

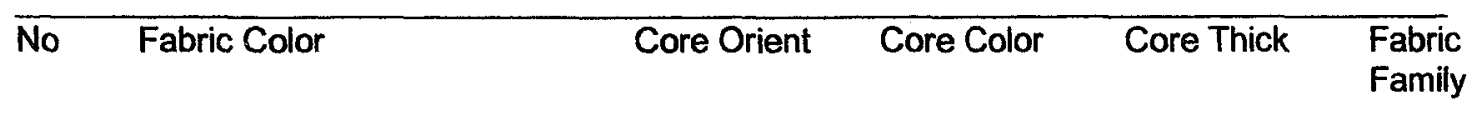

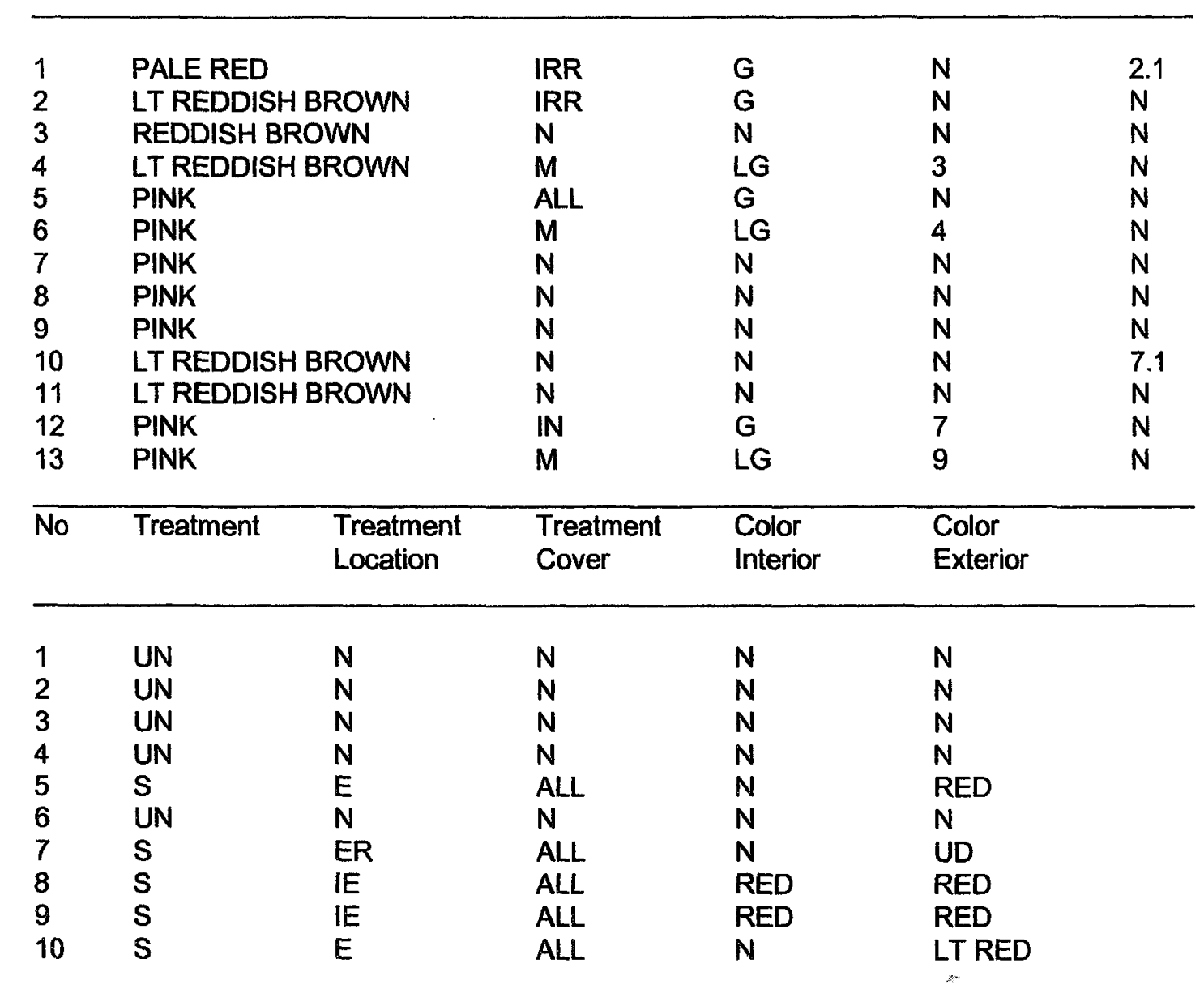

PLATE 130. FIELD B. PHASE 2B (MIXED EB). 
526

\begin{tabular}{llllll}
\hline No & Treatment & $\begin{array}{l}\text { Treatment } \\
\text { Location }\end{array}$ & $\begin{array}{l}\text { Treatment } \\
\text { Cover }\end{array}$ & $\begin{array}{l}\text { Color } \\
\text { Interior }\end{array}$ & $\begin{array}{l}\text { Color } \\
\text { Exterior }\end{array}$ \\
\hline 11 & S & E & ALL & N & RED \\
12 & S & E & ALL & N & RED \\
13 & SB & IR & ALL & DK RED & N \\
\hline Other & & & & \\
\hline
\end{tabular}

1 Lines on interiorlexterior suggest motion used to finish rim; surface burn visible.

3 Sample too small to confirm stance or diameter.

5 Sample too small to confirm stance or diameter.

6 Sample too small to confirm stance or diameter.

$7 \quad$ Slip applied in net pattern on exterior wall.

8 Sample too small to confirm stance or diameter.

9 Sample too small to confirm stance or diameter.

10 Sample too small to confirm stance or diameter.

11 Thin section sample 48.

13 A broad band of wet-smoothing lines appear immediately below rim on exterior wall; fine lines suggestive of wiping sweep horizontally and diagonally across the "textured" lower surface of the exterior face; a few diagonal lines are noted on the upper margin.

PLATE 130 (CONT.). 

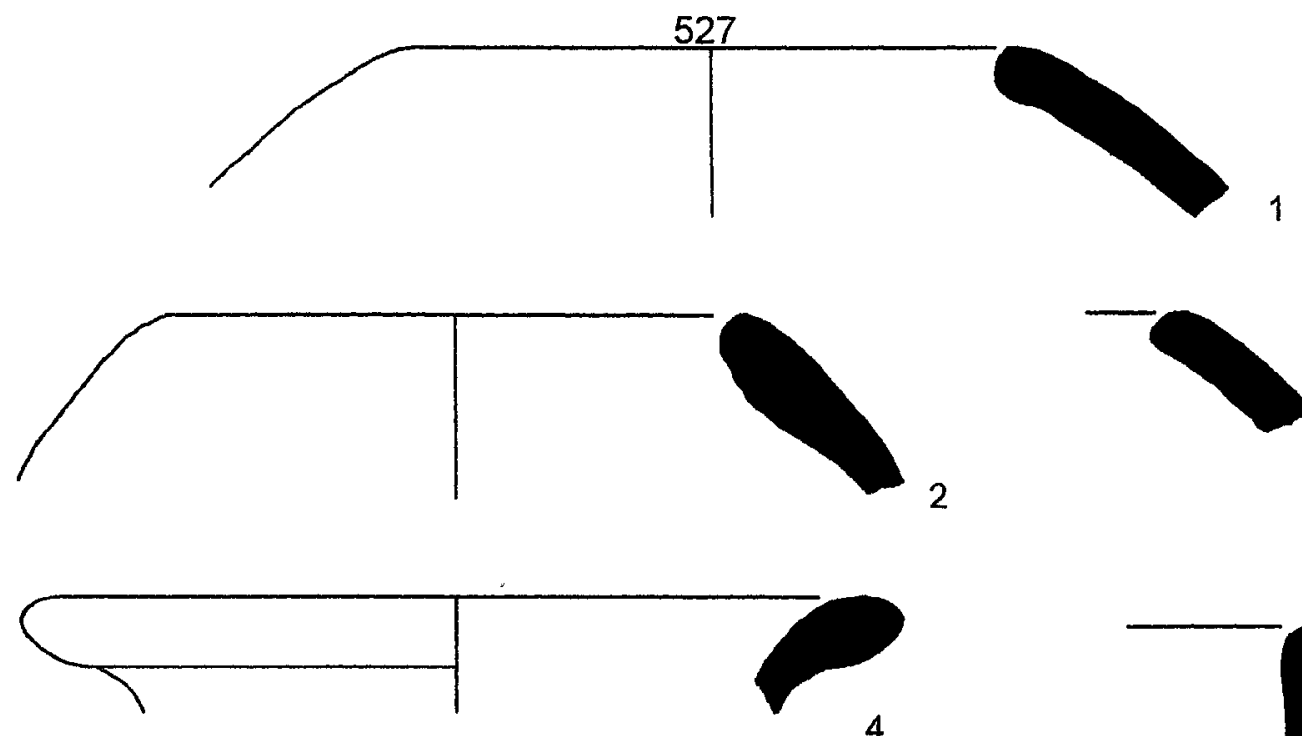

4
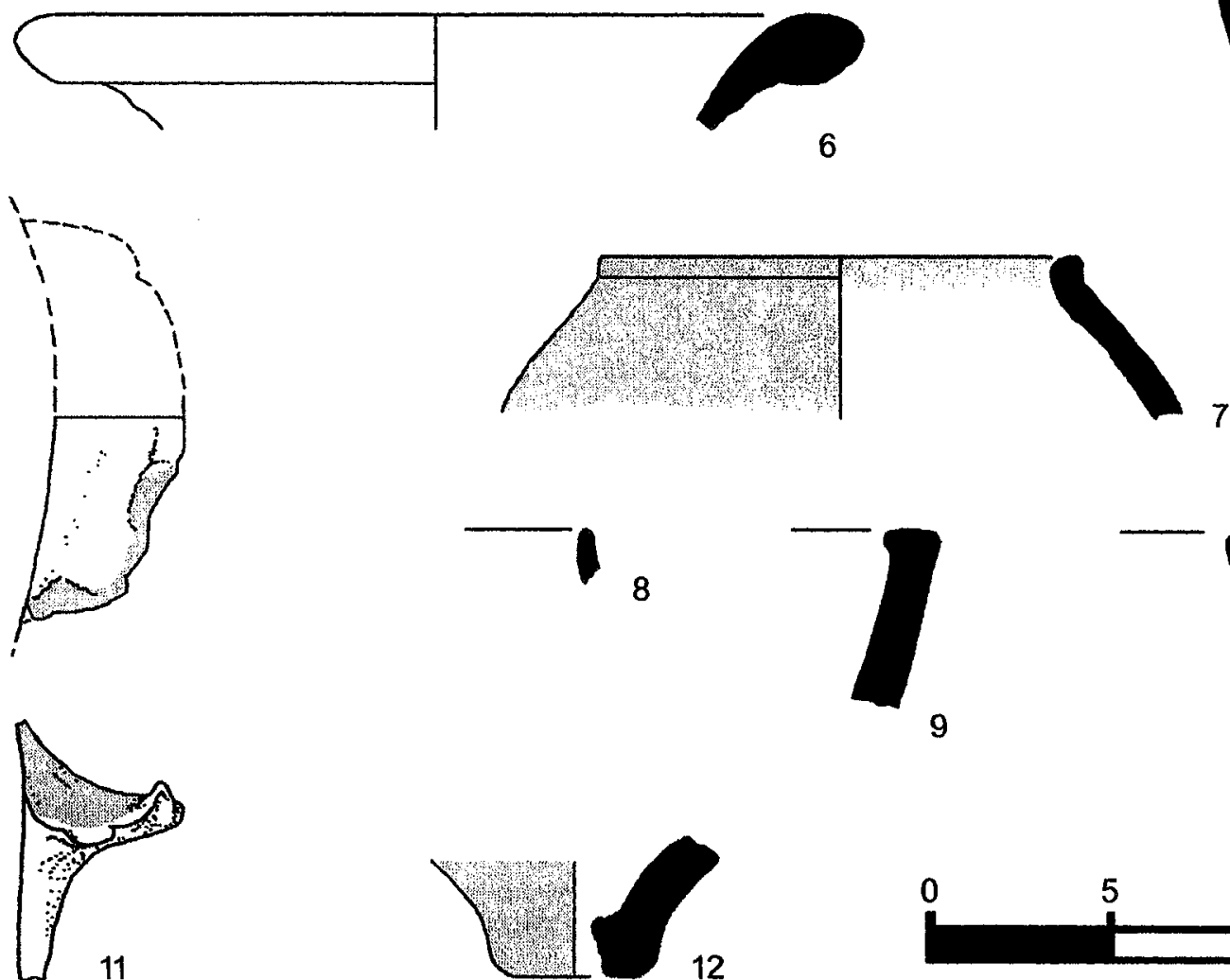

9

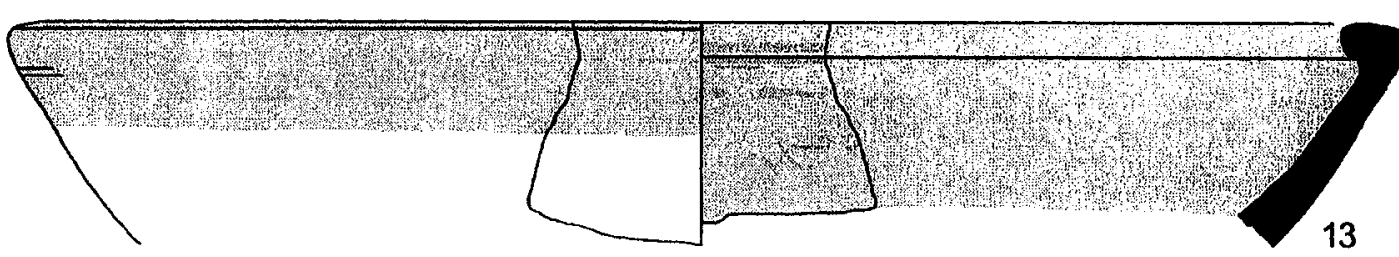

PLATE 130 (CONT.).

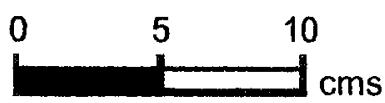


528

\begin{tabular}{llllllll}
\hline No & Reg & Square & Locus & Vessel & Part & $\begin{array}{l}\text { Body } \\
\text { Thick }\end{array}$ & Dia \\
\hline 1 & 1799 & NW 9-1 & 51 & NECKED JAR & R31 & 13 & 13 \\
2 & 1796 & NW 9-1 & 51 & UD & B12 & 14 & 24 \\
3 & 1795 & NW 9-1 & 51 & UD & B12 & 11 & 20 \\
4 & 1797 & NW 9-1 & 51 & UD & B12 & 8 & 13 \\
5 & 1852 & NW 9-1 & 55 & HOLE MOUTH JAR & R02 & 11 & 12 \\
6 & 1853 & NW 9-1 & 53 & PLATTER BOWL & R53 & 16 & 40
\end{tabular}

\begin{tabular}{lllll}
\hline No Fabric Color & Core Orient & Core Color & Core Thick & Fabric \\
Family
\end{tabular}

\begin{tabular}{|c|c|c|c|c|c|c|}
\hline $\begin{array}{l}1 \\
2 \\
3 \\
4 \\
5 \\
6\end{array}$ & \multicolumn{2}{|c|}{$\begin{array}{l}\text { PINK } \\
\text { PINK } \\
\text { PINK } \\
\text { PINKISH GREY } \\
\text { REDDISH BROWN } \\
\text { LT BROWN }\end{array}$} & $\begin{array}{l}M \\
\text { IRR } \\
M \\
\text { ALL } \\
M \\
N\end{array}$ & $\begin{array}{l}G \\
L G \\
G \\
G \\
L G \\
N\end{array}$ & $\begin{array}{l}4 \\
N \\
5 \\
N \\
3 \\
N\end{array}$ & $\begin{array}{l}\mathrm{N} \\
19 \\
7.2 \\
4 \\
5.1 \\
16\end{array}$ \\
\hline No & Treatment & $\begin{array}{l}\text { Treatment } \\
\text { Location }\end{array}$ & $\begin{array}{l}\text { Treatment } \\
\text { Cover }\end{array}$ & $\begin{array}{l}\text { Color } \\
\text { Interior }\end{array}$ & & \\
\hline $\begin{array}{l}1 \\
2 \\
3 \\
4 \\
5 \\
6\end{array}$ & $\begin{array}{l}S \\
S \\
S \\
\text { UN } \\
\text { UN } \\
\text { SB }\end{array}$ & $\begin{array}{l}E \\
E \\
E \\
N \\
N \\
I E\end{array}$ & $\begin{array}{l}\text { ALL } \\
\text { ALL } \\
\text { ALL } \\
N \\
N \\
\text { ALL }\end{array}$ & $\begin{array}{l}N \\
N \\
N \\
N \\
N \\
\text { UD }\end{array}$ & $\begin{array}{l}\mathrm{RE} \\
\mathrm{RE} \\
\mathrm{RE} \\
\mathrm{N} \\
\mathrm{N} \\
\mathrm{RE}\end{array}$ & WN \\
\hline
\end{tabular}

$5 \quad$ Surface burn visible.

PLATE 131. FIELD C. PHASE 1A (LATE EB I?). 

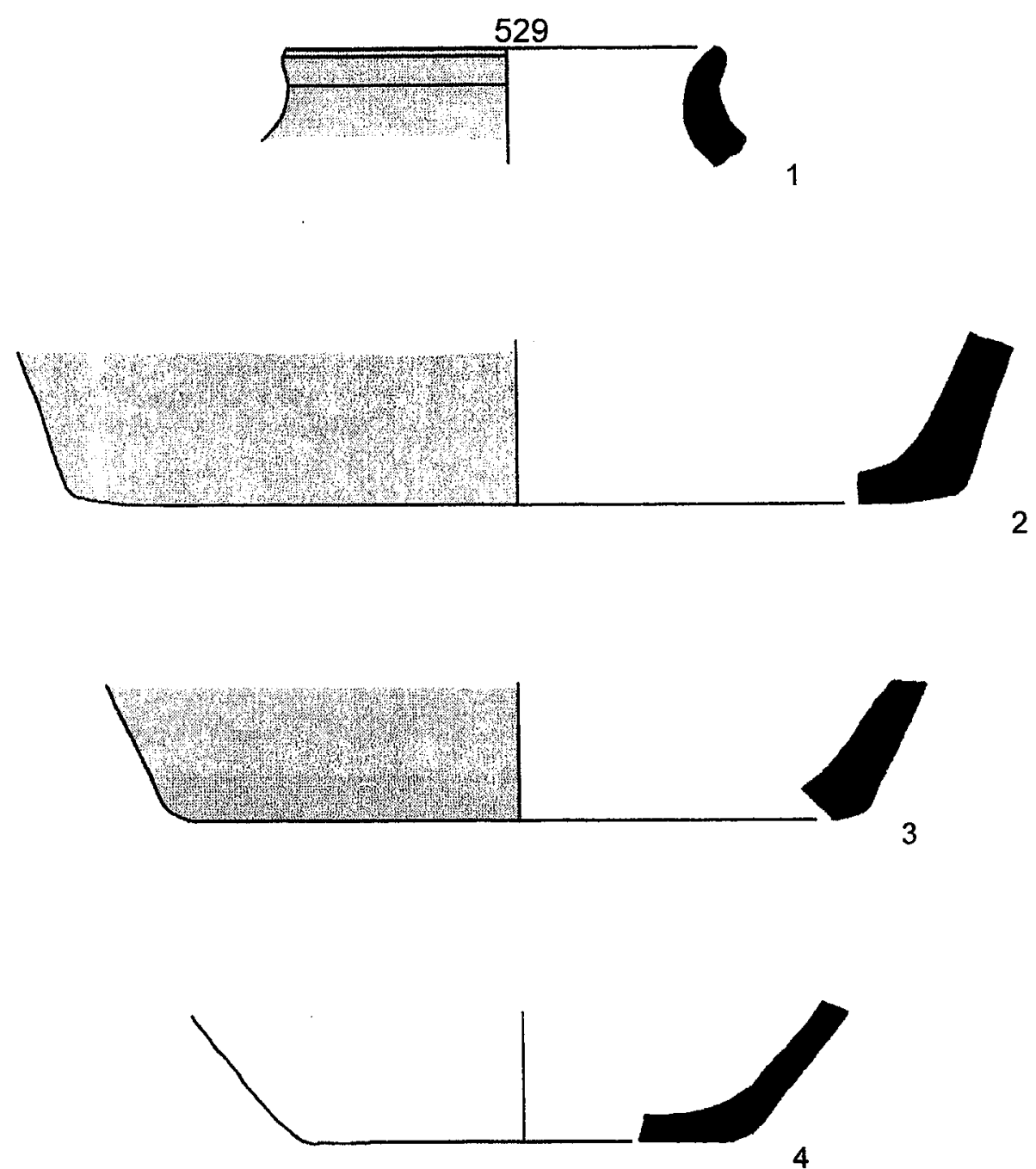

4

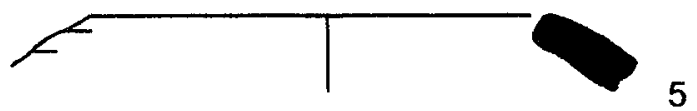

5

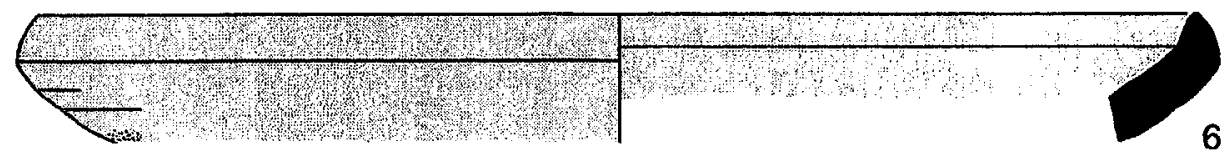

PLATE 131 (CONT.).

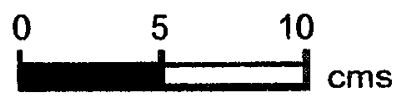




\begin{tabular}{llllllll}
\hline No & Reg & Square & Locus & Vessel & Part & $\begin{array}{l}\text { Body } \\
\text { Thick }\end{array}$ & Dia \\
\hline 1 & 1790 & NW 9-1 & 51 & HOLE MOUTH BOWL & R09 & 8 & 30 \\
2 & 1792 & NW 9-1 & 51 & HOLE MOUTH BOWL & R17 & 13 & 26 \\
3 & 1793 & NW 9-1 & 51 & HOLE MOUTH JAR & R04 & 14 & 22 \\
4 & 1794 & NW 9-1 & 51 & HOLE MOUTH JAR & R19 & 8 & 20 \\
5 & 1789 & NW 9-1 & 51 & HOLE MOUTH BOWL & R19 & 7 & 20 \\
6 & 1791 & NW 9-1 & 51 & HOLE MOUTH JAR & R19 & 13 & 20 \\
7 & 1854 & NW 9-1 & 53 & HOLE MOUTH BOWL & R07 & 8 & 12 \\
8 & 1788 & NW 9-1 & 51 & HOLE MOUTH JAR & R19 & 9 & 10
\end{tabular}

\begin{tabular}{lllll}
\hline No Fabric Color & Core Orient & Core Color & Core Thick & Fabric \\
& & & Family
\end{tabular}

\begin{tabular}{|c|c|c|c|c|c|c|}
\hline $\begin{array}{l}1 \\
2 \\
3 \\
4 \\
5 \\
6 \\
7 \\
8\end{array}$ & $\begin{array}{l}\text { PINK } \\
\text { PINK } \\
\text { PINK } \\
\text { PINK } \\
\text { PINK } \\
\text { PINK } \\
\text { REDDISH } \\
\text { PINKISH W }\end{array}$ & $\begin{array}{l}W N \\
E\end{array}$ & $\begin{array}{l}M \\
N \\
M \\
N \\
N \\
M \\
N \\
N\end{array}$ & $\begin{array}{l}\text { LG } \\
N \\
L G \\
N \\
N \\
L G \\
N \\
N\end{array}$ & $\begin{array}{l}3 \\
N \\
6 \\
N \\
N \\
5 \\
N \\
N\end{array}$ & $\begin{array}{l}19 \\
19 \\
19 \\
19 \\
19 \\
19 \\
3 \\
19\end{array}$ \\
\hline No & Treatment & $\begin{array}{l}\text { Treatment } \\
\text { Location }\end{array}$ & $\begin{array}{l}\text { Treatment } \\
\text { Cover }\end{array}$ & $\begin{array}{l}\text { Color } \\
\text { Interior }\end{array}$ & & \\
\hline $\begin{array}{l}1 \\
2 \\
3 \\
4 \\
5 \\
6 \\
7 \\
8\end{array}$ & $\begin{array}{l}S \\
S \\
S \\
S \\
S \\
\text { UN } \\
\text { UN } \\
S\end{array}$ & $\begin{array}{l}\text { IR } \\
\text { IR } \\
\text { ER } \\
\text { ER } \\
\text { ER } \\
\text { N } \\
N \\
\text { ER }\end{array}$ & $\begin{array}{l}\text { ALL } \\
\text { ALL } \\
\text { ALL } \\
\text { ALL } \\
\text { ALL } \\
N \\
N \\
N\end{array}$ & $\begin{array}{l}N \\
N \\
N \\
N \\
N \\
N \\
N \\
N\end{array}$ & $\begin{array}{l}\text { RE } \\
\text { DK } \\
\text { RE } \\
\text { DK } \\
\text { DK } \\
N \\
N \\
\text { RE }\end{array}$ & $\begin{array}{l}\text { JWN } \\
\text { BROWN } \\
\text { SWN } \\
\text { BROWN } \\
\text { BROWN }\end{array}$ \\
\hline
\end{tabular}

Other

2 Interior lines show rim smoothing and body scraping.

$4 \quad$ Interior lines show rim smoothing and body scraping.

7 Lines on interior/exterior suggest motion used to finish rim.

8 Sample too small to confirm stance or diameter.

PLATE 132. FIELD C. PHASE 1A (LATE EB I ?). 

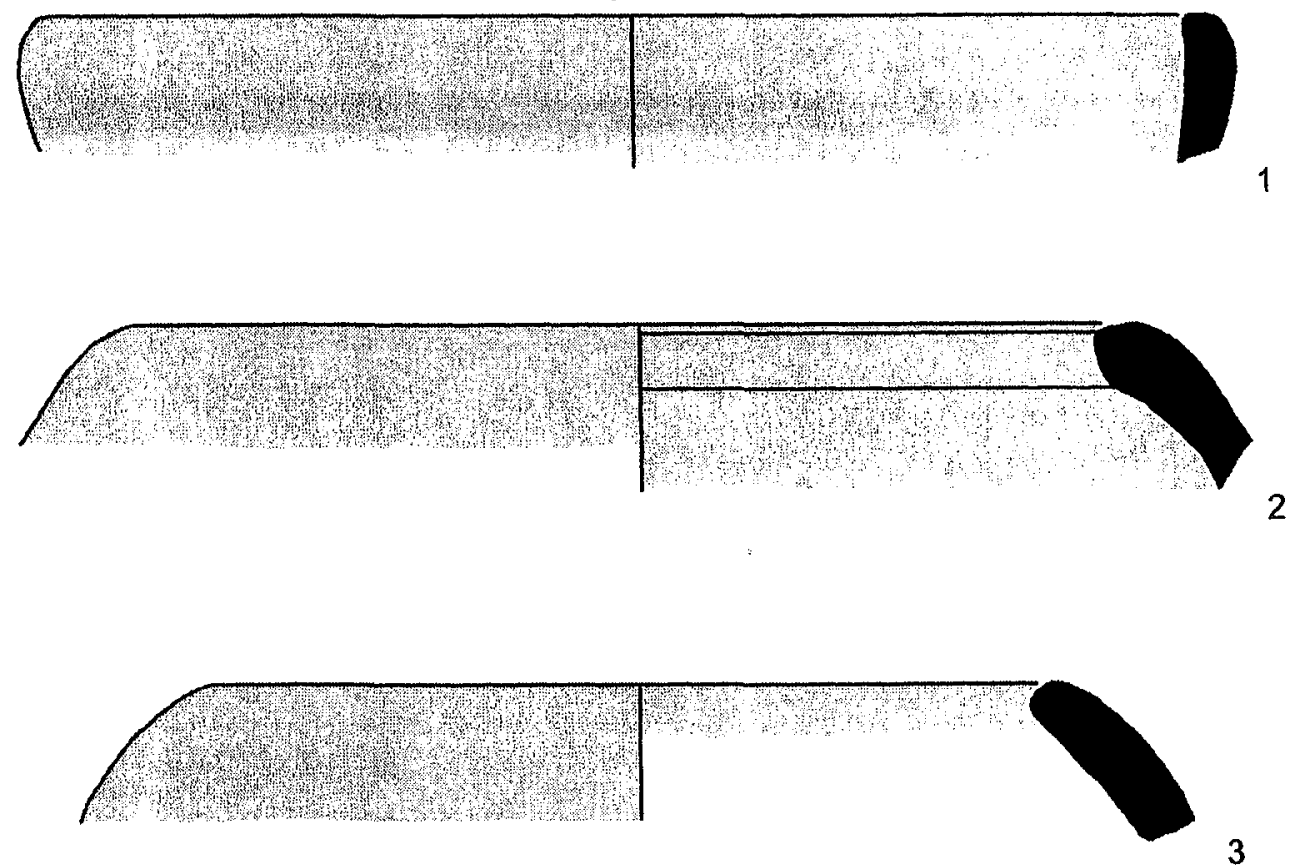

3
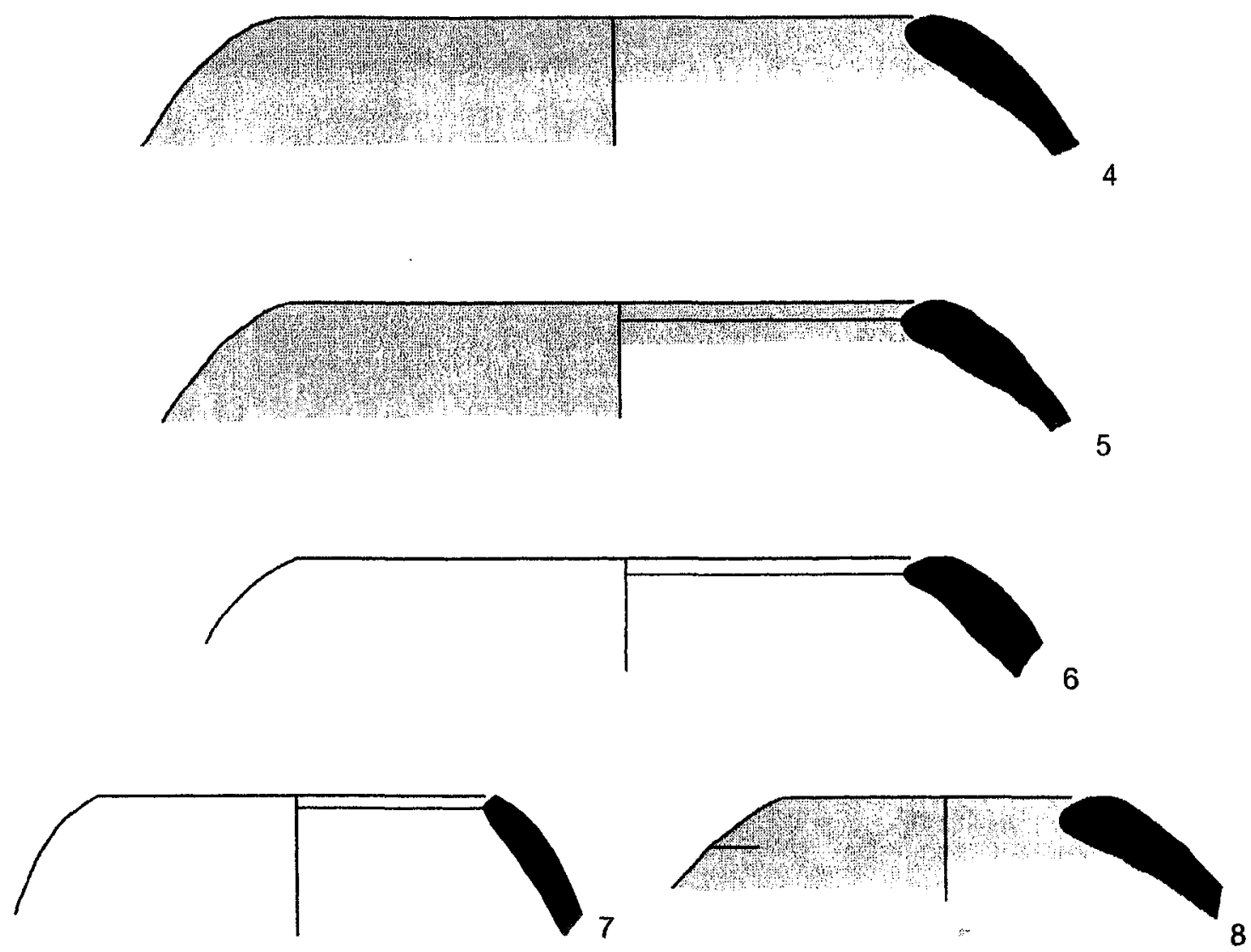

PLATE 132 (CONT.).

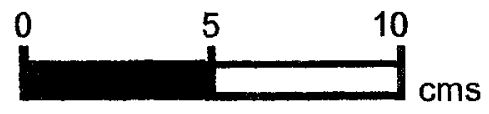


532

\begin{tabular}{llllllll}
\hline No & Reg & Square & Locus & Vessel & Part & $\begin{array}{l}\text { Body } \\
\text { Thick }\end{array}$ & $\begin{array}{l}\text { Dia } \\
\end{array}$ \\
& & & & & & \\
1 & 1864 & NW 9-1 & 64 & HOLE MOUTH JAR & R14 & 11 & 11 \\
2 & 1857 & NW 9-1 & 64 & HOLE MOUTH JAR & R07 & 13 & 10 \\
3 & 1856 & NW 9-1 & 64 & NECKED JAR & R43 & 15 & 22 \\
4 & 2424 & NW 9-1 & 64 & PLATTER BOWL & R53 & 8 & N \\
5 & 1860 & NW 9-1 & 64 & UD & B12 & 12 & 20 \\
6 & 1862 & NW 9-1 & 64 & UD & B12 & 10 & 13 \\
7 & 1861 & NW 9-1 & 64 & UD & B10 & 7 & 7 \\
8 & 1859 & NW 9-1 & 64 & UD & B12 & 11 & 9 \\
9 & 1863 & NW 9-1 & 64 & UD & BOD & 8 & N \\
10 & 1858 & NW 9-1 & 64 & UD & H21 & 7 & N
\end{tabular}

\begin{tabular}{|c|c|c|c|}
\hline $\begin{array}{ll}\text { No } & \text { Fabric Color }\end{array}$ & Core Orient & Core Color & Core Thick \\
\hline
\end{tabular}

\begin{tabular}{|c|c|c|c|c|c|c|}
\hline 1 & \multicolumn{2}{|c|}{ PALE RED } & $\mathbf{M}$ & $\mathbf{G}$ & 5 & $\mathbf{N}$ \\
\hline 2 & \multicolumn{2}{|c|}{ LT REDDISH BROWN } & ALL & $\mathbf{G}$ & $\mathbf{N}$ & $\mathbf{N}$ \\
\hline$\overline{3}$ & \multicolumn{2}{|c|}{ LT REDDISH BROWN } & $M$ & LG & 6 & 10.1 \\
\hline 4 & \multicolumn{2}{|l|}{ RED } & $N$ & $\mathrm{~N}$ & $\mathbf{N}$ & $N$ \\
\hline 5 & \multirow{2}{*}{\multicolumn{2}{|c|}{$\begin{array}{l}\text { LTRED } \\
\text { PALE RED }\end{array}$}} & $\mathbf{M}$ & $\mathbf{G}$ & 6 & 11 \\
\hline 6 & & & $\mathbf{M}$ & $\mathbf{G}$ & 5 & 2.2 \\
\hline 7 & \multicolumn{2}{|l|}{ PINK } & IRR & G & $\mathbf{N}$ & $\mathbf{N}$ \\
\hline 8 & \multicolumn{2}{|c|}{ LT REDDISH BROWN } & $\mathrm{ALL}$ & G & $\mathbf{N}$ & 2.1 \\
\hline 9 & \multicolumn{2}{|l|}{ LT RED } & $N$ & $\mathbf{N}$ & $\mathrm{N}$ & 12.1 \\
\hline 10 & \multicolumn{2}{|l|}{ PINK } & N & $N$ & $N$ & 7.1 \\
\hline No & Treatment & $\begin{array}{l}\text { Treatment } \\
\text { Location }\end{array}$ & $\begin{array}{l}\text { Treatment } \\
\text { Cover }\end{array}$ & $\begin{array}{l}\text { Color } \\
\text { Interior }\end{array}$ & $\begin{array}{l}\text { Color } \\
\text { Exterior }\end{array}$ & \\
\hline 1 & $S$ & ER & ALL & $\mathbf{N}$ & LT RED & \\
\hline 2 & $\mathrm{~S}$ & ER & ALL & $\mathbf{N}$ & DUSKY RED & \\
\hline 3 & $\mathbf{S}$ & ER & ALL & $\mathbf{N}$ & DK RED & \\
\hline 4 & B & IR & ALL & $\mathbf{N}$ & $\mathbf{N}$ & \\
\hline 5 & UN & $\mathbf{N}$ & $\mathbf{N}$ & $\mathbf{N}$ & $\mathbf{N}$ & \\
\hline 6 & 1 & $\mathbf{E}$ & ALL & $\mathrm{N}$ & $\mathbf{N}$ & \\
\hline 7 & UD & $\mathbf{N}$ & $\mathbf{N}$ & $\mathbf{N}$ & $\mathbf{N}$ & \\
\hline 8 & UN & $\mathbf{N}$ & $\mathbf{N}$ & $\mathbf{N}$ & $\mathbf{N}$ & \\
\hline 9 & 1 & $E$ & ALL & $\mathbf{N}$ & $\mathbf{N}$ & \\
\hline 10 & $S$ & $E$ & ALL & $N$ & RED & \\
\hline
\end{tabular}

PLATE 133. FIELD C. PHASE 1B (LATE EB I - EARLY EB II). 
Other

$2 \quad$ Roughly finished.

$4 \quad$ Sample too small to confirm stance or diameter; Metallic Ware.

6 Combed Metallic Ware.

9 Combed Metallic Ware.

PLATE 133 (CONT.). 

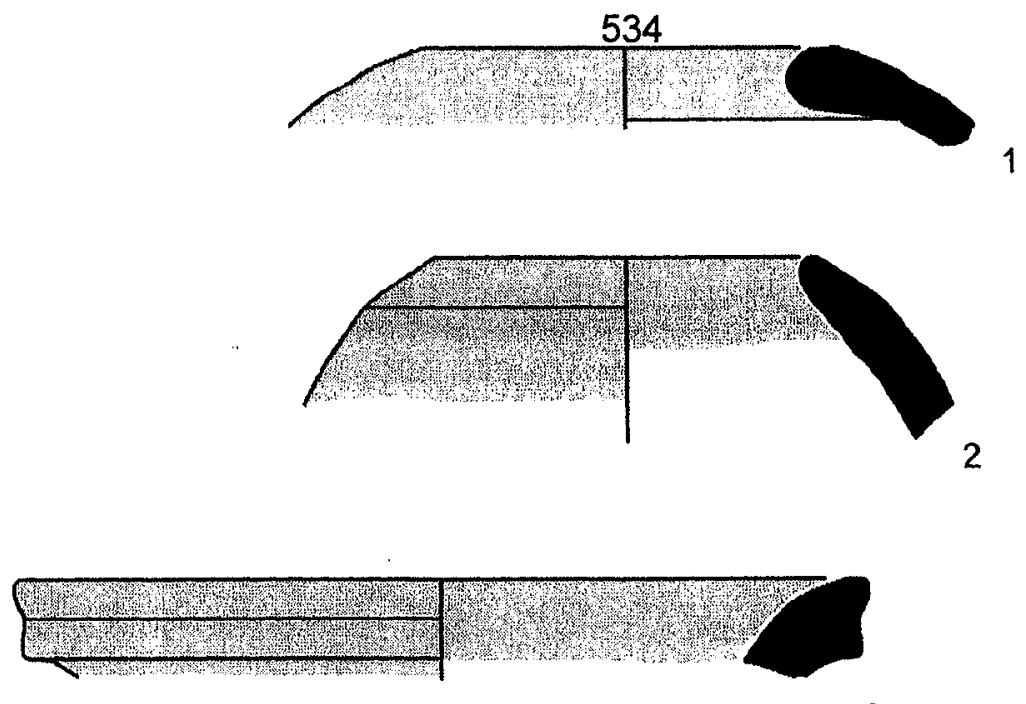

3
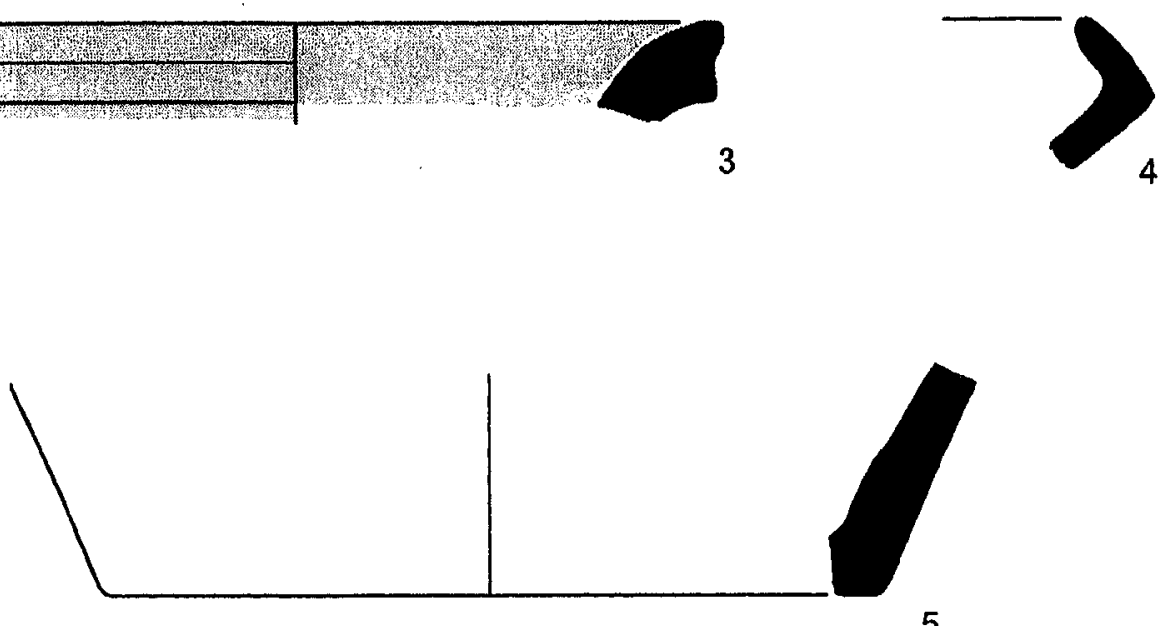

5

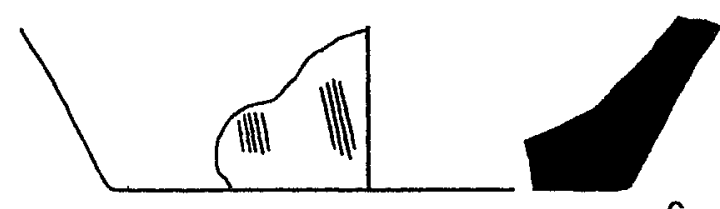

6
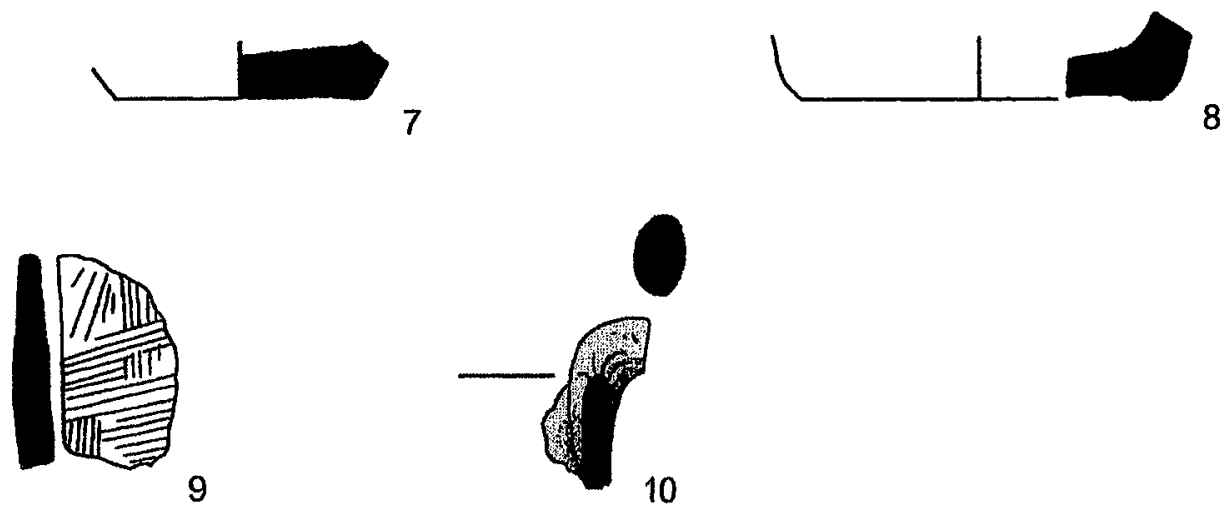

PLATE 133 (CONT.).

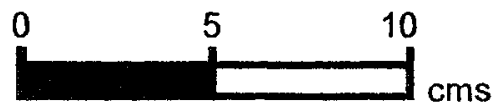




\begin{tabular}{llllllll}
\hline No & Reg & Square & Locus & Vessel & Part & $\begin{array}{c}\text { Body } \\
\text { Thick }\end{array}$ & Dia \\
\hline 1 & 1615 & SW 6-1 & 208 & HOLE MOUTH BOWL & R21 & 10 & 13 \\
2 & 1617 & SW 6-1 & 208 & UD & R82 & N & N \\
3 & 2295 & SW 6-1 & 210 & HOLE MOUTH JAR & R31 & 11 & N \\
4 & 1618 & SW 6-1 & 208 & HOLE MOUTH JAR & R14 & 10 & N \\
5 & 1612 & SW 6-1 & 210 & NECKED JAR & R31 & 12 & 18 \\
6 & 1613 & SW 6-1 & 210 & NECKED JAR & R40 & 18 & 16 \\
7 & 1616 & SW 6-1 & 208 & UD & B11 & 11 & 10
\end{tabular}

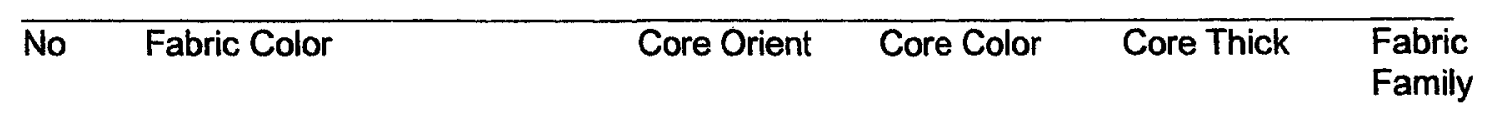

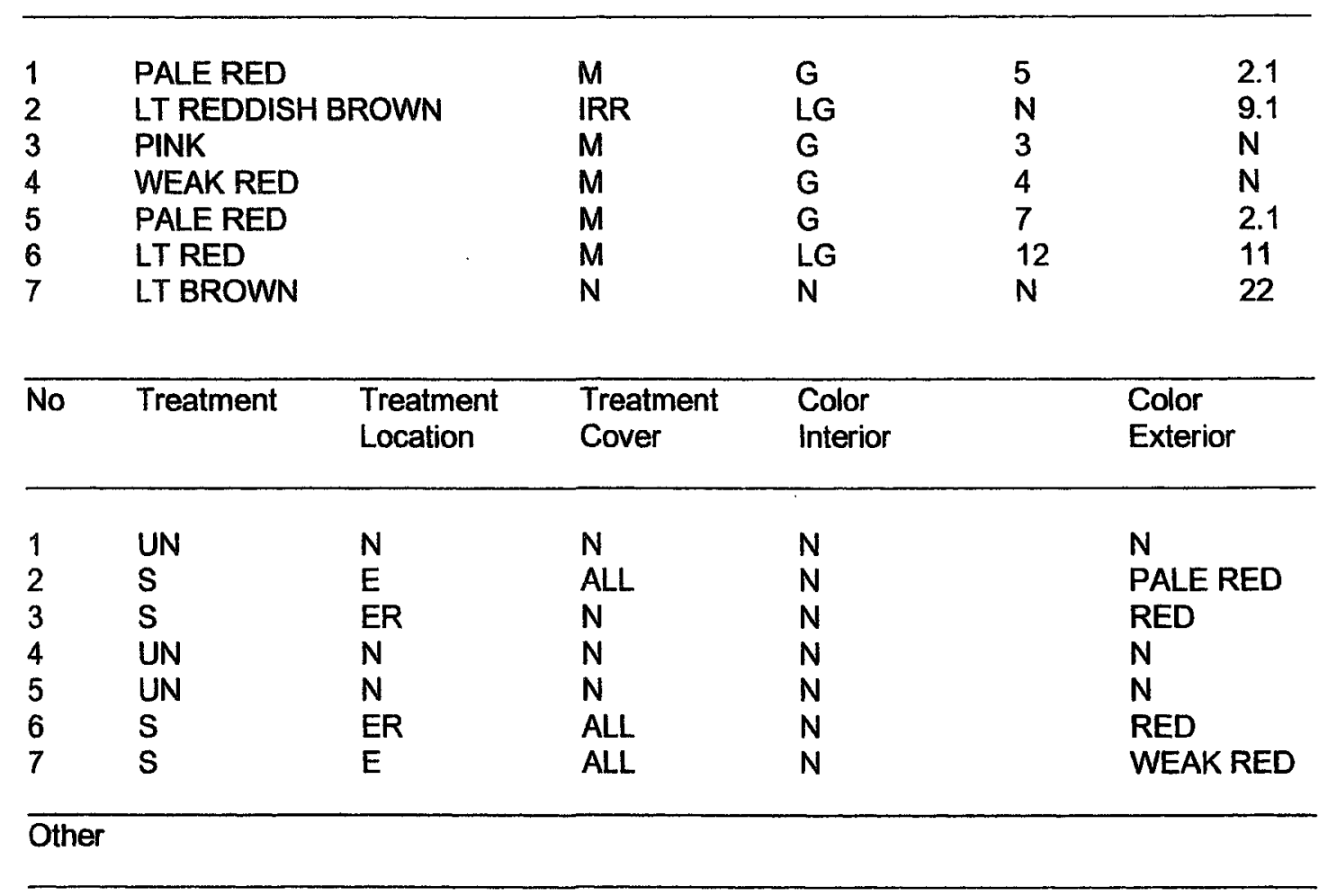

3 Sample too small to confirm stance or diameter.

4 Sample too small to confirm stance or diameter.

6 Features in break suggests rim rolled outwardly and lip sealed against exterior wall in finishing motions.

7 Surface burn visible.

PLATE 134. FIELD C. PHASE 1B (LATE EB I - EARLY EB II). 


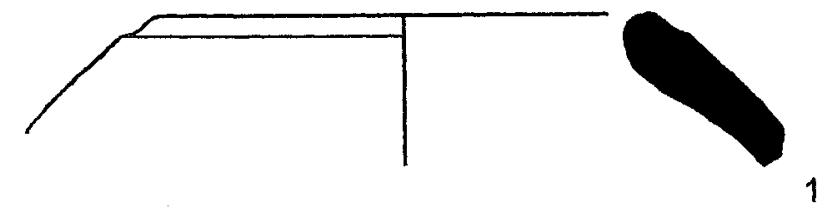

.

2
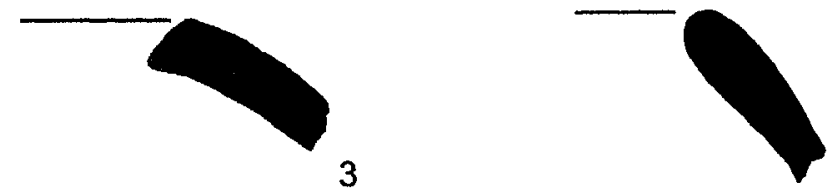

4

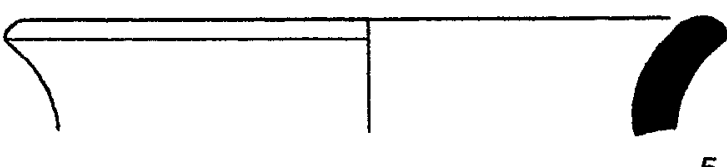

5

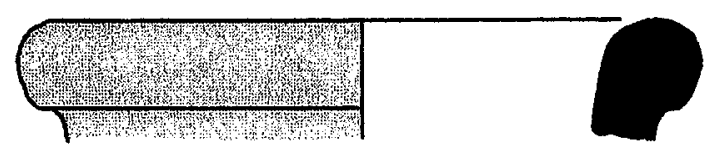

6

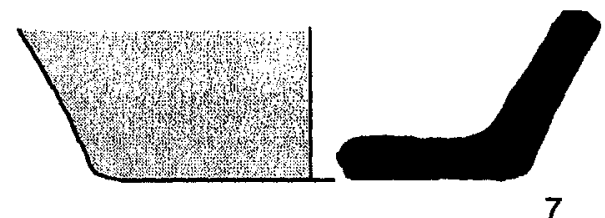

PLATE 134 (CONT.).

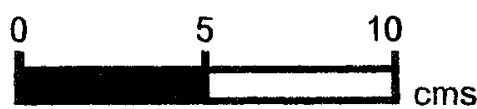


537

\begin{tabular}{llllllll}
\hline No & Reg & Square & Locus & Vessel & Part & $\begin{array}{c}\text { Body } \\
\text { Thick }\end{array}$ & Dia \\
\hline & & & & & & & \\
1 & 1755 & SW 9-1 & 157 & CARINATED BOWL & R58 & 7 & 12 \\
2 & 1754 & SW 9-1 & 157 & HOLE MOUTH JAR & R14 & 9 & 20 \\
3 & 1676 & SW 9-1 & 156 & JUG & B12 & 7 & 4 \\
4 & 1757 & SW 9-1 & 156 & NECKED JAR & R40 & 12 & N \\
5 & 1756 & SW 9-1 & 157 & UD & H20 & 6 & N
\end{tabular}

\begin{tabular}{lllll}
\hline No Fabric Color & Core Orient & Core Color & Core Thick & $\begin{array}{l}\text { Fabric } \\
\text { Family }\end{array}$
\end{tabular}

\begin{tabular}{llllll}
\hline 1 & PINK & N & N & $N$ & $N$ \\
2 & LTRED & $N$ & $N$ & $N$ & $N$ \\
3 & LTRED & M & LG & 4 & 12.2 \\
4 & PINK & M & LG & 5 & 17.1 \\
5 & LTRED & N & N & N & N
\end{tabular}

\begin{tabular}{|c|c|c|c|c|c|}
\hline No & Treatment & $\begin{array}{l}\text { Treatment } \\
\text { Location }\end{array}$ & $\begin{array}{l}\text { Treatment } \\
\text { Cover }\end{array}$ & $\begin{array}{l}\text { Color } \\
\text { Interior }\end{array}$ & $\begin{array}{l}\text { Color } \\
\text { Exterior }\end{array}$ \\
\hline
\end{tabular}

\begin{tabular}{llllll}
\hline 1 & SB & E & ALL & N & RED \\
2 & S & ER & ALL & N & RED \\
3 & SB & E & ALL & N & DUSKY RED \\
4 & S & ER & ALL & N & RED \\
5 & UN & N & N & $N$ & N
\end{tabular}

\section{Other}

1 Sample too small to confirm stance or diameter.

3 Metallic Ware.

4 Sample too small to confirm stance or diameter.

5 Metallic Ware.

PLATE 135. FIELD C. PHASE 1B (LATE EB I - EARLY EB II). 

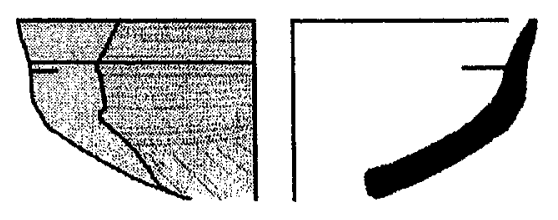

1

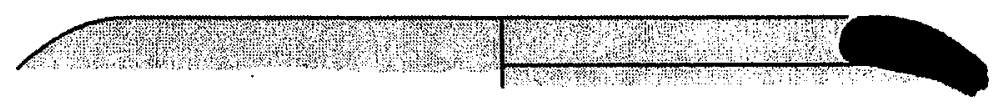

2
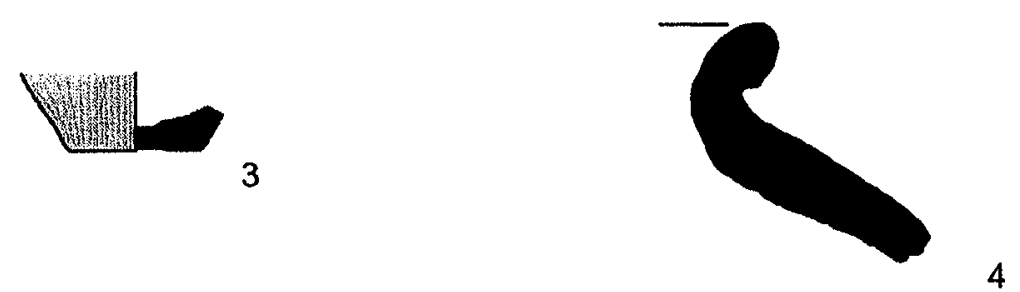

PLATE 135 (CONT.).

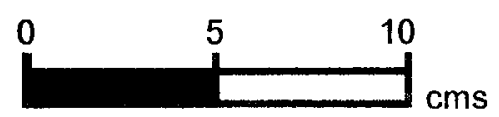


539

\begin{tabular}{llllllll}
\hline No & Reg & Square & Locus & Vessel & Part & $\begin{array}{l}\text { Body } \\
\text { Thick }\end{array}$ & $\begin{array}{c}\text { Dia } \\
\end{array}$ \\
& & & & & & & \\
\hline 1 & 1818 & NW 9-1 & 41 & HOLE MOUTH BOWL & R01 & 13 & 16 \\
2 & 1819 & NW 9-1 & 41 & NECKED JAR & R31 & 7 & 18 \\
3 & 1816 & NW 9-1 & 41 & NECKED JAR & R30 & 8 & 12 \\
4 & 1827 & NW 9-1 & 41 & NECKED JAR & R31 & 8 & 10 \\
5 & 1817 & NW 9-1 & 41 & NECKED JAR & R43 & 6 & 10 \\
6 & 1826 & NW 9-1 & 41 & UD & B12 & 11 & 20 \\
7 & 1825 & NW 9-1 & 41 & UD & B12 & 9 & 20 \\
8 & 1824 & NW 9-1 & 41 & UD & B12 & 12 & 13 \\
9 & 1822 & NW 9-1 & 41 & UD & H27 & 8 & N \\
10 & 1823 & NW 9-1 & 41 & UD & H10 & 16 & N
\end{tabular}

\begin{tabular}{lllll}
\hline No Fabric Color & Core Orient & Core Color Core Thick & Fabric \\
Family
\end{tabular}

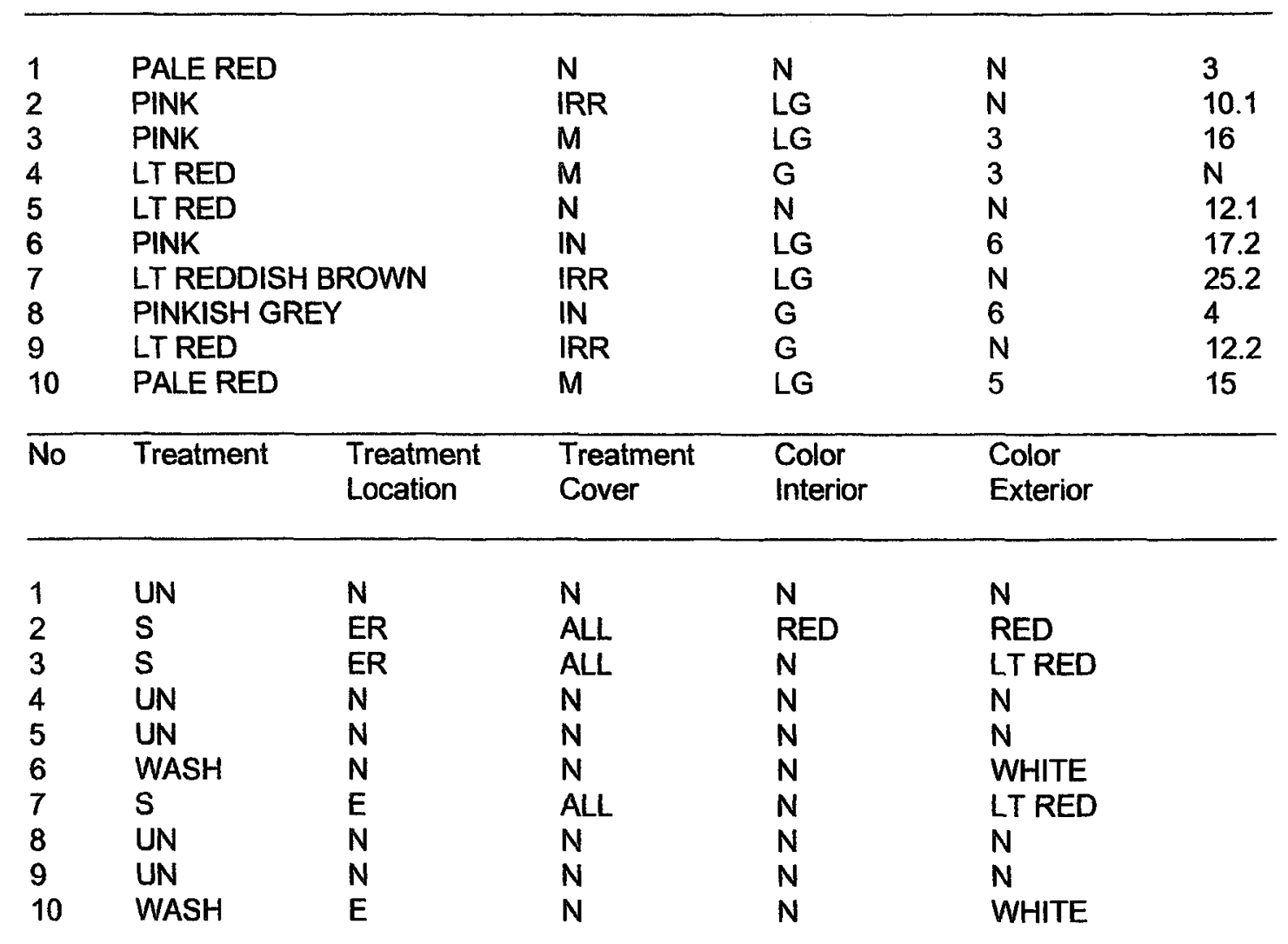

PLATE 136. FIELD C. PHASE 1C (LATE EB I - EARLY EB || ?). 
Other

1 Lines on interior/exterior suggest motion used to finish rim.

2 Sample too small to confirm stance or diameter.

3 Only area immediately below rim is smooth on interior wall.

4 Fine lines of smoothing visible on interiorlexterior walls; Metallic Ware.

5 Metallic Ware.

6 Vertical scraping visible on interior face.

9 Metallic Ware.

PLATE 136 (CONT.). 

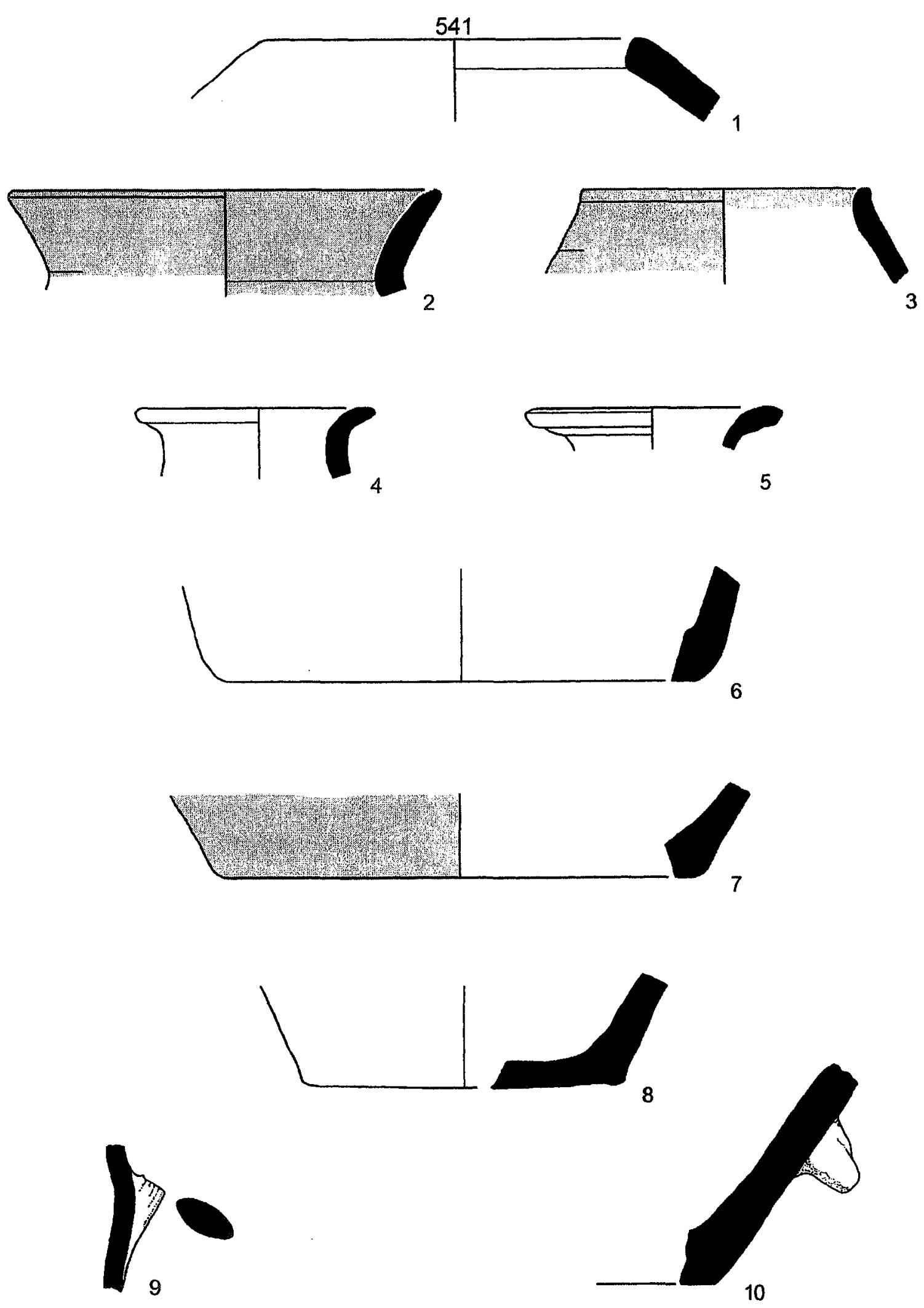

PLATE 136 (CONT.).

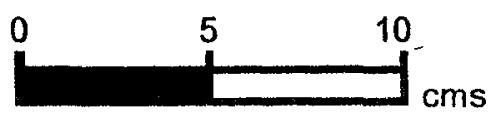


542

\begin{tabular}{llllllll}
\hline No & Reg & Square & Locus & Vessel & Part & $\begin{array}{c}\text { Body } \\
\text { Thick }\end{array}$ & Dia \\
\hline & & & & & & & \\
1 & 1815 & NW 9-1 & 42 & HOLE MOUTH BOWL & R14 & 11 & 18 \\
2 & 1810 & NW 9-1 & 42 & HOLE MOUTH JAR & R11 & 13 & 17 \\
3 & 1809 & NW 9-1 & 42 & HOLE MOUTH JAR & R08 & 11 & 16 \\
4 & 1808 & NW 9-1 & 42 & HOLE MOUTH JAR & R04 & 11 & 11 \\
5 & 1800 & NW 9-1 & 43 & NECKED JAR & R32 & 8 & 12 \\
6 & 2311 & NW 9-1 & 42 & LEDGE RIM BOWL & R60 & 12 & N \\
7 & 1813 & NW 9-1 & 42 & UD & B12 & 8 & 14 \\
8 & 1814 & NW 9-1 & 42 & UD & BOD & 7 & N \\
9 & 1811 & NW 9-1 & 42 & UD & H20 & 10 & N \\
\hline No & Fabric Color & & Core Orient Core Color & Core Thick & Fabric \\
& & & & & & & Family
\end{tabular}

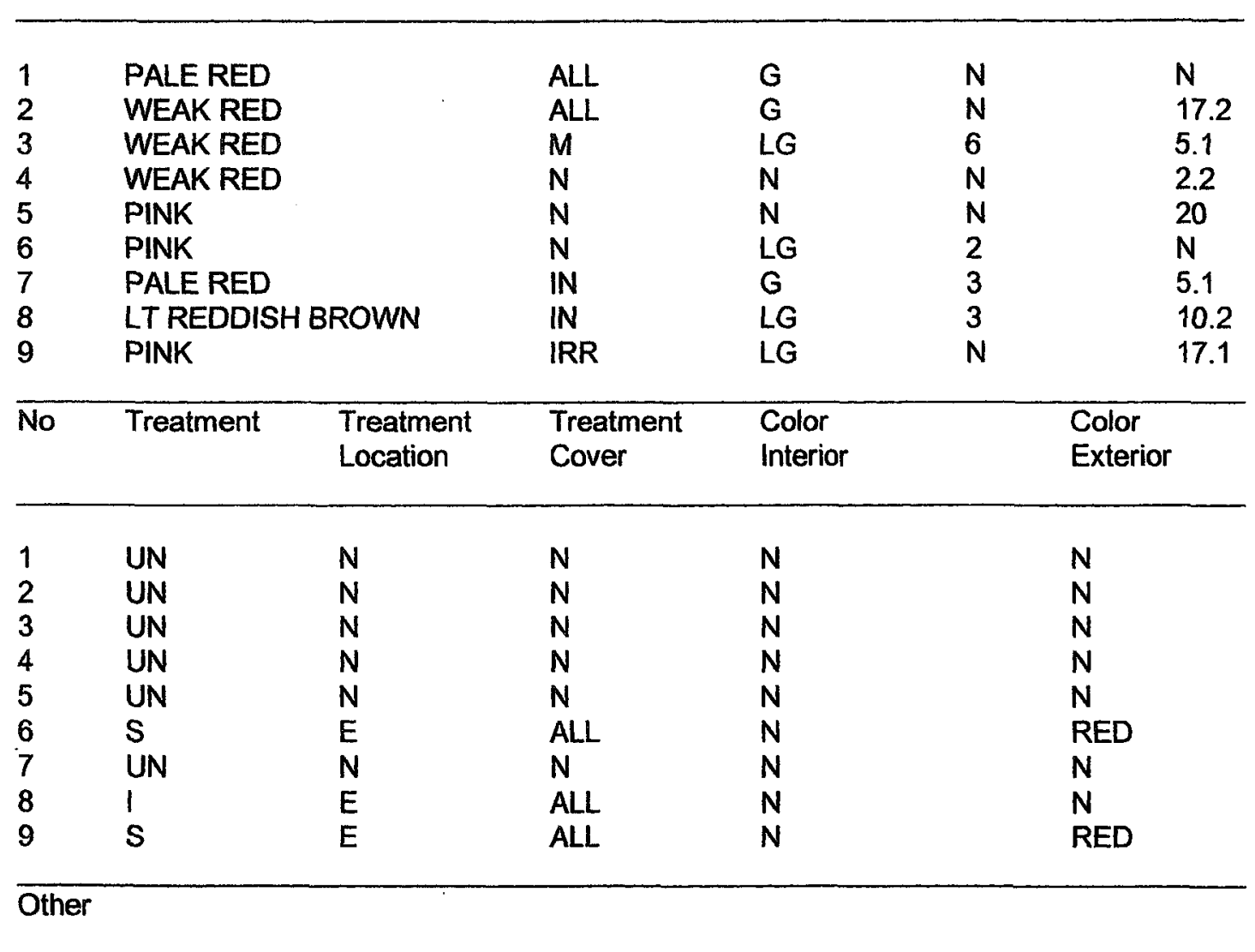

1 Surface burn visible.

$2 \quad$ Also in Fabric Family 5.1; surface burn visible.

3 Scraping and smoothing marks visible on interior wall.

6 Sample too small to confirm stance or diameter.

8 Also in Fabric Family 1; combed Metallic Ware.

PLATE 137. FIELD C. PHASE 1C (LATE EB I - EARLY EB II ?). 

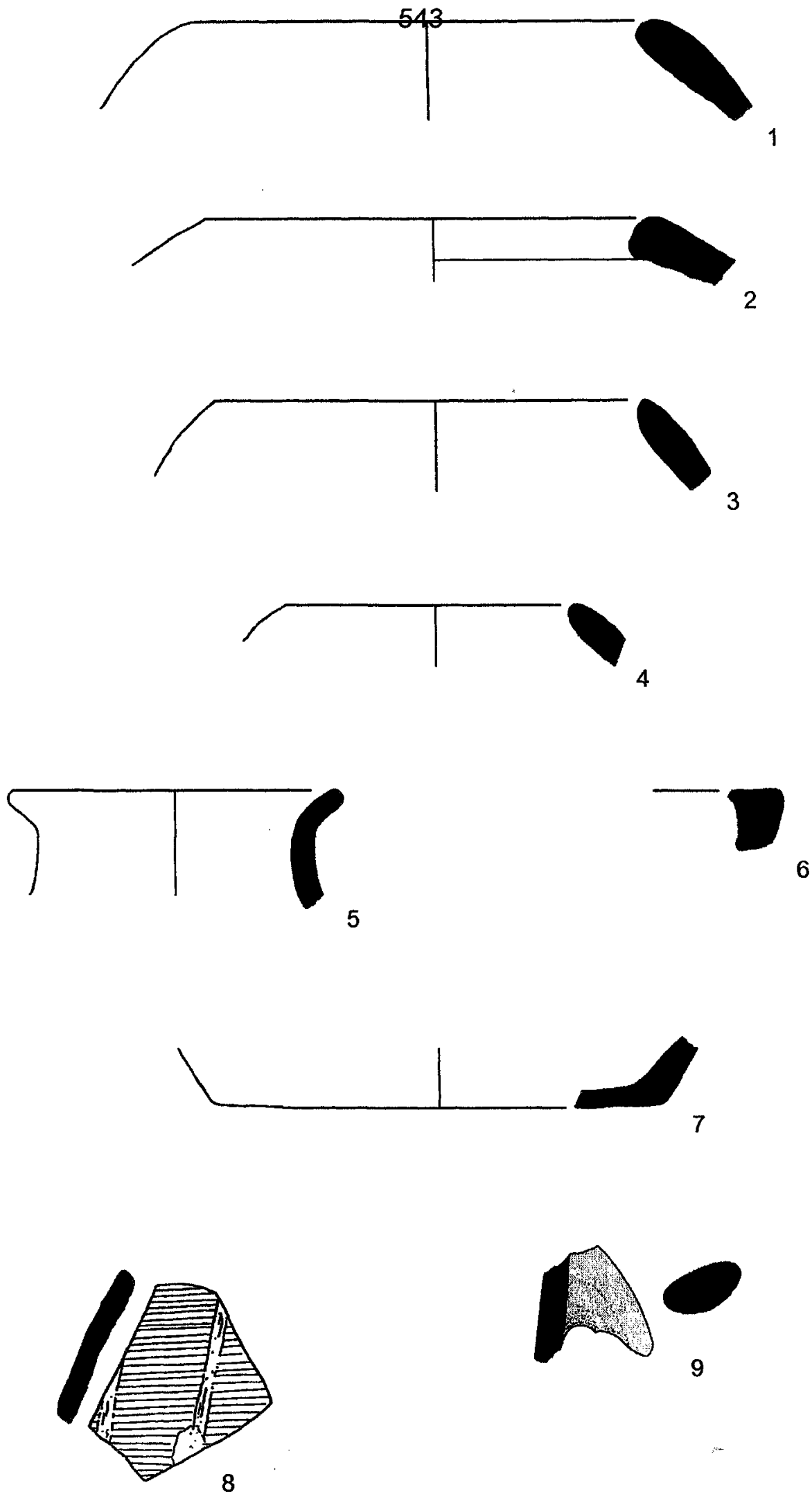

\section{9}

PLATE 137 (CONT.).

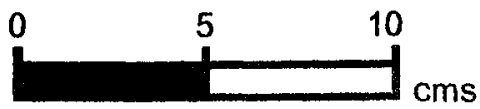




\begin{tabular}{llllllll}
\hline No & Reg & Square & Locus & Vessel & Part & $\begin{array}{l}\text { Body } \\
\text { Thick }\end{array}$ & Dia \\
& & & & & & & \\
\hline & 1657 & SW 6-1 & 187 & HOLE MOUTH BOWL & R20 & 17 & 26 \\
2 & 1654 & SW 6-1 & 187 & HOLE MOUTH BOWL & R20 & 9 & 15 \\
3 & 1659 & SW 6-1 & 186 & NECKED JAR & R43 & 12 & 18 \\
4 & 2471 & SW 6-1 & 187 & NECKED JAR & R42 & 11 & N \\
5 & 1655 & SW 6-1 & 187 & NECKED JAR & R32 & 8 & 11 \\
6 & 1664 & SW 6-1 & 179 & NECKED JAR & R34 & 6 & 10 \\
7 & 1660 & SW 6-1 & 186 & UD & H10 & 12 & N \\
8 & 1628 & SW 6-1 & 188 & UD & B12 & 7 & 7 \\
9 & 1658 & SW 6-1 & 187 & UD & H27 & 8 & U \\
10 & 1661 & SW 6-1 & 186 & HOLE MOUTH JARIBOWL & R19 & 13 & 40 \\
11 & 1656 & SW 6-1 & 187 & HOLE MOUTH BOWL & R04 & 15 & 50
\end{tabular}

\begin{tabular}{lllll}
\hline No Fabric Color & Core Orient Core Color Core Thick & Fabric \\
Family
\end{tabular}

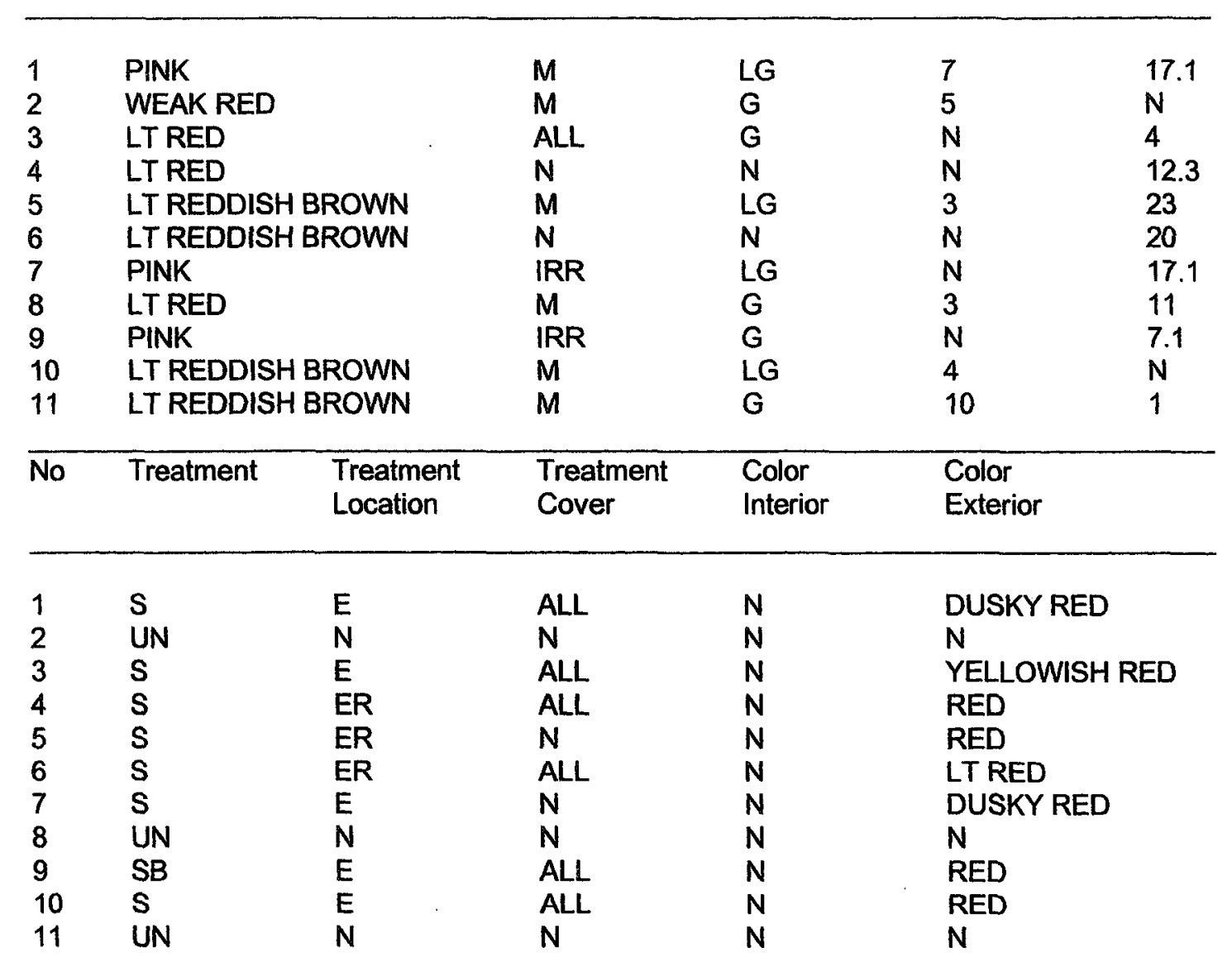

PLATE 138. FIELD C. PHASE 1C (LATE EB I - EARLY EB $\|$ ?). 
Other

2 Irregular mouth; folding and smoothing clearly visible on interior wall; surface burn visible.

4 Sample too small to confirm stance or diameter; voids in section suggests everted folding; Thin section sample 25.

$6 \quad$ Void in section suggests rim folded outwardly and down; intrusive?

10 Sample too small to confirm stance or diameter.

PLATE 138 (CONT.).

Reproduced with permission of the copyright owner. Further reproduction prohibited without permission. 

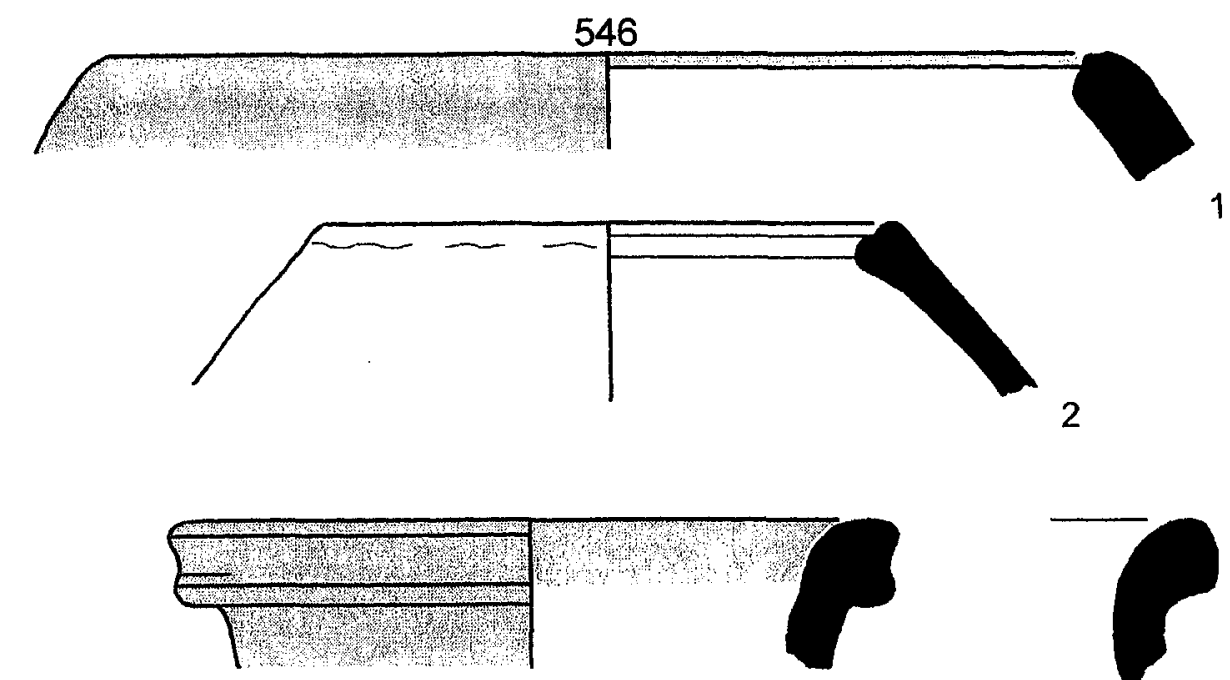

3
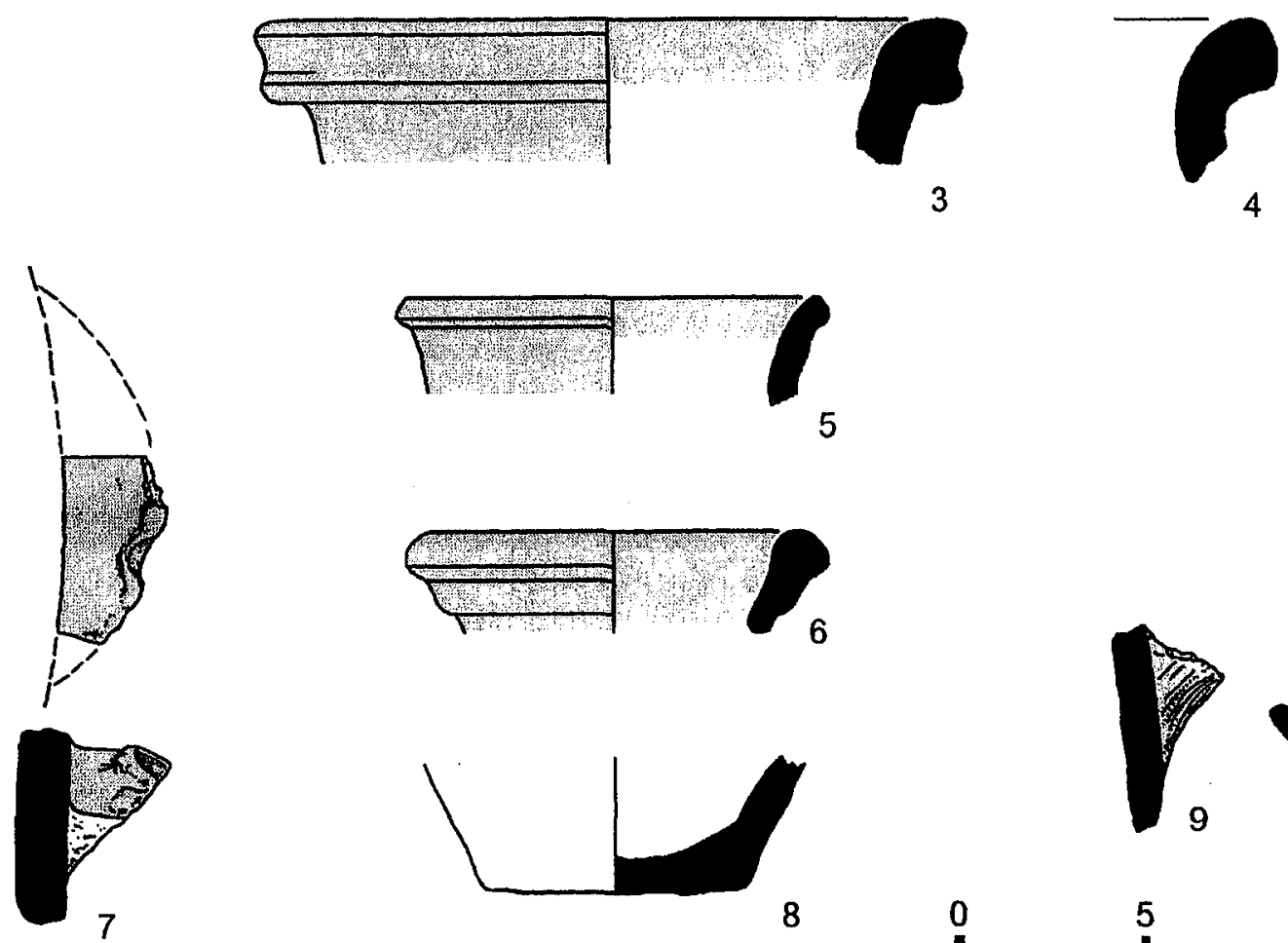

5
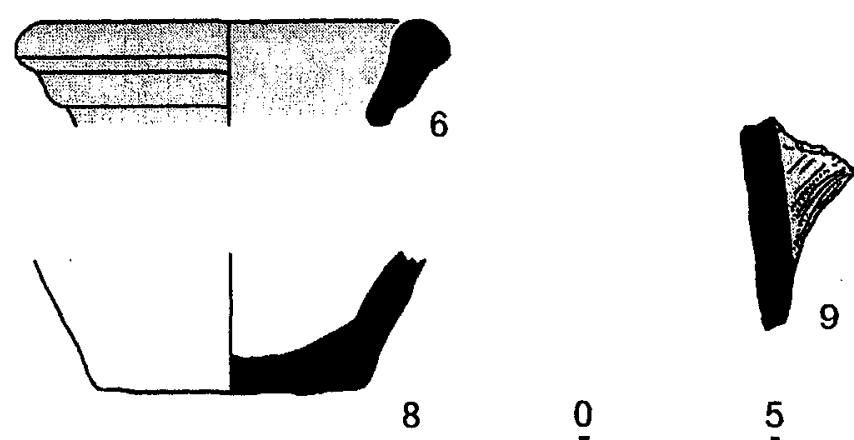

8
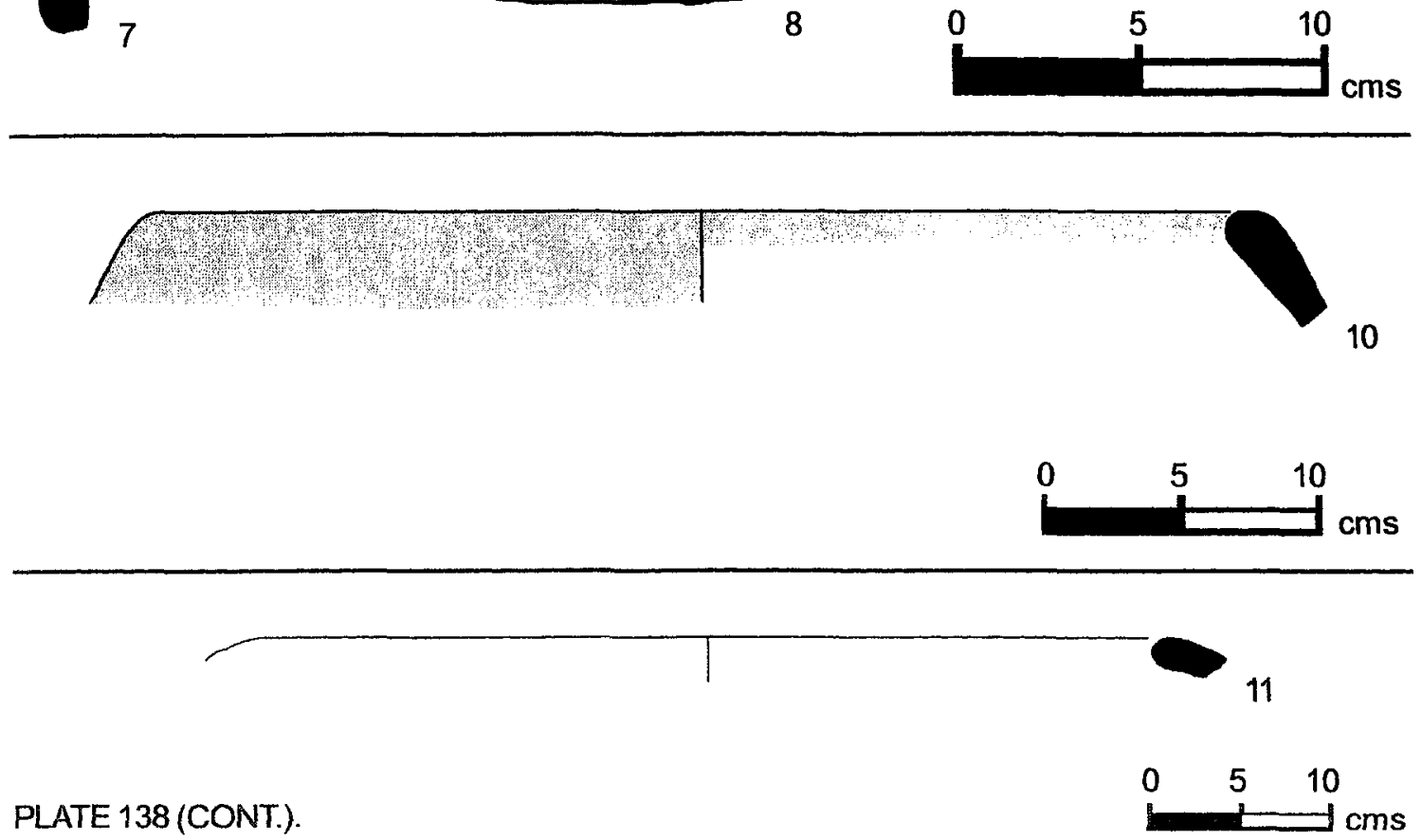
547

\begin{tabular}{llllllll}
\hline No & Reg & Square & Locus & Vessel & Part & $\begin{array}{l}\text { Body } \\
\text { Thick }\end{array}$ & Dia \\
& & & & & & & \\
\hline & 1636 & SW 6-1 & 189 & CARINATED BOWL & R58 & 5 & 13 \\
2 & 1632 & SW 6-1 & 189 & CARINATED BOWL & R58 & 6 & 11 \\
3 & 1619 & SW 6-1 & 193 & HOLE MOUTH BOWL & R12 & 12 & 30 \\
4 & 1631 & SW 6-1 & 189 & HOLE MOUTH BOWL & R11 & 8 & 20 \\
5 & 1620 & SW 6-1 & 193 & HOLE MOUTH JAR & R17 & 15 & 25 \\
6 & 1624 & SW 6-1 & 193 & UD & H20 & N & N \\
7 & 1633 & SW 6-1 & 189 & HOLE MOUTH BOWL & R11 & 10 & 20 \\
8 & 1622 & SW 6-1 & 193 & NECKED JAR & R31 & 10 & 18 \\
9 & 1637 & SW 6-1 & 189 & NECKED JAR & R42 & 11 & 18 \\
10 & 2450 & SW 6-1 & 193 & NECKED JAR & R42 & 13 & $\mathrm{~N}$ \\
11 & 1625 & SW 6-1 & 193 & UD & H10 & N & N \\
12 & 1635 & SW 6-1 & 189 & UD & H20 & 10 & N \\
13 & 1623 & SW 6-1 & 193 & UD & H20 & N & N \\
14 & 1626 & SW 6-1 & 193 & TWIN VESSEL & BOD & N & N \\
\hline No & Fabric Color & & Core Orient Core Color & Core Thick & Fabric \\
& & & & & & & Family
\end{tabular}

\begin{tabular}{|c|c|c|c|c|c|c|}
\hline 1 & \multicolumn{2}{|l|}{ LT RED } & $\mathbf{N}$ & $\mathrm{N}$ & $\mathrm{N}$ & $\mathbf{N}$ \\
\hline 2 & \multicolumn{2}{|c|}{ LT REDDISH BROWN } & ALL & LG & $\mathrm{N}$ & 13.2 \\
\hline 3 & \multicolumn{2}{|l|}{ PINK } & $\mathbf{N}$ & $\mathrm{N}$ & $\mathrm{N}$ & $\mathbf{N}$ \\
\hline 4 & \multicolumn{2}{|c|}{ WEAK RED } & $\mathbf{N}$ & $\mathbf{N}$ & $\mathrm{N}$ & 1 \\
\hline 5 & \multicolumn{2}{|c|}{ LT REDDISH BROWN } & $\mathbf{M}$ & $\mathbf{G}$ & 8 & 22 \\
\hline 6 & \multicolumn{2}{|c|}{ PINKISH GREY } & IRR & LG & $\mathrm{N}$ & 4 \\
\hline 7 & \multicolumn{2}{|c|}{ REDDISH BROWN } & IRR & LG & $\mathrm{N}$ & 6 \\
\hline 8 & \multicolumn{2}{|c|}{ LT REDDISH BROWN } & ALL & $\mathbf{G}$ & $\mathrm{N}$ & 2.1 \\
\hline 9 & \multicolumn{2}{|c|}{ LT REDDISH BROWN } & IRR & LG & $\hat{N}$ & 22 \\
\hline 10 & \multicolumn{2}{|l|}{ PINK } & IN & $\mathbf{G}$ & 10 & 7.2 \\
\hline 11 & \multicolumn{2}{|c|}{ LT REDDISH BROWN } & IRR & LG & $\mathrm{N}$ & 11 \\
\hline 12 & \multicolumn{2}{|c|}{ LT REDDISH BROWN } & $\mathbb{N}$ & G & 7 & 17.2 \\
\hline 13 & \multicolumn{2}{|l|}{ LT RED } & $\mathbf{N}$ & $\mathbf{N}$ & $\mathbf{N}$ & 8 \\
\hline 14 & \multicolumn{2}{|c|}{ LT REDDISH BROWN } & IRR & LG & $\mathrm{N}$ & 10.2 \\
\hline No & Treatment & $\begin{array}{l}\text { Treatment } \\
\text { Location }\end{array}$ & $\begin{array}{l}\text { Treatment } \\
\text { Cover }\end{array}$ & $\begin{array}{l}\text { Color } \\
\text { Interior }\end{array}$ & & $\begin{array}{l}\text { Color } \\
\text { Exterior }\end{array}$ \\
\hline 1 & $\mathbf{S}$ & IE & ALL & UD & & UD \\
\hline 2 & SB & $\mathrm{IE}$ & ALL & RED & & DK RED \\
\hline 3 & SB & ER & ALL & RED & & RED \\
\hline 4 & UN & $\mathbf{N}$ & $\mathbf{N}$ & $\mathbf{N}$ & & $\mathrm{N}$ \\
\hline 5 & $\mathrm{~S}$ & $E$ & $\mathrm{~N}$ & $\mathbf{N}$ & & $\mathrm{N}$ \\
\hline 6 & $\mathbf{S}$ & $E$ & ALL & $\mathbf{N}$ & & LT RED \\
\hline 7 & UN & $\mathbf{N}$ & $\mathbf{N}$ & $\mathbf{N}$ & & $\mathbf{N}$ \\
\hline 8 & UN & $\mathbf{N}$ & $\mathbf{N}$ & $\mathrm{N}$ & & $\mathrm{N}$ \\
\hline
\end{tabular}

PLATE 139. FIELD C. PHASE 1C (LATE EB I - EARLY EB II ?). 


\section{8}

\begin{tabular}{llllll}
\hline No & Treatment & $\begin{array}{l}\text { Treatment } \\
\text { Location }\end{array}$ & $\begin{array}{l}\text { Treatment } \\
\text { Cover }\end{array}$ & $\begin{array}{l}\text { Color } \\
\text { Interior }\end{array}$ & $\begin{array}{l}\text { Color } \\
\text { Exterior }\end{array}$ \\
\hline 9 & S & ER & ALL & N & RED \\
10 & S & ER & ALL & N & RED \\
11 & S & E & ALL & N & DUSKY RED \\
12 & S & E & ALL & N & RED \\
13 & S & E & ALL & N & PALE RED \\
14 & S & E & ALL & N & RED \\
\hline
\end{tabular}

\section{Other}

1 Burn on rim suggests use as lamp; surface burn visible.

3 Carefully executed, finished, and fired.

4 Fine marks on interior show rim smoothing; finger marks visible on body interior; surface burn visible.

$7 \quad$ Finger marks visible on body interior; surface burn visible.

10 Thin section sample 10; sample too small to confirm stance or diameter.

PLATE 139 (CONT.). 

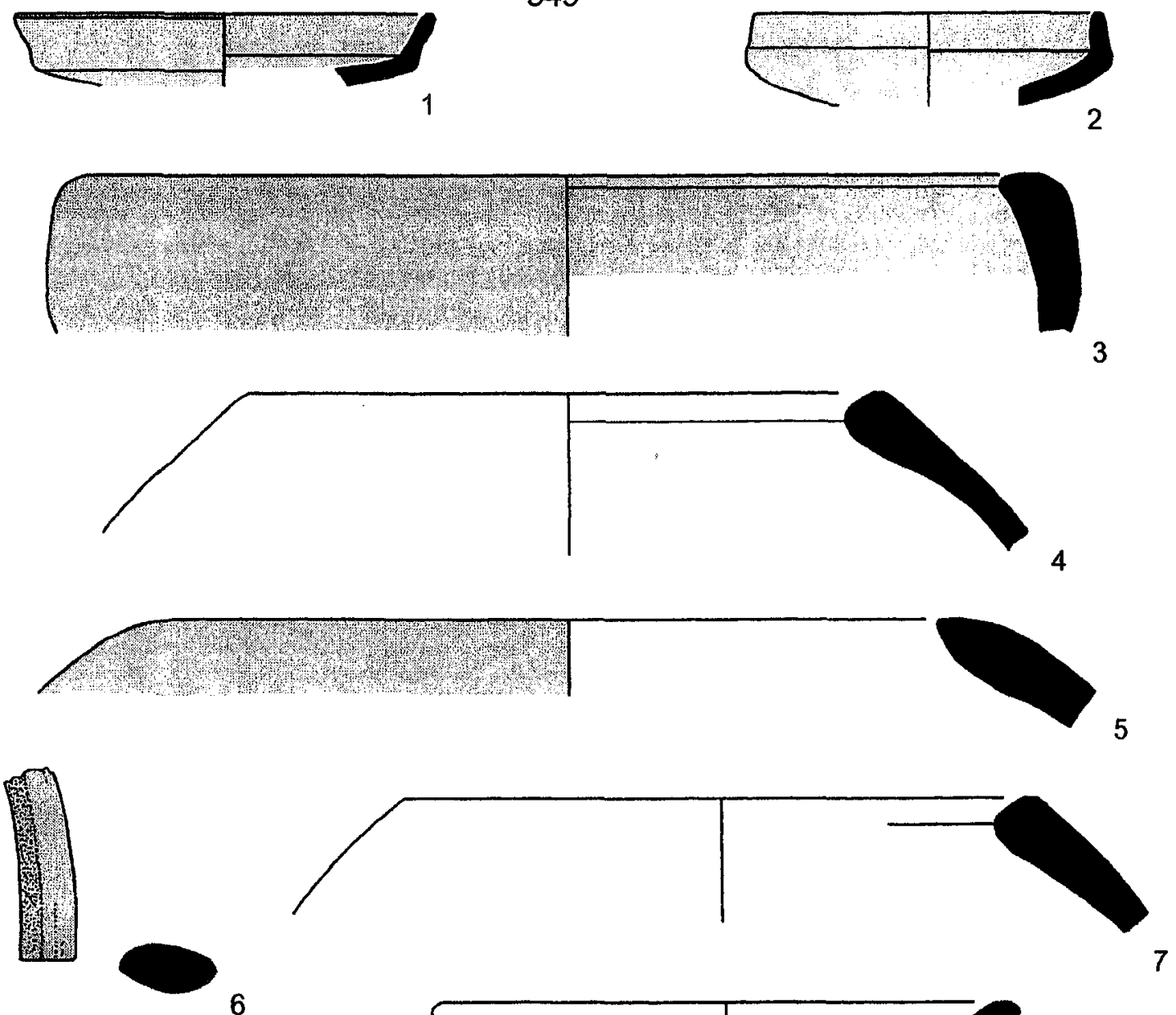

6

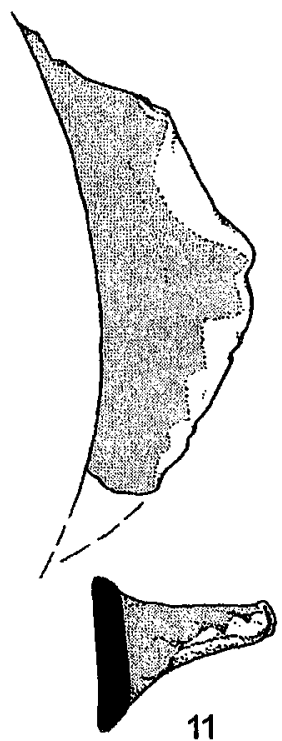

PLATE 139 (CONT.).

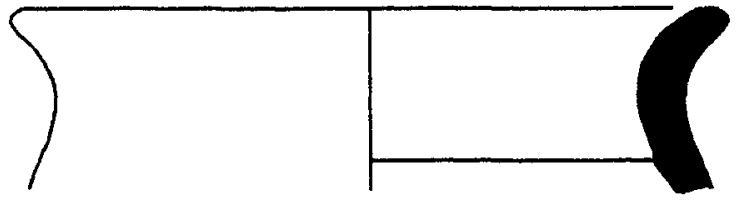

8
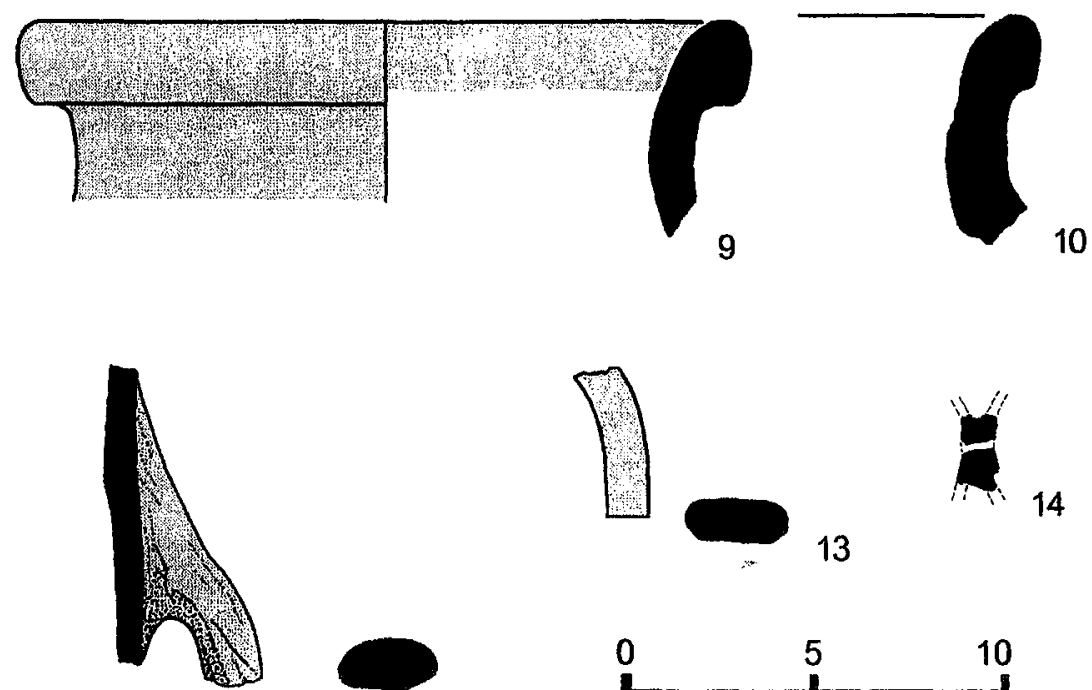

13
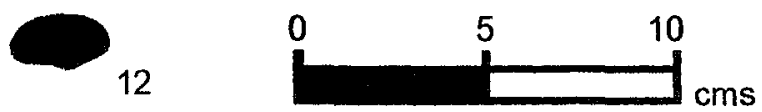


\begin{tabular}{llllllll}
\hline No & Reg & Square & Locus & Vessel & Part & $\begin{array}{c}\text { Body } \\
\text { Thick }\end{array}$ & Dia \\
& & & & & & & \\
1 & 1736 & SW 9-1 & 127 & VAT & R60 & 10 & 35 \\
2 & 1734 & SW 9-1 & 127 & HOLE MOUTH JAR & R04 & 13 & 25 \\
3 & 1731 & SW 9-1 & 127 & HOLE MOUTH BOWL & R17 & 10 & 22 \\
4 & 2288 & SW 9-1 & 127 & HOLE MOUTH JAR & R04 & 10 & 20 \\
5 & 1710 & SW 9-1 & 127 & HOLE MOUTH JAR & R01 & 12 & 20 \\
6 & 1715 & SW 9-1 & 127 & HOLE MOUTH JAR & R17 & 11 & 20 \\
7 & 1716 & SW 9-1 & 127 & HOLE MOUTH JAR & R11 & 12 & 16 \\
8 & 1733 & SW 9-1 & 127 & HOLE MOUTH BOWL & R11 & 10 & 10 \\
9 & 1711 & SW 9-1 & 127 & HOLE MOUTH JAR & R14 & 15 & 16 \\
10 & 1717 & SW 9-1 & 127 & HOLE MOUTH JAR & R17 & 17 & 15 \\
11 & 1713 & SW 9-1 & 127 & HOLE MOUTH BOWL & R14 & 10 & 10
\end{tabular}

\begin{tabular}{lllll}
\hline No Fabric Color & Core Orient & Core Color Core Thick & $\begin{array}{l}\text { Fabric } \\
\text { Family }\end{array}$
\end{tabular}

\begin{tabular}{|c|c|c|c|c|c|c|}
\hline 1 & \multirow{2}{*}{\multicolumn{2}{|c|}{$\begin{array}{l}\text { LT REDDISH BROWN } \\
\text { LT REDDISH BROWN }\end{array}$}} & IRR & LG & $N$ & $N$ \\
\hline 2 & & & $M$ & $G$ & 6 & $\mathrm{~N}$ \\
\hline 3 & \multicolumn{2}{|c|}{ PALE RED } & $\mathbf{M}$ & $\mathbf{G}$ & 6 & $\mathrm{~N}$ \\
\hline 4 & \multicolumn{2}{|l|}{ PINK } & $M$ & $G$ & 8 & $N$ \\
\hline 5 & \multicolumn{2}{|l|}{ PINK } & $\mathbf{M}$ & LG & 7 & 11 \\
\hline 6 & \multicolumn{2}{|l|}{ WEAK RED } & $M$ & $\mathrm{G}$ & 6 & 2.1 \\
\hline 7 & \multicolumn{2}{|c|}{ WEAK RED } & ALL & $\mathrm{G}$ & $N$ & 1 \\
\hline 8 & \multicolumn{2}{|l|}{ PALE RED } & $\mathbf{M}$ & LG & 6 & $N$ \\
\hline 9 & \multicolumn{2}{|l|}{ LT RED } & $M$ & $G$ & 9 & 2.2 \\
\hline 10 & \multicolumn{2}{|c|}{ WEAK RED } & $A L L$ & G & $\mathrm{N}$ & 2.1 \\
\hline 11 & \multicolumn{2}{|c|}{ LT REDDISH BROWN } & ALL & $G$ & $N$ & 2.1 \\
\hline No & Treatment & $\begin{array}{l}\text { Treatment } \\
\text { Location }\end{array}$ & $\begin{array}{l}\text { Treatment } \\
\text { Cover }\end{array}$ & $\begin{array}{l}\text { Color } \\
\text { Interior }\end{array}$ & $\begin{array}{l}\text { Color } \\
\text { Exterior }\end{array}$ & \\
\hline 1 & $S$ & IR & ALL & RED & $\mathbf{N}$ & \\
\hline 2 & UN & $\mathrm{N}$ & $\mathrm{N}$ & $\mathrm{N}$ & $\mathrm{N}$ & \\
\hline 3 & UN & $\mathrm{N}$ & $\mathbf{N}$ & $N$ & $\mathbf{N}$ & \\
\hline 4 & UN & $\mathbf{N}$ & $\mathbf{N}$ & $N$ & $N$ & \\
\hline 5 & $\mathbf{S}$ & $\mathrm{E}$ & ALL & $\mathrm{N}$ & DUSKY RED & \\
\hline 6 & UN & $N$ & $N$ & $N$ & $N$ & \\
\hline 7 & $\mathrm{~s}$ & ER & ALL & $\mathrm{N}$ & DK RED & \\
\hline 8 & UN & $N$ & $N$ & $N$ & $\mathbf{N}$ & \\
\hline 9 & $\mathrm{~s}$ & ER & ALL & $\mathrm{N}$ & DUSKY RED & \\
\hline 10 & $S$ & ER & ALL & $N$ & RED & \\
\hline 11 & UN & $N$ & $N$ & $N$ & $\mathrm{~N}$ & \\
\hline
\end{tabular}

PLATE 140. FIELD C. PHASE 1C (LATE EB I - EARLY EB $\|$ ?). 
Other

2 Surface burn visible.

3 Sample too small to confirm stance or diameter.

4 Potter's mark.

5 Spouted vessel.

6 Surface burn visible.

8 Surface burn visible; sample too small to confirm stance or diameter.

PLATE 140 (CONT.). 


\section{2}
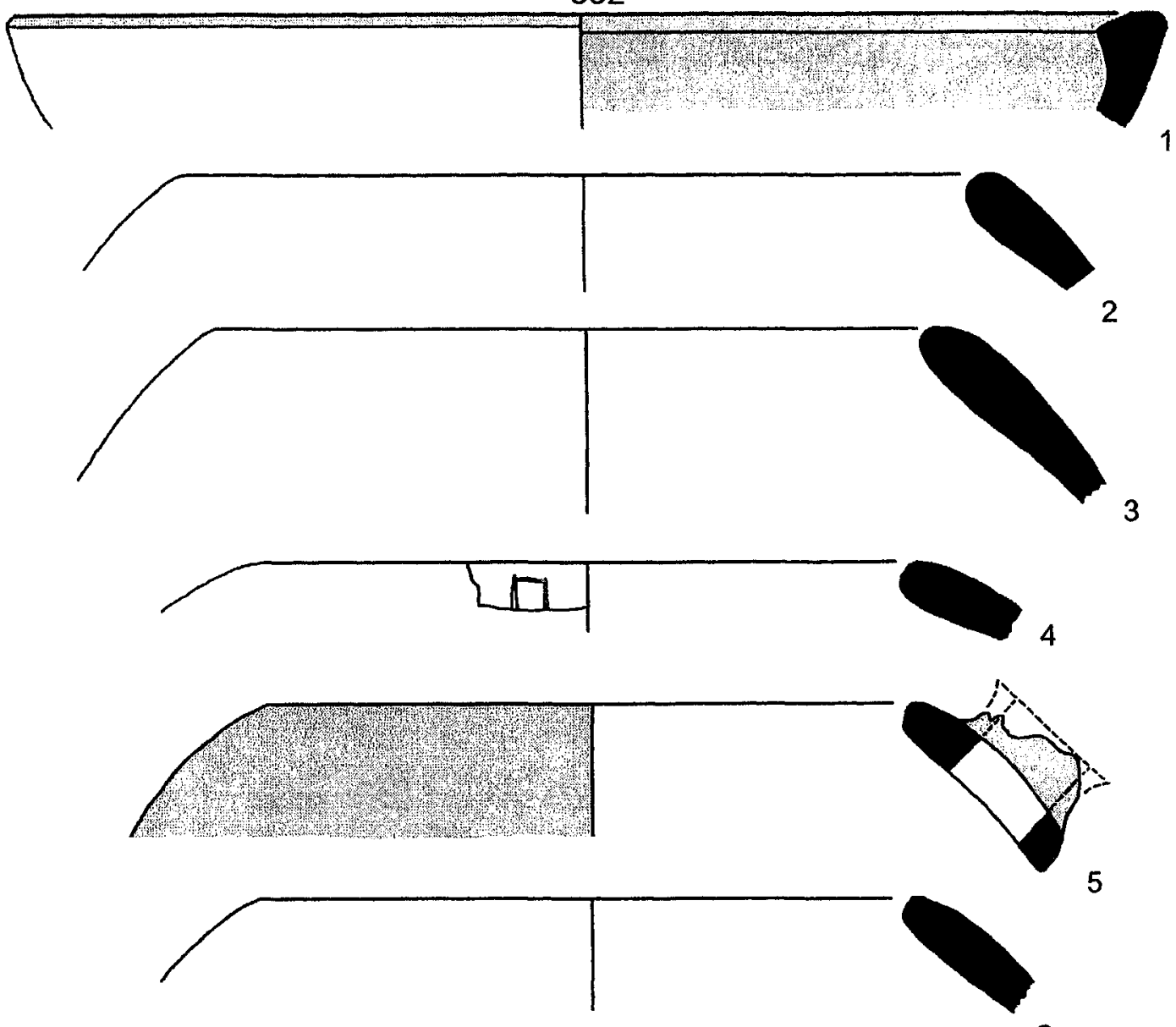

6
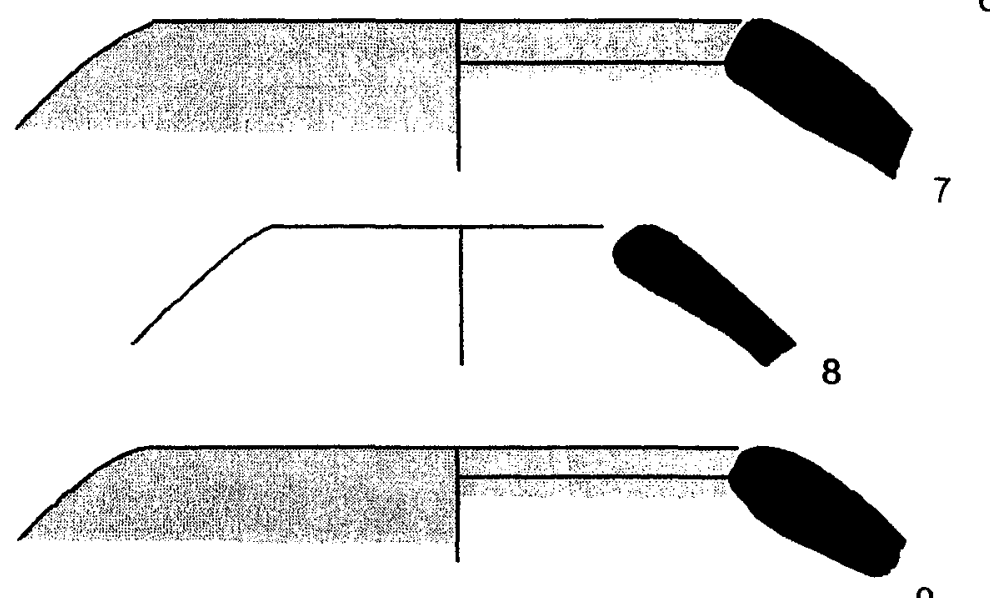

9
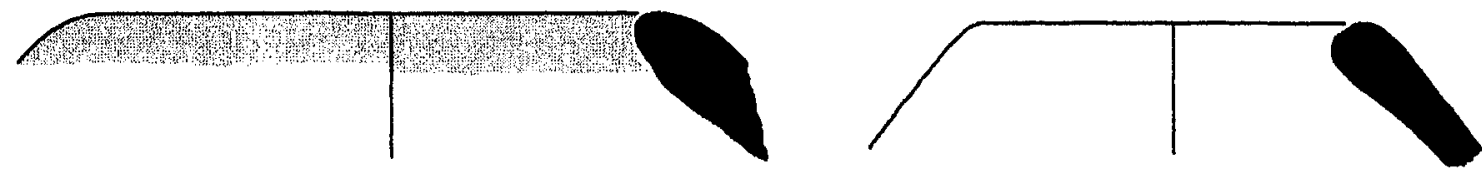

10

PLATE 140 (CONT.).

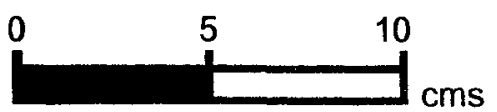




\begin{tabular}{llllllll}
\hline No & Reg & Square & Locus & Vessel & Part & $\begin{array}{l}\text { Body } \\
\text { Thick }\end{array}$ & Dia \\
\hline & & & & & & \\
1 & 1721 & SW 9-1 & 127 & NECKED JAR & R43 & 14 & 20 \\
2 & 1724 & SW 9-1 & 127 & NECKED JAR & R43 & 17 & 20 \\
3 & 1714 & SW 9-1 & 127 & UD & R00 & 80 & N \\
4 & 1712 & SW 9-1 & 127 & NECKED JAR & R43 & 13 & 22 \\
5 & 1723 & SW 9-1 & 127 & UD & H10 & 10 & N \\
6 & 1719 & SW 9-1 & 127 & NECKED JAR & R31 & 7 & 16 \\
7 & 1730 & SW 9-1 & 127 & NECKED JAR & RD0 & 19 & N \\
8 & 1729 & SW 9-1 & 127 & UD & BOD & 11 & N \\
9 & 1720 & SW 9-1 & 127 & NECKED JAR & R42 & 15 & 18 \\
10 & 1727 & SW 9-1 & 127 & UD & H10 & 14 & N \\
11 & 1726 & SW 9-1 & 127 & UD & H20 & 10 & N \\
12 & 1728 & SW 9-1 & 127 & UD & B13 & 5 & 4 \\
13 & 1718 & SW 9-1 & 127 & PLATTER BOWL & R53 & 9 & 38
\end{tabular}

\begin{tabular}{lllll}
\hline No Fabric Color & Core Orient Core Color Core Thick & $\begin{array}{l}\text { Fabric } \\
\text { Family }\end{array}$ \\
& & & Can
\end{tabular}

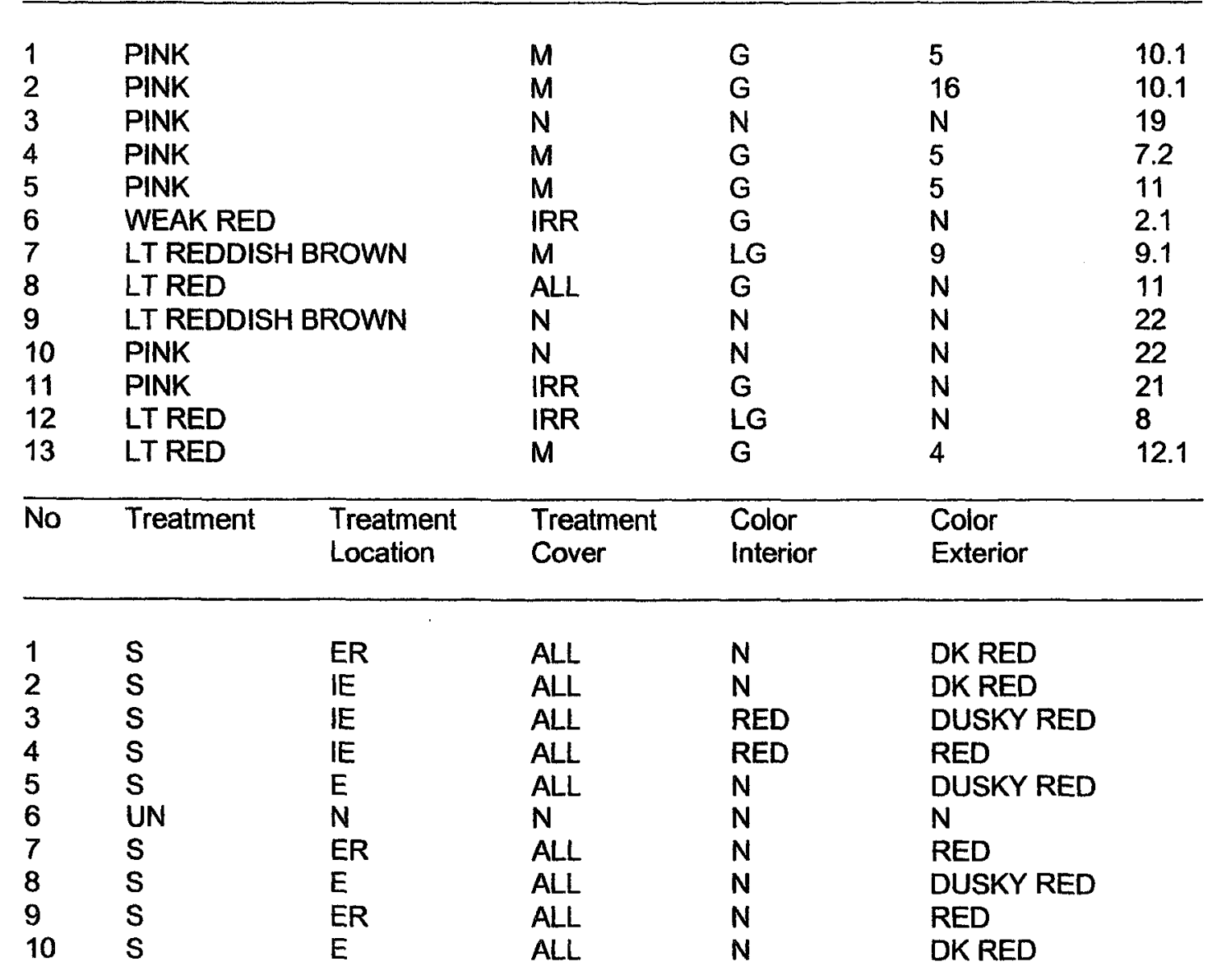

PLATE 141. FIELD C. PHASE 1C (LATE EB I - EARLY EB \| ?). 


\begin{tabular}{llllll}
\hline No & Treatment & $\begin{array}{l}\text { Treatment } \\
\text { Location }\end{array}$ & $\begin{array}{l}\text { Treatment } \\
\text { Cover }\end{array}$ & $\begin{array}{l}\text { Color } \\
\text { Interior }\end{array}$ & $\begin{array}{l}\text { Color } \\
\text { Exterior }\end{array}$ \\
\hline 11 & S & E & ALL & N & DK RED \\
12 & B & E & ALL & N & N \\
13 & B & IE & ALL & N & N \\
\hline Other & & & \\
\hline
\end{tabular}

$1 \quad$ Also in Fabric Families 19 and 12.2.

3 Sample too small to confirm stance or diameter; rim-handle; also in Fabric Family 23.

$4 \quad$ Thin section sample 27.

$5 \quad$ Also in Fabric Family 18.

6 Surface burn visible.

7 Sample too small to confirm stance or diameter.

PLATE 141 (CONT.). 

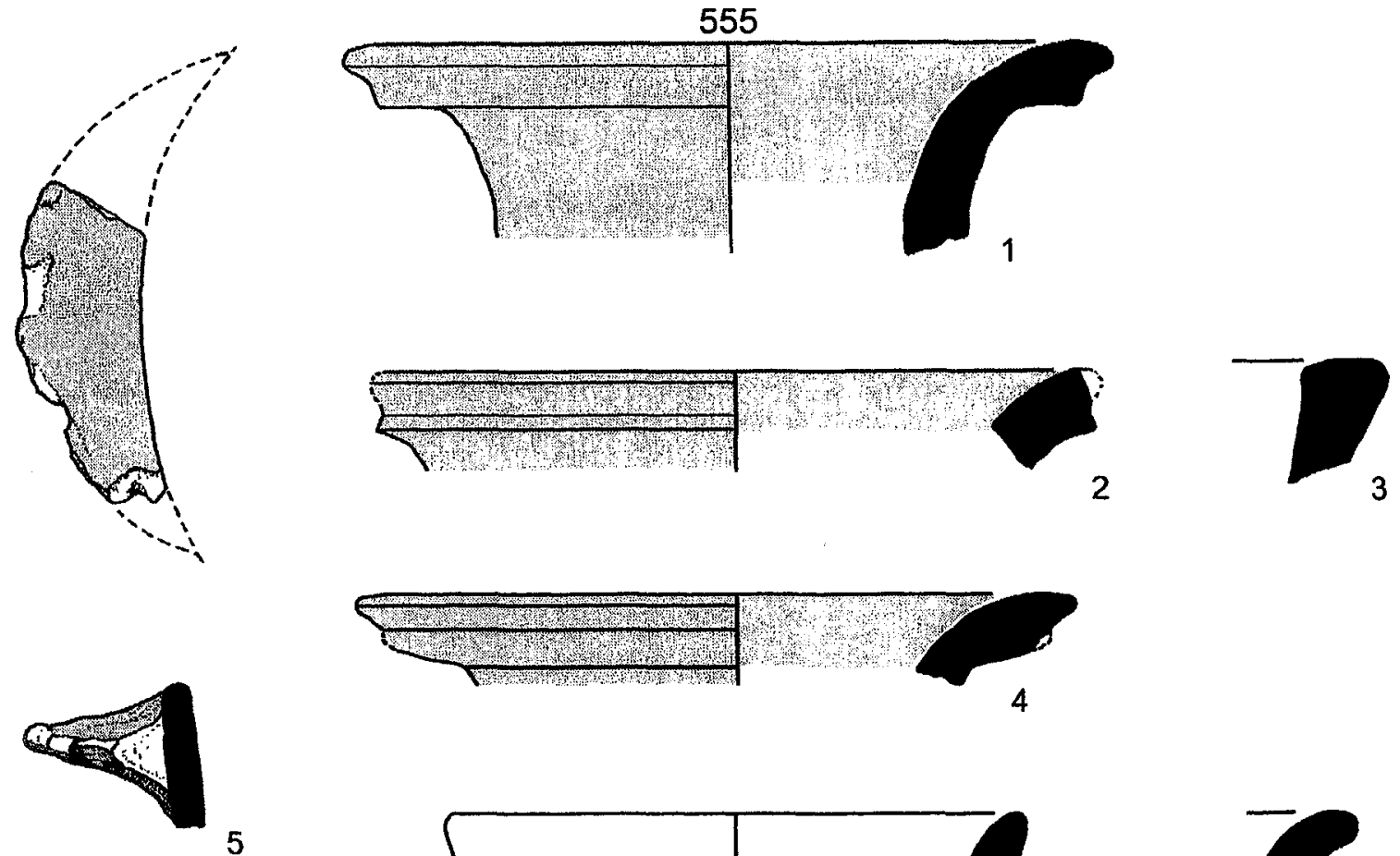

5
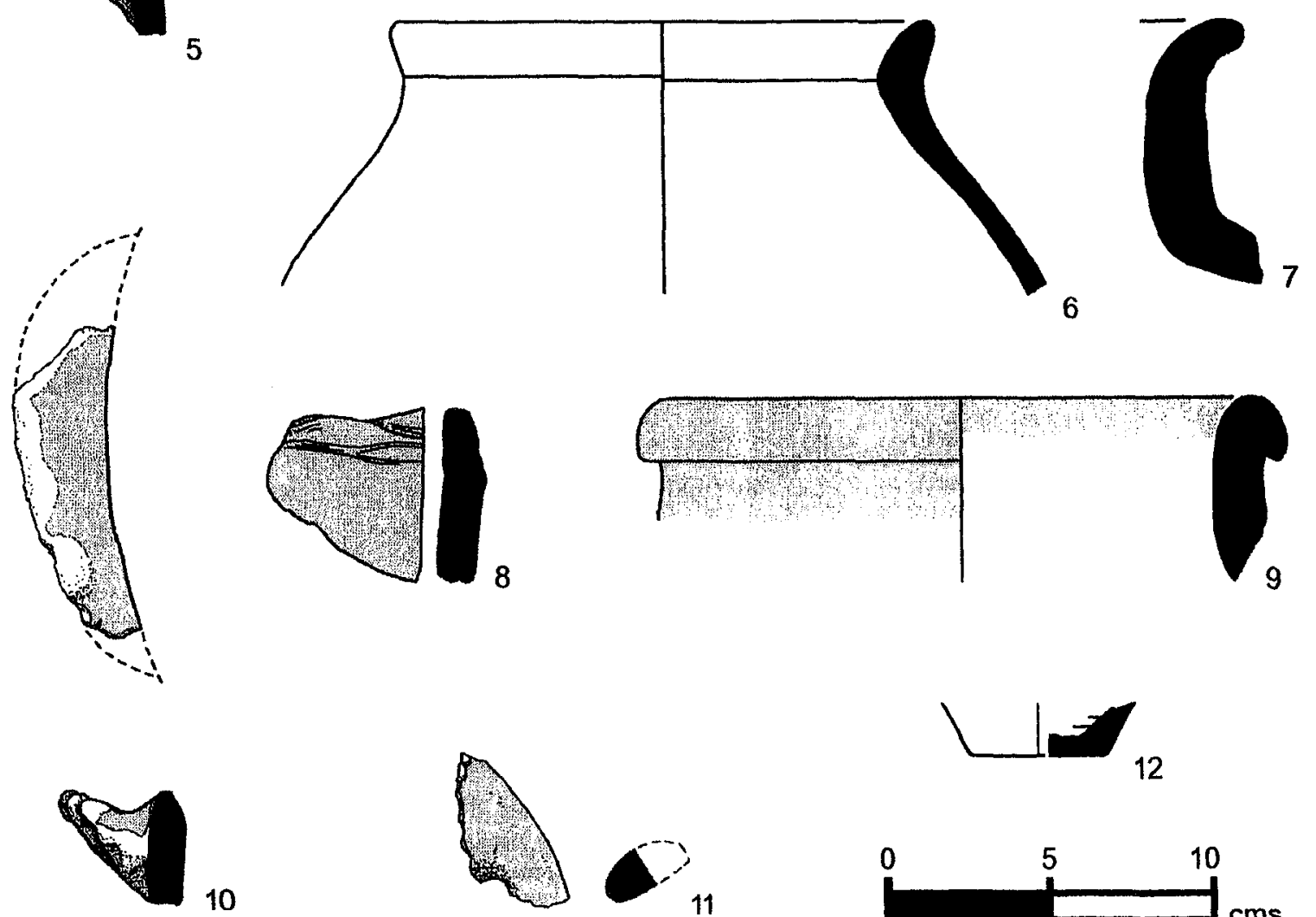

10
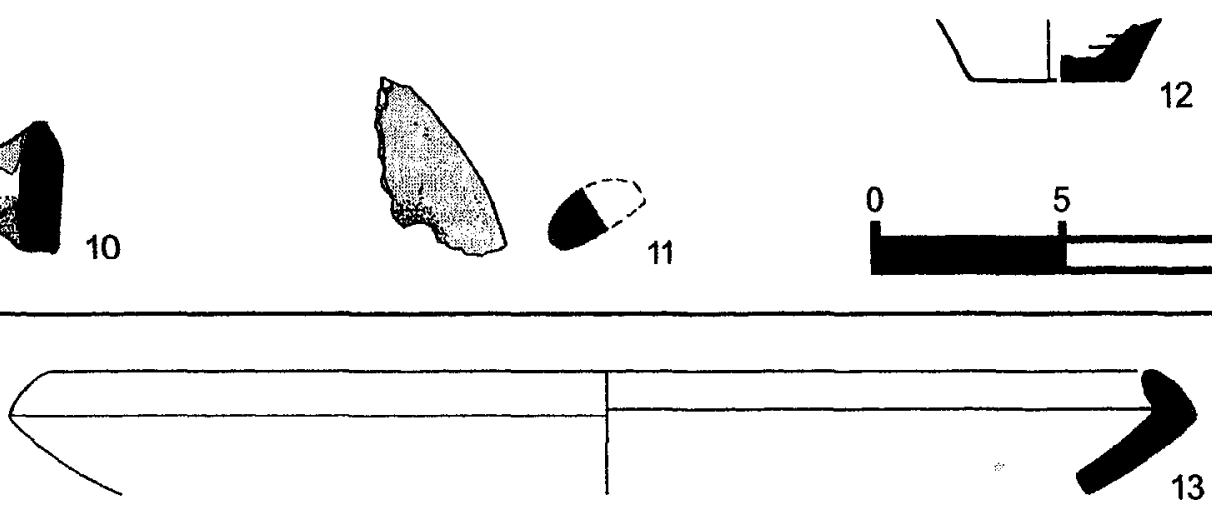

13

PLATE 141 (CONT.).

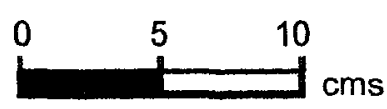




\begin{tabular}{llllllll}
\hline No & Reg & Square & Locus & Vessel & Part & $\begin{array}{l}\text { Body } \\
\text { Thick }\end{array}$ & Dia \\
\hline 1 & 1708 & SW 9-1 & 139 & NECKED JAR & R43 & 15 & 16 \\
2 & 2467 & SW 9-1 & 139 & HOLE MOUTH BOWL & R19 & 10 & $\mathrm{~N}$ \\
3 & 2286 & SW 9-1 & 142 & NECKED JAR & R43 & 7 & 7 \\
4 & 1770 & SW 9-1 & 142 & UD & B12 & 10 & 18 \\
5 & 1706 & SW 9-1 & 139 & UD & B12 & 9 & 17 \\
6 & 1704 & SW 9-1 & 139 & UD & H14 & 12 & N \\
7 & 1707 & SW 9-1 & 139 & UD & H10 & 9 & N \\
8 & 1705 & SW 9-1 & 139 & UD & H46 & 10 & N
\end{tabular}

\begin{tabular}{lllll}
\hline No Fabric Color & Core Orient & Core Color Core Thick & $\begin{array}{l}\text { Fabric } \\
\text { Family }\end{array}$
\end{tabular}

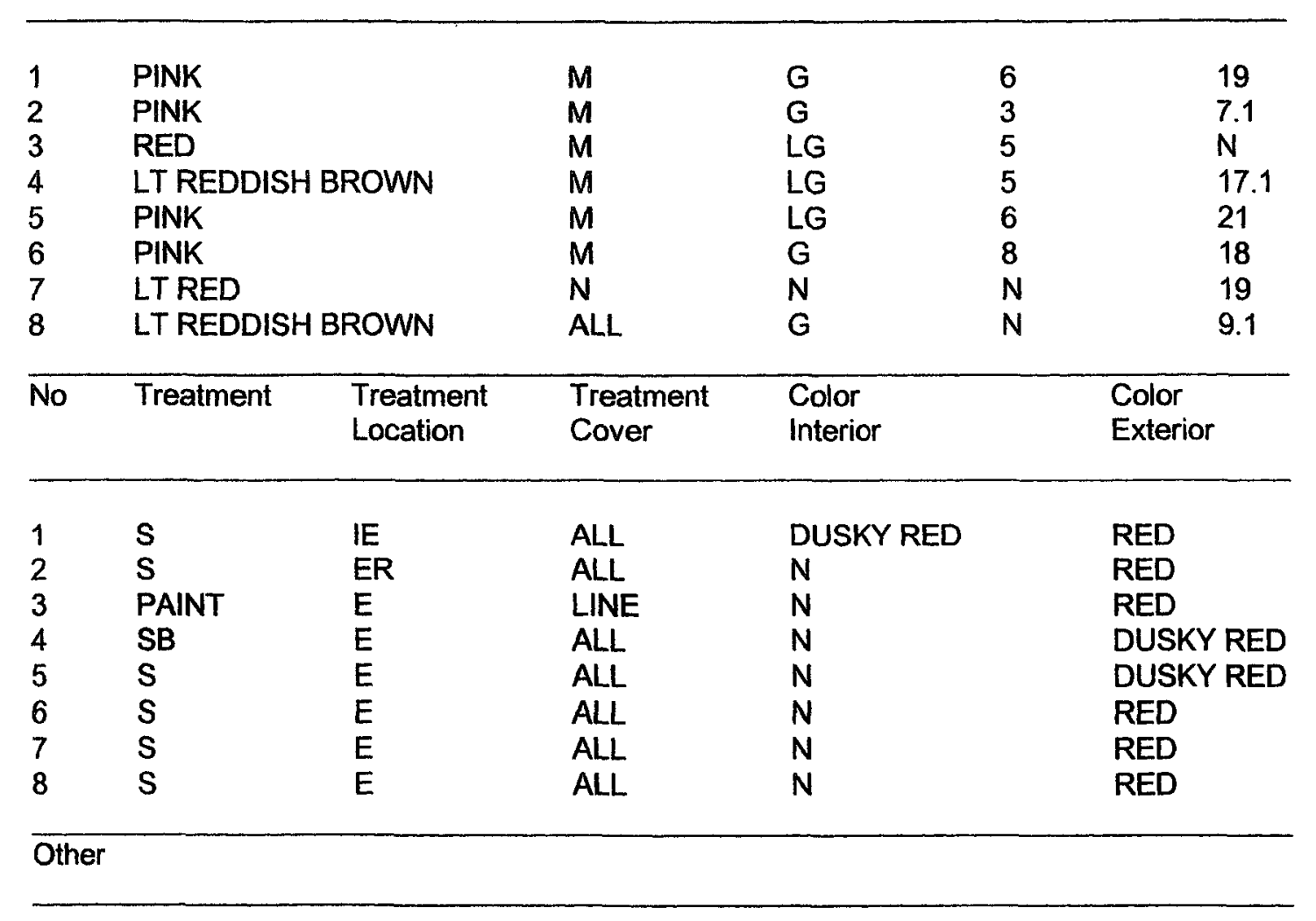

2 Sample too small to confirm stance or diameter; thin section sample 31.

3 A sequence of small puncture marks is visible around neck; Metallic Ware.

4 A deep groove marks the exterior wall.

6 Surface burn visible.

PLATE 142. FIELD C. PHASE 1C (LATE EB I - EARLY EB \| ?). 

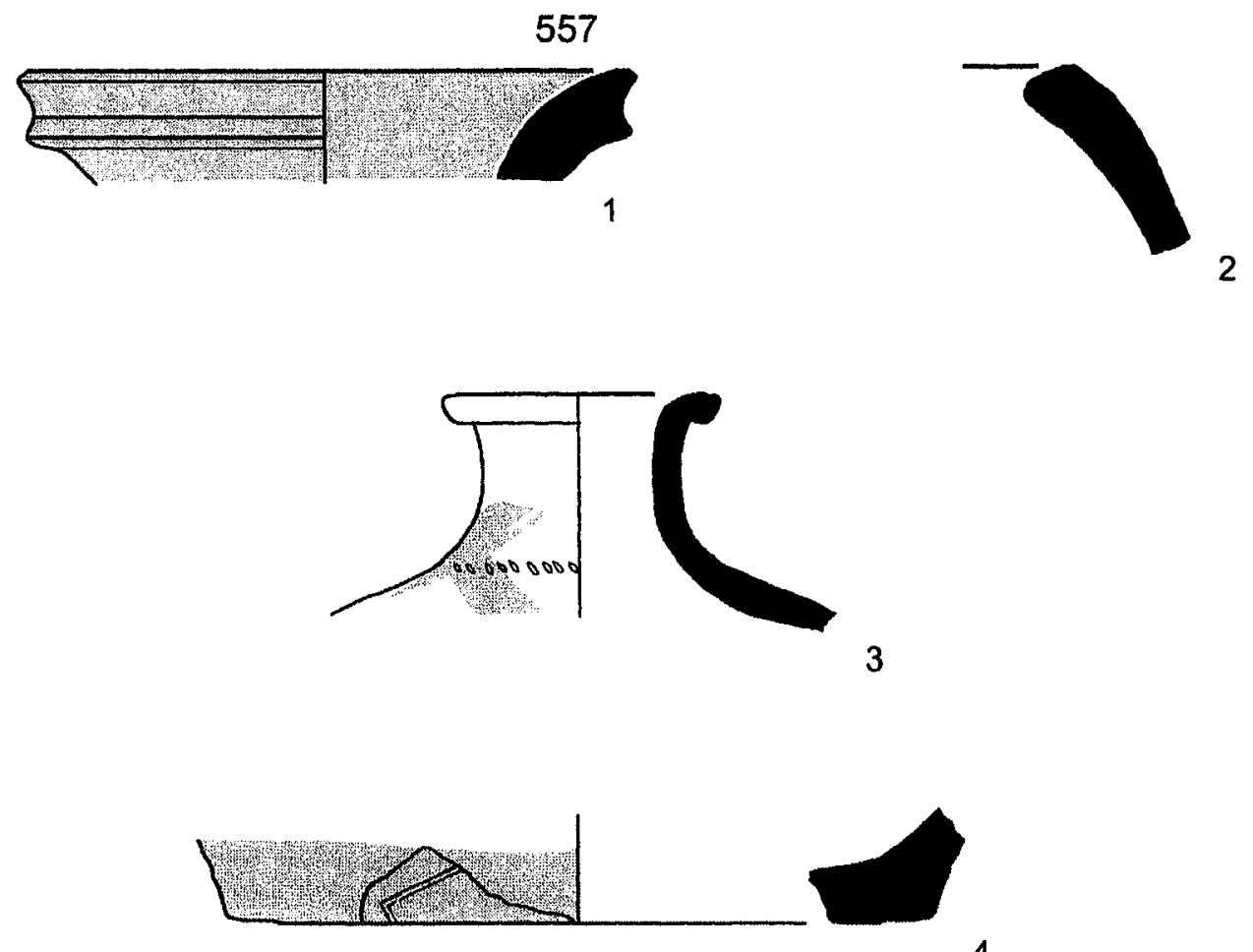

4
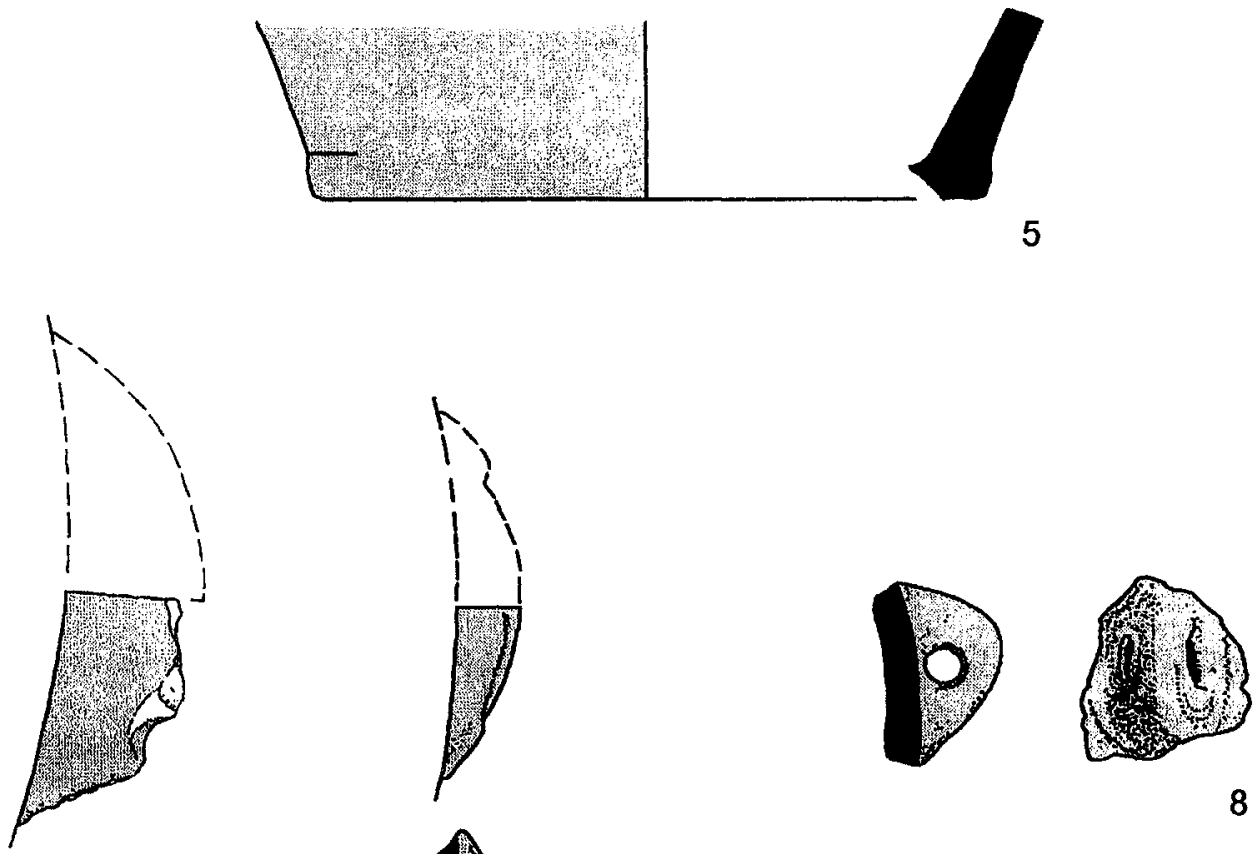

8
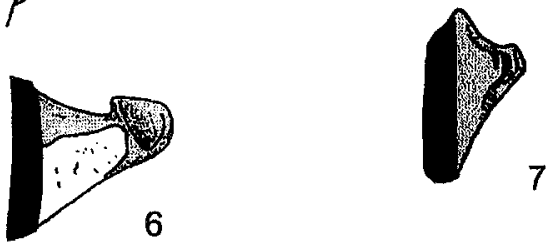

6

PLATE 142 (CONT.).

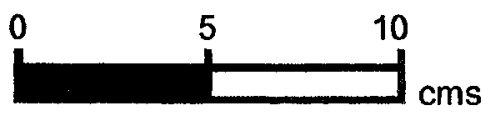




\begin{tabular}{llllllll}
\hline No & Reg & Square & Locus & Vessel & Part & $\begin{array}{c}\text { Body } \\
\text { Thick }\end{array}$ & Dia \\
\hline & & & & & & & \\
1 & 1596 & SW 6-1 & 167 & BOWL & R53 & 6 & 19 \\
2 & 1593 & SW 6-1 & 167 & HOLE MOUTH BOWL & R18 & 4 & 22 \\
3 & 1609 & SW 6-1 & 167 & HOLE MOUTH JARIBOWL & R14 & 11 & 15 \\
4 & 1597 & SW 6-1 & 167 & HOLE MOUTH JAR & R18 & 7 & 15 \\
5 & 1592 & SW 6-1 & 167 & NECKED JAR & R42 & 12 & 21 \\
6 & 1599 & SW 6-1 & 167 & NECKED JAR & R42 & 15 & 20 \\
7 & 1595 & SW 6-1 & 167 & NECKED JAR & R42 & 15 & 15 \\
8 & 1598 & SW 6-1 & 167 & HOLE MOUTH BOWL & R02 & 8 & 24
\end{tabular}

\begin{tabular}{lllll}
\hline No Fabric Color & Core Orient & Core Color & Core Thick & Fabric \\
& & & Family
\end{tabular}

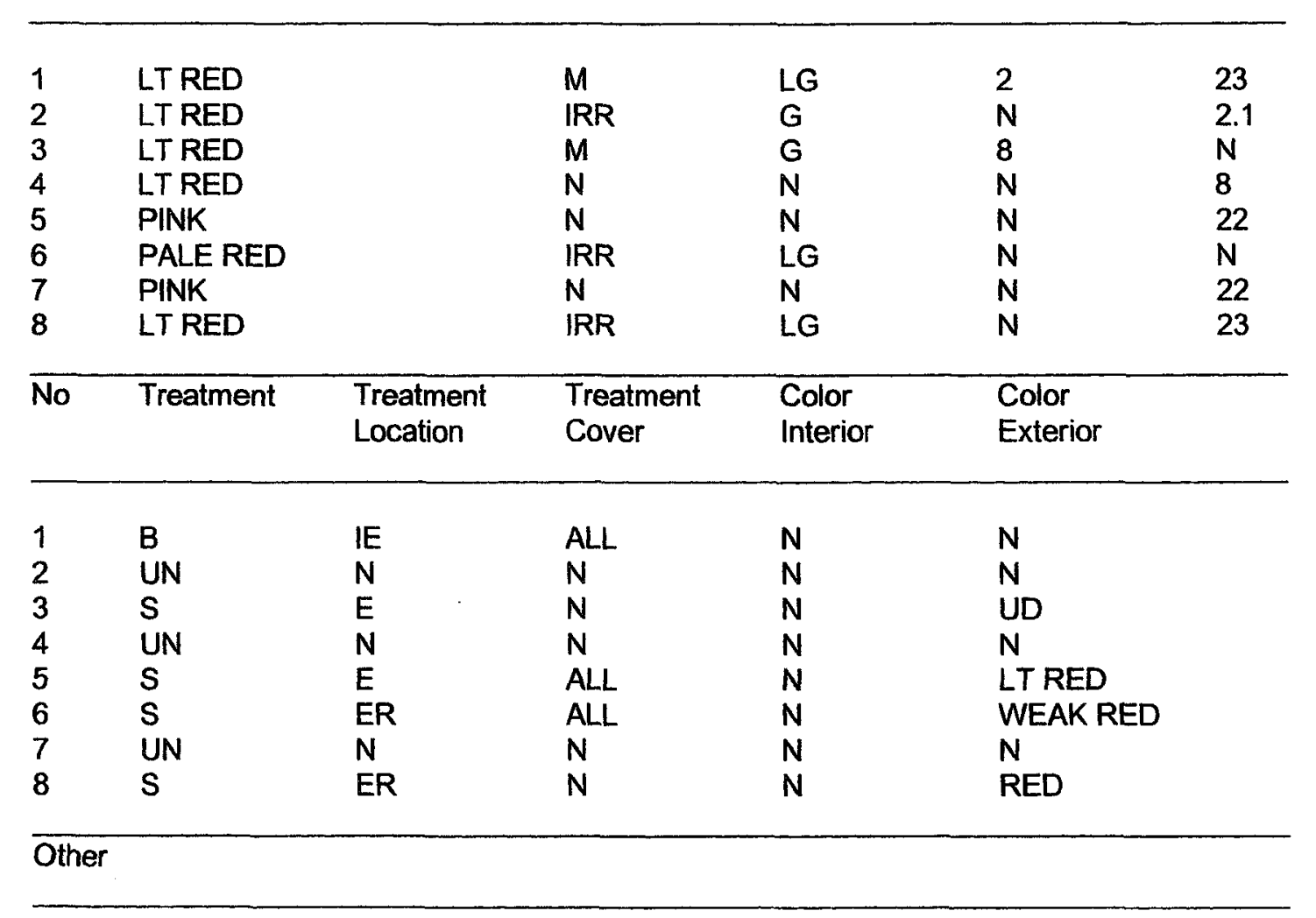

3 Sample too small to confirm stance or diameter.

$4 \quad$ Features in break suggest rim folding.

PLATE 143. FIELD C. PHASE 1D (LATE EB I - EARLY EB II ?). 

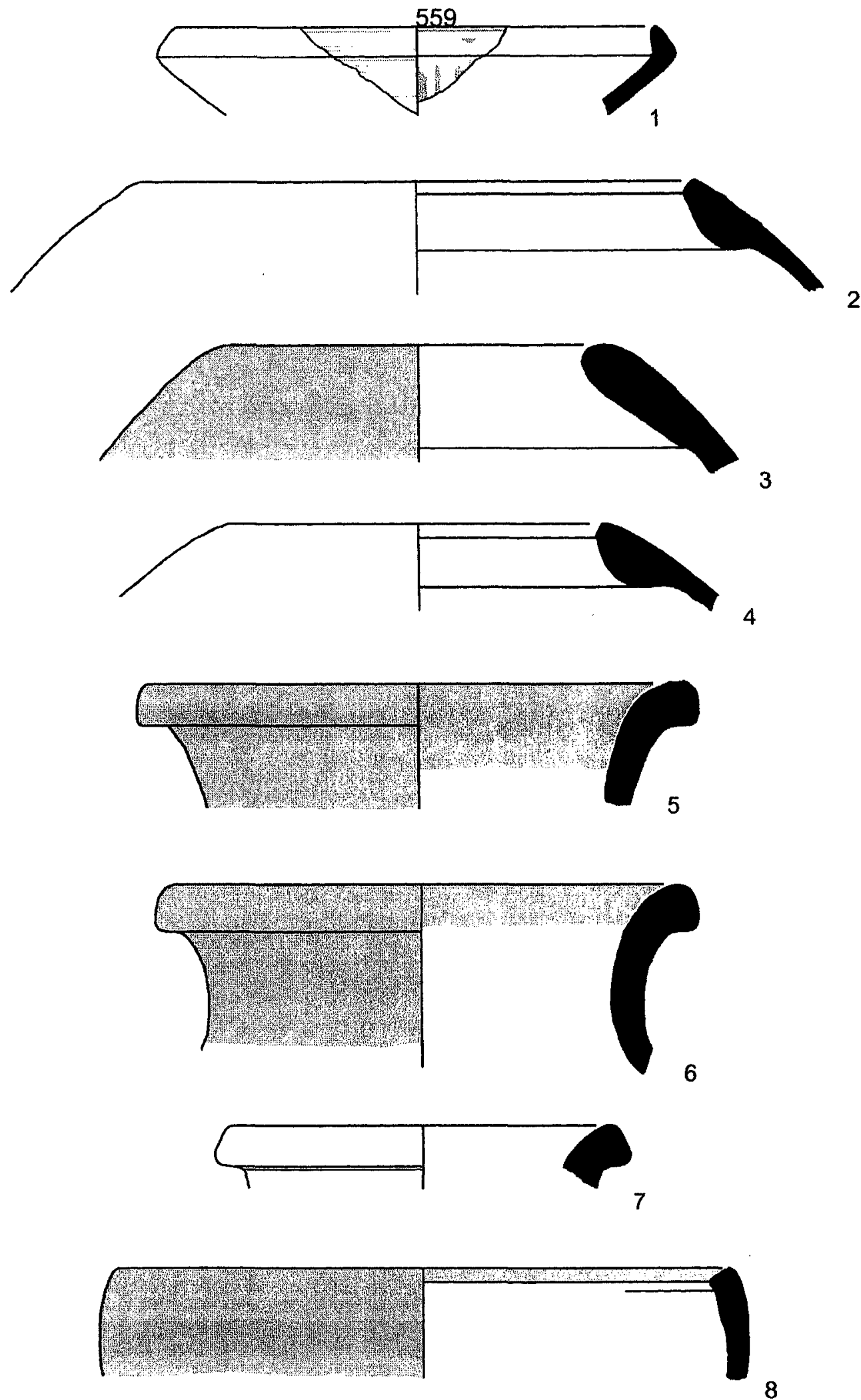

PLATE 143 (CONT.).

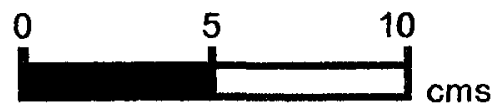


560

\begin{tabular}{lllllllll}
\hline No & Reg & Square & Locus & Vessel & Part & $\begin{array}{c}\text { Body } \\
\text { Thick }\end{array}$ & Dia \\
\hline 1 & & & & & & & \\
2 & 1608 & SW 6-1 & 167 & UD & B11 & 15 & 25 \\
3 & 1611 & SW 6-1 & 167 & UD & B12 & 12 & 24 \\
4 & 1594 & SW 6-1 & 167 & NECKED JAR & R34 & 10 & 14 \\
5 & 1610 & SW 6-1 & 167 & CARINATED BOWL & R58 & 5 & 14 \\
6 & 1601 & SW 6-1 & 167 & UD & H27 & 8 & N \\
7 & 1602 & SW 6-1 & 167 & UD & H27 & 5 & N \\
8 & 1604 & SW 6-1 & 167 & UD & B10 & 7 & 5 \\
9 & 1606 & SW 6-1 & 167 & UD & BOD & 6 & N \\
10 & 1605 & SW 6-1 & 167 & UD & BOD & 5 & N \\
& 1603 & SW 6-1 & 167 & UD & H27 & 8 & N
\end{tabular}

\begin{tabular}{lllll}
\hline No Fabric Color & Core Orient Core Color Core Thick & $\begin{array}{l}\text { Fabric } \\
\text { Family }\end{array}$ \\
\end{tabular}

\begin{tabular}{|c|c|c|c|c|c|c|}
\hline 1 & \multicolumn{2}{|c|}{ LT REDDISH BROWN } & $\mathbf{N}$ & $\mathbf{N}$ & $\mathbf{N}$ & $\mathbf{N}$ \\
\hline 2 & \multicolumn{2}{|c|}{ LT REDDISH BROWN } & $\mathbf{N}$ & $\mathbf{N}$ & $\mathbf{N}$ & $\mathbf{N}$ \\
\hline 3 & \multicolumn{2}{|c|}{ PINK } & IRR & G & $\mathbf{N}$ & 16 \\
\hline 4 & \multicolumn{2}{|c|}{ LT REDDISH BROWN } & $N$ & $\mathbf{N}$ & $\mathbf{N}$ & 23 \\
\hline 5 & \multicolumn{2}{|c|}{ PINK } & $M$ & LG & 3 & $\mathrm{~N}$ \\
\hline 6 & \multicolumn{2}{|l|}{ PINK } & $\mathrm{N}$ & $\mathrm{N}$ & $\mathbf{N}$ & 23 \\
\hline 7 & \multicolumn{2}{|c|}{ LT REDDISH BROWN } & $\mathbb{N}$ & G & 4 & 21 \\
\hline 8 & \multicolumn{2}{|l|}{ RED } & $\mathrm{N}$ & $\mathbf{N}$ & $N$ & 12.1 \\
\hline 9 & \multicolumn{2}{|l|}{ RED } & $\mathbf{N}$ & $\mathrm{N}$ & $\mathbf{N}$ & $N$ \\
\hline 10 & \multicolumn{2}{|l|}{ PINK } & $N$ & $N$ & $N$ & 25.1 \\
\hline No & Treatment & $\begin{array}{l}\text { Treatment } \\
\text { Location }\end{array}$ & $\begin{array}{l}\text { Treatment } \\
\text { Cover }\end{array}$ & $\begin{array}{l}\text { Color } \\
\text { Interior }\end{array}$ & $\begin{array}{l}\text { Color } \\
\text { Exterior }\end{array}$ & \\
\hline 1 & UN & $\mathbf{N}$ & $N$ & $N$ & $\mathbf{N}$ & \\
\hline 2 & $\mathrm{~S}$ & $E$ & ALL & $N$ & PALE RED & \\
\hline 3 & $\mathrm{~s}$ & $E$ & ALL & $\mathbf{N}$ & LTRED & \\
\hline 4 & UN & $N$ & $N$ & $N$ & $\mathbf{N}$ & \\
\hline 5 & UN & $\mathbf{N}$ & $N$ & $N$ & $N$ & \\
\hline 6 & UN & $N$ & $N$ & $N$ & $N$ & \\
\hline 7 & SB & $E$ & ALL & $N$ & DUSKY RED & \\
\hline 8 & 1 & $E$ & ALL & $\mathbf{N}$ & $\mathbf{N}$ & \\
\hline 9 & i & $E$ & ALL & $N$ & $\mathbf{N}$ & \\
\hline 10 & $s$ & $E$ & ALL & $\mathrm{N}$ & DUSKY RED & \\
\hline
\end{tabular}

PLATE 144. FIELD C. PHASE 1D (LATE EB I - EARLY EB ॥ ?). 
Other

3 Interior face is hand smoothed and covered with self slip; exterior face is ridged, slipped and burnished; form appears entirely handmade.

5 Possibly intrusive

6 Possibly intrusive.

8 Combed Metallic Ware.

9 Combed Metallic Ware.

PLATE 144 (CONT.).

Reproduced with permission of the copyright owner. Further reproduction prohibited without permission. 

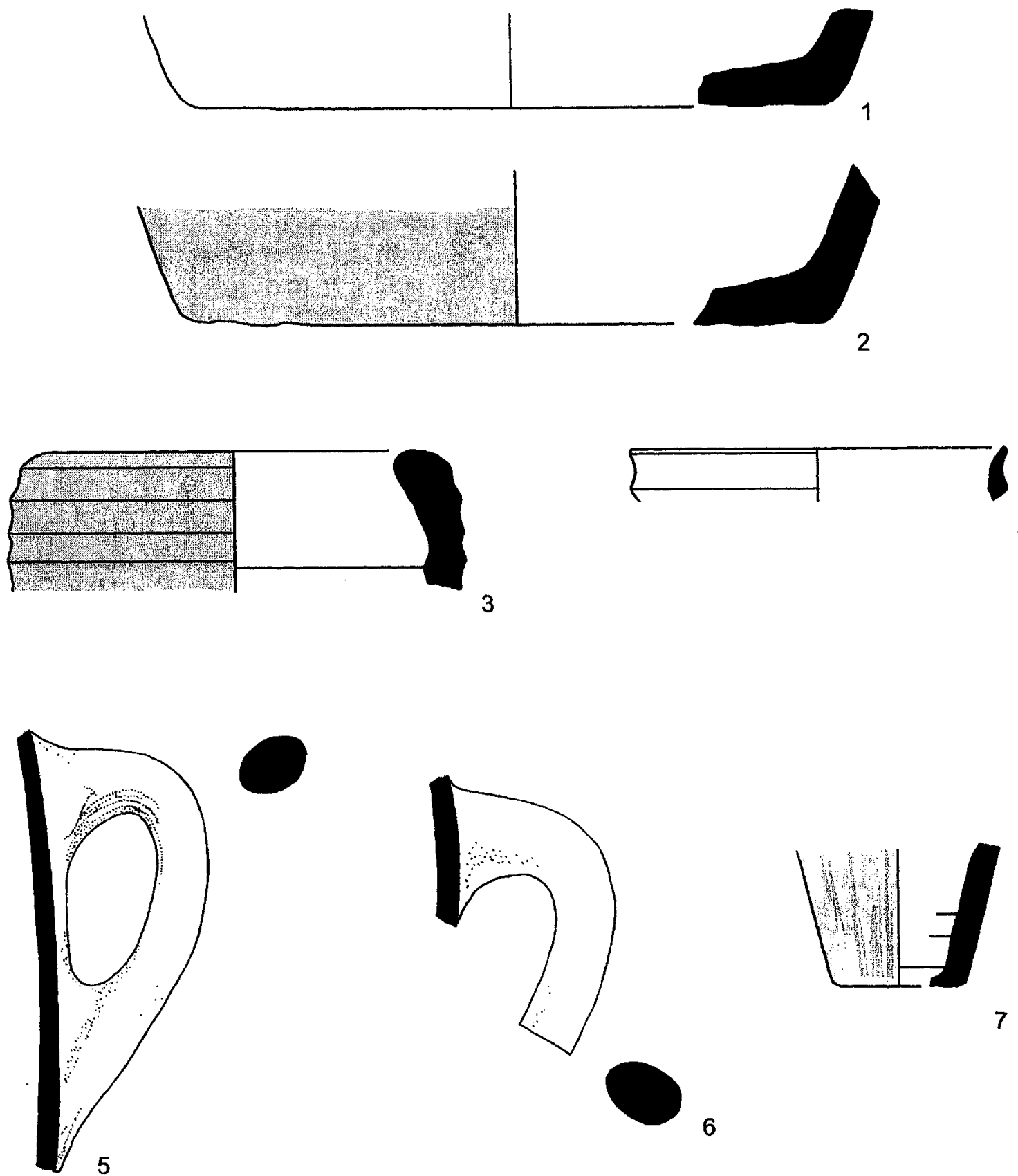

7
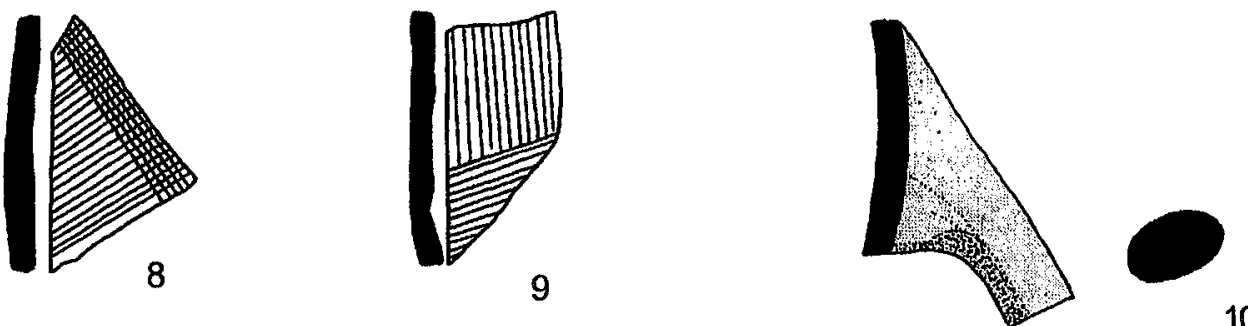

PLATE 144 (CONT.).

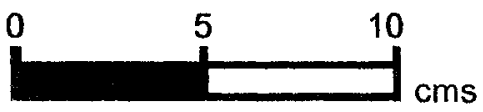




\begin{tabular}{llllllll}
\hline No & Reg & Square & Locus & Vessel & Part & $\begin{array}{c}\text { Body } \\
\text { Thick }\end{array}$ & $\begin{array}{c}\text { Dia } \\
\end{array}$ \\
& & & & & & & \\
1 & 2207 & SW 6-1 & 170 & HOLE MOUTH JAR & R14 & 7 & 22 \\
2 & 2203 & SW 6-1 & 170 & HOLE MOUTH JAR & R21 & N & 22 \\
3 & 2198 & SW 6-1 & 170 & HOLE MOUTH BOWL & R17 & N & 18 \\
4 & 2195 & SW 6-1 & 170 & HOLE MOUTH JAR & R04 & N & 10 \\
5 & 2211 & SW 6-1 & 170 & HOLE MOUTH JARIBOWL & R14 & N & 15 \\
6 & 1665 & SW 6-1 & 171 & NECKED JAR & R40 & 15 & 20 \\
7 & 2210 & SW 6-1 & 170 & NECKED JAR & R31 & 10 & 10 \\
8 & 1667 & SW 6-1 & 171 & HOLE MOUTH JARIBOWL & R01 & 8 & N \\
9 & 2199 & SW 6-1 & 170 & PLATTER BOWL & R56 & N & N \\
10 & 1666 & SW 6-1 & 171 & LEDGE RIM BOWL & R53 & 12 & N
\end{tabular}

\begin{tabular}{lllll}
\hline No Fabric Color & Core Orient & Core Color Core Thick & Fabric \\
& & & Family
\end{tabular}

\begin{tabular}{|c|c|c|c|c|c|c|}
\hline 1 & \multicolumn{2}{|l|}{ WEAK RED } & IRR & $\mathbf{G}$ & $\mathbf{N}$ & 1 \\
\hline 2 & \multicolumn{2}{|c|}{ LT REDDISH BROWN } & IRR & G & $\mathbf{N}$ & $\mathbf{N}$ \\
\hline 3 & \multicolumn{2}{|l|}{ LTRED } & IRR & LG & $\mathrm{N}$ & 2.2 \\
\hline 4 & \multicolumn{2}{|c|}{ REDDISH BROWN } & IRR & G & $\mathbf{N}$ & $\mathrm{N}$ \\
\hline 5 & \multicolumn{2}{|c|}{ REDDISH BROWN } & IRR & $\mathbf{G}$ & $\mathbf{N}$ & $\mathbf{N}$ \\
\hline 6 & \multicolumn{2}{|c|}{ LTBROWN } & $\mathrm{N}$ & $\mathbf{N}$ & $\mathbf{N}$ & 16 \\
\hline 7 & \multicolumn{2}{|c|}{ LT REDDISH BROWN } & $\mathrm{N}$ & $\mathbf{N}$ & $\mathrm{N}$ & $\mathrm{N}$ \\
\hline 8 & \multicolumn{2}{|c|}{ LT REDDISH BROWN } & $M$ & LG & 5 & $N$ \\
\hline 9 & \multicolumn{2}{|l|}{ RED } & $M$ & $G$ & $\mathbf{N}$ & 12.2 \\
\hline 10 & \multicolumn{2}{|l|}{ PINK } & $\mathbf{N}$ & $\mathbf{N}$ & $\mathrm{N}$ & $\mathrm{N}$ \\
\hline No & Treatment & $\begin{array}{l}\text { Treatment } \\
\text { Location }\end{array}$ & $\begin{array}{l}\text { Treatment } \\
\text { Cover }\end{array}$ & $\begin{array}{l}\text { Color } \\
\text { Interior }\end{array}$ & $\begin{array}{l}\text { Color } \\
\text { Exterior }\end{array}$ & \\
\hline 1 & UN & $\mathbf{N}$ & $\mathrm{N}$ & $\mathrm{N}$ & $\mathrm{N}$ & \\
\hline 2 & UN & $\mathbf{N}$ & $\mathbf{N}$ & $\mathrm{N}$ & $\mathbf{N}$ & \\
\hline 3 & UN & $\mathbf{N}$ & $N$ & $N$ & $N$ & \\
\hline 4 & UN & $N$ & $N$ & $N$ & $N$ & \\
\hline 5 & UN & $N$ & $\mathbf{N}$ & $\mathbf{N}$ & $\mathbf{N}$ & \\
\hline 6 & $\mathrm{~s}$ & ER & ALL & $\mathrm{N}$ & LT RED & \\
\hline 7 & $\mathbf{S}$ & IE & ALL & DUSKY RED & DUSKY RED & \\
\hline 8 & UN & $N$ & $N$ & $\mathbf{N}$ & $\bar{N}$ & \\
\hline 9 & $\mathrm{~B}$ & $\mathrm{IE}$ & ALL & $\mathrm{N}$ & $N$ & \\
\hline 10 & $\mathrm{SB}$ & IE & ALL & DK RED & DK RED & \\
\hline
\end{tabular}

PLATE 145. FIELD C. PHASE 1D (LATE EB I - EARLY EB II ?). 


\section{Other}

$1 \quad$ Rim folding is clear in section.

2 Rim "margin" appears wet-turned; splaying clay forms small ridge; surface burn visible.

3 Fine lines on interiorlexterior faces show rim shaping and smoothing; surface burn visible.

4 Surface burn visible.

$5 \quad$ Lip is too weathered to confirm stance or diameter; surface burn visible.

8 Sample too small to confirm stance or diameter.

9 Well burnished all over, including base; Metallic Ware; sample too small to confirm stance or diameter.

10 Sample too small to confirm stance or diameter.

PLATE 145 (CONT.). 

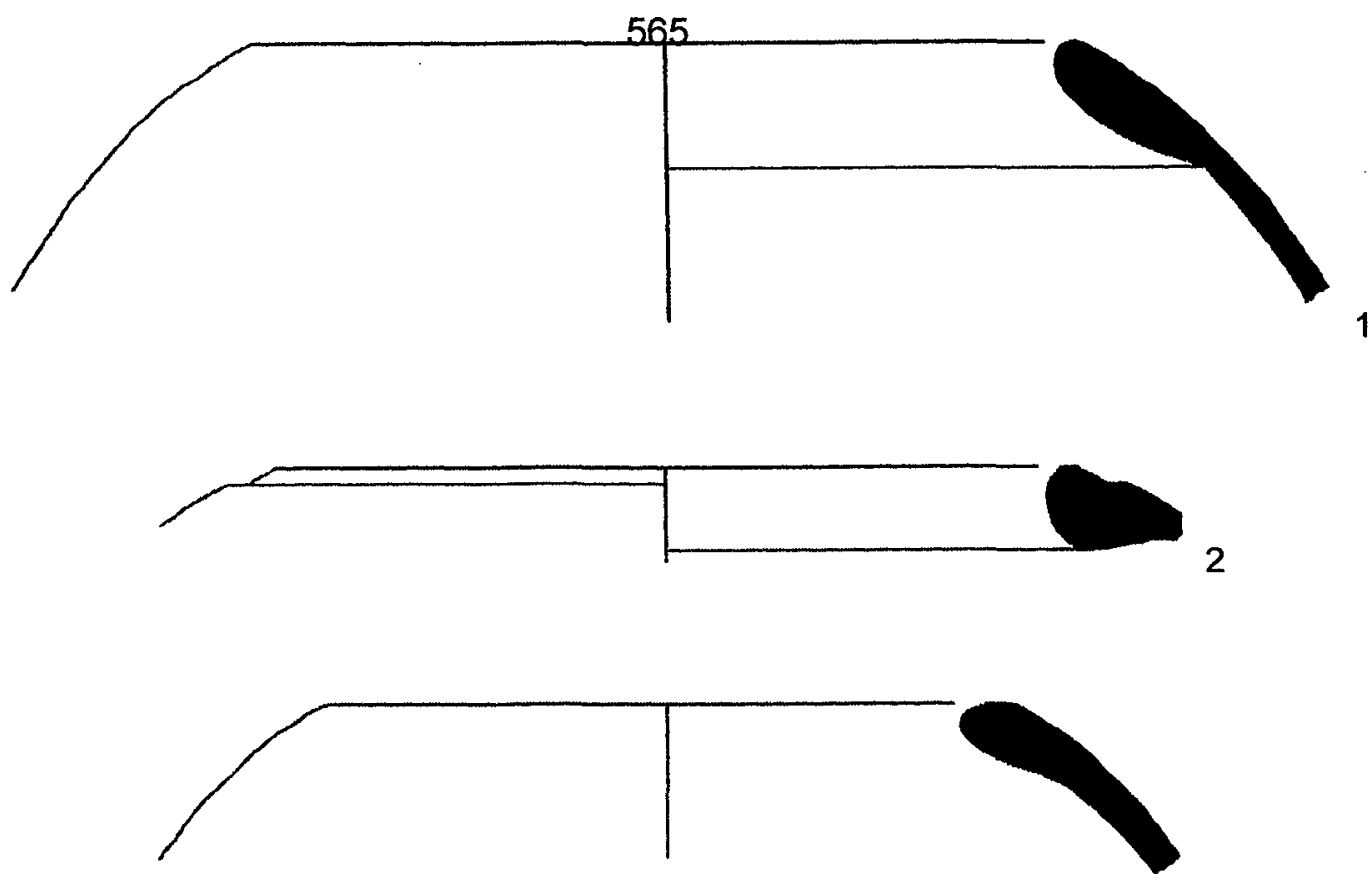

3
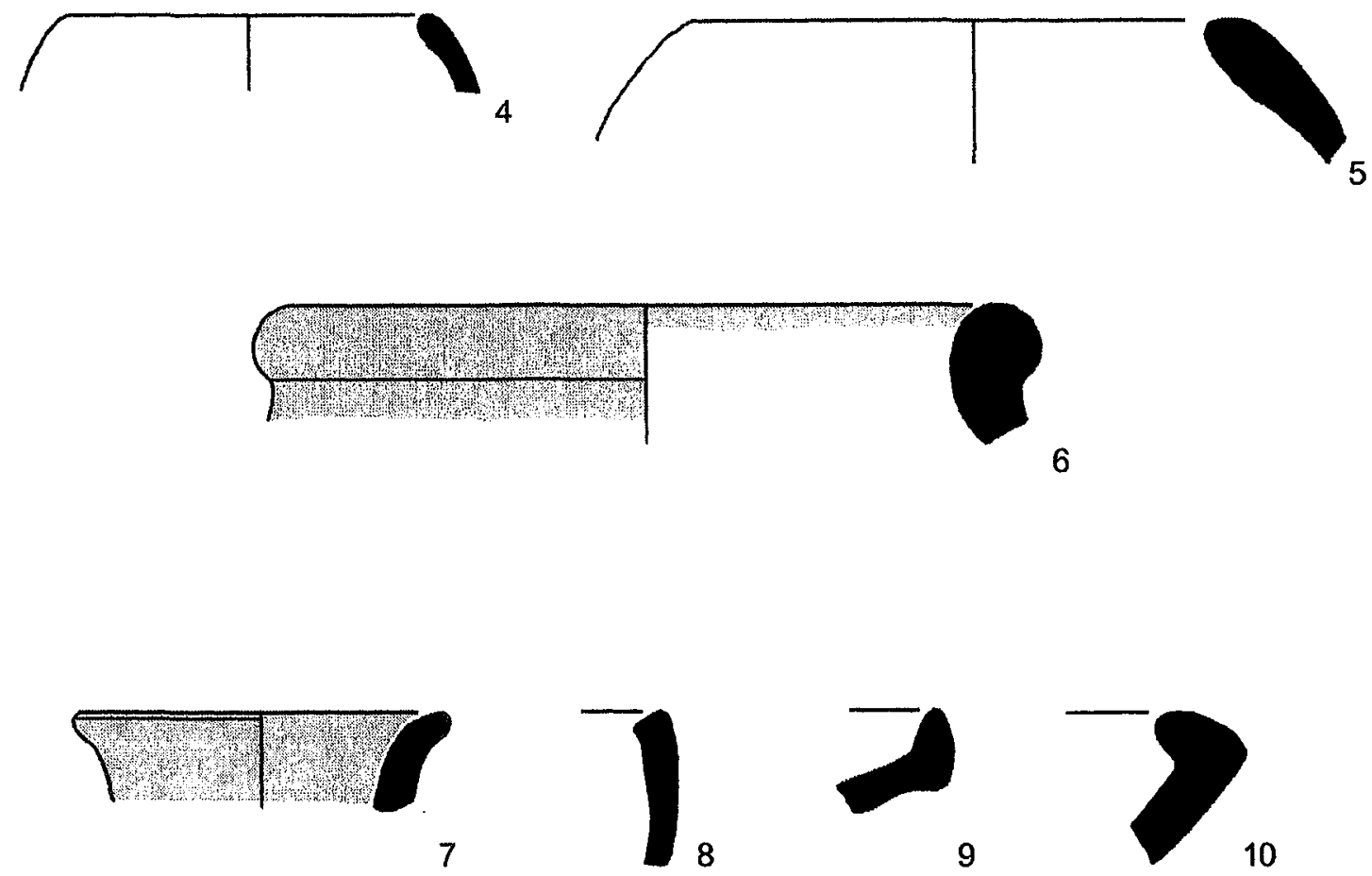

PLATE 145 (CONT.).

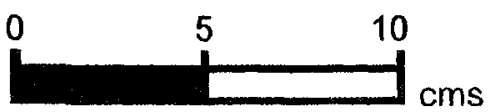


566

\begin{tabular}{lllllllll}
\hline No & Reg & Square & Locus & Vessel & Part & $\begin{array}{c}\text { Body } \\
\text { Thick }\end{array}$ & Dia \\
\hline 1 & 2206 & SW 6-1 & 170 & UD & BOD & $\mathrm{N}$ & $\mathrm{N}$ \\
2 & 2200 & SW 6-1 & 170 & UD & H27 & $\mathrm{N}$ & $\mathrm{N}$ \\
3 & 2208 & SW 6-1 & 170 & UD & H14 & $\mathrm{N}$ & $\mathrm{N}$ \\
4 & 2196 & SW 6-1 & 170 & UD & B12 & $\mathrm{N}$ & 20 \\
5 & 2201 & SW 6-1 & 170 & UD & B12 & $\mathrm{N}$ & 3 \\
6 & 2202 & SW 6-1 & 170 & UD & B12 & $\mathrm{N}$ & $\mathrm{N}$ \\
7 & 2209 & SW 6-1 & 170 & UD & B12 & $\mathrm{N}$ & $\mathrm{N}$ \\
8 & 2197 & SW 6-1 & 170 & HOLE MOUTH BOWL & R20 & 8 & 36 \\
& & & & & & & & \\
\hline No & Fabric Color & & Core Orient Core Color & Core Thick & Fabric \\
& & & & & & & & Family
\end{tabular}

\begin{tabular}{|c|c|c|c|c|c|c|}
\hline 1 & \multicolumn{2}{|l|}{ RED } & IN & $\mathbf{G}$ & $\mathbf{N}$ & 9.1 \\
\hline 2 & \multicolumn{2}{|l|}{ LT BROWN } & IRR & LG & $\mathbf{N}$ & 21 \\
\hline 3 & \multicolumn{2}{|c|}{ LT REDDISH BROWN } & $N$ & $N$ & $\mathbf{N}$ & 19 \\
\hline 4 & \multicolumn{2}{|c|}{ LT REDDISH BROWN } & $N$ & $N$ & $\mathrm{~N}$ & $\mathrm{~N}$ \\
\hline 5 & \multicolumn{2}{|c|}{ REDDISH BROWN } & $N$ & $\mathbf{N}$ & $\mathrm{N}$ & 13.2 \\
\hline 6 & \multicolumn{2}{|c|}{ REDDISH YELLOW } & $\mathbf{N}$ & $\mathbf{N}$ & $N$ & 8 \\
\hline 7 & \multicolumn{2}{|l|}{ RED } & $\mathrm{N}$ & $\mathbf{N}$ & $N$ & $\mathbf{N}$ \\
\hline 8 & \multicolumn{2}{|l|}{ PINK } & $N$ & $\mathbf{N}$ & $\mathbf{N}$ & $\mathrm{N}$ \\
\hline No & Treatment & $\begin{array}{l}\text { Treatment } \\
\text { Location }\end{array}$ & $\begin{array}{l}\text { Treatment } \\
\text { Cover }\end{array}$ & $\begin{array}{l}\text { Color } \\
\text { Interior }\end{array}$ & $\begin{array}{l}\text { Color } \\
\text { Exterior }\end{array}$ & \\
\hline 1 & 1 & $\mathrm{E}$ & ALL & $\mathbf{N}$ & $N$ & \\
\hline 2 & SB & $\bar{E}$ & ALL & $N$ & RED & \\
\hline$\overline{3}$ & $\mathrm{~s}$ & $\bar{E}$ & $A L L$ & $N$ & RED & \\
\hline 4 & UN & $\mathbf{N}$ & $N$ & $N$ & $\mathbf{N}$ & \\
\hline 5 & $\mathrm{~s}$ & $\mathbf{E}$ & $\mathbf{N}$ & $\mathbf{N}$ & $\mathrm{N}$ & \\
\hline 6 & SB & $\mathrm{IE}$ & ALL & RED & RED & \\
\hline 7 & UN & $\mathbf{N}$ & $N$ & $N$ & $\mathrm{~N}$ & \\
\hline 8 & $\mathrm{~s}$ & ER & ALL & $N$ & RED & \\
\hline
\end{tabular}

1 Combed Metallic Ware.

2 Also in Fabric Family 17:2.

$4 \quad$ Surface burn visible.

$5 \quad$ Burn marks on break suggests secondary use of broken base as lamp.

6 Sample too small to confirm stance or diameter.

7 Sample too small to confirm stance or diameter.

$8 \quad$ Complete spout preserved.

PLATE 146. FIELD C. PHASE 1D (LATE EB I - EARLY EB $\|$ ?). 

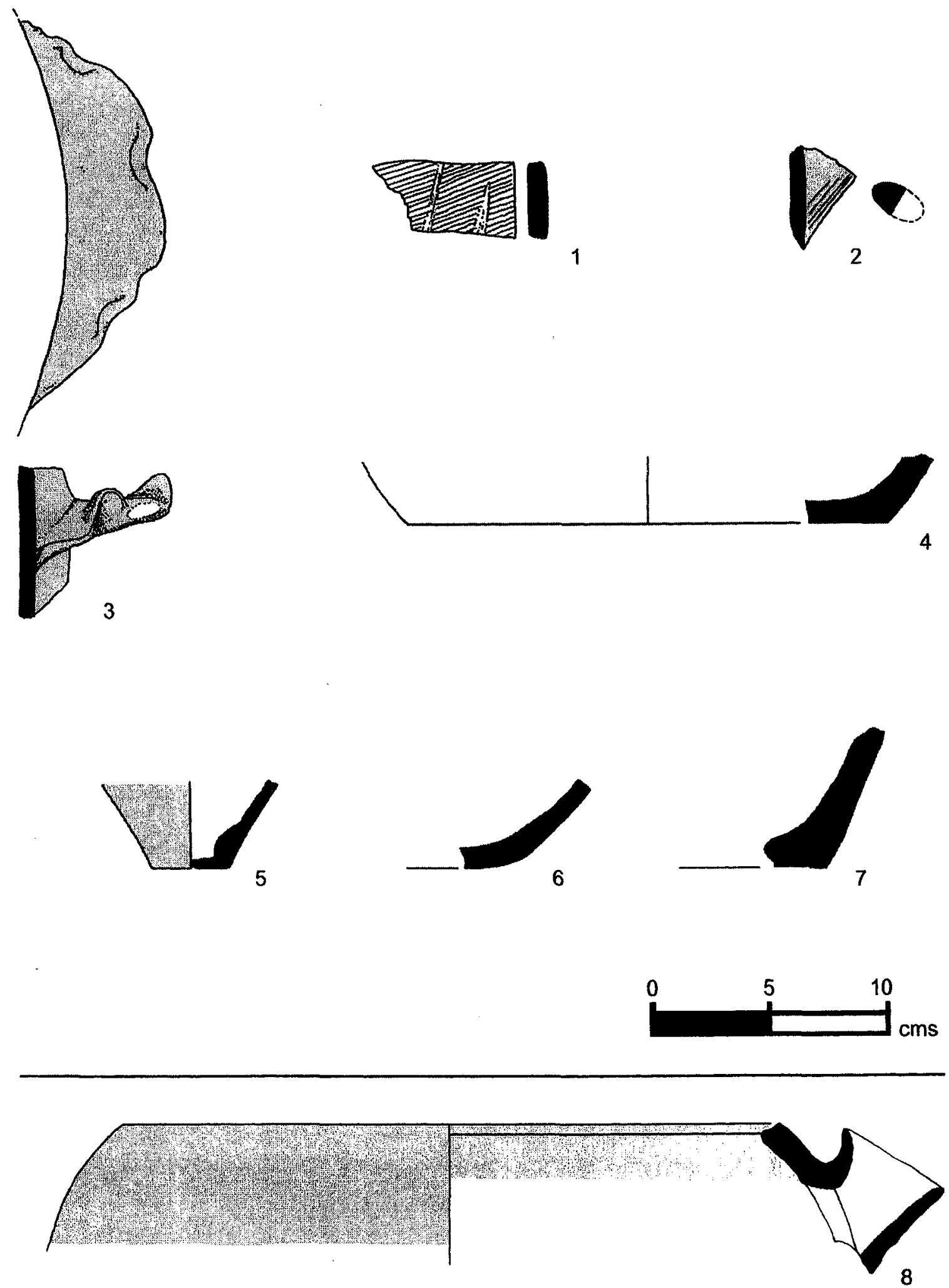

PLATE 146 (CONT).

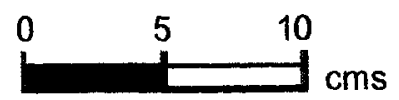




No Reg Square Locus Vessel

Part
Body Dia Thick

\begin{tabular}{llllllll}
\hline 1 & 1837 & NW 9-1 & 30 & LEDGE RIM BOWL & R60 & 13 & 28 \\
2 & 1843 & NW 9-1 & 57 & HOLE MOUTH BOWL & R18 & 13 & 13 \\
3 & 1849 & NW 9-1 & 57 & HOLE MOUTH BOWL & R11 & 8 & 10 \\
4 & 1838 & NW 9-1 & 62 & HOLE MOUTH BOWL & R04 & 11 & 20 \\
5 & 1829 & NW 9-1 & 30 & HOLE MOUTH JAR & R08 & 15 & 20 \\
6 & 1840 & NW 9-1 & 60 & HOLE MOUTH JARIBOWL & R14 & 11 & 16 \\
7 & 2431 & NW 9-1 & 62 & PLATTER BOWL & R53 & N & N \\
8 & 1828 & NW 9-1 & 30 & NECKED JAR & R42 & 16 & 20 \\
9 & 1841 & NW 9-1 & 62 & UD & BOD & N & N \\
10 & 1848 & NW 9-1 & 57 & UD & B12 & 16 & 20 \\
11 & 1836 & NW 9-1 & 30 & UD & BOD & 10 & N \\
12 & 1831 & NW 9-1 & 30 & LEDGE RIM BOWL & R60 & 12 & 54
\end{tabular}

\begin{tabular}{lllll}
\hline No Fabric Color & Core Orient & Core Color & Core Thick & $\begin{array}{l}\text { Fabric } \\
\text { Family }\end{array}$ \\
\hline
\end{tabular}

\begin{tabular}{|c|c|c|c|c|c|c|}
\hline 1 & \multicolumn{2}{|l|}{ PINK } & M & $\mathbf{G}$ & 6 & $\mathbf{N}$ \\
\hline 2 & \multicolumn{2}{|l|}{ WEAK RED } & ALL & $\mathbf{G}$ & $N$ & 1 \\
\hline 3 & \multicolumn{2}{|l|}{ PALE RED } & $\mathbf{N}$ & $\mathbf{N}$ & $\mathbf{N}$ & 4 \\
\hline 4 & \multicolumn{2}{|c|}{ WEAK RED } & $\mathbf{M}$ & LG & 7 & 2.2 \\
\hline 5 & \multirow{2}{*}{\multicolumn{2}{|c|}{$\begin{array}{l}\text { LT REDDISH BROWN } \\
\text { REDDISH BROWN }\end{array}$}} & $\mathbf{N}$ & $\mathbf{N}$ & $\mathbf{N}$ & $N$ \\
\hline 6 & & & M & LG & 5 & 2.1 \\
\hline 7 & \multicolumn{2}{|l|}{ RED } & $\mathbf{N}$ & $\mathbf{N}$ & $N$ & $N$ \\
\hline 8 & \multicolumn{2}{|c|}{ LT REDDISH BROWN } & IRR & LG & $\mathbf{N}$ & $\mathbf{N}$ \\
\hline 9 & \multicolumn{2}{|l|}{ RED } & IN & $\mathbf{G}$ & 5 & 9.1 \\
\hline 10 & \multicolumn{2}{|c|}{ LT REDDISH BROWN } & M & $\mathbf{G}$ & 10 & 21 \\
\hline 11 & \multicolumn{2}{|l|}{ RED } & $N$ & $\mathbf{N}$ & $\mathbf{N}$ & $\mathbf{N}$ \\
\hline 12 & \multicolumn{2}{|c|}{ LT REDDISH BROWN } & M & LG & 4 & $N$ \\
\hline No & Treatment & $\begin{array}{l}\text { Treatment } \\
\text { Location }\end{array}$ & $\begin{array}{l}\text { Treatment } \\
\text { Cover }\end{array}$ & $\begin{array}{l}\text { Color } \\
\text { Interior }\end{array}$ & $\begin{array}{l}\text { Color } \\
\text { Exterior }\end{array}$ & \\
\hline 1 & SB & IE & ALL & RED & RED & \\
\hline 2 & UN & $\mathbf{N}$ & $\mathbf{N}$ & $\mathbf{N}$ & $\mathbf{N}$ & \\
\hline 3 & UN & $N$ & $\mathbf{N}$ & $\mathbf{N}$ & $\mathbf{N}$ & \\
\hline 4 & UN & $\mathbf{N}$ & $\mathbf{N}$ & $\mathbf{N}$ & $\mathbf{N}$ & \\
\hline 5 & UN & $N$ & $N$ & $\mathbf{N}$ & $\mathbf{N}$ & \\
\hline 6 & UN & $\mathbf{N}$ & $\mathbf{N}$ & $\mathbf{N}$ & $\mathbf{N}$ & \\
\hline 7 & $B$ & IR & ALL & $N$ & $N$ & \\
\hline 8 & $\mathbf{S}$ & ER & ALL & $\mathbf{N}$ & LT RED & \\
\hline 9 & 1 & $E$ & ALL & $\mathbf{N}$ & $\mathbf{N}$ & \\
\hline 10 & UN & $\mathrm{N}$ & $\mathbf{N}$ & $\mathbf{N}$ & $\mathbf{N}$ & \\
\hline 11 & 1 & $E$ & ALL & $\mathbf{N}$ & $\mathbf{N}$ & \\
\hline 12 & UN & $N$ & $\mathbf{N}$ & $\mathbf{N}$ & $\mathbf{N}$ & \\
\hline
\end{tabular}

PLATE 147. FIELD C. PHASE 2A (EB II). 


\section{Other}

3 Swipe lines on exterior suggest motion in finishing the rim; surface burn visible.

$4 \quad$ Fine lines suggest motion used to finish rim.

6 Sample too small to confirm stance or diameter.

7 Sample too small to confirm stance or diameter; Metallic Ware.

9 Combed Metallic Ware.

11 Combed Metallic Ware.

12 Interior face weathered; exterior face is "textured" with slight concavity under rim.

PLATE 147 (CONT.). 

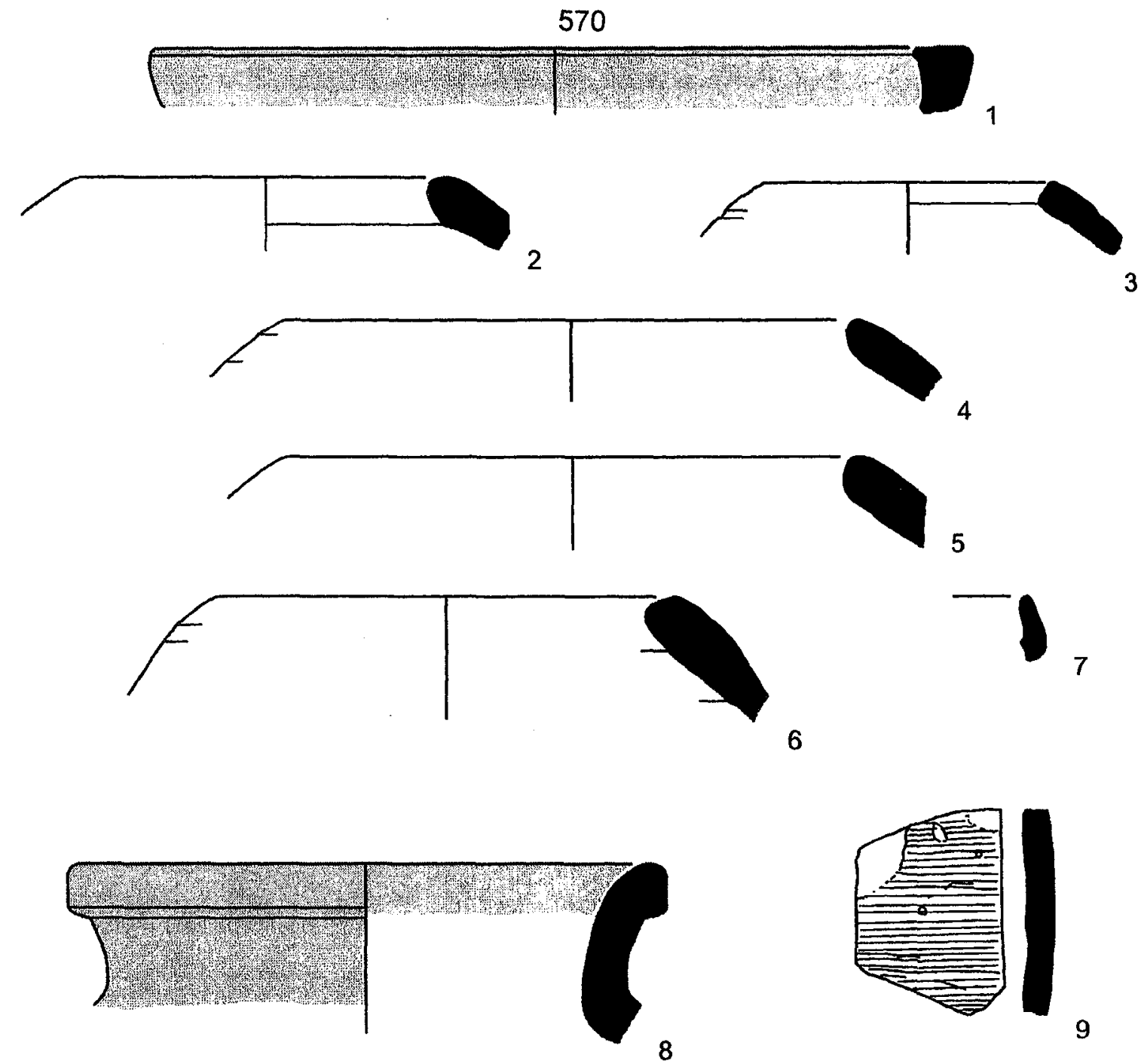

10
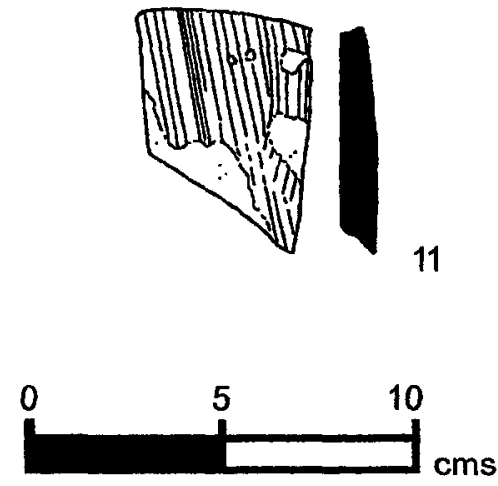

PLATE 147 (CONT.). 
571

\begin{tabular}{llllllll}
\hline No & Reg & Square & Locus & Vessel & Part & $\begin{array}{c}\text { Body } \\
\text { Thick }\end{array}$ & $\begin{array}{c}\text { Dia } \\
\end{array}$ \\
& & & & & & & \\
1 & 1875 & NW 9-1 & 63 & HOLE MOUTH BOWL & R11 & 11 & 30 \\
2 & 1868 & NW 9-1 & 63 & HOLE MOUTH BOWL & R14 & 17 & 25 \\
3 & 1871 & NW 9-1 & 63 & HOLE MOUTH BOWL & R17 & 11 & 24 \\
4 & 1877 & NW 9-1 & 63 & HOLE MOUTH JAR & R21 & 17 & 22 \\
5 & 1876 & NW 9-1 & 63 & HOLE MOUTH JAR & R20 & 12 & 20 \\
6 & 1888 & NW 9-1 & 63 & HOLE MOUTH JAR & R01 & 10 & 16 \\
7 & 1866 & NW 9-1 & 63 & NECKED JAR & R31 & 13 & 20 \\
8 & 1865 & NW 9-1 & 63 & NECKED JAR & R40 & 11 & 17 \\
9 & 1878 & NW 9-1 & 63 & NECKED JAR & R30 & 6 & 13
\end{tabular}

\begin{tabular}{lllll}
\hline No Fabric Color & Core Orient & Core Color & Core Thick & Fabric \\
Family
\end{tabular}

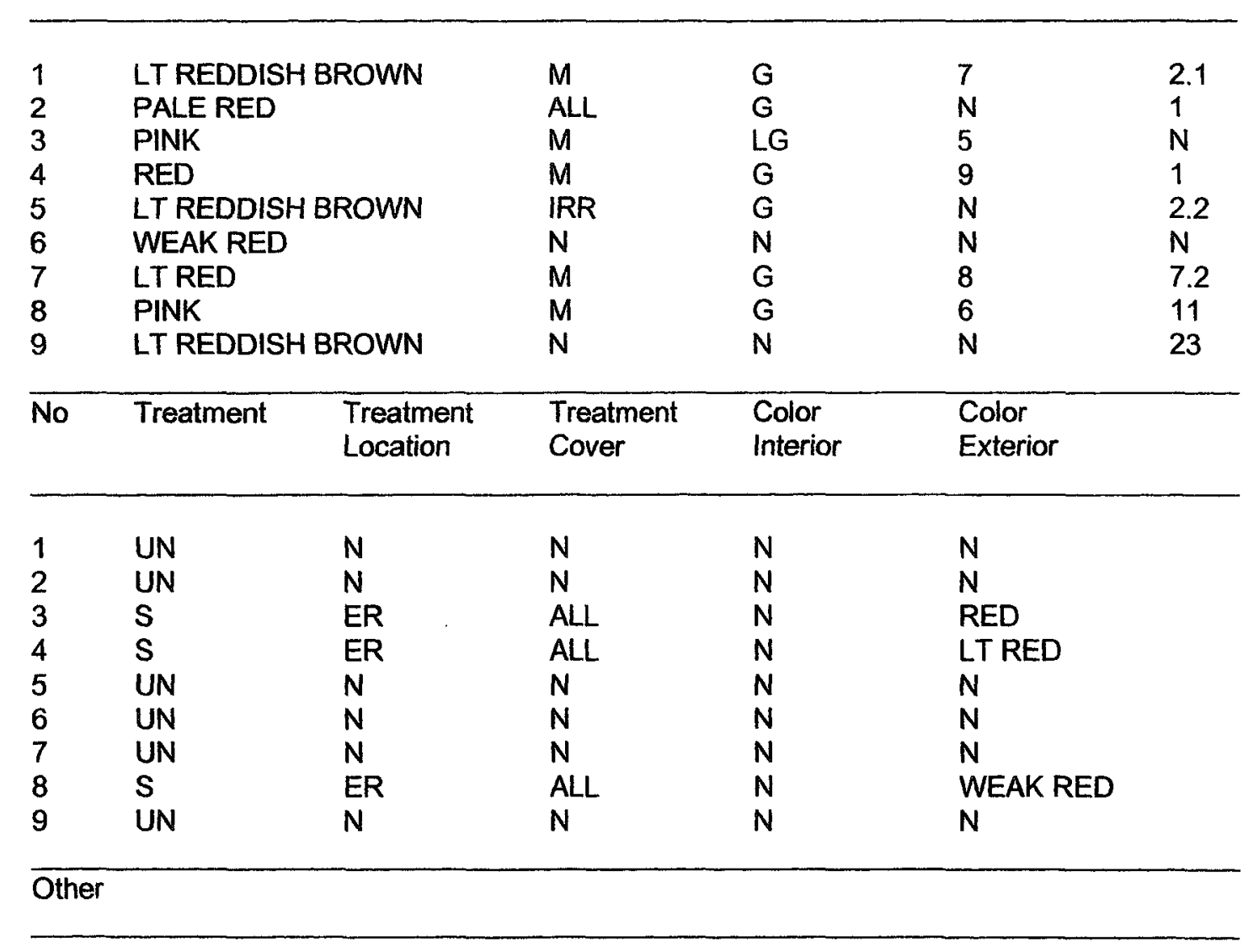

\footnotetext{
$1 \quad$ Elliptical rim shape; ledges of pushed clay on interiorlexterior of lip.

4 Ridge creates margin around rim.

6 Horizontal finish lines on interior wall; surface burn visible.

9 Sample too small to confirm stance or diameter.
}

PLATE 148. FIELD C. PHASE 2A (EB II). 

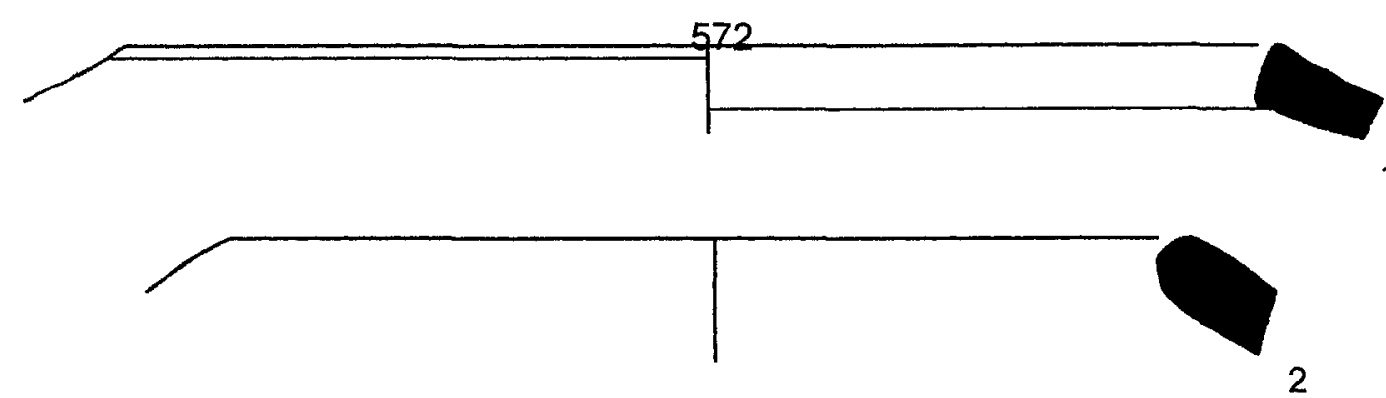

2
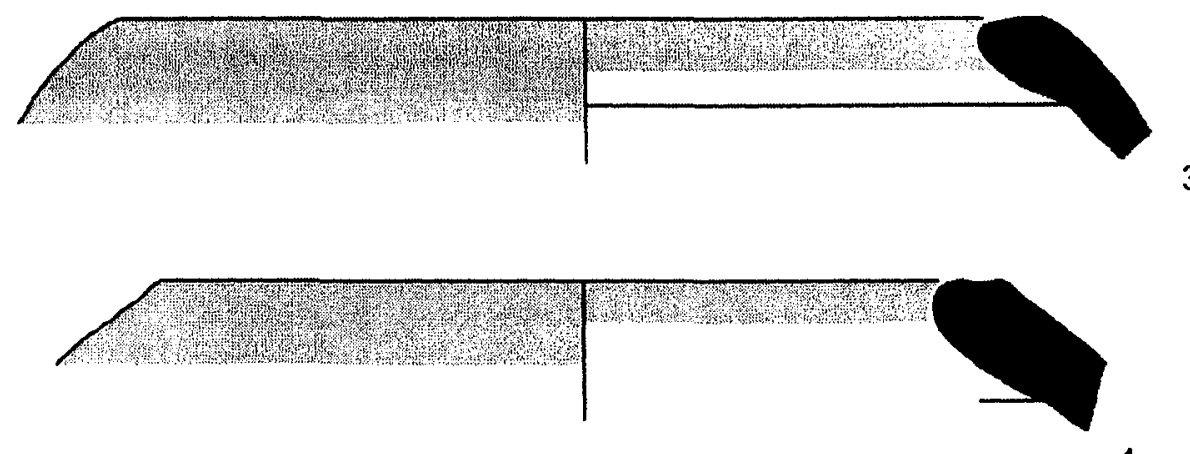

4
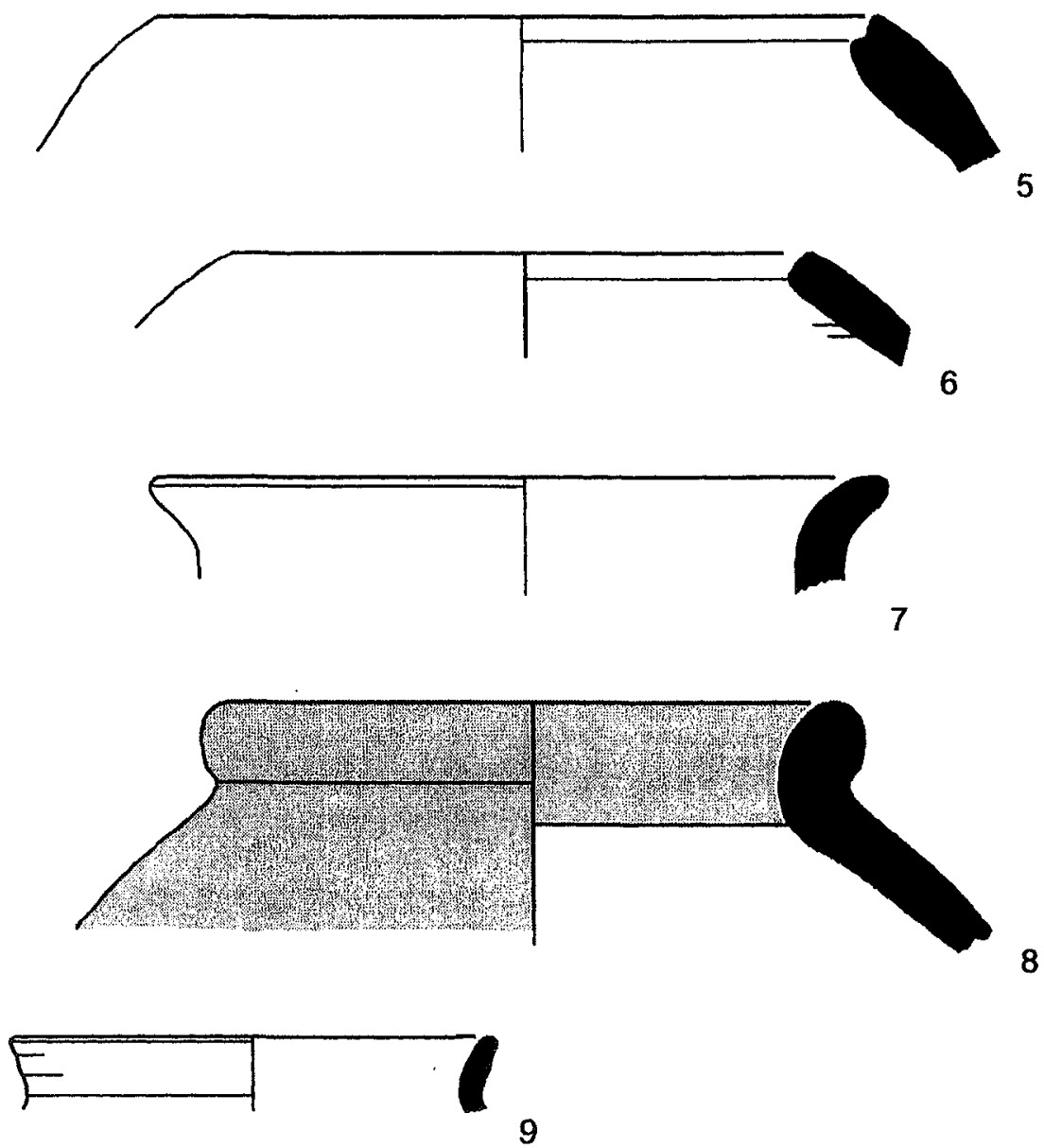

PLATE 148 (CONT.).

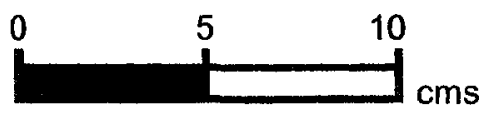




\begin{tabular}{|c|c|c|c|c|c|c|c|}
\hline No & Reg & Square & Locus & Vessel & Part & $\begin{array}{l}\text { Body } \\
\text { Thick }\end{array}$ & Dia \\
\hline 1 & 1885 & NW 9-1 & 63 & JUG & NECK & 10 & 4 \\
\hline 2 & 1887 & NW 9-1 & 63 & UD & BOD & 7 & $N$ \\
\hline 3 & 1880 & NW 9-1 & 63 & UD & $\mathrm{H} 27$ & 7 & $\mathbf{N}$ \\
\hline 4 & 1879 & NW 9-1 & 63 & UD & $\mathrm{H} 27$ & 8 & $N$ \\
\hline 5 & 1884 & NW 9-1 & 63 & UD & $\mathrm{B} 12$ & 13 & 26 \\
\hline 6 & 1883 & NW 9-1 & 63 & UD & $\mathrm{B} 11$ & 14 & 26 \\
\hline 7 & 1886 & NW 9-1 & 63 & UD & B11 & 9 & 11 \\
\hline 8 & 1869 & NW 9-1 & 63 & UD & $\mathrm{B} 11$ & 9 & 5 \\
\hline 9 & 1882 & NW 9-1 & 63 & JUG & $\mathrm{B} 12$ & 6 & 6 \\
\hline 10 & 1873 & NW 9-1 & 63 & PLATTER BOWL & R53 & 11 & 45 \\
\hline 11 & 1870 & NW 9-1 & 63 & HOLE MOUTH BOWL & $\mathrm{R} 19$ & 13 & 50 \\
\hline
\end{tabular}

\begin{tabular}{lllll}
\hline No Fabric Color & Core Orient & Core Color Core Thick & $\begin{array}{l}\text { Fabric } \\
\text { Family }\end{array}$
\end{tabular}

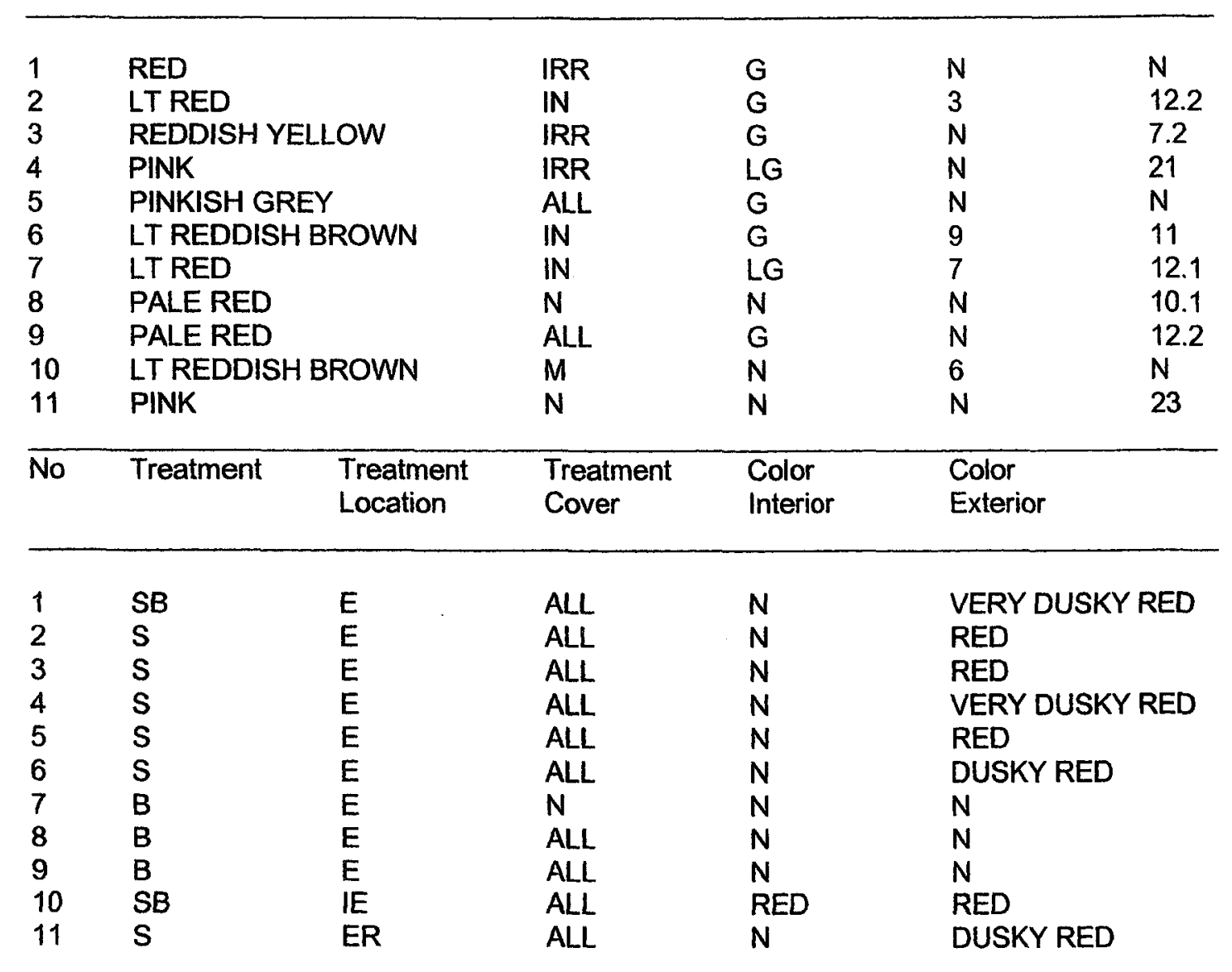

PLATE 149. FIELD C. PHASE 2A (EB II). 


\section{Other}

1 Metallic Ware.

2 Metallic Ware.

7 Metallic Ware.

9 Metallic Ware.

10 Metallic Ware.

PLATE 149 (CONT.). 

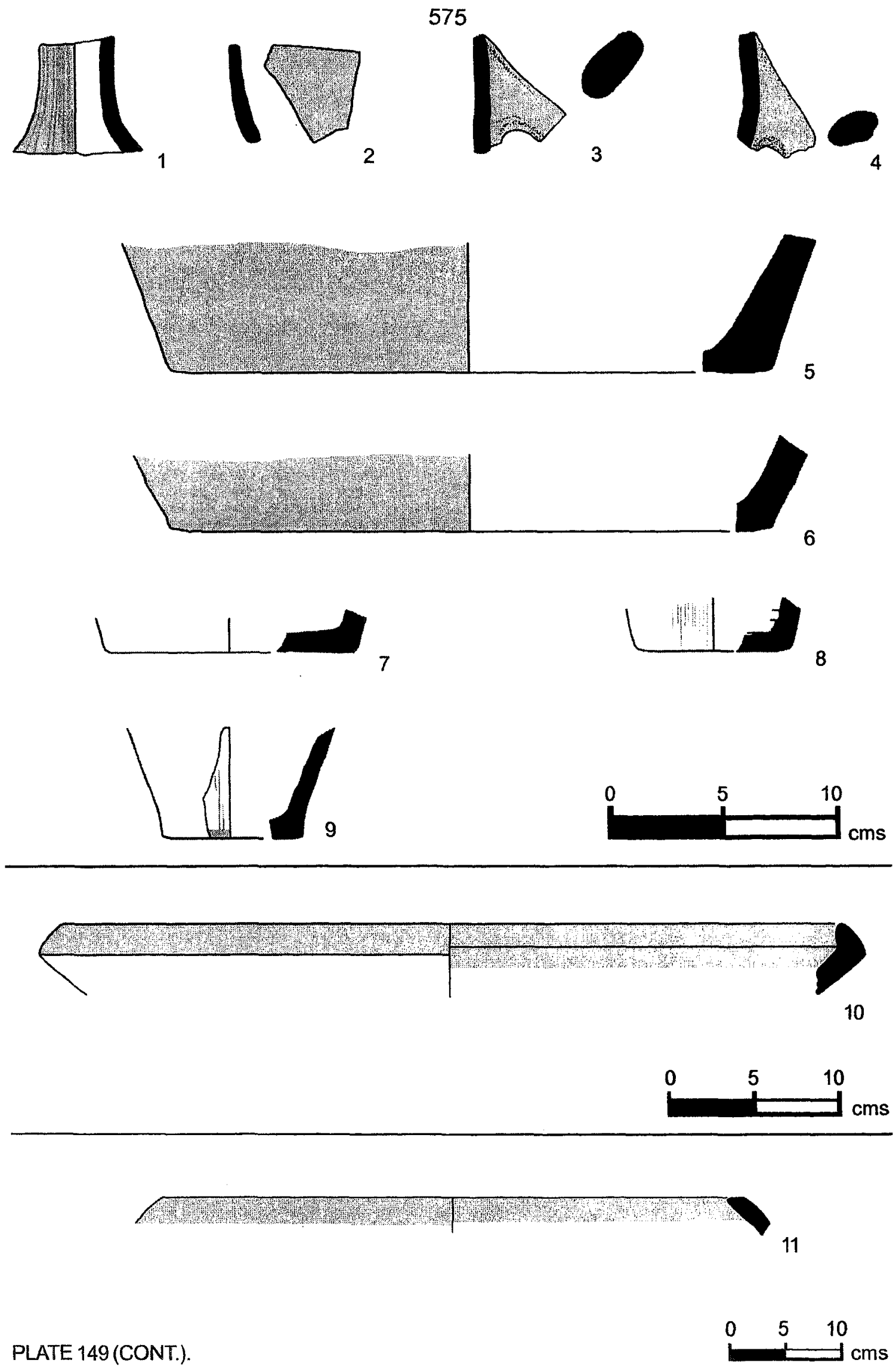
576

\begin{tabular}{llllllll}
\hline No & Reg & Square & Locus & Vessel & Part & $\begin{array}{l}\text { Body } \\
\text { Thick }\end{array}$ & Dia \\
\hline 1 & 1557 & SW 6-1 & 115 & LEDGE RIM BOWL & R51 & 11 & 18 \\
2 & 1558 & SW 6-1 & 115 & NECKED JAR & R43 & 7 & 11 \\
3 & 1555 & SW 6-1 & 115 & NECKED JAR & R43 & 6 & 12 \\
4 & 1559 & SW 6-1 & 115 & UD & H27 & 9 & $\mathrm{~N}$ \\
5 & 1560 & SW 6-1 & 115 & UD & B23 & 7 & N \\
6 & 1561 & SW 6-1 & 115 & UD & BOD & 9 & N \\
7 & 1562 & SW 6-1 & 115 & UD & BOD & 5 & N \\
8 & 1556 & SW 6-1 & 115 & PLATTER BOWL & R56 & 9 & 40 \\
\hline No & Fabric Color & & Core Orient Core Color & Core Thick & Fabric \\
& & & & & & & Family
\end{tabular}

\begin{tabular}{|c|c|c|c|c|c|c|}
\hline 1 & \multicolumn{2}{|l|}{ PINK } & $M$ & LG & 4 & 23 \\
\hline 2 & \multicolumn{2}{|c|}{ LT REDDISH BROWN } & $N$ & $\mathrm{~N}$ & $\mathrm{~N}$ & 2.1 \\
\hline 3 & \multicolumn{2}{|c|}{ LT RED } & $M$ & LG & 3 & $\mathbf{N}$ \\
\hline 4 & \multicolumn{2}{|l|}{ PINK } & IN & $G$ & 4 & $N$ \\
\hline 5 & \multicolumn{2}{|l|}{ PINK } & $\mathrm{N}$ & $\mathbf{N}$ & $\mathbf{N}$ & $\mathbf{N}$ \\
\hline 6 & \multicolumn{2}{|l|}{ RED } & ALL & $\mathbf{G}$ & $N$ & 12.2 \\
\hline 7 & \multicolumn{2}{|l|}{ LTRED } & $\mathbf{N}$ & $\mathbf{N}$ & $\mathbf{N}$ & 12.1 \\
\hline 8 & \multicolumn{2}{|c|}{ LT REDDISH BROWN } & $N$ & $N$ & $N$ & 12.1 \\
\hline$\overline{\text { No }}$ & Treatment & $\begin{array}{l}\text { Treatment } \\
\text { Location }\end{array}$ & $\begin{array}{l}\text { Treatment } \\
\text { Cover }\end{array}$ & $\begin{array}{l}\text { Color } \\
\text { Interior }\end{array}$ & $\begin{array}{l}\text { Co } \\
\text { Ex }\end{array}$ & \\
\hline 1 & SB & $\mathrm{IE}$ & $N$ & RED & RE & \\
\hline 2 & $\mathrm{~S}$ & ER & ALL & $N$ & & LOW \\
\hline 3 & UN & $\mathrm{N}$ & $\mathrm{N}$ & $\mathbf{N}$ & $\mathbf{N}$ & \\
\hline 4 & UN & $\mathbf{N}$ & $N$ & $N$ & $\mathrm{~N}$ & \\
\hline 5 & $s$ & $E$ & ALL & $N$ & RE & \\
\hline 6 & 1 & $E$ & ALL & $N$ & $\mathbf{N}$ & \\
\hline 7 & 1 & $E$ & ALL & $N$ & $\mathbf{N}$ & \\
\hline 8 & SB & $\mathbf{I R}$ & ALL & RED & $N$ & \\
\hline
\end{tabular}

\footnotetext{
1 Very rough exterior face.

3 Metallic Ware.

6 Combed Metallic Ware.

7 Combed Metallic Ware.

8 Deep groove where folded lip meets interior face.
}

PLATE 150. FIELD C. PHASE 2A (EB II). 

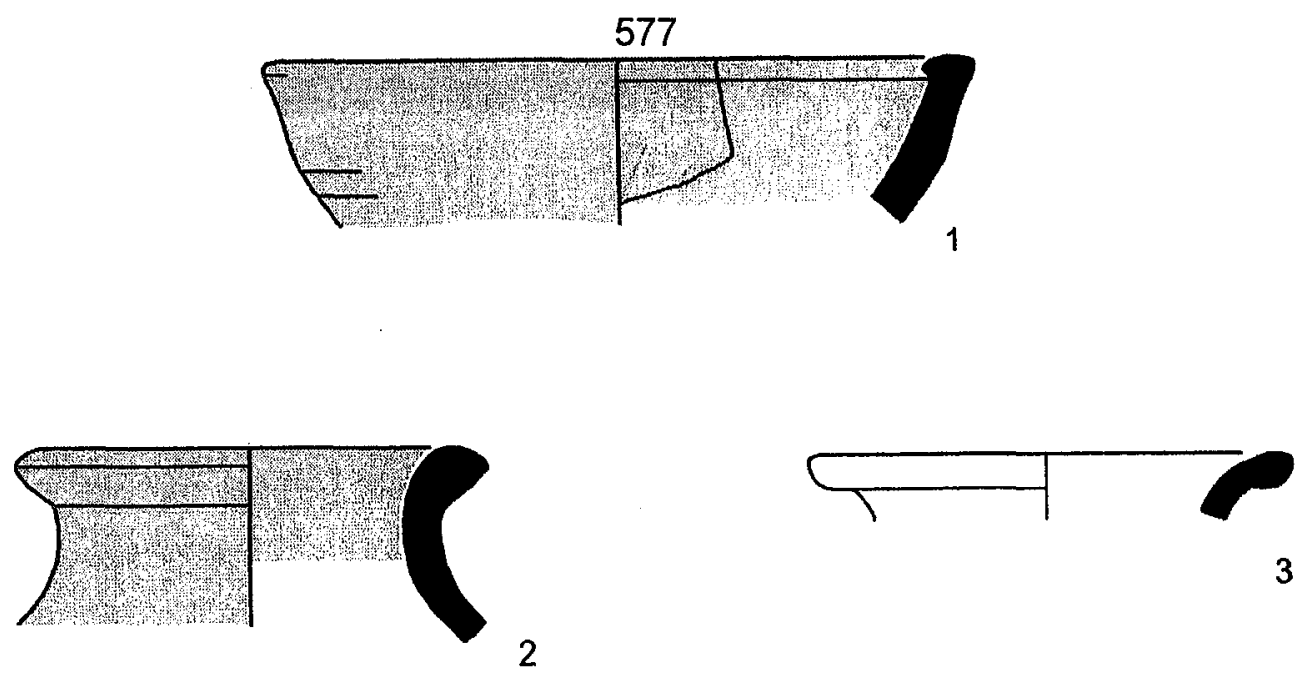

2
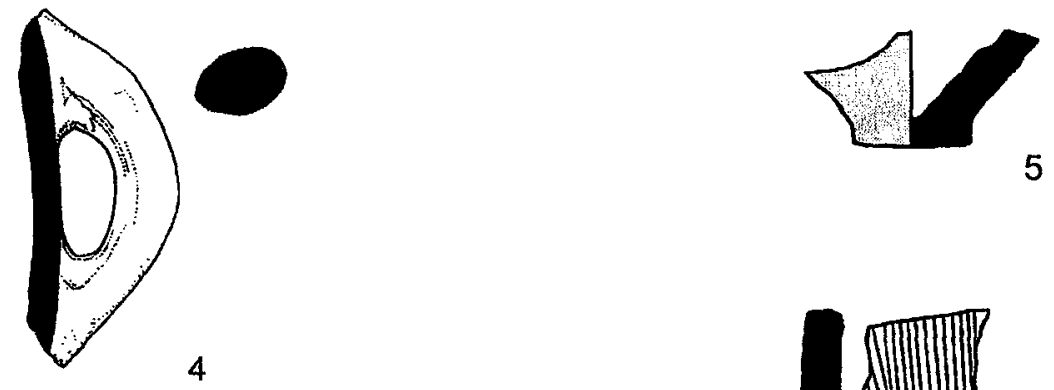

5

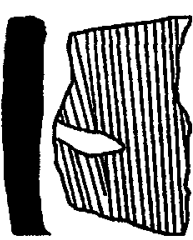

6

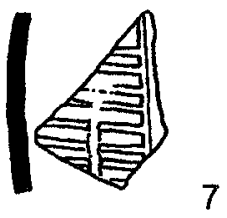

7
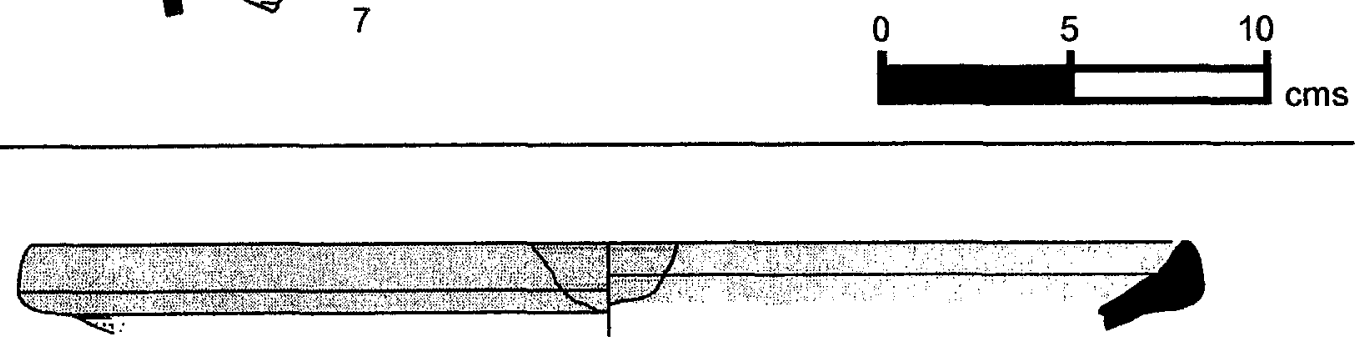

8

PLATE 150 (CONT.).

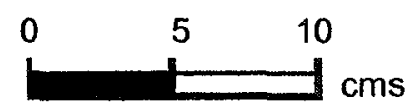




\begin{tabular}{llllllll}
\hline No & Reg & Square & Locus & Vessel & Part & $\begin{array}{c}\text { Body } \\
\text { Thick }\end{array}$ & Dia \\
\hline 1 & 1571 & SW 6-1 & 121 & BOWL & R50 & 11 & 22 \\
2 & 1578 & SW 6-1 & 121 & HOLE MOUTH JAR & R14 & 14 & 20 \\
3 & 1582 & SW 6-1 & 121 & HOLE MOUTH JAR & R18 & 12 & 20 \\
4 & 1585 & SW 6-1 & 121 & HOLE MOUTH JARIBOWL & R20 & 19 & 20 \\
5 & 1570 & SW 6-1 & 121 & HOLE MOUTH JAR & R07 & 11 & 18 \\
6 & 1574 & SW 6-1 & 121 & HOLE MOUTH BOWL & R02 & 9 & 14 \\
7 & 1580 & SW 6-1 & 121 & NECKED JAR & R43 & 8 & 26 \\
8 & 1584 & SW 6-1 & 121 & NECKED JAR & R40 & 16 & 18 \\
9 & 1575 & SW 6-1 & 121 & NECKED JAR & R42 & 14 & 18
\end{tabular}

\begin{tabular}{lllll}
\hline No Fabric Color & Core Orient & Core Color & Core Thick & Fabric \\
& & & Family
\end{tabular}

\begin{tabular}{|c|c|c|c|c|c|c|}
\hline 1 & \multirow{2}{*}{\multicolumn{2}{|c|}{$\begin{array}{l}\text { PINK } \\
\text { PALE RED }\end{array}$}} & $M$ & $G$ & 5 & $N$ \\
\hline 2 & & & EX & $\mathbf{G}$ & 10 & $\mathrm{~N}$ \\
\hline 3 & WEAK RED & & IN & G & 10 & $\mathrm{~N}$ \\
\hline 4 & \multicolumn{2}{|l|}{ LTRED } & M & LG & 6 & $\mathbf{N}$ \\
\hline 5 & \multicolumn{2}{|l|}{ LTRED } & $\mathbf{M}$ & G & 4 & $\mathrm{~N}$ \\
\hline 6 & \multicolumn{2}{|c|}{ REDDISH BROWN } & M & G & 5 & $\mathbf{N}$ \\
\hline 7 & \multicolumn{2}{|l|}{ LT RED } & $M$ & $\mathbf{G}$ & 4 & $\mathrm{~N}$ \\
\hline 8 & \multicolumn{2}{|l|}{ PINK } & $\mathrm{N}$ & $\mathbf{N}$ & $\mathrm{N}$ & $\mathbf{N}$ \\
\hline 9 & \multicolumn{2}{|l|}{ PINK } & $N$ & $\mathrm{~N}$ & $\mathrm{~N}$ & $\mathrm{~N}$ \\
\hline No & Treatment & $\begin{array}{l}\text { Treatment } \\
\text { Location }\end{array}$ & $\begin{array}{l}\text { Treatment } \\
\text { Cover }\end{array}$ & $\begin{array}{l}\text { Color } \\
\text { Interior }\end{array}$ & $\begin{array}{l}\text { Color } \\
\text { Exterior }\end{array}$ & \\
\hline 1 & WASH & IE & ALL & WHITE & WHITE & \\
\hline 2 & UN & $\mathrm{N}$ & $\mathbf{N}$ & $\mathrm{N}$ & $\mathrm{N}$ & \\
\hline 3 & UN & $\mathrm{N}$ & $\mathrm{N}$ & $\mathrm{N}$ & $\mathrm{N}$ & \\
\hline 4 & UN & $\mathrm{N}$ & $\mathrm{N}$ & $\mathrm{N}$ & $\mathbf{N}$ & \\
\hline 5 & UN & $\mathbf{N}$ & $\mathbf{N}$ & $\mathbf{N}$ & $\mathrm{N}$ & \\
\hline 6 & UN & $\mathbf{N}$ & $\mathrm{N}$ & $\mathbf{N}$ & $\mathrm{N}$ & \\
\hline 7 & UN & $\mathrm{N}$ & $\mathrm{N}$ & $\mathbf{N}$ & $\mathrm{N}$ & \\
\hline 8 & $\mathrm{~S}$ & ER & ALL & $\mathrm{N}$ & WEAK RED & \\
\hline 9 & $s$ & ER & $N$ & $\mathrm{~N}$ & WEAK RED & \\
\hline
\end{tabular}

1 Rim interiorlexterior wet-smoothed; possible scrape lines on interior face; base appears scraped and smoothed.

4 Sample too small to confirm stance or diameter.

6 Fine lines suggest motion used to finish rim; horizontal marks on interior face show tool dragging.

$7 \quad$ Metallic Ware.

PLATE 151. FIELD C. PHASE 2A (EB II). 

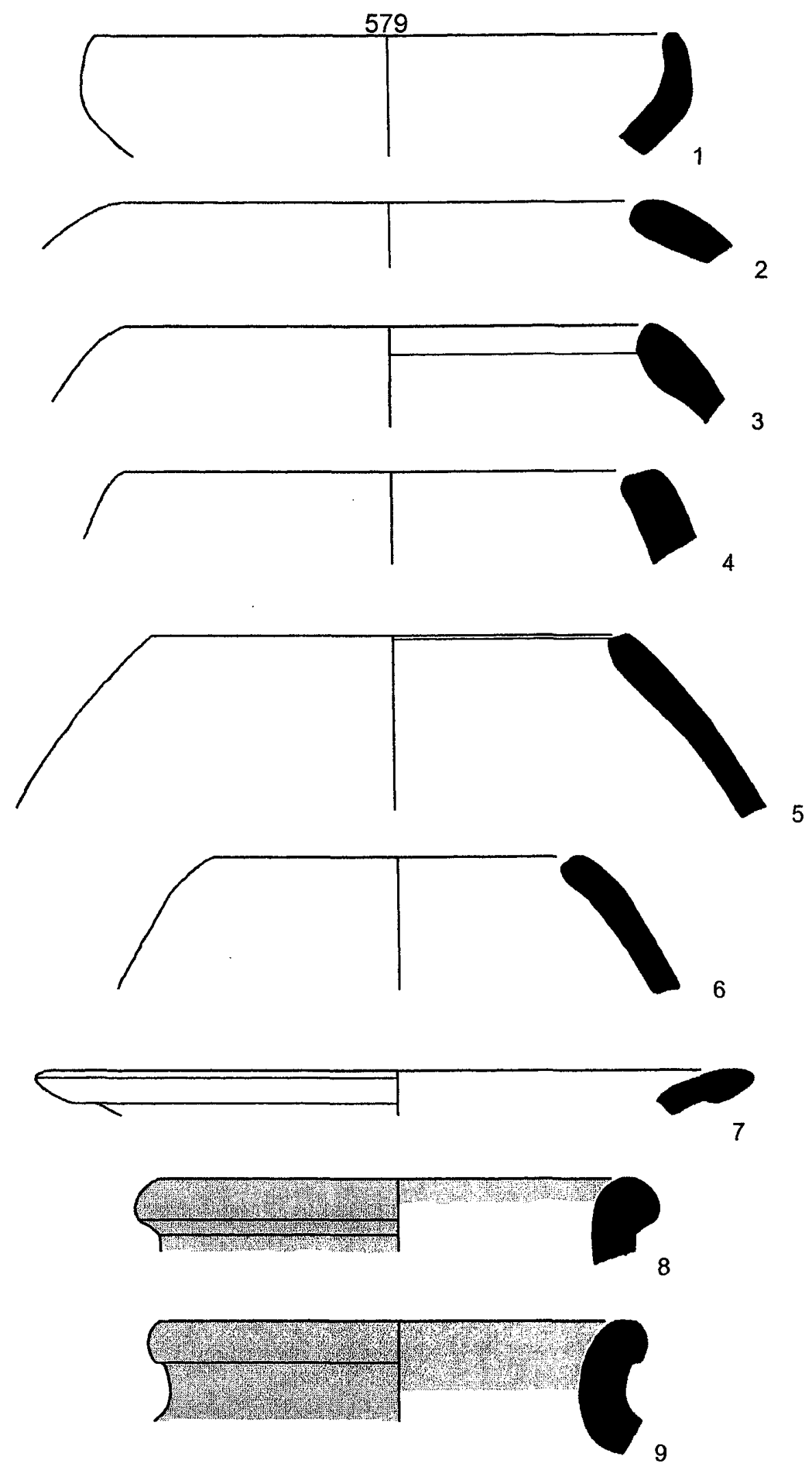

PLATE 151 (CONT.).

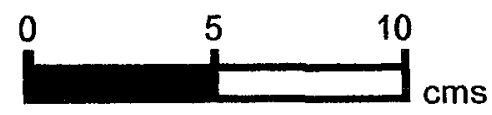




\begin{tabular}{llllllll}
\hline No & Reg & Square & Locus & Vessel & Part & $\begin{array}{c}\text { Body } \\
\text { Thick }\end{array}$ & Dia \\
\hline 1 & 1579 & SW 6-1 & 121 & NECKED JAR & R42 & N & 18 \\
2 & 1581 & SW 6-1 & 121 & CHANNELED RIM JAR & R35 & 8 & 17 \\
3 & 1572 & SW 6-1 & 121 & NECKED JAR & R43 & 8 & 11 \\
4 & 1577 & SW 6-1 & 121 & CHANNELED RIM JAR & R35 & 7 & 9 \\
5 & 1586 & SW 6-1 & 121 & UD & B12 & 7 & 18 \\
6 & 1583 & SW 6-1 & 121 & PLATTER BOWL & R53 & 11 & 46 \\
7 & 1573 & SW 6-1 & 121 & PLATTER BOWL & R56 & 12 & 44 \\
8 & 1576 & SW 6-1 & 121 & PLATTER BOWL & R53 & 11 & 40
\end{tabular}

\begin{tabular}{lllll}
\hline No Fabric Color & Core Orient & Core Color Core Thick & Fabric \\
& & & Family
\end{tabular}

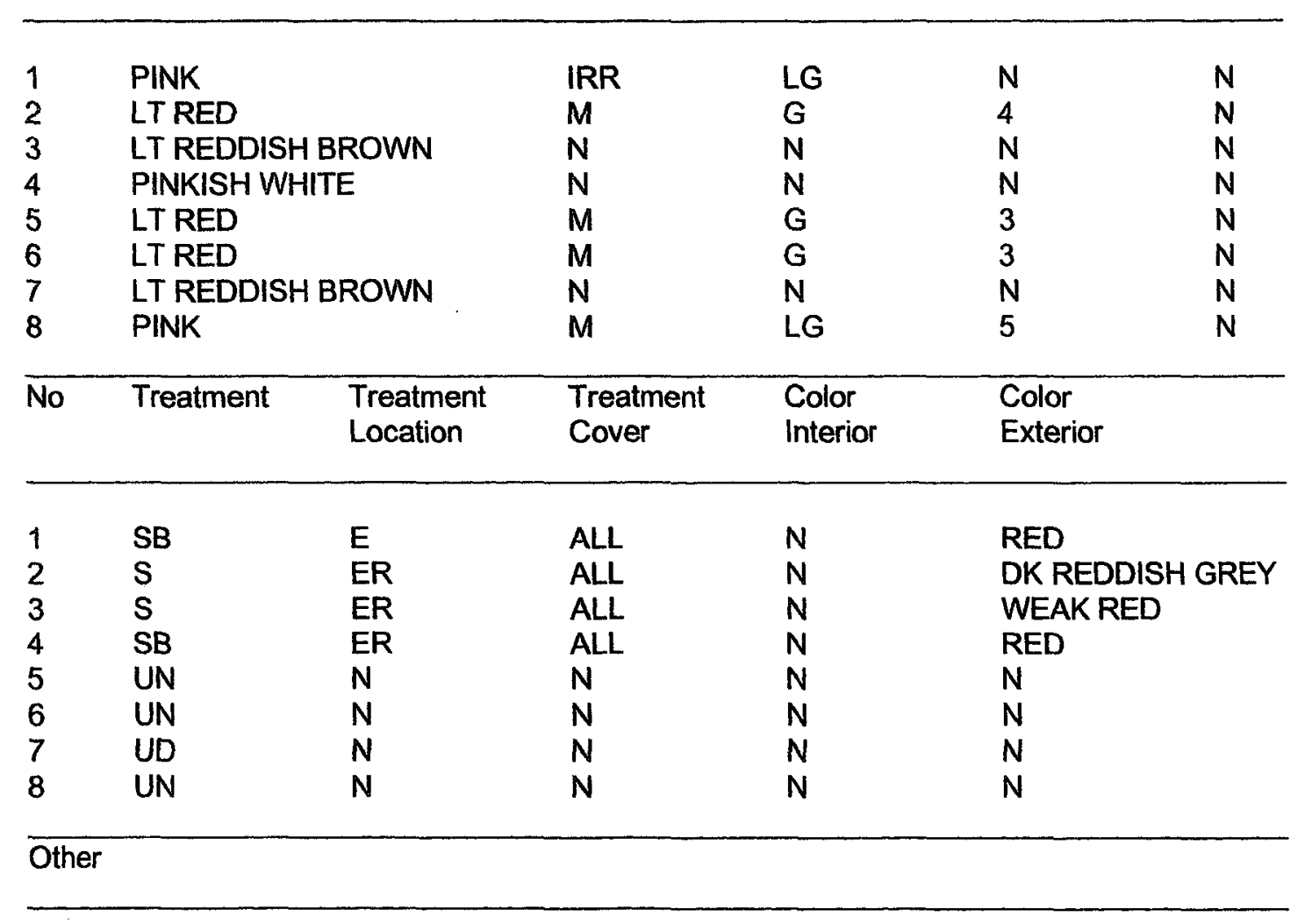

$5 \quad$ Interior face displays pressed finger marks in vertical strokes; Metallic Ware.

6 Interior face displays faint marks left by radial wiping; wheel burnish on circumference of rim; exterior face displays concavity in marginal band; Metallic Ware.

7 Several examples of "dragging" inclusions may be seen on base following a clockwise direction; some tool marks visible.

PLATE 152. FIELD C. PHASE 2A (EB II). 

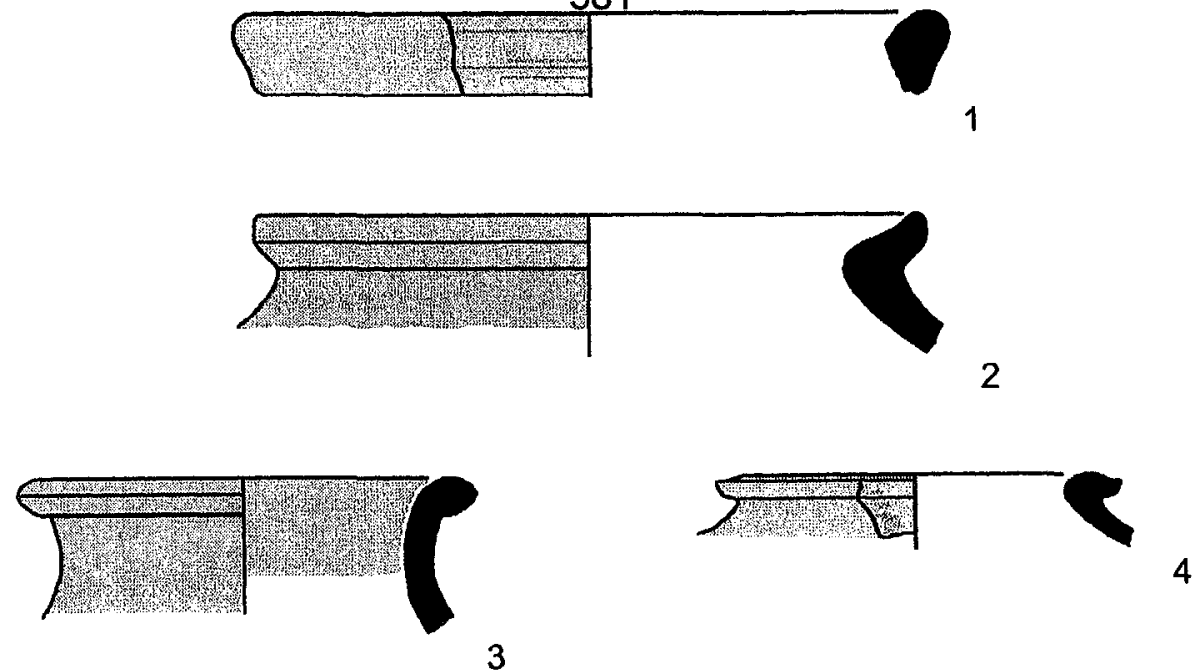

3
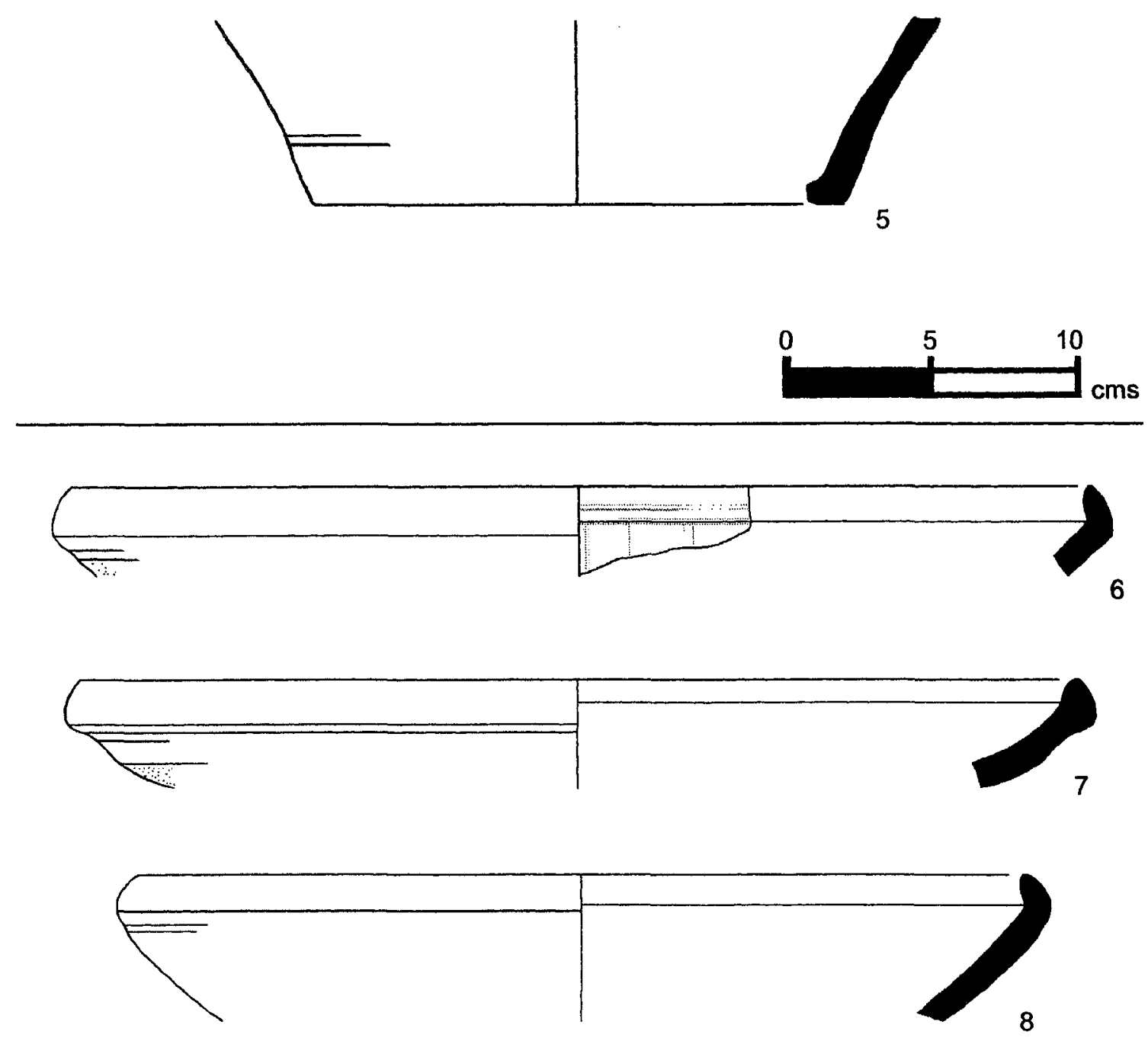

PLATE 152 (CONT.).

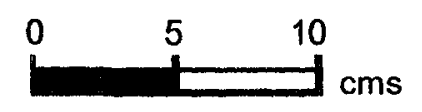


582

\begin{tabular}{llllllll}
\hline No & Reg & Square & Locus & Vessel & Part & $\begin{array}{c}\text { Body } \\
\text { Thick }\end{array}$ & Dia \\
\hline & & & & & & & \\
1 & 1549 & SW 6-1 & 123 & PLATTER BOWL & R53 & 8 & 32 \\
2 & 1548 & SW 6-1 & 123 & PLATTER BOWL & R56 & 10 & 40 \\
3 & 1550 & SW 6-1 & 123 & HOLE MOUTH JAR & R01 & 14 & 20 \\
4 & 1551 & SW 6-1 & 123 & PLATTER BOWL & R56 & 9 & 35
\end{tabular}

\begin{tabular}{lllll}
\hline No Fabric Color Core Orient Core Color Core Thick & Fabric \\
Family
\end{tabular}

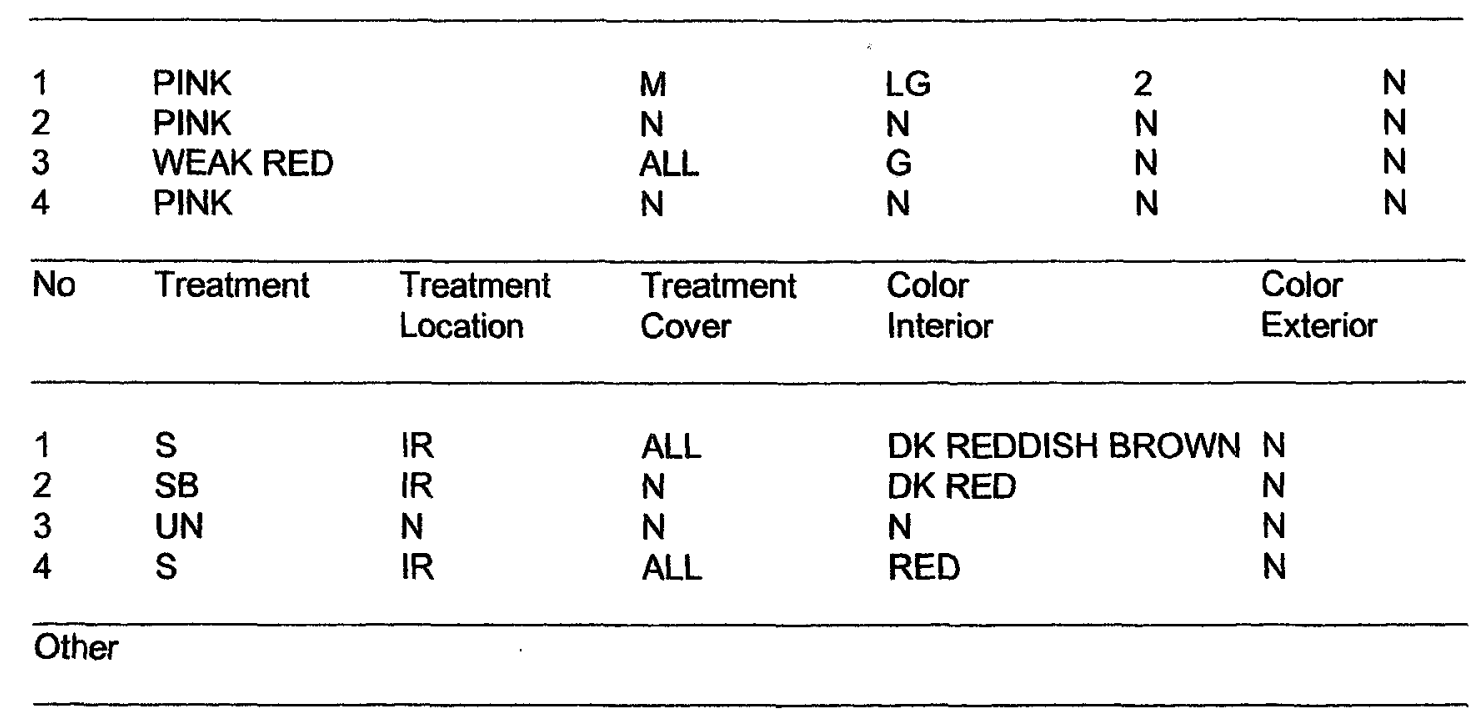

2 Exterior face radially burnished; fine lines of wet slip visible in marginal concavity; small clay "bulges" on large inclusion suggest concavity turned in a clockwise direction.

3 Surface burn visible.

4 Lines of wet-smoothing in marginal concavity are clear.

PLATE 153. FIELD C. PHASE 2A (EB II). 

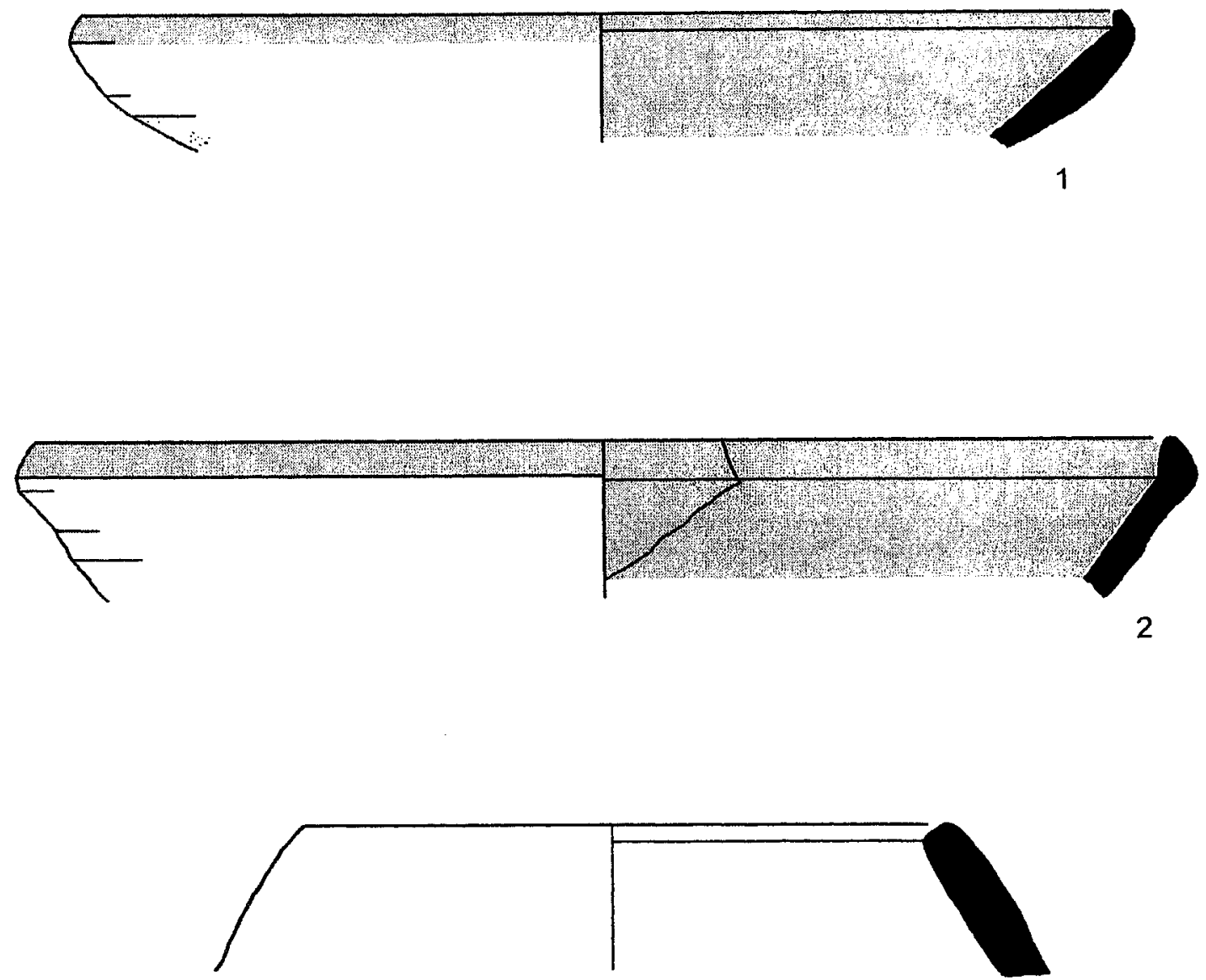

3

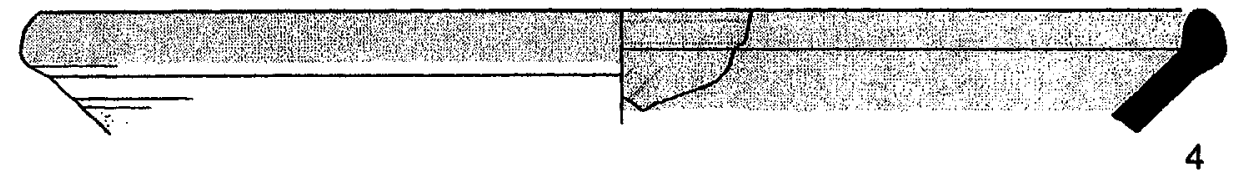

PLATE 153 (CONT.).

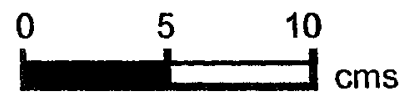




\begin{tabular}{llllllll}
\hline No & Reg & Square & Locus & Vessel & Part & $\begin{array}{l}\text { Body } \\
\text { Thick }\end{array}$ & $\begin{array}{c}\text { Dia } \\
\end{array}$ \\
& & & & & & & \\
1 & 1540 & SW 6-1 & 155 & PLATTER BOWL & R54 & 10 & 38 \\
2 & 1535 & SW 6-1 & 155 & CARINATED BOWL & R58 & 5 & 24 \\
3 & 1537 & SW 6-1 & 155 & LEDGE RIM BOWL & R51 & 7 & 20 \\
4 & 1534 & SW 6-1 & 155 & BOWL & R50 & 7 & 10 \\
5 & 1539 & SW 6-1 & 155 & CARINATED BOWL & R58 & 6 & 14 \\
6 & 1536 & SW 6-1 & 155 & HOLE MOUTH BOWL & R07 & 10 & 20 \\
7 & 1542 & SW 6-1 & 155 & HOLE MOUTH JAR & R14 & 10 & 18 \\
8 & 1529 & SW 6-1 & 155 & HOLE MOUTH BOWL & R01 & 8 & 10 \\
9 & 1544 & SW 6-1 & 155 & UD & H27 & 9 & N \\
10 & 1543 & SW 6-1 & 155 & UD & H27 & 5 & N
\end{tabular}

\begin{tabular}{lllll}
\hline No Fabric Color Core Orient Core Color Core Thick & Fabric \\
Family
\end{tabular}

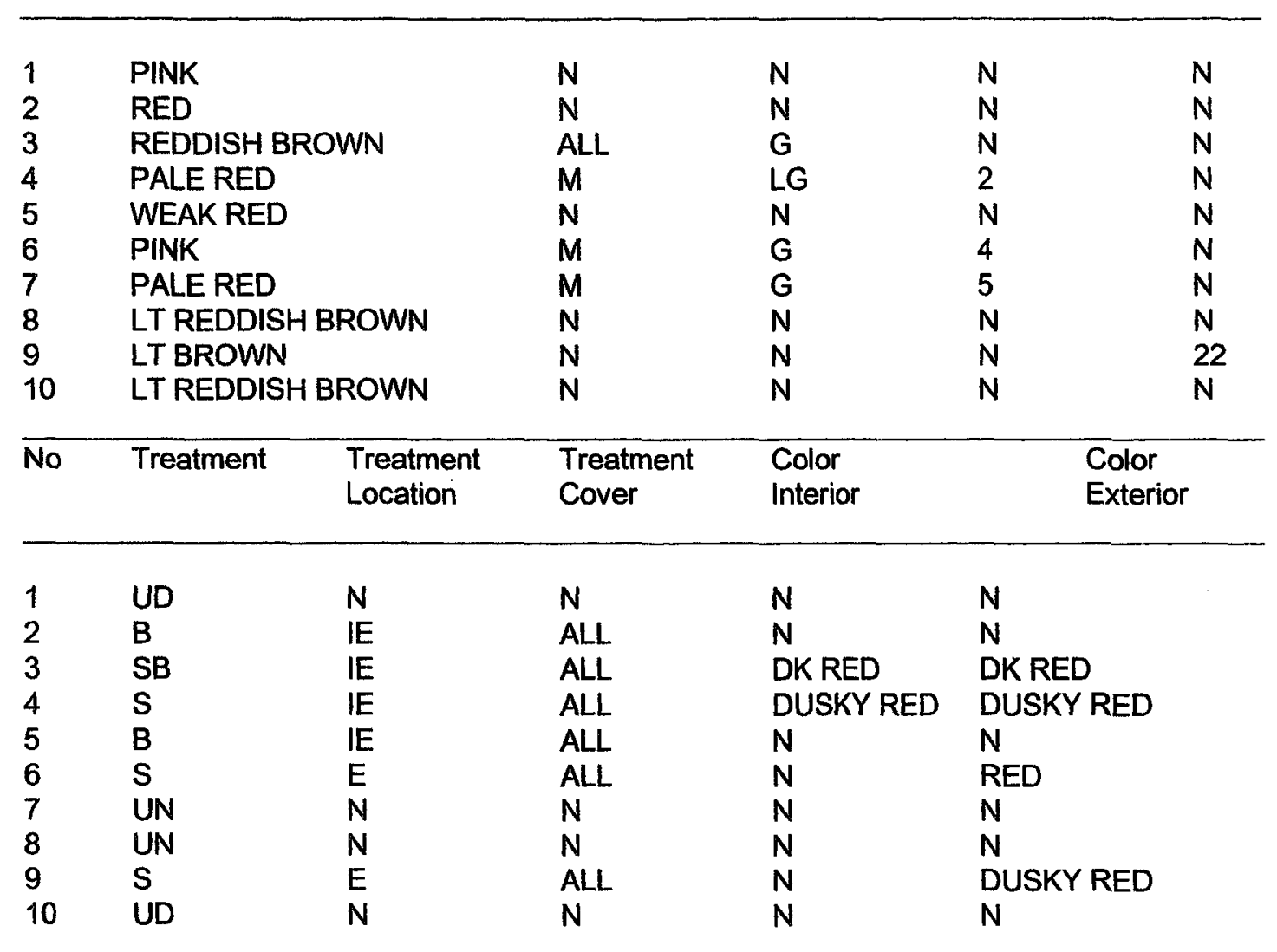

PLATE 154. FIELD C. PHASE 2A (EB II). 
Other

1 Bore hole beneath rim, ca. $5 \mathrm{~mm}$ dia; dry-scrape marks below smoothed rim horizon on exterior.

2 Interior and exterior are well burnished; scraping visible below keel; Metallic Ware.

3 Highly burnished.

$4 \quad$ Burn on rim suggests use as lamp.

5 Fine smoothing lines visible on rim; scraping marks visible below keel; Metallic Ware.

7 Surface burn visible.

8 Lines on interior/exterior suggest motion used to finish rim.

9 Three vertical slashes on shoulder.

PLATE 154 (CONT.).

Reproduced with permission of the copyright owner. Further reproduction prohibited without permission. 

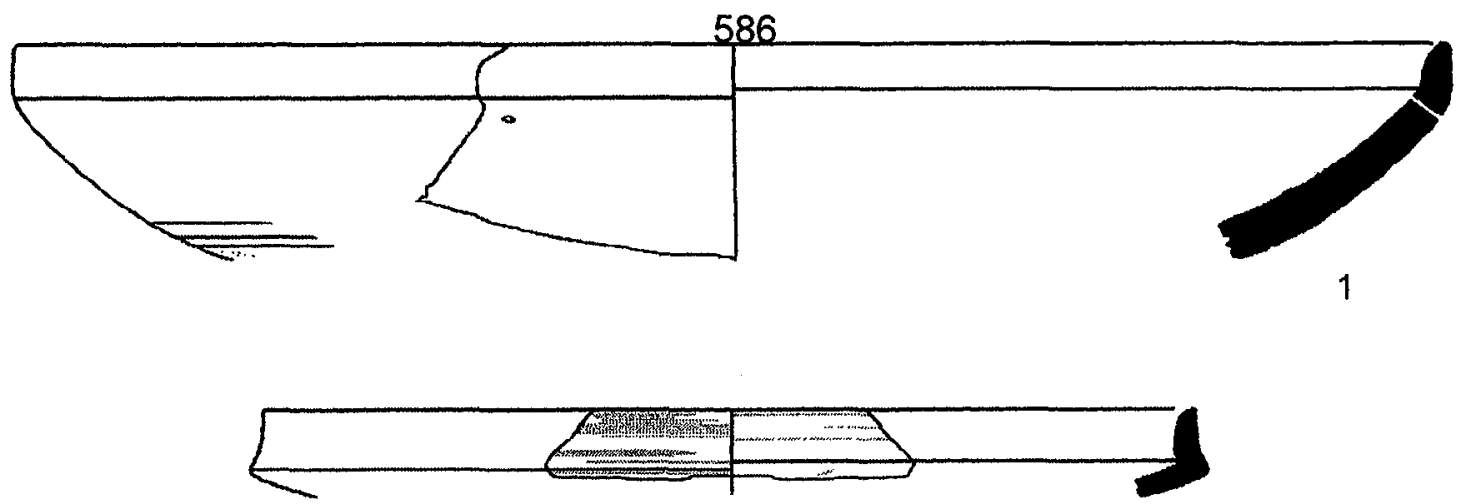

2
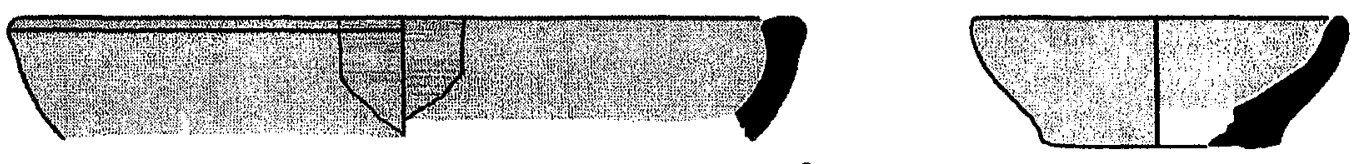

3

4
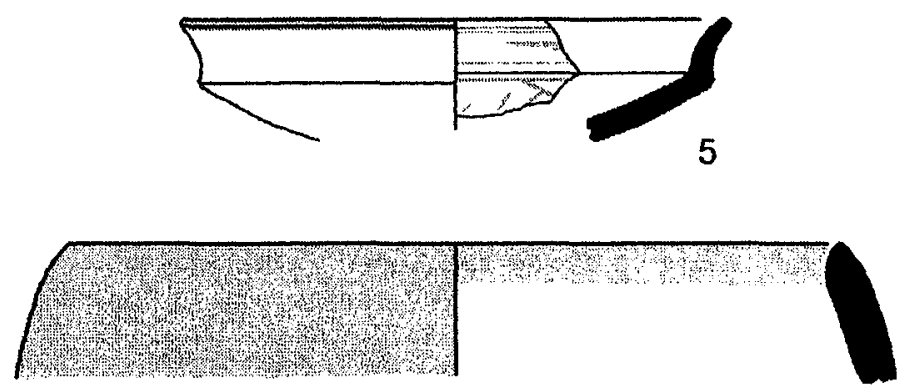

6
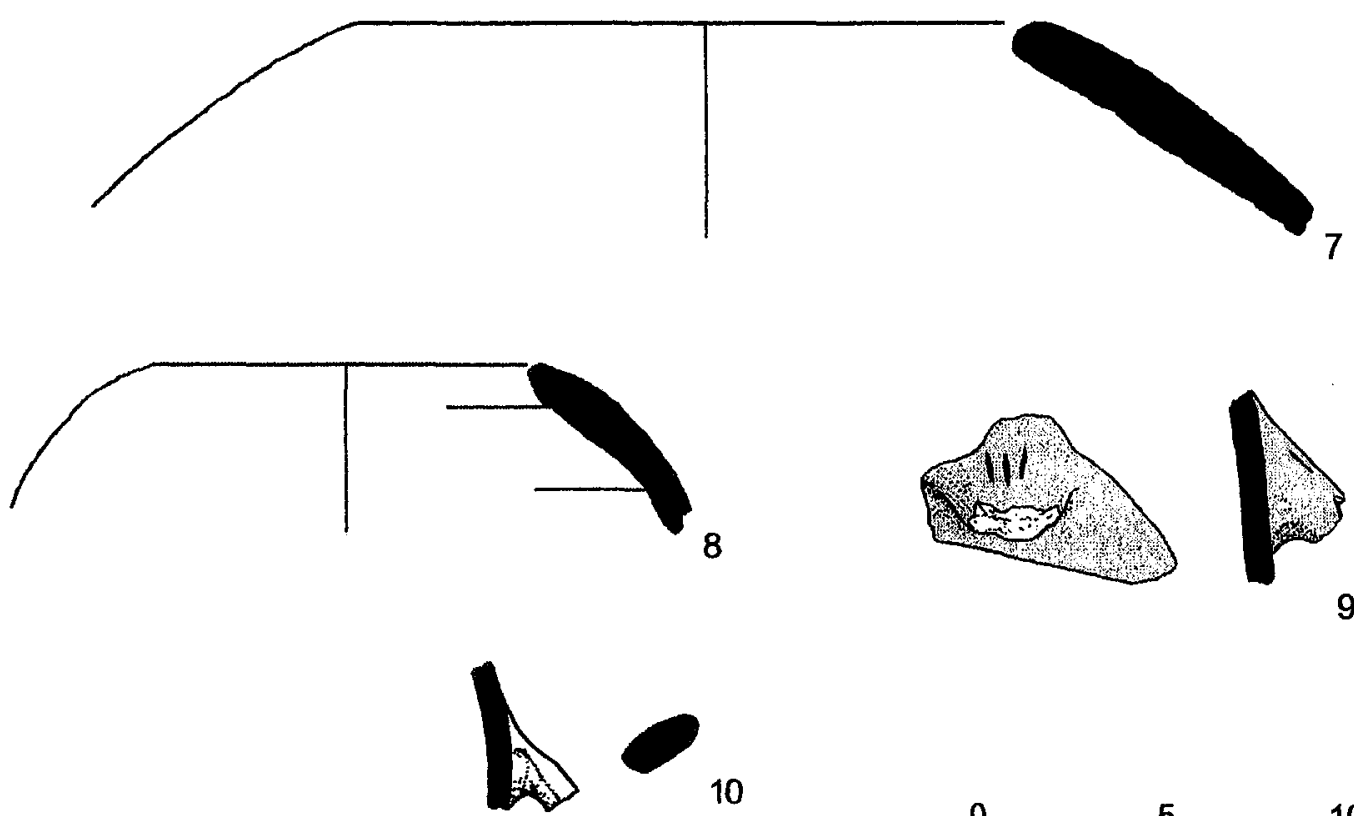

PLATE 154 (CONT.).

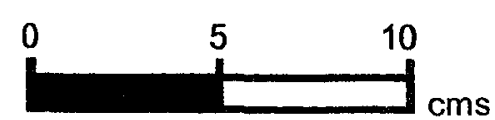




\begin{tabular}{llllllll}
\hline No & Reg & Square & Locus & Vessel & Part & $\begin{array}{l}\text { Body } \\
\text { Thick }\end{array}$ & Dia \\
\hline & & & & & & & \\
1 & 1533 & SW 6-1 & 155 & NECKED JAR & R40 & 13 & 20 \\
2 & 1532 & SW 6-1 & 155 & NECKED JAR & R42 & 13 & 20 \\
3 & 1531 & SW 6-1 & 155 & NECKED JAR & R32 & 7 & 13 \\
4 & 1538 & SW 6-1 & 155 & NECKED JAR & R43 & 6 & 10 \\
5 & 1546 & SW 6-1 & 155 & UD & B12 & 20 & 14 \\
6 & 1545 & SW 6-1 & 155 & UD & B12 & 9 & 16 \\
7 & 1530 & SW 6-1 & 155 & PLATTER BOWL & R53 & 9 & 48 \\
8 & 1528 & SW 6-1 & 155 & PLATTER BOWL & R56 & 9 & 48 \\
9 & 1541 & SW 6-1 & 155 & HOLE MOUTH BOWL & R12 & 12 & 44
\end{tabular}

\begin{tabular}{lllll}
\hline No Fabric Color & Core Orient & Core Color Core Thick & $\begin{array}{l}\text { Fabric } \\
\text { Family }\end{array}$
\end{tabular}

\begin{tabular}{|c|c|c|c|c|c|c|}
\hline 1 & \multicolumn{2}{|c|}{ LT REDDISH BROWN } & M & LG & 5 & $\mathrm{~N}$ \\
\hline 2 & \multicolumn{2}{|l|}{ PALE RED } & ALL & G & $\mathbf{N}$ & $\mathrm{N}$ \\
\hline 3 & \multicolumn{2}{|l|}{ PINK } & $N$ & $\mathrm{~N}$ & $\mathbf{N}$ & $N$ \\
\hline 4 & \multicolumn{2}{|l|}{ LT RED } & $N$ & $\mathbf{N}$ & $\mathbf{N}$ & $\mathrm{N}$ \\
\hline 5 & \multicolumn{2}{|l|}{ PINK } & IRR & $\mathbf{G}$ & $\mathrm{N}$ & $\mathrm{N}$ \\
\hline 6 & \multicolumn{2}{|l|}{ LT RED } & $N$ & $N$ & $N$ & $\mathrm{~N}$ \\
\hline 7 & \multicolumn{2}{|l|}{ LT RED } & $M$ & G & 3 & $\mathrm{~N}$ \\
\hline 8 & \multicolumn{2}{|l|}{ PINK } & IRR & LG & $N$ & $\mathrm{~N}$ \\
\hline 9 & \multicolumn{2}{|l|}{ PINK } & ALL & LG & $N$ & $N$ \\
\hline No & Treatment & $\begin{array}{l}\text { Treatment } \\
\text { Location }\end{array}$ & $\begin{array}{l}\text { Treatment } \\
\text { Cover }\end{array}$ & $\begin{array}{l}\text { Color } \\
\text { Interior }\end{array}$ & $\begin{array}{l}\text { Color } \\
\text { Exterior }\end{array}$ & \\
\hline 1 & $S$ & ER & ALL & $N$ & RED & \\
\hline 2 & $S$ & $E$ & ALL & $N$ & WEAK RED & \\
\hline 3 & WASH & $E$ & ALL & $\mathbf{N}$ & WHITE & \\
\hline 4 & UN & $N$ & $\mathbf{N}$ & $\mathbf{N}$ & $\mathbf{N}$ & \\
\hline 5 & UD & $N$ & $N$ & $\mathbf{N}$ & $\mathbf{N}$ & \\
\hline 6 & 1 & $E$ & ALL & $\mathbf{N}$ & $N$ & \\
\hline 7 & B & $\mathbb{I E}$ & $A L L$ & $N$ & $N$ & \\
\hline 8 & SB & $\mathrm{IE}$ & ALL & DK RED & DK RED & \\
\hline 9 & $S$ & ER & ALL & $N$ & RED & \\
\hline
\end{tabular}

PLATE 155. FIELD C. PHASE 2A (EB II). 
Other

1 Voids in break suggest that the rim was rolled outwardly and lip sealed against exterior wall in finishing motions.

4 Metallic Ware.

5 Surface burn visible.

$6 \quad$ Combed Metallic Ware.

7 Metallic Ware.

8 Interior face appears burnished in several directions and possibly wiped radially; deep concavity under rim.

$9 \quad$ Surface burn visible.

PLATE 155 (CONT.). 

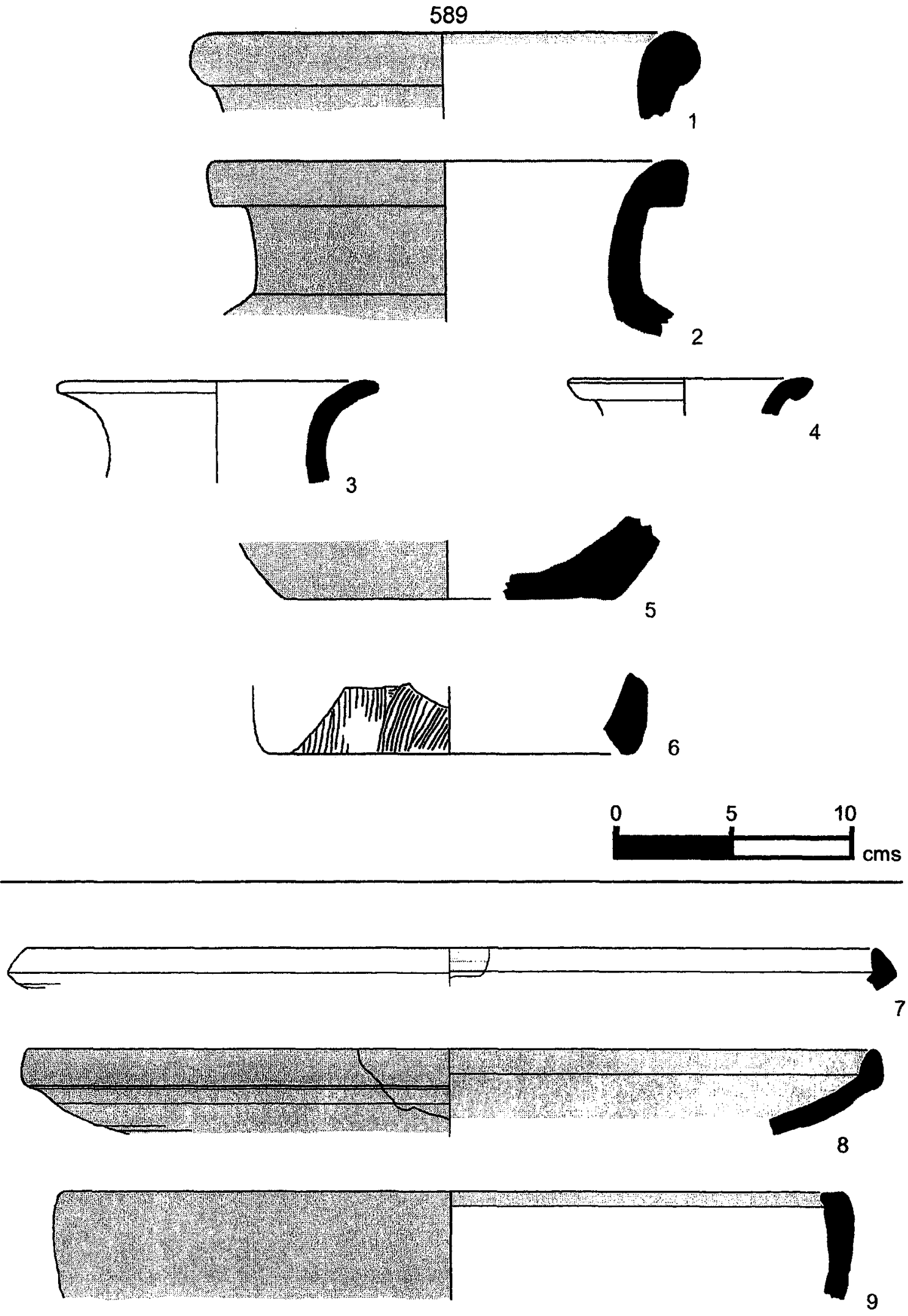

PLATE 155 (CONT.).

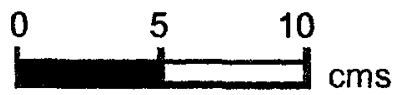




\begin{tabular}{llllllll}
\hline No & Reg & Square & Locus & Vessel & Part & $\begin{array}{c}\text { Body } \\
\text { Thick }\end{array}$ & $\begin{array}{c}\text { Dia } \\
\end{array}$ \\
& & & & & & & \\
1 & 1517 & SW 6-1 & 162 & LEDGE RIM BOWL & R52 & 10 & 33 \\
2 & 1502 & SW 6-1 & 162 & LEDGE RIM BOWL & R53 & 9 & 25 \\
3 & 1501 & SW 6-1 & 162 & LEDGE RIM BOWL & R51 & 7 & 22 \\
4 & 1504 & SW 6-1 & 162 & BOWL & R52 & 5 & 12 \\
5 & 1516 & SW 6-1 & 162 & BOWL & R50 & 5 & 20 \\
6 & 1510 & SW 6-1 & 162 & LEDGE RIM BOWL & R53 & 6 & 15 \\
7 & 1503 & SW 6-1 & 162 & HOLE MOUTH JAR & R11 & 8 & 17 \\
8 & 1507 & SW 6-1 & 162 & HOLE MOUTH JAR & R14 & 7 & 15 \\
9 & 1511 & SW 6-1 & 162 & HOLE MOUTH BOWL & R01 & 9 & 15 \\
10 & 1506 & SW 6-1 & 162 & HOLE MOUTH JAR & R04 & 9 & 13
\end{tabular}

\begin{tabular}{lllll}
\hline No Fabric Color & Core Orient & Core Color Core Thick & Fabric \\
& & & Family
\end{tabular}

\begin{tabular}{|c|c|c|c|c|c|c|}
\hline 1 & \multicolumn{2}{|c|}{ LT REDDISH BROWN } & $N$ & $\mathbf{N}$ & $\mathrm{N}$ & 24 \\
\hline 2 & \multicolumn{2}{|l|}{ PINK } & $\mathbf{N}$ & $\mathbf{N}$ & $\mathrm{N}$ & 16 \\
\hline 3 & \multicolumn{2}{|l|}{ PALE RED } & $M$ & LG & 8 & $\mathrm{~N}$ \\
\hline 4 & \multicolumn{2}{|c|}{ LT REDDISH BROWN } & $\mathbf{N}$ & $\mathbf{N}$ & $\mathrm{N}$ & 23 \\
\hline 5 & \multicolumn{2}{|c|}{ PINK } & $\mathbf{N}$ & $\mathbf{N}$ & $\mathbf{N}$ & 23 \\
\hline 6 & \multicolumn{2}{|c|}{ LT REDDISH BROWN } & $M$ & G & 3 & 7.2 \\
\hline 7 & \multicolumn{2}{|c|}{ LT REDDISH BROWN } & ALL & $\mathbf{G}$ & $\mathrm{N}$ & 3 \\
\hline 8 & \multicolumn{2}{|l|}{ LT RED } & $\mathbf{N}$ & $\mathbf{N}$ & $\mathrm{N}$ & 10.1 \\
\hline 9 & \multicolumn{2}{|l|}{ WEAK RED } & $M$ & G & 5 & 5.1 \\
\hline 10 & \multicolumn{2}{|l|}{ WEAK RED } & EX & $\mathbf{G}$ & 5 & 5.1 \\
\hline No & Treatment & $\begin{array}{l}\text { Treatment } \\
\text { Location }\end{array}$ & $\begin{array}{l}\text { Treatment } \\
\text { Cover }\end{array}$ & $\begin{array}{l}\text { Color } \\
\text { Interior }\end{array}$ & $\begin{array}{l}\text { Color } \\
\text { Exterior }\end{array}$ & \\
\hline 1 & B & 1 & ALL & $\mathbf{N}$ & $N$ & \\
\hline 2 & SB & $\mathbb{I R}$ & NET & WEAK RED & $\mathbf{N}$ & \\
\hline 3 & SB & $\mathrm{IE}$ & $A L L$ & RED & $\mathrm{N}$ & \\
\hline 4 & UN & $\mathbf{N}$ & $N$ & $\mathrm{~N}$ & $\mathbf{N}$ & \\
\hline 5 & SB & IR & NET & RED & $\mathbf{N}$ & \\
\hline 6 & $\mathbf{S}$ & $\mathbb{R}$ & ALL & DUSKY RED & $N$ & \\
\hline 7 & UN & $\mathbf{N}$ & $\mathbf{N}$ & $\mathbf{N}$ & $\mathbf{N}$ & \\
\hline 8 & $\mathrm{~S}$ & E & ALL & $\mathrm{N}$ & DK RED & BROWN \\
\hline 9 & UN & $\bar{N}$ & $N$ & $\mathrm{~N}$ & $N$ & \\
\hline 10 & UN & $\mathbf{N}$ & $\mathbf{N}$ & $\mathrm{N}$ & $N$ & \\
\hline
\end{tabular}

PLATE 156. FIELD C. PHASE 2A (EB II). 
Other

1 Inclusions and voids in break suggest rim rolled inwards; upper exterior face has deep concavity under rim and appears wet-smoothed; lower exterior face is very lightly "textured".

2 Net pattern burnish over red slip; tool scrape band on exterior wall below rim.

3 Section suggests rim folding; interior face is radially burnished, rim is well burnished; slightly concave upper exterior face is marked by fine lines of wet-smoothing; lower exterior face highly burnished.

4 Interior face and flaring rim are very well smoothed; upper exterior face has wetsmoothing marks while lower exterior face is irregularly finished and "textured."

6 Roughly formed.

8 Marks on interior face show smoothing of rim fold.

9 Fine lines on interiorlexterior suggest motion used in finishing rim.

10 Surface burn visible.

PLATE 156 (CONT.). 


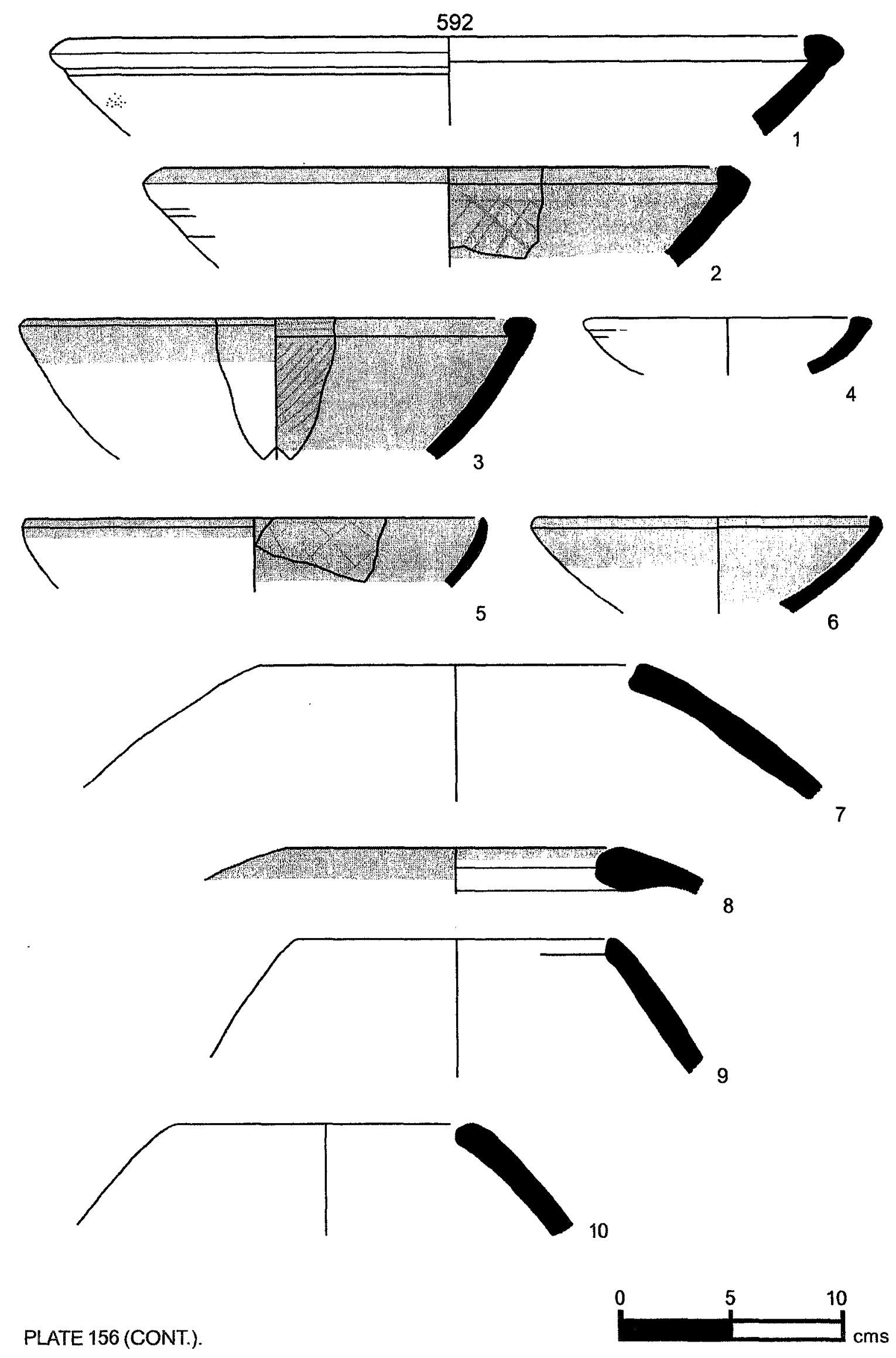




\begin{tabular}{llllllll}
\hline No & Reg & Square & Locus & Vessel & Part & $\begin{array}{c}\text { Body } \\
\text { Thick }\end{array}$ & $\begin{array}{c}\text { Dia } \\
\end{array}$ \\
& & & & & & & \\
1 & 1512 & SW 6-1 & 162 & NECKED JAR & R40 & 13 & 20 \\
2 & 1508 & SW 6-1 & 162 & NECKED JAR & R42 & 13 & 18 \\
3 & 1513 & SW 6-1 & 162 & NECKED JAR & R32 & 7 & 16 \\
4 & 1518 & SW 6-1 & 162 & UD & H14 & 6 & N \\
5 & 1515 & SW 6-1 & 162 & NECKED JAR & R43 & 7 & 12 \\
6 & 1509 & SW 6-1 & 162 & NECKED JAR & R30 & 5 & 9 \\
7 & 1505 & SW 6-1 & 162 & NECKED JAR & R30 & 6 & 9 \\
8 & 1519 & SW 6-1 & 162 & UD & B11 & 7 & 8 \\
9 & 1514 & SW 6-1 & 162 & PLATTER BOWL & R53 & 8 & 45 \\
10 & 1500 & SW 6-1 & 162 & PLATTER BOWL & R53 & 12 & 41
\end{tabular}

\begin{tabular}{lllll}
\hline No Fabric Color & Core Orient & Core Color & Core Thick & Fabric \\
& & & Family
\end{tabular}

\begin{tabular}{|c|c|c|c|c|c|c|}
\hline 1 & \multicolumn{2}{|c|}{ LT REDDISH BROWN } & $\mathbf{M}$ & G & 8 & 7.2 \\
\hline 2 & \multicolumn{2}{|c|}{ LT REDDISH BROWN } & $\mathrm{N}$ & $\mathrm{N}$ & $\mathbf{N}$ & 22 \\
\hline 3 & \multicolumn{2}{|c|}{ LT BROWN } & $\mathbf{N}$ & $\mathrm{N}$ & $\mathrm{N}$ & 10.2 \\
\hline 4 & \multicolumn{2}{|l|}{ PINK } & IRR & LG & $\mathrm{N}$ & $\mathrm{N}$ \\
\hline 5 & \multicolumn{2}{|c|}{ LT REDDISH BROWN } & $\mathbf{N}$ & $\mathbf{N}$ & $\mathrm{N}$ & $\mathrm{N}$ \\
\hline 6 & \multicolumn{2}{|c|}{ PINK } & $\mathbf{N}$ & $\mathrm{N}$ & $\mathrm{N}$ & 23 \\
\hline 7 & \multicolumn{2}{|c|}{ LT REDDISH BROWN } & $N$ & $\mathbf{N}$ & $\mathbf{N}$ & 8 \\
\hline 8 & \multicolumn{2}{|c|}{ LT RED } & $\mathbb{N}$ & $\mathbf{G}$ & 4 & $\mathbf{N}$ \\
\hline 9 & \multicolumn{2}{|l|}{ LTBROWN } & $\mathbf{N}$ & $\mathbf{N}$ & $\mathrm{N}$ & 24 \\
\hline 10 & \multicolumn{2}{|c|}{ LT REDDISH BROWN } & $\mathbf{N}$ & $\mathbf{N}$ & $\mathbf{N}$ & 7.1 \\
\hline No & Treatment & $\begin{array}{l}\text { Treatment } \\
\text { Location }\end{array}$ & $\begin{array}{l}\text { Treatment } \\
\text { Cover }\end{array}$ & $\begin{array}{l}\text { Color } \\
\text { Interior }\end{array}$ & $\begin{array}{l}\text { Co } \\
\text { Ex }\end{array}$ & \\
\hline 1 & $\mathrm{~S}$ & IE & ALL & DUSKY RED & & \\
\hline 2 & $\mathbf{S}$ & IE & ALL & $\mathbf{N}$ & & \\
\hline 3 & $\mathbf{S}$ & ER & ALL & $\mathbf{N}$ & & RED \\
\hline 4 & $\mathbf{S}$ & $E$ & LINE & $\mathbf{N}$ & DU & \\
\hline 5 & $\mathbf{S}$ & ER & ALL & $\mathbf{N}$ & DU & \\
\hline 6 & UN & $\mathrm{N}$ & $\mathbf{N}$ & $\mathbf{N}$ & $\mathrm{N}$ & \\
\hline 7 & $\mathrm{~S}$ & ER & ALL & $\mathbf{N}$ & & \\
\hline 8 & UN & $\mathrm{N}$ & $\mathbf{N}$ & $\mathbf{N}$ & $\mathbf{N}$ & \\
\hline 9 & SB & $\mathbf{I R}$ & ALL & RED & $\mathbf{N}$ & \\
\hline 10 & SB & $\mathbb{R}$ & ALL & DUSKY RED & $\mathrm{N}$ & \\
\hline
\end{tabular}

PLATE 157. FIELD C. PHASE 2A (EB II). 


\section{Other}

2 Roughly formed.

$7 \quad$ Fine smoothing lines visible on interior wall; surface burn visible.

8 Metallic Ware.

9 The folding-over of the lip to create a thickened rim is clearly seen in the broken section.

10 Interior face shows burnish parallel to rim; exterior face shows wet-smoothed band and dry scraped surface.

PLATE 157 (CONT.). 

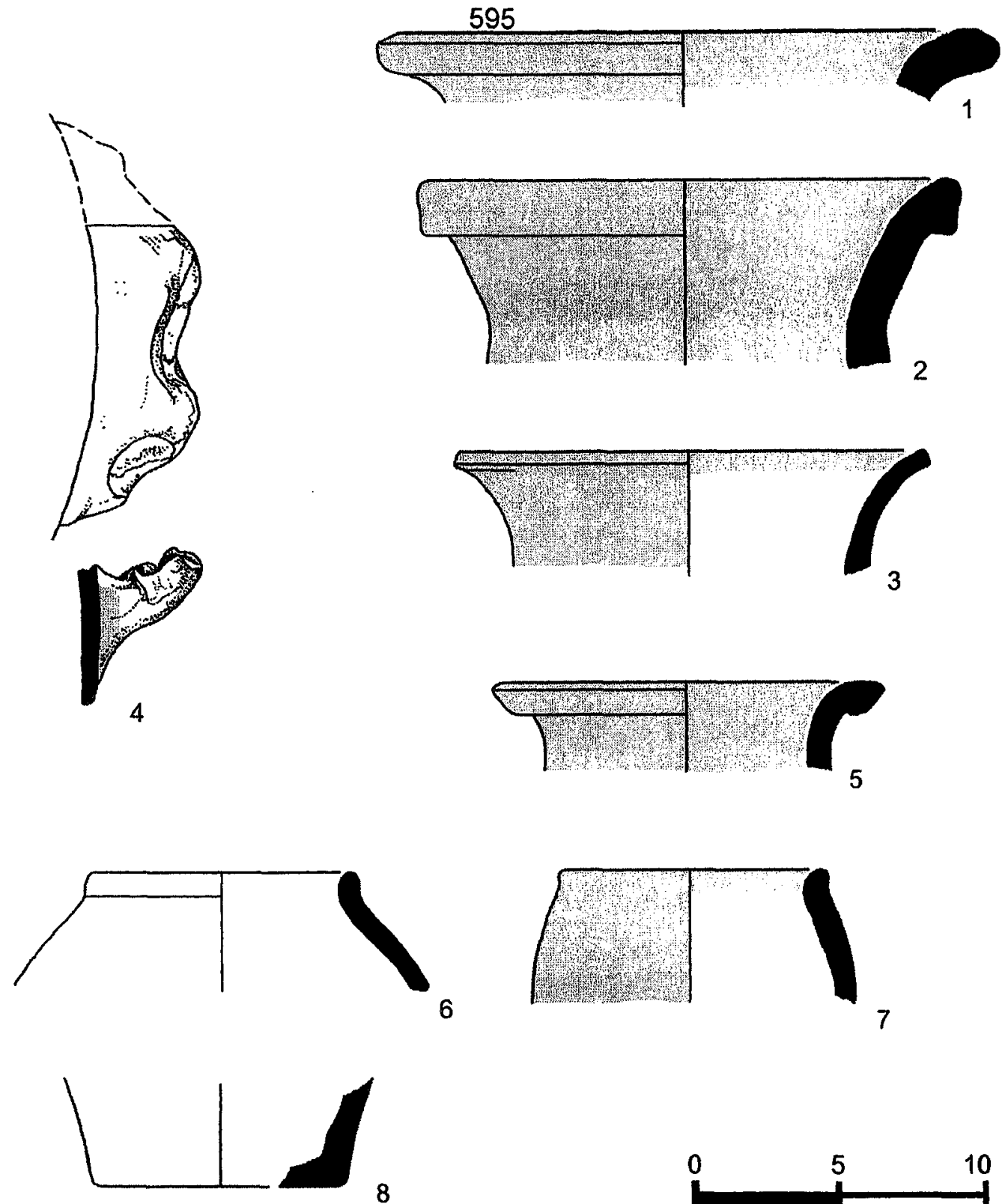

8
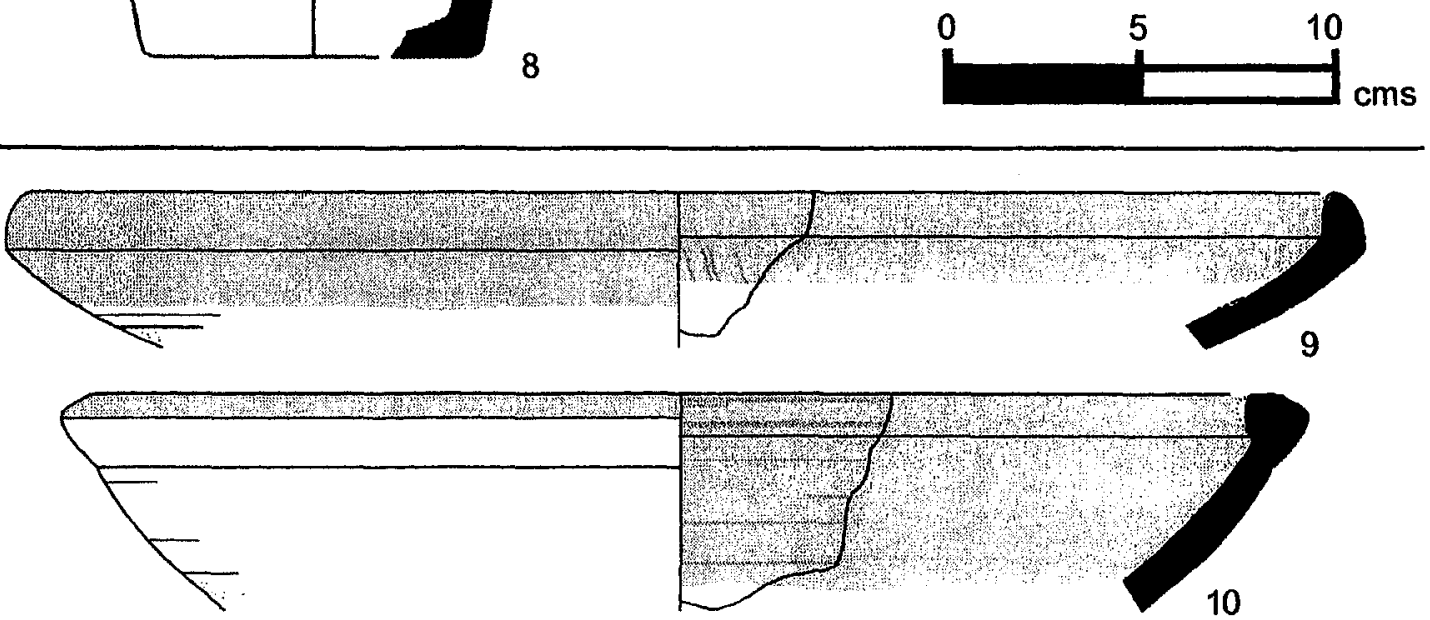

PLATE 157 (CONT.).

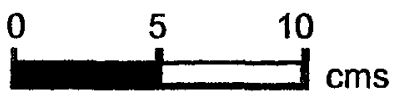




\begin{tabular}{llllllll}
\hline No & Reg & Square & Locus & Vessel & Part & $\begin{array}{c}\text { Body } \\
\text { Thick }\end{array}$ & $\begin{array}{c}\text { Dia } \\
\text { n }\end{array}$ \\
& 1645 & SW 6-1 & 163 & LEDGE RIM BOWL & R53 & 5 & 9 \\
2 & 1648 & SW 6-1 & 163 & LEDGE RIM BOWL & R53 & 13 & 30 \\
3 & 1646 & SW 6-1 & 163 & NECKED JAR & R42 & 17 & 19 \\
4 & 1647 & SW 6-1 & 163 & NECKED JAR & R34 & 13 & 15 \\
5 & 1649 & SW 6-1 & 163 & HOLE MOUTH BOWL & R02 & 8 & 17 \\
6 & 1650 & SW 6-1 & 163 & HOLE MOUTH JARIBOWL & R14 & 9 & 17
\end{tabular}

\begin{tabular}{lllll}
\hline No Fabric Color & Core Orient & Core Color & Core Thick & $\begin{array}{l}\text { Fabric } \\
\text { Family }\end{array}$
\end{tabular}

\begin{tabular}{|c|c|c|c|c|c|c|}
\hline $\begin{array}{l}1 \\
2 \\
3 \\
4 \\
5 \\
6\end{array}$ & \multicolumn{2}{|c|}{$\begin{array}{l}\text { LT BROWN } \\
\text { LT REDDISH BROWN } \\
\text { LT REDDISH BROWN } \\
\text { LT GREY } \\
\text { LT REDDISH BROWN } \\
\text { LT REDDISH BROWN }\end{array}$} & $\begin{array}{l}N \\
N \\
M \\
M \\
E X \\
M\end{array}$ & $\begin{array}{l}N \\
N \\
G \\
G \\
G \\
G\end{array}$ & $\begin{array}{l}N \\
N \\
12 \\
7 \\
5 \\
4\end{array}$ & $\begin{array}{l}23 \\
8 \\
22 \\
4 \\
3 \\
N\end{array}$ \\
\hline No & Treatment & $\begin{array}{l}\text { Treatment } \\
\text { Location }\end{array}$ & $\begin{array}{l}\text { Treatment } \\
\text { Cover }\end{array}$ & $\begin{array}{l}\text { Color } \\
\text { Interior }\end{array}$ & $\begin{array}{l}\text { Color } \\
\text { Exterior }\end{array}$ & \\
\hline $\begin{array}{l}1 \\
2 \\
3 \\
4 \\
5 \\
6\end{array}$ & $\begin{array}{l}\text { UN } \\
S \\
S \\
S \\
\text { UN } \\
\text { UD }\end{array}$ & $\begin{array}{l}N \\
\text { IE } \\
E R \\
E \\
N \\
N\end{array}$ & $\begin{array}{l}N \\
A L L \\
N \\
A L L \\
N \\
N\end{array}$ & $\begin{array}{l}N \\
\text { RED } \\
\text { WEAK RED } \\
N \\
N \\
N\end{array}$ & $\begin{array}{l}N \\
\text { RED } \\
\text { WEAK RED } \\
\text { RED } \\
\text { N } \\
N\end{array}$ & \\
\hline
\end{tabular}

\section{Other}

$3 \quad$ Features in break suggest rim folding from interior to exterior.

4 Upper interior surface is hand smoothed, lower interior surface is unfinished; exterior surface is ridged, slipped, and possibly burnished; form appears entirely handmade.

5 Marks on rim show finishing motion; marks on interior wall show diagonal pulling with tool; burn visible on surface.

6 Rim folding is very clear in section; sample too small to confirm stance or diameter.

PLATE 158. FIELD C. PHASE 2A (EB II). 

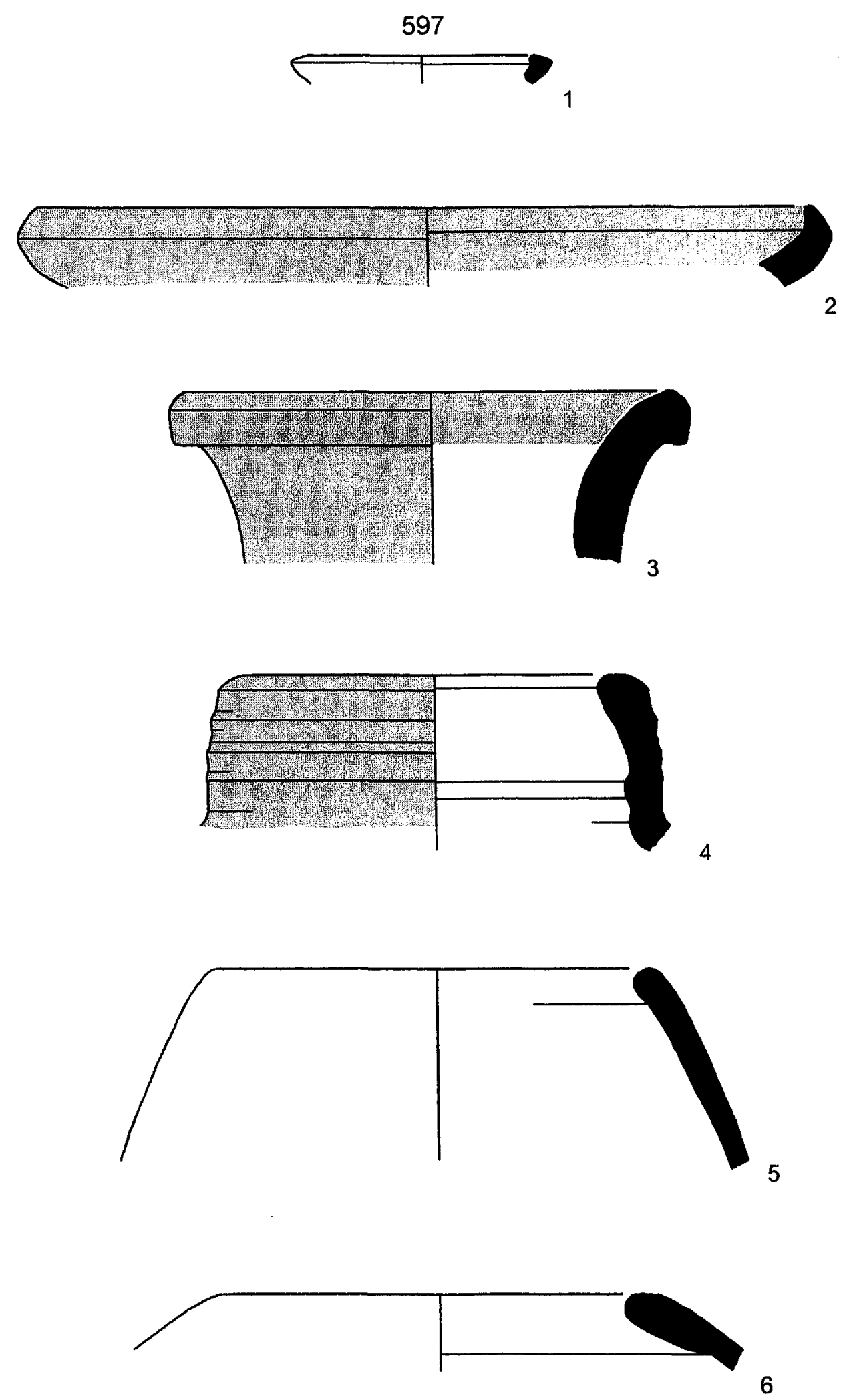

PLATE 158 (CONT.).

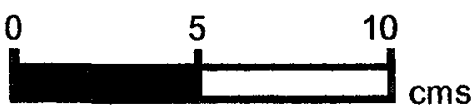




\begin{tabular}{llllllll}
\hline No & Reg & Square & Locus & Vessel & Part & $\begin{array}{l}\text { Body } \\
\text { Thick }\end{array}$ & Dia \\
& & & & & & & \\
1 & 1641 & SW 6-1 & 166 & LEDGE RIM BOWL & H60 & 13 & 32 \\
2 & 1640 & SW 6-1 & 166 & PLATTER BOWL & R53 & 9 & 30 \\
3 & 1652 & SW 6-1 & 166 & HOLE MOUTH JAR & R11 & 12 & 18 \\
4 & 1653 & SW 6-1 & 166 & NECKED JAR & R43 & 6 & 11 \\
5 & 1639 & SW 6-1 & 166 & HOLE MOUTH BOWL & R12 & 11 & 16 \\
6 & 2436 & SW 6-1 & 166 & NECKED JAR & R43 & 5 & N \\
7 & 1643 & SW 6-1 & 166 & UD & BOD & 7 & N \\
8 & 2448 & SW 6-1 & 166 & NECKED JAR & R42 & 15 & N \\
9 & 1642 & SW 6-1 & 166 & UD & B11 & 7 & 12 \\
10 & 1644 & SW 6-1 & 166 & PLATTER BOWL & R53 & 10 & 40 \\
11 & 1638 & SW 6-1 & 166 & UD & B12 & 11 & 40
\end{tabular}

\begin{tabular}{lllll}
\hline No Fabric Color & Core Orient & Core Color & Core Thick & $\begin{array}{l}\text { Fabric } \\
\text { Family }\end{array}$ \\
\end{tabular}

\begin{tabular}{|c|c|c|c|c|c|c|}
\hline 1 & \multicolumn{2}{|l|}{ PINK } & $\mathbf{N}$ & $N$ & $N$ & 17.2 \\
\hline 2 & \multicolumn{2}{|l|}{ PINK } & $\mathbf{N}$ & $\mathbf{N}$ & $\mathbf{N}$ & 24 \\
\hline 3 & \multicolumn{2}{|l|}{ PALE RED } & $N$ & $N$ & $\mathrm{~N}$ & $\mathrm{~N}$ \\
\hline 4 & \multicolumn{2}{|c|}{ LTRED } & IRR & G & $\mathrm{N}$ & 12.2 \\
\hline 5 & \multicolumn{2}{|c|}{ REDDISH BROWN } & EX & G & 7 & $N$ \\
\hline 6 & \multicolumn{2}{|l|}{ RED } & $N$ & $\mathrm{~N}$ & $N$ & $\mathrm{~N}$ \\
\hline 7 & \multicolumn{2}{|l|}{ LT RED } & $\mathbb{N}$ & G & 4 & 9.1 \\
\hline 8 & \multicolumn{2}{|l|}{ PINK } & $M$ & LG & 5 & 22 \\
\hline 9 & \multicolumn{2}{|l|}{ RED } & $M$ & LG & 2 & $\mathrm{~N}$ \\
\hline 10 & \multicolumn{2}{|l|}{ LT RED } & $N$ & $N$ & $N$ & $N$ \\
\hline 11 & \multicolumn{2}{|l|}{ LT RED } & $\mathbb{N}$ & G & 5 & 7.2 \\
\hline No & Treatment & $\begin{array}{l}\text { Treatment } \\
\text { Location }\end{array}$ & $\begin{array}{l}\text { Treatment } \\
\text { Cover }\end{array}$ & $\begin{array}{l}\text { Color } \\
\text { Interior }\end{array}$ & $\begin{array}{l}\text { Color } \\
\text { Exterior }\end{array}$ & \\
\hline 1 & $S$ & $\mathbb{I E}$ & ALL & RED & RED & \\
\hline 2 & SB & $\mathbb{I R}$ & $A L L$ & RED & RED & \\
\hline 3 & UN & $\mathrm{N}$ & $N$ & $N$ & $N$ & \\
\hline 4 & UN & $\mathbf{N}$ & $\mathbf{N}$ & $\mathbf{N}$ & $\mathrm{N}$ & \\
\hline 5 & UN & $\mathbf{N}$ & $N$ & $\mathbf{N}$ & $N$ & \\
\hline 6 & UN & $\mathbf{N}$ & $N$ & $\mathbf{N}$ & $N$ & \\
\hline 7 & 1 & $E$ & ALL & $\mathrm{N}$ & $N$ & \\
\hline 8 & $\mathrm{~S}$ & $E$ & ALL & $\mathbf{N}$ & RED & \\
\hline 9 & UN & $\mathbf{N}$ & $\mathbf{N}$ & $\mathbf{N}$ & $N$ & \\
\hline 10 & B & IE & ALL & $\mathrm{N}$ & $N$ & \\
\hline 11 & $S$ & $\mathrm{E}$ & ALL & $N$ & RED & \\
\hline
\end{tabular}

PLATE 159. FiELD C. PHASE 2A (EB II). 
Other

1 Surface burn visible.

2 Wheel burnish on rim, radial burnish on interior face; margin of wet-smoothing visible on exterior wall.

4 Sample too small to confirm stance or diameter; Metallic Ware.

5 Surface burn visible; lines on interior/exterior suggest motion used to finish rim.

6 Sample too small to confirm stance or diameter; Metallic Ware.

7 Combed Metallic Ware; also in Fabric Family 12.2.

8 Thin section sample 11.

9 Metallic Ware.

10 Metallic Ware; very shallow tool cut beneath rim.

PLATE 159 (CONT.). 

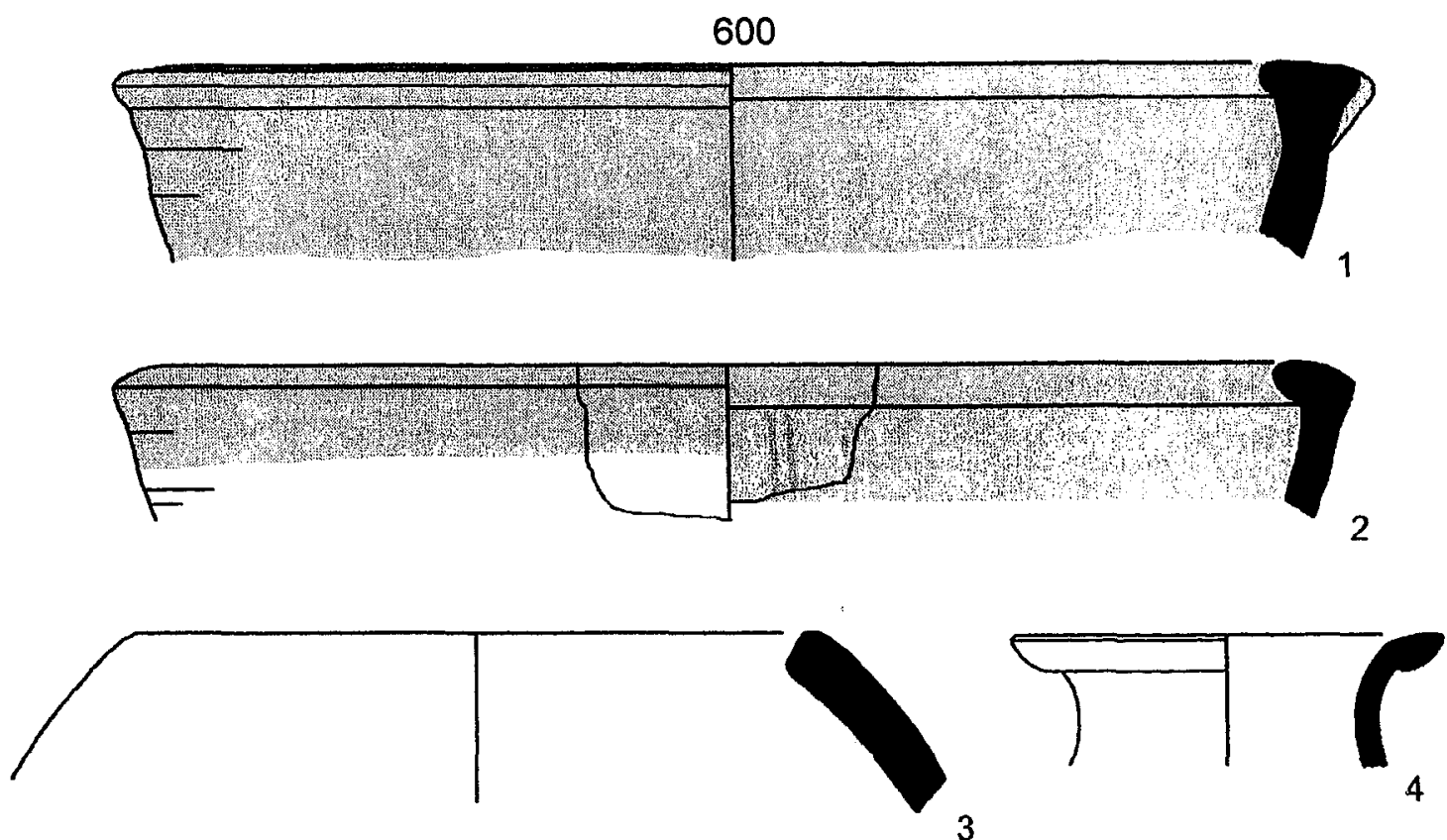

3
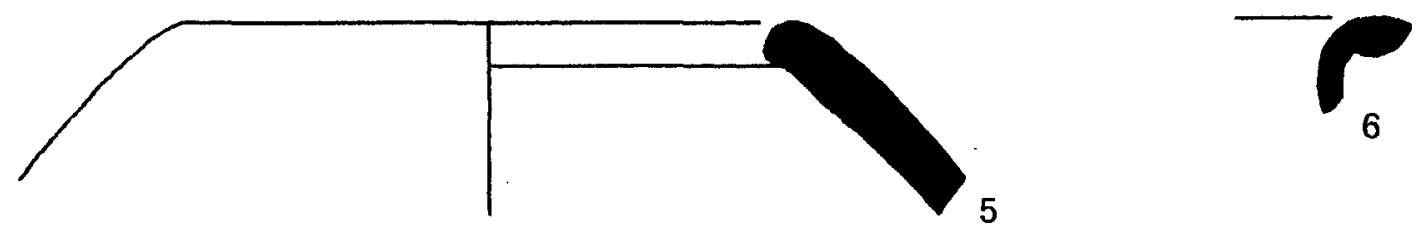

5
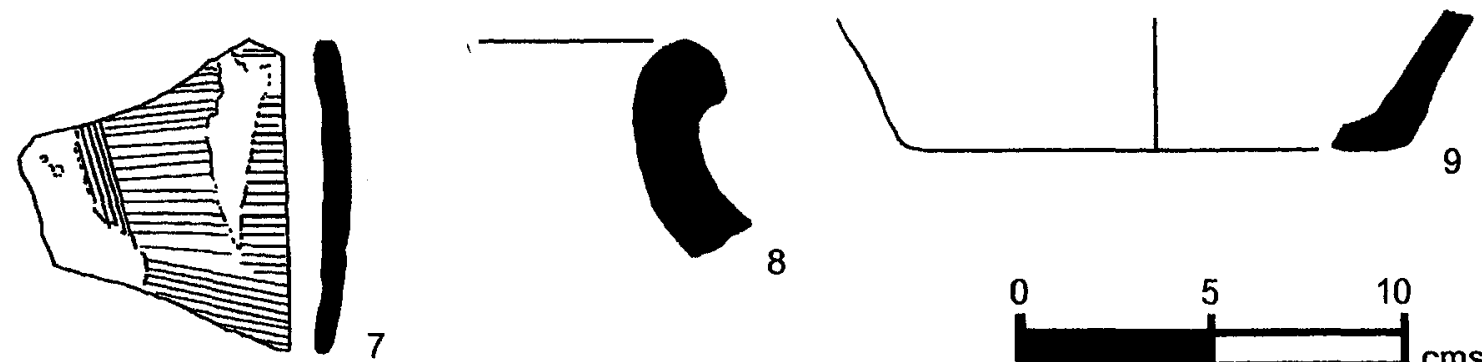

8
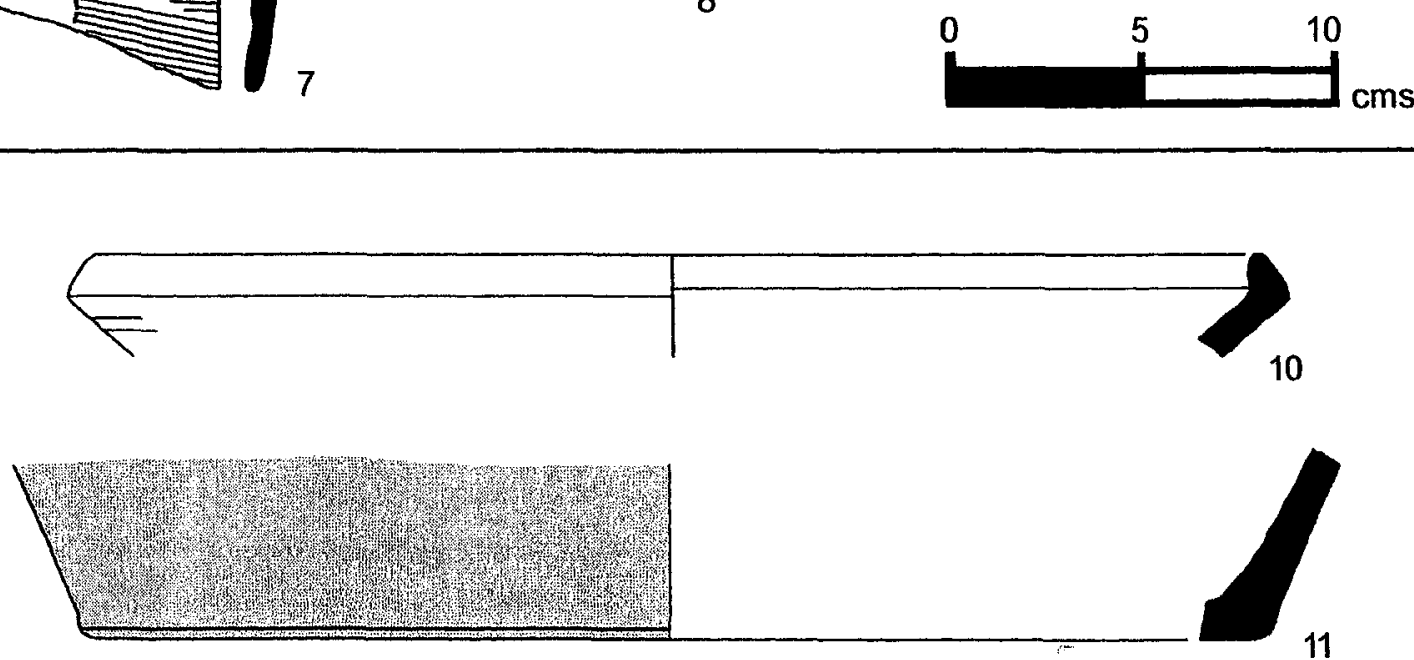

PLATE 159 (CONT.).

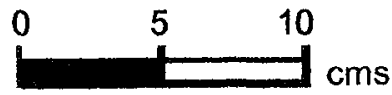




\begin{tabular}{llllllll}
\hline No & Reg & Square & Locus & Vessel & Part & $\begin{array}{l}\text { Body } \\
\text { Thick }\end{array}$ & Dia \\
\hline 1 & 1680 & SW 9-1 & 110 & PLATTER BOWL & R53 & 8 & 20 \\
2 & 1678 & SW 9-1 & 110 & HOLE MOUTH JAR & R14 & 10 & 28 \\
3 & 1690 & SW 9-1 & 110 & HOLE MOUTH JAR & R04 & 8 & 20 \\
4 & 1696 & SW 9-1 & 110 & HOLE MOUTH JAR & R17 & 7 & 15 \\
5 & 1681 & SW 9-1 & 110 & HOLE MOUTH BOWL & R11 & 8 & 15 \\
6 & 1689 & SW 9-1 & 110 & HOLE MOUTH JAR & R14 & 12 & 15 \\
7 & 1692 & SW 9-1 & 110 & HOLE MOUTH JAR & R19 & 13 & 12 \\
8 & 1694 & SW 9-1 & 110 & HOLE MOUTH JARIBOWL & R18 & 6 & 10 \\
9 & 1695 & SW 9-1 & 110 & HOLE MOUTH JAR & R20 & 9 & 12 \\
\hline No & Fabric Color & & Core Orient Core Color & Core Thick & Fabric \\
& & & & & & Family
\end{tabular}

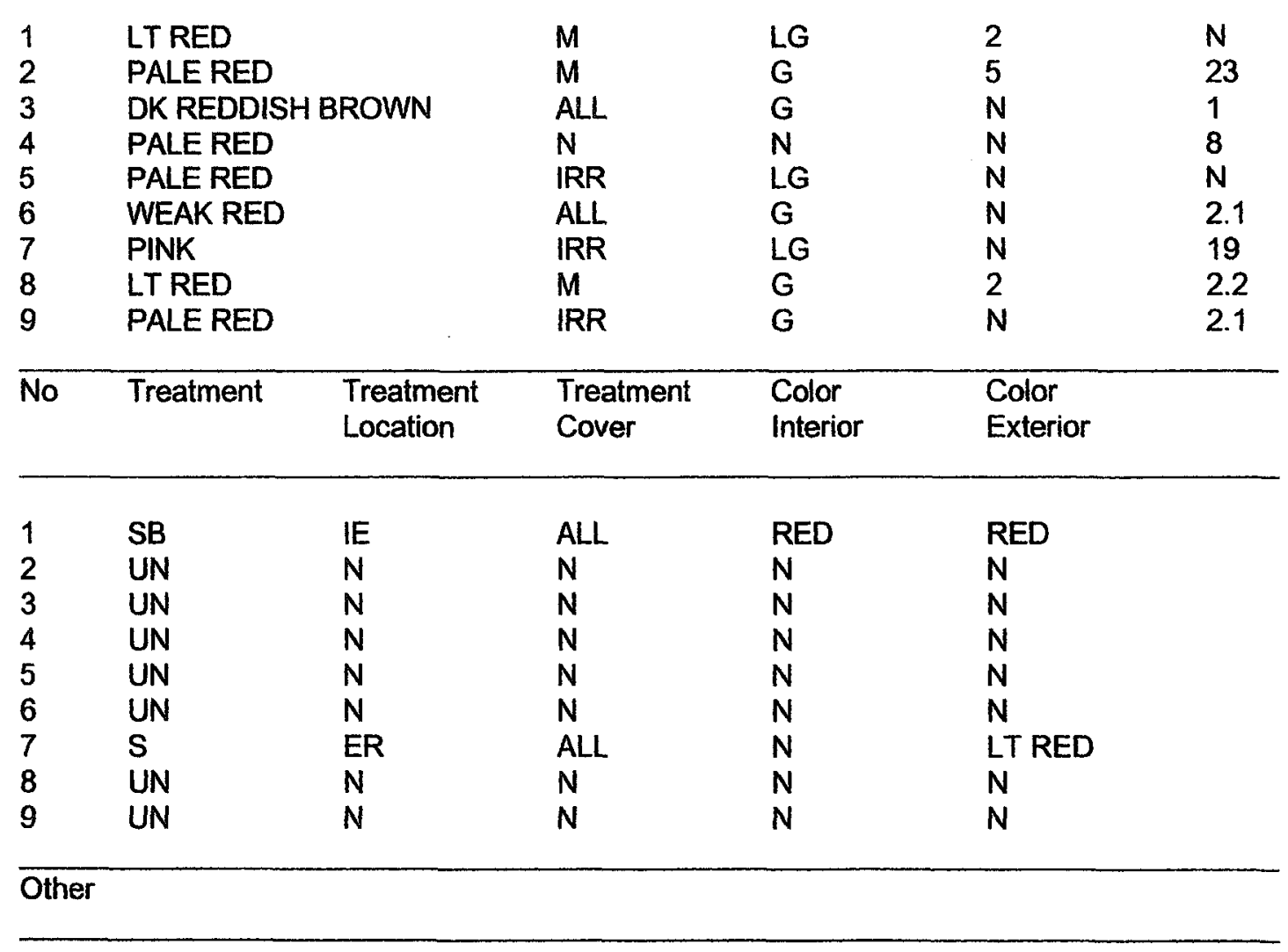

1 Soot on lip suggests use as lamp; surface burn visible; Metallic Ware.

4 Broken section suggests rim folding; interior face shows lines of fold smoothing.

$5 \quad$ Lines on interior/exterior suggest motion used to finish rim.

6 Surface burn visible.

8 Surface burn visible; sample too small to confirm stance or diameter.

9 Surface burn visible.

PLATE 160. FIELD C. PHASE 2A (EB II). 
602

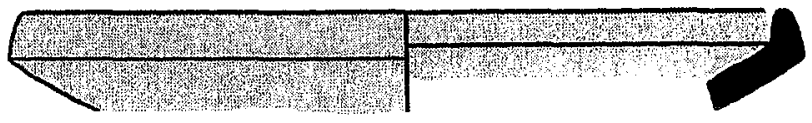

1
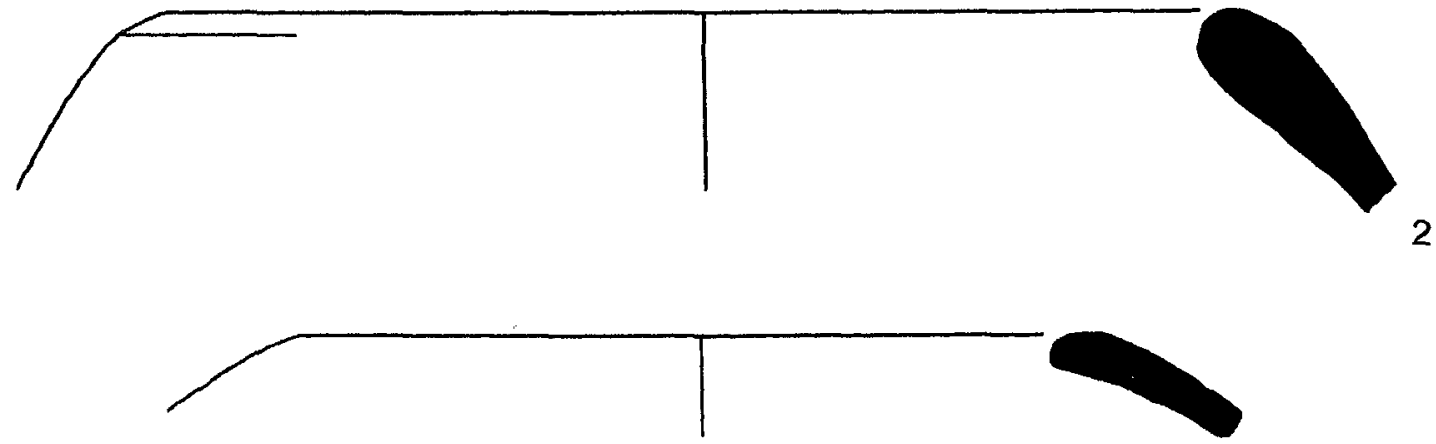

3
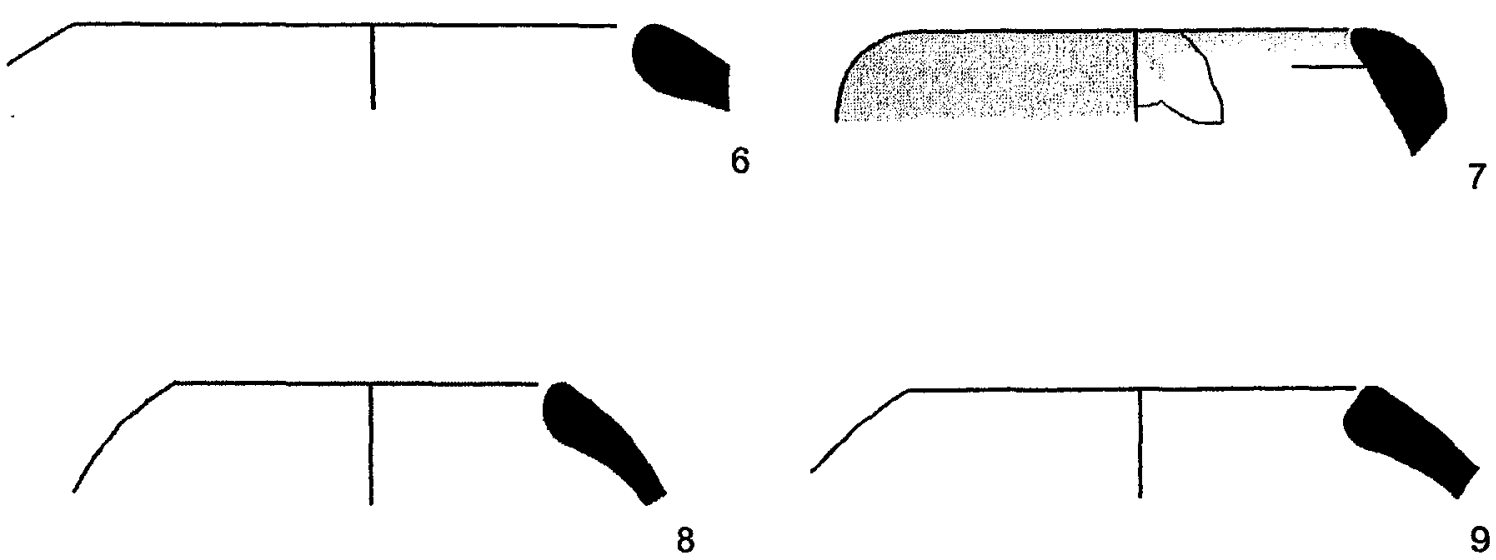

PLATE 160 (CONT.).

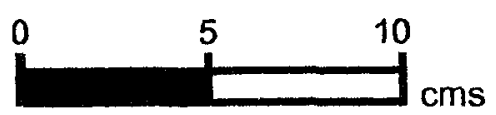




\begin{tabular}{llllllll}
\hline No & Reg & Square & Locus & Vessel & Part & $\begin{array}{c}\text { Body } \\
\text { Thick }\end{array}$ & $\begin{array}{c}\text { Dia } \\
\end{array}$ \\
& & & & & & & \\
1 & 1682 & SW 9-1 & 110 & NECKED JAR & R32 & 8 & 10 \\
2 & 1698 & SW 9-1 & 110 & NECKED JAR & R43 & 9 & 22 \\
3 & 1691 & SW 9-1 & 110 & HOLE MOUTH BOWL & R28 & 9 & 20 \\
4 & 1699 & SW 9-1 & 110 & UD & B 3 & 10 & 12 \\
5 & 1683 & SW 9-1 & 110 & UD & H20 & N & N \\
6 & 1693 & SW 9-1 & 110 & BOWL & R50 & 13 & 26 \\
7 & 1702 & SW 9-1 & 110 & GUTTER RIM BOWL & R29 & 11 & 50
\end{tabular}

\begin{tabular}{lllll}
\hline No Fabric Color & Core Orient & Core Color & Core Thick Fabric \\
Family
\end{tabular}

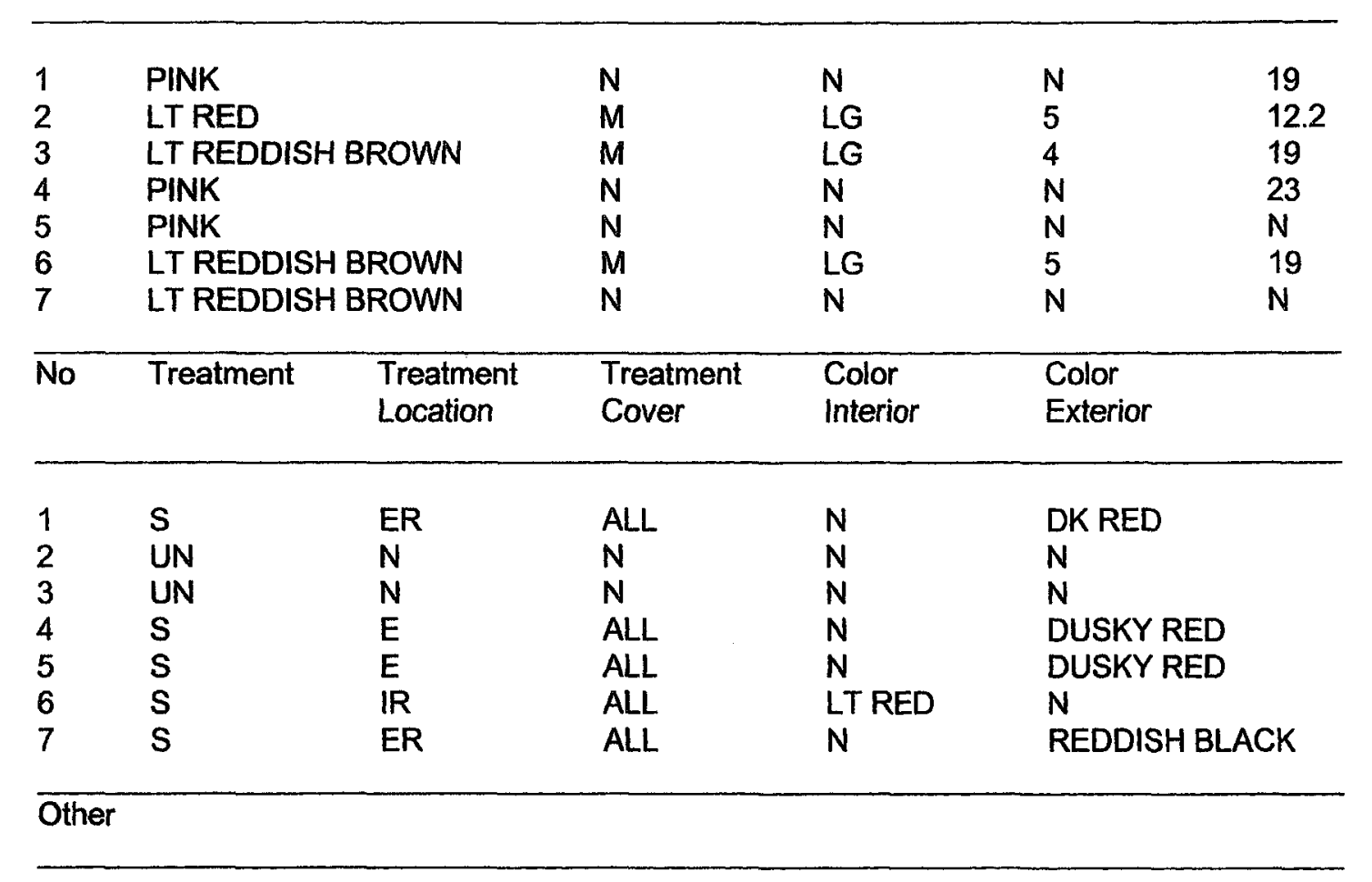

2 Metallic Ware.

3 Roughly formed; surface burn visible.

PLATE 161. FIELD C. PHASE 2A (EB II). 

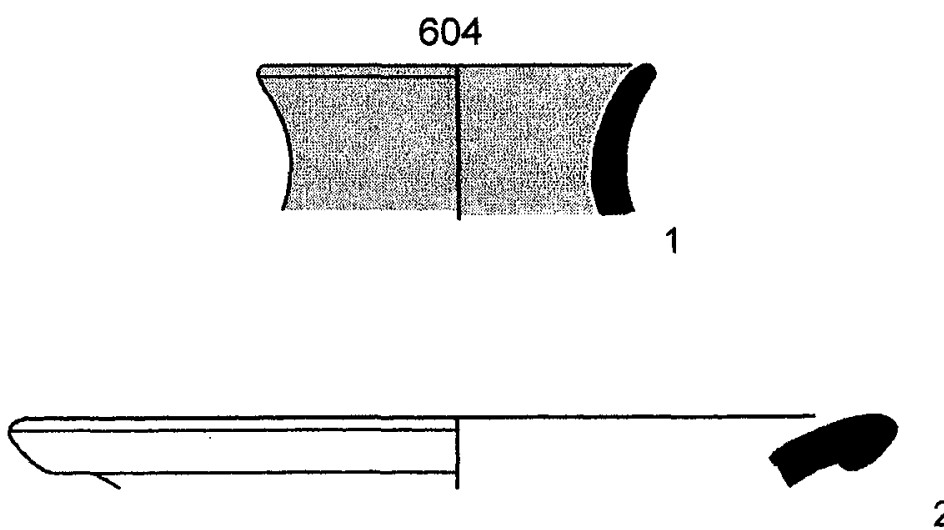

2

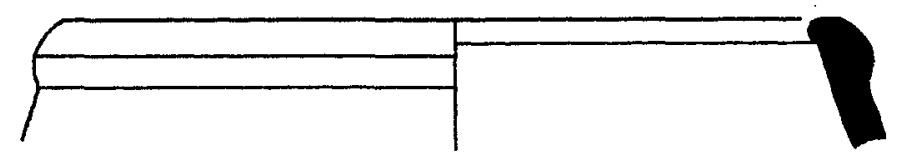

3

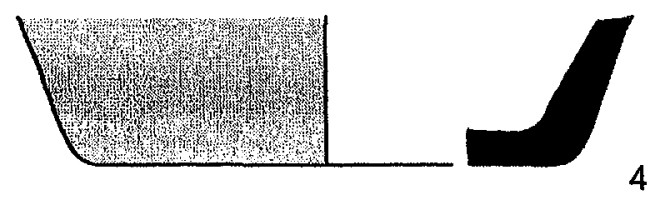

4
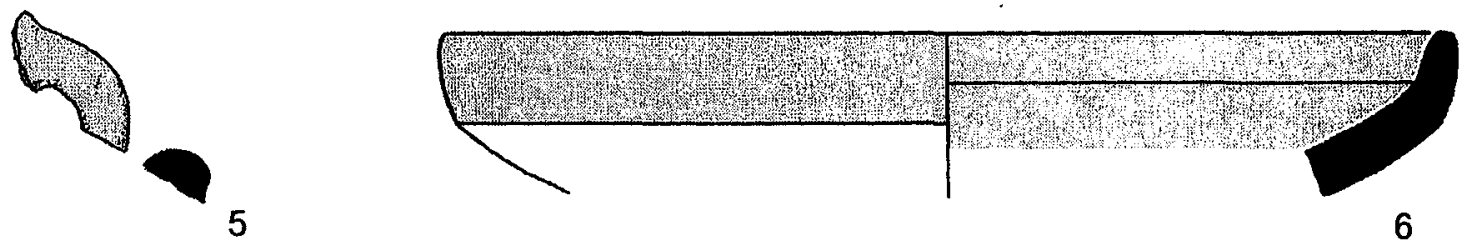

5
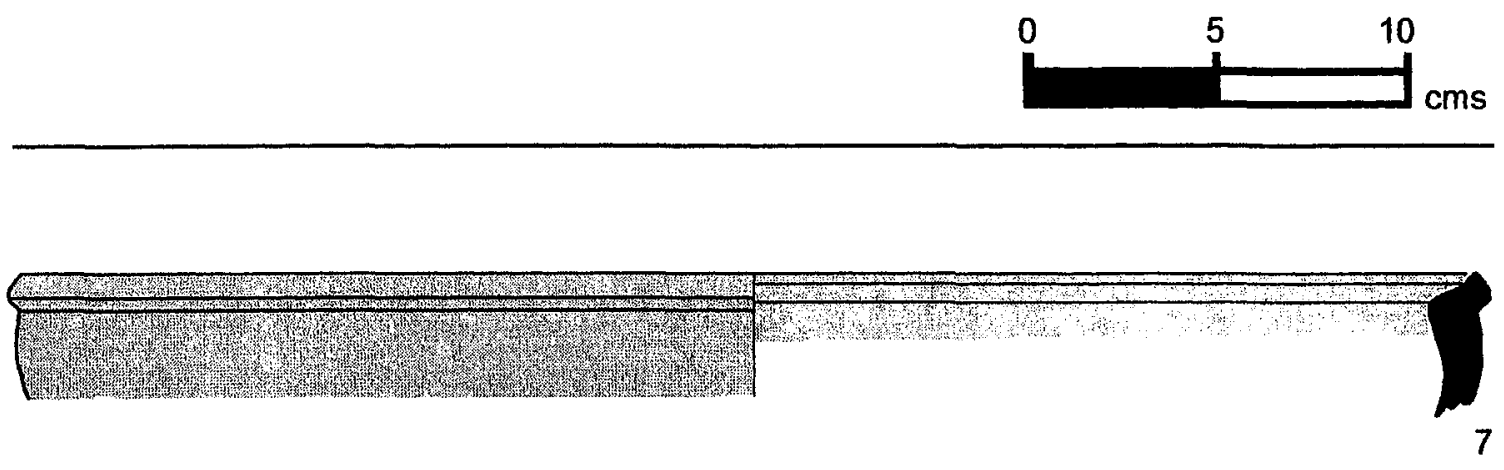

PLATE 161 (CONT.).

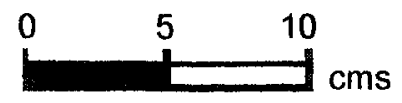




\begin{tabular}{|c|c|c|c|c|c|c|c|}
\hline$\overline{\text { No }}$ & $\operatorname{Reg}$ & Square & Locus & Vessel & Part & $\begin{array}{l}\text { Body } \\
\text { Thick }\end{array}$ & $\overline{\text { Dia }}$ \\
\hline 1 & 1779 & SW 9-1 & 145 & CARINATED BOWL & R58 & 4 & 12 \\
\hline 2 & 1774 & SW 9-1 & 145 & PLATTER BOWL & R53 & 9 & 30 \\
\hline 3 & 1776 & SW 9-1 & 145 & HOLE MOUTH JAR & $\mathrm{R} 20$ & 14 & 22 \\
\hline 4 & 1778 & SW 9-1 & 145 & HOLE MOUTH BOWL & $\mathrm{R} 18$ & 9 & 20 \\
\hline 5 & 1777 & SW 9-1 & 145 & HOLE MOUTH JAR & R11 & 6 & 16 \\
\hline 6 & 1780 & SW 9-1 & 145 & NECKED JAR & $\mathrm{R} 42$ & 13 & 20 \\
\hline 7 & 1775 & SW 9-1 & 145 & NECKED JAR & R32 & 9 & 11 \\
\hline 8 & 1782 & SW 9-1 & 145 & NECKED JAR & $\mathrm{R} 32$ & 10 & 13 \\
\hline 9 & 1784 & SW 9-1 & 145 & UD & $\mathrm{H} 14$ & 9 & $\mathbf{N}$ \\
\hline 10 & 1781 & SW 9-1 & 145 & NECKED JAR & $\mathrm{H} 60$ & 7 & 13 \\
\hline No & & & & Color & & & $\begin{array}{l}\text { Fabric } \\
\text { Family }\end{array}$ \\
\hline
\end{tabular}

\begin{tabular}{|c|c|c|c|c|c|c|}
\hline 1 & \multicolumn{2}{|c|}{ REDDISH BROWN } & $\mathbf{N}$ & $\mathbf{N}$ & $N$ & $\mathbf{N}$ \\
\hline 2 & \multicolumn{2}{|l|}{ LT RED } & $\mathbf{N}$ & $\mathbf{N}$ & $\mathbf{N}$ & $\mathbf{N}$ \\
\hline 3 & \multicolumn{2}{|l|}{ WEAK RED } & $\mathbf{M}$ & $\mathbf{G}$ & 8 & $\mathrm{~N}$ \\
\hline 4 & \multicolumn{2}{|l|}{ WEAK RED } & EX & $\mathbf{G}$ & 8 & $\mathbf{N}$ \\
\hline 5 & \multicolumn{2}{|c|}{ DUSKY RED } & $\mathbf{N}$ & $\mathbf{N}$ & $\mathbf{N}$ & $\mathrm{N}$ \\
\hline 6 & \multicolumn{2}{|c|}{ LT REDDISH BROWN } & ALL & G & $\mathbf{N}$ & $N$ \\
\hline 7 & \multicolumn{2}{|c|}{ PINK } & $M$ & LG & 3 & $N$ \\
\hline 8 & \multicolumn{2}{|c|}{ LT REDDISH BROWN } & $M$ & G & 5 & $N$ \\
\hline 9 & \multicolumn{2}{|l|}{ WEAK RED } & ALL & LG & $\mathrm{N}$ & $\mathrm{N}$ \\
\hline 10 & \multicolumn{2}{|l|}{ LT RED } & $M$ & G & 2 & $N$ \\
\hline No & Treatment & $\begin{array}{l}\text { Treatment } \\
\text { Location }\end{array}$ & $\begin{array}{l}\text { Treatment } \\
\text { Cover }\end{array}$ & $\begin{array}{l}\text { Color } \\
\text { Interior }\end{array}$ & $\begin{array}{l}\text { Color } \\
\text { Exterior }\end{array}$ & \\
\hline 1 & B & IE & LINE & $\mathbf{N}$ & $\mathbf{N}$ & \\
\hline 2 & B & IE & ALL & $\mathbf{N}$ & $\mathbf{N}$ & \\
\hline 3 & $s$ & ER & ALL & $\mathrm{N}$ & DUSKY RED & \\
\hline 4 & UN & $\mathbf{N}$ & $\mathbf{N}$ & $\mathbf{N}$ & $\mathbf{N}$ & \\
\hline 5 & UN & $\mathbf{N}$ & $\mathbf{N}$ & $\mathbf{N}$ & $\mathbf{N}$ & \\
\hline 6 & $\mathrm{~s}$ & $E$ & ALL & $\mathrm{N}$ & LT RED & \\
\hline 7 & $\mathrm{~s}$ & ER & ALL & $\mathbf{N}$ & DUSKY RED & \\
\hline 8 & $\mathrm{~S}$ & ER & $A L L$ & $\mathbf{N}$ & WEAK RED & \\
\hline 9 & $\mathbf{S}$ & $E$ & ALL & $\mathbf{N}$ & LT RED & \\
\hline 10 & WASH & ER & ALL & $\mathbf{N}$ & WHITE & \\
\hline
\end{tabular}

PLATE 162. FIELD C. PHASE 2A (EB II). 


\section{Other}

1 Metallic Ware.

2 Metallic Ware.

3 Thin and shallow concavity on lip.

$4 \quad$ Surface burn visible.

5 Surface burn visible; voids in break suggest folding.

6 Features in break suggest rim folding from interior to exterior.

9 Surface burn visible.

PLATE 162 (CONT.). 

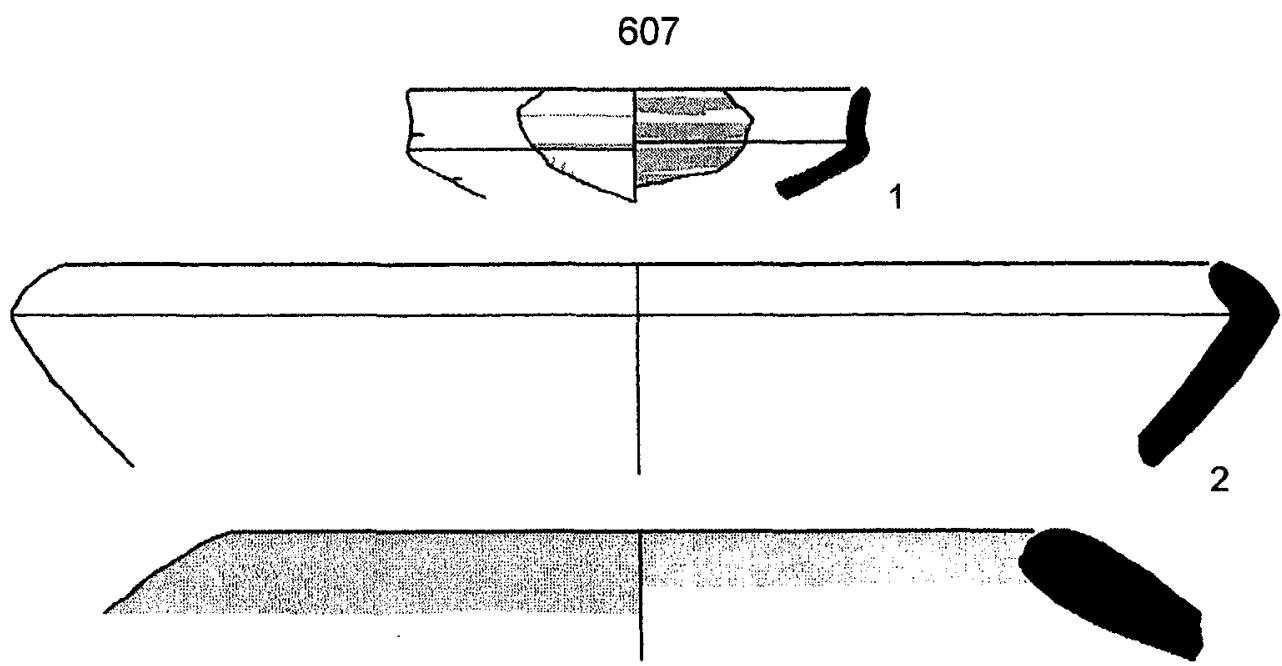

3
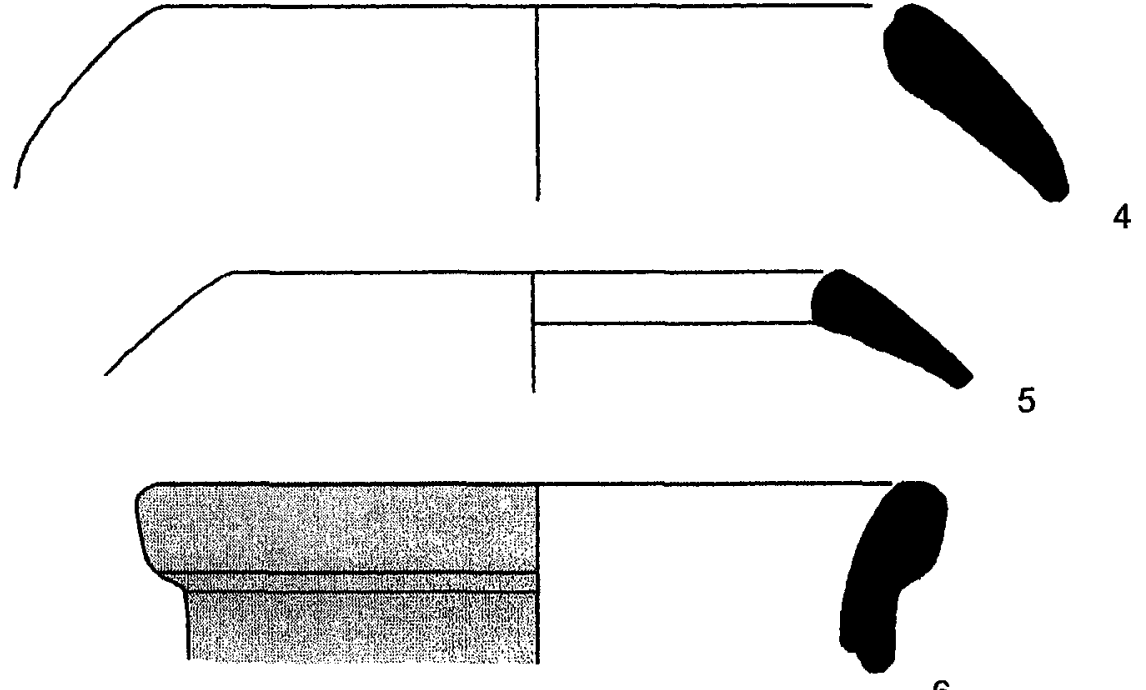

6
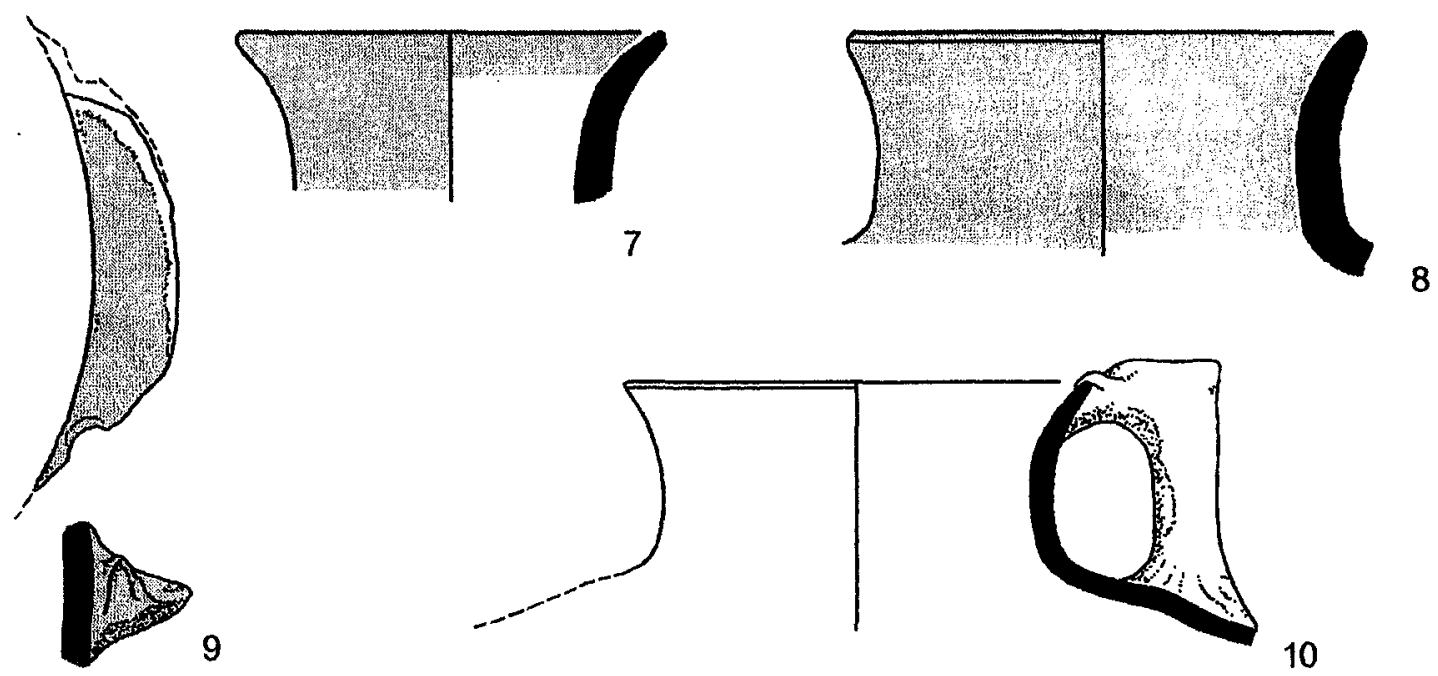

PLATE 162 (CONT.).

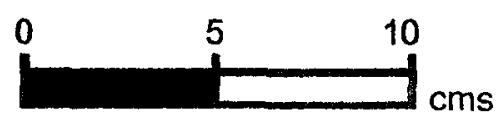




\begin{tabular}{llllllll}
\hline No & Reg & Square & Locus & Vessel & Part & $\begin{array}{c}\text { Body } \\
\text { Thick }\end{array}$ & Dia \\
& & & & & & & \\
1 & 1746 & SW 9-1 & 153 & HOLE MOUTH JAR & R20 & 9 & 11 \\
2 & 1741 & SW 9-1 & 153 & HOLE MOUTH BOWL & R19 & 8 & 15 \\
3 & 1750 & SW 9-1 & 152 & HOLE MOUTH JARIBOWL & R19 & 9 & 45 \\
4 & 1747 & SW 9-1 & 153 & NECKED JAR & R43 & 8 & 15 \\
5 & 1742 & SW 9-1 & 153 & HOLE MOUTH JAR & R14 & 10 & 12 \\
6 & 2220 & SW 9-1 & 153 & HOLE MOUTH JAR & R11 & 9 & N \\
7 & 1743 & SW 9-1 & 153 & UD & H20 & 7 & N \\
8 & 1751 & SW 9-1 & 152 & UD & H21 & 24 & 13 \\
9 & 1752 & SW 9-1 & 152 & UD & H27 & 7 & N \\
10 & 1753 & SW 9-1 & 152 & UD & H20 & N & N \\
11 & 2322 & SW 9-1 & 153 & UD & B10 & 8 & N
\end{tabular}

\begin{tabular}{lllll}
\hline No Fabric Color Core Orient & Core Color Core Thick & $\begin{array}{l}\text { Fabric } \\
\text { Family }\end{array}$
\end{tabular}

\begin{tabular}{|c|c|c|c|c|c|c|}
\hline 1 & \multicolumn{2}{|l|}{ PINK } & $M$ & LG & 7 & $N$ \\
\hline 2 & \multicolumn{2}{|l|}{ PALE RED } & IRR & LG & $N$ & 2.2 \\
\hline 3 & \multicolumn{2}{|c|}{ REDDISH BROWN } & $M$ & $G$ & 5 & $\mathrm{~N}$ \\
\hline 4 & \multicolumn{2}{|l|}{ LT RED } & $\mathbf{N}$ & $\mathbf{N}$ & $\mathrm{N}$ & $N$ \\
\hline 5 & \multicolumn{2}{|l|}{ LT RED } & $M$ & $\mathbf{G}$ & 5 & 1 \\
\hline 6 & \multicolumn{2}{|c|}{ LT REDDISH BROWN } & M & LG & 7 & $N$ \\
\hline 7 & \multicolumn{2}{|l|}{ PINK } & $N$ & $N$ & $N$ & 20 \\
\hline 8 & \multicolumn{2}{|l|}{ PINK } & M & LG & 5 & 17.2 \\
\hline 9 & \multicolumn{2}{|l|}{ PINK } & $\mathbb{N}$ & LG & 5 & 21 \\
\hline 10 & \multicolumn{2}{|l|}{ PINK } & ALL & LG & $\mathrm{N}$ & 9.1 \\
\hline 11 & \multicolumn{2}{|l|}{ PINK } & $N$ & 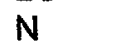 & $N$ & $N$ \\
\hline No & Treatment & $\begin{array}{l}\text { Treatment } \\
\text { Location }\end{array}$ & $\begin{array}{l}\text { Treatment } \\
\text { Cover }\end{array}$ & $\begin{array}{l}\text { Color } \\
\text { Interior }\end{array}$ & $\begin{array}{l}\text { Color } \\
\text { Exterior }\end{array}$ & \\
\hline 1 & $S$ & ER & ALL & $N$ & DK RED & \\
\hline 2 & UN & $N$ & $\mathbf{N}$ & $\mathbf{N}$ & $N$ & \\
\hline 3 & UD & $N$ & $N$ & $\mathbf{N}$ & $\mathbf{N}$ & \\
\hline 4 & UN & $\mathrm{N}$ & $N$ & $\mathrm{~N}$ & $\mathbf{N}$ & \\
\hline 5 & UN & $N$ & $\mathbf{N}$ & $\mathrm{N}$ & $N$ & \\
\hline 6 & $\mathrm{~S}$ & ER & ALL & $\mathbf{N}$ & RED & \\
\hline 7 & $\mathrm{~S}$ & $E$ & ALL & $\mathrm{N}$ & DK RED & \\
\hline 8 & $\mathbf{S}$ & IE & ALL & RED & RED & \\
\hline 9 & $\mathrm{~S}$ & $E$ & ALL & $\mathrm{N}$ & DK RED & \\
\hline 10 & $S$ & $E$ & ALL & $N$ & RED & \\
\hline 11 & $\mathrm{~S}$ & $E$ & ALL & $\mathbf{N}$ & RED & \\
\hline
\end{tabular}

PLATE 163. FIELD C. PHASE 2A (EB II). 
Other

3 Sample too small to confirm stance or diameter.

4 Metallic Ware.

6 Sample too small to confirm stance or diameter.

11 Sample too small to confirm stance or diameter.

PLATE 163 (CONT.).

Reproduced with permission of the copyright owner. Further reproduction prohibited without permission. 

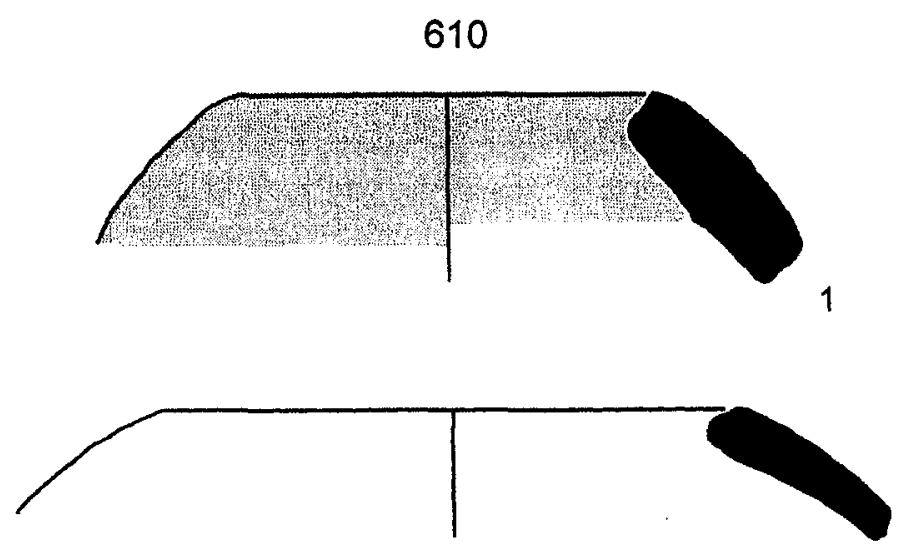

2

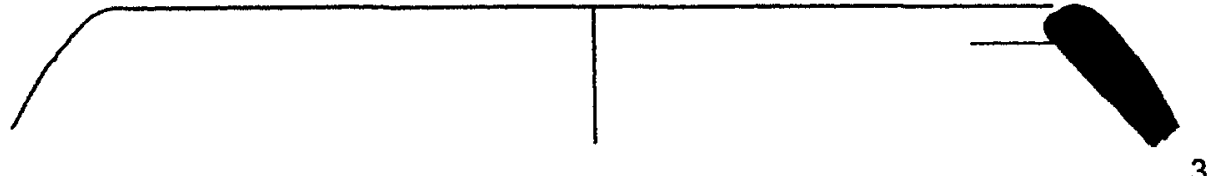

3
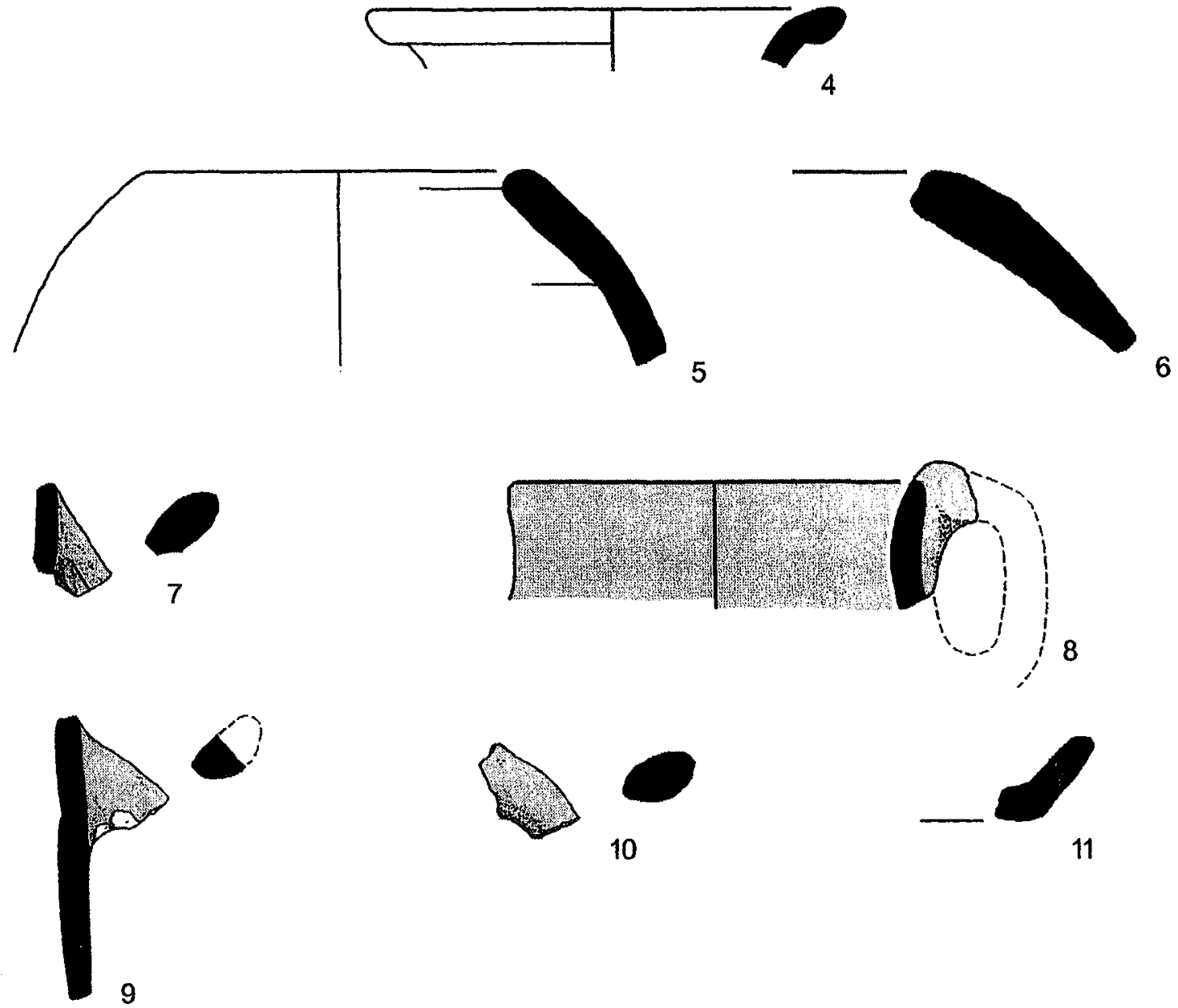

PLATE 163 (CONT.).

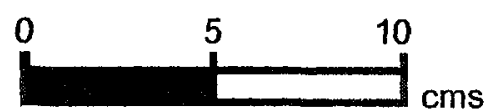




\begin{tabular}{llllllll}
\hline No & Reg & Square & Locus & Vessel & Part & $\begin{array}{c}\text { Body } \\
\text { Thick }\end{array}$ & Dia \\
\hline & & & & & & & \\
1 & 1759 & SW 9-1 & 155 & HOLE MOUTH JAR & R14 & 10 & 24 \\
2 & 1760 & SW 9-1 & 155 & HOLE MOUTH BOWL & R09 & 16 & 35 \\
3 & 1762 & SW 9-1 & 155 & HOLE MOUTH JAR & R14 & 11 & 20 \\
4 & 1761 & SW 9-1 & 155 & NECKED JAR & R31 & 12 & 26 \\
5 & 1765 & SW 9-1 & 155 & NECKED JAR & R31 & 11 & N \\
6 & 1763 & SW 9-1 & 155 & UD & H20 & N & N
\end{tabular}

\begin{tabular}{lllll}
\hline No Fabric Color & Core Orient & Core Color & Core Thick & Fabric \\
Family
\end{tabular}

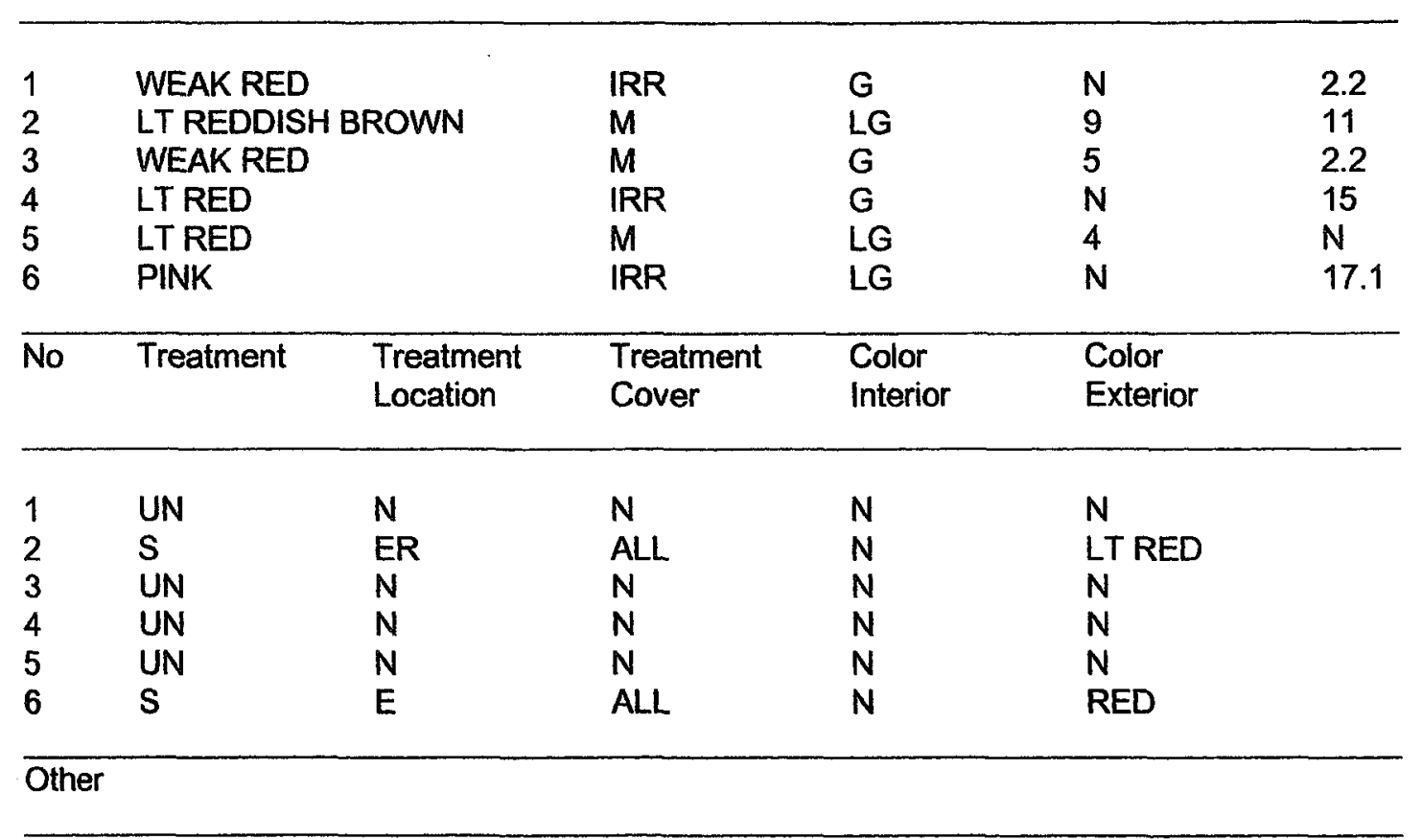

1 Fine lines on rim suggest finishing motion.

3 Surface burn visible.

4 Sample too small to confirm stance or diameter.

5 Sample too small to confirm stance or diameter.

PLATE 164. FIELD C. PHASE 2A (EB II). 

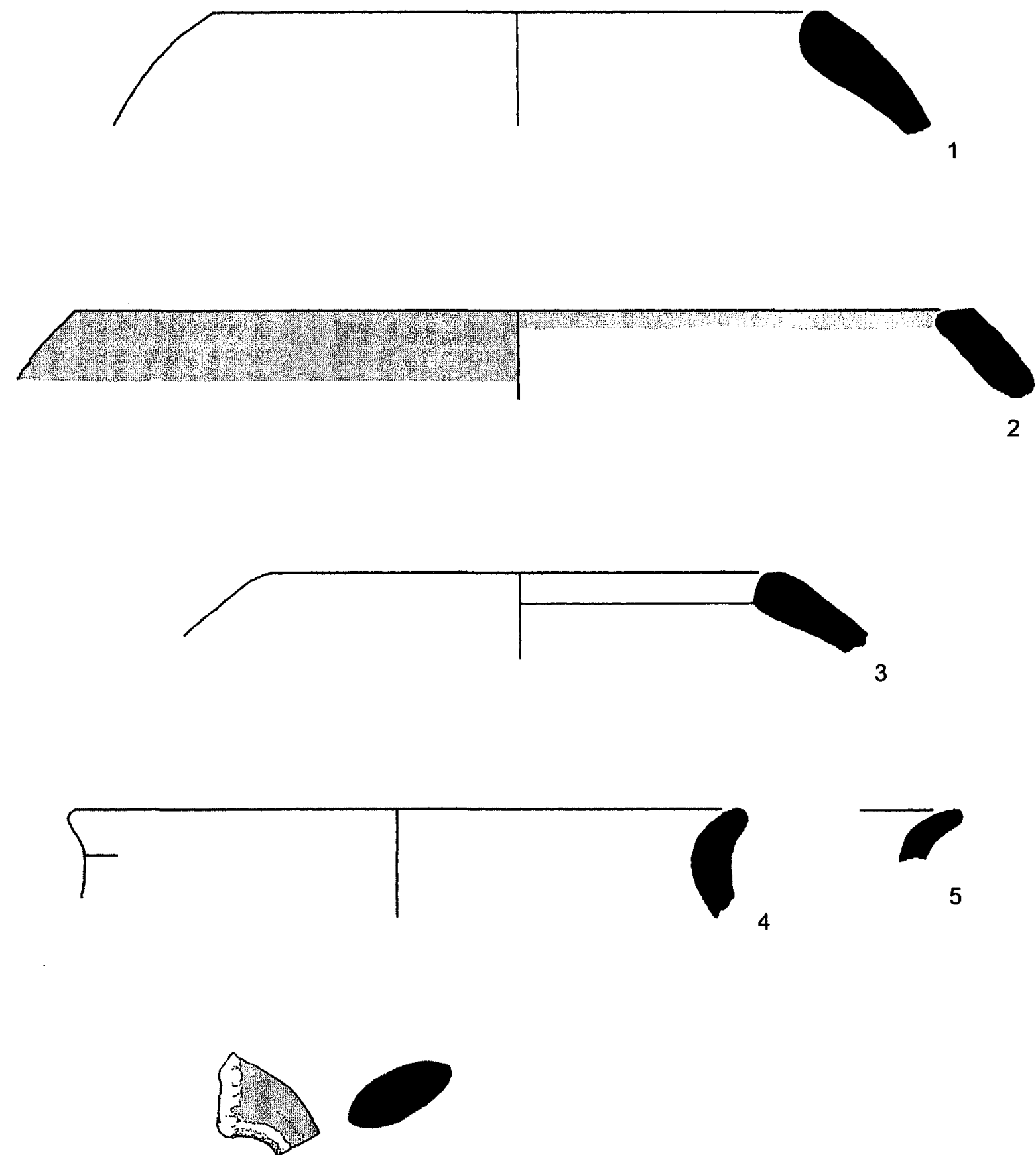

6

PLATE 164 (CONT.).

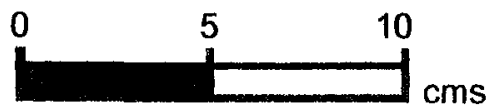




\begin{tabular}{llllllll}
\hline No & Reg & Square & Locus & Vessel & Part & $\begin{array}{l}\text { Body } \\
\text { Thick }\end{array}$ & Dia \\
\hline 1 & 1568 & SW 6-1 & 94 & BOWL & R50 & 6 & 20 \\
2 & 1565 & SW 6-1 & 94 & CARINATED BOWL & R58 & 6 & 15 \\
3 & 1567 & SW 6-1 & 94 & HOLE MOUTH JARIBOWL & R01 & 15 & 20 \\
4 & 1739 & SW 9-1 & 154 & HOLE MOUTH JAR & R19 & 12 & 20 \\
5 & 1564 & SW 6-1 & 94 & NECKED JAR & R43 & 8 & 10 \\
6 & 1589 & SW 6-1 & 144 & NECKED JAR & R43 & 9 & 10 \\
7 & 1569 & SW 6-1 & 94 & UD & B11 & 8 & 5 \\
8 & 1587 & SW 6-1 & 130 & PLATTER BOWL & R56 & 19 & 45 \\
9 & 1588 & SW 6-1 & 130 & PLATTER BOWL & R56 & 12 & 45 \\
\hline No & \multicolumn{2}{l|}{ Fabric Color } & & Core Orient Core Color & Core Thick & Fabric \\
& & & & & & Family
\end{tabular}

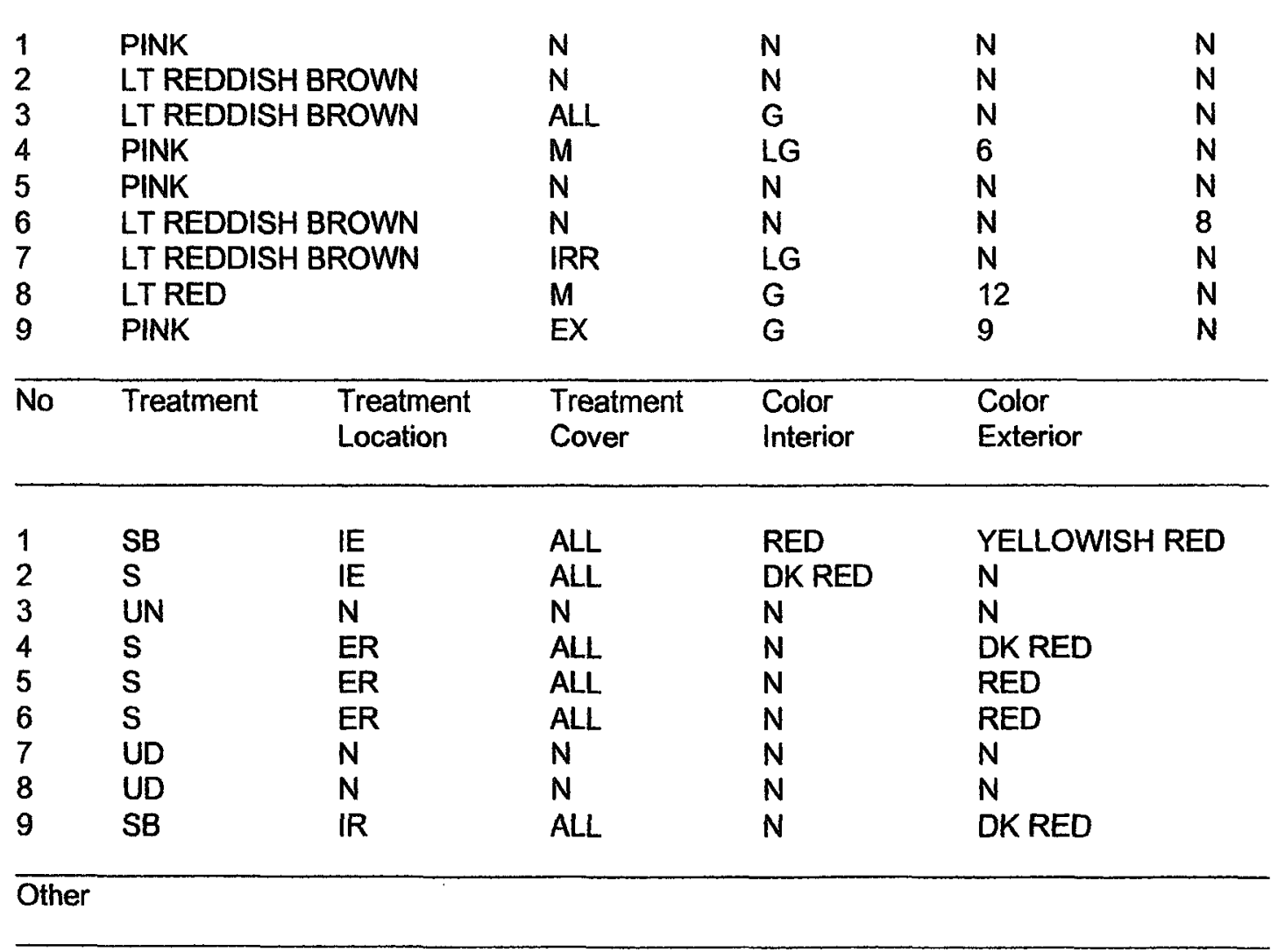

1 Radial burnish over slip on interior face; exterior is horizontally burnished.

2 Burn on rim suggests use as lamp; carination is very unsharp; surface burn visible.

3 Sample too small to confirm stance or diameter; surface burn visible.

4 Sample too small to confirm stance or diameter.

8 Very poorly fired.

9 Exterior face has wet-smoothed marginal band as well as marks suggestive of dry scraping; rim is wheel burnished, while interior face is radially burnished.

PLATE 165. FIELD C. PHASE 2B (LATE EB \| ?). 

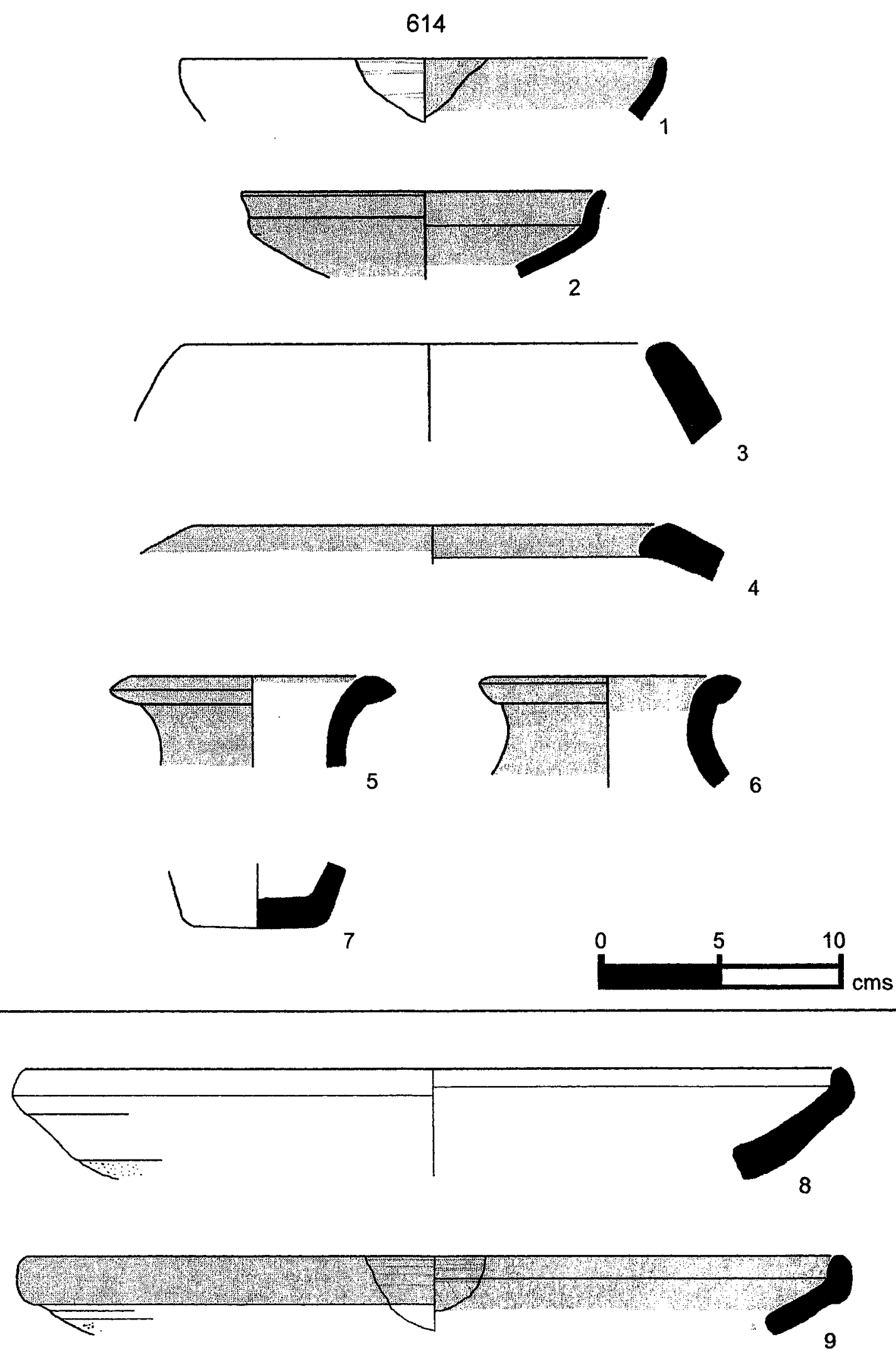

PLATE 165 (CONT.).

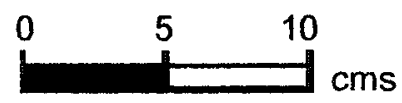




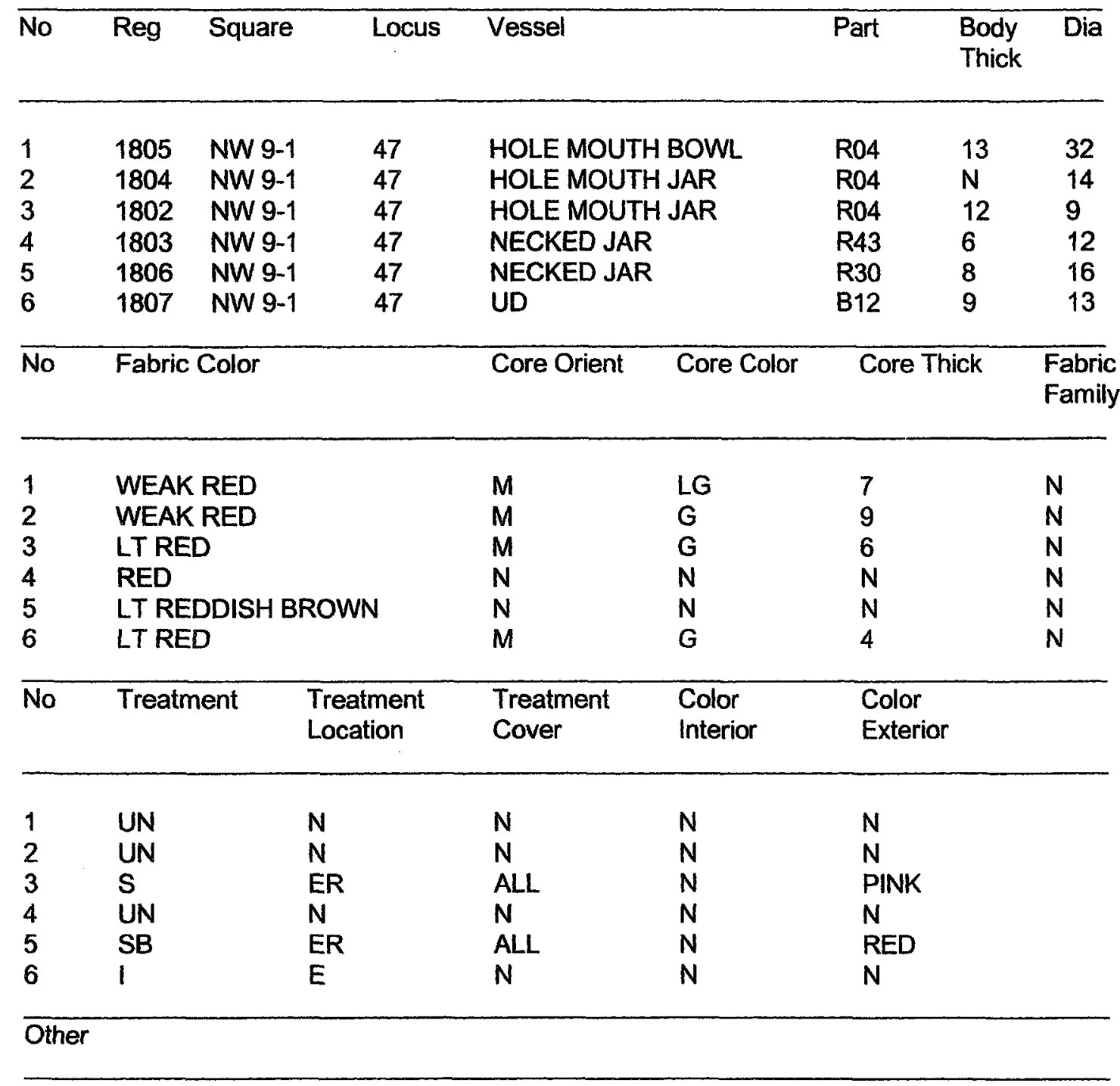

2 Surface burn visible.

6 Combed Metallic Ware.

PLATE 166. FIELD C. UNPHASED (MIXED EB). 

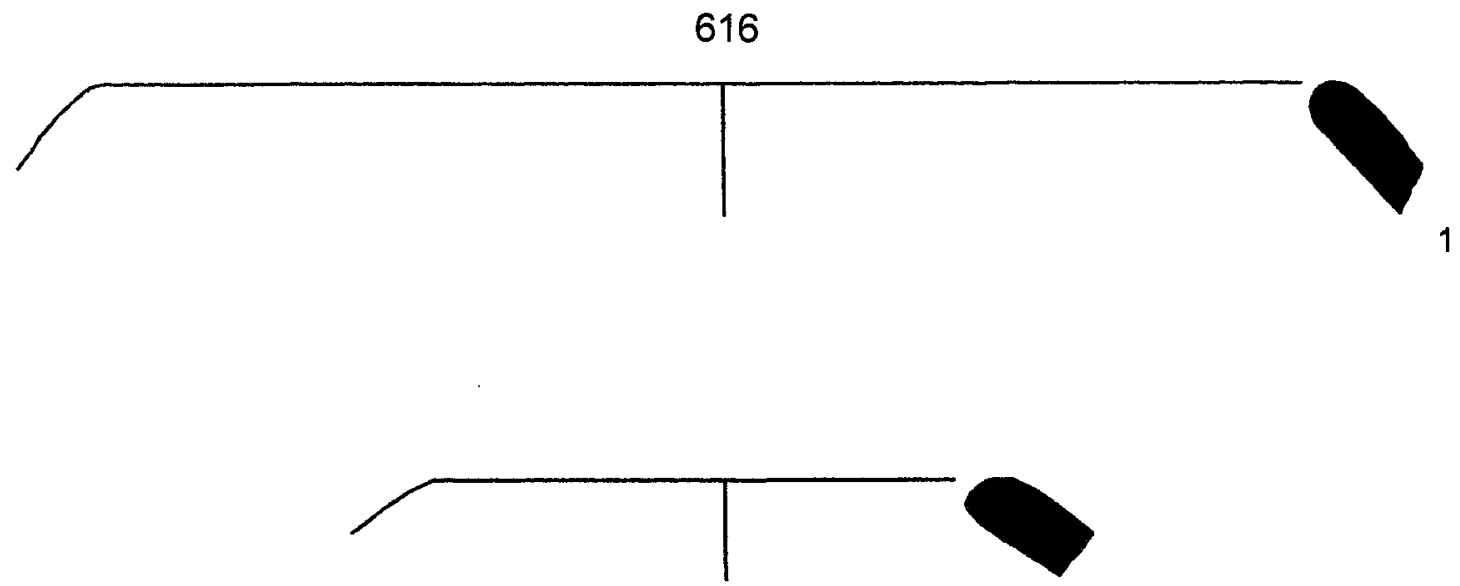

2

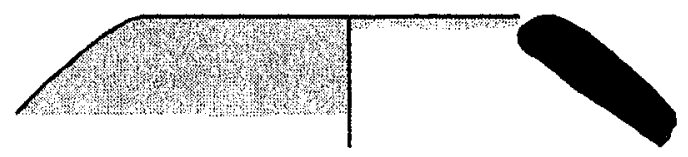

3
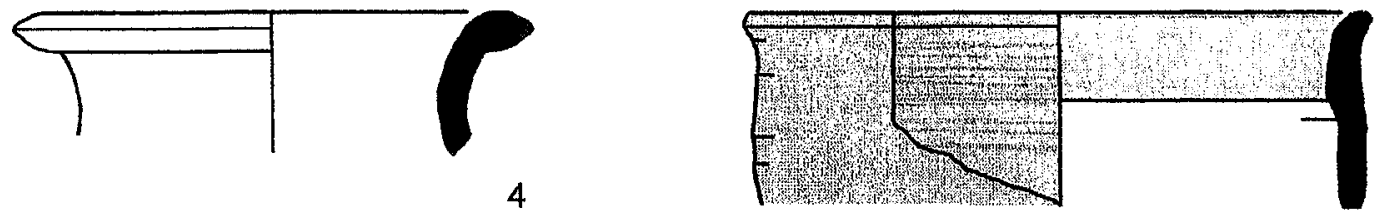

5

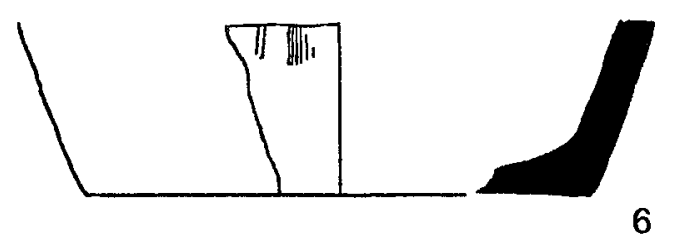

PLATE 166 (CONT.).

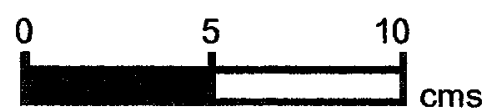




\begin{tabular}{|c|c|c|c|c|c|c|c|c|}
\hline No & Reg & Square & Locus & Vessel & & Part & $\begin{array}{l}\text { Body } \\
\text { Thick }\end{array}$ & $\overline{\text { Dia }}$ \\
\hline $\begin{array}{l}1 \\
2\end{array}$ & $\begin{array}{l}1970 \\
1972\end{array}$ & $\begin{array}{l}\text { SW 7-7 } \\
\text { SW 7-7 }\end{array}$ & $\begin{array}{l}170 \\
170\end{array}$ & $\begin{array}{l}\text { HOLE MOU' } \\
\text { UD }\end{array}$ & JAR & $\begin{array}{l}\mathrm{R} 19 \\
\mathrm{~B} 12\end{array}$ & $\begin{array}{l}13 \\
14\end{array}$ & $\begin{array}{l}16 \\
26\end{array}$ \\
\hline$\overline{\text { No }}$ & \multicolumn{3}{|c|}{ Fabric Color } & Core Orient & Core Color & \multicolumn{2}{|c|}{ Core Thick } & $\begin{array}{l}\text { Fabric } \\
\text { Family }\end{array}$ \\
\hline $\begin{array}{l}1 \\
2\end{array}$ & \multicolumn{3}{|l|}{ PINK } & $\begin{array}{l}\mathbf{N} \\
\mathbb{N}\end{array}$ & $\begin{array}{l}N \\
G\end{array}$ & \multicolumn{2}{|l|}{$N$} & $\begin{array}{l}19 \\
15\end{array}$ \\
\hline$\overline{\text { No }}$ & \multicolumn{2}{|c|}{ Treatment } & $\begin{array}{l}\text { Treatment } \\
\text { Location }\end{array}$ & $\begin{array}{l}\text { Treatment } \\
\text { Cover }\end{array}$ & $\begin{array}{l}\text { Color } \\
\text { Interior }\end{array}$ & \multicolumn{3}{|c|}{$\begin{array}{l}\text { Color } \\
\text { Exterior }\end{array}$} \\
\hline $\begin{array}{l}1 \\
2\end{array}$ & $\begin{array}{l}S \\
S\end{array}$ & & $\begin{array}{l}E R \\
E\end{array}$ & $\begin{array}{l}\text { ALL } \\
\text { ALL }\end{array}$ & $\begin{array}{l}N \\
N\end{array}$ & $\begin{array}{l}\text { RE } \\
\text { VE }\end{array}$ & DUSK & RED \\
\hline
\end{tabular}

PLATE 167. FIELD D. PHASE 1A (EB I). 

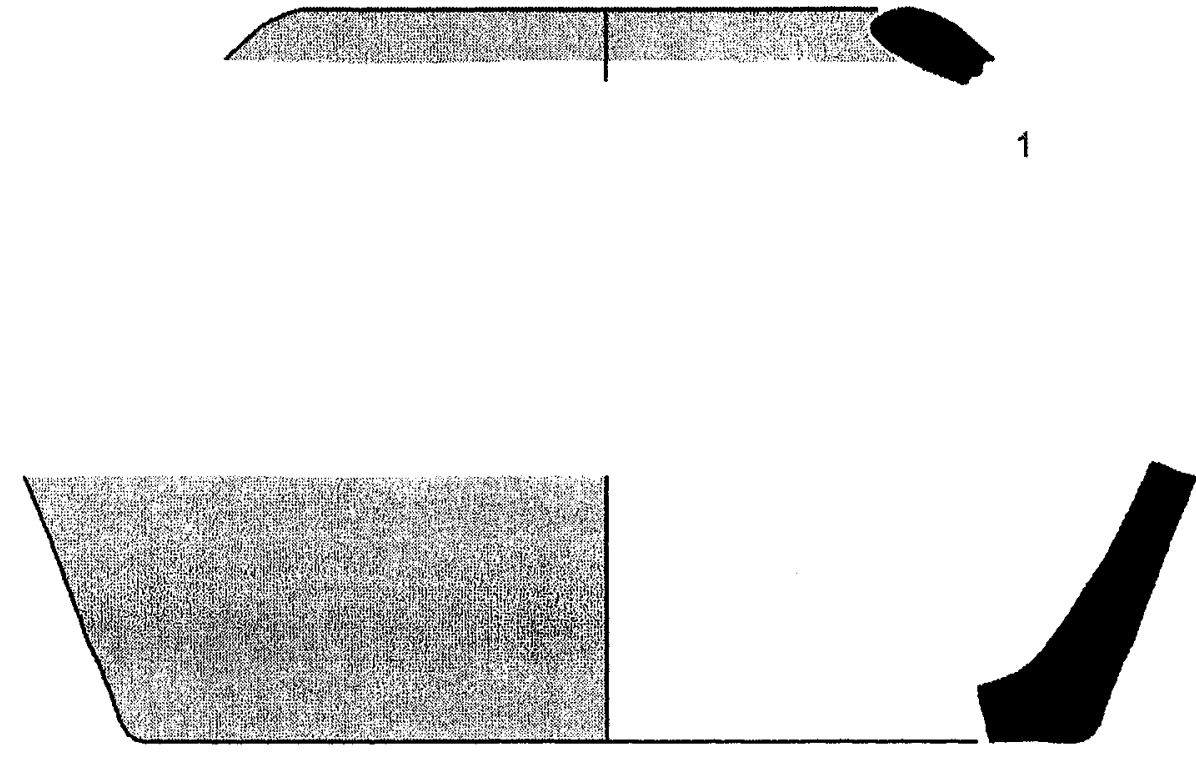

PLATE 167 (CONT.).

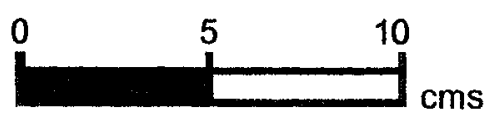




\begin{tabular}{lllllllll}
\hline No & Reg & Square & Locus & Vessel & Part & $\begin{array}{l}\text { Body } \\
\text { Thick }\end{array}$ & Dia \\
\hline & & & & & & & & \\
1 & 1975 & SW 7-7 & 177 & LEDGE RIM BOWL & R53 & 9 & 20 \\
2 & 1974 & SW 7-7 & 177 & HOLE MOUTH BOWL & R14 & 10 & 17 \\
3 & 1973 & SW 7-7 & 177 & UD & B11 & 8 & 16 \\
4 & 1976 & SW 7-7 & 177 & UD & B11 & 16 & 18
\end{tabular}

\begin{tabular}{llll}
\hline No Fabric Color & Core Orient Core Color Core Thick & Fabric \\
& & & Family
\end{tabular}

\begin{tabular}{|c|c|c|c|c|c|c|}
\hline $\begin{array}{l}1 \\
2 \\
3 \\
4\end{array}$ & $\begin{array}{l}\text { PINK } \\
\text { LT REDDIS } \\
\text { LT REDDIS } \\
\text { PINK }\end{array}$ & $\begin{array}{l}\text { ROWN } \\
\text { ROWN }\end{array}$ & $\begin{array}{l}M \\
M \\
N \\
M\end{array}$ & $\begin{array}{l}L G \\
G \\
N \\
G\end{array}$ & $\begin{array}{l}4 \\
5 \\
N \\
9\end{array}$ & $\begin{array}{l}N \\
15 \\
N \\
N\end{array}$ \\
\hline No & Treatment & $\begin{array}{l}\text { Treatment } \\
\text { Location }\end{array}$ & $\begin{array}{l}\text { Treatment } \\
\text { Cover }\end{array}$ & $\begin{array}{l}\text { Color } \\
\text { Interior }\end{array}$ & $\begin{array}{l}\text { Color } \\
\text { Exterior }\end{array}$ & \\
\hline $\begin{array}{l}1 \\
2 \\
3 \\
4\end{array}$ & $\begin{array}{l}\text { SB } \\
\text { S } \\
\text { PAINT } \\
\text { S }\end{array}$ & $\begin{array}{l}E R \\
E R \\
E \\
E\end{array}$ & $\begin{array}{l}\text { ALL } \\
\text { ALL } \\
\text { LINE } \\
\text { ALL }\end{array}$ & $\begin{array}{l}N \\
N \\
N \\
N\end{array}$ & $\begin{array}{l}\text { RED } \\
\text { RED } \\
\text { RED } \\
\text { DUSKY RED }\end{array}$ & \\
\hline
\end{tabular}

Other

1 Groove cut under rim exterior.

PLATE 168. FIELD D. PHASE 1B (EB I). 

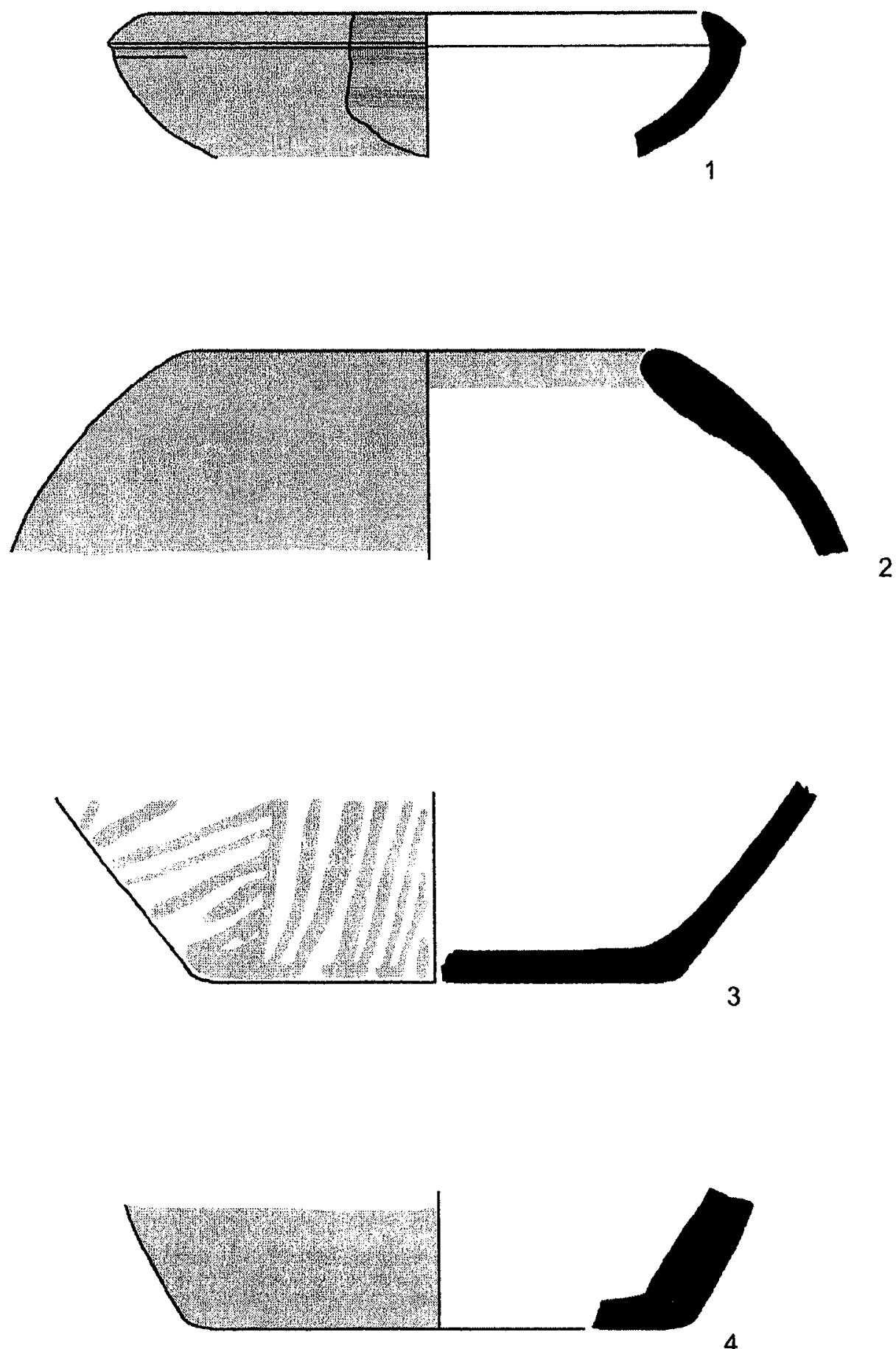

PLATE 168 (CONT.).

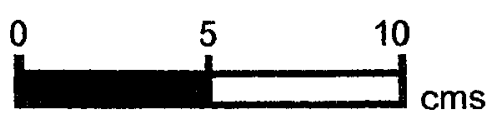




\section{1}

\begin{tabular}{|c|c|c|c|c|c|c|c|c|}
\hline$\overline{\text { No }}$ & Reg & Square & Locus & Vessel & & Part & $\begin{array}{l}\text { Body } \\
\text { Thick }\end{array}$ & $\overline{\text { Dia }}$ \\
\hline 1 & 1968 & SW 7-7 & 176 & UD & & $\mathrm{H} 12$ & 9 & N \\
\hline$\overline{\text { No }}$ & \multicolumn{3}{|c|}{ Fabric Color } & Core Orient & Core Color & \multicolumn{2}{|c|}{ Core Thick } & $\begin{array}{l}\text { Fabric } \\
\text { Family }\end{array}$ \\
\hline 1 & \multicolumn{3}{|c|}{ LT GREY } & IRR & LG & $N$ & & 4 \\
\hline No & \multicolumn{2}{|c|}{ Treatment } & $\begin{array}{l}\text { Treatment } \\
\text { Location }\end{array}$ & $\begin{array}{l}\text { Treatment } \\
\text { Cover }\end{array}$ & $\begin{array}{l}\text { Color } \\
\text { Interior }\end{array}$ & \multicolumn{2}{|c|}{$\begin{array}{l}\text { Color } \\
\text { Exterior }\end{array}$} & \\
\hline 1 & $S$ & & $E$ & ALL & $N$ & \multicolumn{2}{|c|}{ RED } & \\
\hline
\end{tabular}

1 Surface burn visible.

PLATE 169. FIELD D. PHASE 1C (EB I). 


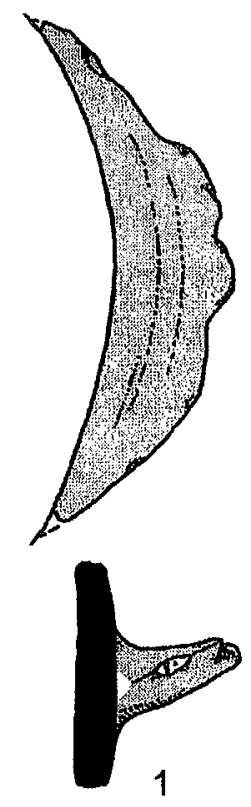

PLATE 169 (CONT.).

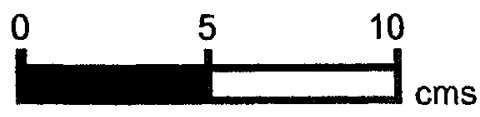




\begin{tabular}{llllllll}
\hline No & Reg & Square & Locus & Vessel & Part & $\begin{array}{l}\text { Body } \\
\text { Thick }\end{array}$ & $\begin{array}{c}\text { Dia } \\
\text { n }\end{array}$ \\
\hline 1 & 1948 & SW 7-7 & 161 & LEDGE RIM BOWL & R51 & 10 & 18 \\
2 & 1946 & SW 7-7 & 161 & UD & R39 & 9 & 20 \\
3 & 1949 & SW 7-7 & 161 & HOLE MOUTH JAR & R01 & 13 & 20 \\
4 & 1950 & SW 7-7 & 161 & HOLE MOUTH JARIBOWL & R04 & 13 & 18 \\
5 & 1947 & SW 7-7 & 161 & NECKED JAR & R31 & 10 & 11
\end{tabular}

\begin{tabular}{lllll}
\hline No Fabric Color & Core Orient & Core Color & Core Thick & Fabric \\
& & & Family
\end{tabular}

\begin{tabular}{|c|c|c|c|c|c|c|}
\hline $\begin{array}{l}1 \\
2 \\
3 \\
4 \\
5\end{array}$ & $\begin{array}{l}\text { LT RED } \\
\text { PINK } \\
\text { PALE RED } \\
\text { WEAK RED } \\
\text { PINK }\end{array}$ & & $\begin{array}{l}\text { M } \\
\text { IRR } \\
\text { IRR } \\
\text { IRR } \\
\text { N }\end{array}$ & $\begin{array}{l}L G \\
G \\
G \\
G \\
N\end{array}$ & $\begin{array}{l}2 \\
N \\
N \\
N \\
N\end{array}$ & $\begin{array}{l}12.1 \\
11 \\
N \\
N \\
16\end{array}$ \\
\hline No & Treatment & $\begin{array}{l}\text { Treatment } \\
\text { Location }\end{array}$ & $\begin{array}{l}\text { Treatment } \\
\text { Cover }\end{array}$ & $\begin{array}{l}\text { Color } \\
\text { Interior }\end{array}$ & $\begin{array}{l}\text { Color } \\
\text { Exterior }\end{array}$ & \\
\hline $\begin{array}{l}1 \\
2 \\
3 \\
4 \\
5\end{array}$ & $\begin{array}{l}\text { SB } \\
S \\
\text { UN } \\
\text { UN } \\
S\end{array}$ & $\begin{array}{l}\text { IR } \\
\text { ER } \\
N \\
N \\
\text { ER }\end{array}$ & $\begin{array}{l}A L L \\
A L L \\
N \\
N \\
A L L\end{array}$ & $\begin{array}{l}\text { RED } \\
N \\
N \\
N \\
N\end{array}$ & $\begin{array}{l}\mathbf{N} \\
\text { LT RED } \\
\mathbf{N} \\
\mathbf{N} \\
\text { BLACK }\end{array}$ & \\
\hline
\end{tabular}

2 Surface burn visible.

3 Surface burn visible; lines on exterior show motion used to finish rim.

$4 \quad$ Surface burn visible; sample too small to confirm stance or diameter.

5 Also in Fabric Family 7.1; sequence of rips on shoulder; black slip uneven, appears to be wiped on exterior surface.

PLATE 170. FIELD D. PHASE 2A (MIXED EB). 

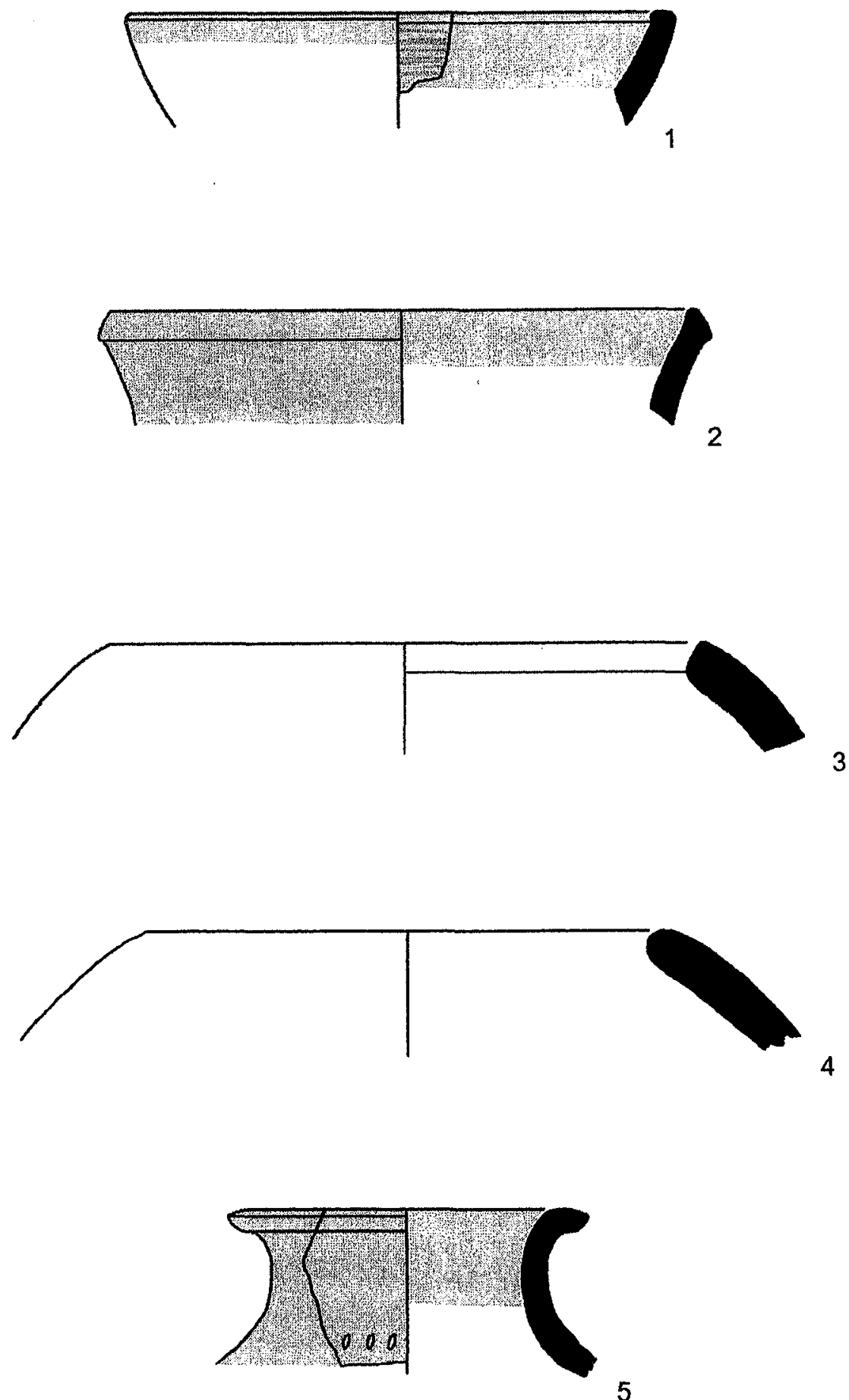

5

PLATE 170 (CONT).

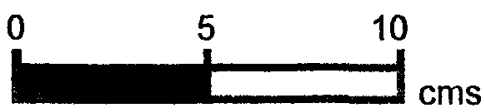




\begin{tabular}{llllllll}
\hline No & Reg & Square & Locus & Vessel & Part & $\begin{array}{l}\text { Body } \\
\text { Thick }\end{array}$ & Dia \\
\hline & & & & & & & \\
1 & 1897 & SW 7-7 & 163 & LEDGE RIM BOWL & R51 & 7 & 22 \\
2 & 1900 & SW 7-7 & 163 & NECKED JAR & R30 & 9 & 13 \\
3 & 1901 & SW 7-7 & 163 & NECKED JAR & R31 & 10 & $\mathrm{~N}$ \\
4 & 1903 & SW 7-7 & 163 & UD & H27 & 6 & $\mathrm{~N}$ \\
5 & 1904 & SW 7-7 & 163 & UD & B23 & 11 & 2 \\
6 & 1894 & SW 7-7 & 163 & HOLE MOUTH JARIBOWL & R04 & 9 & N \\
7 & 1899 & SW 7-7 & 163 & PLATTER BOWL & R56 & 12 & 40 \\
8 & 1893 & SW 7-7 & 163 & PLATTER BOWL & R56 & 10 & 50 \\
9 & 1896 & SW 7-7 & 163 & PLATTER BOWL & R56 & 10 & 45 \\
10 & 1895 & SW 7-7 & 163 & PLATTER BOWL & R80 & 13 & 45 \\
11 & 1898 & SW 7-7 & 163 & UD & B12 & 5 & 40 \\
\hline No & Fabric Color & & Core Orient Core Color & Core Thick & Fabric \\
& & & & & & & Family
\end{tabular}

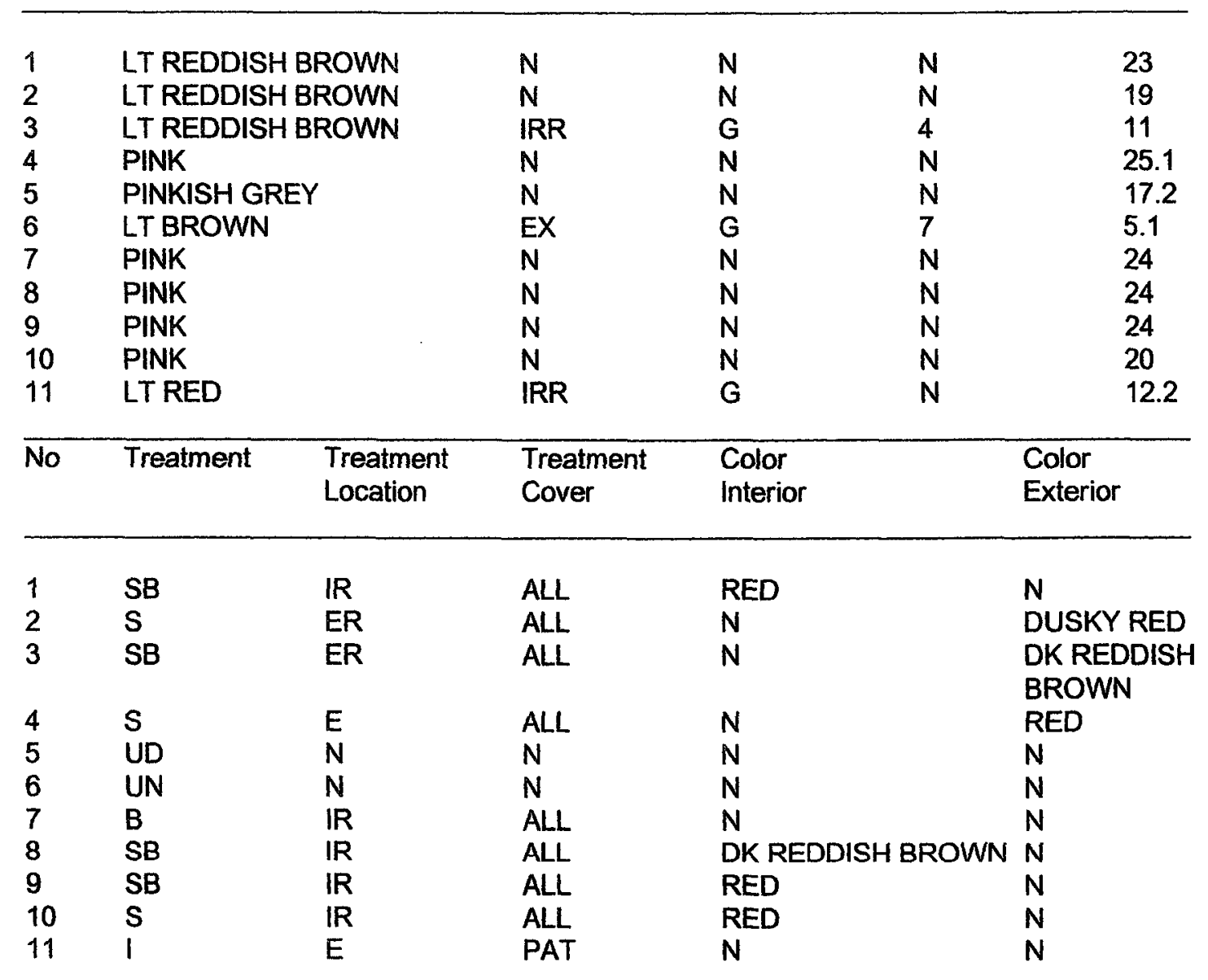

PLATE 171. FIELD D. PHASE 2A (MIXED EB). 
Other

3 Sample too small to confirm stance or diameter.

5 Very weathered.

6 Lines on interior face show wall scraping and rim finish; surface burn visible.

7 Sample too small to confirm stance or diameter; possibly from Locus 166.

8 Radially burnished.

9 Features in break suggest inward rim folding.

11 Combed Metallic Ware.

PLATE 171 (CONT.). 


\section{7}
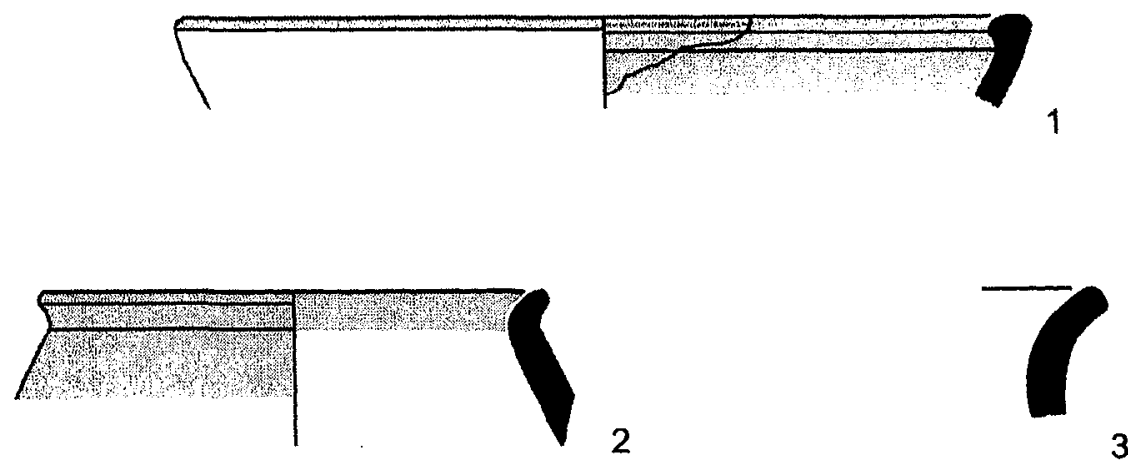

3
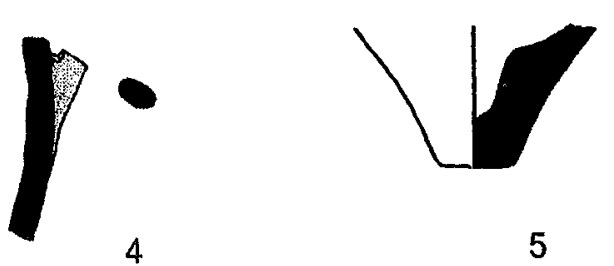

5
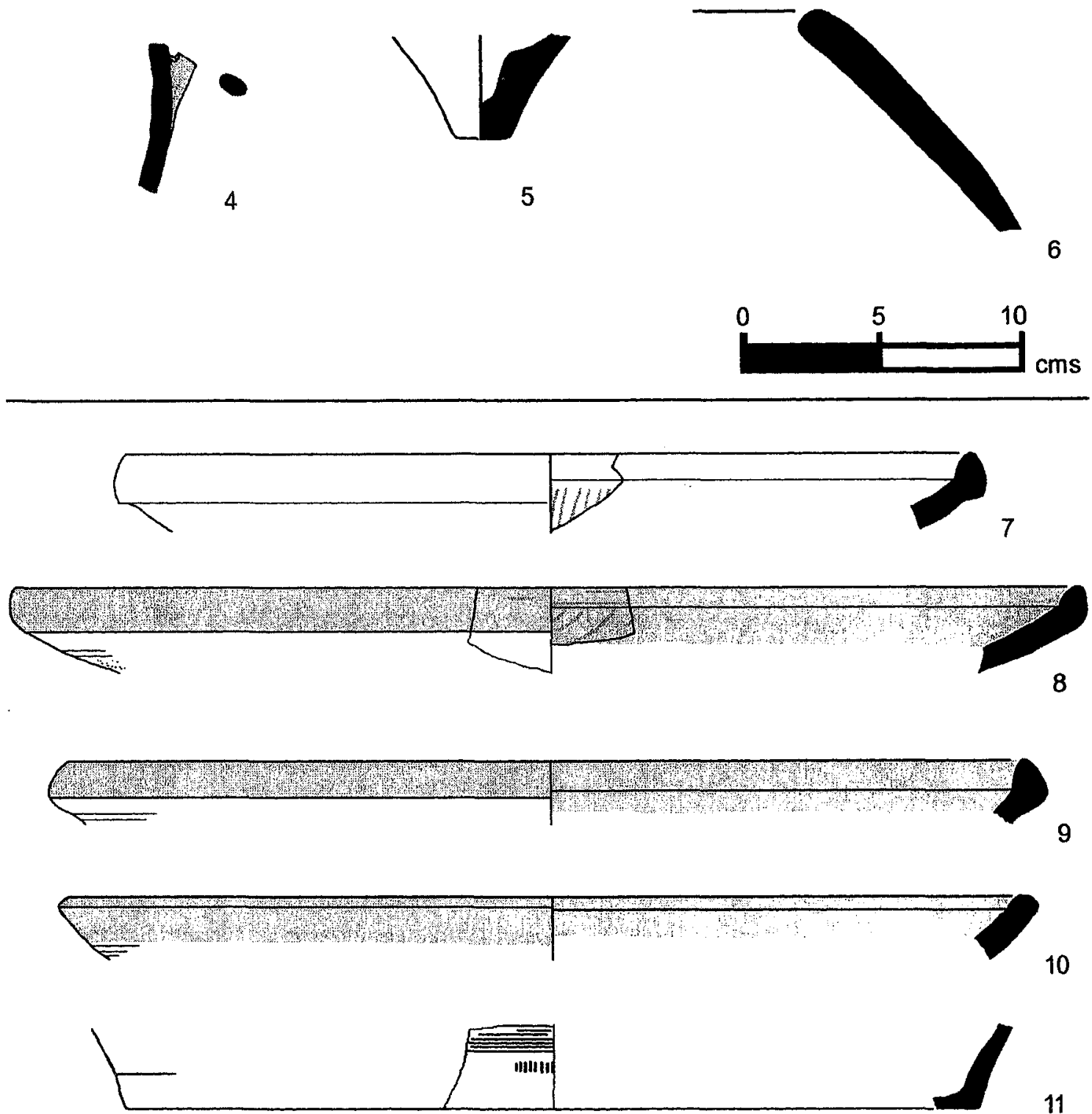

PLATE 171 (CONT.).

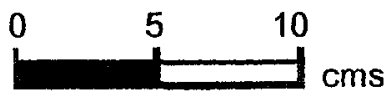




\begin{tabular}{|c|c|c|c|c|c|c|c|c|}
\hline No & $\operatorname{Reg}$ & Square & Locus & Vessel & & Part & $\begin{array}{l}\text { Body } \\
\text { Thick }\end{array}$ & $\overline{\text { Dia }}$ \\
\hline $\begin{array}{l}1 \\
2 \\
3\end{array}$ & $\begin{array}{l}1891 \\
1892 \\
1890\end{array}$ & $\begin{array}{l}\text { SW 7-7 } \\
\text { SW 7-7 } \\
\text { SW 7-7 }\end{array}$ & $\begin{array}{l}164 \\
164 \\
164\end{array}$ & $\begin{array}{l}\text { NECKED JAI } \\
\text { UD } \\
\text { LEDGE RIM }\end{array}$ & WL & $\begin{array}{l}\mathrm{R} 40 \\
\mathrm{H} 14 \\
\mathrm{R} 53\end{array}$ & $\begin{array}{l}8 \\
8 \\
13\end{array}$ & $\begin{array}{l}24 \\
N \\
45\end{array}$ \\
\hline No & Fabric & Color & & Core Orient & Core Color & Cor & ick & $\begin{array}{l}\text { Fabric } \\
\text { Family }\end{array}$ \\
\hline $\begin{array}{l}1 \\
2 \\
3\end{array}$ & $\begin{array}{l}\text { PINK } \\
\text { PINK } \\
\text { LTRE }\end{array}$ & DDISH BR & ROWN & $\begin{array}{l}\mathbf{N} \\
\mathrm{ALL} \\
\mathbf{M}\end{array}$ & $\begin{array}{l}N \\
G \\
G\end{array}$ & $\begin{array}{l}N \\
N \\
7\end{array}$ & & $\begin{array}{l}20 \\
18 \\
11\end{array}$ \\
\hline No & Treatr & ient & $\begin{array}{l}\text { Treatment } \\
\text { Location }\end{array}$ & $\begin{array}{l}\text { Treatment } \\
\text { Cover }\end{array}$ & $\begin{array}{l}\text { Color } \\
\text { Interior }\end{array}$ & $\begin{array}{l}\text { Co } \\
\text { Ext }\end{array}$ & & \\
\hline $\begin{array}{l}1 \\
2 \\
3\end{array}$ & $\begin{array}{l}\mathrm{S} \\
\mathrm{S} \\
\mathrm{SB}\end{array}$ & & $\begin{array}{l}E R \\
E \\
I R\end{array}$ & $\begin{array}{l}\text { ALL } \\
\text { ALL } \\
\text { ALL }\end{array}$ & $\begin{array}{l}N \\
N \\
\text { DK RED }\end{array}$ & $\begin{array}{l}\text { RE } \\
\text { RE } \\
N\end{array}$ & & \\
\hline
\end{tabular}

1 Smoothing lines on interior face run diagonally.

3 Mold marks visible below a wet-smoothed, marginal band on exterior face; interior face is radially burnished.

PLATE 172. FIELD D. PHASE 2A (MIXED EB). 

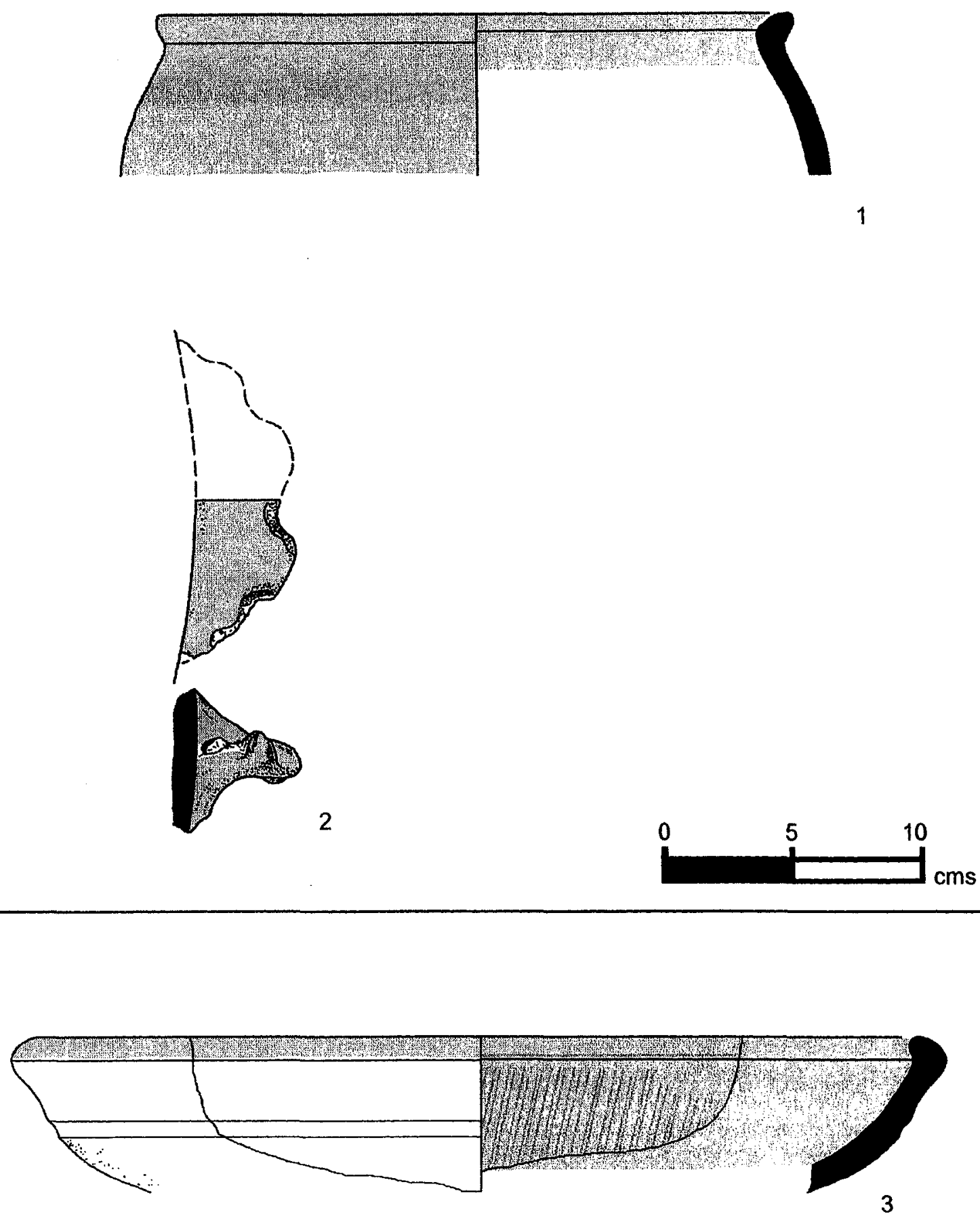

PLATE 172 (CONT.).

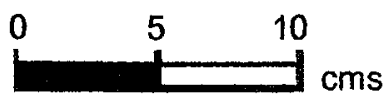


630

\begin{tabular}{llllllll}
\hline No & Reg & Square & Locus & Vessel & Part & $\begin{array}{l}\text { Body } \\
\text { Thick }\end{array}$ & Dia \\
\hline & & & & & & & \\
1 & 1989 & SW 7-7 & 166 & LEDGE RIM BOWL & R58 & 8 & 12 \\
2 & 1984 & SW 7-7 & 166 & BOWL & R50 & 6 & 20 \\
3 & 1990 & SW 7-7 & 166 & PLATTER BOWL & R53 & 11 & 34 \\
4 & 1979 & SW 7-7 & 166 & HOLE MOUTH JAR & R21 & 7 & 17 \\
5 & 2001 & SW 7-7 & 166 & UD & R00 & 10 & N \\
6 & 1985 & SW 7-7 & 166 & HOLE MOUTH BOWL & R11 & 16 & 20 \\
7 & 1988 & SW 7-7 & 166 & HOLE MOUTH BOWL & R18 & 10 & 18 \\
8 & 1987 & SW 7-7 & 166 & HOLE MOUTH JARIBOWL & R18 & 10 & 15 \\
9 & 1992 & SW 7-7 & 166 & NECKED JAR & R42 & 12 & 20 \\
10 & 2000 & SW 7-7 & 166 & JUG & NECK & 7 & N \\
11 & 1978 & SW 7-7 & 166 & NECKED JAR & R31 & 9 & 12 \\
12 & 1991 & SW 7-7 & 166 & NECKED JAR & R32 & 7 & 7 \\
\hline No & Fabric Color & & Core Orient $\quad$ Core Color & Core Thick & Fabric \\
& & & & & & Family
\end{tabular}

\begin{tabular}{|c|c|c|c|c|c|c|}
\hline 1 & \multicolumn{2}{|l|}{ LT RED } & $\mathbf{N}$ & $\mathbf{N}$ & $N$ & $\mathrm{~N}$ \\
\hline 2 & \multicolumn{2}{|l|}{ PINK } & $M$ & LG & 2 & $\mathbf{N}$ \\
\hline 3 & \multicolumn{2}{|l|}{ PINK } & M & $G$ & 5 & N \\
\hline 4 & \multicolumn{2}{|l|}{ LTRED } & IRR & $G$ & $N$ & $N$ \\
\hline 5 & \multicolumn{2}{|l|}{ PINK } & $N$ & $N$ & $N$ & $N$ \\
\hline 6 & \multicolumn{2}{|c|}{ WEAK RED } & EX & G & 10 & $N$ \\
\hline 7 & \multicolumn{2}{|c|}{ LT REDDISH BROWN } & $\mathbf{N}$ & $\mathbf{N}$ & $\mathbf{N}$ & $\mathrm{N}$ \\
\hline 8 & \multicolumn{2}{|l|}{ LT RED } & IRR & G & $\mathrm{N}$ & $\mathbf{N}$ \\
\hline 9 & \multicolumn{2}{|l|}{ PINK } & M & LG & 7 & $\mathbf{N}$ \\
\hline 10 & \multicolumn{2}{|l|}{ PINK } & $\mathrm{N}$ & $\mathbf{N}$ & $\mathrm{N}$ & $\mathbf{N}$ \\
\hline 11 & \multicolumn{2}{|l|}{ PINK } & $N$ & $N$ & $N$ & $N$ \\
\hline 12 & \multicolumn{2}{|c|}{ LTREDDISH BROWN } & $\mathbf{N}$ & $N$ & $N$ & $N$ \\
\hline No & Treatment & $\begin{array}{l}\text { Treatment } \\
\text { Location }\end{array}$ & $\begin{array}{l}\text { Treatment } \\
\text { Cover }\end{array}$ & $\begin{array}{l}\text { Color } \\
\text { Interior }\end{array}$ & $\begin{array}{l}\text { Color } \\
\text { Exterior }\end{array}$ & \\
\hline 1 & SB & IE & ALL & DUSKY RED & DUSKY RED & \\
\hline 2 & SB & IE & $A L L$ & RED & RED & \\
\hline 3 & $\mathrm{~s}$ & IR & ALL & RED & $\mathbf{N}$ & \\
\hline 4 & UN & $N$ & $N$ & $N$ & $N$ & \\
\hline 5 & $S$ & IE & ALL & RED & RED & \\
\hline 6 & UN & $\mathbf{N}$ & $\mathrm{N}$ & $\mathbf{N}$ & $\mathbf{N}$ & \\
\hline 7 & UN & $N$ & $N$ & $N$ & $N$ & \\
\hline 8 & UN & $\mathrm{N}$ & $\mathbf{N}$ & $\mathbf{N}$ & $\mathrm{N}$ & \\
\hline 9 & $\mathbf{s}$ & ER & $A L L$ & $\mathbf{N}$ & DUSKY RED & \\
\hline 10 & $\mathbf{S}$ & E & ALL & $\mathbf{N}$ & RED & \\
\hline 11 & WASH & ER & ALL & $\mathrm{N}$ & WHITE & \\
\hline 12 & UN & 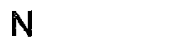 & $N$ & $N$ & $N$ & \\
\hline
\end{tabular}

PLATE 173. FIELD D. PHASE 2A (MIXED EB). 


\section{Other}

$2 \quad$ Burn mark on rim suggests use as lamp.

4 "Margin" appears wet turned, splaying clay forms small ridge; rim folding is suggested in break; surface burn visible.

5 Deep crosshatch incision on interior wall; perhaps a grater?; sample too small to confirm stance or diameter.

6 Surface burn visible.

8 Sample too small to confirm stance or diameter.

10 Break mark suggests loop handle emerged from shoulder.

PLATE 173 (CONT.). 

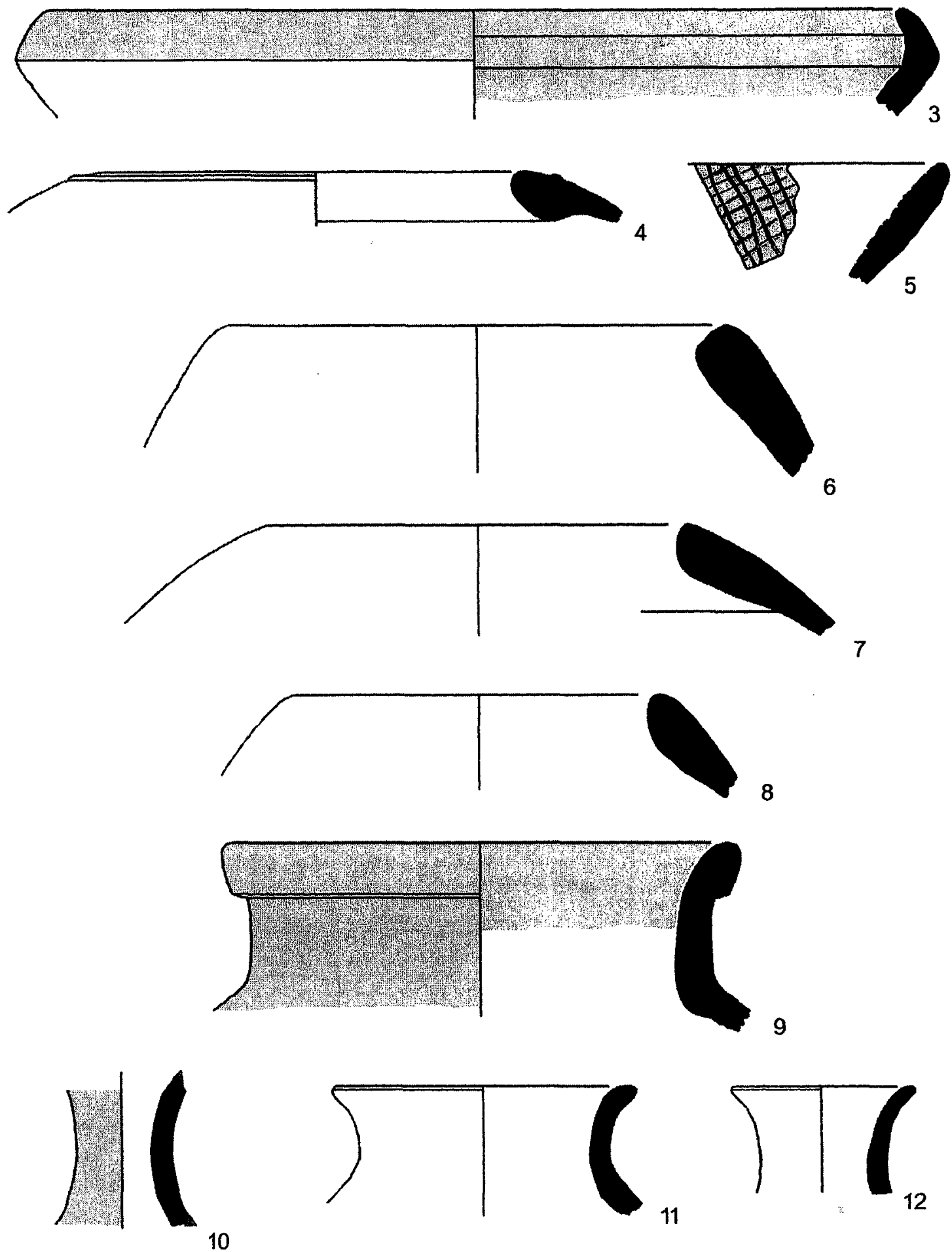

10

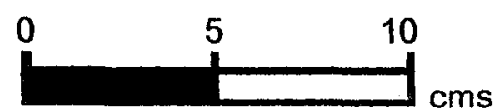


633

\begin{tabular}{|c|c|c|c|c|c|c|c|}
\hline No & $\operatorname{Reg}$ & Square & Locus & Vessel & Part & $\begin{array}{l}\text { Body } \\
\text { Thick }\end{array}$ & $\mathrm{Dia}$ \\
\hline 1 & 1993 & SW 7-7 & 166 & UD & $\mathrm{H} 21$ & 11 & 32 \\
\hline 2 & 1999 & SW 7-7 & 166 & JUG & B13 & 6 & 5 \\
\hline 3 & 1998 & SW 7-7 & 166 & JUG & B12 & 4 & 4 \\
\hline 4 & 2003 & SW 7-7 & 166 & UD & $\mathrm{B} 12$ & 12 & $N$ \\
\hline 5 & 1995 & SW 7-7 & 166 & UD & $\mathrm{H} 14$ & 7 & $N$ \\
\hline 6 & 1996 & SW 7-7 & 166 & UD & $\mathrm{H} 10$ & $N$ & $\mathbf{N}$ \\
\hline 7 & 1994 & SW 7-7 & 166 & UD & $\mathrm{H} 27$ & 13 & $\mathbf{N}$ \\
\hline 8 & 1997 & SW 7-7 & 166 & UD & $\mathrm{H} 27$ & 8 & $\mathbf{N}$ \\
\hline 9 & 1980 & SW 7-7 & 166 & PLATTER BOWL & R53 & 8 & 44 \\
\hline 10 & 1982 & SW 7-7 & 166 & LEDGE RIM BOWL & R53 & 15 & 40 \\
\hline 11 & 1983 & SW 7-7 & 166 & PLATTER BOWL & R57 & 14 & 40 \\
\hline 12 & 1981 & SW 7-7 & 166 & HOLE MOUTH JAR & R20 & 10 & 56 \\
\hline
\end{tabular}

\begin{tabular}{lllll}
\hline No Fabric Color & Core Orient & Core Color & Core Thick & Fabric \\
& & & Family
\end{tabular}

\begin{tabular}{|c|c|c|c|c|c|c|}
\hline 1 & \multicolumn{2}{|c|}{ LT REDDISH BROWN } & $M$ & G & 4 & $\mathrm{~N}$ \\
\hline 2 & \multicolumn{2}{|l|}{ LT RED } & $\mathrm{N}$ & $\mathbf{N}$ & $\mathrm{N}$ & $\mathbf{N}$ \\
\hline 3 & \multicolumn{2}{|l|}{ LT RED } & $\mathrm{N}$ & $\mathrm{N}$ & $\mathbf{N}$ & $\mathbf{N}$ \\
\hline 4 & \multicolumn{2}{|l|}{ PINK } & IRR & $\mathrm{G}$ & $\mathrm{N}$ & $N$ \\
\hline 5 & \multicolumn{2}{|l|}{ PINK } & IRR & $\mathbf{G}$ & $N$ & $N$ \\
\hline 6 & \multicolumn{2}{|l|}{ LT RED } & IRR & G & $N$ & $\mathbf{N}$ \\
\hline 7 & \multicolumn{2}{|l|}{ PINK } & IRR & LG & $N$ & N \\
\hline 8 & \multicolumn{2}{|c|}{ LT REDDISH BROWN } & $N$ & $N$ & $\mathrm{~N}$ & $\mathrm{~N}$ \\
\hline 9 & \multicolumn{2}{|c|}{ RED } & $N$ & $N$ & $N$ & $N$ \\
\hline 10 & \multicolumn{2}{|l|}{ LT RED } & $M$ & G & 9 & N \\
\hline 11 & \multicolumn{2}{|l|}{ PINK } & $M$ & G & 6 & N \\
\hline 12 & \multicolumn{2}{|l|}{ LT RED } & IN & $\mathbf{G}$ & 3 & $N$ \\
\hline No & Treatment & $\begin{array}{l}\text { Treatment } \\
\text { Location }\end{array}$ & $\begin{array}{l}\text { Treatment } \\
\text { Cover }\end{array}$ & $\begin{array}{l}\text { Color } \\
\text { Interior }\end{array}$ & $\begin{array}{l}\text { Color } \\
\text { Exterior }\end{array}$ & \\
\hline 1 & UN & $\mathrm{N}$ & $\mathrm{N}$ & $\mathrm{N}$ & $\mathrm{N}$ & \\
\hline 2 & B & $E$ & ALL & $\mathbf{N}$ & $\mathbf{N}$ & \\
\hline 3 & 1 & $E$ & ALL & $N$ & $\mathbf{N}$ & \\
\hline 4 & $\mathrm{~S}$ & $\mathrm{E}$ & ALL & $\mathbf{N}$ & DUSKY RED & \\
\hline 5 & $\mathrm{~s}$ & E & ALL & $N$ & RED & \\
\hline 6 & UD & $\mathbf{N}$ & $\mathbf{N}$ & $N$ & $\mathrm{~N}$ & \\
\hline 7 & $\mathbf{s}$ & $\mathbf{E}$ & ALL & $\mathrm{N}$ & LT RED & \\
\hline 8 & $\mathbf{s}$ & $E$ & ALL & $N$ & DUSKY RED & \\
\hline 9 & B & IE & ALL & $N$ & $\mathbf{N}$ & \\
\hline 10 & $\mathrm{~B}$ & IE & ALL & $N$ & $N$ & \\
\hline 11 & SB & IR & $A L L$ & LTRED & $\mathbf{N}$ & \\
\hline 12 & UN & $N$ & $\mathbf{N}$ & $N$ & $N$ & \\
\hline
\end{tabular}

PLATE 174. FIELD D. PHASE 2A (MIXED EB). 


\section{Other}

1 Possibly intrusive.

$2 \quad$ Large "swirling" glob of clay in center of base interior.

3 Some signs of burn on broken edge; combed; string-cut base.

4 Sample too small to confirm stance or diameter.

9 Metallic Ware.

10 Slight groove on exterior, just under carination.

11 Radial burnish over slip on interior face; very narrow band of wet-smoothing immediately under rim; scraping grooves on a "textured" surface occupy the rest of the exterior face; some inclusion "drag" lines suggest scraping in a counter-clockwise direction.

PLATE 174 (CONT.). 

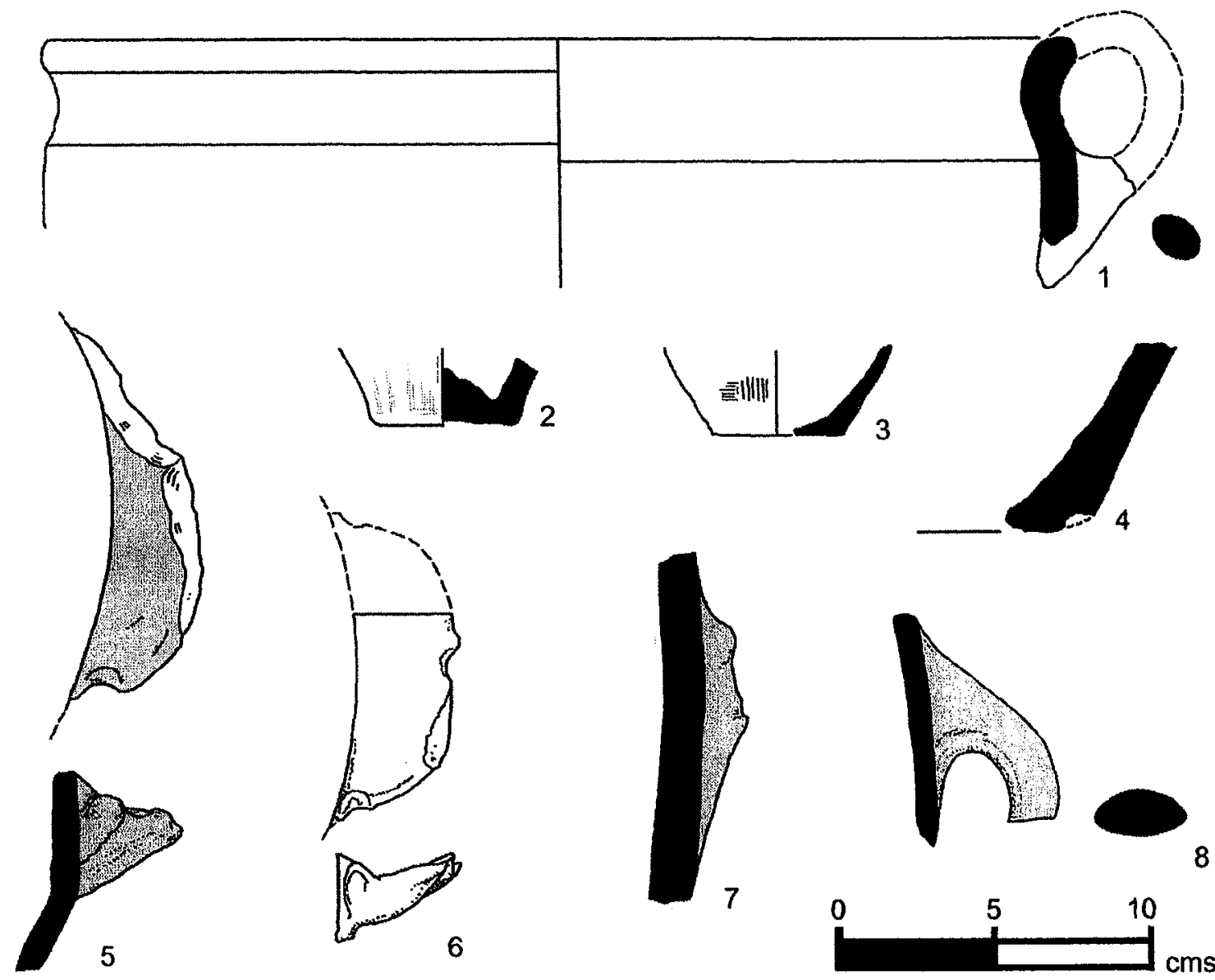

6

7
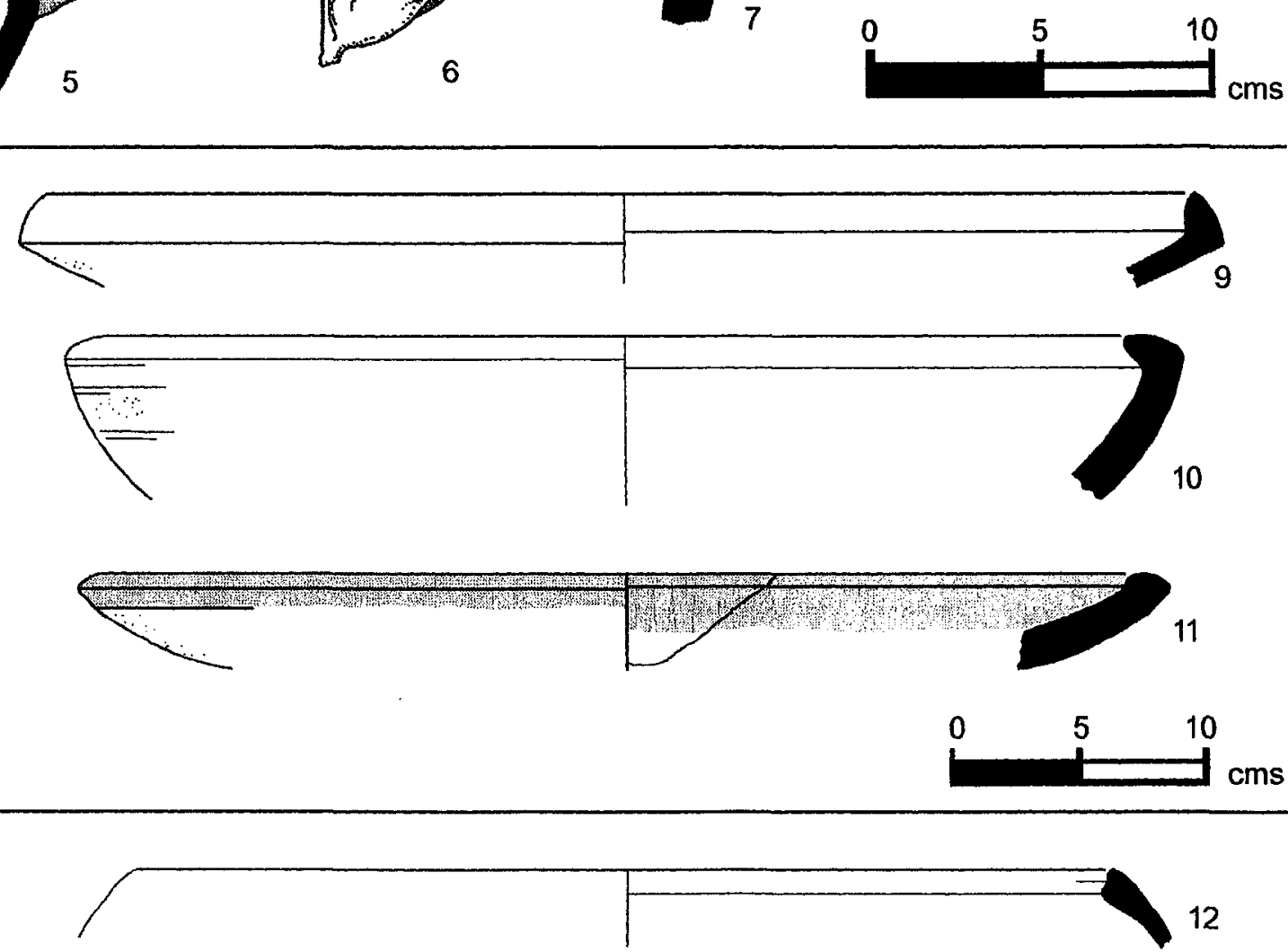

PLATE 174 (CONT.).

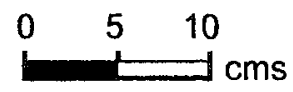




\begin{tabular}{llllllll}
\hline No & Reg & Square & Locus & Vessel & Part & $\begin{array}{l}\text { Body } \\
\text { Thick }\end{array}$ & Dia \\
\hline & & & & & & \\
1 & 2026 & SW 7-7 & 168 & LEDGE RIM BOWL & R51 & 9 & 25 \\
2 & 2025 & SW 7-7 & 169 & HOLE MOUTH BOWL & R14 & 10 & 20 \\
3 & 2024 & SW 7-7 & 169 & HOLE MOUTH JARIBOWL & R19 & 9 & 14 \\
4 & 2028 & SW 7-7 & 168 & HOLE MOUTH JARIBOWL & R14 & 12 & N \\
5 & 2019 & SW 7-7 & 169 & BOW RIM JAR & R33 & 13 & 18 \\
6 & 2021 & SW 7-7 & 169 & NECKED JAR & R32 & 11 & 13 \\
7 & 2027 & SW 7-7 & 168 & NECKED JAR & R31 & 7 & 9 \\
8 & 2020 & SW 7-7 & 169 & HOLE MOUTH BOWL & R01 & 17 & 40 \\
9 & 2023 & SW 7-7 & 169 & HOLE MOUTH BOWL & R19 & 11 & 40 \\
\hline No & Fabric Color & & Core Orient Core Color & Core Thick & Fabric \\
& & & & & & Family
\end{tabular}

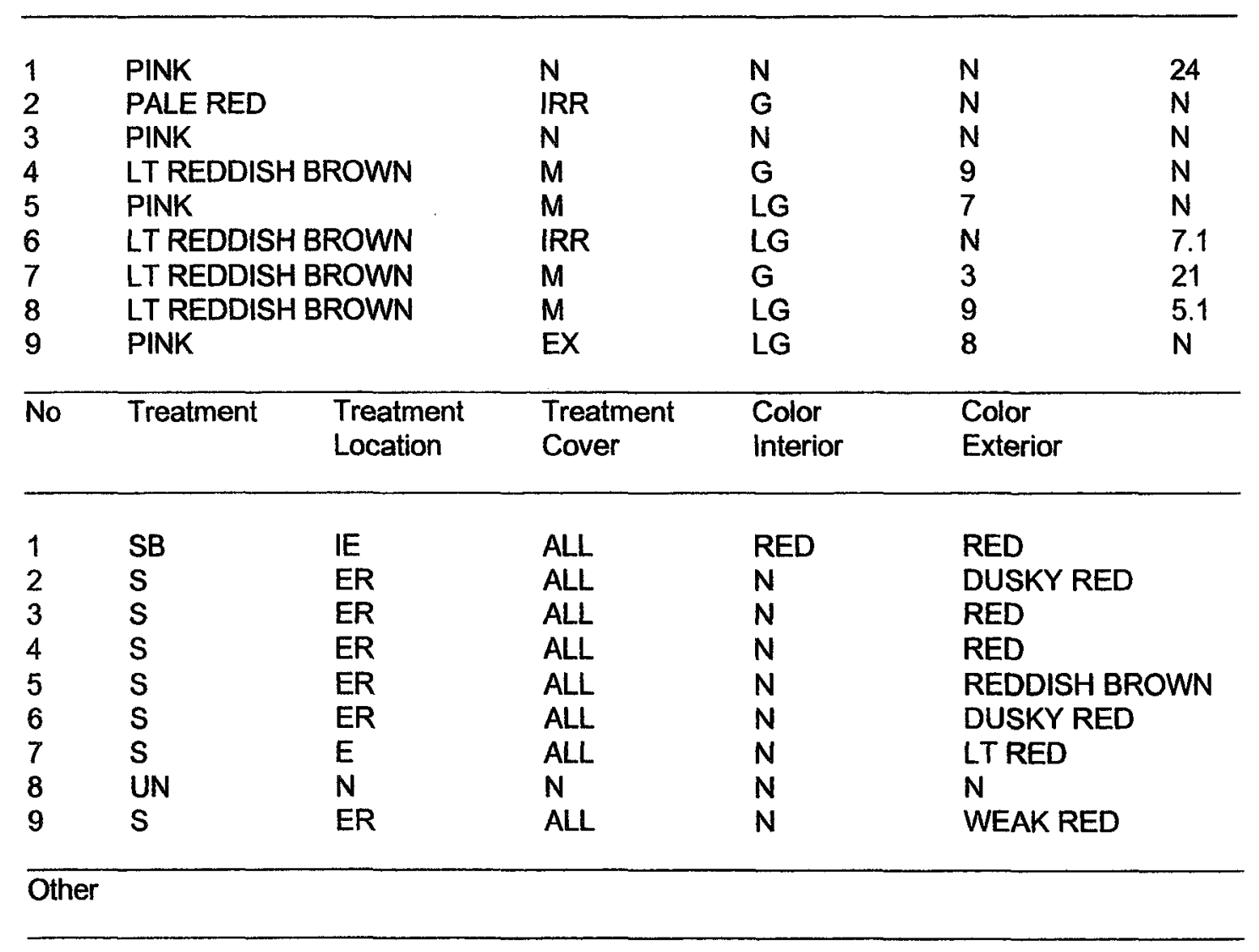

$1 \quad$ Features in section suggest rim folding.

$4 \quad$ Sample too small to confirm stance or diameter.

8 Surface burn visible.

PLATE 175. FIELD D. PHASE 2A (MIXED EB). 
637

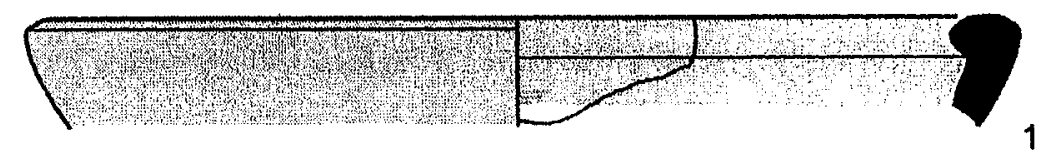

1
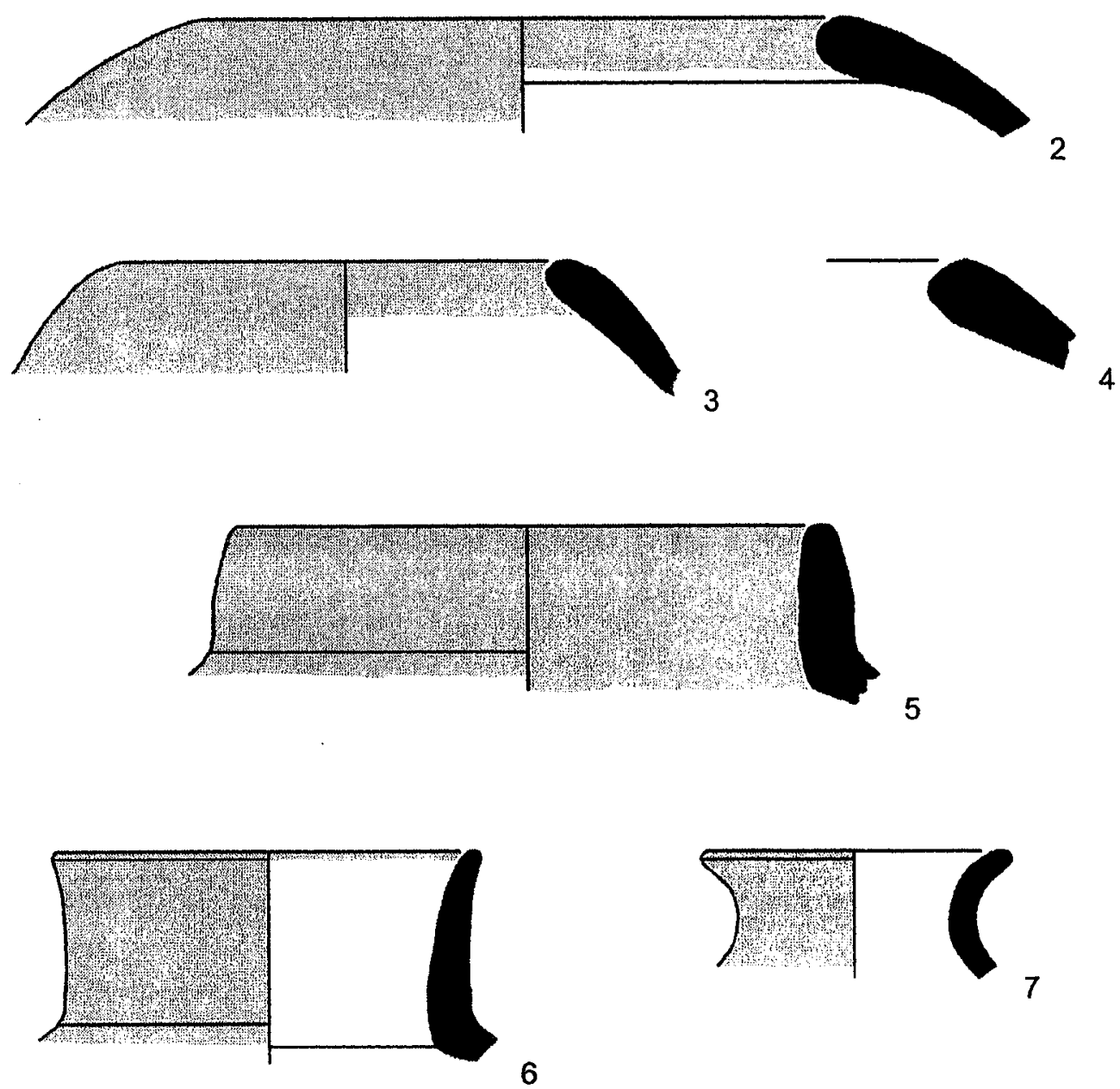

6
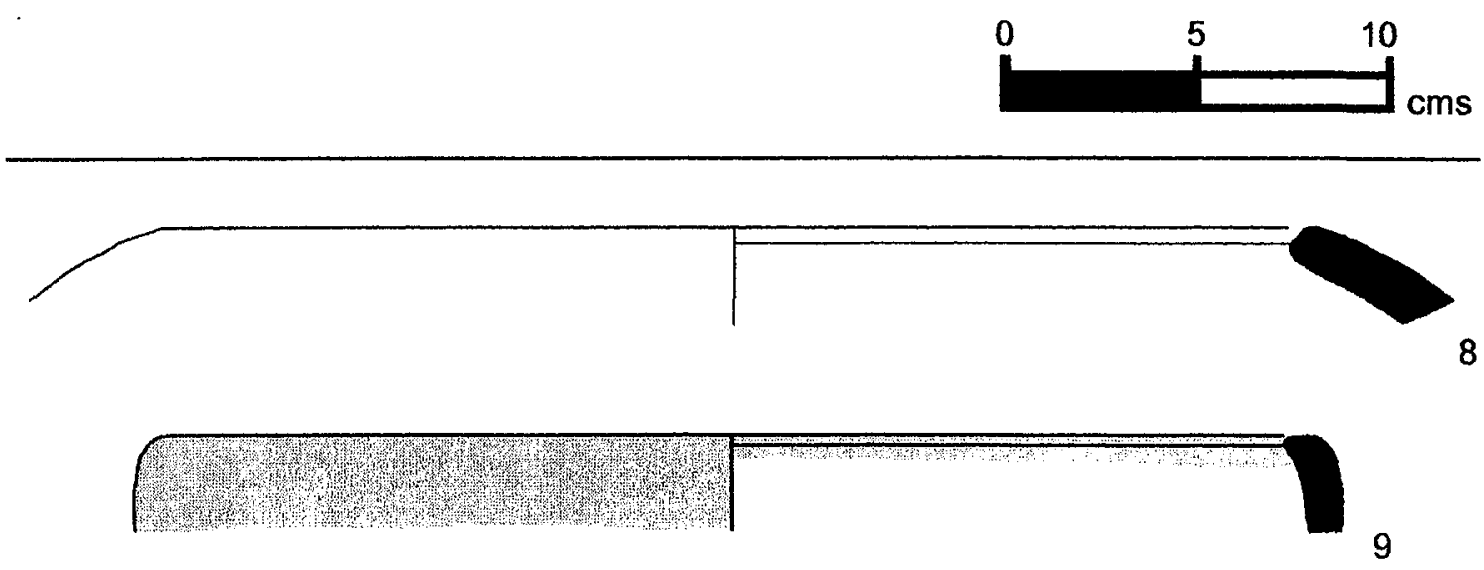

PLATE 175 (CONT.).

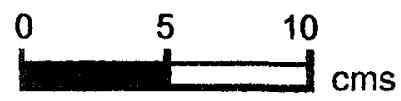


638

\begin{tabular}{llllllll}
\hline No & Reg & Square & Locus & Vessel & Part & $\begin{array}{l}\text { Body } \\
\text { Thick }\end{array}$ & Dia \\
\hline 1 & 2014 & SW 7-7 & 172 & HOLE MOUTH BOWL & R14 & 10 & 24 \\
2 & 2018 & SW 7-7 & 172 & HOLE MOUTH JARIBOWL & R18 & 9 & 16 \\
3 & 2017 & SW 7-7 & 172 & NECKED JAR & R43 & 6 & 14 \\
4 & 2012 & SW 7-7 & 172 & BOW RIM JAR & R33 & 10 & 18 \\
5 & 2015 & SW 7-7 & 172 & PLATTER BOWL & R53 & 8 & 42 \\
6 & 2016 & SW 7-7 & 172 & LEDGE RIM BOWL & R53 & 13 & 40 \\
7 & 2013 & SW 7-7 & 172 & PLATTER BOWL & R56 & 9 & 40
\end{tabular}

\begin{tabular}{lllll}
\hline No Fabric Color & Core Orient & Core Color Core Thick & Fabric \\
& & & Family
\end{tabular}

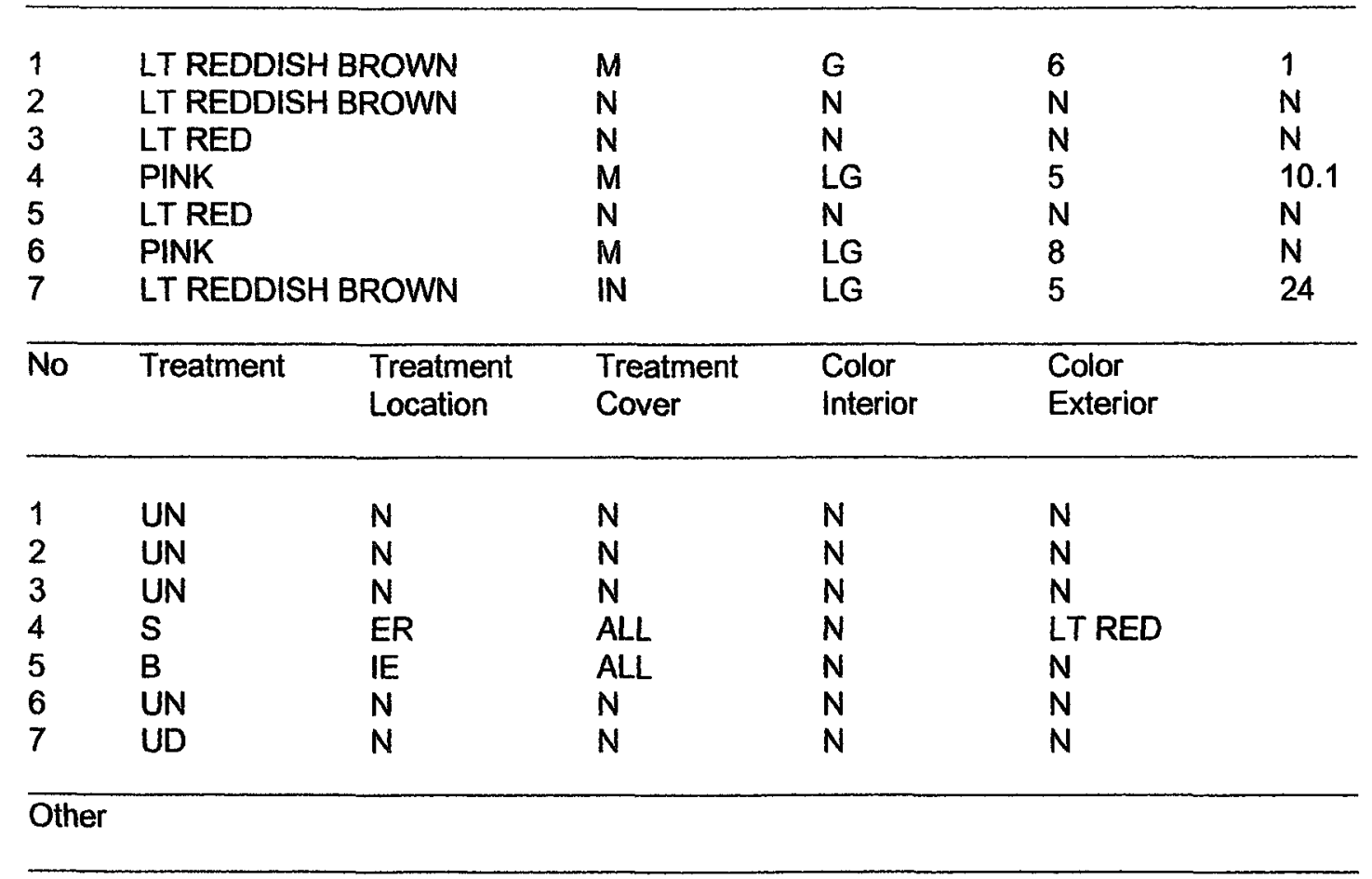

1 Surface burn visible.

2 Sample too small to confirm stance or diameter.

3 Metallic Ware.

$4 \quad$ Also in Fabric Family 19.

5 Metallic Ware.

6 Fine horizontal finish lines on rim; coarse diagonal scraping lines on exterior face.

7 Heavily weathered.

PLATE 176. FIELD D. PHASE 2A (MIXED EB). 

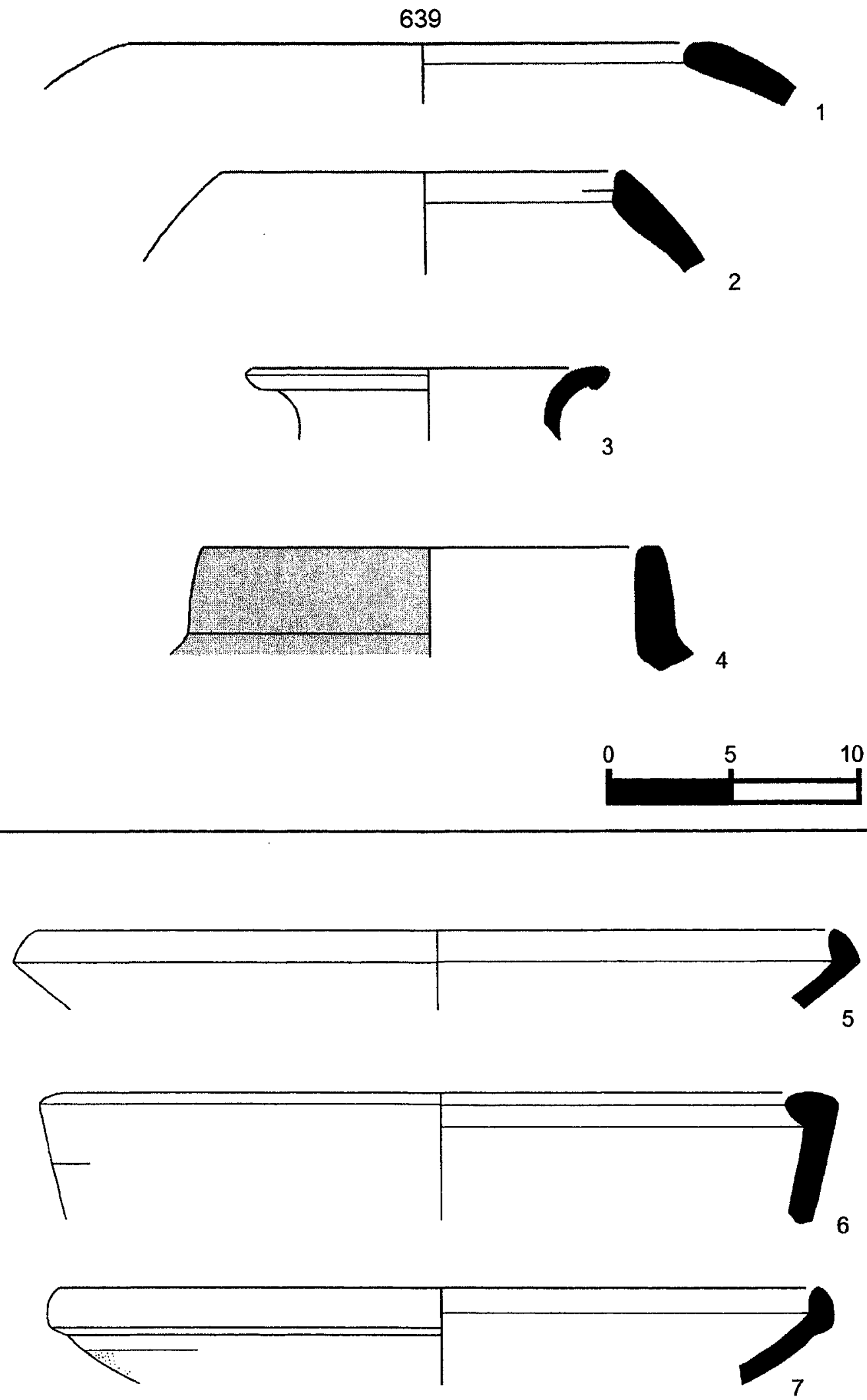

PLATE 176 (CONT.).

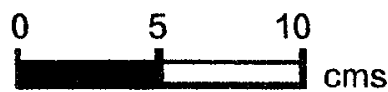


640

\begin{tabular}{llllllll}
\hline No & Reg & Square & Locus & Vessel & Part & $\begin{array}{l}\text { Body } \\
\text { Thick }\end{array}$ & Dia \\
\hline 1 & & & & & & & \\
2 & 2030 & SW 7-7 & 173 & HOLE MOUTH BOWL & R00 & 7 & 25 \\
3 & 2036 & SW 7-7 & 173 & HOLE MOUTH JAR & R04 & 10 & 15 \\
4 & 2037 & SW 7-7 & 174 & HOLE MOUTH JAR & R14 & 11 & 25 \\
5 & 2039 & SW 7-7 & 174 & HOLE MOUTH JAR & R22 & N & 20 \\
6 & 2040 & SW 7-7 & 174 & NECKED JAR & R42 & 10 & 20 \\
7 & 2464 & SW 7-7 & 173 & UD & B12 & 9 & 8 \\
8 & 2034 & SW 7-7 & 173 & UD & H27 & 16 & N \\
9 & 2032 & SW 7-7 $7-7$ & 173 & UD & H27 & 9 & N \\
10 & 2038 & SW 7-7 & 173 & UD & H27 & 6 & N \\
11 & 2031 & SW 7-7 & 174 & PLATTER BOWL & R56 & 12 & 48 \\
& & & & LEDGE RIM BOWL & R53 & 15 & 42
\end{tabular}

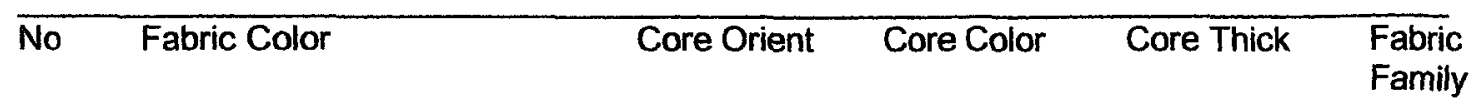

\begin{tabular}{|c|c|c|c|c|c|c|}
\hline 1 & \multirow{2}{*}{\multicolumn{2}{|c|}{ WEAK RED }} & IRR & G & $\mathbf{N}$ & 2.2 \\
\hline 2 & & LT REDDISH BROWN & $N$ & $N$ & $N$ & $N$ \\
\hline 3 & \multicolumn{2}{|c|}{ LT REDDISH BROWN } & EX & G & 6 & 15 \\
\hline 4 & \multicolumn{2}{|l|}{ LT RED } & IRR & G & $\mathbf{N}$ & 9.2 \\
\hline 5 & \multicolumn{2}{|c|}{ LT REDDISH BROWN } & $N$ & $N$ & $N$ & 25.1 \\
\hline 6 & \multicolumn{2}{|c|}{ LT REDDISH BROWN } & $N$ & $N$ & $N$ & 10.2 \\
\hline 7 & \multicolumn{2}{|c|}{ LTRED } & $M$ & $G$ & 10 & 7.1 \\
\hline 8 & \multicolumn{2}{|l|}{ PINK } & IRR & G & $\mathbf{N}$ & 21 \\
\hline 9 & \multicolumn{2}{|c|}{ PINKISH GREY } & $N$ & $N$ & $N$ & 4 \\
\hline 10 & \multicolumn{2}{|c|}{ LT REDDISH BROWN } & $M$ & G & 6 & 11 \\
\hline 11 & \multicolumn{2}{|c|}{ PINK } & $N$ & $N$ & $\mathrm{~N}$ & 12.1 \\
\hline No & Treatment & $\begin{array}{l}\text { Treatment } \\
\text { Location }\end{array}$ & $\begin{array}{l}\text { Treatment } \\
\text { Cover }\end{array}$ & $\begin{array}{l}\text { Color } \\
\text { Interior }\end{array}$ & $\begin{array}{l}\text { Color } \\
\text { Exterior }\end{array}$ & \\
\hline 1 & UN & $N$ & $N$ & $\mathbf{N}$ & $N$ & \\
\hline 2 & $S$ & ER & ALL & $\mathbf{N}$ & LT RED & \\
\hline 3 & UN & $\mathbf{N}$ & $\mathbf{N}$ & $\mathbf{N}$ & $\mathrm{N}$ & \\
\hline 4 & WASH & ER & ALL & $\mathbf{N}$ & WHITE & \\
\hline 5 & UN & $\mathrm{N}$ & $\mathbf{N}$ & $\mathbf{N}$ & $\mathrm{N}$ & \\
\hline 6 & UN & $\mathbf{N}$ & $\mathbf{N}$ & $\mathbf{N}$ & $\mathbf{N}$ & \\
\hline 7 & $\mathbf{s}$ & $E$ & ALL & $\mathbf{N}$ & LT RED & \\
\hline 8 & UN & $\mathbf{N}$ & $\mathbf{N}$ & $\mathbf{N}$ & $\mathbf{N}$ & \\
\hline 9 & $S$ & $E$ & ALL & $N$ & RED & \\
\hline 10 & SB & $\mathbb{R}$ & ALL & LT RED & $N$ & \\
\hline 11 & SB & IR & ALL & RED & RED & \\
\hline
\end{tabular}

PLATE 177. FIELD D. PHASE 2A (MIXED EB). 
Other

1 Sample too small to confirm stance or diameter.

2 Surface burn visible.

3 Fine marks on rim exterior show finishing motions; surface burn visible.

5 Sample too small to confirm stance or diameter; Metallic Ware.

6 Thin section sample 34; sample too small to confirm stance or diameter.

PLATE 177 (CONT.). 

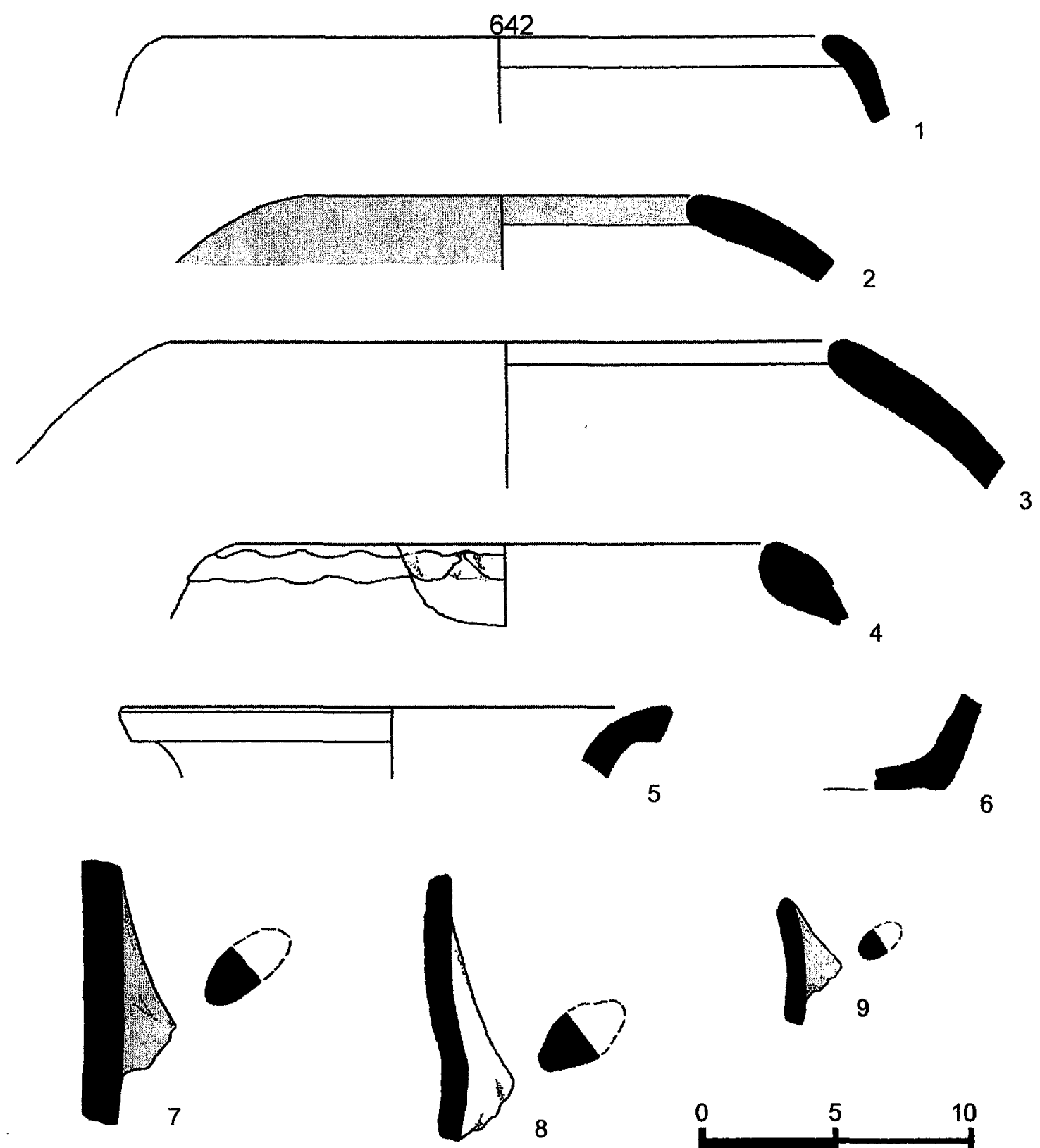

6

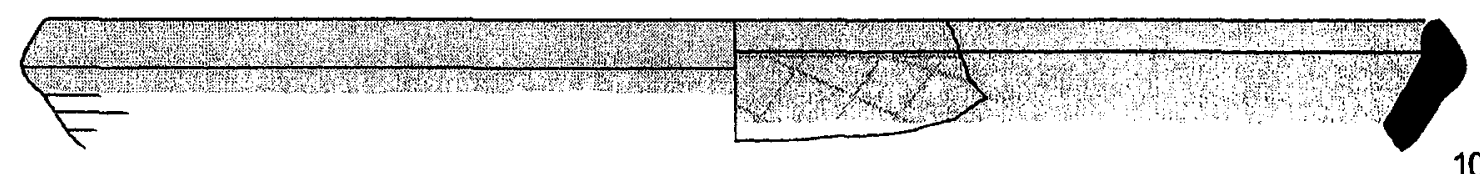

PLATE 177 (CONT).

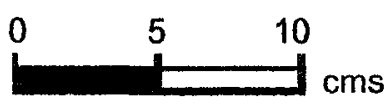


643

\begin{tabular}{llllllll}
\hline No & Reg & Square & Locus & Vessel & Part & $\begin{array}{c}\text { Body } \\
\text { Thick }\end{array}$ & Dia \\
\hline & & & & & & & \\
1 & 2041 & SW 7-7 & 175 & PLATTER BOWL & R53 & 7 & 20 \\
2 & 2042 & SW 7-7 & 175 & HOLE MOUTH JAR & R11 & 9 & 14 \\
3 & 2043 & SW 7-7 & 175 & NECKED JAR & R43 & 12 & 24 \\
4 & 2486 & SW 7-7 & 175 & NECK JAR & R42 & N & N \\
5 & 2045 & SW 7-7 & 175 & BOWL & R58 & 15 & 45 \\
6 & 2044 & SW 7-7 & 175 & LEDGE RIM BOWL & R51 & 11 & 40
\end{tabular}

\begin{tabular}{lllll}
\hline No Fabric Color & Core Orient & Core Color Core Thick & $\begin{array}{l}\text { Fabric } \\
\text { Family }\end{array}$ \\
\end{tabular}

\begin{tabular}{|c|c|c|c|c|c|c|}
\hline $\begin{array}{l}1 \\
2 \\
3 \\
4 \\
5 \\
6\end{array}$ & $\begin{array}{l}\text { LTRED } \\
\text { WEAK RED } \\
\text { PINK } \\
\text { LT RED } \\
\text { PINK } \\
\text { LT RED }\end{array}$ & & $\begin{array}{l}M \\
N \\
M \\
\text { IRR } \\
\text { IN } \\
N\end{array}$ & $\begin{array}{l}G \\
N \\
G \\
G \\
G \\
N\end{array}$ & $\begin{array}{l}3 \\
N \\
6 \\
N \\
N \\
N\end{array}$ & $\begin{array}{l}7.2 \\
6 \\
16 \\
8 \\
N \\
N\end{array}$ \\
\hline No & Treatment & $\begin{array}{l}\text { Treatment } \\
\text { Location }\end{array}$ & $\begin{array}{l}\text { Treatment } \\
\text { Cover }\end{array}$ & $\begin{array}{l}\text { Color } \\
\text { Interior }\end{array}$ & $\begin{array}{l}\text { Color } \\
\text { Exterior }\end{array}$ & \\
\hline $\begin{array}{l}1 \\
2 \\
3 \\
4 \\
5 \\
6\end{array}$ & $\begin{array}{l}\text { B } \\
\text { S } \\
\text { UN } \\
\text { UN } \\
\text { S } \\
\text { UN }\end{array}$ & $\begin{array}{l}\text { IE } \\
\text { ER } \\
N \\
N \\
\text { IE } \\
N\end{array}$ & $\begin{array}{l}\text { LINE } \\
\text { ALL } \\
N \\
N \\
\text { ALL } \\
N\end{array}$ & $\begin{array}{l}N \\
N \\
N \\
N \\
\text { LTRED } \\
N\end{array}$ & $\begin{array}{l}N \\
\text { RED } \\
N \\
N \\
\text { LT RED } \\
N\end{array}$ & \\
\hline
\end{tabular}

3 Sloppily executed.

4 Sample too small to confirm stance or diameter; Thin section sample 50.

5 Sample too small to confirm stance or diameter.

6 Very weathered; sample too small to confirm stance or diameter.

PLATE 178. FIELD D. PHASE 2A (MIXED EB). 

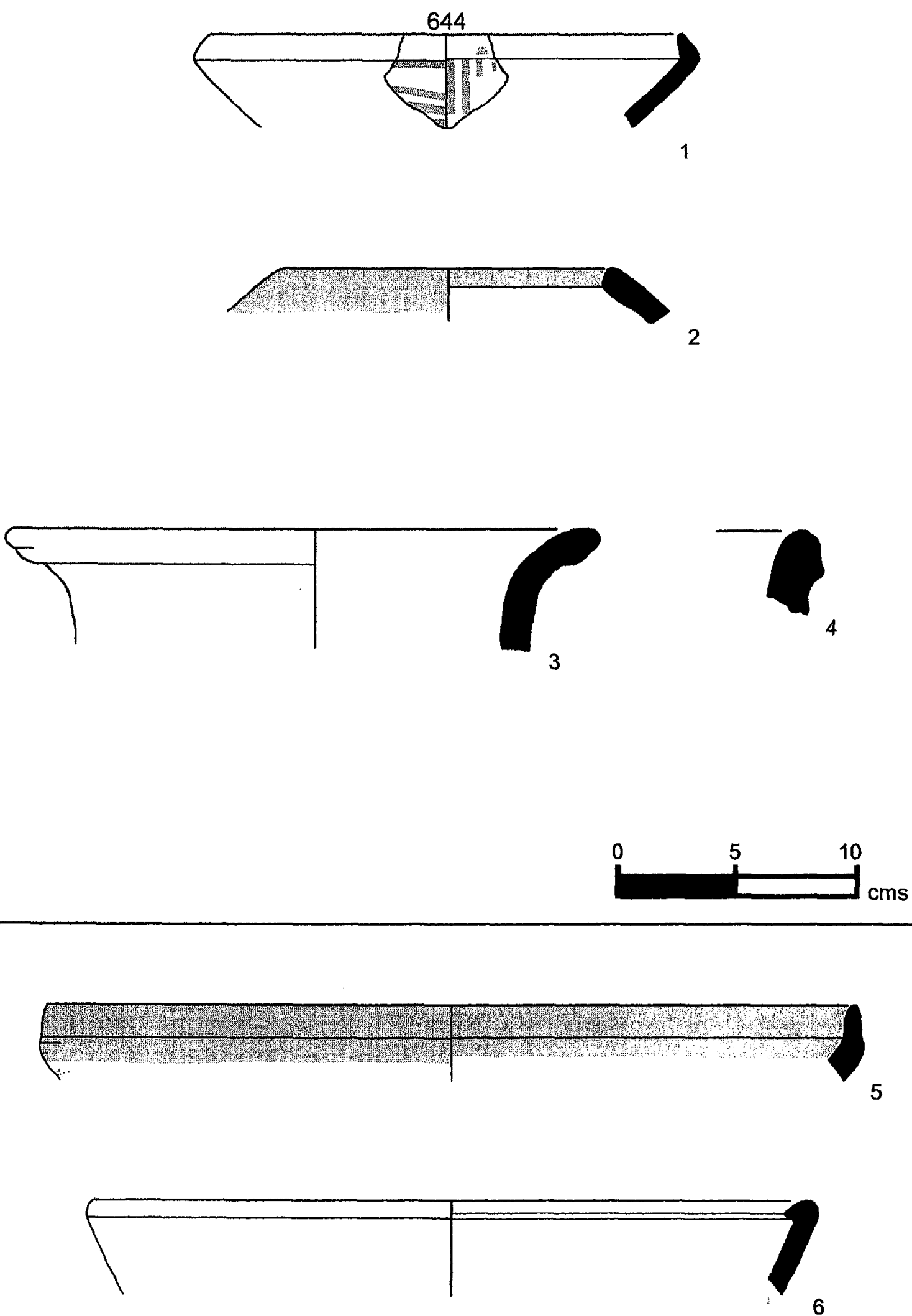

6

PLATE 178 (CONT.).

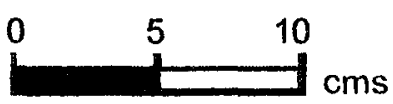


645

\begin{tabular}{|c|c|c|c|c|c|c|c|}
\hline No & $\operatorname{Reg}$ & Square & Locus & Vessel & Part & $\begin{array}{l}\text { Body } \\
\text { Thick }\end{array}$ & $\overline{\text { Dia }}$ \\
\hline 1 & 1671 & SW 6-7 & 243 & BOWL & $\mathrm{R} 50$ & 13 & 30 \\
\hline 2 & 1669 & SW 6-7 & 246 & LEDGE RIM BOWL & $\mathrm{R} 51$ & 8 & 30 \\
\hline 3 & 1672 & SW 6-7 & 243 & NECKED JAR & R31 & 12 & 20 \\
\hline 4 & 1673 & SW 6-7 & 244 & UD & $\mathrm{B} 23$ & 11 & 5 \\
\hline 5 & 1670 & SW 6-7 & 246 & UD & $\mathrm{H} 27$ & 7 & $\mathbf{N}$ \\
\hline 6 & 1674 & SW 6-7 & 220 & LEDGE RIM BOWL & $\mathrm{R} 53$ & 14 & 38 \\
\hline 7 & 1668 & SW 6-7 & 246 & LEDGE RIM BOWL & R51 & 14 & 42 \\
\hline
\end{tabular}

\begin{tabular}{|c|c|c|c|c|c|c|}
\hline 1 & PINK & & $N$ & $N$ & $N$ & $\mathbf{N}$ \\
\hline 2 & RED & & $M$ & G & 5 & 11 \\
\hline 3 & LT RED & & $M$ & LG & 3 & $N$ \\
\hline 4 & PINK & & $M$ & LG & 4 & 17.1 \\
\hline 5 & PINK & & $\mathbf{N}$ & $N$ & $\mathrm{~N}$ & $\mathrm{~N}$ \\
\hline 6 & PINK & & $\mathbf{M}$ & G & 3 & 16 \\
\hline 7 & PINK & & $M$ & LG & 4 & 15 \\
\hline$\overline{\text { No }}$ & Treatment & $\begin{array}{l}\text { Treatment } \\
\text { Location }\end{array}$ & $\begin{array}{l}\text { Treatment } \\
\text { Cover }\end{array}$ & $\begin{array}{l}\text { Color } \\
\text { Interior }\end{array}$ & & $\begin{array}{l}\text { Color } \\
\text { Exterior }\end{array}$ \\
\hline 1 & $S$ & IR & ALL & RED & & $N$ \\
\hline 2 & SB & $\mathbb{R}$ & ALL & RED & & $\mathbf{N}$ \\
\hline 3 & WASH & ER & ALL & $\mathbf{N}$ & & WHITE \\
\hline 4 & $S$ & $E$ & ALL & $N$ & & LT RED \\
\hline 5 & $\mathrm{~S}$ & $E$ & ALL & $\mathbf{N}$ & & REDDISH BROWN \\
\hline 6 & SB & $\mathbb{I R}$ & ALL & RED & & $N$ \\
\hline 7 & SB & ER & ALL & REDDIS & LOW & LT RED \\
\hline
\end{tabular}

\section{Other}

$1 \quad$ Lower exterior wall has scrape marks.

2 Poorly fired.

3 Lines on interior show wet-smoothing of rim.

$6 \quad$ Net pattern burnish over red slip on interior face.

$7 \quad$ Moid marks visible on lower exterior wall.

PLATE 179. FIELD D. PHASE 2B (MIXED EB). 


\section{6}
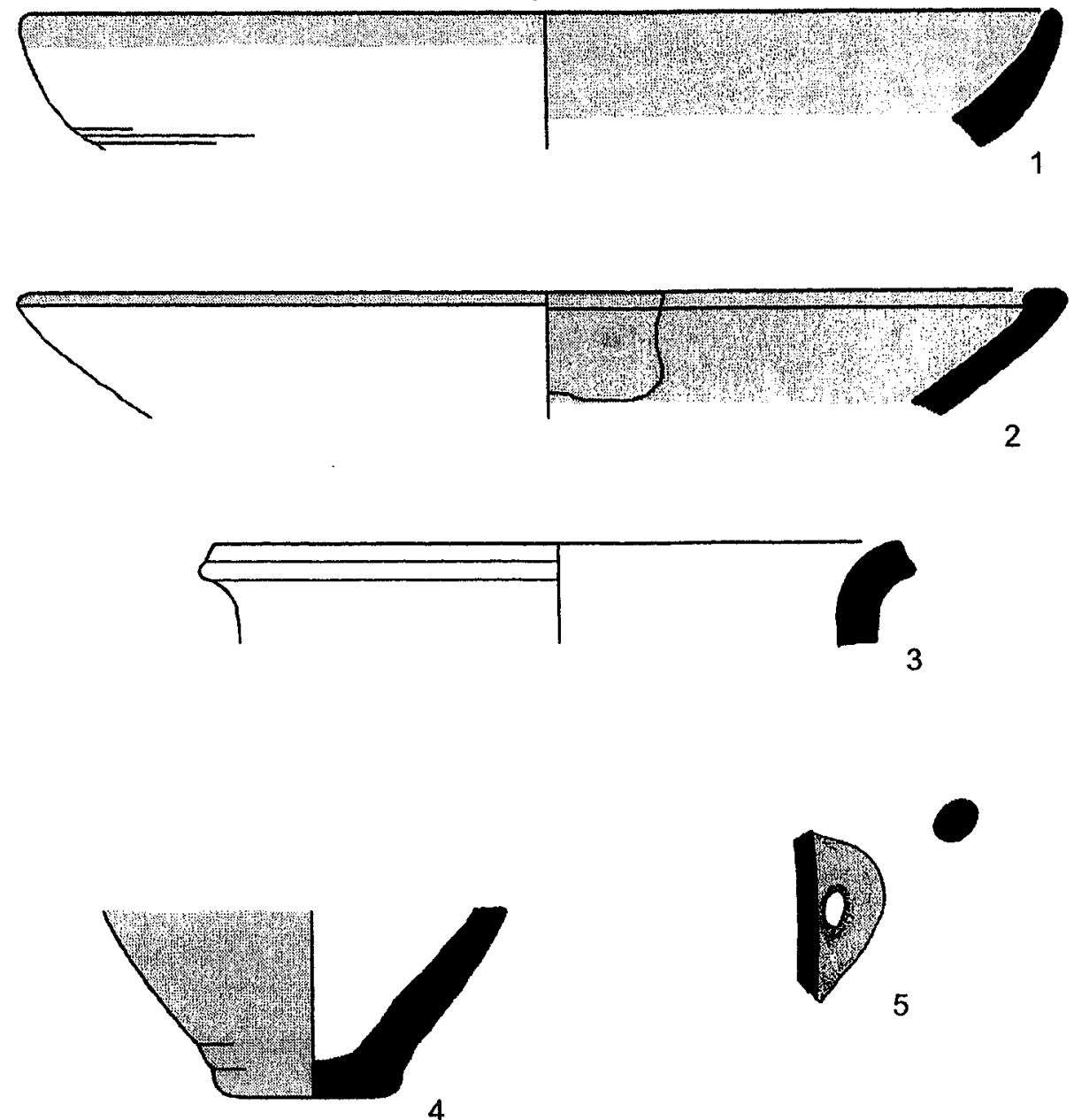

5
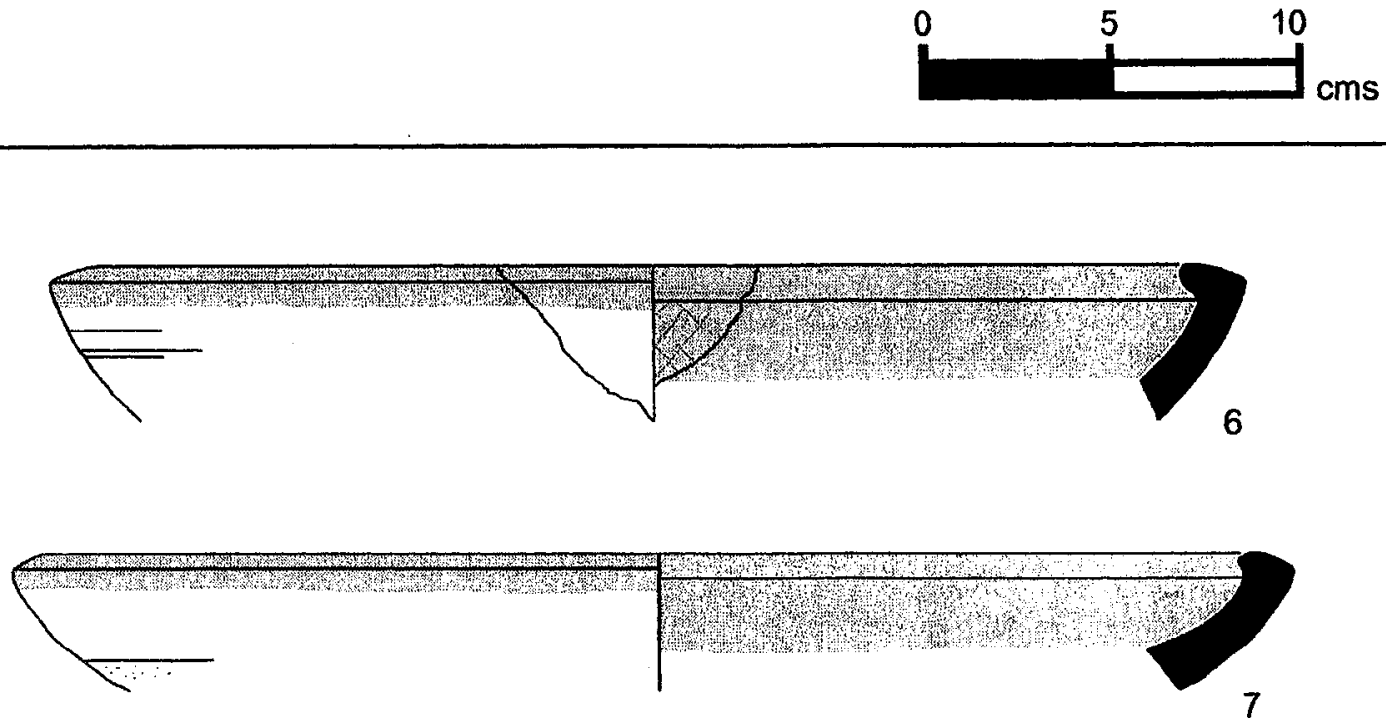

PLATE 179 (CONT.).

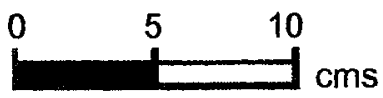


647

\begin{tabular}{llllllll}
\hline No & Reg & Square & Locus & Vessel & Part & $\begin{array}{c}\text { Body } \\
\text { Thick }\end{array}$ & \begin{tabular}{c} 
Dia \\
\hline 1
\end{tabular} \\
\hline & 1921 & SW 7-7 & 149 & LEDGE RIM BOWL & R51 & 11 & 26 \\
2 & 1915 & SW 7-7 & 151 & HOLE MOUTH BOWL & R01 & 14 & 20 \\
3 & 1914 & SW 7-7 & 151 & HOLE MOUTH JAR & R04 & 10 & 10 \\
4 & 1916 & SW 7-7 & 151 & NECKED JAR & R30 & 7 & 14 \\
5 & 1920 & SW 7-7 & 149 & UD & B12 & 11 & 15 \\
6 & 1919 & SW 7-7 & 149 & UD & BOD & 17 & N
\end{tabular}

\begin{tabular}{lllll}
\hline No Fabric Color & Core Orient & Core Color & Core Thick & $\begin{array}{l}\text { Fabric } \\
\text { Family }\end{array}$
\end{tabular}

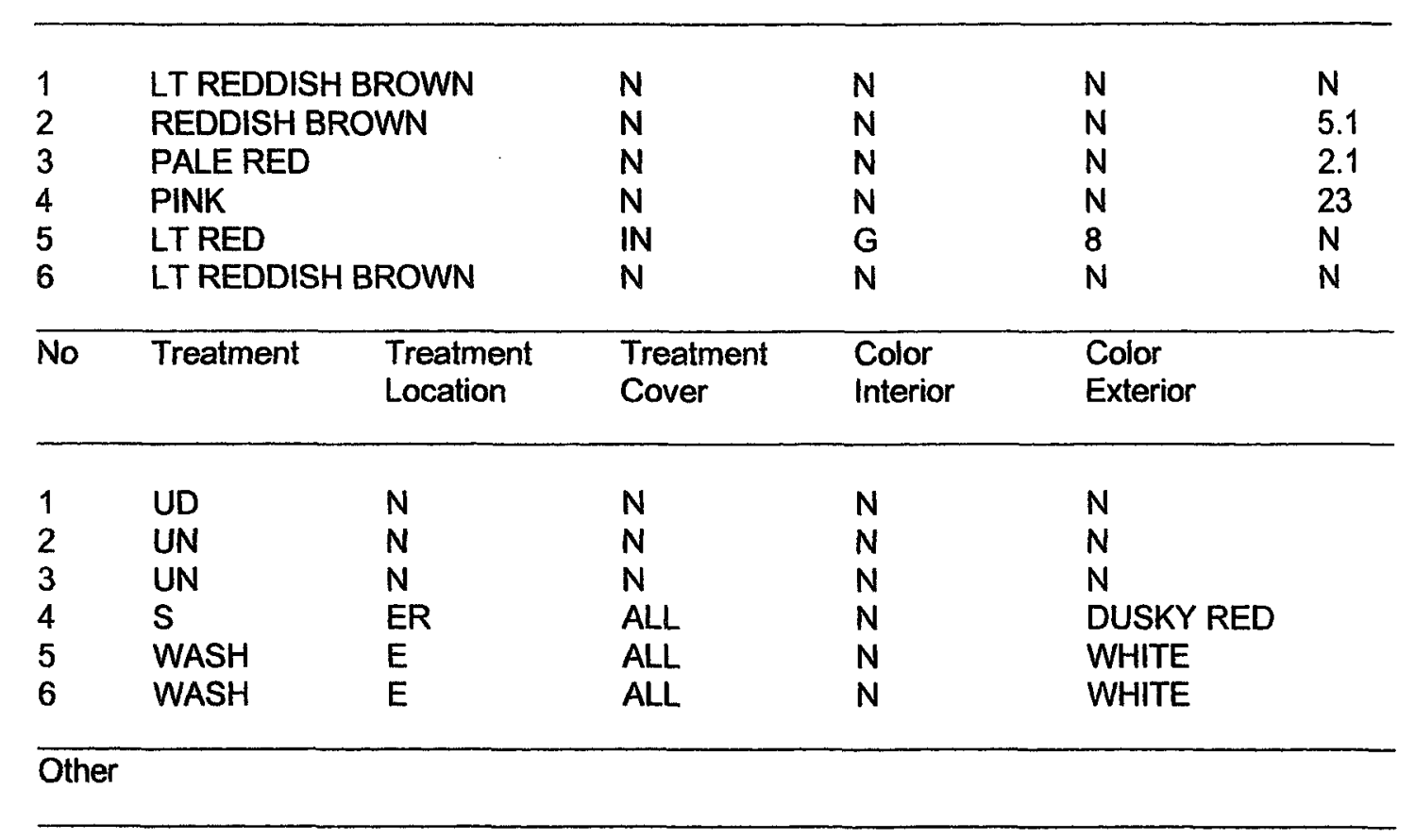

1 Sample too small to confirm stance or diameter.

2. Surface burn visible; scrape lines visible on interior surface, the angle and direction of pull 3 Suggests a right hand

4 Some scrapes on exterior surface; slip color varies, patchy.

5 Metallic Ware.

6 Rope molding from vessel shoulder.

PLATE 180. FIELD D. PHASE 2B (MIXED EB). 

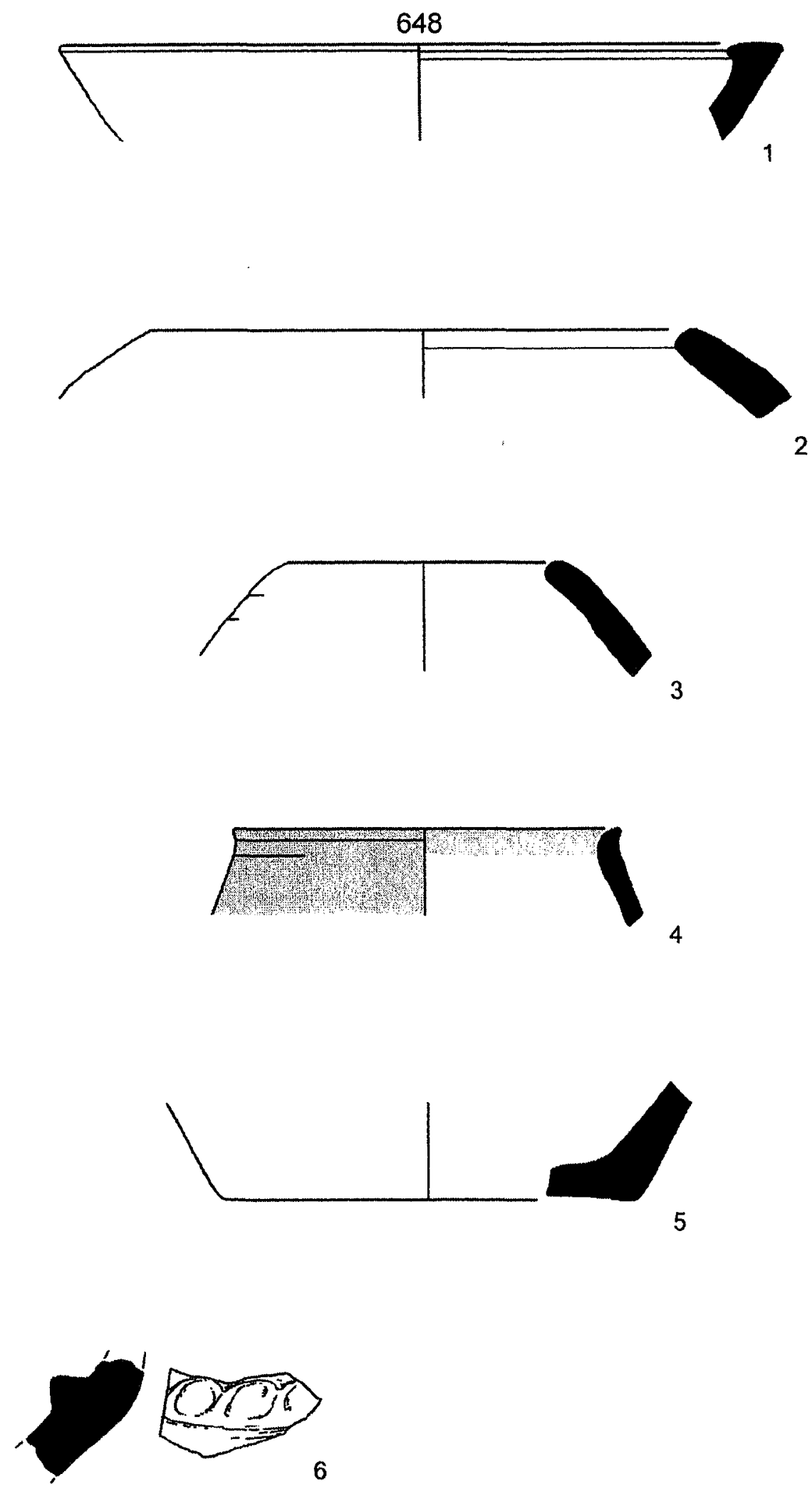

PLATE 180 (CONT.).

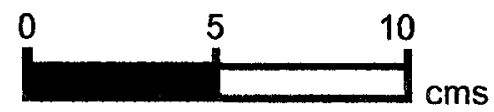




\begin{tabular}{lllllllll}
\hline No & Reg & Square & Locus & Vessel & Part & $\begin{array}{l}\text { Body } \\
\text { Thick }\end{array}$ & Dia \\
\hline & 1909 & SW 7-7 & 153 & LEDGE RIM BOWL & R60 & 13 & 35 \\
1 & 1912 & SW 7-7 & 153 & LEDGE RIM BOWL & R51 & 9 & 38 \\
2 & 1908 & SW 7-7 & 153 & LEDGE RIM BOWL & R51 & 10 & 30 \\
3 & 1906 & SW 7-7 & 153 & LEDGE RIM BOWL & R51 & 11 & 32 \\
4 & 1911 & SW 7-7 & 153 & UD & B12 & 6 & 7 \\
5 & & & & & & & &
\end{tabular}

\begin{tabular}{lllll}
\hline No Fabric Color & Core Orient & Core Color & Core Thick & Fabric \\
& & & Family
\end{tabular}

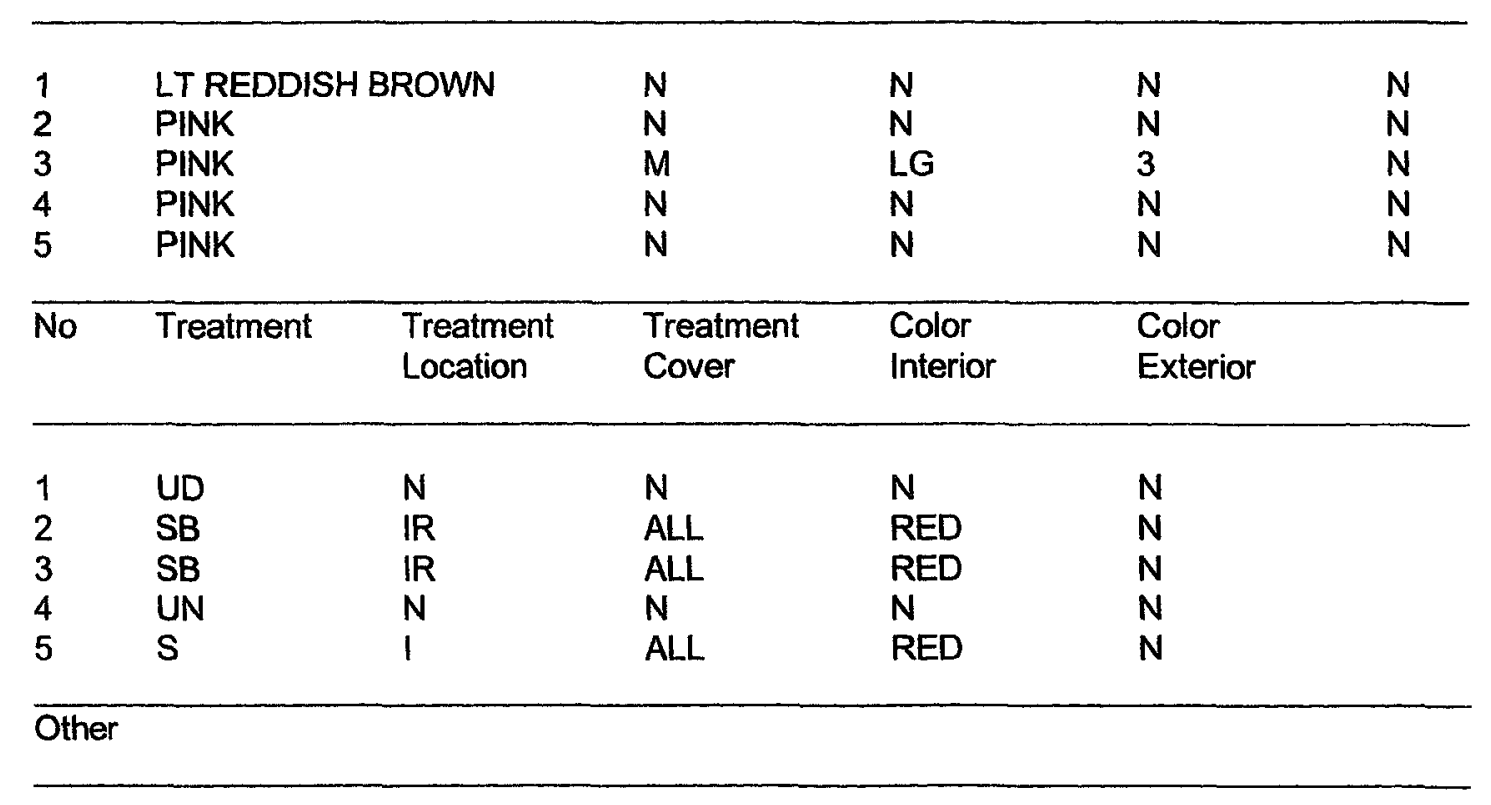

\footnotetext{
1 Weathered; possibly finished with a white wash.

2 Rim broken; interior face is radially burnished.

3 Features in break suggests rim folding inward; interior face radially burnished, rim is well burnished; untreated exterior face is marked by slight concavity, with fine lines of wetsmoothing; lower exterior face marked by scraping.

4 Rim folded inward; interior face wet-smoothed; upper portion of exterior face has wetsmoothed marginal band; lower portion is scraped smooth.

$5 \quad$ String cut base; possibly intrusive.
}

PLATE 181. FIELD D. PHASE 2B (MIXED EB). 

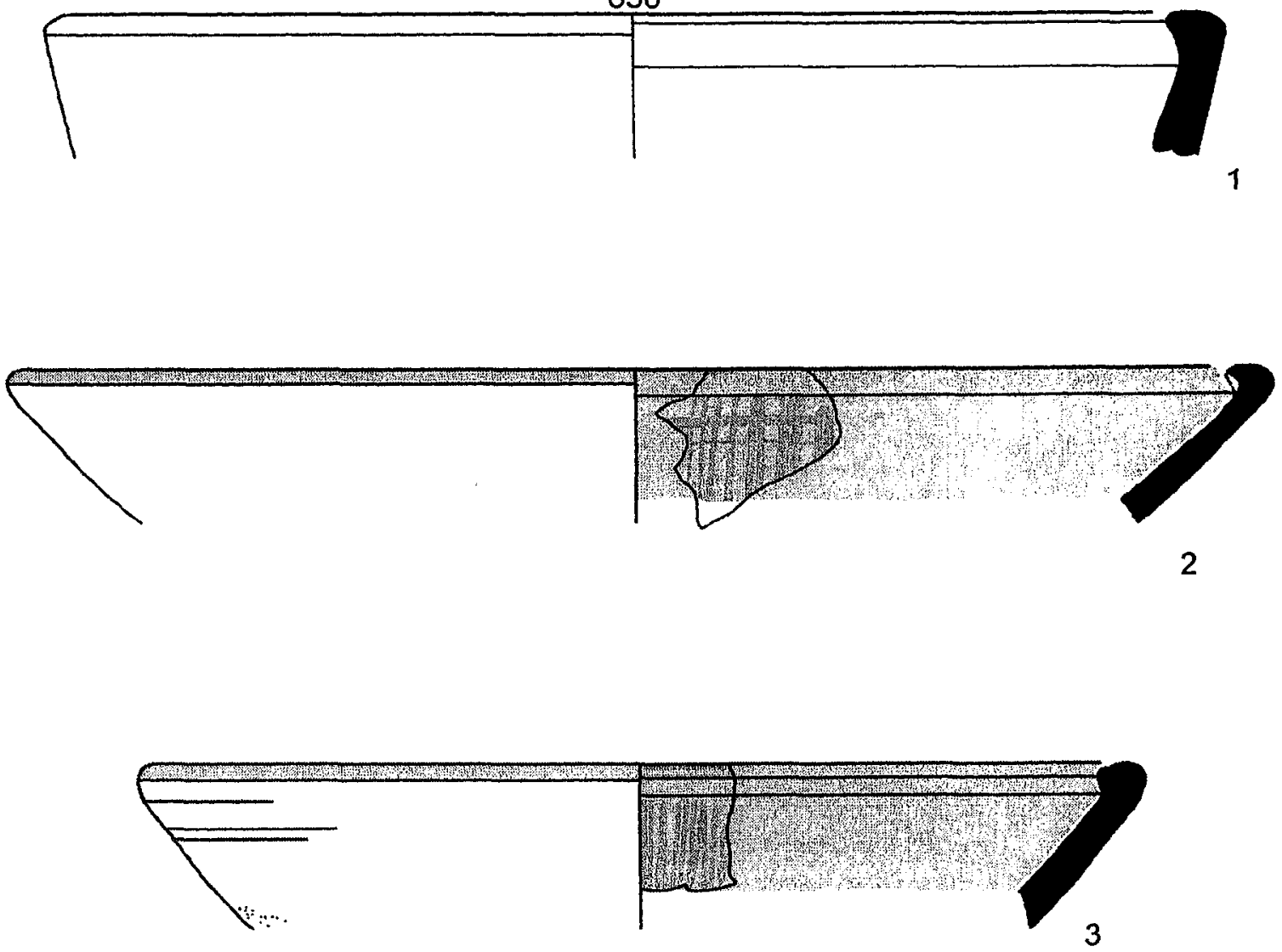

3
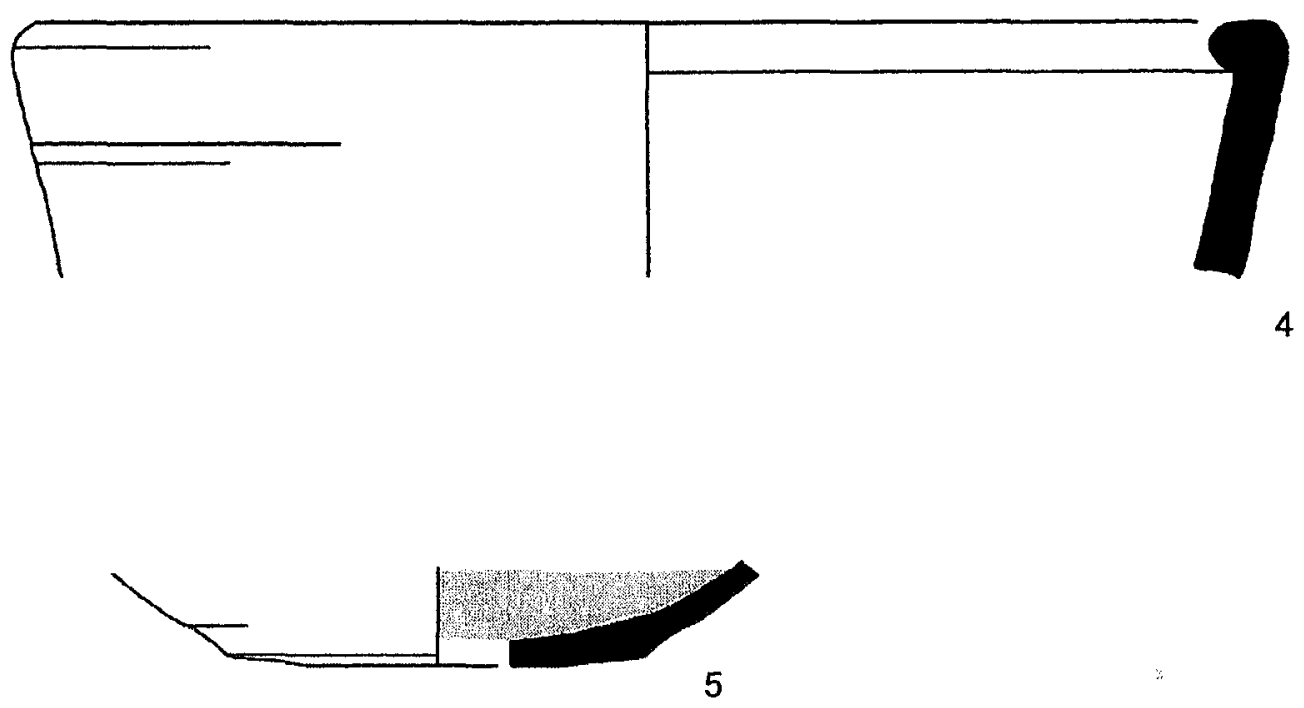

PLATE 181 (CONT.).

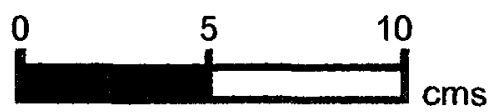




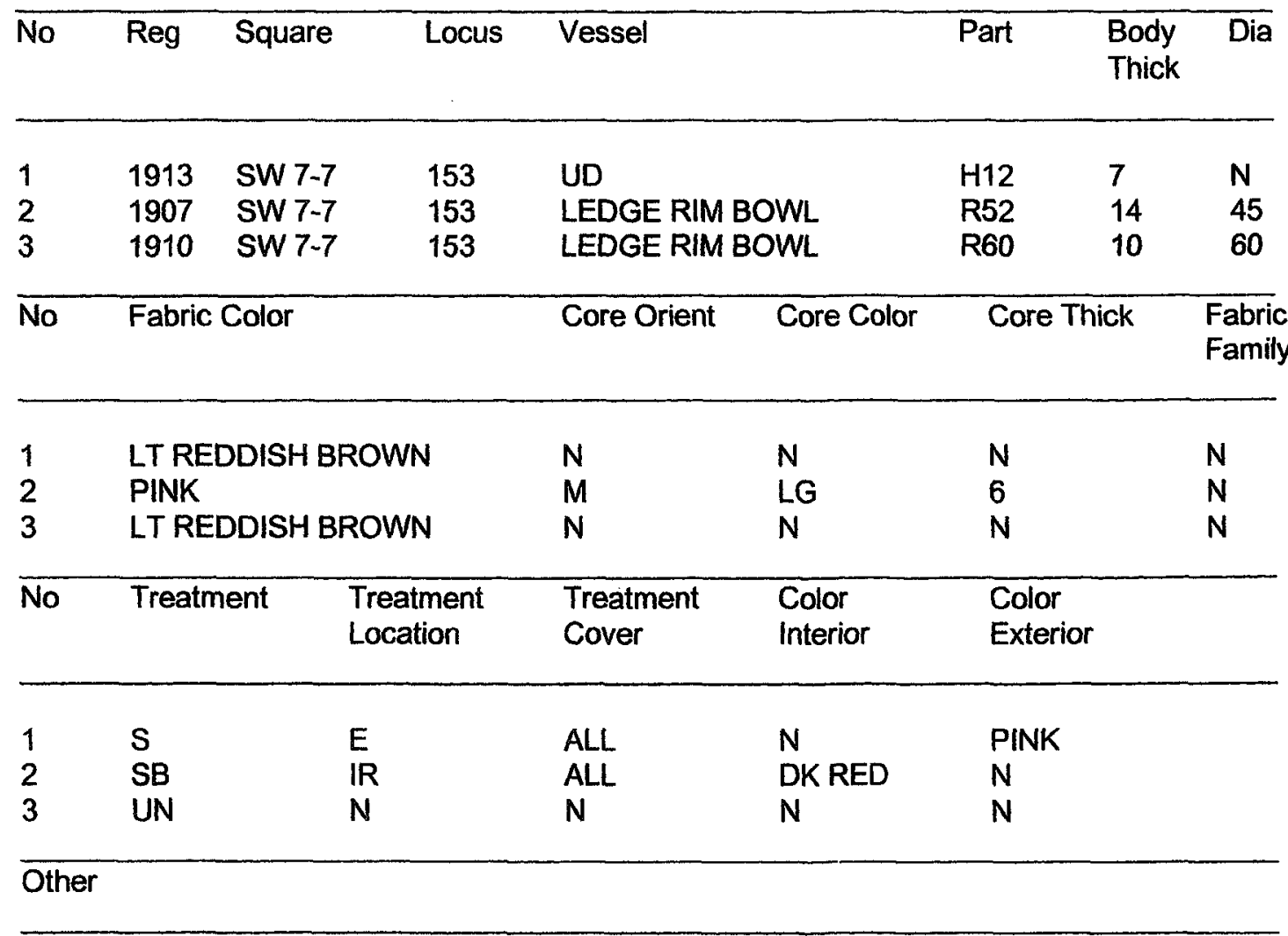

2 Interior face appears wet-smoothed; net-pattern burnish over slip; rim is well burnished; upper exterior face is also wet-smoothed with deep marginal concavity under rim; below concavity, surface becomes irregular with few scrape marks.

3 Voids in break suggest rim folding inwardly; voids suggestive of molding techniques are visible on the exterior face.

PLATE 182. FIELD D. PHASE 2B (MIXED EB). 

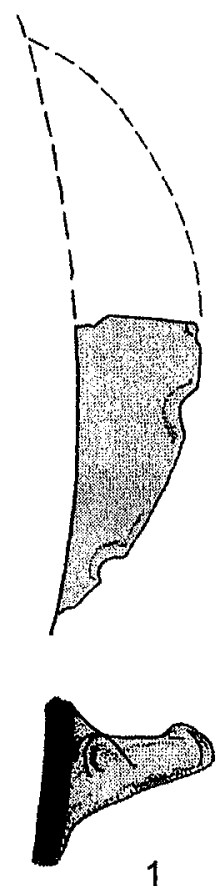

1
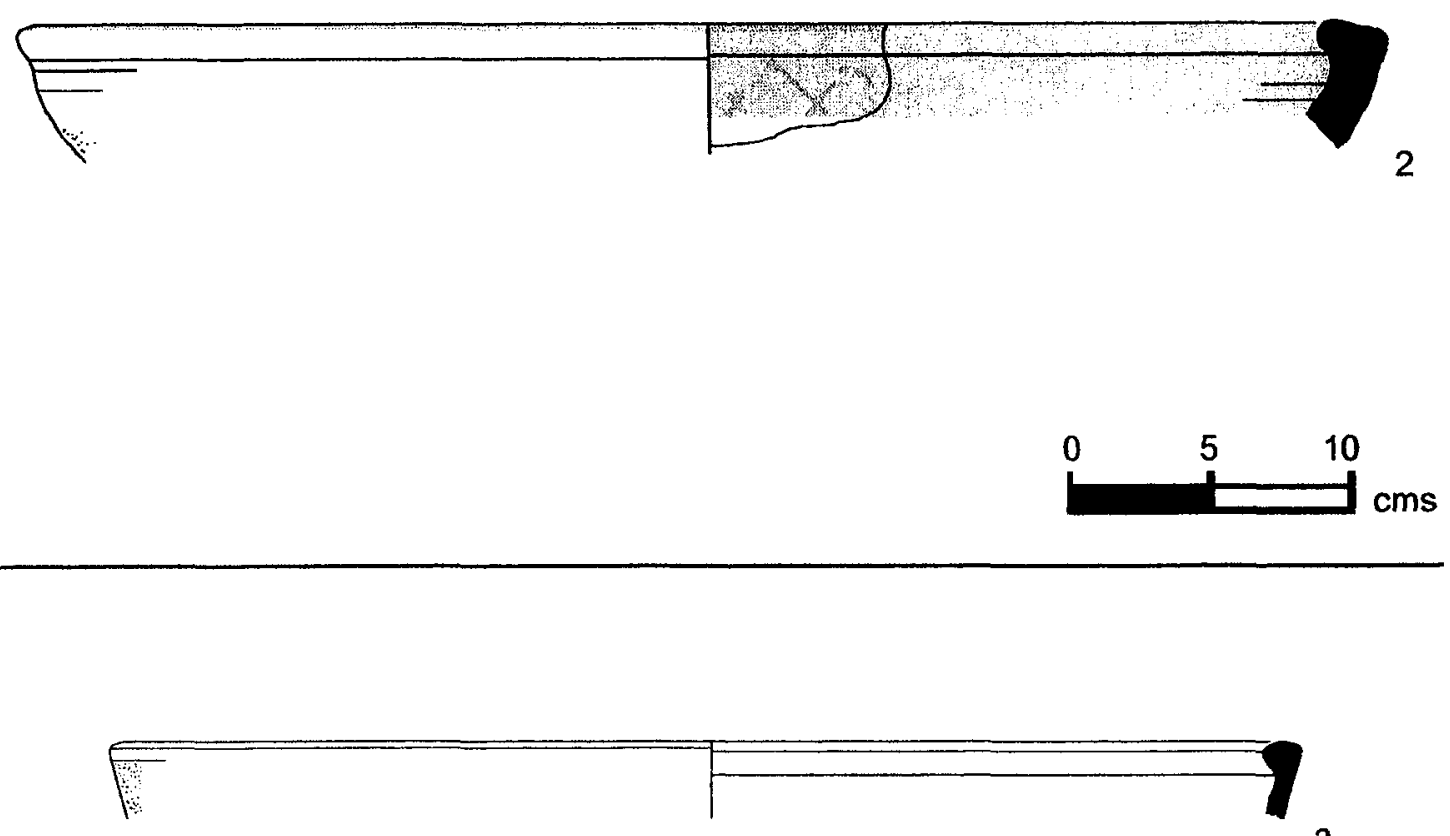

3

PLATE 182 (CONT.). 
653

\begin{tabular}{llllllll}
\hline No & Reg & Square & Locus & Vessel & Part & $\begin{array}{c}\text { Body } \\
\text { Thick }\end{array}$ & Dia \\
\hline 1 & 1933 & SW 7-7 & 157 & HOLE MOUTH JAR & R14 & 13 & 22 \\
2 & 1923 & SW 7-7 & 157 & HOLE MOUTH JAR & R01 & 11 & 15 \\
3 & 1928 & SW 7-7 & 157 & HOLE MOUTH BOWL & R02 & 11 & 11 \\
4 & 1924 & SW 7-7 & 157 & NECKED JAR & R43 & 10 & 24 \\
5 & 2490 & SW 7-7 & 157 & PLATTER BOWL & R55 & 19 & N \\
6 & 1934 & SW 7-7 & 157 & NECKED JAR & R31 & 39 & 12 \\
7 & 1922 & SW 7-7 & 157 & NECKED JAR & R31 & 8 & 12 \\
8 & 1931 & SW 7-7 & 157 & UD & B23 & 7 & 4 \\
\hline No & Fabric Color & & Core Orient $\quad$ Core Color & Core Thick & Fabric \\
& & & & & & & Family
\end{tabular}

\begin{tabular}{|c|c|c|c|c|c|c|}
\hline 1 & \multicolumn{2}{|c|}{ REDDISH BROWN } & $\mathbf{N}$ & $\mathbf{N}$ & $\mathbf{N}$ & $\mathrm{N}$ \\
\hline 2 & \multicolumn{2}{|l|}{ PALE RED } & IRR & G & $\mathbf{N}$ & 2.1 \\
\hline 3 & \multicolumn{2}{|l|}{ LTRED } & IRR & G & $\mathrm{N}$ & 3 \\
\hline 4 & \multicolumn{2}{|l|}{ PINK } & IRR & LG & $\mathrm{N}$ & $\mathrm{N}$ \\
\hline 5 & \multicolumn{2}{|l|}{ PINK } & $\mathrm{N}$ & $\mathrm{N}$ & $N$ & 19 \\
\hline 6 & \multicolumn{2}{|l|}{ PINK } & $\mathbf{N}$ & $\mathbf{N}$ & $\mathbf{N}$ & $\mathbf{N}$ \\
\hline 7 & \multicolumn{2}{|c|}{ LT REDDISH BROWN } & $\mathrm{N}$ & $\mathbf{N}$ & $\mathrm{N}$ & 8 \\
\hline 8 & \multicolumn{2}{|l|}{ PINK } & IRR & LG & $\mathbf{N}$ & 20 \\
\hline$\overline{\text { No }}$ & Treatment & $\begin{array}{l}\text { Treatment } \\
\text { Location }\end{array}$ & $\begin{array}{l}\text { Treatment } \\
\text { Cover }\end{array}$ & $\begin{array}{l}\text { Color } \\
\text { Interior }\end{array}$ & $\begin{array}{l}\text { Color } \\
\text { Exterior }\end{array}$ & \\
\hline 1 & UN & $\mathbf{N}$ & $\mathbf{N}$ & $\mathbf{N}$ & $\mathbf{N}$ & \\
\hline 2 & UN & $\mathbf{N}$ & $\mathbf{N}$ & $\mathbf{N}$ & $\mathbf{N}$ & \\
\hline 3 & UN & $\mathrm{N}$ & $\mathrm{N}$ & $\mathrm{N}$ & $N$ & \\
\hline 4 & UN & $\mathbf{N}$ & $\mathbf{N}$ & $\mathbf{N}$ & $\mathbf{N}$ & \\
\hline 5 & SB & IR & ALL & RED & $\mathbf{N}$ & \\
\hline 6 & UN & $\mathbf{N}$ & $\mathbf{N}$ & $N$ & $N$ & \\
\hline 7 & SB & ER & ALL & $\mathbf{N}$ & LT RED & \\
\hline 8 & $S$ & $E$ & ALL & $N$ & DK GREY & \\
\hline$\overline{\mathrm{Ot}}$ & & & & & & \\
\hline
\end{tabular}

2 Surface burn visible.

$3 \quad$ Also classified in Fabric Family 2.1.

$4 \quad$ Fracture lines in break suggest rim folding.

5 Thin section sample 54; sample too small to confirm stance or diameter.

8 Burn marks along upper edge suggest a secondary use of this broken base as a lamp.

PLATE 183. FIELD D. PHASE 2B (MIXED EB). 

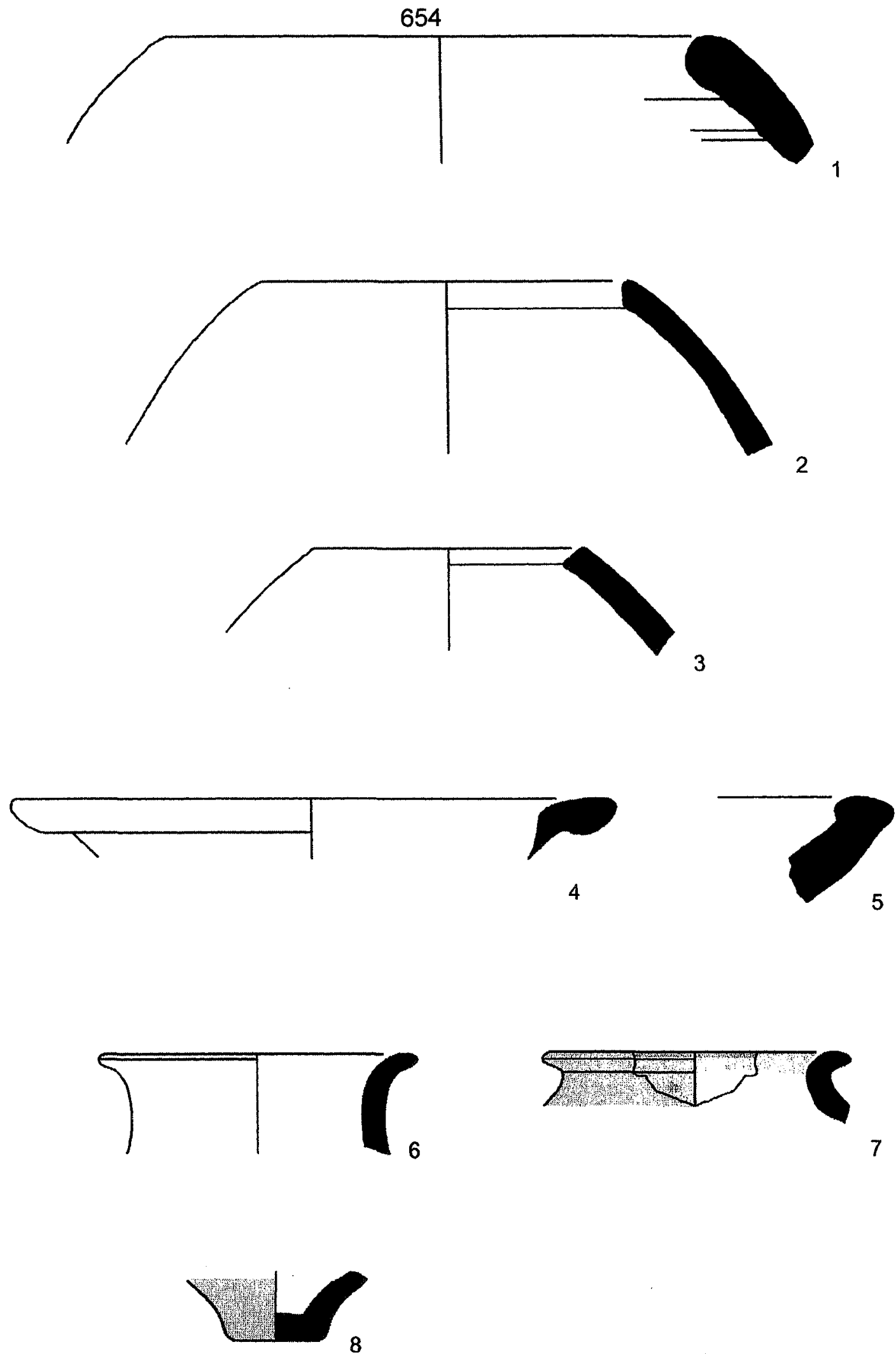

4

PLATE 183 (CONT.).

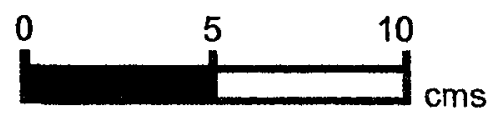




\begin{tabular}{llllllll}
\hline No & Reg & Square & Locus & Vessel & Part & $\begin{array}{c}\text { Body } \\
\text { Thick }\end{array}$ & \begin{tabular}{c} 
Dia \\
\hline
\end{tabular} \\
\hline & 1929 & SW 7-7 & 157 & LEDGE RIM BOWL & R53 & 9 & 46 \\
2 & 1927 & SW 7-7 & 157 & LEDGE RIM BOWL & R51 & 14 & 46 \\
3 & 1932 & SW 7-7 & 157 & NECKED JAR & R53 & 13 & 44 \\
4 & 1925 & SW 7-7 & 157 & HOLE MOUTH BOWL & R12 & 13 & 40 \\
5 & 1926 & SW 7-7 & 157 & LEDGE RIM BOWL & R51 & 19 & 57 \\
6 & 1930 & SW 7-7 & 157 & PLATTER BOWL & R56 & 14 & 52
\end{tabular}

\begin{tabular}{lllll}
\hline No Fabric Color & Core Orient & Core Color & Core Thick & $\begin{array}{l}\text { Fabric } \\
\text { Family }\end{array}$ \\
& & & &
\end{tabular}

\begin{tabular}{llllll}
\hline 1 & LTRED & $N$ & $N$ & $N$ & 8 \\
2 & PINK & $M$ & LG & 3 & 17.2 \\
3 & PINK & $N$ & $N$ & $N$ & $N$ \\
4 & LTREDDISH BROWN & $M$ & LG & 5 & 8 \\
5 & PINK & M & LG & 10 & 15 \\
6 & PINKISHGREY & $\mathbb{N}$ & LG & 8 & 17.2
\end{tabular}

\begin{tabular}{llllll}
\hline No & Treatment & $\begin{array}{l}\text { Treatment } \\
\text { Location }\end{array}$ & $\begin{array}{l}\text { Treatment } \\
\text { Cover }\end{array}$ & $\begin{array}{l}\text { Color } \\
\text { Interior }\end{array}$ & $\begin{array}{l}\text { Color } \\
\text { Exterior }\end{array}$ \\
\hline 1 & UN & N & N & N & $N$ \\
2 & SB & IR & ALL & YELLOWISH RED & $\mathrm{N}$ \\
3 & SB & IR & ALL & RED & $\mathrm{N}$ \\
4 & UN & N & N & N & DK REDDISH BROWN N \\
5 & S & IR & ALL & DK RED & N \\
6 & SB & IR & ALL & LT RED & \\
\hline
\end{tabular}

\section{Other}

1 Small groove below rim exterior.

2 Radial burnish over slip on interior face; rim is well burnished.

3 Scrape marks and "texture" on exterior surface continue nearly to the rim, i.e. no smoothed margin below rim.

$4 \quad$ Fine lines on interiorlexterior show rim smoothing; diagonal tool marks on interior show body scraping; flecks suggest either white slip or scum.

5 Interior face, weathered, but some fragments of slip remain; upper exterior face, broad, wet-smoothed marginal band under rim; lower exterior face, "textured."

6 "Scribbled" radial burnish over slip; rim folding suggested by deep groove at the intersection of rim and interior face.

PLATE 184. FIELD D. PHASE 2B (MIXED EB). 

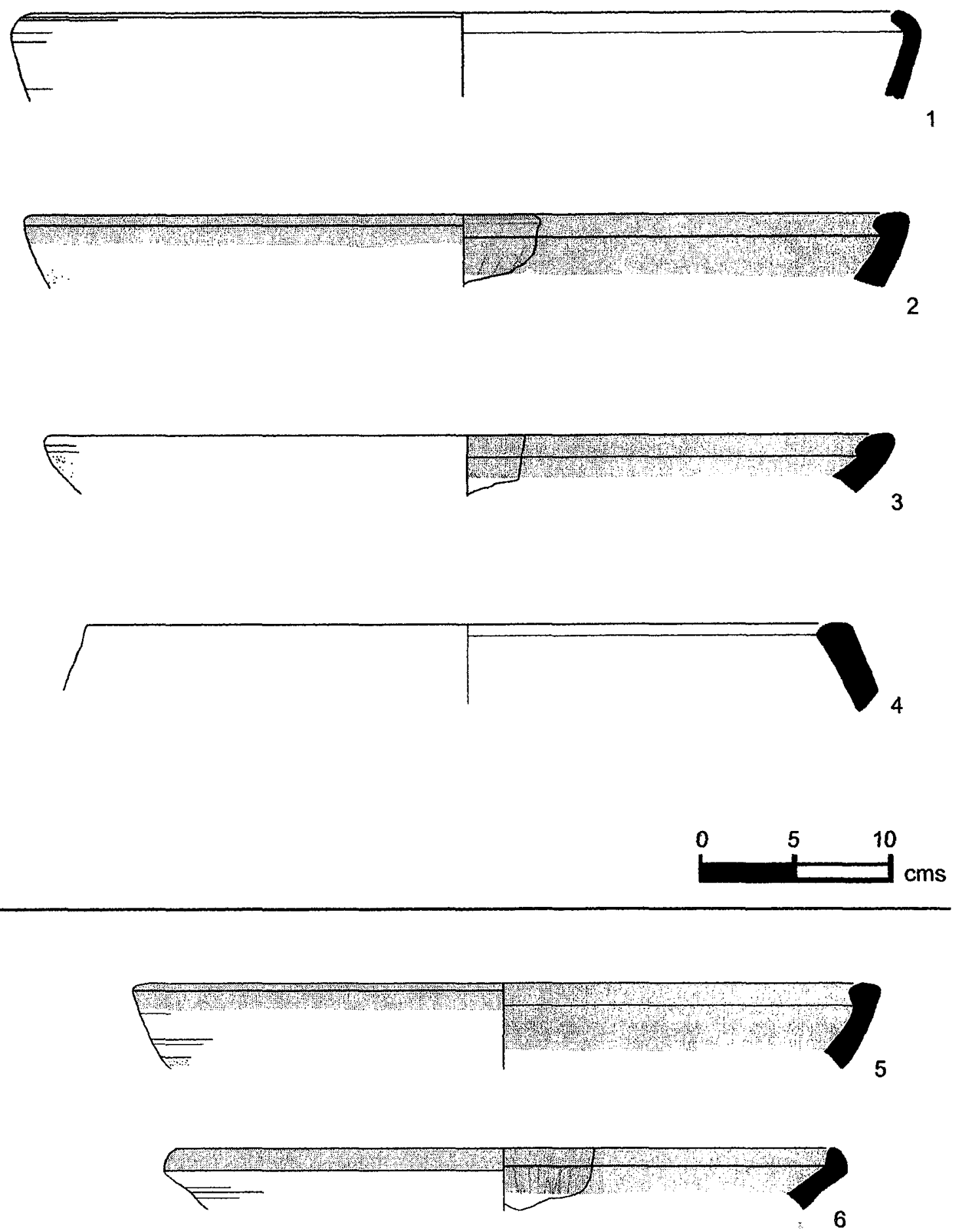

PLATE 184 (CONT.). 


\section{BIBLIOGRAPHY}

Ahlström, G. W.

1978 Wine Presses and Cup-Marks of the Jenin-Megiddo Survey. Bulletin of the American Schools of Oriental Research 231: 19-49.

Albright, W. F.

1926 The Jordan Valley in the Bronze Age. Annual of the American Schools of Oriental Research 6: 13-74.

1954 A Survey of the Archeological Chronology of Palestine from Neolithic to Middle Bronze. Pp. 28-33 in Relative Chronologies in Old World Archaeology, ed. R. W. Ehrich. Chicago: University of Chicago.

1965 Some Remarks on the Archaeological Chronology of Palestine before about 1500 B.C. Pp. 47-60 in Chronologies in Old World Archaeology, revised edition, ed. R. W. Ehrich. Chicago: University of Chicago Press.

Amiran, $\mathbf{R}$.

1952 Connections between Anatolia and Palestine in the Early Bronze Age. Israel Exploration Journal 2: 89-103.

1960 Yanik Tepe, Shengavit and the Khirbet Kerak Ware. Anatolian Studies 15: $165-67$.

1967 Khirbet Kerak Ware at 'Ai. Israel Exploration Journal 17: 185-86.

1969 Ancient Pottery of the Holy Land. Jerusalem: Massada.

1970 The Beginnings of Urbanization in Canaan. Pp. 83-100 in Near Eastern Archaeology in the Twentieth Century: Essays in Honor of Nelson Glueck, ed. J. A. Sanders. Garden City: Doubleday.

1974 The Painted Pottery Style of the EB II in Palestine. Levant 6: 65-68.

Amiran, R., and Ilan, O.

1996 Early Arad II: The Chalcolithic and Early Bronze Ib Settlements and the Early Bronze // City: Architecture and Town Planning. Sixth-Eighteenth Seasons of Excavations, 1971-1978, 1980-1984. Jerusalem: Israel Exploration Society. 
Arnold, D. E.

1985 Ceramic Theory and Cultural Process. Cambridge: Cambridge University.

Baly, D

1974 The Geography of the Bible, revised edition. New York: Harper and Row.

Beck, $P$.

1985 An Early Bronze Age "Family" of Bowls from Tel Aphek. Tel Aviv 12: 1728.

Ben-Tor, A.

1968 Problems in the Early Bronze Age II-III. Unpublished Ph.D. Dissertation, Hebrew University (Hebrew).

1973 Plans of Dwellings and Temples in Early Bronze Age Palestine. Eretz Israel 11: $92-98$ (Hebrew).

1975 The First Season of Excavations at Tell-Yarmuth: August 1970. Qedem 1: $55-87$.

1982 The Relations between Egypt and the Land of Canaan during the Third Millennium B.C. Journal of Jewish Studies 33: 3-18.

1986 The Trade Relations of Palestine in the Early Bronze Age. Journal of the Economic and Social History of the Orient 29: 1-27.

1991 The Early Bronze Age. Pp. 81-125 in The Archaeology of Ancient /srael, ed. A. Ben-Tor. Trans. R. Greenberg, from Hebrew. New Haven: Yale University.

Ben-Tor, A., and Bonfil, R., eds.

1997 Hazor V: An Account of the Fifth Season of Excavation, 1968. Jerusalem: The Israel Exploration Society - The Hebrew University of Jerusalem.

Betts, A. V. G., ed.

1992 Excavations at Tell Um Hammad 1982 -1984: The Early Assemblages (EB I - II). Edinburgh: Edinburgh University.

Biran, A., ed.

1996 Dan I: A Chronicle of the Excavations, the Pottery Neolithic, the Early Bronze Age and the Middle Bronze Age Tombs. Jerusalem: Nelson Glueck School of Biblical Archaeology. 
Blakely, J.

1990 Historical Geography and its Impact on the Analysis and Publication of

Excavated Ceramics in the British and American Traditions of Palestinian

Archaeology. Unpublished Ph.D. Dissertation, University of

Pennsylvania.

Blakely, J., and Toombs, L. E.

1980 The Tell el-Hesi Field Manual: The Joint Archaeological Expedition to Tell el-Hesi, Vol. 1. Cambridge: ASOR.

Bliss, F. J.

1894 A Mound of Many Cities or Tell el Hesy Excavated. London: Pub. for the Committee of the Palestine Exploration Fund by A.P. Watt and Son.

Boardman, J.

2001 Aspects of "Colonization." Bulletin of the American Schools of Oriental Research 322: 33-42.

Brandl, B.

1989 Observations on the Early Bronze Age Strata of Tel Erani. Pp. 357-87 in L'urbanisation de la Palestine à l'age du Bronze ancien: Bilan et perspectives des recherches actuelles, ed. P. de Miroschedji. Actes du Colloque d'Emmaüs (20-24 Octobre 1986). BAR International Series $527(i)$.

Braun, D. P.

1983 Pots as Tools. Pp. 107-34 in Archaeological Hammers and Theories, eds. J. A. Moore and A. S. Keene. New York: Academic.

Braun, E.

1985 En Shadud: Salvage Excavations at a Farming Community in the Jezreel Valley, Israel. BAR International Series 249. Oxford: BAR.

1989 The Problem of the Apsidal House: New Aspects of Early Bronze I Domestic Architecture in Israel, Jordan, and Lebanon. Palestine Exploration Quarterly 121 (Jan.-June): 1-43.

1996 Cultural Diversity and Change in the Early Bronze I of Israel and Jordan: Towards an Understanding of the Chronological Progression and Patterns of Regionalism in Early Bronze I Society. Unpublished Ph.D. Dissertation, Tel Aviv University.

1997 Yiftah'el: Salvage and Rescue Excavations at a Prehistoric Village in Lower Galilee, Israel. Jerusalem: Israel Antiquities Authority.

Bright, J.

1981 A History of Israel. 3rd edition. Philadelphia: Westminster. 
Broshi, M., and Gophna, R.

1984 The Settlements and Population of Palestine during the Early Bronze IIIII. Bulletin of the American Schools of Oriental Research 253: 41-53.

Bullard, R.

1970 Geological Studies in Field Archaeology. Biblical Archaeologist 33/4: 98132.

Burney, C.

1989 The Khirbet Kerak Question and the Early Trans-Caucasian Background. pp. 331-9 in L'urbanisation de la Palestine á l'age du Bronze ancien: Bilan et perspectives des recherches actuelles, ed. P. de Miroschedji. Actes du Colloque d'Emmalis (20-24 Octobre 1986). BAR International Series $527(i)$.

Callaway, J. A.

1964 Pottery from the Tombs at 'Ai (et-Tell). London: Quaritch.

1972 The Early Bronze Age Sanctuary at 'Ai (et-Tell). London: Quaritch.

1978 New Perspectives on Early Bronze III in Canaan. Pp. 46-58 in Archaeology in the Levant: Essays for Kathleen Kenyon, eds. R. Moorey and P. Parr. Warminster: Aris and Phillips.

1980 The Early Bronze Age Citadel and Lower City at Ai (et-Tell). A Report of the Joint Archeological Expedition to Ai (et-Tell): No. 2. Cambridge: American Schools of Oriental Research.

Campbell, E. F., Jr.

1961 The Chronology of Israel and the Ancient Near East: Section B. The Ancient Near East: Chronological Bibliography and Charts. Pp. 214-28 in The Bible and the Ancient Near East, ed. G. E. Wright. New York: Doubleday.

Carmi, I., and Segal, D.

1992 Rehovot Radiocarbon Measurements IV. Radiocarbon 34: 115-32.

Chapman, R. L.

1989 The Three Ages Revisited: A Critical Study of Levantine Usage. Part I: The Critique. Palestine Exploration Quarterly 121 (July-Dec.): 89-111.

1990 The Three Ages Revisited: A Critical Study of Levantine Usage. Part II: The Proposal. Palestine Exploration Quarterly 122 (Jan.-June): 1-20.

Clarke, D. L.

1968 Analytical Archaeology. 2nd edition, revised B. Chapman. London: Methuen and Company. 
Crowfoot, G.

1932 Pots, Ancient and Modern. Palestine Exploration Fund Quarterly Statement 64: 179-87.

Dessel, J. P., and Joffe, A. H.

2000 Alternative Approaches to Early Bronze Age Pottery. Pp. 31-58 in Ceramics and Change in the Early Bronze Age of the Southern Levant, eds. G. Philip and D. Baird. Levantine Archaeology 2. Sheffield: Sheffield Academic Press.

Dever, W. G.

1973 The EB IV-MB I Horizon in Transjordan and Southern Palestine. Bulletin of the American Schools of Oriental Research 210: 37-63.

1980a Archaeological Method in Israel: A Continuing Revolution. Biblical Archaeologist 43: 41-8.

1980b New Vistas on the EB IV ('MB I') Horizon in Syria-Palestine. Bulletin of the American Schools of Oriental Research 237: 35-64.

1988 Impact of the "New Archaeology." Pp. 337-52 in Benchmarks in Time and Culture: An Introduction to Palestinian Archaeology Dedicated to Joseph A. Callaway, eds. J. F. Drinkard, Jr., G. L. Mattingly, and J. M. Miller. Atlanta: Scholars Press.

Dever, W. G., and Richard, S.

1977 A Reevaluation of Tell Beit Mirsim Stratum J. Bulletin of the American Schools of Oriental Research 226: 1-14.

Engberg, R. M., and Shipton, G. M.

1934 Notes on the Chalcolithic and Early Bronze Age Pottery of Megiddo. Studies in Ancient Oriental Civilization 10. Chicago: University of Chicago.

Esse, D.

1982 Beyond Subsistence: Beth Yerah and Northern Palestine in the Early Bronze Age. Unpublished Ph.D. Dissertation, University of Chicago.

1984 A Chronological Mirage: Reflections on Early Bronze IC in Palestine. Journal of Near Eastern Studies 43: 317-30.

1989 Secondary State Formation and Collapse in Early Bronze Age Palestine. Pp. 81-96 in L'urbanisation de la Palestine a l'age du Bronze ancien: Bilan et perspectives des recherches actuelles, ed. P. de Miroschedji. Actes du Colloque d'Emmaus (20-24 Octobre 1986). BAR International Series 527(i). 
1991 Subsistence, Trade, and Social Change in Early Bronze Age Palestine. Studies in Ancient Oriental Civilization 50. Chicago: University of Chicago.

Esse, D., and Hopke, P.

1986 Levantine Trade in the Early Bronze Age: From Pots to Peoples. Pp. 327-39 in Proceedings of the 24th International Archaeometry

Symposium, eds. J. Olin and M. J. Blackman. Washington, D.C.: The Smithsonian Institution.

Falconer, S. E

1987 Heartland of Villages: Reconsidering Early Urbanism in the Southern Levant. Unpublished Ph.D. Dissertation, University of Arizona.

Fargo, V. M.

1979a Early Bronze Age Pottery at Tell el-Hesi. Bulletin of the American Schools of Oriental Research 236: $23-40$.

1979b Settlement in Southern Palestine During Early Bronze III. Unpublished Ph.D. Dissertation, University of Chicago.

Finkelstein, 1., Ussishkin, D., Halpern, B., eds.

2000 Megiddo III: The 1992-1996 Seasons. Tel Aviv: Emery and Claire Yass Publications in Archaeology.

Fischer, $\mathrm{P}$.

2000 The Early Bronze Age at Tell Abu al-Kharaz, Jordan Valley: A Study of Pottery Typology and Provenance, Radiocarbon Dates, and the Synchronization of Palestine and Egypt During Dynasty 0-2. Pp. 201-32 in Ceramics and Change in the Early Bronze Age of the Southern Levant, eds. G. Philip and D. Baird. Levantine Archaeology 2. Sheffield: Sheffield Academic Press.

Fox, E.

2001 Sacred Geography: A Tale of Murder and Archaeology in the Holy Land. New York: Henry Holt and Company.

Franken, H. J.

1969 Excavations at Tell Deir 'Alla. Vol. 1. Documenta et monumenta orientis antiqui, Vol. 16. Leiden: E. J. Brill.

1982 A Technological Study of Iron Age I Pottery from Tell Deir 'Alla. Pp. 14144 in Studies in the History and Archaeology of Jordan I, ed. A. Hadidi. Amman: Department of Antiquities.

Franken, H. J., and Kalsbeek, J.

1975 Potters of a Medieval Village in the Jordan Valley: Excavations at Tell Deir 'Alla. Amsterdam: North-Holland. 
Freedman, D. N.

1961 The Chronology of Israel and the Ancient Near East: Section A. Old Testament Chronology. Pp. 203-13 in The Bible and the Ancient Near East, ed. G. E. Wright. New York: Doubleday.

1978 The Real Story of the Ebla Tablets, Ebla, and the Cities of the Plain. Biblical Archaeologist 41: 143-64.

Gal, Z.

1992 Lower Galilee During the Iron Age. Trans. M. R. Josephy, from Hebrew. Winona Lake: Eisenbrauns.

Genz, $\mathrm{H}$.

2000 Grain wash Decoration in Early Bronze Age III? The Evidence from Khirbet ez-Zeraqon. Pp. 279-86 in Ceramics and Change in the Early Bronze Age of the Southern Levant, eds. G. Philip and D. Baird. Levantine Archaeology 2. Sheffield: Sheffield Academic Press.

Geraty, L. T., et al., eds.

1989 Madaba Plains Project: The 1984 Season at Tell el-'Umeiri and Vicinity and Subsequent Studies. Berrien Springs: Andrews University.

1991 Madaba Plains Project: The 1987 Season at Tell el-'Umeiri and Vicinity and Subsequent Studies. Berrien Springs: Andrews University.

Gitin, S.

1996 Formulating a Ceramic Corpus: The Late Iron II, Persian and Hellenistic Pottery at Tell Gezer. Pp. 75-101 in Retrieving the Past: Essays on Archaeological Research and Methodology in Honor of Gus W. Van Beek, ed. J. E. Seger. Winona Lake: Eisenbrauns.

Glock, A

n.d. a The Early Bronze Defenses on the South Slope. Unpublished Manuscript from The Taanach Excavations archives.

n.d. b Excavations on the South Slope in 1966. Unpublished Manuscript from The Taanach Excavations archives.

n.d. c Preliminary Phasing of Early Bronze Tell Ta'annek. Unpublished Manuscript from The Taanach Excavations archives.

n.d. d Report of the Excavation of the South Slope of Tell Ta'annek, 1963. Unpublished Manuscript from The Taanach Excavations archives.

n.d. e Stone Forms: Ta'annek 1963. Unpublished Manuscript from The Taanach Excavations archives. 
n.d. f Summary of Research Project. Unpublished Manuscript from the Taanach Excavations archives.

1969 Field Report for the South Slope Excavations at Tell Ta'annek, 1968. Unpublished Manuscript from The Taanach Excavations archives.

1971 A New Ta'annek Tablet. Bulletin of the American Schools of Oriental Research 204: 17-30.

1972 Taanach in Jezreel: A Review. Unpublished Manuscript from The Taanach Excavations archives.

1975 Homo Faber: The Pot and the Potter at Taanach. Bulletin of the American Schools of Oriental Research 219: 9-28.

1993 Taanach. Pp. 1428-33 in vol. 4 of The New Encyclopedia of Archaeological Excavations in the Holy Land, ed. E. Stern. New York: Simon and Schuster.

Goldberg, P., and Bar-Yosef, O.

1990 The Effect of Man on Geomorphological Processes Based upon Evidence from the Levant and Adjacent Areas. Pp. 71-86 in Man's Role in the Shaping of the Eastern Mediterranean Landscape. Proceedings of the Inqua/Bai Symposium on the Impact of Ancient Man on the Landscape of the Eastern Mediterranean Region and the Near East, eds. S. Bottema, G. Entjes-Nieborg, and W. Van Zeist. Groningen, Netherlands. 6-9 March 1989. Rotterdam/Brookfield: A. A. Balkema.

Goldberg, P., and Rosen, A. M.

1987 Early Holocene Palaeoenvironments of Israel. Pp. 23-33 in Shiqmim 1: Studies Conerning Chalcolithic Societies in the Northern Negev Desert, Israel (1982-1984), ed. T. E. Levy. British Archaeological Reports International Series, 356 (i-ii). Oxford: British Archaeological Reports.

Gophna, R.

1974 The Settlement of the Coastal Plain of Eretz-Israel during the Early Bonze Age. Unpublished Ph.D. Dissertation, Tel Aviv University (Hebrew).

1984 The Settlement Landscape of Palestine in the Early Bronze Age II-III and Middle Bronze Age II. Israel Exploration Journal 34/1: 24-31.

1992 Early Bronze Age Fortification Wall and Middle Bronze Age Rampart at Tel Poran. Tel-Aviv 19/2: 267-73.

Graesser, C., Jr.

n.d. Area C Report. Unpublished Manuscript from The Taanach Excavations archive. 
Greenberg, R.

1996a The Early Bronze Age Levels. Pp. 84-160 in Dan I. A Chronicle of the Excavations, the Pottery Neolithic, the Early Bronze Age and the Middle Bronze Age Tombs, ed. A. Biran. Jerusalem: Nelson Glueck School of Biblical Archaeology, Hebrew Union College-Jewish Institute of Religion.

1996b The Hula Valley from the Beginning of the Early Bronze Age to the End of the Middle Bronze Age IIA: A Study in Regional Archaeology. Unpublished Ph.D. Dissertation, Hebrew University.

1997 The Early Bronze Age Phases in Area L. Pp. 183-93 in Hazor V: An Account of the Fifth Season of Excavation, 1968, eds. A. Ben-Tor and R. Bonfil. Jerusalem: The Israel Exploration Society - The Hebrew University of Jerusalem.

2000 Changes in Ceramic Production between Early Bronze Age II and III in Northern Israel, Based on the Pottery of Tel Hazor and Tel Dan. Pp. 183-200 in Ceramics and Change in the Early Bronze Age of the Southern Levant, eds. G. Philip and D. Baird. Levantine Archaeology 2. Sheffield: Sheffield Academic Press.

Greenberg, R., and Porat, N.

1996 A Third Millennium Levantine Pottery Production Center: Typology, Petrography, and Provenance of the Metallic Ware of Northern Israel and Adjacent Regions. Bulletin of the American Schools of Oriental Research 301: 5-24.

Hanbury-Tenison, J. W.

1986 The Late Chalcolithic to Early Bronze I Transition in Palestine and Transjordan. British Archaeological Reports International Series, 311.

Oxford: British Archaeological Reports.

Harlan, J. R.

1985 The Early Bronze Age Environment of the Southern Ghor and the Moab Plateau. Pp. 125-30 in Studies in the History and Archaeology of Jordan II, ed. A. Hadidi. Amman: Department of Antiquities.

Harris, E.

1979 Principles of Archaeological Stratigraphy. New York: Academic.

Harrison, T.

1997 Shifting Patterns of Settlement in the Highlands of Central Jordan during the Early Bronze Age. Bulletin of the American Schools of Oriental Research 306: 1-37.

Helms, S. W.

1976 The Early Bronze Gate at Ras en-Naqura (Ros ha-Niqra). Zeitschrift des Deutschen Palastina-Vereins 92/1: 1-9. 
Hennessy, J. B.

1967 The Foreign Relations of Palestine During the Early Bronze Age. Colt Archaeological Institute Publications. London: Bernard Quaritch.

Hendrix, R.; Drey, P.; and Storfjell, J. B.

1996 Ancient Potten of Transjordan: An Introduction Utilizing Published Whole Forms Late Neolithic through Late /slamic. Berrien Springs: Institute of Archaeology/Horn Archaeological Museum.

Hillers, D.

n.d. Area D Report. Unpublished Manuscript from The Taanach Excavations archive.

Hillers, D., trans.

1962a Tell Ta annak, by E. Sellin, 1904. Appleton: Aid Association for Lutherans.

1962b A Gleaning of Tell Ta 'annak in Palestine, by E. Sellin, 1905. Appleton: Aid Association for Lutherans.

Hodder, 1.

1999 The Archaeological Process: An Introduction. Malden: Blackwell.

Hodder, I., and Orton, C.

1976 Spatial Analysis in Archaeology. Cambridge: Cambridge University.

Homes-Fredericq, D., and Franken, H. J., eds.

1986 Pottery and Potters--Past and Present: 7000 Years of Ceramic Art in Jordan. Ausstellungskataloge der Universitat Tubingen. NR. 20.

Tubingen: Attempto.

James, P., et al.

1991 Centuries of Darkness: A Challenge to the Conventional Chronology of Old World Archaeology. London: Jonathan Cape.

Joffe, A. H.

1991 Settlement and Society in Early Bronze I and II Canaan (Bronze Age).

Unpublished Ph.D. Dissertation, University of Arizona.

1993 Settlement and Society in the Early Bronze Age I and II, Southern Levant: Complementarity and Contradiction in a Small-scale Complex Society. Monographs in Mediterranean Archaeology 4, ed. A. B. Knapp. Sheffield: Sheffield Academic Press.

2000 The Early Bronze Age Pottery from Area J. Pp. 161-85 in Megiddo III: the 1992-1996 Seasons, eds. I. Finkelstein, D. Ussishkin, and B. Halpern. Tel Aviv: Emery and Claire Yass Publications in Archaeology. 
Kapitan, T., ed.

1999 Archaeology, History and Culture in Palestine and the Near East: Essays in Memory of Albert E. Glock. Atlanta: Scholars Press.

Karmon, $Y$.

1971 Israel: A Regional Geography. London: Wiley-Interscience.

Kempinski, A.

1978 The Rise of an Urban Culture: The Urbanization of Palestine in the Early Bronze Age 3000-2150. Israel Ethnographic Society Studies 4. Jerusalem: Israel Ethnographic Society.

Kempinski, A., and Gilead, I.

1991 New Excavations at Tel Erani: A Preliminary Report of the 1985-1988

Seasons. Tel-Aviv 18/2: 164-91.

Kenyon, K. M.

1958 Some Notes on the Early and Middle Bronze Age Strata of Megiddo.

Eretz Israel 5: 51-60.

1970 Archaeology in the Holy Land. $3^{\text {rd }}$ ed. London: Benn.

Kuhn, T. S.

1970 The Structure of Scientific Revolutions. $2^{\text {nd }}$ ed. Chicago: University of Chicago.

Lapp, P. W.

1964 The 1963 Excavations at Ta'annek. Bulletin of the American Schools of Oriental Research 173: 4-44.

1967a Taanach by the Waters of Megiddo. Biblical Archaeologist 30: 2-27.

1967b The 1966 Excavations at Tell Ta'annek. Bulletin of the American Schools of Oriental Research 185: 2-39.

1968 Tell Ta'annak. Revue Biblique 75: 93-8.

1969 The 1968 Excavations at Tell Ta'annek. Bulletin of the American Schools of Oriental Research 195: 2-49.

1970 Palestine in the Early Bronze Age. Pp. 101-32 in Near Eastern Archaeology in the Twentieth Century, ed. J. A. Sanders. Garden City: Doubleday.

Lasken, J. E.

1990 Toward a New Chronology of Ancient Egypt. Discussions in Egyptology 17: $87-141$. 
Leonard, A., Jr.

1992 The Jordan Valley Survey, 1953: Some Unpublished Soundings

Conducted by James Mellaart. Annual of the American Schools of Oriental Research 50. Winona Lake: Eisenbrauns.

Levy, T. E.

1983 The Emergence of Specialized Pastoralism in the Southern Levant. World Archaeology 15: 15-36.

Liphschitz, N.; Gophna, R.; and Lev-Yadun, S.

1989 Man's Impact on the Vegetational Landscape of Israel in the Early Bronze Age II-III. Pp. 263-8 in L'urbanisation de la Palestine à l'age du Bronze ancien: Bilan et perspectives des recherches actuelles, ed. P. de Miroschedji. Actes du Colloque d'Emmaüs (20-24 Octobre 1986). BAR International Series 527(i).

Liphschitz, N., and Waisel, Y.

1980 Dendroarchaeological Investigations in Israel (Taannach). Israel Exploration Journal 30: 132-6.

London, G.

1979 Origins of Certain Non-Painted Decorations on Ancient Pottery. Unpublished Manuscript from The Taanach Excavations archives.

MacDonald, $B$.

1988 The Wadi al-Hasa Archaeological Survey, 1979-1983, West-Central Jordan. Waterloo: Wilfrid Laurier University.

Matson, F. R., ed.

1965 Ceramics and Man. Chicago: Aldine.

Mazar, A.

1990 Archaeology and the Land of the Bible, 10,000-586 B.C.E. New York: Doubleday.

Mazar, A.; Ziv-Esudri, A.; and Cohen-Weinberger, A.

2000 The Early Bronze Age II-III at Tel Beth Shean: Preliminary Observations. Pp. 255-78 in Ceramics and Change in the Early Bronze Age of the Southern Levant, eds. G. Philip and D. Baird. Levantine Archaeology 2. Sheffield: Sheffield Academic Press.

Mazar, B.; Stekelis, M.; and Avi-Yonah, M.

1952 The Excavations at Beth-Yerah (Khirbet el-Kerak). Israel Exploration Journal 2: 165-173, 218-229.

McCreery, D.

1980 The Nature and Cultural Implications of Early Bronze Age Agriculture in the Southern Ghor of Jordan. Unpublished Ph.D. Dissertation, University of Pittsburgh. 
Meehl, M.

1995 A Stratigraphic Analysis of the Unpublished Early Iron Age Materials from Tell Ta'annek in Light of Recent Jezreel Valley Excavations.

Unpublished Ph.D. Dissertation, John Hopkins University.

Meyers, E. M., ed.

1997 The Oxford Encyclopedia of Archaeology in the Near East. New York:

Oxford University.

Meyerhof, E. L.

1989 The Bronze Age Necropolis at Kibbutz Hazorea, Israel. BAR International Series 534. Oxford: BAR.

Miller, J. M., ed.

1991 Archaeological Sunvey of the Kerak Plateau. ASOR Archaeological

Reports 1. Atlanta: Scholars Press.

Miroschedji, P. R. de

1971 L'Epoque pré-urbaine en Palestine. Cahiers de la Revue Biblique 13.

Paris: Gahalda.

1989a Le processus d'urbanisation en Palestine au Bronze ancien: chronologie et rythmes. Pp. 63-79 in L'urbanisation de la Palestine à l'age du Bronze ancien: Bilan et perspectives des recherches actuelles, ed. P. R. de Miroschedji. Actes du Colloque d'Emmaús (20-24 Octobre 1986). BAR International Series 527(i).

2000 An Early Bronze Age III Pottery Sequence for Southern Israel. Pp. 31545 in Ceramics and Change in the Early Bronze Age of the Southern Levant, eds. G. Philip and D. Baird. Levantine Archaeology 2. Sheffield: Sheffield Academic Press.

Miroschedji, P. R. de, ed.

1988 Yarmouth 1: Rapport sur les trois premiemes campagnes de fouilles a Tel Yarmouth (Israel). Paris: Editions Recherche sur les Civilisations.

1989b L'urbanisation de la Palestine à l'age du Bronze ancien: Bilan et perspectives des recherches actuelles. Actes du Colloque d'Emmaüs (20-24 octobre 1986). B.A.R. International Series 527(i).

Munsell

1994 Munsell Soil Color Charts, revised edition. New Windsor: Macbeth Division of Kollmorgen Instruments Corporation.

Orni, E., and Efrat, E.

1980 Geography of Israel, $4^{\text {th }}$ ed. Jerusalem: Israel Universities. 
Osborne, G. R.

1991 The Hermeneutical Spiral: A Comprehensive Introduction to Biblical Interpretation. Downer's Grove: InterVarsity Press.

Petrie, W. M. F.

1904 Method and Aims in Archaeology. London: MacMillan.

Pettinato, G.

1979 Catalogo dei Testi Cuneiformi de Tell Mardikh-Ebla. Materiali Epigraphici di Ebla 1. Naples: Istituto Universitario Orientale di Napoli.

1981 The Archives of Ebla. Garden City: Doubleday.

Philip, G., and Baird, D., eds.

2000 Ceramics and Change in the Early Bronze Age of the Southern Levant. Levantine Archaeology 2. Sheffield: Sheffield Academic Press.

Picard, L.

1943 Structure and Evolution of Palestine. Jerusalem: Hebrew University.

Pirenne, $\mathrm{H}$.

1937 Mahomet et Charlemagne. $5^{\text {th }}$ ed. Paris: Alcan.

Prausnitz, M. W.

1954 Abydos and Combed Ware. Palestine Exploration Quarterly 86: 91-6.

Rast, W. E.

1978 Taanach I. Studies in the Iron Age Pottery, ed. A. E. Glock. Cambridge: ASOR.

1980 Palestine in the $3^{\text {rd }}$ Millenium: Evidence for Interconnections. Scripta Mediterranea 1: 5-20.

1992 Through the Ages in Palestinian Archaeology: An Introductory Handbook. Philadelphia: Trinity.

Rast, W. E., and Schaub, R. T.

1974 Survey of the Southeastern Plain of the Dead Sea, 1973. Annual of the Department of Antiquities of Jordan 19: 5-53.

1978 A Preliminary Report of Excavations at Bab edh-Dhra, 1975. Annual of the American Schools of Oriental Research 43: 1-32.

1981 The Southeastern Dead Sea Plain Expedition: An Interim Report of the 1977 Season. Annual of the American Schools of Oriental Research 46. Cambridge: ASOR. 
Richard, S.

1980 Toward a Consensus of Opinion on the End of the Early Bronze Age in Palestine-Transjordan. Bulletin of the American Schools of Oriental Research 237: 5-34.

1987 Archaeological Sources for the History of Palestine. The Early Bronze Age: The Rise and Collapse of Urbanism. Biblical Archaeologist 50/1: 22-43.

Richard, S., and Boraas, R. S.

1988 The Early Bronze IV Fortified Site of Khirbet Iskander, Jordan: Third Preliminary Report, 1984 Season. Bulletin of the American Schools of Oriental Research Supplement 25: 107-30.

Robinson, $E$.

1856 Later Biblical Researches in Palestine and in the Adjacent Regions. Reprint ed. New York: Arno Press, 1977.

Rohl, D. M.

1995 A Test of Time. Vol. 1. The Bible - From Myth to History. London: Century.

Rosen, A.

1983 Environmental Change and Man's Effect on the Landscape at Tel Lachish from the Early Bronze Age through the Byzantine Period. Abstracts, Israel Pleistocene Association Annual Meeting 1983: 44-5.

1989 Environmental Change at the End of Early Bronze Age Palestine. Pp. 247-56 in L'urbanisation de la Palestine à l'age du Bronze ancien: Bilan et perspectives des recherches actuelles, ed. P. de Miroschedji. Actes du Colloque d'Emmalls (20-24 Octobre 1986). BAR International Series $527(\mathrm{i})$.

1995 The Social Response to Environmental Change in Early Bronze Age Canaan. Journal of Anthropological Archaeology 14: 26-44.

Ross, J. F.

1980 The Early Bronze Age in Palestine. Pp. 147-70 in Historical Essays in Honor of Kenneth R. Rossman, ed. by K. Newmyer. Crete: Doane College.

Ross, J. F.

1987 A Bibliography of Early Bronze Age Sites in Palestine. Pp. 315-53 in Archaeology and Biblical Interpretation: Essays in Memory of D. Glenn Rose, eds. L. G. Perdue, L. E. Toombs, and G. L. Johnson. Atlanta: John Knox Press. 
Rye, O. S., and Evans, C.,

1976 Traditional Pottery Techniques of Pakistan: Field and Laboratory

Studies. Washington, D.C.: Smithsonian Institution.

Sauer, J. A.

1994 A New Climatic and Archaeological View of the Early Biblical Traditions.

Pp. 366-98 in Scripture and Other Artifacts: Essays on the Bible and Archaeology in Honor of Philip J. King, eds. M. D. Coogan, J. C. Exum and L. E. Stager. Louisville: Westminster John Knox.

Schaub, R. T.

1973 The Early Bronze IA-IB Pottery of the Bab edh-Dhra' Cemetery, Jordan. Unpublished Ph.D. Dissertation, University of Pittsburgh.

Schaub, R. T., and Rast, W. E.

1984 Preliminary Report of the 1981 Expedition to the Dead Sea Plain, Jordan. Bulletin of the American Schools of Oriental Research 254: 35-60.

1989 Bab edh-Dhra: Excavations in the Cemetery Directed by Paul W. Lapp (1965-67). Reports of the Expedition to the Dead Sea Plain, Jordan 1. Winona Lake: Eisenbrauns.

Schiffer, M. B.

1987 Formation Processes of the Archeological Record. Albuquerque: University of New Mexico.

Seger, J. D.

1989 Some Provisional Correlations in EB III Stratigraphy in Southern Palestine. Pp. 117-35 in L'urbanisation de la Palestine à l'age du Bronze ancien: Bilan et perspectives des recherches actuelles, ed. P. de Miroschedji. Actes du Colloque d'Emmaüs (20-24 Octobre 1986). BAR International Series 527(i).

Seger, J. D., et al.

1990 The Bronze Age Settlements at Tell Halif: Phase II Excavations, 19831987. Pp. 1-32 in Preliminary Reports of ASOR-Sponsored Excavations, 1983-1987, ed. W. E. Rast. Bulletin of the American Schools of Oriental Research Supplement 26. Baltimore: Johns Hopkins University Press for the American Schools of Oriental Research.

Sellin, E.

1904 Tell Ta annak. Denkschriften der kaiserlichen Akademie der Wissenschaften in Wien, Philosophisch-historische Klasse. Band L. Wien.

1905 Eine Nachlese auf dem Tell Ta annek in Palaestina. Denkschriften der kaiserlichen Akademie der Wissenschaften in Wien, Philosophischhistorische Klasse. Band LII. Wein. 
Shehadeh, $\mathbf{N}$.

1985 The Climate of Jordan in the Past and Present. Pp. 25-37 in Studies in the History and Archaeology of Jordan II, ed. A. Hadidi. Amman:

Department of Antiquities.

Shepard, A. O.

1956 Ceramics for the Archaeologist. Washington, D.C.: Carnegie Institution of Washington, Publication 609.

Silberman, N. A.

1999 Albert E. Glock (1925-1992): A Remembrance. Pp. 1-10 in Archaeology, History and Culture in Palestine and the Near East. Essays in Memory of Albert E. Glock, ed. T. Kapitan. Atlanta: Scholars Press.

Stager, L.

1992 The Periodization of Palestine From Neolithic through Early Bronze Times. Pp. 22-41 in Chronologies in Old World Archaeology, ed. R. Ehrich. $3^{\text {rd }}$ ed. Chicago: University of Chicago.

Stern, E., ed.

1993 The New Encyclopedia of Archaeological Excavations in the Holy Land. Jerusalem: Israel Exploration Society and Carta.

Sukenik, E. L.

1948 Archaeological Investigations at 'Affula Conducted on Behalf of the Hebrew University, Jerusalem. Journal of the Palestine Oriental Society 21: 1-79.

Thompson, T. L.

1979 The Settlement of Palestine in the Bronze Age. Beihefte Zum Tubinger Atlas Des Vorderen Orients, Reine B, 8. Wiesbaden: Ludwig Reichert.

Trigger, B. G.

1989 A History of Archaeological Thought. Cambridge: Cambridge University Press.

de Vaux, R.

1971 Palestine in the Early Bronze Age. Pp. 208-37 in The Cambridge Ancient History, $3^{\text {rd }}$ revised edition, $1 / 2$. Cambridge: Cambridge University.

Vincent, H. L.

1934 Chronique: vers l'aube de I'histoire en Palestine. Revue Biblique 43: 403-31.

Voyatzoglou, $\mathrm{M}$.

1974 The Jar Makers of Thrapsano in Crete. Expedition 16/2: 18-24. 
Wagner, $\mathbf{N}$.

1972 Early Bronze Houses at 'Ai (et Tell). Palestine Exploration Quarterly 104: 5-25.

Walker, A.

1978 Principles of Excavation. Pp. 1 - 22 in Manual of Field Excavation:

Handbook of Field Archaeologists, eds. W. G. Dever and H. D. Lance.

Cincinnati: Hebrew Union College.

Willey, F. R., and Sabloff, J. A.

1980 A History of American Archaeology. $2^{\text {nd }}$ ed. San Francisco: W. H.

Freeman.

Wolf, $E$.

1955 Types of Latin American Peasantry: A Preliminary Discussion. American Anthropologist 57: 452-71.

Wood, B.

1990 The Sociology of Pottery in Ancient Palestine: The Ceramic Industry and the Diffusion of Ceramic Style in the Bronze and Iron Ages. Journal for the Study of the Old Testament Supplement Series 103. JSOT/ASOR Monographs 4. Sheffield: Sheffield Academic Press.

Wright, G. E.

1936 The Chronology of Palestine in the Early Bronze Age. Bulletin of the American Schools of Oriental Research 63: 12-21.

1937 The Pottery of Palestine from the Earliest times to the End of the Early Bronze Age. New Haven: American Schools of Oriental Research.

1958 The Problem of the Transition between the Chalcolithic and Bronze Ages. Eretz-/srael 5: 37-45.

1961 The Archaeology of Palestine. Pp. 73-112 in The Bible and the Ancient Near East, ed. G. E. Wright. New York: Doubleday.

1962 Biblical Archaeology, revised edition. Philadelphia: Westminster.

1971 Archaeology of Palestine from the Neolithic Through the Middle Bronze Age. Journal of the American Oriental Society 91: 276-93.

Wylie, A.

1992 The Interplay of Evidential Constraints and Political Interests: Recent Archaeological Research on Gender. American Antiquity 57: 15-35. 
Yakar, J.

1989 The So-Called Anatolian Elements in the Late Chalcolithic and Early Bronze Age Cultures of Palestine: A Question of Ethnocultural Origins. Pp. 341-54 in L'urbanisation de la Palestine dे l'age du Bronze ancien: Bilan et perspectives des recherches actuelles, ed. P. de Miroschedji. Actes du Colloque d'Emmaủs (20-24 octobre 1986). BAR International Series $527(i)$.

Yeivin, $\mathrm{S}$.

1960 Early Contacts Between Canaan and Egypt. Israel Exploration Journal 10: 193-203.

1961 First Preliminary Report on the Excavations at Tel "Gat" (Tell Sheykh Amed el-Areyney'), Seasons 1956-1958. Jerusalem: Tel Gat Expedition.

Ziadeh, M. G. H.

1991 Change and Continuity in a Palestinian Village: An Archaeological Study

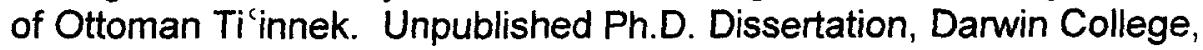
University of Cambridge.

1995 Ethno-history and "Reverse Chronology" at Ti'innik, a Palestinian Village. Antiquity 69: 999-1008.

Zori, N.

1977 The Land of Issachar: Archaeological Survey. Jerusalem: Israel Exploration Society (Hebrew).

Zukerman, S.

1996 Tel Qashish and the Jezreel Valley. Unpublished MA Thesis, Hebrew University of Jerusalem (Hebrew). 